NATIONAL LABORATORY

MANAGED BY UT-BATTELLE

FOR THE DEPARTMENT OF ENERGY

\title{
Intermediate Ethanol Blends Catalyst Durability Program
}

\section{February 2012}

Prepared by

Brian H. West

C. Scott Sluder

Keith E. Knoll

John E. Orban

Jingyu Feng

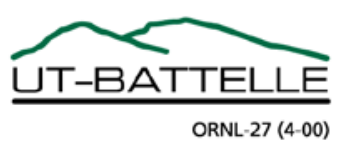




\section{DOCUMENT AVAILABILITY}

Reports produced after January 1, 1996, are generally available free via the U.S. Department of Energy (DOE) Information Bridge.

Web site http://www.osti.gov/bridge

Reports produced before January 1, 1996, may be purchased by members of the public from the following source.

National Technical Information Service

5285 Port Royal Road

Springfield, VA 22161

Telephone 703-605-6000 (1-800-553-6847)

TDD 703-487-4639

Fax 703-605-6900

E-mail info@ntis.gov

Web site http://www.ntis.gov/support/ordernowabout.htm

Reports are available to DOE employees, DOE contractors, Energy Technology Data Exchange (ETDE) representatives, and International Nuclear Information System (INIS) representatives from the following source.

Office of Scientific and Technical Information

P.O. Box 62

Oak Ridge, TN 37831

Telephone 865-576-8401

Fax 865-576-5728

E-mail reports@osti.gov

Web site http://www.osti.gov/contact.html

This report was prepared as an account of work sponsored by an agency of the United States Government. Neither the United States Government nor any agency thereof, nor any of their employees, makes any warranty, express or implied, or assumes any legal liability or responsibility for the accuracy, completeness, or usefulness of any information, apparatus, product, or process disclosed, or represents that its use would not infringe privately owned rights. Reference herein to any specific commercial product, process, or service by trade name, trademark, manufacturer, or otherwise, does not necessarily constitute or imply its endorsement, recommendation, or favoring by the United States Government or any agency thereof. The views and opinions of authors expressed herein do not necessarily state or reflect those of the United States Government or any agency thereof. 
Fuels Technologies Program

\title{
INTERMEDIATE ETHANOL BLENDS CATALYST DURABILITY PROGRAM
}

\author{
Brian H. West \\ C. Scott Sluder \\ Oak Ridge National Laboratory \\ Keith E. Knoll \\ National Renewable Energy Laboratory \\ John E. Orban \\ Jingyu Feng \\ Battelle Memorial Institute
}

Date Published: February 2012

Prepared by

OAK RIDGE NATIONAL LABORATORY

Oak Ridge, Tennessee 37831-6283

managed by

UT-BATTELLE, LLC

for the

U.S. DEPARTMENT OF ENERGY

under contract DE-AC05-00OR22725 



\section{CONTENTS}

Page

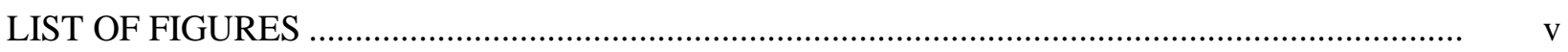

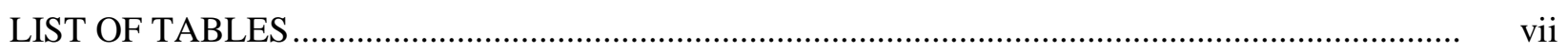

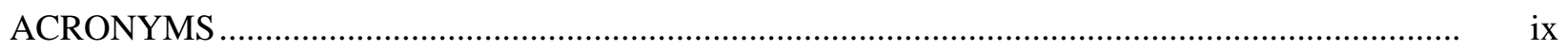

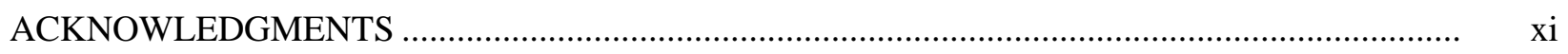

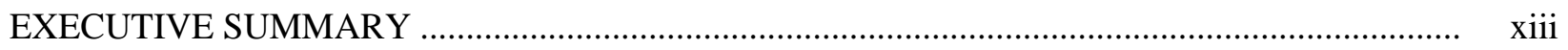

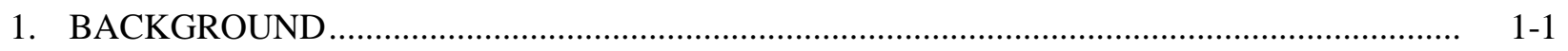

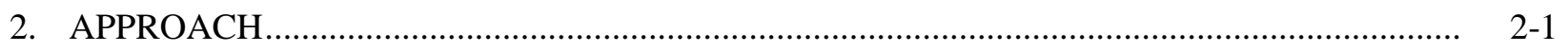

2.1 SUBCONTRACT LABORATORIES ..................................................................... $2-1$

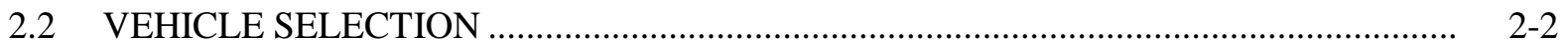

2.2.1 Vehicle Model Identification........................................................................ 2-2

2.2.2 Vehicle Acceptance ..................................................................................... 2-4

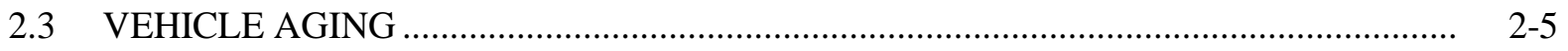

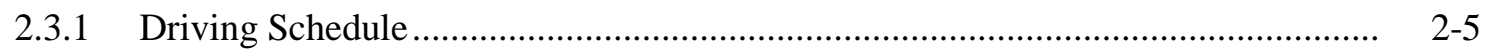

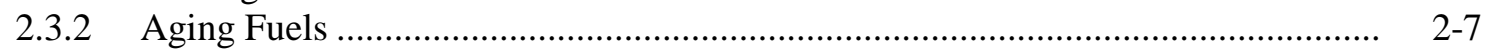

2.3.3 Vehicle Maintenance .................................................................................. 2-7

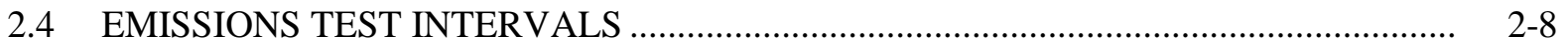

2.4.1 Vehicle Instrumentation and Configuration ...................................................... 2-8

2.4.2 Chassis Dynamometer Laboratories...................................................................... 2-8

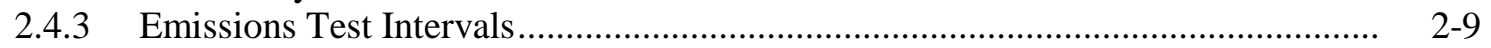

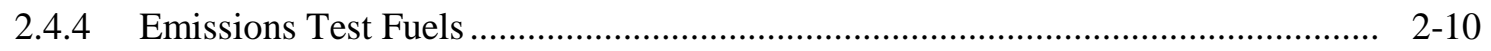

2.4.5 Fuel Change and Adaptation Procedures......................................................... 2-10

2.4.6 Emissions Test Procedure........................................................................... 2-12

2.4.7 Wide-Open Throttle Tests ......................................................................... 2-12

2.4.8 Compression and Leak-Down Tests.............................................................. 2-13

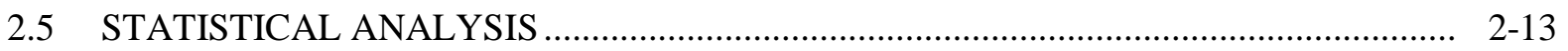

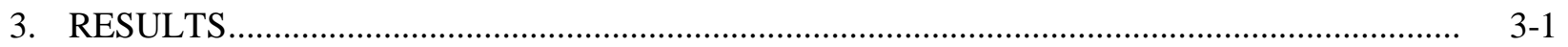

3.1 APPLICATION OF LONG-TERM FUEL TRIM AT WIDE-OPEN

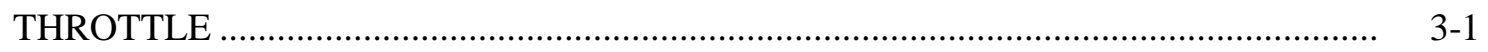

3.2 EMISSIONS AND FUEL ECONOMY …................................................................. $\quad 3-4$

3.2.1 Fuel Economy Calculation ................................................................................ $3-4$

3.2.2 Vehicle Dynamometer Coefficients .............................................................. 3-5

3.2.3 Nonmethane Organic Gas Estimations .............................................................. 3-6

3.2.4 End-of-Test Emissions Results.................................................................... 3-8

3.2.5 Statistical Analysis of Emissions Results ........................................................ 3-12

4. SUMMARY OF UNSCHEDULED MAINTENANCE AND VEHICLE

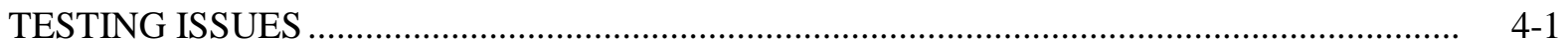

4.1 UNSCHEDULED MAINTENANCE .................................................................... $4-1$

4.2 VEHICLE TESTING ISSUES ................................................................................. $4-3$

4.2.1 Nissan Quest Testing Issues ............................................................................. $4-3$ 
4.2.2 Jeep Liberty Start-of-Test Emissions Tests ....................................................

4.2.3 Ethanol and Aldehyde Emissions Issues ............................................................. 4-5

APPENDIX A. VEHICLE EMISSIONS STANDARDS ........................................................... A-1

APPENDIX B. STATISTICAL ANALYSIS MODEL AND HYPOTHESES FOR ANALYZING VEHICLE DURABILITY TEST DATA …............................... B-1

APPENDIX C. DETAILED VEHICLE INFORMATION ........................................................ C-1

APPENDIX D. DETAILED STATISTICAL RESULTS BY PARAMETER .............................. D-1

APPENDIX E. DETAILED STATISTICAL RESULTS BY VEHICLE MODEL ........................ E E-1 


\section{LIST OF FIGURES}

Figure

Page

2.1 The standard road cycle for vehicle emissions control system aging .................................. 2-5

2.2 Mileage accumulation dynamometers at the Environmental Testing

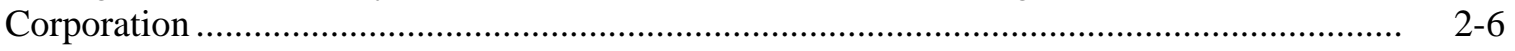

2.3 Test track at the Transportation Research Center ............................................................. 2-6

2.4 Sliding scale for emissions test scheduling................................................................... 2-9

3.1 Typical time-speed driving profile for the wide-open throttle tests..................................... $3-2$

3.2 Wide-open throttle (WOT) test lambda data for a 2009 Ford Explorer................................. 3-2

3.3 Wide-open throttle (WOT) test lambda data for a 2009 Honda Civic .................................. 3-3

3.4 Code of Federal Regulations (CFR) fuel economy equation scaling, using different R factors, for emissions test fuels used at Southwest Research Institute .................. 3-5

3.5 Regression of nonmethane organic gas/nonmethane hydrocarbon (NMOG/ $\mathrm{NMHC}$ ) ratios to fuel ethanol content

3.6 Nonmethane organic gas (NMOG) estimate error for test results from the Transportation Research Center.....

3.7 Median change in fuel economy and $\mathrm{CO}, \mathrm{NO}_{\mathrm{x}}$, nonmethane hydrocarbon (NMHC), nonmethane organic gas (NMOG), and $\mathrm{CH}_{4}$ emissions relative to $\mathrm{E} 0$

3.8 Median change in ethanol, acetaldehyde, and formaldehyde emissions relative to E0

4.1 Jeep Liberty start-of-test (SOT) nonmethane hydrocarbon (NMHC) emissions using E0 before and after battery disconnection.

4.2 Jeep Liberty start-of-test (SOT) CO emissions using E0 before and after battery disconnection 



\section{LIST OF TABLES}

Table

Page

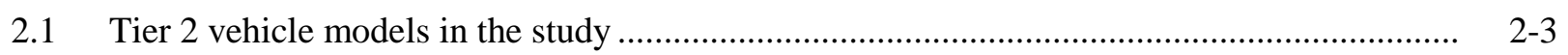

2.2 Non-Tier-2 vehicle models in the study..................................................................... $2-4$

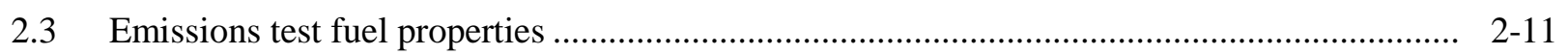

3.1 Long-term fuel trim (LFT) at wide-open throttle (WOT) status for the program vehicles ...................................................................................................... $3-4$

3.2 Summary of minimum, average, and maximum emissions test (Federal Test Procedure with E0 fuel) results for Tier 2 vehicles ........................................................... 3-9

3.3 Summary of minimum, average, and maximum emissions test (Federal Test Procedure with E0 fuel) results for pre-Tier-2 vehicles.................................................. 3-10

3.4 Summary of minimum, average, and maximum emissions test (Federal Test Procedure with E10, E15, or E20 fuel) results for Tier 2 vehicles

3.5 Summary of minimum, average, and maximum emissions test results for pre-Tier-2 vehicles tested with ethanol-blended emissions test fuels

(Federal Test Procedure with E15 or E20 fuel)

3.6 Summary of results by emission/performance parameter ................................................... $3-13$

3.7 Median change in fuel economy and emissions relative to E0 with interquartile range (Federal Test Procedure results at start-of-test)

4.1 Notable unscheduled maintenance issues 



\section{ACRONYMS}

\begin{tabular}{|c|c|}
\hline AFR & air : fuel ratio \\
\hline BMI & Battelle Memorial Institute \\
\hline CFR & Code of Federal Regulations \\
\hline CMB & carbon mass balance \\
\hline $\mathrm{CO}$ & carbon monoxide \\
\hline CRC & Coordinating Research Council \\
\hline DOE & U.S. Department of Energy \\
\hline EERE & $\begin{array}{l}\text { Office of Energy Efficiency and Renewable } \\
\text { Energy (DOE) }\end{array}$ \\
\hline EOT & end-of-test \\
\hline EPA & U.S. Environmental Protection Agency \\
\hline ETC & Environmental Testing Corporation \\
\hline ETW & equivalent test weight \\
\hline FFV & flexible-fuel vehicle \\
\hline FTP & Federal Test Procedure \\
\hline FUL & full useful life \\
\hline LDT & light duty truck \\
\hline LFT & $\begin{array}{l}\text { long-term fuel trim (also known as learned } \\
\text { fuel trim) }\end{array}$ \\
\hline LVW & loaded vehicle weight \\
\hline MAD & mileage accumulation dynamometer \\
\hline MID & midlife aging \\
\hline MIL & malfunction indicator lamp \\
\hline NLEV & National Low Emission Vehicle (Program) \\
\hline NMHC & nonmethane hydrocarbon \\
\hline NMOG & nonmethane organic gas \\
\hline $\mathrm{NO}_{\mathrm{X}}$ & oxides of nitrogen \\
\hline NREL & National Renewable Energy Laboratory \\
\hline ORNL & Oak Ridge National Laboratory \\
\hline RVP & Reid vapor pressure \\
\hline SOT & start-of-test \\
\hline SRC & standard road cycle \\
\hline SwRI & Southwest Research Institute \\
\hline TRC & Transportation Research Center Inc. \\
\hline UEGO & universal exhaust gas oxygen sensor \\
\hline WOT & wide-open throttle \\
\hline
\end{tabular}





\section{ACKNOWLEDGMENTS}

This report and the work described were sponsored by the U.S. Department of Energy (DOE) Office of Energy Efficiency and Renewable Energy (EERE) Vehicle Technologies Program and the EERE Biomass Program. The authors gratefully acknowledge the support and direction of Kevin Stork, Steve Przesmitzki, Joan Glickman, and Brian Duff at DOE. This work has also benefited from substantial input and direction from numerous peers within the Coordinating Research Council and the U.S. Environmental Protection Agency. Several Oak Ridge National Laboratory (ORNL) staff, including Ron Graves and Tim Theiss, made important contributions to this work. Likewise, several National Renewable Energy Laboratory staff, including Wendy Clark and Bob McCormick, made equally important contributions. We acknowledge and appreciate the thorough review and input from Mike Kass and Howard Haynes at ORNL. Assistance with management and statistical analysis of the vehicle data by Marcie Mohnsen, Cynthia Cooper, Bryan Fair, Paul Feder, and Robert Krile at Battelle Memorial Institute is appreciated. The authors are also indebted to the staffs of the Southwest Research Institute, Transportation Research Center, and Environmental Testing Corporation, in particular Marty Heimrich, Brent Shoffner, Karrie Honchell, Walt Dudek, and Keith Vertin. The authors also wish to thank Brenda Smith, V. J. Ewing, and Kathy Jones for their tireless dedication in preparation of the final manuscript.

The authors are indebted to many technical experts in industry and government. While these experts provided valuable guidance and information as noted above, this consultation does not constitute endorsement by their organizations of either the study or the results. 



\section{EXECUTIVE SUMMARY}

\section{E.1 INTRODUCTION}

In the summer of 2007, the U.S. Department of Energy (DOE) initiated a test program to evaluate the potential impacts of intermediate ethanol blends (also known as mid-level blends) on legacy vehicles and other engines. ${ }^{*}$ The purpose of the test program was to develop information important to assessing the viability of using intermediate blends as a contributor to meeting national goals for the use of renewable fuels. Through a wide range of experimental activities, DOE is evaluating the effects of E15 and E20gasoline blended with $15 \%$ and $20 \%$ ethanol — on tailpipe and evaporative emissions, catalyst and engine durability, vehicle driveability, engine operability, and vehicle and engine materials.

This report provides the results of the catalyst durability study, a substantial part of the overall test program. Results from additional projects will be reported separately. The principal purpose of the catalyst durability study was to investigate the effects of adding up to $20 \%$ ethanol to gasoline on the durability of catalysts and other aspects of the emissions control systems of vehicles.

Section 1 provides further information about the purpose and context of the study. Section 2 describes the experimental approach for the test program, including vehicle selection, aging and emissions test cycle, fuel selection, and data handling and analysis. Section 3 summarizes the effects of the ethanol blends on emissions and fuel economy of the test vehicles. Section 4 summarizes notable unscheduled maintenance and testing issues experienced during the program. The appendixes provide additional detail about the statistical models used in the analysis, detailed statistical analyses, and detailed vehicle specifications.

\section{E.2 BACKGROUND}

The Energy Independence and Security Act of 2007 requires significant increases in the nation's use of renewable fuels to meet its transportation energy needs. The law expands the renewable fuel standard to require use of 36 billion gallons of renewable fuel by 2022. Given that ethanol is currently the most widely used renewable fuel in the U.S. market, it is reasonable to project that ethanol will likely make a significant contribution to meeting the 36-billion-gallon requirement.

The vast majority of ethanol currently used for transportation in the United States is blended with gasoline to create E10 — gasoline with up to 10\% ethanol. The remaining ethanol is sold in the form of E85-a gasoline blend with as much as $83 \%$ ethanol that can only be used in flexible-fuel vehicles (FFVs). Consumption of E85 is currently limited by the size of the FFV fleet, the number of E85 fueling stations, and occasional unfavorable pricing of E85 (on a dollars per unit energy basis).

The E10 market in the United States is reaching saturation; in 201013.2 billion gallons of ethanol were produced, and more than $90 \%$ of gasoline was sold as E10. ${ }^{\dagger}$ Although DOE remains committed to expanding the E85 infrastructure, the E85 market has represented less than 1\% of the ethanol consumed each year, making it difficult for that market to absorb projected volumes of ethanol in the near term. As a result, since 2007 DOE and others have been assessing the viability of using mid-level ethanol blends as an additional way to accommodate growing volumes of ethanol.

\footnotetext{
*The test program has been co-led and co-funded by the U.S. Department of Energy (DOE) Office of Energy Efficiency and Renewable Energy (EERE) Biomass Program and the EERE Vehicle Technologies Program with technical support from the Oak Ridge National Laboratory and the National Renewable Energy Laboratory. DOE and the laboratory team have worked closely with representatives from the U.S. Environmental Protection Agency, U.S. auto manufacturers, engine companies, and other organizations to develop and conduct the test program.

${ }^{\dagger}$ U.S. Energy Information Administration, Monthly Energy Review, DOE/EIA-0035(2011/07), July 27, 2011, available at http://www.eia.gov/FTPROOT/multifuel/mer/00351107.pdf.
} 


\section{E.3 DEVELOPMENT OF TEST PROGRAM}

The Coordinating Research Council E-87 program $^{*}$ and DOE V1 program ${ }^{\dagger}$ identified several high-salesvolume vehicle models that did not apply long-term (or learned) fuel trim (LFT) at open loop conditions, and thus produced hotter exhaust and catalyst temperatures at full power operation when operated with ethanol blends compared to ethanol-free gasoline. Based on the literature, there was concern that increasing the ethanol fraction in gasoline for these vehicles could result in increased emissions over time. ${ }^{\ddagger, \S}$ Because of this concern, DOE supported the development and execution of a catalyst durability study unprecedented in size and scope.

To assess the durability of emissions control systems, the U.S. Environmental Protection Agency's (EPA's) vehicle test procedures allow for whole vehicle "aging” using the standard road cycle (SRC).* In this program, vehicles at Southwest Research Institute and Environmental Testing Corporation were driven on mileage accumulation dynamometers (MADs), while vehicles at Transportation Research Center were driven on a closed test track. In all three cases, vehicles were operated recursively over the SRC. Vehicles were purchased in matched sets and aged on the MADs or on the track using a separate dedicated ethanol blend for each vehicle of a set. Emissions were measured using the Federal Test Procedure (FTP) at start-of-test (SOT), at one or two midlife points, and again at end-of-test (EOT). All test vehicles were driven at least 50,000 miles from SOT to EOT, while many vehicles were driven more than 100,000 miles. All vehicles were near or beyond their regulatory full useful life mileage at EOT. In total, 82 vehicles were driven more than 6 million miles in this project.

Vehicles from the six largest vehicle manufacturers were represented in the study, including cars and light trucks from General Motors, Ford, Chrysler, Toyota, Honda, and Nissan. Eighteen Tier 2 vehicle models (i.e., vehicle models built to meet EPA's Tier 2 emission standards) from model years 2005 through 2009 and eight pre-Tier-2 vehicle models from model years 2000-2003 were aged using the SRC protocol. Emissions were tested periodically throughout the program.

Vehicles were acquired to establish matched sets of two, three, or four vehicles of each model being tested. Each vehicle of a set was dedicated to a specific gasoline-ethanol blend for aging. Retail, top-tier ethanol-free gasoline $^{\dagger \dagger}$ (RE0) was splash blended with ASTM D4806 ethanol to produce $10 \%$, 15\%, and $20 \%$ ethanol blends (RE10, RE15, and RE20) for vehicle aging. Four pairs of vehicles were aged with RE0 and RE15, five vehicle sets with four matched vehicles were aged with RE0, RE10, RE15, and RE20. The remaining 18 vehicle sets were aged with RE0, RE15, and RE20. Emissions tests were conducted with Federal Certification Gasoline (E0) similarly blended to make the appropriate emissions test fuels (E10, E15, and E20). All vehicles, including those dedicated to ethanol-blended fuels, were emissions tested with the E0 fuel at each test interval. Time and budget constraints necessitated the use of

\footnotetext{
*Transportation Research Center Inc., Mid-Level Ethanol Blends Catalyst Durability Study Screening, CRC Report E-87-1, Coordinating Research Council, Inc., Alpharetta, Georgia, June 2009.

${ }^{\dagger}$ Keith Knoll et al., Effects of Intermediate Ethanol Blends on Legacy Vehicles and Small Non-Road Engines, Report 1Updated, NREL/TP-540-43543/ORNL/TM-2008/117, February 2009, available at http://www.nrel.gov/docs/fy09osti/43543.pdf.

${ }^{\ddagger} \mathrm{R}$. Bechtold et al., Technical Issues Associated with the Use of Intermediate Ethanol Blends (>E10) in the U.S. Legacy Fleet: Assessment of Prior Studies, ORNL/TM-2007/37, Oak Ridge National Laboratory, August 2007, available at http://info.ornl.gov/sites/publications/files/Pub7767.pdf.

${ }^{\S}$ Orbital Engine Company, Market Barriers to the Uptake of Biofuels Study; Testing Gasoline Containing 20\% Ethanol (E20), Phase 2B Final Report to the Department of the Environment and Heritage, Australia, May 2004.

${ }^{* *}$ U.S. Environmental Protection Agency, "Emission Durability Procedures and Component Durability Procedures for New Light-Duty Vehicles, Light-Duty Trucks and Heavy-Duty Vehicles,” Final Rule and Proposed Rule, 40 CFR Part 86, in Federal Register, Vol. 71(10), Tuesday, January 17, 2006.

${ }^{{ }^{\dagger}}$ Top-tier gasoline contains more deposit-control additives than the minimum allowable by EPA (http://www.toptiergas.com/).
} 
splash blends (as opposed to match blends) in this program. When using match blends, certain fuel properties such as volatility and octane can be tailored to match the desired ethanol blend level. When splash blends are used, it is understood that properties such as volatility and octane will vary with ethanol content, ${ }^{* \dagger}$ but it was felt that these variations would not impact the change in emissions due to aging on the SRC.

\section{E.4 SUMMARY OF FINDINGS}

Statistical analysis of emissions test results determined the following.

- $\quad$ Aging vehicles on the SRC increased emissions over time, as expected.

- Aging with ethanol blends did not affect emissions changes over time differently than aging with ethanol-free gasoline.

- Whether vehicles applied LFT under open-loop conditions did not affect emissions and fuel economy results.

- Addition of $10 \%$ to $20 \%$ ethanol to certification gasoline caused the following general fleetwide changes in measured tailpipe emissions and fuel economy compared to gasoline. (These immediate effects are largely consistent with findings of the DOE V1 study. ${ }^{\ddagger \S}$ )

— Median CO emissions decreased by 0.03 to $0.14 \mathrm{~g} / \mathrm{mile}$.

— Median nonmethane hydrocarbon emissions decreased by 0.002 to $0.008 \mathrm{~g} / \mathrm{mile}$.

- Median $\mathrm{NO}_{\mathrm{x}}$ emissions increased by 0.001 to $0.004 \mathrm{~g} / \mathrm{mile}$.

— Median ethanol emissions increased by 2.3 to $4.6 \mathrm{mg} / \mathrm{mile}$.

- Median acetaldehyde and formaldehyde emissions increased slightly (by less than $1 \mathrm{mg} / \mathrm{mile}$ ).

- Nonmethane organic gas and methane emissions were largely unchanged.

— Fuel economy was decreased by about 3\% to 7\%, consistent with the energy density of the test fuel.

\footnotetext{
*J. E. Anderson et al., "Octane Numbers of Ethanol- and Methanol-Gasoline Blends Estimated from Molar Concentrations,” Energy Fuels 2010, 24, pp. 6576-6585.

${ }^{\dagger}$ American Petroleum Institute, Determination of the Potential Property Ranges of Mid-Level Ethanol Blends, Final Report, April 2010.

${ }^{\ddagger}$ Keith Knoll et al., Effects of Intermediate Ethanol Blends on Legacy Vehicles and Small Non-Road Engines, Report 1Updated, NREL/TP-540-43543/ORNL/TM-2008/117, February 2009, available at http://www.nrel.gov/docs/fy09osti/43543.pdf. ${ }^{\S}$ Keith Knoll et al., "Effects of Mid-Level Ethanol Blends on Conventional Vehicle Emissions," SAE paper 2009-01-2723, SAE International, Warrendale, Pennsylvania, November 2009.
} 



\section{BACKGROUND}

The Energy Independence and Security Act of 2007 requires significant increases in the nation's use of renewable fuels to meet its transportation energy needs. The law establishes a new renewable fuel standard that requires the nation to use 36 billion gallons of renewable fuel in its vehicles by 2022. Given that ethanol is the most widely used renewable fuel in the United States and production is expected to continue to grow over the next several years, ethanol—both from corn ${ }^{*}$ and from cellulosic feedstockswill likely make up a significant portion of the renewable fuels required by the new standard. Most of the ethanol used in the United States is blended with gasoline to create E10-gasoline with up to 10\% ethanol. The remaining ethanol is sold in the form of E85-a gasoline blend with as much as 83\% ethanol that can only be used in flexible-fuel vehicles (FFVs). Consumption of E85 is currently limited by the size of the FFV fleet, the number of E85 fueling stations, and occasionally by unfavorable pricing of E85 (on a cost per unit energy basis). ${ }^{\dagger}$ While U.S. automakers have committed to significantly ramping up production of FFVs, only about 5\% of the existing U.S. fleet is replaced each year. That means a significant number of the non-FFVs in use today will remain in the vehicle stock for many years to come.

The E10 market in the United States was largely saturated in 2010, with 13.2 billion gallons of ethanol produced domestically, 400 million gallons exported, and gasoline consumption just under 140 billion gallons. ${ }^{\ddagger}$ Although the U.S. Department of Energy (DOE) remains committed to expanding the E85 infrastructure, it will be difficult for that market to absorb projected volumes of ethanol in the near term. Given this reality, DOE and others have been assessing the viability of using mid-level ethanol blends as an additional way to potentially accommodate growing volumes of ethanol.

In early 2007, DOE tasked Oak Ridge National Laboratory (ORNL) to conduct a literature search on intermediate ethanol blends, which indicated that insufficient data existed to predict the impacts of these fuels on U.S. vehicles and engines. ${ }^{\S}$ Due to the lack of data, DOE then initiated a test program to assess the potential impacts of mid-level ethanol blends on conventional vehicles (non-FFVs) and other engines that rely on gasoline. The latter include small non-road engines such as those used in lawn and garden equipment and other non-automotive engines such as those used in marine applications, motorcycles, and snowmobiles. ${ }^{* *}$ The DOE team developed a number of vehicle and non-automotive testing projects to help understand the potential effects of intermediate blends on legacy equipment. Vehicle-related projects were denoted V1, V2, and so on. ${ }^{\dagger \dagger}$ This report provides the results of V4, the Catalyst Durability Study $\left(\right.$ DOE Catalyst Study ${ }^{\ddagger \ddagger}$ ).

\footnotetext{
${ }^{*}$ The law puts a 15-billion-gallon limit on the amount of noncellulosic corn-based ethanol that can contribute to meeting the renewable fuel standard. Fifteen billion gallons is a little over $40 \%$ of the 36 billion gallon total.

${ }^{\dagger}$ Less than $1 \%$ of the ethanol used in the United States today is sold in the form of E85. About 8-9 million flexible-fuel vehicles, or about $4 \%$ of the U.S. fleet, are in use today, with about $1 \%$ of U.S. fueling stations providing E85.

${ }^{\ddagger}$ U.S. Energy Information Administration, Monthly Energy Review, DOE/EIA-0035(2011/07), July 27, 2011, available at http://www.eia.gov/totalenergy/data/monthly/pdf/mer.pdf.

${ }^{\S}$ R. Bechtold et al., Technical Issues Associated with the Use of Intermediate Ethanol Blends (>E10) in the U.S. Legacy Fleet, ORNL/TM-2007/37, Oak Ridge National Laboratory, August 2007, available at http://info.ornl.gov/sites/publications/files/Pub7767.pdf.

${ }^{* * *}$ Keith Knoll et al., Effects of Intermediate Ethanol Blends on Legacy Vehicles and Small Non-Road Engines, Report 1Updated, NREL/TP-540-43543/ORNL/TM-2008/117, February 2009, available at http://www.nrel.gov/docs/fy09osti/43543.pdf.

${ }^{\dagger}$ Brian West, et al., “Mid-Level Ethanol Blends Test Program,” presented at the 2010 U.S. DOE Hydrogen Program and Vehicle Technologies Program Annual Merit Review and Peer Evaluation Meeting, June 9, 2010, available at http://www1.eere.energy.gov/vehiclesandfuels/pdfs/merit_review_2010/fuel_technologies/ft005_west_2010_o.pdf.

非Federal Register, Vol. 76(17), Wednesday, January 26, 2011, Notices.
} 
In 2009, Growth Energy and a number of ethanol producers submitted a waiver request to the U.S. Environmental Protection Agency (EPA) to allow 15\% ethanol in gasoline. EPA granted partial approval to the waiver in October $2010^{*}$ and January $2011,^{\dagger}$ citing the DOE research program in the rulings.

The DOE program has been co-led and co-funded by the DOE Office of Energy Efficiency and Renewable Energy (EERE) Vehicle Technologies Program and EERE Biomass Program with technical support from ORNL and the National Renewable Energy Laboratory (NREL). DOE requested that the program be conducted as rapidly as possible. Multiple sites and parallel resources were combined to expedite the program.

${ }^{*}$ Federal Register, Vol. 75(213), Thursday, November 4, 2010, Notices.

${ }^{\dagger}$ Federal Register, Vol. 76(17), Wednesday, January 26, 2011, Notices. 


\section{APPROACH}

EPA regulations allow the following two standard options for evaluating emissions durability.

A. Standard whole vehicle exhaust durability procedure using the standard road cycle (SRC).

B. Standard bench aging exhaust durability procedure using the standard bench aging exhaust durability schedule. $^{*}$

Project leadership felt that option A was more robust and offered more convincing proof of the effects of mid-level ethanol blends; therefore, option A was used in this project. In this vehicle aging program, entire vehicles were aged, using a separate vehicle for each fuel blend. In most cases, vehicles were aged to their regulatory full useful life (FUL) mileage or beyond. Because manufacturers frequently use different control algorithms, catalyst formulations, etc., even among their own models, the aging program included vehicles from a number of manufacturers and car lines. Emissions tests were conducted throughout the aging program to assess the emissions compliance and emissions control deterioration as the vehicles accumulated mileage. This approach is described in Sect. 2.3.

\subsection{SUBCONTRACT LABORATORIES}

Southwest Research Institute (SwRI) in San Antonio, Texas, was initially selected as the laboratory to execute the planned testing program. However, after initiation of the program Transportation Research Center Inc. (TRC) in East Liberty, Ohio, and Environmental Testing Corporation (ETC) in Denver, Colorado, were added to expand and accelerate the anticipated testing efforts. It is worth noting that ETC is located at an elevation of roughly 5,000 feet; the impacts of testing at altitude may have been relevant for a fraction of the test fleet.

The SwRI and TRC contracts and testing programs were managed by ORNL, while NREL managed the contract and testing at ETC. Minor differences in the test plans at each laboratory owing to differences in the facilities, timing and management of the subcontracts, and specific vehicles assigned to each laboratory will be discussed in greater detail in later sections of this report. The SwRI contract was initiated by ORNL as a Coordinating Research Council (CRC ${ }^{\dagger}$ ) project (E-87-2). Members of the CRC Emissions Committee and the ORNL project manager participated in on-site meetings at SwRI and quarterly CRC Emissions Committee meetings to discuss progress and to help resolve technical issues with the test program.

The emissions test data from all three sites were forwarded to Battelle Memorial Institute (BMI) throughout the program. BMI was subcontracted by ORNL to serve as a clearinghouse for the data and to conduct statistical analyses to determine the impact of the ethanol fuels, if any, on the emissions test results. BMI created a database incorporating the data from the test sites for use in statistical analyses and additionally hosted a website where stakeholders could access the latest data during the program.

\footnotetext{
*U.S. Environmental Protection Agency, "Emission Durability Procedures and Component Durability Procedures for New LightDuty Vehicles, Light-Duty Trucks and Heavy-Duty Vehicles,” Final Rule and Proposed Rule. 40 CFR Part 86, in Federal Register, Vol. 71(10), Tuesday, January 17, 2006.

${ }^{\dagger}$ Coordinating Research Council (CRC) is a nonprofit organization that directs engineering and environmental studies on the interaction between automotive/other mobility equipment and petroleum products. Sustaining Members of CRC are the American Petroleum Institute and a group of automobile manufacturer members (Chrysler, Ford, General Motors, Honda, Mitsubishi, Nissan, Toyota, and Volkswagen). For more information see: http://crcao.org/.
} 


\subsection{VEHICLE SELECTION}

\subsubsection{Vehicle Model Identification}

A number of relevant criteria were used to select the Tier 2 vehicle models used in the program. These criteria included manufacturer, model year, sales/registration volumes, and whether a vehicle model did or did not apply long-term (or learned) fuel trim (LFT or non-LFT, respectively) at wide-open throttle (WOT). Several previous and ongoing studies provided information that impacted vehicle selection: EPA and DOE's EPAct/V2 vehicle study at SwRI, ${ }^{*}$ CRC's E-87-1 study, ${ }^{\dagger}$ and DOE's previous 16-vehicle screening study (DOE V1). ${ }^{\ddagger}$ Guidance from DOE and EPA on vehicle selection stipulated that all Tier 2 vehicles should include the 19 models from the EPAct study but allowed for a range of model years for these vehicles. One exception to the EPAct vehicle list was that the 2006 Nissan Quest (a high-priority CRC E-87-1 vehicle) replaced the Toyota Sienna.

In selecting the non-Tier-2 vehicles, similar factors were considered. The results of the CRC E-87-1 screening study, the DOE V1 study, relevant sales volumes, and matching with a similar late-model Tier 2 vehicle were all considered.

A database consisting of numbers of registered vehicles (as of July 1, 2008) by model year, manufacturer, model type, number of cylinders, fuel type, and engine size was purchased from R. L. Polk. Criteria for selecting additional models (beyond the 18 EPAct vehicle models) included the number of registered vehicles for each manufacturer and engine size. Selection was limited to vehicles from the six vehicle manufacturers with the highest vehicle registration volume: General Motors, Ford, Chrysler, Toyota, Honda, and Nissan. The CRC E-87-2 committee also provided input to the selection process. The study included vehicles certified to both Tier 1/NLEV (National Low Emission Vehicle Program) (model years 2000-2003) and Tier 2 (model years 2004 to 2009) standards. The non-Tier-2 fleet was limited to eight models by budget constraints. Extra care was required during acquisition of matched older vehicles due to the challenge of procuring matched older vehicles that had not exceeded their regulatory FUL and did not have repair or maintenance problems. Most of the Tier1/NLEV vehicles matched the model type (or replacement model type) and engine size for a subset of the Tier 2 models tested. A total of 19 Tier 2 and 8 Tier 1/NLEV vehicle models were chosen and are shown in Tables 2.1 and 2.2.

\footnotetext{
*Brian West, et al., "Mid-Level Ethanol Blends Test Program,” presented at the 2010 U.S. DOE Hydrogen Program and Vehicle Technologies Program Annual Merit Review and Peer Evaluation Meeting, June 9, 2010, available at http://www1.eere.energy.gov/vehiclesandfuels/pdfs/merit_review_2010/fuel_technologies/ft005_west_2010_o.pdf.

${ }^{\dagger}$ Transportation Research Center Inc., Mid-Level Ethanol Blends Catalyst Durability Study Screening, CRC Report E-87-1, Coordinating Research Council, Inc., Alpharetta, Georgia, June 2009.

${ }^{\ddagger}$ Keith Knoll et al., Effects of Intermediate Ethanol Blends on Legacy Vehicles and Small Non-Road Engines, Report 1Updated, NREL/TP-540-43543/ORNL/TM-2008/117, February 2009, available at http://www.nrel.gov/docs/fy09osti/43543.pdf.
} 
Table 2.1. Tier 2 vehicle models in the study

\begin{tabular}{|c|c|c|c|c|c|c|}
\hline $\begin{array}{l}\text { Test } \\
\text { site }\end{array}$ & $\begin{array}{c}\text { Model } \\
\text { year }\end{array}$ & Vehicle model & $\begin{array}{c}\text { Engine family } \\
\text { number }\end{array}$ & $\begin{array}{c}\text { Engine } \\
\text { displacement } \\
\text { (liters) }\end{array}$ & $\begin{array}{c}\text { Engine } \\
\text { configuration }\end{array}$ & $\begin{array}{c}\text { Tier } 2 \\
\text { emissions } \\
\text { standard }^{b}\end{array}$ \\
\hline \multirow{7}{*}{ 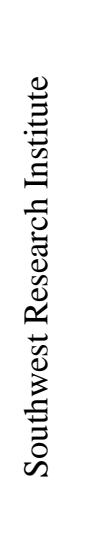 } & 2007 & Honda Accord & 7HNXV02.4KKC & 2.4 & $\mathrm{I} 4$ & Bin 5 \\
\hline & 2006 & Chevrolet Silverado & 6GMXT05.3379 & 5.3 & V8 & Bin 8 \\
\hline & 2008 & Nissan Altima & 8NSXV02.5G5A & 2.5 & $\mathrm{I} 4$ & Bin 5 \\
\hline & 2008 & Ford Taurus & 8FMXV03.5VEP & 3.5 & V6 & Bin 5 \\
\hline & 2007 & Dodge Caravan & 7CRXT03.8NEO & 3.8 & V6 & Bin 5 \\
\hline & 2006 & Chevrolet Cobalt & 6GMXV02.4029 & 2.4 & $\mathrm{I} 4$ & Bin 5 \\
\hline & 2007 & Dodge Caliber & 7CRXB02.4MES & 2.4 & I4 & Bin 5 \\
\hline \multirow{8}{*}{ 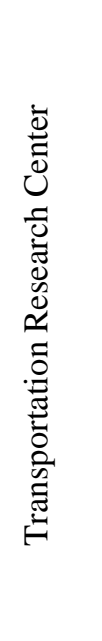 } & 2009 & Jeep Liberty & 9CRXT03.74PO & 3.7 & V6 & Bin 5 \\
\hline & 2009 & Ford Explorer & 9FMXT04.03DC & 4.0 & V6 & Bin 4 \\
\hline & 2009 & Honda Civic & 9HNXV01.8XB9 & 1.8 & $\mathrm{I} 4$ & Bin 5 \\
\hline & 2009 & Toyota Corolla & 9TYXV01.8BEA & 1.8 & I4 & Bin 5 \\
\hline & 2005 & Toyota Tundra & 5TYXT04.0NEM & 4.0 & V6 & Bin 5 \\
\hline & 2006 & Chevrolet Impala & 6GMXV03.9048 & 3.9 & V6 & Bin 5 \\
\hline & 2005 & Ford F150 & 5FMXT05.4R17 & 5.4 & V8 & Bin 8 \\
\hline & 2006 & Nissan Quest & 6NSXT03.5G7B & 3.5 & V6 & Bin 5 \\
\hline \multirow{4}{*}{ 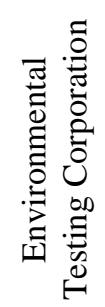 } & 2009 & Saturn Outlook & 9GMXT03.6151 & 3.6 & V6 & Bin 5 \\
\hline & 2009 & Toyota Camry & 9TYXV02.4BEA & 2.4 & $\mathrm{I} 4$ & Bin 5 \\
\hline & 2009 & Ford Focus & 9FMXV02.0VDX & 2.0 & $\mathrm{I} 4$ & Bin 4 \\
\hline & 2009 & Honda Odyssey & 9HNXT03.5J29 & 3.5 & V6 & Bin 5 \\
\hline
\end{tabular}

a"Engine family" and "test group” are often used interchangeably.

${ }^{b}$ Emissions standards are provided in Appendix A. 
Table 2.2. Non-Tier-2 vehicle models in the study

\begin{tabular}{|c|c|c|c|c|c|c|}
\hline $\begin{array}{l}\text { Test } \\
\text { site }^{a}\end{array}$ & $\begin{array}{l}\text { Model } \\
\text { year }\end{array}$ & Vehicle model & $\begin{array}{l}\text { Engine family } \\
\text { number }\end{array}$ & $\begin{array}{c}\text { Engine } \\
\text { displacement } \\
\text { (liters) }\end{array}$ & $\begin{array}{c}\text { Engine } \\
\text { configuration }\end{array}$ & $\begin{array}{l}\text { Emissions } \\
\text { standard }^{b}\end{array}$ \\
\hline \multirow{3}{*}{ 晃 } & 2000 & Chevrolet Silverado & YMXТ05.3181 & 5.3 & V8 & Tier $1 / \mathrm{LDT}^{c}{ }^{c}$ \\
\hline & 2002 & Nissan Frontier & 2NSXT02.4C4B ${ }^{d}$ & 2.4 & I4 & $\mathrm{NLEV} / \mathrm{LDT} 1^{c}$ \\
\hline & 2002 & Dodge Durango & 2CRXT04.75B0 & 4.7 & V8 & Tier $1 / \mathrm{LDT}^{c}{ }^{c}$ \\
\hline \multirow{3}{*}{$\underset{\sim}{\mathscr{U}}$} & 2003 & Toyota Camry & 3TYXV02.4HHA & 2.4 & I4 & ULEV \\
\hline & 2003 & Ford Taurus & 3FMXV03.0VF3 & 3.0 & V6 & NLEV \\
\hline & 2003 & Chevrolet Cavalier & 3GMXV02.2025 & 2.2 & I4 & NLEV \\
\hline \multirow{2}{*}{ 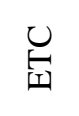 } & 2000 & Honda Accord & YHNXV02.3PF3 & 2.3 & I4 & NLEV \\
\hline & 2000 & Ford Focus & YFMXV02.0VF3 & 2.0 & I4 & NLEV \\
\hline
\end{tabular}

${ }^{a}$ SwRI $=$ Southwest Research Institute, TRC = Transportation Research Center Inc., ETC = Environmental Testing Corporation. ${ }^{b}$ Emissions standards provided in Appendix A. LDT = light duty truck, ULEV = ultralow emission vehicle, NLEV = National Low Emission Vehicle (Program).

${ }^{c}$ LDT1-LDT3 are light truck emissions categories based on vehicle weight. (See Appendix A.)

d،Engine family" on Frontier vehicles did not exactly match the EPA database for the 2002 Frontier (see Appendix C).

\subsubsection{Vehicle Acceptance}

Matched sets of vehicles were needed to provide a direct comparison of fuel effects on essentially identical vehicles. The subcontract laboratories procured the necessary vehicles under the direction of the program leadership. The vehicle sets were matched to prevent confounding of the data by undesirable vehicle attribute changes. The engine family, engine displacement, evaporative emissions control family, model year, powertrain control unit calibration, axle ratios, wheel size, and tire size were constrained to be identical within a vehicle set. Physical inspections of the vehicles to eliminate obvious problematic vehicles (such as those with gross fluid leaks or obvious and excessive body damage) were also a part of the selection process. Odometer mileage was used to identify candidate pre-titled vehicles with the goal of restricting the range of odometer readings within a vehicle set to a maximum of 10,000 miles (this goal was met in 24 of 27 cases). The number of vehicles in a matched set varied during the test program according to the number of fuels being targeted for test. In some cases four ethanol blend levels were tested (E0, E10, E15, and E20), and in other cases a subset of these fuels was tested. In all cases, one vehicle from each set was dedicated to a given ethanol blend level.

Upon purchase of suitably matched vehicle sets, the vehicles were inspected to ensure that any necessary maintenance (e.g., tires, brakes, fluid changes, overlooked scheduled maintenance) was performed before beginning the program. Vehicles were then subjected to a single emissions test to ensure that they were emissions compliant before instrumentation was installed. A few vehicles were rejected during this process, either because they exhibited maintenance issues that were deemed unacceptable or because they were found not to correctly match the other vehicles of their sets. Upon acceptance, instrumentation was installed and testing initiated, as detailed in other sections of this report. 


\subsection{VEHICLE AGING}

\subsubsection{Driving Schedule}

EPA specifies the SRC as a driving schedule to be used for aging vehicle emissions control systems. Details on the SRC can be found in the Code of Federal Regulations (CFR). ${ }^{*}$ The SRC contains driving elements typical of both city and highway driving, including, for example, cruise conditions, mild acceleration and deceleration events, idle conditions, and hard acceleration events. The SRC is shown graphically in Fig. 2.1.

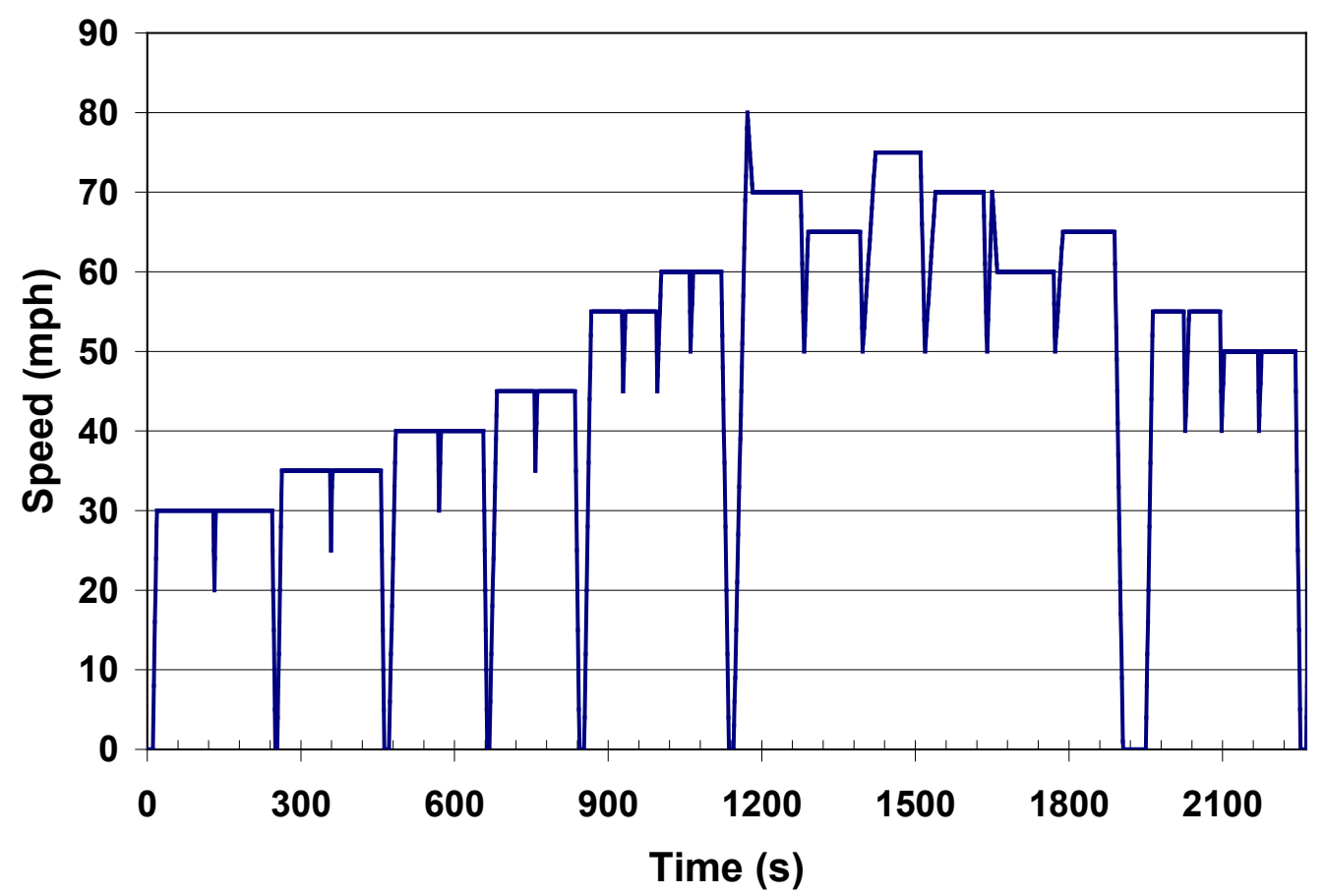

Fig. 2.1. The standard road cycle for vehicle emissions control system aging.

Both SwRI and ETC implemented the SRC using mileage accumulation dynamometers (MADs). Use of MADs offers the advantage of not requiring a driver during mileage accumulation; however, the number of vehicles that can be aged simultaneously is limited by the number of dynamometers available. Figure 2.2 shows several vehicles under test on the MADs at ETC. TRC implemented the SRC on a 7.5-mile closed track. This method of aging offers the ability to age a larger number of vehicles simultaneously; however, it requires a driver for each vehicle and scheduling delays can occur in the event of adverse weather conditions such as heavy snowfall. Figure 2.3 shows a view of the TRC highspeed track.

In this testing program vehicles were aged in around-the-clock operation to bring the program to a successful conclusion as rapidly as possible. Vehicles on MADs stopped several times per day for refueling but otherwise only stopped for maintenance or emissions tests, thus accumulating on the order of 1,000 miles per vehicle per test day. Vehicles tested on the track at TRC were stopped for driver breaks in addition to refueling, maintenance, and emissions tests and the occasional track safety shutdown due to

\footnotetext{
*U.S. Environmental Protection Agency, "Emission Durability Procedures and Component Durability Procedures for New LightDuty Vehicles, Light-Duty Trucks and Heavy-Duty Vehicles,” Final Rule and Proposed Rule. 40 CFR Part 86, in Federal Register, Vol. 71(10), Tuesday, January 17, 2006.
} 
inclement weather, accumulating on average 600-800 miles per vehicle per test day. Thus the vehicles did not experience many extended soak periods (extended periods with engine off) during the mileage accumulation portions of the program regardless of whether they were aged using MADs or the TRC track. Around-the-clock operation accelerates mileage accumulation and allows for more rapid assessment of catalyst durability. Limiting the soak periods would not be expected to affect tailpipe emissions changes associated with mileage accumulation.

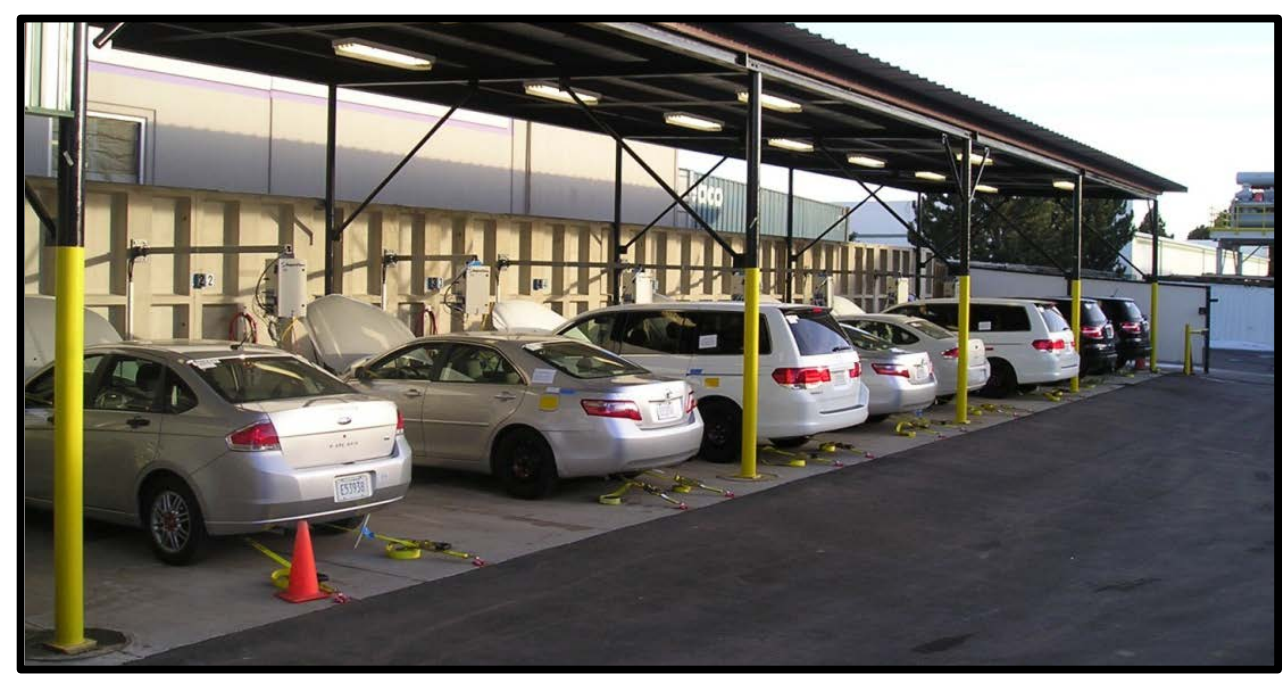

Fig. 2.2. Mileage accumulation dynamometers at the Environmental Testing Corporation.

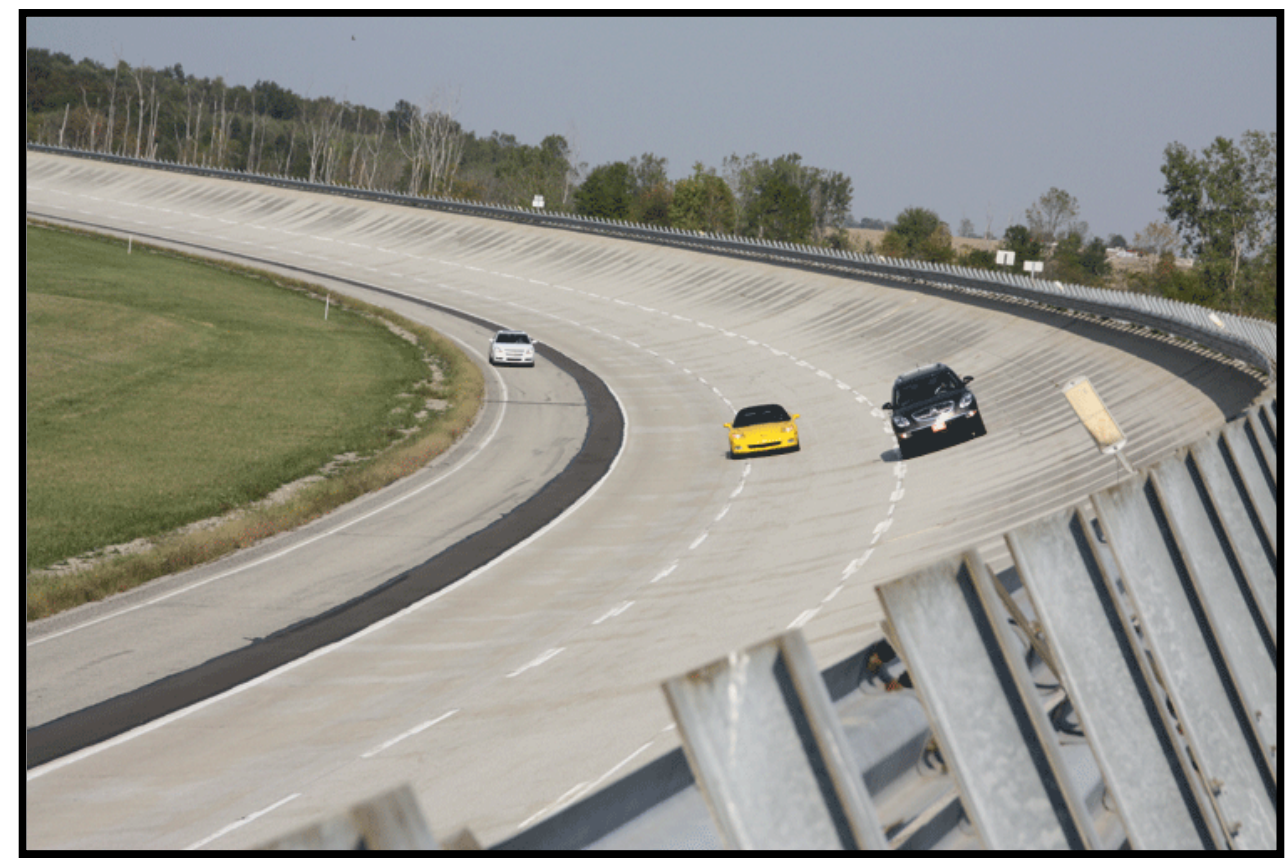

Fig. 2.3. Test track at the Transportation Research Center. 


\subsubsection{Aging Fuels}

Aging was conducted by assigning one vehicle of each set to a fuel with a given ethanol concentration (including E0). Because the vehicles would be accruing considerable mileage and because of the relatively large number of vehicles involved in the program, it was necessary to use splash blended fuels for the aging program to reduce the fuel cost to a manageable level. For this purpose, top-tier retail gasoline ${ }^{*}$ that did not contain ethanol was purchased locally and splash blended to produce the necessary ethanol-containing blends. SwRI acquired top-tier gasoline and splash blended it with retail ethanol (E95) on-site to produce the $10 \%, 15 \%$, and $20 \%$ ethanol blends required. TRC and ETC procured the ethanol blends from the terminal, pre-blended to the desired levels. The aging fuels were termed RE0, RE10, RE15, and RE20 to convey that they were blended using retail gasoline (also frequently referred to as "road fuel") and to denote the nominal ethanol content of each fuel. In all cases the ethanol content was tested before use of the fuel batch to ensure it fell within the desired range (ethanol content $\pm 1 \%$ ). Additional fuel analyses were also conducted; these analyses varied from site to site. SwRI and ETC analyzed each lot of fuel while TRC retained samples of each lot and subsequently analyzed some of the samples.

Time and budget constraints necessitated the use of splash blends as opposed to match blends in this program. When using match blends, certain fuel properties such as volatility and octane can be tailored to match the desired ethanol blend level. When splash blends are used, it is understood that properties such as volatility and octane will vary with ethanol content ${ }^{\dagger, \neq}$, but it was felt that these variations would not impact the change in emissions due to aging on the SRC. Because the aging fuels were splash blended, the octane number, Reid vapor pressure (RVP), and other fuel properties varied depending upon the ethanol content and whether the gasoline was a summer or winter blend.

The test laboratories implemented procedures to prevent misfueling during the aging program. At TRC, for example, the fuel filler doors were retrofitted with a keyed lock; the key needed to open the lock was located at the appropriate fuel pump.

\subsubsection{Vehicle Maintenance}

Because all of the vehicles were each driven at least 50,000 miles, maintenance was a required part of the aging program. As previously mentioned, all pre-titled vehicles were checked initially to ensure that any routine or scheduled maintenance was performed before the beginning of the program. During the aging program, the owner's manual for each vehicle model was consulted to determine the maintenance schedule. Scheduled maintenance (including lubricating oil changes; brake service; spark plug, tire, and belt replacements) was performed by the test laboratories on-site to minimize downtime in the program. Oil changes were scheduled such that they never occurred less than 500 miles before an emissions test sequence. Oil samples were collected at each oil change and retained for potential future analysis. A selection of these samples was analyzed at the end of the program as a part of the engine component inspection activity at SwRI. ${ }^{\S}$

Occasionally there was a need for unscheduled maintenance on the vehicles. Unscheduled maintenance was frequently performed on-site, but occasionally local dealership service departments were used.

\footnotetext{
*Top-tier gasoline contains more deposit-control additives than the minimum allowable by EPA (http://www.toptiergas.com/).

${ }^{\dagger} \mathrm{J}$. E. Anderson et al., "Octane Numbers of Ethanol- and Methanol-Gasoline Blends Estimated from Molar Concentrations,” Energy Fuels, 2010, 24, pp. 6576-6585.

${ }^{\ddagger}$ American Petroleum Institute, Determination of the Potential Property Ranges of Mid-Level Ethanol Blends, Final Report, April 2010.

${ }^{\S}$ Brent A. Shoffner et al., Powertrain Component Inspection from Mid-Level Blends Vehicle Aging Study, ORNL/TM-2011/65, Prepared by Southwest Research Institute for Oak Ridge National Laboratory, November 2010, available at http://info.ornl.gov/sites/publications/files/Pub28733.pdf.
} 
Unscheduled maintenance included events such as transmission replacement or repair, wheel bearing replacement, and body damage repair from animal strikes on the test track. The test laboratories were instructed to stop mileage accumulation and investigate any occurrence of a malfunction indicator lamp (MIL). Upon gathering information about the possible causes of the MILs, the test laboratories contacted the program leadership to discuss the most appropriate actions to address the MILs. In cases where component parts were replaced that could conceivably be related to the fuel being used, the original parts were labeled and retained for possible analysis later in the program. Vehicle maintenance issues are summarized in Sect. 4.

\subsection{EMISSIONS TEST INTERVALS}

The primary purpose of this program was to investigate the potential impacts of the use of mid-level ethanol blends on the emissions control systems of vehicles; hence, emissions tests were an essential part of the program. Vehicles dedicated to RE0 aging fuel were only emissions tested using ethanol-free emissions fuel. Vehicles dedicated to an ethanol-containing retail fuel blend (RE10, RE15, or RE20) were subjected to emissions tests using both an emissions test fuel with matching ethanol level and ethanol-free fuel. The Federal Test Procedure (FTP) driving schedule was used for all emissions tests in the program. WOT tests were incorporated at each test interval both to examine the vehicles' use of LFT at WOT conditions and to desulfurize the catalysts before emissions tests. All emissions and WOT tests were conducted using the certification fuel blends.

\subsubsection{Vehicle Instrumentation and Configuration}

Because FTP test results can be influenced by differences in tire condition and tire pressure, a duplicate set of wheels and tires for the driven wheels was acquired for each vehicle so that the vehicle would use the same set of wheels and tires for each FTP test throughout the program. This approach reduced concerns about the impacts of replacement tires that would be needed for the vehicles as they completed the lengthy aging program. The tires used for emissions tests were retained at the emissions laboratory and were reinstalled when vehicles arrived for emissions tests and subsequently removed and replaced as the vehicles returned to mileage accumulation.

Additionally, instrumentation was installed in each vehicle to support the LFT evaluations during WOT tests. Thermocouples were installed in the vehicle exhausts to monitor catalyst inlet and outlet gas temperatures. In some cases thermocouples were also installed in the catalyst monolith for more direct assessment of the catalyst temperature. A universal exhaust gas oxygen sensor (UEGO) was also installed upstream of the first catalyst to characterize the engine air : fuel ratio (AFR) during WOT tests. The UEGOs were removed from the vehicles before mileage accumulation to avoid damage and reinstalled during each emissions test sequence. The thermocouples and UEGOs were used primarily in the WOT tests to assess the use of LFT at WOT and its impact on catalyst temperature.

\subsubsection{Chassis Dynamometer Laboratories}

All three test sites used modern 48 in. single roll motoring dynamometers for emissions testing. TRC used their four-wheel-drive-capable AVL dynamometer; tests at SwRI used a Horiba two-wheel-drive unit, and ETC used their Burke Porter two-wheel-drive dynamometers. All laboratories used full flow dilution tunnels with bag benches for determining emissions of carbon monoxide (CO), carbon dioxide, total hydrocarbons, and oxides of nitrogen $\left(\mathrm{NO}_{\mathrm{X}}\right)$. Methane $\left(\mathrm{CH}_{4}\right)$ was measured by gas chromatographic flame ionization analyzer at all sites. Ethanol measurements at SwRI were conducted using the impinger method throughout the program. TRC initially used an Innova 1312 photoacoustic spectrometer to measure ethanol but switched to an impinger method, as will be discussed later in the report. ETC used an Innova 1312 photoacoustic spectrometer for ethanol measurements throughout the program. All three 
laboratories used di-nitrophenylhydrazine cartridges to trap carbonyls for later analysis by highperformance liquid chromatography.

\subsubsection{Emissions Test Intervals}

Emissions tests were conducted at several points during the program to assess both the emissions compliance of the vehicles and to track changes in emissions due to aging with different fuels. Emissions tests were conducted at the start-of-test (SOT), midlife aging (MID1 and MID2), and end-of-test (EOT). Vehicles purchased new were aged 4,000 miles using RE0 fuel before the initial emissions tests to degreen (or break in) the catalysts and powertrain. Thus for the new vehicles, the SOT tests occurred at 4,000 odometer miles. Vehicles purchased from the in-use fleet (pre-titled or used vehicles) had accumulated mileage before their acquisition for this program. These mileages varied but were generally consistent with the age of the vehicle and typically ranged less than 10,000 odometer miles from highest to lowest in each vehicle set. Thus, the pre-titled cars underwent SOT tests at various mileages, but the mileage accumulation for each vehicle of a set was always the same.

Midpoint emissions tests were scheduled according to the mileage accumulated on the vehicles before the start of the program. For vehicles purchased new, the midlife emissions tests were conducted at 60,000 odometer miles (or 56,000 test miles given the 4,000-mile break-in period before the SOT emissions tests). New vehicles that were tested at ETC received a second midpoint test at 90,000 odometer miles (MID2). Midpoint tests were scheduled for pre-titled cars in accordance with the previously accrued mileage on the vehicles. Determination of the midlife schedule in terms of odometer miles was made according to a sliding scale, shown in Fig. 2.4.

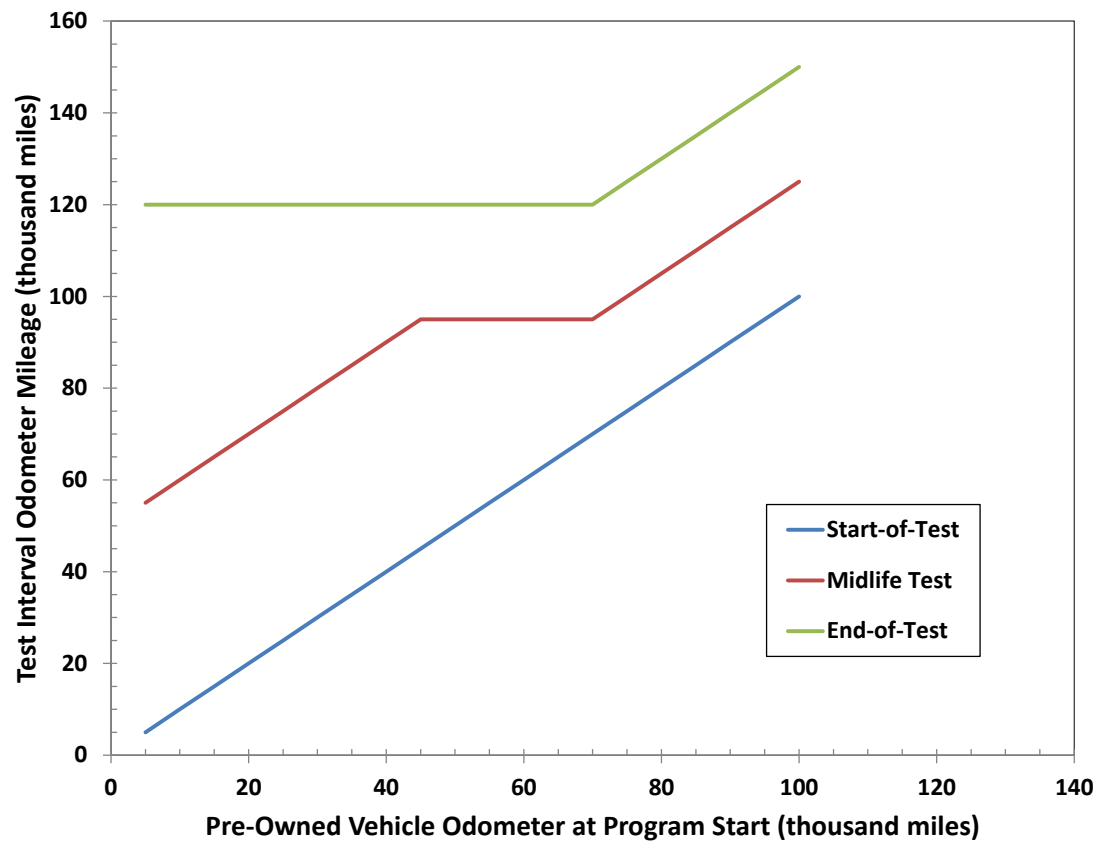

Fig. 2.4. Sliding scale for emissions test scheduling.

Vehicles with less than 45,000 miles at the start of the program were driven 50,000 miles before the midpoint emissions test. Vehicles with mileages between 45,000 and 70,000 miles were driven to 90,000 miles before the midpoint emissions test. Finally, vehicles with more than 75,000 miles were driven 25,000 miles before the midpoint emissions test. 
The EOT emissions tests were also scheduled according to the sliding scale shown in Fig. 2.4. If the highest mileage vehicle of a set had previously accrued mileage less than 70,000 miles, then the EOT test was performed at 120,000 odometer miles. If the vehicle had in excess of 70,000 miles at SOT, the EOT test was scheduled to occur after an additional 50,000 miles of aging (or 25,000 miles beyond the midpoint test).

In all cases, the mileage used in determining the midpoint and EOT scheduling was the highest odometer mileage vehicle of each vehicle set. Thus, the highest mileage vehicle of a set determined the total aging mileages and all vehicles of a given set were aged an equal number of miles. This strategy also resulted in a minimum of 25,000 miles of aging between any two emissions test intervals.

\subsubsection{Emissions Test Fuels}

The emissions test fuels were splash blends using emissions certification gasoline and denatured ethanol. TRC sourced the emissions fuel components (UTG-96 Federal Certification Gasoline and denatured ethanol) from Chevron-Phillips Specialty Chemical Company. SwRI obtained Haltermann EEE certification gasoline, and ETC used both Chevron-Phillips and Haltermann fuels. The ethanol blends were splash blended on-site at each test laboratory and subsequently analyzed to provide the fuel properties needed to support data analysis. Additional fuel analyses beyond those required for emissions tests were also performed on selected samples. These emissions test fuels were termed E0, E10, E15, and E20 to denote that they were different from the retail fuels used for vehicle aging (RE0, for example). As with the aging fuels, the octane number, RVP, and other properties of the emissions fuels varied with the ethanol content as a consequence of the splash blended nature of the fuels. Because all emissions tests were conducted at a nominal $25^{\circ} \mathrm{C}$ and because tracking emissions changes over time was the primary program objective, the use of splash blends in lieu of match blends was not expected to impact the results. In addition, acquisition of match blends would have presented unreasonable cost and time delay burdens to the program. Table 2.3 shows selected fuel properties for typical batches of emissions test fuels at each laboratory.

\subsubsection{Fuel Change and Adaptation Procedures}

Fuel change and adaptation procedures were required both to transition vehicles from the retail fuels used for aging to the certification fuel blends used for emissions testing, as well as to transition between ethanol-blended and ethanol-free certification fuels during emissions tests. The procedure for fuel change and vehicle adaptation was as follows.

1. Drain vehicle fuel tank.

2. Fill the fuel tank to about $40 \%$ of capacity with the desired fuel.

3. Start the engine and allow it to idle for $2 \mathrm{~min}$; then stop the engine.

4. Drain vehicle fuel tank.

5. Key-on for 30 s to allow the engine control unit to observe the empty fuel tank; then return to key-off.

6. Fill the fuel tank to about $40 \%$ of capacity with the desired fuel.

7. Perform three $\mathrm{LA} 4^{*}$ driving cycles, and allow the vehicle to idle in park for 2 min before engine shutdown.

8. Move vehicle to soak area without starting or driving.

9. Soak 12 to $36 \mathrm{~h}$ for cold start FTP test.

ETC additionally conducted a single drain-and-fill to $40 \%$ fuel tank capacity and an evaporative canister butane loading procedure before each individual FTP test per the CFR protocol.

*LA4, also known as the Urban Dynamometer Driving Schedule (UDDS), refers to the first two phases (or "bags”) of the Federal Test Procedure. 
Table 2.3. Emissions test fuel properties

\begin{tabular}{|c|c|c|c|c|c|c|c|c|c|c|c|}
\hline \multirow{3}{*}{ Fuel Characteristic } & \multirow{2}{*}{$\begin{array}{c}\text { Test Site } \\
\text { Fuel }\end{array}$} & \multicolumn{4}{|c|}{ SouthWest Research Institute ${ }^{a}$} & \multicolumn{3}{|c|}{ Transportation Research Center ${ }^{a}$} & \multicolumn{3}{|c|}{ Environmental Testing Corp ${ }^{a}$} \\
\hline & & EO & E10 & E15 & $\mathrm{E} 20$ & $\mathrm{EO}^{b}$ & E15 & E20 & EO & E15 & E20 \\
\hline & \begin{tabular}{|c|} 
Batch \\
ASTM Method \\
\end{tabular} & GA-6889 & GB-6968 & GB-7467 & GB-7198 & ORNLE0 & ORNLE15 & ORNLE20 & 949727 & 949728 & 949729 \\
\hline Carbon (wt\%) & D5291 & 86.31 & 82.99 & 81 & 79.58 & 87.2 & 81.32 & 79.2 & 87.61 & 81.33 & 78.64 \\
\hline Hydrogen (wt\%) & D5291 & 12.98 & 13.22 & 13.19 & 13.36 & 12.8 & 13.36 & 13.33 & 13.58 & 13.27 & 13.16 \\
\hline Oxygen (wt\%) & D5599/D5622 ${ }^{c}$ & 0 & 3.77 & 5.64 & 7.38 & 0 & 6 & 7.65 & 0 & 5.46 & 7.44 \\
\hline Specific Gravity & $\mathrm{D} 4052$ & 0.7437 & 0.7484 & 0.7516 & 0.7525 & 0.7439 & 0.7532 & 0.7563 & 0.7385 & 0.7492 & 0.7525 \\
\hline \begin{tabular}{|l|} 
Net Heating Value (BTU/Ibm) \\
\end{tabular} & D240 & 18611 & 17853 & 17345 & 17093 & 18581 & 17298 & 16809 & 18614 & 17449 & 17030 \\
\hline Ethanol Content (vol \%) & D5599/D4815 ${ }^{d}$ & 0 & 10.04 & 15.21 & 20.16 & 0 & 14.53 & 20.49 & 0 & 14.8 & 20.3 \\
\hline Distillation & D86 & & & & & & & & & & \\
\hline $\mathrm{IBP}\left({ }^{\circ} \mathrm{F}\right)$ & & 88 & 89 & 89 & 90 & 86 & 89 & 90 & 89 & 97 & 96 \\
\hline $5 \%\left({ }^{\circ} \mathrm{F}\right)$ & & 113 & 115 & 117 & 119 & 110 & 111 & 110 & 115 & 118 & 121 \\
\hline $10 \%\left({ }^{\circ} \mathrm{F}\right)$ & & 127 & 124 & 126 & 128 & 120 & 121 & 122 & 127 & 126 & 128 \\
\hline $20 \%\left({ }^{\circ} \mathrm{F}\right)$ & & 149 & 137 & 139 & 141 & 138 & 134 & 136 & 144 & 136 & 139 \\
\hline $30 \%\left({ }^{\circ} \mathrm{F}\right)$ & & 175 & 149 & 150 & 152 & 162 & 147 & 149 & 165 & 148 & 150 \\
\hline $40 \%\left({ }^{\circ} \mathrm{F}\right)$ & & 203 & 157 & 159 & 160 & 194 & 158 & 160 & 190 & 157 & 158 \\
\hline $50 \%\left({ }^{\circ} \mathrm{F}\right)$ & & 222 & 202 & 164 & 164 & 220 & 166 & 165 & 213 & 164 & 164 \\
\hline $60 \%\left({ }^{\circ} \mathrm{F}\right)$ & & 233 & 228 & 214 & 169 & 233 & 218 & 169 & 226 & 212 & 167 \\
\hline $70 \%\left({ }^{\circ} \mathrm{F}\right)$ & & 244 & 239 & 235 & 236 & 246 & 241 & 237 & 237 & 236 & 227 \\
\hline $80 \%\left({ }^{\circ} \mathrm{F}\right)$ & & 265 & 258 & 255 & 256 & 267 & 261 & 258 & 255 & 255 & 250 \\
\hline $90 \%\left({ }^{\circ} \mathrm{F}\right)$ & & 319 & 312 & 307 & 308 & 313 & 306 & 301 & 299 & 296 & 294 \\
\hline $95 \%\left({ }^{\circ} \mathrm{F}\right)$ & & 337 & 334 & 333 & 331 & 345 & 339 & 341 & 345 & 345 & 347 \\
\hline $\mathrm{FBP}\left({ }^{\circ} \mathrm{F}\right)$ & & 396 & 376 & 383 & 372 & 388 & 390 & 388 & 390 & 402 & 399 \\
\hline DVPE (psi) & D5191 & 8.74 & 9.61 & 9.36 & 8.74 & $\mathrm{~N} / \mathrm{A}$ & 10.09 & 9.87 & 7.91 & 8.55 & 8.33 \\
\hline $\begin{array}{l}{ }^{a} \text { All test sites used multiple batc } \\
b \text { TRC E0 properties were provide } \\
{ }^{c} \text { SwRI and ETC fuels analyzed b } \\
{ }^{d} \text { SwRI and ETC fuels analyzed b }\end{array}$ & $\begin{array}{l}\text { ches of each fu } \\
\text { ed by Chevron-F } \\
\text { by D5599; TRC }\end{array}$ & spec & Demic & pany & w & p. & 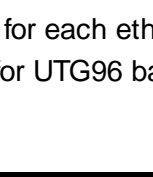 & . & & & \\
\hline
\end{tabular}




\subsubsection{Emissions Test Procedure}

Emissions tests at SwRI and TRC were generally conducted in duplicate for each vehicle and fuel combination, although additional tests were conducted occasionally when test-to-test variability was unusually high or if there was a known problem with any of the measurements. ETC conducted a minimum of three tests for each vehicle and fuel combination throughout the program. Vehicles were typically tested first at the ethanol level corresponding to their respective aging fuels, then using E0 (for the vehicles being aged using ethanol-blended fuels), although there were a few exceptions. Vehicles aged with RE0 were only emissions tested using E0. The typical procedure for tests at each test interval was as follows.

1. Reinstall emissions test tires and wide-range oxygen sensors.

2. Conduct fuel drain and adaptation procedure to emissions fuel at the same ethanol level as the vehicle aging fuel.

3. Conduct WOT test procedure.

4. Conduct duplicate (or triplicate) cold-start FTP tests.

5. Conduct fuel drain and adaptation procedure to E0 emissions fuel (for vehicles aged using ethanolblended fuels).

6. Conduct WOT test procedure.

7. Conduct duplicate (or triplicate) cold-start FTP tests.

8. Uninstall emissions test tires and wide-range oxygen sensors.

9. Conduct compression and leak-down tests.

The data from the FTP tests were examined after each test sequence to determine whether any tests were obviously flawed before the vehicles were released to return to mileage accumulation; however, the nonmethane organic gas (NMOG) speciation was not typically available until after the vehicles returned to mileage accumulation. In the event that any test was determined to be flawed, a repeat test was conducted before the car resumed mileage accumulation.

\subsubsection{Wide-Open Throttle Tests}

As mentioned previously, WOT tests were included in the program both to assess whether the vehicles applied LFT at WOT and to desulfurize the catalysts before emissions testing. The procedure for the WOT tests was similar to the CRC E-60 Program but with slight modifications as in the DOE V1 program. ${ }^{*}$ The WOT tests were performed on the emissions dynamometer as follows.

1. Drive from idle to $55 \mathrm{mph}$ and hold at $55 \mathrm{mph}$ for $5 \mathrm{~min}$.

2. Reduce speed to $30 \mathrm{mph}$ and hold at $30 \mathrm{mph}$ for $1 \mathrm{~min}$.

3. Reduce speed to idle and hold for $1 \mathrm{~min}$.

4. Accelerate at WOT for a minimum of $10 \mathrm{~s}$ to achieve speed in excess of $70 \mathrm{mph}$. Continue WOT above $70 \mathrm{mph}$ if necessary to achieve minimum $10 \mathrm{~s}$ WOT. Hold peak speed for $15 \mathrm{~s}$ then decelerate to $30 \mathrm{mph}$.

5. Repeat steps $2-4$ to achieve five WOT excursions.

6. Repeat steps $1-5$ for a total of 10 WOT accelerations.

Thermocouple and UEGO readings were recorded to monitor the catalyst temperature and engine AFR at a sample rate of at least $10 \mathrm{~Hz}$ during the WOT tests. These data were used to determine whether or not a vehicle applied LFT at WOT and to examine the catalyst temperatures for both types.

*Keith Knoll et al., Effects of Intermediate Ethanol Blends on Legacy Vehicles and Small Non-Road Engines, Report 1Updated, NREL/TP-540-43543/ORNL/TM-2008/117, February 2009, available at http://www.nrel.gov/docs/fy09osti/43543.pdf. 
The WOT test was conducted at each emissions test interval using E0 and the emissions fuel with the same ethanol level as the retail fuel (road fuel) used in the vehicle during mileage accumulation.

Additionally, at the beginning of the program, all vehicles at SwRI and TRC were WOT-tested using both E0 and E20 to examine whether all cars of a given model responded in the same way to the difference in ethanol content.

\subsubsection{Compression and Leak-Down Tests}

After the completion of emissions and WOT tests at each test interval, compression and leak-down tests were conducted. These tests were added to the test program in an effort to monitor the vehicles for abnormal degradation of the engines as a consequence of using fuels containing more than $10 \%$ ethanol. SwRI conducted one compression and leak-down test on each vehicle at each mileage interval. A need to establish the variability of the compression and leak-down tests was later identified, and TRC and ETC were asked to conduct three compression and leak-down tests on each vehicle at each test interval as a means of providing additional data. SwRI was also asked to perform additional compression and leakdown tests on several vehicles at the end of the program. The procedures in use at each site varied slightly in accordance with the instructions provided by the manufacturers of the leak-down tools that each site used. In general, however, a procedure for these tests was as follows.

1. Start and warm the vehicle until the cooling fan cycles on two times.

2. Conduct compression and leak-down tests. Use a battery charger during all compression tests to reduce the impact of battery condition on the test result.

3. Repeat steps 1 and 2 until three compression and leak-down tests have been performed.

While there were a few unusually high leak-down rates or low compression test results, there was no correlation between the two measurements, and none of the atypical results correlated to any out-ofcompliance emissions results or fuel-ethanol concentrations. The application of compression and leakdown measurements to vehicle aging are summarized in a separate technical paper. ${ }^{*}$

\subsection{STATISTICAL ANALYSIS}

Statistical analyses were conducted for the immediate and long-term effects of the fuel ethanol content on vehicle emissions for each vehicle model. Some immediate impacts of blending ethanol into gasoline are known. For example, it is well-accepted that the fuel economy (but not necessarily the engine's fuel efficiency) measured during an emissions test will decrease consistent with the change in the energy density of the fuel. This effect is immediate and does not require extended aging to become observable. However, the long-term aging effects posed by mid-level ethanol blends are not known and are the subject of this testing program. These effects, if present, require aging the vehicle before they become observable. One hypothetical example of a long-term effect might be more rapid decrease in the catalyst performance when aged using E15 relative to a vehicle that is aged using E0. The statistical model constructed for this program was designed to separate immediate and long-term effects. Details of the statistical model are presented in Appendix B.

Following the individual vehicle model analyses, a second set of statistical analyses was conducted to evaluate the overall effect of ethanol across the fleet of vehicle types tested. Specifically, the average (or median) test fuel and aging fuel effects were investigated to determine whether they were statistically

\footnotetext{
${ }^{*}$ C. S. Sluder and B. H. West, "Limitations and Recommended Practice in the Use of Compression and Leak-Down Tests to Monitor Gradual Engine Degradation,” SAE International Journal of Engines, December 2011, 4(3), pp. $2767-2777$.
} 
significantly different ${ }^{*}$ from zero. A t-test (for Gaussian distributed data) and a sign test (a nonparametric statistical test which does not require the assumption of a particular data distribution) were used in this determination. Additionally, a Wilcoxon two-sample test was applied to determine whether there was a difference between the LFT and non-LFT vehicles.

*Statistical significance corresponds to 95\% confidence. Specifically, under the assumptions of the analysis, there was no more than a 1 in 20 chance that the observed outcomes (or an outcome more extreme) could have occurred by chance alone. 


\section{RESULTS}

\subsection{APPLICATION OF LONG-TERM FUEL TRIM AT WIDE-OPEN THROTTLE}

Manufacturers use LFT to continuously adjust the vehicle fueling system to adapt to minor changes in fuel delivery. Such changes may occur as a result of variations in fuel formulations, variations in manufacturing tolerances in the fuel system components, and fuel system aging or clogging. LFT ensures that the vehicle continues to operate at stoichiometric conditions during most types of driving. Stoichiometric operation is important because it results in the lowest overall emissions profile and allows the catalyst to operate most efficiently for removing pollutants from the exhaust gases. Vehicle manufacturers often use fuel-rich combustion during high-power events such as WOT to prevent the catalyst and engine components from overheating and becoming damaged as a result of high exhaust gas temperatures and flow rates. While rich operation results in increased hydrocarbon and CO emissions during WOT events, overall it reduces vehicle emissions because it protects the catalyst from premature damage and allows it to be more efficient over the lifetime of the vehicle. While some engine calibrations apply stored values of LFT during WOT conditions to adjust the enrichment, others do not. Because ethanol blending adds an oxygen-bearing species to the fuel, additional fuel must be added at any given condition to maintain consistent stoichiometry. Vehicles that do not apply LFT at WOT are thus less enriched under these open-loop conditions, which can result in higher catalyst temperatures and may degrade the catalyst more rapidly than if there were no ethanol in the fuel. ${ }^{*,+, \neq}$ The data collected during the WOT tests at the SOT interval were used to determine whether a vehicle model applied LFT at WOT. Characterizing the vehicles in this way allowed the emissions results from subgroups of LFT and nonLFT at WOT vehicles to be analyzed to address the concern noted above. Figure 3.1 shows a typical timespeed profile for the WOT test, with the 10 WOT events noted.

The LFT or non-LFT determination was accomplished by examining the AFR data for a given vehicle tested with both E0 and E20 to determine whether the lambda ratio ${ }^{\S}$ at WOT conditions was nominally the same with both fuels or whether lambda was considerably leaner with E20. (Lambda is typically 6\%8\% leaner with E20 when LFT is not applied.) During the entire WOT test procedure, the vehicles experience stoichiometric cruise and idle conditions, decelerations that frequently cause fuel shutoff, and hard accelerations that result in fuel enrichment. Example data sets are shown in the histograms of Figs. 3.2 and 3.3. The periods of operation near stoichiometry result in the large amount of data around a lambda value of 1.0. As the vehicles are intended to operate at or near stoichiometry under most driving conditions, these data are the most prevalent. The data at lower lambda values are indicative of enriched operation during WOT acceleration events. A third grouping of data, not shown, is caused by fuel shutoff during deceleration events, which results in lambda values greater than 1.1. The fuel shutoff data are not shown as they are not important in making the LFT at WOT determination. Examination of the data at a lambda of about 0.85 in Fig. 3.2, for example, shows that the data collected using E0 and the data collected using E20 agree very closely in terms of the average lambda during enrichment. The agreement between these two conditions indicates that the 2009 Ford Explorer does apply LFT at WOT.

\footnotetext{
${ }^{*}$ R. Bechtold et al., Technical Issues Associated with the Use of Intermediate Ethanol Blends (>E10) in the U.S. Legacy Fleet: Assessment of Prior Studies, ORNL/TM-2007/37, Oak Ridge National Laboratory, August 2007, available at http://info.ornl.gov/sites/publications/files/Pub7767.pdf.

${ }^{\dagger}$ Keith Knoll et al., Effects of Intermediate Ethanol Blends on Legacy Vehicles and Small Non-Road Engines, Report 1Updated, NREL/TP-540-43543/ORNL/TM-2008/117, February 2009, available at http://www.nrel.gov/docs/fy09osti/43543.pdf.

${ }_{\ddagger}^{\ddagger}$ Transportation Research Center Inc., Mid-Level Ethanol Blends Catalyst Durability Study Screening, CRC Report E-87-1, Coordinating Research Council, Inc., Alpharetta, Georgia, June 2009.

${ }^{\S}$ Lambda is the normalized air : fuel ratio, or excess air factor. Lambda $<1$ indicates rich combustion (excess fuel), lambda $=1$ indicates stoichiometric combustion, and lambda $>1$ indicates lean combustion (excess air).
} 


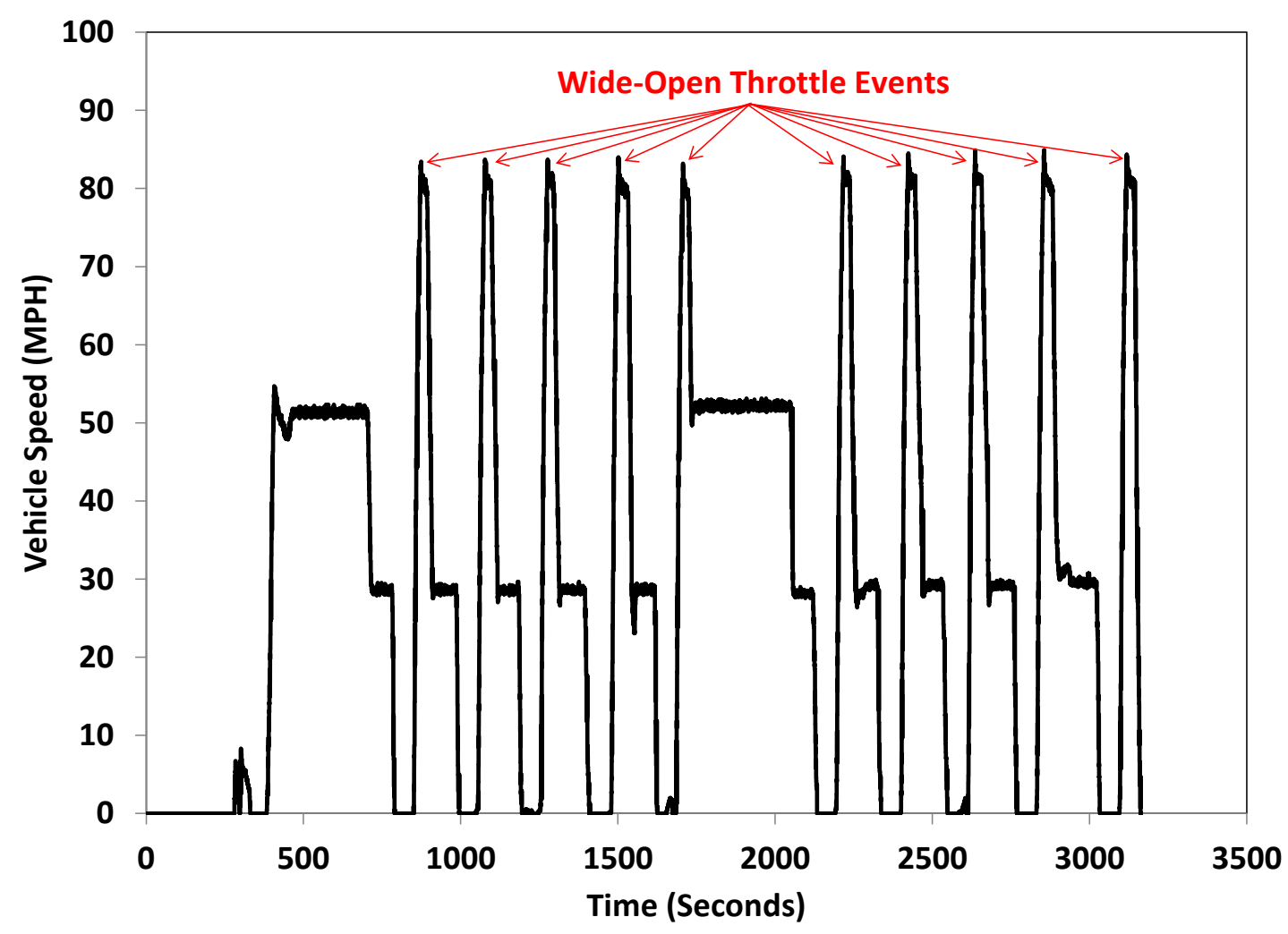

Fig. 3.1. Typical time-speed driving profile for the wide-open throttle tests.

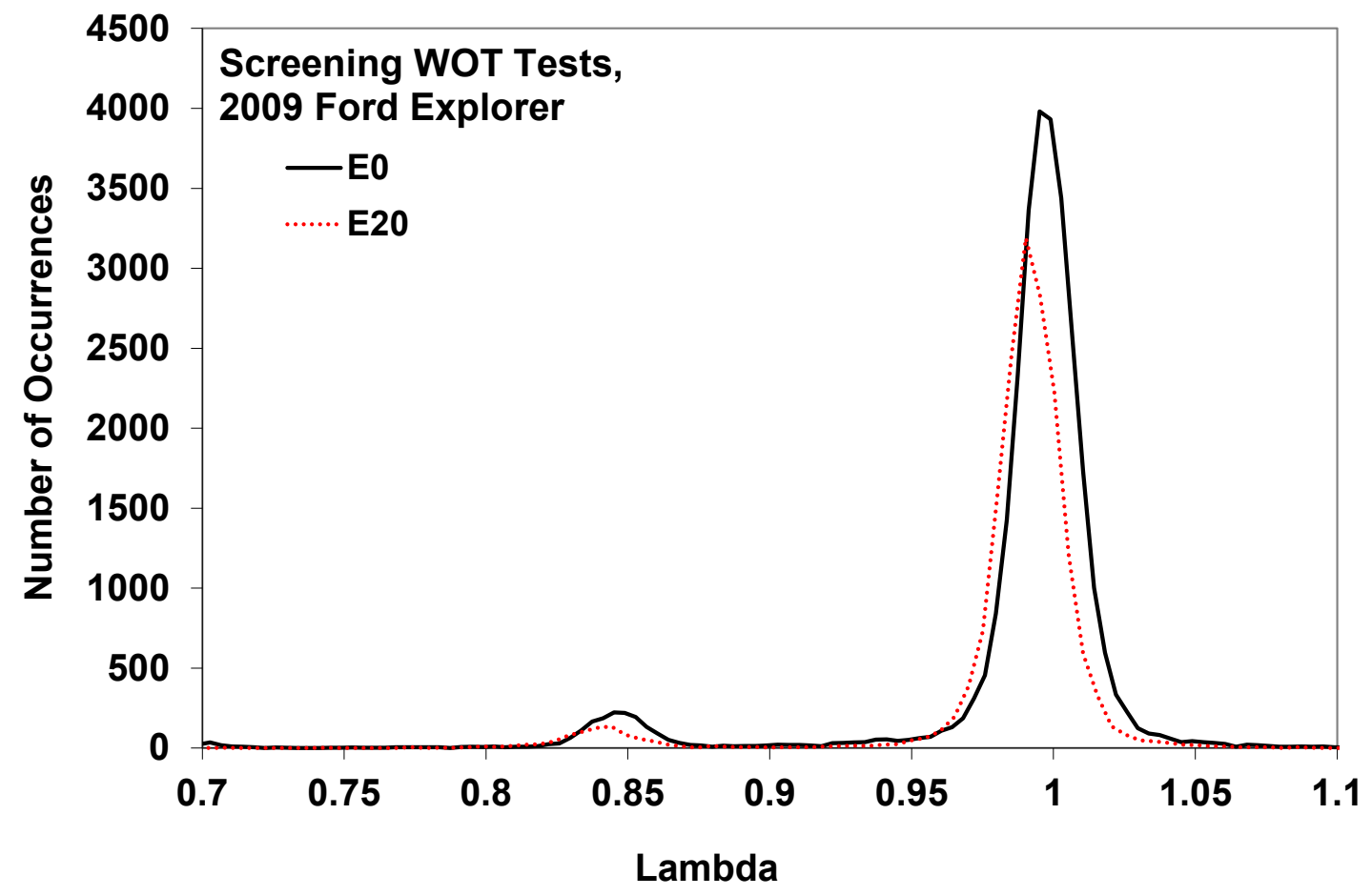

Fig. 3.2. Wide-open throttle (WOT) test lambda data for a 2009 Ford Explorer. 


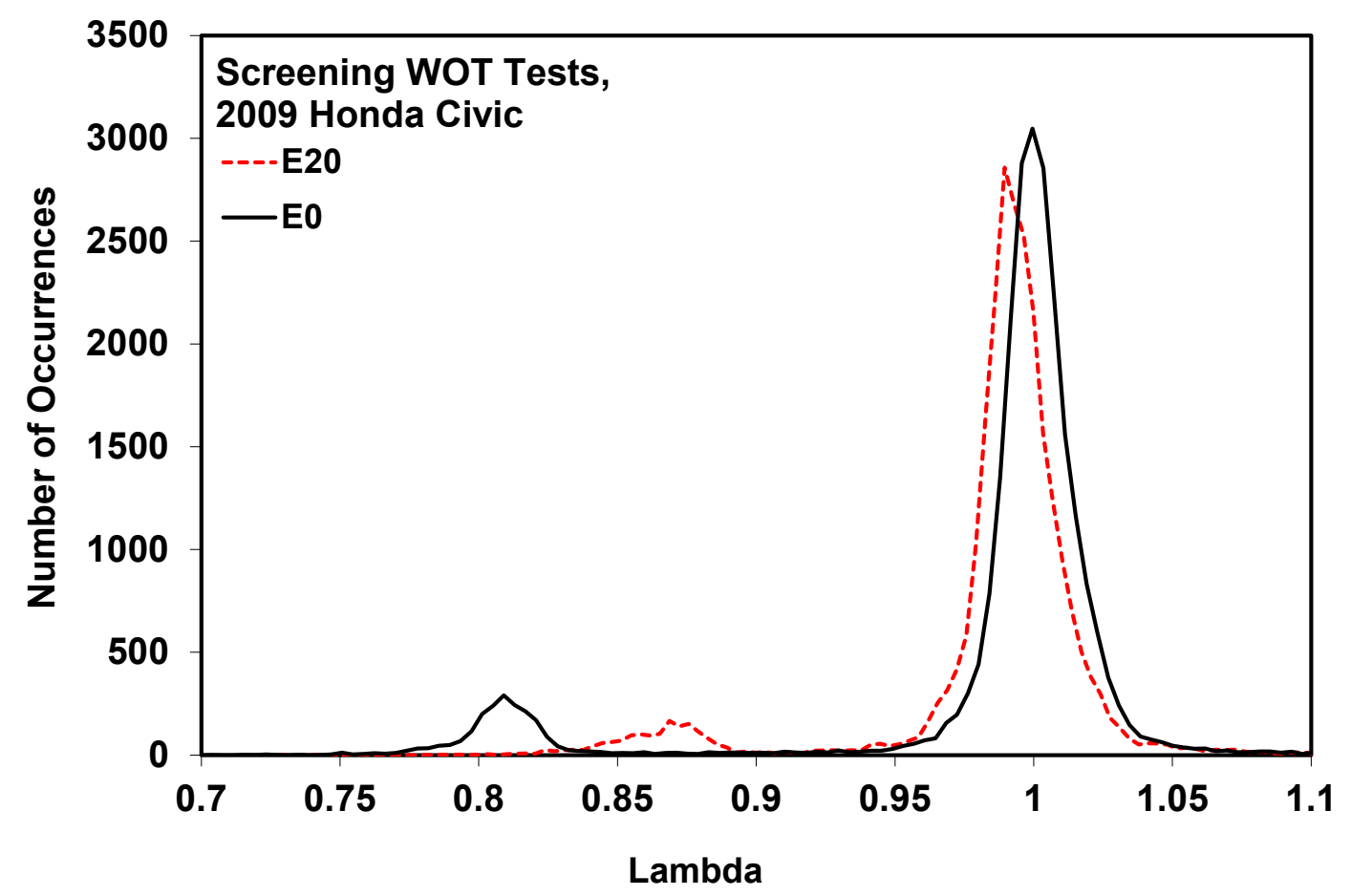

Fig. 3.3. Wide-open throttle (WOT) test lambda data for a 2009 Honda Civic.

The data shown in Fig. 3.3 indicate that stoichiometric operation is the most prevalent, and the data from enriched operation are present at a lower incidence. However in this case, the data indicate that the lambda during enrichment averaged about 0.82 when using E0 but averaged about 0.87 when using E20, which shows that conditions at WOT are less rich when E20 is used. The separation between the average enrichment values for these two conditions indicates that the 2009 Honda Civic does not apply LFT at WOT. It is worth clarifying that the use of E20 at WOT for non-LFT cars causes less enrichment and not fuel-lean operation, as this would be a very different condition with lambda results higher than the stoichiometric condition. Furthermore, while these two cases give a clear indication of the LFT at WOT status, there were some cars for which this status was more difficult to determine with confidence. Vehicles characterized as not applying LFT at WOT may do so by design or may have had inadequate time or operating range for complete adaption. Table 3.1 shows the LFT at WOT status as determined for the vehicles in this testing program.

Previous experience in CRC E-87-1 and DOE V1 showed that about half the tested vehicles did not apply LFT at WOT. Vehicles that do not apply LFT at WOT tend to exhibit higher exhaust and catalyst temperatures during WOT events. Previous work indicated that the catalyst temperature difference during WOT conditions for non-LFT cars using E20 was $29^{\circ} \mathrm{C}-35^{\circ} \mathrm{C}$ hotter than with E0. ${ }^{*}$ Concern over premature catalyst degradation as a result of this increase in temperature was a prime motivator for this study. Based on WOT measurements during this program, seventy percent (19/27) of the vehicle models tested were found to not apply LFT at WOT. Early in the program, before all vehicles had been acquired or WOT tested, LFT status closer to 50\% was generally assumed based on a "best guess at this time," which was developed from the prior CRC and DOE studies of similar vehicles. ${ }^{\dagger}$

${ }^{*}$ Keith Knoll et al., Effects of Intermediate Ethanol Blends on Legacy Vehicles and Small Non-Road Engines, Report 1Updated, NREL/TP-540-43543/ORNL/TM-2008/117, February 2009, available at http://www.nrel.gov/docs/fy09osti/43543.pdf.

${ }^{\dagger}$ Catalyst Durability, V4/E-87-2 Project Status, Mid-Level Ethanol Blends Coordination Group Meeting, May 5, 2010, available at http://www.regulations.gov/\#!documentDetail;D=EPA-HQ-OAR-2009-0211-13993. 
Table 3.1. Long-term fuel trim (LFT) at wide-open throttle (WOT) status for the program vehicles

\begin{tabular}{|c|c|c|c|c|c|}
\hline Vehicle & $\begin{array}{l}\text { LFT at } \\
\text { WOT? }\end{array}$ & Vehicle & $\begin{array}{l}\text { LFT at } \\
\text { WOT? }\end{array}$ & Vehicle & $\begin{array}{l}\text { LFT at } \\
\text { WOT? }\end{array}$ \\
\hline 2007 Accord & No & 2009 Civic & No & 2009 Odyssey & No \\
\hline 2006 Silverado & Yes & 2009 Corolla & No & 2000 Silverado & Yes \\
\hline 2008 Altima & No & 2005 Tundra & No & 2002 Frontier & No \\
\hline 2008 Taurus & Yes & 2006 Impala & $\mathrm{No}^{a}$ & 2002 Durango & No \\
\hline 2007 Caravan & No & 2005 F150 & Yes & 2003 Camry & No \\
\hline 2006 Cobalt & No & 2006 Quest & No & 2003 Taurus & No \\
\hline 2007 Caliber & No & 2009 Outlook & Yes & 2003 Cavalier & No \\
\hline 2009 Liberty & No & 2009 Camry & Yes & 2000 Accord & No \\
\hline 2009 Explorer & Yes & 2009 Focus & Yes & 2000 Focus & No \\
\hline
\end{tabular}

${ }^{a}$ Vehicle classified as “No" based on some WOT results; however, some results did indicate application of LFT at WOT.

\subsection{EMISSIONS AND FUEL ECONOMY}

\subsubsection{Fuel Economy Calculation}

To date, EPA has only required emissions and fuel economy testing of gasoline-fuelled vehicles with a certification gasoline that does not contain ethanol. Hence, the testing requirements and calculations used in this testing program are those required for certification gasoline. The fuel economy equation that is specified in CFR for gasoline-fuelled vehicles is based on a carbon mass balance (CMB) approach to determine the amount of fuel used by measuring the carbon-bearing emissions that are produced; however, it also incorporates scaling factors based on the net heating value of the fuel and the "sensitivity" of fuel economy to changes in the heating value. ${ }^{* \dagger}$ The impact of the scaling factors is a fixed offset in the resultant fuel economy that is dependent upon fuel properties other than those required for a typical CMB calculation. This algorithm was put in place in 1988 to correct for differences between certification fuels. The algorithm adjusts the calculated fuel economy to be equivalent, on a British thermal unit per mile basis, to tests conducted with certification fuel as it was formulated in 1975 to address corporate average fuel economy credit issues associated with fuel property variations. An R factor was defined as the sensitivity of the fuel economy result to changes in fuel energy content. The R factor was defined to be 0.6 based on tests using 1980s vehicles. Since that time, the Auto/Oil test program has established that the $\mathrm{R}$ factor for 1990s vehicles is higher (about 0.93 ). ${ }^{\ddagger}$ The CFR fuel economy equation, if rearranged, is a CMB calculation with a multiplier based on fuel properties and the $\mathrm{R}$ factor. The choice of $\mathrm{R}$ factor can reduce the observed impact of fuel properties on fuel economy quite significantly. For example, Fig. 3.4 shows the fuel economy multiplier with both an R factor of 0.6 per CFR and an R factor of 0.93 as determined by the Auto/Oil study. These factors were calculated using the actual net heating value and specific gravity of emissions test fuels at SwRI.

\footnotetext{
*Federal Register Vol. 51(206), Friday, October 24, 1986, pp. 37844-37852.

${ }^{\dagger} 40$ CFR Pt. 600.

${ }^{\ddagger}$ Albert Hochhauser et al., "Fuel Composition Effects on Automotive Fuel Economy—Auto/Oil Air Quality Improvement Research Program,” SAE paper 930138, SAE International, Warrendale, Pennsylvania, March 1993.
} 


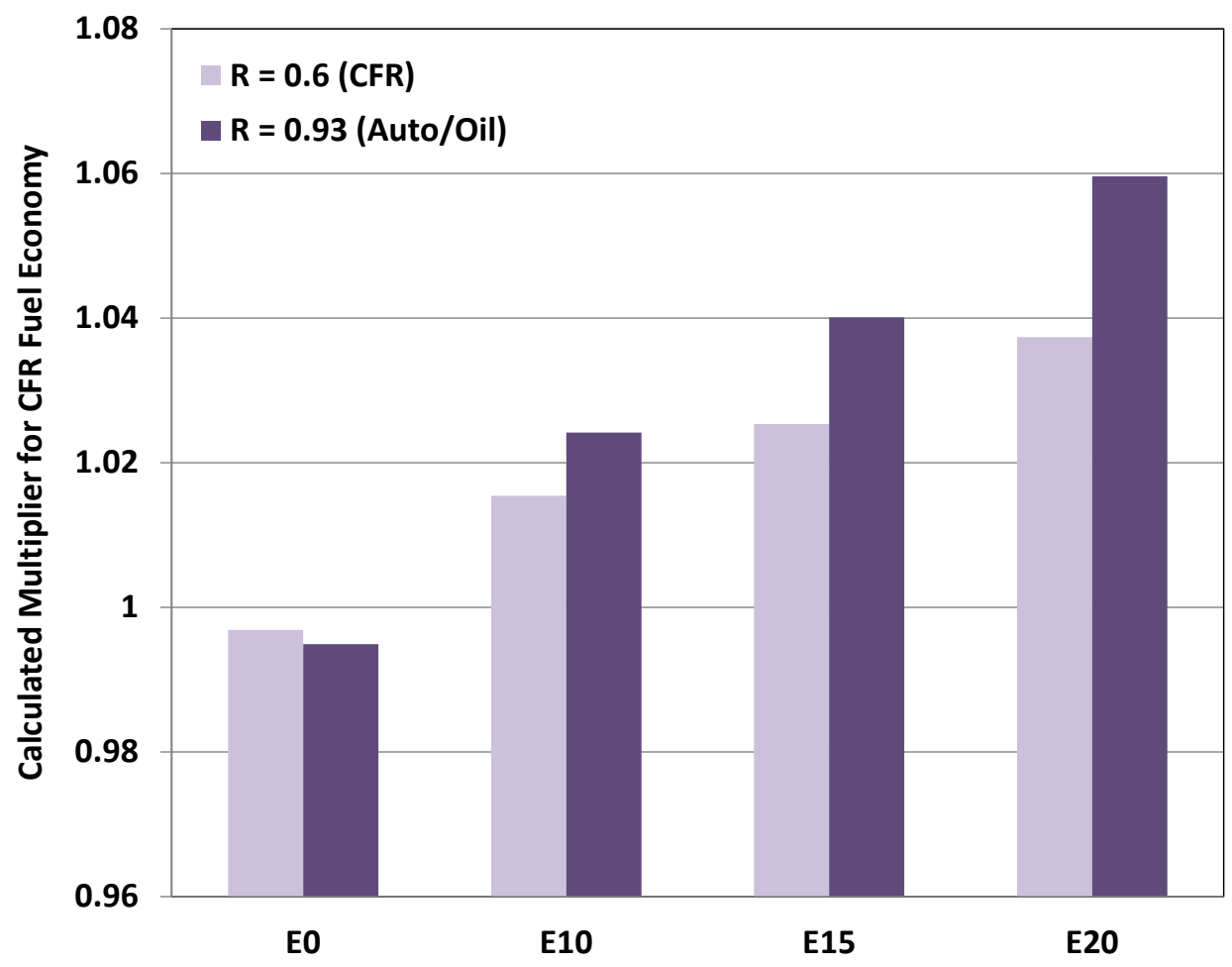

Fig. 3.4. Code of Federal Regulations (CFR) fuel economy equation scaling, using different $\mathbf{R}$ factors, for emissions test fuels used at Southwest Research Institute.

The differences caused by the CFR equation and choice of $\mathrm{R}$ factor are large compared with the range of variation of fuel energy content for the fuels in this study. Given these facts, the present study was conducted with fuel economy calculated based on a CMB approach without the scaling factors that are included in the CFR equation. This approach allows a straightforward evaluation of the impact of ethanol content on fuel economy.

\subsubsection{Vehicle Dynamometer Coefficients}

Dynamometer coefficients and equivalent test weights (ETWs) for modern motoring chassis dynamometers are available for all U.S.-legal vehicles from a database maintained by EPA.* Four parameters are needed by the dynamometer controller to match the vehicle load-speed profile, including three coefficients (A, B, and C) and the ETW. For most of the vehicles tested in this program, the EPA database was consulted for vehicles with matching engine families to determine target coefficients, and the test laboratories conducted dynamometer coast downs to determine the appropriate set coefficients for their respective dynamometers. In some cases the vehicle manufacturers were consulted to assist in selecting the appropriate coefficients and ETW. Dynamometer coast downs were conducted on each vehicle of a set; then the $\mathrm{A}, \mathrm{B}$, and $\mathrm{C}$ set coefficients were averaged so that each vehicle of a set used the same dynamometer coefficients for all testing.

\footnotetext{
*U.S. Environmental Protection Agency, “Cars and Light Trucks; Annual Certification Test Results and Data,” http://www.epa.gov/otaq/crttst.htm.
} 
A number of the pre-Tier-2 vehicles that were included in this program were originally certified for emissions compliance using an older style chassis dynamometer in which only the ETW and a target horsepower at $50 \mathrm{mph}$ were needed to set the dynamometer to model the vehicle load-speed profile. Because the parameters needed for an older vehicle to operate on a newer style dynamometer do not generally exist, they were determined using methods established in the literature. ${ }^{*, \dagger}$ The coefficients and ETW settings used for each vehicle are provided in Appendix C.

\subsubsection{Nonmethane Organic Gas Estimations}

During the program the method in use for calculating NMOG at two of the test sites came into question. Specifically, TRC found the use of the Innova photoacoustic multigas analyzer for determining ethanol concentration in the vehicle exhaust to be inadequate. This approach had previously been approved by the California Air Resources Board for fuels containing at least 10\% ethanol. ${ }^{\neq}$TRC switched to the older impinger and gas chromatography approach for the remainder of the program. ETC continued to use the Innova instrument, but the data produced were later deemed to be unreliable, presumably due to the exceedingly long length of the sample line. EPA subsequently expressed a lack of confidence in the ethanol measurements made by the photoacoustic instrument in this program and requested an estimation technique be developed based on correlation of the data obtained using the gas chromatography method. SwRI had used the chromatography method throughout the program, and considerable data using this method were also available from TRC. An NMOG estimation procedure was developed using the complete data sets and used to estimate NMOG results for all tests at all sites.

Development of the estimation technique was as follows. The data collected using chromatography for ethanol quantification in the exhaust gases were used to develop a correlation between NMHC and NMOG as a function of the ethanol content of the test fuel being used. The data were first binned according to the nominal fuel ethanol content (0,10\%, 15\%, and 20\%). A regression between NMOG and NMHC data was determined for each fuel ethanol level and each of the two test sites (TRC and SwRI) that were the sources of the data. Lines of best fit were determined, with the slopes of the lines providing an NMOG/NMHC ratio for each fuel ethanol level at each test site. The NMOG/NMHC ratios from both SwRI and TRC were plotted versus the nominal fuel ethanol content and a best-fit line determined. This line provided a means of assessing the appropriate NMOG/NMHC ratio as a function of the fuel ethanol content. Figure 3.5 shows the ratios from each site and the lines of best fit.

The two dashed lines in Fig. 3.5 show the site-specific correlations, while the solid line in the center shows the correlation based on data from both sites. The site-specific correlations provided the best representation of the data from each site. The need to estimate NMOG for results from ETC and early TRC results (where no reliable ethanol data were available) and the need to evaluate the NMOG results statistically on a common basis without confounding effects from the test location necessitated that one common correlation be used for all three sites. With this need in mind, and no defensible reason to

\footnotetext{
${ }^{*}$ Charles Brownell et al., "Simulation of 8.65 inch Uncoupled Twin-Roll Hydrokinetic Dynamometer Operation on a 48 inch Single-Roll Electric Dynamometer,” SAE paper 940486, SAE International, Warrendale, Pennsylvania, March 1994.

${ }^{\dagger}$ SAE International, Chassis Dynamometer Simulation of Road Load Using Coastdown Techniques, Surface Vehicle Recommended Practice, SAE Standard J2264, Warrendale, Pennsylvania, April 1995.

${ }^{\ddagger}$ California Air Resources Board, Use of Innova Photoacoustic Multi-Gas Monitor to Measure Ethanol Exhaust and Evaporative Vehicle Emissions, Mail-Out MSO 2000-08, June 29, 2000.
} 
eliminate either the TRC or SwRI data, the correlation using data from both sites was used to estimate NMOG emissions for all of the tests conducted in this program. This correlation was updated several times as additional data that could be included were generated. The error introduced by this technique was most typically on the order of 2-4 mg/mile compared with actual test data. An example of the error introduced for data from TRC is shown in Fig. 3.6. The slight positive bias in the error is a result of the influence of the relatively higher NMOG/NMHC ratios determined at SwRI on the overall correlation. Given that the NMOG certification levels for the vehicles in the program were Tier 2 Bin 4 (70 mg/mile) or higher, this level of error was not anticipated to cause undue difficulty in assessing the degradation of the emissions control systems under test. Additional detail about the NMOG estimation approach can be found in a separate publication.

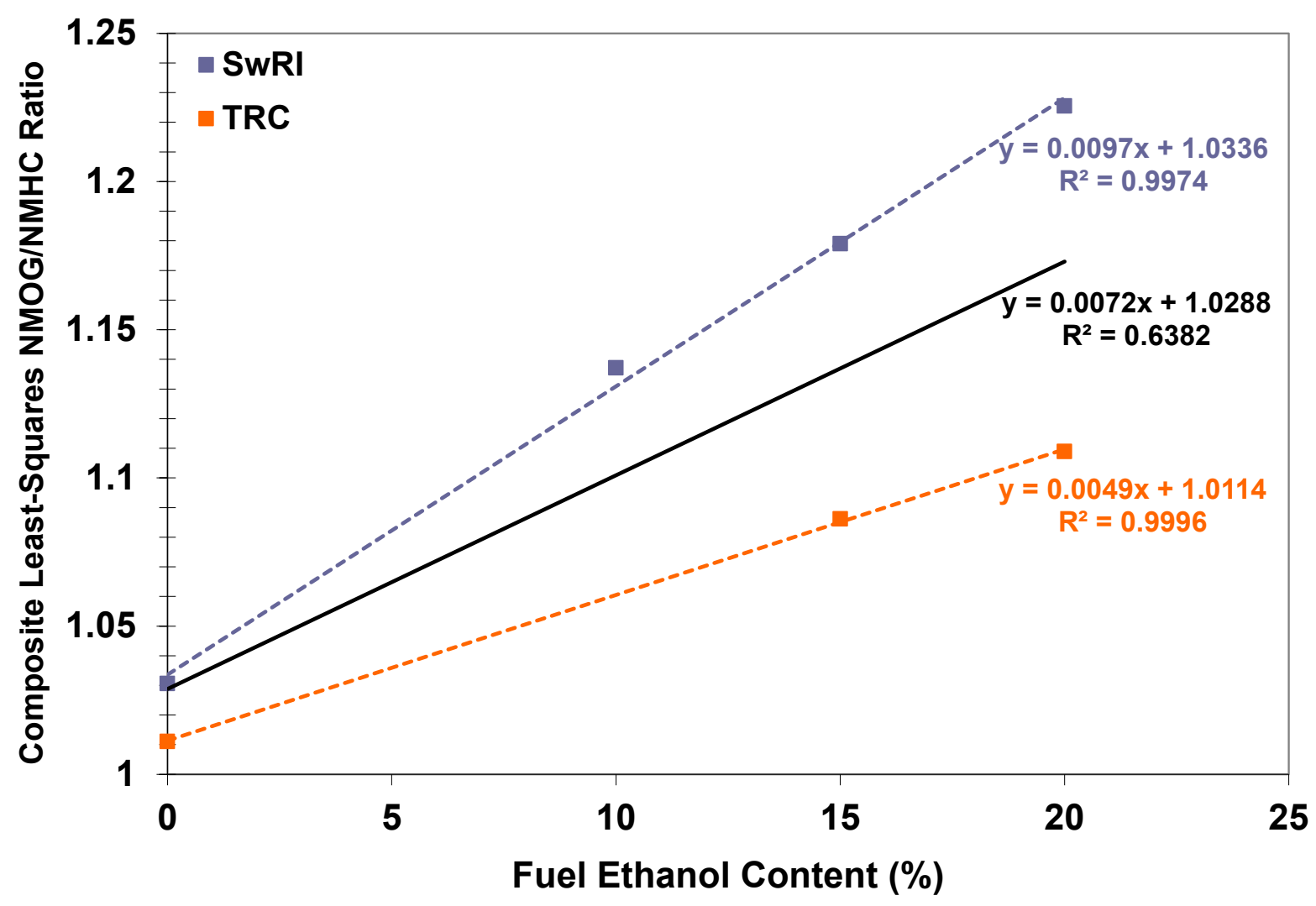

Fig. 3.5. Regression of nonmethane organic gas/nonmethane hydrocarbon (NMOG/NMHC) ratios to fuel ethanol content.

${ }^{*}$ C. Scott Sluder and Brian H. West, NMOG Emissions Characterizations and Estimation for Vehicles Using Ethanol-Blended Fuels, ORNL/TM-2011/461, Oak Ridge National Laboratory, October 15, 2011, available at http://info.ornl.gov/sites/publications/Files/Pub33272.pdf. 


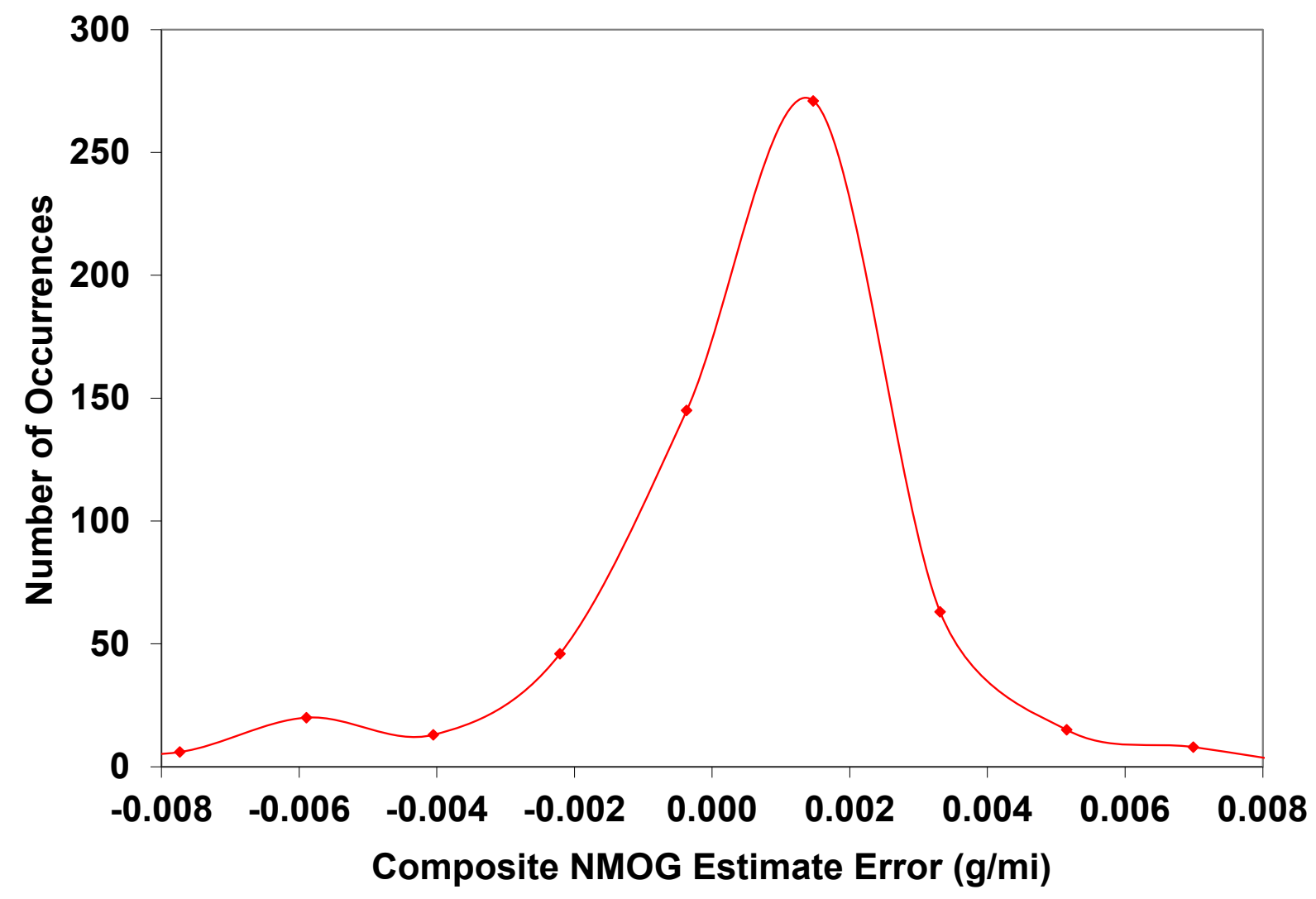

Fig. 3.6. Nonmethane organic gas (NMOG) estimate error for test results from the Transportation Research Center.

\subsubsection{End-of-Test Emissions Results}

Data in Tables 3.2-3.5 show the minimum, average, and maximum emissions test results for $\mathrm{CO}, \mathrm{NO}_{\mathrm{X}}$, and NMOG for all vehicles at EOT. Data values are presented with one additional decimal place beyond the applicable standards. Tier 2 standards for CO are generally to one decimal place (e.g., $4.2 \mathrm{~g} / \mathrm{mile}$ ), $\mathrm{NO}_{\mathrm{X}}$ standards are generally to two decimal places (e.g., $0.07 \mathrm{~g} / \mathrm{mile}$ ), and NMOG standards are generally to three decimal places (e.g., $0.090 \mathrm{~g} / \mathrm{mile}$ ).

Table 3.2 summarizes the EOT emissions test results with the E0 emissions certification gasoline for the Tier 2 vehicles. The minimum, maximum, and average of all tests for each vehicle are shown. Similarly, Table 3.3 summarizes the emissions test results with E0 fuel for the pre-Tier-2 vehicles.

Tables 3.4 and 3.5 summarize the EOT emissions test results with the relevant ethanol blend (E10, E15, or E20) for the Tier 2 and pre-Tier-2 vehicles, respectively.

It is important to note that all of the pre-Tier-2 vehicles were thousands of miles beyond their regulatory FUL at EOT.

Emissions standards for light duty vehicles are provided in Appendix A. 
Table 3.2. Summary of minimum, average, and maximum emissions test (Federal Test Procedure with E0 fuel) results for Tier 2 vehicles

(all results in $\mathrm{g} / \mathrm{mile}$ )

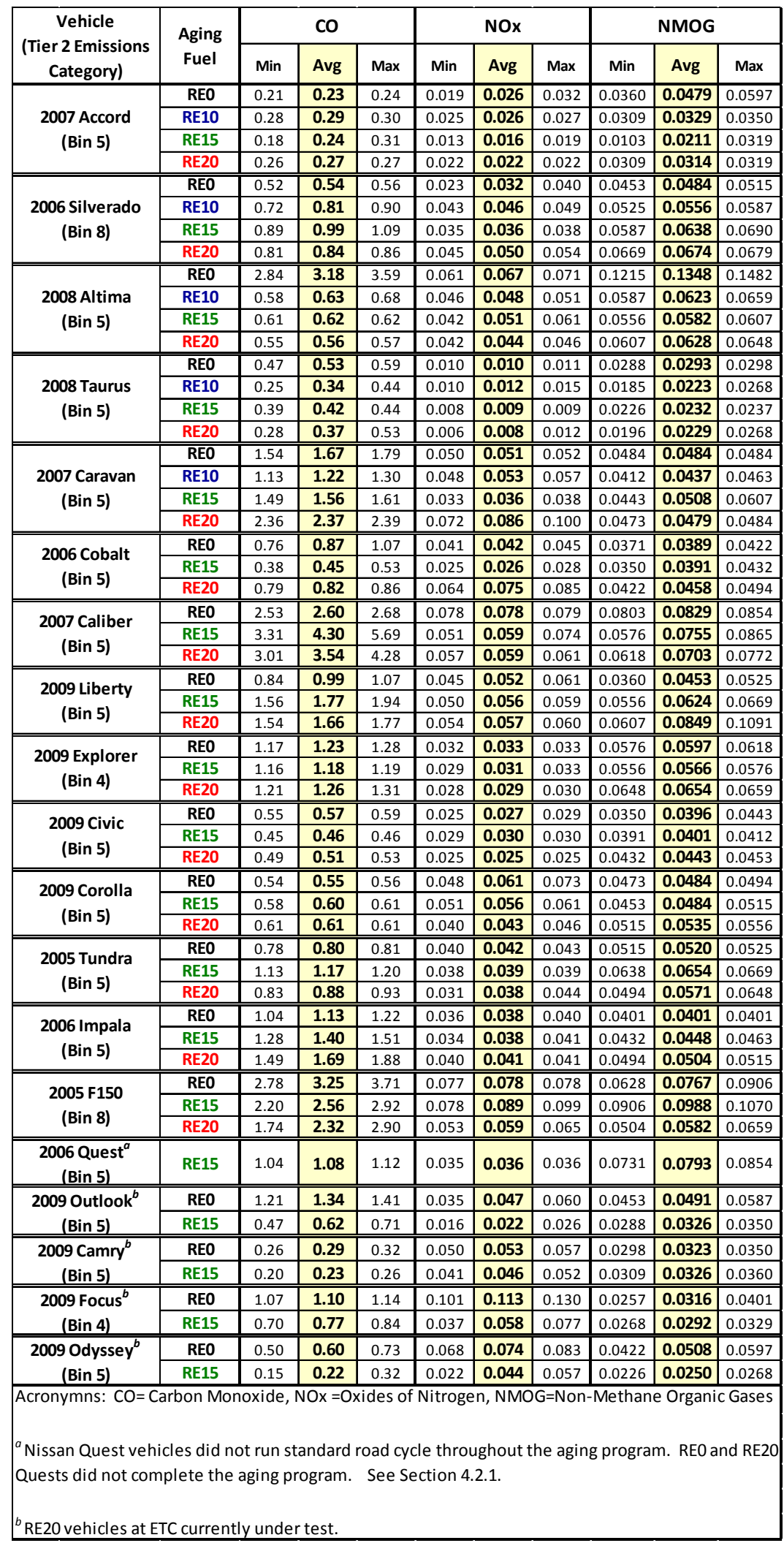


Table 3.3. Summary of minimum, average, and maximum emissions test (Federal Test Procedure with E0 fuel) results for pre-Tier-2 vehicles

(all results in $\mathrm{g} / \mathrm{mile}$ )

\begin{tabular}{|c|c|c|c|c|c|c|c|c|c|c|}
\hline \multirow{2}{*}{$\begin{array}{c}\text { Vehicle } \\
\text { (Emissions } \\
\text { Category) }\end{array}$} & \multirow{2}{*}{$\begin{array}{l}\text { Aging } \\
\text { Fuel }\end{array}$} & \multicolumn{3}{|c|}{$\mathrm{CO}$} & \multicolumn{3}{|c|}{ NOx } & \multicolumn{3}{|c|}{ NMOG } \\
\hline & & Min & Avg & Max & Min & Avg & Max & Min & Avg & Max \\
\hline \multirow{3}{*}{$\begin{array}{c}2000 \text { Silverado } \\
\text { (Tier 1/LDT3) }\end{array}$} & REO & 2.91 & 3.08 & 3.24 & 0.439 & 0.448 & 0.456 & 0.2717 & 0.2717 & 0.2717 \\
\hline & RE15 & 1.97 & 2.12 & 2.21 & 0.351 & 0.364 & 0.384 & 0.1740 & 0.1830 & 0.1997 \\
\hline & RE20 & 1.42 & 1.79 & 2.00 & 0.361 & 0.389 & 0.411 & 0.1626 & 0.1909 & 0.2151 \\
\hline \multirow{3}{*}{$\begin{array}{l}2002 \text { Frontier } \\
\text { (NLEV/LDT1) }\end{array}$} & REO & 3.05 & 3.26 & 3.48 & 0.125 & 0.131 & 0.137 & 0.0700 & 0.0731 & 0.0762 \\
\hline & RE15 & 1.94 & 3.92 & 6.04 & 0.093 & 0.216 & 0.421 & 0.0854 & 0.0990 & 0.1163 \\
\hline & RE20 & 3.97 & 4.17 & 4.38 & 0.120 & 0.131 & 0.140 & 0.0937 & 0.1026 & 0.1112 \\
\hline \multirow{3}{*}{$\begin{array}{l}2002 \text { Durango } \\
\text { (Tier1/LDT3) }\end{array}$} & REO & 1.45 & 2.03 & 2.76 & 0.387 & 0.441 & 0.484 & 0.0607 & 0.1043 & 0.1606 \\
\hline & RE15 & 2.31 & 2.55 & 2.80 & 0.376 & 0.391 & 0.407 & 0.1492 & 0.1580 & 0.1667 \\
\hline & RE20 & 2.52 & 2.54 & 2.55 & 0.604 & 0.605 & 0.606 & 0.1513 & 0.1554 & 0.1595 \\
\hline \multirow{3}{*}{$\begin{array}{c}2003 \text { Camry } \\
\text { (ULEV) }\end{array}$} & REO & 1.24 & 1.29 & 1.34 & 0.136 & 0.144 & 0.152 & 0.0638 & 0.0674 & 0.0710 \\
\hline & RE15 & 0.57 & 0.64 & 0.70 & 0.108 & 0.118 & 0.127 & 0.0319 & 0.0340 & 0.0360 \\
\hline & RE20 & 2.46 & 2.60 & 2.73 & 0.261 & 0.286 & 0.310 & 0.1482 & 0.1709 & 0.1935 \\
\hline \multirow{3}{*}{$\begin{array}{c}2003 \text { Taurus } \\
\text { (NLEV) }\end{array}$} & REO & 0.31 & 0.33 & 0.35 & 0.077 & 0.080 & 0.083 & 0.0576 & 0.0623 & 0.0669 \\
\hline & RE15 & 0.55 & 0.59 & 0.62 & 0.134 & 0.137 & 0.140 & 0.0772 & 0.0813 & 0.0854 \\
\hline & RE20 & 0.63 & 0.64 & 0.64 & 0.059 & 0.064 & 0.068 & 0.0638 & 0.0762 & 0.0885 \\
\hline \multirow{3}{*}{$\begin{array}{l}2003 \text { Cavalier } \\
\text { (NLEV) }\end{array}$} & REO & 1.45 & 1.57 & 1.69 & 0.264 & 0.280 & 0.296 & 0.1143 & 0.1189 & 0.1235 \\
\hline & RE15 & 0.69 & 0.71 & 0.72 & 0.090 & 0.092 & 0.093 & 0.0607 & 0.0618 & 0.0628 \\
\hline & RE20 & 1.01 & 1.06 & 1.11 & 0.090 & 0.091 & 0.092 & 0.0926 & 0.0983 & 0.1040 \\
\hline \multirow{3}{*}{$\begin{array}{l}2000 \text { Accord } \\
\text { (NLEV) }\end{array}$} & REO & 4.79 & 5.48 & 5.74 & 0.100 & 0.130 & 0.152 & 0.1070 & 0.1338 & 0.1462 \\
\hline & RE15 & 3.02 & 3.17 & 3.26 & 0.174 & 0.192 & 0.205 & 0.0865 & 0.0878 & 0.0895 \\
\hline & RE20 & 1.00 & 1.05 & 1.08 & 0.108 & 0.113 & 0.117 & 0.0576 & 0.0611 & 0.0669 \\
\hline \multirow{3}{*}{$\begin{array}{l}2000 \text { Focus } \\
\text { (NLEV) }\end{array}$} & REO & 1.11 & 1.29 & 1.50 & 0.072 & 0.097 & 0.152 & 0.0638 & 0.0948 & 0.1091 \\
\hline & RE15 & 0.47 & 0.50 & 0.53 & 0.106 & 0.117 & 0.124 & 0.0340 & 0.0391 & 0.0494 \\
\hline & RE20 & 1.72 & 1.89 & 1.99 & 0.233 & 0.239 & 0.245 & 0.0690 & 0.0710 & 0.0731 \\
\hline cronymns: CC & 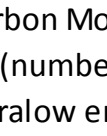 & 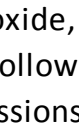 & . & 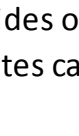 & 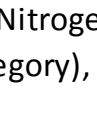 & 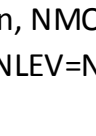 & Al & 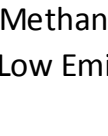 & . & \\
\hline
\end{tabular}


Table 3.5. Summary of minimum, average, and maximum emissions test results for pre-Tier-2 vehicles tested with ethanol-blended emissions test fuels (Federal Test Procedure with E15 or E20 fuel) (all results in g/mile)

\begin{tabular}{|c|c|c|c|c|c|c|c|c|c|c|c|}
\hline \multirow{2}{*}{$\begin{array}{l}\text { Vehicle } \\
\text { (Emissions } \\
\text { Category) }\end{array}$} & \multirow{2}{*}{$\begin{array}{c}\text { Emissions } \\
\text { Test Fuel }\end{array}$} & \multicolumn{3}{|c|}{ CO } & \multicolumn{3}{|c|}{ NOx } & \multicolumn{3}{|c|}{ NMOG } & \multirow{2}{*}{$\begin{array}{l}\text { Aging } \\
\text { Fuel }\end{array}$} \\
\hline & & Min & Avg & Max & Min & Avg & Max & Min & Avg & Max & \\
\hline \multirow{2}{*}{$\begin{array}{c}2000 \text { Silverado } \\
\text { (Tier 1/LDT3) }\end{array}$} & E15 & 1.55 & 1.72 & 1.97 & 0.352 & 0.370 & 0.382 & 0.1676 & 0.1763 & 0.1859 & RE15 \\
\hline & E20 & 1.51 & 1.57 & 1.63 & 0.433 & 0.436 & 0.438 & 0.1923 & 0.1941 & 0.1959 & RE20 \\
\hline \multirow{2}{*}{$\begin{array}{l}2002 \text { Frontier } \\
\text { (NLEV/LDT1) }\end{array}$} & E15 & 1.86 & 4.02 & 5.63 & 0.058 & 0.102 & 0.190 & 0.0792 & 0.0933 & 0.1044 & RE15 \\
\hline & E20 & 3.95 & 4.57 & 5.11 & 0.086 & 0.117 & 0.138 & 0.1152 & 0.1203 & 0.1259 & RE20 \\
\hline \multirow{2}{*}{$\begin{array}{c}2002 \text { Durango } \\
\text { (Tier1/LDT3) }\end{array}$} & E15 & 2.00 & 2.34 & 2.66 & 0.452 & 0.462 & 0.471 & 0.1389 & 0.1523 & 0.1607 & RE15 \\
\hline & E20 & 2.14 & 2.23 & 2.31 & 0.691 & 0.701 & 0.712 & 0.1449 & 0.1454 & 0.1460 & RE20 \\
\hline \multirow{2}{*}{$\begin{array}{c}2003 \text { Camry } \\
\text { (ULEV) }\end{array}$} & E15 & 0.69 & 0.72 & 0.74 & 0.070 & 0.084 & 0.098 & 0.0344 & 0.0436 & 0.0528 & RE15 \\
\hline & E20 & 2.40 & 2.65 & 2.89 & 0.267 & 0.267 & 0.267 & 0.1627 & 0.1716 & 0.1805 & RE20 \\
\hline \multirow{2}{*}{$\begin{array}{c}2003 \text { Taurus } \\
\text { (NLEV) }\end{array}$} & E15 & 0.34 & 0.35 & 0.36 & 0.153 & 0.155 & 0.157 & 0.0585 & 0.0620 & 0.0654 & RE15 \\
\hline & E20 & 0.35 & 0.38 & 0.40 & 0.107 & 0.122 & 0.136 & 0.0522 & 0.0528 & 0.0534 & RE20 \\
\hline \multirow{2}{*}{$\begin{array}{c}2003 \text { Cavalier } \\
\text { (NLEV) }\end{array}$} & E15 & 0.52 & 0.56 & 0.59 & 0.084 & 0.085 & 0.086 & 0.0539 & 0.0608 & 0.0677 & RE15 \\
\hline & E20 & 0.65 & 0.68 & 0.70 & 0.088 & 0.092 & 0.095 & 0.0985 & 0.1027 & 0.1069 & RE20 \\
\hline \multirow{2}{*}{$\begin{array}{c}2000 \text { Accord } \\
\text { (NLEV) }\end{array}$} & E15 & 1.97 & 2.25 & 2.71 & 0.168 & 0.189 & 0.213 & 0.0872 & 0.1119 & 0.1251 & RE15 \\
\hline & E20 & 0.97 & 1.12 & 1.23 & 0.130 & 0.135 & 0.143 & 0.0617 & 0.0657 & 0.0701 & RE20 \\
\hline \multirow{2}{*}{$\begin{array}{c}2000 \text { Focus } \\
\text { (NLEV) }\end{array}$} & E15 & 0.30 & 0.37 & 0.48 & 0.096 & 0.120 & 0.141 & 0.0310 & 0.0421 & 0.0505 & RE15 \\
\hline & E20 & 0.81 & 1.01 & 1.16 & 0.173 & 0.190 & 0.207 & 0.0546 & 0.0594 & 0.0665 & RE20 \\
\hline \multicolumn{12}{|c|}{$\begin{array}{l}\text { Acronymns: } \mathrm{CO}=\text { Carbon Monoxide, NOx =Oxides of Nitrogen, NMOG=Non-Methane Organic Gases, LDT=light duty } \\
\text { truck (number following indicates category), NLEV=National Low Emission Vehicle (Program), ULEV=ultralow } \\
\text { emissions vehicle. }\end{array}$} \\
\hline
\end{tabular}

\subsubsection{Statistical Analysis of Emissions Results}

Within each parameter (emissions or fuel economy), statistical models have been separately fit to data for the 26 different vehicle models. Each of these statistical models aggregates test data for multiple individual vehicles, road test fuels (RE0, RE10, RE15, and RE20), mileage points (SOT, MID, and EOT), and emissions test fuels (E0, E10, E15, and E20). The Nissan Quest was omitted from these analyses because it did not run the SRC for the duration of the program and because the RE0 vehicle did not reach EOT.

Table 3.6 summarizes the emissions results at the fleet level. In this table, the immediate impacts of ethanol at SOT are shown in the second column. FUL aging effects both with and without ethanol added to the fuels are shown in the third and fourth columns. The road fuel aging effect (third column) is defined as the effect of vehicle aging on each parameter absent ethanol in the road fuel. The differential road aging effect of ethanol (fourth column) is defined as the additional deterioration (or potentially amelioration of deterioration) associated with ethanol over and above that associated with vehicle aging alone. A result of "Increase" or "Decrease" in the table corresponds to statistical significance with 95\% confidence. A “marginal” result corresponds to statistical significance with $90 \%$ confidence.

As shown, CO, NMHC, and fuel economy were lower in vehicles tested with ethanol fuels before any aging, while $\mathrm{NO}_{\mathrm{x}}$, ethanol, acetaldehyde, and formaldehyde emissions were higher. There was no statistically significant change to NMOG or $\mathrm{CH}_{4}$ emissions for vehicles tested with ethanol fuels before any aging. As expected, mileage accumulation with RE0 road fuel corresponded to fleetwide increases in emissions (with the exception of ethanol emissions) and an increase in fuel economy. This is the road fuel aging effect. Where it could be determined, there was no statistically significant fleetwide differential effect of emission/performance parameter results for aging the vehicles with ethanol-containing blends (RE10, RE15, RE20) versus retail gasoline (RE0). The road aging effect was neither systematically enhanced nor suppressed under road aging with ethanol blends. 
Table 3.6. Summary of results by emission/performance parameter

\begin{tabular}{|l|l|l|l|}
\hline \multicolumn{1}{|c|}{ Parameter } & \multicolumn{1}{|c|}{$\begin{array}{c}\text { Immediate } \\
\text { ethanol effect }\end{array}$} & \multicolumn{1}{c|}{ Road fuel aging effect } & $\begin{array}{c}\text { Differential road aging } \\
\text { effect of ethanol }\end{array}$ \\
\hline $\mathrm{CO}$ & Decrease & Increase & No \\
\hline $\mathrm{NO}_{\mathrm{X}}$ & Increase & Increase & No \\
\hline $\mathrm{NMHC}^{a}$ & Decrease & Increase & No \\
\hline $\mathrm{NMOG}^{b}$ & None & Increase & No \\
\hline Fuel economy & Decrease & Increase & No \\
\hline Ethanol & Increase & $\begin{array}{l}\text { Inconclusive-not linear with } \\
\text { mileage }\end{array}$ & Inconclusive \\
\hline Acetaldehyde & Increase & Increase (marginal) & No \\
\hline Formaldehyde & Increase & Increase & No \\
\hline CH & Increase & No \\
\hline $\begin{array}{l}{ }^{a} \text { nonmethane hydrocarbons } \\
{ }^{n} \text { nonmethane organic gases }\end{array}$ & & \\
\hline
\end{tabular}

Table 3.7 summarizes the median change in emissions and fuel economy for each ethanol blend relative to E0 for the fleet at the start of testing, thus reflecting the short-term, or immediate ethanol emissions effect. Data in Table 3.7 expand on column 2 (immediate ethanol effect) of Table 3.6 by showing statistical results for each ethanol blend. The median change is shown in bold type in the shaded center column for each ethanol blend, and the minor columns to the left and right represent the 25th and 75th percentile of the changes across the fleet for each ethanol blend. Note that E10 results are for only 5 vehicle models, E15 results are for 26 vehicle models, and E20 results are for 22 vehicle models.

Results from Table 3.7 are shown graphically in Figs. 3.7 and 3.8. Figure 3.7 shows the median change in fuel economy and $\mathrm{CO}, \mathrm{NO}_{\mathrm{x}}, \mathrm{NMHC}, \mathrm{NMOG}$, and $\mathrm{CH}_{4}$ emissions, and the range bars show the interquartile range (25th percentile to 75th percentile) across all vehicles in the test fleet at SOT. The results in Fig. 3.7 are shown as a percent change relative to the E0 tests for the same vehicle. For example, fuel economy at SOT for E15 test fuel across the vehicle fleet ranges from $4.5 \%$ to $5.5 \%$ lower (median of 5.1\% lower) than for E0 test fuels. These results are as expected and are consistent with previous studies. Similar results for ethanol, acetaldehyde, and formaldehyde are shown in Fig. 3.8, except units are change in milligrams per mile compared to E0. Here again the colored bars represent the median change and the range bars show the interquartile range. While the statistical models find a statistically significant increase in formaldehyde with increasing ethanol (Table 3.6), note in Table 3.7 and Fig. 3.8 that the levels are extremely low, increasing by less than $0.2 \mathrm{mg} / \mathrm{mile}$ (less than $1 \%$ of the Tier 2/Bin 5 formaldehyde standard of $18 \mathrm{mg} / \mathrm{mile}$ ).

Appendix B provides details regarding the statistical models used in these analyses. A more detailed discussion of the statistical results is provided in Appendixes D and E. In Appendix D the results are presented and discussed by emission parameter, analyzed at the vehicle and fleet level. Appendix E provides the results by vehicle type with a summary table and nine figures shown for each of the 26 vehicles analyzed. Note that the Nissan Quest was omitted from this analysis due to the lack of an RE0 comparison vehicle. Similarly, ethanol results are based on only the vehicles at SwRI, and aldehydes analysis is based on SwRI and TRC vehicles. 
Table 3.7. Median change in fuel economy and emissions relative to E0 with interquartile range

(Federal Test Procedure results at start-of-test)

\begin{tabular}{|c|c|c|c|c|c|c|c|c|c|}
\hline \multirow{2}{*}{$\begin{array}{c}\text { Parameter } \\
\text { (unit of change) }\end{array}$} & \multicolumn{3}{|c|}{ E10 } & \multicolumn{3}{|c|}{ E15 } & \multicolumn{3}{|c|}{ E20 } \\
\hline & $\begin{array}{c}25 \text { th } \\
\text { percentile }\end{array}$ & median & $\begin{array}{c}\text { 75th } \\
\text { percentile }\end{array}$ & $\begin{array}{c}25 \text { th } \\
\text { percentile }\end{array}$ & median & $\begin{array}{c}75 \text { th } \\
\text { percentile }\end{array}$ & $\begin{array}{c}25 \text { th } \\
\text { percentile }\end{array}$ & median & $\begin{array}{c}\text { 75th } \\
\text { percentile }\end{array}$ \\
\hline $\begin{array}{c}\text { Fuel Economy } \\
(\%)\end{array}$ & $-4.02 \%$ & $-3.67 \%$ & $-3.25 \%$ & $-5.49 \%$ & $-5.12 \%$ & $-4.54 \%$ & $-6.98 \%$ & $-6.46 \%$ & $-6.19 \%$ \\
\hline $\begin{array}{l}\text { CO } \\
(\%)\end{array}$ & $-7.57 \%$ & $-2.36 \%$ & $3.54 \%$ & $-22.86 \%$ & $-11.18 \%$ & $-4.29 \%$ & $-38.60 \%$ & $-20.43 \%$ & $-8.71 \%$ \\
\hline $\begin{array}{c}\text { NOx } \\
(\%)\end{array}$ & $12.08 \%$ & $34.26 \%$ & $34.34 \%$ & $-4.64 \%$ & $5.94 \%$ & $30.21 \%$ & $6.04 \%$ & $12.32 \%$ & $20.99 \%$ \\
\hline $\begin{array}{c}\text { NMHC } \\
(\%)\end{array}$ & $-11.82 \%$ & $-7.02 \%$ & $14.62 \%$ & $-21.23 \%$ & $-9.85 \%$ & $-4.09 \%$ & $-27.07 \%$ & $-17.05 \%$ & $-8.26 \%$ \\
\hline $\begin{array}{c}\text { NMOG } \\
(\%)\end{array}$ & $-3.53 \%$ & $-1.36 \%$ & $22.38 \%$ & $-10.66 \%$ & $-0.07 \%$ & $6.91 \%$ & $-14.99 \%$ & $-0.90 \%$ & $6.91 \%$ \\
\hline $\begin{array}{l}\text { Ethanol } \\
\text { (mg/mi) }\end{array}$ & 1.185 & 2.335 & 2.349 & 3.204 & 3.551 & 5.237 & 4.307 & 4.642 & 6.422 \\
\hline $\begin{array}{c}\text { Acetaldehyde } \\
(\mathrm{mg} / \mathrm{mi})\end{array}$ & 0.296 & 0.409 & 0.468 & 0.472 & 0.626 & 0.733 & 0.607 & 0.915 & 1.113 \\
\hline $\begin{array}{c}\text { Formaldehyde } \\
(\mathrm{mg} / \mathrm{mi})\end{array}$ & 0.007 & 0.025 & 0.025 & -0.068 & 0.066 & 0.113 & 0.042 & 0.135 & 0.192 \\
\hline $\begin{array}{l}\mathrm{CH} 4 \\
(\%)\end{array}$ & $-4.70 \%$ & $3.17 \%$ & $11.02 \%$ & $-4.00 \%$ & $4.47 \%$ & $10.17 \%$ & $-4.59 \%$ & $1.62 \%$ & $20.00 \%$ \\
\hline
\end{tabular}

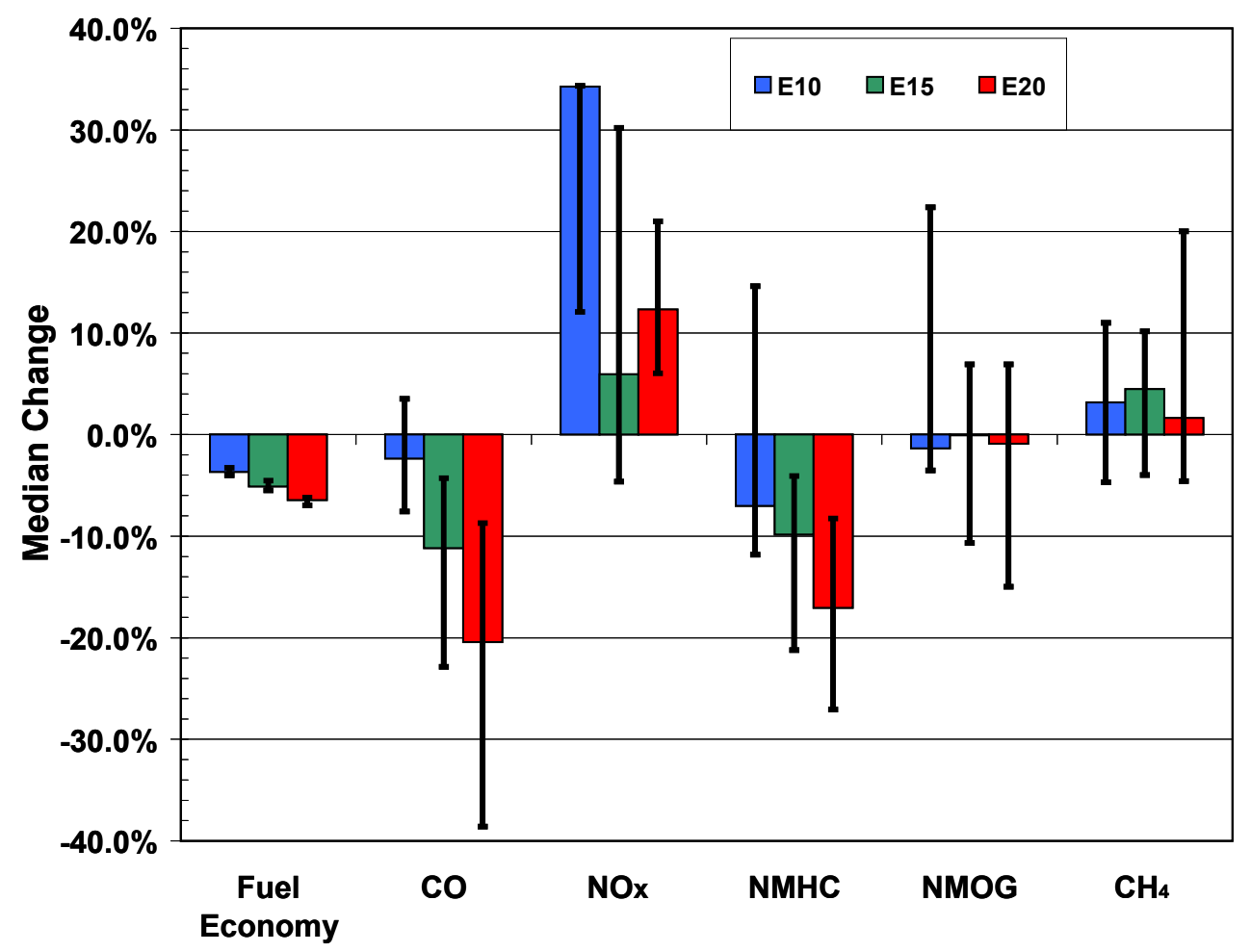

Fig. 3.7. Median change in fuel economy and $\mathrm{CO}, \mathrm{NO}_{\mathrm{x}}$, nonmethane hydrocarbon (NMHC), nonmethane organic gas (NMOG), and $\mathrm{CH}_{4}$ emissions relative to E0. Range bars show interquartile range (25th to 75th percentile). Results for Federal Test Procedure at start-of-test. 


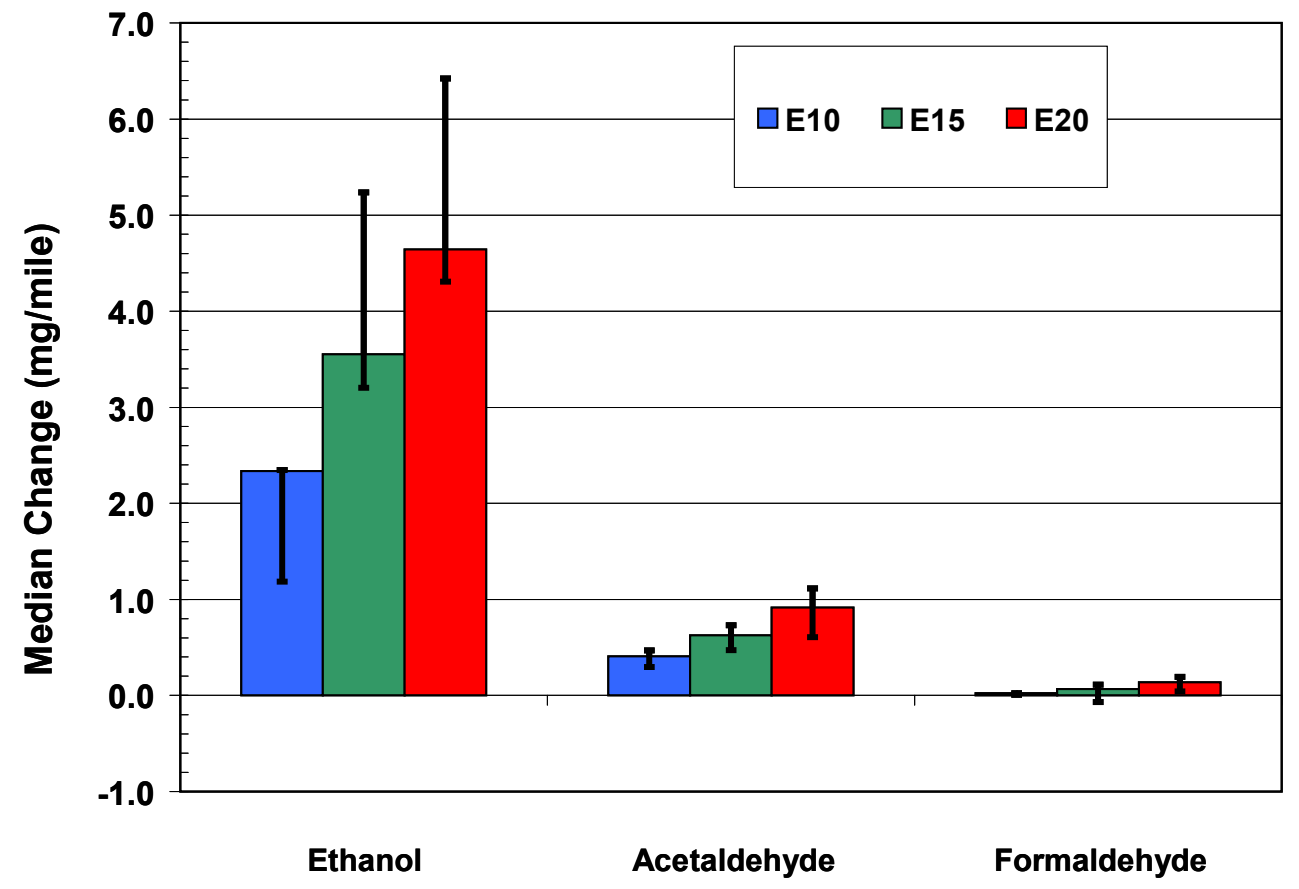

Fig. 3.8. Median change in ethanol, acetaldehyde, and formaldehyde emissions relative to E0. Range bars show interquartile range (25th to 75th percentile). Results for Federal Test Procedure at start-of-test. 



\section{SUMMARY OF UNSCHEDULED MAINTENANCE AND VEHICLE TESTING ISSUES}

\subsection{UNSCHEDULED MAINTENANCE}

Table 4.1 summarizes some of the more notable unscheduled maintenance occurrences during the program. Routine scheduled and unscheduled maintenance (such as oil changes, transmission service, wheel bearing replacement, and body work) are not shown. Incidents that resulted in excessive downtime, rigorous investigations, potential fuel-related issues, or complete vehicle replacement are described.

Table 4.1. Notable unscheduled maintenance issues

\begin{tabular}{|c|c|}
\hline Vehicle model & Maintenance issues \\
\hline $\begin{array}{c}2007 \\
\text { Honda Accord }\end{array}$ & $\begin{array}{l}\text { RE10 Accord rejected early in program due to relatively high oil consumption. Noted at first oil } \\
\text { change, RE10 vehicle consumed roughly } 3 \text { times the oil of companion vehicles over the same } \\
\text { distance. Due to concern that oil consumption could impact catalyst efficiency over time, vehicle } \\
\text { replaced after } \sim 7 \mathrm{k} \text { miles of aging. }\end{array}$ \\
\hline $\begin{array}{l}2006 \\
\text { Chevrolet } \\
\text { Silverado }\end{array}$ & $\begin{array}{l}\text { RE20 fuel pump failed at 32,400 test miles ( } 49,500 \text { odometer miles). Pump was replaced and } \\
\text { vehicle resumed testing. Failed pump was returned to the manufacturer for root cause analysis. } \\
\text { Manufacturer disassembled the pump and determined that failure was due to mechanical failure } \\
\text { of internal electrical connector; not deemed a fuel-related failure. }\end{array}$ \\
\hline $\begin{array}{c}2007 \\
\text { Dodge } \\
\text { Caravan }\end{array}$ & $\begin{array}{l}\text { First vehicle assigned to RE20 rejected due to marginal emissions performance during screening } \\
\text { tests. Vehicle replaced before start-of-test (SOT). }\end{array}$ \\
\hline $\begin{array}{l}2006 \\
\text { Chevrolet } \\
\text { Cobalt }\end{array}$ & $\begin{array}{l}\text { At end-of-test (EOT) ( } 72,000 \text { test miles, } 120,000 \text { odometer miles), RE15 vehicle fuel pump } \\
\text { found to be leaking due to a cracked fuel feed nipple. The pump was replaced and the vehicle } \\
\text { completed emissions tests. The broken fuel nipple was analyzed with Fourier transform infrared } \\
\text { (FTIR) spectrometer to determine whether the inner surface had changed relative to the outer } \\
\text { surface. No molecular change between the inner and outer surfaces was noted. Failure was } \\
\text { attributed to vehicle age. }\end{array}$ \\
\hline $\begin{array}{c}2007 \\
\text { Dodge Caliber }\end{array}$ & $\begin{array}{l}\text { RE20 Caliber tripped a catalyst temperature limit during mileage accumulation at 2,500 test } \\
\text { miles (43,000 odometer miles). The catalyst had experienced severe thermal damage, indicative } \\
\text { of a misfire event. Review of data logs and inspection of the vehicle found no clear cause of } \\
\text { misfire. The original RE20 vehicle was shipped to the manufacturer for additional root cause } \\
\text { analysis. The manufacturer replaced the catalyst and conducted extensive tests. The anomaly } \\
\text { could not be replicated on the original test vehicle and did not recur in the program. A } \\
\text { replacement vehicle was acquired and aged to EOT. }\end{array}$ \\
\hline $\begin{array}{c}2009 \\
\text { Jeep Liberty }\end{array}$ & Apparent adaptation issues noted at SOT. (See Sect. 4.2.2). \\
\hline $\begin{array}{l}2006 \\
\text { Chevrolet } \\
\text { Impala }\end{array}$ & $\begin{array}{l}\text { All three Impalas (RE0, RE15, RE20) experienced malfunction indicator lamp (MIL) } \\
\text { illumination associated with manifold absolute pressure sensor performance and evaporative } \\
\text { emissions system leaks between SOT and midlife tests. After repeated trips to the shop, } \\
\text { replacement of canister vent solenoids eventually resolved the issue. This problem was not } \\
\text { deemed fuel related. }\end{array}$ \\
\hline $\begin{array}{c}2006 \\
\text { Nissan Quest }\end{array}$ & $\begin{array}{l}\text { 1. Problems with traction control on 2WD dynamometer prompted move from Southwest } \\
\text { Research Institute to Transportation Research Center Inc. to allow emissions tests on 4WD } \\
\text { dynamometer and aging on track (in lieu of 2WD mileage accumulation dynamometer). } \\
\text { After SOT and initial standard road cycle (SRC) aging on track, DOE directed protocol } \\
\text { changes to accelerate completion of this vehicle set. Changes included modification of } \\
\text { aging protocol from SRC to series of steady high speed laps on track and omission of } \\
\text { midlife emissions tests. }\end{array}$ \\
\hline
\end{tabular}


Table 4.1. Notable unscheduled maintenance issues (continued)

\begin{tabular}{|c|c|}
\hline Vehicle model & Maintenance issues \\
\hline $\begin{array}{c}2006 \\
\text { Nissan Quest } \\
\text { (continued) }\end{array}$ & $\begin{array}{l}\text { 2. Exhaust catalyst on RE0 and RE20 vehicles failed during aging (appeared to be failure of } \\
\text { mounting mat, catalyst monoliths moved downstream inside their can). Catalysts were } \\
\text { returned to the manufacturer for root cause analysis. While no specific cause was given, } \\
\text { failures did not appear to be related to test fuel or aging protocol. Vehicles not replaced; } \\
\text { only RE15 vehicle reached full useful life. (See Sect. 4.2.1). }\end{array}$ \\
\hline $\begin{array}{l}2009 \\
\text { Ford Focus }\end{array}$ & $\begin{array}{l}\text { RE15 vehicle experienced a transmission failure at 70,300 miles. Failure was related to } \\
\text { excessive wear of band for planetary gear set. Transmission was replaced and mileage } \\
\text { accumulation resumed. RE20 vehicle experienced a similar transmission failure at 90,285 miles. } \\
\text { Transmission was replaced and mileage accumulation was resumed. }\end{array}$ \\
\hline $\begin{array}{c}2009 \\
\text { Honda } \\
\text { Odyssey }\end{array}$ & $\begin{array}{l}\text { RE0 vehicle began setting P0420 fault code (catalyst system efficiency below threshold- } \\
\text { bank 1) at about 80,000 miles. MIL illuminated four times leading up to 90,000 mile emissions } \\
\text { test interval, including during prep cycle for emissions. MIL was not cleared before emissions } \\
\text { testing due to possible impact on adaptive controls. Following 90,000 mile emissions test, } \\
\text { Bank1/Sensor } 2 \text { oxygen sensor signal was seen to exhibit excessive noise. Sensor was replaced } \\
\text { and issue was resolved. Exhaust mass emissions were comparable before and after sensor } \\
\text { replacement at 90,000 miles. }\end{array}$ \\
\hline 2000 & $\begin{array}{l}\text { 1. Shortly after SOT (at } 112,000 \text { odometer miles), the RE15 vehicle fuel gauge registered } \\
\text { "empty” after a fuel fill. The fuel level sender was replaced. After } 131 \text { miles of aging on the } \\
\text { SRC, the vehicle stopped and would not start. Fuel pump was replaced and testing resumed. } \\
\text { Manufacturer was contacted and fuel pump and sender set aside to afford the opportunity for } \\
\text { root cause analysis. }\end{array}$ \\
\hline $\begin{array}{l}\text { Chevrolet } \\
\text { Silverado }\end{array}$ & $\begin{array}{l}\text { 2. Exhaust leak on RE15 vehicle discovered after EOT. Because of concern over potential } \\
\text { effect on emissions measurements, the vehicle was repaired and retested. Repair consisted } \\
\text { of removal and replacement of exhaust manifold, broken fastener, and gasket. Because of an } \\
\text { unrelated transmission leak, the transmission was also swapped at the same time (swapped } \\
\text { with RE0 vehicle). Results of repeat tests after repair were consistent with the original EOT } \\
\text { tests, indicating the leak was very minor. }\end{array}$ \\
\hline $\begin{array}{c}2002 \\
\text { Dodge } \\
\text { Durango }\end{array}$ & $\begin{array}{l}\text { Evaporative emissions hose on RE20 vehicle split at throttle body connection after } 25,000 \text { miles } \\
\text { of aging ( } 89,000 \text { odometer miles). Hose replaced and vehicle resumed mileage accumulation. } \\
\text { Hose section analyzed with FTIR spectrometer. Analysis suggests that material is nitrile rubber. } \\
\text { There were no signs of any chemical differences between the inside and outside of the hose. } \\
\text { Failure attributed to vehicle age. }\end{array}$ \\
\hline $\begin{array}{c}2003 \\
\text { Chevrolet } \\
\text { Cavalier } \\
\end{array}$ & $\begin{array}{l}\text { High oil consumption on RE20 vehicle noted at 14,700 test miles (102,000 odometer miles). } \\
\text { Vehicle replaced. }\end{array}$ \\
\hline $\begin{array}{l}2000 \\
\text { Honda Accord }\end{array}$ & $\begin{array}{l}\text { 1. RE0 vehicle illuminated MIL (P0420) at about } 25,000 \text { miles }(\sim 130,000 \text { total odometer } \\
\text { miles). Emission test showed elevated levels of } \mathrm{CO} \text { and } \mathrm{NO}_{\mathrm{X}} \text {. Following emissions test and } \\
\text { wide-open throttle (WOT), vehicle was returned to mileage accumulation. After } \\
1,000 \text { additional miles, high catalyst outlet temperature }\left(>840^{\circ} \mathrm{C}\right) \text { triggered test shutdown. } \\
\text { Catalyst monolith found to be fractured and front face partially melted. Vehicle removed } \\
\text { from test. Spare RE0 Honda Accord used as replacement. } \\
\text { 2. Second RE0 vehicle experienced a transmission failure within first 1,000 miles of mileage } \\
\text { accumulation. Transmission was replaced and mileage accumulation was resumed. } \\
\text { Following } 25,000 \text {-mile-emissions test and WOT, vehicle was returned to mileage } \\
\text { accumulation. Catalyst monolith found to be fractured and front face partially melted } \\
\text { shortly after aging resumed, with catalyst failure mode nearly identical to first RE0 failure. } \\
\text { Vehicle removed from test. Third Honda Accord used as RE0 replacement; vehicle } \\
\text { completed 50,000 miles of aging without further incident. }\end{array}$ \\
\hline
\end{tabular}


Table 4.1. Notable unscheduled maintenance issues (continued)

\begin{tabular}{|c|c|}
\hline Vehicle model & Maintenance issues \\
\hline \multirow{2}{*}{$\begin{array}{l}2000 \\
\text { Honda Accord } \\
\text { (continued) }\end{array}$} & $\begin{array}{l}\text { 3. RE15 vehicle experienced two MIL illuminations at 40,000 accumulated miles } \\
\text { (135,000 odometer miles): a P0420 (catalyst efficiency) and a P1381 (cylinder position } \\
\text { sensor interruption). There was no evidence of a catalyst temperature excursion. Ignition } \\
\text { coil, position sensor, and ignition module were replaced, and mileage accumulation was } \\
\text { resumed. No further issues were observed. }\end{array}$ \\
\hline & $\begin{array}{l}\text { 4. RE20 vehicle experienced a coolant boilover within first 1,000 miles of mileage } \\
\text { accumulation. High coolant temperature alarm shut down test sequence. Inspection showed } \\
\text { excessive engine oil in coolant; head gasket failure suspected but not verified. Spare vehicle } \\
\text { was used as replacement. }\end{array}$ \\
\hline $\begin{array}{l}2000 \\
\text { Ford Focus }\end{array}$ & $\begin{array}{l}\text { RE0 vehicle experienced a misfire on cylinders } 2 \text { and } 3 \text { (MIL P0302 and P0303) at about } \\
8,000 \text { accumulated miles ( } ~ 95,000 \text { odometer miles). Cause of failure diagnosed as failed plug } \\
\text { wire which caused subsequent failure of ignition coil. Misfire resulted in high temperature } \\
\text { catalyst exposure and deactivation of the catalyst coating. Spare vehicle was used as } \\
\text { replacement. }\end{array}$ \\
\hline
\end{tabular}

\subsection{VEHICLE TESTING ISSUES}

\subsubsection{Nissan Quest Testing Issues}

The Nissan Quests were reassigned from SwRI to TRC during the program due to problems with the traction control feature on these vehicles when tested on the two-wheel-drive dynamometer. Moving the vehicles to TRC allowed emissions tests on these vehicles using a four-wheel-drive dynamometer. SOT tests were successfully conducted on all three Quests at TRC using the four-wheel-drive dynamometer. Aging these vehicles on the track averted the two-wheel-drive issues that occurred on the MADs. Initial attempts to resolve the traction control problems on the two-wheel drive dynamometer and the change in test laboratories resulted in undesired program delays. Consequently, DOE directed that these vehicles begin using a nonstandard driving schedule for aging in an effort to accelerate completion of the program for these vehicles. After less than 20,000 miles of aging on the track using the SRC, the drive schedule was changed to a series of high-speed laps, at 65,70 , and $75 \mathrm{mph}$, and the midpoint emissions tests on these vehicles were cancelled to further accelerate completion of the vehicle set.

Additionally, two of the three Quests (the RE0 and RE20 vehicles) experienced catalyst failures during the aging process. The RE0 failure occurred just before the change in mileage accumulation protocol (at about 17,000 test miles), and the RE20 failure occurred at just over 30,000 test miles. Both failures were identified through a MIL illumination associated with catalyst performance. Upon inspection, the catalyst monoliths on both vehicles were found to have moved toward the rear of the catalyst housing by about 1 in., perhaps indicating a problem with the matting surrounding the monoliths. Both failed catalysts were returned to Nissan for analysis. The failures were not considered fuel related. At the direction of DOE, the RE0 and RE20 vehicles were dropped from the program.

Because no RE0 baseline data were available after SOT and because the results from the RE15 vehicle at EOT could not be assumed to be typical of aging on the SRC, the emissions results from the Quests were not used in the statistical analysis of emissions results. However, the EOT RE15 results that were obtained are included in the tabulated EOT results in Sect. 3.2.4. 


\subsubsection{Jeep Liberty Start-of-Test Emissions Tests}

During the initial emissions tests conducted at 4,000 odometer miles on the Jeep Liberty vehicles, a nonmethane hydrocarbon (NMHC) noncompliance issue and high-CO state were noted when the vehicles were tested using E0. The SOT emissions results did not closely agree with the results previously obtained in the single screening FTP test on each vehicle. No significant mileage was accrued between these emissions tests, and hence, there was no reason to expect a large difference in the results. Moreover, all three vehicles were only exposed briefly to E20 during the screening WOT test, and none of the vehicles had yet been aged using an ethanol-containing fuel. An incomplete or incorrect adaptation from E15 and E20 to E0 during the course of testing was suspected as the cause of the higher E0 emissions. The problem was determined to occur in bag 1 and bag 3, probably during the first few seconds of openloop operation after start-up. Bag 2 exhibited typically low emissions levels. The first step in responding to this situation was to check that complete emissions test data had been collected in the abnormal state. Next, the vehicles were re-prepped by performing the fuel adaptation procedure twice; then a repeat FTP test was performed. Even after the additional prep and adaptation, abnormally high NMHC and CO emissions were noted. Finally, the vehicles were forced into readjustment by disconnecting the batteries (to force an LFT reset) followed by once again performing the fuel adaptation procedure. After this step the results of FTPs were found to be in close agreement with the original screening FTP, allowing the full course of emissions tests to be run again with the vehicles at this lower $\mathrm{CO}$ condition. Comparisons of the NMHC and CO results from before and after the battery disconnection are shown in Figs. 4.1 and 4.2. Results are shown for the single screening test, the two SOT tests, and the two SOT retests. (Note that NMHC emissions are compared against the relevant NMOG standard. NMOG emissions were not measured for the screening tests but are always higher than NMHC.)

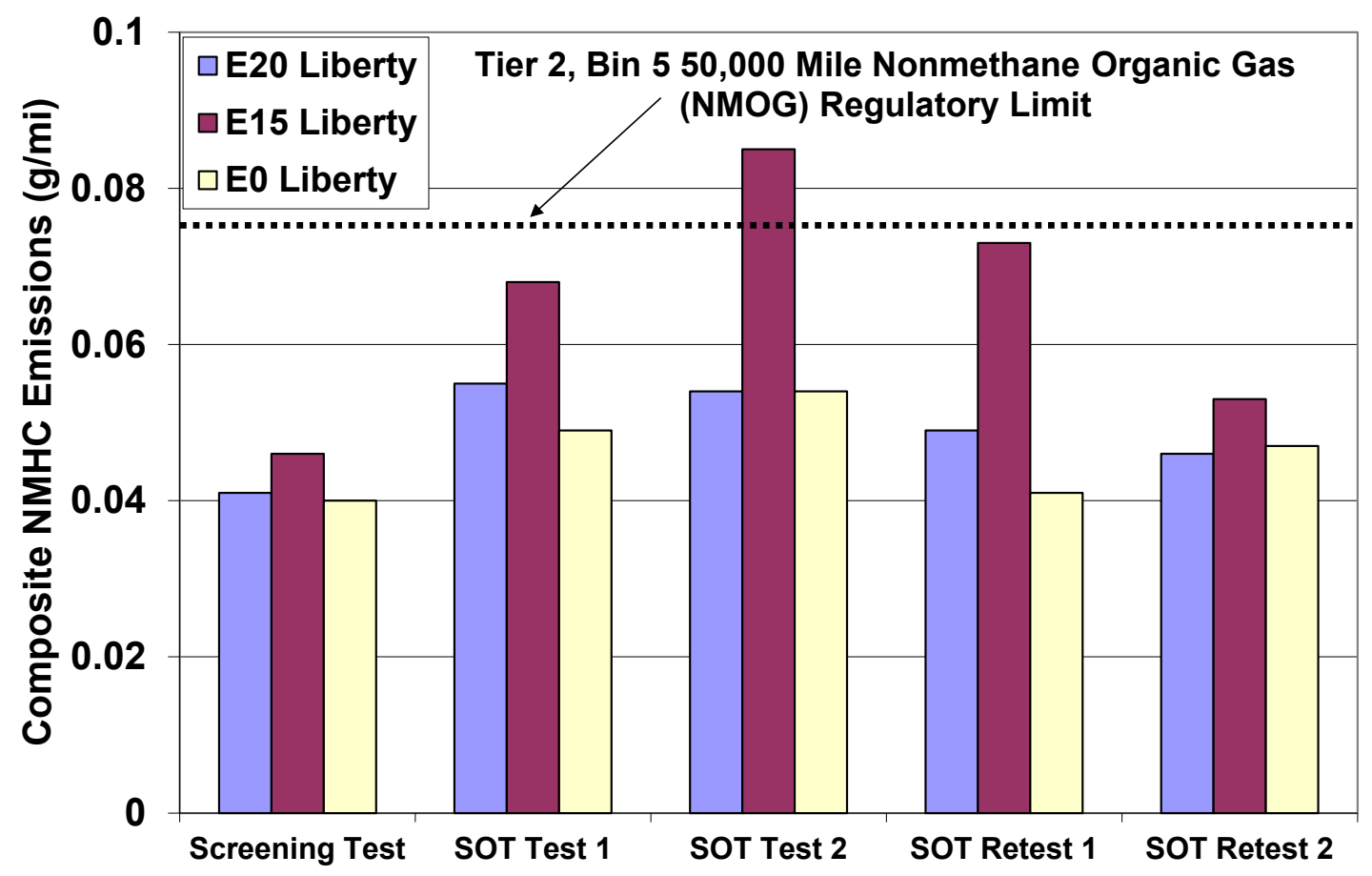

Fig. 4.1. Jeep Liberty start-of-test (SOT) nonmethane hydrocarbon (NMHC) emissions using E0 before and after battery disconnection. 


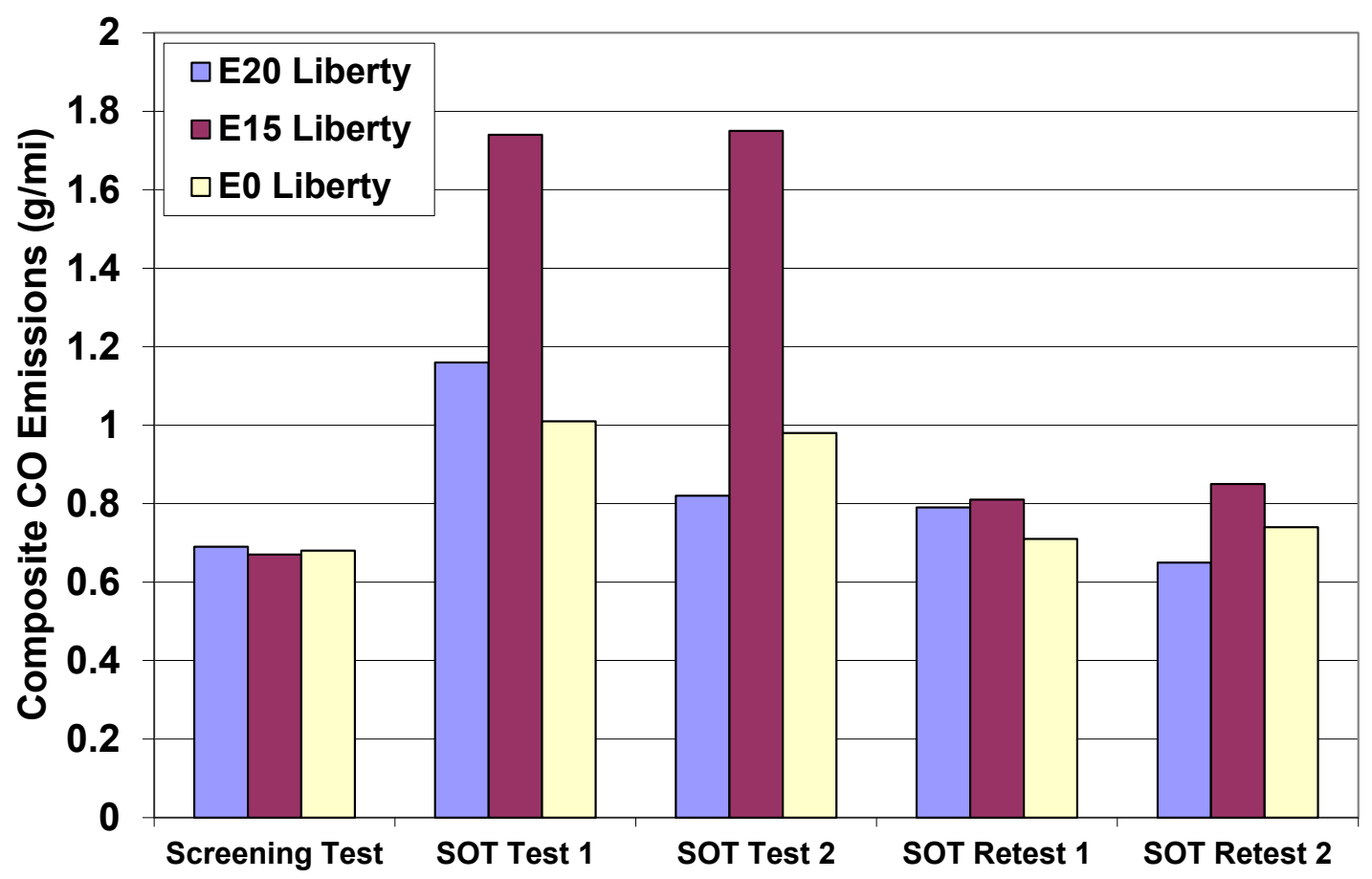

Fig. 4.2. Jeep Liberty start-of-test (SOT) CO emissions using EO before and after battery disconnection.

The exact cause of the high-emissions condition for the Liberty vehicles may never be known with certainty; however, it appears very likely that the situation was caused by inadequate adaptation after exposure to E15 and E20 during screening and SOT. It is worth noting that this problem did not reoccur during subsequent emissions test intervals, leading to the conclusion that the original problem was likely a result of the imposed test sequence. This finding raises an issue that could be further investigated. As there was no E10 test vehicle in this group, no data exist to determine whether this situation may also have arisen if E10 were used. The retest results collected after battery disconnection were used as the baseline for the statistical analyses for this program. The results from the high-emissions state were retained in the program database for completeness.

\subsubsection{Ethanol and Aldehyde Emissions Issues}

As described briefly in Sect. 3.2.3, NMOG emissions were estimated for all tests based on a correlation between NMOG and NMHC. Some problems with ethanol and aldehyde measurements precluded calculation of NMOG emissions for some tests, but results for NMHC were available for virtually all tests.

The application of the photoacoustic analyzer used for tests early in the TRC program and used at ETC throughout the program was deemed unreliable. Impingers were used at TRC for some of the later tests. The photoacoustic analyzer is an approved method for ethanol measurement, but results are dependent on laboratory setup. Sample lines need to be short and/or heated to minimize retention of ethanol in the sampling system. 
All sites used di-nitrophenylhydrazine cartridges to trap carbonyls (aldehydes and ketones) for later analysis by high performance liquid chromatography. Aldehyde results from ETC were notably much lower than expected, and the problem was traced to a sample leak for all phase 1 (bag 1) samples. The bulk of the aldehydes and other organics are emitted in phase 1, so without reliable phase 1 results, the weighted FTP results are unusable. 
APPENDIX A.

VEHICLE EMISSIONS STANDARDS 



\section{APPENDIX A. VEHICLE EMISSIONS STANDARDS}

Emissions from vehicles have been regulated by the U.S. Environmental Protection Agency and the California Air Resources Board since the early 1970s. Tier 0 refers to standards that were phased in during the 1970s as a result of the 1970 Clean Air Act. These standards were amended in the late 1970s and first met in 1981. Tier 0 standards were in force until 1994. Tier 1 standards were phased in from 1994 through 1996. Table A.1 shows the Tier 0, Tier 1, and National Low Emission Vehicle (NLEV) Program emissions standards. Table A.2 gives the footnotes (i.e., superscript numbers in brackets [x]) for Table A.1, and Table A.3 defines the acronyms used in Tables A.1, A.4, and A.5.

Phase-in of Tier 2 standards began in 2004, although some manufacturers had the option of early compliance under the NLEV Program. Full useful life (FUL) for Tier 2 vehicles is 100,000 miles, 120,000 miles, or 150,000 miles, depending on a number of factors. The rule is described in detail in the Federal Register, Vol. 65(28). Tier 2 FUL standards are shown in Table A.4, and Tier 2 50,000-mile standards are shown in Table A.5.

Table A.1. Federal certification exhaust emission standards for light duty vehicles and light duty trucks

[All emissions in grams/mile on Federal Test Procedure (Source: www.epa.gov/otaq/standards.htm)]

\begin{tabular}{|c|c|c|c|c|c|c|c|c|c|c|c|c|c|c|c|c|}
\hline & \multirow{3}{*}{\begin{tabular}{|c|}
$\begin{array}{c}\text { Vehicle } \\
\text { Type }\end{array}$ \\
\end{tabular}} & \multirow{3}{*}{$\begin{array}{l}\text { Emission } \\
\text { Category }\end{array}$} & \multicolumn{14}{|c|}{ Vehicle Useful Life } \\
\hline & & & \multicolumn{7}{|c|}{5 Years / 50,000 Miles } & \multicolumn{7}{|c|}{10 Years $/ 100,000$ Miles } \\
\hline & & & $\mathrm{THC}^{\{2,5,38\}}$ & $\mathrm{NMHC}^{[3]}$ & NMOG & $\mathrm{CO}^{[35,39]}$ & NOx & $\mathrm{PM}^{[2 \mathrm{Z}]}$ & $\mathrm{HCHO}$ & $\mathrm{THC}^{[2,5]}$ & $\mathrm{NMHC}^{[3]}$ & NMOG & $\mathrm{CO}^{|\$ 8|}$ & NOx & $\mathrm{PM}^{[28]}$ & $\mathrm{HCHO}$ \\
\hline \multirow[t]{6}{*}{ Federal } & \multirow{2}{*}{\begin{tabular}{|l} 
LDV \\
{$[3 r, 40,43 \mid$}
\end{tabular}} & Tier 0 & 0.41 & [6] 0.34 & - & 3.4 & 1.0 & [4] 0.20 & - & & & & & & & \\
\hline & & Tier 1 & ${ }^{[28]} 0.41$ & 0.25 & - & 3.4 & ${ }^{[7]} 0.4$ & 0.08 & - & - & 0.31 & - & 4.2 & ${ }^{[9]} 0.6$ & 0.10 & - \\
\hline & \multirow{2}{*}{$\begin{array}{l}\text { LDT1 } \\
{[37,40,43]} \\
\end{array}$} & Tier $0^{[26]}$ & & & & & & & & 0.80 & ${ }^{[6]} 0.67$ & - & 10 & 1.2 & [4] 0.26 & - \\
\hline & & Tier 1 & - & 0.25 & - & 3.4 & 0.4 & 0.08 & - & {$[26,28] 0.80$} & 0.31 & - & 4.2 & 0.6 & 0.10 & - \\
\hline & \multirow{2}{*}{\begin{tabular}{|l} 
LDT2 \\
{$[37,40,43]$} \\
\end{tabular}} & Tier $0^{[26]}$ & & & & & & & & 0.80 & ${ }^{[6]} 0.67$ & - & 10 & 1.7 & [4] 0.13 & - \\
\hline & & Tier 1 & - & 0.32 & - & 4.4 & ${ }^{[3]} 0.7$ & 0.08 & - & {$[26,28] 0.80$} & 0.40 & - & 5.5 & 0.97 & 0.10 & - \\
\hline \multirow{12}{*}{$\begin{array}{l}\text { Federal } \\
\text { National } \\
\text { Low } \\
\text { Emission } \\
\text { Vehicle } \\
\text { (NLEV) } \\
\text { Program }\end{array}$} & \multirow{4}{*}{\begin{tabular}{|l} 
LDV \\
{$[36,40,41]$}
\end{tabular}} & TLEV & ${ }^{[28]} 0.41$ & - & ${ }^{[1,31]} 0.125$ & 3.4 & ${ }^{[34]} 0.4$ & 0.08 & 0.015 & - & - & ${ }^{[1,3]]} 0.156$ & 4.2 & ${ }^{[34]} 0.6$ & \begin{tabular}{ll|}
{$[32]$} & 0.08 \\
\end{tabular} & 0.018 \\
\hline & & LEV $^{[42]}$ & ${ }^{[28]} 0.41$ & - & ${ }^{[1,31]} 0.075$ & 3.4 & ${ }^{[34]} 0.2$ & 0.08 & 0.015 & - & - & ${ }^{[1,31]} 0.090$ & 4.2 & ${ }^{[34]} 0.3$ & $\begin{array}{ll}{ }^{[32]} & 0.08 \\
\end{array}$ & 0.018 \\
\hline & & ULEV $^{[(42]}$ & [28] 0.41 & - & ${ }^{[1,31]} 0.040$ & 1.7 & ${ }^{[34]} 0.2$ & 0.08 & 0.008 & - & - & ${ }^{[1,31]} 0.055$ & 2.1 & [34] 0.3 & $\begin{array}{ll}{[32]} & 0.04\end{array}$ & 0.011 \\
\hline & & ZEV & 0.00 & 0.00 & 0.000 & 0.0 & ${ }^{[34]} 0.0$ & 0.00 & 0.000 & 0.00 & 0.000 & 0.000 & 0.0 & ${ }^{[34]} 0.0$ & 0.00 & 0.000 \\
\hline & \multirow{4}{*}{\begin{tabular}{|l} 
LDT1 \\
{$[36,40,41]$}
\end{tabular}} & TLEV & - & - & ${ }^{(1,31)} 0.125$ & 3.4 & ${ }^{[36]} 0.4$ & 0.08 & 0.015 & 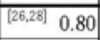 & & ${ }^{[1,31]} 0.156$ & 4.2 & $\begin{array}{l}{[34]} \\
{[36}\end{array}$ & \begin{tabular}{ll|} 
[32] & 0.08 \\
\end{tabular} & 0.018 \\
\hline & & LEV $^{[42]}$ & . & - & ${ }^{[1,31]} 0.075$ & 3.4 & ${ }^{[34]} 0.2$ & 0.08 & 0.015 & $\begin{array}{|ll|}{[26,28]} & 0.80 \\
\end{array}$ & - & ${ }^{[1,31]} 0.090$ & 4.2 & [34] 0.3 & ${ }^{[32]} 0.08$ & 0.018 \\
\hline & & ULEV $^{[42]}$ & - & - & ${ }^{[1,31]} 0.040$ & 1.7 & ${ }^{[34]} 0.2$ & 0.08 & 0.008 & 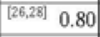 & & ${ }^{[1,31]} 0.055$ & 2.1 & ${ }^{[34]} 0.3$ & \begin{tabular}{ll|}
{$[32]$} & 0.04
\end{tabular} & 0.011 \\
\hline & & ZEV & 0.00 & 0.00 & 0.000 & 0.0 & ${ }^{[34]} 0.0$ & 0.00 & 0.000 & 0.00 & 0.000 & 0.000 & 0.0 & ${ }^{[34]} 0.0$ & 0.00 & 0.000 \\
\hline & \multirow{4}{*}{\begin{tabular}{|l} 
LDT2 \\
{$[36,40,41]$}
\end{tabular}} & TLEV & - & - & ${ }^{(1,31)} 0,160$ & 4.4 & ${ }^{[36]} 0.7$ & 0.08 & 0.018 & 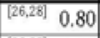 & - & ${ }^{[1,31]} 0.200$ & 5.5 & [34] 0.9 & 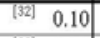 & 0.023 \\
\hline & & $\mathrm{LEV}^{[42]}$ & $=$ & - & ${ }^{[1,31]} 0.100$ & 4.4 & ${ }^{[34]} 0.4$ & 0.08 & 0.018 & 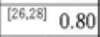 & - & ${ }^{[1.31]} 0.130$ & 5.5 & [34] 0.5 & ${ }^{[32]} \quad 0.10$ & 0.023 \\
\hline & & ULEV $^{[(42]}$ & - & - & ${ }^{[1,31]} 0.050$ & 2.2 & ${ }^{[34]} 0.4$ & 0.08 & 0.009 & ${ }^{[26,28]} 0.80$ & - & ${ }^{[1,31]} 0.070$ & 2.8 & ${ }^{[34]} 0.5$ & ${ }^{[32]} \quad 0.05$ & 0.013 \\
\hline & & ZEV & 0.00 & 0.00 & 0.000 & 0.0 & ${ }^{[34]} 0.0$ & 0.00 & 0.000 & 0.00 & 0.000 & 0.000 & 0.0 & [34] 0.0 & 0.00 & 0.000 \\
\hline \multirow{12}{*}{$\begin{array}{l}\text { Federal } \\
\text { Clean } \\
\text { Fueled } \\
\text { Vehicle } \\
\text { (CFV) } \\
\text { Program }\end{array}$} & \multirow{4}{*}{$\begin{array}{l}\text { LDV } \\
{[37,40,41]}\end{array}$} & LEV & 0.41 & - & ${ }^{[30]} 0.075$ & 3.4 & ${ }^{[34]} 0.2$ & - & 0.015 & - & - & 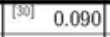 & 4.2 & ${ }^{[34]} 0.3$ & [10] 0.08 & 0.018 \\
\hline & & ILEV $^{[33]}$ & ${ }^{[28]} 0.41$ & - & 0.075 & 3.4 & ${ }^{[34]} 0.2$ & . & 0.015 & $=$ & - & 0.090 & 4.2 & ${ }^{[34]} 0.3$ & ${ }^{[10]} 0.08$ & 0.018 \\
\hline & & ULEV & [28] 0.41 & - & ${ }^{[30]} 0.040$ & 1.7 & ${ }^{[34]} 0.2$ & - & 0.008 & - & - & ${ }^{[30]} 0.055$ & 2.1 & ${ }^{[34]} 0.3$ & [10] 0.04 & 0.011 \\
\hline & & ZEV & 0.00 & 0.00 & 0.000 & 0.0 & ${ }^{[30]} 0.0$ & 0.00 & 0.000 & 0.00 & 0.000 & 0.000 & 0.0 & ${ }^{[34]} 0.0$ & 0.00 & 0.000 \\
\hline & \multirow{4}{*}{\begin{tabular}{|l} 
LDT1 \\
{$[37,40,41]$}
\end{tabular}} & LEV & - & - & 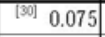 & 3.4 & $\begin{array}{ll}{[34]} & 0.2 \\
\end{array}$ & - & 0.015 & 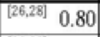 & 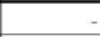 & 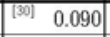 & 4.2 & ${ }^{[34]} 0.3$ & \begin{tabular}{ll|}
{$[10]$} & 0.08 \\
\end{tabular} & 0.018 \\
\hline & & ILEV $^{[33]}$ & - & - & 0.075 & 3.4 & ${ }^{[34]} 0.2$ & - & 0.015 & 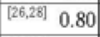 & - & 0.090 & 4.2 & ${ }^{[34]} 0.3$ & $\begin{array}{ll}{[10]} & 0.08\end{array}$ & 0.018 \\
\hline & & ULEV & . & $=$ & ${ }^{[30]} 0.040$ & 1.7 & ${ }^{[34]} 0.2$ & . & 0.008 & 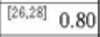 & . & {$\left[\begin{array}{ll}{[30]} & 0.055 \\
\end{array}\right.$} & 2.1 & ${ }^{[34]} 0.3$ & $\begin{array}{ll}{[10]} & 0.04\end{array}$ & 0.011 \\
\hline & & ZEV & 0.00 & 0.00 & 0.000 & 0.0 & ${ }^{[30]} 0.0$ & 0.00 & 0.000 & 0.00 & 0.000 & 0.000 & 0.0 & ${ }^{[34]} 0.0$ & 0.00 & 0.000 \\
\hline & \multirow{4}{*}{\begin{tabular}{|c|} 
LDT2 \\
{$[37,40,41]$}
\end{tabular}} & LEV & - & - & ${ }^{[30]} 0.100$ & 4.4 & ${ }^{[34]} 0.4$ & - & 0.018 & 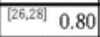 & - & 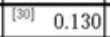 & 5.5 & [34] 0.5 & \begin{tabular}{ll|}
{$[10]$} & 0.08
\end{tabular} & 0.023 \\
\hline & & ILEV ${ }^{[33]}$ & - & - & 0.100 & 4.4 & ${ }^{[34]} 0.4$ & - & 0.018 & ${ }^{[26,28]} 0.80$ & - & 0.130 & 5.5 & ${ }^{[34]} 0.5$ & $\begin{array}{ll}{[10]} & 0.08\end{array}$ & 0.023 \\
\hline & & ULEV & - & - & ${ }^{[30]} 0.050$ & 2.2 & ${ }^{[34]} 0.4$ & - & 0.009 & ${ }^{[26,28]} 0.80$ & - & {$\left[\begin{array}{ll}{[30]} & 0.070 \\
\end{array}\right.$} & 2.8 & [34] 0.5 & ${ }^{[10]} \quad 0.04$ & 0.013 \\
\hline & & ZEV & 0.00 & 0.00 & 0.000 & 0.0 & ${ }^{[34]} 0.0$ & 0.00 & 0.000 & 0.00 & 0.000 & 0.000 & 0.0 & ${ }^{[34]} 0.0$ & 0.00 & 0.000 \\
\hline
\end{tabular}


Table A.2. Footnotes used in Table A.1

(Source: www.epa.gov/otaq/standards.htm)

Footnotes to the tables of emission standards

1. NMHC FOR DIESEL CYCLE VEHICLES

2. THCE FOR METHANOL VEHICLES

3. THCE FOR TIER 0 METHANOL VEHICLES, NMHCE FOR OTHER ALCOHOL VEHICLES

4. APPLIES TO DIESEL VEHICLES ONLY

5. DOES NOT APPLY TO CNG VEHICLES

6. CNG VEHICLES ONLY

7. 1.0 FOR DIESEL-FUELED VEHICLES THROUGH 2003 MODEL YEAR

8. DOES NOT APPLY TO DIESEL-FUELED VEHICLES

9. 1.25 FOR DIESEL-FUELED VEHICLES THROUGH 2003 MODEL YEAR

10. DIESEL-FUELED VEHICLES ONLY

11. METHANOL AND ETHANOL VEHICLES ONLY

12. GASOLINE VEHICLES ONLY

13. 0.7 THROUGH MODEL YEAR 1997

14. 1.0 THROUGH MODEL YEAR 1997

15. 1.1 THROUGH MODEL YEAR 1997

16. 1.5 THROUGH MODEL YEAR 1997

17. 1.3 THROUGH MODEL YEAR 1997

18. 1.8 THROUGH MODEL YEAR 1997

19. 2.0 THROUGH MODEL YEAR 1997

20. 2.8 THROUGH MODEL YEAR 1997

21. 1.48 FOR DIESEL-FUELED VEHICLES

22. 2.07 FOR DIESEL-FUELED VEHICLES

23. OTHER EQUIVALENT SCHEDULES ALLOWED.

24. PC/LDV MAY BE COMBINED WITH LDT1 \& LDT2 FOR TIER 1 PHASE-IN

25. PC/LDV \& LDT1 COMBINED WITH LDT2 FOR SFTP PHASE-IN

26. STANDARDS APPLY AT A USEFUL LIFE OF 11 YEARS $/ 120,000$ MILES

27. GASOLINE AND DIESEL VEHICLES ONLY

28. TOTAL HC COMPLIANCE STATEMENT ALLOWED (IN LIEU OF TEST DATA)

29. PARTICULATES COMPLIANCE STATEMENT ALLOWED FOR NON-DIESEL CYCLE VEHICLES (IN LIEU OF SUPPLYING ACTUAL TEST DATA)

30. SPECIAL NMOG STANDARDS APPLY TO DUAL \& FLEXIBLE FUEL VEHICLES, SEE 40 CFR 88.104-94(h) \& (i)

31. DUAL \& FLEXIBLE FUEL VEHICLES MAY MEET NEXT HIGHER (LESS STRINGENT) NMOG STANDARD WHEN OPERATING ON GASOLINE.

32. $0.10 \mathrm{GM} /$ MILE PARTICULATE STANDARD APPLIES TO NON-DIESEL VEHICLES

33. SPECIAL EVAPORATIVE REQUIREMENTS APPLY (5.0 GRAMS MAX WITH THE EVAPORATIVE SYSTEM DISCONNECTED)

34. HIGHWAY NOx EMISSIONS SHALL NOT EXCEED 1.33 TIMES THE APPLICABLE FTP (CITY) NOX STANDARDS

35. COLD CO EMISSIONS FOR GASOLINE FUELED VEHICLES SHALL NOT EXCEED 10.0 GR/MI (LDV, LDT1, LDT2) OR 12.5 GM/MI (LDT3 \& LDT4) AT 50K MILES

36. CALIFORNIA OBD-II SYSTEM REQUIRED, REF 40 CFR 86.1717-99

37. FEDERAL OBD SYSTEM REQUIRED BEGINNING WITH 1994 MODEL YEAR VEHICLES, REF 40 CFR 86.1806-01

38. IDLE CO EMISSIONS FROM GASOLINE, METHANOL, CNG \& LPG TRUCKS SHALL NOT EXCEED 0.50 PERCENT EXHAUST GAS AT 120K MILES/11 YEARS COMPLIANCE STATEMENT ALLOWED (IN LIEU OF ACTUAL TEST DATA)

39. CERTIFICATION SHORT TEST (CST) EMISSIONS FROM GASOLINE VEHICLES SHALL NOT EXCEED 100 PPM HC OR 0.50 PERCENT EXHAUST GAS CO AT IDLE AND 2500 RPM AT 4K MILES: COMPLIANCE STATEMENT ALLOWED (IN LIEU OF DATA)

40. TIER 1, NLEV \& CFV VEHICLES MUST MEET TIER 1 EMISSION STANDARDS AT HIGH ALTITUDE: TIER 0 VEHICLES MUST MEET SPECIAL HIGH ALTITUDE STANDARDS: COMPLIANCE STATEMENT ALLOWED (IN LIEU OF ACTUAL TEST DATA)

41. NLEV AND CFV (LDV, LDT1, LDT2) VEHICLES MUST MEET SPECIAL 50 DEG F EMISSION STANDARDS AT 4K MILES (NOT APPLICABLE TO DIESEL, CNG, OR HYBRID ELECTRIC VEHICLES)： REF. 40 CFR 86.1708 \& 1709-99 (b) (1) (iv)

42. SPECIAL INTERIM IN-USE EMISSION STANDARDS APPLY TO 1999 LEV AND 1999 TO 2002 ULEV VEHICLES: REF, 40 CFR 86.1808 \& 1809-99(C) AS CORRECTED IN EPA GUIDANCE LETTER VPCD-98-03, APRIL 8, 1998.

43. TIER 0 AND TIER 1 EMISSION STANDARDS DO NOT APPLY TO ETHANOL VEHICLES 
Table A.3. Acronyms used in Tables A.1, A.4, and A.5

\begin{tabular}{|c|c|}
\hline Acronym & Definition \\
\hline ALVW & adjusted loaded vehicle weight ([VCW+GWVR]/2) \\
\hline CFV & Clean Fueled Vehicle (Program) \\
\hline $\mathrm{CO}$ & carbon monoxide \\
\hline GVWR & gross vehicle weight rating \\
\hline $\mathrm{HCHO}$ & formaldehyde \\
\hline HLDT & heavy light duty truck \\
\hline ILEV & inherently low emission vehicle \\
\hline LDT1 & light duty truck, category 1 (GVWR $\leq 6,000 \mathrm{lb}, \mathrm{LVW}<3,750 \mathrm{lb})$ \\
\hline LDT2 & light duty truck, category $2(\mathrm{GVWR} \leq 6,000 \mathrm{lb}, 3,751 \leq \mathrm{LVW} \leq 5,750 \mathrm{lb})$ \\
\hline LDT3 & light duty truck, category $3(6,000<$ GVWR $\leq 8,500 \mathrm{lb}$, ALVW $\leq 5,750 \mathrm{lb})$ \\
\hline LDT4 & light duty truck, category $4(6,000<$ GVWR $\leq 8,500 \mathrm{lb}, 5,750<$ ALVW $\leq 3,450 \mathrm{lb})$ \\
\hline LDV & light duty vehicle (passenger car) \\
\hline LEV & low emission vehicle \\
\hline LVW & loaded vehicle weight (VCW + 300 lb) \\
\hline MDPV & medium duty passenger vehicle \\
\hline NLEV & National Low Emission Vehicle (Program) \\
\hline NMHC & nonmethane hydrocarbons \\
\hline NMOG & nonmethane organic gases \\
\hline $\mathrm{NO}_{\mathrm{X}}$ & oxides of nitrogen \\
\hline $\mathrm{PM}$ & particulate matter \\
\hline THC & total hydrocarbons \\
\hline TLEV & transitional low emission vehicle \\
\hline ULEV & ultralow emission vehicle \\
\hline VCW & $\begin{array}{l}\text { vehicle curb weight [weight of vehicle with full tanks and components included but without } \\
\text { passengers or luggage (load)] }\end{array}$ \\
\hline ZEV & zero emission vehicle \\
\hline
\end{tabular}


Table A.4. Tier 2 and interim non-Tier-2 full useful life exhaust emissions standards [All emissions in grams/mile (Source: www.epa.gov/otaq/standards.htm)]

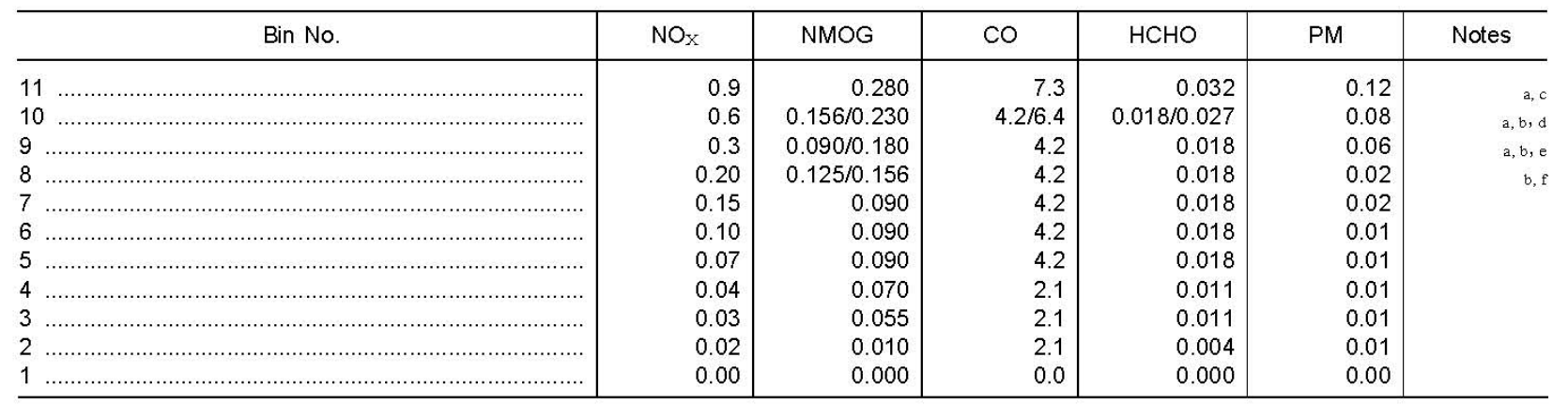

Notes:

a This bin and its corresponding intermediate life bin are deleted at end of 2006 model year (end of 2008 model year for HLDTs and MDPVs)

${ }^{b}$ Higher NMOG, $\mathrm{CO}$ and $\mathrm{HCHO}$ values apply for HLDTs and MDPVs only.

$c$ This bin is only for MDPVs.

d Optional NMOG standard of $0.280 \mathrm{~g} / \mathrm{mi}$ applies for qualifying LDT4s and qualifying MDPVs only.

e Optional NMOG standard of $0.130 \mathrm{~g} / \mathrm{mi}$ applies for qualifying LDT2s only.

f Higher NMOG standard deleted at end of 2008 model year.

Table A.5. Tier 2 and interim non-Tier-2 intermediate full useful life (50,000 mile) exhaust emissions standards

[All emissions in grams/mile (Source: www.epa.gov/otaq/standards.htm)]

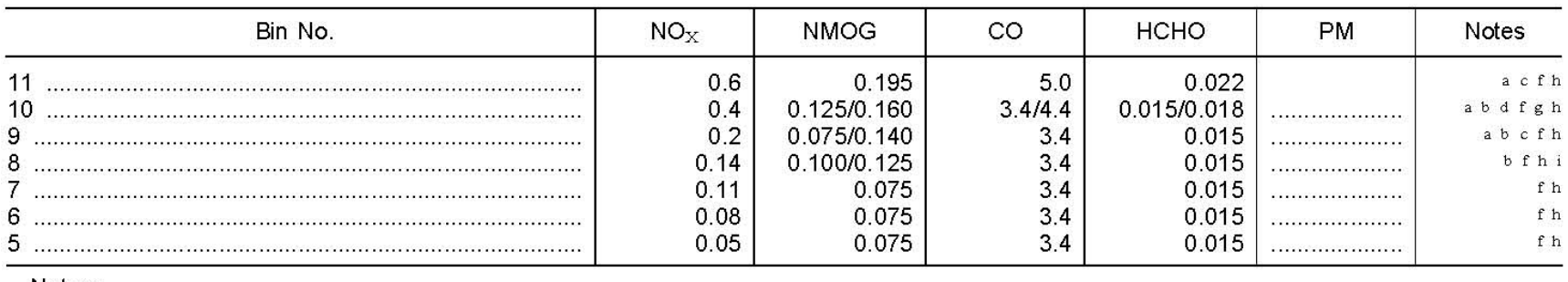

Notes:

a This bin deleted at end of 2006 model year (end of 2008 model year for HLDTs and MDPVS ).

b Higher NMOG, CO and HCHO values apply for HLDTs and MDPVs only.

c This bin is only for MDPVs.

a Optional NMOG standard of $0.195 \mathrm{~g} / \mathrm{mi}$ applies for qualifying LDT4s and qualifying MDPVs only.

e Optional NMOG standard of $0.100 \mathrm{~g} / \mathrm{mi}$ applies for qualifying LDT2s only.

f The full useful life PM standards from Table S04-1 also apply at intermediate useful life.

$\mathrm{g}$ Intermediate life standards of this bin are optional for diesels.

$\mathrm{h}$ Intermediate life standards are optional for vehicles certified to a useful life of 150,000 miles.

${ }^{i}$ Higher NMOG standard deleted at end of 2008 model year. 
APPENDIX B.

STATISTICAL ANALYSIS MODEL AND HYPOTHESES FOR ANALYZING VEHICLE DURABILITY TEST DATA 



\section{APPENDIX B. STATISTICAL ANALYSIS MODEL AND HYPOTHESES FOR ANALYZING VEHICLE DURABILITY TEST DATA}

\section{Assuming Linear Effect of Test Miles}

$\mathrm{Y}_{\mathrm{jklm}}=$ Emissions measure (or natural log of emissions measure) from $\mathrm{m}^{\text {th }}$ test on vehicle $\mathrm{l}$ (operated on road fuel REk) under emission test fuel $E k$ at $j^{\text {th }}$ set of emissions tests following $X_{j}$ miles,

where

$\mathrm{j}=1,2,3$ corresponding to $\mathrm{X}_{\mathrm{j}}$ test miles $\left(\mathrm{X}_{1}=0\right.$ miles and $\mathrm{X}_{2}$ and $\mathrm{X}_{3}$ are as follows:

$\mathrm{X}_{2}=50,000$ miles, if starting odometer (SO) is less than 45,000 miles;

95,000 - SO, if SO is between 45,000 and 70,000 miles;

25,000 miles, if SO is greater than 70,000 miles.

$\mathrm{X}_{3}=120,000-\mathrm{X} 2$, if SO is less than 70,000 miles;

25,000 miles, if SO is greater than 70,000 miles.

Here we assume that the full useful life (FUL) of every vehicle model is 120,000 miles.

$\mathrm{k}=0,10,15,20$ corresponding to Ek, the emissions test fuel containing $\mathrm{k} \%$ ethanol, $\mathrm{k}=0,10$, 15, 20;

$\mathrm{l}=1,2,3$, 4 vehicles, each associated with one unique REk, the road fuel containing $\mathrm{k} \%$ ethanol, $\mathrm{k}=0,10,15,20$;

$\mathrm{m}=1,2$ replicate tests;

The statistical model for evaluating the immediate and durability effects of ethanol on emissions and fuel economy for each vehicle model was as follows.

$$
\mathrm{Y}_{\mathrm{jklm}}=\mu+\beta_{0} \mathrm{X}_{\mathrm{j}}+\gamma_{1, \mathrm{Ek}} \mathrm{T}_{\mathrm{Ek}}+\beta_{1, \mathrm{Rk}} \mathrm{X}_{\mathrm{j}} \mathrm{R}_{\mathrm{REk}}+\beta_{2, \mathrm{Rk}} \mathrm{X}_{\mathrm{j}} \mathrm{T}_{\mathrm{Ek}} \mathrm{R}_{\mathrm{REk}}+\delta_{\mathrm{l}}+\eta_{\mathrm{jkl}}+\varepsilon_{\mathrm{m}(\mathrm{jkl})}
$$

where

$\mu$ is a constant that represents the Vehicle 1 (RE0 tested vehicle) baseline ( 0 miles) average emissions with the E0 test fuel;

$\beta_{0}$ is the effect (per mile) of aging with road fuel RE0 on emissions using E0 test fuel;

$\gamma_{1, \mathrm{Ek}}$ is the "ethanol effect" on emissions using test fuel Ek ( $\mathrm{k}=10,15$, and 20);

$\beta_{1, \mathrm{Rk}}$ is the "road fuel durability" effect (per mile) of operating with road fuel REk on E0 emissions;

$\beta_{2, \mathrm{Rk}}$ is the effect (per mile) of the interaction of the "ethanol" and "durability" (i.e., change in emissions/mile increase with Ek test fuel and REk road fuel over and above the additive effects of $\gamma_{1, \mathrm{Ek}}$ and $\beta_{1, \mathrm{REk}}$ for $\mathrm{k}=10,15$, and 20 , noting that $\beta_{2, \mathrm{REO}}=0$ );

$\delta_{1}$ is the vehicle effect $\left(\delta_{1}=0\right)$;

$\eta_{\mathrm{jkl}}$ is the random effect of differences among test setups (between pairs of replicates);

$\varepsilon_{\mathrm{m}(\mathrm{jkl})}$ is the random effect of differences among replicate tests (within the same test setup);

$\mathrm{T}$ and $\mathrm{R}$ are indicator variables (i.e., $\mathrm{T}_{\mathrm{Ek}}=1$ if Ek is the test fuel; 0, otherwise).

To address the study questions, the following statistical hypotheses were tested.

$\mathrm{H}_{1 \mathrm{k}}: \gamma_{1, \mathrm{Ek}}=0 ; \mathrm{k}=10,15,20 \quad$ No immediate effect of $\mathrm{k} \%$ ethanol in the test fuel

$\mathrm{H}_{2 \mathrm{k}}: \beta_{1, \mathrm{Rk}} ; \mathrm{k}=10,15,20 \quad$ No effect of $\mathrm{k} \%$ road fuel on $\mathrm{E} 0$ emissions 
No interaction between the immediate effect of the test fuel and the road fuel (i.e., effects are additive)

Figure B.1 illustrates how the model parameters are related to changes in measured emissions. Figure B.2 is an example of modeled results from a full data set for a single vehicle model. The error bars can represent confidence bounds on the predicted emissions.

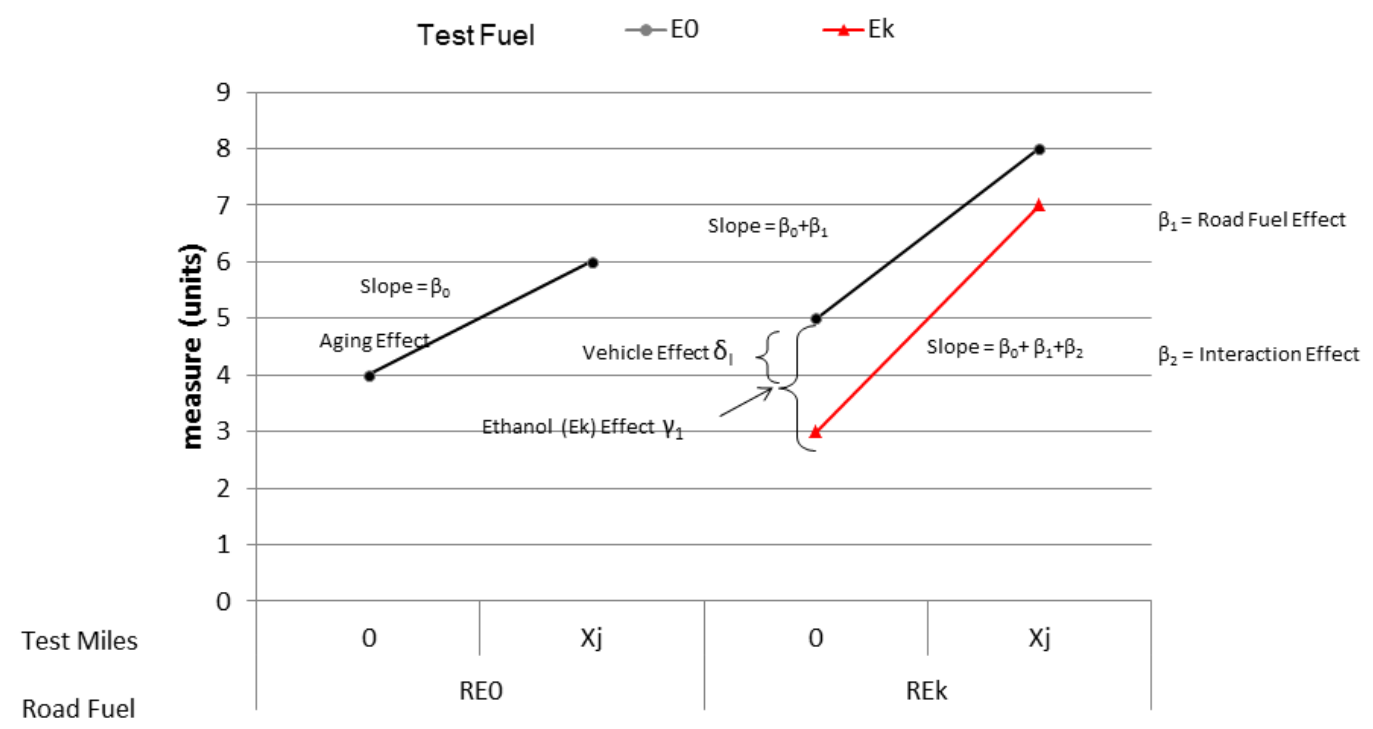

Fig. B.1. Illustration of model parameters.

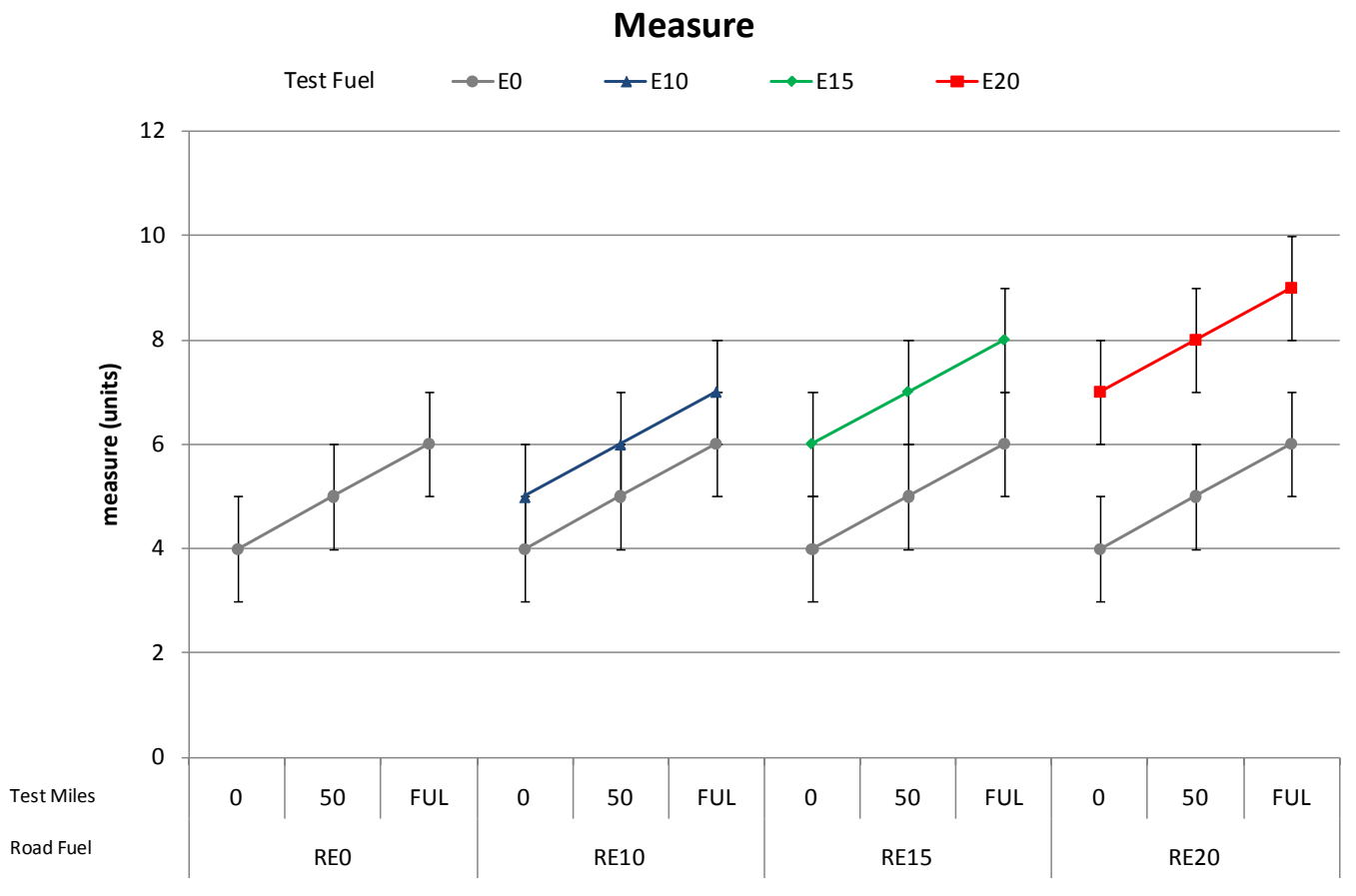

Fig. B.2. Example of a statistical model data set for a single vehicle type (error bars can represent $95 \%$ confidence bounds on the predicted emissions). 
The statistical analyses for this project were done in Stata, v. 11.2. Before fitting the models, an outlier detection program was executed to identify any outliers. If any observation was outside the range (mean3*standard deviation, mean+3*standard deviation), it was identified as a potential outlier. After comparing the results by fitting the model both with and without the potential outlier, if the results were significantly different (for example, a slope changed from insignificant to significant), the outlier was excluded from the analysis and noted in the summary table. Otherwise the potential outlier was not considered as an outlier, and it was included in the analysis.

The statistical models fit for each emission parameter and vehicle model were linear mixed effects models using the xtmixed procedure in Stata. The models included terms for mileage; interaction between mileage and road fuel; and interaction among mileage, test fuel, and road fuel, as covariates; road fuel and test fuel as fixed effects; and test-to-test setup as a random effect. The remaining error left unexplained by the model was assumed to represent the random differences between replicate tests within a test setup. If the interaction among mileage, test fuel, and road fuel was not significant, which indicated there was no significant slope difference between test fuel for the same road fuel, this term was dropped from the model. For the ethanol and aldehydes parameters, the emission data were log-transformed before fitting the model. To avoid the complexity of reporting the comparison results in the original units as ratios, approximating adjustments were made. The estimates and their confidence intervals were produced using the delta method and exponentiation of the log transformed model parameters.

By default, the xtmixed procedure in Stata uses the residual method to calculate degrees of freedom. With the relatively small sample sizes for this evaluation, it was more appropriate to calculate the degrees of freedom using the Satterthwaite estimation method. The xtmixed procedure in Stata does not have this calculation as an option. Therefore, it had to be calculated directly from the estimated variance components. The procedure used was as follows.

For any fixed effect or any linear combination of fixed effects, Stata provided the estimate $\widehat{\beta}$ and the variance of $\widehat{\beta}, . \operatorname{Var}(\beta)$. It also output the two model variance components $\left(\eta_{\mathrm{jkl}}\right.$ and $\left.\varepsilon_{\mathrm{m}(\mathrm{jkl})}\right)$. Because the two variance components are independent, we know that the estimated variance can be written as a linear combination of the two variance components:

$$
\widehat{\operatorname{Var}(\beta)}=\mathrm{c}_{1} \eta_{\mathrm{jkl}}+\mathrm{c}_{2} \varepsilon_{\mathrm{m}(\mathrm{jkl})},
$$

where $c_{1}, c_{2}$ depend only on the study design and not on the values of the data. A similar equation can be generated by taking the original data, making minor random perturbations to it, and calculating a perturbated estimated variance $\sqrt{\operatorname{ar}(\beta})^{\prime}$ and corresponding model variance components, $\left(\eta_{\mathrm{jkl}}\right)^{\prime}$ and $\left(\varepsilon_{\mathrm{m}(\mathrm{jkl})}\right)^{\prime}$ :

$$
\widehat{\operatorname{Var}(\beta})^{\prime}=\mathrm{c}_{1}\left(\eta_{\mathrm{jkl}}\right)^{\prime}+\mathrm{c}_{2}\left(\varepsilon_{\mathrm{m}(\mathrm{jkl})}\right)^{\prime} .
$$

The study design is identical for the new data, so the $c_{1}, c_{2}$ will be identical. Solving these two equations simultaneously provides the $\mathrm{c}_{1}, \mathrm{c}_{2}$.

The degrees of freedom for the original $\widehat{\operatorname{Var}(\beta)}$ can then be calculated using Satterthwaite approximation as

$$
D O F=\frac{\left[c_{1} \eta_{j k l}+c_{2} \varepsilon_{m(j k l)}\right]^{2}}{\left[\frac{c_{1}^{2} \eta_{j k l}^{2}}{v\left(\eta_{j k l}\right)}+\frac{c_{2}^{2} \varepsilon_{m(j k l)}^{2}}{v\left(\varepsilon_{m(j k l)}\right)}\right]},
$$

where $v\left(\eta_{\mathrm{jkl}}\right)$ and $v\left(\varepsilon_{\mathrm{m}(\mathrm{jkl})}\right)$ are the corresponding degrees of freedom for each variance component. 
For some models, the assumption of a linear relationship between emission and mileage did not prove reasonable. In these cases, a mixed effects model, which included road fuel, test fuel, the interaction between test stage and road fuel as fixed effects and test-to-test setup as random effect, was used instead. 
APPENDIX C. DETAILED VEHICLE INFORMATION 



\section{APPENDIX C. DETAILED VEHICLE INFORMATION}

This appendix contains detailed vehicle specifications such as powertrain configuration, engine family (test group), equivalent test weight, dynamometer coefficients, and individual vehicle identification numbers (VINs) for the vehicles tested at the three sites [Southwest Research Institute (SwRI), Transportation Research Center (TRC), and Environmental Testing Corporation (ETC)]. There is one table per vehicle model. Table C.1 shows the contents of this appendix.

Table C.1. List of Appendix C tables

\begin{tabular}{|c|c|c|c|}
\hline Vehicle model & Page & Vehicle model & Page \\
\hline 2007 Honda Accord & $\mathrm{C}-4$ & 2006 Nissan Quest & C-8 \\
\hline 2006 Chevrolet Silverado & $\mathrm{C}-4$ & 2009 Saturn Outlook & C-9 \\
\hline 2008 Nissan Altima & $\mathrm{C}-4$ & 2009 Toyota Camry & C-9 \\
\hline 2008 Ford Taurus & C-5 & 2009 Ford Focus & C-9 \\
\hline 2007 Dodge Caravan & C-5 & 2009 Honda Odyssey & C-10 \\
\hline 2006 Chevrolet Cobalt & C-5 & 2000 Chevrolet Silverado & C-10 \\
\hline 2007 Dodge Caliber & C-6 & 2002 Nissan Frontier & C-11 \\
\hline 2009 Jeep Liberty & C-6 & 2002 Dodge Durango & C-11 \\
\hline 2009 Ford Explorer & C-6 & 2003 Toyota Camry & C-12 \\
\hline 2009 Honda Civic & $\mathrm{C}-7$ & 2003 Ford Taurus & $\mathrm{C}-12$ \\
\hline 2009 Toyota Corolla & $\mathrm{C}-7$ & 2003 Chevrolet Cavalier & $\mathrm{C}-12$ \\
\hline 2005 Toyota Tundra & $\mathrm{C}-7$ & 2000 Honda Accord & $\mathrm{C}-13$ \\
\hline 2006 Chevrolet Impala & C-8 & 2000 Ford Focus & C-13 \\
\hline 2005 Ford F150 & C-8 & & \\
\hline
\end{tabular}




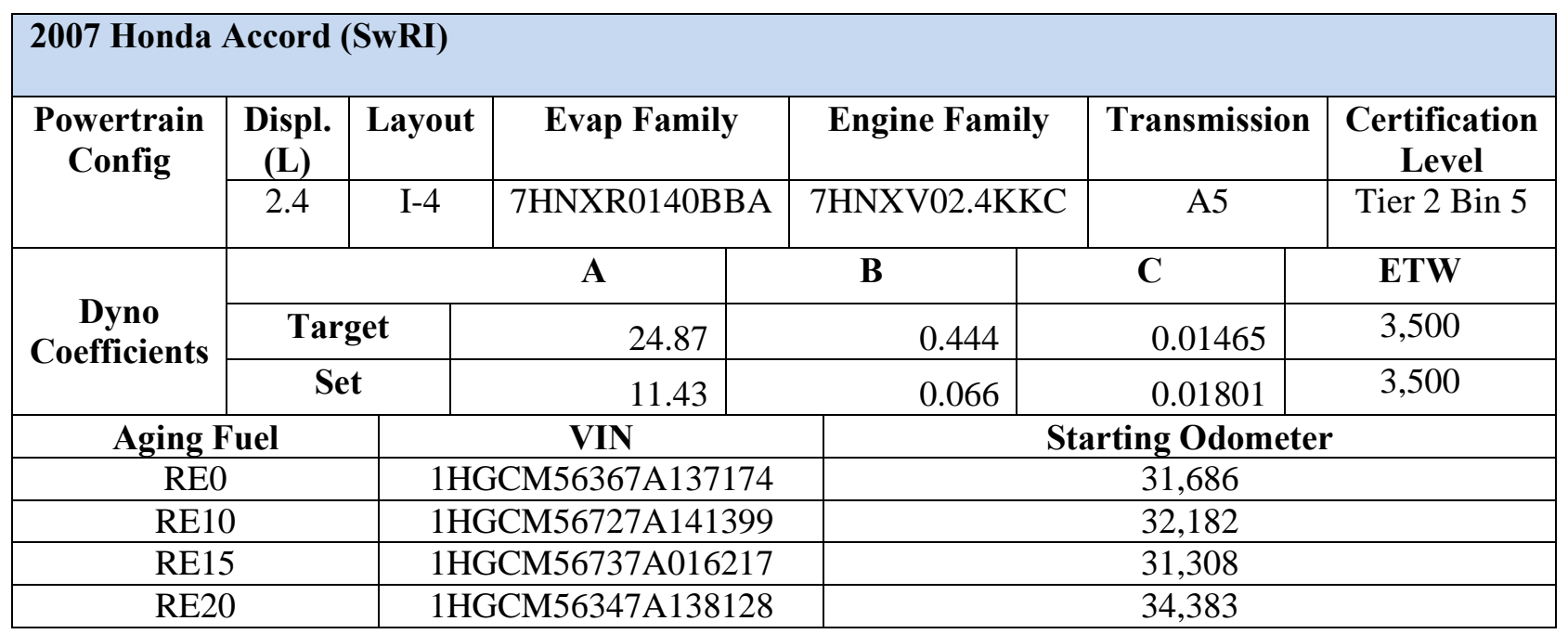

\begin{tabular}{|c|c|c|c|c|c|c|}
\hline \multicolumn{7}{|c|}{2006 Chevrolet Silverado (SwRI) } \\
\hline \multirow[t]{2}{*}{$\begin{array}{l}\text { Powertrain } \\
\text { Config }\end{array}$} & \begin{tabular}{|c} 
Displ. \\
(L)
\end{tabular} & Layout & Evap Fami & Engine Family & Transmission & $\begin{array}{c}\text { Certification } \\
\text { Level }\end{array}$ \\
\hline & 5.3 & V-8 & 6GMXR0176820 & 6GMXT05.337 & A4 & Tier 2 Bin 8 \\
\hline \multirow{3}{*}{$\begin{array}{c}\text { Dyno } \\
\text { Coefficients }\end{array}$} & \multicolumn{3}{|r|}{$\mathbf{A}$} & $\mathbf{B}$ & $\mathbf{C}$ & ETW \\
\hline & \multicolumn{2}{|c|}{ Target } & 28.96 & 1.6815 & 0.02177 & 5,250 \\
\hline & \multicolumn{2}{|c|}{ Set } & 11.77 & 1.097 & 0.02665 & 5,250 \\
\hline \multicolumn{2}{|c|}{ Aging Fuel } & \multicolumn{2}{|r|}{ VIN } & \multicolumn{3}{|c|}{ Starting Odometer } \\
\hline \multicolumn{2}{|c|}{ RE0 } & \multicolumn{2}{|c|}{ 1GCEK19B16Z26799؛ } & \multicolumn{3}{|c|}{27,606} \\
\hline \multicolumn{2}{|c|}{ RE10 } & \multicolumn{2}{|c|}{ 1GCEK19B66Z154114 } & \multicolumn{3}{|c|}{14,319} \\
\hline \multicolumn{2}{|c|}{ RE15 } & \multicolumn{2}{|c|}{ 1GCEK19B96Z19468 } & \multicolumn{3}{|c|}{17,121} \\
\hline \multicolumn{2}{|c|}{ RE20 } & \multicolumn{2}{|c|}{ 1GCEK19B56EZ2020 } & \multicolumn{3}{|c|}{17,103} \\
\hline
\end{tabular}

\begin{tabular}{|c|c|c|c|c|c|c|}
\hline \multicolumn{7}{|c|}{2008 Nissan Altima (SwRI) } \\
\hline \multirow[t]{2}{*}{$\begin{array}{l}\text { Powertrain } \\
\text { Config }\end{array}$} & $\begin{array}{c}\text { Displ. } \\
\text { (L) }\end{array}$ & Layout & Evap Fan & Engine Family & Transmission & $\begin{array}{c}\text { Certification } \\
\text { Level }\end{array}$ \\
\hline & 2.5 & $\mathrm{I}-4$ & 8NSR0120 & 8NSXV02.5G5A & CVT & Tier 2 Bin 5 \\
\hline \multirow{3}{*}{$\begin{array}{c}\text { Dyno } \\
\text { Coefficients }\end{array}$} & \multicolumn{3}{|r|}{$\mathbf{A}$} & B & $\mathbf{C}$ & ETW \\
\hline & \multicolumn{2}{|c|}{ Target } & 46.47 & -0.4531 & 0.02414 & 3,500 \\
\hline & \multicolumn{2}{|c|}{ Set } & 19.71 & -0.3066 & 0.021358 & 3,500 \\
\hline \multicolumn{2}{|c|}{ Aging Fuel } & \multicolumn{2}{|r|}{ VIN } & \multicolumn{3}{|c|}{ Starting Odometer } \\
\hline \multicolumn{2}{|c|}{ RE0 } & \multicolumn{2}{|c|}{ 1N4AL21E28C198677 } & \multicolumn{3}{|c|}{19,263} \\
\hline \multicolumn{2}{|c|}{ RE10 } & \multicolumn{2}{|c|}{ 1N4AL21E08C198208 } & \multicolumn{3}{|c|}{19,517} \\
\hline \multicolumn{2}{|c|}{ RE15 } & \multicolumn{2}{|c|}{ 1N4AL21E08C231286 } & \multicolumn{3}{|c|}{9,935} \\
\hline \multicolumn{2}{|c|}{ RE20 } & \multicolumn{2}{|c|}{ 1N4A121E08C218263 } & \multicolumn{3}{|c|}{10,295} \\
\hline
\end{tabular}




\begin{tabular}{|c|c|c|c|c|c|c|}
\hline \multicolumn{7}{|c|}{2008 Ford Taurus (SwRI) } \\
\hline \multirow[t]{2}{*}{$\begin{array}{l}\text { Powertrain } \\
\text { Config }\end{array}$} & $\begin{array}{l}\text { Displ. } \\
\text { (L) }\end{array}$ & Layout & Evap Fam & Engine Family & Transmission & $\begin{array}{c}\text { Certification } \\
\text { Level }\end{array}$ \\
\hline & 3.5 & V-6 & 8FMXR0145KBK & 8FMXV03.5VEP & A6 & Tier 2 Bin 5 \\
\hline \multirow{3}{*}{$\begin{array}{c}\text { Dyno } \\
\text { Coefficients }\end{array}$} & \multicolumn{3}{|r|}{$\mathbf{A}$} & B & $\mathbf{C}$ & ETW \\
\hline & \multicolumn{2}{|c|}{ Target } & 37.32 & 0.4299 & 0.02115 & 4,250 \\
\hline & \multicolumn{2}{|c|}{ Set } & 20.71 & -0.3787 & 0.028959 & 4,250 \\
\hline \multicolumn{2}{|c|}{ Aging Fuel } & \multicolumn{2}{|r|}{ VIN } & \multicolumn{3}{|c|}{ Starting Odometer } \\
\hline \multicolumn{2}{|c|}{ RE0 } & \multicolumn{2}{|c|}{ 1FAHP24W28G175013 } & \multicolumn{3}{|c|}{17,230} \\
\hline \multicolumn{2}{|c|}{ RE10 } & \multicolumn{2}{|c|}{ 1FAHP24W58G174230 } & \multicolumn{3}{|c|}{15,662} \\
\hline \multicolumn{2}{|c|}{ RE15 } & \multicolumn{2}{|c|}{ 1FAHP24W58G175717 } & \multicolumn{3}{|c|}{17,098} \\
\hline \multicolumn{2}{|c|}{ RE20 } & \multicolumn{2}{|c|}{ 1FAHP24W38G177188 } & \multicolumn{3}{|c|}{13,081} \\
\hline
\end{tabular}

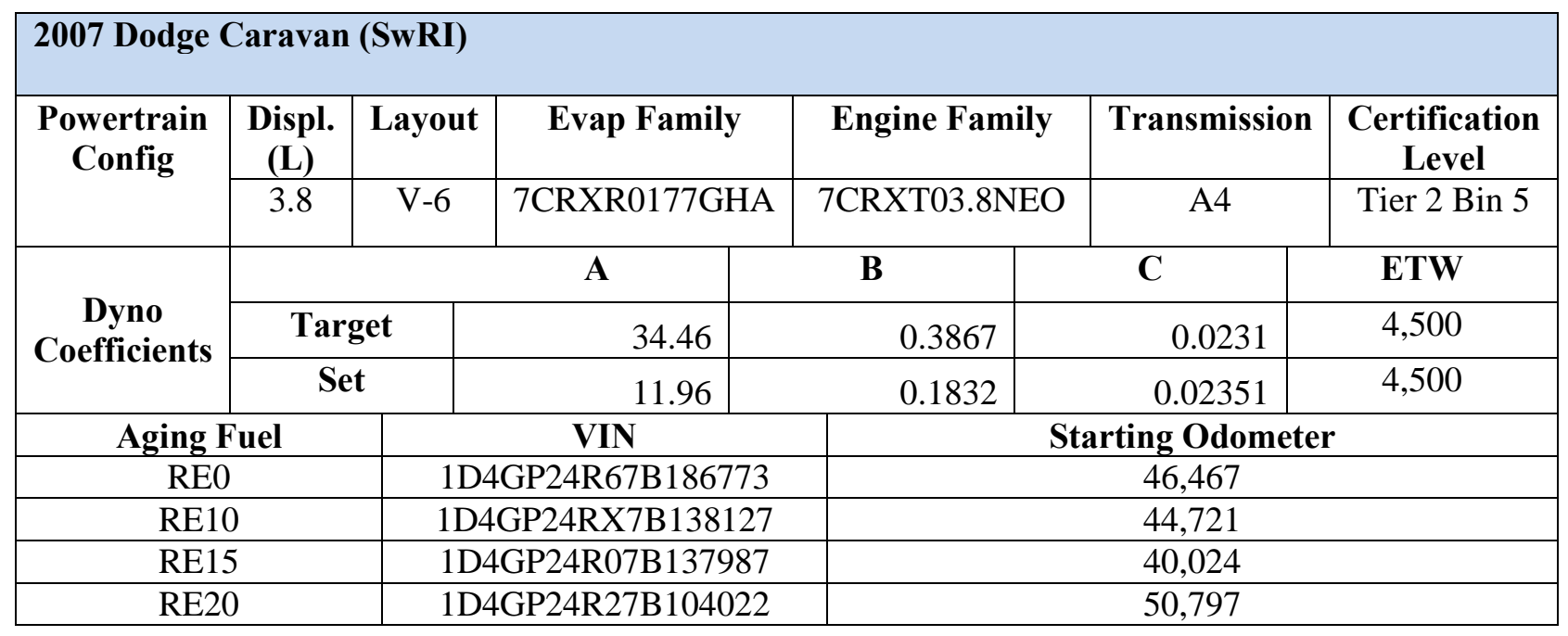

\begin{tabular}{|c|c|c|c|c|c|c|}
\hline \multicolumn{7}{|c|}{2006 Chevrolet Cobalt (SwRI) } \\
\hline \multirow[t]{2}{*}{$\begin{array}{l}\text { Powertrain } \\
\text { Config }\end{array}$} & $\begin{array}{c}\text { Displ. } \\
\text { (L) }\end{array}$ & Layout & Evap Family & Engine Family & Transmission & $\begin{array}{c}\text { Certification } \\
\text { Level }\end{array}$ \\
\hline & 2.4 & $\mathrm{I}-4$ & 6GMXR0105817 & 6GMSV02.4029 & A4 & Tier 2 Bin 5 \\
\hline \multirow{3}{*}{$\begin{array}{c}\text { Dyno } \\
\text { Coefficients }\end{array}$} & \multicolumn{3}{|r|}{$\mathbf{A}$} & $\mathbf{B}$ & $\mathbf{C}$ & ETW \\
\hline & \multicolumn{2}{|c|}{ Target } & 26.11 & 0.4655 & 0.01565 & 3,125 \\
\hline & \multicolumn{2}{|c|}{ Set } & 9.54 & 0.2268 & 0.01598 & 3,125 \\
\hline \multicolumn{2}{|c|}{ Aging Fuel } & \multicolumn{2}{|r|}{ VIN } & \multicolumn{3}{|c|}{ Starting Odometer } \\
\hline \multicolumn{2}{|c|}{ RE0 } & \multicolumn{2}{|c|}{ 1G1AK55F367813690 } & \multicolumn{3}{|c|}{38,862} \\
\hline \multicolumn{2}{|c|}{ RE10 } & \multicolumn{2}{|c|}{$\mathrm{N} / \mathrm{A}$} & \multicolumn{3}{|c|}{ N/A } \\
\hline \multicolumn{2}{|c|}{ RE15 } & \multicolumn{2}{|c|}{ 1G1AK55F367666822 } & \multicolumn{3}{|c|}{47,672} \\
\hline \multicolumn{2}{|c|}{ RE20 } & \multicolumn{2}{|c|}{ 1G1AK55F367638180 } & \multicolumn{3}{|c|}{38,454} \\
\hline
\end{tabular}




\begin{tabular}{|c|c|c|c|c|c|c|}
\hline \multicolumn{7}{|c|}{2007 Dodge Caliber (SwRI) } \\
\hline \multirow[t]{2}{*}{$\begin{array}{l}\text { Powertrain } \\
\text { Config }\end{array}$} & $\begin{array}{l}\text { Displ. } \\
\text { (L) }\end{array}$ & Layout & Evap Famil & Engine Family & Transmission & $\begin{array}{c}\text { Certification } \\
\text { Level }\end{array}$ \\
\hline & 2.4 & $\mathrm{I}-4$ & 7CRXR0112GH & 7CRXB02.4ME5 & CVT & Tier 2 Bin 5 \\
\hline \multirow{3}{*}{$\begin{array}{c}\text { Dyno } \\
\text { Coefficients }\end{array}$} & \multicolumn{3}{|r|}{$\mathbf{A}$} & B & $\mathbf{C}$ & ETW \\
\hline & \multicolumn{2}{|c|}{ Target } & 43.86 & 0.2502 & 0.02394 & 3,375 \\
\hline & \multicolumn{2}{|c|}{ Set } & -7.72 & 1.187 & 0.0125 & 3,375 \\
\hline \multicolumn{2}{|c|}{ Aging Fuel } & \multicolumn{2}{|r|}{ VIN } & \multicolumn{3}{|c|}{ Starting Odometer } \\
\hline \multicolumn{2}{|c|}{ RE0 } & \multicolumn{2}{|c|}{ 1B3HB48B47D22598 } & \multicolumn{3}{|c|}{41,126} \\
\hline \multicolumn{2}{|c|}{ RE10 } & \multicolumn{2}{|c|}{ N/A } & \multicolumn{3}{|c|}{ N/A } \\
\hline \multicolumn{2}{|c|}{ RE15 } & \multicolumn{2}{|c|}{ 1В3HВ48B67D56398 } & \multicolumn{3}{|c|}{48,037} \\
\hline \multicolumn{2}{|c|}{ RE20 } & \multicolumn{2}{|c|}{ 1B3HB48B47D147730 } & \multicolumn{3}{|c|}{46,853} \\
\hline
\end{tabular}

\begin{tabular}{|c|c|c|c|c|c|c|}
\hline \multicolumn{7}{|c|}{2009 Jeep Liberty (TRC) } \\
\hline \multirow[t]{2}{*}{$\begin{array}{c}\text { Powertrain } \\
\text { Config }\end{array}$} & \begin{tabular}{|c|} 
Displ. \\
(L)
\end{tabular} & Layout & Evap Family & Engine Family & Transmission & $\begin{array}{c}\text { Certification } \\
\text { Level }\end{array}$ \\
\hline & 3.7 & $\mathrm{~V}-6$ & 9CRXR0150PK0 & 9CRXT03.74PO & A4 & Tier 2 Bin 5 \\
\hline \multirow{3}{*}{$\begin{array}{c}\text { Dyno } \\
\text { Coefficients }\end{array}$} & \multicolumn{3}{|r|}{$\mathbf{A}$} & $\mathbf{B}$ & $\mathbf{C}$ & ETW \\
\hline & \multicolumn{2}{|c|}{ Target } & 54.27 & 0.5165 & 0.02833 & 4,500 \\
\hline & \multicolumn{2}{|c|}{ Set } & 23.180 & 0.245 & 0.029 & 4,500 \\
\hline \multicolumn{2}{|c|}{ Aging Fuel } & \multicolumn{2}{|r|}{ VIN } & \multicolumn{3}{|c|}{ Starting Odometer } \\
\hline \multicolumn{2}{|c|}{ RE0 } & \multicolumn{2}{|c|}{ 1J8GP28K09W523520 } & \multicolumn{3}{|c|}{ New } \\
\hline \multirow{2}{*}{\multicolumn{2}{|c|}{$\begin{array}{l}\text { RE10 } \\
\text { RE15 }\end{array}$}} & \multicolumn{2}{|r|}{ N/A } & \multicolumn{3}{|c|}{ N/A } \\
\hline & & \multicolumn{2}{|c|}{ 1J8GP28K49W520670 } & \multicolumn{3}{|c|}{ New } \\
\hline \multicolumn{2}{|c|}{$\begin{array}{l}\text { RE15 } \\
\text { RE20 }\end{array}$} & \multicolumn{2}{|c|}{ 1J8GP28K69W517351 } & \multicolumn{3}{|c|}{ New } \\
\hline
\end{tabular}

\begin{tabular}{|c|c|c|c|c|c|c|}
\hline \multicolumn{7}{|c|}{2009 Ford Explorer (TRC) } \\
\hline \multirow[t]{2}{*}{$\begin{array}{l}\text { Powertrain } \\
\text { Config }\end{array}$} & $\begin{array}{l}\text { Displ. } \\
\text { (L) }\end{array}$ & Layout & Evap Family & Engine Family & Transmission & $\begin{array}{c}\text { Certification } \\
\text { Level }\end{array}$ \\
\hline & 4.0 & V-6 & 9FMXR0195GBR & 9FMXT04.03DC & A5 & Tier 2 Bin 4 \\
\hline \multirow{3}{*}{$\begin{array}{c}\text { Dyno } \\
\text { Coefficients }\end{array}$} & \multicolumn{3}{|r|}{$\mathbf{A}$} & $\mathbf{B}$ & $\mathbf{C}$ & ETW \\
\hline & \multicolumn{2}{|c|}{ Target } & & & & \\
\hline & \multicolumn{2}{|c|}{ Set } & 13.168 & 0.425 & 0.027 & 5,000 \\
\hline \multicolumn{2}{|c|}{ Aging Fuel } & \multicolumn{2}{|r|}{ VIN } & \multicolumn{3}{|c|}{ Starting Odometer } \\
\hline \multicolumn{2}{|c|}{ RE0 } & \multicolumn{2}{|c|}{ 1FMEU63E79UA03855 } & \multicolumn{3}{|c|}{ New } \\
\hline \multicolumn{2}{|c|}{ RE10 } & \multicolumn{2}{|c|}{ N/A } & \multicolumn{3}{|c|}{ N/A } \\
\hline \multicolumn{2}{|c|}{ RE15 } & \multicolumn{2}{|c|}{ 1FMEU63E19UA02233 } & \multicolumn{3}{|c|}{ New } \\
\hline \multicolumn{2}{|c|}{ RE20 } & \multicolumn{2}{|c|}{ 1FMEU63E89UA03279 } & \multicolumn{3}{|c|}{ New } \\
\hline
\end{tabular}




\begin{tabular}{|c|c|c|c|c|c|c|}
\hline \multicolumn{7}{|c|}{2009 Honda Civic (TRC) } \\
\hline \multirow[t]{2}{*}{$\begin{array}{l}\text { Powertrain } \\
\text { Config }\end{array}$} & $\begin{array}{l}\text { Displ. } \\
\text { (L) }\end{array}$ & Layout & Evap Family & Engine Family & Transmission & $\begin{array}{c}\text { Certification } \\
\text { Level }\end{array}$ \\
\hline & 1.8 & $\mathrm{I}-4$ & 9HNXR0106VEA & 9HNXV01.8XB9 & A5 & Tier 2 Bin 5 \\
\hline \multirow{3}{*}{$\begin{array}{c}\text { Dyno } \\
\text { Coefficients }\end{array}$} & \multicolumn{3}{|r|}{$\mathbf{A}$} & B & $\mathbf{C}$ & ETW \\
\hline & \multicolumn{2}{|c|}{ Target } & 25.71 & 0.2759 & 0.01645 & 3,125 \\
\hline & \multicolumn{2}{|c|}{ Set } & 10.270 & 0.151 & 0.016 & 3,125 \\
\hline \multicolumn{2}{|c|}{ Aging Fuel } & \multicolumn{2}{|r|}{ VIN } & \multicolumn{3}{|c|}{ Starting Odometer } \\
\hline \multicolumn{2}{|c|}{ RE0 } & \multicolumn{2}{|c|}{ 2HGFA16359H330824 } & \multicolumn{3}{|c|}{ New } \\
\hline \multicolumn{2}{|c|}{ RE10 } & \multicolumn{2}{|c|}{ N/A } & \multicolumn{3}{|c|}{ N/A } \\
\hline \multicolumn{2}{|c|}{ RE15 } & \multicolumn{2}{|c|}{ 2HGFA163Х9Н337767 } & \multicolumn{3}{|c|}{ New } \\
\hline \multicolumn{2}{|c|}{ RE20 } & \multicolumn{2}{|c|}{ 2HGFA16309H334618 } & \multicolumn{3}{|c|}{ New } \\
\hline
\end{tabular}

\begin{tabular}{|c|c|c|c|c|c|c|c|}
\hline \multicolumn{8}{|c|}{2009 Toyota Corolla (TRC) } \\
\hline \multirow[t]{2}{*}{$\begin{array}{l}\text { Powertrain } \\
\text { Config }\end{array}$} & $\begin{array}{c}\text { Displ. } \\
\text { (L) }\end{array}$ & Layout & Evap Fa & \multicolumn{2}{|c|}{ Engine Family } & Transmission & $\begin{array}{c}\text { Certification } \\
\text { Level }\end{array}$ \\
\hline & 1.8 & $\mathrm{I}-4$ & 9TYXR0115P12 & \multicolumn{2}{|c|}{ 9TYXV01.8BEA } & A4 & Tier 2 Bin 5 \\
\hline \multirow{3}{*}{$\begin{array}{c}\text { Dyno } \\
\text { Coefficients }\end{array}$} & \multicolumn{3}{|r|}{$\mathbf{A}$} & $\mathbf{B}$ & & $\mathbf{C}$ & ETW \\
\hline & \multicolumn{2}{|c|}{ Target } & 33.029 & -0.03433 & & 0.023937 & 3,250 \\
\hline & \multicolumn{2}{|c|}{ Set } & 12.773 & -0.009 & & 0.023 & 3,250 \\
\hline \multicolumn{2}{|c|}{ Aging Fuel } & \multicolumn{2}{|r|}{ VIN } & \multicolumn{4}{|c|}{ Starting Odometer } \\
\hline \multicolumn{2}{|c|}{ RE0 } & \multicolumn{2}{|c|}{ 2T1BU40E89C145385 } & \multicolumn{4}{|c|}{ New } \\
\hline \multicolumn{2}{|c|}{ RE10 } & \multirow{2}{*}{\multicolumn{2}{|c|}{$\frac{\mathrm{N} / \mathrm{A}}{2 \mathrm{~T} 1 \mathrm{BU} 40 \mathrm{E} 09 \mathrm{C}}$}} & \multicolumn{4}{|c|}{ N/A } \\
\hline \multicolumn{2}{|c|}{ RE15 } & & & \multicolumn{4}{|c|}{ New } \\
\hline \multicolumn{2}{|c|}{ RE20 } & \multicolumn{2}{|c|}{ 2T1BU40E79C113978 } & \multicolumn{4}{|c|}{ New } \\
\hline
\end{tabular}

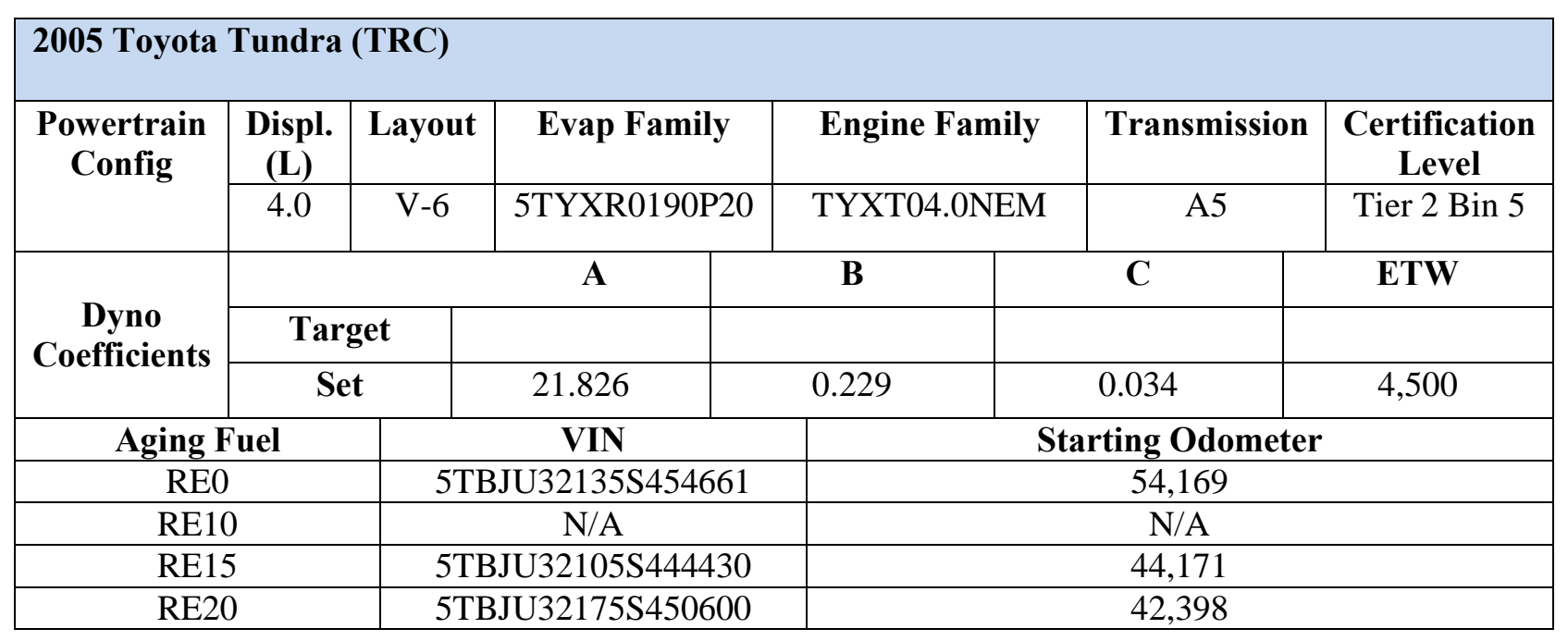




\begin{tabular}{|c|c|c|c|c|c|c|}
\hline \multicolumn{7}{|c|}{2006 Chevrolet Impala (TRC) } \\
\hline \multirow[t]{2}{*}{$\begin{array}{l}\text { Powertrain } \\
\text { Config }\end{array}$} & $\begin{array}{l}\text { Displ. } \\
\text { (L) }\end{array}$ & Layout & Evap Family & Engine Family & Transmission & $\begin{array}{c}\text { Certification } \\
\text { Level }\end{array}$ \\
\hline & 3.9 & V-6 & 6GMXR0133810 & 6GMXV03.9048 & A4 & Tier 2 Bin 5 \\
\hline \multirow{3}{*}{$\begin{array}{c}\text { Dyno } \\
\text { Coefficients }\end{array}$} & \multicolumn{3}{|r|}{$\mathbf{A}$} & $\mathbf{B}$ & $\mathbf{C}$ & ETW \\
\hline & \multicolumn{2}{|c|}{ Target } & & & & \\
\hline & \multicolumn{2}{|c|}{ Set } & 11.510 & 0.093 & 0.018 & 4,000 \\
\hline \multicolumn{2}{|c|}{ Aging Fuel } & \multicolumn{2}{|r|}{ VIN } & \multicolumn{3}{|c|}{ Starting Odometer } \\
\hline \multicolumn{2}{|c|}{ RE0 } & \multicolumn{2}{|c|}{ 2G1WC581969116199 } & \multicolumn{3}{|c|}{30,997} \\
\hline \multicolumn{2}{|c|}{ RE10 } & \multicolumn{2}{|c|}{ N/A } & \multicolumn{3}{|c|}{ N/A } \\
\hline \multicolumn{2}{|c|}{ RE15 } & \multicolumn{2}{|c|}{ 2G1WC581X69183846 } & \multicolumn{3}{|c|}{36,323} \\
\hline \multicolumn{2}{|c|}{ RE20 } & \multicolumn{2}{|c|}{ 2G1WC581469113906 } & \multicolumn{3}{|c|}{37,772} \\
\hline
\end{tabular}

\begin{tabular}{|c|c|c|c|c|c|c|}
\hline \multicolumn{7}{|c|}{2005 Ford F150 (TRC) } \\
\hline \multirow[t]{2}{*}{$\begin{array}{c}\text { Powertrain } \\
\text { Config }\end{array}$} & \begin{tabular}{|c|} 
Displ. \\
(L)
\end{tabular} & Layout & Evap Family & Engine Family & Transmission & $\begin{array}{c}\text { Certification } \\
\text { Level }\end{array}$ \\
\hline & 5.4 & $\mathrm{~V}-8$ & 5FMXR0240NBM & 5FMXT05.4R17 & A & Tier 2 Bin 8 \\
\hline \multirow{3}{*}{$\begin{array}{c}\text { Dyno } \\
\text { Coefficients }\end{array}$} & \multicolumn{3}{|r|}{$\mathbf{A}$} & B & $\mathbf{C}$ & ETW \\
\hline & \multicolumn{2}{|c|}{ Target } & & & & \\
\hline & \multicolumn{2}{|c|}{ Set } & 13.132 & 0.581 & 0.032 & 6,000 \\
\hline \multicolumn{2}{|c|}{ Aging Fuel } & \multicolumn{2}{|r|}{ VIN } & \multicolumn{3}{|c|}{ Starting Odometer } \\
\hline \multicolumn{2}{|c|}{ RE0 } & \multicolumn{2}{|c|}{ 1FTPX14555FA81636 } & \multicolumn{3}{|c|}{42,314} \\
\hline \multicolumn{2}{|c|}{ RE10 } & \multicolumn{2}{|r|}{ N/A } & \multicolumn{3}{|c|}{ N/A } \\
\hline \multicolumn{2}{|c|}{ RE15 } & \multicolumn{2}{|c|}{ 1FTPX14595NA31506 } & \multicolumn{3}{|c|}{44,685} \\
\hline \multicolumn{2}{|c|}{ RE20 } & \multicolumn{2}{|c|}{ 1FTPX14585NA46126 } & \multicolumn{3}{|c|}{51,388} \\
\hline
\end{tabular}

\begin{tabular}{|c|c|c|c|c|c|c|}
\hline \multicolumn{7}{|c|}{2006 Nissan Quest (TRC) } \\
\hline \multirow[t]{2}{*}{$\begin{array}{l}\text { Powertrain } \\
\text { Config }\end{array}$} & $\begin{array}{c}\text { Displ. } \\
\text { (L) }\end{array}$ & Layout & Evap F & Engine Family & Transmission & $\begin{array}{c}\text { Certification } \\
\text { Level }\end{array}$ \\
\hline & 3.5 & V-6 & 6NSXR0120PBB & 6NSXT03.5G7B & A5 & Tier 2 Bin 5 \\
\hline \multirow{3}{*}{$\begin{array}{c}\text { Dyno } \\
\text { Coefficients }\end{array}$} & \multicolumn{3}{|r|}{$\mathbf{A}$} & B & $\mathbf{C}$ & ETW \\
\hline & \multicolumn{2}{|c|}{ Target } & & & & \\
\hline & \multicolumn{2}{|c|}{ Set } & 14.660 & -0.231 & 0.034 & 4,750 \\
\hline \multicolumn{2}{|c|}{ Aging Fuel } & \multicolumn{2}{|r|}{ VIN } & \multicolumn{3}{|c|}{ Starting Odometer } \\
\hline \multicolumn{2}{|c|}{ RE0 } & \multicolumn{2}{|c|}{ 5N1BV28U16N124511 } & \multicolumn{3}{|c|}{49,998} \\
\hline \multicolumn{2}{|c|}{ RE10 } & \multicolumn{2}{|c|}{ N/A } & \multicolumn{3}{|c|}{ N/A } \\
\hline \multicolumn{2}{|c|}{ RE15 } & \multicolumn{2}{|c|}{ 5N1BV28U96N124840 } & \multicolumn{3}{|c|}{55,076} \\
\hline \multicolumn{2}{|c|}{ RE20 } & \multicolumn{2}{|c|}{ 5N1BV28U16N124511 } & \multicolumn{3}{|c|}{49,848} \\
\hline
\end{tabular}




\begin{tabular}{|c|c|c|c|c|c|c|}
\hline \multicolumn{7}{|c|}{2009 Saturn Outlook (ETC) } \\
\hline \multirow[t]{2}{*}{$\begin{array}{c}\text { Powertrain } \\
\text { Config }\end{array}$} & $\begin{array}{c}\text { Displ. } \\
\text { (L) }\end{array}$ & Layout & Evap Family & Engine Family & Transmission & $\begin{array}{c}\text { Certification } \\
\text { Level }\end{array}$ \\
\hline & 3.6 & V-6 & 9GMXR0197972 & 9GMXT03.6151 & A6 & Tier 2 Bin 5 \\
\hline \multirow{3}{*}{$\begin{array}{c}\text { Dyno } \\
\text { Coefficients }\end{array}$} & \multicolumn{3}{|r|}{$\mathbf{A}$} & B & $\mathbf{C}$ & ETW \\
\hline & \multicolumn{2}{|c|}{ Target } & 48.31 & 0.5976 & 0.02597 & 5,250 \\
\hline & \multicolumn{2}{|c|}{ Set } & 30.44 & 0.1266 & 0.0287 & 5,250 \\
\hline \multicolumn{2}{|c|}{ Aging Fuel } & \multicolumn{2}{|r|}{ VIN } & \multicolumn{3}{|c|}{ Starting Odometer } \\
\hline \multicolumn{2}{|c|}{ RE0 } & \multicolumn{2}{|c|}{ 5GZER13D59J180937 } & \multicolumn{3}{|c|}{ New } \\
\hline \multicolumn{2}{|c|}{ RE10 } & \multicolumn{2}{|c|}{ N/A } & \multicolumn{3}{|c|}{ N/A } \\
\hline \multicolumn{2}{|c|}{ RE15 } & \multicolumn{2}{|c|}{ 5GZER13D49J181741 } & \multicolumn{3}{|c|}{ New } \\
\hline \multicolumn{2}{|c|}{ RE20 } & \multicolumn{2}{|c|}{ 5GZER13D39J197980 } & \multicolumn{3}{|c|}{11,638} \\
\hline
\end{tabular}

\begin{tabular}{|c|c|c|c|c|c|c|}
\hline \multicolumn{7}{|c|}{2009 Toyota Camry (ETC) } \\
\hline \multirow[t]{2}{*}{$\begin{array}{l}\text { Powertrain } \\
\text { Config }\end{array}$} & $\begin{array}{c}\text { Displ. } \\
\text { (L) }\end{array}$ & Layout & Evap Family & Engine Family & Transmission & $\begin{array}{c}\text { Certification } \\
\text { Level }\end{array}$ \\
\hline & 2.4 & $\mathrm{I}-4$ & 9TYXR0130A12 & 9TYXV02.4BEA & A5 & Tier 2 Bin 5 \\
\hline \multirow{3}{*}{$\begin{array}{c}\text { Dyno } \\
\text { Coefficients }\end{array}$} & \multicolumn{3}{|r|}{$\mathbf{A}$} & B & $\mathbf{C}$ & ETW \\
\hline & \multicolumn{2}{|c|}{ Target } & 29.35 & 0.1659 & 0.01845 & 3,750 \\
\hline & \multicolumn{2}{|c|}{ Set } & 11.64 & -0.1228 & 0.02084 & 3,750 \\
\hline \multicolumn{2}{|c|}{ Aging Fuel } & \multicolumn{2}{|r|}{ VIN } & \multicolumn{3}{|c|}{ Starting Odometer } \\
\hline \multicolumn{2}{|c|}{ RE0 } & \multicolumn{2}{|c|}{ 4T1BE46K89U375470 } & \multicolumn{3}{|c|}{ New } \\
\hline \multicolumn{2}{|c|}{ RE10 } & \multicolumn{2}{|c|}{ N/A } & \multicolumn{3}{|c|}{ N/A } \\
\hline \multicolumn{2}{|c|}{ RE15 } & \multicolumn{2}{|c|}{ 4T1BE46K79U892484 } & \multicolumn{3}{|c|}{ New } \\
\hline \multicolumn{2}{|c|}{ RE20 } & \multicolumn{2}{|c|}{ 4T1BE46K79U288823 } & \multicolumn{3}{|c|}{12,226} \\
\hline
\end{tabular}

\begin{tabular}{|c|c|c|c|c|c|c|}
\hline \multicolumn{7}{|c|}{2009 Ford Focus (ETC) } \\
\hline \multirow[t]{2}{*}{$\begin{array}{c}\text { Powertrain } \\
\text { Config }\end{array}$} & \begin{tabular}{|c} 
Displ. \\
(L)
\end{tabular} & Layout & Evap Family & Engine Family & Transmission & $\begin{array}{c}\text { Certification } \\
\text { Level }\end{array}$ \\
\hline & 2.0 & $\mathrm{I}-4$ & 9FMXR0125NAA & 9FMXV02.0VDX & A4 & Tier 2 Bin 4 \\
\hline \multirow{3}{*}{$\begin{array}{c}\text { Dyno } \\
\text { Coefficients }\end{array}$} & \multicolumn{3}{|r|}{$\mathbf{A}$} & $\mathbf{B}$ & $\mathbf{C}$ & ETW \\
\hline & \multicolumn{2}{|c|}{ Target } & 24.40 & 0.7652 & 0.01193 & 3,000 \\
\hline & \multicolumn{2}{|c|}{ Set } & 8.26 & 0.6083 & 0.01289 & 3,000 \\
\hline \multicolumn{2}{|c|}{ Aging Fuel } & \multicolumn{2}{|r|}{ VIN } & \multicolumn{3}{|c|}{ Starting Odometer } \\
\hline \multicolumn{2}{|c|}{ RE0 } & \multicolumn{2}{|c|}{ 1FAHP35N29W172017 } & \multicolumn{3}{|c|}{ New } \\
\hline \multicolumn{2}{|c|}{ RE10 } & \multicolumn{2}{|r|}{ N/A } & \multicolumn{3}{|c|}{ N/A } \\
\hline \multicolumn{2}{|c|}{ RE15 } & \multicolumn{2}{|c|}{ 1FAHP35NX9W178664 } & \multicolumn{3}{|c|}{ New } \\
\hline \multicolumn{2}{|c|}{ RE20 } & \multicolumn{2}{|c|}{ 1FAHP36N89W168617 } & \multicolumn{3}{|c|}{16,133} \\
\hline
\end{tabular}




\begin{tabular}{|c|c|c|c|c|c|c|}
\hline \multicolumn{7}{|c|}{2009 Honda Odyssey (ETC) } \\
\hline \multirow[t]{2}{*}{$\begin{array}{l}\text { Powertrain } \\
\text { Config }\end{array}$} & $\begin{array}{l}\text { Displ. } \\
\text { (L) }\end{array}$ & Layout & Evap Family & Engine Family & Transmission & $\begin{array}{c}\text { Certification } \\
\text { Level }\end{array}$ \\
\hline & 3.5 & V-6 & 9HNXR01562EA & 9HNXT03.5J29 & A5 & Tier 2 Bin 5 \\
\hline \multirow{3}{*}{$\begin{array}{c}\text { Dyno } \\
\text { Coefficients }\end{array}$} & \multicolumn{3}{|r|}{$\mathbf{A}$} & B & $\mathbf{C}$ & ETW \\
\hline & \multicolumn{2}{|c|}{ Target } & 36.13 & 0.5849 & 0.02162 & 5,000 \\
\hline & \multicolumn{2}{|c|}{ Set } & 21.32 & 0.1407 & 0.02412 & 5,000 \\
\hline \multicolumn{2}{|c|}{ Aging Fuel } & \multicolumn{2}{|r|}{ VIN } & \multicolumn{3}{|c|}{ Starting Odometer } \\
\hline \multicolumn{2}{|c|}{ RE0 } & \multicolumn{2}{|c|}{ 5FNRL38229B024871 } & \multicolumn{3}{|c|}{ New } \\
\hline \multicolumn{2}{|c|}{ RE10 } & \multicolumn{2}{|c|}{ N/A } & \multicolumn{3}{|c|}{ N/A } \\
\hline \multicolumn{2}{|c|}{ RE15 } & \multicolumn{2}{|c|}{ 5FNRL38219B024876 } & \multicolumn{3}{|c|}{ New } \\
\hline \multicolumn{2}{|c|}{ RE20 } & \multicolumn{2}{|c|}{ 5FNRL38289B033459 } & \multicolumn{3}{|c|}{19,540} \\
\hline
\end{tabular}

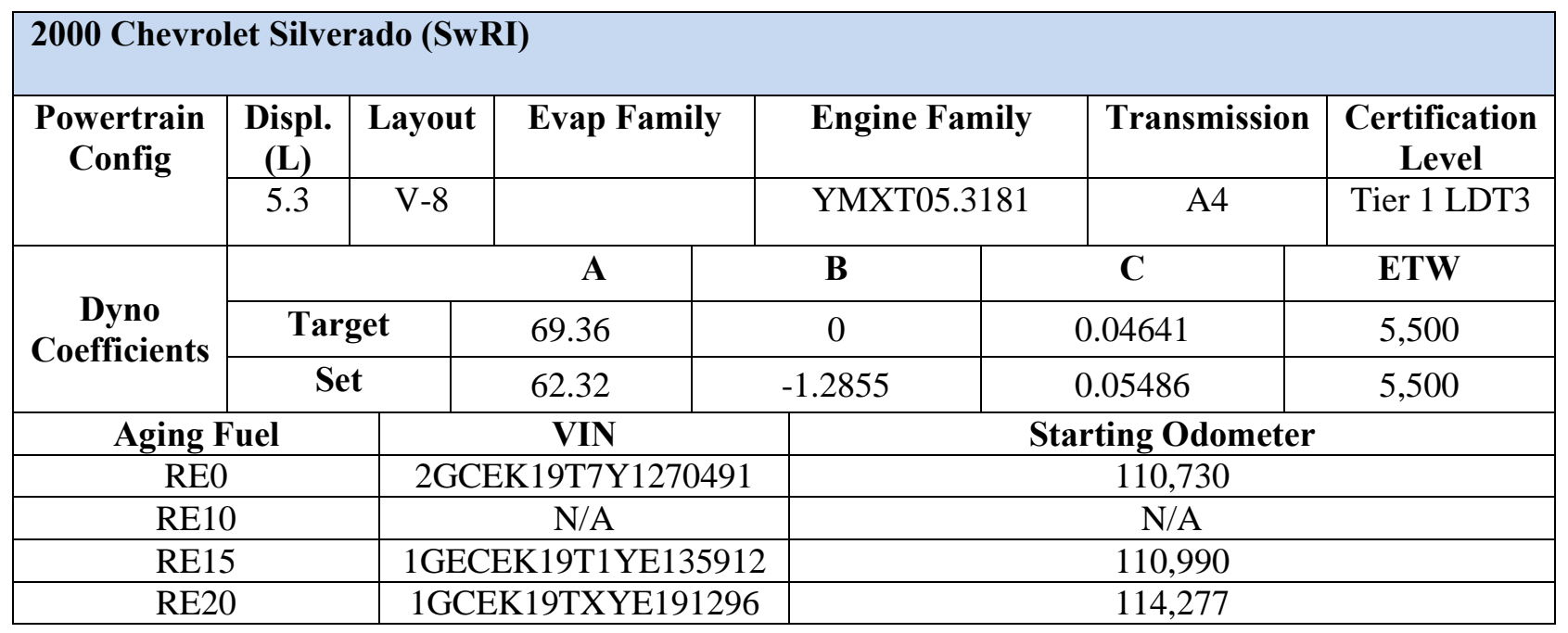




\begin{tabular}{|c|c|c|c|c|c|c|}
\hline \multicolumn{7}{|c|}{2002 Nissan Frontier (SwRI) } \\
\hline \multirow[t]{2}{*}{$\begin{array}{c}\text { Powertrain } \\
\text { Config }\end{array}$} & \begin{tabular}{|c|} 
Displ. \\
(L)
\end{tabular} & Layout & Evap Family & Engine Family & Transmission & $\begin{array}{c}\text { Certification } \\
\text { Level }\end{array}$ \\
\hline & 2.4 & $\mathrm{I}-4$ & 2NSXR0110RCC & 2NSXT02.4C4B & A4 & NLEV LDT1 \\
\hline \multirow{3}{*}{$\begin{array}{c}\text { Dyno } \\
\text { Coefficients }\end{array}$} & \multicolumn{3}{|r|}{$\mathbf{A}$} & B & $\mathbf{C}$ & ETW \\
\hline & \multicolumn{2}{|c|}{ Target } & 45.22 & 0 & 0.03021 & 3,625 \\
\hline & \multicolumn{2}{|c|}{ Set } & 15.63 & 0.0328 & 0.02745 & 3,625 \\
\hline \multicolumn{2}{|c|}{ Aging Fuel } & \multicolumn{2}{|r|}{ VIN } & \multicolumn{3}{|c|}{ Starting Odometer } \\
\hline \multicolumn{2}{|c|}{ RE0 } & \multicolumn{2}{|c|}{ 1N6DD26S02C389876 } & \multicolumn{3}{|c|}{94,498} \\
\hline \multicolumn{2}{|c|}{ RE10 } & \multicolumn{2}{|c|}{$\mathrm{N} / \mathrm{A}$} & \multicolumn{3}{|c|}{ N/A } \\
\hline \multicolumn{2}{|c|}{ RE15 } & \multicolumn{2}{|c|}{ 1N6DD26S42C344018 } & \multicolumn{3}{|c|}{90,650} \\
\hline \multicolumn{2}{|c|}{ RE20 } & \multicolumn{2}{|c|}{ 1N6DD26S02C346445 } & \multicolumn{3}{|c|}{96,408} \\
\hline \multicolumn{7}{|c|}{$\begin{array}{l}\text { "The EPA online emissions database (U.S. Environmental Protection Agency, "Cars and Light Trucks; Annual Certification Test } \\
\text { Results and Data," http://www.epa.gov/otaq/crttst.htm) contains only two entries for } 2002 \text { Nissan light trucks using a 2.4 L four- } \\
\text { cylinder engine. The Frontier entry shows a four-speed automatic transmission, ETW of 3,625 lb, and LDT1 emissions standards. } \\
\text { The XTerra entry shows a five-speed manual transmission, ETW of 4,000 lb, and LDT2 emissions standards. Confusion arose } \\
\text { during vehicle acquisition as the engine family number listed in the EPA database for the Frontier (2NSXT02.4C4A) could only } \\
\text { be found in XTerra vehicles, and the EPA-listed XTerra engine family (2NSXT02.4C4B) was only found in Frontier vehicles. } \\
\text { Three matching Frontiers were acquired, with matching engine family, as shown. Frontiers were weighed and found to have curb } \\
\text { weights of about 3,200 pounds. The manufacturer was consulted and confirmed that the Frontiers should be tested at } \\
\text { 3,625 pounds. }\end{array}$} \\
\hline
\end{tabular}

\begin{tabular}{|c|c|c|c|c|c|c|}
\hline \multicolumn{7}{|c|}{2002 Dodge Durango (SwRI) } \\
\hline \multirow[t]{2}{*}{$\begin{array}{l}\text { Powertrain } \\
\text { Config }\end{array}$} & \begin{tabular}{|c|} 
Displ. \\
$(\mathbf{L})$
\end{tabular} & Layout & Evap Family & Engine Family & Transmission & $\begin{array}{c}\text { Certification } \\
\text { Level }\end{array}$ \\
\hline & 4.7 & V-8 & 2CRXE0101GDH & 2CRXT04.75B0 & A4 & Tier 1 LDT3 \\
\hline \multirow{3}{*}{$\begin{array}{c}\text { Dyno } \\
\text { Coefficients }\end{array}$} & \multicolumn{3}{|r|}{$\mathbf{A}$} & $\mathbf{B}$ & $\mathbf{C}$ & ETW \\
\hline & \multicolumn{2}{|c|}{ Target } & 32.61 & 0.1049 & 0.03253 & 4,750 \\
\hline & \multicolumn{2}{|c|}{ Set } & 17.03 & 0.4993 & 0.02793 & 4,750 \\
\hline \multicolumn{2}{|c|}{ Aging Fuel } & \multicolumn{2}{|r|}{ VIN } & \multicolumn{3}{|c|}{ Starting Odometer } \\
\hline \multicolumn{2}{|c|}{ RE0 } & \multicolumn{2}{|c|}{ 1B4HR38N42F134968 } & \multicolumn{3}{|c|}{70,556} \\
\hline \multicolumn{2}{|c|}{ RE10 } & \multicolumn{2}{|c|}{$\mathrm{N} / \mathrm{A}$} & \multicolumn{3}{|c|}{ N/A } \\
\hline \multicolumn{2}{|c|}{ RE15 } & \multicolumn{2}{|c|}{ 1B4HR38NX129581 } & \multicolumn{3}{|c|}{59,764} \\
\hline \multicolumn{2}{|c|}{ RE20 } & \multicolumn{2}{|c|}{ 1B4HR48N02F148582 } & \multicolumn{3}{|c|}{63,713} \\
\hline
\end{tabular}




\begin{tabular}{|c|c|c|c|c|c|c|}
\hline \multicolumn{7}{|c|}{2003 Toyota Camry (TRC) } \\
\hline \multirow[t]{2}{*}{$\begin{array}{l}\text { Powertrain } \\
\text { Config }\end{array}$} & $\begin{array}{l}\text { Displ. } \\
\text { (L) }\end{array}$ & Layout & Evap Family & Engine Family & Transmission & $\begin{array}{c}\text { Certification } \\
\text { Level }\end{array}$ \\
\hline & 2.4 & $\mathrm{I}-4$ & 3TYXR0135AK1 & 3TYXV02.4HHA & A4 & ULEV \\
\hline \multirow{3}{*}{$\begin{array}{c}\text { Dyno } \\
\text { Coefficients }\end{array}$} & \multicolumn{3}{|r|}{$\mathbf{A}$} & $\mathbf{B}$ & $\mathbf{C}$ & ETW \\
\hline & \multicolumn{2}{|c|}{ Target } & & & & \\
\hline & \multicolumn{2}{|c|}{ Set } & 8.153 & 0.057 & 0.019 & 3,500 \\
\hline \multicolumn{2}{|c|}{ Aging Fuel } & \multicolumn{2}{|r|}{ VIN } & \multicolumn{3}{|c|}{ Starting Odometer } \\
\hline \multicolumn{2}{|c|}{ RE0 } & \multicolumn{2}{|c|}{ 4T1BE32K93V710212 } & \multicolumn{3}{|c|}{76,695} \\
\hline \multicolumn{2}{|c|}{ RE10 } & \multicolumn{2}{|c|}{ N/A } & \multicolumn{3}{|c|}{ N/A } \\
\hline \multicolumn{2}{|c|}{ RE15 } & \multicolumn{2}{|c|}{ JTDBE32К330193579 } & \multicolumn{3}{|c|}{76,550} \\
\hline \multicolumn{2}{|c|}{ RE20 } & \multicolumn{2}{|c|}{ JTDBE32K730174467 } & \multicolumn{3}{|c|}{80,729} \\
\hline
\end{tabular}

\begin{tabular}{|c|c|c|c|c|c|c|}
\hline \multicolumn{7}{|c|}{2003 Ford Taurus (TRC) } \\
\hline \multirow[t]{2}{*}{$\begin{array}{c}\text { Powertrain } \\
\text { Config }\end{array}$} & \begin{tabular}{|c|} 
Displ. \\
(L)
\end{tabular} & Layout & Evap Family & Engine Family & Transmission & $\begin{array}{c}\text { Certification } \\
\text { Level }\end{array}$ \\
\hline & 3.0 & $\mathrm{~V}-6$ & 3FMXR0115BAE & 3FMXV03.0VF3 & A4 & NLEV \\
\hline \multirow{3}{*}{$\begin{array}{c}\text { Dyno } \\
\text { Coefficients }\end{array}$} & \multicolumn{3}{|r|}{$\mathbf{A}$} & B & $\mathbf{C}$ & ETW \\
\hline & \multicolumn{2}{|c|}{ Target } & & & & \\
\hline & \multicolumn{2}{|c|}{ Set } & 10.396 & 0.428 & 0.014 & 3,625 \\
\hline \multicolumn{2}{|c|}{ Aging Fuel } & \multicolumn{2}{|r|}{ VIN } & \multicolumn{3}{|c|}{ Starting Odometer } \\
\hline \multicolumn{2}{|c|}{ RE0 } & \multicolumn{2}{|c|}{ 1FAHP56S93A163402 } & \multicolumn{3}{|c|}{92,710} \\
\hline \multicolumn{2}{|c|}{ RE10 } & \multicolumn{2}{|r|}{ N/A } & \multicolumn{3}{|c|}{ N/A } \\
\hline \multicolumn{2}{|c|}{ RE15 } & \multicolumn{2}{|c|}{ 1FAFP55S53G275037 } & \multicolumn{3}{|c|}{88,130} \\
\hline \multicolumn{2}{|c|}{ RE20 } & \multicolumn{2}{|c|}{ 1FAFP55S13A216277 } & \multicolumn{3}{|c|}{83,671} \\
\hline
\end{tabular}

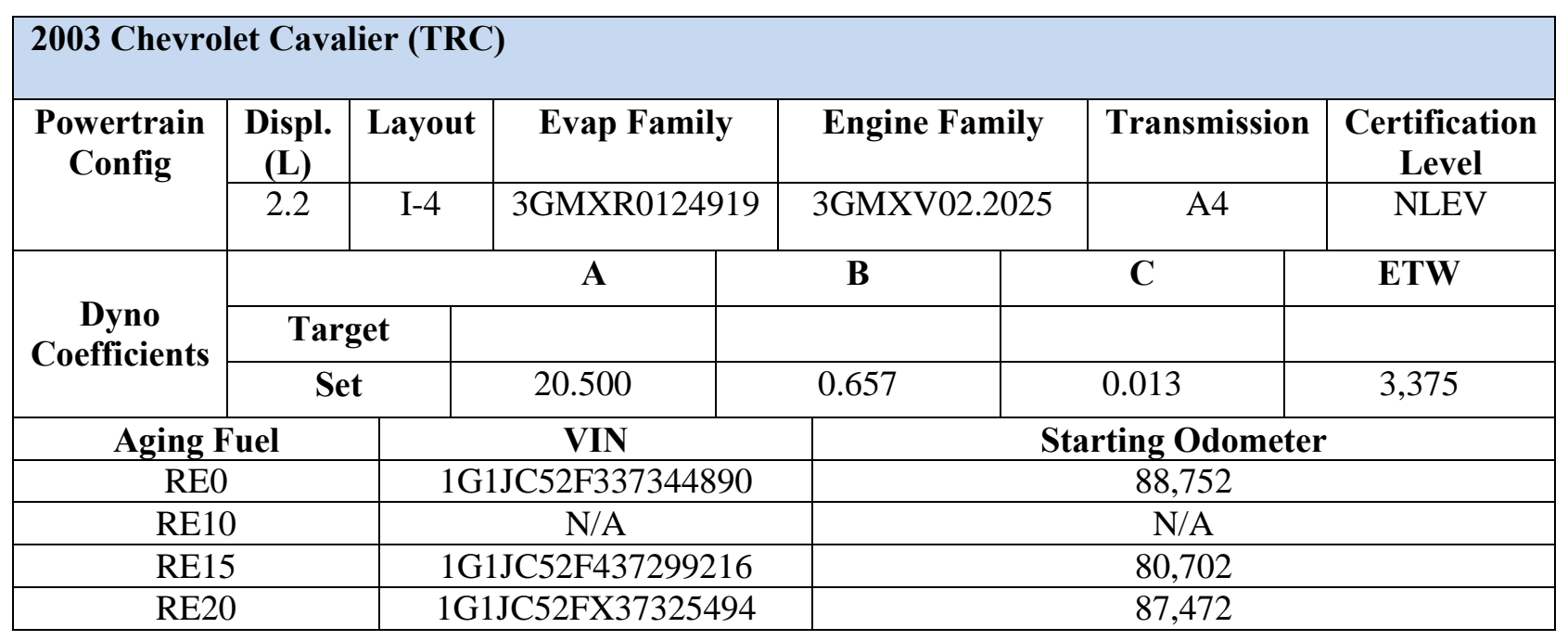




\begin{tabular}{|c|c|c|c|c|c|c|}
\hline \multicolumn{7}{|c|}{2000 Honda Accord (ETC) } \\
\hline \multirow[t]{2}{*}{$\begin{array}{l}\text { Powertrain } \\
\text { Config }\end{array}$} & $\begin{array}{l}\text { Displ. } \\
\text { (L) }\end{array}$ & Layout & Evap Family & Engine Family & Transmission & $\begin{array}{c}\text { Certification } \\
\text { Level }\end{array}$ \\
\hline & 2.3 & $\mathrm{I}-4$ & YHNXR0130AAA & YHNXV02.3PF3 & A4 & NLEV \\
\hline \multirow{3}{*}{$\begin{array}{c}\text { Dyno } \\
\text { Coefficients }\end{array}$} & \multicolumn{3}{|r|}{$\mathbf{A}$} & B & $\mathbf{C}$ & ETW \\
\hline & \multicolumn{2}{|c|}{ Target } & 26.01 & 0.4918 & 0.01591 & 3,375 \\
\hline & \multicolumn{2}{|c|}{ Set } & 7.68 & 0.0291 & 0.0197 & 3,375 \\
\hline \multicolumn{2}{|c|}{ Aging Fuel } & \multicolumn{2}{|r|}{ VIN } & \multicolumn{3}{|c|}{ Starting Odometer } \\
\hline \multicolumn{2}{|c|}{ RE0 } & \multicolumn{2}{|c|}{ 1HGCG5649YA027642 } & \multicolumn{3}{|c|}{91,475} \\
\hline \multicolumn{2}{|c|}{ RE10 } & \multicolumn{2}{|c|}{ N/A } & \multicolumn{3}{|c|}{ N/A } \\
\hline \multicolumn{2}{|c|}{ RE15 } & \multicolumn{2}{|c|}{ 1HGCG5647YA153420 } & \multicolumn{3}{|c|}{95,285} \\
\hline \multicolumn{2}{|c|}{ RE20 } & \multicolumn{2}{|c|}{ 1HGCG5649YA049592 } & \multicolumn{3}{|c|}{89,499} \\
\hline
\end{tabular}

\begin{tabular}{|c|c|c|c|c|c|c|}
\hline \multicolumn{7}{|c|}{2000 Ford Focus (ETC) } \\
\hline \multirow[t]{2}{*}{$\begin{array}{l}\text { Powertrain } \\
\text { Config }\end{array}$} & $\begin{array}{l}\text { Displ. } \\
\text { (L) }\end{array}$ & Layout & Evap Family & Engine Family & Transmission & $\begin{array}{c}\text { Certification } \\
\text { Level }\end{array}$ \\
\hline & 2.0 & $\mathrm{I}-4$ & YFMXR0080BBE & YFMXV02.0VF & A4 & NLEV \\
\hline \multirow{3}{*}{$\begin{array}{c}\text { Dyno } \\
\text { Coefficients }\end{array}$} & \multicolumn{3}{|r|}{$\mathbf{A}$} & B & $\mathbf{C}$ & ETW \\
\hline & \multicolumn{2}{|c|}{ Target } & 30.85 & 0.5080 & 0.01649 & 3,125 \\
\hline & \multicolumn{2}{|c|}{ Set } & 16.03 & 0.1742 & 0.0183 & 3,125 \\
\hline \multicolumn{2}{|c|}{ Aging Fuel } & \multicolumn{2}{|r|}{ VIN } & \multicolumn{3}{|c|}{ Starting Odometer } \\
\hline \multicolumn{2}{|c|}{ RE0 } & \multicolumn{2}{|c|}{ 1FAFP34P3YW412653 } & \multicolumn{3}{|c|}{102,994} \\
\hline \multicolumn{2}{|c|}{ RE10 } & \multicolumn{2}{|r|}{ N/A } & \multicolumn{3}{|c|}{ N/A } \\
\hline \multicolumn{2}{|c|}{ RE15 } & \multicolumn{2}{|c|}{ 1FAFP34P9YW400216 } & \multicolumn{3}{|c|}{85,425} \\
\hline \multicolumn{2}{|c|}{ RE20 } & \multicolumn{2}{|c|}{ 1FAFP34P4YW422950 } & \multicolumn{3}{|c|}{69,919} \\
\hline
\end{tabular}



APPENDIX D.

DETAILED STATISTICAL RESULTS BY PARAMETER 



\section{APPENDIX D. DETAILED STATISTICAL RESULTS BY PARAMETER}

\section{D.1 Introduction}

For each parameter (emissions or fuel economy) statistical models have been separately fit to data for 26 different vehicle models from the Federal Test Procedure (FTP). [The Nissan Quest was omitted from these analyses because it did not run the standard road cycle (SRC) for the duration of the program and because the RE0 vehicle did not reach end-of-test (EOT).] Each of these statistical models aggregates test data for multiple individual vehicles, road test fuels (RE0, RE10, RE15, and RE20), mileage points [startof-test (SOT), midlife aging (MID), and EOT], and emissions test fuels (E0, E10, E15, and E20). The discussion below provides references to these individual parameter models but, more importantly, summarizes the observed results at the fleet level. For each parameter, the results of immediate ethanol effects are provided first. The immediate ethanol effect is the change in the emission/performance parameter as estimated by the statistical model for a vehicle at acquisition (i.e., before beginning its road fuel aging) that is operated with an ethanol blend test fuel (E10, E15, or E20) as compared to a vehicle of the same design that is operated on E0. Results for the immediate ethanol effect are presented for each of the three separate ethanol blend test fuels and overall for all of them.

Following the immediate ethanol effects, the results of aging are discussed. Aging is presented as the change in emission/performance parameter as estimated by the statistical model over a normalized 100,000-mile test period. Aging was evaluated for each vehicle model and for all road fuels (RE0, RE10, RE15, and RE20). The model estimates of data from vehicles run with RE0 and tested at three intervals with E0 provide a base evaluation of aging effects. Estimates were also developed for vehicles run with an "RExx" ethanol blend road fuel and tested at three intervals with the "Exx" blend of the same ethanol content as well as E0. Note that it was possible for the Exx and E0 test results for an RExx ethanol blend to provide different aging estimates. If this happened, the E0 test results for the RExx vehicle are reported as the aging effect, and the incremental Exx impact on aging is separately reported. This situation occurred in only a few instances, and the results are shown in the tables but are not discussed further hereafter. In addition to separately estimating the aging effect for each vehicle model under each road fuel, the RE10, RE15, and RE20 statistical model aging results were jointly tested to determine whether there was evidence of a differential ethanol road fuel effect on aging.

In Tables D.1 through D.9, results are presented by parameter in the following order: CO, oxides of nitrogen $\left(\mathrm{NO}_{\mathrm{X}}\right)$, nonmethane hydrocarbon ( $\mathrm{NMHC}$ ), nonmethane organic gas (NMOG), fuel economy, ethanol, acetaldehyde, formaldehyde, and $\mathrm{CH}_{4}$. Each table shows separate statistical model results for each vehicle model and one emission parameter or fuel economy. The components of these tables are as follows.

- Emissions (units) - The emission/performance parameter being modeled and its corresponding test units.

- V1 results (immediate effect of ethanol)—A reference column that indicates, where known, the trend of the immediate effect of ethanol for that parameter based on the V1 study. (Note that the V1 study used the LA92 (unified cycle), while the study reported here used the FTP.) ${ }^{*}$

- Vehicle model - The year and model of the vehicles tested.

- LFT@WOT_An indicator regarding whether the vehicle model applies long-term or learned fuel trim (LFT) at wide-open throttle (WOT) (see Sect. 3.1).

*Keith Knoll et al., Effects of Intermediate Ethanol Blends on Legacy Vehicles and Small Non-Road Engines, Report 1Updated, NREL/TP-540-43543/ORNL/TM-2008/117, February 2009, available at http://www.nrel.gov/docs/fy09osti/43543.pdf. 
- Standard-U.S. Environmental Protection Agency Emission standard.

- Ethanol effect (units at zero miles; E0: $\Delta$ units versus E0; E10, E15, and E20: percent change versus E0; E10, E15, and E20: overall p-value)—The estimated true performance level at E0 is shown and the E10, E15, and E20 ethanol effect sizes are displayed both as differences relative to E0 level and as percentages of the E0 level. A p-value for the joint test of any ethanol effect.

- Aging effect with RE0 ( $\Delta$ units per 100,000 miles; RE0/E0: overall p-value)—The estimated aging effect per 100,000 miles of a vehicle driven with RE0 and tested with E0 and the corresponding p-value for the statistical test of whether the aging effect is different from zero.

- RExx aging effect on E0 emissions ( $\Delta$ units per 100,000 miles; RE10/E0, RE15/E0, and RE20/E0: overall p-value)—The estimated aging effects per 100,000 miles for vehicles driven with RE10, RE15, and RE20 and tested with E0. An overall p-value is provided for the test of whether all three ethanol fuel aging effects are statistically indistinguishable from the RE0 aging effect.

Two important special cases are presented for some of the vehicles in Tables D.1 to D.9. If the "Vehicle Model” value is appended with the symbol "\#," the data for that vehicle were transformed by the natural logarithm before fitting the model. This special case only occurred for some of the vehicles with acetaldehyde and formaldehyde. In these cases, the ethanol effect increased with increasing test miles, as contrasted with the nontransformed models where the ethanol effect was constant. To enable reporting of only a single ethanol effect, it was decided to present the value as estimated for the zero test mileage. The same is true for the aging effects where the reported slopes of units per 100,000 miles apply to the zero test mileage. If the "Vehicle Model" value is appended with the symbol "\#\#," the data did not support the assumption of a response linear with test mileage. As a consequence, such cases were fit with the test mileage as a categorical variable. This special case only occurred for the 2006 Silverado with fuel economy, all of the vehicle models for ethanol emission, and for a small number of vehicle models for each of acetaldehyde and formaldehyde emissions parameters. The implication of this modeling is that the ethanol effect for each of E10, E15, and E20 has separate results at each of the three mileage test points. Again to facilitate reporting of only a single value, the approach in these models was to average the effects at the three separate time points (SOT, MID, and EOT). For road fuel aging, the lack of linearity prevented the same calculation of slope in emission/performance parameter result with miles driven. As a proxy for the aging effect, the difference in outcome at the final mileage point and the first mileage point (zero miles) was calculated and divided by the number of miles between these two and then adjusted to a reference 100,000 miles. In both of these special cases, care should be exercised to only interpret the results within the limitations of the modeling.

Cell values in Tables D.1 through D.9 that are appended with an asterisk (“*”) indicate that the statistical test for this particular result (i.e., different from zero) is significant with 95\% confidence. In the overall p-value columns, a value of 0.05 or less is asterisked as significant.

Figures D.1 through D.9 provide specific fleet analysis results for each of the following: $\mathrm{CO}, \mathrm{NO}_{\mathrm{X}}$, NMHC, NMOG, fuel economy, ethanol, acetaldehyde, formaldehyde, and $\mathrm{CH}_{4}$. Each figure contains four quadrant plots and two tables. The components of the figures are as follows.

- $\quad$ Test Fuel Effect (zero miles)

- The upper left quadrant plot is of the immediate estimated ethanol fuel effect across the tested fleet. Each vehicle model and ethanol level is a separate plotted point. The source of the plotted values is the same as those data in Tables D.1 through D.9, "Ethanol Effect ( $\Delta$ units versus E0; E10, E15, and E20)." Note that plot symbols are randomly offset horizontally to enhance differentiation of the individual values. Under the plot are statistics for testing whether the entire set of ethanol test fuel vehicle results is statistically different from that of the E0 test fuel. Both a nonparametric result (testing the hypothesis that the median difference is zero versus the 
alternative that it is not zero) and a parametric result (testing the hypothesis that the mean difference is zero versus the alternative that it is not zero) are provided. In most cases the two results produce similar statistical conclusions (i.e., whether to reject the hypothesis and conclude the alternative). The parametric test is preferred because of its greater sensitivity. However, the parametric tests shown here are only strictly applicable when the test samples meet certain assumptions dealing with variability and normality of the underlying populations of data. The data collected suggest some concerns with these assumptions. Therefore, while the parametric results are shown, the more conservative nonparametric results are the basis for the discussion of results that follows. The statistical tests include a separate test for each of the three ethanol fuel blends (E10, E15, and E20) and a single test for any fuel differences (overall). If the value for the test is 0.05 or less, it can be interpreted that the hypothesis (denoted with "H:") is unlikely to be true, as the probability of the hypothesis being true and simultaneously collecting a random set of data with the observed characteristics is less than 1 in 20 . Therefore it can be concluded that a statistically significant difference exists, and the original hypothesis can be rejected. Note that a p-value greater than 0.05 does not constitute proof that the original hypothesis is necessarily true, only that there is insufficient evidence to reject it.

- The lower left quadrant graph has the same data points as the plot above it, but the data are divided within each ethanol fuel grouping depending on whether the vehicle model was found to apply LFT at WOT. The statistical tests below the graph are the nonparametric and parametric comparisons of whether the test fuel effect among the LFT vehicles is different from those without it. The nonparametric test for this difference cannot be readily extended to the aggregate of all three ethanol test fuels, so this p-value is identified with an "NA."

- $\quad$ Road Fuel Effect on E0 Emission

- The upper right quadrant plot is of the road fuel aging effects for RE0, RE10, RE15, and RE20, evaluated with E0 Federal Test Procedure results. The source of the plotted values is the same as those data in Tables D.1 through D.9, "Aging Effect with RE0 ( $\Delta$ units per 100,000 miles; RE0/E0)" and "RExx Aging Effect on E0 Emissions ( $\Delta$ units per 100,000 miles; RE10/E0, RE15/E0, and RE20/E0).” As identified above, base aging is represented by the RE0 results. Under the plot, both nonparametric and parametric test results are shown for the hypothesis that no aging effect for RE0 vehicles exists compared to the alternative hypothesis that some aging effect occurs across all the vehicle models. The RE10, RE15, and RE20 aging effects represent the sum of aging inherent in the vehicle models themselves (same as RE0 aging) and any incremental aging effect (could be positive or negative) from the use of ethanol blends rather than RE0. Separate nonparametric and parametric test statistics are provided for the hypothesis of zero aging across all vehicle models run with each of the fuels, RE10, RE15, and RE20. Additionally, an overall test determines whether there was any evidence of aggregate aging for RE10, RE15, and RE20 versus RE0.

- The lower right quadrant graph has the same data points as the plot above it, but they are divided within each ethanol fuel grouping depending on whether the vehicle model was found to apply LFT at WOT. The statistical tests below the graph are the nonparametric and parametric comparisons of whether the road fuel aging effects among the LFT vehicles are different from those without it. The nonparametric test for this difference cannot be readily extended to the aggregate of all three ethanol test fuels, so this p-value is identified as "not applicable" ("NA").

\section{D.2 Discussion}

Considering the 26 vehicle models tested, there were 5 vehicles tested with E10, 26 vehicles tested with E15, and 22 vehicles tested with E20, for a total of 53 ethanol blend test cases, for which there were 
53 statistical models which could be used to test the ethanol effect. Each parameter is discussed below in light of these 53 test cases.

\section{D.2.1 Carbon monoxide}

\section{Immediate ethanol effect}

Consistent with the previously reported V1 results ${ }^{*}$, testing with ethanol blends resulted in lower CO levels than E0 in most cases. As shown in Table D.1, across the three ethanol fuel blends, 44 of the 53 statistical models showed lower CO levels when tested with ethanol blends. For 10 of those 44 models, the lower CO levels were statistically significant. Referencing CO results in Table D.1, decreases by fuel and vehicle model ranged to nearly as much as the E0 test results at zero miles, though most reductions were less than $50 \%$ of the E0 test results at zero miles. Combining all the vehicles, as shown in Fig. D.1, results in the conclusion that across all three ethanol fuels and over the fleet, ethanol tested CO, on median, is lower than E0 tested CO for the same vehicle models, with a p-value less than 0.0001 based on a sign test. Figure D.1 further shows no differentiation in immediate ethanol effect as a function of LFT (p-values 1.0000, 0.3891, and 0.8447 for the Wilcoxon test with E10, E15, and E20, respectively).

\section{Road fuel aging and differential ethanol road fuel effect on aging}

Across the fleet as shown in Table D.1, in 21 of 26 cases, vehicles run with RE0 and subsequently tested with E0 showed a trend of increasing CO emission rates ( 9 of them statistically significant) with increasing total miles driven. Increases were as great as $+7.93 \mathrm{~g} /$ mile (2000 Accord). In most cases, though, the positive effect did not exceed about $+3.00 \mathrm{~g} / \mathrm{mile}$. With a p-value of 0.0025 , as shown in Fig. D.1, the median across all tested statistical models for the change in CO levels per 100,000 miles driven under RE0 fuel was greater than zero at the statistically significant level. Hence, there is evidence of systematic aging for $\mathrm{CO}$ emissions across the fleet.

When examining aging in vehicles aged with ethanol fuel blends, the same general trend was observed as with RE0. Specifically, 46 of the 53 cases showed a positive aging effect (Table D.1). The observed increases were comparable to the RE0 aging effect. With a p-value less than 0.0001 (Fig. D.1), the median change in CO levels with ethanol test fuels was greater than zero for the fleet overall at the statistically significant level. From Table D.1, only 5 of 26 vehicle models provided some evidence for a different aging effect with ethanol blended aging fuels than with RE0. Hence, it appears reasonable to conclude that the use of ethanol fuels does not change the aging that is observed for CO. Finally, Fig. D.1 provides no strong evidence that the aging effect, regardless of which road fuel is used, is influenced by application of LFT, as evaluated in the nonparametric test statistics.

\section{D.2.2 Oxides of nitrogen}

\section{Immediate ethanol effect}

The $\mathrm{NO}_{\mathrm{X}}$ emissions levels were higher with ethanol blended fuels as compared to E0 in most statistical models, as shown in Table D.2. Across the three ethanol fuel blends, 39 of the 53 cases showed higher $\mathrm{NO}_{\mathrm{X}}$ levels when tested with ethanol blends. Five of the 39 higher model results were statistically significant. Referencing $\mathrm{NO}_{\mathrm{X}}$ results in Table D.2, the increases by fuel and vehicle model ranged to as much as the E0 test fuel result measured at zero miles. Combining all the vehicles, as shown in Fig. D.2, results in the conclusion that across all three ethanol fuels and over the fleet, ethanol tested $\mathrm{NO}_{\mathrm{X}}$, on

\footnotetext{
*Keith Knoll et al., Effects of Intermediate Ethanol Blends on Legacy Vehicles and Small Non-Road Engines, Report 1Updated, NREL/TP-540-43543/ORNL/TM-2008/117, February 2009, available at http://www.nrel.gov/docs/fy09osti/43543.pdf.
} 
median, is higher than $\mathrm{E} 0$ tested $\mathrm{NO}_{\mathrm{X}}$ for the same vehicles, with a p-value of 0.0009 based on a sign test. Figure D.2 further shows no differentiation in immediate ethanol effect as a function of LFT (p-values 0.5637, 0.9556, and 0.1364 for the Wilcoxon test with E10, E15, and E20, respectively).

\section{Road fuel aging and differential ethanol road fuel effect on aging}

Across the fleet, as shown in Table D.2, in 25 of 26 cases, vehicles run with RE0 and subsequently tested with $\mathrm{E} 0$ showed a trend of increasing $\mathrm{NO}_{\mathrm{X}}$ emission rates (15 of them statistically significant) with increasing total miles driven. Increases were as great as $+0.479 \mathrm{~g} / \mathrm{mile}$ (2000 Silverado). In most cases, though, the positive effect did not exceed about $+0.15 \mathrm{~g} / \mathrm{mile}$. With a p-value less than 0.0001 , as shown in Fig. D.2, the median of the change in $\mathrm{NO}_{\mathrm{X}}$ levels across all tested statistical models per 100,000 miles driven under RE0 fuel was greater than zero at the statistically significant level. Hence, there is evidence of systematic aging for $\mathrm{NO}_{\mathrm{X}}$ emissions across the fleet.

When examining aging in vehicles run with ethanol fuel blends, the same general trend was observed as with RE0. Specifically, 51 of the 53 cases showed a positive aging effect (Table D.2). The observed increases were of a comparable magnitude to the RE0 aging effect. With a p-value less than 0.0001 (Fig. D.2), the median change in $\mathrm{NO}_{\mathrm{X}}$ levels with ethanol test fuels was greater than zero at the statistically significant level for the fleet overall. From Table D.2, only 5 of 26 vehicle models provided some evidence for a different aging effect under ethanol road fuels than under RE0. Hence, it appears reasonable to conclude that the use of ethanol fuels does not change the aging that is observed for $\mathrm{NO}_{\mathrm{X}}$. Finally, Fig. D.2 provides no strong evidence that the aging effect, regardless of which road fuel is used, is influenced by application of LFT.

\section{D.2.3 Nonmethane hydrocarbons}

\section{Immediate ethanol effect}

Consistent with the previously reported V1 results, NMHC levels were lower for testing ethanol blend fuels than E0 in most statistical models, as shown in Table D.3. Across the three ethanol fuel blends, 48 of the 53 statistical models showed lower NMHC levels when tested with ethanol blends. Eight of the 48 model results were statistically significant. Referencing NMHC results in Table D.3, the reductions by fuel and vehicle were as great as $42 \%$ relative to the E0 test fuel result. Combining all the vehicles, as shown in Fig. D.3, results in the conclusion that across all three ethanol fuels and over the fleet, ethanoltested NMHCs, on median, are lower than E0-tested NMHCs for the same vehicles, with a p-value less than 0.0001 based on a sign test. Figure D.3 further shows no differentiation in immediate ethanol effect as a function of LFT (p-values 0.5637, 0.3439, and 0.7539 for the Wilcoxon test with E10, E15, and E20, respectively).

\section{Road fuel aging and differential ethanol road fuel effect on aging}

Across the fleet, as shown in Table D.3, in 18 of 26 cases, vehicles run with RE0 and subsequently tested with E0 showed a trend of increasing NMHC emission rates (8 of them statistically significant) with increasing total miles driven. One of the eight observed decreasing trends was statistically significant. Where increases were seen, they ranged up to $+0.159 \mathrm{~g} /$ mile (2000 Accord). In most cases, though, the positive effect did not exceed about $+0.05 \mathrm{~g}$ /mile. With a p-value of 0.0433 , as shown in Fig. D.3, the median across all tested statistical models of the change in NMHC levels per 100,000 miles driven under RE0 fuel was greater than zero at the statistically significant level. Hence, there is evidence of systematic aging for NMHC emissions across the fleet. 
When examining aging in vehicles run with ethanol fuel blends, the same general trend was observed as with RE0. Specifically, 39 of the 53 cases showed a positive aging effect (Table D.3). The observed increases were of a comparable magnitude to the RE0 aging effect. With a p-value of 0.0004 (Fig. D.3), the median change in NMHC levels with ethanol test fuels was greater than zero for the fleet overall at the statistically significant level. From Table D.3, only 5 of 26 vehicle models provided some evidence for a different aging effect under ethanol road fuels than under RE0. Hence, it appears reasonable to conclude that the use of ethanol fuels does not change the aging that is observed for NMHCs. Finally, Fig. D.3 provides no strong evidence that the aging effect, regardless of which road fuel is used, is influenced by LFT.

\section{D.2.4 Nonmethane organic gases}

\section{Immediate ethanol effect}

NMOG levels for ethanol blend test fuels were similar to E0 in most statistical models, as shown in Table D.4. Across the three ethanol fuel blends, 29 of the 53 cases showed lower NMOG levels and 24 of the 53 cases showed higher NMOG levels when tested with ethanol blends. The only statistically significant differences were for three of the cases with lower NMOG with ethanol blends. Referencing Table D.4, NMOG levels for the ethanol fuels were between 33\% lower and 25\% higher than the E0 test fuel results. Combining all the vehicles, as shown in Fig. D.4, results in the conclusion that across all three ethanol fuels and over the fleet, ethanol tested NMOG, on median, is no different than E0 tested NMOG for the same vehicle models, with a p-value of 0.4799 based on a sign test. Figure D.4 further shows no differentiation in immediate ethanol effect as a function of LFT (p-values 1.0000, 0.4528, and 0.9687 for the Wilcoxon test with E10, E15, and E20, respectively).

\section{Road fuel aging and differential ethanol road fuel effect on aging}

Across the fleet, as shown in Table D.4, in 19 of 26 cases, vehicles run with RE0 and subsequently tested with E0 showed a trend of increasing NMOG emission rates with increasing miles driven (8 of the 19 are statistically significant increases). One of the seven observed decreasing trends was statistically significant. Where increases were seen, they were as great as $+0.165 \mathrm{~g} / \mathrm{mile}$ (2000 Accord). In most cases, though, the positive effect did not exceed about $+0.05 \mathrm{~g} / \mathrm{mile}$. With a p-value of 0.0433 , as shown in Fig. D.4, the median across all tested statistical models of the change in NMOG levels per 100,000 miles driven under RE0 fuel was greater than zero at the statistically significant level. Hence, there is evidence of systematic aging for NMOG emissions across the fleet.

When examining aging in vehicles run with ethanol fuel blends, the same general trend was observed as with RE0. Specifically, 39 of the 53 cases showed a positive aging effect (Table D.4). The observed increases were of a comparable magnitude to the RE0 aging effect. With a p-value of 0.0008 (Fig. D.4), the median change in NMOG levels with ethanol test fuels was greater than zero for the fleet overall at the statistically significant level. From Table D.4, only 3 of 26 vehicle models provided some evidence for a different aging effect under ethanol road fuels than under RE0. Hence, it appears reasonable to conclude that the use of ethanol fuels does not change the aging that is observed for NMOG. Finally, Fig. D.4 provides no strong evidence that the aging effect, regardless of which road fuel is used, is influenced by LFT. 


\section{D.2.5 Fuel economy}

\section{Immediate ethanol effect}

As expected, fuel economy was lower with ethanol blended fuels than with E0 in all 53 fuel and statistical model combinations, as shown in Table D.5. Only the reduction in fuel economy with E10 in the 2007 Accord was not statistically significant. Referencing fuel economy results in Table D.5, the reductions by fuel and vehicle model were as great as $7.6 \%$ relative to the E0 test fuel result, with larger fuel economy losses as the ethanol content increased from $10 \%$ to $15 \%$ to $20 \%$. Combining all the vehicles, as shown in Fig. D.5, results in the conclusion that across all three ethanol fuels and over the fleet, ethanol tested fuel economy, on median, is lower than E0 tested fuel economy for the same vehicles, with a p-value less than 0.0001 based on a sign test.

\section{Road fuel aging and differential ethanol road fuel effect on aging}

Across the fleet, as shown in Table D.5, in 21 of 26 cases, vehicles run with RE0 and subsequently tested with E0 showed a trend of increasing fuel economy ( 5 of them statistically significant) with increasing total miles driven. Three of the five observed decreasing trends (2008 Altima, 2003 Cavalier, and 2000 Focus) were statistically significant. Where increases were seen, they ranged up to $+1.4 \mathrm{mpg}$ (2003 Taurus), and decreases were as great as $-2.3 \mathrm{mpg}$ (2003 Cavalier). With a p-value of 0.0025, as shown in Fig. D.5, the median across all tested statistical models of the change in fuel economy per 100,000 miles driven under RE0 fuel was greater than zero at the statistically significant level. Hence, there is evidence of systematic aging resulting in better fuel economy across the fleet.

When examining aging in vehicles run with ethanol fuel blends, the same general trend was observed as with RE0. Specifically, 38 of the 53 cases showed a positive aging effect (Table D.5). The observed increases were of a comparable magnitude to the RE0 aging effect. With a p-value of 0.0022 (Fig. D.5), the median change in fuel economy with ethanol test fuels was greater than zero for the fleet overall, at the statistically significant level. From Table D.5, only 5 of 26 vehicle models provided some evidence for a different aging effect under ethanol road fuels than under RE0. Hence, it appears reasonable to conclude that the use of ethanol fuels does not change the effect of aging on fuel economy. Finally, Fig. D.5 provides no strong evidence that the aging effect, regardless of which road fuel is used, is influenced by LFT.

\section{D.2.6 Ethanol}

\section{Immediate ethanol effect}

Due to a lack of reliable ethanol data for some of the vehicle sets from the program, Table D.6 contains results for a smaller number of vehicles than Tables D.1-D.5 and D.7-D.9.

Consistent with the previously reported V1 results, ethanol emission levels were higher for testing ethanol blend fuels than E0 in all 25 cases, as shown in Table D.6. All but 2 of the 25 results were higher at the statistically significant level. Combining all the vehicle models, as shown in Fig. D.6, results in the conclusion that across all three ethanol fuels and over the fleet, ethanol tested ethanol emissions, on median, are higher than E0 tested ethanol emissions for the same vehicles, with a p-value less than 0.0001 based on a sign test. Figure D.6 further shows no differentiation in immediate ethanol effect as a function of LFT (p-values 1.0000, 0.9093, and 0.9093 for the Wilcoxon test with E10, E15, and E20, respectively). 


\section{Road fuel aging and differential ethanol road fuel effect on aging}

Because the ethanol models demonstrated a lack of linearity with test mileage, a categorical data model was fit to reveal any potential relationship between the zero mileage, middle mileage, and final mileage data points. As a consequence, the modeled road fuel aging effects, as a single slope, are not applicable. As an approximation, road fuel aging effects were determined using only the initial and final mileage data points.

Across the fleet, as shown in Table D.6, in 7 of 10 cases, vehicles run with RE0 and subsequently tested with E0 showed a trend of decreasing ethanol emission rates (none of them statistically significant) with increasing total miles driven. Decreases were as great as $-0.299 \mathrm{mg} / \mathrm{mile}$ and increases as great as $+0.318 \mathrm{mg} / \mathrm{mile}$. With a p-value of 0.5078, as shown in Fig. D.6, the median of the change in ethanol emission levels across all tested statistical models per 100,000 miles driven under RE0 fuel was not significantly different from zero. Hence, there is no evidence of systematic aging for ethanol emissions across the fleet.

When examining aging in vehicles run with ethanol fuel blends, a different trend was observed than with RE0. Specifically, 19 of the 25 cases showed a positive aging effect (Table D.6). With a p-value of 0.0146 (Fig. D.6), the median change in ethanol emission levels with ethanol test fuels was greater than zero for the fleet overall, at the statistically significant level. However, from Table D.6, none of the 10 vehicle models provided any evidence for a different aging effect under ethanol road fuels than under RE0. This finding appears to present a contradiction between the Table D.6 and Fig. D.6 results. In light of the modeling limitation discussed previously, neither can provide a high degree of certainty. Therefore, it would probably be best to interpret the aging effects with regard to ethanol emissions as inconclusive.

\section{D.2.7 Acetaldehyde}

\section{Immediate ethanol effect}

Due to a lack of reliable ethanol data for some of the vehicle sets from the program, Table D.7 contains results for a smaller number of vehicles than Tables D.1-D.5 and D.9.

Consistent with the previously reported V1 results, acetaldehyde levels were higher for testing ethanol blend fuels than E0 in most cases, as shown in Table D.7. Across the three ethanol fuel blends, all 45 cases showed higher acetaldehyde levels when tested with ethanol blends. Forty-four of the 45 results were higher at the statistically significant level. Referencing acetaldehyde results in Table D.7, the increases were at least $+0.5 \mathrm{mg} / \mathrm{mile}$ in a majority of the vehicle models. Combining all the vehicles, as shown in Fig. D.7, results in the conclusion that across all three ethanol fuels and over the fleet, ethanol tested acetaldehyde, on median, is higher than E0 tested acetaldehyde for the same models, with a p-value less than 0.0001 based on a sign test. Figure D.7 further shows no differentiation in immediate ethanol effect as a function of LFT (p-values 1.0000, 0.4070, and 0.8273 for the Wilcoxon test with E10, E15, and E20, respectively).

\section{Road fuel aging and differential ethanol road fuel effect on aging}

Across the fleet, as shown in Table D.7, in 15 of 20 cases vehicles run with RE0 and subsequently tested with E0 showed a trend of increasing acetaldehyde emission rates (3 of them statistically significant) with increasing total miles driven. The increase was as large as $+1.489 \mathrm{mg} / \mathrm{mile}$ (2000 Silverado). In most cases, though, the positive effect did not exceed about $+0.20 \mathrm{mg} / \mathrm{mile}$. With a p-value of 0.0636 , as shown in Fig. D.7, the median of the change in acetaldehyde levels across all tested statistical models per 
100,000 miles driven under RE0 fuel was not greater than zero at the statistically significantly level. Hence, there is no evidence of systematic aging for acetaldehyde emissions across the fleet.

When examining aging in vehicles run with ethanol fuel blends, the level of aging was comparable to the vehicles run with E0. Specifically, 29 of the 45 cases showed a positive aging effect (Table D.7), similar to the 15 of 20 positive results with RE0. With a p-value of 0.0725 (Fig. D.7), the median change in acetaldehyde levels with ethanol test fuels was not statistically significant, but it just marginally missed being significant, whereas the difference was significant but only marginally so for the RE0 fuel. From Table D.7, only 1 of 20 cases provided some evidence for a different aging effect under ethanol road fuels than under RE0. Hence, it appears reasonable to conclude that the use of ethanol fuels does not change the aging that is observed for acetaldehyde. Finally, Fig. D.7 provides no strong evidence that the aging effect, regardless of which road fuel is used, is influenced by LFT.

\section{D.2.8 Formaldehyde}

\section{Immediate ethanol effect}

Due to a lack of reliable ethanol data for some of the vehicle sets from the program, Table D.8 contains results for a smaller number of vehicles than Tables D.1-D.5 and D.9.

Consistent with the previously reported V1 results, formaldehyde levels were higher for ethanol blend fuels than E0 in most cases, as shown in Table D.8. Across the three ethanol fuel blends, 36 of the 45 vehicle models showed higher formaldehyde levels when tested with ethanol blends. For 4 of the 45 cases, results were higher at the statistically significant level. Referencing formaldehyde results in Table D.8, the magnitude of the increases was highly variable. Combining all the vehicles, as shown in Fig. D.8, results in the conclusion that across all three ethanol fuels and over the fleet, ethanol-tested formaldehyde, on median, is higher than E0-tested formaldehyde for the same vehicles, with a p-value of 0.0001 based on a sign test. Figure D.8 further shows no differentiation in immediate ethanol effect as a function of LFT (p-values 0.7671, 0.6945, and 0.3153 for the Wilcoxon test with E10, E15, and E20, respectively).

\section{Road fuel aging and differential ethanol road fuel effect on aging}

Across the fleet, as shown in Table D.8, in 16 of 20 cases, vehicles run with RE0 and subsequently tested with E0 showed a trend of increasing formaldehyde emission rates ( 6 of them statistically significant) with increasing total miles driven. The increase was as large as $+4.363 \mathrm{mg} / \mathrm{mile}$ (2000 Silverado). In most cases, though, the positive effect did not exceed about $+1.00 \mathrm{mg} / \mathrm{mile}$. With a p-value of 0.0118 , as shown in Table D.8, the median of the change in formaldehyde levels across all tested statistical models per 100,000 miles driven under RE0 fuel was greater than zero at the statistically significant level. Hence, there is evidence of systematic aging for formaldehyde emissions across the fleet.

When examining aging in vehicles run with ethanol fuel blends, the level of aging was comparable to the models run with E0. Specifically, 33 of the 45 cases showed a positive aging effect (Table D.8), similar to the 16 of 20 positive with RE0. With a p-value of 0.0025 (Fig. D.8), the median change in formaldehyde levels with ethanol test fuels was different from zero at the statistically significant level. From Table D.8, only 3 of 20 cases provided some evidence for a different aging effect under ethanol road fuels than under RE0. Hence, it appears reasonable to conclude that the use of ethanol fuels does not change the effect of aging on formaldehyde emissions. Finally, Fig. D.8 provides no strong evidence that the aging effect, regardless of which road fuel is used, is influenced by LFT. 


\section{D.2.9 Methane}

\section{Immediate ethanol effect}

The $\mathrm{CH}_{4}$ levels were a close mixture of higher and lower for testing ethanol blend fuels compared to E0, as shown in Table D.9. Across the three ethanol fuel blends, 31 of the 53 cases showed higher $\mathrm{CH}_{4}$ levels when tested with ethanol blends. Four of the 31 higher model results and one of the 22 lower model results were statistically significant. Referencing $\mathrm{CH}_{4}$ results in Table D.9, the differences ranged from $-0.002 \mathrm{~g} / \mathrm{mile}$ to $0.006 \mathrm{~g} / \mathrm{mile}$. Combining all the vehicles, as shown in Fig. D.9, results in the conclusion that across all three ethanol fuels and over the fleet, ethanol tested $\mathrm{CH}_{4}$, on median, is not significantly different than $\mathrm{E} 0$ tested $\mathrm{CH}_{4}$ for the same vehicles, with a p-value of 0.2624 based on a sign test. Figure D.9 further shows no differentiation in immediate ethanol effect as a function of LFT (p-values 0.1765, 0.1303, and 0.3903 for the Wilcoxon Test with E10, E15, and E20, respectively).

\section{Road fuel aging and differential ethanol road fuel effect on aging}

Across the fleet, as shown in Table D.9, in all 26 cases, vehicles run with RE0 and subsequently tested with E0 showed a trend of increasing $\mathrm{CH}_{4}$ emission rates (16 of them statistically significant) with increasing total miles driven. The increase was as great as $+0.05 \mathrm{~g} / \mathrm{mile}$ (2000 Accord). In most cases, though, the positive effect did not exceed about $+0.02 \mathrm{~g} / \mathrm{mile}$. With a p-value less than 0.0001 , as shown in Fig. D.9, the median of the change in $\mathrm{CH}_{4}$ levels across all tested statistical models per 100,000 miles driven under RE0 fuel was greater than zero at the statistically significant level. Hence, there is evidence of systematic aging for $\mathrm{CH}_{4}$ emissions across the fleet.

When examining aging in vehicles run with ethanol fuel blends, the same general trend was observed as with RE0. Specifically, all 53 of the cases showed a positive aging effect (Table D.9). The observed increases were of a comparable magnitude to the RE0 aging effect. With a p-value less than 0.0001 (Fig. D.9), the median change in $\mathrm{CH}_{4}$ levels with ethanol test fuels was greater than zero for the fleet overall, at the statistically significant level. From Table D.9, only 6 of 26 vehicle models provided some evidence for a different aging effect under ethanol road fuels than under RE0. Hence, it appears reasonable to conclude that the use of ethanol fuels does not change the aging that is observed for $\mathrm{CH}_{4}$. Finally, Fig. D.9 provides no strong evidence that the aging effect, regardless of which road fuel is used, is influenced by LFT, as evaluated in the nonparametric test statistics. 
Table D.1. Federal Test Procedure CO emissions by vehicle model

\begin{tabular}{|c|c|c|c|c|c|c|c|c|c|c|c|c|c|c|c|c|c|c|}
\hline \multirow{3}{*}{$\mid \begin{array}{c}\text { Emissions } \\
\text { (units) }\end{array}$} & \multirow{3}{*}{$\begin{array}{l}\text { V1 Results } \\
\text { (Immediate } \\
\text { Effect of } \\
\text { Ethanol) }+\end{array}$} & \multirow{3}{*}{ Vehicle Model } & \multirow{3}{*}{$\begin{array}{l}\text { Apply LFT } \\
@ \text { @OT? }\end{array}$} & \multirow{3}{*}{ Standard } & \multicolumn{8}{|c|}{ Ethanol Effect $\ddagger$} & \multicolumn{2}{|c|}{$\begin{array}{c}\text { Aging Effect with } \\
\text { REO }\end{array}$} & \multicolumn{4}{|c|}{ RExx Aging Effect on EO Emissions \# } \\
\hline & & & & & \multirow{2}{*}{\begin{tabular}{|c|}
$\begin{array}{l}\text { units at } \\
\text { ok mi }\end{array}$ \\
E0 \\
\end{tabular}} & \multicolumn{3}{|c|}{$\Delta$ units vs. EO } & \multicolumn{3}{|c|}{ \% change vs. EO } & \multirow{2}{*}{$\begin{array}{c}\text { Overall } p- \\
\text { value }\end{array}$} & \multirow{2}{*}{\begin{tabular}{|c|}
$\begin{array}{c}\Delta \text { units } \\
\text { per } \\
100 \mathrm{~K} \mathrm{mi}\end{array}$ \\
REO/E0 \\
\end{tabular}} & \multirow{2}{*}{$\begin{array}{c}\text { Overall } p- \\
\text { value }\end{array}$} & \multicolumn{3}{|c|}{$\Delta$ units per $100 \mathrm{~K} \mathrm{mi}$} & \multirow{2}{*}{$\begin{array}{c}\text { Overall } p- \\
\text { value }\end{array}$} \\
\hline & & & & & & E10 & E15 & E20 & E10 & E15 & E20 & & & & RE10/E0 & RE15/E0 & RE20/E0 & \\
\hline \multirow{26}{*}{ CO (g/mi) } & \multirow{26}{*}{ Decrease } & 2007 Accord & No & T2 B5 & 0.215 & $-0.104 *$ & $\begin{array}{l}-0.070 * \\
\end{array}$ & \begin{tabular}{|c|c|}
$-0.083 *$ \\
\end{tabular} & $-48.37 \% *$ & $-32.56 \% *$ & $-38.60 \% *$ & $<0.01 *$ & -0.003 & 0.95 & 0.027 & 0.043 & 0.047 & 0.77 \\
\hline & & 2006 Silverado & Yes & T2 B8 & 0.792 & \begin{tabular}{l|l}
0.028 \\
\end{tabular} & \begin{tabular}{|c|c|}
-0.066 \\
\end{tabular} & \begin{tabular}{|c|c|}
-0.067 \\
\end{tabular} & $3.54 \%$ & $-8.33 \%$ & $-8.46 \%$ & 0.87 & -0.055 & 0.81 & 0.012 & 0.071 & -0.169 & 0.73 \\
\hline & & 2008 Altima & No & T2 B5 & 0.408 & 0.066 & -0.067 & -0.153 & $16.17 \%$ & $-16.42 \%$ & $-37.49 \%$ & 0.42 & 0.224 & 0.54 & 0.221 & 0.226 & 0.161 & 0.98 \\
\hline & & 2008 Taurus & Yes & T2 B5 & 0.410 & -0.031 & 0.037 & -0.066 & $-7.57 \%$ & $9.03 \%$ & $-16.11 \%$ & 0.48 & -0.021 & 0.81 & -0.005 & $0.140 *$ & -0.122 & 0.07 \\
\hline & & 2007 Caravan & No & T2 B5 & 1.143 & -0.027 & -0.146 & -0.383 & $-2.36 \%$ & $-12.77 \%$ & $-33.49 \%$ & 0.34 & 0.002 & 1.00 & 0.191 & 0.456 & $1.360^{*}$ & 0.14 \\
\hline & & 2006 Cobalt & No & T2 B5 & 0.526 & $\mathrm{NA}$ & -0.001 & -0.156 & $\mathrm{NA}$ & $-0.19 \%$ & $-29.65 \%$ & 0.49 & 0.268 & 0.39 & $\mathrm{NA}$ & \begin{tabular}{|c|c|}
-0.033 \\
\end{tabular} & 0.225 & 0.61 \\
\hline & & 2007 Caliber & No & T2 B5 & 0.999 & $\mathrm{NA}$ & -0.214 & $-1.049 *$ & $\mathrm{NA}$ & $-21.43 \%$ & $\begin{array}{l}-105 \% * \\
\end{array}$ & $<0.01 *$ & $2.274 *$ & $<0.01 *$ & $\mathrm{NA}$ & $4.729 *$ & $2.748 *$ & $<0.01 *$ \\
\hline & & 2009 Liberty & No & T2 B5 & 0.770 & NA & -0.176 & -0.324 & NA & $-22.86 \%$ & $-42.08 \%$ & 0.23 & 0.223 & 0.46 & $N A$ & $0.579 *$ & 0.445 & 0.62 \\
\hline & & 2009 Explorer & Yes & T2 B4 & 1.065 & NA & -0.070 & $-0.167 *$ & NA & $-6.57 \%$ & $-15.68 \% *$ & $0.01 *$ & 0.146 & 0.05 & $N A$ & 0.082 & $0.140 *$ & 0.60 \\
\hline & & 2009 Civic & No & T2 B5 & 0.452 & NA & $-0.122 *$ & -0.038 & NA & $-27.01 \% *$ & $-8.41 \%$ & $<0.01 *$ & 0.044 & 0.236 & $N A$ & $0.097^{*}$ & 0.032 & 0.208 \\
\hline & & 2009 Corolla & No & T2 B5 & 0.352 & NA & -0.033 & -0.087 & NA & $-9.38 \%$ & $-24.74 \%$ & 0.56 & 0.106 & 0.42 & $\mathrm{NA}$ & $0.217^{*}$ & 0.204 & 0.76 \\
\hline & & 2005 Tundra & No & T2 B5 & 0.691 & NA & -0.078 & -0.092 & NA & $-11.29 \%$ & $-13.31 \%$ & 0.23 & 0.167 & 0.32 & $\mathrm{NA}$ & $0.293^{*}$ & $0.465 *$ & 0.34 \\
\hline & & 2006 Impala & No & T2 B5 & 1.058 & $\mathrm{NA}$ & -0.117 & -0.093 & $\mathrm{NA}$ & $-11.06 \%$ & $-8.79 \%$ & 0.41 & 0.097 & 0.67 & $\mathrm{NA}$ & $0.579 *$ & 0.342 & 0.25 \\
\hline & & 2005 F150 & Yes & T2 B8 & 1.447 & NA & -0.062 & -0.389 & $\mathrm{NA}$ & $-4.29 \%$ & $-26.89 \%$ & 0.17 & $2.840 *$ & $<0.01 *$ & $\mathrm{NA}$ & $1.404 *$ & $1.257 *$ & $0.05 *$ \\
\hline & & 2009 Outlook & Yes & T2 B5 & 0.267 & NA & -0.104 & $\mathrm{NA}$ & $\mathrm{NA}$ & $-38.91 \%$ & $\mathrm{NA}$ & 0.05 & $0.936 *$ & $<0.01 *$ & $\mathrm{NA}$ & $0.246 *$ & $\mathrm{NA}$ & $<0.01 *$ \\
\hline & & 2009 Camry & Yes & T2 B5 & 0.162 & NA & 0.006 & $\mathrm{NA}$ & $\mathrm{NA}$ & $3.71 \%$ & NA & 0.75 & $0.120 *$ & $<0.01 *$ & $N A$ & 0.051 & $\mathrm{NA}$ & 0.12 \\
\hline & & 2009 Focus & Yes & T2 B4 & 0.500 & NA & -0.039 & $\mathrm{NA}$ & $\mathrm{NA}$ & $-7.80 \%$ & NA & 0.70 & 0.366 & 0.05 & $N A$ & 0.224 & $\mathrm{NA}$ & 0.49 \\
\hline & & 2009 Odyssey & No & T2 B5 & 0.224 & NA & -0.010 & $\mathrm{NA}$ & $\mathrm{NA}$ & $-4.47 \%$ & NA & 0.76 & $0.354^{*}$ & $<0.01 *$ & $N A$ & -0.001 & $\mathrm{NA}$ & $0.01 *$ \\
\hline & & 2000 Silverado & Yes & T1 L3 & 2.064 & NA & $-0.457 *$ & -0.230 & $\mathrm{NA}$ & $-22.14 \% *$ & $-11.14 \%$ & $0.03 *$ & 0.703 & 0.21 & $N A$ & -0.089 & 0.789 & 0.23 \\
\hline & & 2002 Frontier & No & NLEV LEV & 1.447 & NA & 0.131 & 0.168 & $\mathrm{NA}$ & $9.05 \%$ & $11.61 \%$ & 0.90 & 4.491* & $0.01 *$ & $\mathrm{NA}$ & 4.958* & 5.305* & 0.93 \\
\hline & & 2002 Durango & No & T1 L3 & 2.287 & NA & 0.425 & 0.356 & NA & $18.59 \%$ & $15.57 \%$ & 0.07 & -0.345 & 0.49 & $\mathrm{NA}$ & 0.935 & 0.537 & 0.20 \\
\hline & & 2003 Camry & No & ULEV & 0.740 & NA & 0.007 & -0.045 & $\mathrm{NA}$ & $0.95 \%$ & $-6.08 \%$ & 0.95 & 0.450 & 0.29 & $\mathrm{NA}$ & 0.466 & 0.096 & 0.82 \\
\hline & & 2003 Taurus & No & NLEV LEV & 0.593 & NA & $-0.197 *$ & $-0.337 *$ & $\mathrm{NA}$ & $-33.20 \% *$ & $-56.80 \% *$ & $<0.01^{*}$ & -0.258 & 0.12 & $\mathrm{NA}$ & 0.055 & -0.139 & 0.25 \\
\hline & & 2003 Cavalier & No & NLEV LEV & 0.743 & NA & -0.130 & $-0.415^{*}$ & $\mathrm{NA}$ & $-17.49 \%$ & $-55.83 \% *$ & $<0.01 *$ & 1.611* & $<0.01 *$ & $\mathrm{NA}$ & 0.120 & 0.358 & $<0.01 *$ \\
\hline & & 2000 Accord & No & NLEV LEV & 1.424 & NA & -1.251 & -0.124 & $\mathrm{NA}$ & $-87.86 \%$ & $-8.71 \%$ & 0.240 & 7.933* & $0.01 *$ & $\mathrm{NA}$ & 2.760 & 0.482 & 0.090 \\
\hline & & 2000 Focus & No & NLEV LEV & 0.491 & $\mathrm{NA}$ & -0.135 & -0.372 & $\mathrm{NA}$ & $-27.51 \%$ & $-75.80 \%$ & 0.120 & 1.389* & $0.04 *$ & $\mathrm{NA}$ & 0.028 & $1.672 *$ & 0.060 \\
\hline $\begin{array}{l}\text { * Indicates } \\
\text { \# Log-norr } \\
\# \# \text { Data did } \\
\text { NA="Not A } \\
\text { † "Effects o } \\
\text { ‡ Colors de }\end{array}$ & $\begin{array}{l}\text { pplicable" } \\
\text { f Intermediat } \\
\text { note ethanol }\end{array}$ & $\begin{array}{l}\text { lifferent from ze } \\
\text { as used. Results } \\
\text { the assumption } \\
\text { te Ethanol Blend } \\
\text { I blend: E10, blu }\end{array}$ & $\begin{array}{l}\text { Is on Legacy } \\
\text { e; E15, gree }\end{array}$ & $\begin{array}{l}5 \% \text { confiden } \\
\text { ted as chan } \\
\text { ffects with n } \\
\text { y Vehicles ar } \\
\text { en; E20, red }\end{array}$ & $\begin{array}{l}\text { level. } \\
\text { sin emi } \\
\text { eage. }\end{array}$ & Road Eng & ines, Re & rt $1-$ Upc & ated," ORNL & IL/TM-2008 & 3/117 & & & & & & & \\
\hline
\end{tabular}




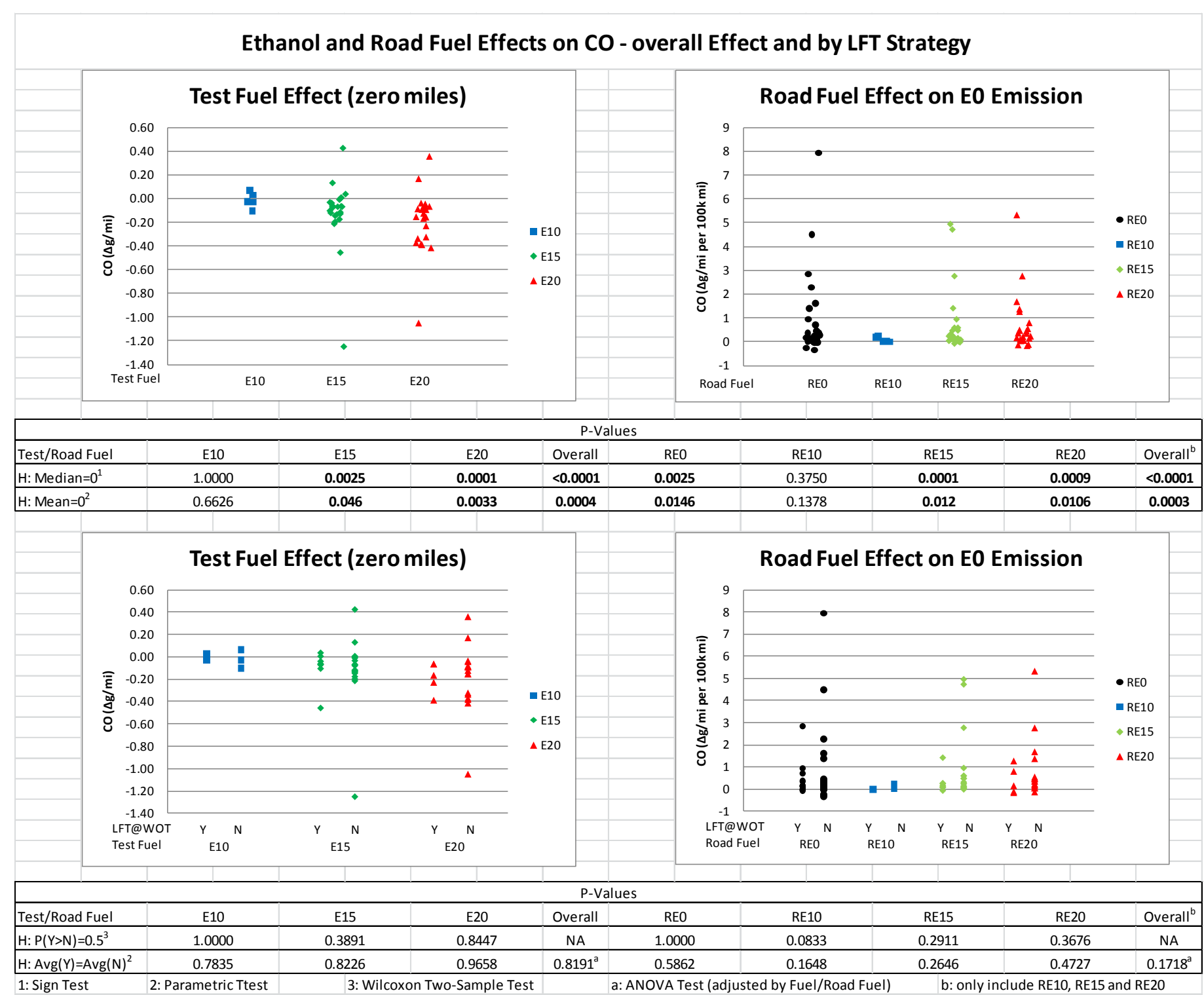

Fig. D.1. Ethanol and road fuel effects on Federal Test Procedure CO emissions. 
Table D.2. Federal Test Procedure $\mathrm{NO}_{\mathrm{x}}$ emissions by vehicle model

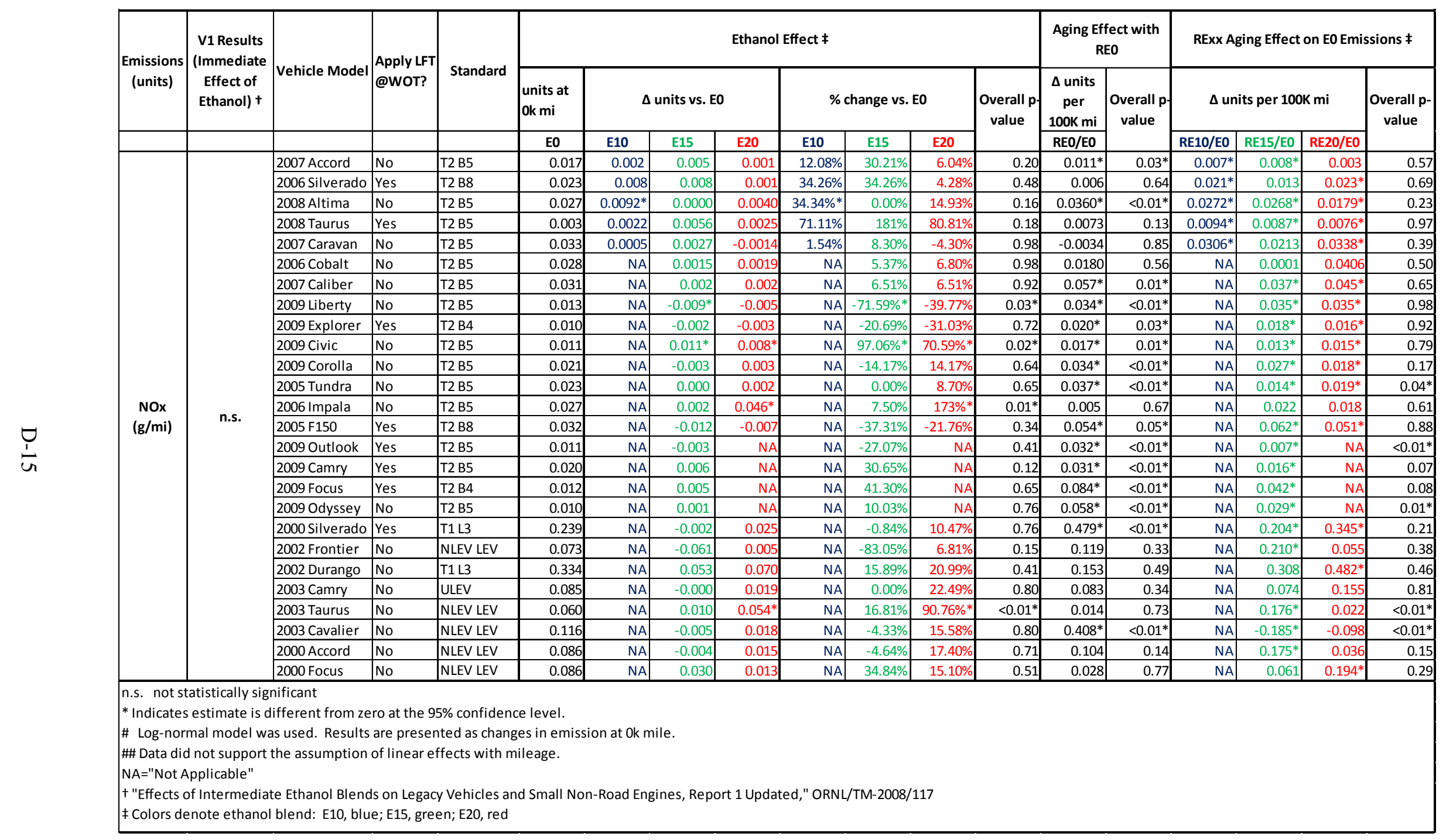


Ethanol and Road Fuel Effects on NOx - overall Effect and by LFT Strategy
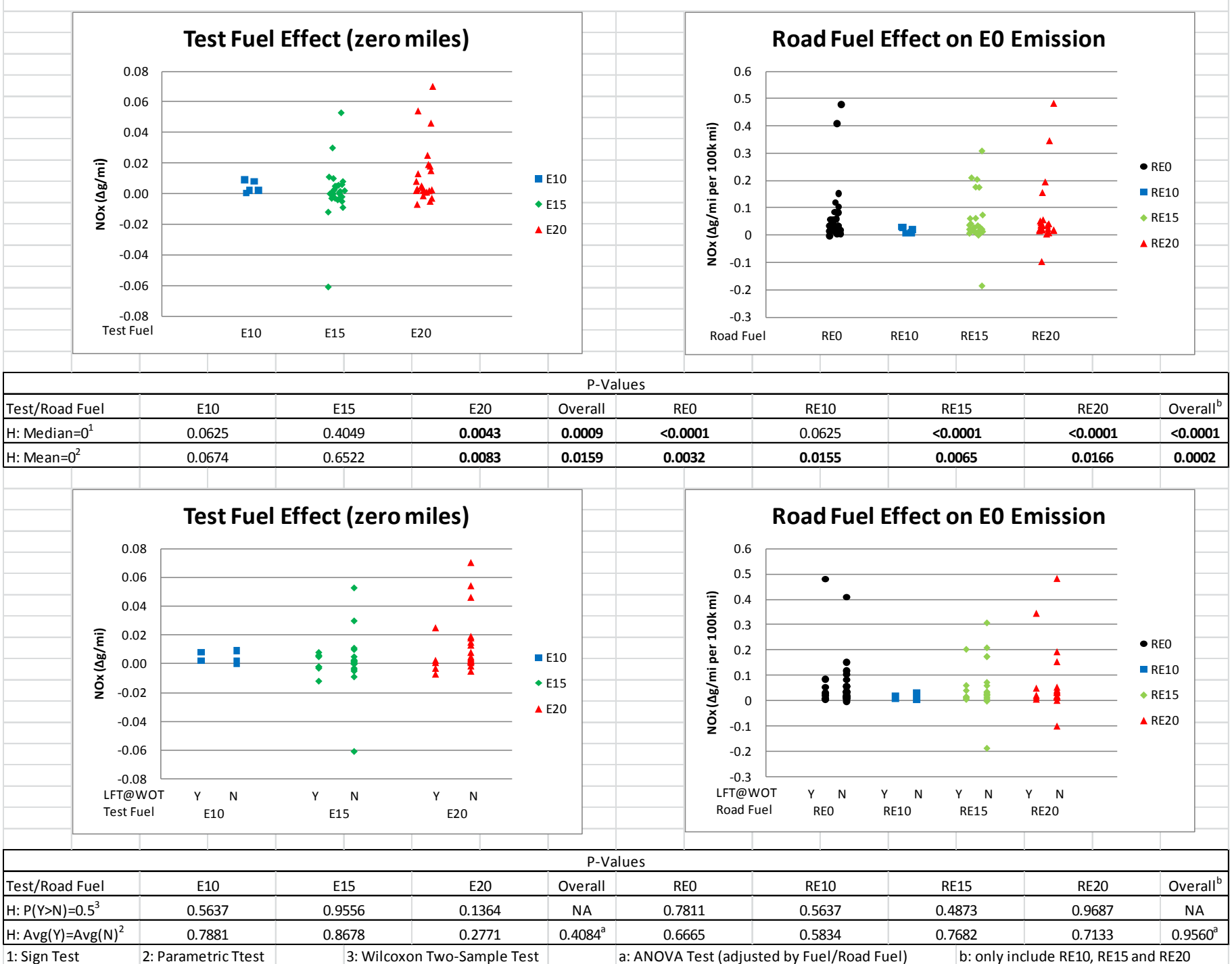

Fig. D.2. Ethanol and road fuel effects on Federal Test Procedure $\mathrm{NO}_{\mathrm{x}}$ emissions. 
Table D.3. Federal Test Procedure nonmethane hydrocarbon emissions by vehicle model

\begin{tabular}{|c|c|c|c|c|c|c|c|c|c|c|c|c|c|c|c|c|c|c|}
\hline \multirow{3}{*}{$\begin{array}{c}\text { Emissions } \\
\text { (units) }\end{array}$} & \multirow{3}{*}{$\begin{array}{c}\text { V1 Results } \\
\text { (Immediate } \\
\text { Effect of } \\
\text { Ethanol) }+\end{array}$} & \multirow{3}{*}{ Vehicle Model } & \multirow{3}{*}{$\begin{array}{l}\text { Apply LFT } \\
\text { @WOT? }\end{array}$} & \multirow{3}{*}{ Standard } & \multicolumn{8}{|c|}{ Ethanol Effect $\ddagger$} & \multicolumn{2}{|c|}{$\begin{array}{c}\text { Aging Effect with } \\
\text { REO }\end{array}$} & \multicolumn{4}{|c|}{ RExx Aging Effect on E0 Emissions ₹ } \\
\hline & & & & & \multirow{2}{*}{\begin{tabular}{|r}
$\begin{array}{l}\text { units at } \\
\text { Ok mi }\end{array}$ \\
E0 \\
\end{tabular}} & \multicolumn{3}{|c|}{$\Delta$ units vs. EO } & \multicolumn{3}{|c|}{ \% change vs. EO } & \multirow{2}{*}{$\begin{array}{c}\text { Overall } p- \\
\text { value }\end{array}$} & \multirow{2}{*}{$\begin{array}{c}\begin{array}{c}\Delta \text { units } \\
\text { per } \\
100 \mathrm{~K} \mathrm{mi}\end{array} \\
\text { REO/EO }\end{array}$} & \multirow{2}{*}{$\begin{array}{c}\text { Overall } \mathrm{p}- \\
\text { value }\end{array}$} & \multicolumn{3}{|c|}{$\Delta$ units per $100 \mathrm{~K} \mathrm{mi}$} & \multirow{2}{*}{$\begin{array}{c}\text { Overall } p \text { - } \\
\text { value }\end{array}$} \\
\hline & & & & & & E10 & E15 & E20 & E10 & E15 & E20 & & & & RE10/E0 & RE15/E0 & RE20/E0 & \\
\hline \multirow{26}{*}{$\begin{array}{l}\text { NMHC } \\
(\mathrm{g} / \mathrm{mi})\end{array}$} & \multirow{26}{*}{ Decrease } & 2007 Accord & No & T2 B5 & 0.027 & -0.0079 & -0.0024 & -0.0075 & $-29.36 \%$ & $-8.92 \%$ & $-27.87 \%$ & 0.09 & 0.0073 & 0.41 & 0.0004 & 0.0005 & 0.0038 & 0.89 \\
\hline & & 2006 Silverado & Yes & T2 B8 & 0.048 & 0.007 & -0.001 & -0.002 & $14.62 \%$ & $-2.09 \%$ & $-4.18 \%$ & 0.95 & 0.005 & 0.82 & 0.013 & 0.014 & 0.006 & 0.97 \\
\hline & & 2008 Altima & No & T2 B5 & 0.057 & 0.0093 & -0.0072 & -0.0073 & $16.42 \%$ & $-12.71 \%$ & $-12.89 \%$ & 0.28 & -0.0010 & 0.97 & 0.0079 & 0.0039 & 0.0001 & 0.91 \\
\hline & & 2008 Taurus & Yes & T2 B5 & 0.022 & -0.0026 & -0.0009 & -0.0031 & $-11.82 \%$ & $-4.09 \%$ & $-14.09 \%$ & 0.25 & 0.0036 & 0.30 & -0.0020 & $0.0080 *$ & -0.0013 & $0.04^{*}$ \\
\hline & & 2007 Caravan & No & T2 B5 & 0.043 & -0.003 & -0.007 & -0.007 & $-7.02 \%$ & $-16.37 \%$ & $-16.37 \%$ & 0.23 & 0.007 & 0.58 & -0.003 & 0.010 & 0.004 & 0.75 \\
\hline & & 2006 Cobalt & No & T2 B5 & 0.040 & NA & -0.0039 & -0.0083 & $\mathrm{NA}$ & $-9.80 \%$ & $-20.86 \%$ & $0.05 *$ & -0.0025 & 0.73 & NA & -0.0015 & 0.0025 & 0.80 \\
\hline & & 2007 Caliber & No & T2 B5 & 0.048 & NA & -0.0016 & $-0.0117 *$ & $\mathrm{NA}$ & $-3.36 \%$ & $-24.59 \% *$ & $0.02 *$ & $0.0416 *$ & $<0.01 *$ & NA & $0.0437 *$ & $0.0289 *$ & 0.28 \\
\hline & & 2009 Liberty & No & T2 B5 & 0.052 & NA & -0.011 & -0.019 & $\mathrm{NA}$ & $-21.26 \%$ & $-36.72 \%$ & 0.11 & -0.000 & 0.99 & NA & -0.003 & 0.011 & 0.58 \\
\hline & & 2009 Explorer & Yes & T2 B4 & 0.051 & NA & -0.005 & $-0.010 *$ & $\mathrm{NA}$ & $-9.90 \%$ & $-19.80 \% *$ & $<0.01 *$ & 0.008 & 0.08 & NA & 0.005 & $0.009 *$ & 0.65 \\
\hline & & 2009 Civic & No & T2 B5 & 0.026 & $\mathrm{NA}$ & $-0.011 *$ & $-0.011 *$ & $\mathrm{NA}$ & $-41.59 \% *$ & $-41.59 \% *$ & $<0.01 *$ & $0.011 *$ & $0.04 *$ & $\mathrm{NA}$ & $0.011 *$ & 0.007 & 0.57 \\
\hline & & 2009 Corolla & No & T2 B5 & 0.031 & NA & -0.0018 & -0.0057 & $\mathrm{NA}$ & $-5.74 \%$ & $-18.16 \%$ & 0.59 & 0.0115 & 0.21 & NA & $0.0153 *$ & 0.0137 & 0.93 \\
\hline & & 2005 Tundra & No & T2 B5 & 0.051 & $\mathrm{NA}$ & -0.007 & \begin{tabular}{|c|}
-0.009 \\
\end{tabular} & $\mathrm{NA}$ & $-13.78 \%$ & $-17.72 \%$ & 0.21 & 0.005 & 0.72 & $\mathrm{NA}$ & -0.015 & 0.000 & 0.07 \\
\hline & & 2006 Impala & No & T2 B5 & 0.039 & $\mathrm{NA}$ & -0.003 & \begin{tabular}{l|l|l|l|}
-0.004 \\
\end{tabular} & NA & $-7.61 \%$ & $-10.14 \%$ & 0.10 & -0.005 & 0.35 & NA & $0.010^{*}$ & 0.002 & 0.05 \\
\hline & & 2005 F150 & Yes & T2 B8 & 0.052 & $\mathrm{NA}$ & $-0.015^{*}$ & $-0.014 *$ & $\mathrm{NA}$ & \begin{tabular}{|l|}
$-29.00 \% *$ \\
\end{tabular} & $-27.07 \% *$ & $<0.01^{*}$ & $0.047 *$ & $<0.01^{*}$ & $\mathrm{NA}$ & $0.040 *$ & $0.020 *$ & 0.12 \\
\hline & & 2009 Outlook & Yes & T2 B5 & 0.026 & NA & 0.000 & $\mathrm{NA}$ & $\mathrm{NA}$ & $0.00 \%$ & $\mathrm{NA}$ & 0.95 & $0.018^{*}$ & $<0.01^{*}$ & NA & 0.004 & $\mathrm{NA}$ & $0.04^{*}$ \\
\hline & & 20009 Camry & Yes & T2 B5 & 0.020 & NA & 0.0003 & NA & NA & $1.49 \%$ & $\mathrm{NA}$ & 0.89 & $0.0122^{*}$ & $0.01 *$ & NA & 0.0045 & $\mathrm{NA}$ & 0.13 \\
\hline & & 2009 Focus & Yes & T2 B4 & 0.037 & NA & -0.009 & NA & NA & $-24.62 \%$ & $\mathrm{NA}$ & 0.07 & -0.012 & 0.13 & NA & -0.001 & $\mathrm{NA}$ & 0.23 \\
\hline & & 2009 Camry & No & T2 B5 & 0.021 & NA & -0.000 & NA & $\mathrm{NA}$ & $0.00 \%$ & $\mathrm{NA}$ & 0.97 & $0.023 *$ & $<0.01 *$ & NA & 0.001 & $\mathrm{NA}$ & $<0.01^{*}$ \\
\hline & & 2000 Silverado & Yes & T1 L3 & 0.201 & NA & -0.026 & -0.022 & NA & $-12.92 \%$ & $-10.93 \%$ & 0.12 & 0.069 & 0.21 & $\mathrm{NA}$ & -0.049 & 0.037 & 0.15 \\
\hline & & 2002 Frontier & No & NLEV LEV & 0.084 & NA & $-0.019 *$ & $-0.027 *$ & NA & \begin{tabular}{|l|}
$-22.72 \% *$ \\
\end{tabular} & $-32.29 \% *$ & $<0.01^{*}$ & $\begin{array}{l}-0.022 \\
\end{array}$ & 0.15 & NA & $0.042 *$ & 0.005 & $<0.01^{*}$ \\
\hline & & 2002 Durango & No & T1 L3 & 0.145 & NA & -0.011 & -0.012 & NA & $-7.57 \%$ & $-8.26 \%$ & 0.13 & $-0.068^{*}$ & $0.02 *$ & NA & 0.011 & -0.020 & 0.07 \\
\hline & & 2003 Camry & No & ULEV & 0.042 & NA & -0.001 & -0.003 & NA & $-2.38 \%$ & $-7.14 \%$ & 0.84 & 0.030 & 0.11 & $\mathrm{NA}$ & 0.012 & -0.018 & 0.28 \\
\hline & & 2003 Taurus & No & NLEV LEV & 0.082 & NA & -0.016 & -0.024 & NA & $-19.51 \%$ & $-29.26 \%$ & 0.12 & -0.028 & 0.50 & $\mathrm{NA}$ & -0.020 & -0.030 & 0.97 \\
\hline & & 2003 Cavalier & No & NLEV LEV & 0.069 & NA & -0.0058 & 0.0000 & NA & $-8.46 \%$ & $0.00 \%$ & 0.67 & $0.0854 *$ & $<0.01 *$ & $\mathrm{NA}$ & 0.0012 & 0.0491* & $0.04^{*}$ \\
\hline & & 2000 Accord & No & NLEV LEV & 0.048 & NA & -0.011 & -0.001 & $\mathrm{NA}$ & $-22.71 \%$ & $-2.06 \%$ & 0.80 & $0.159 *$ & $0.03 *$ & $\mathrm{NA}$ & 0.073 & 0.036 & 0.28 \\
\hline & & 2000 Focus & No & NLEV LEV & 0.061 & $\mathrm{NA}$ & -0.013 & $\begin{array}{ll}-0.002 \\
\end{array}$ & $\mathrm{NA}$ & $-21.23 \%$ & $-3.27 \%$ & 0.68 & 0.015 & 0.78 & $\mathrm{NA}$ & -0.040 & 0.048 & 0.28 \\
\hline \multicolumn{19}{|c|}{$\begin{array}{l}\text { *Indicates estimate is different from zero at the } 95 \% \text { confidenc } \\
\# \text { Log-normal model was used. Results are presented as chang } \\
\text { \#\# Data did not support the assumption of linear effects with mi } \\
\text { NA="Not Applicable" } \\
+ \text { "Effects of Intermediate Ethanol Blends on Legacy Vehicles anc } \\
\text { ‡ Colors denote ethanol blend: E10, blue; E15, green; E20, red }\end{array}$} \\
\hline
\end{tabular}


Ethanol and Road Fuel Effects on NMHC - overall Effect and by LFT Strategy

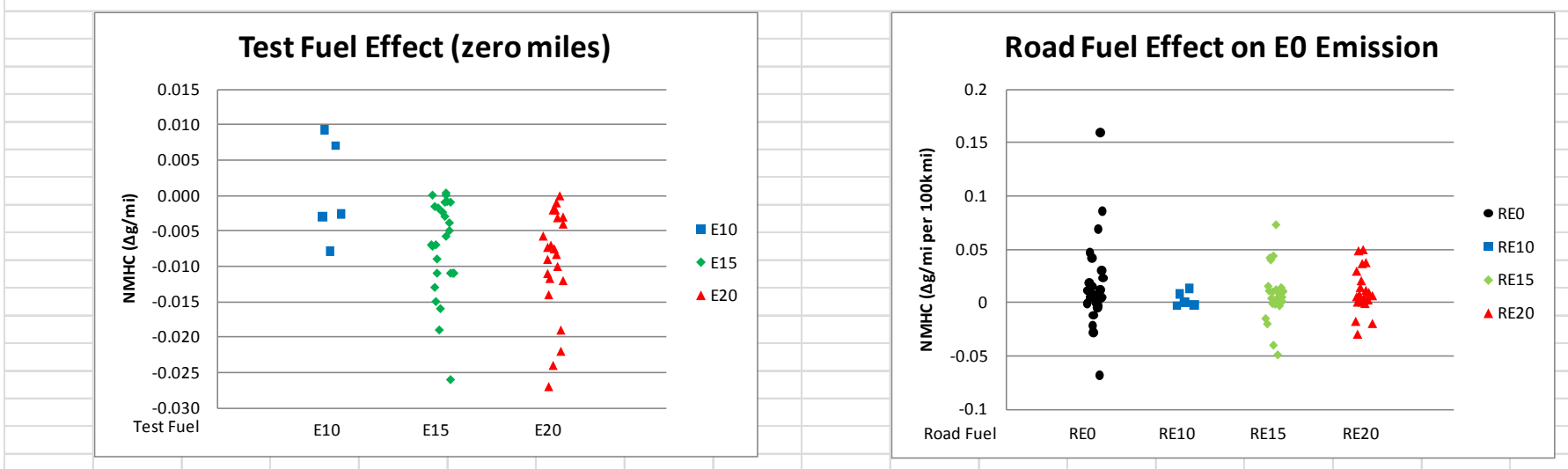

\begin{tabular}{|c|c|c|c|c|c|c|c|c|c|}
\hline \multicolumn{10}{|c|}{ P-Values } \\
\hline Test/Road Fuel & E10 & E15 & E20 & Overall & REO & RE10 & RE15 & RE20 & Overall ${ }^{b}$ \\
\hline H: Median $=0^{1}$ & 1.0000 & $<0.0001$ & $<0.0001$ & $<0.0001$ & 0.0433 & 1.0000 & 0.0290 & 0.0072 & 0.0004 \\
\hline $\mathrm{H}:$ Mean $=0^{2}$ & 0.8718 & $<0.0001$ & $<0.0001$ & $<0.0001$ & 0.0585 & 0.3515 & 0.1626 & 0.0361 & 0.0117 \\
\hline
\end{tabular}

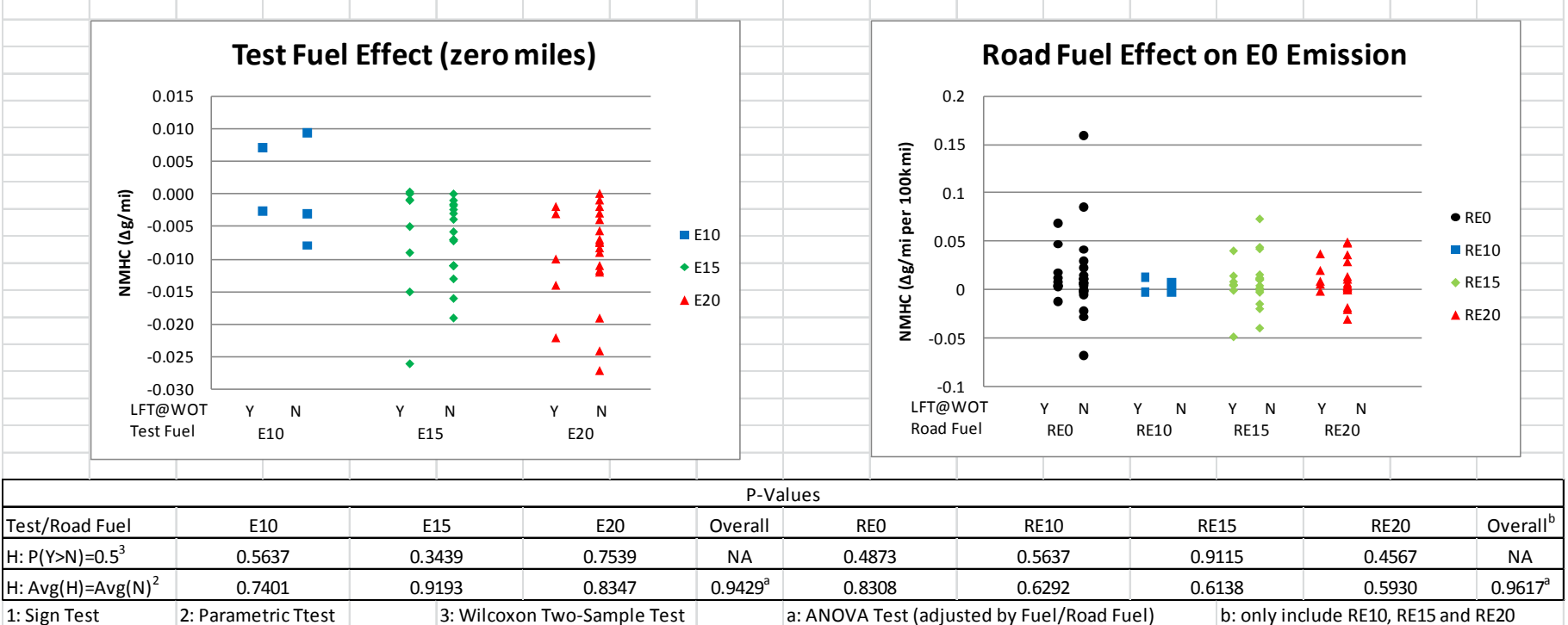

Fig. D.3. Ethanol and road fuel effects on Federal Test Procedure nonmethan hydrocarbon (NMHC) emissions. 
Table D.4. Federal Test Procedure nonmethane organic gas (NMOG) emissions by vehicle model

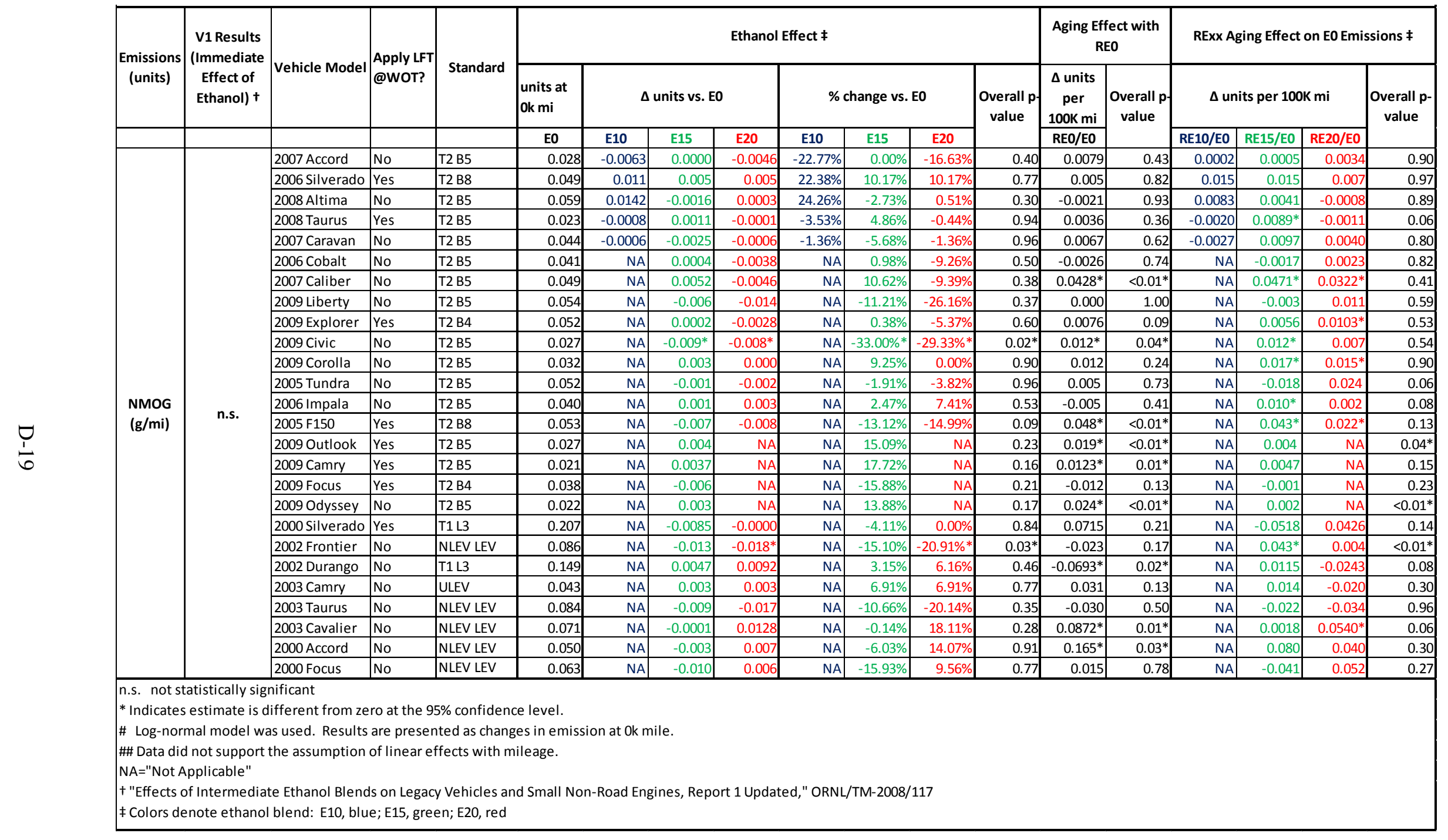




\section{Ethanol and Road Fuel Effects on NMOG - overall Effect and by LFT Strategy}
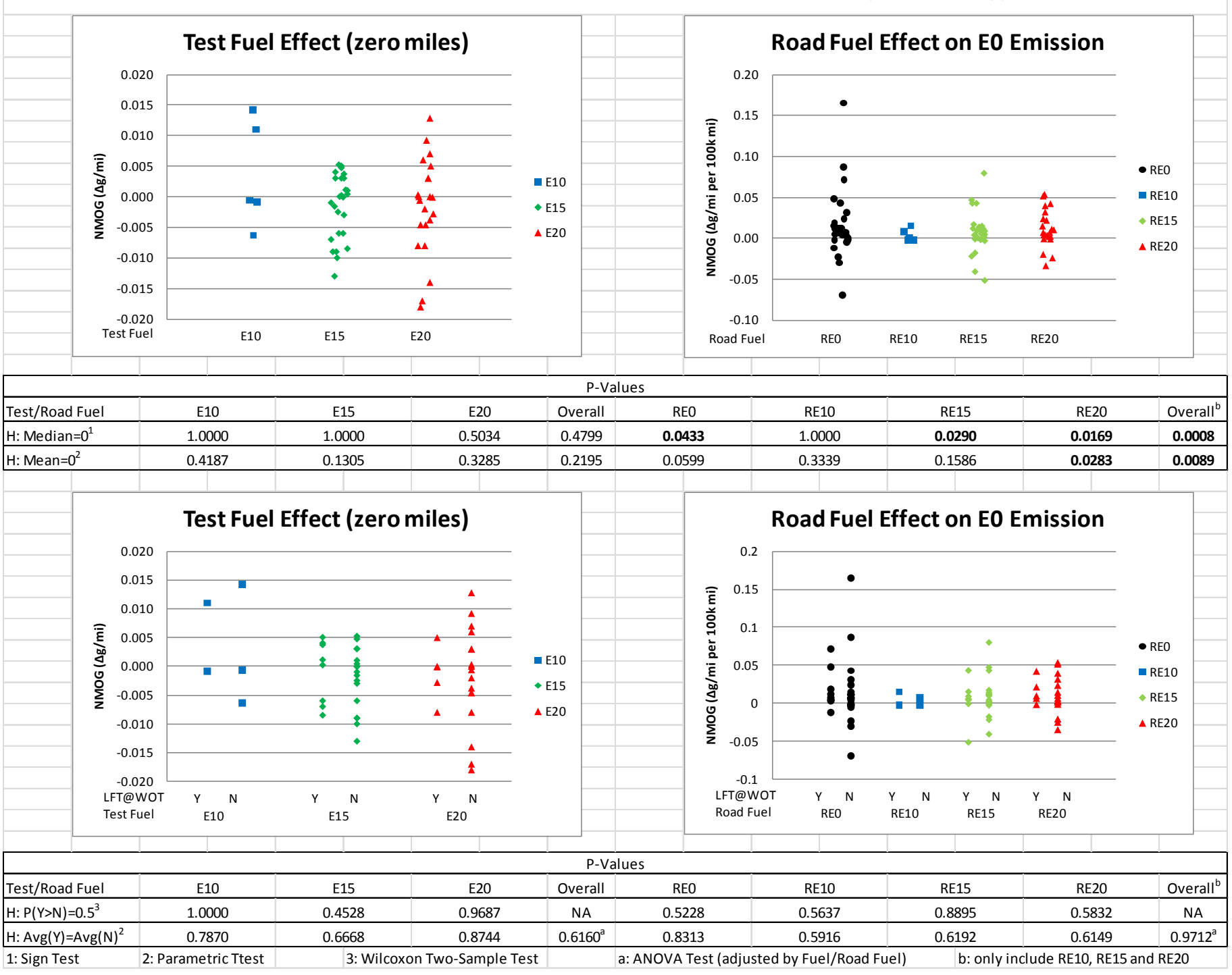

Fig. D.4. Ethanol and road fuel effects on Federal Test Procedure nonmethane organic gas (NMOG) emissions. 
Table D.5. Federal Test Procedure fuel economy by vehicle model

\begin{tabular}{|c|c|c|c|c|c|c|c|c|c|c|c|c|c|c|c|c|c|c|}
\hline \multirow{29}{*}{ 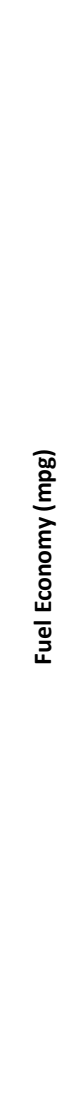 } & \multirow{3}{*}{$\begin{array}{c}\text { V1 Results } \\
\text { (Immediate } \\
\text { Effect of } \\
\text { Ethanol) † }\end{array}$} & \multirow{3}{*}{ Vehicle Model } & \multirow{3}{*}{$\mid \begin{array}{l}\text { Apply LFT } \\
\text { @WOT? }\end{array}$} & \multirow{3}{*}{ Standard } & \multicolumn{8}{|c|}{ Ethanol Effect $\ddagger$} & \multicolumn{2}{|c|}{$\begin{array}{c}\text { Aging Effect with } \\
\text { REO }\end{array}$} & \multicolumn{4}{|c|}{ RExx Aging Effect on E0 Emissions ¥ } \\
\hline & & & & & \multirow{2}{*}{ 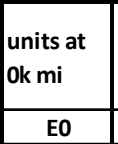 } & \multicolumn{3}{|c|}{$\Delta$ units vs. EO } & \multicolumn{3}{|c|}{$\%$ change vs. EO } & \multirow{2}{*}{$\begin{array}{c}\text { Overall } p \\
\text { value }\end{array} \mid$} & \multirow{2}{*}{\begin{tabular}{|c|}
$\begin{array}{c}\Delta \text { units } \\
\text { per } \\
100 \mathrm{~K} \mathrm{mi}\end{array}$ \\
REO/E0
\end{tabular}} & \multirow{2}{*}{$\begin{array}{c}\text { Overall } p- \\
\text { value }\end{array}$} & \multicolumn{3}{|c|}{$\Delta$ units per $100 \mathrm{~K} \mathrm{mi}$} & \multirow{2}{*}{$\begin{array}{c}\text { Overall p- } \\
\text { value }\end{array}$} \\
\hline & & & & & & E10 & E15 & E20 & E10 & E15 & E20 & & & & \begin{tabular}{|l|} 
RE10/E0 \\
\end{tabular} & RE15/E0 & RE20/E0 & \\
\hline & \multirow{26}{*}{ Decrease } & 2007 Accord & No & T2 B5 & 26.77 & -0.549 & $-0.915 *$ & $-2.046 *$ & $-2.05 \%$ & $-3.42 \% *$ & $-7.64 \% *$ & $<0.01 *$ & 1.105 & 0.11 & 0.886 & 0.431 & 0.229 & 0.59 \\
\hline & & 2006 Silverado\#\# & Yes & T2 B8 & 15.81 & $-0.580 *$ & $-0.898 *$ & $-1.157 *$ & $-3.67 \% *$ & $-5.68 \% *$ & $-7.32 \% *$ & $<0.01 *$ & 0.606 & 0.21 & 0.267 & 0.079 & 0.163 & 0.79 \\
\hline & & 2008 Altima & No & $\mathrm{T} 2 \mathrm{~B} 5$ & 28.27 & $-1.168 *$ & $-1.553 *$ & $-1.751 *$ & $-4.13 \% *$ & $-5.49 \% *$ & $-6.19 \% *$ & $<0.01 *$ & $-1.534 *$ & $0.02 *$ & -0.247 & -0.226 & -0.020 & 0.20 \\
\hline & & 2008 Taurus & Yes & T2 B5 & 20.61 & $-0.669 *$ & $-1.044 *$ & $-1.333 *$ & $-3.25 \% *$ & $-5.07 \% *$ & $-6.47 \% *$ & $<0.01 *$ & 0.421 & 0.10 & $0.529 *$ & -0.288 & 0.338 & $0.02^{*}$ \\
\hline & & 2007 Caravan & No & T2 B5 & 19.63 & $-0.790 *$ & $-1.098 *$ & $-1.336 *$ & $-4.02 \% *$ & $-5.59 \% *$ & $-6.81 \% *$ & $<0.01 *$ & -0.230 & 0.41 & -0.058 & -0.333 & $0.556 *$ & $0.03^{*}$ \\
\hline & & 2006 Cobalt & No & T2 B5 & 27.73 & $\mathrm{NA}$ & $-1.258 *$ & $-1.656 *$ & NA & $-4.54 \% *$ & $-5.97 \% *$ & $<0.01 *$ & 0.651 & 0.33 & $\mathrm{NA}$ & 0.033 & 0.390 & 0.71 \\
\hline & & 2007 Caliber & No & T2 B5 & 27.57 & $\mathrm{NA}$ & $-1.386 *$ & $-1.774 *$ & $\mathrm{NA}$ & $-5.03 \% *$ & $-6.43 \% *$ & $<0.01 *$ & $0.994 *$ & $0.04 *$ & $\mathrm{NA}$ & 0.288 & -0.131 & 0.15 \\
\hline & & 2009 Liberty & No & T2 B5 & 17.60 & $\mathrm{NA}$ & $-0.858 *$ & $-1.086 *$ & $\mathrm{NA}$ & $-4.88 \% *$ & $-6.17 \% *$ & $<0.01 *$ & 0.848 & 0.06 & $\mathrm{NA}$ & $0.787 *$ & $0.768 *$ & 0.99 \\
\hline & & 2009 Explorer & Yes & T2 B4 & 16.43 & $\mathrm{NA}$ & $-0.900 *$ & $-1.117 *$ & $\mathrm{NA}$ & $-5.48 \% *$ & $-6.80 \% *$ & $<0.01 *$ & 0.337 & 0.32 & $\mathrm{NA}$ & 0.342 & 0.385 & 0.99 \\
\hline & & 2009 Civic & No & $\mathrm{T} 2 \mathrm{~B} 5$ & 31.07 & $\mathrm{NA}$ & $-1.633^{*}$ & $-2.200 *$ & $\mathrm{NA}$ & $-5.26 \% *$ & $-7.08 \% *$ & $<0.01 *$ & 0.388 & 0.36 & $\mathrm{NA}$ & -0.095 & 0.037 & 0.63 \\
\hline & & 2009 Corolla & No & T2 B5 & 32.25 & $\mathrm{NA}$ & $-1.533^{*}$ & $-2.333^{*}$ & $\mathrm{NA}$ & $-4.75 \% *$ & $-7.23 \% *$ & $<0.01 *$ & 0.957 & 0.11 & $\mathrm{NA}$ & $0.948 *$ & $1.224 *$ & 0.85 \\
\hline & & 2005 Tundra & No & T2 B5 & 19.33 & $\mathrm{NA}$ & $-1.077^{*}$ & $-1.281 *$ & $\mathrm{NA}$ & $-5.57 \% *$ & $-6.63 \% *$ & $<0.01 *$ & -0.077 & 0.89 & $\mathrm{NA}$ & -0.275 & -0.477 & 0.83 \\
\hline & & 2006 Impala & No & T2 B5 & 21.00 & $N A$ & \begin{tabular}{|l|l|}
$-1.267 *$ \\
\end{tabular} & \begin{tabular}{|c|}
$-1.486 *$ \\
\end{tabular} & NA & $-6.03 \% *$ & $-7.08 \% *$ & $<0.01 *$ & 0.109 & 0.84 & $\mathrm{NA}$ & \begin{tabular}{l|l|}
0.439 \\
\end{tabular} & -0.108 & 0.60 \\
\hline & & 2005 F150 & Yes & T2 B8 & 14.67 & $\mathrm{NA}$ & $-0.816 *$ & $-0.983 *$ & $\mathrm{NA}$ & $-5.56 \% *$ & $-6.70 \% *$ & $<0.01 *$ & $0.565 *$ & $0.02 *$ & $\mathrm{NA}$ & $1.009 *$ & $0.438 *$ & $0.04^{*}$ \\
\hline & & 2009 Outlook & Yes & T2 B5 & 17.98 & $\mathrm{NA}$ & $-0.916^{*}$ & NA & $\mathrm{NA}$ & $-5.10 \% *$ & $\mathrm{NA}$ & $<0.01 *$ & 0.279 & 0.14 & $\mathrm{NA}$ & $0.628^{*}$ & $\mathrm{NA}$ & 0.13 \\
\hline & & 2009 Camry & Yes & T2 B5 & 27.42 & $\mathrm{NA}$ & $-1.497^{*}$ & $\mathrm{NA}$ & NA & $-5.46 \% *$ & $\mathrm{NA}$ & $<0.01 *$ & 0.113 & 0.80 & $\mathrm{NA}$ & -0.020 & $\mathrm{NA}$ & 0.81 \\
\hline & & 2009 Focus & Yes & T2 B4 & 30.68 & $\mathrm{NA}$ & $-1.350 *$ & $\mathrm{NA}$ & $\mathrm{NA}$ & $-4.40 \% *$ & $\mathrm{NA}$ & $<0.01 *$ & 1.127 & 0.10 & $\mathrm{NA}$ & 0.263 & $\mathrm{NA}$ & 0.27 \\
\hline & & 2009 Odyssey & No & $\mathrm{T} 2 \mathrm{~B} 5$ & 19.48 & $N A$ & \begin{tabular}{|l|l|}
$-0.839 *$ \\
\end{tabular} & $\mathrm{NA}$ & $\mathrm{NA}$ & $-4.31 \% *$ & $\mathrm{NA}$ & $0.03 *$ & 0.518 & 0.33 & $\mathrm{NA}$ & 0.617 & $\mathrm{NA}$ & 0.88 \\
\hline & & 2000 Silverado & Yes & T1 L3 & 14.28 & $N A$ & $-0.727 *$ & $-0.829 *$ & $\mathrm{NA}$ & $-5.09 \% *$ & $-5.81 \% *$ & $<0.01 *$ & 0.594 & 0.35 & $\mathrm{NA}$ & $1.201 *$ & 0.230 & 0.29 \\
\hline & & 2002 Frontier & No & NLEV LEV & 22.48 & $\mathrm{NA}$ & -0.074* & $\mid-1.569 *$ & NA & $-0.33 \% *$ & $-6.98 \% *$ & $<0.01 *$ & $0.953 *$ & $0.02 *$ & $\mathrm{NA}$ & -0.119 & $0.990 *$ & $0.01^{*}$ \\
\hline & & 2002 Durango & No & T1 L3 & 15.69 & $\mathrm{NA}$ & $-0.809 *$ & -0.872* & NA & $-5.16 \% *$ & $-5.56 \% *$ & $<0.01 *$ & 0.673 & 0.06 & $\mathrm{NA}$ & 0.485 & $0.739 *$ & 0.71 \\
\hline & & 2003 Camry & No & ULEV & 25.97 & $N A$ & $-1.350 *$ & $-1.650 *$ & $\mathrm{NA}$ & $-5.20 \% *$ & $-6.35 \% *$ & $<0.01 *$ & 0.699 & 0.55 & $\mathrm{NA}$ & 1.376 & $4.029 *$ & 0.27 \\
\hline & & 2003 Taurus & No & NLEV LEV & 21.75 & $N A$ & $-1.116 *$ & $-1.349 *$ & $\mathrm{NA}$ & $-5.13 \% *$ & $-6.20 \% *$ & $<0.01 *$ & $1.385 *$ & $<0.01 *$ & $\mathrm{NA}$ & $0.646 *$ & 1.491* & 0.06 \\
\hline & & 2003 Cavalier & No & NLEV LEV & 24.23 & $\mathrm{NA}$ & $-1.476 *$ & $-1.466 *$ & $\mathrm{NA}$ & $-6.09 \% *$ & $-6.05 \% *$ & $<0.01 *$ & $-2.320 *$ & $<0.01 *$ & $\mathrm{NA}$ & $1.613 *$ & 0.694 & $<0.01^{*}$ \\
\hline & & 2000 Accord & No & NLEV LEV & 26.98 & $\mathrm{NA}$ & $-1.201 *$ & $-1.740 *$ & $\mathrm{NA}$ & $-4.45 \% *$ & $-6.45 \% *$ & $<0.01 *$ & 0.043 & 0.96 & $\mathrm{NA}$ & -0.208 & 0.105 & 0.91 \\
\hline & & 2000 Focus & No & NLEV LEV & 27.87| & $\mathrm{NA}$ & $-0.752 *$ & $-1.753 *$ & $\mathrm{NA}$ & $-2.70 \% *$ & $-6.29 \% *$ & $<0.01 *$ & $-1.494 *$ & $0.05 *$ & $\mathrm{NA}$ & -0.992 & 0.198 & 0.11 \\
\hline \multicolumn{19}{|c|}{$\begin{array}{l}\text { * Indicates estimate is different from zero at the } 95 \% \text { confidence } \\
\text { \# Log-normal model was used. Results are presented as changes } \\
\text { \#\# Data did not support the assumption of linear effects with mile } \\
\text { NA="Not Applicable" } \\
\text { + "Effects of Intermediate Ethanol Blends on Legacy Vehicles and } \\
\text { \# Colors denote ethanol blend: E10, blue; E15, green; E20, red }\end{array}$} \\
\hline
\end{tabular}



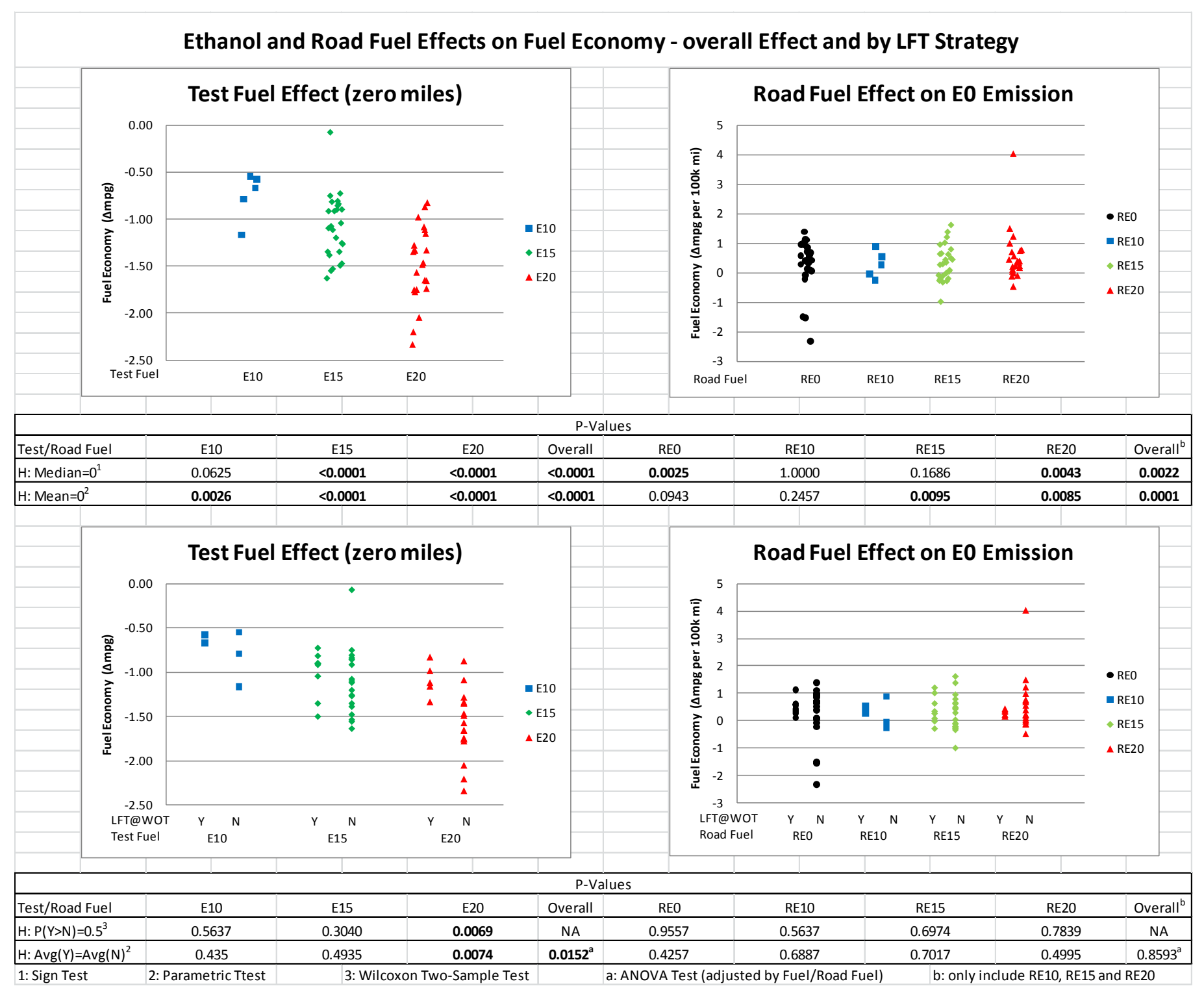

Fig. D.5. Ethanol and road fuel effects on Federal Test Procedure fuel economy. 
Table D.6. Federal Test Procedure ethanol emissions by vehicle model

\begin{tabular}{|c|c|c|c|c|c|c|c|c|c|c|c|c|c|c|c|c|c|c|}
\hline \multirow{3}{*}{$\mid \begin{array}{c}\text { Emissions } \\
\text { (units) }\end{array}$} & \multirow{3}{*}{$\begin{array}{c}\text { V1 Results } \\
\text { (Immediate } \\
\text { Effect of } \\
\text { Ethanol) }+\end{array}$} & \multirow{3}{*}{ Vehicle Model } & \multirow{3}{*}{$\begin{array}{l}\text { Apply LFT } \\
\text { @WOT? }\end{array}$} & \multirow{3}{*}{ Standard } & \multicolumn{8}{|c|}{ Ethanol Effect $¥$} & \multicolumn{2}{|c|}{$\begin{array}{c}\text { Aging Effect with } \\
\text { REO }\end{array}$} & \multicolumn{4}{|c|}{ RExx Aging Effect on EO Emissions ¥ } \\
\hline & & & & & \multirow{2}{*}{\begin{tabular}{|c|}
$\begin{array}{l}\text { units at } \\
0 \mathrm{k} \mathrm{mi}\end{array}$ \\
E0
\end{tabular}} & \multicolumn{3}{|c|}{$\Delta$ units vs. EO } & \multicolumn{3}{|c|}{$\%$ change vs. EO } & \multirow{2}{*}{$\begin{array}{c}\text { Overall } p- \\
\text { value }\end{array}$} & \multirow{2}{*}{\begin{tabular}{|c|}
$\begin{array}{c}\Delta \text { units } \\
\text { per } \\
100 \mathrm{~K} \mathrm{mi}\end{array}$ \\
RE0/E0 \\
\end{tabular}} & \multirow{2}{*}{$\begin{array}{c}\text { Overall } p \\
\text { value }\end{array}$} & \multicolumn{3}{|c|}{$\Delta$ units per $100 \mathrm{~K} \mathrm{mi}$} & \multirow{2}{*}{$\begin{array}{l}\text { Overall p- } \\
\text { value }\end{array}$} \\
\hline & & & & & & E10 & E15 & E20 & E10 & E15 & E20 & & & & RE10/E0 & \begin{tabular}{|l|} 
RE15/E0 \\
\end{tabular} & RE20/E0 & \\
\hline \multirow{10}{*}{$\begin{array}{l}\text { Ethanol } \\
(\mathrm{mg} / \mathrm{mi})\end{array}$} & \multirow{10}{*}{ Increase } & 2007 Accord\#\# & No & T2 B5 & 0.097 & $0.656 *$ & $0.901 *$ & $1.445 *$ & $674 \% *$ & $926 \% *$ & 1485\%* & $<0.01^{*}$ & 0.033 & 0.92 & 0.098 & -0.163 & 0.095 & 0.81 \\
\hline & & 2006 Silverado\#\# & Yes & $\mathrm{T} 2 \mathrm{~B} 8$ & 0.167 & $2.349 *$ & $3.499 *$ & $4.366 *$ & $1404 \% *$ & $2092 \% *$ & $2610 \% *$ & $<0.01^{*}$ & -0.058 & 0.97 & 0.732 & 0.505 & 0.418 & 0.97 \\
\hline & & 2008 Altima\#\# & No & $\mathrm{T} 2 \mathrm{~B} 5$ & 0.016 & $2.335 *$ & $3.328 *$ & $4.369 *$ & \begin{tabular}{|l|}
$14751 \% *$ \\
\end{tabular} & $21024 \% *$ & $27600 \% *$ & $<0.01 *$ & 0.318 & 0.72 & 0.230 & 1.131 & 1.076 & 0.68 \\
\hline & & 2008 Taurus\#\# & Yes & $\mathrm{T} 2 \mathrm{~B} 5$ & 0.098 & 1.185 & 1.463 & $3.593 *$ & $1211 \%$ & $1496 \%$ & $3673 \% *$ & $<0.01^{*}$ & \begin{tabular}{|c|c|}
-0.037 \\
\end{tabular} & 0.97 & \begin{tabular}{|c|}
-0.608 \\
\end{tabular} & 0.065 & -0.018 & 0.92 \\
\hline & & 2007 Caravan\#\# & No & $\mathrm{T} 2 \mathrm{~B} 5$ & 0.264 & $2.743 *$ & $3.602 *$ & $6.241 *$ & $1038 \% *$ & $1363 \% *$ & $2361 \% *$ & $<0.01 *$ & -0.235 & 0.92 & 1.312 & -0.486 & 1.292 & 0.81 \\
\hline & & 2006 Cobalt\#\# & No & T2 B5 & \begin{tabular}{l|l}
0.070 \\
\end{tabular} & $\mathrm{NA}$ & $3.204 *$ & $4.915 *$ & $\mathrm{NA}$ & $4551 \% *$ & 6981\%* & $0.01 *$ & 0.046 & 0.99 & $\mathrm{NA}$ & 0.068 & -1.420 & 0.86 \\
\hline & & 2007 Caliber\#\# & No & $\mathrm{T} 2 \mathrm{~B} 5$ & 0.034 & $\mathrm{NA}$ & $3.888 *$ & $4.307 *$ & $\mathrm{NA}$ & $11370 \% *$ & $12600 \% *$ & $<0.01^{*}$ & -0.056 & 0.97 & $\mathrm{NA}$ & -0.100 & 2.298 & 0.30 \\
\hline & & 2000 Silverado\#\# & Yes & T1 L3 & 0.000 & $\mathrm{NA}$ & $10.453 *$ & 14.629* & $\mathrm{NA}$ & $\mathrm{NA}$ & $\mathrm{NA}$ & $<0.01 *$ & -0.000 & 1.00 & $\mathrm{NA}$ & 2.003 & 4.930 & 0.76 \\
\hline & & 2002 Frontier\#\# & No & NLEV LEV & 0.114 & $\mathrm{NA}$ & $5.237 *$ & $6.422 *$ & $\mathrm{NA}$ & $4575 \% *$ & $5610 \% *$ & $<0.01 *$ & -0.220 & 0.89 & $\mathrm{NA}$ & 0.528 & 0.155 & 0.92 \\
\hline & & 2002 Durango\#\# & No & T1 L3 & 0.366 & $\mathrm{NA}$ & 9.733* & $11.046 *$ & $\mathrm{NA}$ & $2663 \% *$ & $3022 \% *$ & $<0.01 *$ & -0.299 & 0.88 & $\mathrm{NA}$ & 1.100 & 0.142 & 0.77 \\
\hline \multicolumn{19}{|c|}{$\begin{array}{l}\text { *Indicates estimate is different from zero at the } 95 \% \text { confidence } \\
\text { \# Log-normal model was used. Results are presented as change } \\
\text { \#\# Data did not support the assumption of linear effects with mil } \\
\text { NA="Not Applicable" } \\
\text { † "Effects of Intermediate Ethanol Blends on Legacy Vehicles and } \\
\text { \# Colors denote ethanol blend: E10, blue; E15, green; E20, red }\end{array}$} \\
\hline
\end{tabular}


Ethanol and Road Fuel Effects on Ethanol - overall Effect and by LFT Strategy
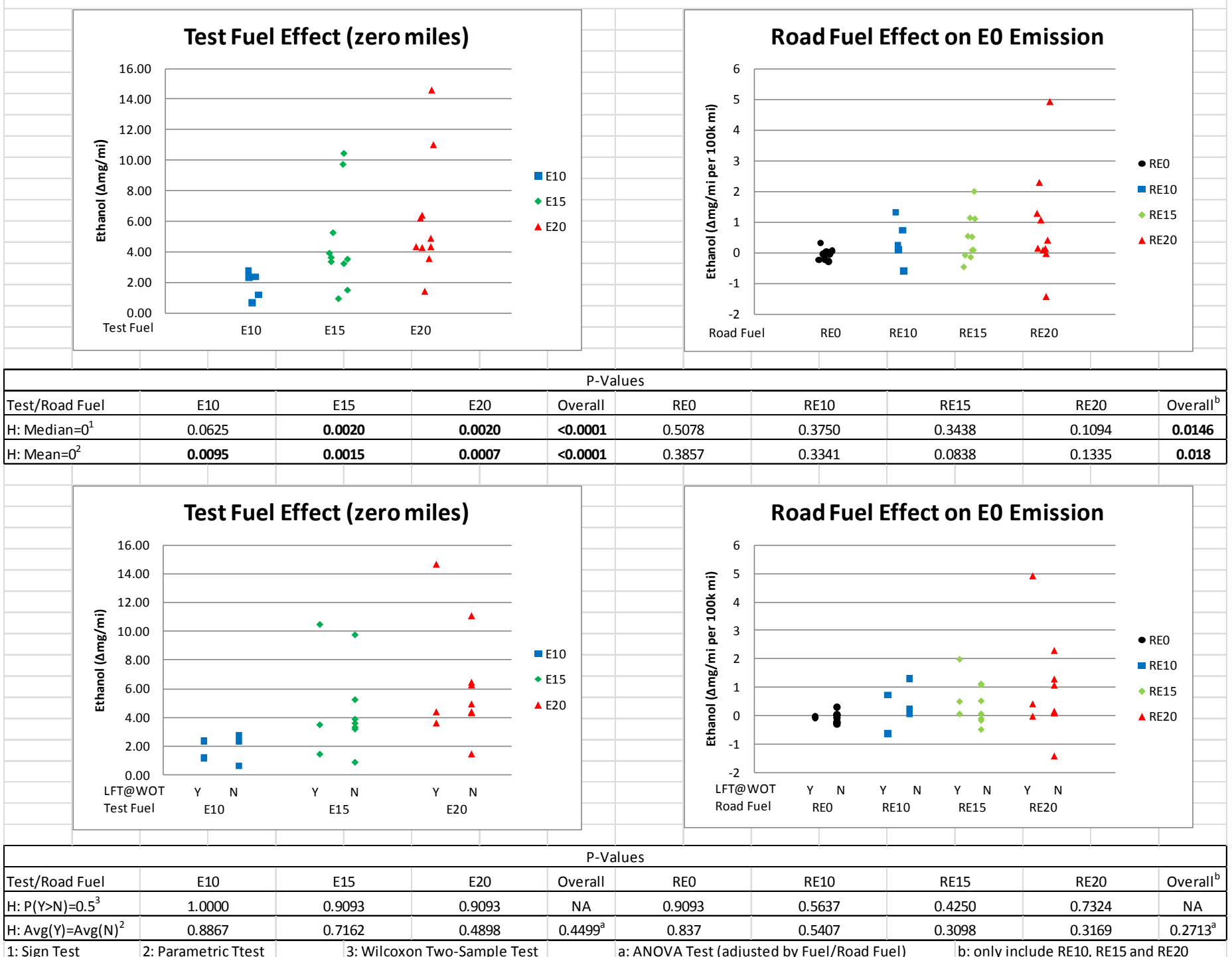

Fig. D.6. Ethanol and road fuel effects on Federal Test Procedure ethanol emissions. 
Table D.7. Federal Test Procedure acetaldehyde emissions by vehicle model

\begin{tabular}{|c|c|c|c|c|c|c|c|c|c|c|c|c|c|c|c|c|c|c|}
\hline \multirow{3}{*}{$\mid \begin{array}{c}\text { Emissions } \\
\text { (units) }\end{array}$} & \multirow{3}{*}{$\begin{array}{c}\text { V1 Results } \\
\text { (Immediate } \\
\text { Effect of } \\
\text { Ethanol) }+\end{array}$} & \multirow{3}{*}{ Vehicle Model } & \multirow{3}{*}{$\mid \begin{array}{l}\text { Apply LFT } \\
\text { @WOT? }\end{array}$} & \multirow{3}{*}{ Standard } & \multicolumn{8}{|c|}{ Ethanol Effect $¥$} & \multicolumn{2}{|c|}{$\begin{array}{c}\text { Aging Effect with } \\
\text { REO }\end{array}$} & \multicolumn{4}{|c|}{ RExx Aging Effect on E0 Emissions \# } \\
\hline & & & & & \multirow{2}{*}{\begin{tabular}{|r|}
$\begin{array}{l}\text { units at } \\
\text { Ok mi }\end{array}$ \\
E0 \\
\end{tabular}} & \multicolumn{3}{|c|}{$\Delta$ units vs. EO } & \multicolumn{3}{|c|}{ \% change vs. EO } & \multirow{2}{*}{$\begin{array}{c}\text { Overall } p \\
\text { value }\end{array}$} & \multirow{2}{*}{\begin{tabular}{|c|}
$\begin{array}{c}\Delta \text { units } \\
\text { per } \\
100 \mathrm{~K} \mathrm{mi}\end{array}$ \\
REO/EO \\
\end{tabular}} & \multirow{2}{*}{$\begin{array}{c}\text { Overall } p \\
\text { value }\end{array}$} & \multicolumn{3}{|c|}{$\Delta$ units per $100 \mathrm{~K} \mathrm{mi}$} & \multirow{2}{*}{$\begin{array}{c}\text { Overall p- } \\
\text { value }\end{array}$} \\
\hline & & & & & & E10 & E15 & E20 & E10 & E15 & E20 & & & & \begin{tabular}{|l|} 
RE10/E0 \\
\end{tabular} & RE15/E0 & RE20/E0 & \\
\hline \multirow{20}{*}{ 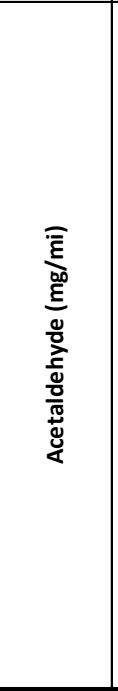 } & \multirow{20}{*}{ Increase } & 2007 Accord \#\# & No & T2 B5 & 0.126 & $0.215 *$ & $0.497 *$ & $0.610^{*}$ & $171 \% *$ & $394 \% *$ & $484 \% *$ & $<0.01 *$ & 0.145 & 0.28 & 0.058 & 0.146 & $0.249 *$ & 0.52 \\
\hline & & 2006 Silverado \# & Yes & T2 B8 & 0.224 & $0.468 *$ & $0.857 *$ & $0.997 *$ & $209 \% *$ & $382 \% *$ & $444 \% *$ & $<0.01 *$ & $0.124 *$ & $0.02 *$ & $0.184 *$ & $0.119 *$ & $0.109 *$ & 0.59 \\
\hline & & 2008 Altima\# & No & T2 B5 & 0.194 & $0.409 *$ & $0.656 *$ & $0.901 *$ & $211 \% *$ & $339 \% *$ & $465 \% *$ & $<0.01 *$ & $0.151 *$ & $0.02 *$ & $0.083 *$ & 0.058 & 0.055 & 0.62 \\
\hline & & 2008 Taurus\# & Yes & T2 B5 & 0.087 & $0.296 *$ & $0.366 *$ & $0.696 *$ & $340 \% *$ & $420 \% *$ & $799 \% *$ & $<0.01 *$ & $0.087^{*}$ & $<0.01 *$ & 0.026 & 0.029 & 0.022 & 0.18 \\
\hline & & 2007 Caravan\# & No & T2 B5 & 0.212 & $0.521 *$ & $0.718 *$ & 1.293* & $246 \% *$ & $339 \% *$ & $610 \% *$ & $<0.01 *$ & 0.023 & 0.79 & 0.023 & 0.059 & -0.020 & 0.88 \\
\hline & & 2006 Cobalt\#\# & No & T2 B5 & 0.099 & $\mathrm{NA}$ & 0.490 & $1.140 *$ & $\mathrm{NA}$ & $496 \%$ & $1153 \% *$ & $0.04 *$ & 0.059 & 0.94 & $\mathrm{NA}$ & 0.072 & 0.013 & 1.00 \\
\hline & & 2007 Caliber\# & No & T2 B5 & 0.233 & $\mathrm{NA}$ & $0.820 *$ & 1.111* & $\mathrm{NA}$ & $352 \% *$ & $477 \% *$ & $<0.01 *$ & 0.155 & 0.12 & $\mathrm{NA}$ & $0.201 *$ & $0.152 *$ & 0.85 \\
\hline & & 2009 Liberty\# & No & T2 B5 & 0.237 & $\mathrm{NA}$ & $0.586 *$ & $0.664 *$ & $\mathrm{NA}$ & $247 \% *$ & $280 \% *$ & $<0.01 *$ & 0.018 & 0.73 & $\mathrm{NA}$ & -0.042 & -0.022 & 0.67 \\
\hline & & 2009 Explorer\# & Yes & T2 B4 & 0.243 & $\mathrm{NA}$ & $0.613^{*}$ & $0.871 *$ & $\mathrm{NA}$ & $252 \% *$ & $358 \% *$ & $<0.01 *$ & 0.018 & 0.80 & $\mathrm{NA}$ & -0.033 & -0.034 & 0.81 \\
\hline & & 2009 Civic\# & No & T2 B5 & 0.137 & NA & $0.239 *$ & $0.468^{*}$ & NA & $175 \% *$ & $342 \% *$ & $<0.01 *$ & 0.077 & 0.12 & $\mathrm{NA}$ & 0.063 & 0.020 & 0.51 \\
\hline & & 2009 Corolla\# & No & T2 B5 & 0.175 & $\mathrm{NA}$ & $0.511^{*}$ & $0.556^{*}$ & $\mathrm{NA}$ & $292 \% *$ & $318 \% *$ & $<0.01 *$ & 0.073 & 0.34 & $\mathrm{NA}$ & 0.060 & 0.062 & 0.97 \\
\hline & & 2005 Tundra\# & No & T2 B5 & 0.252 & $\mathrm{NA}$ & $0.748^{*}$ & $0.984^{*}$ & $\mathrm{NA}$ & $297 \% *$ & $390 \% *$ & $<0.01 *$ & -0.053 & 0.40 & $\mathrm{NA}$ & $-0.105^{*}$ & -0.044 & 0.54 \\
\hline & & 2006 Impala\# & No & T2 B5 & 0.287 & $\mathrm{NA}$ & $0.453^{*}$ & $0.928^{*}$ & $\mathrm{NA}$ & $158 \% *$ & $324 \% *$ & $<0.01 *$ & -0.040 & 0.60 & $\mathrm{NA}$ & -0.089 & -0.079 & 0.87 \\
\hline & & 2005 F150\# & Yes & T2 B8 & 0.195 & $\mathrm{NA}$ & $0.655 *$ & $0.603 *$ & $N A$ & $336 \% *$ & $309 \% *$ & $<0.01 *$ & -0.016 & 0.73 & $\mathrm{NA}$ & 0.037 & -0.042 & 0.30 \\
\hline & & 2000 Silverado\# & Yes & $\mathrm{T} 1 \mathrm{~L} 3$ & 1.019 & $\mathrm{NA}$ & $2.967 *$ & $3.356 *$ & $\mathrm{NA}$ & $291 \% *$ & $329 \% *$ & $<0.01 *$ & 1.489 & 0.27 & $\mathrm{NA}$ & -0.013 & -0.058 & 0.55 \\
\hline & & 2002 Frontier\# & No & NLEV LEV & 0.230 & $\mathrm{NA}$ & $0.638 *$ & $1.108 *$ & $\mathrm{NA}$ & $278 \% *$ & $483 \% *$ & $<0.01 *$ & 0.000 & 1.00 & $\mathrm{NA}$ & 0.152 & 0.156 & 0.70 \\
\hline & & 2002 Durango\# & No & T1 L3 & 0.777 & $\mathrm{NA}$ & 1.895* & $2.334 *$ & $\mathrm{NA}$ & $244 \% *$ & $300 \% *$ & $<0.01 *$ & -0.096 & 0.32 & $\mathrm{NA}$ & $0.200 *$ & $0.198 *$ & 0.11 \\
\hline & & 2003 Camry\# & No & ULEV & 0.253 & $\mathrm{NA}$ & $0.428 *$ & $0.096 *$ & $\mathrm{NA}$ & $169 \% *$ & $37.9 \% *$ & $<0.01 *$ & -0.054 & 0.73 & $\mathrm{NA}$ & -0.001 & -0.237 & 0.56 \\
\hline & & 2003 Taurus & No & NLEV LEV & 0.268 & $\mathrm{NA}$ & $0.680 *$ & 1.114* & $\mathrm{NA}$ & $253 \% *$ & $415 \% *$ & $<0.01 *$ & 0.051 & 0.63 & $\mathrm{NA}$ & 0.041 & $-0.104 *$ & 0.20 \\
\hline & & 2003 Cavalier\# & No & NLEV LEV & 0.273 & $\mathrm{NA}$ & $0.414 *$ & $0.592 *$ & $\mathrm{NA}$ & $151 \% *$ & $217 \% *$ & $<0.01 *$ & 0.257 & 0.15 & $\mathrm{NA}$ & -0.066 & $0.376 *$ & $0.04^{*}$ \\
\hline \multicolumn{19}{|c|}{$\begin{array}{l}\text { * Indicates estimate is different from zero at the } 95 \% \text { confidence } \\
\text { \# Log-normal model was used. Results are presented as changes } \\
\text { \# Data did not support the assumption of linear effects with mil } \\
\text { NA="Not Applicable" } \\
+ \text { "Effects of Intermediate Ethanol Blends on Legacy Vehicles and } \\
\text { ‡ Colors denote ethanol blend: E10, blue; E15, green; E20, red }\end{array}$} \\
\hline
\end{tabular}



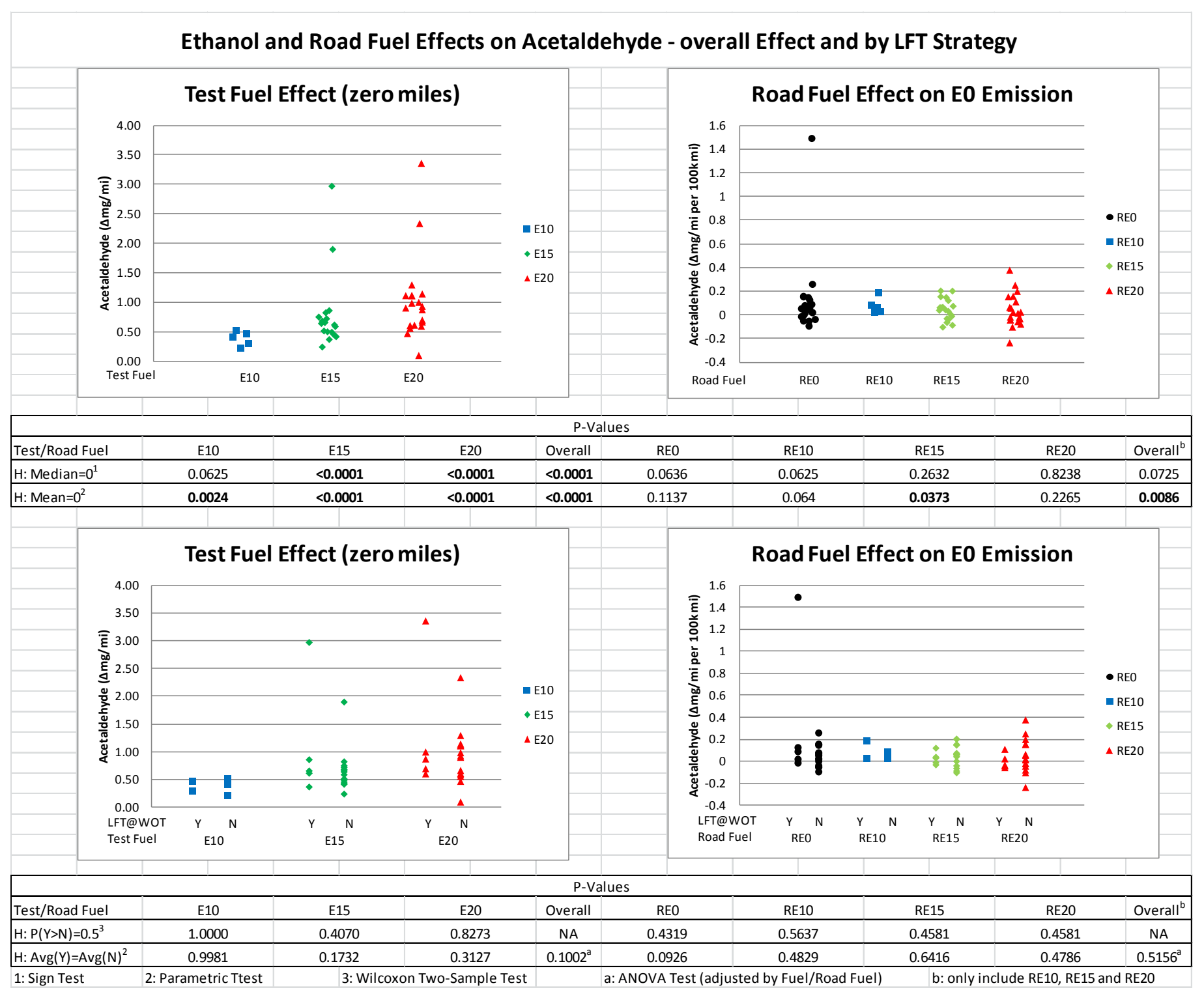

Fig. D.7. Ethanol and road fuel effects on Federal Test Procedure acetaldehyde emissions. 
Table D.8. Federal Test Procedure formaldehyde emissions by vehicle model

\begin{tabular}{|c|c|c|c|c|c|c|c|c|c|c|c|c|c|c|c|c|c|c|}
\hline \multirow{3}{*}{$\begin{array}{c}\text { Emissions } \\
\text { (units) }\end{array}$} & \multirow{3}{*}{$\begin{array}{l}\text { V1 Results } \\
\text { (Immediate } \\
\text { Effect of } \\
\text { Ethanol) }+\end{array}$} & \multirow{3}{*}{ Vehicle Model } & \multirow{3}{*}{$\mid \begin{array}{l}\text { Apply LFT } \\
@ \text { @OT? }\end{array}$} & \multirow{3}{*}{ Standard } & \multicolumn{8}{|c|}{ Ethanol Effect $¥$} & \multicolumn{2}{|c|}{$\begin{array}{c}\text { Aging Effect with } \\
\text { REO }\end{array}$} & \multicolumn{4}{|c|}{ RExx Aging Effect on EO Emissions \# } \\
\hline & & & & & \multirow{2}{*}{\begin{tabular}{|c}
$\begin{array}{l}\text { units at } \\
\text { Ok mi }\end{array}$ \\
EO
\end{tabular}} & \multicolumn{3}{|c|}{$\Delta$ units vs. EO } & \multicolumn{3}{|c|}{ \% change vs. EO } & \multirow{2}{*}{$\left|\begin{array}{c}\text { Overall } p \\
\text { value }\end{array}\right|$} & \multirow{2}{*}{\begin{tabular}{|c|}
$\begin{array}{c}\Delta \text { units } \\
\text { per } \\
100 \mathrm{~K} \mathrm{mi}\end{array}$ \\
REO/EO \\
\end{tabular}} & \multirow{2}{*}{$\begin{array}{c}\text { Overall } p \\
\text { value }\end{array}$} & \multicolumn{3}{|c|}{$\Delta$ units per $100 \mathrm{~K} \mathrm{mi}$} & \multirow{2}{*}{$\begin{array}{c}\text { Overall } p \\
\text { value }\end{array}$} \\
\hline & & & & & & E10 & E15 & E20 & E10 & E15 & E20 & & & & \begin{tabular}{|l|} 
RE10/E0 \\
\end{tabular} & \begin{tabular}{|l|} 
RE15/E0 \\
\end{tabular} & RE20/E0 & \\
\hline \multirow{20}{*}{ 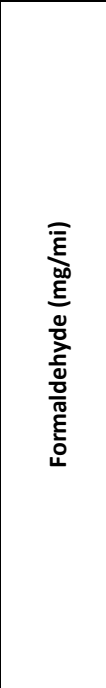 } & \multirow{20}{*}{ Increase } & 2007 Accord\# & No & T2 B5 & 0.430 & 0.084 & $0.521 *$ & $0.473 *$ & $19.55 \%$ & $121 \% *$ & $110 \% *$ & $<0.01 *$ & 0.761 & 0.20 & 0.360 & $1.033 *$ & $1.307 *$ & 0.07 \\
\hline & & 2006 Silverado\# & Yes & T2 B8 & 1.169 & 0.025 & \begin{tabular}{|c|c|}
-0.059 \\
\end{tabular} & 0.064 & $2.14 \%$ & $-5.05 \%$ & $5.47 \%$ & 0.80 & $0.432 *$ & $0.02 *$ & $0.756 *$ & $0.425 *$ & $0.710 *$ & 0.21 \\
\hline & & 2008 Altima\# & No & T2 B5 & 0.488 & -0.006 & \begin{tabular}{|c|c|}
-0.076 \\
\end{tabular} & \begin{tabular}{|c|c|}
-0.008 \\
\end{tabular} & $-1.23 \%$ & $\begin{array}{l}-15.56 \% \\
\end{array}$ & $-1.64 \%$ & 0.63 & 0.002 & 0.99 & $0.341 *$ & $0.254 *$ & $0.282 *$ & 0.25 \\
\hline & & 2008 Taurus\# & Yes & T2 B5 & 0.199 & 0.007 & -0.003 & 0.014 & $3.52 \%$ & $-1.51 \%$ & $7.05 \%$ & 0.94 & $0.257 *$ & $<0.01 *$ & $0.219 *$ & $0.167 *$ & $0.171 *$ & 0.65 \\
\hline & & 2007 Caravan\# & No & T2 B5 & 0.643 & 0.025 & -0.094 & 0.125 & $3.89 \%$ & $-14.63 \%$ & $19.45 \%$ & 0.80 & 0.246 & 0.56 & 0.335 & 0.693 & 0.161 & 0.80 \\
\hline & & 2006 Cobalt\# & No & T2 B5 & 0.226 & NA & -0.143 & 0.018 & $\mathrm{NA}$ & $-63.38 \%$ & $7.98 \%$ & 0.72 & 0.476 & 0.40 & $\mathrm{NA}$ & 0.496 & 0.411 & 0.98 \\
\hline & & 2007 Caliber\# & No & T2 B5 & 0.637 & NA & 0.086 & 0.151 & $\mathrm{NA}$ & $13.50 \%$ & $23.70 \%$ & 0.17 & 0.530 & 0.15 & $\mathrm{NA}$ & $0.520 *$ & $0.433 *$ & 0.98 \\
\hline & & 2009 Liberty\# & No & T2 B5 & 0.454 & NA & 0.061 & 0.035 & $\mathrm{NA}$ & $13.43 \%$ & $7.70 \%$ & 0.96 & 0.092 & 0.79 & $\mathrm{NA}$ & -0.022 & 0.154 & 0.90 \\
\hline & & 2009 Explorer\# & Yes & T2 B4 & 0.485 & $\mathrm{NA}$ & 0.090 & 0.095 & $\mathrm{NA}$ & $18.56 \%$ & $19.59 \%$ & 0.09 & $0.231 *$ & $0.03 *$ & $\mathrm{NA}$ & $0.226 *$ & $0.234 *$ & 0.98 \\
\hline & & 2009 Civic\# & No & T2 B5 & 0.282 & NA & 0.091 & 0.049 & NA & $32.31 \%$ & $17.40 \%$ & 0.69 & 0.263 & 0.24 & NA & 0.197 & 0.241 & 0.96 \\
\hline & & 2009 Corolla\# & No & $\mathrm{T} 2 \mathrm{~B} 5$ & 0.233 & $\mathrm{NA}$ & 0.101 & 0.094 & $\mathrm{NA}$ & $43.29 \%$ & $40.29 \%$ & 0.74 & 0.181 & 0.56 & $\mathrm{NA}$ & 0.086 & 0.050 & 0.94 \\
\hline & & 2005 Tundra\#\# & No & $\mathrm{T} 2 \mathrm{~B} 5$ & 0.314 & $\mathrm{NA}$ & $0.133 *$ & $0.144 *$ & $\mathrm{NA}$ & $42.36 \% *$ & $45.86 \% *$ & $<0.01 *$ & $0.170 *$ & $0.05 *$ & $\mathrm{NA}$ & \begin{tabular}{|c|}
-0.119 \\
\end{tabular} & 0.093 & $0.01^{*}$ \\
\hline & & 2006 Impala\# & No & T2 B5 & 0.648 & $\mathrm{NA}$ & \begin{tabular}{|l|l|}
-0.163 \\
\end{tabular} & 0.201 & $\mathrm{NA}$ & $\begin{array}{l}-25.14 \% \\
\end{array}$ & $31.00 \%$ & 0.40 & -0.165 & 0.55 & $\mathrm{NA}$ & -0.316 & -0.219 & 0.95 \\
\hline & & 2005 F150\# & Yes & T2 B8 & 0.662 & NA & -0.127 & 0.015 & $\mathrm{NA}$ & $-19.19 \%$ & $2.27 \%$ & 0.65 & -0.187 & 0.39 & $\mathrm{NA}$ & -0.154 & $-0.348 *$ & 0.46 \\
\hline & & 2000 Silverado\#\# & Yes & T1 L3 & 3.691 & $\mathrm{NA}$ & 0.324 & 0.566 & $\mathrm{NA}$ & $8.78 \%$ & $15.33 \%$ & 0.18 & $4.363 *$ & $<0.01 *$ & NA & 0.414 & $\mid-0.391$ & $0.02^{*}$ \\
\hline & & 2002 Frontier\# & No & NLEV LEV & 0.618 & NA & 0.035 & 0.166 & $\mathrm{NA}$ & $5.67 \%$ & $26.87 \%$ & 0.43 & 0.236 & 0.51 & $\mathrm{NA}$ & 0.455 & 0.361 & 0.96 \\
\hline & & 2002 Durango\# & No & T1 L3 & 2.198 & $\mathrm{NA}$ & 0.071 & 0.322 & $\mathrm{NA}$ & $3.23 \%$ & $14.65 \%$ & $0.03 *$ & $0.961 *$ & $<0.01 *$ & $\mathrm{NA}$ & $1.811 *$ & $1.641 *$ & 0.45 \\
\hline & & 2003 Camry\# & No & ULEV & 0.692 & $\mathrm{NA}$ & 0.125 & 0.193 & $\mathrm{NA}$ & $18.07 \%$ & $27.90 \%$ & 0.56 & -0.305 & 0.54 & $\mathrm{NA}$ & -0.105 & $-0.815 *$ & 0.33 \\
\hline & & 2003 Taurus & No & NLEV LEV & 0.847 & $\mathrm{NA}$ & 0.236 & 0.166 & $\mathrm{NA}$ & $27.87 \%$ & $19.61 \%$ & 0.15 & -0.252 & 0.51 & $\mathrm{NA}$ & \begin{tabular}{|c|c|}
-0.299 \\
\end{tabular} & $-0.498 *$ & 0.61 \\
\hline & & 2003 Cavalier\# & No & NLEV LEV & 0.745 & $\mathrm{NA}$ & 0.034 & 0.191 & $\mathrm{NA}$ & $4.56 \%$ & $25.64 \%$ & 0.15 & 0.619 & 0.26 & $\mathrm{NA}$ & $-0.546 *$ & 0.161 & $0.04^{*}$ \\
\hline \multicolumn{19}{|c|}{$\begin{array}{l}\text { *Indicates estimate is different from zero at the } 95 \% \text { confidence } \\
\text { \# Log-normal model was used. Results are presented as changes } \\
\text { \#\# Data did not support the assumption of linear effects with mile } \\
\text { NA="Not Applicable" } \\
+ \text { "Effects of Intermediate Ethanol Blends on Legacy Vehicles and } \\
\text { ₹ Colors denote ethanol blend: E10, blue; E15, green; E20, red }\end{array}$} \\
\hline
\end{tabular}




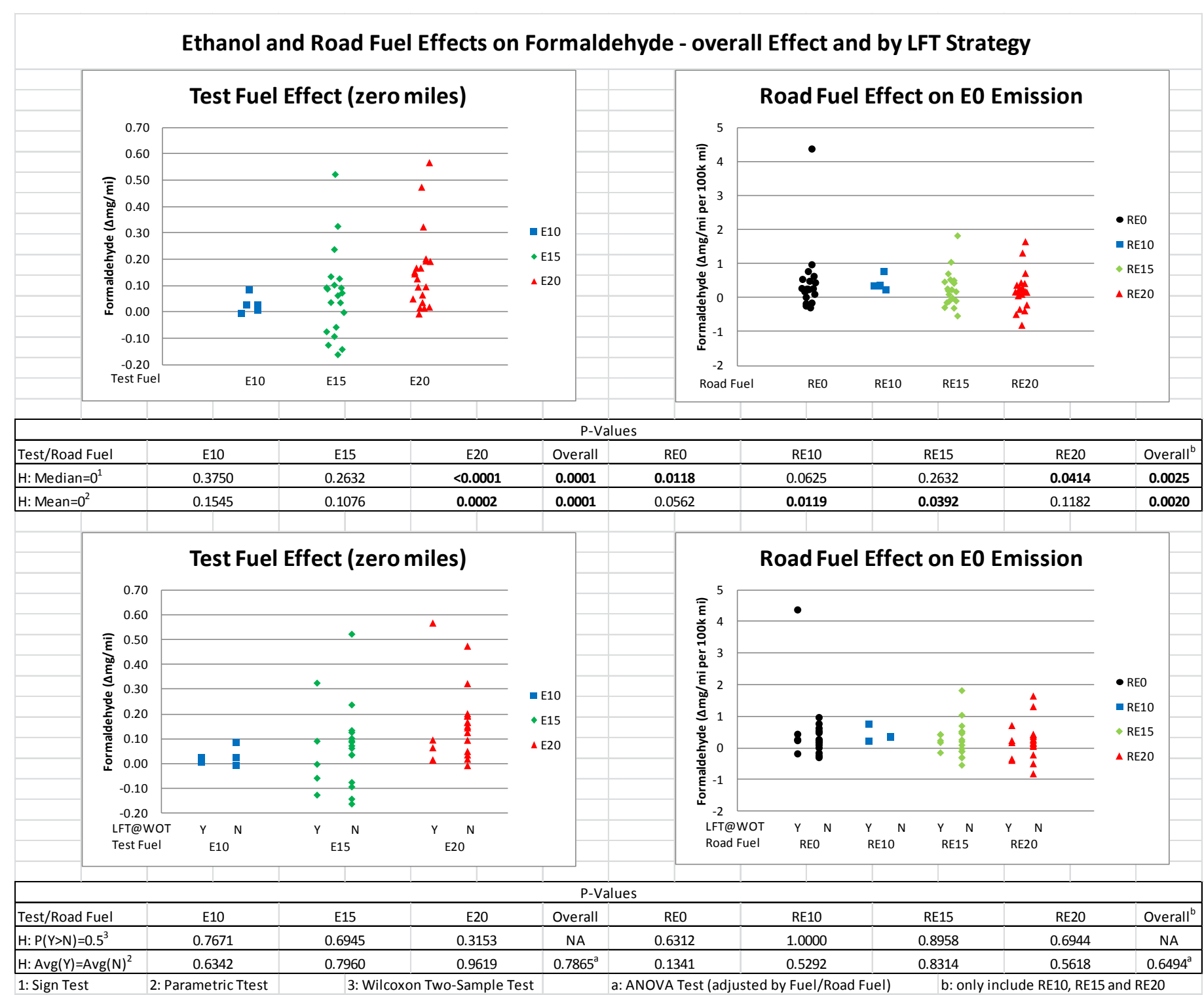

Fig. D.8. Ethanol and road fuel effects on Federal Test Procedure formaldehyde emissions. 
Table D.9. Federal Test Procedure methane $\left(\mathrm{CH}_{4}\right)$ emissions by vehicle model

\begin{tabular}{|c|c|c|c|c|c|c|c|c|c|c|c|c|c|c|c|c|c|c|}
\hline \multirow{3}{*}{$\begin{array}{c}\text { Emissions } \\
\text { (units) }\end{array}$} & \multirow{3}{*}{$\begin{array}{c}\text { V1 Results } \\
\text { (Immediate } \\
\text { Effect of } \\
\text { Ethanol) † }\end{array}$} & \multirow{3}{*}{ Vehicle Model } & \multirow{3}{*}{$\mid \begin{array}{l}\text { Apply LFT } \\
\text { @WOT? }\end{array}$} & \multirow{3}{*}{ Standard } & \multicolumn{8}{|c|}{ Ethanol Effect $\ddagger$} & \multicolumn{2}{|c|}{$\begin{array}{c}\text { Aging Effect with } \\
\text { REO }\end{array}$} & \multicolumn{4}{|c|}{ RExx Aging Effect on EO Emissions ¥ } \\
\hline & & & & & \multirow{2}{*}{\begin{tabular}{|r|}
$\begin{array}{l}\text { units at } \\
0 \mathrm{k} \mathrm{mi}\end{array}$ \\
EO
\end{tabular}} & \multicolumn{3}{|c|}{$\Delta$ units vs. EO } & \multicolumn{3}{|c|}{ \% change vs. EO } & \multirow{2}{*}{$\begin{array}{c}\text { Overall } p- \\
\text { value }\end{array}$} & \multirow{2}{*}{$\begin{array}{c}\begin{array}{c}\Delta \text { units } \\
\text { per } \\
100 \mathrm{~K} \mathrm{mi}\end{array} \\
\text { REO/EO }\end{array}$} & \multirow{2}{*}{$\begin{array}{c}\text { Overall } p \\
\text { value }\end{array}$} & \multicolumn{3}{|c|}{$\Delta$ units per $100 \mathrm{~K} \mathrm{mi}$} & \multirow{2}{*}{$\begin{array}{c}\text { Overall } p- \\
\text { value }\end{array}$} \\
\hline & & & & & & E10 & E15 & E20 & E10 & E15 & E20 & & & & \begin{tabular}{|l|} 
RE10/E0 \\
\end{tabular} & RE15/E0 & RE20/E0 & \\
\hline \multirow{26}{*}{$\begin{array}{c}\mathrm{CH} 4 \\
(\mathrm{~g} / \mathrm{mi})\end{array}$} & \multirow{26}{*}{ NA } & 2007 Accord & No & T2 B5 & 0.004 & -0.0006 & -0.0004 & -0.0005 & \begin{tabular}{|l|}
$-15.93 \%$ \\
\end{tabular} & $-10.62 \%$ & $-13.28 \%$ & 0.29 & 0.0007 & 0.44 & $0.0023 *$ & 0.0010 & 0.0003 & 0.18 \\
\hline & & 2006 Silverado & Yes & T2 B8 & 0.013 & 0.0043 & 0.0009 & 0.0014 & $32.08 \%$ & $6.72 \%$ & $10.45 \%$ & 0.58 & 0.0103 & 0.12 & 0.0070 & $0.0126^{*}$ & $0.0124 *$ & 0.78 \\
\hline & & 2008 Altima & No & T2 B5 & 0.006 & 0.0002 & 0.0003 & -0.0005 & $3.17 \%$ & $4.75 \%$ & $-7.92 \%$ & 0.95 & 0.0000 & 0.99 & $0.0052 *$ & $0.0042^{*}$ & $0.0044 *$ & 0.61 \\
\hline & & 2008 Taurus & Yes & T2 B5 & 0.004 & 0.0004 & 0.0023 & 0.0004 & $11.02 \%$ & $63.35 \%$ & $11.02 \%$ & 0.41 & $0.0093 *$ & $<0.01 *$ & $0.0078 *$ & $0.0085 *$ & $0.0048 *$ & 0.31 \\
\hline & & 2007 Caravan & No & T2 B5 & 0.009 & -0.0004 & -0.0002 & -0.0003 & $-4.70 \%$ & $-2.35 \%$ & $-3.53 \%$ & 0.99 & 0.0037 & 0.31 & 0.0042 & 0.0049 & $0.0082 *$ & 0.62 \\
\hline & & 2006 Cobalt & No & T2 B5 & 0.006 & $\mathrm{NA}$ & -0.0005 & -0.0001 & $N A$ & $-8.76 \%$ & $-1.75 \%$ & 0.91 & 0.0037 & 0.20 & $\mathrm{NA}$ & 0.0007 & 0.0030 & 0.59 \\
\hline & & 2007 Caliber & No & T2 B5 & 0.007 & $\mathrm{NA}$ & -0.0002 & -0.0018 & NA & $-2.83 \%$ & $-25.44 \%$ & 0.89 & $0.0268 *$ & $0.02 *$ & $\mathrm{NA}$ & $0.0402 *$ & $0.0254 *$ & 0.27 \\
\hline & & 2009 Liberty & No & T2 B5 & 0.009 & $\mathrm{NA}$ & -0.0007 & -0.0004 & NA & $-8.03 \%$ & $-4.59 \%$ & 0.60 & $0.0038^{*}$ & $0.02 *$ & $\mathrm{NA}$ & $0.0080 *$ & $0.0046 *$ & 0.03 \\
\hline & & 2009 Explorer & Yes & T2 B4 & 0.010 & $\mathrm{NA}$ & 0.0010 & 0.0007 & NA & $10.17 \%$ & $7.12 \%$ & 0.75 & 0.0038 & 0.14 & $\mathrm{NA}$ & 0.0032 & $0.0061 *$ & 0.49 \\
\hline & & 2009 Civic & No & T2 B5 & 0.004 & $\mathrm{NA}$ & 0.0000 & 0.0007 & NA & $0.00 \%$ & $20.00 \%$ & 0.67 & $0.0030^{*}$ & $0.03^{*}$ & $\mathrm{NA}$ & $0.0026 *$ & $0.0024^{*}$ & 0.90 \\
\hline & & 2009 Corolla & No & T2 B5 & 0.003 & $\mathrm{NA}$ & 0.0008 & 0.0010 & $\mathrm{NA}$ & $25.26 \%$ & $31.58 \%$ & 0.34 & $0.0047^{*}$ & $<0.01^{*}$ & $\mathrm{NA}$ & $0.0058 *$ & $0.0074 *$ & 0.25 \\
\hline & & 2005 Tundra & No & T2 B5 & 0.008 & $\mathrm{NA}$ & 0.0001 & 0.0017 & NA & $1.27 \%$ & $21.52 \%$ & 0.42 & $0.0102^{*}$ & $0.02^{*}$ & $\mathrm{NA}$ & \begin{tabular}{|l|}
$0.0069 *$ \\
\end{tabular} & $0.0072 *$ & 0.69 \\
\hline & & 2006 Impala & No & T2 B5 & 0.014 & $\mathrm{NA}$ & 0.0010 & $0.0033^{*}$ & NA & $7.23 \%$ & $23.86 \% *$ & $<0.01^{*}$ & $0.0139 *$ & $<0.01^{*}$ & $\mathrm{NA}$ & \begin{tabular}{|l|}
$0.0197^{*}$ \\
\end{tabular} & $0.0124 *$ & $<0.01^{*}$ \\
\hline & & 2005 F150 & Yes & T2 B8 & 0.022 & $\mathrm{NA}$ & 0.0030 & 0.0007 & NA & $13.85 \%$ & $3.23 \%$ & 0.68 & $0.0448 *$ & $<0.01 *$ & $\mathrm{NA}$ & $0.0319 *$ & $0.0277 *$ & 0.33 \\
\hline & & 2009 Outlook & Yes & $\mathrm{T} 2 \mathrm{~B} 5$ & 0.006 & $\mathrm{NA}$ & 0.0003 & $\mathrm{NA}$ & NA & $5.03 \%$ & $\mathrm{NA}$ & 0.73 & $0.0100^{*}$ & $<0.01 *$ & $\mathrm{NA}$ & \begin{tabular}{|l|}
$0.0057^{*}$ \\
\end{tabular} & $\mathrm{NA}$ & $0.04^{*}$ \\
\hline & & 2009 Camry & Yes & T2 B5 & 0.002 & $\mathrm{NA}$ & 0.0001 & $\mathrm{NA}$ & NA & 4.19\% & $\mathrm{NA}$ & 0.92 & $0.0078^{*}$ & $<0.01^{*}$ & $\mathrm{NA}$ & \begin{tabular}{|l|}
$0.0055^{*}$ \\
\end{tabular} & $\mathrm{NA}$ & 0.17 \\
\hline & & 2009 Focus & Yes & $\mathrm{T} 2 \mathrm{~B} 4$ & 0.006 & $\mathrm{NA}$ & -0.0006 & $\mathrm{NA}$ & NA & $-10.89 \%$ & $\mathrm{NA}$ & 0.48 & 0.0022 & 0.13 & $\mathrm{NA}$ & \begin{tabular}{|l|l|}
$0.0041^{*}$ \\
\end{tabular} & $\mathrm{NA}$ & 0.25 \\
\hline & & 2009 Odyssey & No & T2 B5 & 0.002 & $\mathrm{NA}$ & 0.0007 & $\mathrm{NA}$ & $\mathrm{NA}$ & $28.68 \%$ & $\mathrm{NA}$ & 0.41 & $0.0085^{*}$ & $<0.01^{*}$ & $\mathrm{NA}$ & \begin{tabular}{|l|}
$0.0025 *$ \\
\end{tabular} & NA & $<0.01^{*}$ \\
\hline & & 2000 Silverado & Yes & T1 L3 & 0.024 & $\mathrm{NA}$ & 0.0016 & $0.0044 *$ & $\mathrm{NA}$ & $6.61 \%$ & $18.19 \% *$ & $<0.01^{*}$ & $0.0130 *$ & $<0.01 *$ & $\mathrm{NA}$ & 0.0049 & $0.0119 *$ & 0.15 \\
\hline & & 2002 Frontier & No & NLEV LEV & 0.015 & $\mathrm{NA}$ & 0.0026 & 0.0040 & $\mathrm{NA}$ & $17.05 \%$ & $26.23 \%$ & 0.09 & $0.0479 *$ & $<0.01 *$ & $\mathrm{NA}$ & $0.0256 *$ & $0.0280 *$ & 0.05 \\
\hline & & 2002 Durango & No & T1 L3 & 0.027 & $\mathrm{NA}$ & $0.0033^{*}$ & $0.0062 *$ & $\mathrm{NA}$ & $12.38 \% *$ & $23.27 \% *$ & $<0.01^{*}$ & 0.0068 & 0.09 & $\mathrm{NA}$ & $0.0078 *$ & $0.0176 *$ & $0.05^{*}$ \\
\hline & & 2003 Camry & No & ULEV & 0.008 & $\mathrm{NA}$ & 0.0003 & -0.0003 & $\mathrm{NA}$ & $3.60 \%$ & $-3.60 \%$ & 0.93 & $0.0126 *$ & $0.01^{*}$ & $\mathrm{NA}$ & $0.0073 *$ & 0.0029 & 0.30 \\
\hline & & 2003 Taurus & No & NLEV LEV & 0.008 & $\mathrm{NA}$ & -0.0003 & $-0.0008 *$ & NA & $-4.00 \%$ & $-10.67 \% *$ & 0.07 & 0.0020 & 0.12 & $\mathrm{NA}$ & $0.0030 *$ & $0.0040 *$ & 0.41 \\
\hline & & 2003 Cavalier & No & NLEV LEV & 0.007 & $\mathrm{NA}$ & -0.0008 & -0.0013 & NA & $-12.00 \%$ & $-19.50 \%$ & 0.56 & $0.0271 *$ & $<0.01^{*}$ & $\mathrm{NA}$ & 0.0028 & 0.0055 & $0.01^{*}$ \\
\hline & & 2000 Accord & No & NLEV LEV & 0.010 & $\mathrm{NA}$ & -0.0040 & -0.0000 & NA & $-41.35 \%$ & $0.00 \%$ & 0.60 & $0.0500 *$ & $<0.01 *$ & $\mathrm{NA}$ & $0.0372 *$ & 0.0051 & $0.05^{*}$ \\
\hline & & 2000 Focus & No & NLEV LEV & 0.008 & $\mathrm{NA}$ & 0.0005 & -0.0003 & NA & $6.41 \%$ & $-3.85 \%$ & 0.87 & 0.0055 & 0.20 & $\mathrm{NA}$ & 0.0047 & $0.0133 *$ & 0.13 \\
\hline \multicolumn{19}{|c|}{$\begin{array}{l}\text { n.s. not statistically significant } \\
\text { *Indicates estimate is different from zero at the } 95 \% \text { confiden } \\
\text { \# Log-normal model was used. Results are presented as chang } \\
\text { \#\# Data did not support the assumption of linear effects with } m \\
\text { NA="Not Applicable" } \\
\text { † "Effects of Intermediate Ethanol Blends on Legacy Vehicles an } \\
\text { ‡ Colors denote ethanol blend: E10, blue; E15, green; E2O, red }\end{array}$} \\
\hline
\end{tabular}




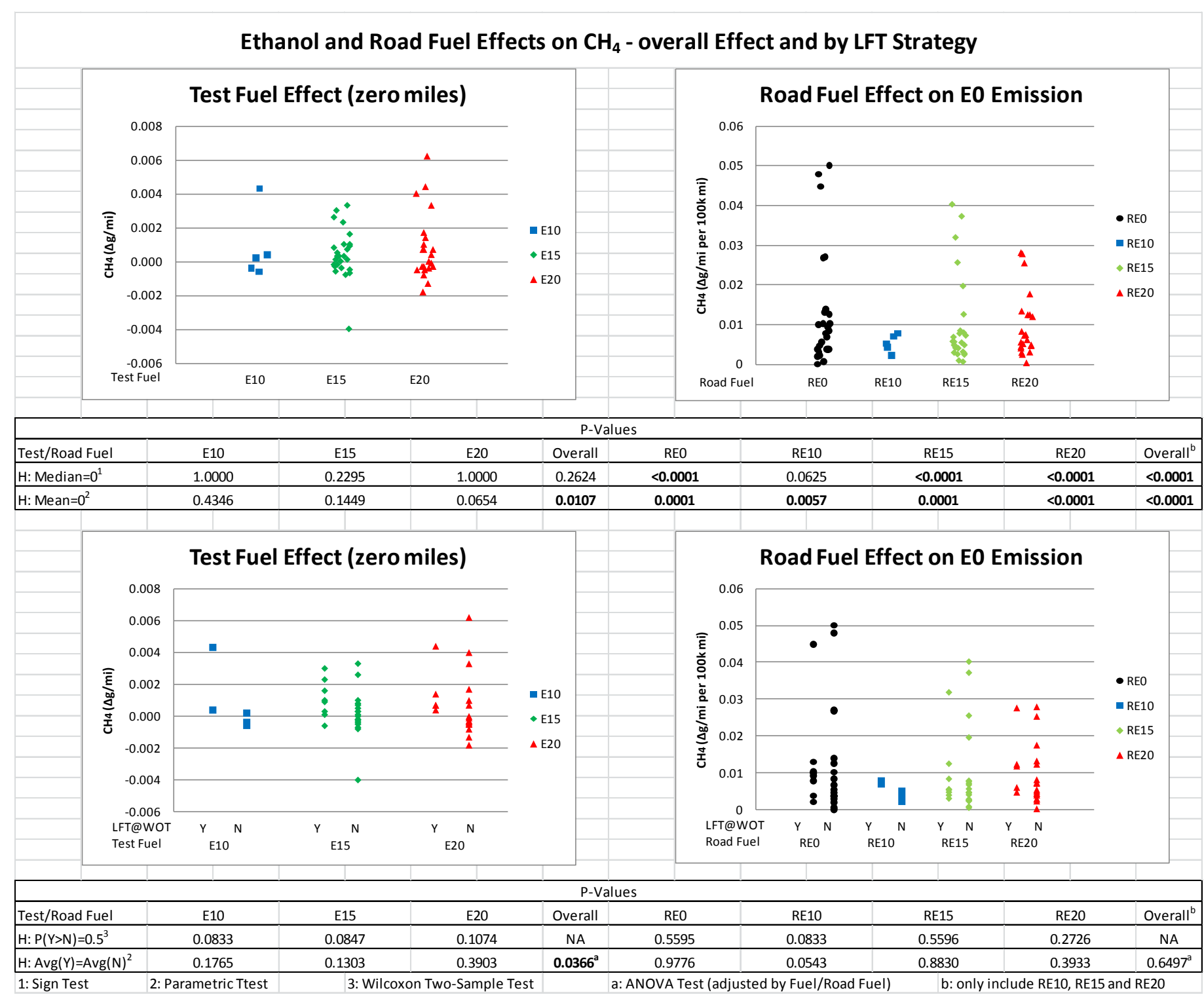

Fig. D.9. Ethanol and road fuel effects on Federal Test Procedure methane $\left(\mathrm{CH}_{4}\right)$ emissions. 
APPENDIX E.

DETAILED STATISTICAL RESULTS BY VEHICLE MODEL 



\section{APPENDIX E. DETAILED STATISTICAL RESULTS BY VEHICLE MODEL}

This appendix contains the results for the statistical analysis of each individual vehicle model. The results for each vehicle include a summary table plus nine additional figures that detail the various characteristics that were analyzed. These characteristics generally include $\mathrm{CO}$, oxides of nitrogen $\left(\mathrm{NO}_{\mathrm{X}}\right)$, nonmethane hydrocarbons (NMHC), nonmethane organic gases (NMOG), ethanol, acetaldehyde, formaldehyde, and methane emissions and fuel economy measured on the Federal Test Procedure (FTP). The FTP cycle consists of three phases, and the results of each phase are used to compute a weighted result." This weighted FTP composite is frequently referred to as the composite to distinguish it from the individual phases. In this appendix, composite refers to the weighted FTP result.

Note that ethanol, acetaldehyde, and formaldehyde results are missing for some cases in which data were not available. Table E.1 lists the page numbers of this appendix for each vehicle model.

Table E.1. Contents of Appendix E

\begin{tabular}{|c|c|c|c|}
\hline Vehicle Model & Page Numbers & Vehicle Model & Page Numbers \\
\hline 2007 Honda Accord & E-4 to E-13 & 2005 Ford F150 & E-128 to E-136 \\
\hline 2006 Chevrolet Silverado & E-14 to E-23 & 2009 Saturn Outlook & E-137 to E-143 \\
\hline 2008 Nissan Altima & E-24 to E-33 & 2009 Toyota Camry & E-144 to E-150 \\
\hline 2008 Ford Taurus & E-34 to E-43 & 2009 Ford Focus & E-151 to E-157 \\
\hline 2007 Dodge Caravan & E-44 to E-53 & 2009 Honda Odyssey & E-158 to E-164 \\
\hline 2006 Chevrolet Cobalt & E-54 to E-63 & 2000 Chevrolet Silverado & E-165 to E-174 \\
\hline 2007 Dodge Caliber & E-64 to E-73 & 2002 Nissan Frontier & E-175 to E-184 \\
\hline 2009 Jeep Liberty & E-74 to E-82 & 2002 Dodge Durango & E-185 to E-194 \\
\hline 2009 Ford Explorer & E-83 to E-91 & 2003 Toyota Camry & E-195 to E-203 \\
\hline 2009 Honda Civic & E-92 to E-100 & 2003 Ford Taurus & E-204 to E-212 \\
\hline 2009 Toyota Corolla & E-101 to E-109 & 2003 Chevrolet Cavalier & E-213 to E-221 \\
\hline 2005 Toyota Tundra & E-110 to E-118 & 2000 Honda Accord & E-222 to E-228 \\
\hline 2006 Chevrolet Impala & E-119 to E-127 & 2000 Ford Focus & E-229 to E-235 \\
\hline
\end{tabular}

* CFR 40, Part 86.144-94, Calculations; Exhaust emissions 


\section{Honda Accord - Composite Emissions Summary}

\begin{tabular}{|c|c|c|c|c|c|c|c|c|c|c|c|c|c|c|}
\hline \multirow{2}{*}{$\begin{array}{c}\text { Emisssion Parameter } \\
\text { (units) }\end{array}$} & \multicolumn{4}{|c|}{ Ethanol Effect } & \multicolumn{2}{|c|}{ Aging Effect with REO } & \multicolumn{4}{|c|}{ RExx Aging Effect on E0 Emissions } & \multirow{2}{*}{\multicolumn{3}{|c|}{$\begin{array}{c}\text { RExx Aging Effect on Exx Emissions } \\
\Delta \text { units per } 100 \mathrm{~K} \mathrm{mi} \\
\end{array}$}} & \multirow{3}{*}{\begin{tabular}{|c|}
$\begin{array}{l}\text { Road and Test } \\
\text { Fuel Effects } \\
\text { are Additive }\end{array}$ \\
$\begin{array}{c}\text { Overall p- } \\
\text { value }\end{array}$ \\
\end{tabular}} \\
\hline & \multicolumn{3}{|c|}{$\Delta$ units vs. EO } & \multirow{2}{*}{$\mid \begin{array}{c}\text { Overall } \\
p \text {-value }\end{array}$} & \multirow{2}{*}{$\frac{\Delta \text { units per } 100 \mathrm{~K} \mathrm{mi}}{\text { REO/EO }}$} & \multirow{2}{*}{$\begin{array}{l}\text { Overall } \\
p \text {-value }\end{array}$} & \multicolumn{3}{|c|}{$\Delta$ units per $100 \mathrm{~K} \mathrm{mi}$} & \multirow{2}{*}{$\begin{array}{l}\text { Overall } \\
p \text {-value }\end{array}$} & & & & \\
\hline Fuels & E10 & E15 & E20 & & & & RE10/E0 & RE15/E0 & RE20/E0 & & RE10/E10 & RE15/E15 & RE20/E20 & \\
\hline $\mathrm{CO}(\mathrm{g} / \mathrm{mi})$ & $-0.104 *$ & $-0.070 *$ & $-0.083^{*}$ & $<0.01 *$ & -0.003 & 0.95 & 0.027 & 0.043 & 0.047 & 0.77 & $\mathrm{NA}$ & NA & $\mathrm{NA}$ & 0.32 \\
\hline NOx $(\mathrm{g} / \mathrm{mi})$ & 0.002 & 0.005 & 0.001 & 0.20 & $0.011 *$ & $0.03^{*}$ & $0.007^{*}$ & $0.008 *$ & 0.003 & 0.57 & $\mathrm{NA}$ & $\mathrm{NA}$ & $\mathrm{NA}$ & 0.55 \\
\hline $\mathrm{NMHC}(\mathrm{g} / \mathrm{mi})^{\mathrm{a}}$ & -0.0079 & -0.0024 & -0.0075 & 0.09 & 0.0073 & 0.41 & 0.0004 & 0.0005 & 0.0038 & 0.89 & $\mathrm{NA}$ & $\mathrm{NA}$ & $\mathrm{NA}$ & 0.81 \\
\hline NMOG $(\mathrm{g} / \mathrm{mi})^{\mathrm{a}}$ & -0.0063 & 0.0000 & -0.0046 & 0.40 & 0.0079 & 0.43 & 0.0002 & 0.0005 & 0.0034 & 0.90 & $\mathrm{NA}$ & $\mathrm{NA}$ & $\mathrm{NA}$ & 0.83 \\
\hline Fuel Econ (mi/gal) & -0.549 & $-0.915 *$ & $-2.046 *$ & $<0.01 *$ & 1.105 & 0.11 & 0.886 & 0.431 & 0.229 & 0.59 & $\mathrm{NA}$ & $\mathrm{NA}$ & $\mathrm{NA}$ & 0.72 \\
\hline Ethanol $(\mathrm{mg} / \mathrm{mi})^{\text {\#\# }}$ & $0.656 *$ & $0.901 *$ & $1.445 *$ & $<0.01 *$ & 0.033 & 0.92 & 0.098 & -0.163 & 0.095 & 0.81 & $\mathrm{NA}$ & $\mathrm{NA}$ & $\mathrm{NA}$ & NA \\
\hline Acetaldehyde $(\mathrm{mg} / \mathrm{mi})^{\text {\#\# }}$ & $0.215 *$ & $0.497 *$ & $0.610^{*}$ & $<0.01 *$ & 0.145 & 0.28 & 0.058 & 0.146 & $0.249^{*}$ & 0.52 & $\mathrm{NA}$ & $\mathrm{NA}$ & $\mathrm{NA}$ & NA \\
\hline Formaldehyde $(\mathrm{mg} / \mathrm{mi})^{\#}$ & 0.084 & $0.521 *$ & $0.473 *$ & $<0.01 *$ & 0.761 & 0.20 & 0.360 & $1.033^{*}$ & $1.307^{*}$ & 0.07 & 0.045 & 0.512 & 0.323 & $0.04 *$ \\
\hline $\mathrm{CH} 4(\mathrm{~g} / \mathrm{mi})$ & -0.0006 & -0.0004 & -0.0005 & 0.29 & 0.0007 & 0.44 & $0.0023^{*}$ & 0.0010 & 0.0003 & 0.18 & $\mathrm{NA}$ & NA & $\mathrm{NA}$ & 0.14 \\
\hline
\end{tabular}

\# Log-normal model was used. Results are presented as changes in emissions at 0k mile.

\#\# Data did not support the assumption of linear effects with mileage.

*Indicates estimate is different from zero at the $95 \%$ confidence level. 
2007 Honda Accord (Composite CO)

\begin{tabular}{|l|r|r|r|}
\hline \multicolumn{1}{|c|}{ Effect } & & $\begin{array}{r}95 \% \text { C.I. } \\
\text { Es\% C.I. }\end{array}$ & $\begin{array}{c}\text { L5 } \\
\text { Upper }\end{array}$ \\
\hline Ethanol Effect (E10 vs. E0) $(\Delta \mathrm{g} / \mathrm{mi})$ & $-0.104^{*}$ & -0.144 & -0.065 \\
\hline Ethanol Effect (E15 vs. E0) $(\Delta \mathrm{g} / \mathrm{mi})$ & $-0.070^{*}$ & -0.111 & -0.029 \\
\hline Ethanol Effect $($ E20 vs. E0) $(\Delta \mathrm{g} / \mathrm{mi})$ & $-0.083^{*}$ & -0.124 & -0.042 \\
\hline Road Fuel Aging Effect & & & \\
\hline Aging Effect with RE0 $(\Delta \mathrm{g} / \mathrm{mi} \mathrm{per} \mathrm{100k} \mathrm{mi)}$ & -0.003 & -0.087 & 0.082 \\
\hline Aging Effect with RE10 $(\Delta \mathrm{g} / \mathrm{mi}$ per 100k mi) & 0.027 & -0.030 & 0.083 \\
\hline Aging Effect with RE15 $(\Delta \mathrm{g} / \mathrm{mi} \mathrm{per} \mathrm{100k} \mathrm{mi)}$ & 0.043 & -0.016 & 0.102 \\
\hline Aging Effect with RE20 $(\Delta \mathrm{g} / \mathrm{mi} \mathrm{per} \mathrm{100k} \mathrm{mi)}$ & 0.047 & -0.012 & 0.106 \\
\hline
\end{tabular}

\begin{tabular}{|l|r|}
\hline \multicolumn{1}{|c|}{ Hypothesis } & p-value \\
\hline No Effect of Ethanol in the Test Fuel (Gamma = 0) & $<0.01^{*}$ \\
\hline No Aging Effect with RE0 (Beta0 $=0)$ & 0.95 \\
\hline No Effect of Ethanol in Road Fuel Aging (Beta1s=0) & 0.77 \\
\hline * Indicates effect is statistically significant at the 95\% confidence level.
\end{tabular}

Initial odometers $32 \mathrm{k}-35 \mathrm{k}$

* Indicates estimate is different from zero at the $95 \%$ confidence level.

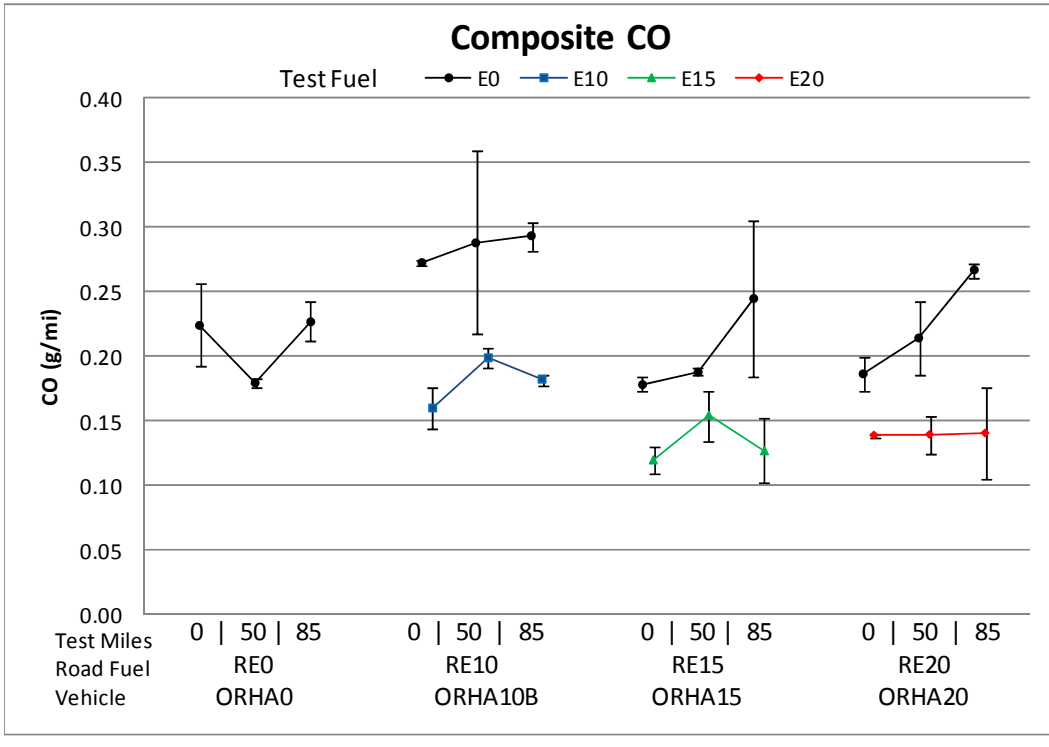

Error bars represent min and max measurements

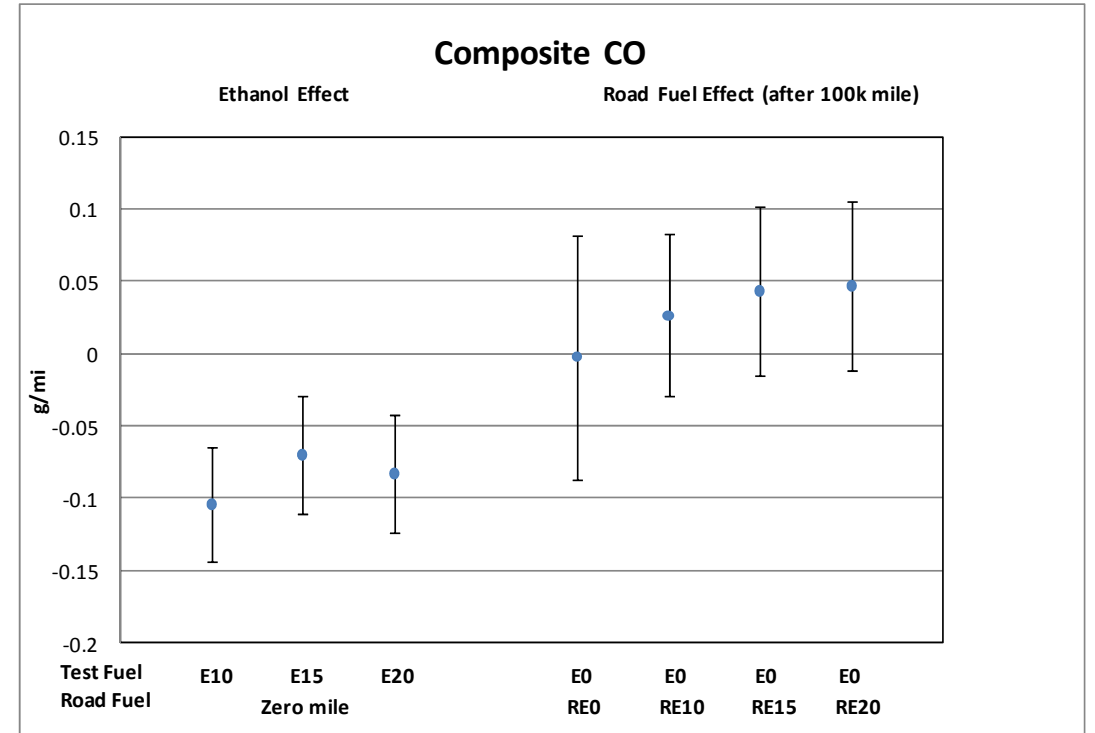

Error bars represent $95 \%$ confidence intervals on the estimated effects 
2007 Honda Accord (Composite NOx)

\begin{tabular}{|l|r|r|r|}
\hline \multicolumn{1}{|c|}{ Effect } & Estimate & $\begin{array}{c}95 \% \text { C.I. } \\
\text { Lower }\end{array}$ & $\begin{array}{c}95 \% \text { C.I. } \\
\text { Upper }\end{array}$ \\
\hline Ethanol Effect (E10 vs. E0) $(\Delta \mathrm{g} / \mathrm{mi})$ & 0.002 & -0.0030 & 0.0068 \\
\hline Ethanol Effect $(E 15$ vs. E0) $(\Delta \mathrm{g} / \mathrm{mi})$ & 0.005 & -0.0001 & 0.0099 \\
\hline Ethanol Effect $(E 20 \mathrm{vs.} \mathrm{E0)}(\Delta \mathrm{g} / \mathrm{mi})$ & 0.001 & -0.0043 & 0.0057 \\
\hline Road Fuel Aging Effect & & & \\
\hline Aging Effect with RE0 $(\Delta \mathrm{g} / \mathrm{mi}$ per 100k mi) & $0.011^{*}$ & 0.0010 & 0.0214 \\
\hline Aging Effect with RE10 $(\Delta \mathrm{g} / \mathrm{mi}$ per 100k mi) & $0.007^{*}$ & 0.0003 & 0.0143 \\
\hline Aging Effect with RE15 $(\Delta \mathrm{g} / \mathrm{mi}$ per 100k mi) & $0.008^{*}$ & 0.0007 & 0.0149 \\
\hline Aging Effect with RE20 $(\Delta \mathrm{g} / \mathrm{mi} \mathrm{per} \mathrm{100k} \mathrm{mi)}$ & 0.003 & -0.0037 & 0.0106 \\
\hline
\end{tabular}

\begin{tabular}{|l|r|}
\hline \multicolumn{1}{|c|}{ Hypothesis } & p-value \\
\hline No Effect of Ethanol in the Test Fuel (Gamma = 0) & 0.20 \\
\hline No Aging Effect with RE0 (Beta0 = 0) & $0.03^{*}$ \\
\hline No Effect of Ethanol in Road Fuel Aging (Beta1s=0) & 0.57 \\
\hline
\end{tabular}

Initial odometers $32 \mathrm{k}-35 \mathrm{k}$

* Indicates estimate is different from zero at the $95 \%$ confidence level.

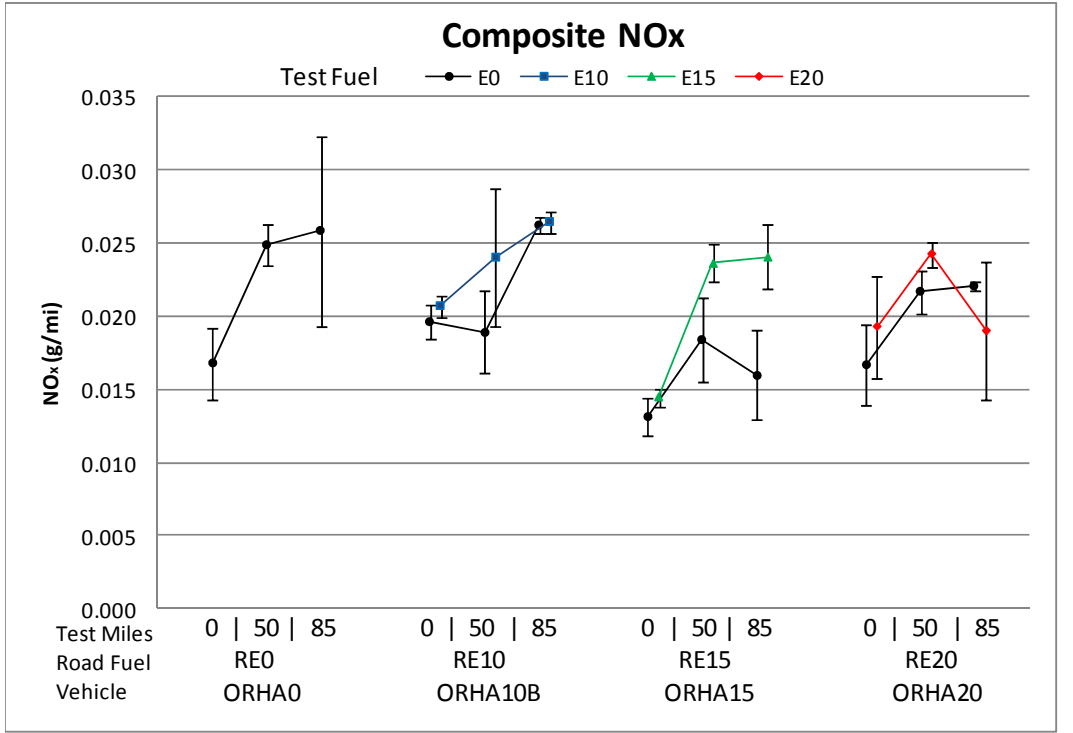

Error bars represent min and max measurements

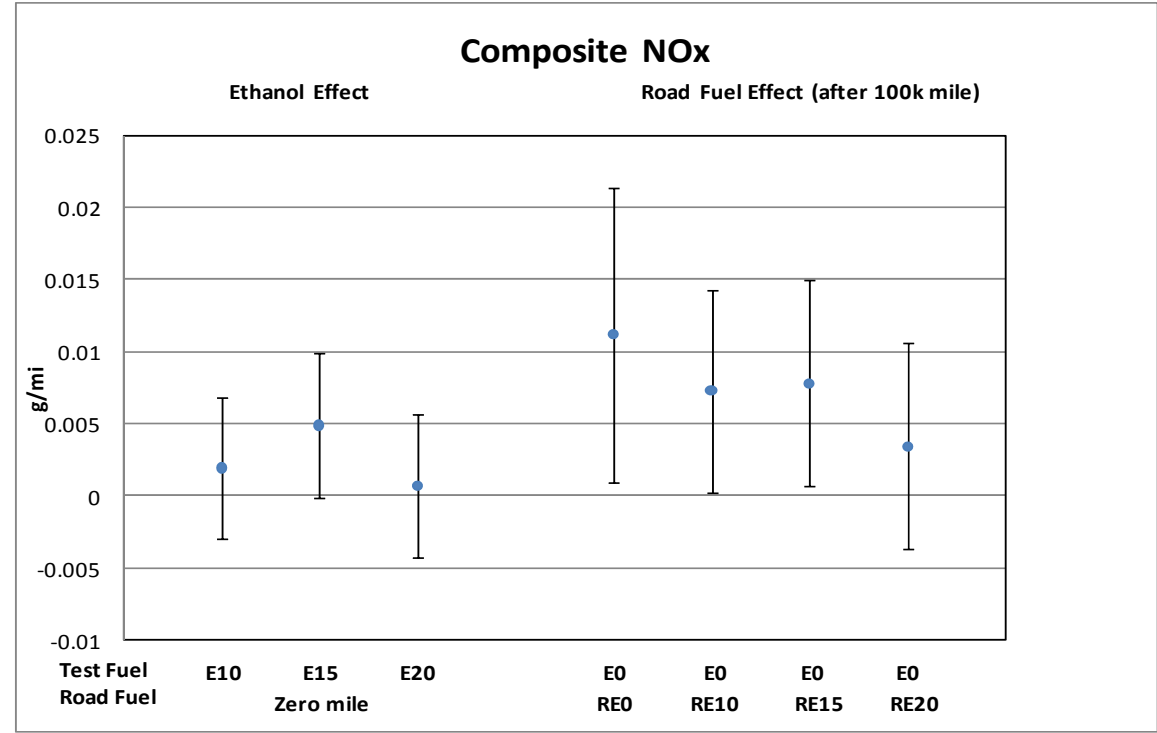

Error bars represent $95 \%$ confidence intervals on the estimated effects 
2007 Honda Accord (Composite Nonmethane Hydrocarbons)

\begin{tabular}{|l|r|r|r|}
\hline \multicolumn{1}{|c|}{ Effect } & Estimate & $\begin{array}{c}\text { 95\% C.I. } \\
\text { Lower }\end{array}$ & $\begin{array}{c}95 \% \text { C.I. } \\
\text { Upper }\end{array}$ \\
\hline Ethanol Effect (E10 vs. E0) $(\Delta \mathrm{g} / \mathrm{mi})$ & -0.0079 & -0.0164 & 0.0006 \\
\hline Ethanol Effect $(E 15 \mathrm{vs.} \mathrm{E0)}(\Delta \mathrm{g} / \mathrm{mi})$ & -0.0024 & -0.0110 & 0.0062 \\
\hline Ethanol Effect $(E 20 \mathrm{vs.} \mathrm{E0)}(\Delta \mathrm{g} / \mathrm{mi})$ & -0.0075 & -0.0161 & 0.0011 \\
\hline Road Fuel Aging Effect & & & \\
\hline Aging Effect with RE0 $(\Delta \mathrm{g} / \mathrm{mi}$ per 100k mi) & 0.0073 & -0.0114 & 0.0261 \\
\hline Aging Effect with RE10 $(\Delta \mathrm{g} / \mathrm{mi} \mathrm{per} \mathrm{100k} \mathrm{mi)}$ & 0.0004 & -0.0118 & 0.0126 \\
\hline Aging Effect with RE15 $(\Delta \mathrm{g} / \mathrm{mi}$ per 100k mi) & 0.0005 & -0.0117 & 0.0128 \\
\hline Aging Effect with RE20 $(\Delta \mathrm{g} / \mathrm{mi}$ per 100k mi) & 0.0038 & -0.0084 & 0.0161 \\
\hline
\end{tabular}

\begin{tabular}{|l|r|}
\hline \multicolumn{1}{|c|}{ Hypothesis } & p-value \\
& \\
\hline No Effect of Ethanol in the Test Fuel (Gamma = 0) & 0.09 \\
\hline No Aging Effect with RE0 (Beta0 = 0) & 0.41 \\
\hline No Effect of Ethanol in Road Fuel Aging (Beta1s=0) & 0.89 \\
\hline
\end{tabular}

Initial odometers $32 \mathrm{k}-35 \mathrm{k}$

* Indicates estimate is different from zero at the $95 \%$ confidence level.

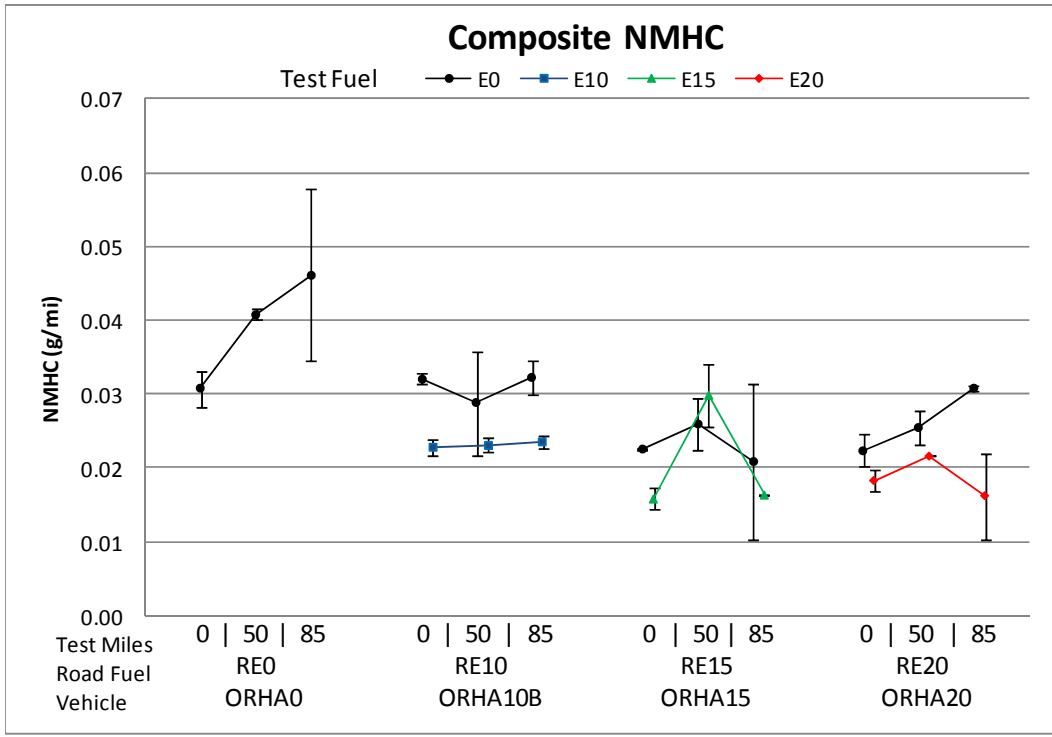

Error bars represent min and max measurements

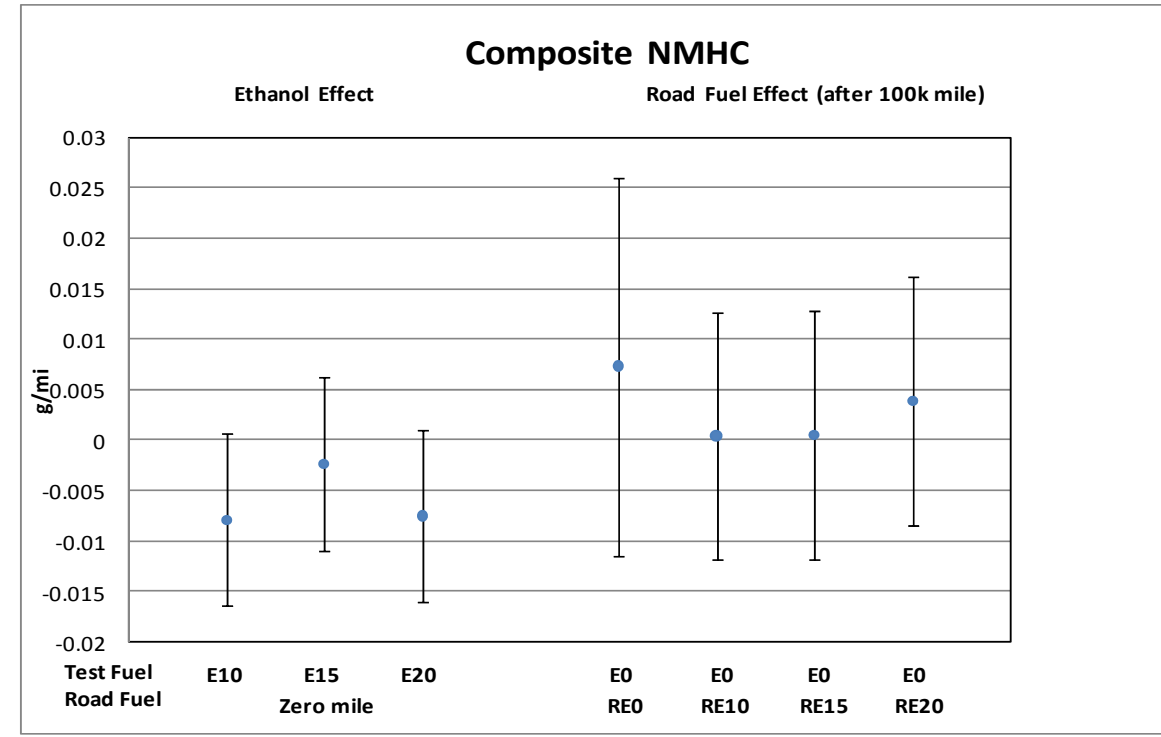

Error bars represent $95 \%$ confidence intervals on the estimated effects 
2007 Honda Accord (Composite Nonmethane Organic Gases)

\begin{tabular}{|l|r|r|r|}
\hline \multicolumn{1}{|c|}{ Effect } & Estimate & $\begin{array}{c}\text { 95\% C.I. } \\
\text { Lower }\end{array}$ & $\begin{array}{c}\text { 95\% C.I. } \\
\text { Upper }\end{array}$ \\
\hline Ethanol Effect (E10 vs. E0) $(\Delta \mathrm{g} / \mathrm{mi})$ & -0.0063 & -0.0159 & 0.0034 \\
\hline Ethanol Effect $(E 15 \mathrm{vs.} \mathrm{E0)}(\Delta \mathrm{g} / \mathrm{mi})$ & 0.0000 & -0.0097 & 0.0097 \\
\hline Ethanol Effect $(E 20 \mathrm{vs.} \mathrm{E0)}(\Delta \mathrm{g} / \mathrm{mi})$ & -0.0046 & -0.0143 & 0.0051 \\
\hline Road Fuel Aging Effect & & & \\
\hline Aging Effect with RE0 $(\Delta \mathrm{g} / \mathrm{mi}$ per 100k mi) & 0.0079 & -0.0131 & 0.0289 \\
\hline Aging Effect with RE10 $(\Delta \mathrm{g} / \mathrm{mi}$ per 100k mi) & 0.0002 & -0.0136 & 0.0139 \\
\hline Aging Effect with RE15 $(\Delta \mathrm{g} / \mathrm{mi}$ per 100k mi) & 0.0005 & -0.0134 & 0.0143 \\
\hline Aging Effect with RE20 $(\Delta \mathrm{g} / \mathrm{mi}$ per 100k mi) & 0.0034 & -0.0105 & 0.0173 \\
\hline
\end{tabular}

\begin{tabular}{|l|r|}
\hline \multicolumn{1}{|c|}{ Hypothesis } & p-value \\
\hline No Effect of Ethanol in the Test Fuel (Gamma = 0) & 0.40 \\
\hline No Aging Effect with RE0 (Beta0 = 0) & 0.43 \\
\hline No Effect of Ethanol in Road Fuel Aging (Beta1s=0) & 0.90 \\
\hline
\end{tabular}

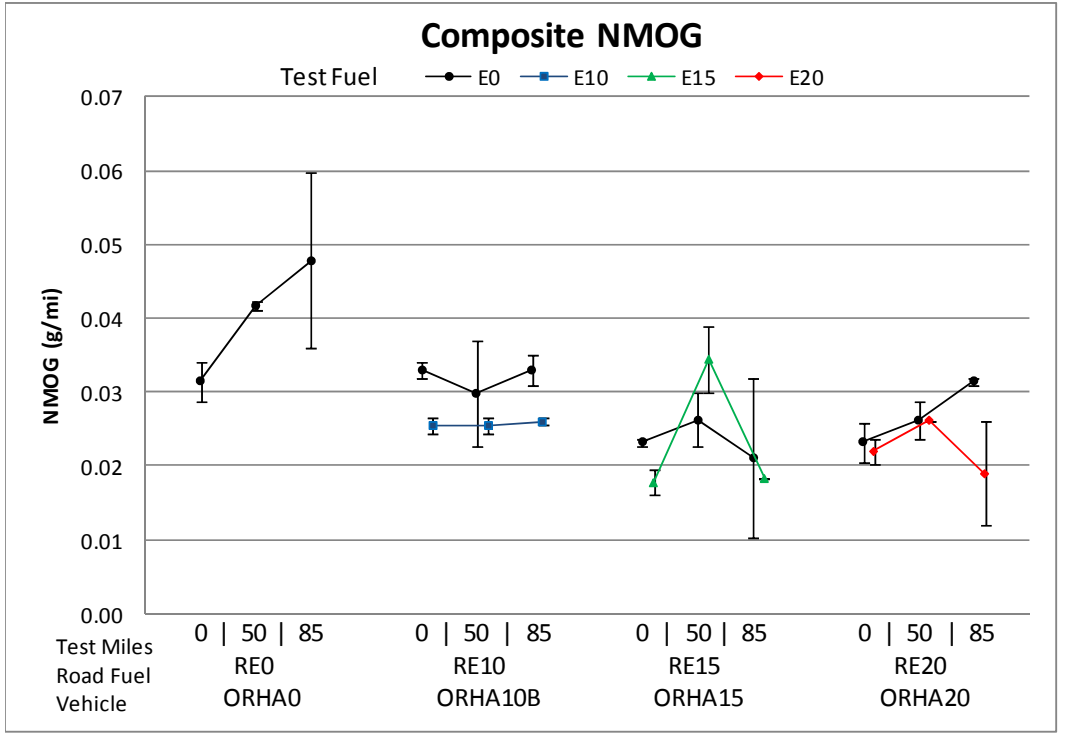

Error bars represent min and max measurements

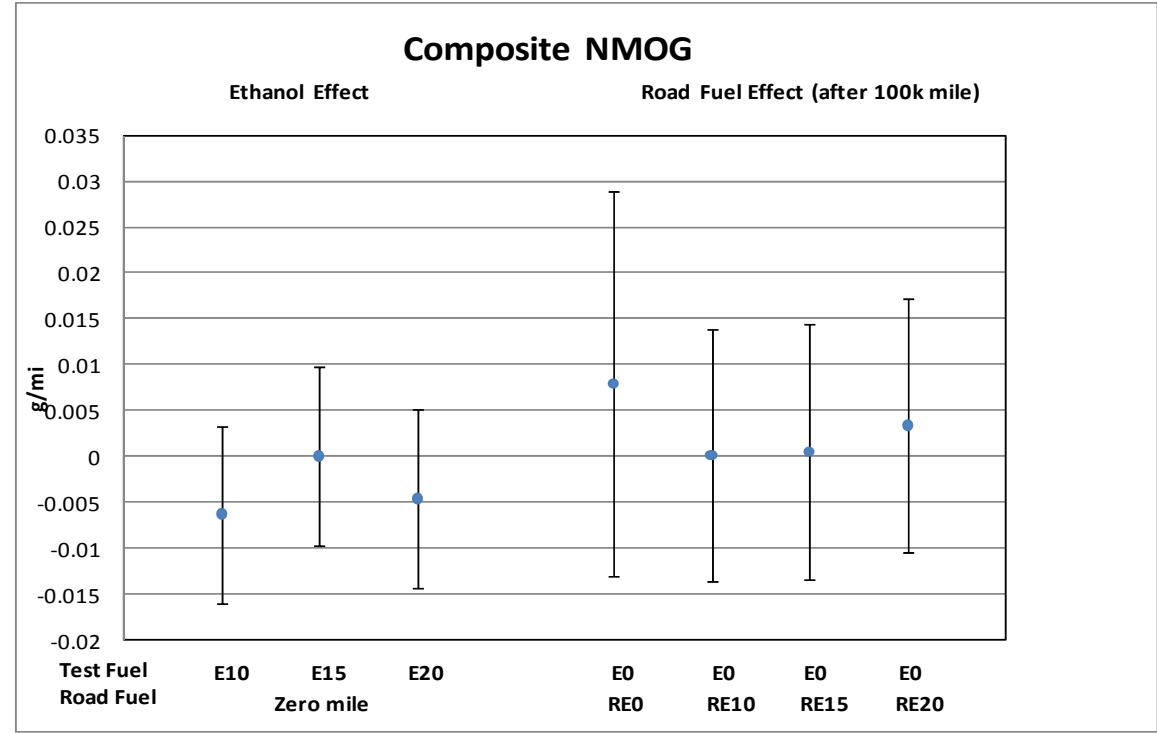

Error bars represent $95 \%$ confidence intervals on the estimated effects 
2007 Honda Accord (Composite Fuel Economy)

\begin{tabular}{|l|r|r|r|}
\hline \multicolumn{1}{|c|}{ Effect } & Estimate & $\begin{array}{c}95 \% \text { C.I. } \\
\text { Lower }\end{array}$ & $\begin{array}{r}\text { 95\% C.I. } \\
\text { Upper }\end{array}$ \\
\hline Ethanol Effect (E10 vs. E0) $(\Delta \mathrm{mi} / \mathrm{gal})$ & -0.549 & -1.221 & 0.124 \\
\hline Ethanol Effect (E15 vs. E0) $(\Delta \mathrm{mi} / \mathrm{gal})$ & $-0.915^{*}$ & -1.588 & -0.241 \\
\hline Ethanol Effect (E20 vs. E0) $(\Delta \mathrm{mi} / \mathrm{gal})$ & $-2.046^{*}$ & -2.720 & -1.372 \\
\hline Road Fuel Aging Effect & & & \\
\hline Aging Effect with RE0 $(\Delta \mathrm{mi} / \mathrm{gal}$ per 100k mi) & 1.105 & -0.276 & 2.487 \\
\hline Aging Effect with RE10 $(\Delta \mathrm{mi} /$ gal per 100k mi) & 0.886 & -0.073 & 1.845 \\
\hline Aging Effect with RE15 $(\Delta \mathrm{mi} /$ gal per 100k mi) & 0.431 & -0.533 & 1.394 \\
\hline Aging Effect with RE20 $(\Delta \mathrm{mi} / \mathrm{gal}$ per 100k mi) & 0.229 & -0.735 & 1.193 \\
\hline
\end{tabular}

\begin{tabular}{|l|r|}
\hline \multicolumn{1}{|c|}{ Hypothesis } & p-value \\
\hline No Effect of Ethanol in the Test Fuel (Gamma $=0)$ & $<0.01^{*}$ \\
\hline No Aging Effect with RE0 (Beta0 $=0)$ & 0.11 \\
\hline No Effect of Ethanol in Road Fuel Aging (Beta1s $=0$ ) & 0.59 \\
\hline${ }^{*}$ Indicates effect is statistically significant at the 95\% confidence level.
\end{tabular}

Initial odometers $32 \mathrm{k}-35 \mathrm{k}$

* Indicates estimate is different from zero at the $95 \%$ confidence level.

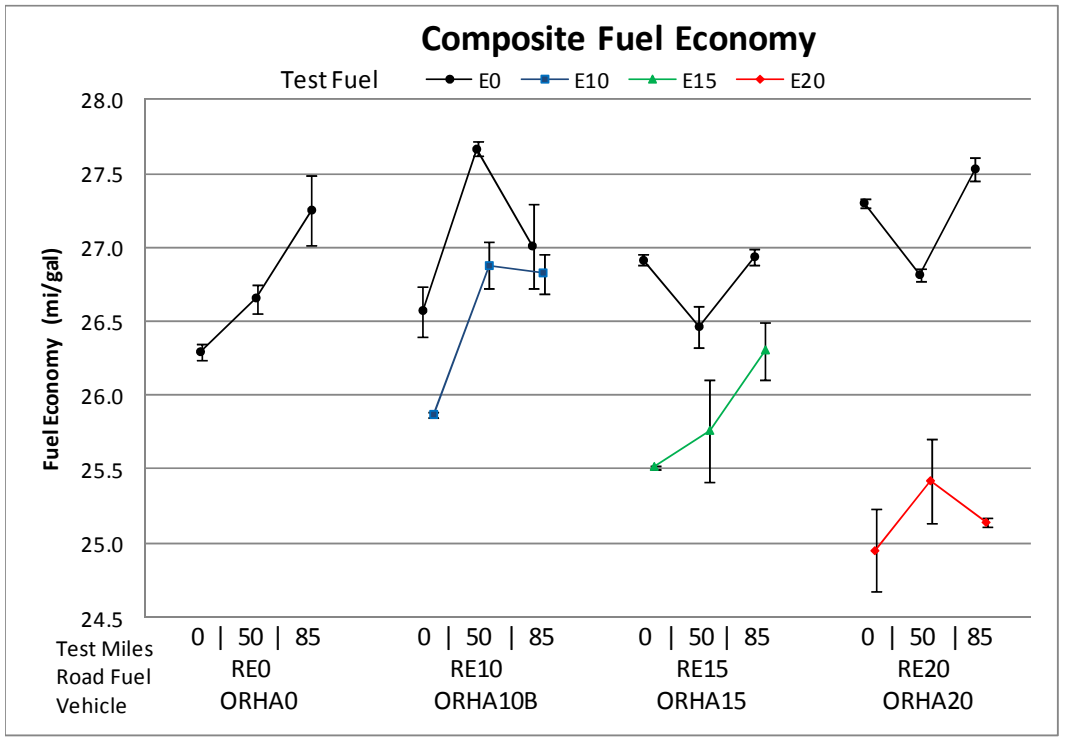

Error bars represent min and max measurements

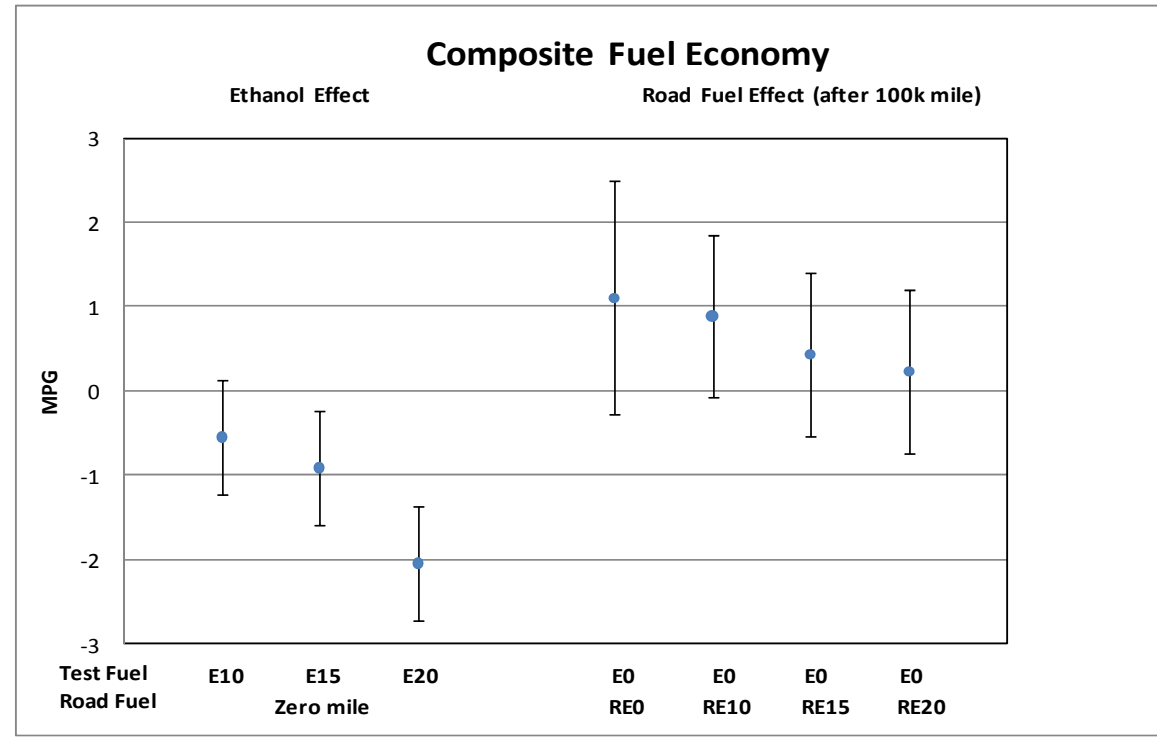

Error bars represent $95 \%$ confidence intervals on the estimated effects 
2007 Honda Accord (Composite Ethanol)

\begin{tabular}{|c|c|c|c|}
\hline Effect & Estimate & $\begin{array}{l}95 \% \text { C.I. } \\
\text { Lower }\end{array}$ & $\begin{array}{l}95 \% \text { C.I. } \\
\text { Upper }\end{array}$ \\
\hline Ethanol Effect (E10 vs. E0) $(\Delta \mathrm{mg} / \mathrm{mi})$ & $0.656^{*}$ & 0.285 & 1.026 \\
\hline Ethanol Effect (E15 vs. E0) $(\Delta \mathrm{mg} / \mathrm{mi})$ & $0.901^{*}$ & 0.531 & 1.271 \\
\hline Ethanol Effect (E20 vs. E0) $(\Delta \mathrm{mg} / \mathrm{mi})$ & $1.445^{*}$ & 1.075 & 1.815 \\
\hline \multicolumn{4}{|l|}{ Road Fuel Aging Effect } \\
\hline Aging Effect with RE0 ( $\Delta \mathrm{mg} / \mathrm{mi}$ per $100 \mathrm{k} \mathrm{mi})$ & 0.033 & -0.729 & 0.794 \\
\hline Aging Effect with RE10 ( $\Delta \mathrm{mg} / \mathrm{mi}$ per $100 \mathrm{k} \mathrm{mi})$ & 0.098 & -0.433 & 0.630 \\
\hline Aging Effect with RE15 ( $\Delta \mathrm{mg} / \mathrm{mi}$ per $100 \mathrm{k} \mathrm{mi})$ & -0.163 & -0.694 & 0.368 \\
\hline Aging Effect with RE20 ( $\Delta \mathrm{mg} / \mathrm{mi}$ per $100 \mathrm{k} \mathrm{mi})$ & 0.095 & -0.436 & 0.626 \\
\hline
\end{tabular}

\begin{tabular}{|l|r|}
\hline \multicolumn{1}{|c|}{ Hypothesis } & p-value \\
\hline No Effect of Ethanol in the Test Fuel (Gamma $=0)$ & $<0.01^{*}$ \\
\hline No Aging Effect with RE0 (Beta0 $=0)$ & 0.92 \\
\hline No Effect of Ethanol in Road Fuel Aging (Beta1s=0) & 0.81 \\
\hline * Indicates effect is statistically significant at the 95\% confidence level.
\end{tabular}

* Indicates estimate is different from zero at the $95 \%$ confidence level.

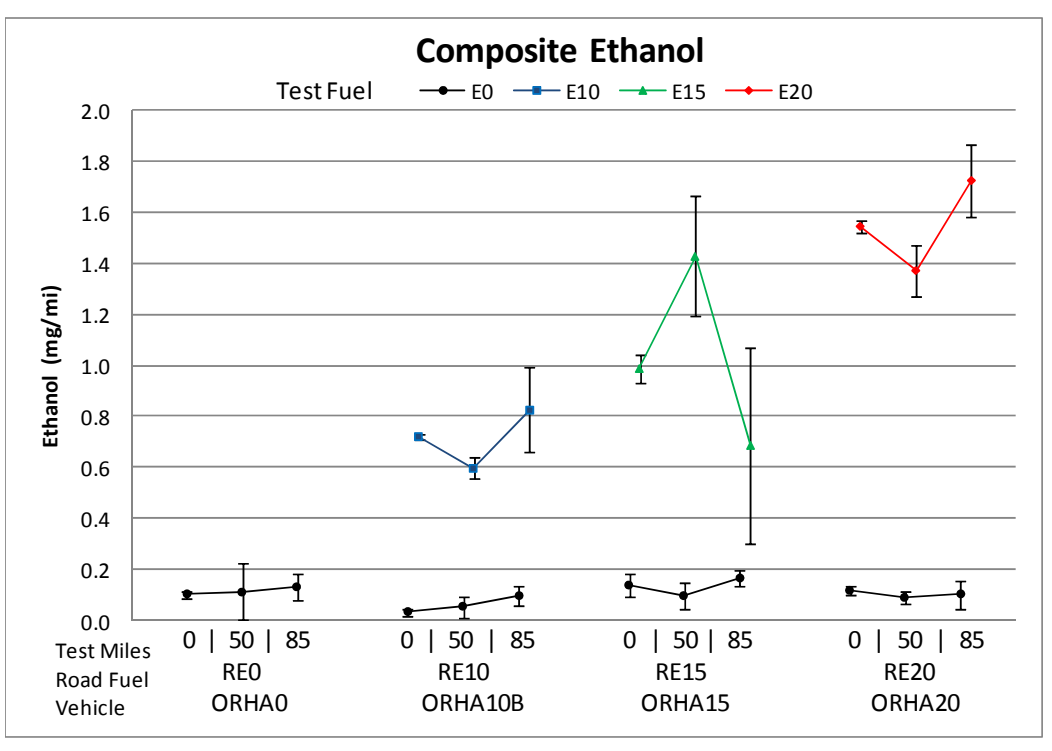

Error bars represent min and max measurements

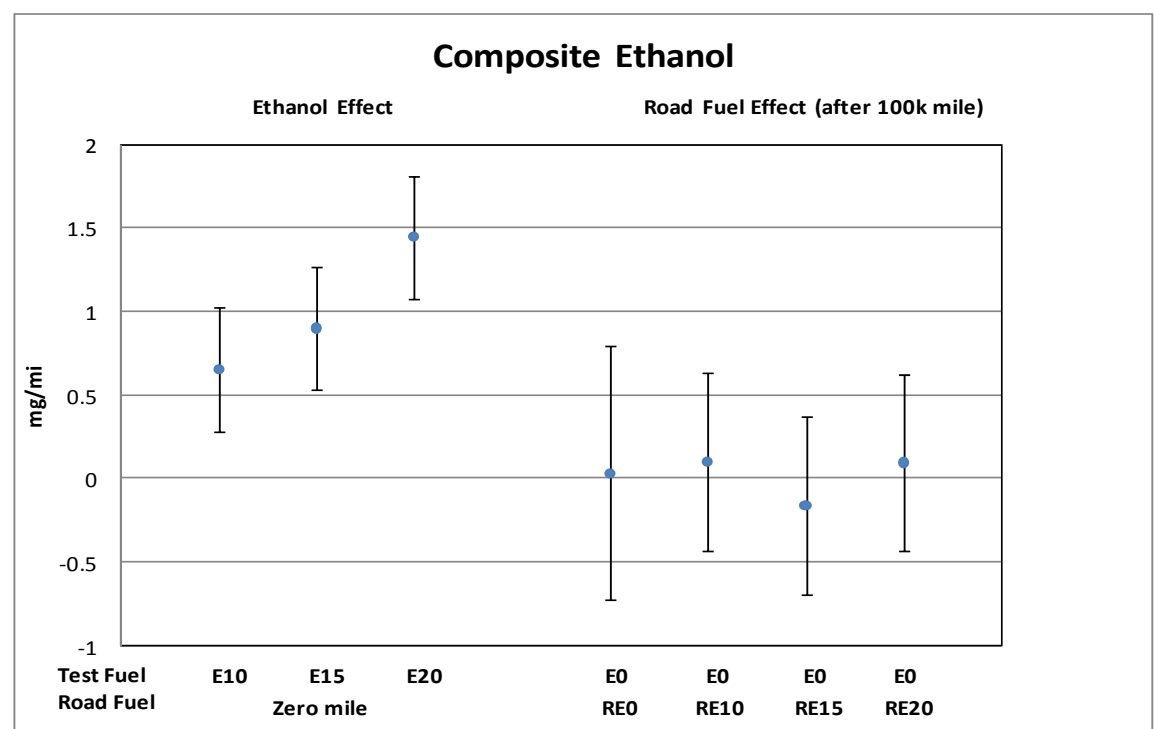

Error bars represent $95 \%$ confidence intervals on the estimated effects 
2007 Honda Accord (Composite Acetaldehyde)

\begin{tabular}{|l|r|r|r|}
\hline \multicolumn{1}{|c|}{ Effect } & Estimate & $\begin{array}{r}\text { 95\% C.I. } \\
\text { Lower }\end{array}$ & $\begin{array}{r}95 \% \text { C.I. } \\
\text { Upper }\end{array}$ \\
\hline Ethanol Effect $($ E10 vs. E0) $(\Delta \mathrm{mg} / \mathrm{mi})$ & $0.215^{*}$ & 0.070 & 0.360 \\
\hline Ethanol Effect $(E 15 \mathrm{vs}$. E0) $(\Delta \mathrm{mg} / \mathrm{mi})$ & $0.497^{*}$ & 0.353 & 0.642 \\
\hline Ethanol Effect $(E 20$ vs. E0) $(\Delta \mathrm{mg} / \mathrm{mi})$ & $0.610^{*}$ & 0.465 & 0.754 \\
\hline Road Fuel Aging Effect & & & \\
\hline Aging Effect with RE0 $(\Delta \mathrm{mg} / \mathrm{mi}$ per 100k mi) & 0.145 & -0.153 & 0.443 \\
\hline Aging Effect with RE10 $(\Delta \mathrm{mg} / \mathrm{mi}$ per 100k mi) & 0.058 & -0.149 & 0.266 \\
\hline Aging Effect with RE15 $(\Delta \mathrm{mg} / \mathrm{mi} \mathrm{per} \mathrm{100k} \mathrm{mi)}$ & 0.146 & -0.062 & 0.354 \\
\hline Aging Effect with RE20 $(\Delta \mathrm{mg} / \mathrm{mi}$ per 100k mi) & $0.249^{*}$ & 0.041 & 0.456 \\
\hline
\end{tabular}

\begin{tabular}{|l|r|}
\hline \multicolumn{1}{|c|}{ Hypothesis } & p-value \\
\hline No Effect of Ethanol in the Test Fuel (Gamma = 0) & $<0.01^{*}$ \\
\hline No Aging Effect with RE0 (Beta0 $=0)$ & 0.28 \\
\hline No Effect of Ethanol in Road Fuel Aging (Beta1s=0) & 0.52 \\
\hline * Indicates effect is statistically significant at the 95\% confidence level.
\end{tabular}

Initial odometers $32 \mathrm{k}-35 \mathrm{k}$

${ }^{*}$ Indicates estimate is different from zero at the $95 \%$ confidence level.
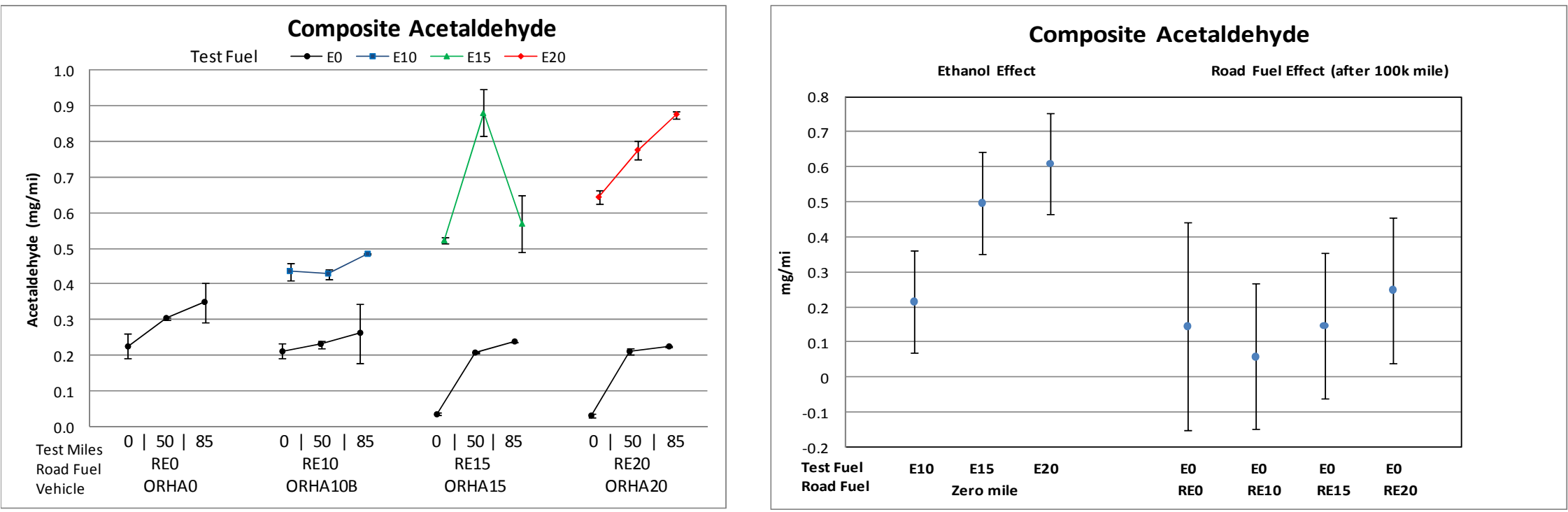

Error bars represent min and max measurements

Error bars represent $95 \%$ confidence intervals on the estimated effects

* The statistical model for Acetaldehyde does not assume the linear relationship between emission and mileage. 
2007 Honda Accord (Composite Formaldehyde)

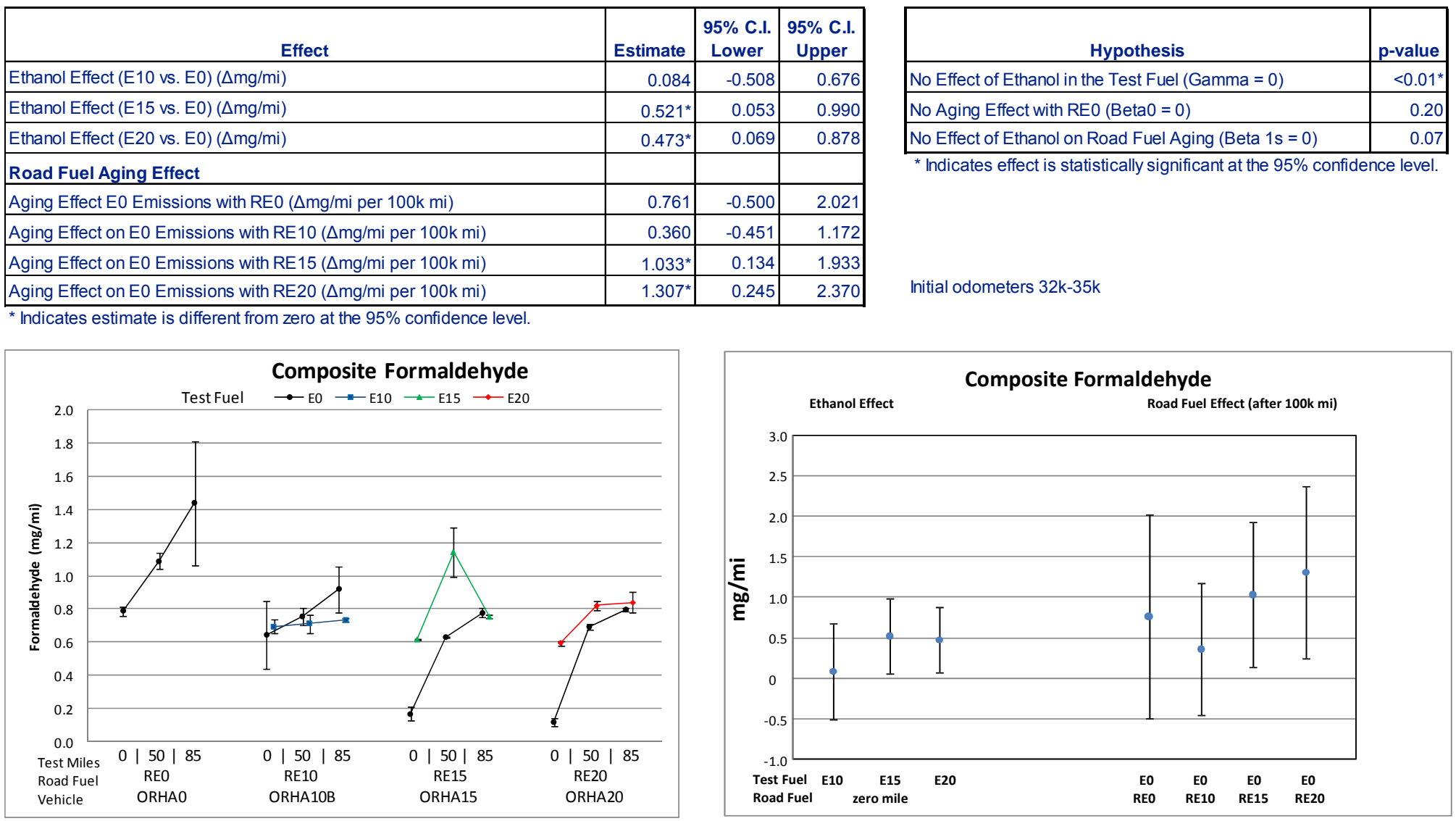

Error bars represent min and max measurements

Error bars represent $95 \%$ confidence intervals on the estimated effects 
2007 Honda Accord (Composite $\mathrm{CH}_{4}$ )

\begin{tabular}{|l|r|r|r|}
\hline \multicolumn{1}{|c|}{ Effect } & Estimate & $\begin{array}{c}95 \% \text { C.I. } \\
\text { Lower }\end{array}$ & $\begin{array}{c}95 \% \text { C.I. } \\
\text { Upper }\end{array}$ \\
\hline Ethanol Effect $(E 10$ vs. E0) $(\Delta \mathrm{g} / \mathrm{mi})$ & -0.0006 & -0.0016 & 0.0003 \\
\hline Ethanol Effect $(E 15$ vs. E0) $(\Delta \mathrm{g} / \mathrm{mi})$ & -0.0004 & -0.0014 & 0.0006 \\
\hline Ethanol Effect $(E 20 \mathrm{vs.} \mathrm{E0)}(\Delta \mathrm{g} / \mathrm{mi})$ & -0.0005 & -0.0015 & 0.0005 \\
\hline Road Fuel Aging Effect & & & \\
\hline Aging Effect with RE0 $(\Delta \mathrm{g} / \mathrm{mi}$ per 100k mi) & 0.0007 & -0.0013 & 0.0027 \\
\hline Aging Effect with RE10 $(\Delta \mathrm{g} / \mathrm{mi}$ per 100k mi) & $0.0023^{*}$ & 0.0010 & 0.0037 \\
\hline Aging Effect with RE15 $(\Delta \mathrm{g} / \mathrm{mi}$ per 100k mi) & 0.0010 & -0.0004 & 0.0024 \\
\hline Aging Effect with RE20 $(\Delta \mathrm{g} / \mathrm{mi} \mathrm{per} \mathrm{100k} \mathrm{mi)}$ & 0.0003 & -0.0010 & 0.0017 \\
\hline
\end{tabular}

\begin{tabular}{|l|r|}
\hline \multicolumn{1}{|c|}{ Hypothesis } & p-value \\
\hline No Effect of Ethanol in the Test Fuel (Gamma = 0) & 0.29 \\
\hline No Aging Effect with RE0 (Beta0 = 0) & 0.44 \\
\hline No Effect of Ethanol in Road Fuel Aging (Beta1s=0) & 0.18 \\
\hline
\end{tabular}

Initial odometers 32k-35k

* Indicates estimate is different from zero at the $95 \%$ confidence level.

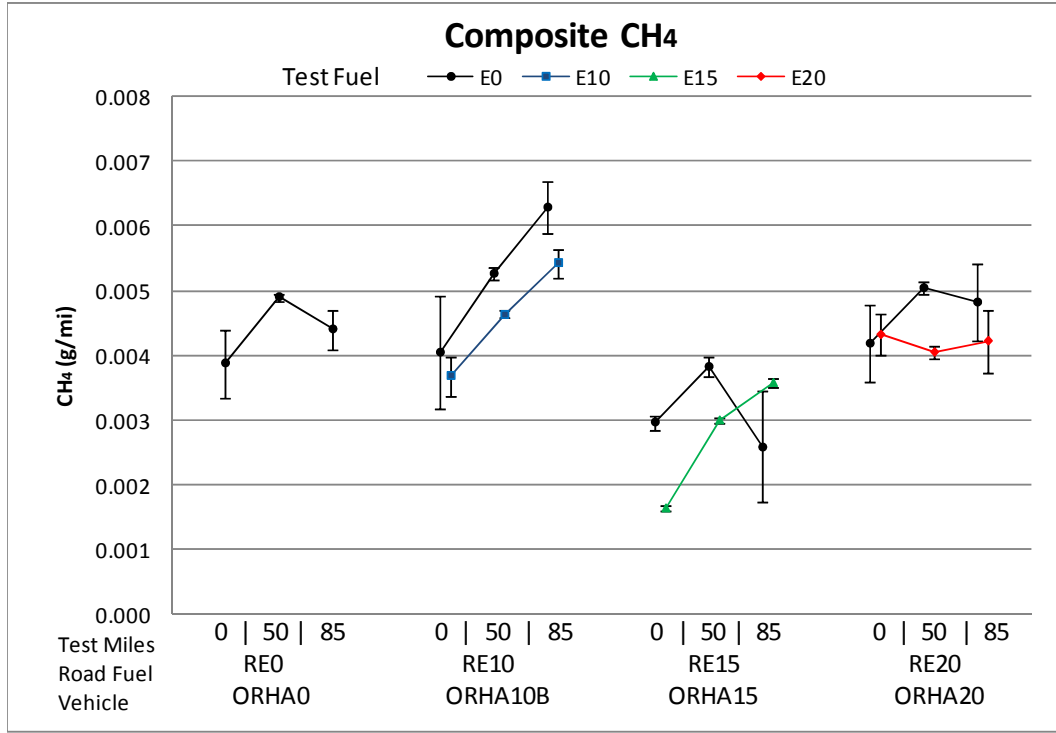

Error bars represent min and max measurements

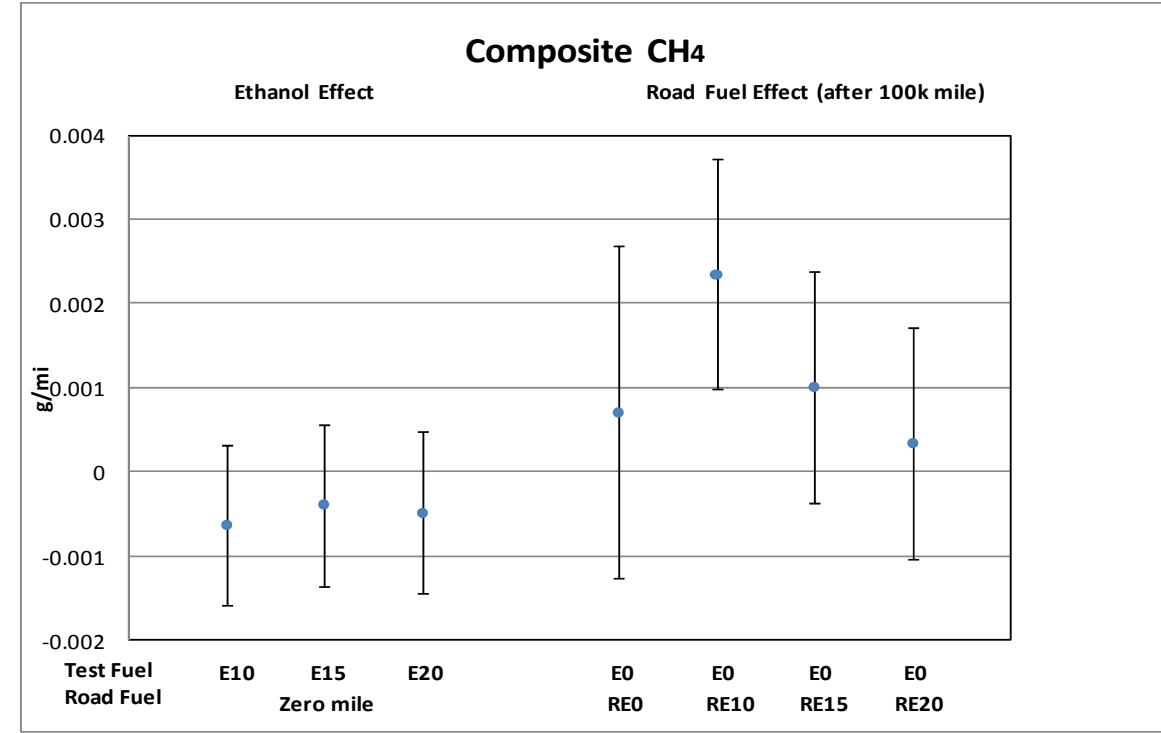

Error bars represent $95 \%$ confidence intervals on the estimated effects 


\section{Chevrolet Silverado - Composite Emissions Summary}

\begin{tabular}{|c|c|c|c|c|c|c|c|c|c|c|c|c|c|c|}
\hline \multirow{3}{*}{$\begin{array}{l}\begin{array}{c}\text { Emisssion Parameter } \\
\text { (units) }\end{array} \\
\text { Fuels } \\
\end{array}$} & \multicolumn{4}{|c|}{ Ethanol Effect } & \multicolumn{2}{|c|}{ Aging Effect with REO } & \multicolumn{4}{|c|}{ RExx Aging Effect on EO Emissions } & \multirow{2}{*}{\multicolumn{3}{|c|}{\begin{tabular}{|c|} 
RExx Aging Effect on Exx Emissions \\
$\Delta$ units per $100 \mathrm{~K}$ mi \\
\end{tabular}}} & \multirow{3}{*}{\begin{tabular}{|c|}
$\begin{array}{c}\text { Road and Test } \\
\text { Fuel Effects } \\
\text { are Additive }\end{array}$ \\
$\begin{array}{c}\text { Overall p- } \\
\text { value }\end{array}$ \\
\end{tabular}} \\
\hline & \multicolumn{3}{|c|}{$\Delta$ units vs. EO } & \multirow{2}{*}{$\begin{array}{l}\text { Overall } \\
p \text {-value }\end{array}$} & \multirow{2}{*}{$\begin{array}{c}\Delta \text { units per } 100 \mathrm{~K} \mathrm{mi} \\
\text { REO/EO }\end{array}$} & \multirow{2}{*}{$\begin{array}{l}\text { Overall } \\
p \text {-value }\end{array}$} & \multicolumn{3}{|c|}{$\Delta$ units per $100 \mathrm{~K} \mathrm{mi}$} & \multirow{2}{*}{$\begin{array}{l}\text { Overall } \\
p \text {-value }\end{array}$} & & & & \\
\hline & E10 & E15 & E20 & & & & RE10/E0 & RE15/E0 & RE20/E0 & & RE10/E10 & RE15/E15 & RE20/E20 & \\
\hline $\mathrm{CO}(\mathrm{g} / \mathrm{mi})$ & 0.028 & -0.066 & -0.067 & 0.87 & -0.055 & 0.81 & 0.012 & 0.071 & -0.169 & 0.73 & $\mathrm{NA}$ & $\mathrm{NA}$ & $\mathrm{NA}$ & 0.96 \\
\hline NOx (g/mi) & 0.008 & 0.008 & 0.001 & 0.48 & 0.006 & 0.64 & $0.021 *$ & 0.013 & $0.023 *$ & 0.69 & NA & $\mathrm{NA}$ & $\mathrm{NA}$ & 0.92 \\
\hline $\mathrm{NMHC}(\mathrm{g} / \mathrm{mi})$ & 0.007 & -0.001 & -0.002 & 0.95 & 0.005 & 0.82 & 0.013 & 0.014 & 0.006 & 0.97 & NA & NA & NA & 0.99 \\
\hline NMOG (g/mi) & 0.011 & 0.005 & 0.005 & 0.77 & 0.005 & 0.82 & 0.015 & 0.015 & 0.007 & 0.97 & NA & NA & NA & 0.99 \\
\hline Fuel Econ (mi/gal) & $-0.580 *$ & $-0.898^{*}$ & $-1.157 *$ & $<0.01 *$ & 0.606 & 0.21 & 0.267 & 0.079 & 0.163 & 0.79 & NA & $\mathrm{NA}$ & $\mathrm{NA}$ & $\mathrm{NA}$ \\
\hline 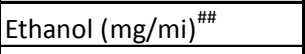 & $2.349 *$ & $3.499 *$ & $4.366 *$ & $<0.01 *$ & -0.058 & 0.97 & 0.732 & 0.505 & 0.418 & 0.97 & $\mathrm{NA}$ & $\mathrm{NA}$ & $\mathrm{NA}$ & $\mathrm{NA}$ \\
\hline Acetaldehyde $(\mathrm{mg} / \mathrm{mi})^{\#}$ & $0.468 *$ & $0.857 *$ & $0.997 *$ & $<0.01 *$ & $0.124 *$ & $0.02 *$ & $0.184 *$ & $0.119 *$ & $0.109 *$ & 0.59 & NA & $\mathrm{NA}$ & $\mathrm{NA}$ & 0.23 \\
\hline Formaldehyde $(\mathrm{mg} / \mathrm{mi})^{\# a}$ & 0.025 & -0.059 & 0.064 & 0.80 & $0.432 *$ & $0.02 *$ & $0.756 *$ & $0.425 *$ & $0.710^{*}$ & 0.21 & $\mathrm{NA}$ & $\mathrm{NA}$ & $\mathrm{NA}$ & 0.20 \\
\hline $\mathrm{CH}_{4}(\mathrm{~g} / \mathrm{mi})$ & 0.0043 & 0.0009 & 0.0014 & 0.58 & 0.0103 & 0.12 & 0.0070 & $0.0126 *$ & $0.0124 *$ & 0.78 & $\mathrm{NA}$ & $\mathrm{NA}$ & NA & 0.64 \\
\hline
\end{tabular}

\# Log-normal model was used. Results are presented as changes in emissions at 0k mile.

\#\# Data did not support the assumption of linear effects with mileage.

(T) * Indicates estimate is different from zero at the $95 \%$ confidence level.

a Test "SW021494" is identified as an outlier and excluded from the analysis. 
2006 Chevrolet Silverado (Composite CO)

\begin{tabular}{|l|r|r|r|}
\hline \multicolumn{1}{|c|}{ Effect } & & $\begin{array}{r}95 \% \text { C.I. } \\
\text { Lo5\% C.I. } \\
\text { Upper }\end{array}$ \\
\hline Ethanol Effect (E10 vs. E0) $(\Delta \mathrm{g} / \mathrm{mi})$ & 0.028 & -0.233 & 0.288 \\
\hline Ethanol Effect $(E 15$ vs. E0) $(\Delta \mathrm{g} / \mathrm{mi})$ & -0.066 & -0.326 & 0.195 \\
\hline Ethanol Effect $(E 20 \mathrm{vs.} \mathrm{E0)}(\Delta \mathrm{g} / \mathrm{mi})$ & -0.067 & -0.328 & 0.193 \\
\hline Road Fuel Aging Effect & & & \\
\hline Aging Effect with RE0 $(\Delta \mathrm{g} / \mathrm{mi} \mathrm{per} \mathrm{100k} \mathrm{mi)}$ & -0.055 & -0.544 & 0.434 \\
\hline Aging Effect with RE10 $(\Delta \mathrm{g} / \mathrm{mi}$ per 100k mi) & 0.012 & -0.334 & 0.358 \\
\hline Aging Effect with RE15 $(\Delta \mathrm{g} / \mathrm{mi}$ per 100k mi) & 0.071 & -0.275 & 0.417 \\
\hline Aging Effect with RE20 $(\Delta \mathrm{g} / \mathrm{mi} \mathrm{per} \mathrm{100k} \mathrm{mi)}$ & -0.169 & -0.515 & 0.177 \\
\hline
\end{tabular}

\begin{tabular}{|l|r|}
\hline \multicolumn{1}{|c|}{ Hypothesis } & p-value \\
\hline No Effect of Ethanol in the Test Fuel (Gamma = 0) & 0.87 \\
\hline No Aging Effect with RE0 (Beta0 = 0) & 0.81 \\
\hline No Effect of Ethanol in Road Fuel Aging (Beta1s=0) & 0.73 \\
\hline * Indicates effect is statistically significant at the 95\% confidence level.
\end{tabular}

Initial odometers $14 \mathrm{k}-28 \mathrm{k}$

* Indicates estimate is different from zero at the $95 \%$ confidence level.

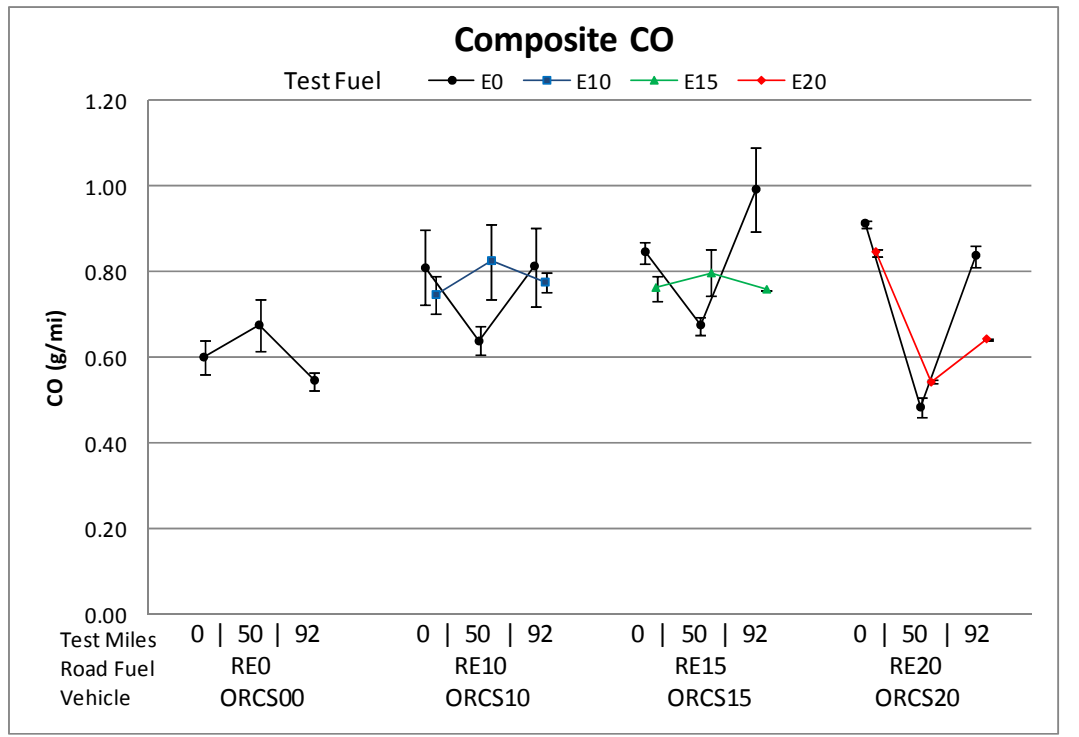

Error bars represent min and max measurements

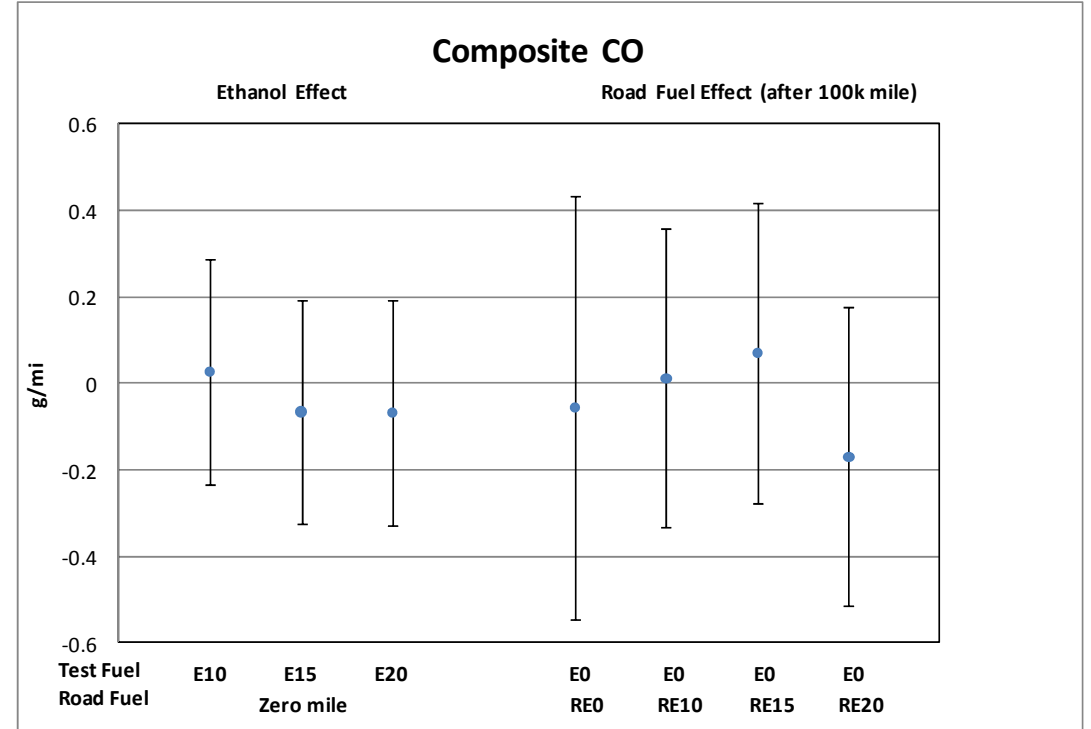

Error bars represent $95 \%$ confidence intervals on the estimated effects 
2006 Chevrolet Silverado (Composite NOx)

\begin{tabular}{|l|r|r|r|}
\hline \multicolumn{1}{|c|}{ Effect } & Estimate & $\begin{array}{c}\text { 95\% C.I. } \\
\text { Lower }\end{array}$ & $\begin{array}{c}\text { 95\% C.I. } \\
\text { Upper }\end{array}$ \\
\hline Ethanol Effect $(E 10 \mathrm{vs.} \mathrm{E0)}(\Delta \mathrm{g} / \mathrm{mi})$ & 0.008 & -0.007 & 0.023 \\
\hline Ethanol Effect $(E 15 \mathrm{vs.} \mathrm{E0)} \Delta \mathrm{g} / \mathrm{mi})$ & 0.008 & -0.008 & 0.023 \\
\hline Ethanol Effect $(E 20 \mathrm{vs.} \mathrm{E0)}(\Delta \mathrm{g} / \mathrm{mi})$ & 0.001 & -0.014 & 0.016 \\
\hline Road Fuel Aging Effect & & & \\
\hline Aging Effect with RE0 $(\Delta \mathrm{g} / \mathrm{mi}$ per 100k mi) & 0.006 & -0.022 & 0.035 \\
\hline Aging Effect with RE10 $(\Delta \mathrm{g} / \mathrm{mi}$ per 100k mi) & $0.021^{*}$ & 0.001 & 0.042 \\
\hline Aging Effect with RE15 $(\Delta \mathrm{g} / \mathrm{mi}$ per 100k mi) & 0.013 & -0.007 & 0.033 \\
\hline Aging Effect with RE20 $(\Delta \mathrm{g} / \mathrm{mi}$ per 100k mi) & $0.023^{*}$ & 0.002 & 0.043 \\
\hline
\end{tabular}

\begin{tabular}{|l|r|}
\hline \multicolumn{1}{|c|}{ Hypothesis } & p-value \\
\hline No Effect of Ethanol in the Test Fuel (Gamma = 0) & 0.48 \\
\hline No Aging Effect with RE0 (Beta0 = 0) & 0.64 \\
\hline No Effect of Ethanol in Road Fuel Aging (Beta1s=0) & 0.69 \\
\hline
\end{tabular}

Initial odometers $14 \mathrm{k}-28 \mathrm{k}$

* Indicates estimate is different from zero at the $95 \%$ confidence level.

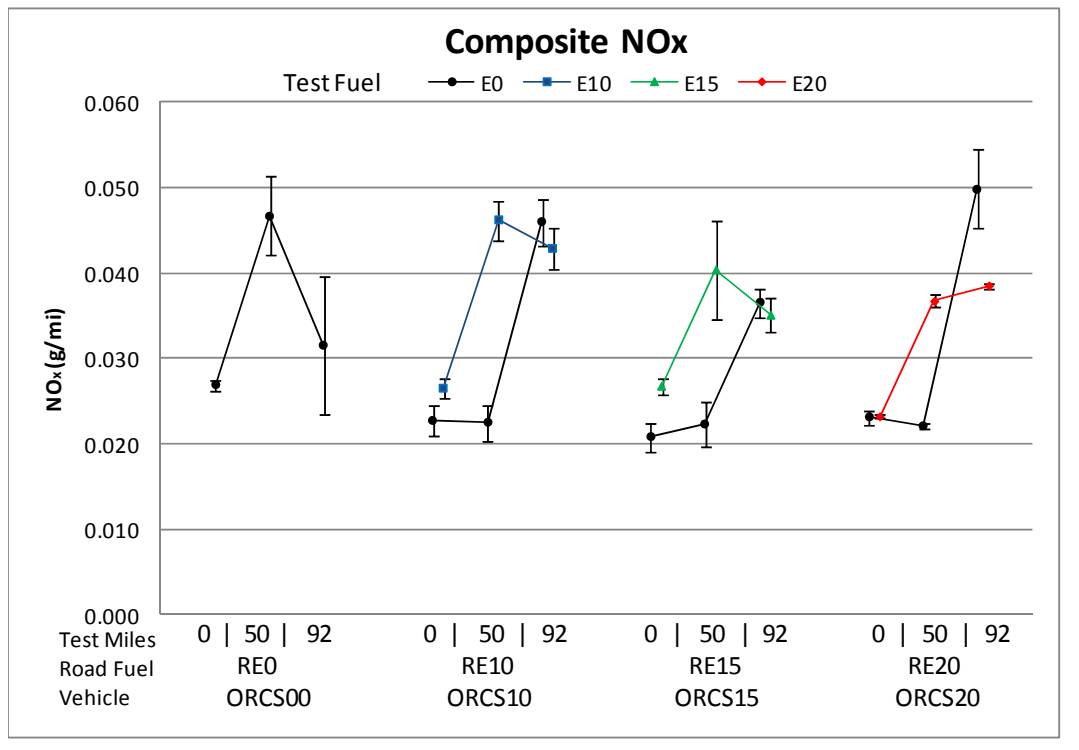

Error bars represent min and max measurements

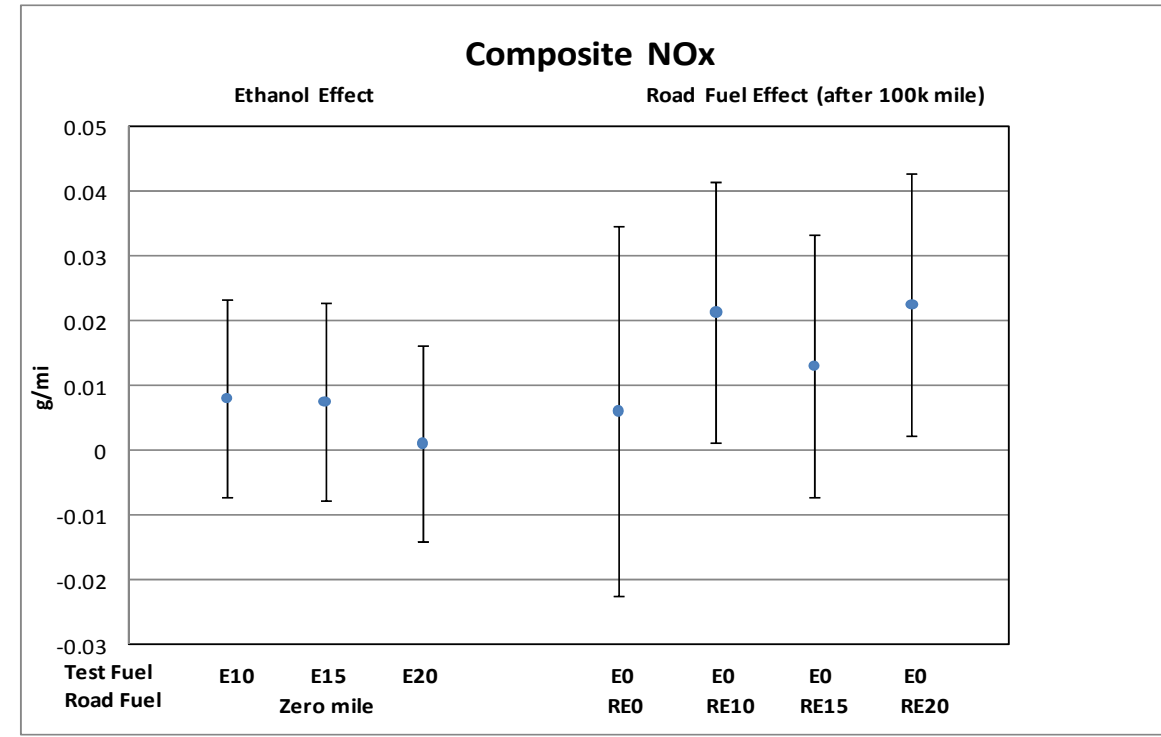

Error bars represent $95 \%$ confidence intervals on the estimated effects 
2006 Chevrolet Silverado (Composite Nonmethane Hydrocarbons)

\begin{tabular}{|l|r|r|r|}
\hline \multicolumn{1}{|c|}{ Effect } & & $\begin{array}{r}95 \% \text { C.I. } \\
\text { Lo5\% C.I. } \\
\text { Estimate }\end{array}$ & $\begin{array}{c}\text { Lower } \\
\text { Upper }\end{array}$ \\
\hline Ethanol Effect (E10 vs. E0) $(\Delta \mathrm{g} / \mathrm{mi})$ & 0.007 & -0.019 & 0.032 \\
\hline Ethanol Effect $(E 15$ vs. E0) $(\Delta \mathrm{g} / \mathrm{mi})$ & -0.001 & -0.026 & 0.025 \\
\hline Ethanol Effect $(E 20 \mathrm{vs.} \mathrm{E0)}(\Delta \mathrm{g} / \mathrm{mi})$ & -0.002 & -0.028 & 0.024 \\
\hline Road Fuel Aging Effect & & & \\
\hline Aging Effect with RE0 $(\Delta \mathrm{g} / \mathrm{mi}$ per 100k mi) & 0.005 & -0.043 & 0.053 \\
\hline Aging Effect with RE10 $(\Delta \mathrm{g} / \mathrm{mi}$ per 100k mi) & 0.013 & -0.021 & 0.047 \\
\hline Aging Effect with RE15 $(\Delta \mathrm{g} / \mathrm{mi}$ per 100k mi) & 0.014 & -0.020 & 0.048 \\
\hline Aging Effect with RE20 $(\Delta \mathrm{g} / \mathrm{mi} \mathrm{per} \mathrm{100k} \mathrm{mi)}$ & 0.006 & -0.028 & 0.040 \\
\hline
\end{tabular}

\begin{tabular}{|l|r|}
\hline \multicolumn{1}{|c|}{ Hypothesis } & p-value \\
\hline No Effect of Ethanol in the Test Fuel (Gamma = 0) & 0.95 \\
\hline No Aging Effect with RE0 (Beta0 = 0) & 0.82 \\
\hline No Effect of Ethanol in Road Fuel Aging (Beta1s=0) & 0.97 \\
\hline${ }^{*}$ Indicates effect is statistically significant at the 95\% confidence level.
\end{tabular}

Initial odometers 14k-28k

${ }^{*}$ Indicates estimate is different from zero at the $95 \%$ confidence level.

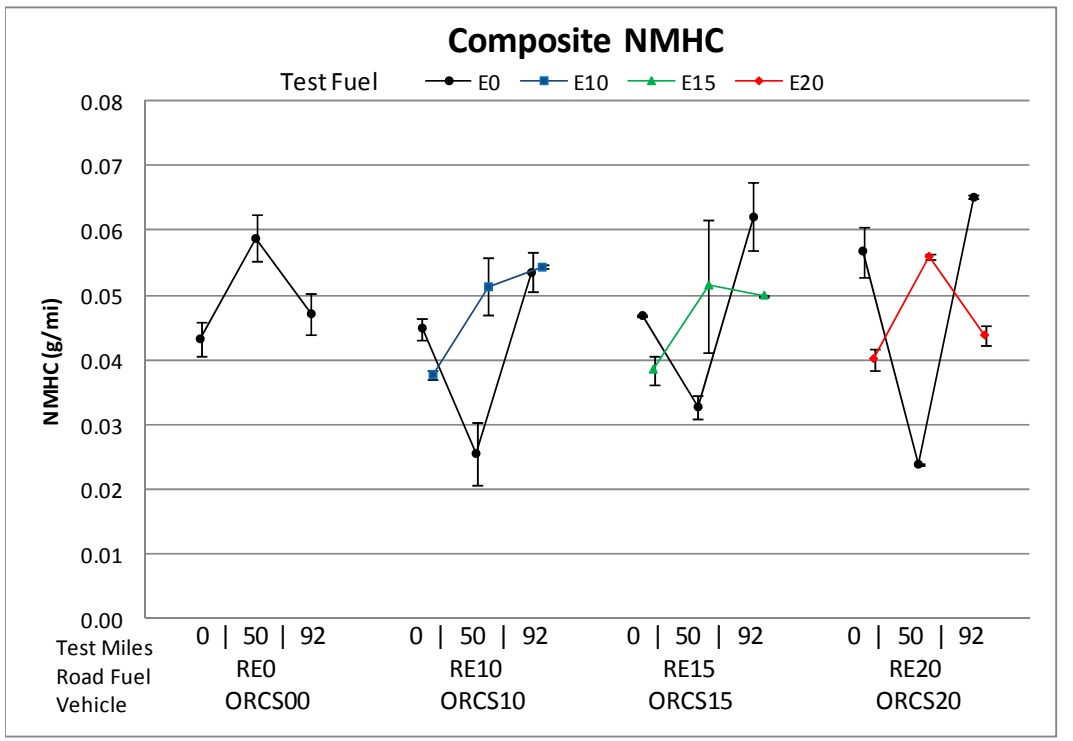

Error bars represent min and max measurements

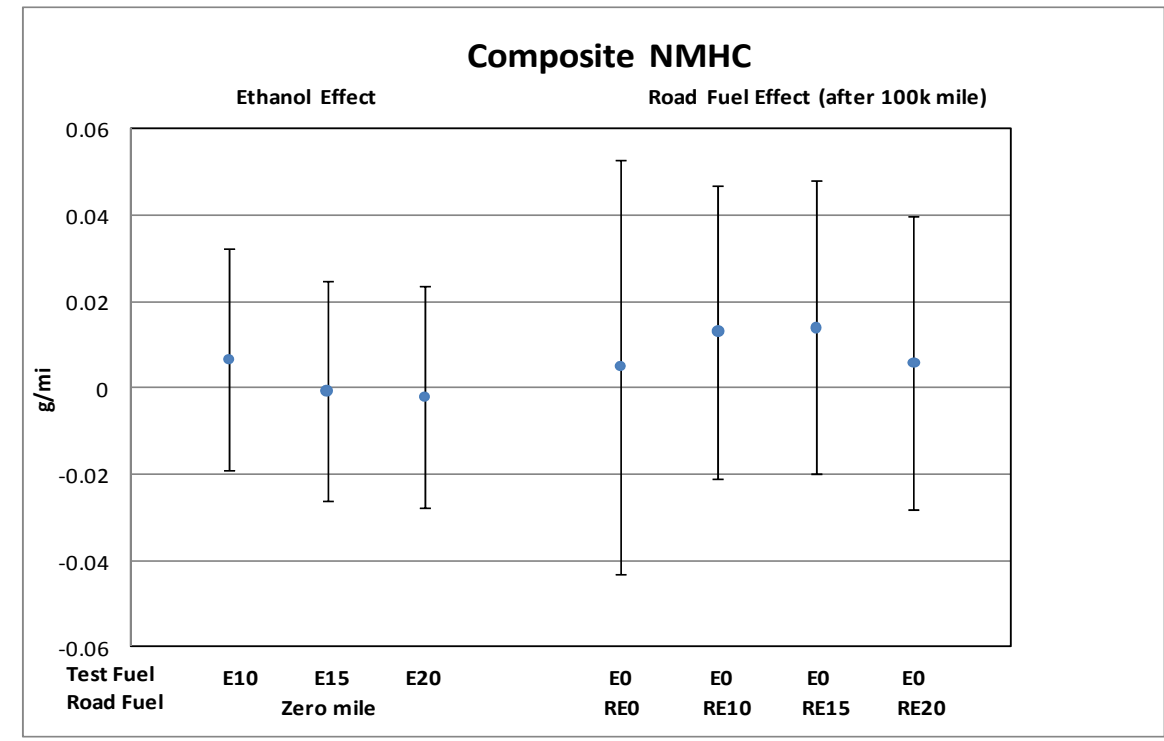

Error bars represent $95 \%$ confidence intervals on the estimated effects 
2006 Chevrolet Silverado (Composite Nonmethane Organic Gases)

\begin{tabular}{|c|c|c|c|}
\hline Effect & Estimate & $\begin{array}{l}95 \% \text { C.I. } \\
\text { Lower }\end{array}$ & $\begin{array}{c}95 \% \text { C.I. } \\
\text { Upper }\end{array}$ \\
\hline Ethanol Effect (E10 vs. E0) $(\Delta \mathrm{g} / \mathrm{mi})$ & 0.011 & -0.016 & 0.038 \\
\hline Ethanol Effect (E15 vs. E0) $(\Delta \mathrm{g} / \mathrm{mi})$ & 0.005 & -0.022 & 0.032 \\
\hline Ethanol Effect (E20 vs. E0) $(\Delta \mathrm{g} / \mathrm{mi})$ & 0.005 & -0.022 & 0.032 \\
\hline \multicolumn{4}{|l|}{ Road Fuel Aging Effect } \\
\hline Aging Effect with RE0 $(\Delta \mathrm{g} / \mathrm{mi}$ per $100 \mathrm{k} \mathrm{mi})$ & 0.005 & -0.045 & 0.055 \\
\hline Aging Effect with RE10 $(\Delta \mathrm{g} / \mathrm{mi}$ per $100 \mathrm{k} \mathrm{mi})$ & 0.015 & -0.021 & 0.050 \\
\hline Aging Effect with RE15 ( $\Delta \mathrm{g} / \mathrm{mi}$ per $100 \mathrm{k} \mathrm{mi})$ & 0.015 & -0.021 & 0.051 \\
\hline Aging Effect with RE20 $(\Delta \mathrm{g} / \mathrm{mi}$ per $100 \mathrm{k}$ mi) & 0.007 & -0.029 & 0.042 \\
\hline
\end{tabular}

\begin{tabular}{|l|r|}
\hline \multicolumn{1}{|c|}{ Hypothesis } & p-value \\
\hline No Effect of Ethanol in the Test Fuel (Gamma = 0) & 0.77 \\
\hline No Aging Effect with RE0 (Beta0 = 0) & 0.82 \\
\hline No Effect of Ethanol in Road Fuel Aging (Beta1s=0) & 0.97 \\
\hline * Indicates effect is statistically significant at the 95\% confidence level.
\end{tabular}

Initial odometers $14 \mathrm{k}-28 \mathrm{k}$

${ }^{*}$ Indicates estimate is different from zero at the $95 \%$ confidence level.

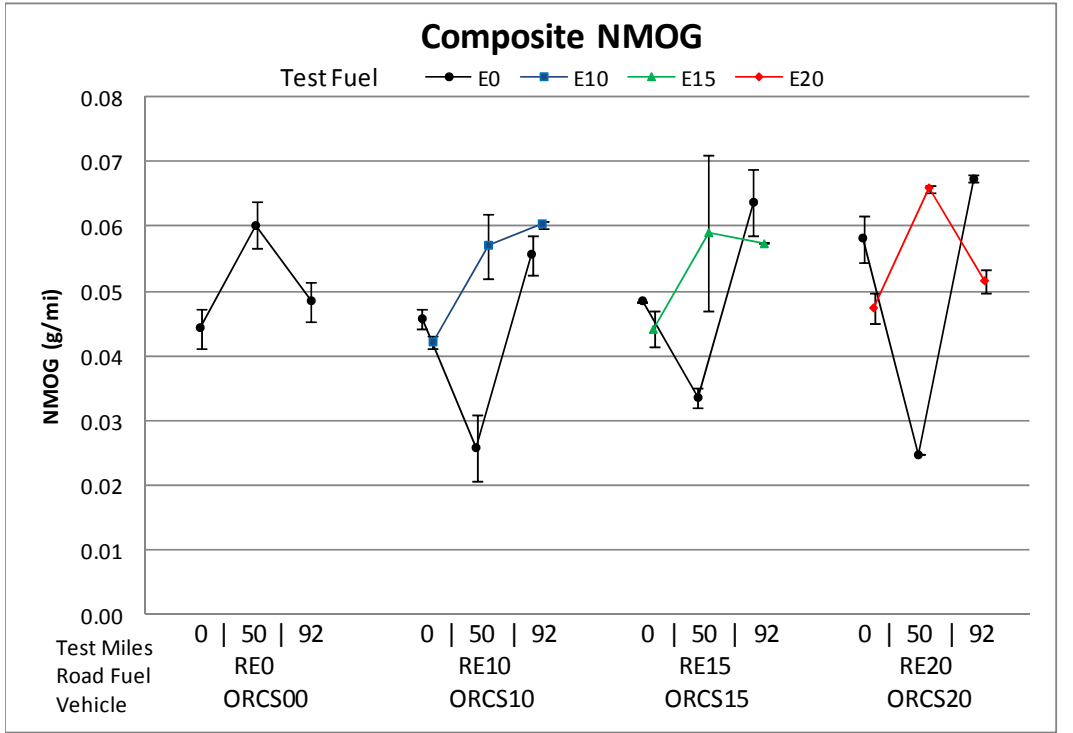

Error bars represent min and max measurements

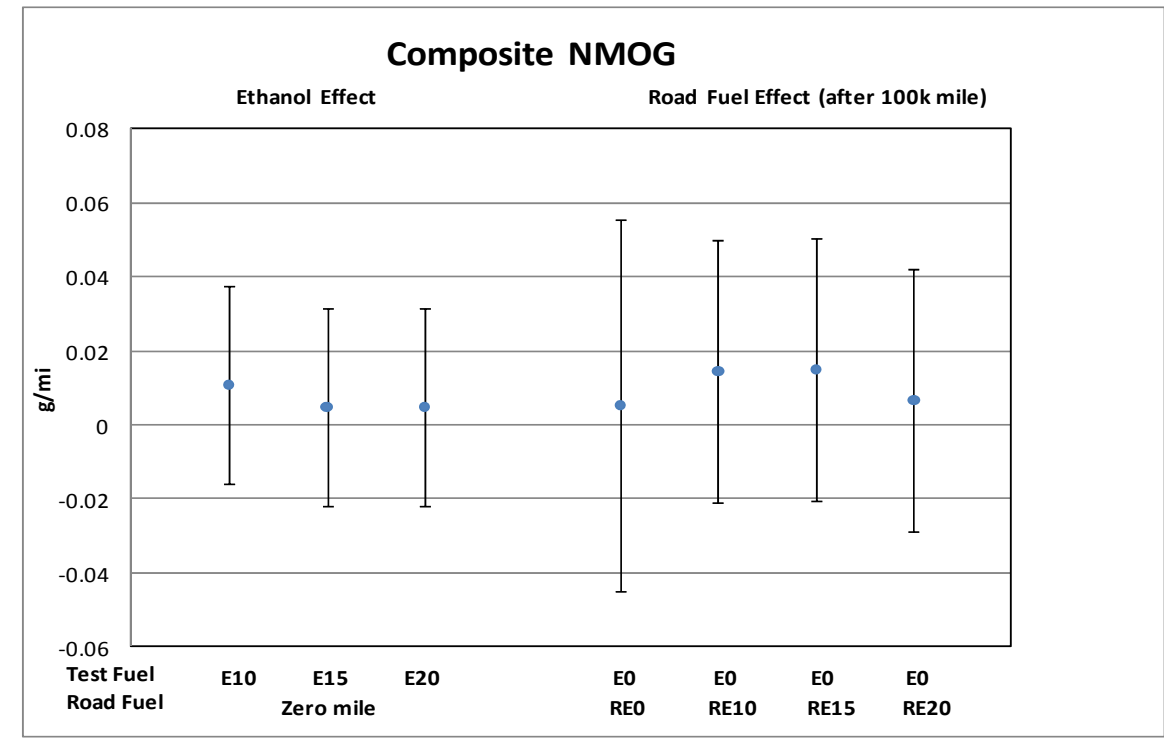

Error bars represent $95 \%$ confidence intervals on the estimated effects 
2006 Chevrolet Silverado (Composite Fuel Economy)

\begin{tabular}{|c|c|c|c|}
\hline Effect & Estimate & $\begin{array}{c}95 \% \text { C.I. } \\
\text { Lower }\end{array}$ & $\begin{array}{c}95 \% \text { C.I. } \\
\text { Upper }\end{array}$ \\
\hline Ethanol Effect (E10 vs. E0) ( $\Delta \mathrm{mi} / \mathrm{gal})$ & $-0.580^{*}$ & -1.141 & -0.020 \\
\hline Ethanol Effect (E15 vs. E0) ( $\Delta \mathrm{mi} / \mathrm{gal})$ & $-0.898^{*}$ & -1.459 & -0.338 \\
\hline Ethanol Effect (E20 vs. E0) ( $\Delta \mathrm{mi} / \mathrm{gal})$ & $-1.157^{*}$ & -1.718 & -0.596 \\
\hline \multicolumn{4}{|l|}{ Road Fuel Aging Effect } \\
\hline Aging Effect with RE0 ( $\Delta \mathrm{mi} / \mathrm{gal}$ per $100 \mathrm{k} \mathrm{mi})$ & 0.606 & -0.448 & 1.661 \\
\hline Aging Effect with RE10 $(\Delta \mathrm{mi} / \mathrm{gal}$ per $100 \mathrm{k} \mathrm{mi})$ & 0.267 & -0.479 & 1.013 \\
\hline Aging Effect with RE15 ( $\Delta \mathrm{mi} / \mathrm{gal}$ per $100 \mathrm{k} \mathrm{mi})$ & 0.079 & -0.667 & 0.825 \\
\hline Aging Effect with RE20 ( $\triangle \mathrm{mi} / \mathrm{gal}$ per $100 \mathrm{k} \mathrm{mi})$ & 0.163 & -0.583 & 0.909 \\
\hline
\end{tabular}

\begin{tabular}{|l|r|}
\hline \multicolumn{1}{|c|}{ Hypothesis } & $p$-value \\
\hline No Effect of Ethanol in the Test Fuel (Gamma $=0)$ & $<0.01^{\star}$ \\
\hline No Aging Effect with RE0 (Beta0 = 0) & 0.21 \\
\hline No Effect of Ethanol in Road Fuel Aging (Beta1s=0) & 0.79 \\
\hline${ }^{*}$ Indicates effect is statistically significant at the 95\% confidence level.
\end{tabular}

Initial odometers $14 \mathrm{k}-28 \mathrm{k}$

${ }^{*}$ Indicates estimate is different from zero at the $95 \%$ confidence level.

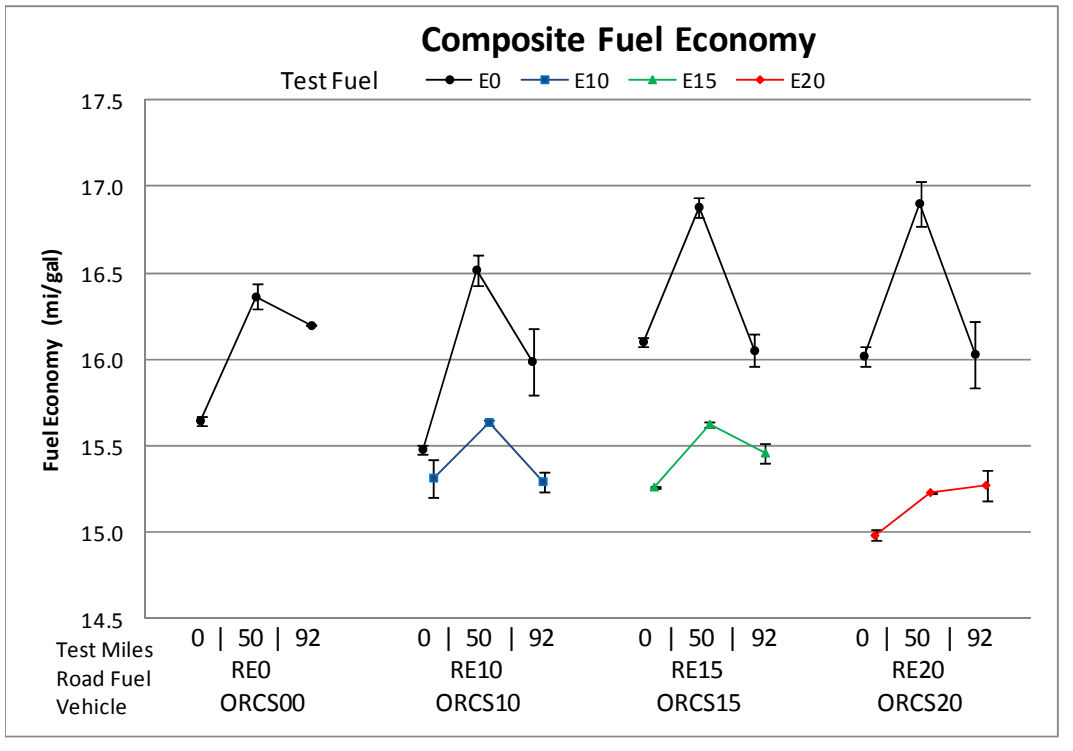

Error bars represent min and max measurements

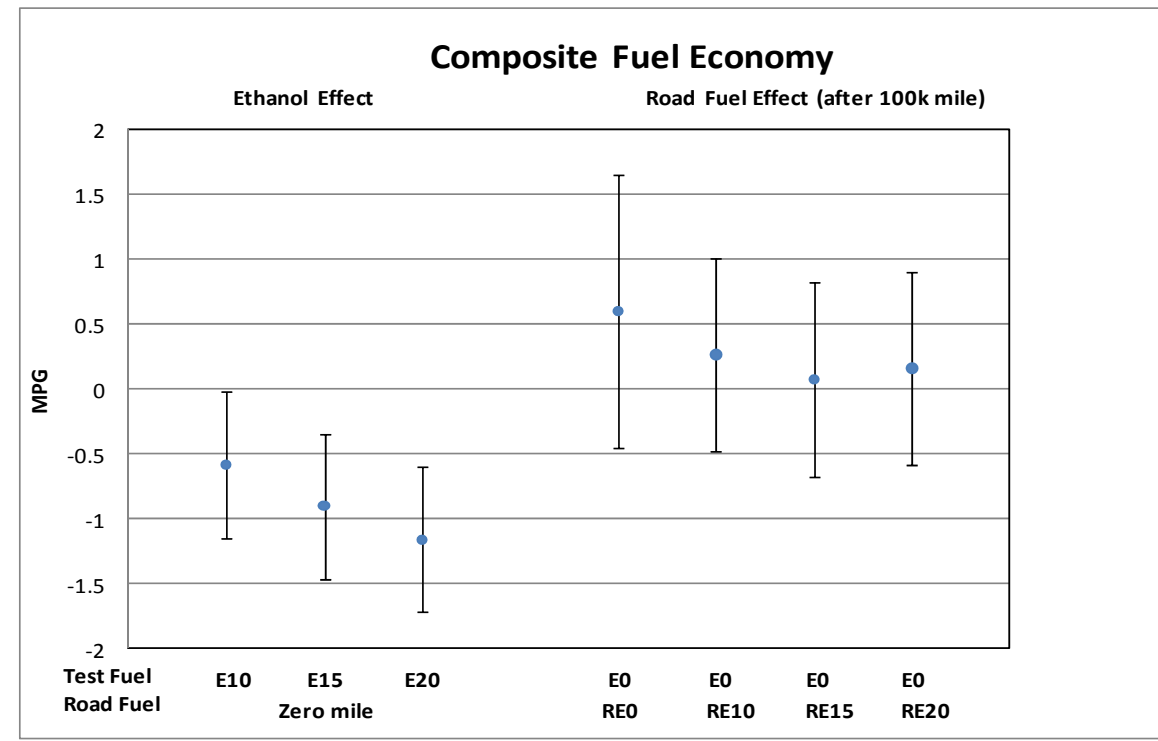

Error bars represent $95 \%$ confidence intervals on the estimated effects 
2006 Chevrolet Silverado (Composite Ethanol)

\begin{tabular}{|c|c|c|c|}
\hline Effect & Estimate & $\begin{array}{c}95 \% \text { C.I. } \\
\text { Lower }\end{array}$ & $\begin{array}{c}95 \% \text { C.I. } \\
\text { Upper }\end{array}$ \\
\hline Ethanol Effect (E10 vs. E0) ( $\Delta \mathrm{mg} / \mathrm{mi})$ & $2.349^{*}$ & 0.520 & 4.178 \\
\hline Ethanol Effect (E15 vs. E0) $(\Delta \mathrm{mg} / \mathrm{mi})$ & $3.499^{*}$ & 1.670 & 5.328 \\
\hline Ethanol Effect (E20 vs. E0) $(\Delta \mathrm{mg} / \mathrm{mi})$ & $4.366^{*}$ & 2.537 & 6.194 \\
\hline \multicolumn{4}{|l|}{ Road Fuel Aging Effect } \\
\hline Aging Effect with RE0 ( $\Delta \mathrm{mg} / \mathrm{mi}$ per $100 \mathrm{k} \mathrm{mi})$ & -0.058 & -3.498 & 3.382 \\
\hline Aging Effect with RE10 ( $\Delta \mathrm{mg} / \mathrm{mi}$ per $100 \mathrm{k} \mathrm{mi})$ & 0.732 & -1.701 & 3.166 \\
\hline Aging Effect with RE15 ( $\Delta \mathrm{mg} / \mathrm{mi}$ per $100 \mathrm{k} \mathrm{mi})$ & 0.505 & -1.928 & 2.939 \\
\hline Aging Effect with RE20 ( $\Delta \mathrm{mg} / \mathrm{mi}$ per $100 \mathrm{k} \mathrm{mi})$ & 0.418 & -2.016 & 2.851 \\
\hline
\end{tabular}

\begin{tabular}{|l|r|}
\hline \multicolumn{1}{|c|}{ Hypothesis } & p-value \\
\hline No Effect of Ethanol in the Test Fuel (Gamma = 0) & $<0.01^{*}$ \\
\hline No Aging Effect with RE0 (Beta0 = 0) & 0.97 \\
\hline No Effect of Ethanol in Road Fuel Aging (Beta1s=0) & 0.97 \\
\hline * Indicates effect is statistically significant at the 95\% confidence level.
\end{tabular}

Initial odometers $14 \mathrm{k}-28 \mathrm{k}$

${ }^{*}$ Indicates estimate is different from zero at the $95 \%$ confidence level.
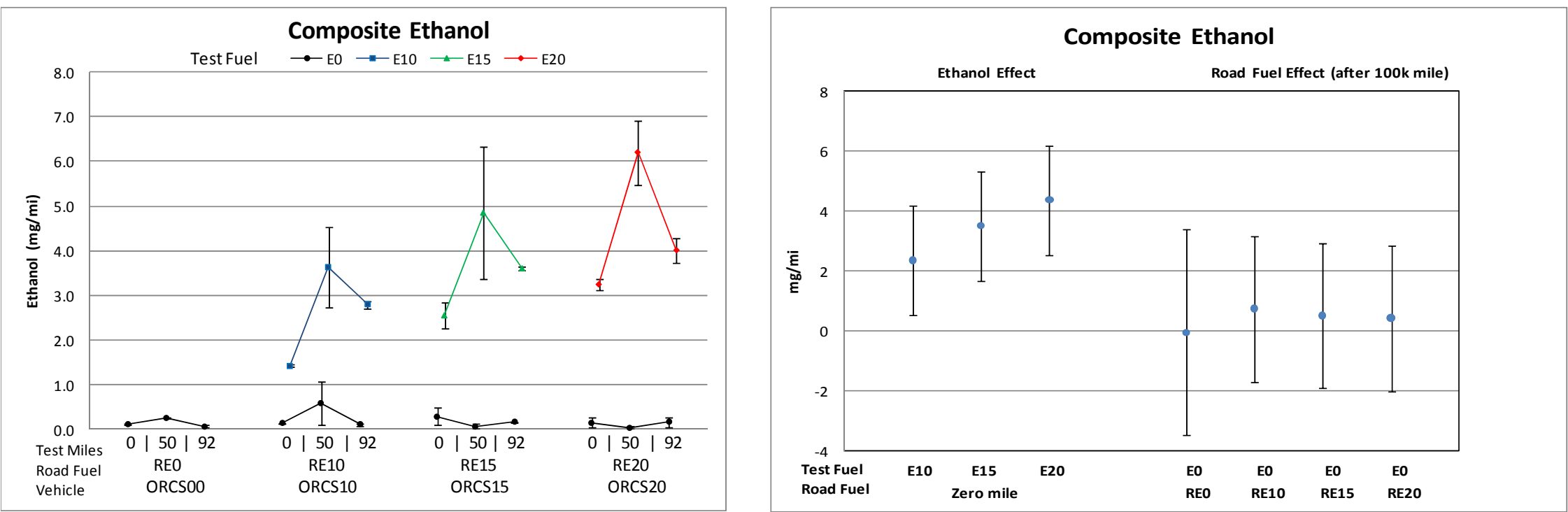

Error bars represent min and max measurements

Error bars represent $95 \%$ confidence intervals on the estimated effects

* The statistical model for Acetaldehyde does not assume the linear relationship between emission and mileage. 
2006 Chevrolet Silverado (Composite Acetaldehyde)

\begin{tabular}{|l|r|r|r|}
\hline \multicolumn{1}{|c|}{ Effect } & & $\begin{array}{r}95 \% \text { C.I. } \\
\text { Low\% C.I. } \\
\text { Upper }\end{array}$ \\
\hline Ethanol Effect (E10 vs. E0) $(\Delta \mathrm{mg} / \mathrm{mi})$ & $0.468^{*}$ & 0.322 & 0.614 \\
\hline Ethanol Effect $(E 15$ vs. E0) $(\Delta \mathrm{mg} / \mathrm{mi})$ & $0.857^{*}$ & 0.627 & 1.087 \\
\hline Ethanol Effect (E20 vs. E0) $(\Delta \mathrm{mg} / \mathrm{mi})$ & $0.997^{*}$ & 0.747 & 1.247 \\
\hline Road Fuel Aging Effect & & & \\
\hline Aging Effect with RE0 $(\Delta \mathrm{mg} / \mathrm{mi}$ per 100k mi) & $0.124^{*}$ & 0.033 & 0.215 \\
\hline Aging Effect with RE10 $(\Delta \mathrm{mg} / \mathrm{mi}$ per 100k mi) & $0.184^{*}$ & 0.086 & 0.282 \\
\hline Aging Effect with RE15 $(\Delta \mathrm{mg} / \mathrm{mi} \mathrm{per} \mathrm{100k} \mathrm{mi)}$ & $0.119^{*}$ & 0.023 & 0.216 \\
\hline Aging Effect with RE20 $(\Delta \mathrm{mg} / \mathrm{mi}$ per 100k mi) & $0.109^{*}$ & 0.023 & 0.196 \\
\hline
\end{tabular}

\begin{tabular}{|l|r|}
\hline \multicolumn{1}{|c|}{ Hypothesis } & p-value \\
\hline No Effect of Ethanol in the Test Fuel (Gamma $=0)$ & $<0.01^{*}$ \\
\hline No Aging Effect with RE0 (Beta0 $=0)$ & $0.02^{*}$ \\
\hline No Effect of Ethanol in Road Fuel Aging (Beta1s=0) & 0.59 \\
\hline * Indicates effect is statistically significant at the 95\% confidence level
\end{tabular}

* Indicates effect is statistically significant at the $95 \%$ confidence level.

Initial odometers $14 \mathrm{k}-28 \mathrm{k}$

(is diferent from zero at the $95 \%$ confidence leve.
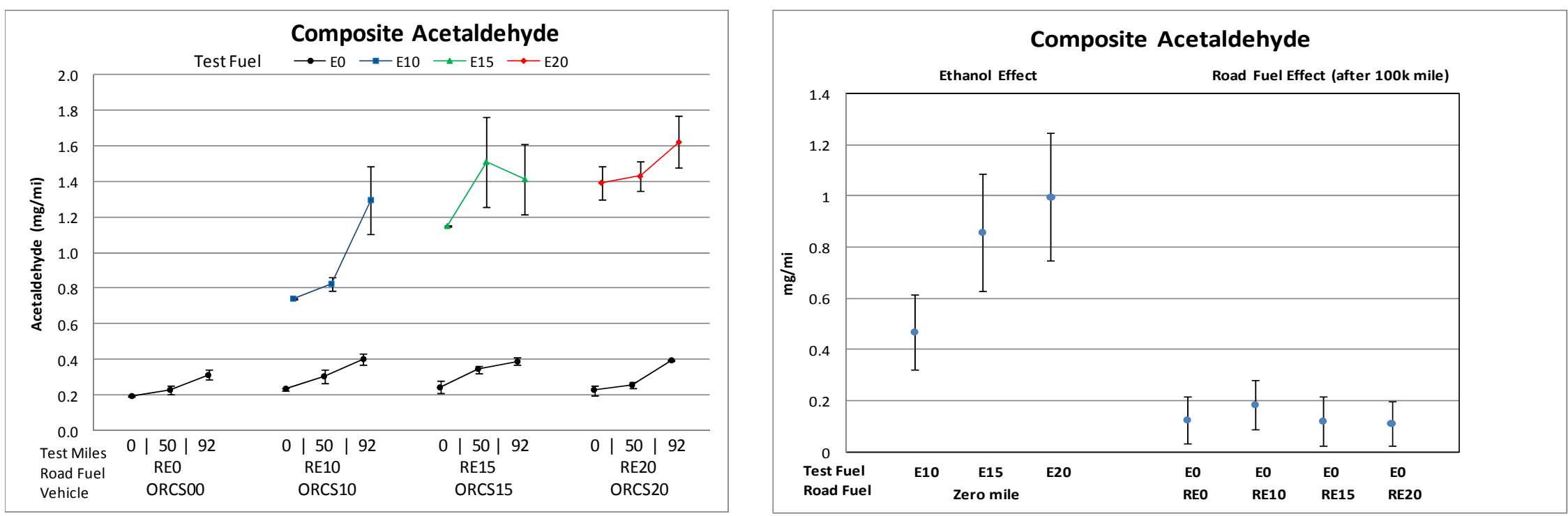

Error bars represent min and max measurements

Error bars represent $95 \%$ confidence intervals on the estimated effects

* The statistical model for Acetaldehyde does not assume the linear relationship between emission and mileage. 
2006 Chevrolet Silverado (Composite Formaldehyde)

\begin{tabular}{|c|c|c|c|}
\hline Effect & Estimate & $\begin{array}{c}95 \% \text { C.I. } \\
\text { Lower }\end{array}$ & $\begin{array}{c}95 \% \text { C.I. } \\
\text { Upper }\end{array}$ \\
\hline Ethanol Effect (E10 vs. E0) $(\Delta \mathrm{mg} / \mathrm{mi})$ & 0.025 & -0.188 & 0.238 \\
\hline Ethanol Effect (E15 vs. E0) $(\Delta \mathrm{mg} / \mathrm{mi})$ & -0.059 & -0.360 & 0.242 \\
\hline Ethanol Effect (E20 vs. E0) $(\Delta \mathrm{mg} / \mathrm{mi})$ & 0.064 & -0.168 & 0.295 \\
\hline \multicolumn{4}{|l|}{ Road Fuel Aging Effect } \\
\hline Aging Effect with RE0 ( $\Delta \mathrm{mg} / \mathrm{mi}$ per $100 \mathrm{k} \mathrm{mi})$ & $0.432^{*}$ & 0.100 & 0.763 \\
\hline Aging Effect with RE10 ( $\Delta \mathrm{mg} / \mathrm{mi}$ per $100 \mathrm{k} \mathrm{mi})$ & $0.756^{*}$ & 0.403 & 1.109 \\
\hline Aging Effect with RE15 ( $\Delta \mathrm{mg} / \mathrm{mi}$ per $100 \mathrm{k} \mathrm{mi})$ & $0.425^{*}$ & 0.035 & 0.815 \\
\hline Aging Effect with RE20 ( $\Delta \mathrm{mg} / \mathrm{mi}$ per $100 \mathrm{k} \mathrm{mi})$ & $0.710^{*}$ & 0.364 & 1.056 \\
\hline
\end{tabular}

\begin{tabular}{|l|r|}
\hline \multicolumn{1}{|c|}{ Hypothesis } & -value \\
\hline No Effect of Ethanol in the Test Fuel (Gamma = 0) & 0.80 \\
\hline No Aging Effect with RE0 (Beta0 $=0)$ & $0.02^{*}$ \\
\hline No Effect of Ethanol in Road Fuel Aging (Beta1s $=0)$ & 0.21 \\
\hline * Indicates effect is statistically significant at the 95\% confidence level.
\end{tabular}

* Indicates estimate is different from zero at the $95 \%$ confidence level.
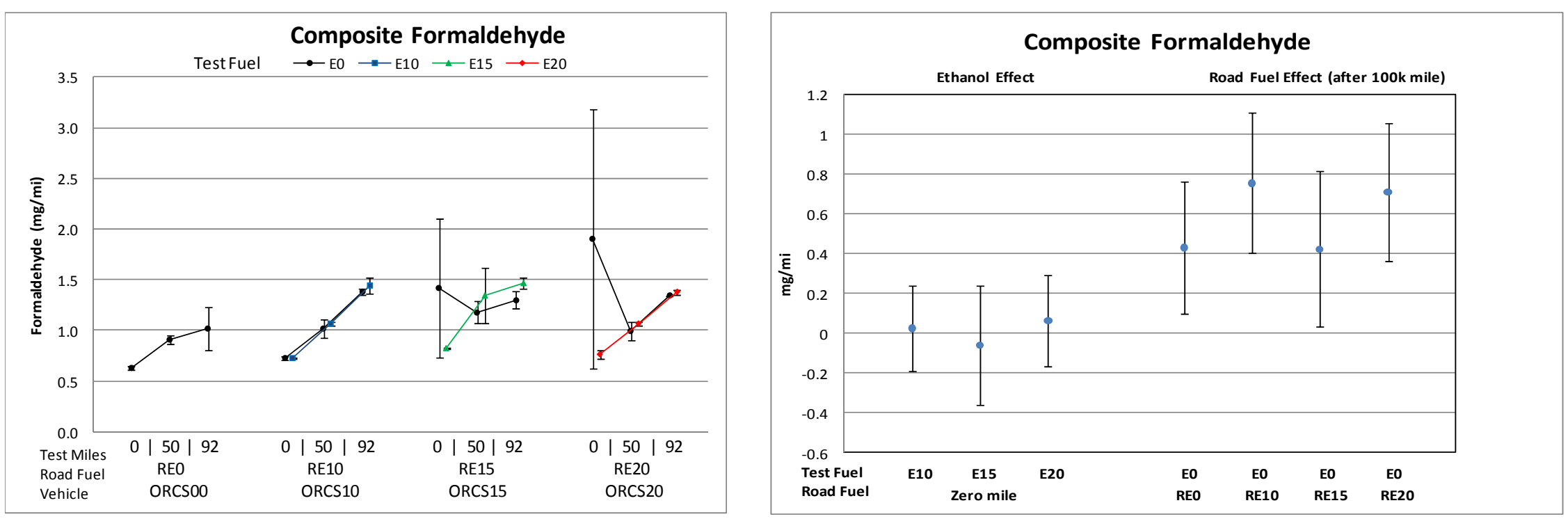

Error bars represent min and max measurements

Error bars represent $95 \%$ confidence intervals on the estimated effects 
2006 Chevrolet Silverado (Composite $\mathrm{CH} 4$ )

\begin{tabular}{|l|r|r|r|}
\hline \multicolumn{1}{|c|}{ Effect } & Estimate & $\begin{array}{c}95 \% \text { C.I. } \\
\text { Lower }\end{array}$ & $\begin{array}{c}\text { 95\% C.I. } \\
\text { Upper }\end{array}$ \\
\hline Ethanol Effect $(E 10 \mathrm{vs.} \mathrm{E0)} \Delta \mathrm{g} / \mathrm{mi})$ & 0.0043 & -0.0028 & 0.0115 \\
\hline Ethanol Effect $(E 15 \mathrm{vs.} \mathrm{E0})(\Delta \mathrm{g} / \mathrm{mi})$ & 0.0009 & -0.0062 & 0.0081 \\
\hline Ethanol Effect $(E 20 \mathrm{vs.} \mathrm{E0})(\Delta \mathrm{g} / \mathrm{mi})$ & 0.0014 & -0.0058 & 0.0085 \\
\hline Road Fuel Aging Effect & & & \\
\hline Aging Effect with RE0 $(\Delta \mathrm{g} / \mathrm{mi}$ per 100k mi) & 0.0103 & -0.0031 & 0.0238 \\
\hline Aging Effect with RE10 $(\Delta \mathrm{g} / \mathrm{mi}$ per 100k mi) & 0.0070 & -0.0025 & 0.0165 \\
\hline Aging Effect with RE15 $(\Delta \mathrm{g} / \mathrm{mi}$ per 100k mi) & $0.0126^{*}$ & 0.0031 & 0.0221 \\
\hline Aging Effect with RE20 $(\Delta \mathrm{g} / \mathrm{mi} \mathrm{per} \mathrm{100k} \mathrm{mi)}$ & $0.0124^{*}$ & 0.0029 & 0.0219 \\
\hline
\end{tabular}

\begin{tabular}{|l|r|}
\hline \multicolumn{1}{|c|}{ Hypothesis } & p-value \\
& \\
\hline No Effect of Ethanol in the Test Fuel (Gamma = 0) & 0.58 \\
\hline No Aging Effect with RE0 (Beta0 = 0) & 0.12 \\
\hline No Effect of Ethanol in Road Fuel Aging (Beta1s=0) & 0.78 \\
\hline
\end{tabular}

Initial odometers $14 \mathrm{k}-28 \mathrm{k}$

* Indicates estimate is different from zero at the $95 \%$ confidence level.

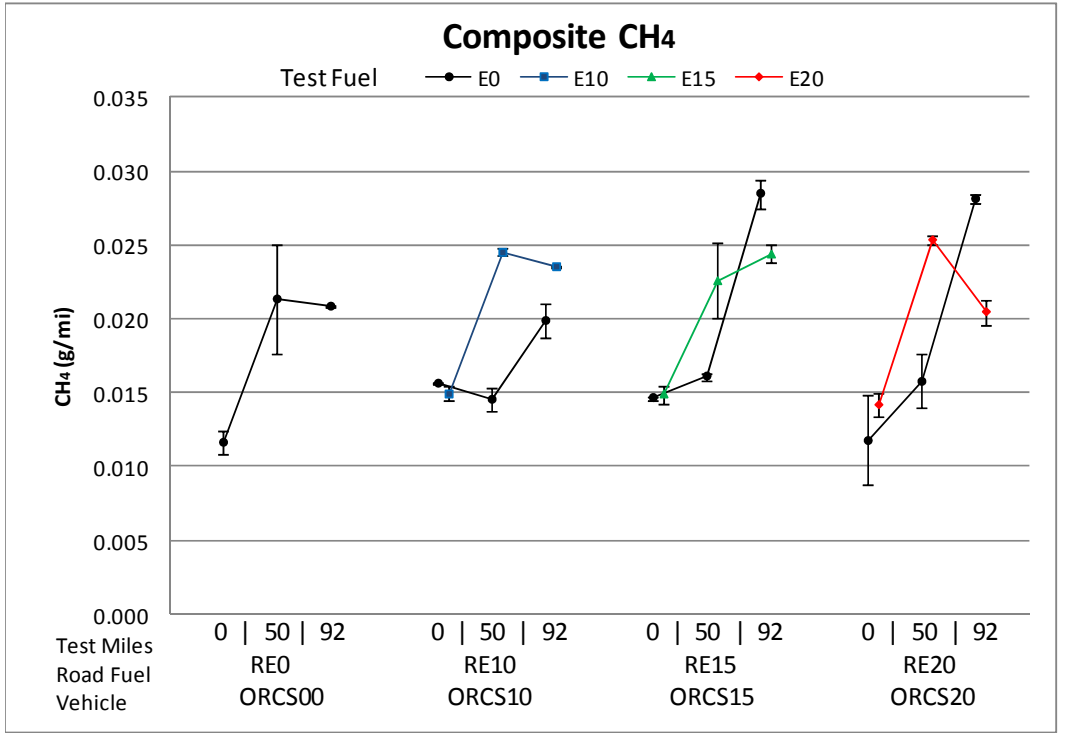

Error bars represent min and max measurements

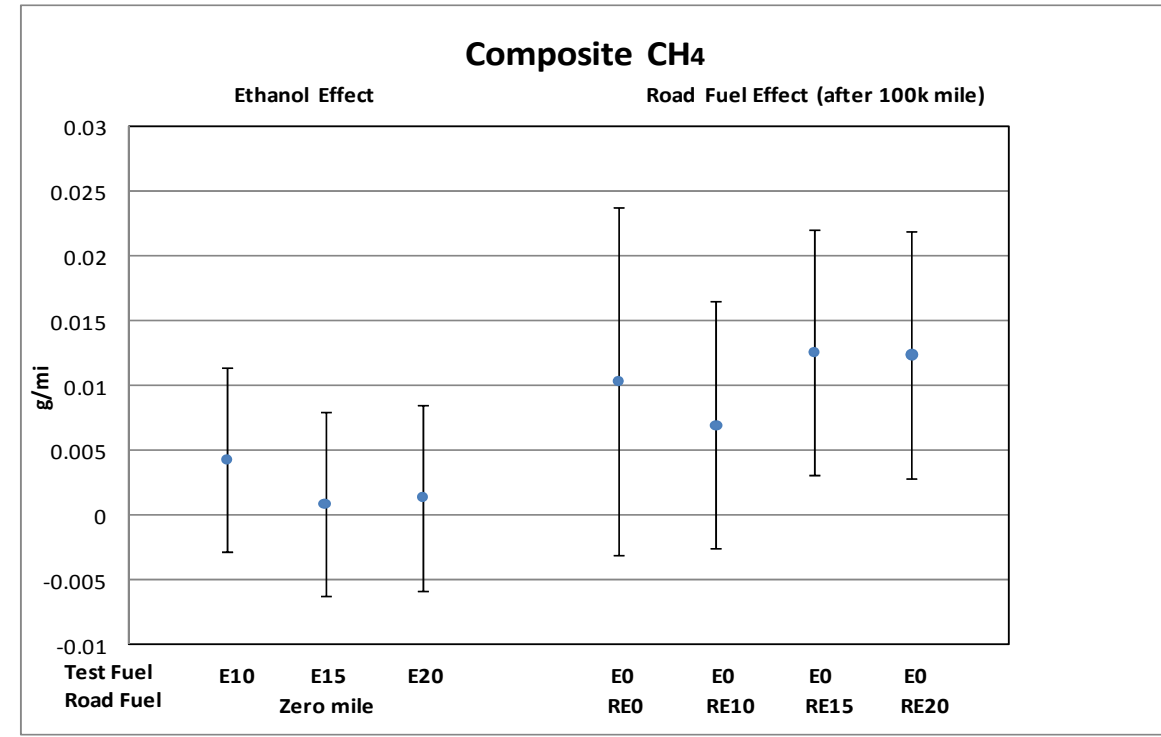

Error bars represent $95 \%$ confidence intervals on the estimated effects 


\section{Nissan Altima - Composite Emissions Summary}

\begin{tabular}{|c|c|c|c|c|c|c|c|c|c|c|c|c|c|c|}
\hline \multirow{2}{*}{$\begin{array}{c}\text { Emisssion Parameter } \\
\text { (units) }\end{array}$} & \multicolumn{4}{|c|}{ Ethanol Effect } & \multicolumn{2}{|c|}{ Aging Effect with REO } & \multicolumn{4}{|c|}{ RExx Aging Effect on E0 Emissions } & \multirow{2}{*}{\multicolumn{3}{|c|}{$\begin{array}{c}\text { RExx Aging Effect on Exx Emissions } \\
\Delta \text { units per } 100 \mathrm{~K} \mathrm{mi}\end{array}$}} & \multirow{3}{*}{\begin{tabular}{|c|}
$\begin{array}{l}\text { Road and Test } \\
\text { Fuel Effects } \\
\text { are Additive }\end{array}$ \\
$\begin{array}{c}\text { Overall p- } \\
\text { value }\end{array}$ \\
\end{tabular}} \\
\hline & \multicolumn{3}{|c|}{$\Delta$ units vs. EO } & \multirow{2}{*}{$\mid \begin{array}{c}\text { Overall } \\
p \text {-value }\end{array}$} & \multirow{2}{*}{$\begin{array}{c}\Delta \text { units per } 100 \mathrm{~K} \mathrm{mi} \\
\mathrm{REO} / \mathrm{E} 0 \\
\end{array}$} & \multirow{2}{*}{$\begin{array}{l}\text { Overall } \\
p \text {-value }\end{array}$} & \multicolumn{3}{|c|}{$\Delta$ units per $100 \mathrm{~K} \mathrm{mi}$} & \multirow{2}{*}{$\begin{array}{l}\text { Overall } \\
p \text {-value }\end{array}$} & & & & \\
\hline Fuels & E10 & E15 & $\mathrm{E} 20$ & & & & RE10/E0 & RE15/E0 & RE20/E0 & & RE10/E10 & RE15/E15 & RE20/E20 & \\
\hline $\mathrm{CO}(\mathrm{g} / \mathrm{mi})^{\mathrm{a}}$ & 0.066 & -0.067 & -0.153 & 0.42 & 0.224 & 0.54 & 0.221 & 0.226 & 0.161 & 0.98 & NA & $\mathrm{NA}$ & NA & 0.99 \\
\hline NOx (g/mi) & $0.0092 *$ & 0.0000 & 0.0040 & 0.16 & $0.0360 *$ & $<0.01 *$ & $0.0272 *$ & $0.0268 *$ & $0.0179 *$ & 0.23 & NA & $\mathrm{NA}$ & NA & 0.88 \\
\hline $\mathrm{NMHC}(\mathrm{g} / \mathrm{mi})^{\mathrm{a}}$ & 0.0093 & -0.0072 & -0.0073 & 0.28 & -0.0010 & 0.97 & 0.0079 & 0.0039 & 0.0001 & 0.91 & $\mathrm{NA}$ & $\mathrm{NA}$ & NA & 0.98 \\
\hline NMOG $(\mathrm{g} / \mathrm{mi})^{\mathrm{a}}$ & 0.0142 & -0.0016 & 0.0003 & 0.30 & -0.0021 & 0.93 & 0.0083 & 0.0041 & -0.0008 & 0.89 & $N A$ & $\mathrm{NA}$ & NA & 0.98 \\
\hline Fuel Econ (mi/gal) & $-1.168 *$ & $-1.553 *$ & $-1.751 *$ & $<0.01^{*}$ & $-1.534 *$ & $0.02 *$ & -0.247 & -0.226 & -0.020 & 0.20 & $N A$ & $\mathrm{NA}$ & NA & 0.65 \\
\hline Ethanol $(\mathrm{mg} / \mathrm{mi})^{\text {\#\# }}$ & $2.335 *$ & $3.328 *$ & $4.369 *$ & $<0.01^{*}$ & 0.318 & 0.72 & 0.230 & 1.131 & 1.076 & 0.68 & $N A$ & $\mathrm{NA}$ & NA & NA \\
\hline Acetaldehyde $(\mathrm{mg} / \mathrm{mi})^{\#}$ & $0.409 *$ & $0.656^{*}$ & $0.901 *$ & $<0.01^{*}$ & $0.151^{*}$ & $0.02 *$ & $0.083^{*}$ & 0.058 & 0.055 & 0.62 & $\mathrm{NA}$ & $\mathrm{NA}$ & NA & 0.12 \\
\hline Formaldehyde $(\mathrm{mg} / \mathrm{mi})^{\#}$ & -0.006 & -0.076 & -0.008 & 0.63 & 0.002 & 0.99 & $0.341 *$ & $0.254^{*}$ & $0.282 *$ & 0.25 & $N A$ & $\mathrm{NA}$ & NA & 0.86 \\
\hline $\mathrm{CH}_{4}(\mathrm{~g} / \mathrm{mi})^{\mathrm{a}}$ & 0.0002 & 0.0003 & -0.0005 & 0.95 & 0.0000 & 0.99 & $0.0052^{*}$ & $0.0042 *$ & $0.0044 *$ & 0.61 & $\mathrm{NA}$ & $\mathrm{NA}$ & NA & 0.32 \\
\hline
\end{tabular}

\# Log-normal model was used. Results are presented as changes in emissions at $0 \mathrm{k}$ mile.

\#\# Data did not support the assumption of linear effects with mileage.

*

a Test "SW023589", "SW023600" and "SW023669" are identified as outliers and excluded from the analysis. 
2008 Nissan Altima (Composite CO)

\begin{tabular}{|c|c|c|c|}
\hline Effect & Estimate & $\begin{array}{c}\text { 95\% C.I. } \\
\text { Lower }\end{array}$ & $\begin{array}{c}95 \% \text { C.I. } \\
\text { Upper }\end{array}$ \\
\hline Ethanol Effect (E10 vs. E0) $(\Delta \mathrm{g} / \mathrm{mi})$ & 0.066 & -0.162 & 0.295 \\
\hline Ethanol Effect (E15 vs. E0) $(\Delta \mathrm{g} / \mathrm{mi})$ & -0.067 & -0.296 & 0.161 \\
\hline Ethanol Effect (E20 vs. E0) $(\Delta \mathrm{g} / \mathrm{mi})$ & -0.153 & -0.381 & 0.076 \\
\hline \multicolumn{4}{|l|}{ Road Fuel Aging Effect } \\
\hline Aging Effect with RE0 ( $\Delta \mathrm{g} / \mathrm{mi}$ per $100 \mathrm{k} \mathrm{mi})$ & 0.224 & -0.571 & 1.018 \\
\hline Aging Effect with RE10 $(\Delta \mathrm{g} / \mathrm{mi}$ per $100 \mathrm{k} \mathrm{mi})$ & 0.221 & -0.059 & 0.501 \\
\hline Aging Effect with RE15 ( $\Delta \mathrm{g} / \mathrm{mi}$ per $100 \mathrm{k} \mathrm{mi})$ & 0.226 & -0.054 & 0.506 \\
\hline Aging Effect with RE20 ( $\Delta \mathrm{g} / \mathrm{mi}$ per $100 \mathrm{k} \mathrm{mi})$ & 0.161 & -0.119 & 0.441 \\
\hline
\end{tabular}

\begin{tabular}{|l|r|}
\hline \multicolumn{1}{|c|}{ Hypothesis } & p-value \\
\hline No Effect of Ethanol in the Test Fuel (Gamma = 0) & 0.42 \\
\hline No Aging Effect with RE0 (Beta0 = 0) & 0.54 \\
\hline No Effect of Ethanol in Road Fuel Aging (Beta1s=0) & 0.98 \\
\hline
\end{tabular}

Initial odometers 10k-20k

${ }^{*}$ Indicates estimate is different from zero at the $95 \%$ confidence level.

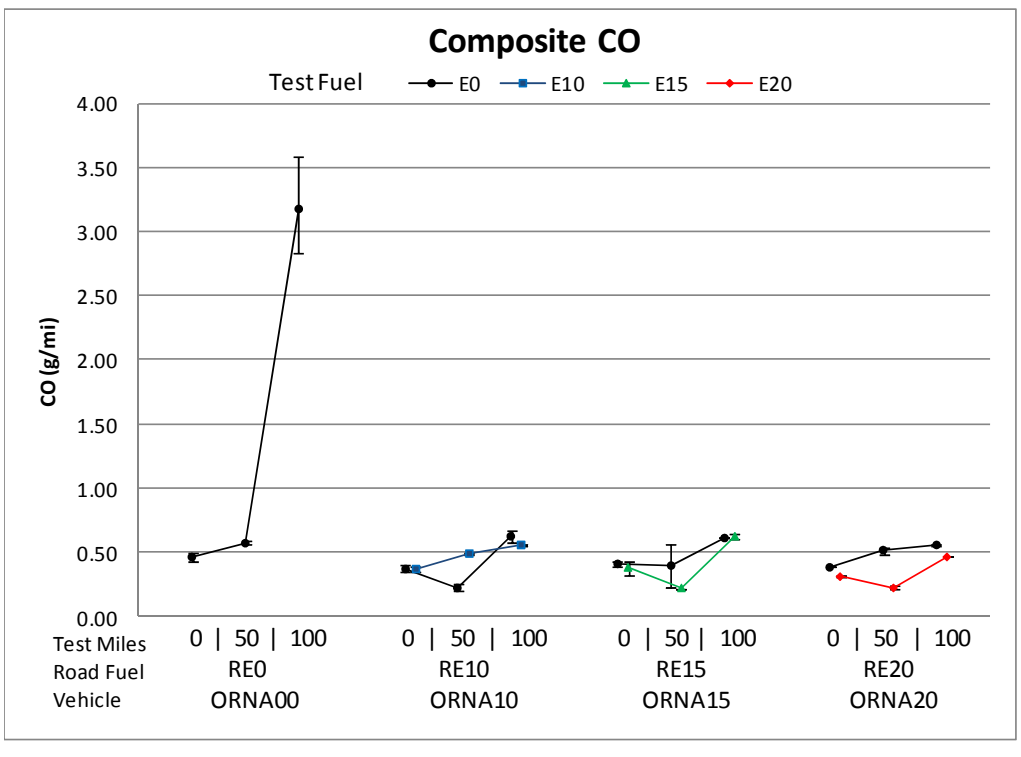

Error bars represent min and max measurements

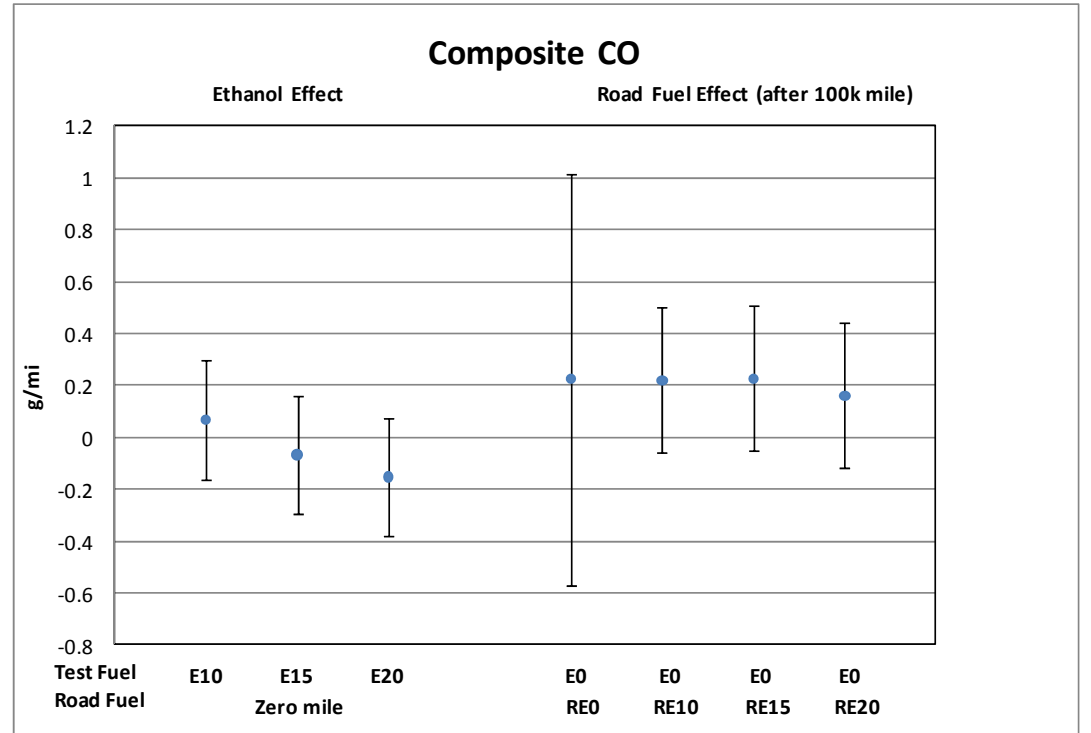

Error bars represent $95 \%$ confidence intervals on the estimated effects 
2008 Nissan Altima (Composite NOx)

\begin{tabular}{|l|r|r|r|}
\hline \multicolumn{1}{|c|}{ Effect } & & $\begin{array}{r}95 \% \text { C.I. } \\
\text { Lo5\% C.I. } \\
\text { Upper }\end{array}$ \\
\hline Ethanol Effect (E10 vs. E0) $(\Delta \mathrm{g} / \mathrm{mi})$ & $0.0092^{*}$ & 0.0004 & 0.0180 \\
\hline Ethanol Effect (E15 vs. E0) $(\Delta \mathrm{g} / \mathrm{mi})$ & 0.0000 & -0.0088 & 0.0089 \\
\hline Ethanol Effect $($ E20 vs. E0) $(\Delta \mathrm{g} / \mathrm{mi})$ & 0.0040 & -0.0048 & 0.0128 \\
\hline Road Fuel Aging Effect & & & \\
\hline Aging Effect with RE0 $(\Delta \mathrm{g} / \mathrm{mi}$ per 100k mi) & $0.0360^{*}$ & 0.0209 & 0.0511 \\
\hline Aging Effect with RE10 $(\Delta \mathrm{g} / \mathrm{mi}$ per 100k mi) & $0.0272^{*}$ & 0.0163 & 0.0380 \\
\hline Aging Effect with RE15 $(\Delta \mathrm{g} / \mathrm{mi} \mathrm{per} \mathrm{100k} \mathrm{mi)}$ & $0.0268^{*}$ & 0.0159 & 0.0376 \\
\hline Aging Effect with RE20 $(\Delta \mathrm{g} / \mathrm{mi} \mathrm{per} \mathrm{100k} \mathrm{mi)}$ & $0.0179^{*}$ & 0.0070 & 0.0288 \\
\hline
\end{tabular}

\begin{tabular}{|l|r|}
\hline \multicolumn{1}{|c|}{ Hypothesis } & p-value \\
\hline No Effect of Ethanol in the Test Fuel (Gamma = 0) & 0.16 \\
\hline No Aging Effect with RE0 (Beta0 = 0) & $<0.01^{*}$ \\
\hline No Effect of Ethanol in Road Fuel Aging (Beta1s=0) & 0.23 \\
\hline
\end{tabular}

Initial odometers 10k-20k

${ }^{*}$ Indicates estimate is different from zero at the $95 \%$ confidence level.

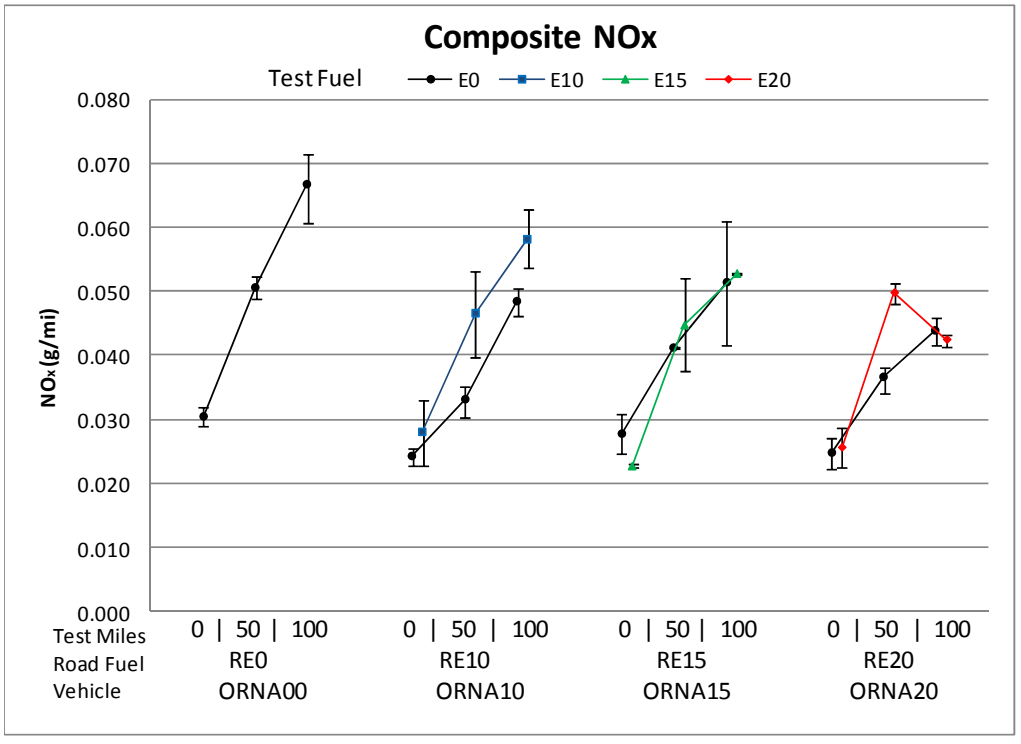

Error bars represent min and max measurements

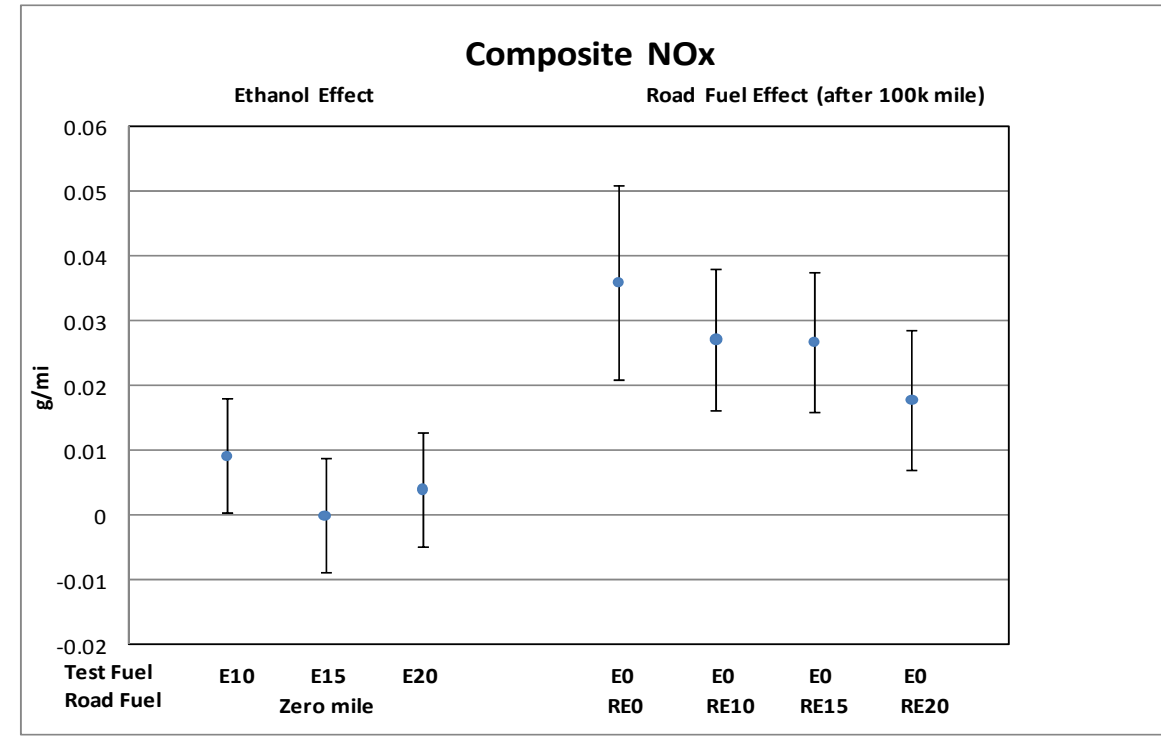

Error bars represent $95 \%$ confidence intervals on the estimated effects 
2008 Nissan Altima (Composite Nonmethane Hydrocarbons)

\begin{tabular}{|l|r|r|r|}
\hline \multicolumn{1}{|c|}{ Effect } & Estimate & $\begin{array}{c}\text { 95\% C.I. } \\
\text { Lower }\end{array}$ & $\begin{array}{c}95 \% \text { C.I. } \\
\text { Upper }\end{array}$ \\
\hline Ethanol Effect $(E 10 \mathrm{vs.} \mathrm{E0)}(\Delta \mathrm{g} / \mathrm{mi})$ & 0.0093 & -0.0054 & 0.0241 \\
\hline Ethanol Effect $(E 15 \mathrm{vs.} \mathrm{E0)} \Delta \mathrm{g} / \mathrm{mi})$ & -0.0072 & -0.0220 & 0.0076 \\
\hline Ethanol Effect $(E 20 \mathrm{vs.} \mathrm{E0)}(\Delta \mathrm{g} / \mathrm{mi})$ & -0.0073 & -0.0220 & 0.0075 \\
\hline Road Fuel Aging Effect & & & \\
\hline Aging Effect with RE0 $(\Delta \mathrm{g} / \mathrm{mi}$ per 100k mi) & -0.0010 & -0.0523 & 0.0504 \\
\hline Aging Effect with RE10 $(\Delta \mathrm{g} / \mathrm{mi}$ per 100k mi) & 0.0079 & -0.0102 & 0.0260 \\
\hline Aging Effect with RE15 $(\Delta \mathrm{g} / \mathrm{mi}$ per 100k mi) & 0.0039 & -0.0142 & 0.0220 \\
\hline Aging Effect with RE20 $(\Delta \mathrm{g} / \mathrm{mi}$ per 100k mi) & 0.0001 & -0.0180 & 0.0182 \\
\hline
\end{tabular}

\begin{tabular}{|l|r|}
\hline \multicolumn{1}{|c|}{ Hypothesis } & p-value \\
& \\
\hline No Effect of Ethanol in the Test Fuel (Gamma = 0) & 0.28 \\
\hline No Aging Effect with RE0 (Beta0 = 0) & 0.97 \\
\hline No Effect of Ethanol in Road Fuel Aging (Beta1s=0) & 0.91 \\
\hline
\end{tabular}

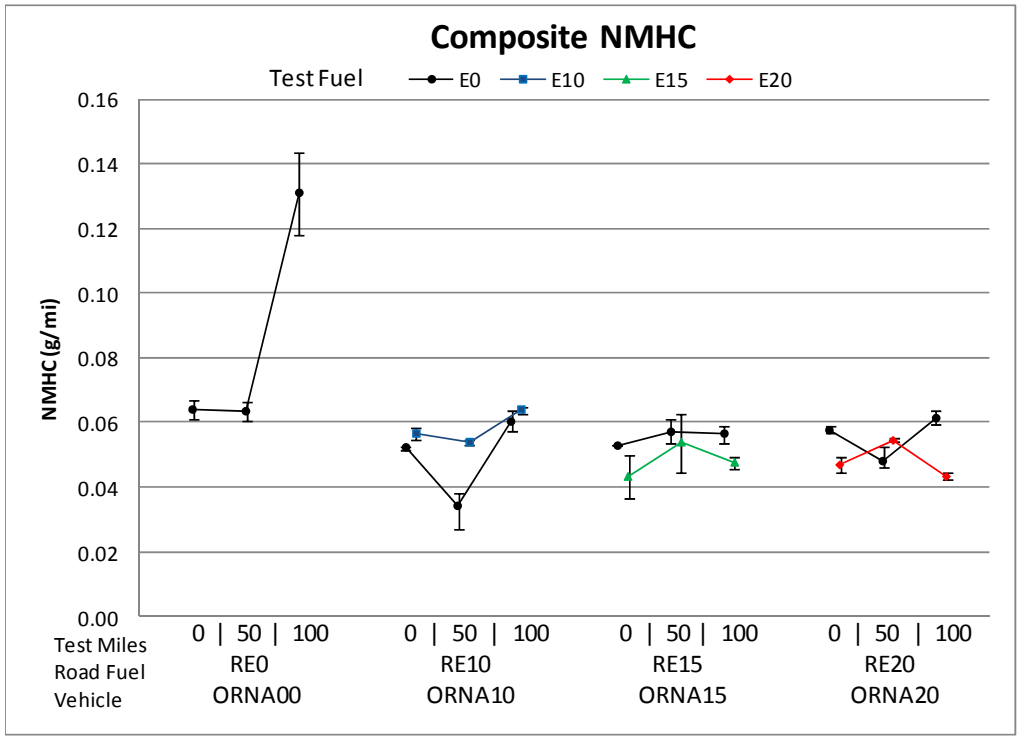

Error bars represent min and max measurements

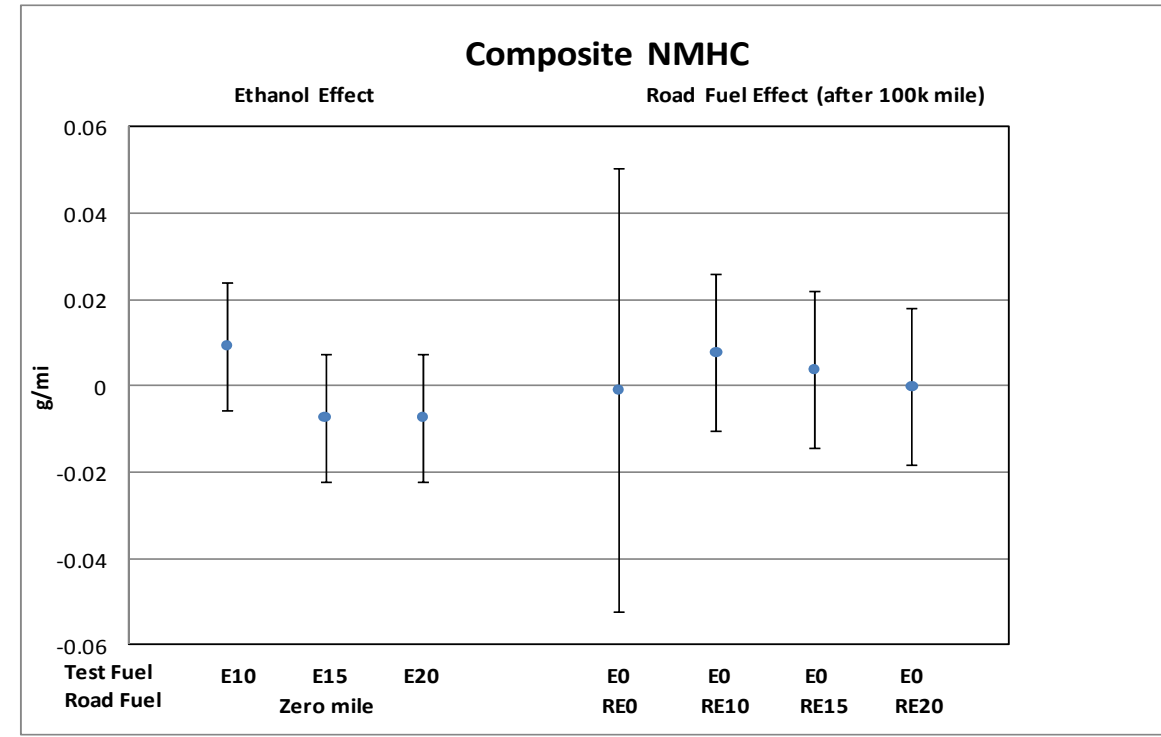

Error bars represent $95 \%$ confidence intervals on the estimated effects 
2008 Nissan Altima (Composite Nonmethane Organic Gases)

\begin{tabular}{|l|r|r|r|}
\hline \multicolumn{1}{|c|}{ Effect } & & $\begin{array}{r}95 \% \text { C.I. } \\
\text { Lo5\% C.I. } \\
\text { Upper }\end{array}$ \\
\hline Ethanol Effect (E10 vs. E0) $(\Delta \mathrm{g} / \mathrm{mi})$ & 0.0142 & -0.0014 & 0.0299 \\
\hline Ethanol Effect $(E 15 \mathrm{vs.} \mathrm{E0)}(\Delta \mathrm{g} / \mathrm{mi})$ & -0.0016 & -0.0173 & 0.0140 \\
\hline Ethanol Effect $($ E20 vs. E0) $(\Delta \mathrm{g} / \mathrm{mi})$ & 0.0003 & -0.0153 & 0.0160 \\
\hline Road Fuel Aging Effect & & & \\
\hline Aging Effect with RE0 $(\Delta \mathrm{g} / \mathrm{mi}$ per 100k mi) & -0.0021 & -0.0565 & 0.0523 \\
\hline Aging Effect with RE10 $(\Delta \mathrm{g} / \mathrm{mi}$ per 100k mi) & 0.0083 & -0.0109 & 0.0275 \\
\hline Aging Effect with RE15 $(\Delta \mathrm{g} / \mathrm{mi}$ per 100k mi) & 0.0041 & -0.0151 & 0.0232 \\
\hline Aging Effect with RE20 $(\Delta \mathrm{g} / \mathrm{mi} \mathrm{per} \mathrm{100k} \mathrm{mi)}$ & -0.0008 & -0.0200 & 0.0183 \\
\hline
\end{tabular}

\begin{tabular}{|l|r|}
\hline \multicolumn{1}{|c|}{ Hypothesis } & p-value \\
& \\
\hline No Effect of Ethanol in the Test Fuel (Gamma = 0) & 0.30 \\
\hline No Aging Effect with RE0 (Beta0 = 0) & 0.93 \\
\hline No Effect of Ethanol in Road Fuel Aging (Beta1s=0) & 0.89 \\
\hline
\end{tabular}

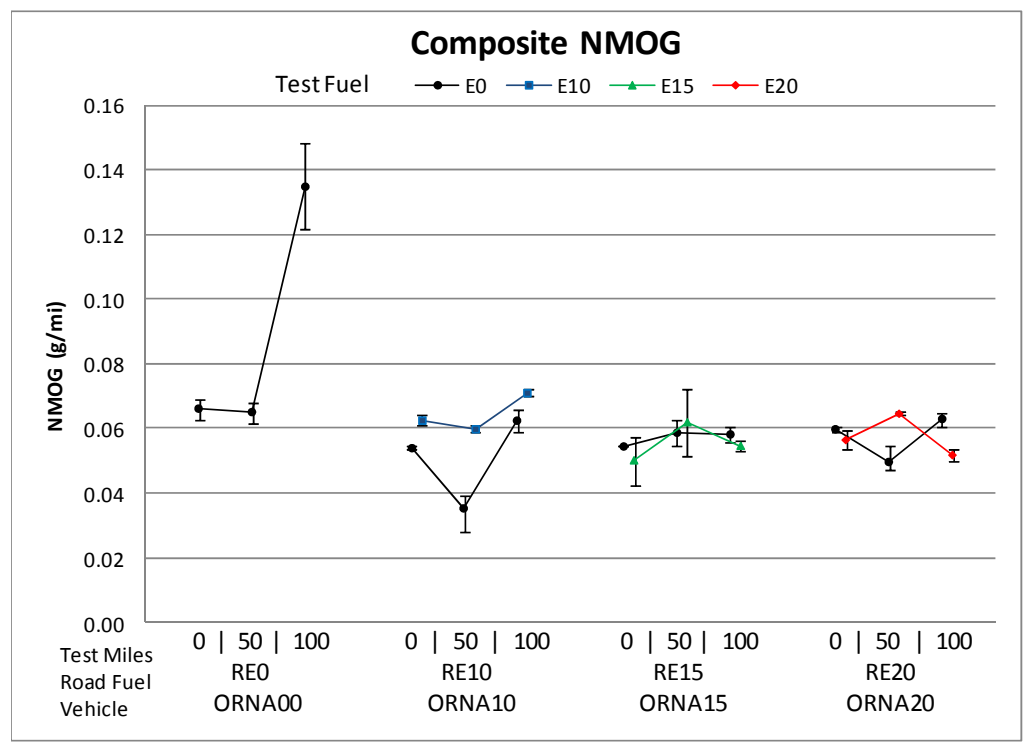

Error bars represent min and max measurements

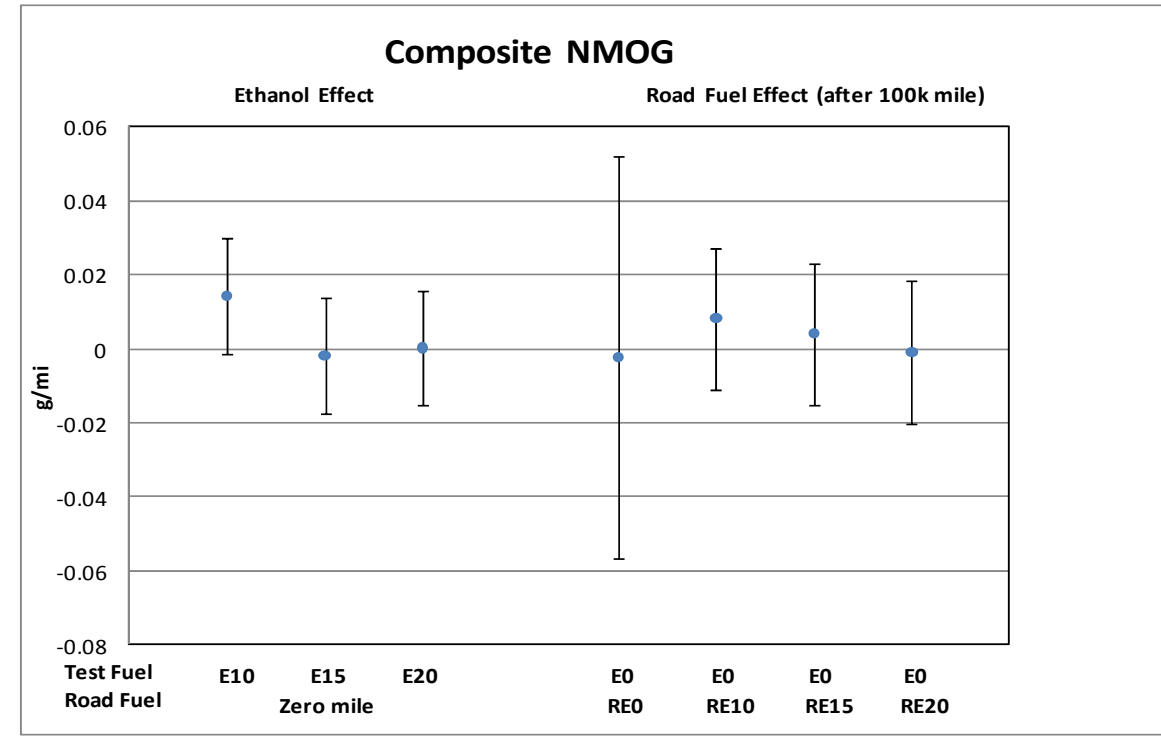

Error bars represent $95 \%$ confidence intervals on the estimated effects 
2008 Nissan Altima (Composite Fuel Economy)

\begin{tabular}{|l|r|r|r|}
\hline \multicolumn{1}{|c|}{ Effect } & & $\begin{array}{r}95 \% \text { C.I. } \\
\text { Lower }\end{array}$ & $\begin{array}{r}\text { 95\% C.I. } \\
\text { Upper }\end{array}$ \\
\hline Ethanol Effect (E10 vs. E0) $(\Delta \mathrm{mi} / \mathrm{gal})$ & $-1.168^{*}$ & -1.892 & -0.445 \\
\hline Ethanol Effect (E15 vs. E0) $(\Delta \mathrm{mi} / \mathrm{gal})$ & $-1.553^{*}$ & -2.279 & -0.827 \\
\hline Ethanol Effect (E20 vs. E0) $(\Delta \mathrm{mi} / \mathrm{gal})$ & $-1.751^{*}$ & -2.475 & -1.027 \\
\hline Road Fuel Aging Effect & & & \\
\hline Aging Effect with RE0 $(\Delta \mathrm{mi} /$ gal per 100k mi) & $-1.534^{*}$ & -2.777 & -0.291 \\
\hline Aging Effect with RE10 $(\Delta \mathrm{mi} / \mathrm{gal}$ per 100k mi) & -0.247 & -1.135 & 0.641 \\
\hline Aging Effect with RE15 $(\Delta \mathrm{mi} /$ gal per 100k mi) & -0.226 & -1.114 & 0.661 \\
\hline Aging Effect with RE20 $(\Delta \mathrm{mi} /$ gal per 100k mi) & -0.020 & -0.868 & 0.908 \\
\hline
\end{tabular}

\begin{tabular}{|l|r|}
\hline \multicolumn{1}{|c|}{ Hypothesis } & $p$-value \\
\hline No Effect of Ethanol in the Test Fuel (Gamma $=0)$ & $<0.01^{*}$ \\
\hline No Aging Effect with RE0 (Beta0 = 0) & $0.02^{*}$ \\
\hline No Effect of Ethanol in Road Fuel Aging (Beta1s=0) & 0.20 \\
\hline${ }^{*}$ Indicates effect is statistically significant at the $95 \%$ confidence level.
\end{tabular}

Initial odometers 10k-20k

${ }^{*}$ Indicates estimate is different from zero at the $95 \%$ confidence level.

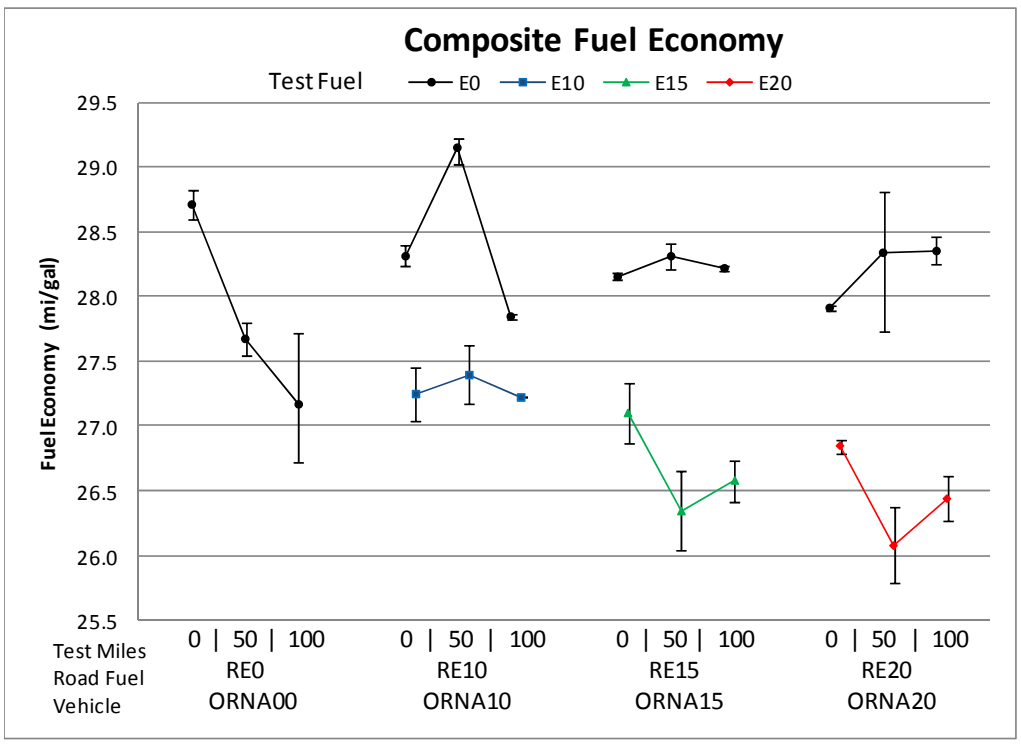

Error bars represent min and max measurements

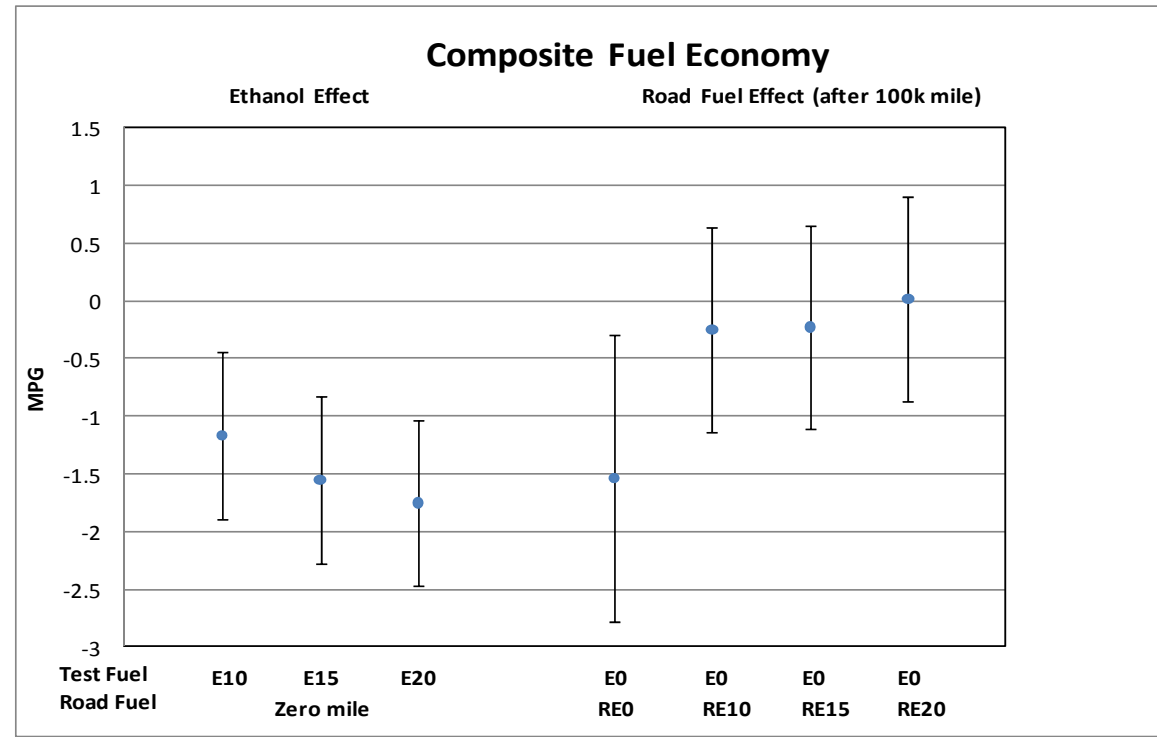

Error bars represent $95 \%$ confidence intervals on the estimated effects 
2008 Nissan Altima (Composite Ethanol)

\begin{tabular}{|l|r|r|r|}
\hline \multicolumn{1}{|c|}{ Effect } & Estimate & $\begin{array}{r}\text { 95\% C.I. } \\
\text { Lower }\end{array}$ & $\begin{array}{r}\text { 95\% C.I. } \\
\text { Upper }\end{array}$ \\
\hline Ethanol Effect $($ E10 vs. E0) $(\Delta \mathrm{mg} / \mathrm{mi})$ & $2.335^{*}$ & 1.097 & 3.574 \\
\hline Ethanol Effect $(E 15$ vs. E0) $(\Delta \mathrm{mg} / \mathrm{mi})$ & $3.328^{*}$ & 2.091 & 4.566 \\
\hline Ethanol Effect $(E 20$ vs. E0) $(\Delta \mathrm{mg} / \mathrm{mi})$ & $4.369^{*}$ & 3.131 & 5.608 \\
\hline Road Fuel Aging Effect & & & \\
\hline Aging Effect with RE0 $(\Delta \mathrm{mg} / \mathrm{mi}$ per 100k mi) & 0.318 & -1.824 & 2.460 \\
\hline Aging Effect with RE10 $(\Delta \mathrm{mg} / \mathrm{mi}$ per 100k mi) & 0.230 & -1.284 & 1.744 \\
\hline Aging Effect with RE15 $(\Delta \mathrm{mg} / \mathrm{mi} \mathrm{per} \mathrm{100k} \mathrm{mi)}$ & 1.131 & -0.382 & 2.644 \\
\hline Aging Effect with RE20 $(\Delta \mathrm{mg} / \mathrm{mi}$ per 100k mi) & 1.076 & -0.438 & 2.589 \\
\hline
\end{tabular}

\begin{tabular}{|l|r|}
\hline \multicolumn{1}{|c|}{ Hypothesis } & p-value \\
\hline No Effect of Ethanol in the Test Fuel (Gamma $=0)$ & $<0.01^{*}$ \\
\hline No Aging Effect with RE0 (Beta0 $=0)$ & 0.72 \\
\hline No Effect of Ethanol in Road Fuel Aging (Beta1s=0) & 0.68 \\
\hline * Indicates effect is statistically significant at the 95\% confidence level
\end{tabular}

Initial odometers 10k-20k

${ }^{*}$ Indicates estimate is different from zero at the $95 \%$ confidence level.

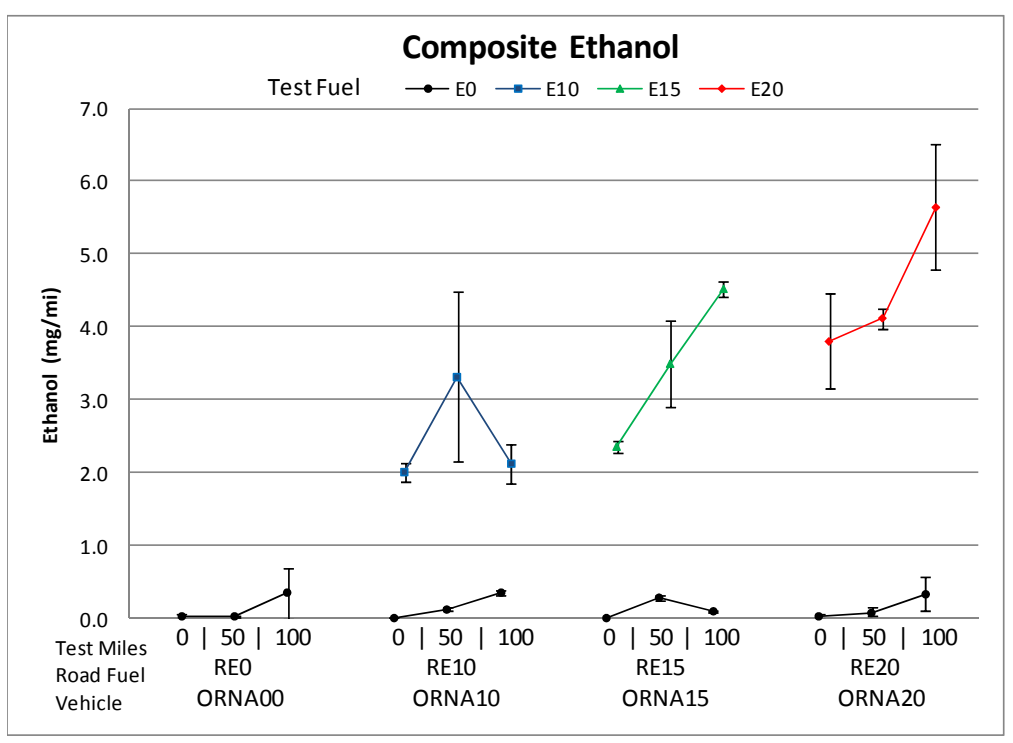

Error bars represent min and max measurements

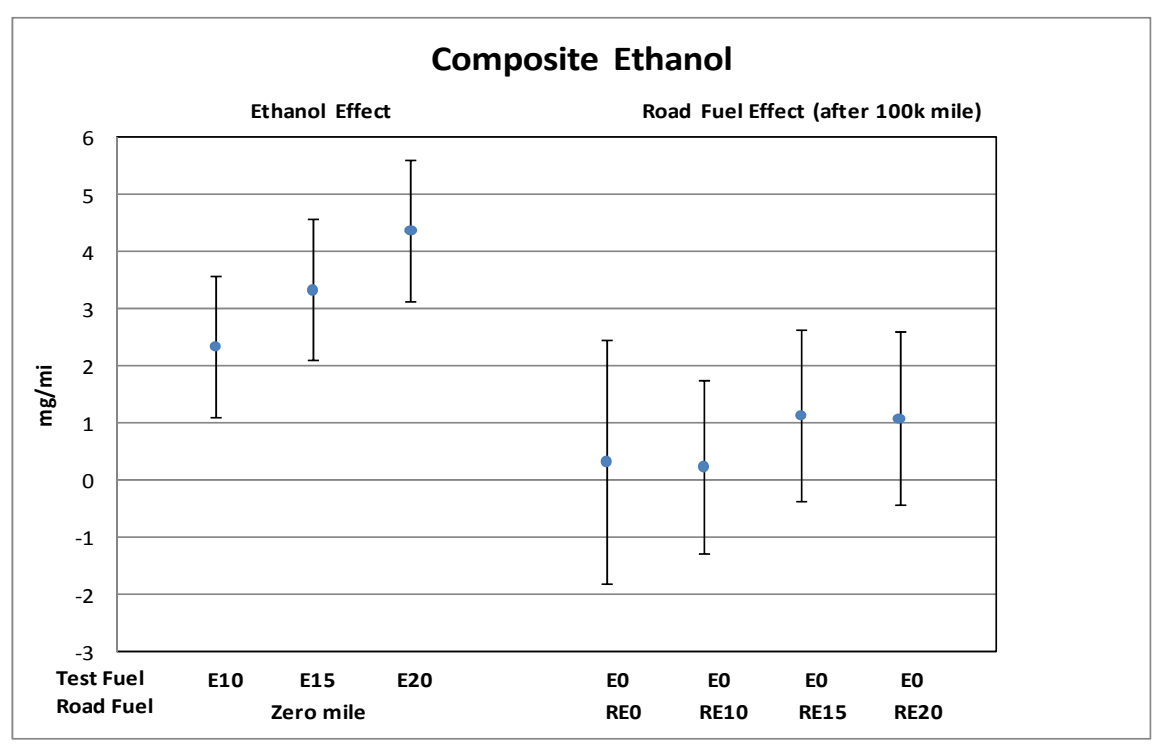

Error bars represent $95 \%$ confidence intervals on the estimated effects 
2008 Nissan Altima (Composite Acetaldehyde)

\begin{tabular}{|l|r|r|r|}
\hline \multicolumn{1}{|c|}{ Effect } & Estimate & $\begin{array}{r}\text { 95\% C.I. } \\
\text { Lower }\end{array}$ & $\begin{array}{r}95 \% \text { C.I. } \\
\text { Upper }\end{array}$ \\
\hline Ethanol Effect $(E 10$ vs. E0) $(\Delta \mathrm{mg} / \mathrm{mi})$ & $0.409^{*}$ & 0.256 & 0.563 \\
\hline Ethanol Effect $(E 15 \mathrm{vs}$. E0) $(\Delta \mathrm{mg} / \mathrm{mi})$ & $0.656^{*}$ & 0.447 & 0.865 \\
\hline Ethanol Effect $(E 20 \mathrm{vs.}$ E0) $(\Delta \mathrm{mg} / \mathrm{mi})$ & $0.901^{*}$ & 0.634 & 1.168 \\
\hline Road Fuel Aging Effect & & & \\
\hline Aging Effect with RE0 $(\Delta \mathrm{mg} / \mathrm{mi}$ per 100k mi) & $0.151^{*}$ & 0.033 & 0.269 \\
\hline Aging Effect with RE10 $(\Delta \mathrm{mg} / \mathrm{mi}$ per 100k mi) & $0.083^{*}$ & 0.001 & 0.166 \\
\hline Aging Effect with RE15 $(\Delta \mathrm{mg} / \mathrm{mi} \mathrm{per} \mathrm{100k} \mathrm{mi)}$ & 0.058 & -0.020 & 0.136 \\
\hline Aging Effect with RE20 $(\Delta \mathrm{mg} / \mathrm{mi}$ per 100k mi) & 0.055 & -0.021 & 0.132 \\
\hline
\end{tabular}

\begin{tabular}{|l|r|}
\hline \multicolumn{1}{|c|}{ Hypothesis } & p-value \\
\hline No Effect of Ethanol in the Test Fuel (Gamma = 0) & $<0.01^{*}$ \\
\hline No Aging Effect with RE0 (Beta0 $=0)$ & $0.02^{*}$ \\
\hline No Effect of Ethanol in Road Fuel Aging (Beta1s=0) & 0.62 \\
\hline * Indicates effect is statistically significant at the 95\% confidence level.
\end{tabular}

Initial odometers 10k-20k

政

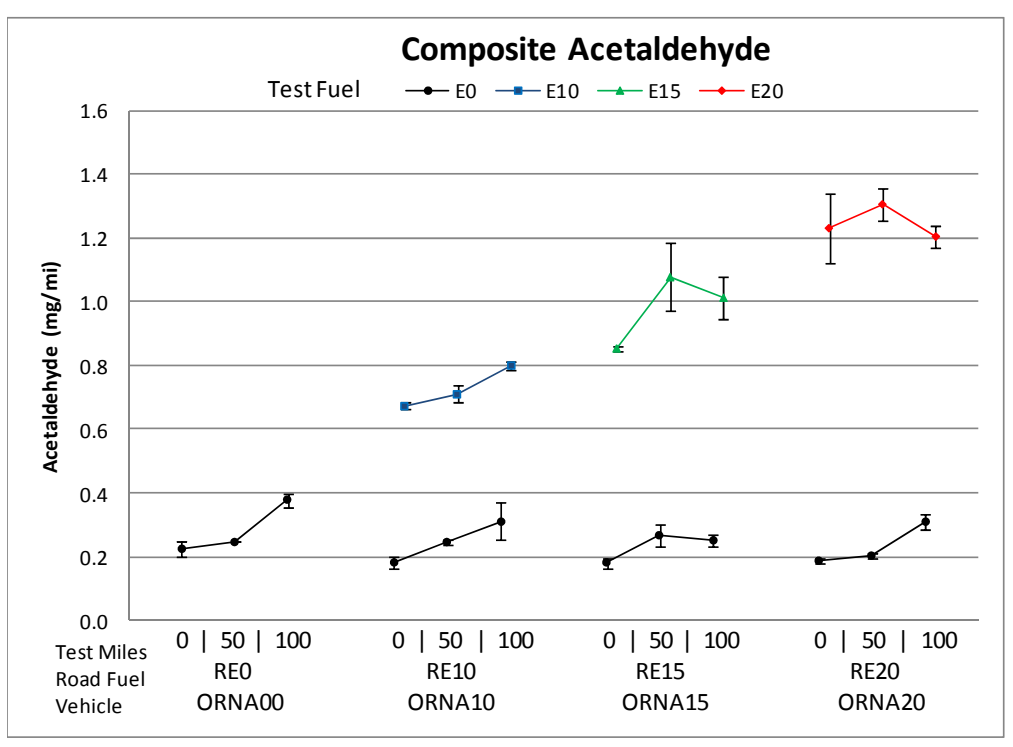

Error bars represent min and max measurements

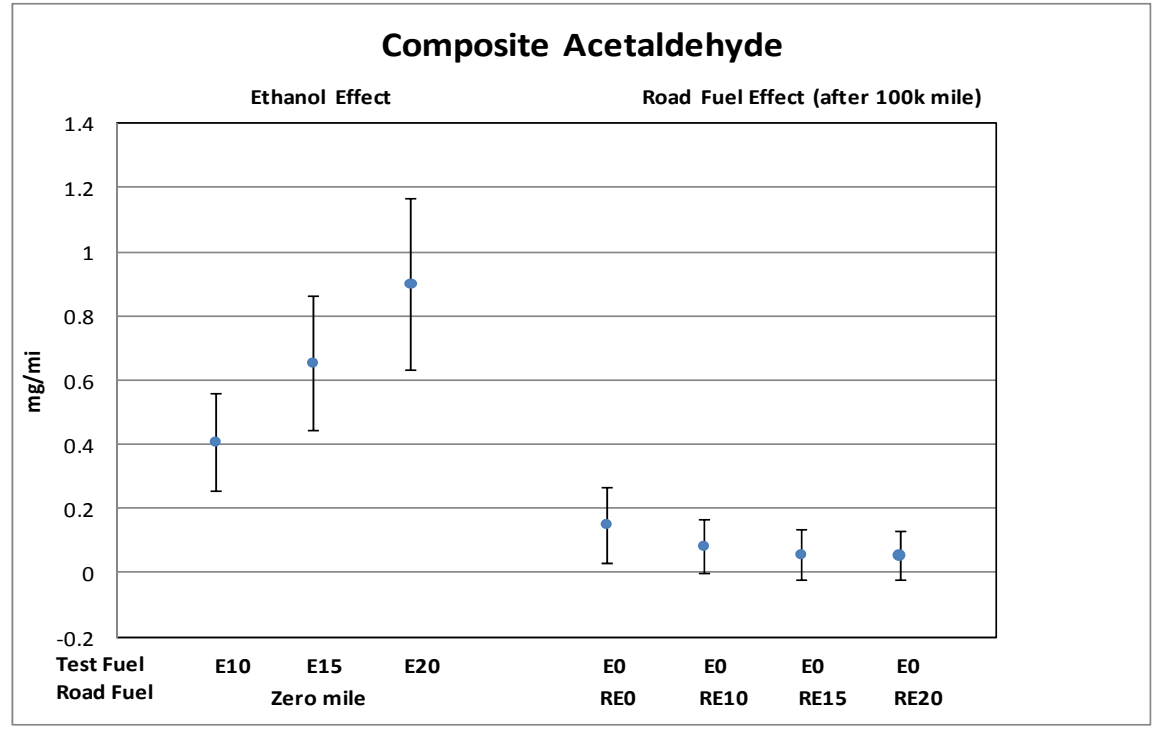

Error bars represent $95 \%$ confidence intervals on the estimated effects 
2008 Nissan Altima (Composite Formaldehyde)

\begin{tabular}{|c|c|c|c|}
\hline Effect & Estimate & $\begin{array}{c}95 \% \text { C.I. } \\
\text { Lower }\end{array}$ & $\begin{array}{c}95 \% \text { C.I. } \\
\text { Upper }\end{array}$ \\
\hline Ethanol Effect (E10 vs. E0) $(\Delta \mathrm{mg} / \mathrm{mi})$ & -0.006 & -0.178 & 0.166 \\
\hline Ethanol Effect (E15 vs. E0) $(\Delta \mathrm{mg} / \mathrm{mi})$ & -0.076 & -0.246 & 0.094 \\
\hline Ethanol Effect (E20 vs. E0) $(\Delta \mathrm{mg} / \mathrm{mi})$ & -0.008 & -0.167 & 0.150 \\
\hline \multicolumn{4}{|l|}{ Road Fuel Aging Effect } \\
\hline Aging Effect with RE0 ( $\Delta \mathrm{mg} / \mathrm{mi}$ per $100 \mathrm{k} \mathrm{mi})$ & 0.002 & -0.280 & 0.284 \\
\hline Aging Effect with RE10 ( $\Delta \mathrm{mg} / \mathrm{mi}$ per $100 \mathrm{k} \mathrm{mi})$ & $0.341^{*}$ & 0.094 & 0.587 \\
\hline Aging Effect with RE15 ( $\Delta \mathrm{mg} / \mathrm{mi}$ per $100 \mathrm{k} \mathrm{mi})$ & $0.254^{*}$ & 0.016 & 0.493 \\
\hline Aging Effect with RE20 ( $\Delta \mathrm{mg} / \mathrm{mi}$ per $100 \mathrm{k} \mathrm{mi})$ & $0.282^{*}$ & 0.062 & 0.502 \\
\hline
\end{tabular}

\begin{tabular}{|l|r|}
\hline \multicolumn{1}{|c|}{ Hypothesis } & -value \\
\hline No Effect of Ethanol in the Test Fuel (Gamma = 0) & 0.63 \\
\hline No Aging Effect with RE0 (Beta0 $=0)$ & 0.99 \\
\hline No Effect of Ethanol in Road Fuel Aging (Beta1s=0) & 0.25 \\
\hline * Indicates effect is statistically significant at the 95\% confidence level.
\end{tabular}

* Indicates estimate is different from zero at the $95 \%$ confidence level.

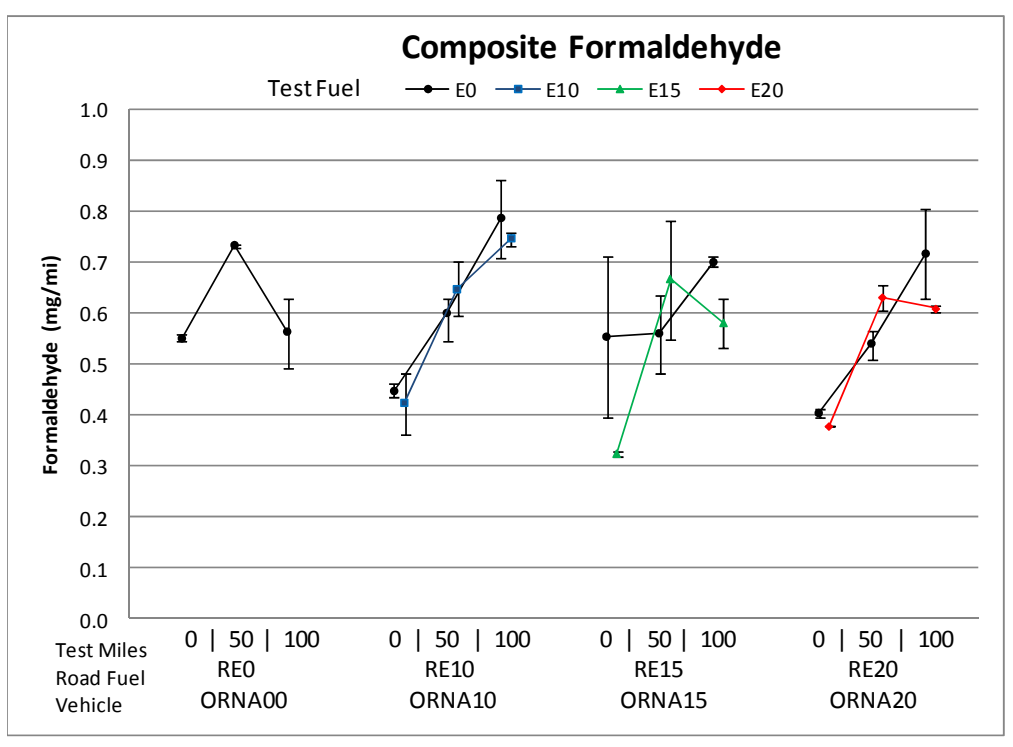

Error bars represent min and max measurements

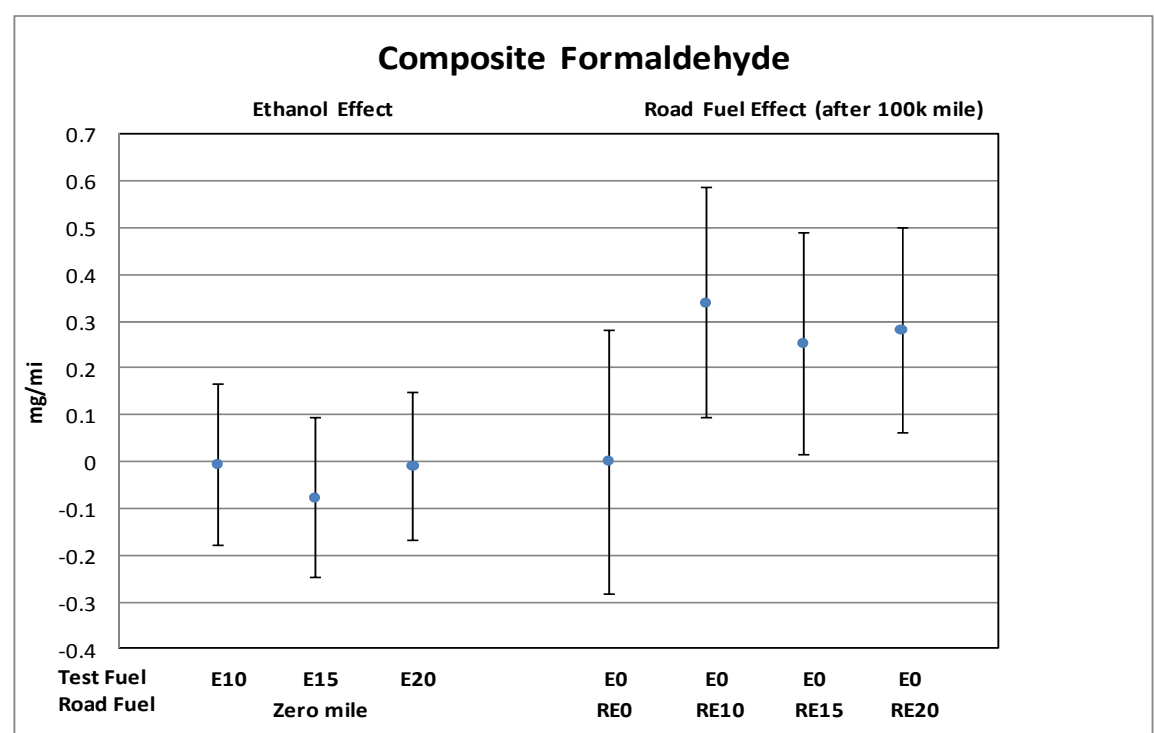

Error bars represent $95 \%$ confidence intervals on the estimated effects 
2008 Nissan Altima (Composite $\mathrm{CH} 4$ )

\begin{tabular}{|l|r|r|r|}
\hline \multicolumn{1}{|c|}{ Effect } & Estimate & $\begin{array}{c}95 \% \text { C.I. } \\
\text { Lower }\end{array}$ & $\begin{array}{c}95 \% \text { C.I. } \\
\text { Upper }\end{array}$ \\
\hline Ethanol Effect $(E 10$ vs. E0) $(\Delta \mathrm{g} / \mathrm{mi})$ & 0.0002 & -0.0021 & 0.0025 \\
\hline Ethanol Effect $(E 15 \mathrm{vs.} \mathrm{E0)}(\Delta \mathrm{g} / \mathrm{mi})$ & 0.0003 & -0.0020 & 0.0027 \\
\hline Ethanol Effect $(E 20 \mathrm{vs.} \mathrm{E0)}(\Delta \mathrm{g} / \mathrm{mi})$ & -0.0005 & -0.0028 & 0.0018 \\
\hline Road Fuel Aging Effect & & & \\
\hline Aging Effect with RE0 $(\Delta \mathrm{g} / \mathrm{mi}$ per 100k mi) & 0.0000 & -0.0080 & 0.0081 \\
\hline Aging Effect with RE10 $(\Delta \mathrm{g} / \mathrm{mi}$ per 100k mi) & $0.0052^{*}$ & 0.0023 & 0.0080 \\
\hline Aging Effect with RE15 $(\Delta \mathrm{g} / \mathrm{mi}$ per 100k mi) & $0.0042^{*}$ & 0.0013 & 0.0070 \\
\hline Aging Effect with RE20 $(\Delta \mathrm{g} / \mathrm{mi} \mathrm{per} \mathrm{100k} \mathrm{mi)}$ & $0.0044^{*}$ & 0.0016 & 0.0073 \\
\hline
\end{tabular}

\begin{tabular}{|l|r|}
\hline \multicolumn{1}{|c|}{ Hypothesis } & p-value \\
\hline No Effect of Ethanol in the Test Fuel (Gamma = 0) & 0.95 \\
\hline No Aging Effect with RE0 (Beta0 = 0) & 0.99 \\
\hline No Effect of Ethanol in Road Fuel Aging (Beta1s=0) & 0.61 \\
\hline
\end{tabular}

Initial odometers 10k-20k

${ }^{*}$ Indicates estimate is different from zero at the $95 \%$ confidence level.

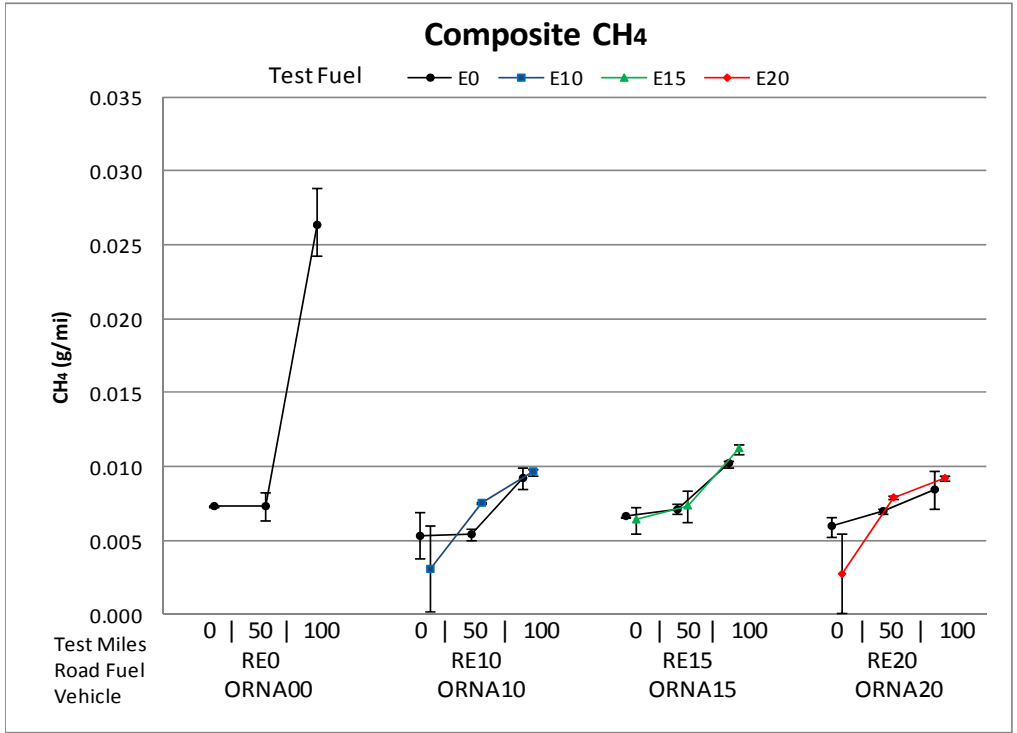

Error bars represent min and max measurements

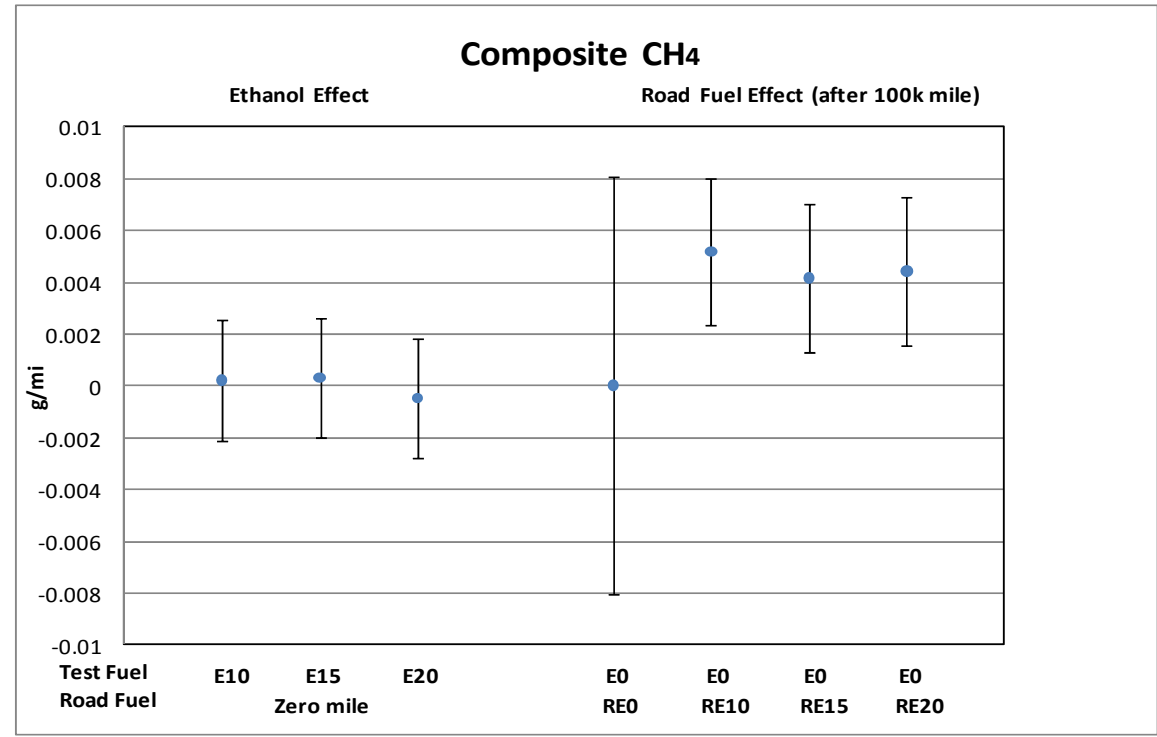

Error bars represent $95 \%$ confidence intervals on the estimated effects 


\section{Ford Taurus - Composite Emissions Summary}

\begin{tabular}{|c|c|c|c|c|c|c|c|c|c|c|c|c|c|c|}
\hline \multirow{2}{*}{$\begin{array}{c}\text { Emisssion Parameter } \\
\text { (units) }\end{array}$} & \multicolumn{4}{|c|}{ Ethanol Effect } & \multicolumn{2}{|c|}{ Aging Effect with REO } & \multicolumn{4}{|c|}{ RExx Aging Effect on E0 Emissions } & \multirow{2}{*}{\multicolumn{3}{|c|}{$\begin{array}{c}\text { RExx Aging Effect on Exx Emissions } \\
\Delta \text { units per } 100 \mathrm{~K} \mathrm{mi}\end{array}$}} & \multirow{3}{*}{\begin{tabular}{|c|}
$\begin{array}{l}\text { Road and Test } \\
\text { Fuel Effects } \\
\text { are Additive }\end{array}$ \\
$\begin{array}{c}\text { Overall p- } \\
\text { value }\end{array}$ \\
\end{tabular}} \\
\hline & \multicolumn{3}{|c|}{$\Delta$ units vs. EO } & \multirow{2}{*}{$-\begin{array}{c}\text { Overall } \\
p \text {-value }\end{array}$} & \multirow{2}{*}{$\frac{\Delta \text { units per } 100 \mathrm{~K} \mathrm{mi}}{\mathrm{REO} / \mathrm{EO}}$} & \multirow{2}{*}{$\begin{array}{l}\text { Overall } \\
p \text {-value }\end{array}$} & \multicolumn{3}{|c|}{$\Delta$ units per $100 \mathrm{~K} \mathrm{mi}$} & \multirow{2}{*}{$\begin{array}{l}\text { Overall } \\
p \text {-value }\end{array}$} & & & & \\
\hline Fuels & E10 & E15 & E20 & & & & RE10/E0 & RE15/E0 & RE20/E0 & & RE10/E10 & RE15/E15 & RE20/E20 & \\
\hline $\mathrm{CO}(\mathrm{g} / \mathrm{mi})^{\mathrm{a}}$ & -0.031 & 0.037 & -0.066 & 0.48 & -0.021 & 0.81 & -0.005 & $0.140 *$ & -0.122 & 0.07 & NA & $\mathrm{NA}$ & NA & 0.85 \\
\hline $\mathrm{NOx}(\mathrm{g} / \mathrm{mi})$ & 0.0022 & 0.0056 & 0.0025 & 0.18 & 0.0073 & 0.13 & $0.0094 *$ & $0.0087 *$ & $0.0076 *$ & 0.97 & NA & $\mathrm{NA}$ & $\mathrm{NA}$ & 0.60 \\
\hline $\mathrm{NMHC}(\mathrm{g} / \mathrm{mi})$ & -0.0026 & -0.0009 & -0.0031 & 0.25 & 0.0036 & 0.30 & -0.0020 & $0.0080 *$ & -0.0013 & $0.04 *$ & NA & $\mathrm{NA}$ & NA & 0.56 \\
\hline $\operatorname{NMOG}(\mathrm{g} / \mathrm{mi})$ & -0.0008 & 0.0011 & -0.0001 & 0.94 & 0.0036 & 0.36 & -0.0020 & $0.0089 *$ & -0.0011 & 0.06 & $\mathrm{NA}$ & $\mathrm{NA}$ & NA & 0.56 \\
\hline Fuel Econ (mi/gal) & $-0.669 *$ & $-1.044 *$ & $-1.333 *$ & $<0.01^{*}$ & 0.421 & 0.10 & $0.529 *$ & -0.288 & 0.338 & $0.02 *$ & NA & $\mathrm{NA}$ & $\mathrm{NA}$ & 0.63 \\
\hline Ethanol $(\mathrm{mg} / \mathrm{mi})^{\# \#}$ & 1.185 & 1.463 & $3.593 *$ & $<0.01 *$ & -0.037 & 0.97 & -0.608 & 0.065 & -0.018 & 0.92 & NA & $\mathrm{NA}$ & $\mathrm{NA}$ & NA \\
\hline Acetaldehyde $(\mathrm{mg} / \mathrm{mi})^{\#}$ & $0.296 *$ & $0.366 *$ & $0.696 *$ & $<0.01 *$ & $0.087 *$ & $<0.01 *$ & 0.026 & 0.029 & 0.022 & 0.18 & NA & $\mathrm{NA}$ & NA & 0.50 \\
\hline Formaldehyde $(\mathrm{mg} / \mathrm{mi})^{\#}$ & 0.007 & -0.003 & 0.014 & 0.94 & $0.257^{*}$ & $<0.01^{*}$ & $0.219 *$ & $0.167 *$ & $0.171^{*}$ & 0.65 & $\mathrm{NA}$ & $\mathrm{NA}$ & $\mathrm{NA}$ & 0.65 \\
\hline $\mathrm{CH}_{4}(\mathrm{~g} / \mathrm{mi})$ & 0.0004 & 0.0023 & 0.0004 & 0.41 & 0.0093* & $<0.01 *$ & $0.0078 *$ & $0.0085 *$ & $0.0048 *$ & 0.31 & NA & $\mathrm{NA}$ & NA & 0.98 \\
\hline
\end{tabular}

\# Log-normal model was used. Results are presented as changes in emissions at 0k mile.

\#\# Data did not support the assumption of linear effects with mileage.

(1) *Indicates estimate is different from zero at the $95 \%$ confidence level.

a Test "SW023476" is identified as an outlier and excluded from the analysis. 
2008 Ford Taurus (Composite CO)

\begin{tabular}{|l|r|r|r|}
\hline \multicolumn{1}{|c|}{ Effect } & Estimate & $\begin{array}{c}\text { 95\% C.I. } \\
\text { Lower }\end{array}$ & $\begin{array}{c}\text { 95\% C.I. } \\
\text { Upper }\end{array}$ \\
\hline Ethanol Effect $(E 10 \mathrm{vs.} \mathrm{E0)}(\Delta \mathrm{g} / \mathrm{mi})$ & -0.031 & -0.144 & 0.081 \\
\hline Ethanol Effect $(E 15 \mathrm{vs.} \mathrm{E0)}(\Delta \mathrm{g} / \mathrm{mi})$ & 0.037 & -0.076 & 0.151 \\
\hline Ethanol Effect $(E 20 \mathrm{vs.} \mathrm{E0)}(\Delta \mathrm{g} / \mathrm{mi})$ & -0.066 & -0.178 & 0.047 \\
\hline Road Fuel Aging Effect & & & \\
\hline Aging Effect with RE0 $(\Delta \mathrm{g} / \mathrm{mi}$ per 100k mi) & -0.021 & -0.213 & 0.171 \\
\hline Aging Effect with RE10 $(\Delta \mathrm{g} / \mathrm{mi}$ per 100k mi) & -0.005 & -0.139 & 0.130 \\
\hline Aging Effect with RE15 $(\Delta \mathrm{g} / \mathrm{mi}$ per 100k mi) & $0.140^{*}$ & 0.004 & 0.275 \\
\hline Aging Effect with RE20 $(\Delta \mathrm{g} / \mathrm{mi}$ per 100k mi) & -0.122 & -0.256 & 0.013 \\
\hline
\end{tabular}

\begin{tabular}{|l|r|}
\hline \multicolumn{1}{|c|}{ Hypothesis } & p-value \\
\hline No Effect of Ethanol in the Test Fuel (Gamma = 0) & 0.48 \\
\hline No Aging Effect with RE0 (Beta0 = 0) & 0.81 \\
\hline No Effect of Ethanol in Road Fuel Aging (Beta1s=0) & 0.07 \\
\hline * Indicates effect is statistically significant at the 95\% confidence level.
\end{tabular}

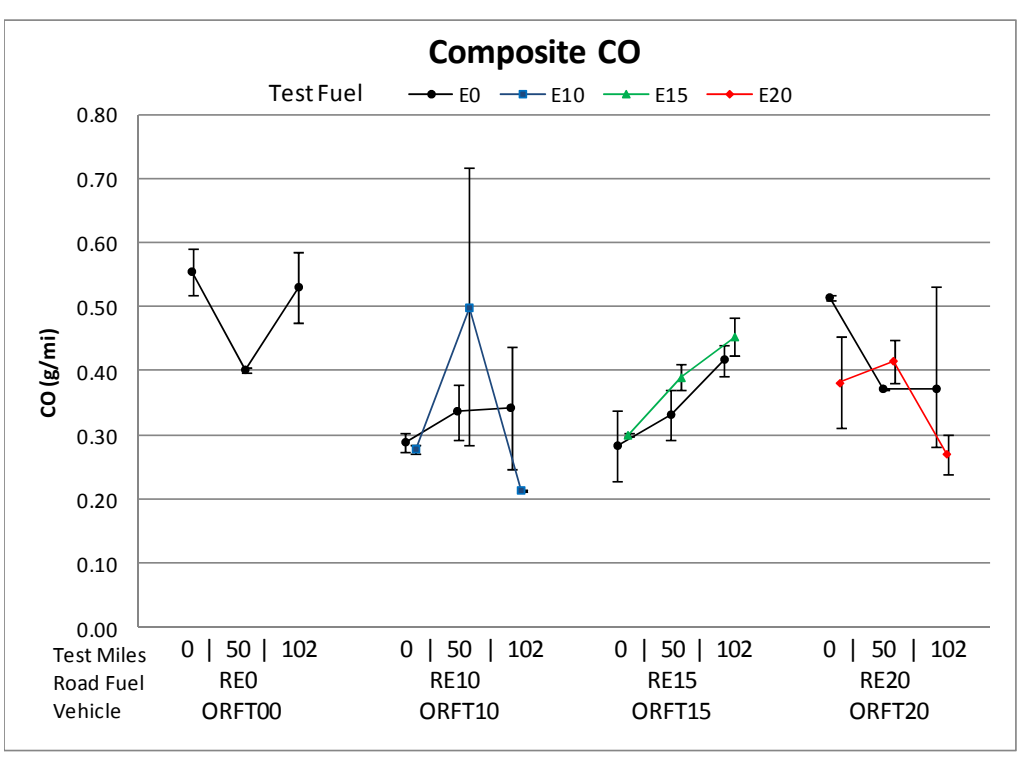

Error bars represent min and max measurements

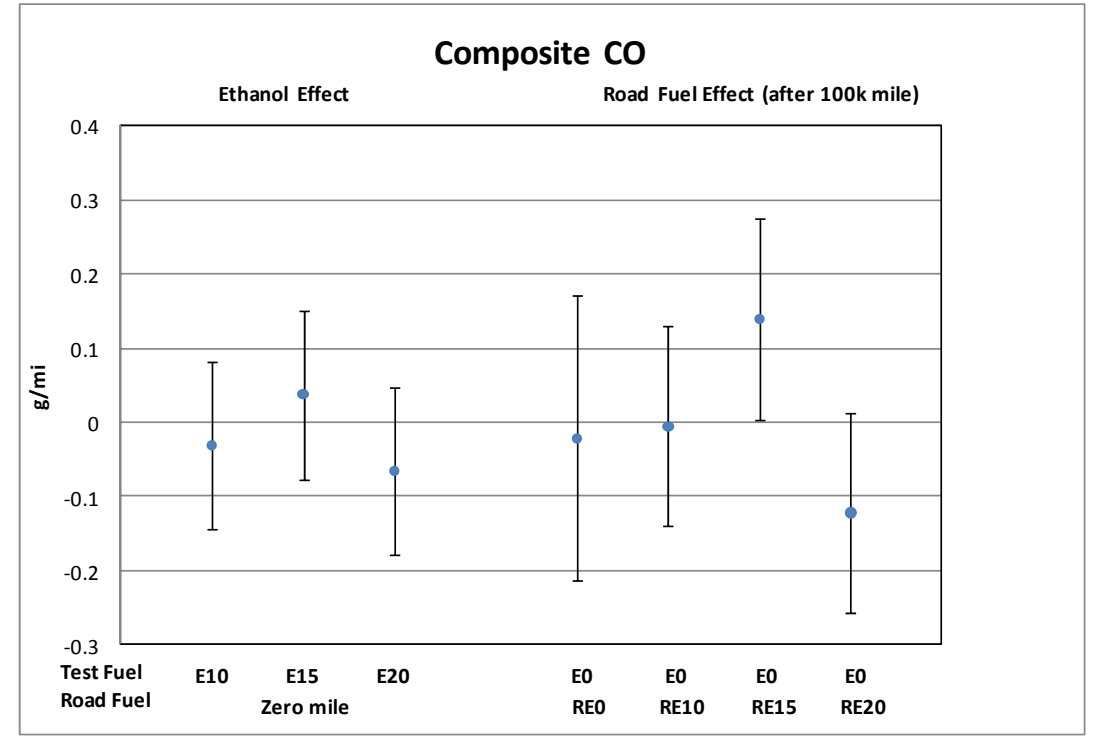

Error bars represent $95 \%$ confidence intervals on the estimated effects 
2008 Ford Taurus (Composite NOx)

\begin{tabular}{|l|r|r|r|}
\hline \multicolumn{1}{|c|}{ Effect } & & $\begin{array}{r}95 \% \text { C.I. } \\
\text { Lo5\% C.I. } \\
\text { Upper }\end{array}$ \\
\hline Ethanol Effect (E10 vs. E0) $(\Delta \mathrm{g} / \mathrm{mi})$ & 0.0022 & -0.0037 & 0.0080 \\
\hline Ethanol Effect $(E 15 \mathrm{vs.} \mathrm{E0)}(\Delta \mathrm{g} / \mathrm{mi})$ & 0.0056 & -0.0003 & 0.0115 \\
\hline Ethanol Effect $($ E20 vs. E0) $(\Delta \mathrm{g} / \mathrm{mi})$ & 0.0025 & -0.0033 & 0.0084 \\
\hline Road Fuel Aging Effect & & & \\
\hline Aging Effect with RE0 $(\Delta \mathrm{g} / \mathrm{mi}$ per 100k mi) & 0.0073 & -0.0026 & 0.0173 \\
\hline Aging Effect with RE10 $(\Delta \mathrm{g} / \mathrm{mi}$ per 100k mi) & $0.0094^{*}$ & 0.0025 & 0.0164 \\
\hline Aging Effect with RE15 $(\Delta \mathrm{g} / \mathrm{mi} \mathrm{per} \mathrm{100k} \mathrm{mi)}$ & $0.0087^{*}$ & 0.0016 & 0.0157 \\
\hline Aging Effect with RE20 $(\Delta \mathrm{g} / \mathrm{mi} \mathrm{per} \mathrm{100k} \mathrm{mi)}$ & $0.0076^{*}$ & 0.0006 & 0.0146 \\
\hline
\end{tabular}

\begin{tabular}{|l|r|}
\hline \multicolumn{1}{|c|}{ Hypothesis } & p-value \\
\hline No Effect of Ethanol in the Test Fuel (Gamma = 0) & 0.18 \\
\hline No Aging Effect with RE0 (Beta0 = 0) & 0.13 \\
\hline No Effect of Ethanol in Road Fuel Aging (Beta1s=0) & 0.97 \\
\hline * Indicates effect is statistically significant at the 95\% confidence level.
\end{tabular}

Initial odometers 9k-17k

* Indicates estimate is different from zero at the $95 \%$ confidence level.

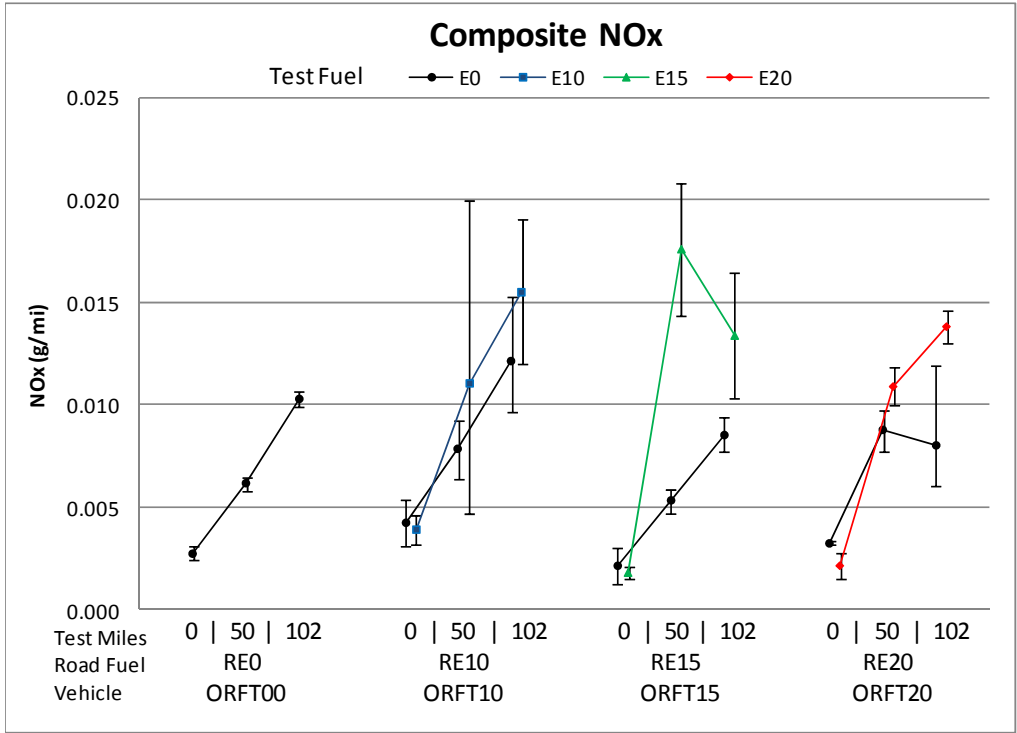

Error bars represent min and max measurements

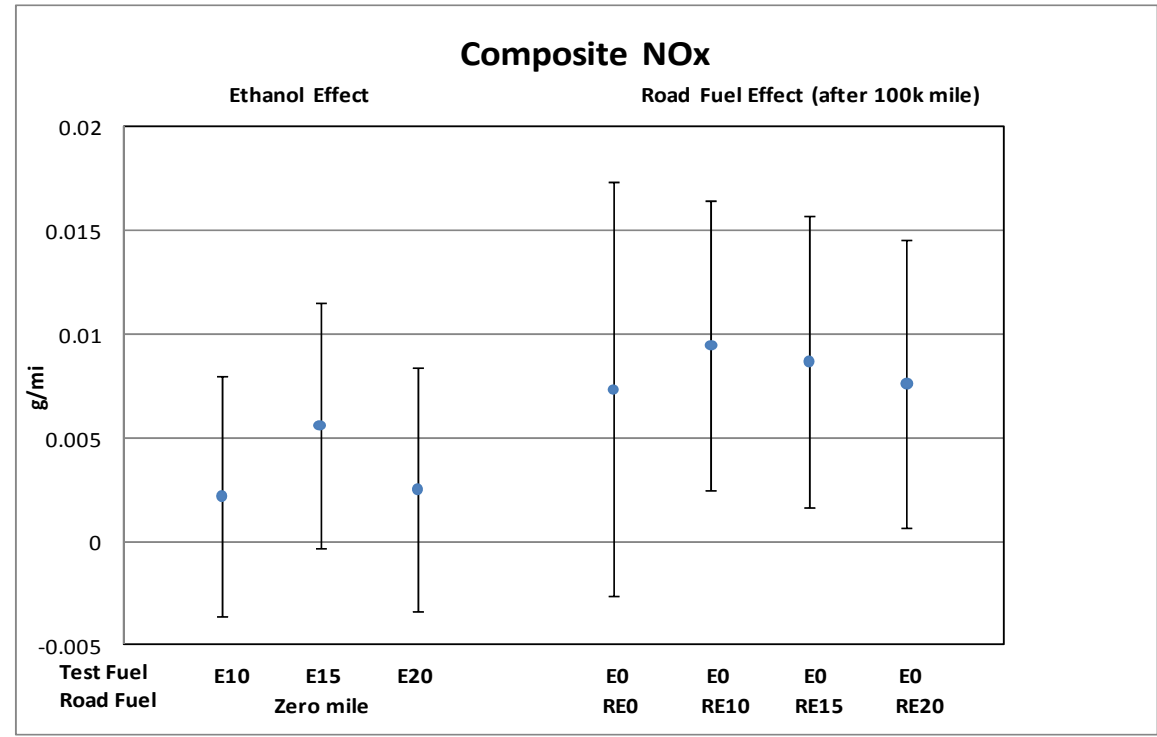

Error bars represent $95 \%$ confidence intervals on the estimated effects 
2008 Ford Taurus (Composite Nonmethane Hydrocarbons)

\begin{tabular}{|l|r|r|r|}
\hline \multicolumn{1}{|c|}{ Effect } & & $\begin{array}{r}95 \% \text { C.I. } \\
\text { Lo5\% C.I. } \\
\text { Upper }\end{array}$ \\
\hline Ethanol Effect (E10 vs. E0) $(\Delta \mathrm{g} / \mathrm{mi})$ & -0.0026 & -0.0068 & 0.0017 \\
\hline Ethanol Effect $(E 15 \mathrm{vs.} \mathrm{E0)}(\Delta \mathrm{g} / \mathrm{mi})$ & -0.0009 & -0.0052 & 0.0034 \\
\hline Ethanol Effect $($ E20 vs. E0) $(\Delta \mathrm{g} / \mathrm{mi})$ & -0.0031 & -0.0074 & 0.0012 \\
\hline Road Fuel Aging Effect & & & \\
\hline Aging Effect with RE0 $(\Delta \mathrm{g} / \mathrm{mi}$ per 100k mi) & 0.0036 & -0.0037 & 0.0109 \\
\hline Aging Effect with RE10 $(\Delta \mathrm{g} / \mathrm{mi}$ per 100k mi) & -0.0020 & -0.0071 & 0.0031 \\
\hline Aging Effect with RE15 $(\Delta \mathrm{g} / \mathrm{mi}$ per 100k mi) & $0.0080^{*}$ & 0.0028 & 0.0132 \\
\hline Aging Effect with RE20 $(\Delta \mathrm{g} / \mathrm{mi} \mathrm{per} \mathrm{100k} \mathrm{mi)}$ & -0.0013 & -0.0064 & 0.0038 \\
\hline
\end{tabular}

\begin{tabular}{|l|r|}
\hline \multicolumn{1}{|c|}{ Hypothesis } & p-value \\
\hline No Effect of Ethanol in the Test Fuel (Gamma = 0) & 0.25 \\
\hline No Aging Effect with RE0 (Beta0 = 0) & 0.30 \\
\hline No Effect of Ethanol in Road Fuel Aging (Beta1s=0) & 0.04 \\
\hline
\end{tabular}

Initial odometers $9 k-17 k$

${ }^{*}$ Indicates estimate is different from zero at the $95 \%$ confidence level.

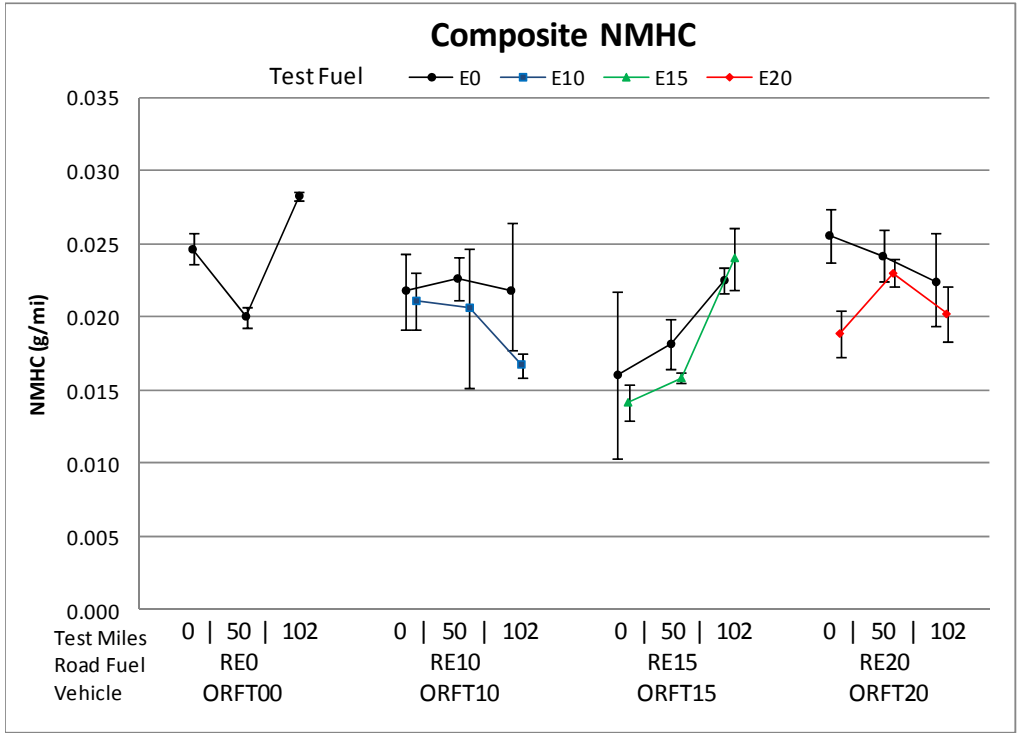

Error bars represent min and max measurements

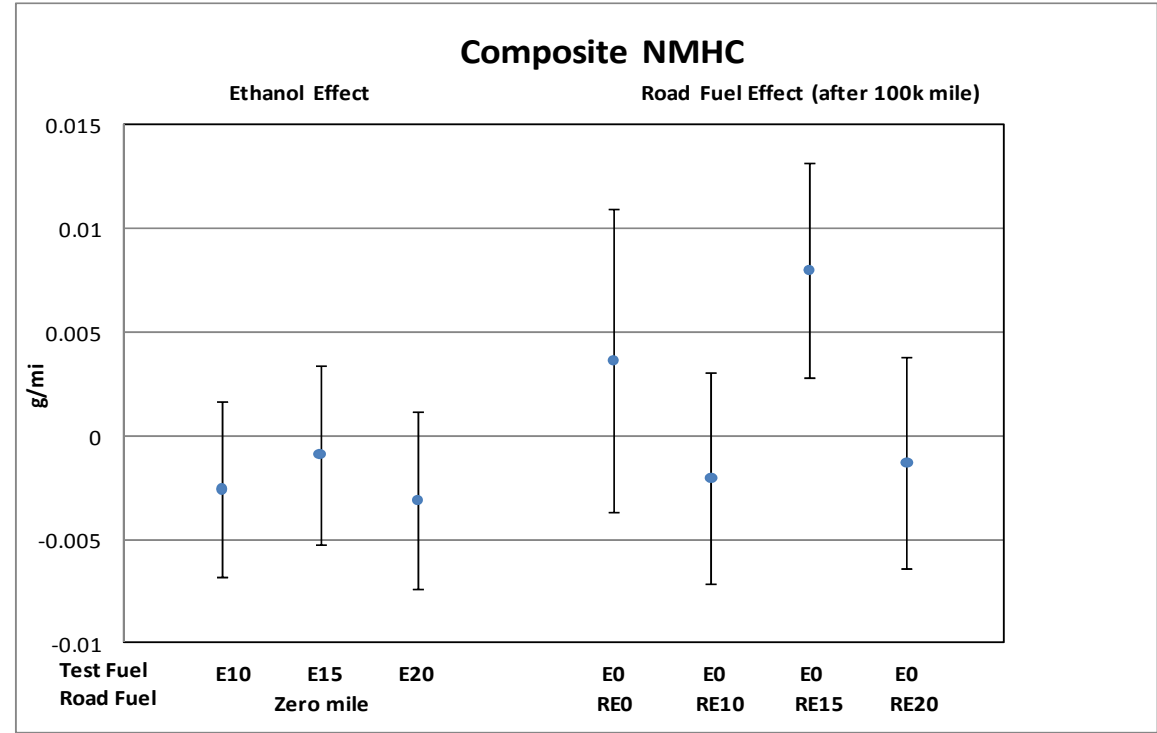

Error bars represent $95 \%$ confidence intervals on the estimated effects 
2008 Ford Taurus (Composite Nonmethane Organic Gases)

\begin{tabular}{|l|r|r|r|}
\hline \multicolumn{1}{|c|}{ Effect } & Estimate & $\begin{array}{c}95 \% \text { C.I. } \\
\text { Lower }\end{array}$ & $\begin{array}{c}95 \% \text { C.I. } \\
\text { Upper }\end{array}$ \\
\hline Ethanol Effect (E10 vs. E0) $(\Delta \mathrm{g} / \mathrm{mi})$ & -0.0008 & -0.0057 & 0.0041 \\
\hline Ethanol Effect $(E 15 \mathrm{vs.} \mathrm{E0)}(\Delta \mathrm{g} / \mathrm{mi})$ & 0.0011 & -0.0039 & 0.0061 \\
\hline Ethanol Effect $(E 20 \mathrm{vs.} \mathrm{E0)}(\Delta \mathrm{g} / \mathrm{mi})$ & -0.0001 & -0.0050 & 0.0049 \\
\hline Road Fuel Aging Effect & & & \\
\hline Aging Effect with RE0 $(\Delta \mathrm{g} / \mathrm{mi}$ per 100k mi) & 0.0036 & -0.0048 & 0.0120 \\
\hline Aging Effect with RE10 $(\Delta \mathrm{g} / \mathrm{mi}$ per 100k mi) & -0.0020 & -0.0078 & 0.0039 \\
\hline Aging Effect with RE15 $(\Delta \mathrm{g} / \mathrm{mi}$ per 100k mi) & $0.0089^{*}$ & 0.0030 & 0.0149 \\
\hline Aging Effect with RE20 $(\Delta \mathrm{g} / \mathrm{mi} \mathrm{per} \mathrm{100k} \mathrm{mi)}$ & -0.0011 & -0.0070 & 0.0048 \\
\hline
\end{tabular}

\begin{tabular}{|l|r|}
\hline \multicolumn{1}{|c|}{ Hypothesis } & p-value \\
& \\
\hline No Effect of Ethanol in the Test Fuel (Gamma = 0) & 0.94 \\
\hline No Aging Effect with RE0 (Beta0 = 0) & 0.36 \\
\hline No Effect of Ethanol in Road Fuel Aging (Beta1s=0) & 0.06 \\
\hline
\end{tabular}

Initial odometers $9 k-17 k$

* Indicates estimate is different from zero at the $95 \%$ confidence level.

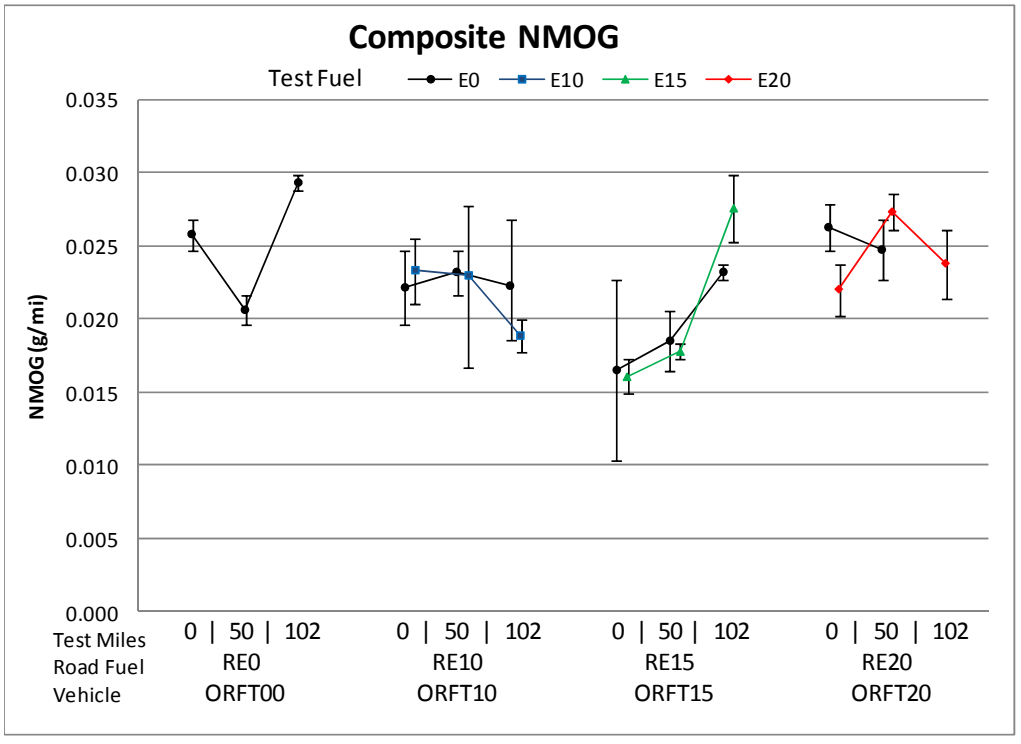

Error bars represent min and max measurements

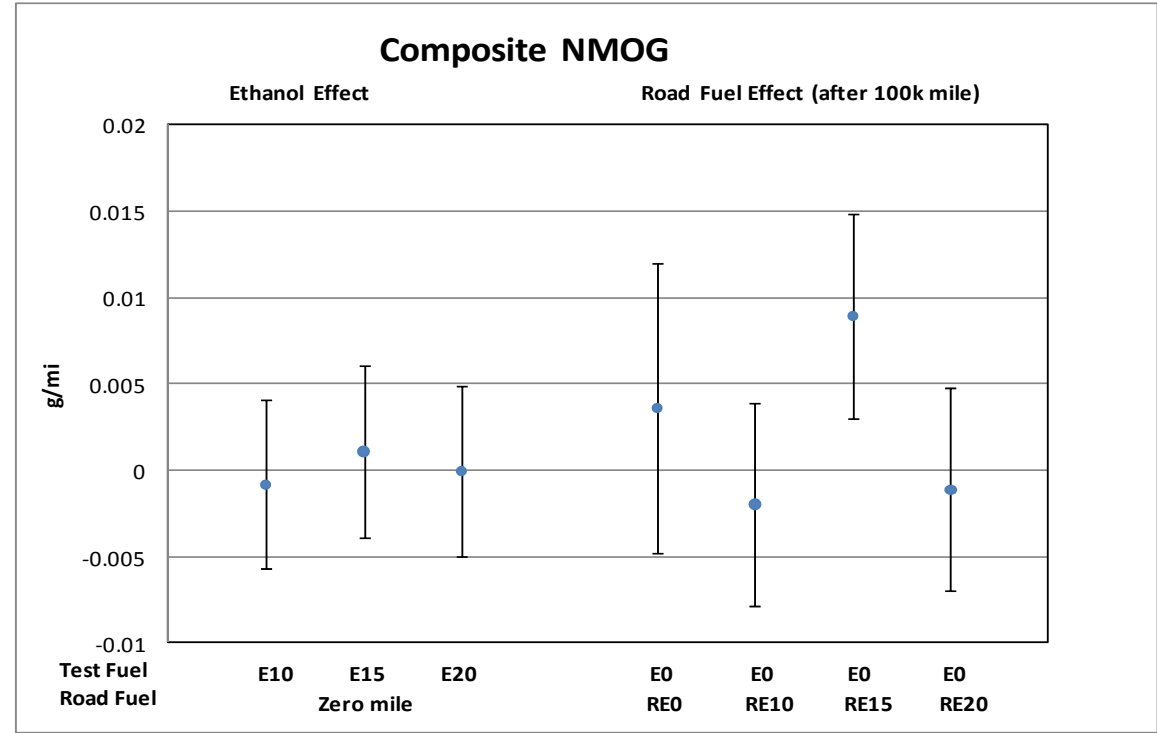

Error bars represent $95 \%$ confidence intervals on the estimated effects 
2008 Ford Taurus (Composite Fuel Economy)

\begin{tabular}{|l|r|r|r|}
\hline \multicolumn{1}{|c|}{ Effect } & & $\begin{array}{r}95 \% \text { C.I. } \\
\text { Lo5\% C.I. } \\
\text { Upper }\end{array}$ \\
\hline Ethanol Effect $($ E10 vs. E0) $(\Delta \mathrm{mi} / \mathrm{gal})$ & $-0.669^{*}$ & -0.966 & -0.373 \\
\hline Ethanol Effect $($ E15 vs. E0) $(\Delta \mathrm{mi} / \mathrm{gal})$ & $-1.044^{*}$ & -1.350 & -0.738 \\
\hline Ethanol Effect $($ E20 vs. E0) $(\Delta \mathrm{mi} / \mathrm{gal})$ & $-1.333^{*}$ & -1.632 & -1.034 \\
\hline Road Fuel Aging Effect & & & \\
\hline Aging Effect with RE0 $(\Delta \mathrm{mi} / \mathrm{gal}$ per 100k mi) & 0.421 & -0.096 & 0.939 \\
\hline Aging Effect with RE10 $(\Delta \mathrm{mi} / \mathrm{gal}$ per 100k mi) & $0.529^{*}$ & 0.172 & 0.886 \\
\hline Aging Effect with RE15 $(\Delta \mathrm{mi} / \mathrm{gal}$ per 100k mi) & -0.288 & -0.654 & 0.078 \\
\hline Aging Effect with RE20 $(\Delta \mathrm{mi} / \mathrm{gal}$ per 100k mi) & 0.338 & -0.016 & 0.692 \\
\hline
\end{tabular}

\begin{tabular}{|l|r|}
\hline \multicolumn{1}{|c|}{ Hypothesis } & -value \\
\hline No Effect of Ethanol in the Test Fuel (Gamma $=0)$ & $<0.01^{*}$ \\
\hline No Aging Effect with RE0 (Beta0 $=0$ ) & 0.10 \\
\hline No Effect of Ethanol in Road Fuel Aging (Beta1s $=0$ ) & $0.02^{*}$ \\
\hline * Indicates effect is statistically significant at the $95 \%$ confidence level.
\end{tabular}

Initial odometers 9k-17k

* Indicates estimate is different from zero at the $95 \%$ confidence level.

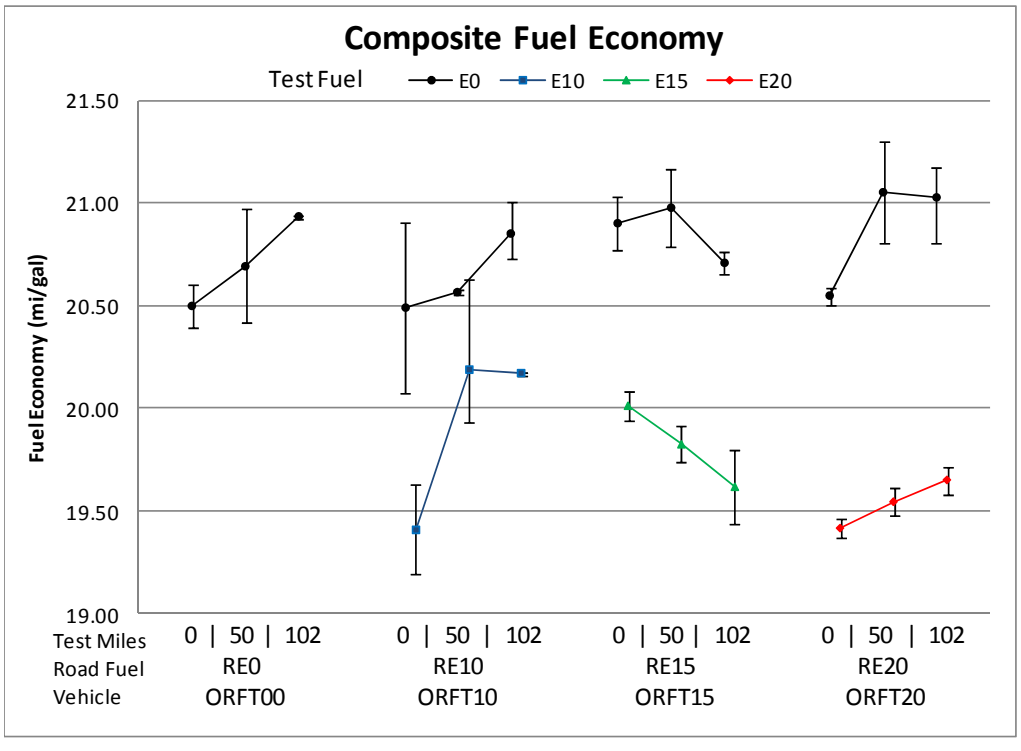

Error bars represent min and max measurements

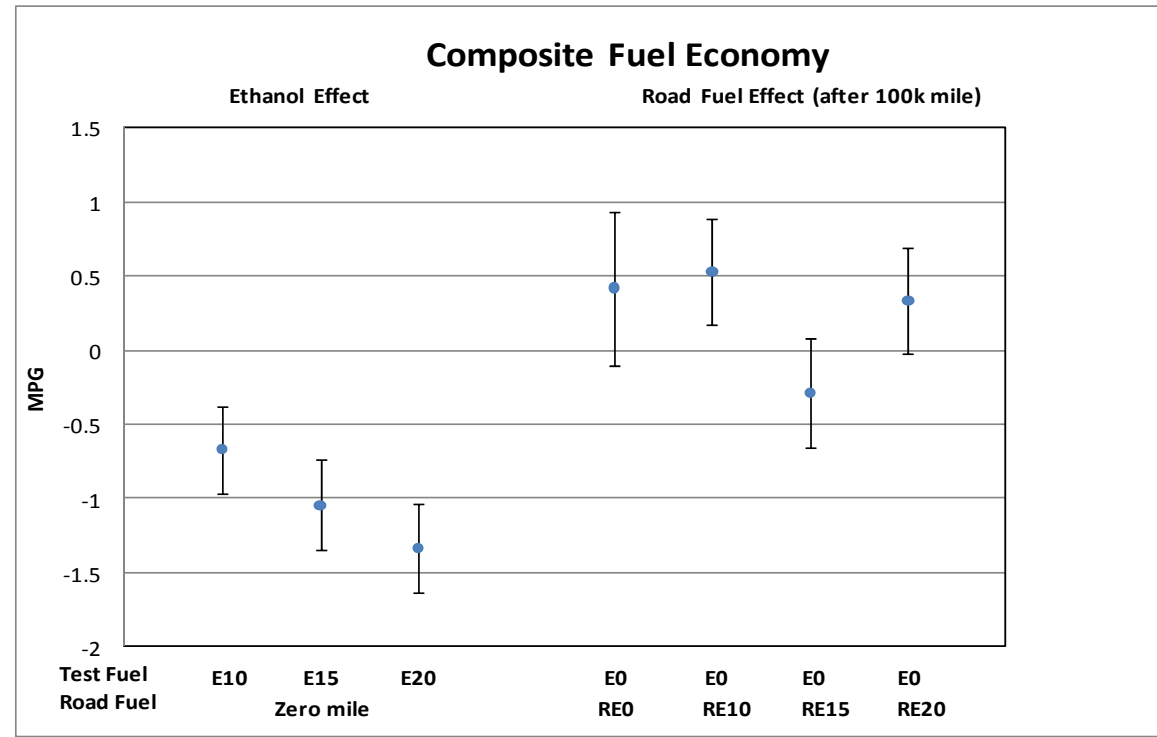

Error bars represent $95 \%$ confidence intervals on the estimated effects 
2008 Ford Taurus (Composite Ethanol)

\begin{tabular}{|l|r|r|r|}
\hline \multicolumn{1}{|c|}{ Effect } & Estimate & $\begin{array}{r}\text { 95\% C.I. } \\
\text { Lower }\end{array}$ & $\begin{array}{r}95 \% \text { C.I. } \\
\text { Upper }\end{array}$ \\
\hline Ethanol Effect $($ E10 vs. E0) $(\Delta \mathrm{mg} / \mathrm{mi})$ & 1.185 & -0.358 & 2.728 \\
\hline Ethanol Effect $(E 15$ vs. E0) $(\Delta \mathrm{mg} / \mathrm{mi})$ & 1.463 & -0.080 & 3.006 \\
\hline Ethanol Effect $(E 20$ vs. E0) $(\Delta \mathrm{mg} / \mathrm{mi})$ & $3.593^{*}$ & 2.050 & 5.136 \\
\hline Road Fuel Aging Effect & & & \\
\hline Aging Effect with RE0 $(\Delta \mathrm{mg} / \mathrm{mi}$ per 100k mi) & -0.037 & -2.645 & 2.571 \\
\hline Aging Effect with RE10 $(\Delta \mathrm{mg} / \mathrm{mi}$ per 100k mi) & -0.608 & -2.451 & 1.235 \\
\hline Aging Effect with RE15 $(\Delta \mathrm{mg} / \mathrm{mi}$ per 100k mi) & 0.065 & -1.779 & 1.909 \\
\hline Aging Effect with RE20 $(\Delta \mathrm{mg} / \mathrm{mi}$ per 100k mi) & -0.018 & -1.865 & 1.829 \\
\hline
\end{tabular}

\begin{tabular}{|l|r|}
\hline \multicolumn{1}{|c|}{ Hypothesis } & p-value \\
\hline No Effect of Ethanol in the Test Fuel (Gamma $=0)$ & $<0.01^{*}$ \\
\hline No Aging Effect with RE0 (Beta0 $=0)$ & 0.97 \\
\hline No Effect of Ethanol in Road Fuel Aging (Beta1s=0) & 0.92 \\
\hline * Indicates effect is statistically significant at the 95\% confidence level
\end{tabular}

Initial odometers 9k-17k

ind

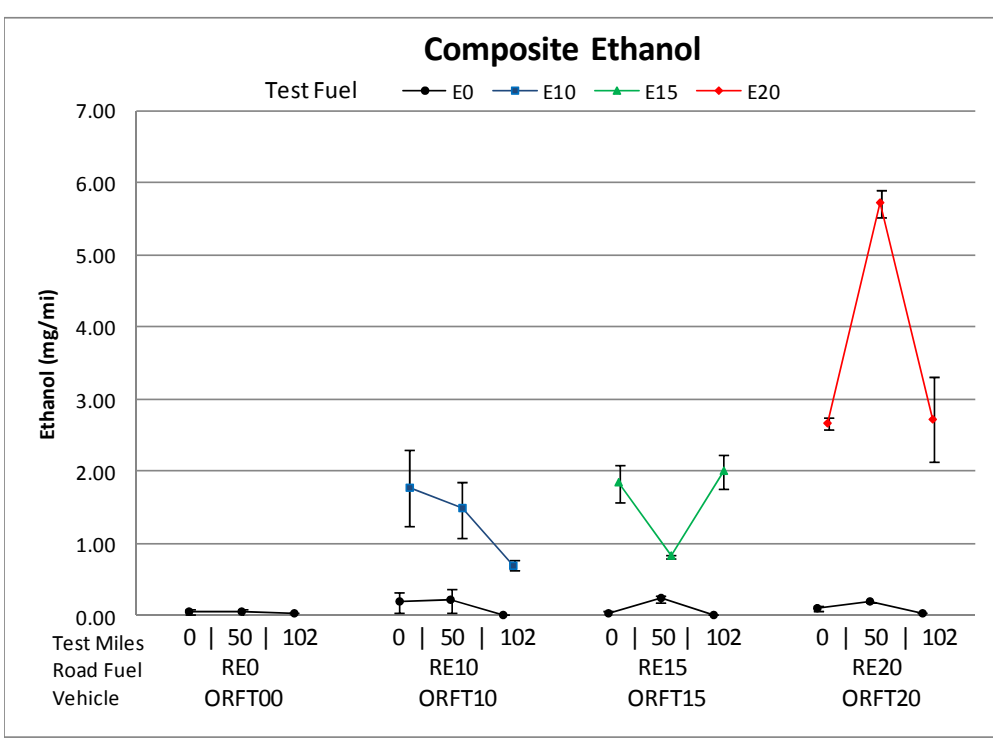

Error bars represent min and max measurements

* The statistical model for Acetaldehyde does not assume the linear relationship between emission and mileage.

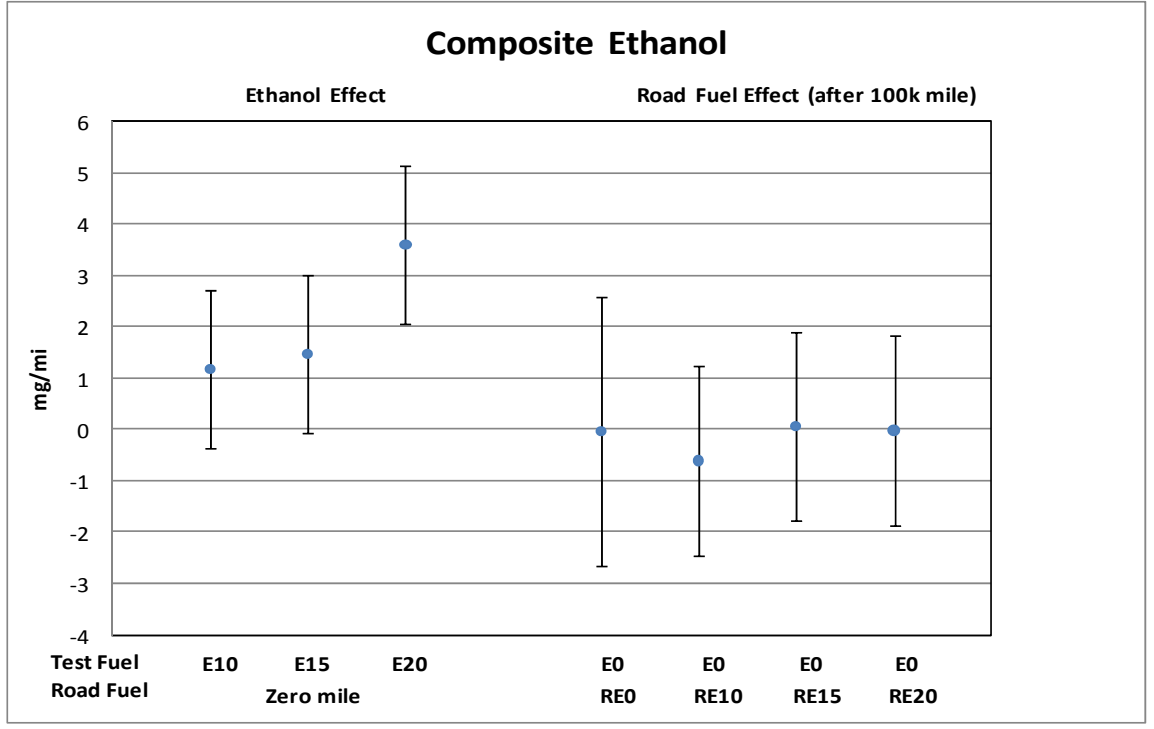

Error bars represent $95 \%$ confidence intervals on the estimated effects 
2008 Ford Taurus (Composite Acetaldehyde)

\begin{tabular}{|l|r|r|r|}
\hline \multicolumn{1}{|c|}{ Effect } & Estimate & $\begin{array}{r}\text { 95\% C.I. } \\
\text { Lower }\end{array}$ & $\begin{array}{r}\text { 95\% C.I. } \\
\text { Upper }\end{array}$ \\
\hline Ethanol Effect $(E 10$ vs. E0) $(\Delta \mathrm{mg} / \mathrm{mi})$ & $0.296^{*}$ & 0.194 & 0.397 \\
\hline Ethanol Effect $(E 15$ vs. E0) $(\Delta \mathrm{mg} / \mathrm{mi})$ & $0.366^{*}$ & 0.249 & 0.483 \\
\hline Ethanol Effect $(E 20$ vs. E0) $(\Delta \mathrm{mg} / \mathrm{mi})$ & $0.696^{*}$ & 0.496 & 0.895 \\
\hline Road Fuel Aging Effect & & & \\
\hline Aging Effect with RE0 $(\Delta \mathrm{mg} / \mathrm{mi}$ per 100k mi) & $0.087^{*}$ & 0.034 & 0.140 \\
\hline Aging Effect with RE10 $(\Delta \mathrm{mg} / \mathrm{mi}$ per 100k mi) & 0.026 & -0.014 & 0.065 \\
\hline Aging Effect with RE15 $(\Delta \mathrm{mg} / \mathrm{mi} \mathrm{per} \mathrm{100k} \mathrm{mi)}$ & 0.029 & -0.009 & 0.066 \\
\hline Aging Effect with RE20 $(\Delta \mathrm{mg} / \mathrm{mi}$ per 100k mi) & 0.022 & -0.016 & 0.060 \\
\hline
\end{tabular}

\begin{tabular}{|l|r|}
\hline \multicolumn{1}{|c|}{ Hypothesis } & p-value \\
\hline No Effect of Ethanol in the Test Fuel (Gamma $=0)$ & $<0.01^{*}$ \\
\hline No Aging Effect with RE0 (Beta0 $=0)$ & $<0.01^{*}$ \\
\hline No Effect of Ethanol in Road Fuel Aging (Beta1s=0) & 0.18 \\
\hline * Indicates effect is statistically significant at the 95\% confidence level.
\end{tabular}

Initial odometers 9k-17k

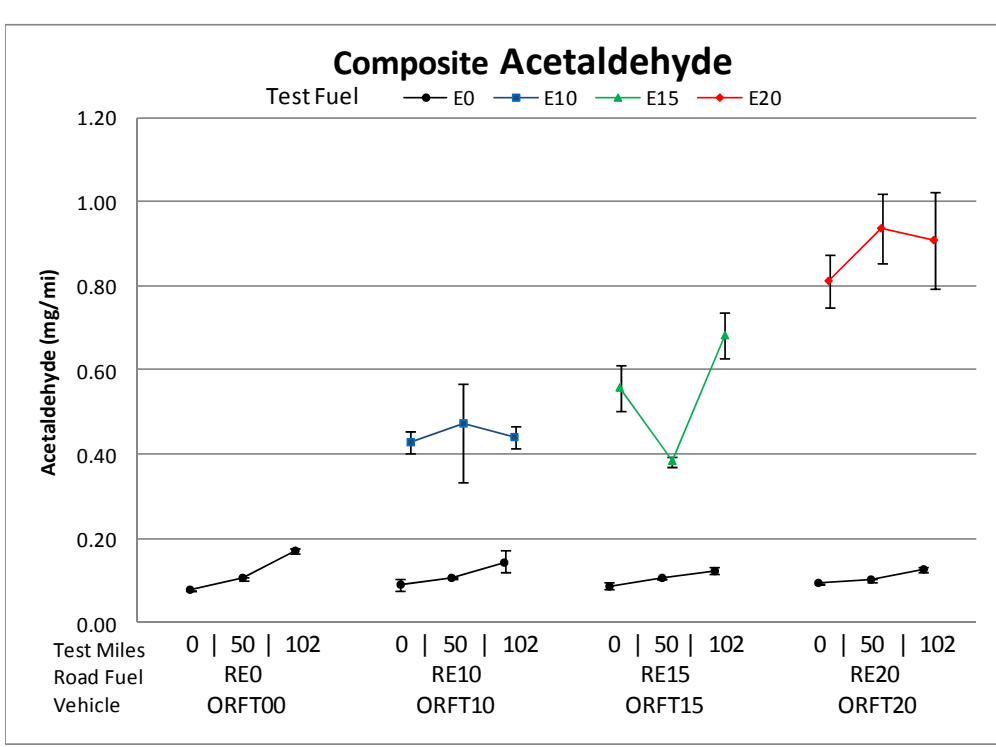

Error bars represent min and max measurements

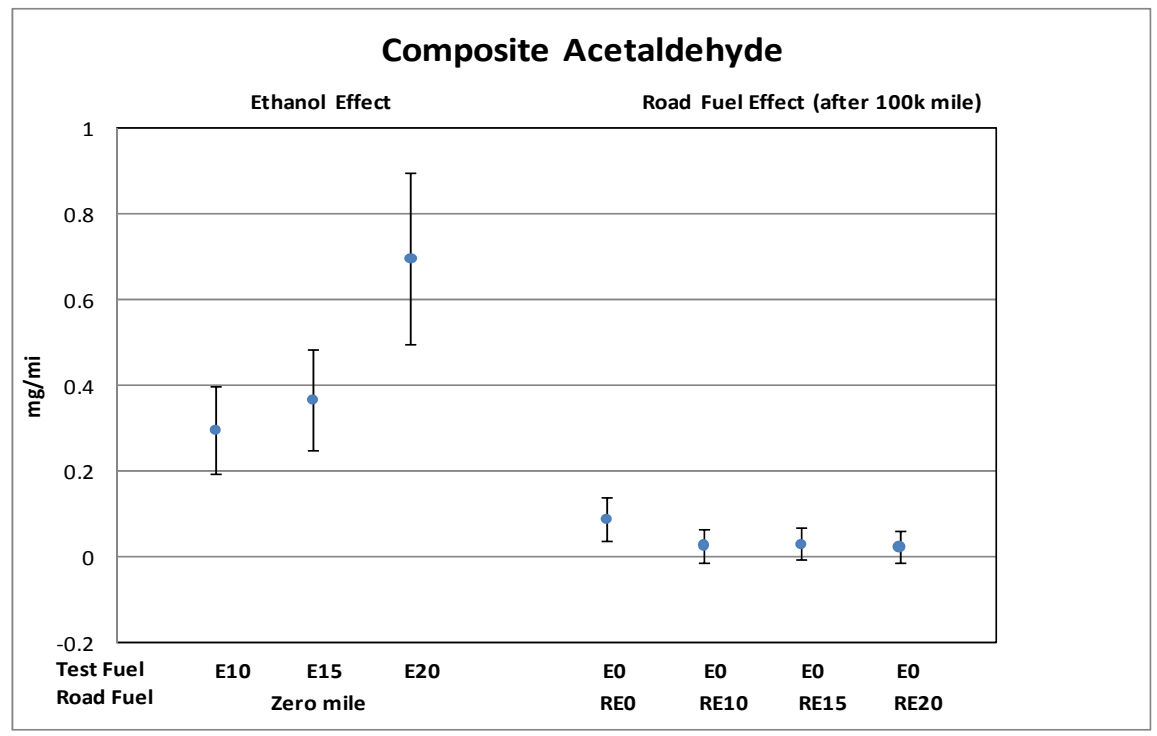

Error bars represent $95 \%$ confidence intervals on the estimated effects 
2008 Ford Taurus (Composite Formaldehyde)

\begin{tabular}{|c|c|c|c|}
\hline Effect & Estimate & $\begin{array}{c}95 \% \text { C.I. } \\
\text { Lower }\end{array}$ & $\begin{array}{l}95 \% \text { C.I. } \\
\text { Upper }\end{array}$ \\
\hline Ethanol Effect (E10 vs. E0) ( $\Delta \mathrm{mg} / \mathrm{mi})$ & 0.007 & -0.063 & 0.078 \\
\hline Ethanol Effect (E15 vs. E0) $(\Delta \mathrm{mg} / \mathrm{mi})$ & -0.003 & -0.073 & 0.067 \\
\hline Ethanol Effect (E20 vs. E0) $(\Delta \mathrm{mg} / \mathrm{mi})$ & 0.014 & -0.063 & 0.090 \\
\hline \multicolumn{4}{|l|}{ Road Fuel Aging Effect } \\
\hline Aging Effect with RE0 ( $\Delta \mathrm{mg} / \mathrm{mi}$ per $100 \mathrm{k} \mathrm{mi})$ & $0.257^{*}$ & 0.116 & 0.399 \\
\hline Aging Effect with RE10 ( $\Delta \mathrm{mg} / \mathrm{mi}$ per $100 \mathrm{k} \mathrm{mi})$ & $0.219^{*}$ & 0.107 & 0.330 \\
\hline Aging Effect with RE15 ( $\Delta \mathrm{mg} / \mathrm{mi}$ per 100k mi) & $0.167^{*}$ & 0.064 & 0.270 \\
\hline Aging Effect with RE20 ( $\Delta \mathrm{mg} / \mathrm{mi}$ per $100 \mathrm{k} \mathrm{mi})$ & $0.171^{*}$ & 0.064 & 0.278 \\
\hline
\end{tabular}

\begin{tabular}{|l|r|}
\hline \multicolumn{1}{|c|}{ Hypothesis } & p-value \\
\hline No Effect of Ethanol in the Test Fuel (Gamma = 0) & 0.94 \\
\hline No Aging Effect with RE0 (Beta0 = 0) & $<0.01^{*}$ \\
\hline No Effect of Ethanol in Road Fuel Aging (Beta1s=0) & 0.65 \\
\hline * Indicates effect is statistically significant at the 95\% confidence level.
\end{tabular}

* Indicates estimate is different from zero at the $95 \%$ confidence level.

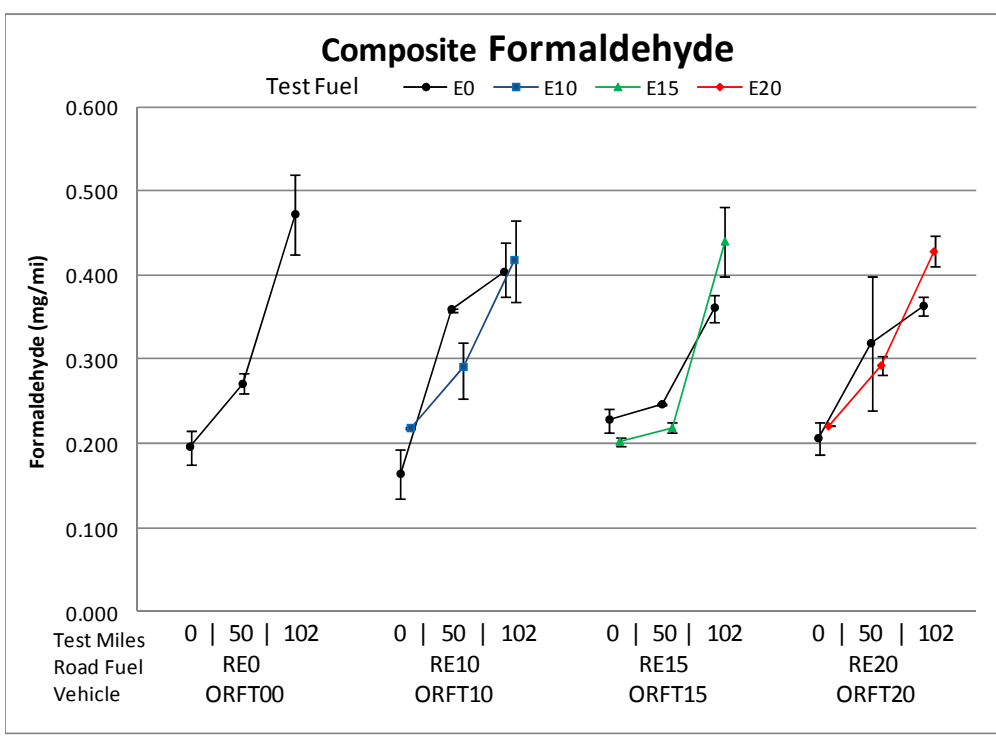

Error bars represent min and max measurements

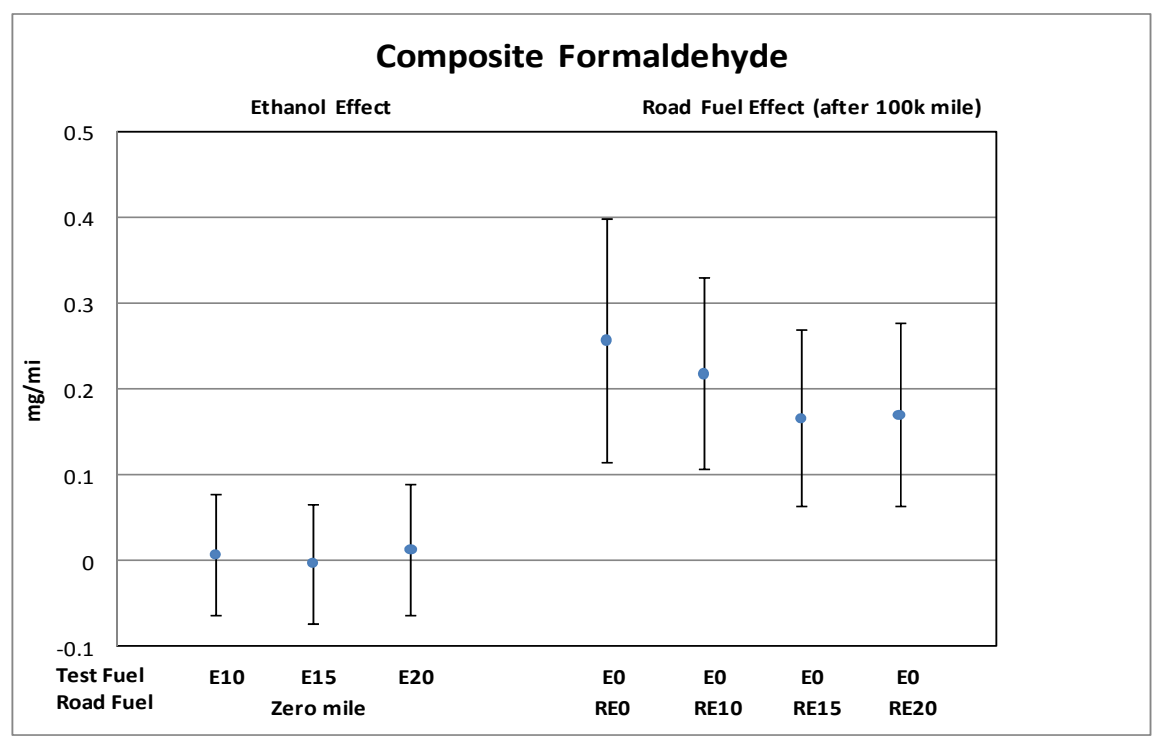

Error bars represent $95 \%$ confidence intervals on the estimated effects 
2008 Ford Taurus (Composite $\mathrm{CH} 4$ )

\begin{tabular}{|l|r|r|r|}
\hline \multicolumn{1}{|c|}{ Effect } & Estimate & $\begin{array}{c}95 \% \text { C.I. } \\
\text { Lower }\end{array}$ & $\begin{array}{c}95 \% \text { C.I. } \\
\text { Upper }\end{array}$ \\
\hline Ethanol Effect (E10 vs. E0) $(\Delta \mathrm{g} / \mathrm{mi})$ & 0.0004 & -0.0025 & 0.0033 \\
\hline Ethanol Effect $(E 15 \mathrm{vs.} \mathrm{E0)}(\Delta \mathrm{g} / \mathrm{mi})$ & 0.0023 & -0.0007 & 0.0052 \\
\hline Ethanol Effect $(E 20 \mathrm{vs.} \mathrm{E0)}(\Delta \mathrm{g} / \mathrm{mi})$ & 0.0004 & -0.0025 & 0.0033 \\
\hline Road Fuel Aging Effect & & & \\
\hline Aging Effect with RE0 $(\Delta \mathrm{g} / \mathrm{mi}$ per 100k mi) & $0.0093^{*}$ & 0.0044 & 0.0143 \\
\hline Aging Effect with RE10 $(\Delta \mathrm{g} / \mathrm{mi}$ per 100k mi) & $0.0078^{*}$ & 0.0043 & 0.0112 \\
\hline Aging Effect with RE15 $(\Delta \mathrm{g} / \mathrm{mi}$ per 100k mi) & $0.0085^{*}$ & 0.0050 & 0.0119 \\
\hline Aging Effect with RE20 $(\Delta \mathrm{g} / \mathrm{mi} \mathrm{per} \mathrm{100k} \mathrm{mi)}$ & $0.0048^{*}$ & 0.0013 & 0.0083 \\
\hline
\end{tabular}

\begin{tabular}{|l|r|}
\hline \multicolumn{1}{|c|}{ Hypothesis } & p-value \\
\hline No Effect of Ethanol in the Test Fuel (Gamma = 0) & 0.41 \\
\hline No Aging Effect with RE0 (Beta0 = 0) & $<0.01^{*}$ \\
\hline No Effect of Ethanol in Road Fuel Aging (Beta1s=0) & 0.31 \\
\hline
\end{tabular}

Initial odometers 9k-17k

${ }^{*}$ Indicates estimate is different from zero at the $95 \%$ confidence level.

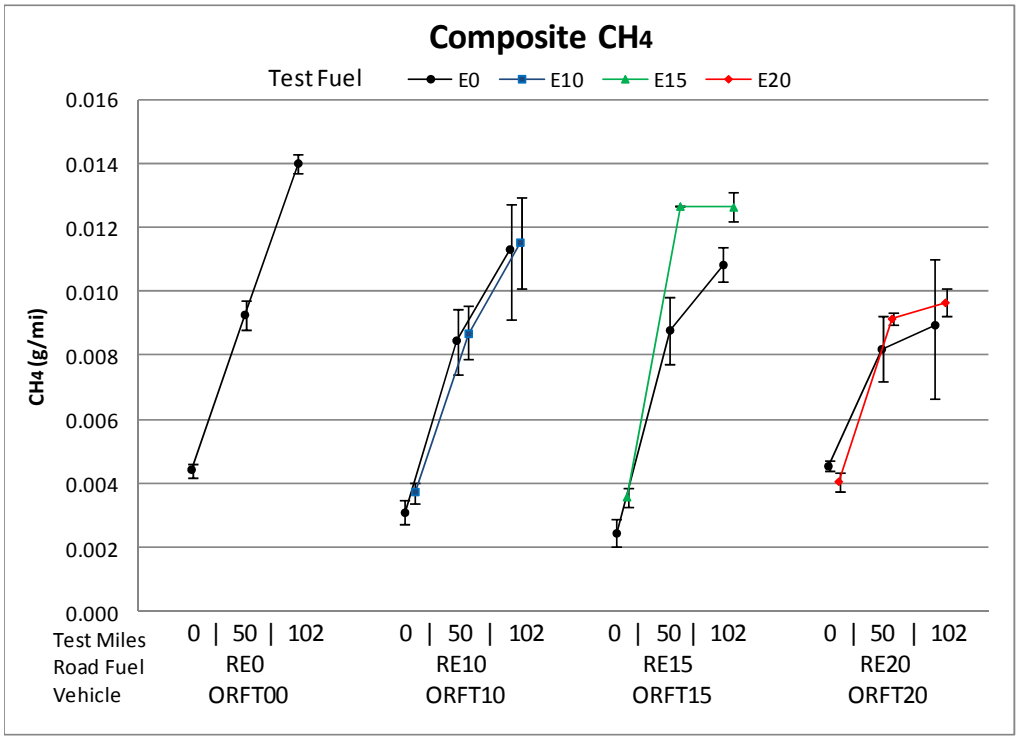

Error bars represent min and max measurements

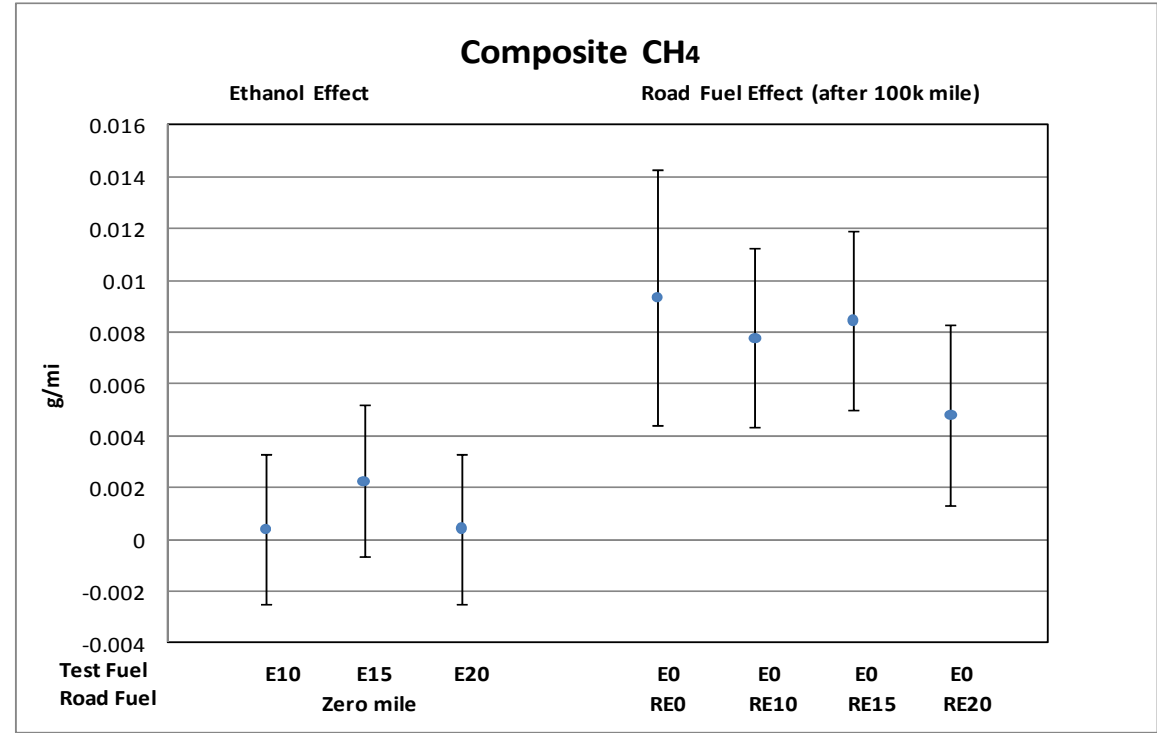

Error bars represent $95 \%$ confidence intervals on the estimated effects 


\section{Dodge Caravan - Composite Emissions Summary}

\begin{tabular}{|c|c|c|c|c|c|c|c|c|c|c|c|c|c|c|}
\hline \multirow{2}{*}{$\begin{array}{l}\text { Emisssion Parameter } \\
\text { (units) }\end{array}$} & \multicolumn{4}{|c|}{ Ethanol Effect } & \multicolumn{2}{|c|}{ Aging Effect with REO } & \multicolumn{4}{|c|}{ RExx Aging Effect on E0 Emissions } & \multirow{2}{*}{\multicolumn{3}{|c|}{$\begin{array}{c}\text { RExx Aging Effect on Exx Emissions } \\
\Delta \text { units per } 100 \mathrm{~K} \mathrm{mi}\end{array}$}} & \multirow{3}{*}{\begin{tabular}{|c|}
$\begin{array}{c}\text { Road and Test } \\
\text { Fuel Effects } \\
\text { are Additive }\end{array}$ \\
$\begin{array}{c}\text { Overall p- } \\
\text { value }\end{array}$ \\
\end{tabular}} \\
\hline & \multicolumn{3}{|c|}{$\Delta$ units vs. EO } & \multirow{2}{*}{$\begin{array}{c}\text { Overall } \\
p \text {-value }\end{array}$} & \multirow{2}{*}{$\frac{\Delta \text { units per } 100 \mathrm{~K} \mathrm{mi}}{\mathrm{REO} / \mathrm{E} 0}$} & \multirow{2}{*}{$\begin{array}{c}\text { Overall } \\
p \text {-value }\end{array}$} & \multicolumn{3}{|c|}{$\Delta$ units per $100 \mathrm{~K} \mathrm{mi}$} & \multirow{2}{*}{$\begin{array}{c}\text { Overall } \\
p \text {-value }\end{array}$} & & & & \\
\hline Fuels & E10 & E15 & E20 & & & & RE10/E0 & RE15/E0 & RE20/E0 & & RE10/E10 & RE15/E15 & RE20/E20 & \\
\hline $\mathrm{CO}(\mathrm{g} / \mathrm{mi})$ & -0.027 & -0.146 & -0.383 & 0.34 & 0.002 & 1.00 & 0.191 & 0.456 & $1.360 *$ & 0.14 & $\mathrm{NA}$ & $N A$ & NA & 0.16 \\
\hline $\mathrm{NOx}(\mathrm{g} / \mathrm{mi})^{\mathrm{a}}$ & 0.0005 & 0.0027 & -0.0014 & 0.98 & -0.0034 & 0.85 & $0.0306^{*}$ & 0.0213 & $0.0338 *$ & 0.39 & NA & $\mathrm{NA}$ & $\mathrm{NA}$ & 0.19 \\
\hline $\mathrm{NMHC}(\mathrm{g} / \mathrm{mi})$ & -0.003 & -0.007 & -0.007 & 0.23 & 0.007 & 0.58 & -0.003 & 0.010 & 0.004 & 0.75 & NA & $\mathrm{NA}$ & $\mathrm{NA}$ & 0.65 \\
\hline NMOG (g/mi) & -0.0006 & -0.0025 & -0.0006 & 0.96 & 0.0067 & 0.62 & -0.0027 & 0.0097 & 0.0040 & 0.80 & NA & $\mathrm{NA}$ & $\mathrm{NA}$ & 0.69 \\
\hline Fuel Econ (mi/gal) & $-0.790 *$ & $-1.098 *$ & $-1.336 *$ & $<0.01^{*}$ & -0.230 & 0.41 & -0.058 & -0.333 & $0.556^{*}$ & $0.03 *$ & NA & $\mathrm{NA}$ & $\mathrm{NA}$ & 0.85 \\
\hline Ethanol $(\mathrm{mg} / \mathrm{mi})^{\# \#}$ & $2.743 *$ & $3.602 *$ & $6.241 *$ & $<0.01 *$ & -0.235 & 0.92 & 1.312 & -0.486 & 1.292 & 0.81 & $\mathrm{NA}$ & $\mathrm{NA}$ & $\mathrm{NA}$ & $\mathrm{NA}$ \\
\hline Acetaldehyde $(\mathrm{mg} / \mathrm{mi})^{\#}$ & $0.521 *$ & $0.718 *$ & 1.293* & $<0.01 *$ & 0.023 & 0.79 & 0.023 & 0.059 & -0.020 & 0.88 & NA & $\mathrm{NA}$ & $\mathrm{NA}$ & 0.83 \\
\hline Formaldehyde $(\mathrm{mg} / \mathrm{mi})^{\#}$ & 0.025 & -0.094 & 0.125 & 0.80 & 0.246 & 0.56 & 0.335 & 0.693 & 0.161 & 0.80 & NA & $\mathrm{NA}$ & $\mathrm{NA}$ & 0.99 \\
\hline $\mathrm{CH}_{4}(\mathrm{~g} / \mathrm{mi})$ & -0.0004 & -0.0002 & -0.0003 & 0.99 & 0.0037 & 0.31 & 0.0042 & 0.0049 & $0.0082 *$ & 0.62 & NA & $\mathrm{NA}$ & NA & 0.58 \\
\hline
\end{tabular}

\# Log-normal model was used. Results are presented as changes in emissions at 0k mile.

\#\# Data did not support the assumption of linear effects with mileage.

(T) * Indicates estimate is different from zero at the $95 \%$ confidence level.

+ a Test "SW024446" is identified as an outlier and excluded from the analysis. 
2007 Dodge Caravan (Composite CO)

\begin{tabular}{|c|c|c|c|}
\hline Effect & Estimate & $\begin{array}{c}95 \% \text { C.I. } \\
\text { Lower }\end{array}$ & $\begin{array}{c}95 \% \text { C.I. } \\
\text { Upper }\end{array}$ \\
\hline Ethanol Effect (E10 vs. E0) $(\Delta \mathrm{g} / \mathrm{mi})$ & -0.027 & -0.499 & 0.444 \\
\hline Ethanol Effect (E15 vs. E0) $(\Delta \mathrm{g} / \mathrm{mi})$ & -0.146 & -0.617 & 0.326 \\
\hline Ethanol Effect (E20 vs. E0) $(\Delta \mathrm{g} / \mathrm{mi})$ & -0.383 & -0.855 & 0.088 \\
\hline \multicolumn{4}{|l|}{ Road Fuel Aging Effect } \\
\hline Aging Effect with RE0 ( $\Delta \mathrm{g} / \mathrm{mi}$ per $100 \mathrm{k} \mathrm{mi})$ & 0.002 & -1.174 & 1.178 \\
\hline Aging Effect with RE10 $(\Delta \mathrm{g} / \mathrm{mi}$ per $100 \mathrm{k}$ mi) & 0.191 & -0.640 & 1.022 \\
\hline Aging Effect with RE15 ( $\Delta \mathrm{g} / \mathrm{mi}$ per 100k mi) & 0.456 & -0.375 & 1.287 \\
\hline Aging Effect with RE20 $(\Delta \mathrm{g} / \mathrm{mi}$ per $100 \mathrm{k} \mathrm{mi})$ & $1.360^{*}$ & 0.534 & 2.187 \\
\hline
\end{tabular}

\begin{tabular}{|l|r|}
\hline \multicolumn{1}{|c|}{ Hypothesis } & p-value \\
\hline No Effect of Ethanol in the Test Fuel (Gamma = 0) & 0.34 \\
\hline No Aging Effect with RE0 (Beta0 = 0) & 1.00 \\
\hline No Effect of Ethanol in Road Fuel Aging (Beta1s=0) & 0.14 \\
\hline
\end{tabular}

Initial odometers 40k-50k

${ }^{*}$ Indicates estimate is different from zero at the $95 \%$ confidence level.

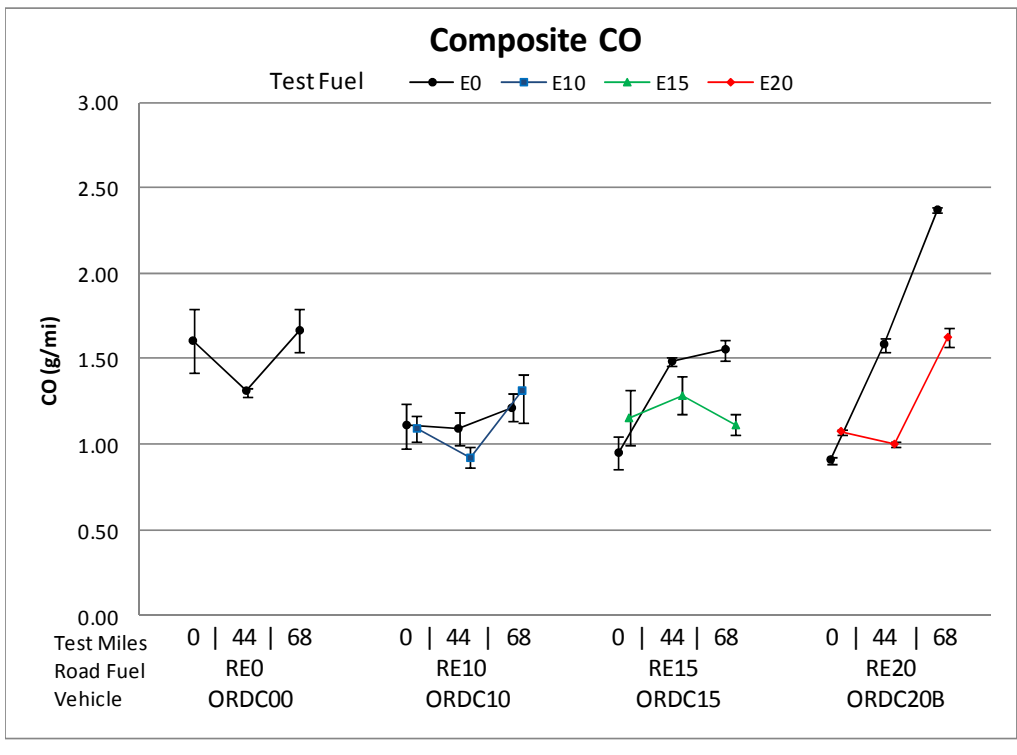

Error bars represent min and max measurements

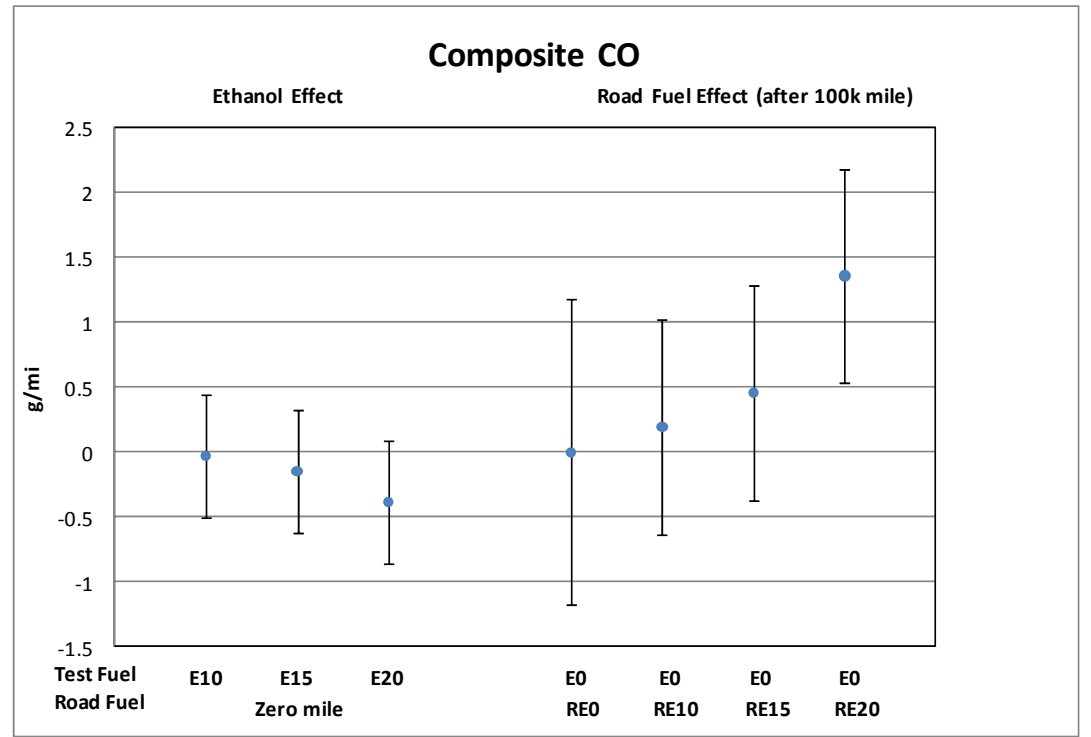

Error bars represent $95 \%$ confidence intervals on the estimated effects 
2007 Dodge Caravan (Composite NOx)

\begin{tabular}{|l|r|r|r|}
\hline \multicolumn{1}{|c|}{ Effect } & & $\begin{array}{r}95 \% \text { C.I. } \\
\text { Lo5\% C.I. } \\
\text { Upper }\end{array}$ \\
\hline Ethanol Effect (E10 vs. E0) $(\Delta \mathrm{g} / \mathrm{mi})$ & 0.0005 & -0.0155 & 0.0166 \\
\hline Ethanol Effect $(E 15 \mathrm{vs.} \mathrm{E0)}(\Delta \mathrm{g} / \mathrm{mi})$ & 0.0027 & -0.0133 & 0.0187 \\
\hline Ethanol Effect $($ E20 vs. E0) $(\Delta \mathrm{g} / \mathrm{mi})$ & -0.0014 & -0.0177 & 0.0148 \\
\hline Road Fuel Aging Effect & & & \\
\hline Aging Effect with RE0 $(\Delta \mathrm{g} / \mathrm{mi}$ per 100k mi) & -0.0034 & -0.0434 & 0.0366 \\
\hline Aging Effect with RE10 $(\Delta \mathrm{g} / \mathrm{mi}$ per 100k mi) & $0.0306^{*}$ & 0.0024 & 0.0589 \\
\hline Aging Effect with RE15 $(\Delta \mathrm{g} / \mathrm{mi} \mathrm{per} \mathrm{100k} \mathrm{mi)}$ & 0.0213 & -0.0069 & 0.0496 \\
\hline Aging Effect with RE20 $(\Delta \mathrm{g} / \mathrm{mi} \mathrm{per} \mathrm{100k} \mathrm{mi)}$ & $0.0338^{*}$ & 0.0053 & 0.0624 \\
\hline
\end{tabular}

\begin{tabular}{|l|r|}
\hline \multicolumn{1}{|c|}{ Hypothesis } & p-value \\
\hline No Effect of Ethanol in the Test Fuel (Gamma = 0) & 0.98 \\
\hline No Aging Effect with RE0 (Beta0 = 0) & 0.85 \\
\hline No Effect of Ethanol in Road Fuel Aging (Beta1s=0) & 0.39 \\
\hline
\end{tabular}

Initial odometers 40k-50k

${ }^{*}$ Indicates estimate is different from zero at the $95 \%$ confidence level.

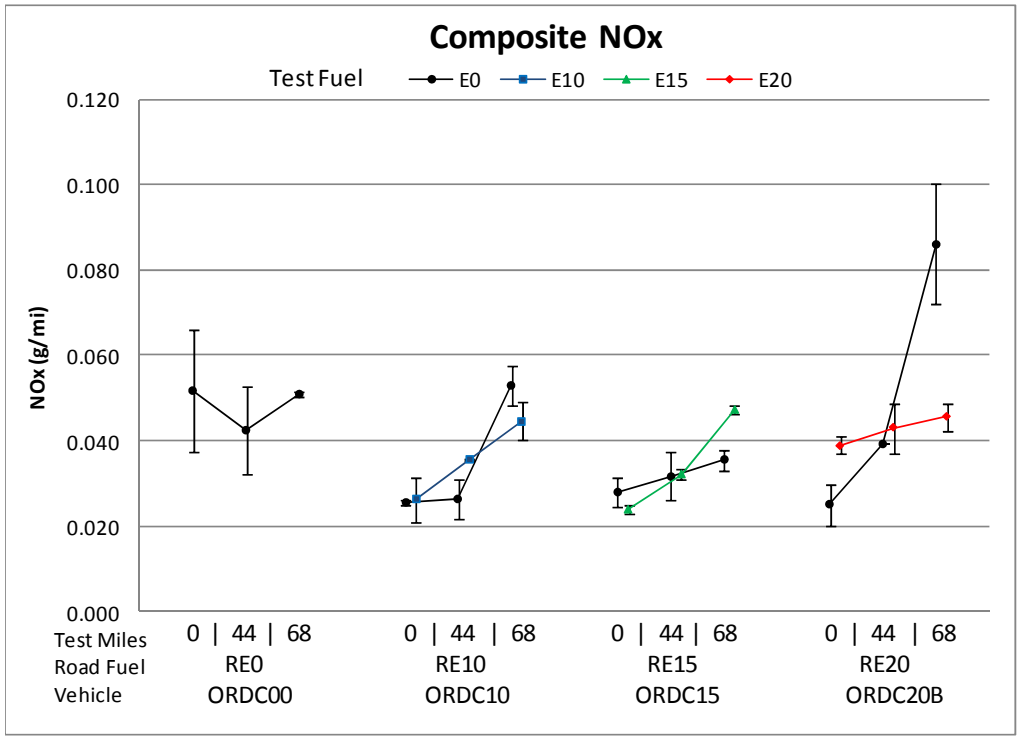

Error bars represent min and max measurements

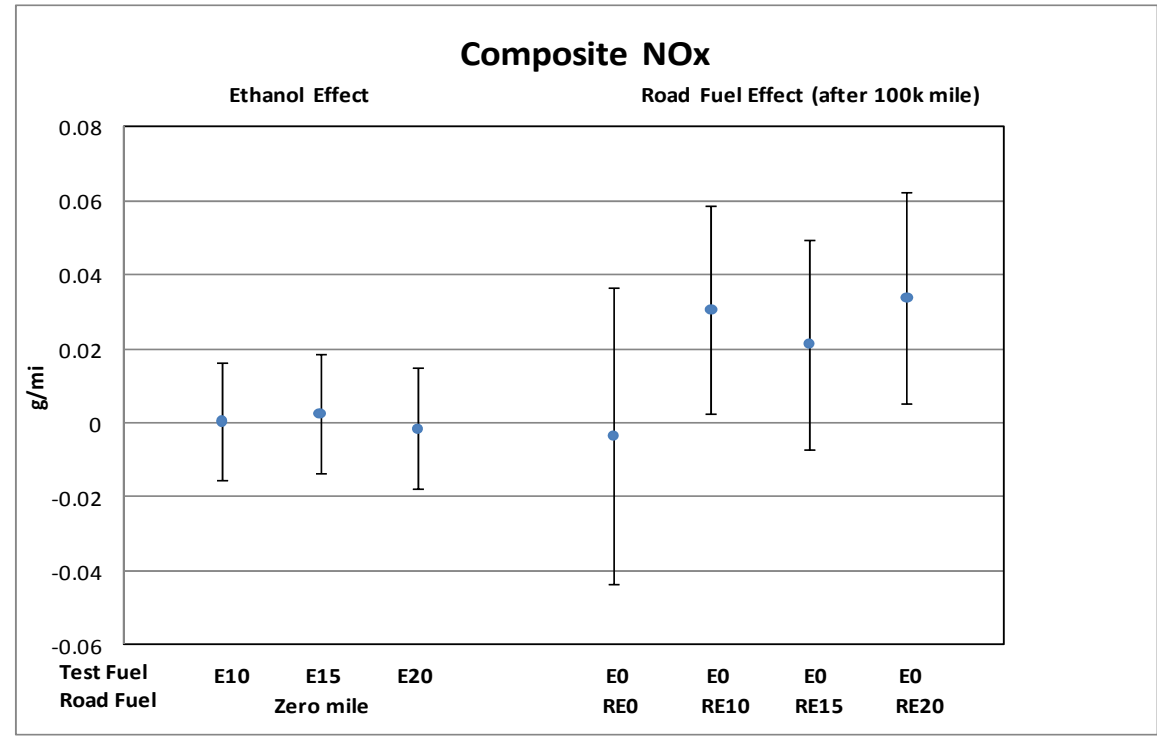

Error bars represent $95 \%$ confidence intervals on the estimated effects 
2007 Dodge Caravan (Composite Nonmethane Hydrocarbons)

\begin{tabular}{|l|r|r|r|}
\hline \multicolumn{1}{|c|}{ Effect } & Estimate & $\begin{array}{c}\text { 95\% C.I. } \\
\text { Lower }\end{array}$ & $\begin{array}{c}95 \% \text { C.I. } \\
\text { Upper }\end{array}$ \\
\hline Ethanol Effect (E10 vs. E0) $(\Delta \mathrm{g} / \mathrm{mi})$ & -0.003 & -0.013 & 0.007 \\
\hline Ethanol Effect $(E 15$ vs. E0) $(\Delta \mathrm{g} / \mathrm{mi})$ & -0.007 & -0.017 & 0.004 \\
\hline Ethanol Effect $(E 20 \mathrm{vs.} \mathrm{E0)}(\Delta \mathrm{g} / \mathrm{mi})$ & -0.007 & -0.018 & 0.003 \\
\hline Road Fuel Aging Effect & & & \\
\hline Aging Effect with RE0 $(\Delta \mathrm{g} / \mathrm{mi}$ per 100k mi) & 0.007 & -0.019 & 0.032 \\
\hline Aging Effect with RE10 $(\Delta \mathrm{g} / \mathrm{mi}$ per 100k mi) & -0.003 & -0.021 & 0.015 \\
\hline Aging Effect with RE15 $(\Delta \mathrm{g} / \mathrm{mi}$ per 100k mi) & 0.010 & -0.009 & 0.028 \\
\hline Aging Effect with RE20 $(\Delta \mathrm{g} / \mathrm{mi} \mathrm{per} \mathrm{100k} \mathrm{mi)}$ & 0.004 & -0.014 & 0.022 \\
\hline
\end{tabular}

\begin{tabular}{|l|r|}
\hline \multicolumn{1}{|c|}{ Hypothesis } & p-value \\
& \\
\hline No Effect of Ethanol in the Test Fuel (Gamma = 0) & 0.23 \\
\hline No Aging Effect with RE0 (Beta0 = 0) & 0.58 \\
\hline No Effect of Ethanol in Road Fuel Aging (Beta1s=0) & 0.75 \\
\hline
\end{tabular}

Initial odometers 40k-50k

${ }^{*}$ Indicates estimate is different from zero at the $95 \%$ confidence level.

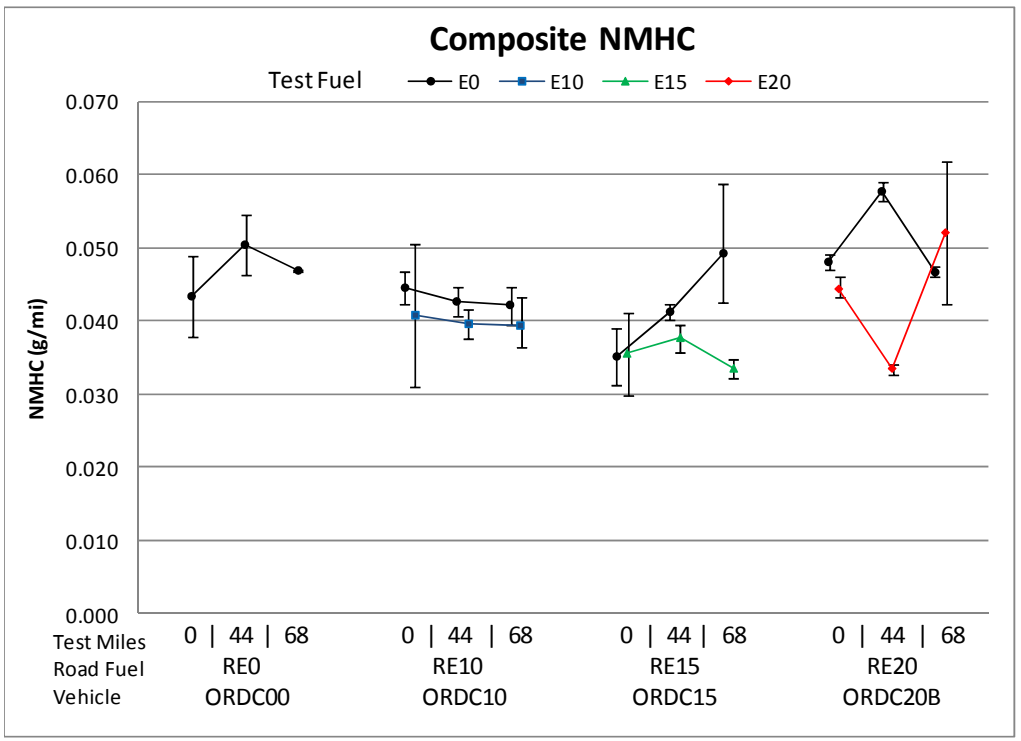

Error bars represent min and max measurement

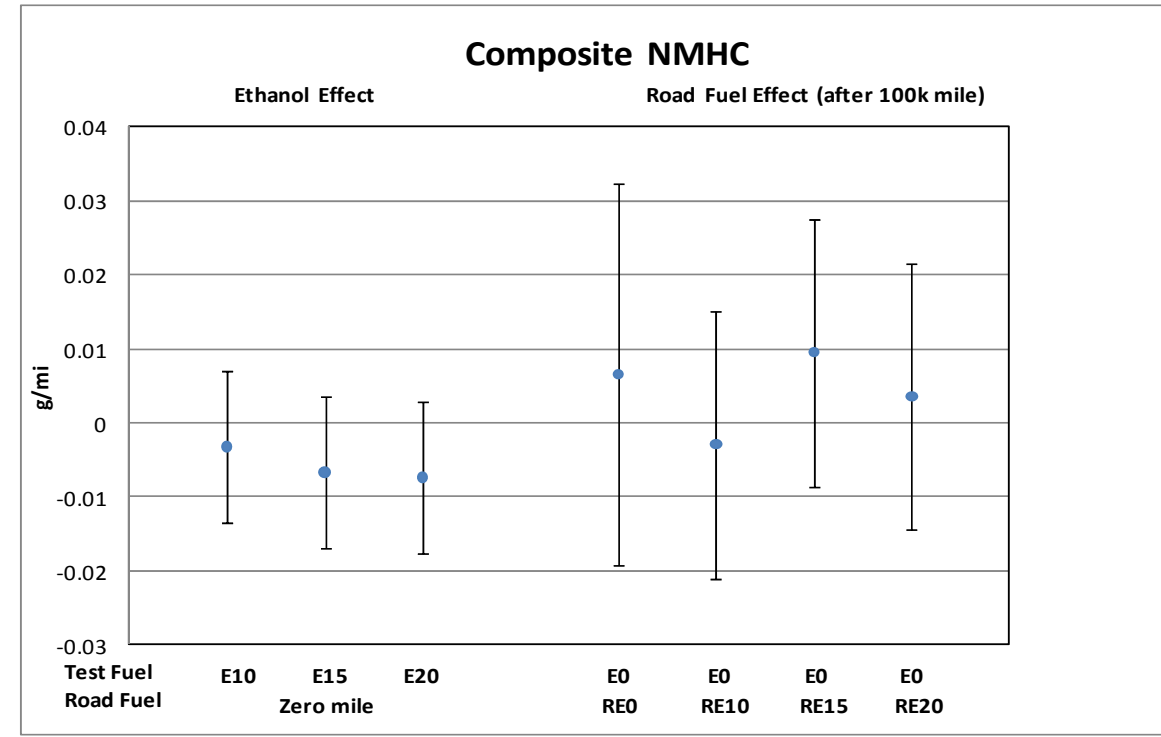

Error bars represent $95 \%$ confidence intervals on the estimated effects 
2007 Dodge Caravan (Composite Nonmethane Organic Gases)

\begin{tabular}{|l|r|r|r|}
\hline \multicolumn{1}{|c|}{ Effect } & & $\begin{array}{c}95 \% \text { C.I. } \\
\text { Lo5\% C.I. } \\
\text { Upper }\end{array}$ \\
\hline Ethanol Effect (E10 vs. E0) $(\Delta \mathrm{g} / \mathrm{mi})$ & -0.0006 & -0.0121 & 0.0108 \\
\hline Ethanol Effect $(E 15 \mathrm{vs.} \mathrm{E0)}(\Delta \mathrm{g} / \mathrm{mi})$ & -0.0025 & -0.0140 & 0.0089 \\
\hline Ethanol Effect $($ E20 vs. E0) $(\Delta \mathrm{g} / \mathrm{mi})$ & -0.0006 & -0.0121 & 0.0109 \\
\hline Road Fuel Aging Effect & & & \\
\hline Aging Effect with RE0 $(\Delta \mathrm{g} / \mathrm{mi}$ per 100k mi) & 0.0067 & -0.0220 & 0.0354 \\
\hline Aging Effect with RE10 $(\Delta \mathrm{g} / \mathrm{mi}$ per 100k mi) & -0.0027 & -0.0229 & 0.0175 \\
\hline Aging Effect with RE15 $(\Delta \mathrm{g} / \mathrm{mi} \mathrm{per} \mathrm{100k} \mathrm{mi)}$ & 0.0097 & -0.0104 & 0.0299 \\
\hline Aging Effect with RE20 $(\Delta \mathrm{g} / \mathrm{mi} \mathrm{per} \mathrm{100k} \mathrm{mi)}$ & 0.0040 & -0.0160 & 0.0241 \\
\hline
\end{tabular}

\begin{tabular}{|l|r|}
\hline \multicolumn{1}{|c|}{ Hypothesis } & p-value \\
\hline No Effect of Ethanol in the Test Fuel (Gamma = 0) & 0.96 \\
\hline No Aging Effect with RE0 (Beta0 = 0) & 0.62 \\
\hline No Effect of Ethanol in Road Fuel Aging (Beta1s=0) & 0.80 \\
\hline
\end{tabular}

Initial odometers 40k-50k

* Indicates estimate is different from zero at the $95 \%$ confidence level.

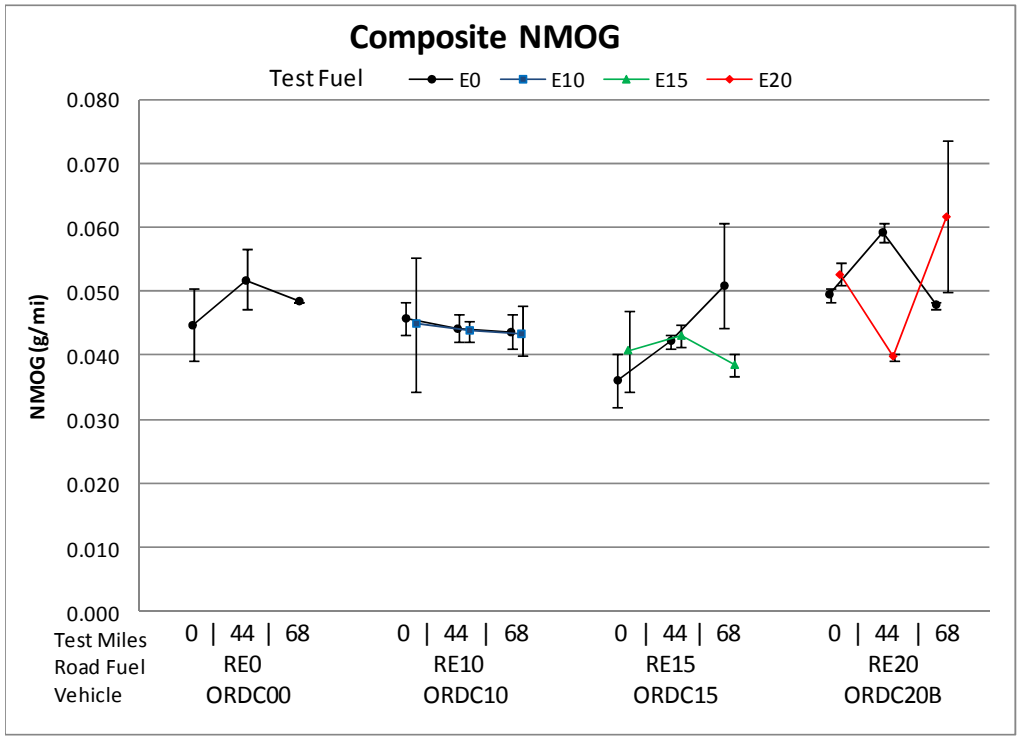

Error bars represent min and max measurement

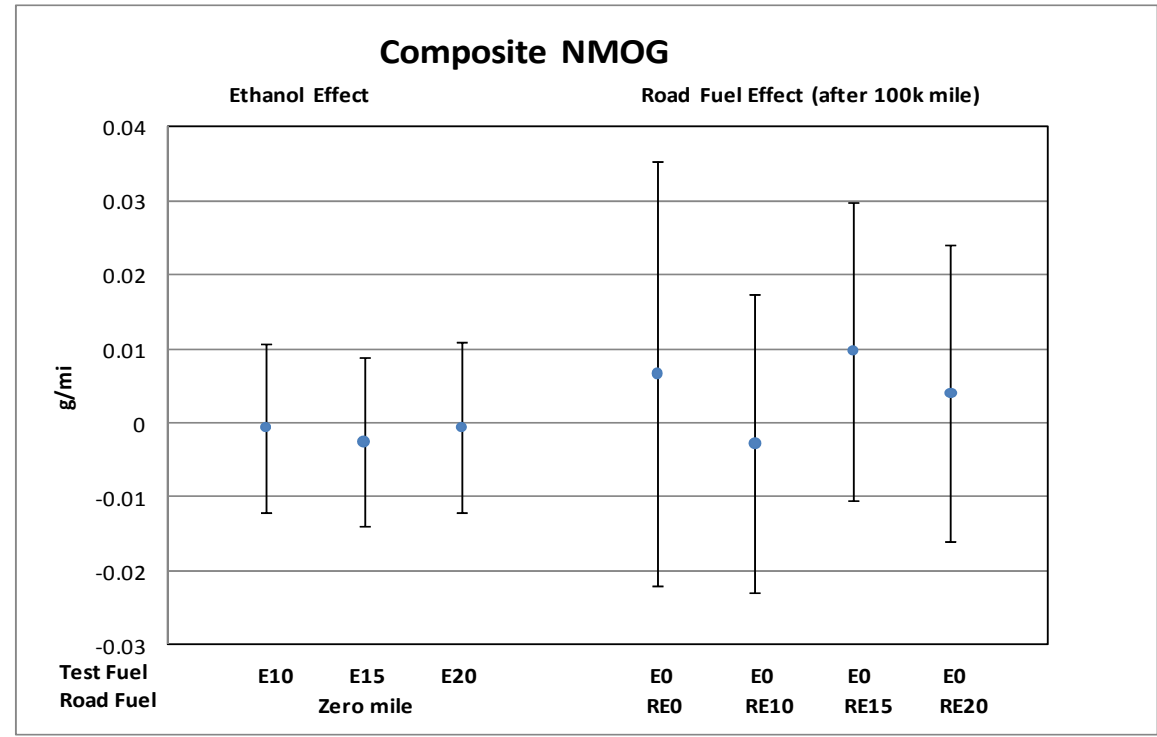

Error bars represent $95 \%$ confidence intervals on the estimated effects 
2007 Dodge Caravan (Composite Fuel Economy)

\begin{tabular}{|c|c|c|c|}
\hline Effect & Estimate & $\begin{array}{c}\text { 95\% C.I. } \\
\text { Lower }\end{array}$ & $\begin{array}{c}95 \% \text { C.I. } \\
\text { Upper }\end{array}$ \\
\hline Ethanol Effect (E10 vs. E0) ( $\Delta \mathrm{mi} / \mathrm{gal})$ & $-0.790^{*}$ & -1.023 & -0.556 \\
\hline Ethanol Effect (E15 vs. E0) ( $\Delta \mathrm{mi} / \mathrm{gal})$ & $-1.098^{*}$ & -1.332 & -0.865 \\
\hline Ethanol Effect (E20 vs. E0) ( $\Delta \mathrm{mi} / \mathrm{gal})$ & $-1.336^{*}$ & -1.570 & -1.103 \\
\hline \multicolumn{4}{|l|}{ Road Fuel Aging Effect } \\
\hline Aging Effect with RE0 ( $\Delta \mathrm{mi} / \mathrm{gal}$ per $100 \mathrm{k} \mathrm{mi})$ & -0.230 & -0.815 & 0.354 \\
\hline Aging Effect with RE10 ( $\Delta \mathrm{mi} / \mathrm{gal}$ per $100 \mathrm{k} \mathrm{mi})$ & -0.058 & -0.469 & 0.353 \\
\hline Aging Effect with RE15 ( $\Delta \mathrm{mi} / \mathrm{gal}$ per $100 \mathrm{k} \mathrm{mi})$ & -0.333 & -0.744 & 0.078 \\
\hline Aging Effect with RE20 ( $\Delta \mathrm{mi} / \mathrm{gal}$ per $100 \mathrm{k} \mathrm{mi})$ & $0.556^{*}$ & 0.149 & 0.964 \\
\hline
\end{tabular}

\begin{tabular}{|l|r|}
\hline \multicolumn{1}{|c|}{ Hypothesis } & p-value \\
\hline No Effect of Ethanol in the Test Fuel (Gamma $=0)$ & $<0.01^{*}$ \\
\hline No Aging Effect with RE0 (Beta0 $=0$ ) & 0.41 \\
\hline No Effect of Ethanol in Road Fuel Aging (Beta1s $=0$ ) & $0.03^{*}$ \\
\hline * Indicates effect is statistically significant at the 95\% confidence level.
\end{tabular}

Initial odometers $40 \mathrm{k}-50 \mathrm{k}$

${ }^{*}$ Indicates estimate is different from zero at the $95 \%$ confidence level.

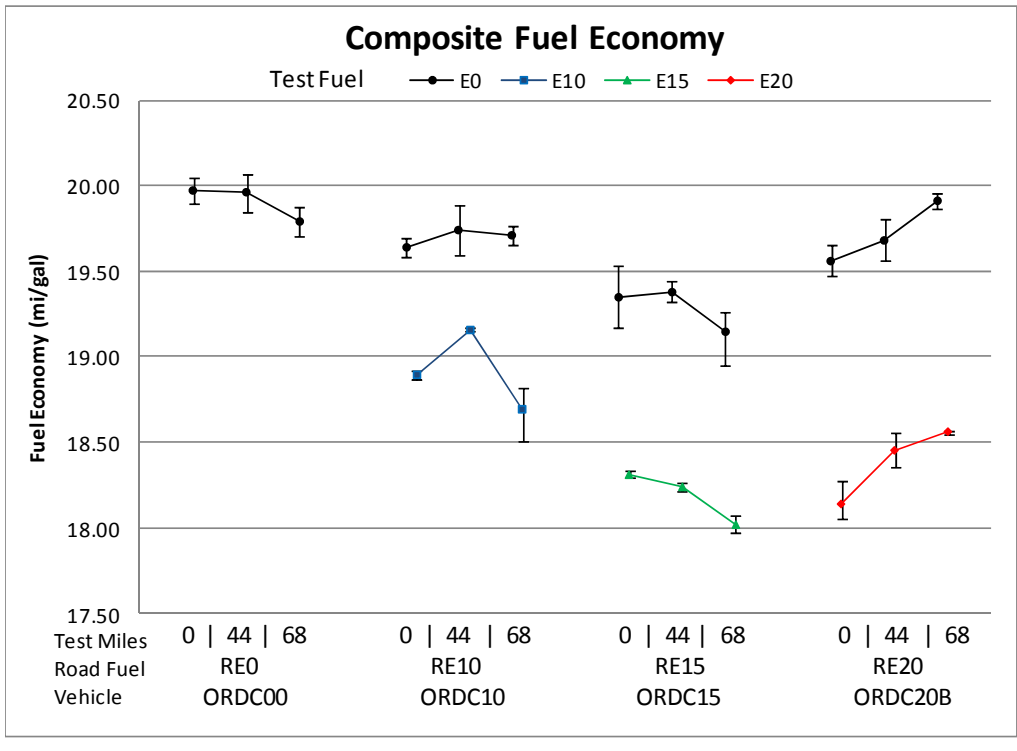

Error bars represent min and max measurements

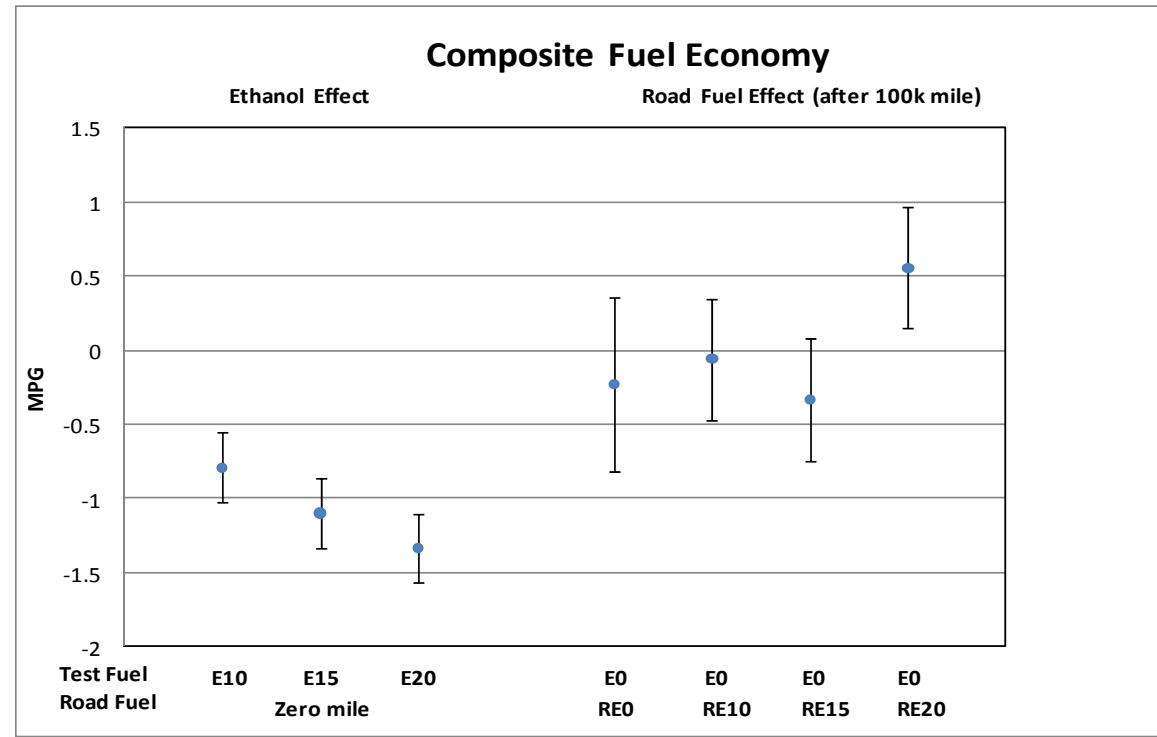

Error bars represent $95 \%$ confidence intervals on the estimated effects 
2007 Dodge Caravan (Composite Ethanol)

\begin{tabular}{|l|r|r|r|}
\hline \multicolumn{1}{|c|}{ Effect } & Estimate & $\begin{array}{r}\text { 95\% C.I. } \\
\text { Lower }\end{array}$ & $\begin{array}{r}\text { 95\% C.I. } \\
\text { Upper }\end{array}$ \\
\hline Ethanol Effect $($ E10 vs. E0) $(\Delta \mathrm{mg} / \mathrm{mi})$ & $2.743^{*}$ & 0.496 & 4.990 \\
\hline Ethanol Effect $(E 15$ vs. E0) $(\Delta \mathrm{mg} / \mathrm{mi})$ & $3.602^{*}$ & 1.354 & 5.849 \\
\hline Ethanol Effect $(E 20$ vs. E0) $(\Delta \mathrm{mg} / \mathrm{mi})$ & $6.241^{*}$ & 3.994 & 8.488 \\
\hline Road Fuel Aging Effect & & & \\
\hline Aging Effect with RE0 $(\Delta \mathrm{mg} / \mathrm{mi}$ per 100k mi) & -0.235 & -5.889 & 5.418 \\
\hline Aging Effect with RE10 $(\Delta \mathrm{mg} / \mathrm{mi}$ per 100k mi) & 1.312 & -2.706 & 5.331 \\
\hline Aging Effect with RE15 $(\Delta \mathrm{mg} / \mathrm{mi} \mathrm{per} \mathrm{100k} \mathrm{mi)}$ & -0.486 & -4.502 & 3.531 \\
\hline Aging Effect with RE20 $(\Delta \mathrm{mg} / \mathrm{mi}$ per 100k mi) & 1.292 & -2.707 & 5.292 \\
\hline
\end{tabular}

\begin{tabular}{|l|r|}
\hline \multicolumn{1}{|c|}{ Hypothesis } & p-value \\
\hline No Effect of Ethanol in the Test Fuel (Gamma $=0)$ & $<0.01^{*}$ \\
\hline No Aging Effect with RE0 (Beta0 $=0)$ & 0.92 \\
\hline No Effect of Ethanol in Road Fuel Aging (Beta1s=0) & 0.81 \\
\hline * Indicates effect is statistically significant at the 95\% confidence level.
\end{tabular}

Initial odometers 40k-50k

${ }^{*}$ Indicates estimate is different from zero at the $95 \%$ confidence level.

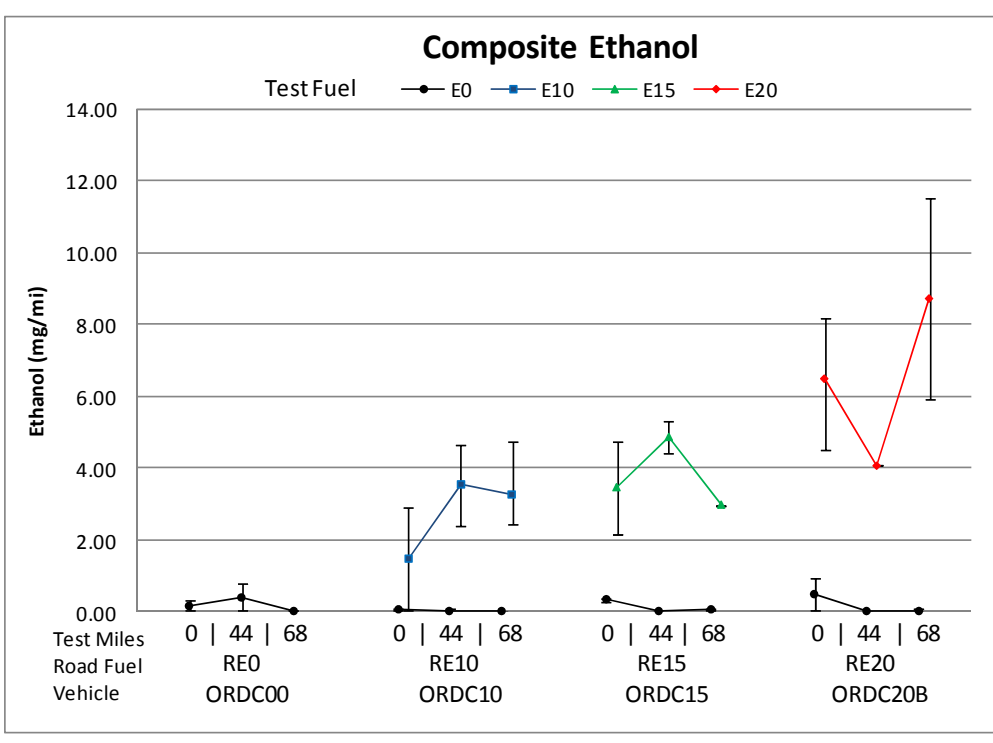

Error bars represent min and max measurements

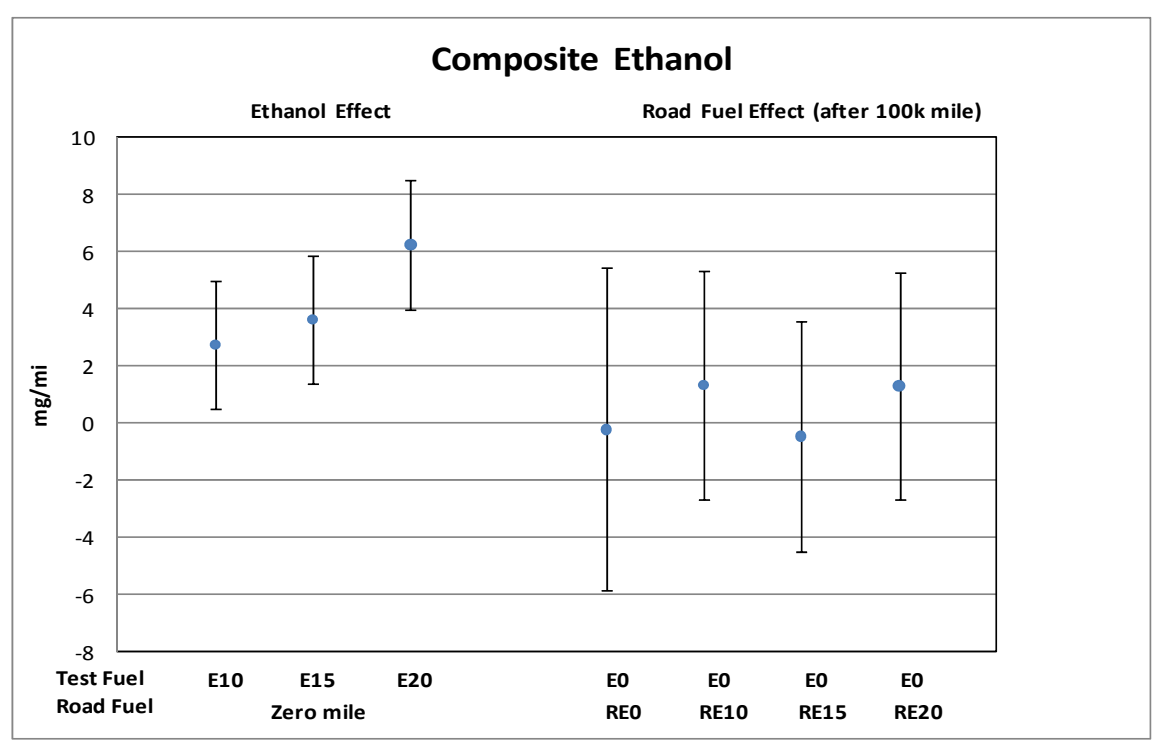

Error bars represent $95 \%$ confidence intervals on the estimated effects 
2007 Dodge Caravan (Composite Acetaldehyde)

\begin{tabular}{|l|r|r|r|}
\hline \multicolumn{1}{|c|}{ Effect } & Estimate & $\begin{array}{r}\text { 95\% C.I. } \\
\text { Lower }\end{array}$ & $\begin{array}{r}\text { 95\% C.I. } \\
\text { Upper }\end{array}$ \\
\hline Ethanol Effect $(E 10$ vs. E0) $(\Delta \mathrm{mg} / \mathrm{mi})$ & $0.521^{*}$ & 0.268 & 0.775 \\
\hline Ethanol Effect $(E 15 \mathrm{vs}$. E0) $(\Delta \mathrm{mg} / \mathrm{mi})$ & $0.718^{*}$ & 0.392 & 1.045 \\
\hline Ethanol Effect $(E 20 \mathrm{vs.}$ E0) $(\Delta \mathrm{mg} / \mathrm{mi})$ & $1.293^{*}$ & 0.782 & 1.803 \\
\hline Road Fuel Aging Effect & & & \\
\hline Aging Effect with RE0 $(\Delta \mathrm{mg} / \mathrm{mi}$ per 100k mi) & 0.023 & -0.135 & 0.182 \\
\hline Aging Effect with RE10 $(\Delta \mathrm{mg} / \mathrm{mi}$ per 100k mi) & 0.023 & -0.102 & 0.147 \\
\hline Aging Effect with RE15 $(\Delta \mathrm{mg} / \mathrm{mi}$ per 100k mi) & 0.059 & -0.096 & 0.215 \\
\hline Aging Effect with RE20 $(\Delta \mathrm{mg} / \mathrm{mi}$ per 100k mi) & -0.020 & -0.152 & 0.113 \\
\hline
\end{tabular}

\begin{tabular}{|l|r|}
\hline \multicolumn{1}{|c|}{ Hypothesis } & p-value \\
\hline No Effect of Ethanol in the Test Fuel (Gamma $=0)$ & $<0.01^{*}$ \\
\hline No Aging Effect with RE0 (Beta0 $=0)$ & 0.79 \\
\hline No Effect of Ethanol in Road Fuel Aging (Beta1s=0) & 0.88 \\
\hline * Indicates effect is statistically significant at the 95\% confidence level
\end{tabular}

Initial odometers 40k-50k

作

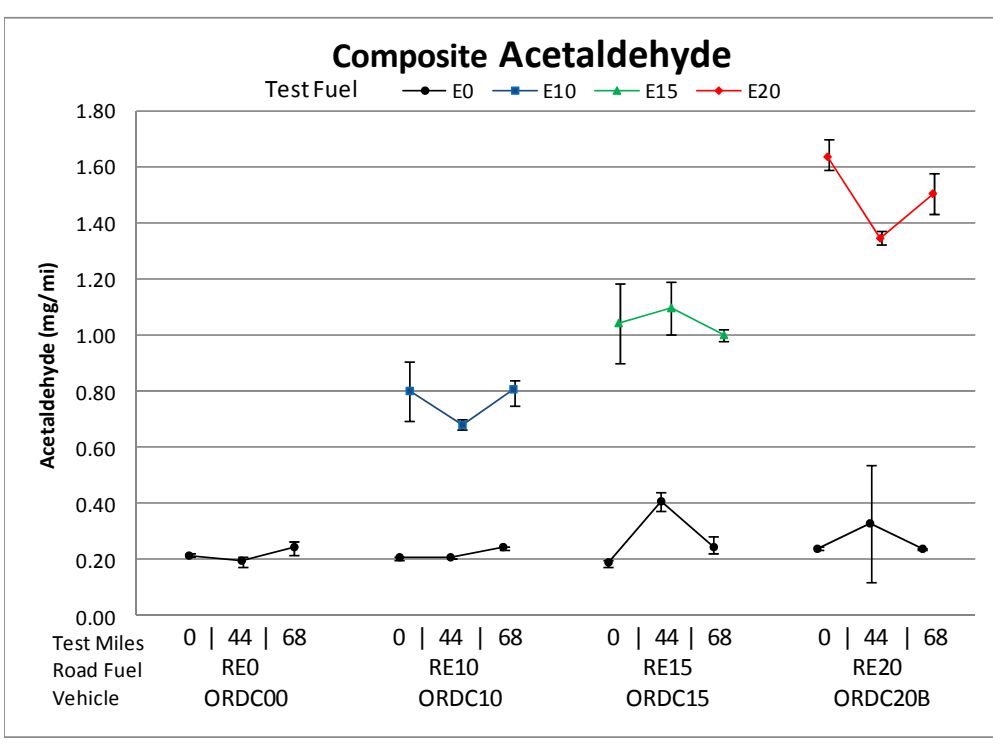

Error bars represent min and max measurements

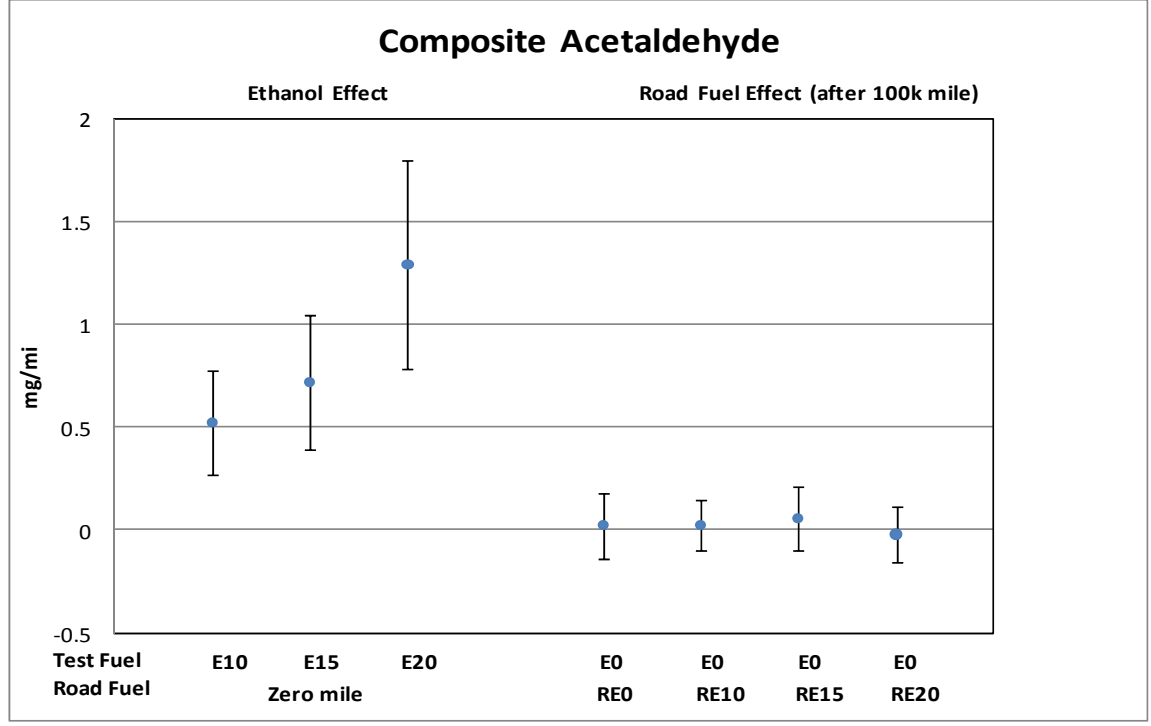

Error bars represent $95 \%$ confidence intervals on the estimated effects 
2007 Dodge Caravan (Composite Formaldehyde)

\begin{tabular}{|c|c|c|c|}
\hline Effect & Estimate & $\begin{array}{c}95 \% \text { C.I. } \\
\text { Lower }\end{array}$ & $\begin{array}{l}95 \% \text { C.I. } \\
\text { Upper }\end{array}$ \\
\hline Ethanol Effect (E10 vs. E0) ( $\Delta \mathrm{mg} / \mathrm{mi})$ & 0.025 & -0.384 & 0.434 \\
\hline Ethanol Effect (E15 vs. E0) $(\Delta \mathrm{mg} / \mathrm{mi})$ & -0.094 & -0.509 & 0.321 \\
\hline Ethanol Effect (E20 vs. E0) $(\Delta \mathrm{mg} / \mathrm{mi})$ & 0.125 & -0.425 & 0.675 \\
\hline \multicolumn{4}{|l|}{ Road Fuel Aging Effect } \\
\hline Aging Effect with RE0 ( $\Delta \mathrm{mg} / \mathrm{mi}$ per $100 \mathrm{k} \mathrm{mi})$ & 0.246 & -0.570 & 1.062 \\
\hline Aging Effect with RE10 ( $\Delta \mathrm{mg} / \mathrm{mi}$ per $100 \mathrm{k} \mathrm{mi})$ & 0.335 & -0.318 & 0.987 \\
\hline Aging Effect with RE15 ( $\Delta \mathrm{mg} / \mathrm{mi}$ per 100k mi) & 0.693 & -0.207 & 1.594 \\
\hline Aging Effect with RE20 ( $\Delta \mathrm{mg} / \mathrm{mi}$ per $100 \mathrm{k} \mathrm{mi})$ & 0.161 & -0.520 & 0.842 \\
\hline
\end{tabular}

\begin{tabular}{|l|r|}
\hline \multicolumn{1}{|c|}{ Hypothesis } & p-value \\
\hline No Effect of Ethanol in the Test Fuel (Gamma = 0) & 0.80 \\
\hline No Aging Effect with RE0 (Beta0 = 0) & 0.56 \\
\hline No Effect of Ethanol in Road Fuel Aging (Beta1s=0) & 0.80 \\
\hline * Indicates effect is statistically significant at the 95\% confidence level.
\end{tabular}

* Indicates estimate is different from zero at the $95 \%$ confidence level.

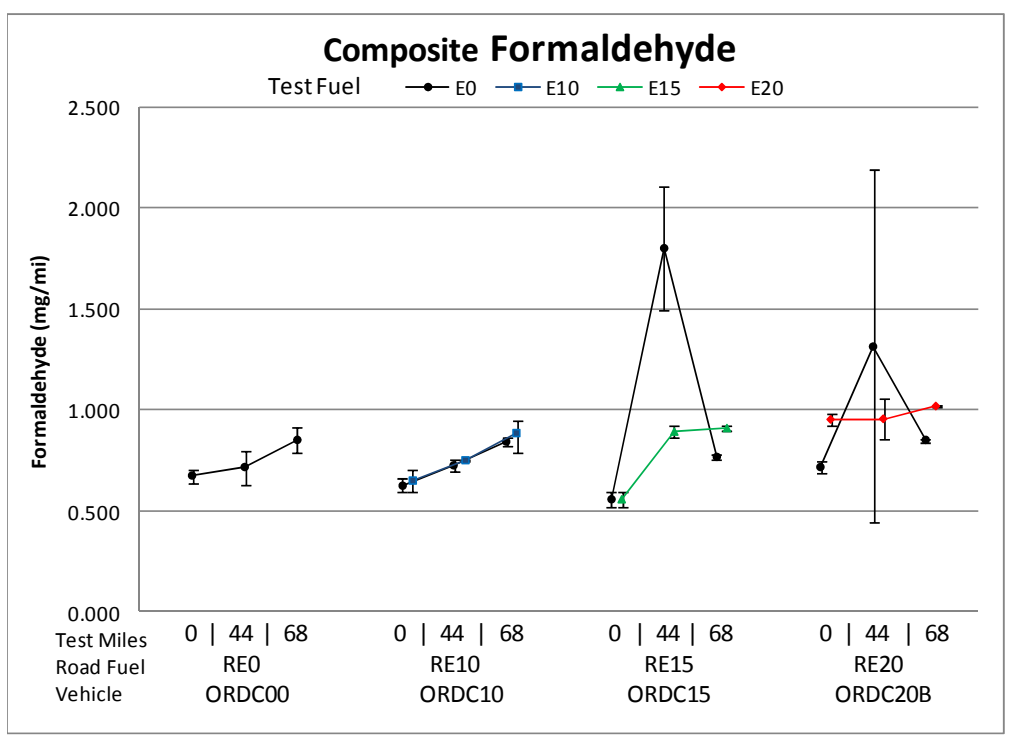

Error bars represent min and max measurements

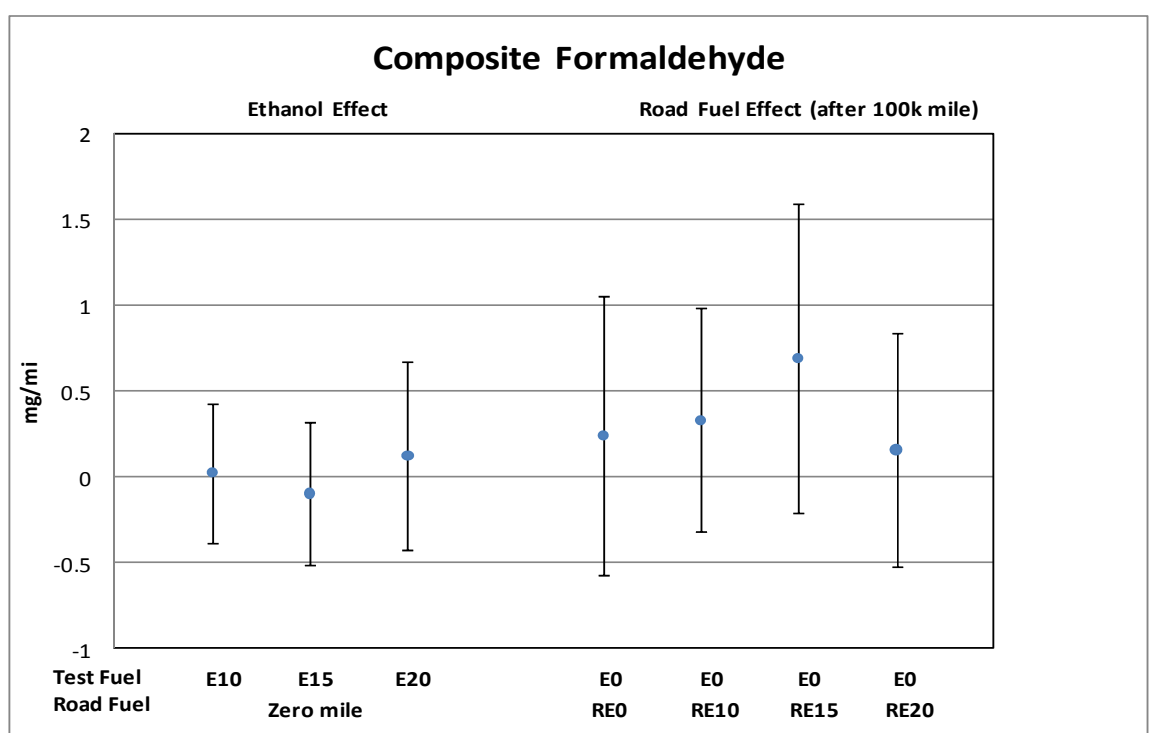

Error bars represent $95 \%$ confidence intervals on the estimated effects 
2007 Dodge Caravan (Composite $\mathrm{CH} 4$ )

\begin{tabular}{|c|c|c|c|}
\hline Effect & Estimate & $\begin{array}{l}\text { 95\% C.I. } \\
\text { Lower }\end{array}$ & $\begin{array}{c}95 \% \text { C.I. } \\
\text { Upper }\end{array}$ \\
\hline Ethanol Effect (E10 vs. E0) $(\Delta \mathrm{g} / \mathrm{mi})$ & -0.0004 & -0.0035 & 0.0027 \\
\hline Ethanol Effect (E15 vs. E0) $(\Delta \mathrm{g} / \mathrm{mi})$ & -0.0002 & -0.0033 & 0.0029 \\
\hline Ethanol Effect (E20 vs. E0) $(\Delta \mathrm{g} / \mathrm{mi})$ & -0.0003 & -0.0034 & 0.0028 \\
\hline \multicolumn{4}{|l|}{ Road Fuel Aging Effect } \\
\hline Aging Effect with RE0 ( $\Delta \mathrm{g} / \mathrm{mi}$ per $100 \mathrm{k} \mathrm{mi})$ & 0.0037 & -0.0040 & 0.0115 \\
\hline Aging Effect with RE10 $(\Delta \mathrm{g} / \mathrm{mi}$ per $100 \mathrm{k} \mathrm{mi})$ & 0.0042 & -0.0013 & 0.0097 \\
\hline Aging Effect with RE15 $(\Delta \mathrm{g} / \mathrm{mi}$ per $100 \mathrm{k} \mathrm{mi})$ & 0.0049 & -0.0005 & 0.0104 \\
\hline \begin{tabular}{|l} 
Aging Effect with RE20 $(\Delta \mathrm{g} / \mathrm{mi}$ per $100 \mathrm{k} \mathrm{mi})$ \\
\end{tabular} & $0.0082^{*}$ & 0.0028 & 0.0137 \\
\hline
\end{tabular}

\begin{tabular}{|l|r|}
\hline \multicolumn{1}{|c|}{ Hypothesis } & -value \\
\hline No Effect of Ethanol in the Test Fuel (Gamma = 0) & 0.99 \\
\hline No Aging Effect with RE0 (Beta0 = 0) & 0.31 \\
\hline No Effect of Ethanol in Road Fuel Aging (Beta1s=0) & 0.62 \\
\hline
\end{tabular}

Initial odometers 40k-50k

*Indicates estimate is different from zero at the $95 \%$ confidence level.

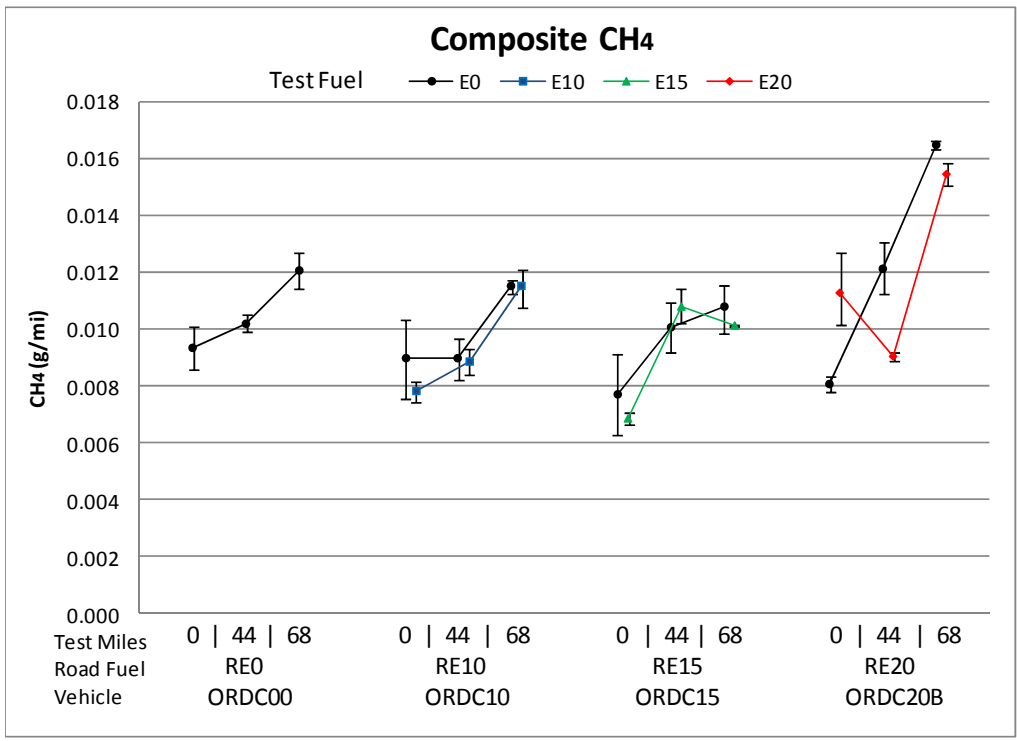

Error bars represent min and max measurements

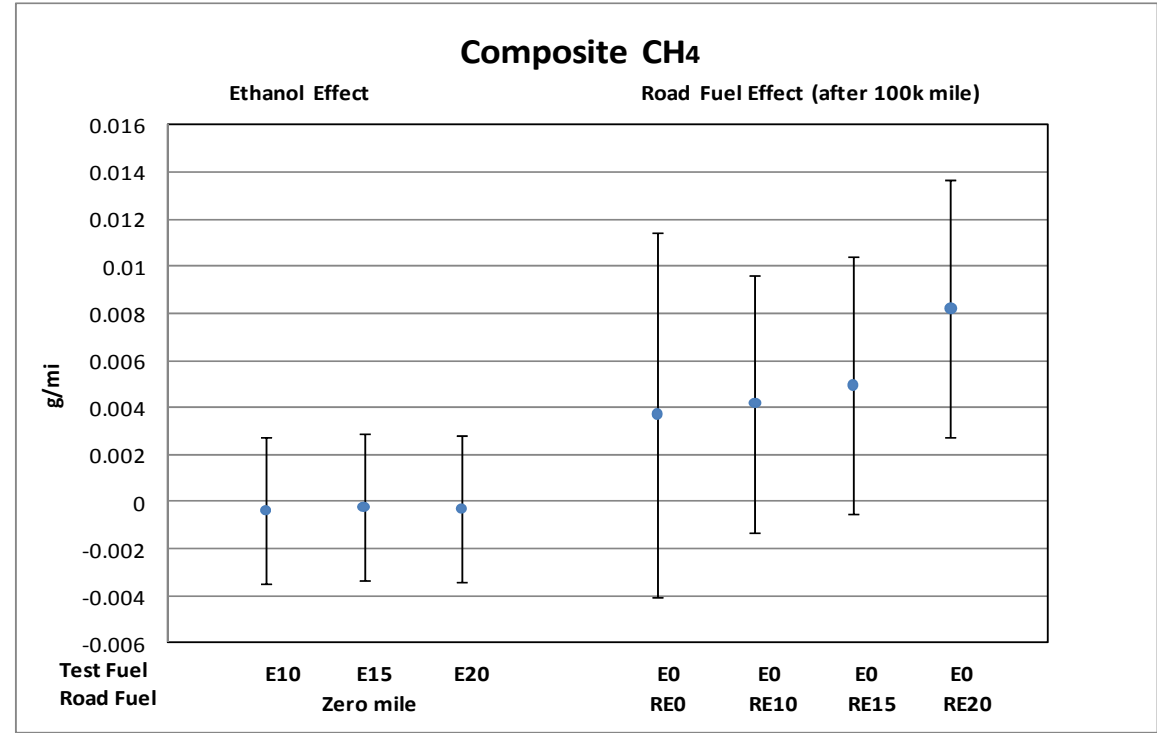

Error bars represent $95 \%$ confidence intervals on the estimated effects 


\section{Chevrolet Cobalt - Composite Emissions Summary}

\begin{tabular}{|c|c|c|c|c|c|c|c|c|c|c|c|c|c|c|}
\hline \multirow{3}{*}{$\begin{array}{l}\begin{array}{c}\text { Emisssion Parameter } \\
\text { (units) }\end{array} \\
\text { Fuels } \\
\end{array}$} & \multicolumn{4}{|c|}{ Ethanol Effect } & \multicolumn{2}{|c|}{ Aging Effect with REO } & \multicolumn{4}{|c|}{ RExx Aging Effect on EO Emissions } & \multirow{2}{*}{\multicolumn{3}{|c|}{$\begin{array}{c}\text { RExx Aging Effect on Exx Emissions } \\
\Delta \text { units per } 100 \mathrm{~K} \mathrm{mi}\end{array}$}} & \multirow{3}{*}{\begin{tabular}{|c|}
$\begin{array}{l}\text { Road and Test } \\
\text { Fuel Effects } \\
\text { are Additive }\end{array}$ \\
$\begin{array}{c}\text { Overall p- } \\
\text { value }\end{array}$ \\
\end{tabular}} \\
\hline & \multicolumn{3}{|c|}{$\Delta$ units vs. EO } & \multirow{2}{*}{$\begin{array}{l}\text { Overall } \\
p \text {-value }\end{array}$} & \multirow{2}{*}{$\begin{array}{c}\Delta \text { units per } 100 \mathrm{~K} \mathrm{mi} \\
\text { REO/EO }\end{array}$} & \multirow{2}{*}{$\begin{array}{l}\text { Overall } \\
p \text {-value }\end{array}$} & \multicolumn{3}{|c|}{$\Delta$ units per $100 \mathrm{~K} \mathrm{mi}$} & \multirow{2}{*}{$\begin{array}{l}\text { Overall } \\
p \text {-value }\end{array}$} & & & & \\
\hline & E10 & E15 & E20 & & & & RE10/E0 & RE15/E0 & RE20/EO & & RE10/E10 & RE15/E15 & RE20/E20 & \\
\hline $\mathrm{CO}(\mathrm{g} / \mathrm{mi})$ & NA & -0.001 & -0.156 & 0.49 & 0.268 & 0.39 & $\mathrm{NA}$ & -0.033 & 0.225 & 0.61 & $\mathrm{NA}$ & $\mathrm{NA}$ & $\mathrm{NA}$ & 0.68 \\
\hline $\mathrm{NOx}(\mathrm{g} / \mathrm{mi})^{\mathrm{a}}$ & $\mathrm{NA}$ & 0.0015 & 0.0019 & 0.98 & 0.0180 & 0.56 & NA & 0.0001 & 0.0406 & 0.50 & $\mathrm{NA}$ & $\mathrm{NA}$ & $\mathrm{NA}$ & 0.36 \\
\hline $\mathrm{NMHC}(\mathrm{g} / \mathrm{mi})$ & $\mathrm{NA}$ & -0.0039 & -0.0083 & $0.05 *$ & -0.0025 & 0.73 & $\mathrm{NA}$ & -0.0015 & 0.0025 & 0.80 & $\mathrm{NA}$ & $\mathrm{NA}$ & $\mathrm{NA}$ & 0.81 \\
\hline NMOG (g/mi) & NA & 0.0004 & -0.0038 & 0.50 & -0.0026 & 0.74 & $\mathrm{NA}$ & -0.0017 & 0.0023 & 0.82 & $\mathrm{NA}$ & $\mathrm{NA}$ & $\mathrm{NA}$ & 0.80 \\
\hline Fuel Econ (mi/gal) & $\mathrm{NA}$ & $-1.258 *$ & $-1.656^{*}$ & $<0.01^{*}$ & 0.651 & 0.33 & $\mathrm{NA}$ & 0.033 & 0.390 & 0.71 & $\mathrm{NA}$ & $\mathrm{NA}$ & $\mathrm{NA}$ & 0.57 \\
\hline Ethanol $(\mathrm{mg} / \mathrm{mi})^{\# \#}$ & $\mathrm{NA}$ & $3.204 *$ & $4.915 *$ & $0.01 *$ & 0.046 & 0.99 & NA & 0.068 & -1.420 & 0.86 & $\mathrm{NA}$ & $\mathrm{NA}$ & $\mathrm{NA}$ & $\mathrm{NA}$ \\
\hline Acetaldehyde $(\mathrm{mg} / \mathrm{mi})^{\mathrm{\# \# b}}$ & NA & 0.490 & $1.140 *$ & $0.04 *$ & 0.059 & 0.94 & NA & 0.072 & 0.013 & 1.00 & $\mathrm{NA}$ & $\mathrm{NA}$ & $\mathrm{NA}$ & $\mathrm{NA}$ \\
\hline Formaldehyde $(\mathrm{mg} / \mathrm{mi})^{\#}$ & $\mathrm{NA}$ & -0.143 & 0.018 & 0.72 & 0.476 & 0.40 & NA & 0.496 & 0.411 & 0.98 & $\mathrm{NA}$ & $\mathrm{NA}$ & $\mathrm{NA}$ & 0.93 \\
\hline $\mathrm{CH}_{4}(\mathrm{~g} / \mathrm{mi})$ & $\mathrm{NA}$ & -0.0005 & -0.0001 & 0.91 & 0.0037 & 0.20 & $\mathrm{NA}$ & 0.0007 & 0.0030 & 0.59 & $\mathrm{NA}$ & $\mathrm{NA}$ & $\mathrm{NA}$ & 0.96 \\
\hline
\end{tabular}

\# Log-normal model was used. Results are presented as changes in emissions at $0 \mathrm{k}$ mile.

\#\# Data did not support the assumption of linear effects with mileage.

* Indicates estimate is different from zero at the $95 \%$ confidence level.

a test "SW024668" and "SW024673" are identified as outliers and excluded from the analysis

b test "SW024056" is identified as an outlier and excluded from the analysis 
2006 Chevrolet Cobalt (Composite CO)

\begin{tabular}{|l|r|r|r|}
\hline \multicolumn{1}{|c|}{ Effect } & Estimate & $\begin{array}{c}\text { 95\% C.I. } \\
\text { Lower }\end{array}$ & $\begin{array}{r}\text { 95\% C.I. } \\
\text { Upper }\end{array}$ \\
\hline Ethanol Effect (E15 vs. E0) $(\Delta \mathrm{g} / \mathrm{mi})$ & -0.001 & -0.293 & 0.291 \\
\hline Ethanol Effect $($ E20 vs. E0) $(\Delta \mathrm{g} / \mathrm{mi})$ & -0.156 & -0.448 & 0.136 \\
\hline Road Fuel Aging Effect & & & \\
\hline Aging Effect with RE0 $(\Delta \mathrm{g} / \mathrm{mi}$ per 100k mi) & 0.268 & -0.422 & 0.958 \\
\hline Aging Effect with RE15 $(\Delta \mathrm{g} / \mathrm{mi}$ per 100k mi) & -0.033 & -0.522 & 0.456 \\
\hline Aging Effect with RE20 $(\Delta \mathrm{g} / \mathrm{mi}$ per 100k mi) & 0.225 & -0.263 & 0.713 \\
\hline
\end{tabular}

\begin{tabular}{|l|r|}
\hline \multicolumn{1}{|c|}{ Hypothesis } & p-value \\
\hline No Effect of Ethanol in the Test Fuel (Gamma = 0) & 0.49 \\
\hline No Aging Effect with RE0 (Beta0 = 0) & 0.39 \\
\hline No Effect of Ethanol in Road Fuel Aging (Beta1s=0) & 0.61 \\
\hline * Indicates effect is statistically significant at the 95\% confidence level.
\end{tabular}

(1) 0

Initial odometers 38k-48k

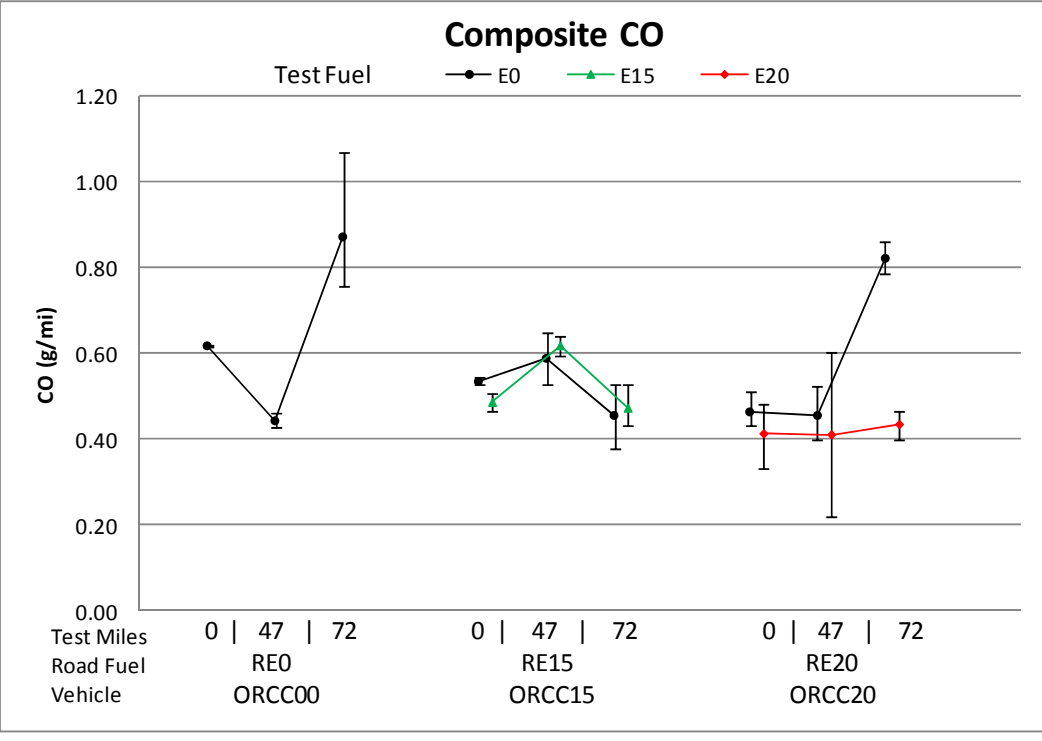

Error bars represent min and max measurements

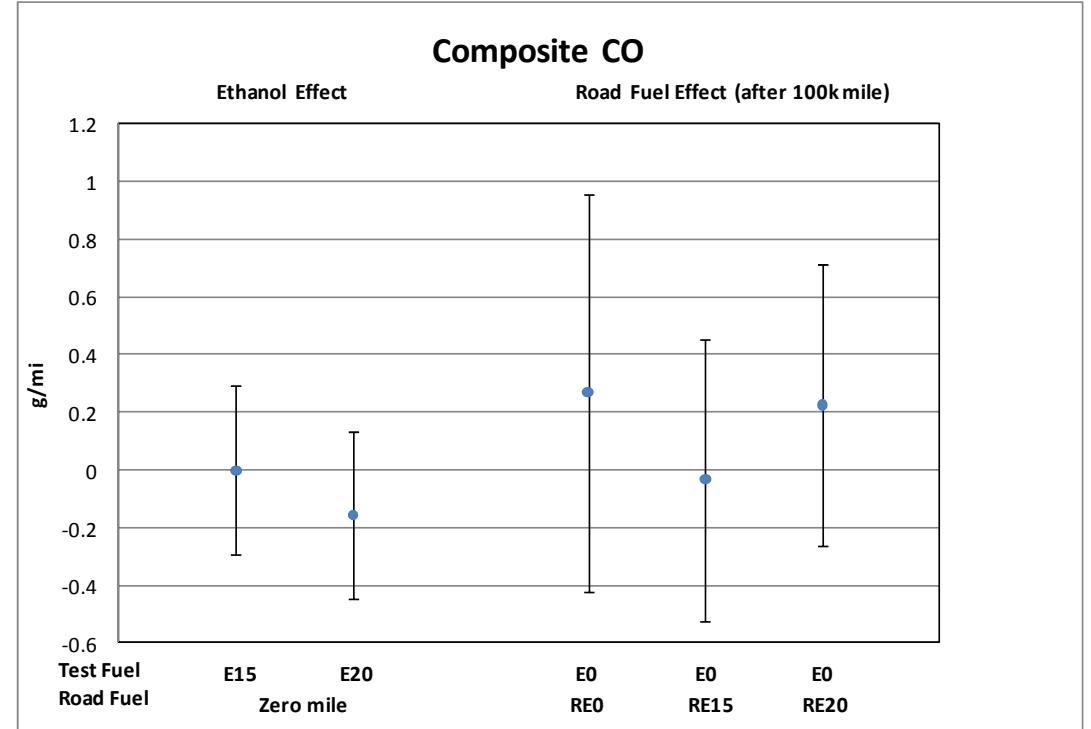

Error bars represent $95 \%$ confidence intervals on the estimated effects 
2006 Chevrolet Cobalt (Composite NOx)

\begin{tabular}{|l|r|r|r|}
\hline \multicolumn{1}{|c|}{ Effect } & & $\begin{array}{c}95 \% \text { C.I. } \\
\text { Low\% C.I. } \\
\text { Upper }\end{array}$ \\
\hline Ethanol Effect $(E 15$ vs. E0) $(\Delta \mathrm{g} / \mathrm{mi})$ & 0.0015 & -0.0288 & 0.0317 \\
\hline Ethanol Effect $(E 20 \mathrm{vs.} \mathrm{E0)}(\Delta \mathrm{g} / \mathrm{mi})$ & 0.0019 & -0.0333 & 0.0371 \\
\hline Road Fuel Aging Effect & & & \\
\hline Aging Effect with RE0 $(\Delta \mathrm{g} / \mathrm{mi}$ per 100k mi) & 0.0180 & -0.0536 & 0.0896 \\
\hline Aging Effect with RE15 $(\Delta \mathrm{g} / \mathrm{mi}$ per 100k mi) & 0.0001 & -0.0505 & 0.0507 \\
\hline Aging Effect with RE20 $(\Delta \mathrm{g} / \mathrm{mi}$ per 100k mi) & 0.0406 & -0.0195 & 0.1008 \\
\hline
\end{tabular}

\begin{tabular}{|l|r|}
\hline \multicolumn{1}{|c|}{ Hypothesis } & p-value \\
\hline No Effect of Ethanol in the Test Fuel (Gamma = 0) & 0.98 \\
\hline No Aging Effect with RE0 (Beta0 = 0) & 0.56 \\
\hline No Effect of Ethanol in Road Fuel Aging (Beta1s=0) & 0.50 \\
\hline
\end{tabular}

* Indicates estimate is different from zero at the $95 \%$ confidence level.

Initial odometers 38k-48k

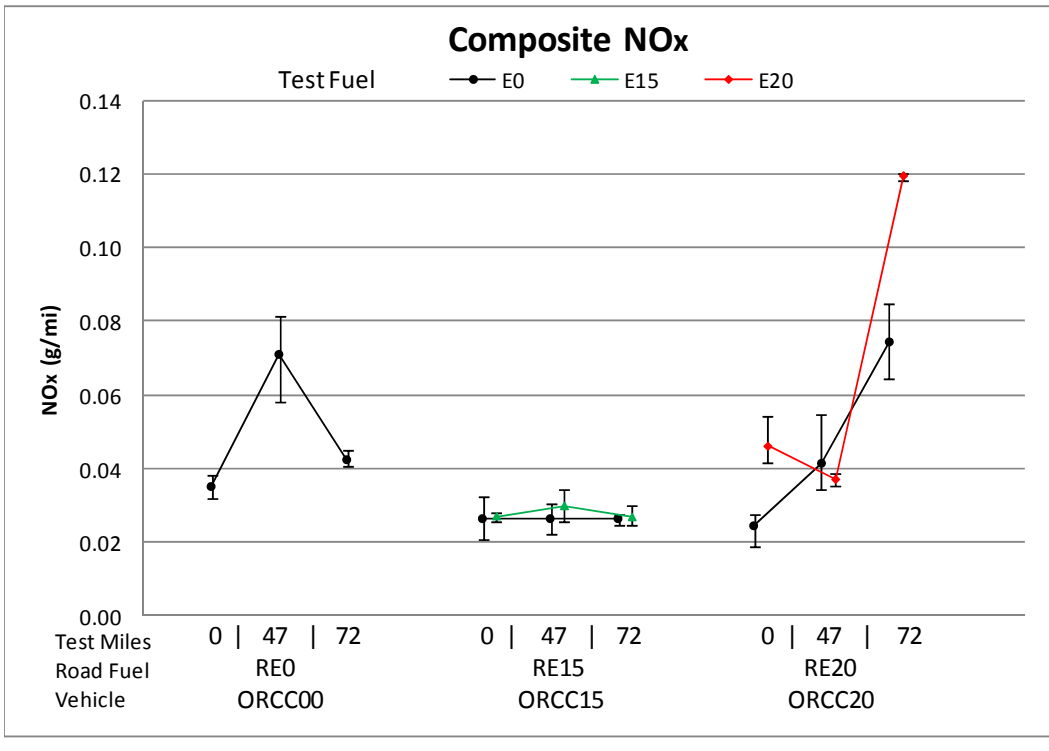

Error bars represent min and max measurements

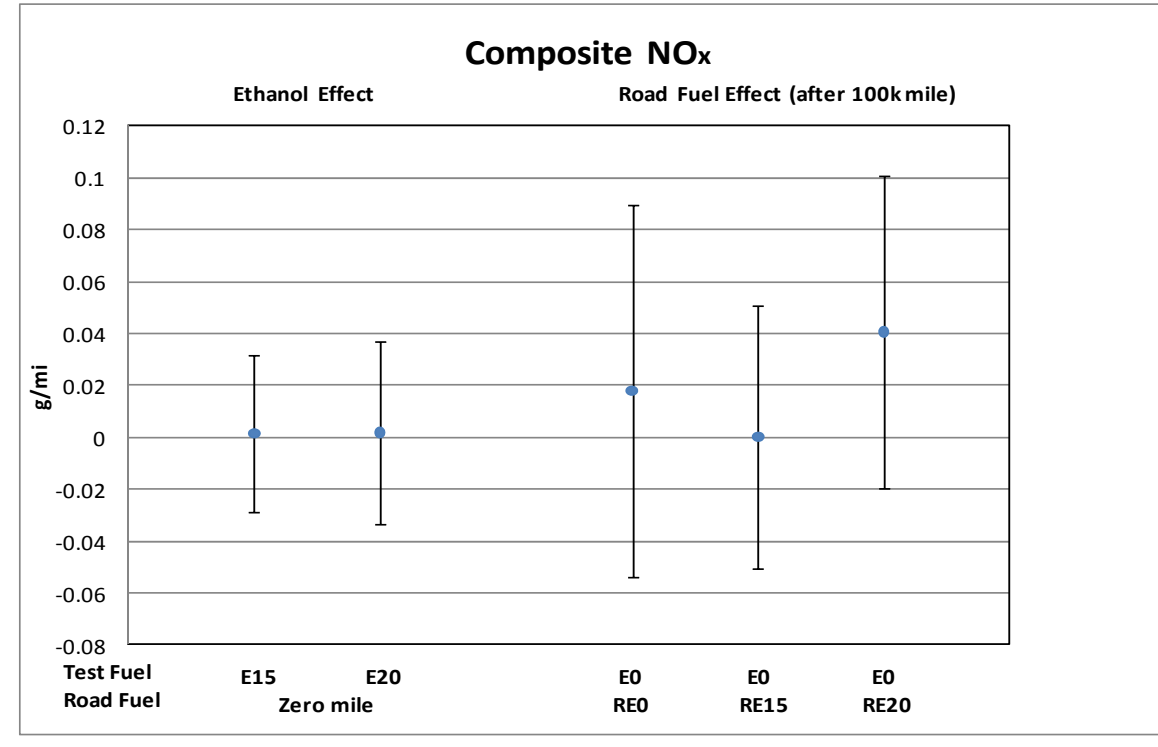

Error bars represent $95 \%$ confidence intervals on the estimated effects 
2006 Chevrolet Cobalt (Composite Nonmethane Hydrocarbons)

\begin{tabular}{|l|r|r|r|}
\hline \multicolumn{1}{|c|}{ Effect } & Estimate & $\begin{array}{c}\text { 95\% C.I. } \\
\text { Lower }\end{array}$ & $\begin{array}{c}\text { 95\% C.I. } \\
\text { Upper }\end{array}$ \\
\hline Ethanol Effect (E15 vs. E0) $(\Delta \mathrm{g} / \mathrm{mi})$ & -0.0039 & -0.0110 & 0.0032 \\
\hline Ethanol Effect $($ E20 vs. E0) $(\Delta \mathrm{g} / \mathrm{mi})$ & -0.0083 & -0.0153 & -0.0012 \\
\hline Road Fuel Aging Effect & & & \\
\hline Aging Effect with RE0 $(\Delta \mathrm{g} / \mathrm{mi}$ per 100k mi) & -0.0025 & -0.0191 & 0.0141 \\
\hline Aging Effect with RE15 $(\Delta \mathrm{g} / \mathrm{mi}$ per 100k mi) & -0.0015 & -0.0134 & 0.0103 \\
\hline Aging Effect with RE20 $(\Delta \mathrm{g} / \mathrm{mi}$ per 100k mi) & 0.0025 & -0.0093 & 0.0142 \\
\hline
\end{tabular}

\begin{tabular}{|l|r|}
\hline \multicolumn{1}{|c|}{ Hypothesis } & p-value \\
\hline No Effect of Ethanol in the Test Fuel (Gamma $=0)$ & $0.05^{*}$ \\
\hline No Aging Effect with RE0 (Beta0 $=0)$ & 0.73 \\
\hline No Effect of Ethanol in Road Fuel Aging (Beta1s=0) & 0.80 \\
\hline${ }^{*}$ Indicates effect is statistically significant at the 95\% confidence level.
\end{tabular}

* Indicates estimate is different from zero at the $95 \%$ confidence level.

Initial odometers $38 \mathrm{k}-48 \mathrm{k}$

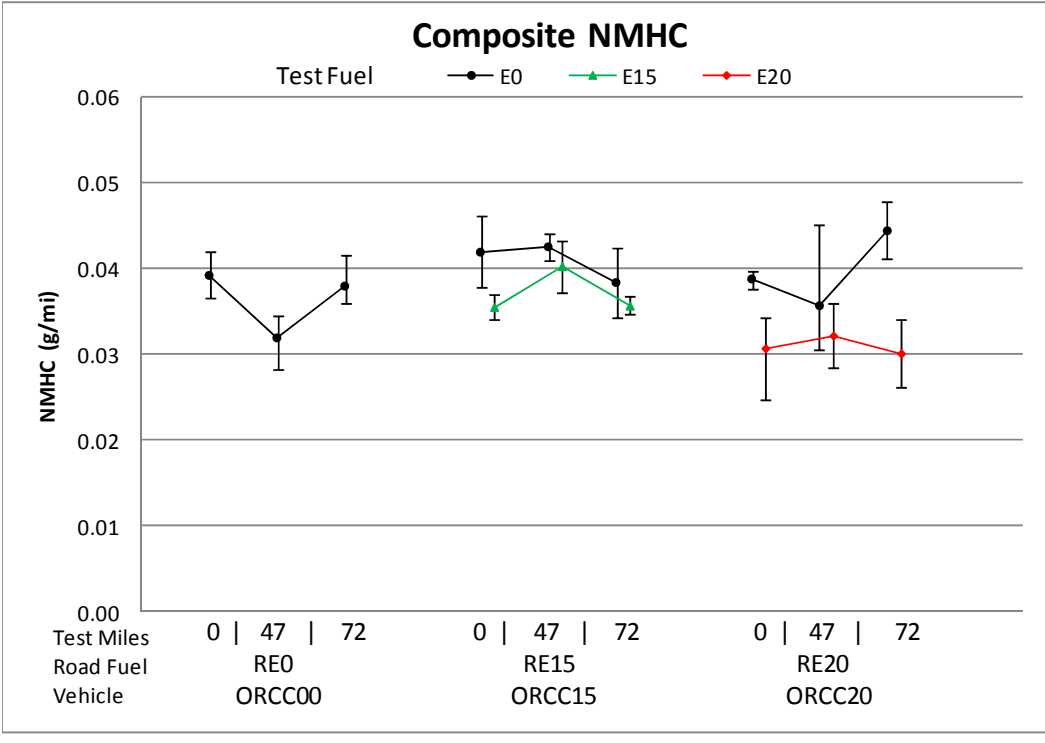

Error bars represent min and max measurements

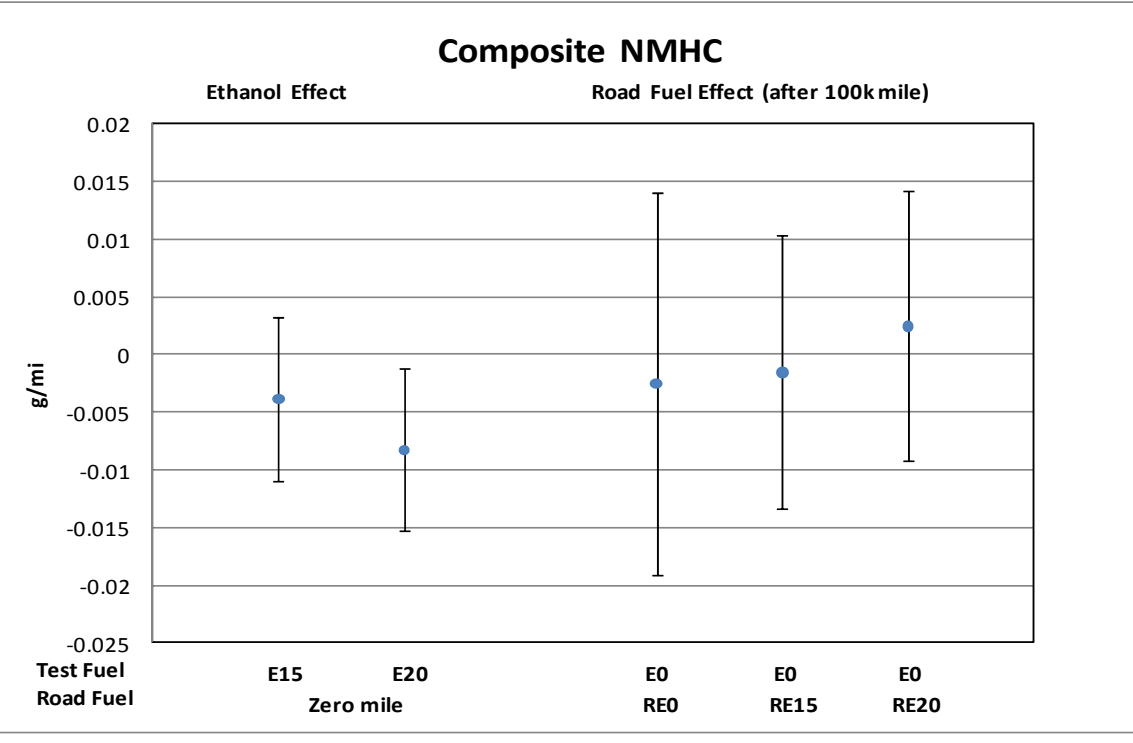

Error bars represent $95 \%$ confidence intervals on the estimated effects 
2006 Chevrolet Cobalt (Composite Nonmethane Organic Gases)

\begin{tabular}{|c|c|c|c|}
\hline Effect & Estimate & $\begin{array}{l}\text { 95\% C.I. } \\
\text { Lower }\end{array}$ & $\begin{array}{c}95 \% \text { C.I. } \\
\text { Upper }\end{array}$ \\
\hline Ethanol Effect (E15 vs. E0) $(\Delta \mathrm{g} / \mathrm{mi})$ & 0.0004 & -0.0071 & 0.0079 \\
\hline Ethanol Effect (E20 vs. E0) $(\Delta \mathrm{g} / \mathrm{mi})$ & -0.0038 & -0.0112 & 0.0036 \\
\hline \multicolumn{4}{|l|}{ Road Fuel Aging Effect } \\
\hline Aging Effect with RE0 ( $\Delta \mathrm{g} / \mathrm{mi}$ per $100 \mathrm{k} \mathrm{mi})$ & -0.0026 & -0.0201 & 0.0150 \\
\hline Aging Effect with RE15 ( $\Delta \mathrm{g} / \mathrm{mi}$ per $100 \mathrm{k} \mathrm{mi})$ & -0.0017 & -0.0142 & 0.0108 \\
\hline Aging Effect with RE20 ( $\Delta \mathrm{g} / \mathrm{mi}$ per $100 \mathrm{k} \mathrm{mi})$ & 0.0023 & -0.0100 & 0.0146 \\
\hline
\end{tabular}

\begin{tabular}{|l|r|}
\hline \multicolumn{1}{|c|}{ Hypothesis } & p-value \\
\hline No Effect of Ethanol in the Test Fuel (Gamma = 0) & 0.50 \\
\hline No Aging Effect with RE0 (Beta0 = 0) & 0.74 \\
\hline No Effect of Ethanol in Road Fuel Aging (Beta1s=0) & 0.82 \\
\hline${ }^{*}$ Indicates effect is statistically significant at the 95\% confidence level.
\end{tabular}

* Indicates estimate is different from zero at the $95 \%$ confidence level.

Initial odometers $38 \mathrm{k}-48 \mathrm{k}$

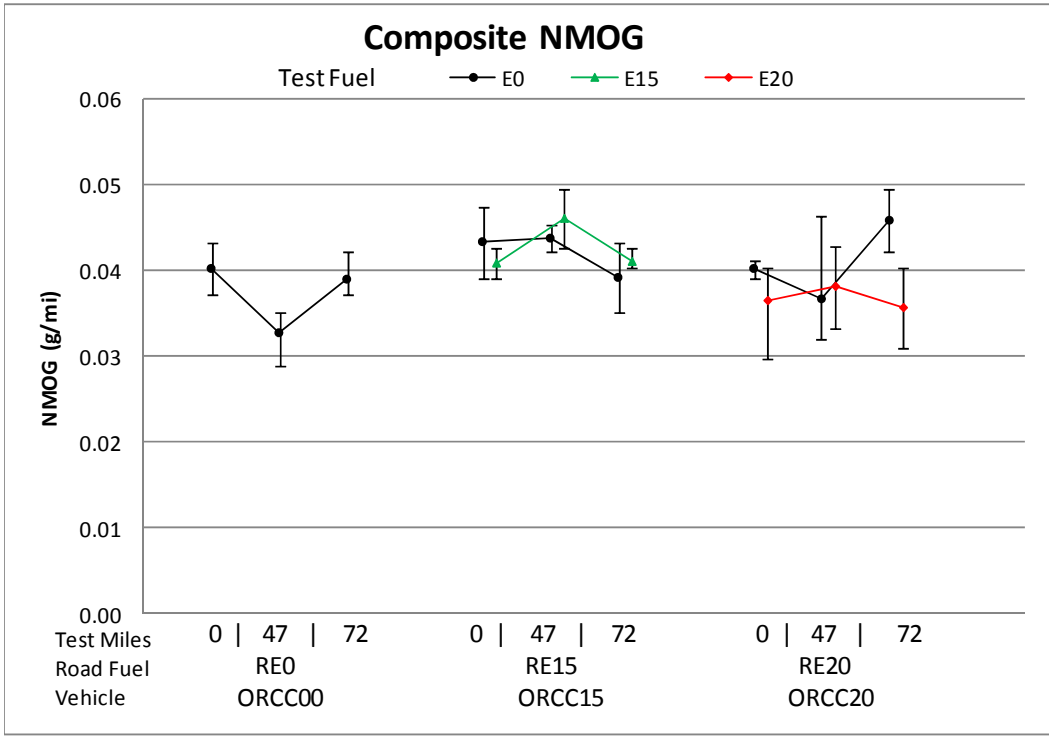

Error bars represent min and max measurements

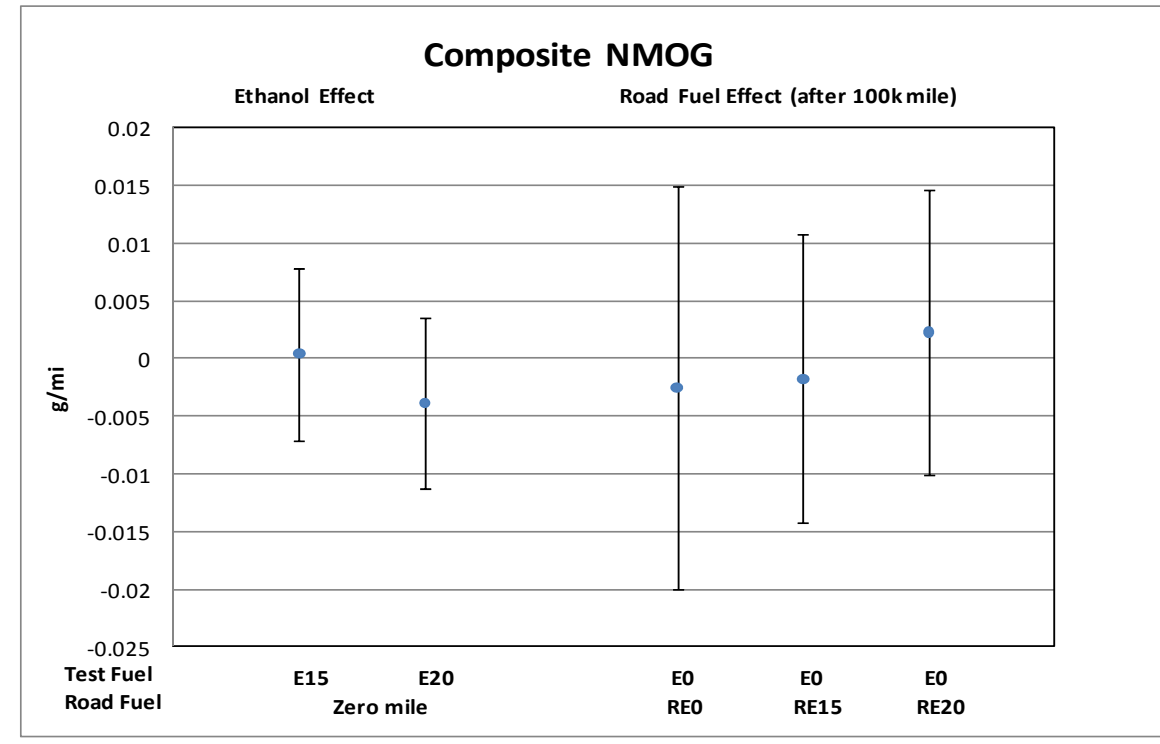

Error bars represent $95 \%$ confidence intervals on the estimated effects 
2006 Chevrolet Cobalt (Composite Fuel Economy)

\begin{tabular}{|l|r|r|r|}
\hline \multicolumn{1}{|c|}{ Effect } & & $\begin{array}{r}95 \% \text { C.I. } \\
\text { Estimate }\end{array}$ & $\begin{array}{r}\text { 95\% C.I. } \\
\text { Upper }\end{array}$ \\
\hline Ethanol Effect (E15 vs. E0) $(\Delta \mathrm{mi} / \mathrm{gal})$ & $-1.258^{*}$ & -1.884 & -0.632 \\
\hline Ethanol Effect (E20 vs. E0) $(\Delta \mathrm{mi} / \mathrm{gal})$ & $-1.656^{*}$ & -2.282 & -1.031 \\
\hline Road Fuel Aging Effect & & & \\
\hline Aging Effect with RE0 $(\Delta \mathrm{mi} / \mathrm{gal}$ per 100k mi) & 0.651 & -0.829 & 2.130 \\
\hline Aging Effect with RE15 $(\Delta \mathrm{mi} /$ gal per 100k mi) & 0.033 & -1.014 & 1.081 \\
\hline Aging Effect with RE20 $(\Delta \mathrm{mi} /$ gal per 100k mi $)$ & 0.390 & -0.657 & 1.437 \\
\hline
\end{tabular}

\begin{tabular}{|l|r|}
\hline \multicolumn{1}{|c|}{ Hypothesis } & -value \\
\hline No Effect of Ethanol in the Test Fuel (Gamma = 0) & $<0.01^{*}$ \\
\hline No Aging Effect with RE0 (Beta0 $=0$ ) & 0.33 \\
\hline No Effect of Ethanol in Road Fuel Aging (Beta1s $=0$ ) & 0.71 \\
\hline * Indicates effect is statistically significant at the 95\% confidence level.
\end{tabular}

${ }^{*}$ Indicates estimate is different from zero at the $95 \%$ confidence level.

Initial odometers 38k-48k

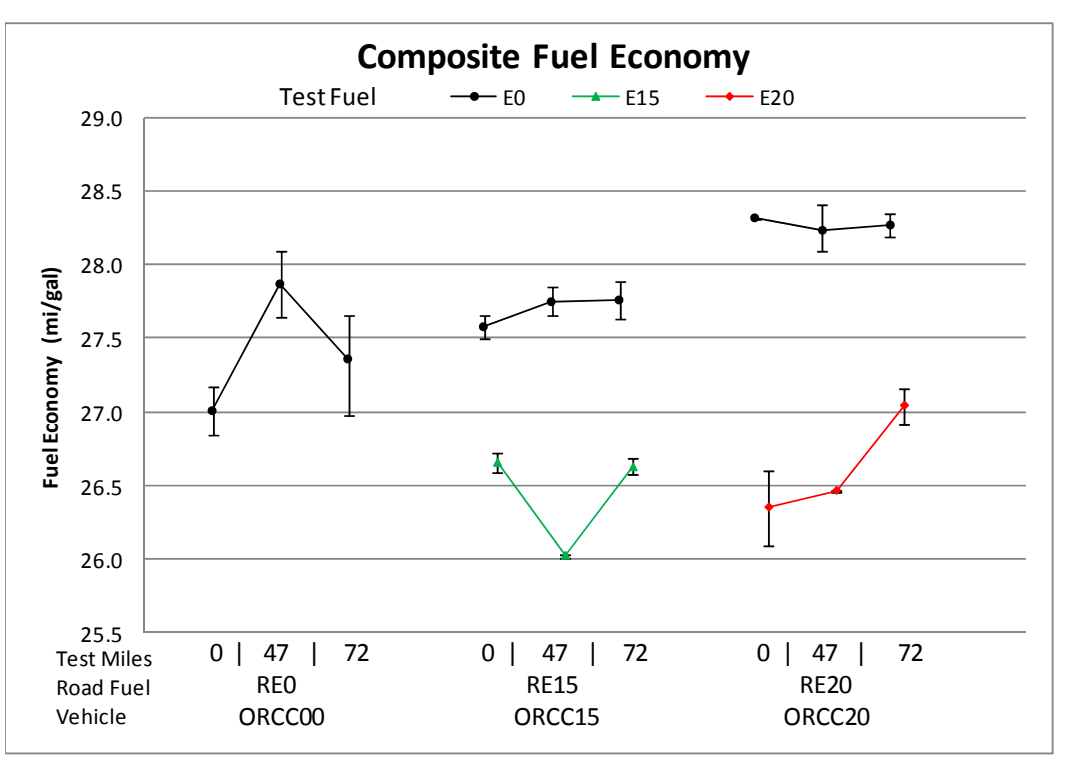

Error bars represent min and max measurements

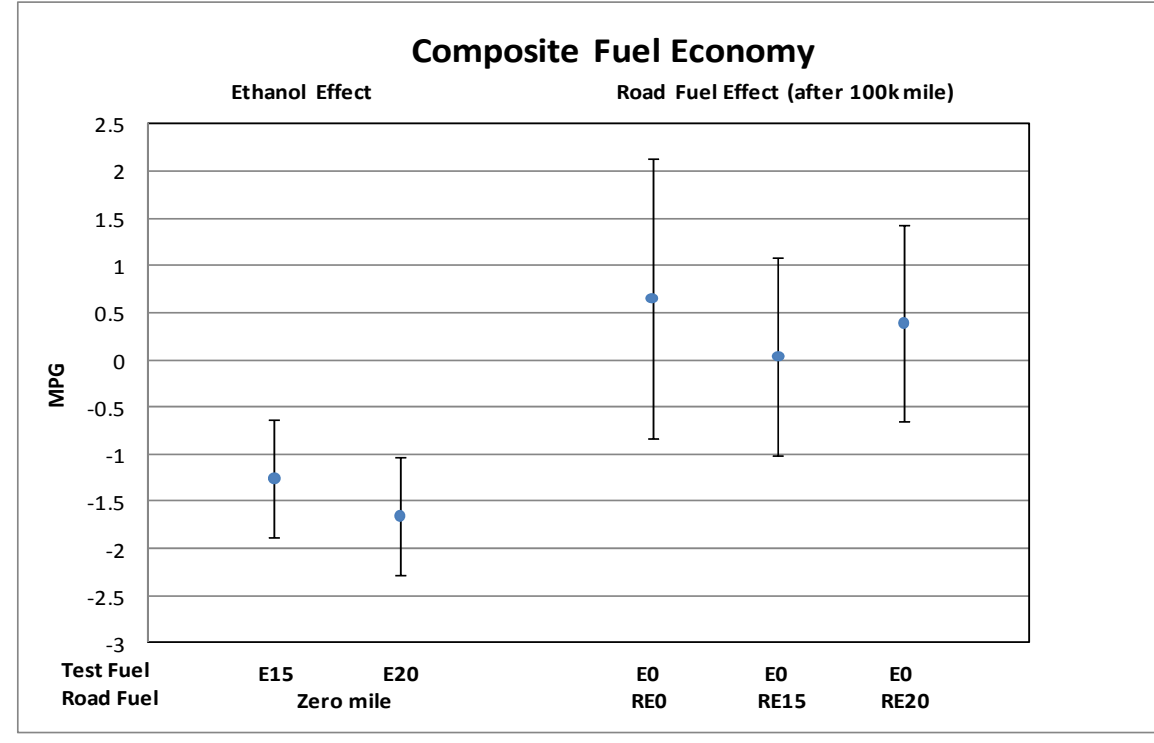

Error bars represent $95 \%$ confidence intervals on the estimated effects 
2006 Chevrolet Cobalt (Composite Ethanol)

\begin{tabular}{|l|r|r|r|}
\hline \multicolumn{1}{|c|}{ Effect } & Estimate & $\begin{array}{r}95 \% \text { C.I. } \\
\text { Lower }\end{array}$ & $\begin{array}{r}95 \% \text { C.I. } \\
\text { Upper }\end{array}$ \\
\hline Ethanol Effect $(E 15 \mathrm{vs.} \mathrm{E0)}(\Delta \mathrm{mg} / \mathrm{mi})$ & $3.204^{*}$ & 0.102 & 6.307 \\
\hline Ethanol Effect $($ E20 vs. E0) $(\Delta \mathrm{mg} / \mathrm{mi})$ & $4.915^{*}$ & 1.739 & 8.092 \\
\hline Road Fuel Aging Effect & & & \\
\hline Aging Effect with RE0 $(\Delta \mathrm{mg} / \mathrm{mi}$ per 100k mi) & 0.046 & -7.429 & 7.520 \\
\hline Aging Effect with RE15 $(\Delta \mathrm{mg} / \mathrm{mi}$ per 100k mi) & 0.068 & -5.214 & 5.351 \\
\hline Aging Effect with RE20 $(\Delta \mathrm{mg} / \mathrm{mi}$ per 100k mi) & -1.420 & -6.707 & 3.867 \\
\hline * Indicates estimate is different from zero at the 95\% confiden
\end{tabular}

\begin{tabular}{|l|r|}
\hline \multicolumn{1}{|c|}{ Hypothesis } & p-value \\
\hline No Effect of Ethanol in the Test Fuel (Gamma = 0) & $0.01^{*}$ \\
\hline No Aging Effect with RE0 (Beta0 = 0) & 0.99 \\
\hline No Effect of Ethanol in Road Fuel Aging (Beta1s=0) & 0.86 \\
\hline
\end{tabular}

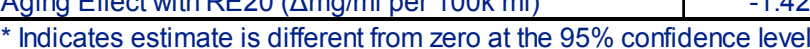

Initial odometers 38k-48k

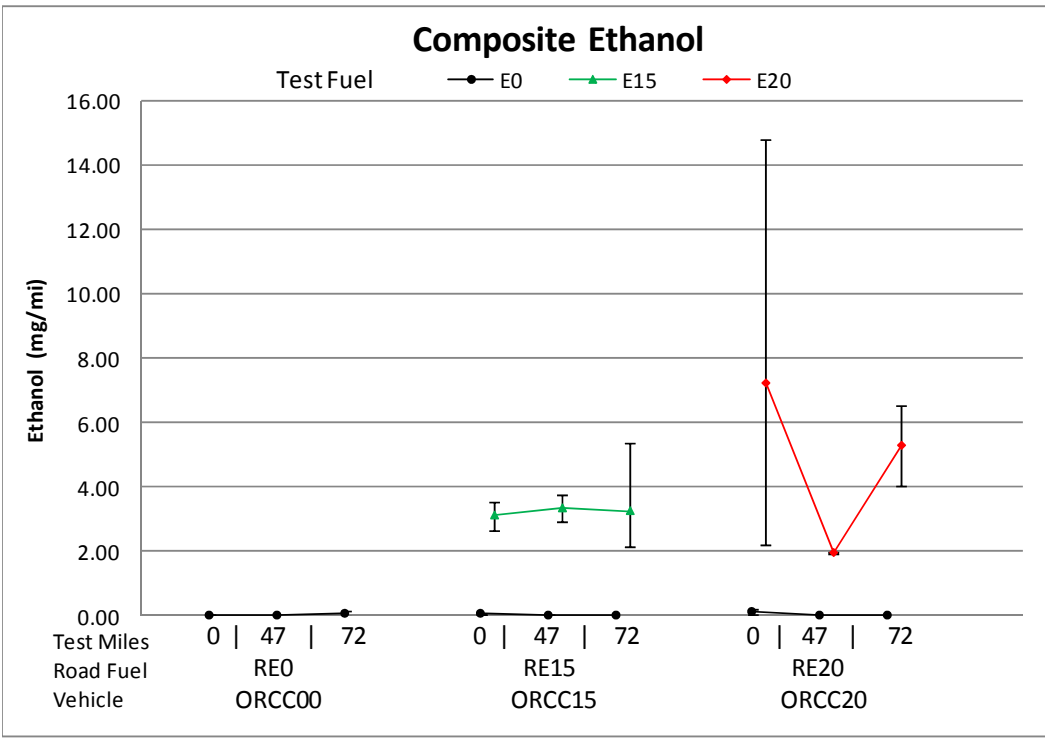

Error bars represent min and max measurements

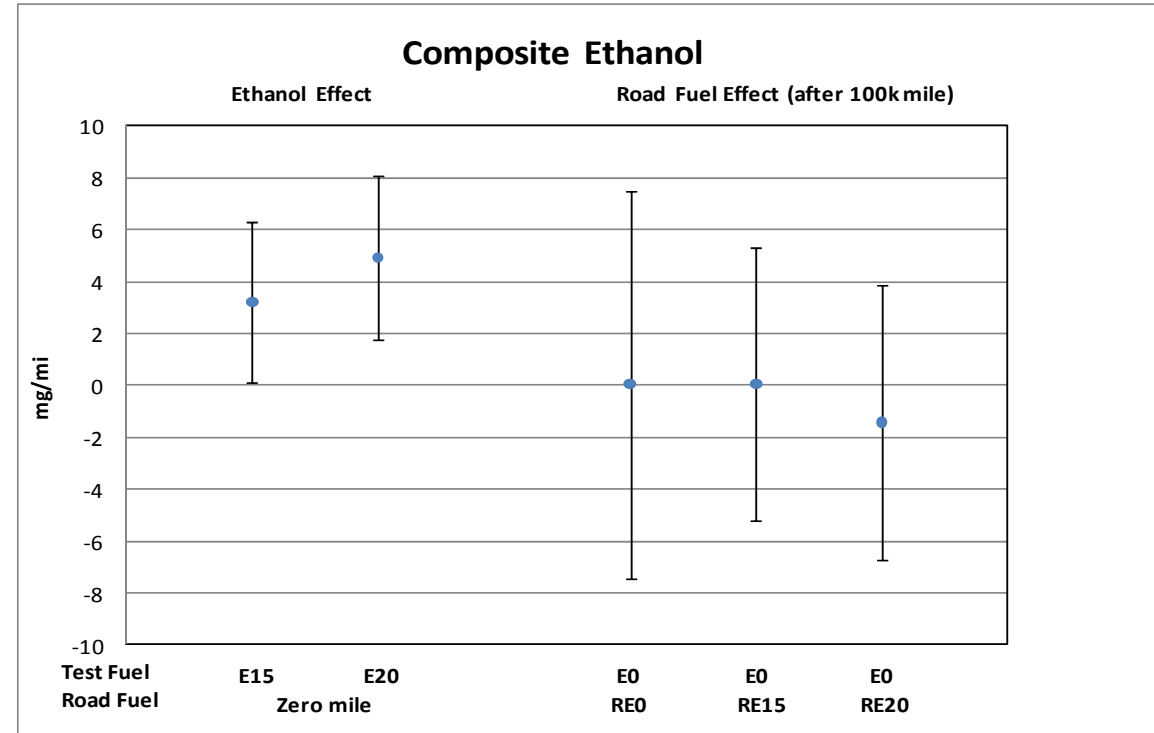

Error bars represent $95 \%$ confidence intervals on the estimated effects 
2006 Chevrolet Cobalt (Composite Acetaldehyde)

\begin{tabular}{|l|r|r|r|}
\hline \multicolumn{1}{|c|}{ Effect } & Estimate & $\begin{array}{r}\text { 95\% C.I. } \\
\text { Lower }\end{array}$ & $\begin{array}{r}\text { 95\% C.I. } \\
\text { Upper }\end{array}$ \\
\hline Ethanol Effect (E15 vs. E0) $(\Delta \mathrm{mg} / \mathrm{mi})$ & 0.490 & -0.348 & 1.329 \\
\hline Ethanol Effect $($ E20 vs. E0) $(\Delta \mathrm{mg} / \mathrm{mi})$ & $1.140^{*}$ & 0.301 & 1.979 \\
\hline Road Fuel Aging Effect & & & \\
\hline Aging Effect with RE0 $(\Delta \mathrm{mg} / \mathrm{mi}$ per 100k mi) & 0.059 & -1.958 & 2.076 \\
\hline Aging Effect with RE15 $(\Delta \mathrm{mg} / \mathrm{mi}$ per 100k mi) & 0.072 & -1.353 & 1.498 \\
\hline Aging Effect with RE20 $(\Delta \mathrm{mg} / \mathrm{mi}$ per 100k mi) & 0.013 & -1.413 & 1.440 \\
\hline
\end{tabular}

\begin{tabular}{|l|r|}
\hline \multicolumn{1}{|c|}{ Hypothesis } & p-value \\
\hline No Effect of Ethanol in the Test Fuel (Gamma = 0) & $0.04^{*}$ \\
\hline No Aging Effect with RE0 (Beta0 = 0) & 0.94 \\
\hline No Effect of Ethanol in Road Fuel Aging (Beta1s $=0$ ) & 1.00 \\
\hline * Indicates effect is statistically significant at the 95\% confidence level.
\end{tabular}

* Indicates estimate is different from zero at the $95 \%$ confidence level.

Initial odometers 38k-48k

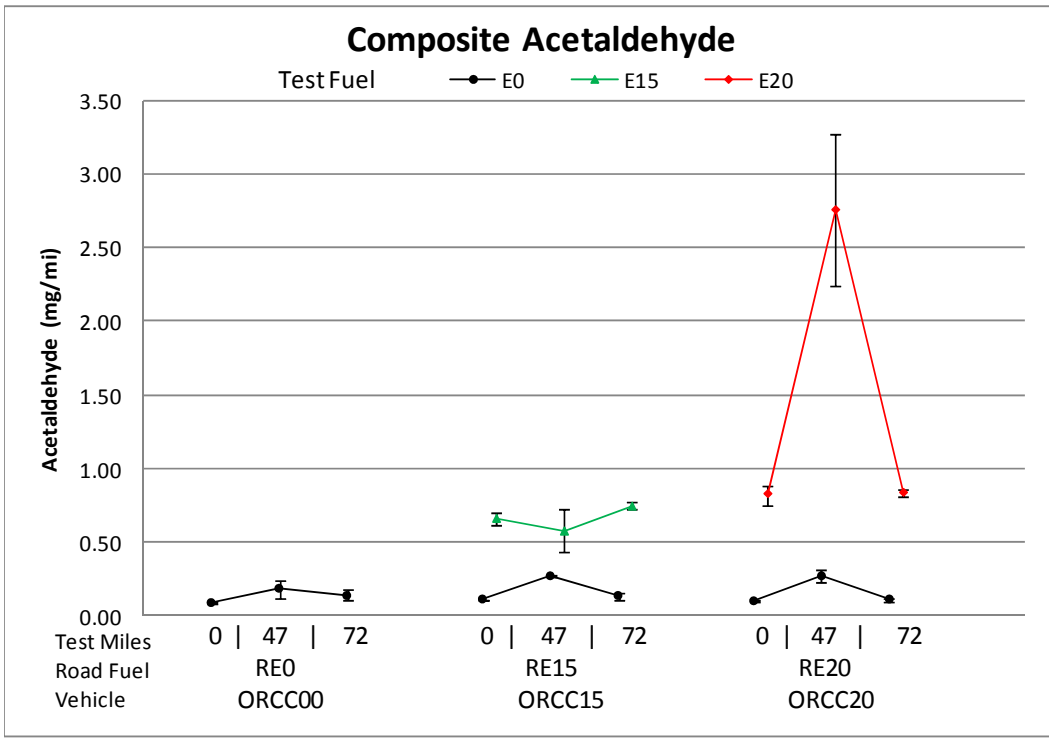

Error bars represent min and max measurements

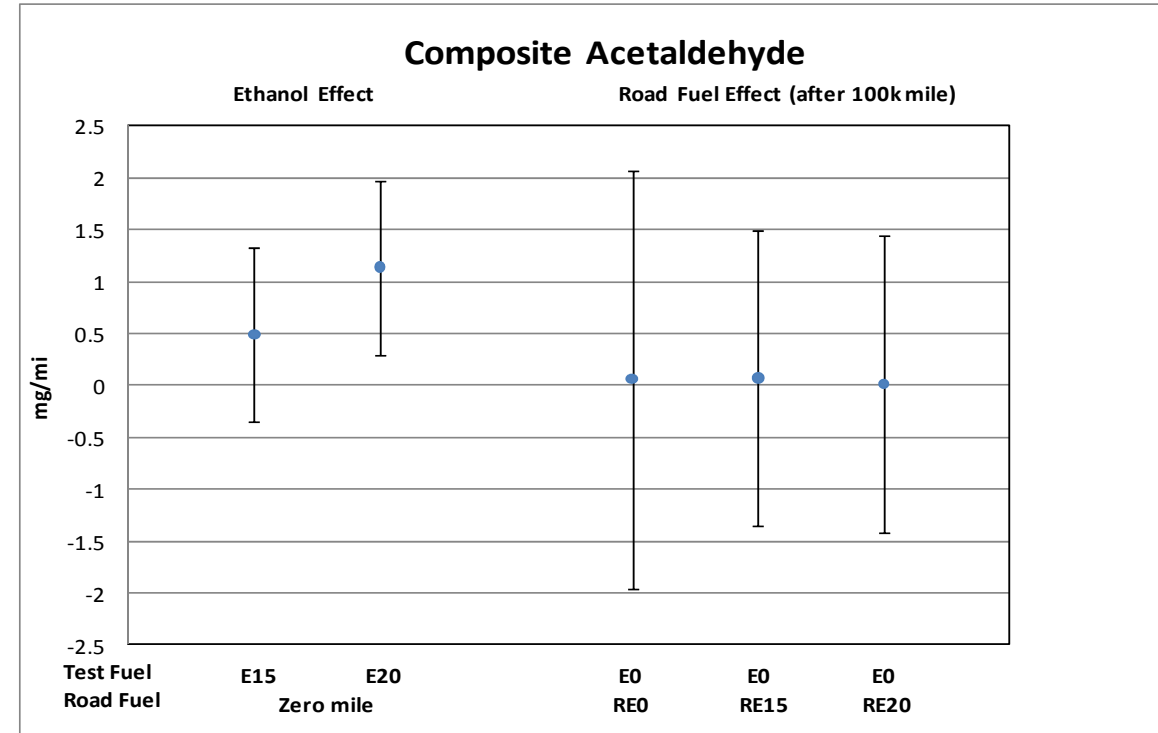

Error bars represent $95 \%$ confidence intervals on the estimated effects 
2006 Chevrolet Cobalt (Composite Formaldehyde)

\begin{tabular}{|l|r|r|r|}
\hline \multicolumn{1}{|c|}{ Effect } & Estimate & $\begin{array}{c}\text { 95\% C.I. } \\
\text { Lower }\end{array}$ & $\begin{array}{r}\text { 95\% C.I. } \\
\text { Upper }\end{array}$ \\
\hline Ethanol Effect (E15 vs. E0) $(\Delta \mathrm{mg} / \mathrm{mi})$ & -0.143 & -0.723 & 0.438 \\
\hline Ethanol Effect $($ E20 vs. E0) $(\Delta \mathrm{mg} / \mathrm{mi})$ & 0.018 & -0.481 & 0.516 \\
\hline Road Fuel Aging Effect & & & \\
\hline Aging Effect with RE0 $(\Delta \mathrm{mg} / \mathrm{mi}$ per 100k mi) & 0.476 & -0.961 & 1.913 \\
\hline Aging Effect with RE15 $(\Delta \mathrm{mg} / \mathrm{mi}$ per 100k mi) & 0.496 & -0.968 & 1.959 \\
\hline Aging Effect with RE20 $(\Delta \mathrm{mg} / \mathrm{mi}$ per 100k mi) & 0.411 & -0.713 & 1.534 \\
\hline
\end{tabular}

\begin{tabular}{|l|r|}
\hline \multicolumn{1}{|c|}{ Hypothesis } & p-value \\
\hline No Effect of Ethanol in the Test Fuel (Gamma = 0) & 0.72 \\
\hline No Aging Effect with RE0 (Beta0 = $)$ & 0.40 \\
\hline No Effect of Ethanol in Road Fuel Aging (Beta1s=0) & 0.98 \\
\hline${ }^{*}$ Indicates effect is statistically significant at the 95\% confidence level.
\end{tabular}

* Indicates estimate is different from zero at the $95 \%$ confidence level.

Initial odometers 38k-48k

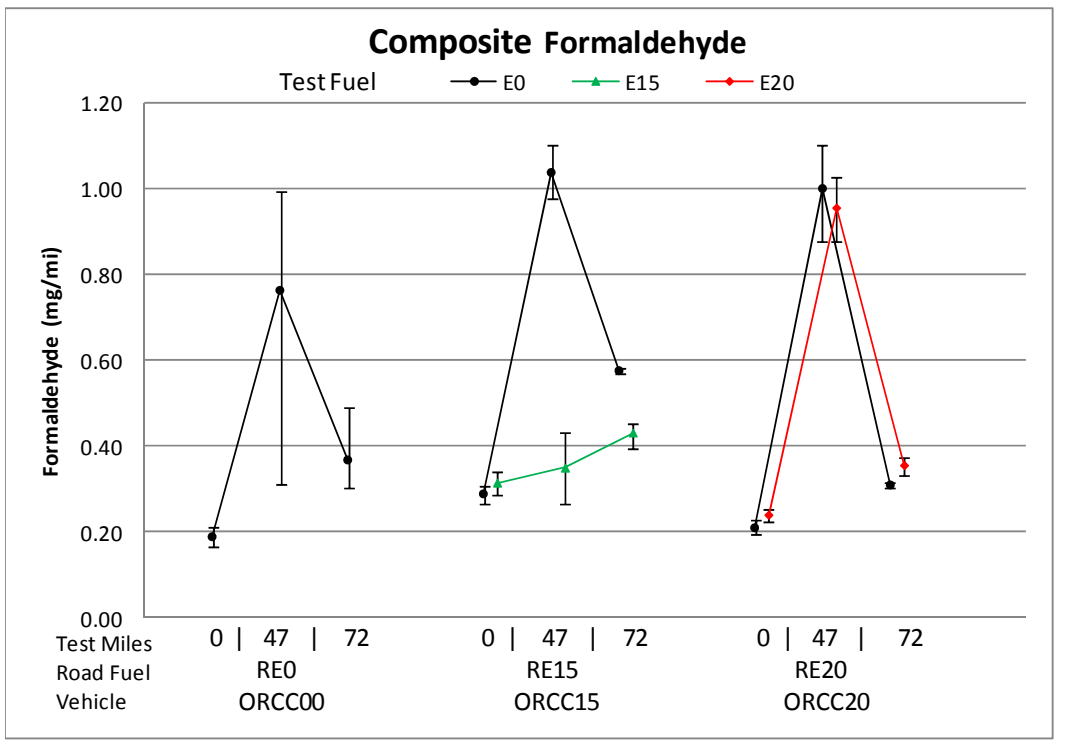

Error bars represent min and max measurements

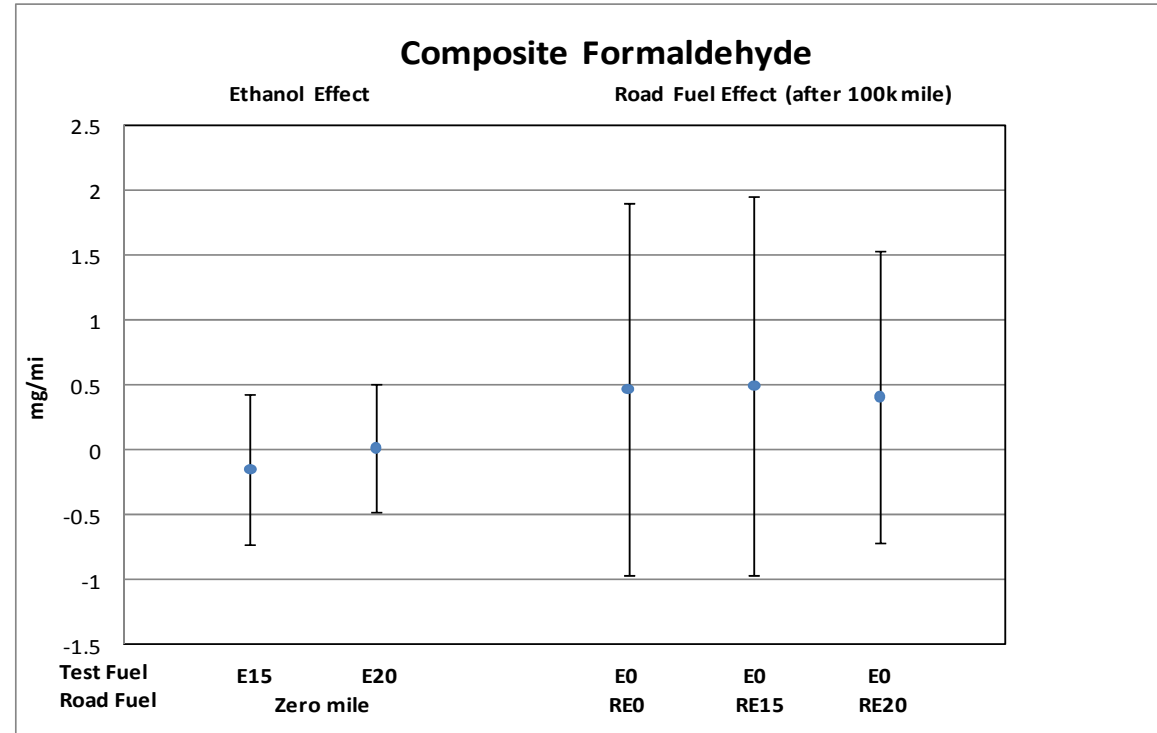

Error bars represent $95 \%$ confidence intervals on the estimated effects 
2006 Chevrolet Cobalt (Composite $\mathrm{CH}_{4}$ )

\begin{tabular}{|l|r|r|c|}
\hline \multicolumn{1}{|c|}{ Effect } & & $95 \%$ C.I. & $\begin{array}{c}95 \% \text { C.I. } \\
\text { Upper }\end{array}$ \\
\hline Ethanol Effect (E15 vs. E0) $(\Delta \mathrm{g} / \mathrm{mi})$ & -0.0005 & -0.0030 & 0.0021 \\
\hline Ethanol Effect (E20 vs. E0) $(\Delta \mathrm{g} / \mathrm{mi})$ & -0.0001 & -0.0027 & 0.0024 \\
\hline Road Fuel Aging Effect & & & \\
\hline Aging Effect with RE0 $(\Delta \mathrm{g} / \mathrm{mi}$ per 100k mi) & 0.0037 & -0.0024 & 0.0097 \\
\hline Aging Effect with RE15 $(\Delta \mathrm{g} / \mathrm{mi}$ per 100k mi) & 0.0007 & -0.0036 & 0.0051 \\
\hline Aging Effect with RE20 $(\Delta \mathrm{g} / \mathrm{mi}$ per 100k mi) & 0.0030 & -0.0013 & 0.0073 \\
\hline
\end{tabular}

\begin{tabular}{|l|r|}
\hline \multicolumn{1}{|c|}{ Hypothesis } & -value \\
\hline No Effect of Ethanol in the Test Fuel (Gamma = 0) & 0.91 \\
\hline No Aging Effect with RE0 (Beta0 = 0) & 0.20 \\
\hline No Effect of Ethanol in Road Fuel Aging (Beta1s=0) & 0.59 \\
\hline
\end{tabular}

* Indicates estimate is different from zero at the $95 \%$ confidence level.

Initial odometers 38k-48k

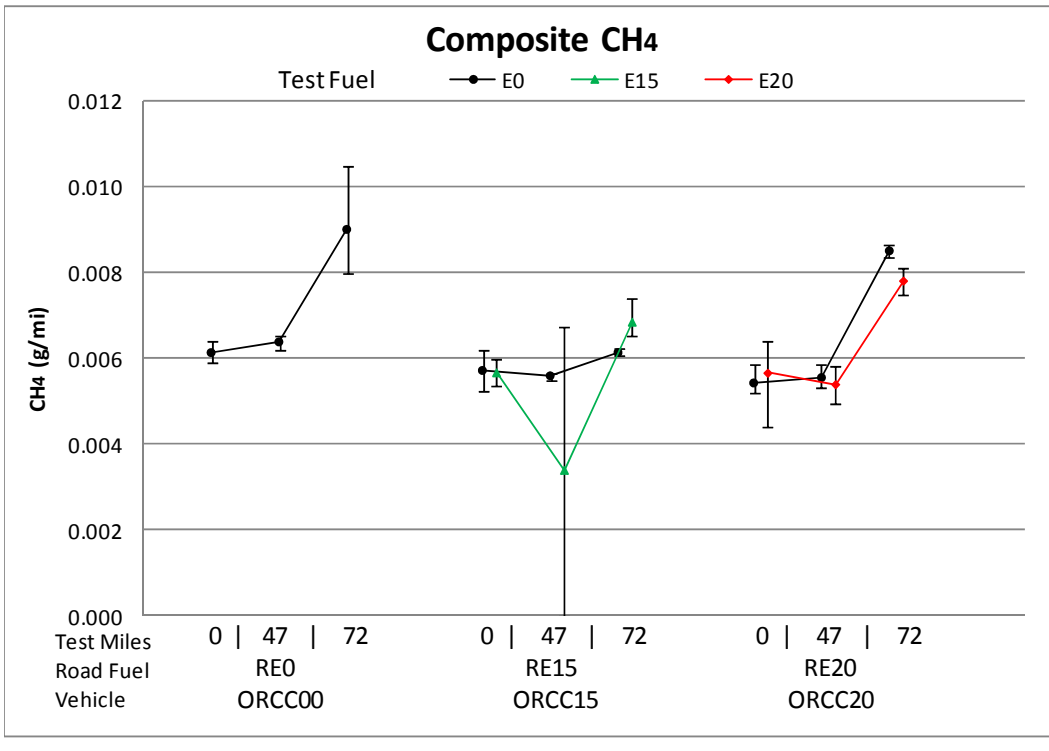

Error bars represent min and max measurements

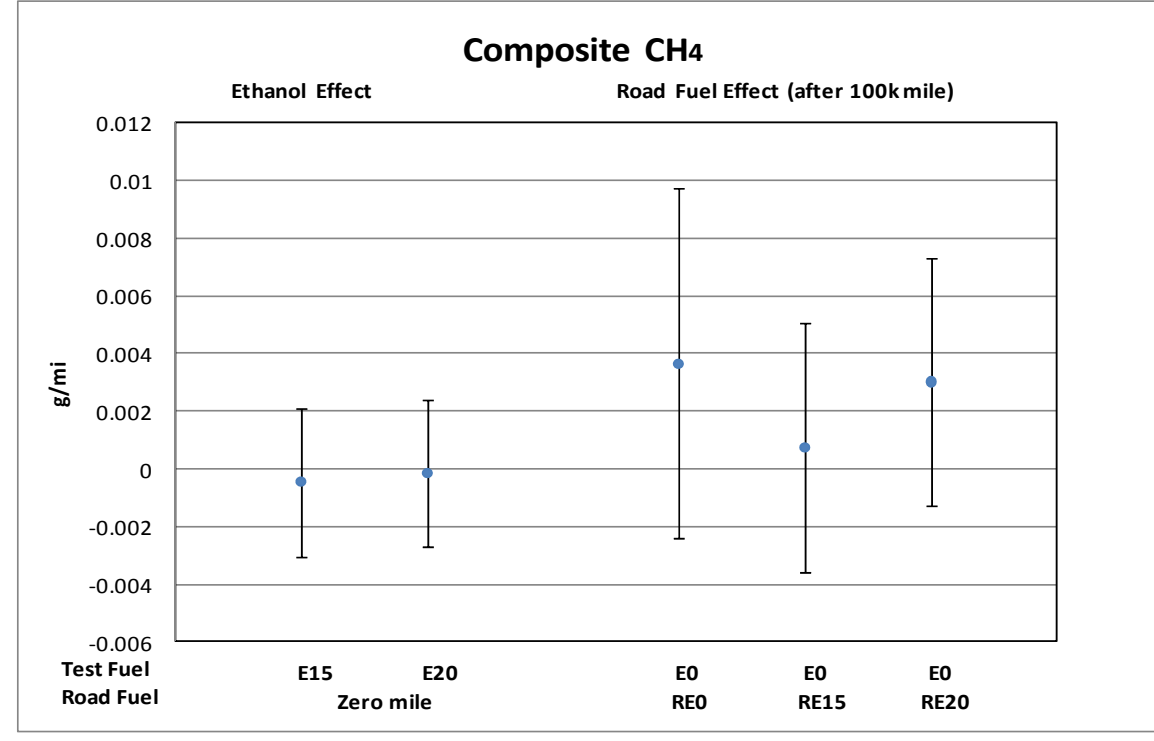

Error bars represent $95 \%$ confidence intervals on the estimated effects 


\section{Dodge Caliber - Composite Emissions Summary}

\begin{tabular}{|c|c|c|c|c|c|c|c|c|c|c|c|c|c|c|}
\hline \multirow{2}{*}{$\begin{array}{c}\text { Emisssion Parameter } \\
\text { (units) }\end{array}$} & \multicolumn{4}{|c|}{ Ethanol Effect } & \multicolumn{2}{|c|}{ Aging Effect with REO } & \multicolumn{4}{|c|}{ RExx Aging Effect on E0 Emissions } & \multirow{2}{*}{\multicolumn{3}{|c|}{$\begin{array}{c}\text { RExx Aging Effect on Exx Emissions } \\
\Delta \text { units per } 100 \mathrm{~K} \mathrm{mi}\end{array}$}} & \multirow{3}{*}{\begin{tabular}{|c|}
$\begin{array}{l}\text { Road and Test } \\
\text { Fuel Effects } \\
\text { are Additive }\end{array}$ \\
$\begin{array}{c}\text { Overall p- } \\
\text { value }\end{array}$
\end{tabular}} \\
\hline & \multicolumn{3}{|c|}{$\Delta$ units vs. EO } & \multirow{2}{*}{$\mid \begin{array}{l}\text { Overall } \\
p \text {-value }\end{array}$} & \multirow{2}{*}{$\begin{array}{c}\Delta \text { units per } 100 \mathrm{~K} \mathrm{mi} \\
\text { REO/EO }\end{array}$} & \multirow{2}{*}{$\begin{array}{l}\text { Overall } \\
p \text {-value }\end{array}$} & \multicolumn{3}{|c|}{$\Delta$ units per $100 \mathrm{~K} \mathrm{mi}$} & \multirow{2}{*}{$\begin{array}{l}\text { Overall } \\
p \text {-value }\end{array}$} & & & & \\
\hline Fuels & E10 & E15 & E20 & & & & RE10/E0 & RE15/E0 & RE20/E0 & & RE10/E10 & RE15/E15 & RE20/E20 & \\
\hline $\mathrm{CO}(\mathrm{g} / \mathrm{mi})$ & $\mathrm{NA}$ & -0.214 & $-1.049 *$ & $<0.01 *$ & $2.274 *$ & $<0.01 *$ & NA & 4.729* & $2.748 *$ & $<0.01 *$ & NA & $\mathrm{NA}$ & $\mathrm{NA}$ & 0.22 \\
\hline $\mathrm{NOx}(\mathrm{g} / \mathrm{mi})$ & $\mathrm{NA}$ & 0.002 & 0.002 & 0.92 & $0.057 *$ & $0.01 *$ & NA & $0.037^{*}$ & $0.045^{*}$ & 0.65 & NA & $\mathrm{NA}$ & $\mathrm{NA}$ & 0.97 \\
\hline NMHC (g/mi) & $\mathrm{NA}$ & -0.0016 & $-0.0117 *$ & $0.02 *$ & $0.0416 *$ & $<0.01 *$ & NA & $0.0437^{*}$ & $0.0289 *$ & 0.28 & NA & $\mathrm{NA}$ & $\mathrm{NA}$ & 0.99 \\
\hline NMOG (g/mi) & $\mathrm{NA}$ & 0.0052 & -0.0046 & 0.38 & $0.0428 *$ & $<0.01 *$ & $\mathrm{NA}$ & $0.0471 *$ & $0.0322 *$ & 0.41 & $\mathrm{NA}$ & $\mathrm{NA}$ & $\mathrm{NA}$ & 0.89 \\
\hline Fuel Econ (mi/gal) & $\mathrm{NA}$ & $-1.386 *$ & $-1.774 *$ & $<0.01 *$ & $0.994 *$ & $0.04 *$ & NA & 0.288 & -0.131 & 0.15 & NA & $\mathrm{NA}$ & $\mathrm{NA}$ & 0.99 \\
\hline Ethanol $(\mathrm{mg} / \mathrm{mi})^{\# \#}$ & $\mathrm{NA}$ & $3.888^{*}$ & $4.307 *$ & $<0.01 *$ & -0.056 & 0.97 & NA & -0.100 & 2.298 & 0.30 & NA & $\mathrm{NA}$ & $\mathrm{NA}$ & $\mathrm{NA}$ \\
\hline Acetaldehyde $(\mathrm{mg} / \mathrm{mi})^{\#}$ & $\mathrm{NA}$ & $0.820 *$ & $1.111 *$ & $<0.01^{*}$ & 0.155 & 0.12 & NA & $0.201 *$ & $0.152 *$ & 0.85 & NA & $\mathrm{NA}$ & $\mathrm{NA}$ & 0.67 \\
\hline Formaldehyde $(\mathrm{mg} / \mathrm{mi})^{\#}$ & $\mathrm{NA}$ & 0.086 & 0.151 & 0.17 & 0.530 & 0.15 & NA & $0.520 *$ & $0.433 *$ & 0.98 & NA & $\mathrm{NA}$ & $\mathrm{NA}$ & 0.99 \\
\hline $\mathrm{CH}_{4}(\mathrm{~g} / \mathrm{mi})$ & $\mathrm{NA}$ & -0.0002 & -0.0018 & 0.89 & $0.0268 *$ & $0.02 *$ & $\mathrm{NA}$ & $0.0402 *$ & $0.0254^{*}$ & 0.27 & NA & $\mathrm{NA}$ & $\mathrm{NA}$ & 0.98 \\
\hline
\end{tabular}

\# Log-normal model was used. Results are presented as changes in emissions at $0 \mathrm{k}$ mile.

\#\# Data did not support the assumption of linear effects with mileage.

*Indicates estimate is different from zero at the $95 \%$ confidence level. 
2007 Dodge Caliber (Composite CO)

\begin{tabular}{|l|r|r|r|}
\hline \multicolumn{1}{|c|}{ Effect } & Estimate & $\begin{array}{r}\text { 95\% C.I. } \\
\text { Lower }\end{array}$ & $\begin{array}{r}\text { 95\% C.I. } \\
\text { Upper }\end{array}$ \\
\hline Ethanol Effect (E15 vs. E0) $(\Delta \mathrm{g} / \mathrm{mi})$ & -0.214 & -0.741 & 0.312 \\
\hline Ethanol Effect $(E 20 \mathrm{vs.} \mathrm{E0)}(\Delta \mathrm{g} / \mathrm{mi})$ & $-1.049^{*}$ & -1.554 & -0.544 \\
\hline Road Fuel Aging Effect & & & \\
\hline Aging Effect with RE0 $(\Delta \mathrm{g} / \mathrm{mi}$ per 100k mi) & $2.274^{*}$ & 0.937 & 3.611 \\
\hline Aging Effect with RE15 $(\Delta \mathrm{g} / \mathrm{mi}$ per 100k mi) & $4.729^{*}$ & 3.861 & 5.596 \\
\hline Aging Effect with RE20 $(\Delta \mathrm{g} / \mathrm{mi}$ per 100k mi) & $2.748^{*}$ & 1.929 & 3.566 \\
\hline
\end{tabular}

\begin{tabular}{|l|c|}
\hline \multicolumn{1}{|c|}{ Hypothesis } & -value \\
\hline No Effect of Ethanol in the Test Fuel (Gamma $=0)$ & $<0.01^{*}$ \\
\hline No Aging Effect with RE0 (Beta0 $=0$ ) & $<0.01^{*}$ \\
\hline No Effect of Ethanol in Road Fuel Aging (Beta1s $=0$ ) & $<0.01^{*}$ \\
\hline * Indicates effect is statistically significant at the $95 \%$ confidence level.
\end{tabular}

Initial odometers $41 \mathrm{k}-48 \mathrm{k}$

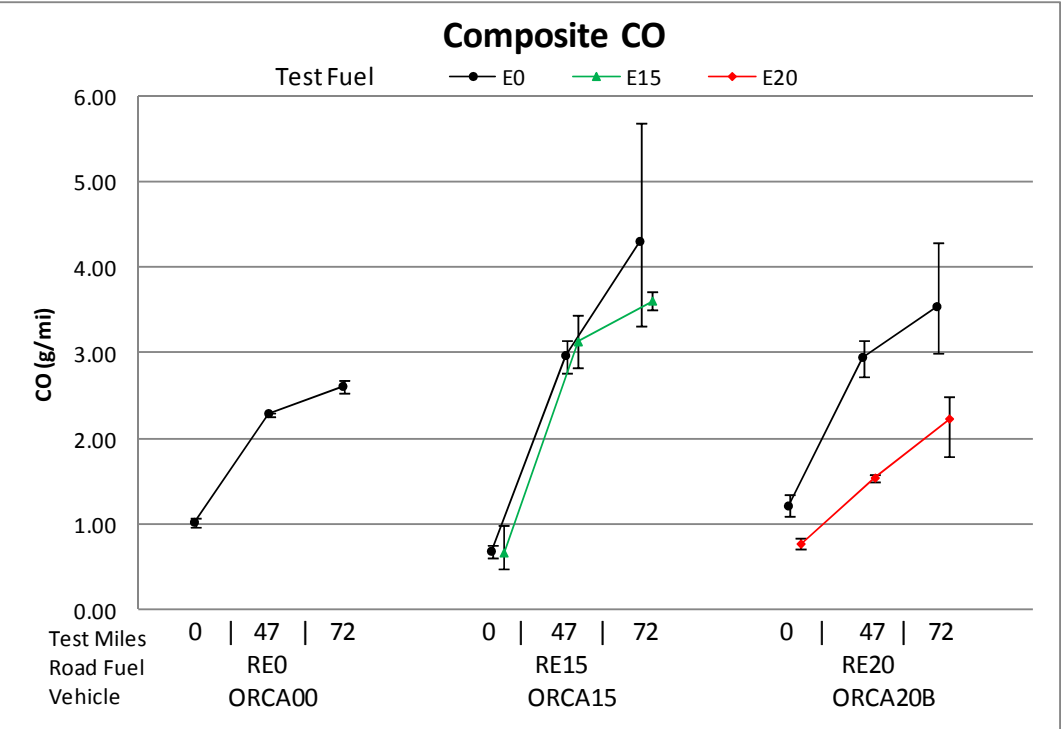

Error bars represent min and max measurements

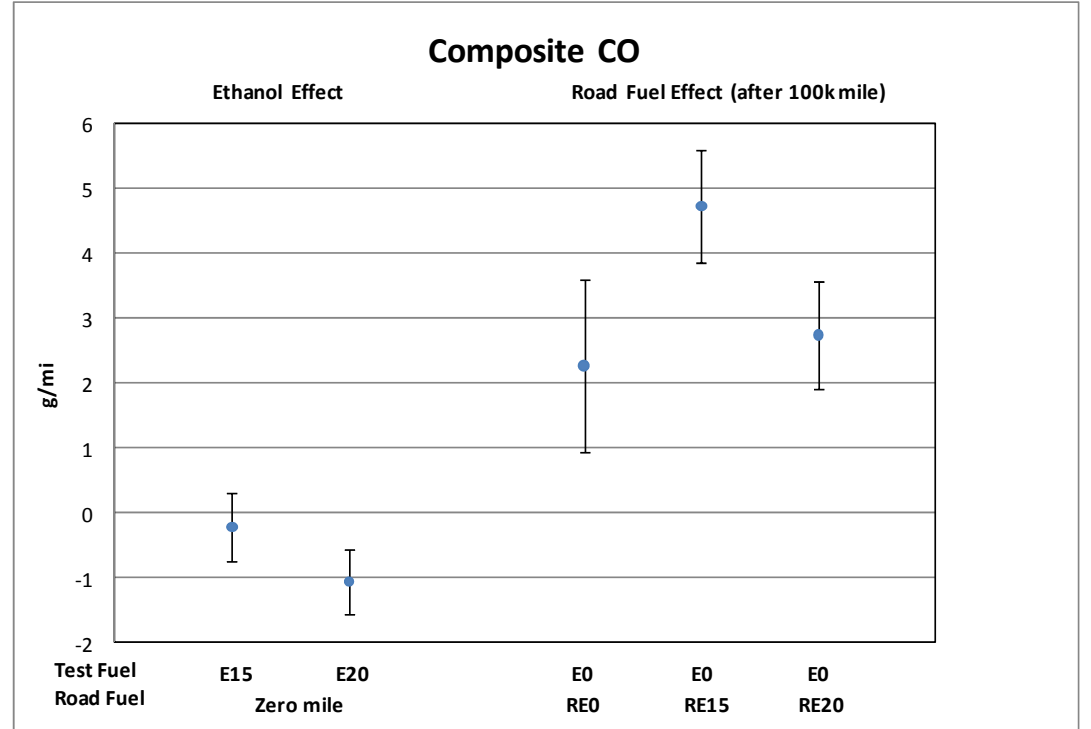

Error bars represent $95 \%$ confidence intervals on the estimated effects 
2007 Dodge Caliber (Composite NOx)

\begin{tabular}{|l|r|r|r|}
\hline \multicolumn{1}{|c|}{ Effect } & & $\begin{array}{r}95 \% \text { C.I. } \\
\text { Low }\end{array}$ & $\begin{array}{r}\text { 95 C.I. } \\
\text { Upper }\end{array}$ \\
\hline Ethanol Effect (E15 vs. E0) $(\Delta \mathrm{g} / \mathrm{mi})$ & 0.002 & -0.015 & 0.019 \\
\hline Ethanol Effect (E20 vs. E0) $(\Delta \mathrm{g} / \mathrm{mi})$ & 0.002 & -0.015 & 0.019 \\
\hline Road Fuel Aging Effect & & & \\
\hline Aging Effect with RE0 $(\Delta \mathrm{g} / \mathrm{mi}$ per 100k mi) & $0.057^{*}$ & 0.017 & 0.098 \\
\hline Aging Effect with RE15 $(\Delta \mathrm{g} / \mathrm{mi} \mathrm{per} \mathrm{100k} \mathrm{mi)}$ & $0.037^{*}$ & 0.008 & 0.066 \\
\hline Aging Effect with RE20 $(\Delta \mathrm{g} / \mathrm{mi}$ per 100k mi) & $0.045^{*}$ & 0.017 & 0.074 \\
\hline
\end{tabular}

\begin{tabular}{|l|r|}
\hline \multicolumn{1}{|c|}{ Hypothesis } & -value \\
\hline No Effect of Ethanol in the Test Fuel (Gamma = 0) & 0.92 \\
\hline No Aging Effect with RE0 (Beta0 = 0) & $0.01^{*}$ \\
\hline No Effect of Ethanol in Road Fuel Aging (Beta1s $=0$ ) & 0.65 \\
\hline * Indicates effect is statistically significant at the 95\% confidence level.
\end{tabular}

Initial odometers $41 \mathrm{k}-48 \mathrm{k}$

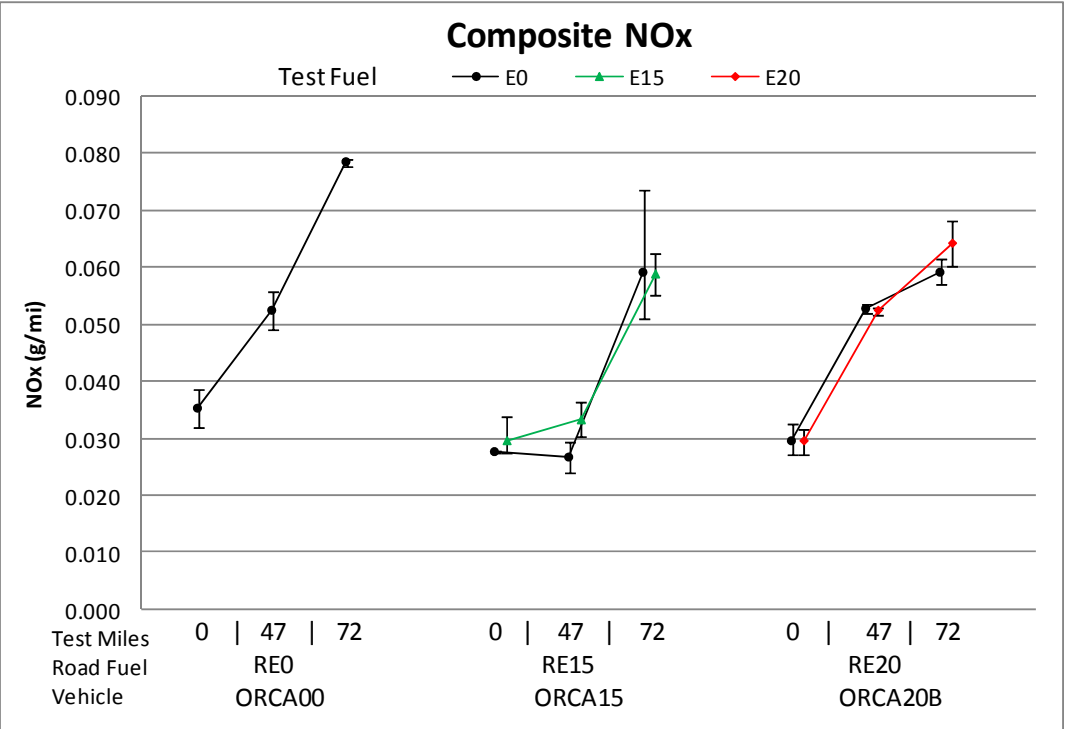

Error bars represent min and max measurements

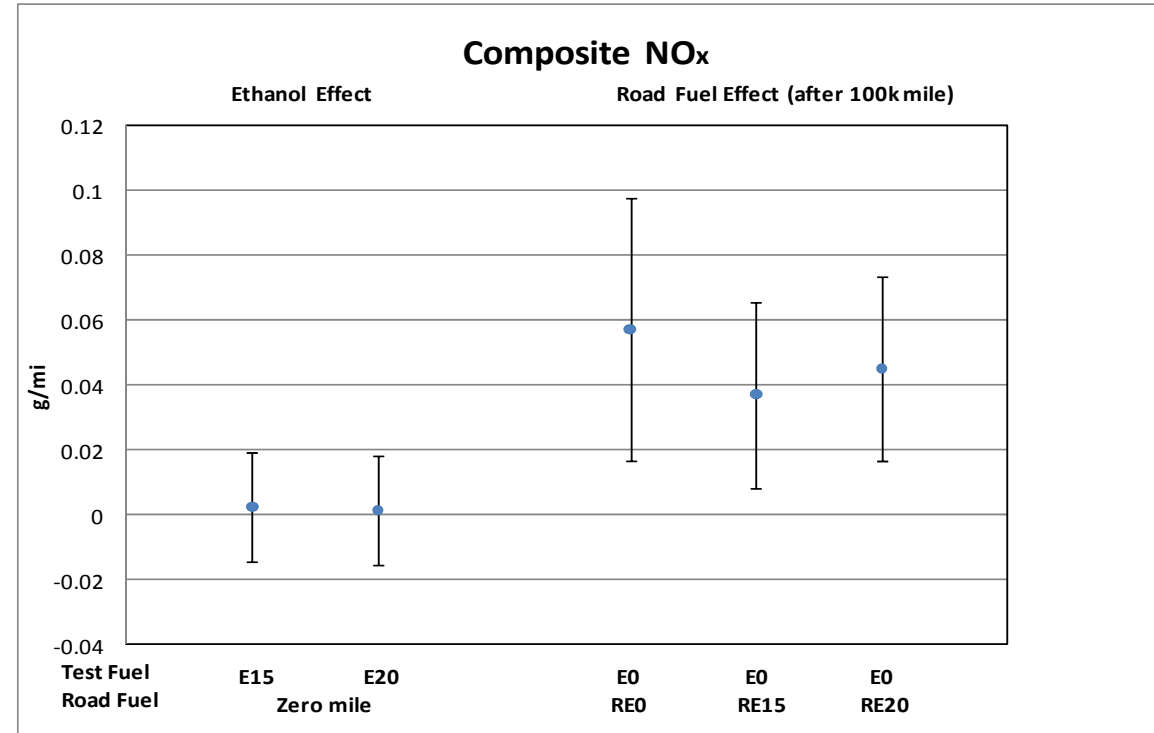

Error bars represent $95 \%$ confidence intervals on the estimated effects 
2007 Dodge Caliber (Composite Nonmethane Hydrocarbons)

\begin{tabular}{|l|r|r|r|}
\hline \multicolumn{1}{|c|}{ Effect } & Estimate & $\begin{array}{c}95 \% \text { C.I. } \\
\text { Lower }\end{array}$ & $\begin{array}{c}\text { 95\% C.I. } \\
\text { Upper }\end{array}$ \\
\hline Ethanol Effect (E15 vs. E0) $(\Delta \mathrm{g} / \mathrm{mi})$ & -0.0016 & -0.0102 & 0.0070 \\
\hline Ethanol Effect $($ E20 vs. E0) $(\Delta \mathrm{g} / \mathrm{mi})$ & $-0.0117^{*}$ & -0.0199 & -0.0035 \\
\hline Road Fuel Aging Effect & & & \\
\hline Aging Effect with RE0 $(\Delta \mathrm{g} / \mathrm{mi}$ per 100k mi) & $0.0416^{*}$ & 0.0198 & 0.0634 \\
\hline Aging Effect with RE15 $(\Delta \mathrm{g} / \mathrm{mi} \mathrm{per} \mathrm{100k} \mathrm{mi)}$ & $0.0437^{*}$ & 0.0295 & 0.0578 \\
\hline Aging Effect with RE20 $(\Delta \mathrm{g} / \mathrm{mi}$ per 100k mi) & $0.0289^{*}$ & 0.0156 & 0.0423 \\
\hline
\end{tabular}

\begin{tabular}{|l|r|}
\hline \multicolumn{1}{|c|}{ Hypothesis } & -value \\
\hline No Effect of Ethanol in the Test Fuel (Gamma $=0)$ & $0.02^{*}$ \\
\hline No Aging Effect with RE0 (Beta0 $=0$ ) & $<0.01^{*}$ \\
\hline No Effect of Ethanol in Road Fuel Aging (Beta1s $=0$ ) & 0.28 \\
\hline * Indicates effect is statistically significant at the 95\% confidence level.
\end{tabular}

* Indicates estimate is different from zero at the $95 \%$ confidence level.

Initial odometers $41 \mathrm{k}-48 \mathrm{k}$

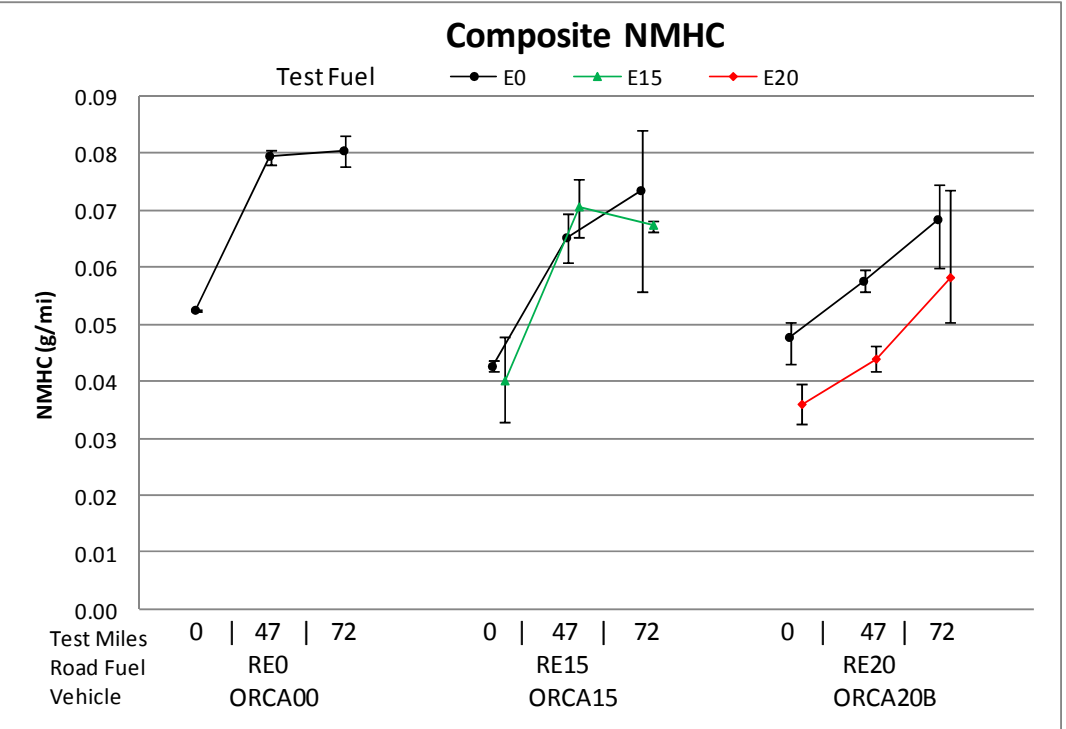

Error bars represent min and max measurements

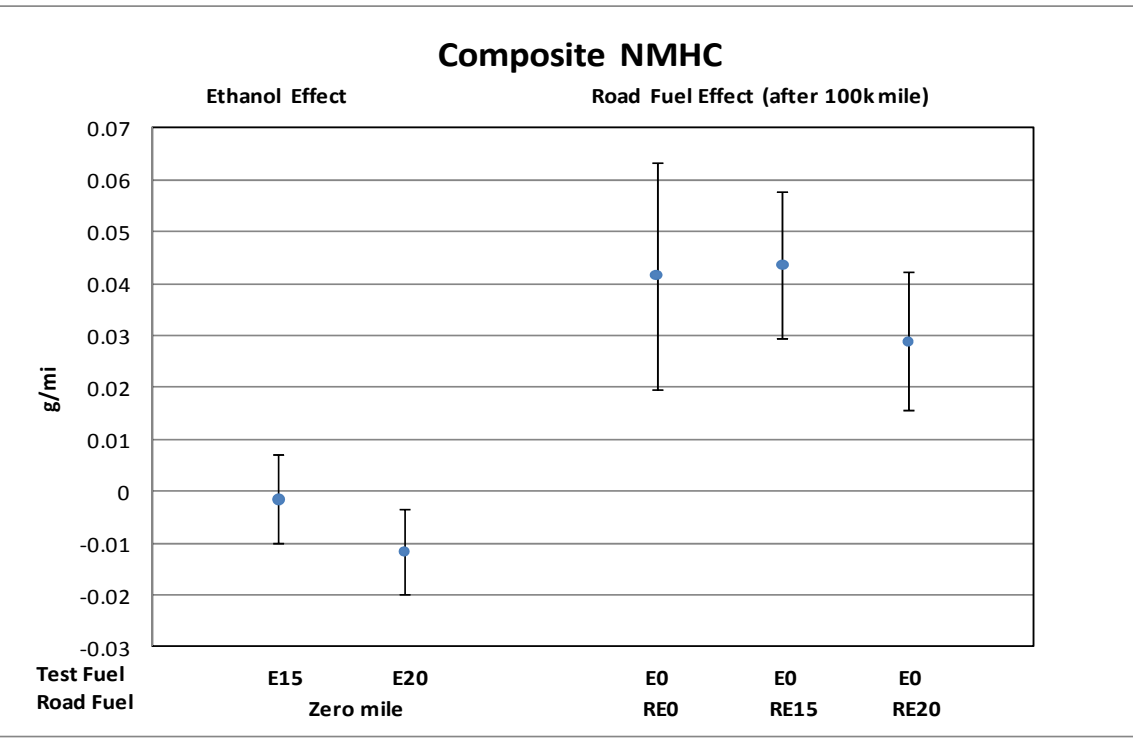

Error bars represent $95 \%$ confidence intervals on the estimated effects 
2007 Dodge Caliber (Composite Nonmethane Organic Gases)

\begin{tabular}{|l|r|r|r|}
\hline \multicolumn{1}{|c|}{ Effect } & Estimate & $\begin{array}{c}95 \% \text { C.I. } \\
\text { Lower }\end{array}$ & $\begin{array}{c}\text { 95\% C.I. } \\
\text { Upper }\end{array}$ \\
\hline Ethanol Effect (E15 vs. E0) $(\Delta \mathrm{g} / \mathrm{mi})$ & 0.0052 & -0.0059 & 0.0164 \\
\hline Ethanol Effect $($ E20 vs. E0) $(\Delta \mathrm{g} / \mathrm{mi})$ & -0.0046 & -0.0158 & 0.0067 \\
\hline Road Fuel Aging Effect & & & \\
\hline Aging Effect with RE0 $(\Delta \mathrm{g} / \mathrm{mi}$ per 100k mi) & $0.0428^{*}$ & 0.0158 & 0.0697 \\
\hline Aging Effect with RE15 $(\Delta \mathrm{g} / \mathrm{mi}$ per 100k mi) & $0.0471^{*}$ & 0.0281 & 0.0661 \\
\hline Aging Effect with RE20 $(\Delta \mathrm{g} / \mathrm{mi}$ per 100k mi) & $0.0322^{*}$ & 0.0130 & 0.0513 \\
\hline
\end{tabular}

\begin{tabular}{|l|r|}
\hline \multicolumn{1}{|c|}{ Hypothesis } & -value \\
\hline No Effect of Ethanol in the Test Fuel (Gamma = 0) & 0.38 \\
\hline No Aging Effect with RE0 (Beta0 $=0$ ) & $<0.01^{*}$ \\
\hline No Effect of Ethanol in Road Fuel Aging (Beta1s $=0$ ) & 0.41 \\
\hline * Indicates effect is statistically significant at the 95\% confidence level.
\end{tabular}

${ }^{*}$ Indicates estimate is different from zero at the $95 \%$ confidence level.

Initial odometers $41 \mathrm{k}-48 \mathrm{k}$

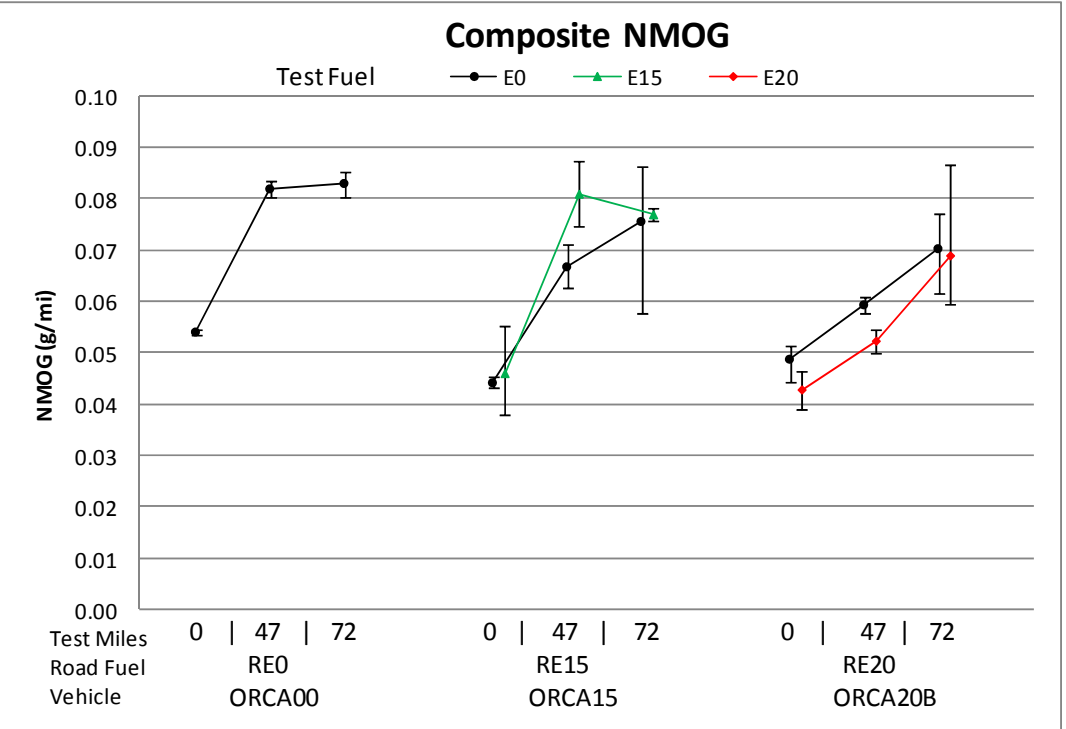

Error bars represent min and max measurements

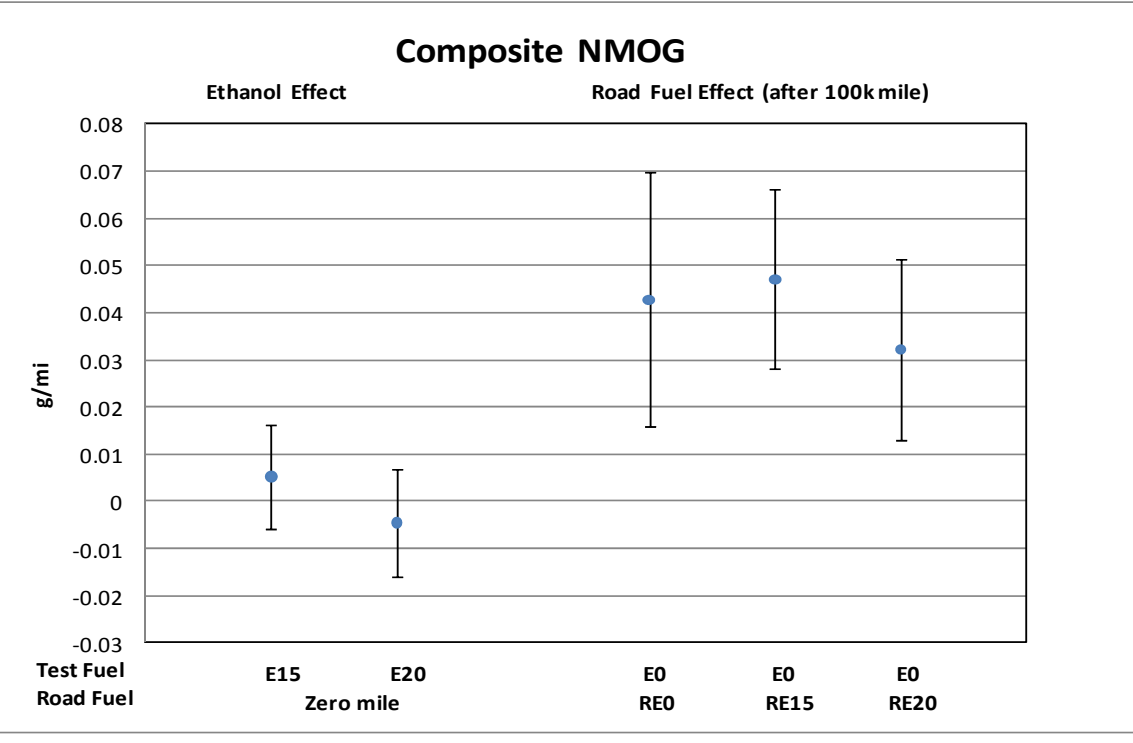

Error bars represent $95 \%$ confidence intervals on the estimated effects 
2007 Dodge Caliber (Composite Fuel Economy)

\begin{tabular}{|l|r|r|r|}
\hline \multicolumn{1}{|c|}{ Effect } & Estimate & $\begin{array}{r}\text { 95\% C.I. } \\
\text { Lower }\end{array}$ & $\begin{array}{r}\text { 95\% C.I. } \\
\text { Upper }\end{array}$ \\
\hline Ethanol Effect (E15 vs. E0) $(\Delta \mathrm{mi} / \mathrm{gal})$ & $-1.386^{*}$ & -1.788 & -0.984 \\
\hline Ethanol Effect (E20 vs. E0) $(\Delta \mathrm{mi} / \mathrm{gal})$ & $-1.774^{*}$ & -2.177 & -1.371 \\
\hline Road Fuel Aging Effect & & & \\
\hline Aging Effect with RE0 $(\Delta \mathrm{mi} /$ gal per 100k mi) & $0.994^{*}$ & 0.031 & 1.957 \\
\hline Aging Effect with RE15 $(\Delta \mathrm{mi} / \mathrm{gal}$ per 100k mi) & 0.288 & -0.394 & 0.970 \\
\hline Aging Effect with RE20 $(\Delta \mathrm{mi} /$ gal per 100k mi) & -0.131 & -0.808 & 0.545 \\
\hline
\end{tabular}

\begin{tabular}{|l|r|}
\hline \multicolumn{1}{|c|}{ Hypothesis } & p-value \\
\hline No Effect of Ethanol in the Test Fuel (Gamma = 0) & $<0.01^{*}$ \\
\hline No Aging Effect with RE0 (Beta0 $=0)$ & $0.04^{*}$ \\
\hline No Effect of Ethanol in Road Fuel Aging (Beta1s=0) & 0.15 \\
\hline${ }^{*}$ Indicates effect is statistically significant at the 95\% confidence level.
\end{tabular}

\begin{tabular}{ll}
-0.131 \\
\hline
\end{tabular}

Initial odometers $41 \mathrm{k}-48 \mathrm{k}$

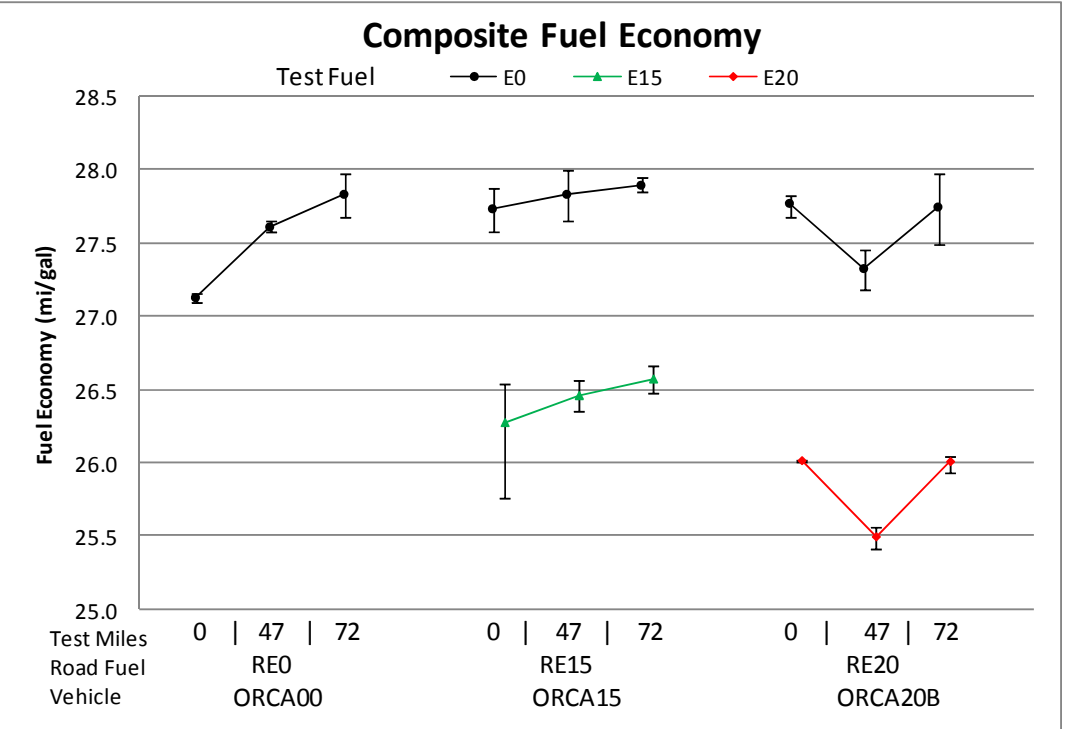

Error bars represent min and max measurements

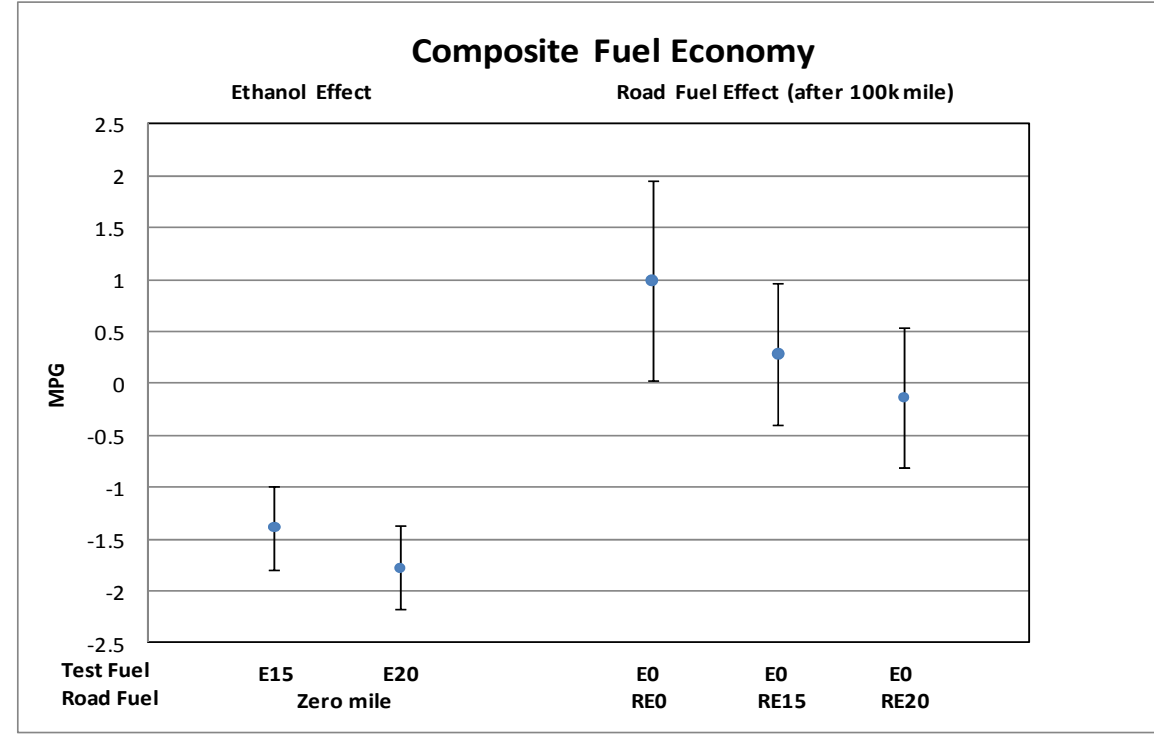

Error bars represent $95 \%$ confidence intervals on the estimated effects 
2007 Dodge Caliber (Composite Ethanol)

\begin{tabular}{|l|r|r|r|}
\hline \multicolumn{1}{|c|}{ Effect } & Estimate & $\begin{array}{r}\text { 95\% C.I. } \\
\text { Lower }\end{array}$ & $\begin{array}{r}\text { 95\% C.I. } \\
\text { Upper }\end{array}$ \\
\hline Ethanol Effect (E15 vs. E0) $(\Delta \mathrm{mg} / \mathrm{mi})$ & $3.888^{*}$ & 2.243 & 5.534 \\
\hline Ethanol Effect $($ E20 vs. E0) $(\Delta \mathrm{mg} / \mathrm{mi})$ & $4.307^{*}$ & 2.652 & 5.963 \\
\hline Road Fuel Aging Effect & & & \\
\hline Aging Effect with RE0 $(\Delta \mathrm{mg} / \mathrm{mi}$ per 100k mi) & -0.056 & -4.013 & 3.900 \\
\hline Aging Effect with RE15 $(\Delta \mathrm{mg} / \mathrm{mi}$ per 100k mi) & -0.100 & -2.922 & 2.723 \\
\hline Aging Effect with RE20 $(\Delta \mathrm{mg} / \mathrm{mi}$ per 100k mi) & 2.298 & -0.538 & 5.135 \\
\hline
\end{tabular}

\begin{tabular}{|l|r|}
\hline \multicolumn{1}{|c|}{ Hypothesis } & p-value \\
\hline No Effect of Ethanol in the Test Fuel (Gamma = 0) & $<0.01^{*}$ \\
\hline No Aging Effect with RE0 (Beta0 $=0)$ & 0.97 \\
\hline No Effect of Ethanol in Road Fuel Aging (Beta1s=0) & 0.30 \\
\hline${ }^{*}$ Indicates effect is statistically significant at the 95\% confidence level.
\end{tabular}

\begin{tabular}{l|l}
\hline & 2.298 \\
\hline
\end{tabular}

Initial odometers $41 \mathrm{k}-48 \mathrm{k}$

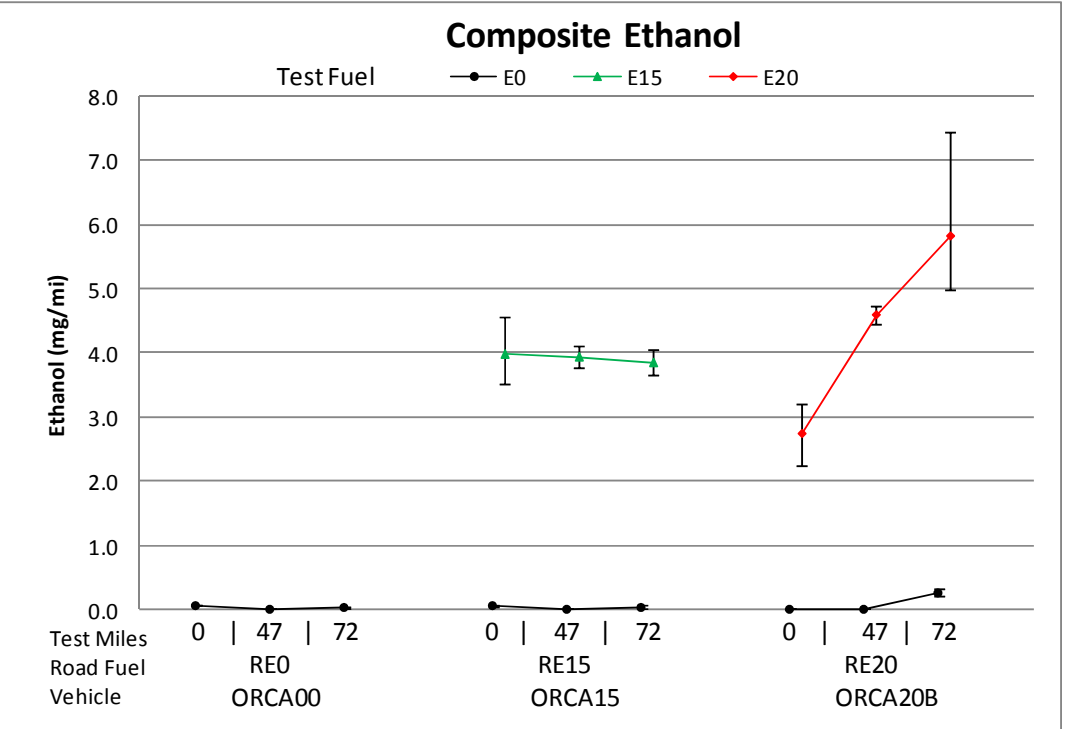

Error bars represent min and max measurements

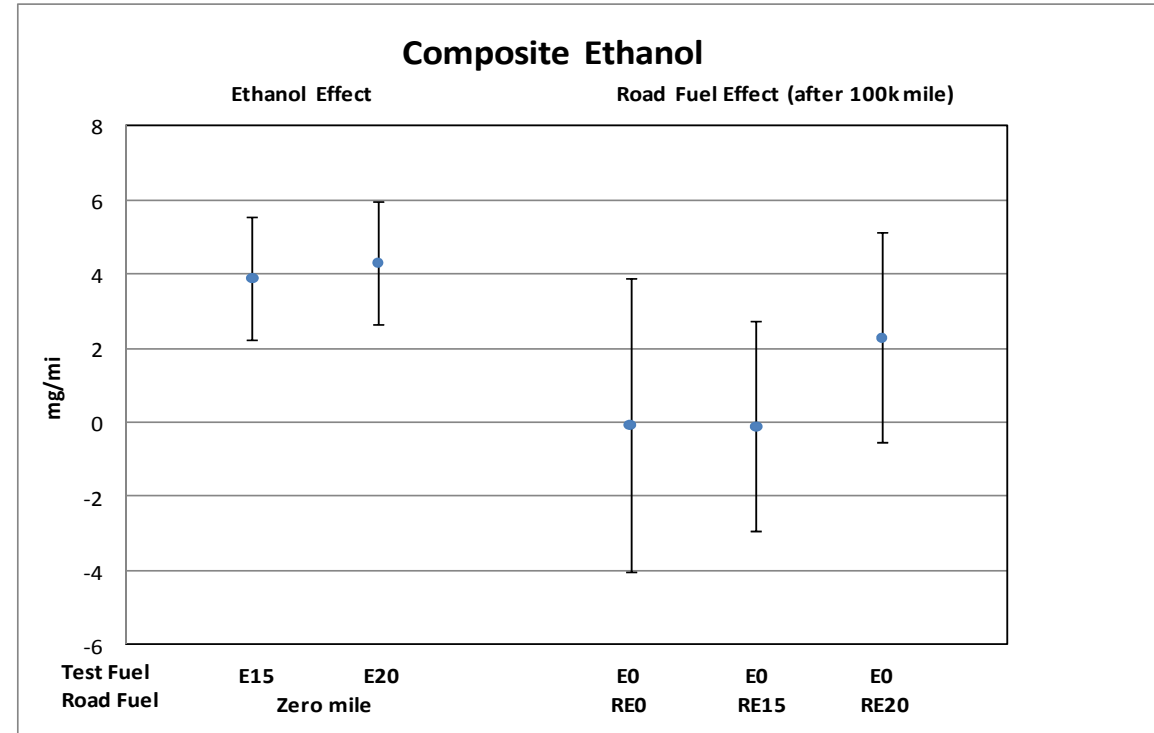

Error bars represent $95 \%$ confidence intervals on the estimated effects 
2007 Dodge Caliber (Composite Acetaldehyde)

\begin{tabular}{|l|r|r|r|}
\hline \multicolumn{1}{|c|}{ Effect } & Estimate & $\begin{array}{r}\text { 95\% C.I. } \\
\text { Lower }\end{array}$ & $\begin{array}{r}\text { 95\% C.I. } \\
\text { Upper }\end{array}$ \\
\hline Ethanol Effect (E15 vs. E0) $(\Delta \mathrm{mg} / \mathrm{mi})$ & $0.820^{*}$ & 0.560 & 1.080 \\
\hline Ethanol Effect (E20 vs. E0) $(\Delta \mathrm{mg} / \mathrm{mi})$ & $1.111^{*}$ & 0.779 & 1.443 \\
\hline Road Fuel Aging Effect & & & \\
\hline Aging Effect with RE0 $(\Delta \mathrm{mg} / \mathrm{mi}$ per 100k mi) & 0.155 & -0.033 & 0.344 \\
\hline Aging Effect with RE15 $(\Delta \mathrm{mg} / \mathrm{mi}$ per 100k mi) & $0.201^{*}$ & 0.056 & 0.346 \\
\hline Aging Effect with RE20 $(\Delta \mathrm{mg} / \mathrm{mi}$ per 100k mi) & $0.152^{*}$ & 0.030 & 0.275 \\
\hline
\end{tabular}

\begin{tabular}{|l|r|}
\hline \multicolumn{1}{|c|}{ Hypothesis } & -value \\
\hline No Effect of Ethanol in the Test Fuel (Gamma = 0) & $<0.01^{*}$ \\
\hline No Aging Effect with RE0 (Beta0 $=0$ ) & 0.12 \\
\hline No Effect of Ethanol in Road Fuel Aging (Beta1s $=0$ ) & 0.85 \\
\hline * Indicates effect is statistically significant at the 95\% confidence level.
\end{tabular}

\begin{tabular}{l|l} 
& $0.152^{2}$ \\
\hline
\end{tabular}

Initial odometers $41 \mathrm{k}-48 \mathrm{k}$

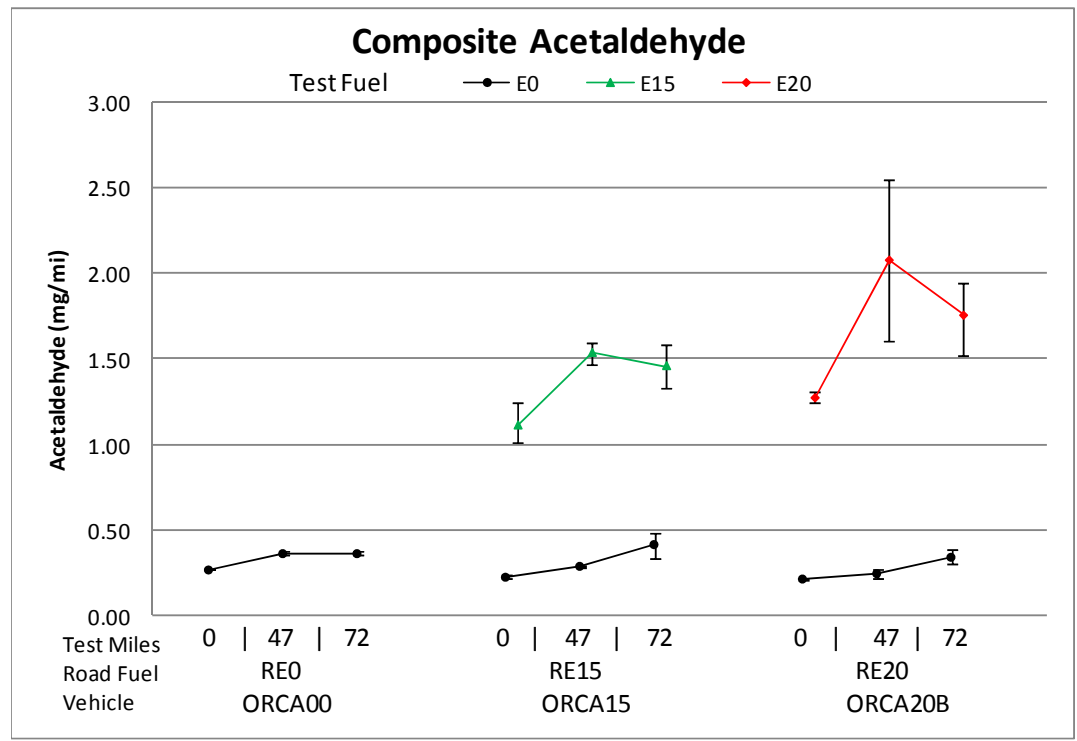

Error bars represent min and max measurements

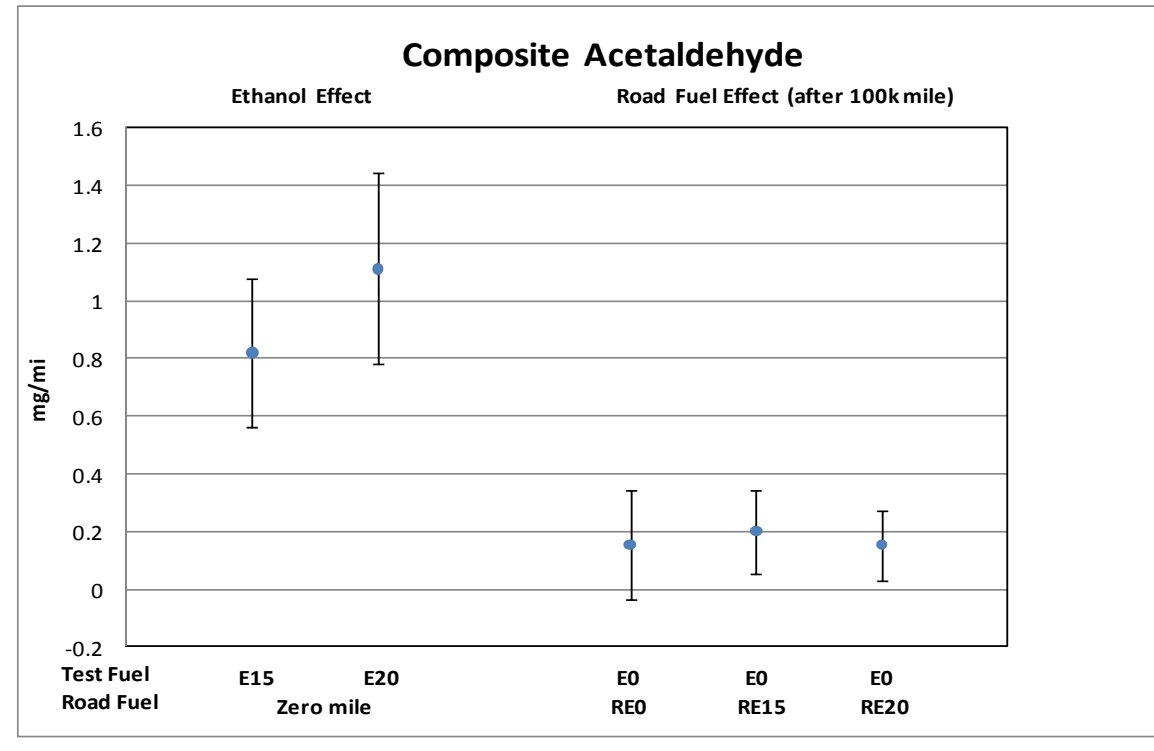

Error bars represent $95 \%$ confidence intervals on the estimated effects 
2007 Dodge Caliber (Composite Formaldehyde)

\begin{tabular}{|l|r|r|r|}
\hline \multicolumn{1}{|c|}{ Effect } & & $\begin{array}{r}95 \% \text { C.I. } \\
\text { Low }\end{array}$ & $\begin{array}{r}\text { 95 C.I. } \\
\text { Upper }\end{array}$ \\
\hline Ethanol Effect (E15 vs. E0) $(\Delta \mathrm{mg} / \mathrm{mi})$ & 0.086 & -0.233 & 0.404 \\
\hline Ethanol Effect (E20 vs. E0) $(\Delta \mathrm{mg} / \mathrm{mi})$ & 0.151 & -0.119 & 0.422 \\
\hline Road Fuel Aging Effect & & & \\
\hline Aging Effect with RE0 $(\Delta \mathrm{mg} / \mathrm{mi} \mathrm{per} \mathrm{100k} \mathrm{mi)}$ & 0.530 & -0.199 & 1.258 \\
\hline Aging Effect with RE15 $(\Delta \mathrm{mg} / \mathrm{mi}$ per 100k mi) & $0.520^{*}$ & 0.007 & 1.033 \\
\hline Aging Effect with RE20 $(\Delta \mathrm{mg} / \mathrm{mi}$ per 100k mi) & $0.433^{*}$ & 0.024 & 0.843 \\
\hline
\end{tabular}

\begin{tabular}{|l|r|}
\hline \multicolumn{1}{|c|}{ Hypothesis } & p-value \\
\hline No Effect of Ethanol in the Test Fuel (Gamma = 0) & 0.17 \\
\hline No Aging Effect with RE0 (Beta0 = 0) & 0.15 \\
\hline No Effect of Ethanol in Road Fuel Aging (Beta1s=0) & 0.98 \\
\hline${ }^{*}$ Indicates effect is statistically significant at the 95\% confidence level.
\end{tabular}

Initial odometers $41 \mathrm{k}-48 \mathrm{k}$

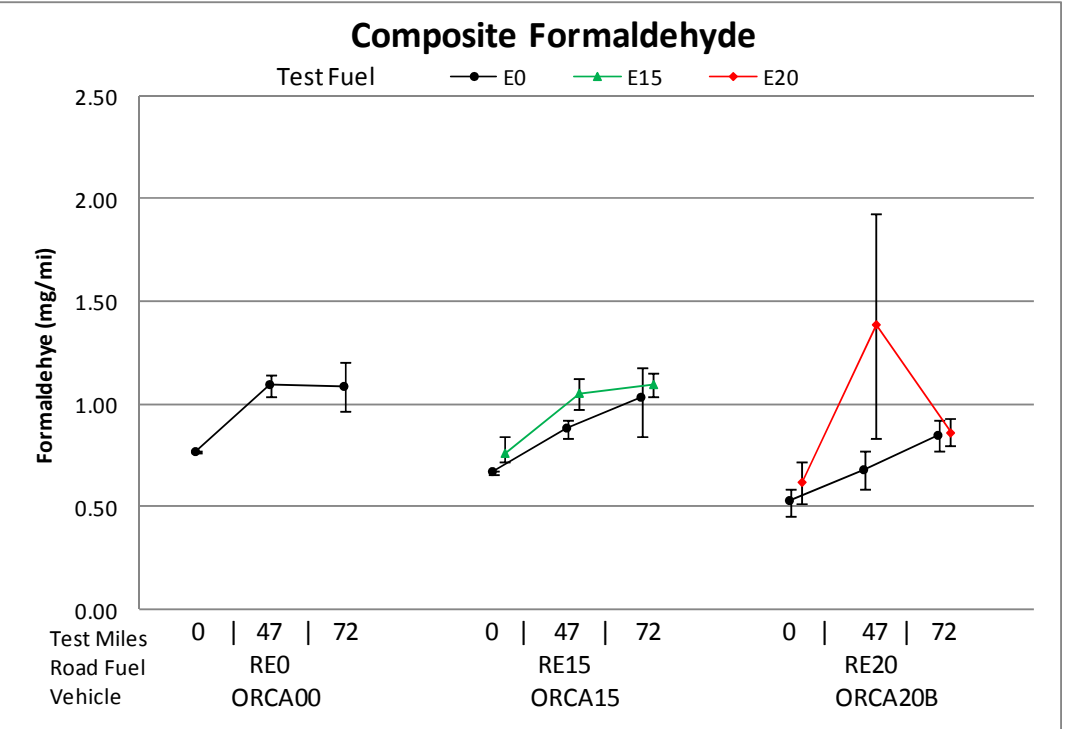

Error bars represent min and max measurements

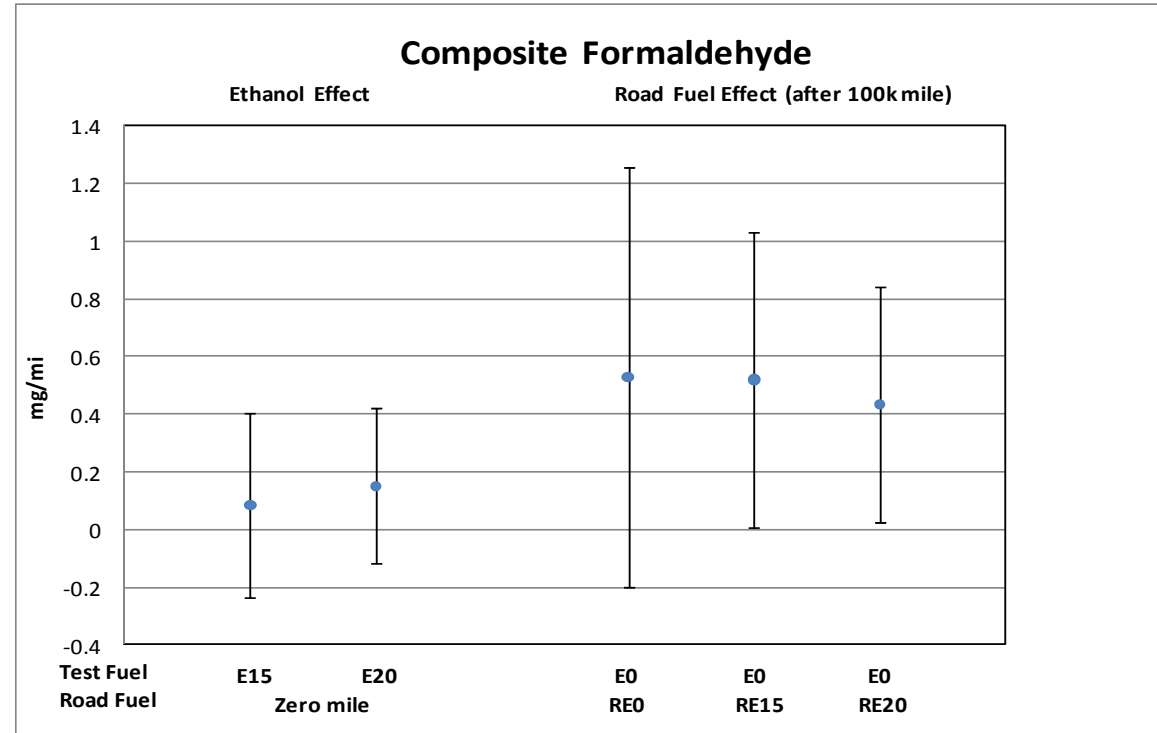

Error bars represent $95 \%$ confidence intervals on the estimated effects 
2007 Dodge Caliber (Composite $\mathrm{CH} 4$ )

\begin{tabular}{|l|r|r|r|}
\hline \multicolumn{1}{|c|}{ Effect } & Estimate & $\begin{array}{c}95 \% \text { C.I. } \\
\text { Lower }\end{array}$ & $\begin{array}{c}\text { 95\% C.I. } \\
\text { Upper }\end{array}$ \\
\hline Ethanol Effect (E15 vs. E0) $(\Delta \mathrm{g} / \mathrm{mi})$ & -0.0002 & -0.0091 & 0.0086 \\
\hline Ethanol Effect $(E 20 \mathrm{vs.} \mathrm{E0)}(\Delta \mathrm{g} / \mathrm{mi})$ & -0.0018 & -0.0107 & 0.0070 \\
\hline Road Fuel Aging Effect & & & \\
\hline Aging Effect with RE0 $(\Delta \mathrm{g} / \mathrm{mi}$ per 100k mi) & $0.0268^{*}$ & 0.0056 & 0.0480 \\
\hline Aging Effect with RE15 $(\Delta \mathrm{g} / \mathrm{mi} \mathrm{per} \mathrm{100k} \mathrm{mi)}$ & $0.0402^{*}$ & 0.0252 & 0.0553 \\
\hline Aging Effect with RE20 $(\Delta \mathrm{g} / \mathrm{mi}$ per 100k mi) & $0.0254^{*}$ & 0.0104 & 0.0403 \\
\hline
\end{tabular}

\begin{tabular}{|l|r|}
\hline \multicolumn{1}{|c|}{ Hypothesis } & -value \\
\hline No Effect of Ethanol in the Test Fuel (Gamma = 0) & 0.89 \\
\hline No Aging Effect with RE0 (Beta0 = 0) & $0.02^{*}$ \\
\hline No Effect of Ethanol in Road Fuel Aging (Beta1s $=0$ ) & 0.27 \\
\hline * Indicates effect is statistically significant at the 95\% confidence level.
\end{tabular}

* Indicates estimate is different from zero at the $95 \%$ confidence level.

Initial odometers $41 \mathrm{k}-48 \mathrm{k}$

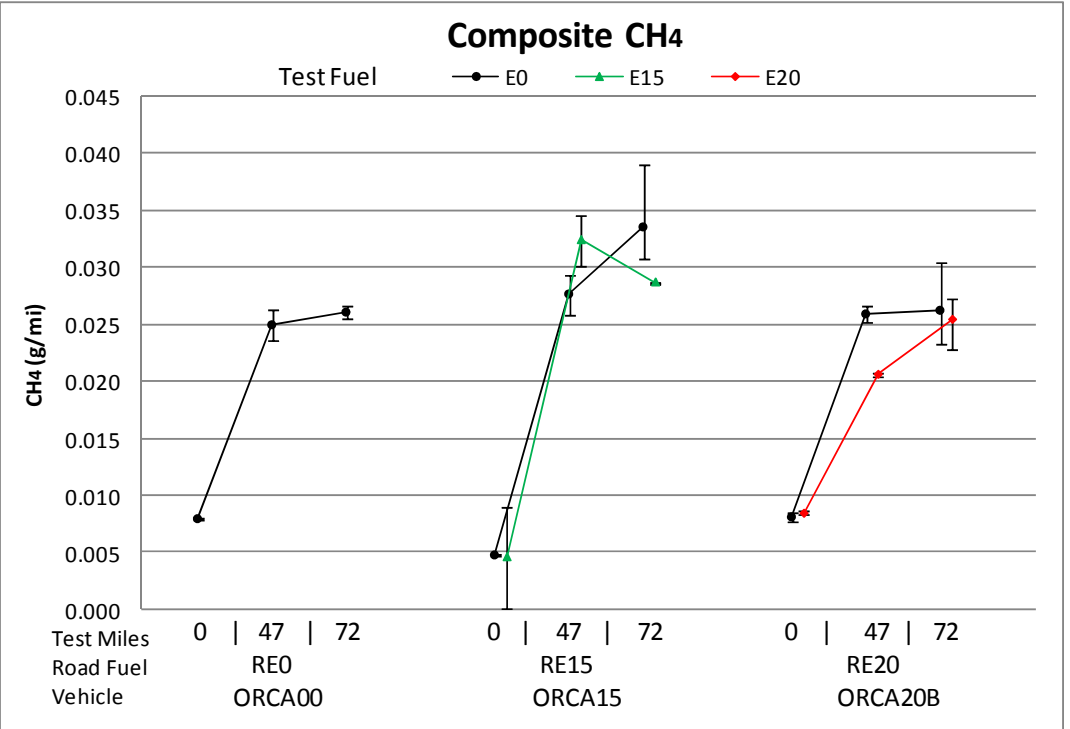

Error bars represent min and max measurements

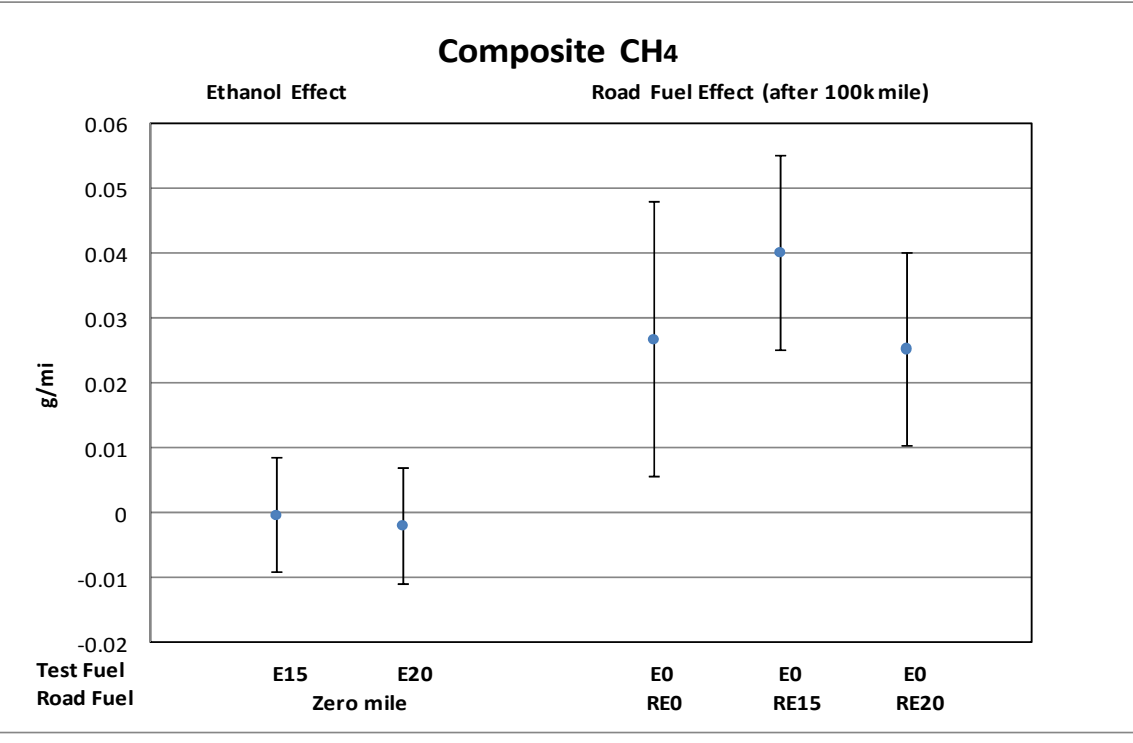

Error bars represent $95 \%$ confidence intervals on the estimated effects 


\section{Jeep Liberty - Composite Emissions Summary}

\begin{tabular}{|c|c|c|c|c|c|c|c|c|c|c|c|c|c|c|}
\hline \multirow{3}{*}{$\begin{array}{l}\begin{array}{c}\text { Emisssion Parameter } \\
\text { (units) }\end{array} \\
\text { Fuels } \\
\end{array}$} & \multicolumn{4}{|c|}{ Ethanol Effect } & \multicolumn{2}{|c|}{ Aging Effect with REO } & \multicolumn{4}{|c|}{ RExx Aging Effect on E0 Emissions } & \multirow{2}{*}{\multicolumn{3}{|c|}{$\begin{array}{c}\text { RExx Aging Effect on Exx Emissions } \\
\Delta \text { units per } 100 \mathrm{~K} \mathrm{mi} \\
\end{array}$}} & \multirow{3}{*}{\begin{tabular}{|c|}
$\begin{array}{c}\text { Road and Test } \\
\text { Fuel Effects } \\
\text { are Additive }\end{array}$ \\
$\begin{array}{c}\text { Overall p- } \\
\text { value }\end{array}$ \\
\end{tabular}} \\
\hline & \multicolumn{3}{|c|}{$\Delta$ units vs. EO } & \multirow{2}{*}{$\mid \begin{array}{c}\text { Overall } \\
p \text {-value }\end{array}$} & \multirow{2}{*}{$\frac{\Delta \text { units per } 100 \mathrm{~K} \mathrm{mi}}{\mathrm{REO} / \mathrm{EO}}$} & \multirow{2}{*}{$\begin{array}{l}\text { Overall } \\
p \text {-value }\end{array}$} & \multicolumn{3}{|c|}{$\Delta$ units per $100 \mathrm{~K} \mathrm{mi}$} & \multirow{2}{*}{$\begin{array}{l}\text { Overall } \\
p \text {-value }\end{array}$} & & & & \\
\hline & E10 & E15 & E20 & & & & RE10/E0 & RE15/E0 & RE20/E0 & & RE10/E10 & RE15/E15 & RE20/E20 & \\
\hline $\mathrm{CO}(\mathrm{g} / \mathrm{mi})$ & NA & -0.176 & -0.324 & 0.23 & 0.223 & 0.46 & $\mathrm{NA}$ & 0.579* & 0.445 & 0.62 & $\mathrm{NA}$ & NA & $\mathrm{NA}$ & 0.08 \\
\hline $\mathrm{NOx}(\mathrm{g} / \mathrm{mi})$ & NA & $-0.009 *$ & -0.005 & $0.03 *$ & $0.034^{*}$ & $<0.01^{*}$ & $\mathrm{NA}$ & $0.035 *$ & $0.035^{*}$ & 0.98 & $\mathrm{NA}$ & NA & $\mathrm{NA}$ & 0.31 \\
\hline $\mathrm{NMHC}(\mathrm{g} / \mathrm{mi})$ & NA & -0.011 & -0.019 & 0.11 & -0.000 & 0.99 & $\mathrm{NA}$ & -0.003 & 0.011 & 0.58 & $\mathrm{NA}$ & NA & $\mathrm{NA}$ & 0.11 \\
\hline NMOG (g/mi) & NA & -0.006 & -0.014 & 0.37 & 0.000 & 1.00 & $\mathrm{NA}$ & -0.003 & 0.011 & 0.59 & $\mathrm{NA}$ & NA & $\mathrm{NA}$ & 0.14 \\
\hline \begin{tabular}{|l|} 
Fuel Econ (mi/gal) \\
\end{tabular} & NA & $-0.858 *$ & $-1.086 *$ & $<0.01 *$ & 0.848 & 0.06 & $N A$ & $0.787 *$ & $0.768 *$ & 0.99 & $\mathrm{NA}$ & $\mathrm{NA}$ & $\mathrm{NA}$ & 0.80 \\
\hline Acetaldehyde $(\mathrm{mg} / \mathrm{mi})^{\#}$ & $N A$ & $0.586 *$ & $0.664 *$ & $<0.01 *$ & 0.018 & 0.73 & $\mathrm{NA}$ & -0.042 & -0.022 & 0.67 & $\mathrm{NA}$ & $\mathrm{NA}$ & $\mathrm{NA}$ & 0.50 \\
\hline Formaldehyde $(\mathrm{mg} / \mathrm{mi})^{\#}$ & NA & 0.061 & 0.035 & 0.96 & 0.092 & 0.79 & $\mathrm{NA}$ & -0.022 & 0.154 & 0.90 & $\mathrm{NA}$ & NA & $\mathrm{NA}$ & 0.98 \\
\hline $\mathrm{CH}_{4}(\mathrm{~g} / \mathrm{mi})$ & NA & -0.0007 & -0.0004 & 0.60 & $0.0038^{*}$ & $0.02 *$ & $\mathrm{NA}$ & $0.0080^{*}$ & $0.0046 *$ & 0.03 & $\mathrm{NA}$ & NA & $\mathrm{NA}$ & 0.16 \\
\hline
\end{tabular}

\# Log-normal model was used. Results are presented as changes in emissions at 0k mile.

\#\# Data did not support the assumption of linear effects with mileage.

*Indicates estimate is different from zero at the $95 \%$ confidence level. 
2009 Jeep Liberty (Composite CO)

\begin{tabular}{|c|c|c|c|}
\hline Effect & Estimate & $\begin{array}{l}95 \% \text { C.I. } \\
\text { Lower }\end{array}$ & \begin{tabular}{|c|}
$95 \%$ C.I. \\
Upper \\
\end{tabular} \\
\hline Ethanol Effect (E15 vs. E0) $(\Delta \mathrm{g} / \mathrm{mi})$ & -0.176 & -0.635 & 0.283 \\
\hline Ethanol Effect (E20 vs. E0) $(\Delta \mathrm{g} / \mathrm{mi})$ & -0.324 & -0.783 & 0.136 \\
\hline \multicolumn{4}{|l|}{ Road Fuel Aging Effect } \\
\hline Aging Effect with RE0 ( $\Delta \mathrm{g} / \mathrm{mi}$ per $100 \mathrm{k} \mathrm{mi})$ & 0.223 & -0.466 & 0.913 \\
\hline Aging Effect with RE15 ( $\Delta \mathrm{g} / \mathrm{mi}$ per $100 \mathrm{k} \mathrm{mi})$ & $0.579^{*}$ & 0.091 & 1.067 \\
\hline Aging Effect with RE20 ( $\Delta \mathrm{g} / \mathrm{mi}$ per $100 \mathrm{k} \mathrm{mi})$ & 0.445 & -0.044 & 0.934 \\
\hline
\end{tabular}

\begin{tabular}{|l|r|}
\hline \multicolumn{1}{|c|}{ Hypothesis } & p-value \\
\hline No Effect of Ethanol in the Test Fuel (Gamma = 0) & 0.23 \\
\hline No Aging Effect with RE0 (Beta0 = 0) & 0.46 \\
\hline No Effect of Ethanol in Road Fuel Aging (Beta1s=0) & 0.62 \\
\hline
\end{tabular}

* Indicates estimate is different from zero at the $95 \%$ confidence level.

Initial Odometers 4k

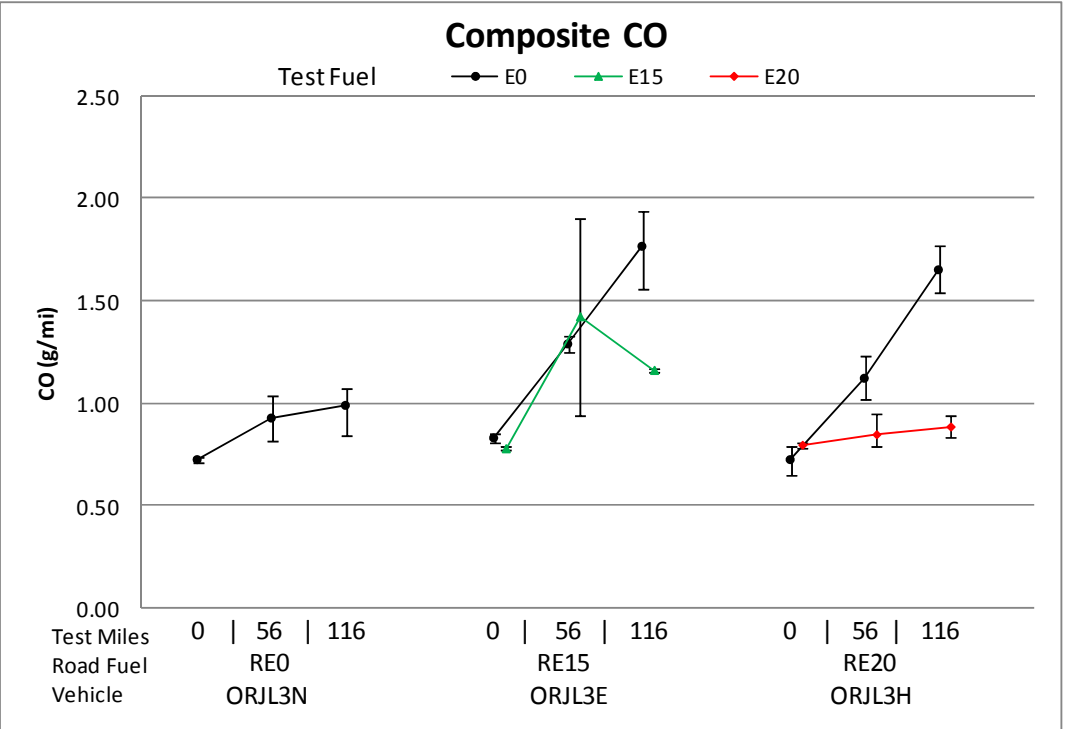

Error bars represent min and max measurements

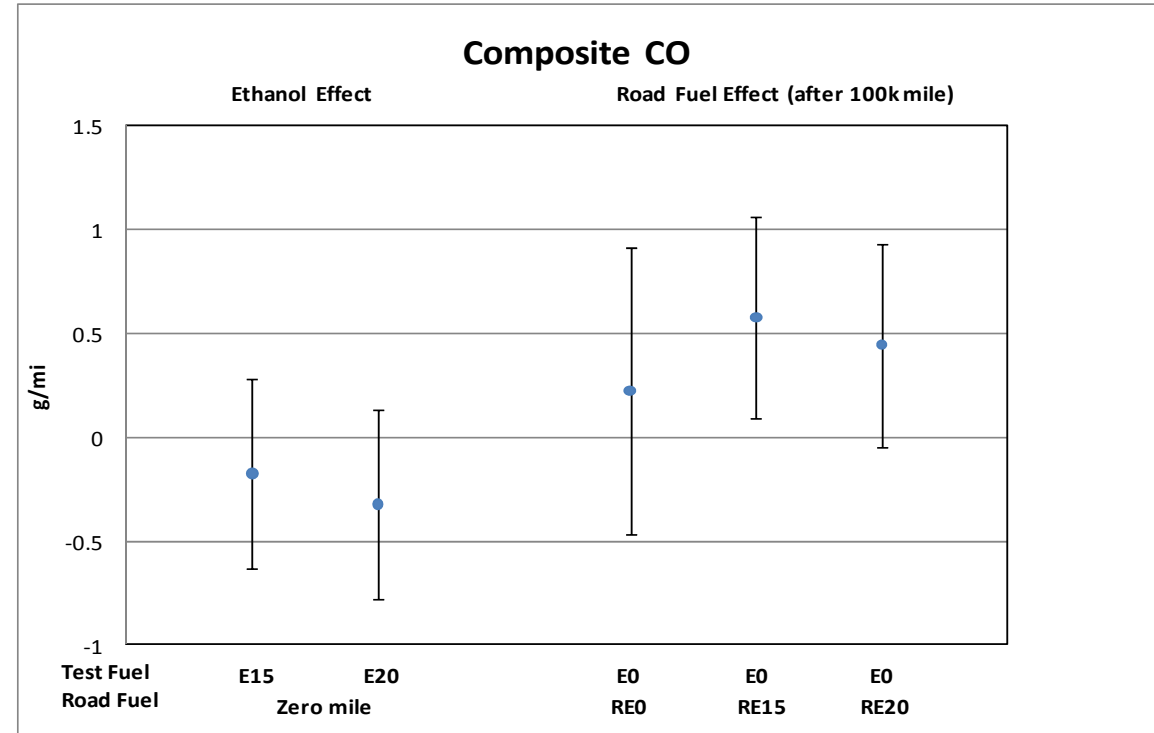

Error bars represent $95 \%$ confidence intervals on the estimated effects 
2009 Jeep Liberty (Composite NOx)

\begin{tabular}{|l|r|r|r|}
\hline \multicolumn{1}{|c|}{ Effect } & Estimate & $\begin{array}{c}\text { 95\% C.I. } \\
\text { Lower }\end{array}$ & $\begin{array}{r}\text { 95\% C.I. } \\
\text { Upper }\end{array}$ \\
\hline Ethanol Effect (E15 vs. E0) $(\Delta \mathrm{g} / \mathrm{mi})$ & $-0.009^{*}$ & -0.016 & -0.001 \\
\hline Ethanol Effect $($ E20 vs. E0) $(\Delta \mathrm{g} / \mathrm{mi})$ & -0.005 & -0.012 & 0.002 \\
\hline Road Fuel Aging Effect & & & \\
\hline Aging Effect with RE0 $(\Delta \mathrm{g} / \mathrm{mi}$ per 100k mi) & $0.034^{*}$ & 0.024 & 0.044 \\
\hline Aging Effect with RE15 $(\Delta \mathrm{g} / \mathrm{mi} \mathrm{per} \mathrm{100k} \mathrm{mi)}$ & $0.035^{*}$ & 0.028 & 0.042 \\
\hline Aging Effect with RE20 $(\Delta \mathrm{g} / \mathrm{mi}$ per 100k mi) & $0.035^{*}$ & 0.027 & 0.043 \\
\hline
\end{tabular}

\begin{tabular}{|l|r|}
\hline \multicolumn{1}{|c|}{ Hypothesis } & p-value \\
\hline No Effect of Ethanol in the Test Fuel (Gamma $=0)$ & $0.03^{*}$ \\
\hline No Aging Effect with RE0 (Beta0 = 0) & $<0.01^{*}$ \\
\hline No Effect of Ethanol in Road Fuel Aging (Beta1s=0) & 0.98 \\
\hline * Indicates effect is statistically significant at the 95\% confidence level.
\end{tabular}

${ }^{*}$ Indicates estimate is different from zero at the $95 \%$ confidence level.

Initial Odometers 4k

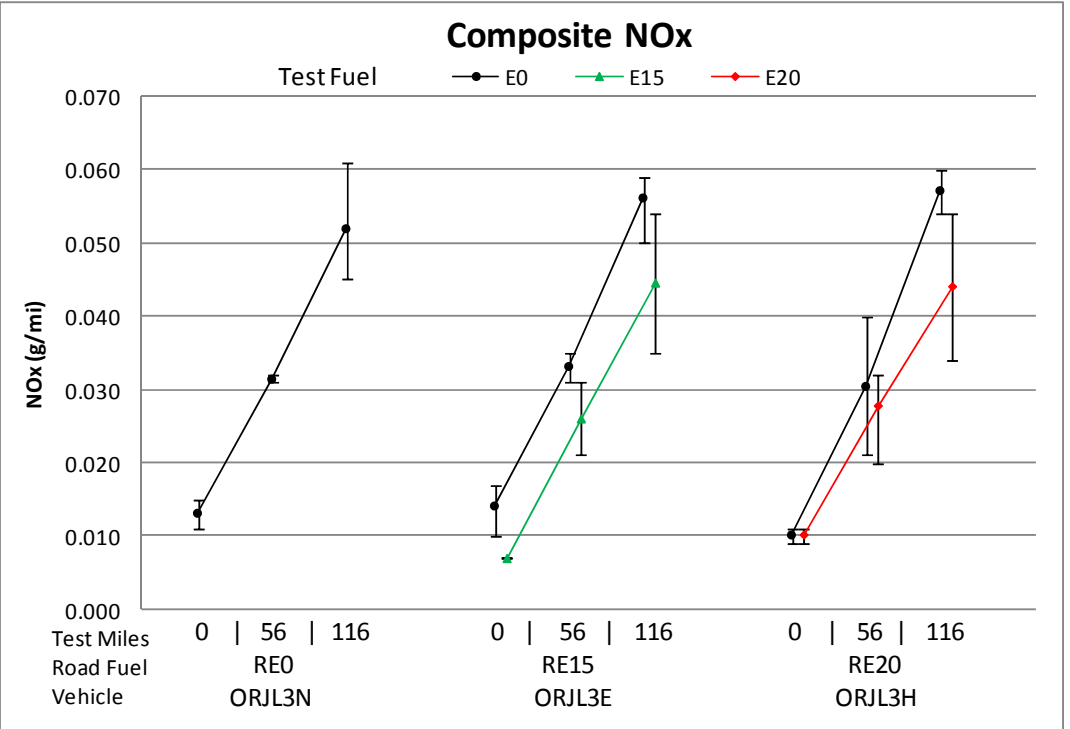

Error bars represent min and max measurements

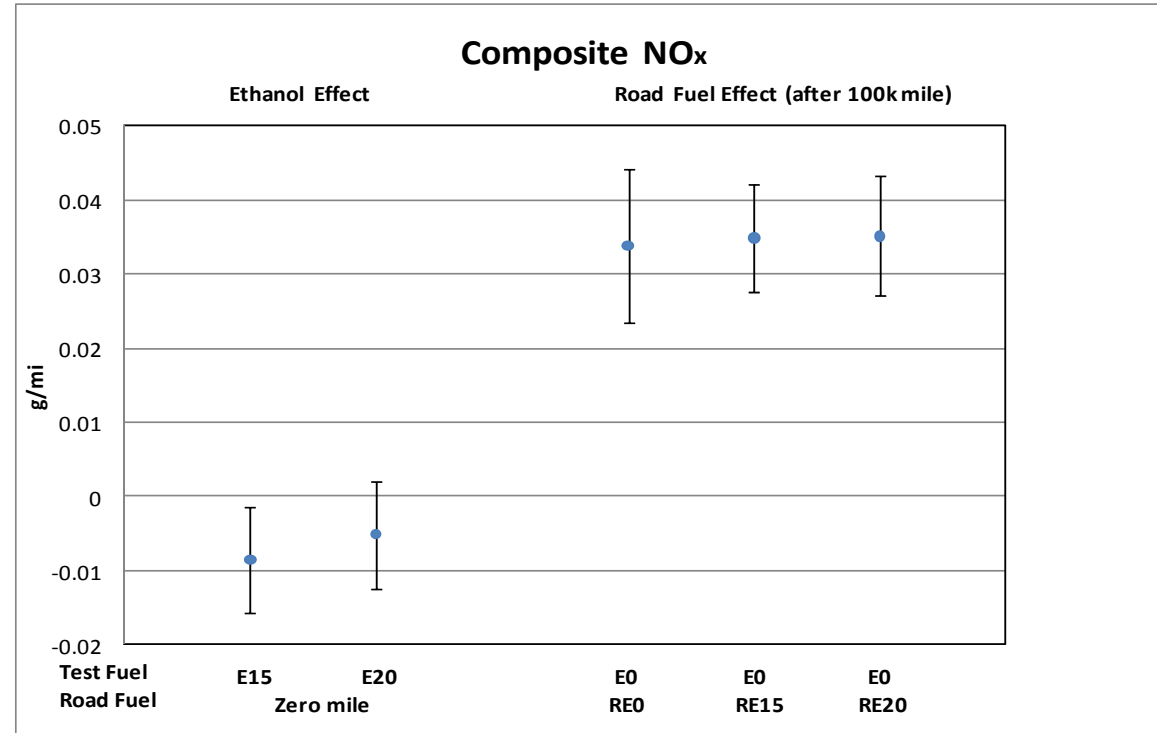

Error bars represent $95 \%$ confidence intervals on the estimated effects 
2009 Jeep Liberty (Composite Nonmethane Hydrocarbons)

\begin{tabular}{|l|r|r|r|}
\hline \multicolumn{1}{|c|}{ Effect } & & $\begin{array}{c}95 \% \text { C.I. } \\
\text { Low\% C.I. } \\
\text { Upper }\end{array}$ \\
\hline Ethanol Effect $(E 15 \mathrm{vs}$. E0) $(\Delta \mathrm{g} / \mathrm{mi})$ & -0.011 & -0.0324 & 0.0096 \\
\hline Ethanol Effect $($ E20 vs. E0) $(\Delta \mathrm{g} / \mathrm{mi})$ & -0.019 & -0.0396 & 0.0025 \\
\hline Road Fuel Aging Effect & & & \\
\hline Aging Effect with RE0 $(\Delta \mathrm{g} / \mathrm{mi}$ per 100k mi) & -0.000 & -0.0318 & 0.0313 \\
\hline Aging Effect with RE15 $(\Delta \mathrm{g} / \mathrm{mi}$ per 100k mi) & -0.003 & -0.0250 & 0.0198 \\
\hline Aging Effect with RE20 $(\Delta \mathrm{g} / \mathrm{mi}$ per 100k mi) & 0.011 & -0.0111 & 0.0336 \\
\hline
\end{tabular}

\begin{tabular}{|l|r|}
\hline \multicolumn{1}{|c|}{ Hypothesis } & p-value \\
\hline No Effect of Ethanol in the Test Fuel (Gamma = 0) & 0.11 \\
\hline No Aging Effect with RE0 (Beta0 = 0) & 0.99 \\
\hline No Effect of Ethanol in Road Fuel Aging (Beta1s=0) & 0.58 \\
\hline
\end{tabular}

* Indicates estimate is different from zero at the $95 \%$ confidence level.

Initial Odometers 4k

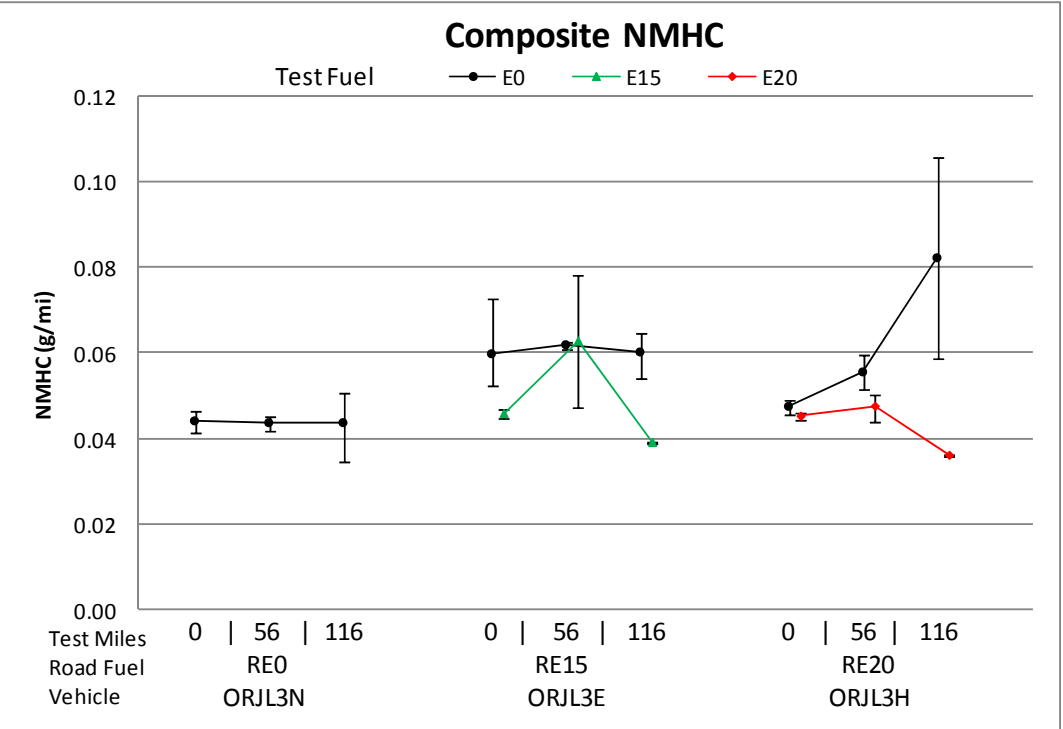

Error bars represent min and max measurements

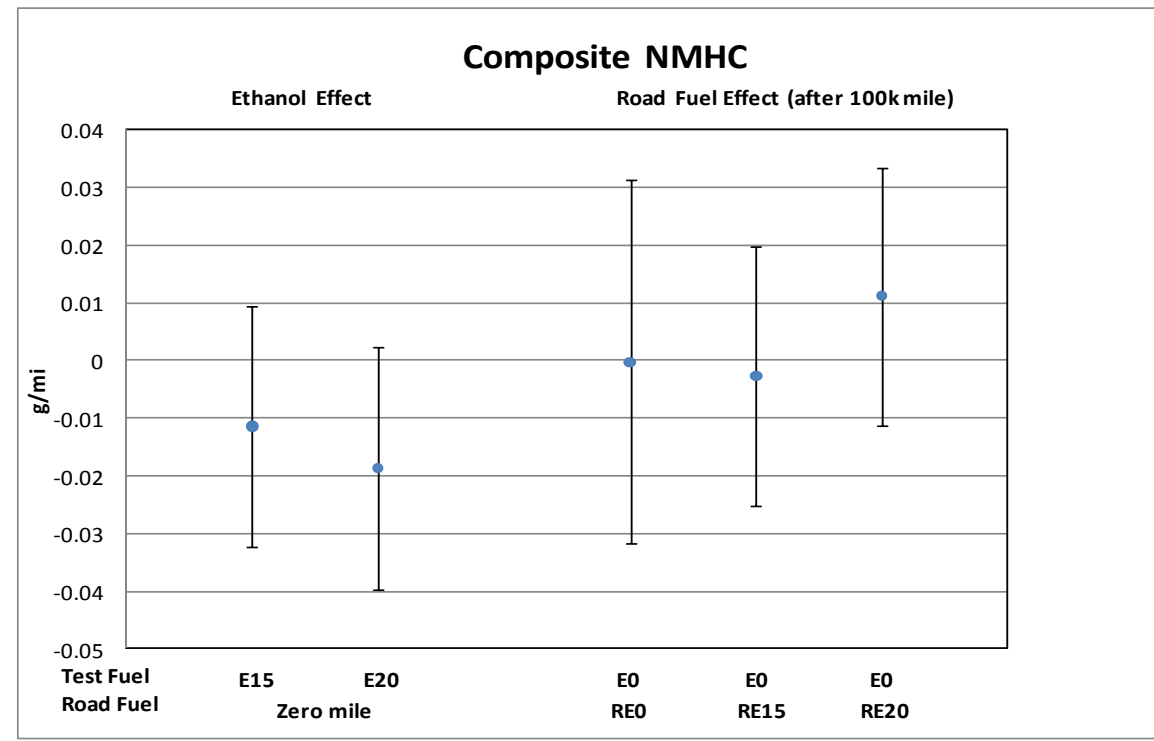

Error bars represent $95 \%$ confidence intervals on the estimated effects 
2009 Jeep Liberty (Composite Nonmethane Organic Gases)

\begin{tabular}{|c|c|c|c|}
\hline Effect & Estimate & $\begin{array}{l}95 \% \text { C.I. } \\
\text { Lower }\end{array}$ & $\begin{array}{c}95 \% \text { C.I. } \\
\text { Upper }\end{array}$ \\
\hline Ethanol Effect (E15 vs. E0) $(\Delta \mathrm{g} / \mathrm{mi})$ & -0.006 & -0.029 & 0.016 \\
\hline Ethanol Effect (E20 vs. E0) $(\Delta \mathrm{g} / \mathrm{mi})$ & -0.014 & -0.036 & 0.010 \\
\hline \multicolumn{4}{|l|}{ Road Fuel Aging Effect } \\
\hline Aging Effect with RE0 ( $\Delta \mathrm{g} / \mathrm{mi}$ per $100 \mathrm{k} \mathrm{mi})$ & 0.000 & -0.034 & 0.034 \\
\hline Aging Effect with RE15 ( $\Delta \mathrm{g} / \mathrm{mi}$ per 100k mi) & -0.003 & -0.028 & 0.021 \\
\hline Aging Effect with RE20 ( $\Delta \mathrm{g} / \mathrm{mi}$ per $100 \mathrm{k} \mathrm{mi})$ & 0.011 & -0.013 & 0.036 \\
\hline
\end{tabular}

\begin{tabular}{|l|r|}
\hline \multicolumn{1}{|c|}{ Hypothesis } & p-value \\
\hline No Effect of Ethanol in the Test Fuel (Gamma $=0)$ & 0.37 \\
\hline No Aging Effect with RE0 (Beta0 $=0)$ & 1.00 \\
\hline No Effect of Ethanol in Road Fuel Aging (Beta1s=0) & 0.59 \\
\hline${ }^{*}$ Indicates effect is statistically significant at the 95\% confidence level.
\end{tabular}

* Indicates estimate is different from zero at the $95 \%$ confidence level.

Initial Odometers 4k

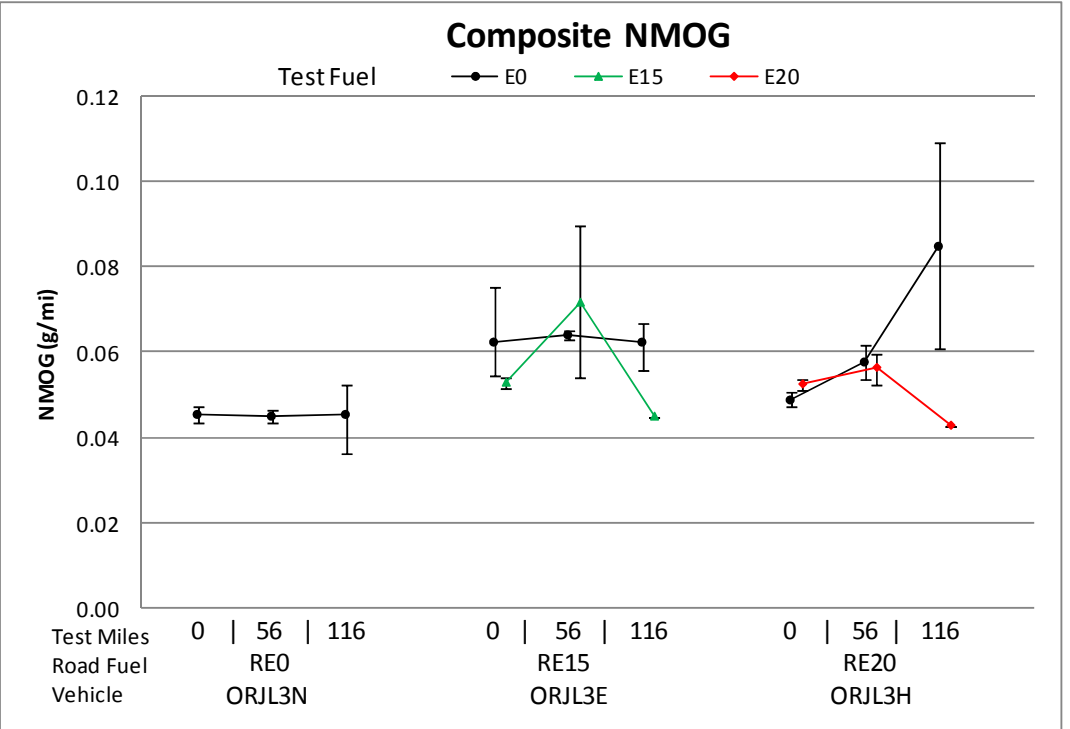

Error bars represent min and max measurements

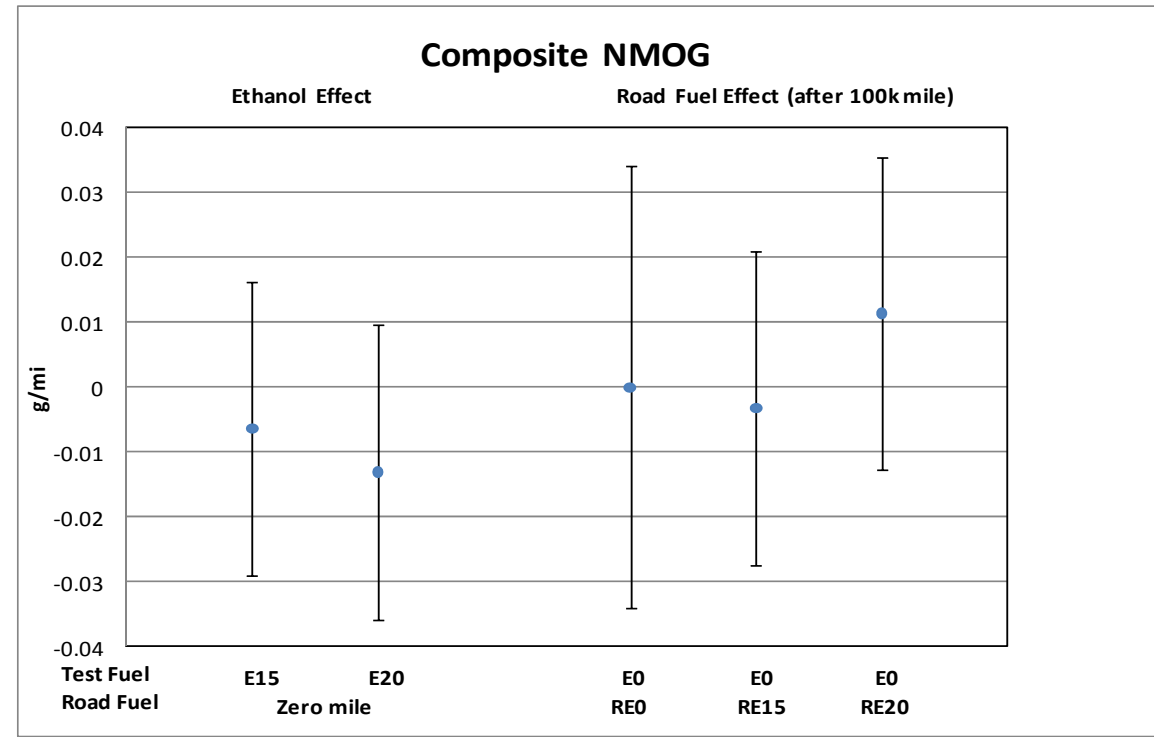

Error bars represent $95 \%$ confidence intervals on the estimated effects 
2009 Jeep Liberty (Composite Fuel Economy)

\begin{tabular}{|c|c|c|c|}
\hline Effect & Estimate & $\begin{array}{c}95 \% \text { C.I. } \\
\text { Lower }\end{array}$ & $\begin{array}{c}95 \% \text { C.I. } \\
\text { Upper }\end{array}$ \\
\hline Ethanol Effect (E15 vs. E0) ( $\Delta \mathrm{mi} / \mathrm{gal})$ & $-0.858^{*}$ & -1.455 & -0.261 \\
\hline Ethanol Effect (E20 vs. E0) $(\Delta \mathrm{mi} / \mathrm{qal})$ & $-1.086^{*}$ & -1.684 & -0.489 \\
\hline \multicolumn{4}{|l|}{ Road Fuel Aging Effect } \\
\hline Aging Effect with RE0 ( $\Delta \mathrm{mi} /$ gal per $100 \mathrm{k} \mathrm{mi})$ & 0.848 & -0.050 & 1.745 \\
\hline Aging Effect with RE15 ( $\Delta \mathrm{mi} / \mathrm{gal}$ per $100 \mathrm{k} \mathrm{mi})$ & $0.787^{*}$ & 0.152 & 1.422 \\
\hline Aging Effect with RE20 ( $\Delta \mathrm{mi} / \mathrm{gal}$ per $100 \mathrm{k} \mathrm{mi})$ & $0.768^{*}$ & 0.133 & 1.403 \\
\hline
\end{tabular}

\begin{tabular}{|l|r|}
\hline \multicolumn{1}{|c|}{ Hypothesis } & p-value \\
\hline No Effect of Ethanol in the Test Fuel (Gamma = 0) & $<0.01^{*}$ \\
\hline No Aging Effect with RE0 (Beta0 = 0) & 0.06 \\
\hline No Effect of Ethanol in Road Fuel Aging (Beta1s=0) & 0.99 \\
\hline
\end{tabular}

${ }^{*}$ Indicates estimate is different from zero at the $95 \%$ confidence level.

Initial Odometers 4k
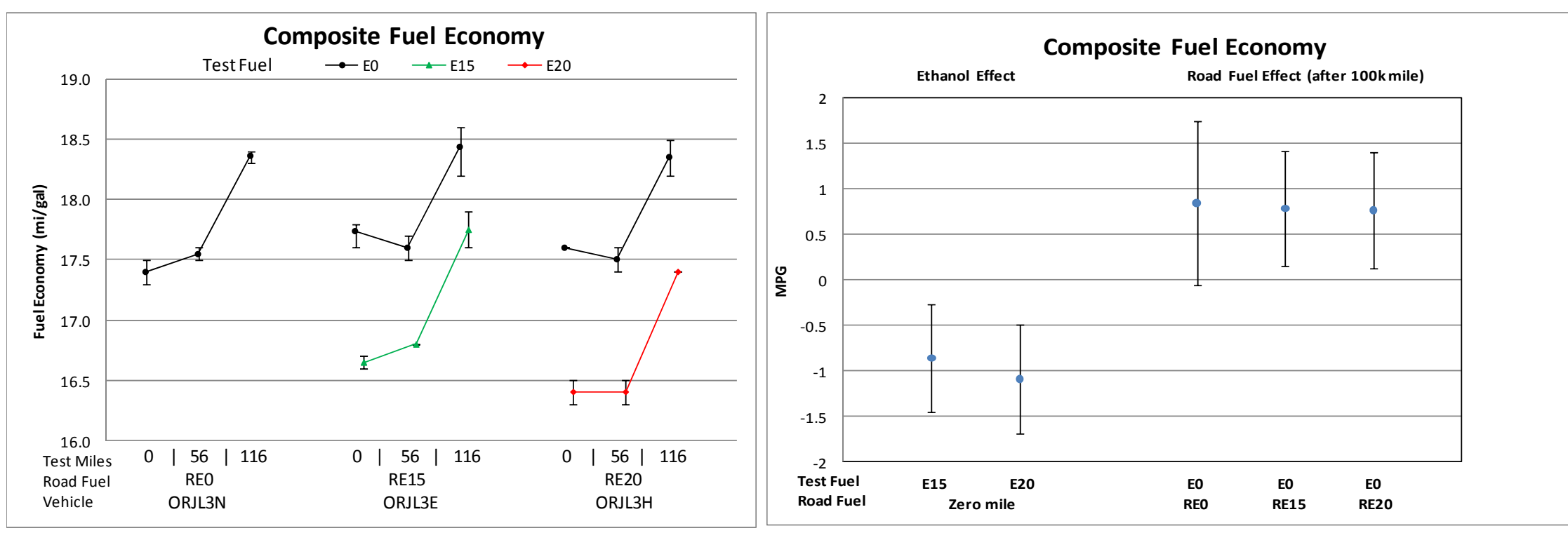

Error bars represent min and max measurements

Error bars represent $95 \%$ confidence intervals on the estimated effects 
2009 Jeep Liberty (Composite Acetaldehyde)

\begin{tabular}{|l|r|r|r|}
\hline \multicolumn{1}{|c|}{ Effect } & Estimate & $\begin{array}{r}\text { 95\% C.I. } \\
\text { Lower }\end{array}$ & $\begin{array}{r}\text { 95\% C.I. } \\
\text { Upper }\end{array}$ \\
\hline Ethanol Effect (E15 vs. E0) $(\Delta \mathrm{mg} / \mathrm{mi})$ & $0.586^{*}$ & 0.281 & 0.890 \\
\hline Ethanol Effect (E20 vs. E0) $(\Delta \mathrm{mg} / \mathrm{mi})$ & $0.664^{*}$ & 0.340 & 0.988 \\
\hline Road Fuel Aging Effect & & & \\
\hline Aging Effect with RE0 $(\Delta \mathrm{mg} / \mathrm{mi}$ per 100k mi) & 0.018 & -0.100 & 0.136 \\
\hline Aging Effect with RE15 $(\Delta \mathrm{mg} / \mathrm{mi}$ per 100k mi) & -0.042 & -0.152 & 0.069 \\
\hline Aging Effect with RE20 $(\Delta \mathrm{mg} / \mathrm{mi}$ per 100k mi) & -0.022 & -0.134 & 0.091 \\
\hline
\end{tabular}

\begin{tabular}{|l|r|}
\hline \multicolumn{1}{|c|}{ Hypothesis } & p-value \\
\hline No Effect of Ethanol in the Test Fuel (Gamma $=0)$ & $<0.01^{*}$ \\
\hline No Aging Effect with RE0 (Beta0 $=0)$ & 0.73 \\
\hline No Effect of Ethanol in Road Fuel Aging (Beta1s=0) & 0.67 \\
\hline${ }^{*}$ Indicates effect is statistically significant at the 95\% confidence level.
\end{tabular}

* Indicates estimate is different from zero at the $95 \%$ confidence level.

Initial Odometers 4k

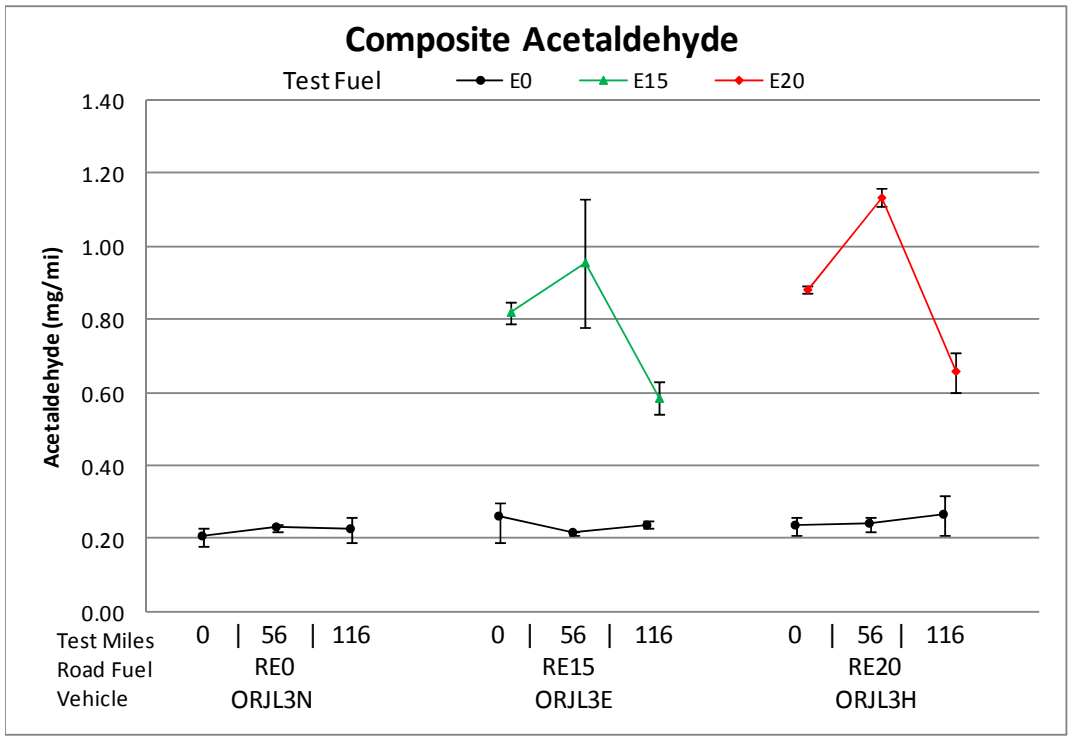

Error bars represent min and max measurements

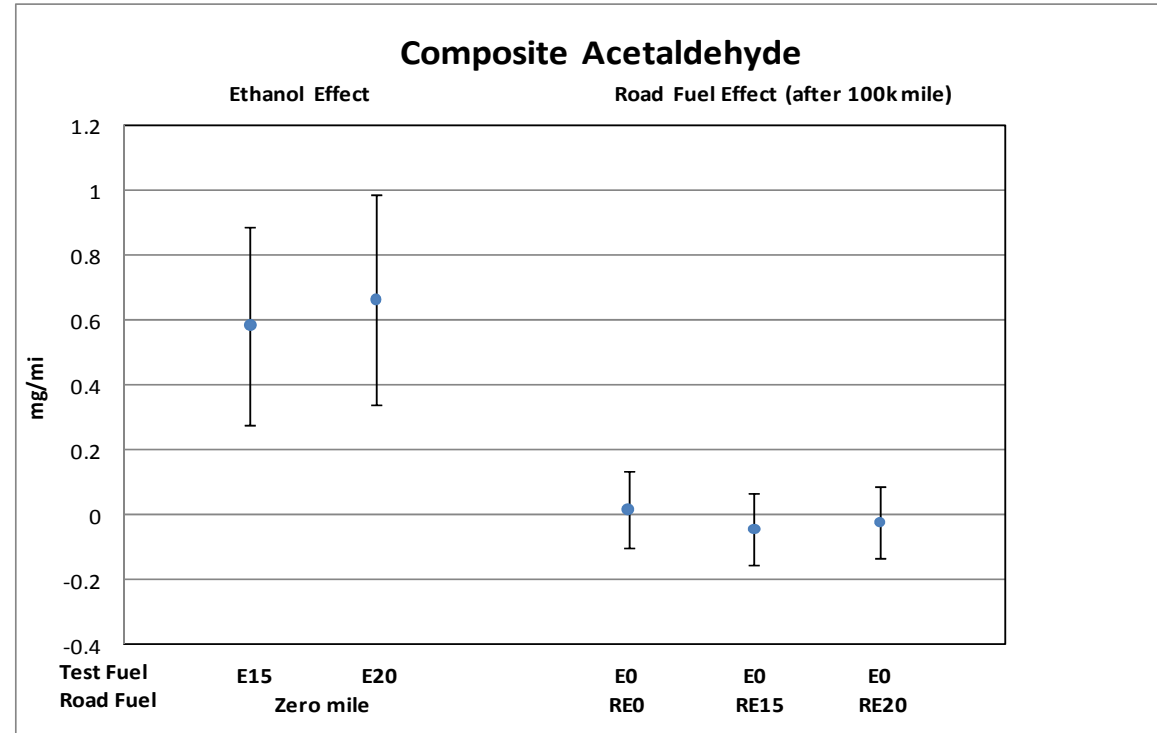

Error bars represent $95 \%$ confidence intervals on the estimated effects 
2009 Jeep Liberty (Composite Formaldehyde)

\begin{tabular}{|l|r|r|r|}
\hline \multicolumn{1}{|c|}{ Effect } & & $\begin{array}{r}\text { 95\% C.I. } \\
\text { Lo5\% C.I. } \\
\text { Upper }\end{array}$ \\
\hline Ethanol Effect $(E 15 \mathrm{vs.}$ E0) $(\Delta \mathrm{mg} / \mathrm{mi})$ & 0.061 & -0.704 & 0.827 \\
\hline Ethanol Effect $(E 20 \mathrm{vs.} \mathrm{E0)}(\Delta \mathrm{mg} / \mathrm{mi})$ & 0.035 & -0.700 & 0.769 \\
\hline Road Fuel Aging Effect & & & \\
\hline Aging Effect with RE0 $(\Delta \mathrm{mg} / \mathrm{mi}$ per 100k mi) & 0.092 & -0.679 & 0.863 \\
\hline Aging Effect with RE15 $(\Delta \mathrm{mg} / \mathrm{mi}$ per 100k mi) & -0.022 & -0.703 & 0.658 \\
\hline Aging Effect with RE20 $(\Delta \mathrm{mg} / \mathrm{mi}$ per 100k mi) & 0.154 & -0.611 & 0.918 \\
\hline
\end{tabular}

\begin{tabular}{|l|r|}
\hline \multicolumn{1}{|c|}{ Hypothesis } & p-value \\
\hline No Effect of Ethanol in the Test Fuel (Gamma = 0) & 0.96 \\
\hline No Aging Effect with RE0 (Beta0 = 0) & 0.79 \\
\hline No Effect of Ethanol in Road Fuel Aging (Beta1s=0) & 0.90 \\
\hline * Indicates effect is statistically significant at the 95\% confidence level.
\end{tabular}

${ }^{*}$ Indicates estimate is different from zero at the $95 \%$ confidence level.

Initial Odometers 4k
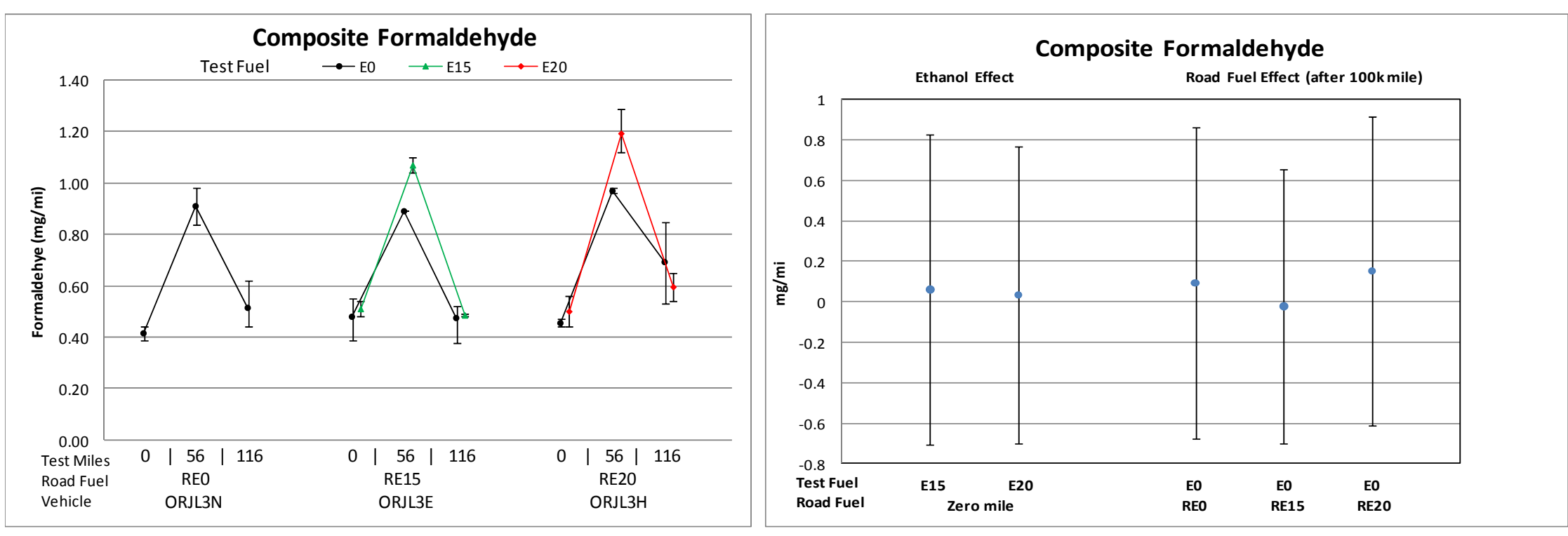

Error bars represent min and max measurements

Error bars represent $95 \%$ confidence intervals on the estimated effects 
2009 Jeep Liberty (Composite $\mathrm{CH} 4$ )

\begin{tabular}{|l|r|r|r|}
\hline \multicolumn{1}{|c|}{ Effect } & & $\begin{array}{c}95 \% \text { C.I. } \\
\text { Lower }\end{array}$ & $\begin{array}{c}95 \% \text { C.I. } \\
\text { Upper }\end{array}$ \\
\hline Ethanol Effect (E15 vs. E0) $(\Delta \mathrm{g} / \mathrm{mi})$ & -0.0007 & -0.0025 & 0.0012 \\
\hline Ethanol Effect (E20 vs. E0) $(\Delta \mathrm{g} / \mathrm{mi})$ & -0.0004 & -0.0022 & 0.0015 \\
\hline Road Fuel Aging Effect & & & \\
\hline Aging Effect with RE0 $(\Delta \mathrm{g} / \mathrm{mi}$ per 100k mi) & $0.0038^{*}$ & 0.0010 & 0.0066 \\
\hline Aging Effect with RE15 $(\Delta \mathrm{g} / \mathrm{mi} \mathrm{per} \mathrm{100k} \mathrm{mi)}$ & $0.0080^{*}$ & 0.0059 & 0.0100 \\
\hline Aging Effect with RE20 $(\Delta \mathrm{g} / \mathrm{mi}$ per 100k mi) & $0.0046^{*}$ & 0.0026 & 0.0065 \\
\hline
\end{tabular}

\begin{tabular}{|l|r|}
\hline \multicolumn{1}{|c|}{ Hypothesis } & p-value \\
\hline No Effect of Ethanol in the Test Fuel (Gamma = 0) & 0.60 \\
\hline No Aging Effect with RE0 (Beta0 = 0) & $0.02^{*}$ \\
\hline No Effect of Ethanol in Road Fuel Aging (Beta1s=0) & 0.03 \\
\hline
\end{tabular}

* Indicates estimate is different from zero at the $95 \%$ confidence level.

Initial Odometers 4k

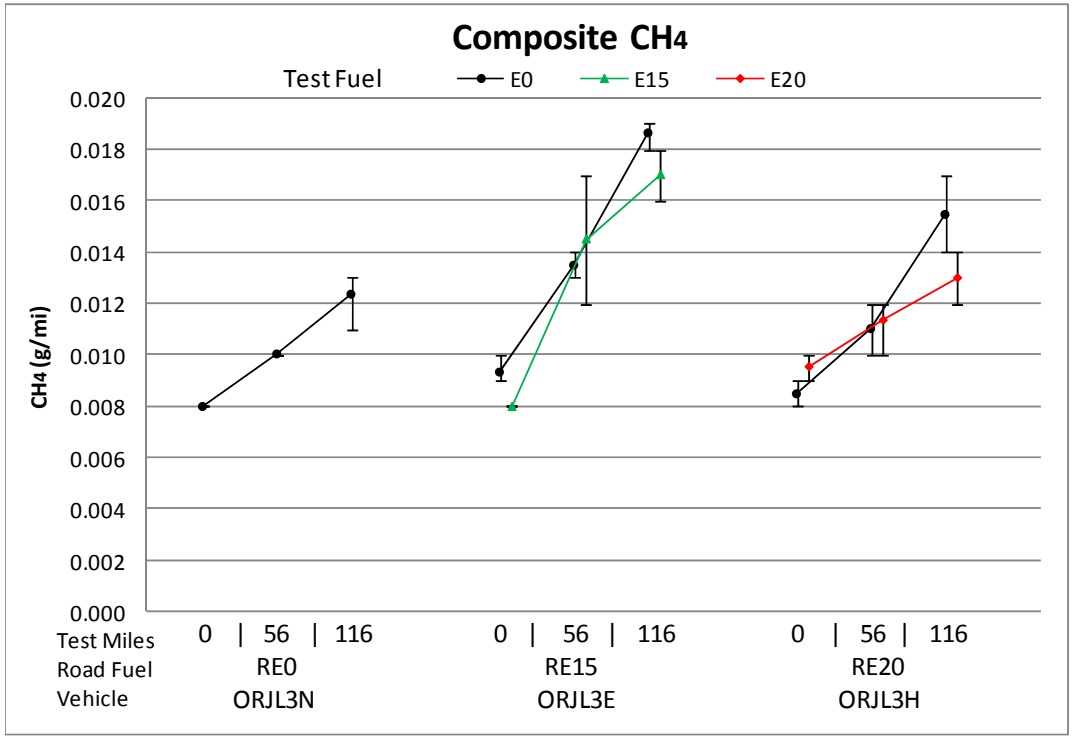

Error bars represent min and max measurements

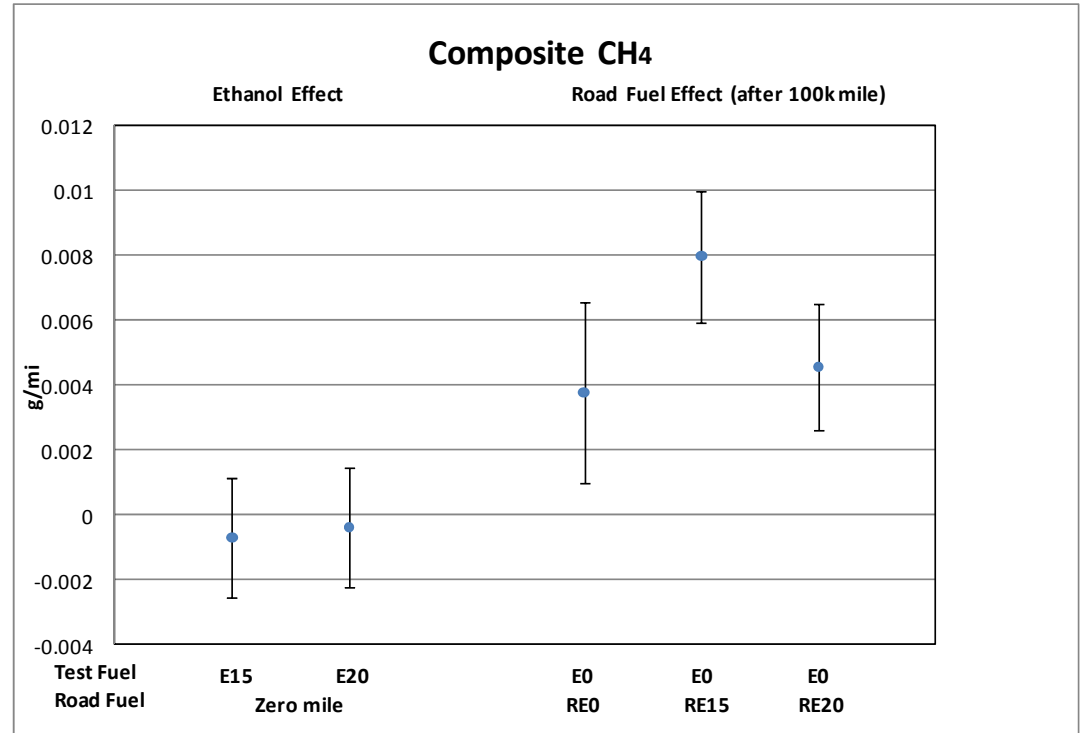

Error bars represent $95 \%$ confidence intervals on the estimated effects 


\section{Ford Explorer - Composite Emissions Summary}

\begin{tabular}{|c|c|c|c|c|c|c|c|c|c|c|c|c|c|c|}
\hline \multirow{2}{*}{$\begin{array}{c}\text { Emisssion Parameter } \\
\text { (units) }\end{array}$} & \multicolumn{4}{|c|}{ Ethanol Effect } & \multicolumn{2}{|c|}{ Aging Effect with REO } & \multicolumn{4}{|c|}{ RExx Aging Effect on E0 Emissions } & \multirow{2}{*}{\multicolumn{3}{|c|}{$\begin{array}{c}\text { RExx Aging Effect on Exx Emissions } \\
\Delta \text { units per } 100 \mathrm{~K} \mathrm{mi}\end{array}$}} & \multirow{3}{*}{\begin{tabular}{|c|}
$\begin{array}{l}\text { Road and Test } \\
\text { Fuel Effects } \\
\text { are Additive }\end{array}$ \\
$\begin{array}{c}\text { Overall p- } \\
\text { value }\end{array}$
\end{tabular}} \\
\hline & \multicolumn{3}{|c|}{$\Delta$ units vs. EO } & \multirow{2}{*}{$\mid \begin{array}{c}\text { Overall } \\
p \text {-value }\end{array}$} & \multirow{2}{*}{$\frac{\Delta \text { units per } 100 \mathrm{~K} \mathrm{mi}}{\text { REO/EO }}$} & \multirow{2}{*}{$\begin{array}{l}\text { Overall } \\
p \text {-value }\end{array}$} & \multicolumn{3}{|c|}{$\Delta$ units per $100 \mathrm{~K} \mathrm{mi}$} & \multirow{2}{*}{$\begin{array}{l}\text { Overall } \\
p \text {-value }\end{array}$} & & & & \\
\hline Fuels & E10 & E15 & E20 & & & & RE10/E0 & RE15/E0 & RE20/E0 & & RE10/E10 & RE15/E15 & RE20/E20 & \\
\hline $\mathrm{CO}(\mathrm{g} / \mathrm{mi})$ & $\mathrm{NA}$ & -0.070 & $-0.167 *$ & $0.01 *$ & 0.146 & 0.05 & NA & 0.082 & $0.140^{*}$ & 0.60 & $\mathrm{NA}$ & $\mathrm{NA}$ & NA & 0.55 \\
\hline $\mathrm{NOx}(\mathrm{g} / \mathrm{mi})$ & $\mathrm{NA}$ & -0.002 & -0.003 & 0.72 & $0.020^{*}$ & $0.03^{*}$ & $\mathrm{NA}$ & $0.018^{*}$ & $0.016 *$ & 0.92 & NA & $\mathrm{NA}$ & $\mathrm{NA}$ & 0.96 \\
\hline $\mathrm{NMHC}(\mathrm{g} / \mathrm{mi})^{\mathrm{a}}$ & $\mathrm{NA}$ & -0.005 & $-0.010 *$ & $<0.01 *$ & 0.008 & 0.08 & $\mathrm{NA}$ & 0.005 & $0.009 *$ & 0.65 & $\mathrm{NA}$ & $\mathrm{NA}$ & $\mathrm{NA}$ & 0.98 \\
\hline NMOG $(\mathrm{g} / \mathrm{mi})^{\mathrm{a}}$ & $\mathrm{NA}$ & 0.0002 & -0.0028 & 0.60 & 0.0076 & 0.09 & NA & 0.0056 & $0.0103 *$ & 0.53 & $\mathrm{NA}$ & $\mathrm{NA}$ & NA & 0.93 \\
\hline Fuel Econ (mi/gal) & $\mathrm{NA}$ & $-0.900 *$ & $-1.117 *$ & $<0.01 *$ & 0.337 & 0.32 & $\mathrm{NA}$ & 0.342 & 0.385 & 0.99 & $\mathrm{NA}$ & $\mathrm{NA}$ & $\mathrm{NA}$ & 0.87 \\
\hline Acetaldehyde $(\mathrm{mg} / \mathrm{mi})^{\#}$ & $\mathrm{NA}$ & $0.613^{*}$ & $0.871^{*}$ & $<0.01 *$ & 0.018 & 0.80 & NA & -0.033 & -0.034 & 0.81 & NA & $\mathrm{NA}$ & NA & 0.97 \\
\hline Formaldehyde $(\mathrm{mg} / \mathrm{mi})^{\# a}$ & $\mathrm{NA}$ & 0.090 & 0.095 & 0.09 & $0.231^{*}$ & $0.03 *$ & NA & $0.226^{*}$ & $0.234 *$ & 0.98 & $\mathrm{NA}$ & $\mathrm{NA}$ & NA & 0.69 \\
\hline $\mathrm{CH}_{4}(\mathrm{~g} / \mathrm{mi})$ & $\mathrm{NA}$ & 0.0010 & 0.0007 & 0.75 & 0.0038 & 0.14 & $\mathrm{NA}$ & 0.0032 & $0.0061 *$ & 0.49 & $\mathrm{NA}$ & $\mathrm{NA}$ & $\mathrm{NA}$ & 0.90 \\
\hline
\end{tabular}

\# Log-normal model was used. Results are presented as changes in emissions at $0 \mathrm{k}$ mile.

\#\# Data did not support the assumption of linear effects with mileage.

* Indicates estimate is different from zero at the $95 \%$ confidence level.

a test " 9748 " is identified as a outlier and excluded from the analysis 
2009 Ford Explorer (Composite CO)

\begin{tabular}{|l|r|r|r|}
\hline \multicolumn{1}{|c|}{ Effect } & Estimate & $\begin{array}{r}\text { 95\% C.I. } \\
\text { Lower }\end{array}$ & $\begin{array}{r}\text { 95\% C.I. } \\
\text { Upper }\end{array}$ \\
\hline Ethanol Effect (E15 vs. E0) $(\Delta \mathrm{g} / \mathrm{mi})$ & -0.070 & -0.170 & 0.030 \\
\hline Ethanol Effect $($ E20 vs. E0) $(\Delta \mathrm{g} / \mathrm{mi})$ & $-0.167^{*}$ & -0.267 & -0.067 \\
\hline Road Fuel Aging Effect & & & \\
\hline Aging Effect with RE0 $(\Delta \mathrm{g} / \mathrm{mi}$ per 100k mi) & 0.146 & -0.004 & 0.297 \\
\hline Aging Effect with RE15 $(\Delta \mathrm{g} / \mathrm{mi}$ per 100k mi) & 0.082 & -0.024 & 0.188 \\
\hline Aging Effect with RE20 $(\Delta \mathrm{g} / \mathrm{mi}$ per 100k mi) & $0.140^{*}$ & 0.034 & 0.246 \\
\hline
\end{tabular}

\begin{tabular}{|l|r|}
\hline \multicolumn{1}{|c|}{ Hypothesis } & p-value \\
\hline No Effect of Ethanol in the Test Fuel (Gamma = 0) & $0.01^{*}$ \\
\hline No Aging Effect with RE0 (Beta0 = 0) & 0.05 \\
\hline No Effect of Ethanol in Road Fuel Aging (Beta1s=0) & 0.60 \\
\hline${ }^{*}$ Indicates effect is statistically significant at the 95\% confidence level.
\end{tabular}

Initial Odometers 4k

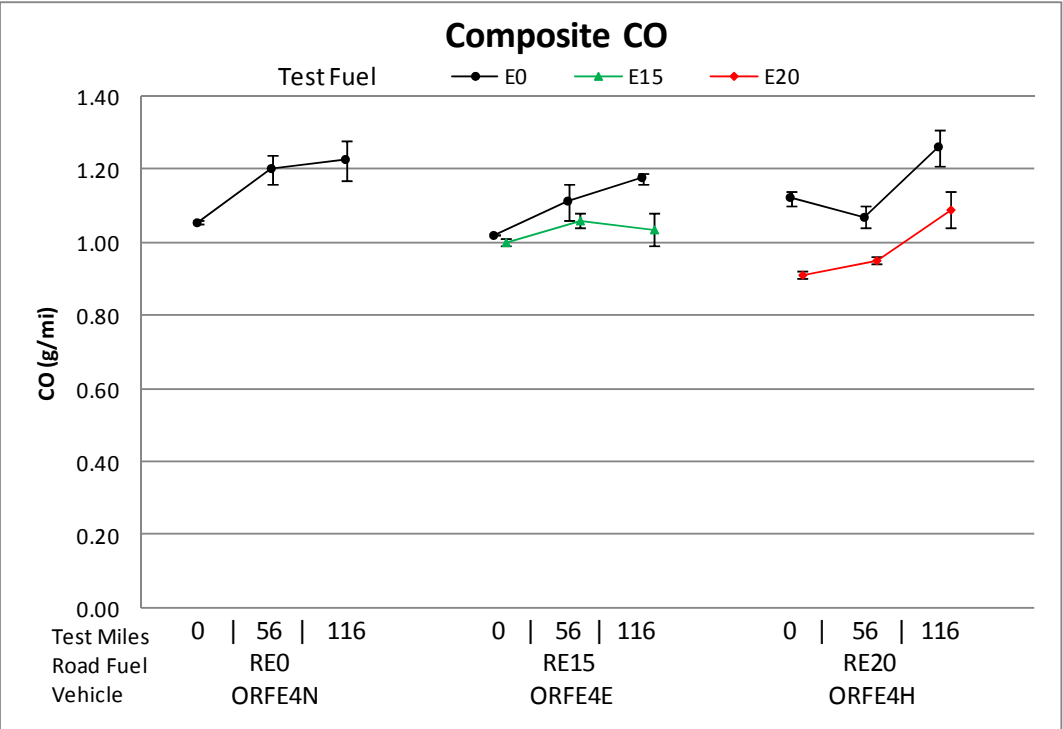

Error bars represent min and max measurements

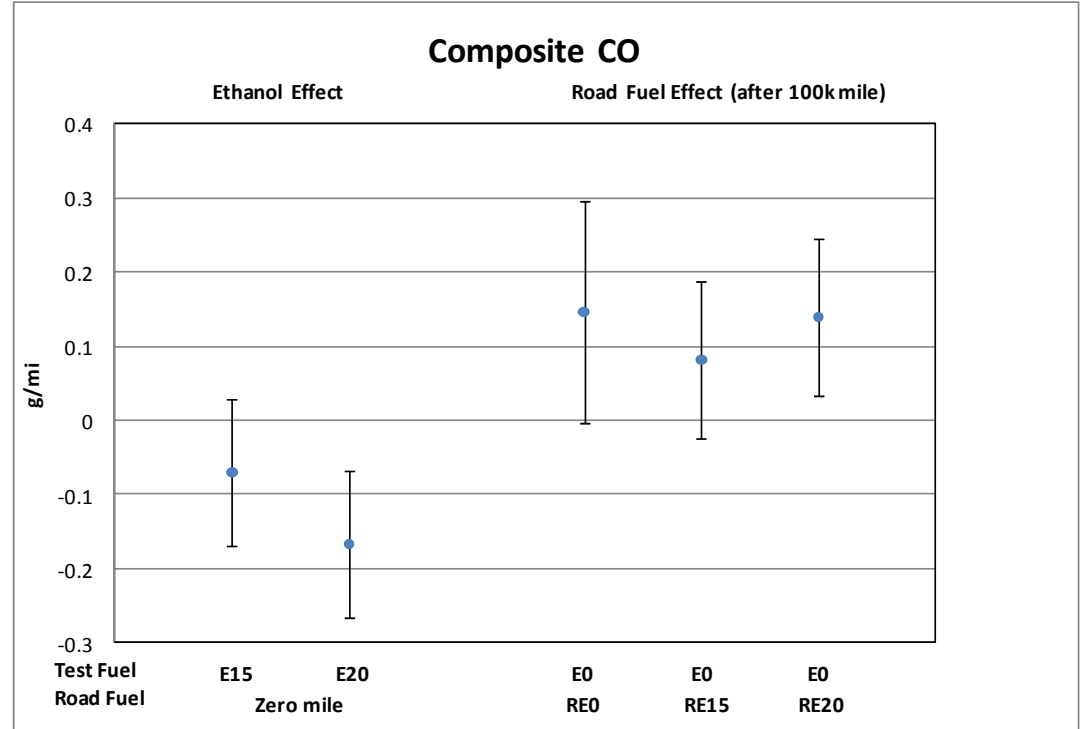

Error bars represent $95 \%$ confidence intervals on the estimated effects 
2009 Ford Explorer (Composite NOx)

\begin{tabular}{|l|r|r|r|}
\hline \multicolumn{1}{|c|}{ Effect } & Estimate & $\begin{array}{c}\text { 95\% C.I. } \\
\text { Lower }\end{array}$ & $\begin{array}{r}\text { 95\% C.I. } \\
\text { Upper }\end{array}$ \\
\hline Ethanol Effect (E15 vs. E0) $(\Delta \mathrm{g} / \mathrm{mi})$ & -0.002 & -0.014 & 0.009 \\
\hline Ethanol Effect (E20 vs. E0) $(\Delta \mathrm{g} / \mathrm{mi})$ & -0.003 & -0.015 & 0.008 \\
\hline Road Fuel Aging Effect & & & \\
\hline Aging Effect with RE0 $(\Delta \mathrm{g} / \mathrm{mi}$ per 100k mi) & $0.020^{*}$ & 0.002 & 0.037 \\
\hline Aging Effect with RE15 $(\Delta \mathrm{g} / \mathrm{mi} \mathrm{per} \mathrm{100k} \mathrm{mi)}$ & $0.018^{*}$ & 0.006 & 0.030 \\
\hline Aging Effect with RE20 $(\Delta \mathrm{g} / \mathrm{mi}$ per 100k mi) & $0.016^{*}$ & 0.004 & 0.028 \\
\hline
\end{tabular}

\begin{tabular}{|l|r|}
\hline \multicolumn{1}{|c|}{ Hypothesis } & -value \\
\hline No Effect of Ethanol in the Test Fuel (Gamma = 0) & 0.72 \\
\hline No Aging Effect with RE0 (Beta0 $=0$ ) & $0.03^{*}$ \\
\hline No Effect of Ethanol in Road Fuel Aging (Beta1s $=0$ ) & 0.92 \\
\hline * Indicates effect is statistically significant at the 95\% confidence level.
\end{tabular}

* Indicates estimate is different from zero at the $95 \%$ confidence level.

Initial Odometers 4k

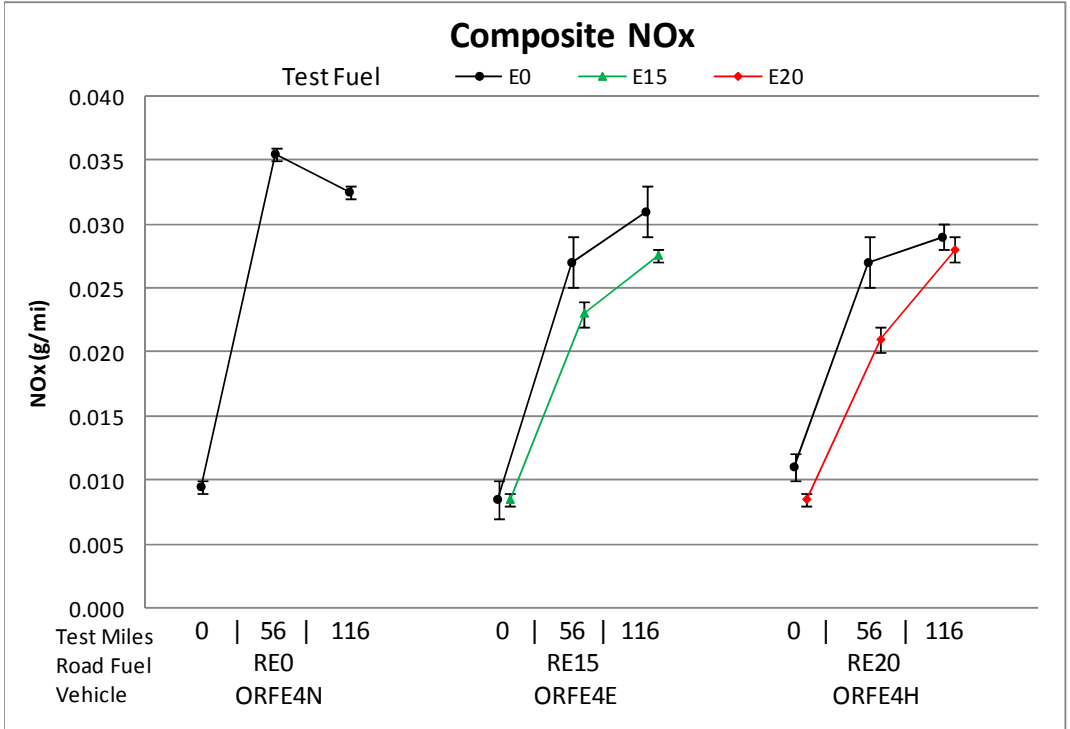

Error bars represent min and max measurements

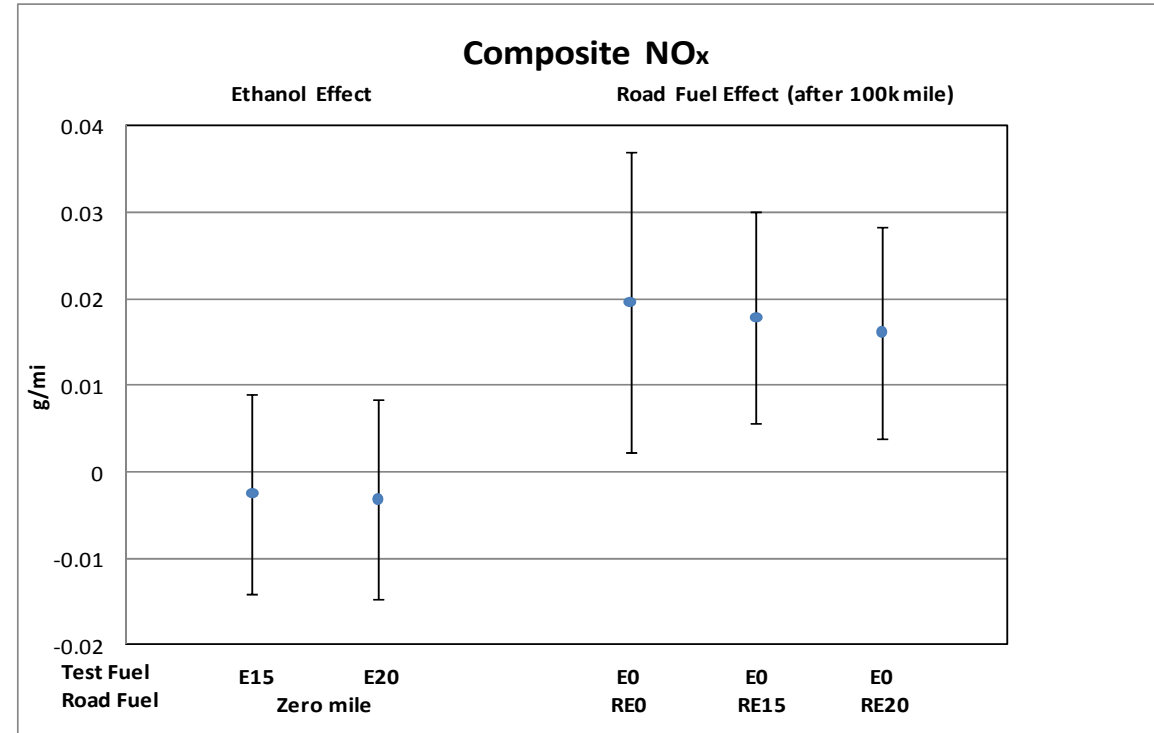

Error bars represent $95 \%$ confidence intervals on the estimated effects 
2009 Ford Explorer (Composite Nonmethane Hydrocarbons)

\begin{tabular}{|l|r|r|r|}
\hline \multicolumn{1}{|c|}{ Effect } & & $\begin{array}{r}95 \% \text { C.I. } \\
\text { Lo5\% C.I. } \\
\text { Upper }\end{array}$ \\
\hline Ethanol Effect $(E 15 \mathrm{vs}$. E0) $(\Delta \mathrm{g} / \mathrm{mi})$ & -0.005 & -0.011 & 0.001 \\
\hline Ethanol Effect $($ E20 vs. E0) $(\Delta \mathrm{g} / \mathrm{mi})$ & $-0.010^{*}$ & -0.016 & -0.004 \\
\hline Road Fuel Aging Effect & & & \\
\hline Aging Effect with RE0 $(\Delta \mathrm{g} / \mathrm{mi}$ per 100k mi) & 0.008 & -0.001 & 0.017 \\
\hline Aging Effect with RE15 $(\Delta \mathrm{g} / \mathrm{mi}$ per 100k mi) & 0.005 & -0.001 & 0.011 \\
\hline Aging Effect with RE20 $(\Delta \mathrm{g} / \mathrm{mi}$ per 100k mi) & $0.009^{*}$ & 0.002 & 0.015 \\
\hline
\end{tabular}

\begin{tabular}{|l|r|}
\hline \multicolumn{1}{|c|}{ Hypothesis } & p-value \\
\hline No Effect of Ethanol in the Test Fuel (Gamma $=0)$ & $<0.01^{*}$ \\
\hline No Aging Effect with RE0 (Beta0 $=0)$ & 0.08 \\
\hline No Effect of Ethanol in Road Fuel Aging (Beta1s=0) & 0.65 \\
\hline${ }^{*}$ Indicates effect is statistically significant at the 95\% confidence level.
\end{tabular}

\begin{tabular}{ll} 
Aging Effect with RE20 $(\Delta \mathrm{g} / \mathrm{mi}$ per $100 \mathrm{k} \mathrm{mi})$ & $0.009 \mathrm{O}$ \\
\hline
\end{tabular}

Initial Odometers 4k

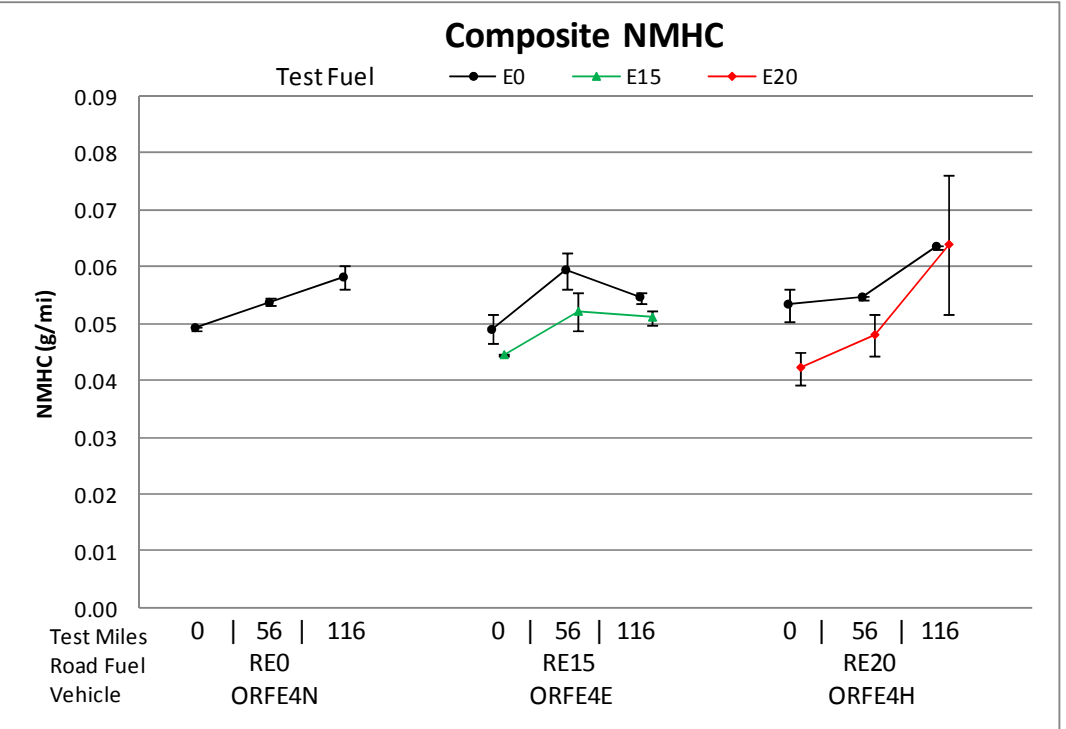

Error bars represent min and max measurements

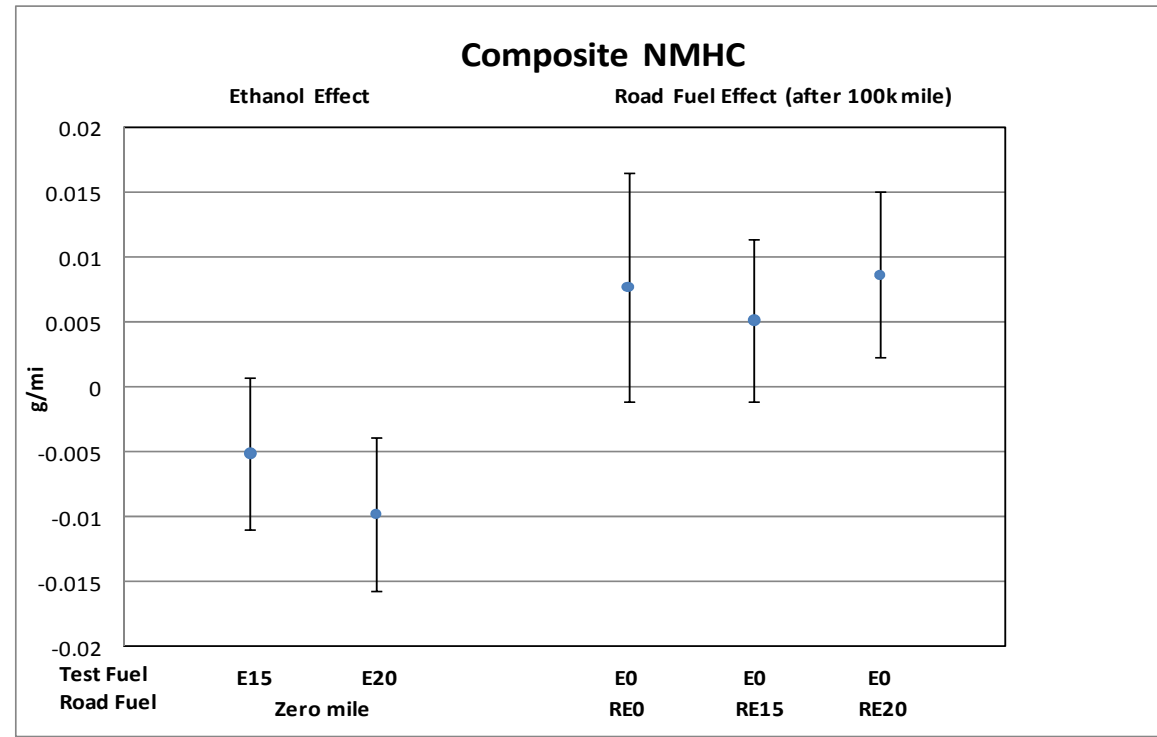

Error bars represent $95 \%$ confidence intervals on the estimated effects 
2009 Ford Explorer (Composite Nonmethane Organic Gases)

\begin{tabular}{|l|r|r|r|}
\hline \multicolumn{1}{|c|}{ Effect } & Estimate & $\begin{array}{c}\text { 95\% C.I. } \\
\text { Lower }\end{array}$ & $\begin{array}{c}\text { 95\% C.I. } \\
\text { Upper }\end{array}$ \\
\hline Ethanol Effect (E15 vs. E0) $(\Delta \mathrm{g} / \mathrm{mi})$ & 0.0002 & -0.0059 & 0.0063 \\
\hline Ethanol Effect $($ E20 vs. E0) $(\Delta \mathrm{g} / \mathrm{mi})$ & -0.0028 & -0.0090 & 0.0034 \\
\hline Road Fuel Aging Effect & & & \\
\hline Aging Effect with RE0 $(\Delta \mathrm{g} / \mathrm{mi}$ per 100k mi) & 0.0076 & -0.0016 & 0.0168 \\
\hline Aging Effect with RE15 $(\Delta \mathrm{g} / \mathrm{mi}$ per 100k mi) & 0.0056 & -0.0009 & 0.0121 \\
\hline Aging Effect with RE20 $(\Delta \mathrm{g} / \mathrm{mi}$ per 100k mi) & $0.0103^{*}$ & 0.0036 & 0.0170 \\
\hline
\end{tabular}

\begin{tabular}{|l|r|}
\hline \multicolumn{1}{|c|}{ Hypothesis } & -value \\
\hline No Effect of Ethanol in the Test Fuel (Gamma = 0) & 0.60 \\
\hline No Aging Effect with RE0 (Beta0 = 0) & 0.09 \\
\hline No Effect of Ethanol in Road Fuel Aging (Beta1s=0) & 0.53 \\
\hline * Indicates effect is statistically significant at the 95\% confidence level.
\end{tabular}

${ }^{*}$ Indicates estimate is different from zero at the $95 \%$ confidence level.

Initial Odometers 4k

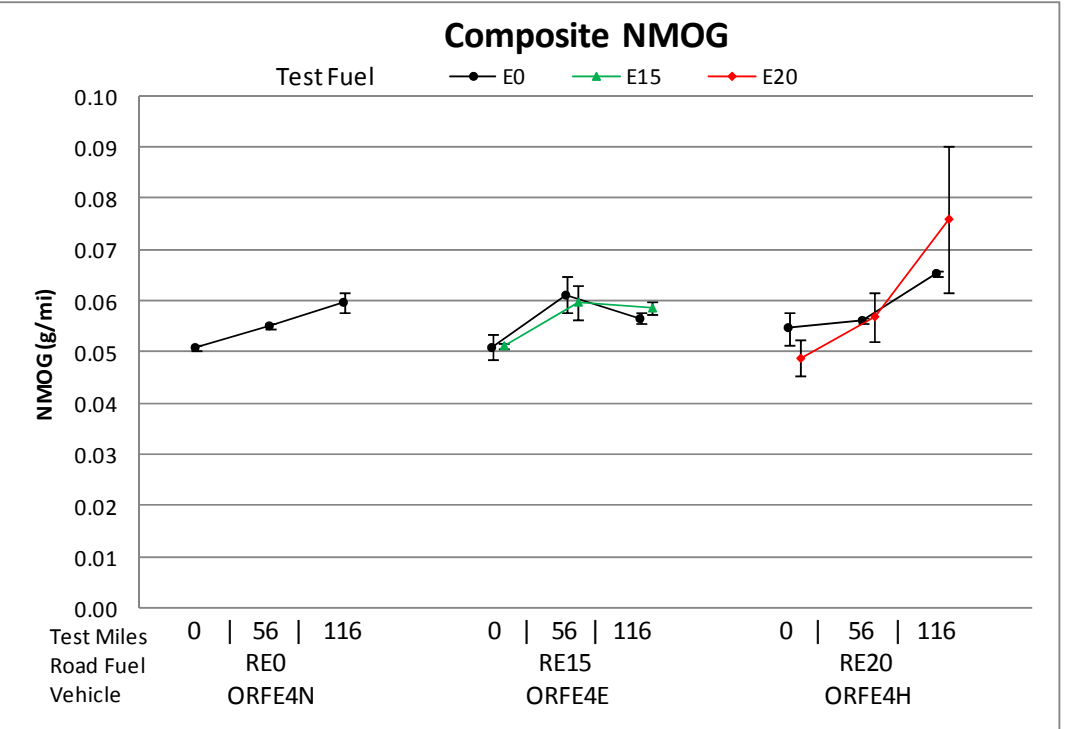

Error bars represent min and max measurements

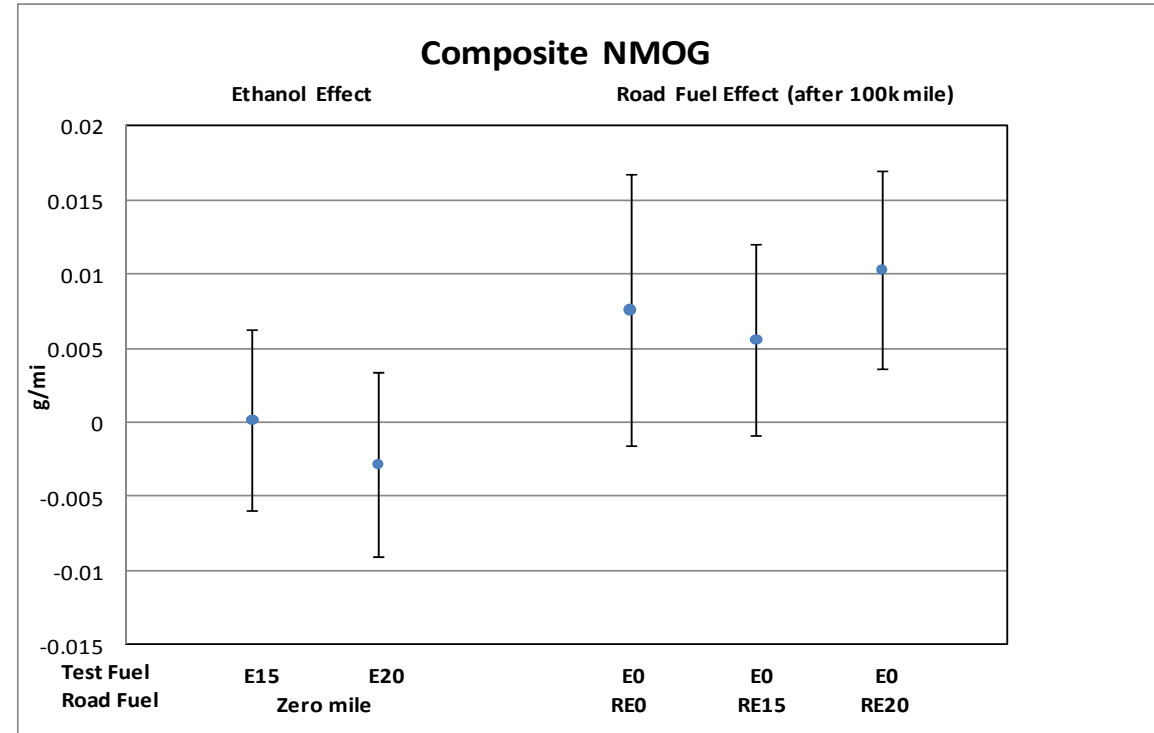

Error bars represent $95 \%$ confidence intervals on the estimated effects 
2009 Ford Explorer (Composite Fuel Economy)

\begin{tabular}{|l|r|r|r|}
\hline \multicolumn{1}{|c|}{ Effect } & & $\begin{array}{r}95 \% \text { C.I. } \\
\text { Estimate }\end{array}$ & $\begin{array}{r}\text { 95\% C.I. } \\
\text { Upper }\end{array}$ \\
\hline Ethanol Effect (E15 vs. E0) $(\Delta \mathrm{mi} / \mathrm{gal})$ & $-0.900^{*}$ & -1.394 & -0.406 \\
\hline Ethanol Effect (E20 vs. E0) $(\Delta \mathrm{mi} / \mathrm{gal})$ & $-1.117^{*}$ & -1.611 & -0.623 \\
\hline Road Fuel Aging Effect & & & \\
\hline Aging Effect with RE0 $(\Delta \mathrm{mi} / \mathrm{gal}$ per 100k mi) & 0.337 & -0.405 & 1.079 \\
\hline Aging Effect with RE15 $(\Delta \mathrm{mi} /$ gal per 100k mi) & 0.342 & -0.183 & 0.866 \\
\hline Aging Effect with RE20 $(\Delta \mathrm{mi} /$ gal per 100k mi) & 0.385 & -0.140 & 0.910 \\
\hline
\end{tabular}

\begin{tabular}{|l|r|}
\hline \multicolumn{1}{|c|}{ Hypothesis } & -value \\
\hline No Effect of Ethanol in the Test Fuel (Gamma = 0) & $<0.01^{*}$ \\
\hline No Aging Effect with RE0 (Beta0 $=0$ ) & 0.32 \\
\hline No Effect of Ethanol in Road Fuel Aging (Beta1s $=0$ ) & 0.99 \\
\hline * Indicates effect is statistically significant at the 95\% confidence level.
\end{tabular}

* Indicates estimate is different from zero at the $95 \%$ confidence level.

Initial Odometers 4k

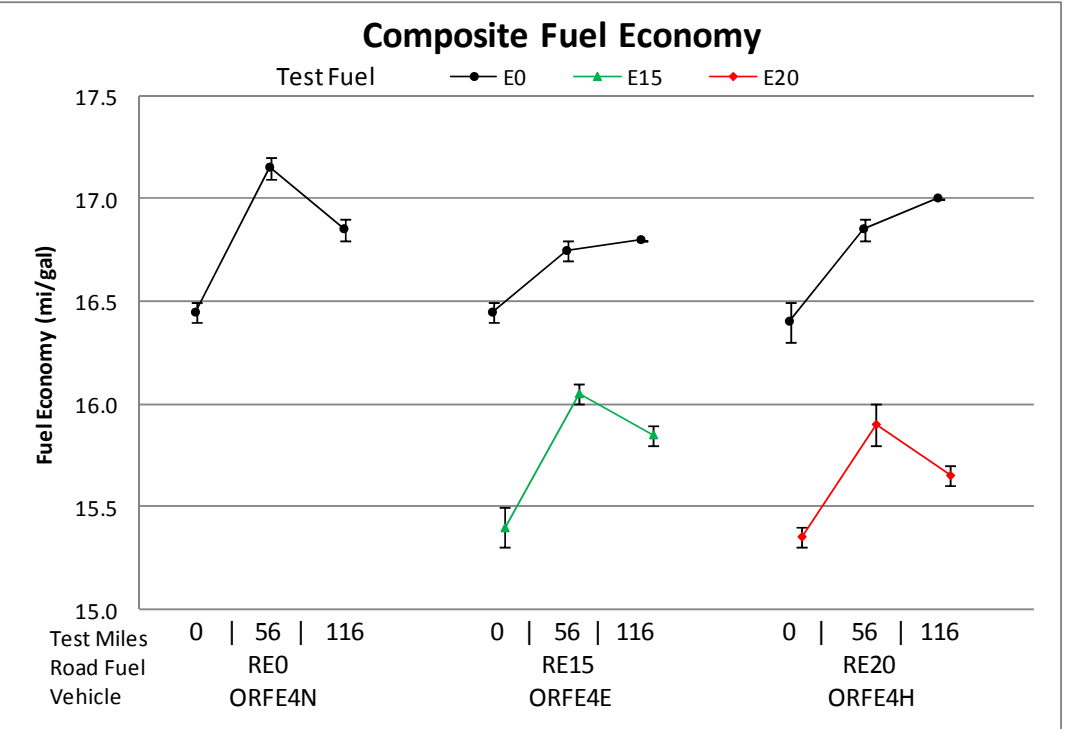

Error bars represent min and max measurements

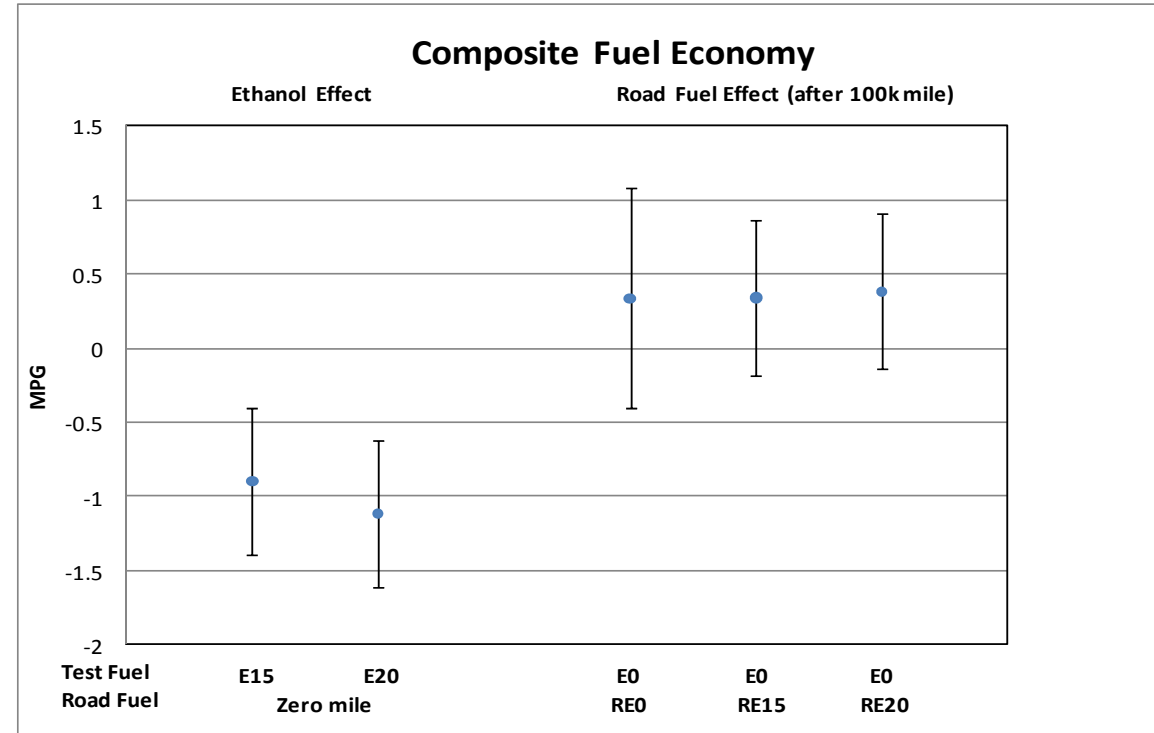

Error bars represent $95 \%$ confidence intervals on the estimated effects 
2009 Ford Explorer (Composite Acetaldehyde)

\begin{tabular}{|l|r|r|r|}
\hline \multicolumn{1}{|c|}{ Effect } & Estimate & $\begin{array}{r}\text { 95\% C.I. } \\
\text { Lower }\end{array}$ & $\begin{array}{r}\text { 95\% C.I. } \\
\text { Upper }\end{array}$ \\
\hline Ethanol Effect (E15 vs. E0) $(\Delta \mathrm{mg} / \mathrm{mi})$ & $0.613^{*}$ & 0.255 & 0.971 \\
\hline Ethanol Effect $($ E20 vs. E0) $(\Delta \mathrm{mg} / \mathrm{mi})$ & $0.871^{*}$ & 0.391 & 1.350 \\
\hline Road Fuel Aging Effect & & & \\
\hline Aging Effect with RE0 $(\Delta \mathrm{mg} / \mathrm{mi}$ per 100k mi) & 0.018 & -0.139 & 0.174 \\
\hline Aging Effect with RE15 $(\Delta \mathrm{mg} / \mathrm{mi}$ per 100k mi) & -0.033 & -0.164 & 0.098 \\
\hline Aging Effect with RE20 $(\Delta \mathrm{mg} / \mathrm{mi}$ per 100k mi) & -0.034 & -0.191 & 0.124 \\
\hline
\end{tabular}

\begin{tabular}{|l|r|}
\hline \multicolumn{1}{|c|}{ Hypothesis } & -value \\
\hline No Effect of Ethanol in the Test Fuel (Gamma = 0) & $<0.01^{*}$ \\
\hline No Aging Effect with RE0 (Beta0 $=0$ ) & 0.80 \\
\hline No Effect of Ethanol in Road Fuel Aging (Beta1s $=0$ ) & 0.81 \\
\hline * Indicates effect is statistically significant at the 95\% confidence level.
\end{tabular}

${ }^{*}$ Indicates estimate is different from zero at the $95 \%$ confidence level.

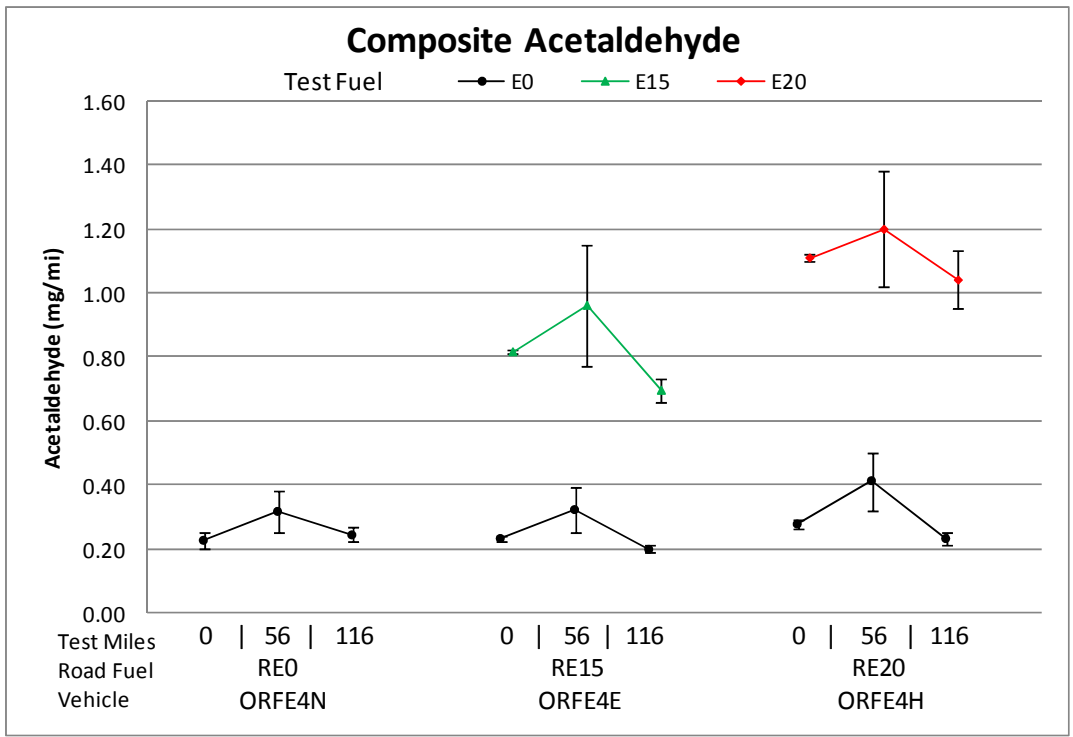

Error bars represent min and max measurements

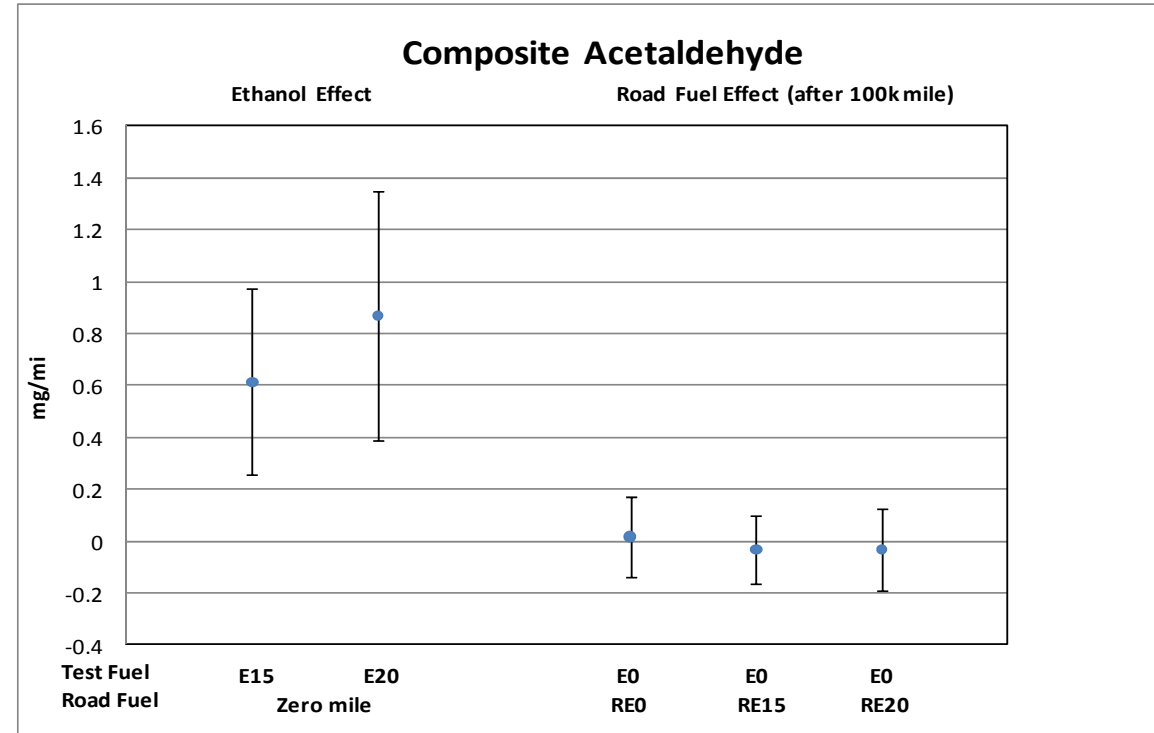

Error bars represent $95 \%$ confidence intervals on the estimated effects 
2009 Ford Explorer (Composite Formaldehyde)

\begin{tabular}{|l|r|r|r|}
\hline \multicolumn{1}{|c|}{ Effect } & Estimate & $\begin{array}{c}\text { 95\% C.I. } \\
\text { Lower }\end{array}$ & $\begin{array}{r}\text { 95\% C.I. } \\
\text { Upper }\end{array}$ \\
\hline Ethanol Effect (E15 vs. E0) $(\Delta \mathrm{mg} / \mathrm{mi})$ & 0.090 & -0.055 & 0.235 \\
\hline Ethanol Effect $($ E20 vs. E0) $(\Delta \mathrm{mg} / \mathrm{mi})$ & 0.095 & -0.066 & 0.257 \\
\hline Road Fuel Aging Effect & & & \\
\hline Aging Effect with RE0 $(\Delta \mathrm{mg} / \mathrm{mi}$ per 100k mi) & $0.231^{*}$ & 0.033 & 0.430 \\
\hline Aging Effect with RE15 $(\Delta \mathrm{mg} / \mathrm{mi}$ per 100k mi) & $0.226^{*}$ & 0.071 & 0.382 \\
\hline Aging Effect with RE20 $(\Delta \mathrm{mg} / \mathrm{mi}$ per 100k mi) & $0.234^{*}$ & 0.062 & 0.406 \\
\hline
\end{tabular}

\begin{tabular}{|l|r|}
\hline \multicolumn{1}{|c|}{ Hypothesis } & -value \\
\hline No Effect of Ethanol in the Test Fuel (Gamma = 0) & 0.09 \\
\hline No Aging Effect with RE0 (Beta0 = 0) & $0.03^{*}$ \\
\hline No Effect of Ethanol in Road Fuel Aging (Beta1s $=0$ ) & 0.98 \\
\hline * Indicates effect is statistically significant at the 95\% confidence level.
\end{tabular}

${ }^{*}$ Indicates estimate is different from zero at the $95 \%$ confidence level.

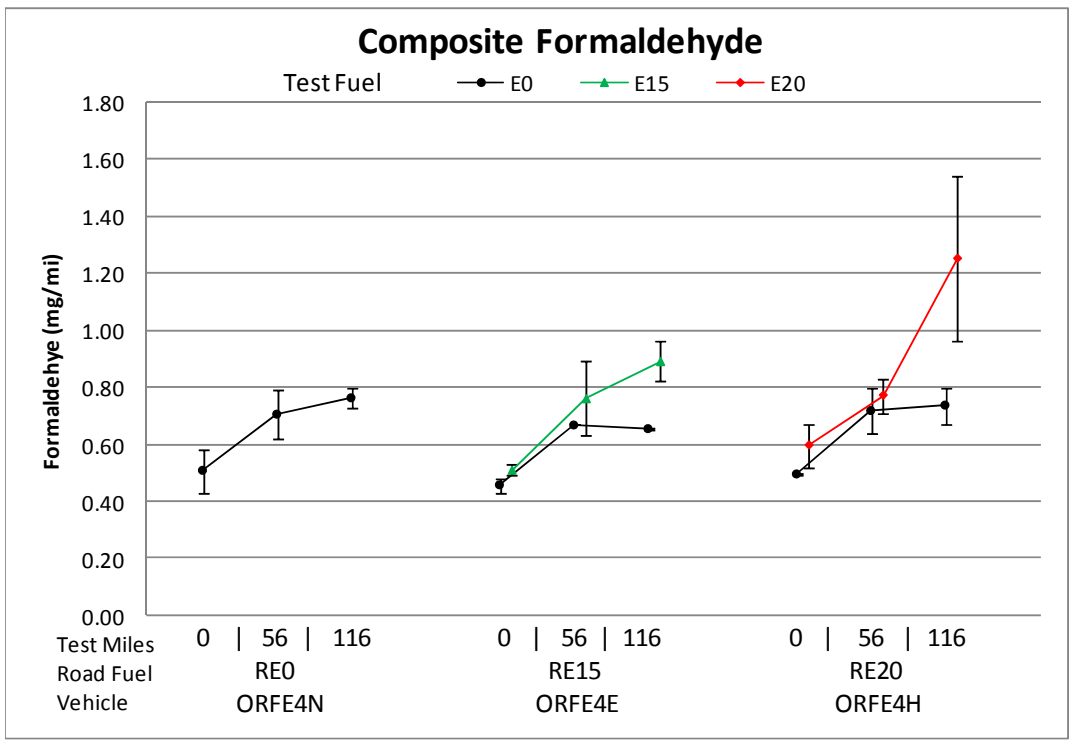

Error bars represent min and max measurements

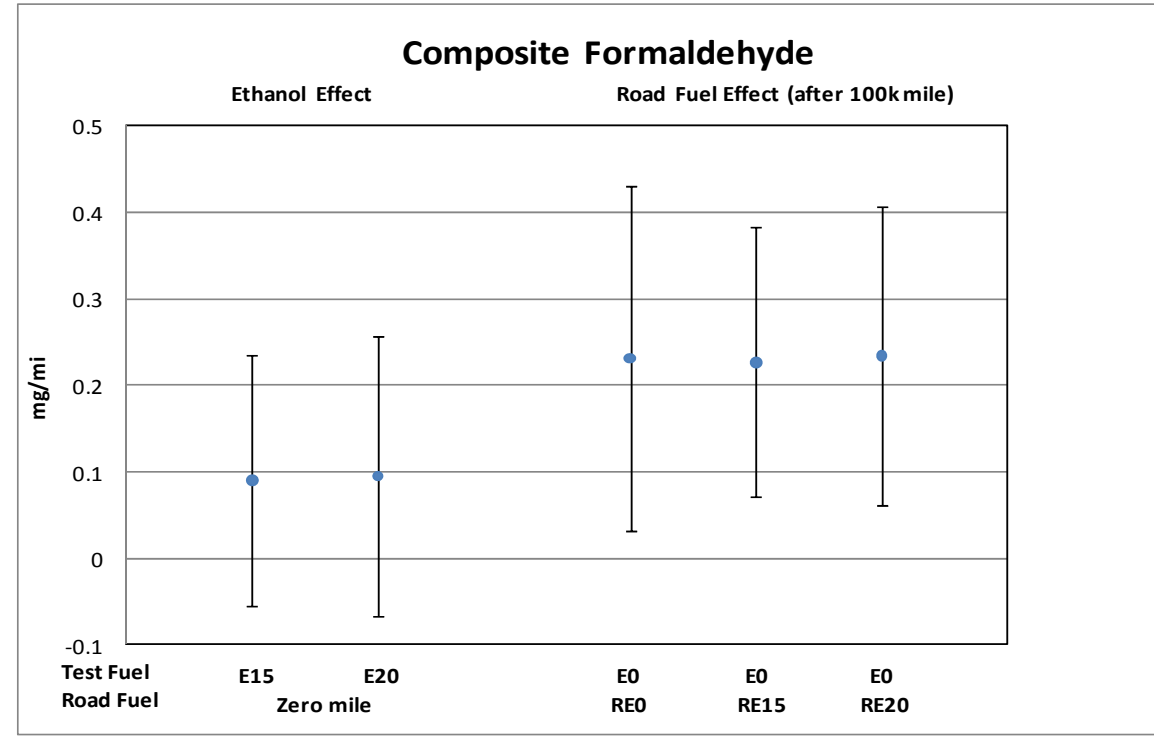

Error bars represent $95 \%$ confidence intervals on the estimated effects 
2009 Ford Explorer (Composite $\mathrm{CH} 4$ )

\begin{tabular}{|l|r|r|r|}
\hline \multicolumn{1}{|c|}{ Effect } & Estimate & $\begin{array}{c}\text { 95\% C.I. } \\
\text { Lower }\end{array}$ & $\begin{array}{c}\text { 95\% C.I. } \\
\text { Upper }\end{array}$ \\
\hline Ethanol Effect (E15 vs. E0) $(\Delta \mathrm{g} / \mathrm{mi})$ & 0.0010 & -0.0027 & 0.0047 \\
\hline Ethanol Effect $($ E20 vs. E0) $(\Delta \mathrm{g} / \mathrm{mi})$ & 0.0007 & -0.0030 & 0.0043 \\
\hline Road Fuel Aging Effect & & & \\
\hline Aging Effect with RE0 $(\Delta \mathrm{g} / \mathrm{mi}$ per 100k mi) & 0.0038 & -0.0017 & 0.0093 \\
\hline Aging Effect with RE15 $(\Delta \mathrm{g} / \mathrm{mi} \mathrm{per} \mathrm{100k} \mathrm{mi)}$ & 0.0032 & -0.0007 & 0.0071 \\
\hline Aging Effect with RE20 $(\Delta \mathrm{g} / \mathrm{mi}$ per 100k mi) & $0.0061^{*}$ & 0.0022 & 0.0100 \\
\hline
\end{tabular}

\begin{tabular}{|l|r|}
\hline \multicolumn{1}{|c|}{ Hypothesis } & p-value \\
\hline No Effect of Ethanol in the Test Fuel (Gamma = 0) & 0.75 \\
\hline No Aging Effect with RE0 (Beta0 = 0) & 0.14 \\
\hline No Effect of Ethanol in Road Fuel Aging (Beta1s=0) & 0.49 \\
\hline${ }^{*}$ Indicates effect is statistically significant at the 95\% confidence level.
\end{tabular}

* Indicates estimate is different from zero at the $95 \%$ confidence leve

Initial Odometers 4k

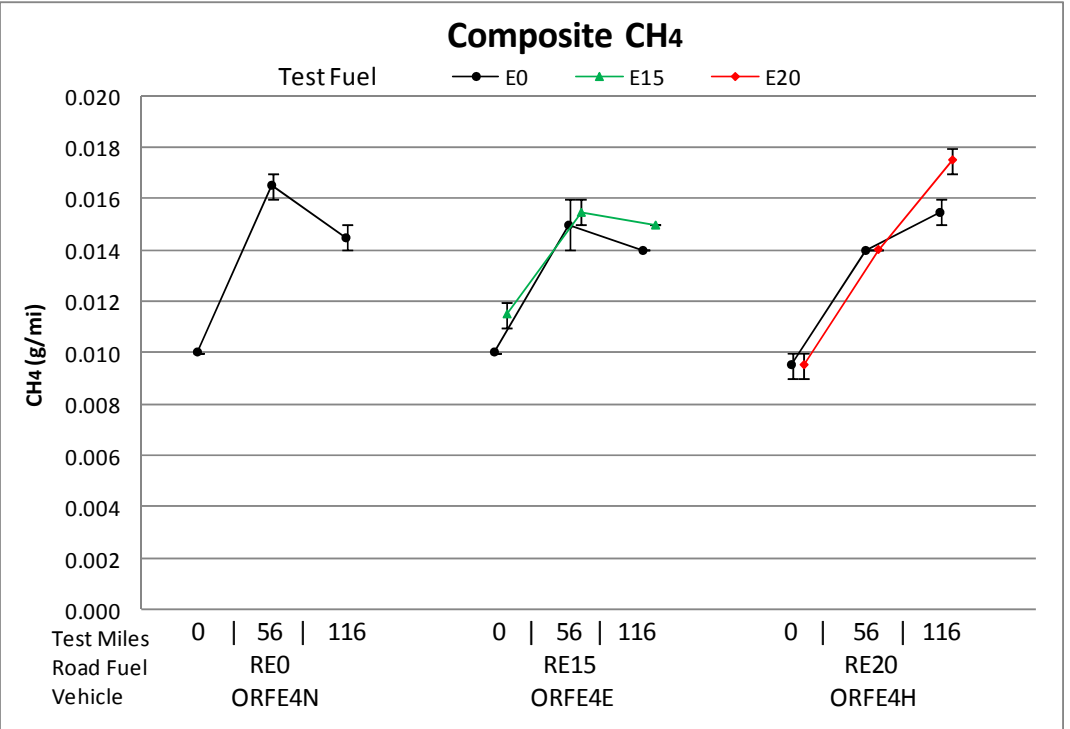

Error bars represent min and max measurements

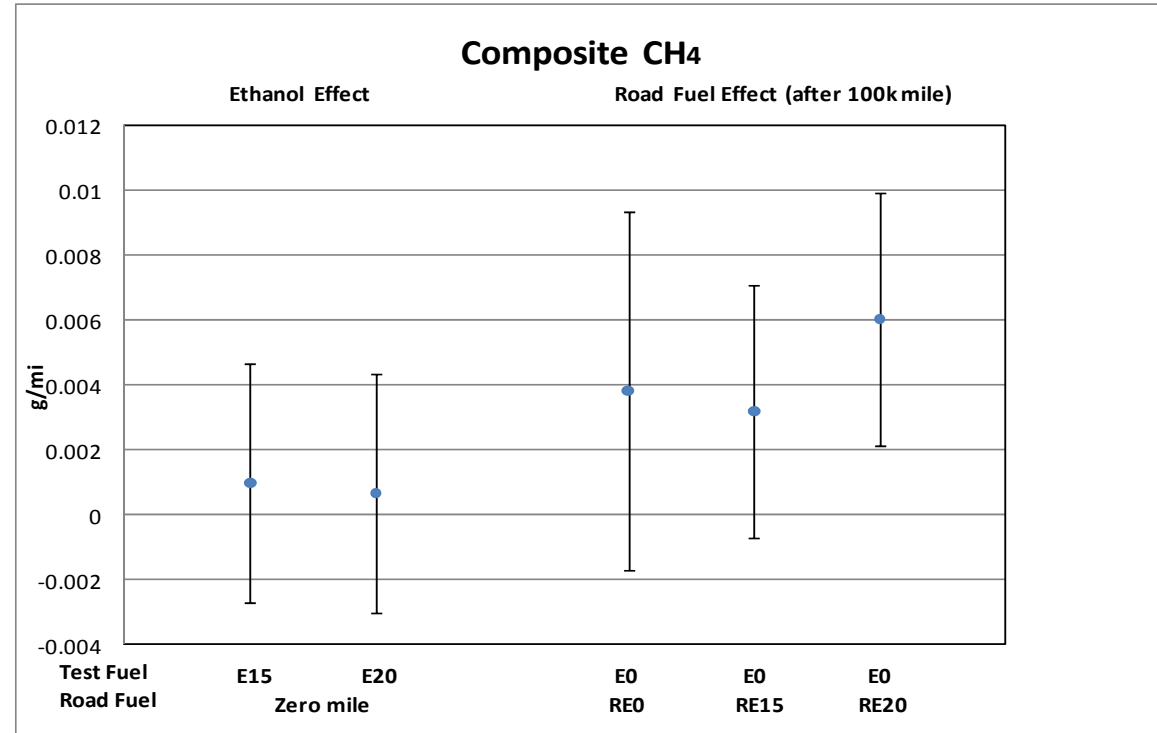

Error bars represent $95 \%$ confidence intervals on the estimated effects 


\section{Honda Civic - Composite Emissions Summary}

\begin{tabular}{|c|c|c|c|c|c|c|c|c|c|c|c|c|c|c|}
\hline \multirow{3}{*}{$\begin{array}{c}\begin{array}{c}\text { Emisssion Parameter } \\
\text { (units) }\end{array} \\
\text { Fuels } \\
\end{array}$} & \multicolumn{4}{|c|}{ Ethanol Effect } & \multicolumn{2}{|c|}{ Aging Effect with REO } & \multicolumn{4}{|c|}{ RExx Aging Effect on E0 Emissions } & \multirow{2}{*}{\multicolumn{3}{|c|}{$\begin{array}{c}\text { RExx Aging Effect on Exx Emissions } \\
\Delta \text { units per } 100 \mathrm{~K} \mathrm{mi}\end{array}$}} & \multirow{3}{*}{\begin{tabular}{|c|}
$\begin{array}{l}\text { Road and Test } \\
\text { Fuel Effects } \\
\text { are Additive }\end{array}$ \\
$\begin{array}{c}\text { Overall p- } \\
\text { value }\end{array}$ \\
\end{tabular}} \\
\hline & \multicolumn{3}{|c|}{$\Delta$ units vs. EO } & \multirow{2}{*}{$\mid \begin{array}{l}\text { Overall } \\
p \text {-value }\end{array}$} & \multirow{2}{*}{$\frac{\Delta \text { units per } 100 \mathrm{~K} \mathrm{mi}}{\text { REO/EO }}$} & \multirow{2}{*}{ Overall } & \multicolumn{3}{|c|}{$\Delta$ units per $100 \mathrm{~K} \mathrm{mi}$} & \multirow{2}{*}{ Overall } & & & & \\
\hline & E10 & E15 & E20 & & & & RE10/E0 & RE15/E0 & RE20/E0 & & RE10/E10 & RE15/E15 & RE20/E20 & \\
\hline $\mathrm{CO}(\mathrm{g} / \mathrm{mi})$ & NA & $-0.122^{*}$ & -0.038 & $<0.01^{*}$ & 0.044 & 0.24 & NA & $0.097 *$ & 0.032 & 0.21 & $\mathrm{NA}$ & NA & NA & 0.54 \\
\hline $\mathrm{NOx}(\mathrm{g} / \mathrm{mi})$ & $\mathrm{NA}$ & $0.011^{*}$ & $0.008^{*}$ & $0.02 *$ & $0.017^{*}$ & $0.01 *$ & NA & $0.013^{*}$ & $0.015^{*}$ & 0.79 & $\mathrm{NA}$ & NA & NA & 0.68 \\
\hline $\mathrm{NMHC}(\mathrm{g} / \mathrm{mi})$ & NA & $-0.011^{*}$ & $-0.011 *$ & $<0.01 *$ & $0.011^{*}$ & $0.04 *$ & NA & $0.011^{*}$ & 0.007 & 0.57 & $\mathrm{NA}$ & NA & NA & 0.10 \\
\hline NMOG (g/mi) & NA & $-0.009 *$ & $-0.008^{*}$ & $0.02 *$ & $0.012 *$ & $0.04 *$ & NA & $0.012 *$ & 0.007 & 0.54 & $\mathrm{NA}$ & NA & NA & 0.13 \\
\hline Fuel Econ (mi/gal) & $\mathrm{NA}$ & $-1.633^{*}$ & $-2.200 *$ & $<0.01 *$ & 0.388 & 0.36 & NA & -0.095 & 0.037 & 0.63 & $\mathrm{NA}$ & $\mathrm{NA}$ & NA & 0.60 \\
\hline Acetaldehyde $(\mathrm{mg} / \mathrm{mi})^{\#}$ & NA & $0.239 *$ & $0.468^{*}$ & $<0.01 *$ & 0.077 & 0.12 & NA & 0.063 & 0.020 & 0.51 & $\mathrm{NA}$ & NA & NA & 0.89 \\
\hline Formaldehyde $(\mathrm{mg} / \mathrm{mi})^{\#}$ & NA & 0.091 & 0.049 & 0.69 & 0.263 & 0.24 & NA & 0.197 & 0.241 & 0.96 & $\mathrm{NA}$ & NA & NA & 0.86 \\
\hline $\mathrm{CH}_{4}(\mathrm{~g} / \mathrm{mi})$ & $\mathrm{NA}$ & 0.0000 & 0.0007 & 0.67 & $0.0030 *$ & $0.03 *$ & $\mathrm{NA}$ & $0.0026 *$ & $0.0024 *$ & 0.90 & $\mathrm{NA}$ & $N A$ & NA & 0.87 \\
\hline
\end{tabular}

\# Log-normal model was used. Results are presented as changes in emissions at $0 \mathrm{k}$ mile.

\#\# Data did not support the assumption of linear effects with mileage.

*Indicates estimate is different from zero at the $95 \%$ confidence level. 
2009 Honda Civic (Composite CO)

\begin{tabular}{|l|r|r|r|}
\hline \multicolumn{1}{|c|}{ Effect } & & $\begin{array}{r}95 \% \text { C.I. } \\
\text { Es\% C.I. }\end{array}$ & $\begin{array}{r}\text { L5timate } \\
\text { Upper }\end{array}$ \\
\hline Ethanol Effect (E15 vs. E0) $(\Delta \mathrm{g} / \mathrm{mi})$ & $-0.122^{*}$ & -0.1748 & -0.0685 \\
\hline Ethanol Effect (E20 vs. E0) $(\Delta \mathrm{g} / \mathrm{mi})$ & -0.038 & -0.0915 & 0.0148 \\
\hline Road Fuel Aging Effect & & & \\
\hline Aging Effect with RE0 $(\Delta \mathrm{g} / \mathrm{mi}$ per 100k mi) & 0.044 & -0.0360 & 0.1236 \\
\hline Aging Effect with RE15 $(\Delta \mathrm{g} / \mathrm{mi} \mathrm{per} \mathrm{100k} \mathrm{mi)}$ & $0.097^{*}$ & 0.0405 & 0.1534 \\
\hline Aging Effect with RE20 $(\Delta \mathrm{g} / \mathrm{mi}$ per 100k mi) & 0.032 & -0.0240 & 0.0888 \\
\hline
\end{tabular}

\begin{tabular}{|l|r|}
\hline \multicolumn{1}{|c|}{ Hypothesis } & p-value \\
\hline No Effect of Ethanol in the Test Fuel (Gamma = 0) & $<0.01^{*}$ \\
\hline No Aging Effect with RE0 (Beta0 = 0) & 0.24 \\
\hline No Effect of Ethanol in Road Fuel Aging (Beta1s=0) & 0.21 \\
\hline
\end{tabular}

${ }^{*}$ Indicates estimate is different from zero at the $95 \%$ confidence level.

Initial Odometers 4k

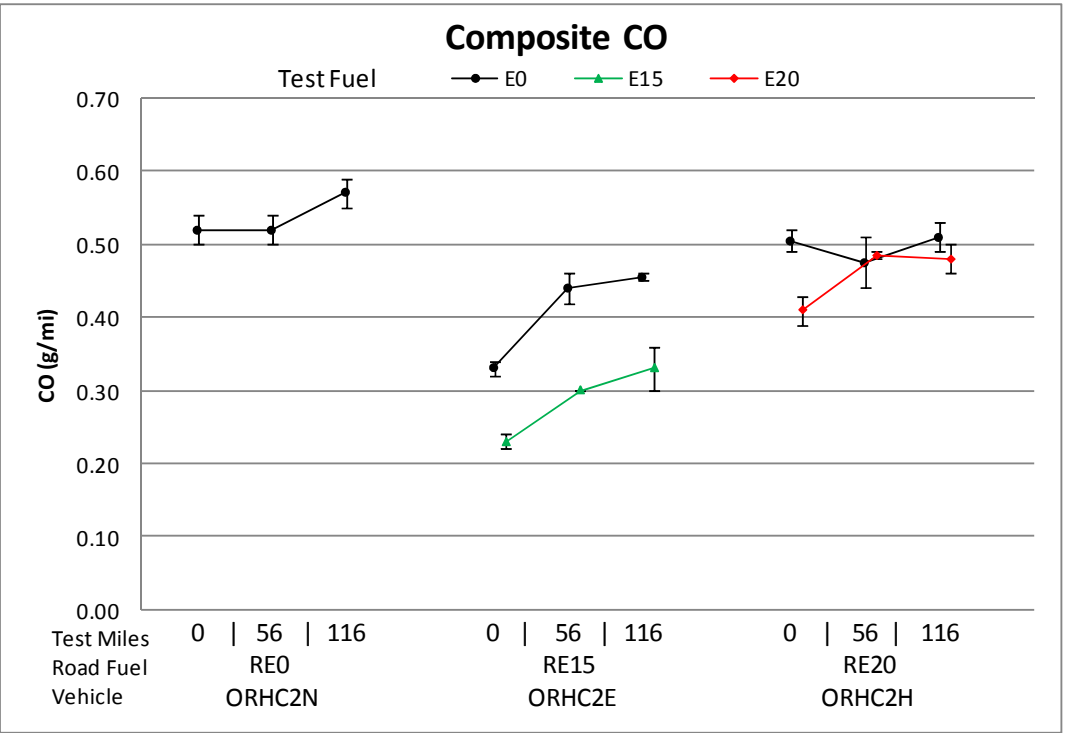

Error bars represent min and max measurements

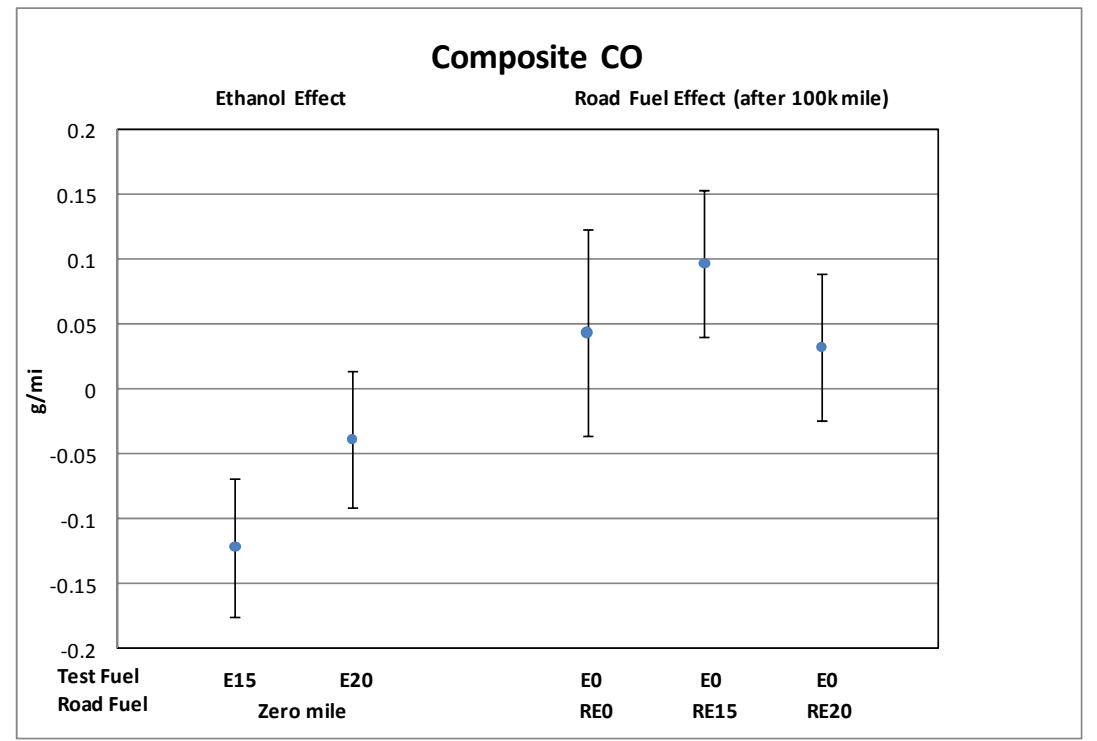

Error bars represent $95 \%$ confidence intervals on the estimated effects 
2009 Honda Civic (Composite NOx)

\begin{tabular}{|l|r|r|r|}
\hline \multicolumn{1}{|c|}{ Effect } & Estimate & $\begin{array}{c}95 \% \text { C.I. } \\
\text { Lower }\end{array}$ & $\begin{array}{c}\text { 95\% C.I. } \\
\text { Upper }\end{array}$ \\
\hline Ethanol Effect (E15 vs. E0) $(\Delta \mathrm{g} / \mathrm{mi})$ & $0.011^{*}$ & 0.0026 & 0.0188 \\
\hline Ethanol Effect $(E 20 \mathrm{vs.} \mathrm{E0)}(\Delta \mathrm{g} / \mathrm{mi})$ & $0.008^{*}$ & 0.0004 & 0.0166 \\
\hline Road Fuel Aging Effect & & & \\
\hline Aging Effect with RE0 $(\Delta \mathrm{g} / \mathrm{mi}$ per 100k mi) & $0.017^{*}$ & 0.0050 & 0.0293 \\
\hline Aging Effect with RE15 $(\Delta \mathrm{g} / \mathrm{mi} \mathrm{per} \mathrm{100k} \mathrm{mi)}$ & $0.013^{*}$ & 0.0042 & 0.0214 \\
\hline Aging Effect with RE20 $(\Delta \mathrm{g} / \mathrm{mi}$ per 100k mi) & $0.015^{*}$ & 0.0062 & 0.0234 \\
\hline
\end{tabular}

\begin{tabular}{|l|r|}
\hline \multicolumn{1}{|c|}{ Hypothesis } & p-value \\
\hline No Effect of Ethanol in the Test Fuel (Gamma $=0)$ & $0.02^{*}$ \\
\hline No Aging Effect with RE0 (Beta0 $=0)$ & $0.01^{*}$ \\
\hline No Effect of Ethanol in Road Fuel Aging (Beta1s=0) & 0.79 \\
\hline${ }^{*}$ Indicates effect is statistically significant at the 95\% confidence level.
\end{tabular}

${ }^{*}$ Indicates estimate is different from zero at the $95 \%$ confidence level.

Initial Odometers 4k
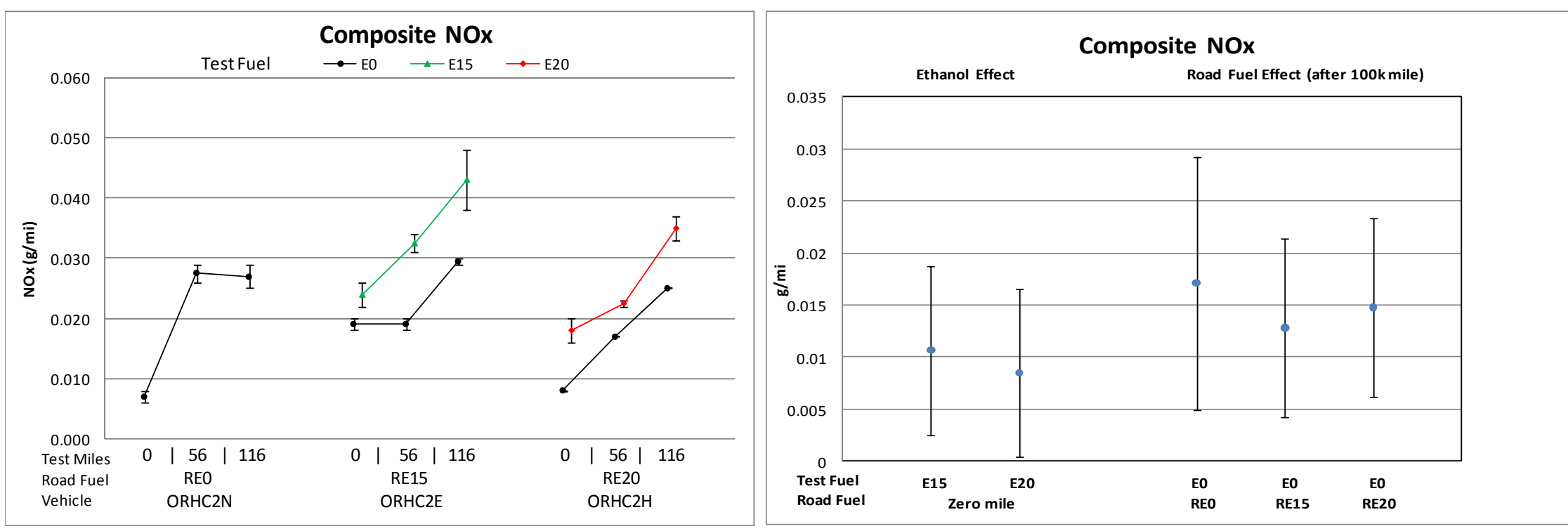

Error bars represent min and max measurements

Error bars represent $95 \%$ confidence intervals on the estimated effects 
2009 Honda Civic (Composite Nonmethane Hydrocarbons)

\begin{tabular}{|l|r|r|r|}
\hline \multicolumn{1}{|c|}{ Effect } & & $\begin{array}{r}\text { 95\% C.I. } \\
\text { Estimate }\end{array}$ & $\begin{array}{c}\text { 95\% C.I. } \\
\text { Upper }\end{array}$ \\
\hline Ethanol Effect $(E 15$ vs. E0) $(\Delta \mathrm{g} / \mathrm{mi})$ & $-0.011^{*}$ & -0.0179 & -0.0038 \\
\hline Ethanol Effect (E20 vs. E0) $(\Delta \mathrm{g} / \mathrm{mi})$ & $-0.011^{*}$ & -0.0185 & -0.0043 \\
\hline Road Fuel Aging Effect & & & \\
\hline Aging Effect with RE0 $(\Delta \mathrm{g} / \mathrm{mi}$ per 100k mi) & $0.011^{*}$ & 0.0008 & 0.0220 \\
\hline Aging Effect with RE15 $(\Delta \mathrm{g} / \mathrm{mi}$ per 100k mi) & $0.011^{*}$ & 0.0032 & 0.0183 \\
\hline Aging Effect with RE20 $(\Delta \mathrm{g} / \mathrm{mi}$ per 100k mi) & 0.007 & -0.0010 & 0.0140 \\
\hline
\end{tabular}

\begin{tabular}{|l|r|}
\hline \multicolumn{1}{|c|}{ Hypothesis } & p-value \\
\hline No Effect of Ethanol in the Test Fuel (Gamma $=0)$ & $<0.01^{*}$ \\
\hline No Aging Effect with RE0 (Beta0 $=0)$ & $0.04^{*}$ \\
\hline No Effect of Ethanol in Road Fuel Aging (Beta1s=0) & 0.57 \\
\hline${ }^{*}$ Indicates effect is statistically significant at the 95\% confidence level.
\end{tabular}

${ }^{*}$ Indicates estimate is different from zero at the $95 \%$ confidence level.

Initial Odometers 4k

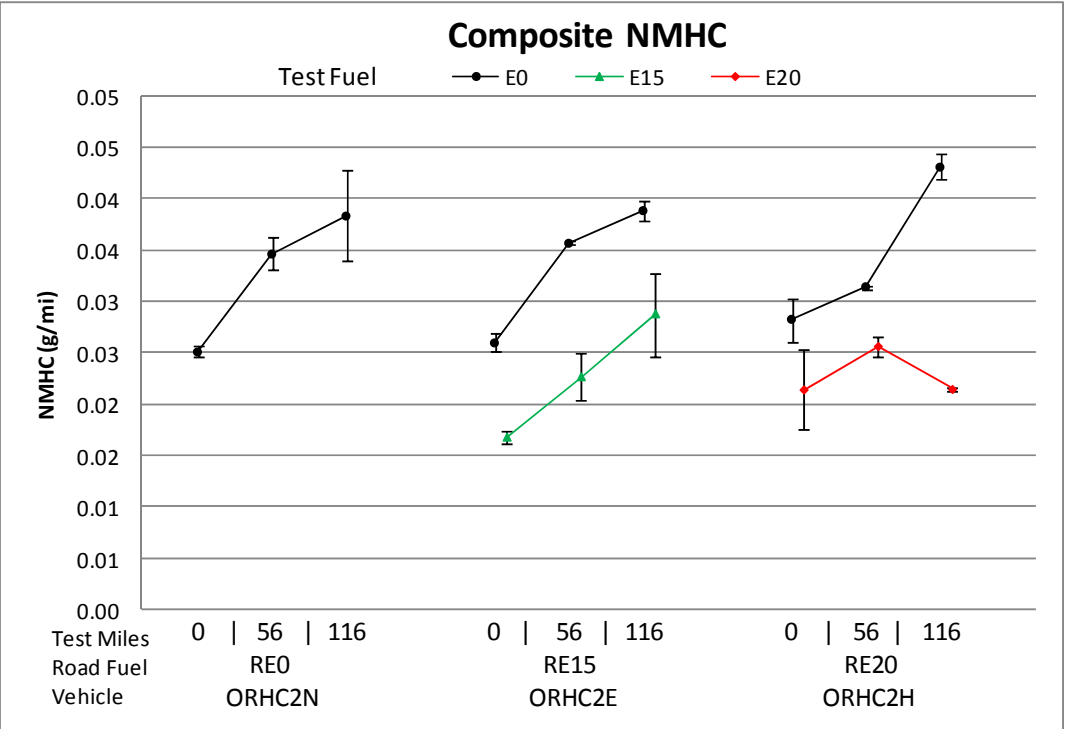

Error bars represent min and max measurements

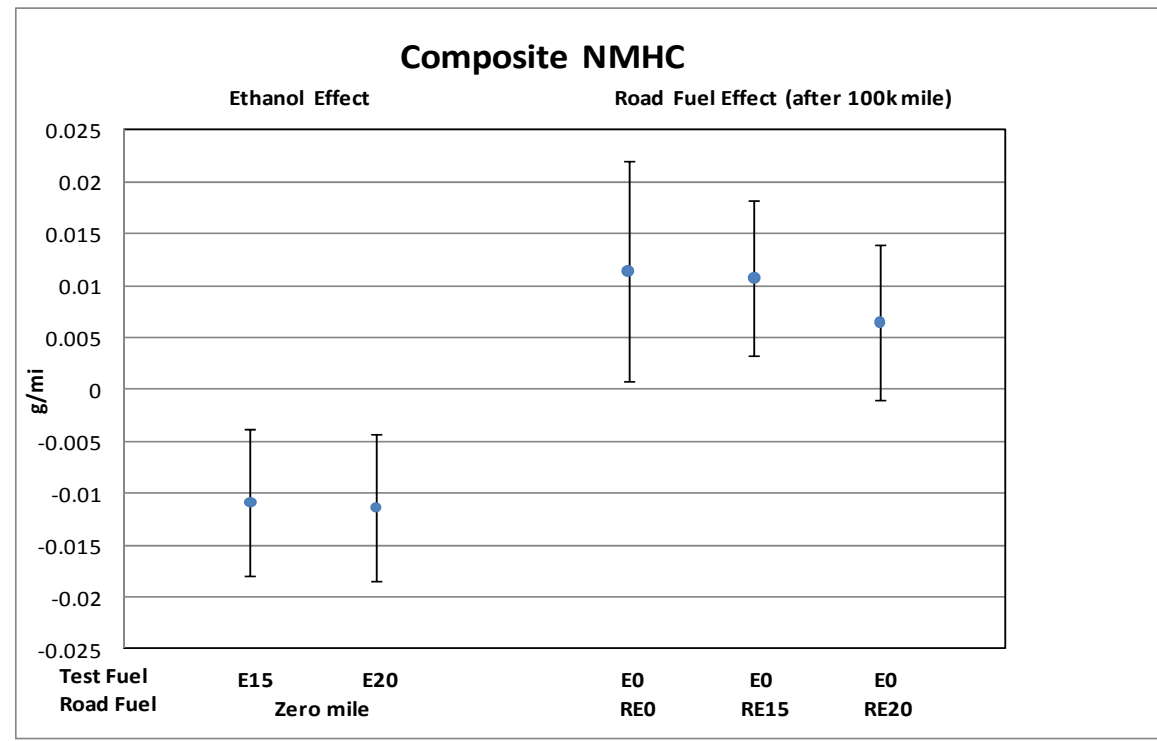

Error bars represent $95 \%$ confidence intervals on the estimated effects 
2009 Honda Civic (Composite Nonmethane Organic Gases)

\begin{tabular}{|l|r|r|r|}
\hline \multicolumn{1}{|c|}{ Effect } & Estimate & $\begin{array}{c}95 \% \text { C.I. } \\
\text { Lower }\end{array}$ & $\begin{array}{c}\text { 95\% C.I. } \\
\text { Upper }\end{array}$ \\
\hline Ethanol Effect $(E 15 \mathrm{vs}$. E0) $(\Delta \mathrm{g} / \mathrm{mi})$ & $-0.009^{*}$ & -0.0161 & -0.0012 \\
\hline Ethanol Effect $($ E20 vs. E0) $(\Delta \mathrm{g} / \mathrm{mi})$ & $-0.008^{*}$ & -0.0154 & -0.0006 \\
\hline Road Fuel Aging Effect & & & \\
\hline Aging Effect with RE0 $(\Delta \mathrm{g} / \mathrm{mi}$ per 100k mi) & $0.012^{*}$ & 0.0004 & 0.0227 \\
\hline Aging Effect with RE15 $(\Delta \mathrm{g} / \mathrm{mi} \mathrm{per} \mathrm{100k} \mathrm{mi)}$ & $0.012^{*}$ & 0.0041 & 0.0199 \\
\hline Aging Effect with RE20 $(\Delta \mathrm{g} / \mathrm{mi}$ per 100k mi) & 0.007 & -0.0010 & 0.0148 \\
\hline
\end{tabular}

\begin{tabular}{|l|r|}
\hline \multicolumn{1}{|c|}{ Hypothesis } & -value \\
\hline No Effect of Ethanol in the Test Fuel (Gamma $=0)$ & $0.02^{*}$ \\
\hline No Aging Effect with RE0 (Beta0 $=0$ ) & $0.04^{*}$ \\
\hline No Effect of Ethanol in Road Fuel Aging (Beta1s $=0$ ) & 0.54 \\
\hline * Indicates effect is statistically significant at the 95\% confidence level.
\end{tabular}

${ }^{*}$ Indicates estimate is different from zero at the $95 \%$ confidence level.

Initial Odometers 4k

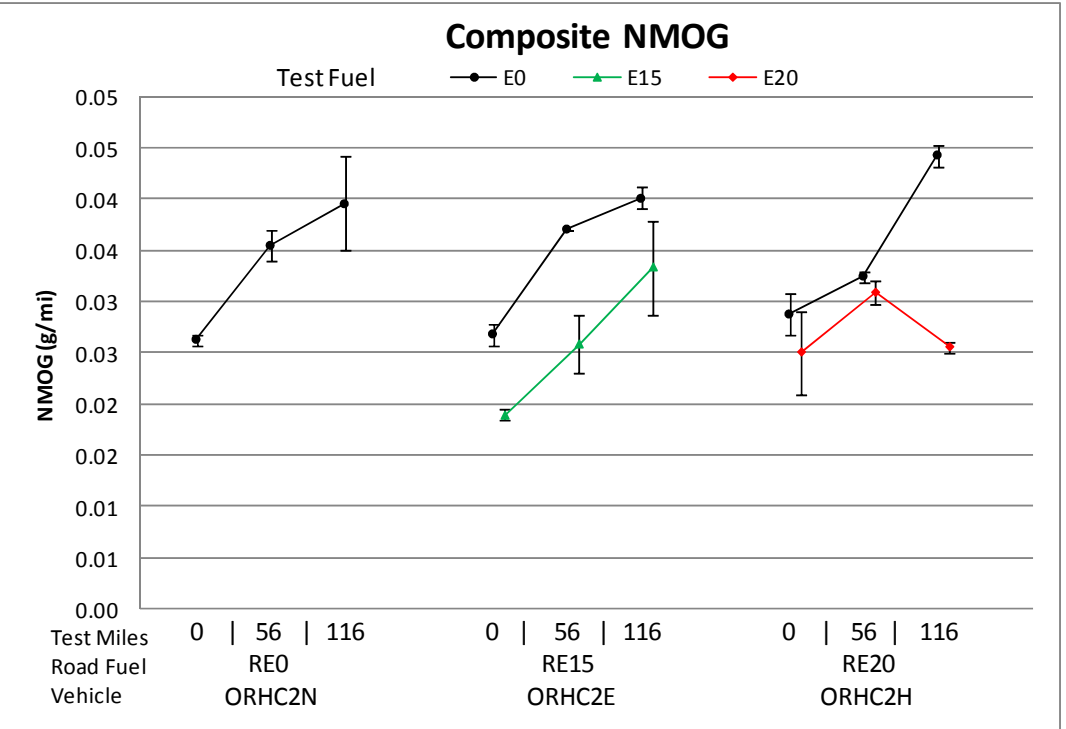

Error bars represent min and max measurements

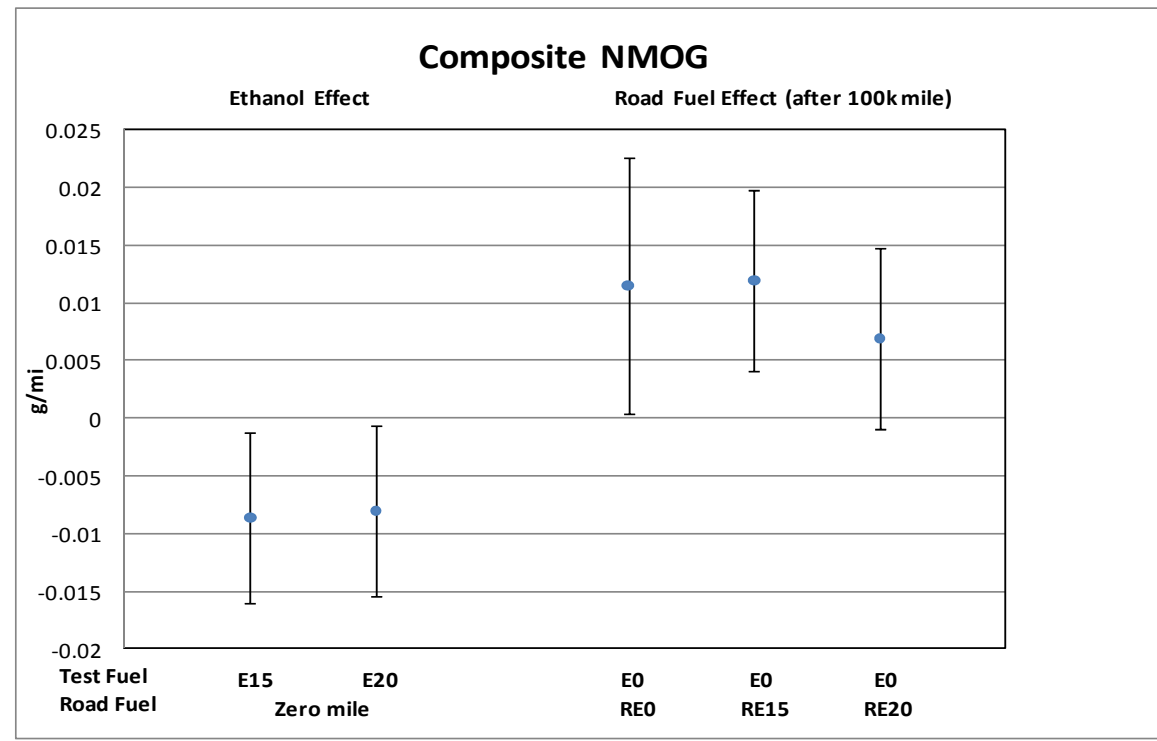

Error bars represent $95 \%$ confidence intervals on the estimated effects 
2009 Honda Civic (Composite Fuel Economy)

\begin{tabular}{|l|r|r|r|}
\hline \multicolumn{1}{|c|}{ Effect } & & $\begin{array}{r}95 \% \text { C.I. } \\
\text { Low }\end{array}$ & $\begin{array}{r}95 \text { C.I. } \\
\text { Upper }\end{array}$ \\
\hline Ethanol Effect (E15 vs. E0) $(\Delta \mathrm{mi} / \mathrm{gal})$ & $-1.633^{*}$ & -2.260 & -1.007 \\
\hline Ethanol Effect $($ E20 vs. E0) $(\Delta \mathrm{mi} / \mathrm{gal})$ & $-2.200^{*}$ & -2.827 & -1.573 \\
\hline Road Fuel Aging Effect & & & \\
\hline Aging Effect with RE0 $(\Delta \mathrm{mi} / \mathrm{gal}$ per 100k mi) & 0.388 & -0.552 & 1.329 \\
\hline Aging Effect with RE15 $(\Delta \mathrm{mi} / \mathrm{gal}$ per 100k mi) & -0.095 & -0.760 & 0.570 \\
\hline Aging Effect with RE20 $(\Delta \mathrm{mi} / \mathrm{gal}$ per 100k mi) & 0.037 & -0.628 & 0.702 \\
\hline
\end{tabular}

\begin{tabular}{|l|r|}
\hline \multicolumn{1}{|c|}{ Hypothesis } & p-value \\
\hline No Effect of Ethanol in the Test Fuel (Gamma = 0) & $<0.01^{*}$ \\
\hline No Aging Effect with RE0 (Beta0 = 0) & 0.36 \\
\hline No Effect of Ethanol in Road Fuel Aging (Beta1s=0) & 0.63 \\
\hline
\end{tabular}

* Indicates estimate is different from zero at the $95 \%$ confidence level.

Initial Odometers 4k

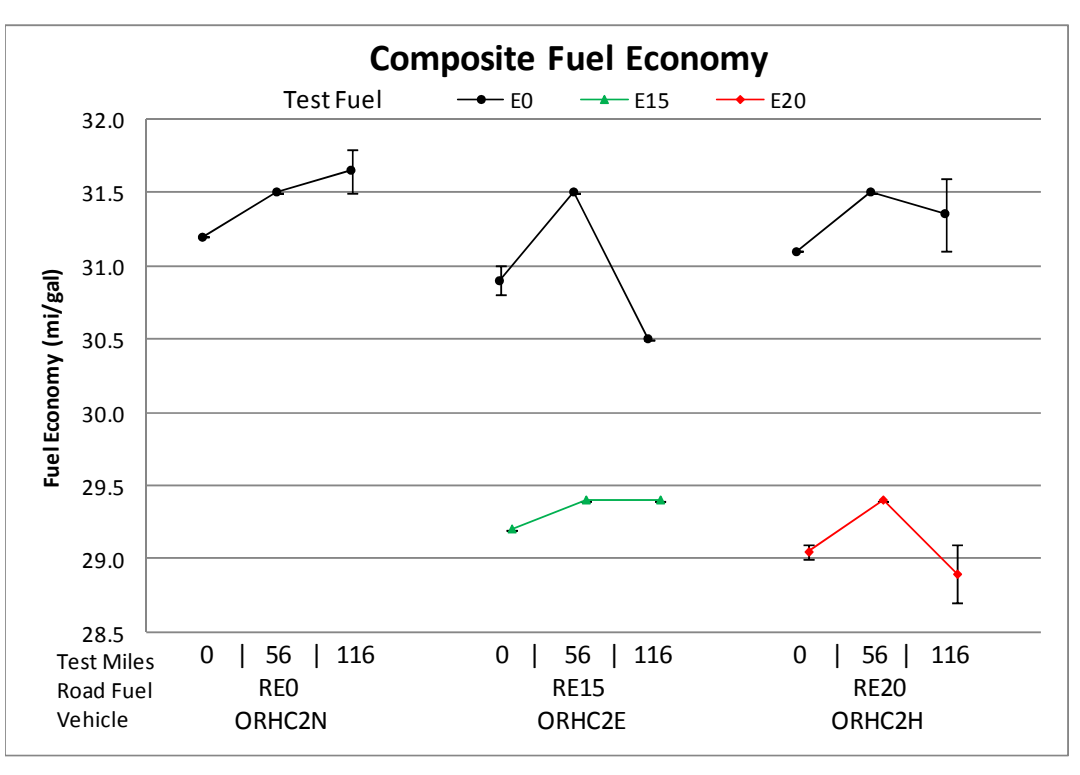

Error bars represent min and max measurements

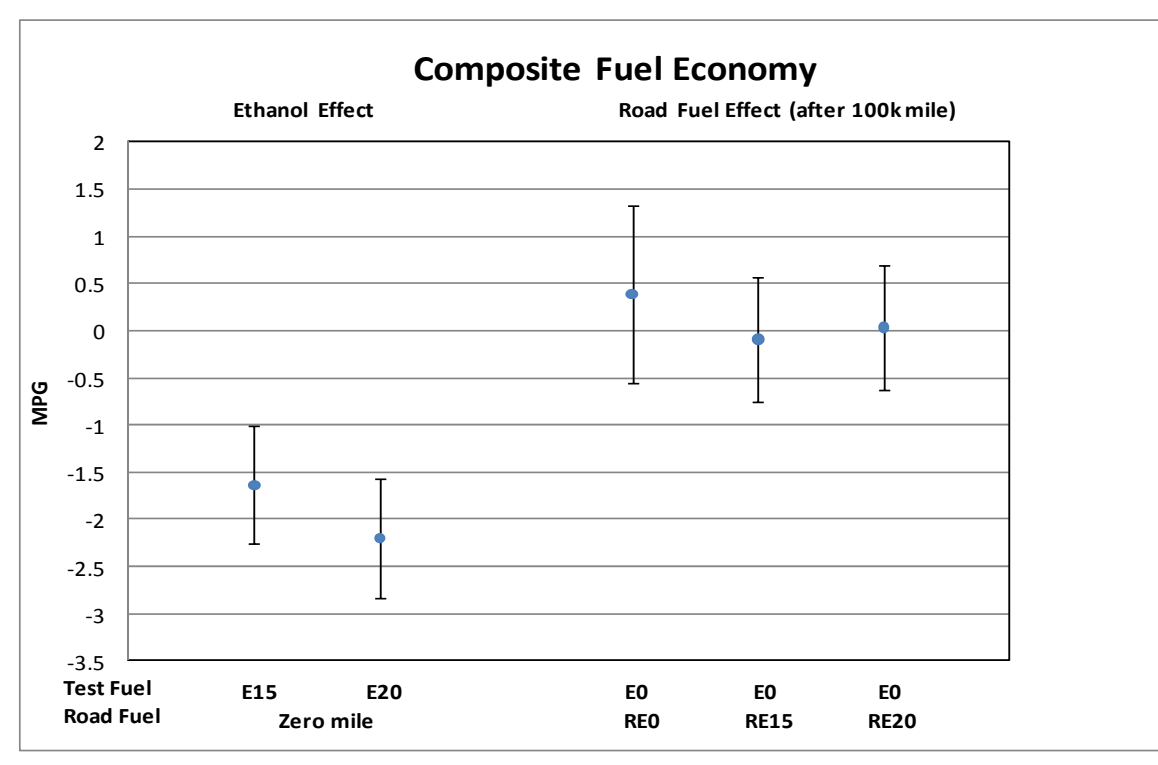

Error bars represent $95 \%$ confidence intervals on the estimated effects 
2009 Honda Civic (Composite Acetaldehyde)

\begin{tabular}{|l|r|r|r|}
\hline \multicolumn{1}{|c|}{ Effect } & Estimate & $\begin{array}{c}95 \% \text { C.I. } \\
\text { Lower }\end{array}$ & $\begin{array}{c}\text { 95\% C.I. } \\
\text { Upper }\end{array}$ \\
\hline Ethanol Effect (E15 vs. E0) $(\Delta \mathrm{mg} / \mathrm{mi})$ & $0.239^{*}$ & 0.0753 & 0.4022 \\
\hline Ethanol Effect $($ E20 vs. E0) $(\Delta \mathrm{mg} / \mathrm{mi})$ & $0.468^{*}$ & 0.2091 & 0.7260 \\
\hline Road Fuel Aging Effect & & & \\
\hline Aging Effect with RE0 $(\Delta \mathrm{mg} / \mathrm{mi}$ per 100k mi) & 0.077 & -0.0222 & 0.1759 \\
\hline Aging Effect with RE15 $(\Delta \mathrm{mg} / \mathrm{mi}$ per 100k mi) & 0.063 & -0.0341 & 0.1606 \\
\hline Aging Effect with RE20 $(\Delta \mathrm{mg} / \mathrm{mi}$ per 100k mi) & 0.020 & -0.0791 & 0.1187 \\
\hline
\end{tabular}

\begin{tabular}{|l|r|}
\hline \multicolumn{1}{|c|}{ Hypothesis } & -value \\
\hline No Effect of Ethanol in the Test Fuel (Gamma $=0)$ & $<0.01^{*}$ \\
\hline No Aging Effect with RE0 (Beta0 $=0$ ) & 0.12 \\
\hline No Effect of Ethanol in Road Fuel Aging (Beta1s $=0$ ) & 0.51 \\
\hline * Indicates effect is statistically significant at the 95\% confidence level.
\end{tabular}

* Indicates estimate is different from zero at the $95 \%$ confidence level.

Initial Odometers 4k
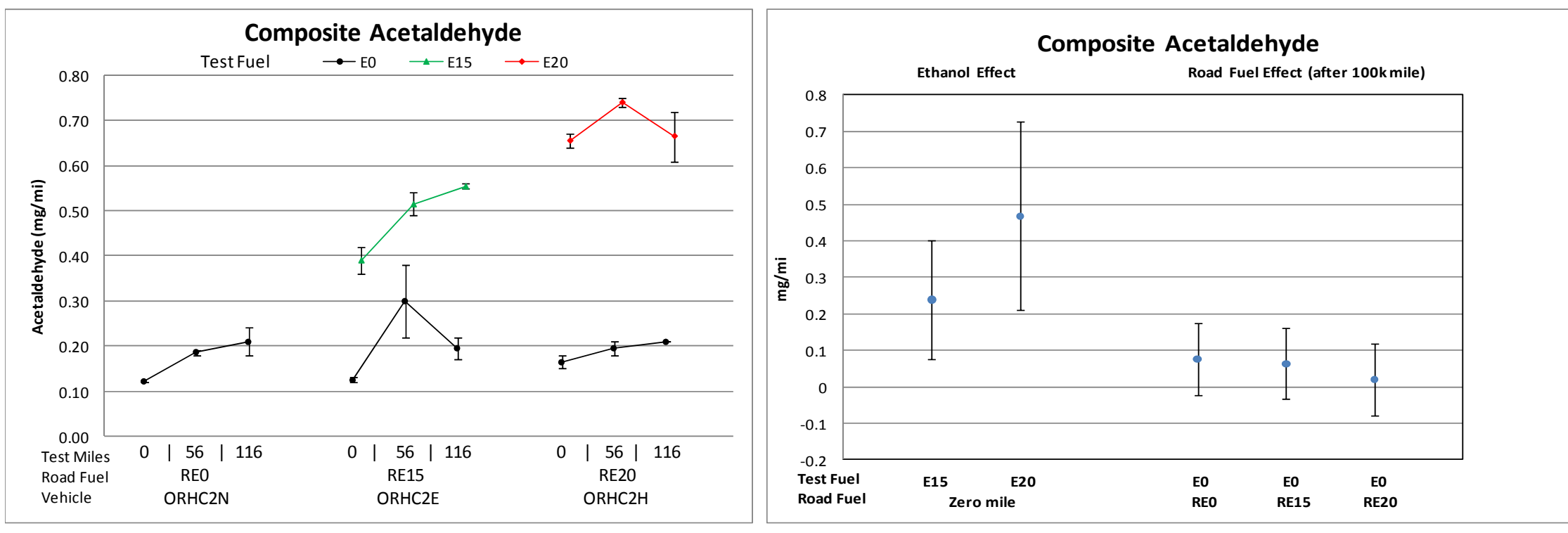

Error bars represent min and max measurements

Error bars represent $95 \%$ confidence intervals on the estimated effects 
2009 Honda Civic (Composite Formaldehyde)

\begin{tabular}{|l|r|r|r|}
\hline \multicolumn{1}{|c|}{ Effect } & & $\begin{array}{c}95 \% \text { C.I. } \\
\text { Low\% C.I. } \\
\text { Upper }\end{array}$ \\
\hline Ethanol Effect (E15 vs. E0) $(\Delta \mathrm{mg} / \mathrm{mi})$ & 0.091 & -0.2651 & 0.4474 \\
\hline Ethanol Effect (E20 vs. E0) $(\Delta \mathrm{mg} / \mathrm{mi})$ & 0.049 & -0.3949 & 0.4932 \\
\hline Road Fuel Aging Effect & & & \\
\hline Aging Effect with RE0 $(\Delta \mathrm{mg} / \mathrm{mi}$ per 100k mi) & 0.263 & -0.2234 & 0.7488 \\
\hline Aging Effect with RE15 $(\Delta \mathrm{mg} / \mathrm{mi}$ per 100k mi) & 0.197 & -0.1914 & 0.5850 \\
\hline Aging Effect with RE20 $(\Delta \mathrm{mg} / \mathrm{mi}$ per 100k mi) & 0.241 & -0.2755 & 0.7572 \\
\hline
\end{tabular}

\begin{tabular}{|l|r|}
\hline \multicolumn{1}{|c|}{ Hypothesis } & p-value \\
\hline No Effect of Ethanol in the Test Fuel (Gamma = 0) & 0.69 \\
\hline No Aging Effect with RE0 (Beta0 = 0) & 0.24 \\
\hline No Effect of Ethanol in Road Fuel Aging (Beta1s=0) & 0.96 \\
\hline${ }^{*}$ Indicates effect is statistically significant at the 95\% confidence level.
\end{tabular}

* Indicates estimate is different from zero at the $95 \%$ confidence level.

Initial Odometers 4k

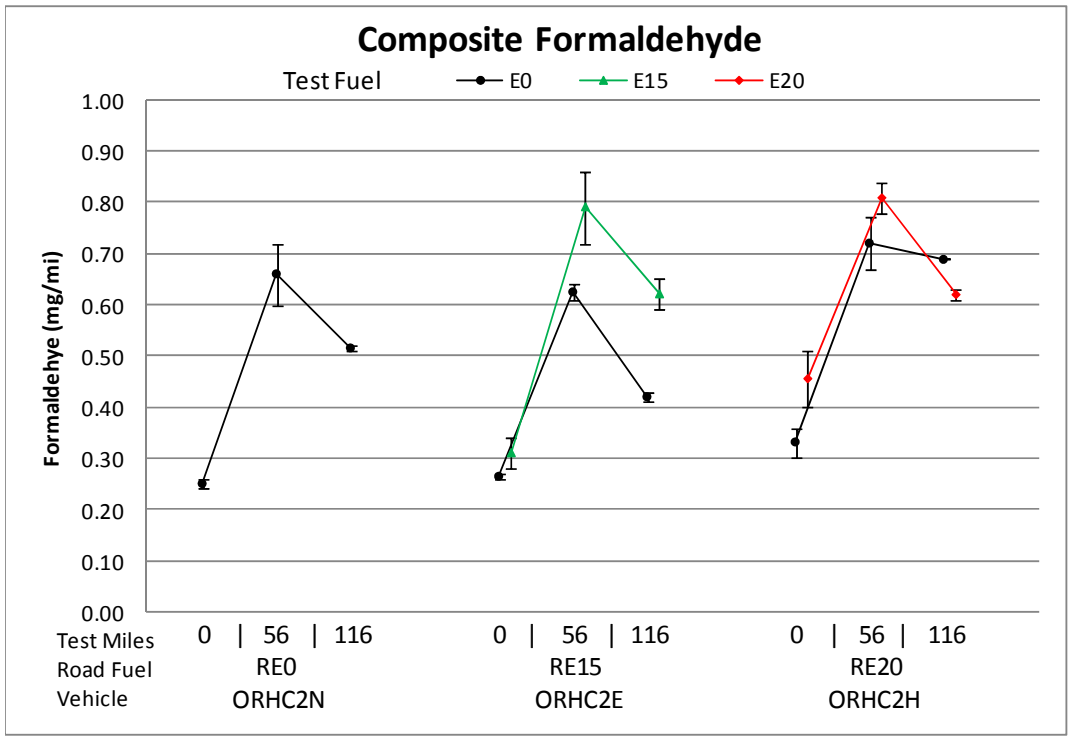

Error bars represent min and max measurements

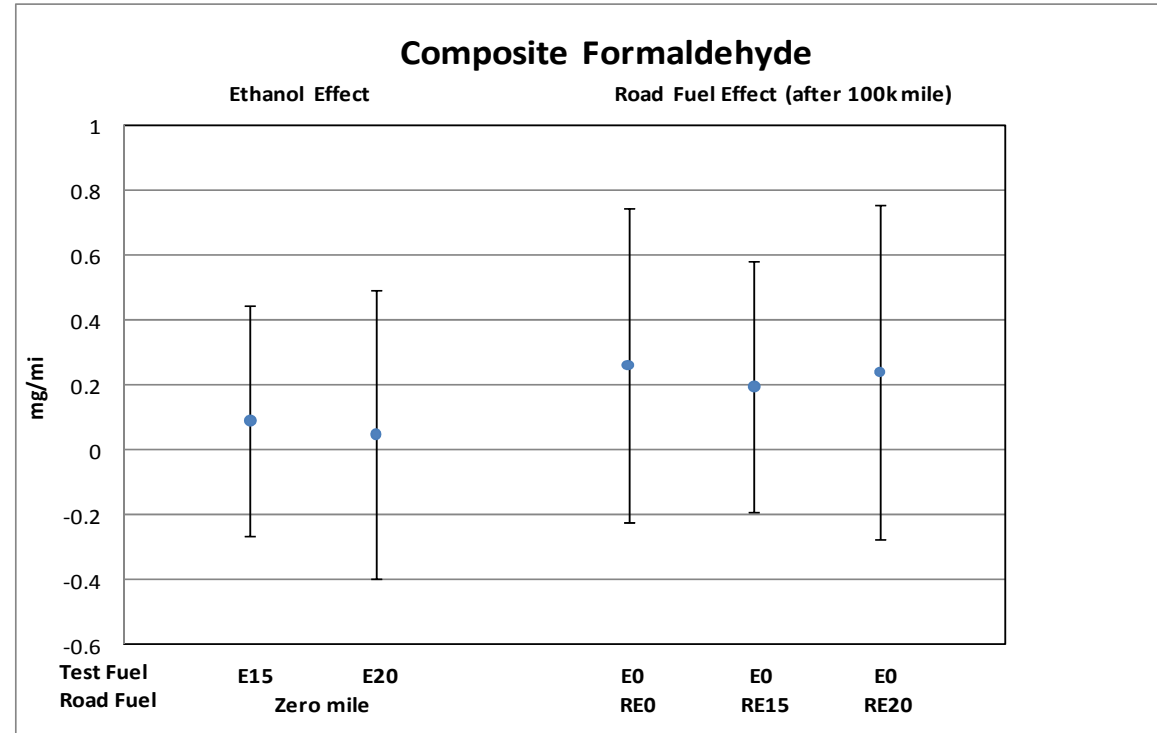

Error bars represent $95 \%$ confidence intervals on the estimated effects 
2009 Honda Civic (Composite $\mathrm{CH} 4$ )

\begin{tabular}{|l|r|r|r|}
\hline \multicolumn{1}{|c|}{ Effect } & & $\begin{array}{c}95 \% \text { C.I. } \\
\text { Lower }\end{array}$ & $\begin{array}{c}95 \text { C.I. } \\
\text { Upper }\end{array}$ \\
\hline Ethanol Effect (E15 vs. E0) $(\Delta \mathrm{g} / \mathrm{mi})$ & 0.0000 & -0.0017 & 0.0017 \\
\hline Ethanol Effect (E20 vs. E0) $(\Delta \mathrm{g} / \mathrm{mi})$ & 0.0007 & -0.0010 & 0.0024 \\
\hline Road Fuel Aging Effect & & & \\
\hline Aging Effect with RE0 $(\Delta \mathrm{g} / \mathrm{mi}$ per 100k mi) & $0.0030^{*}$ & 0.0004 & 0.0055 \\
\hline Aging Effect with RE15 $(\Delta \mathrm{g} / \mathrm{mi} \mathrm{per} \mathrm{100k} \mathrm{mi)}$ & $0.0026^{*}$ & 0.0008 & 0.0044 \\
\hline Aging Effect with RE20 $(\Delta \mathrm{g} / \mathrm{mi}$ per 100k mi) & $0.0024^{*}$ & 0.0006 & 0.0042 \\
\hline
\end{tabular}

\begin{tabular}{|l|r|}
\hline \multicolumn{1}{|c|}{ Hypothesis } & p-value \\
\hline No Effect of Ethanol in the Test Fuel (Gamma = 0) & 0.67 \\
\hline No Aging Effect with RE0 (Beta0 = 0) & $0.03^{*}$ \\
\hline No Effect of Ethanol in Road Fuel Aging (Beta1s=0) & 0.90 \\
\hline * Indicates effect is statistically significant at the 95\% confidence level.
\end{tabular}

* Indicates estimate is different from zero at the $95 \%$ confidence level.

Initial Odometers 4k

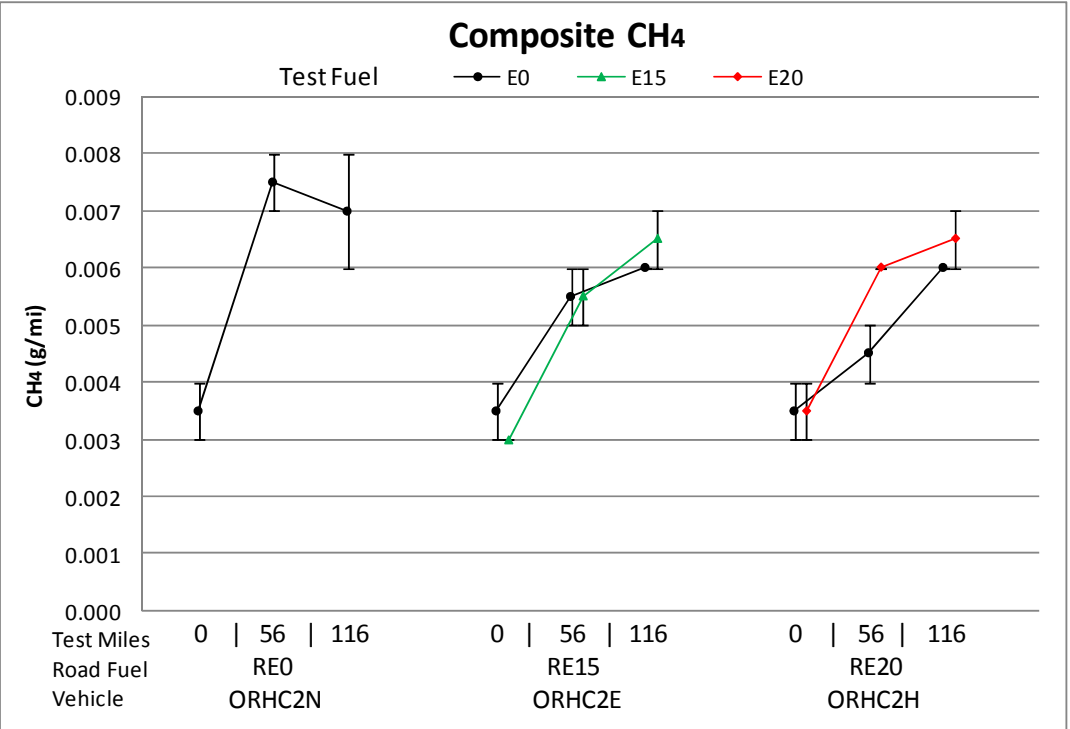

Error bars represent min and max measurements

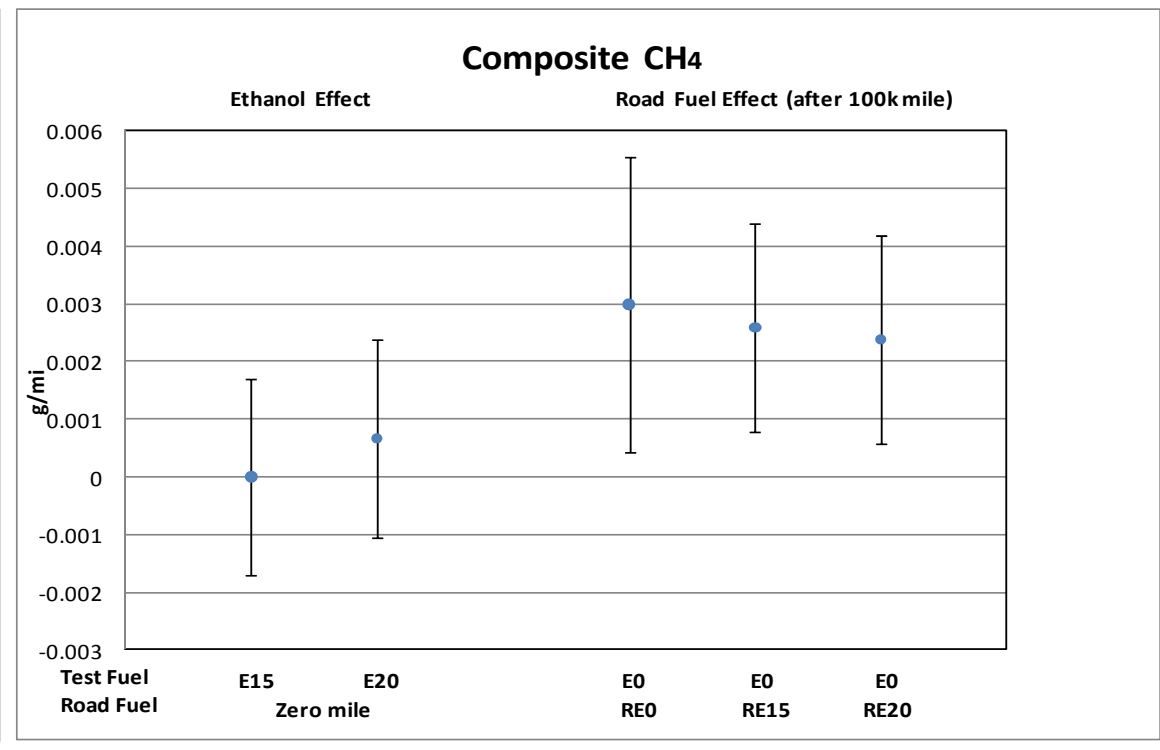

Error bars represent $95 \%$ confidence intervals on the estimated effects 


\section{Toyota Corolla - Composite Emissions Summary}

\begin{tabular}{|c|c|c|c|c|c|c|c|c|c|c|c|c|c|c|}
\hline \multirow{2}{*}{$\begin{array}{c}\text { Emisssion Parameter } \\
\text { (units) }\end{array}$} & \multicolumn{4}{|c|}{ Ethanol Effect } & \multicolumn{2}{|c|}{ Aging Effect with REO } & \multicolumn{4}{|c|}{ RExx Aging Effect on E0 Emissions } & \multirow{2}{*}{\multicolumn{3}{|c|}{$\begin{array}{c}\text { RExx Aging Effect on Exx Emissions } \\
\Delta \text { units per } 100 \mathrm{~K} \mathrm{mi}\end{array}$}} & \multirow{3}{*}{\begin{tabular}{|c|}
$\begin{array}{c}\text { Road and Test } \\
\text { Fuel Effects } \\
\text { are Additive }\end{array}$ \\
$\begin{array}{c}\text { Overall p- } \\
\text { value }\end{array}$ \\
\end{tabular}} \\
\hline & \multicolumn{3}{|c|}{$\Delta$ units vs. EO } & \multirow{2}{*}{$\mid \begin{array}{c}\text { Overall } \\
p \text {-value }\end{array}$} & \multirow{2}{*}{$\frac{\Delta \text { units per } 100 \mathrm{~K} \mathrm{mi}}{\text { REO/EO }}$} & \multirow{2}{*}{$\begin{array}{l}\text { Overall } \\
p \text {-value }\end{array}$} & \multicolumn{3}{|c|}{$\Delta$ units per $100 \mathrm{~K} \mathrm{mi}$} & \multirow{2}{*}{$\begin{array}{l}\text { Overall } \\
p \text {-value }\end{array}$} & & & & \\
\hline Fuels & E10 & E15 & E20 & & & & RE10/E0 & RE15/E0 & RE20/E0 & & RE10/E10 & RE15/E15 & RE20/E20 & \\
\hline $\mathrm{CO}(\mathrm{g} / \mathrm{mi})$ & NA & -0.033 & -0.087 & 0.56 & 0.106 & 0.42 & NA & $0.217^{*}$ & 0.204 & 0.76 & NA & $\mathrm{NA}$ & $\mathrm{NA}$ & 0.85 \\
\hline NOx (g/mi) & $\mathrm{NA}$ & -0.003 & 0.003 & 0.64 & $0.034^{*}$ & $<0.01^{*}$ & NA & $0.027^{*}$ & $0.018^{*}$ & 0.17 & $\mathrm{NA}$ & $\mathrm{NA}$ & $\mathrm{NA}$ & 0.81 \\
\hline $\mathrm{NMHC}(\mathrm{g} / \mathrm{mi})^{\mathrm{a}}$ & $\mathrm{NA}$ & -0.0018 & -0.0057 & 0.59 & 0.0115 & 0.21 & $\mathrm{NA}$ & $0.0153^{*}$ & 0.0137 & 0.93 & $\mathrm{NA}$ & $\mathrm{NA}$ & $\mathrm{NA}$ & 0.90 \\
\hline NMOG $(\mathrm{g} / \mathrm{mi})^{\mathrm{a}}$ & $\mathrm{NA}$ & 0.003 & 0.000 & 0.90 & 0.012 & 0.24 & NA & $0.017^{*}$ & $0.015^{*}$ & 0.90 & NA & NA & $\mathrm{NA}$ & 0.95 \\
\hline Fuel Econ (mi/gal) & $\mathrm{NA}$ & $-1.533^{*}$ & $-2.333^{*}$ & $<0.01 *$ & 0.957 & 0.11 & $N A$ & $0.948 *$ & $1.224^{*}$ & 0.85 & $\mathrm{NA}$ & NA & $\mathrm{NA}$ & 0.87 \\
\hline Acetaldehyde $(\mathrm{mg} / \mathrm{mi})^{\#}$ & $\mathrm{NA}$ & $0.511^{*}$ & $0.556^{*}$ & $<0.01 *$ & 0.073 & 0.34 & NA & 0.060 & 0.062 & 0.97 & NA & NA & $\mathrm{NA}$ & 0.91 \\
\hline Formaldehyde $(\mathrm{mg} / \mathrm{mi})^{\#}$ & $\mathrm{NA}$ & 0.101 & 0.094 & 0.74 & 0.181 & 0.56 & NA & 0.086 & 0.050 & 0.94 & $\mathrm{NA}$ & NA & $\mathrm{NA}$ & 0.96 \\
\hline $\mathrm{CH}_{4}(\mathrm{~g} / \mathrm{mi})$ & $\mathrm{NA}$ & 0.0008 & 0.0010 & 0.34 & $0.0047 *$ & $<0.01^{*}$ & $N A$ & $0.0058^{*}$ & $0.0074 *$ & 0.25 & NA & NA & $\mathrm{NA}$ & 0.55 \\
\hline
\end{tabular}

\# Log-normal model was used. Results are presented as changes in emissions at $0 \mathrm{k}$ mile.

\#\# Data did not support the assumption of linear effects with mileage.

*Indicates estimate is different from zero at the $95 \%$ confidence level.

a test "9474" is identified as an outlier and excluded from the analysis 
2009 Toyota Corolla (Composite CO)

\begin{tabular}{|l|r|r|r|}
\hline \multicolumn{1}{|c|}{ Effect } & & $\begin{array}{r}\text { 95\% C.I. } \\
\text { Lo5\% C.I. }\end{array}$ & $\begin{array}{r}\text { 95. } \\
\text { Upper }\end{array}$ \\
\hline Ethanol Effect $(E 15$ vs. E0) $(\Delta \mathrm{g} / \mathrm{mi})$ & -0.033 & -0.230 & 0.163 \\
\hline Ethanol Effect $($ E20 vs. E0) $(\Delta \mathrm{g} / \mathrm{mi})$ & -0.087 & -0.283 & 0.110 \\
\hline Road Fuel Aging Effect & & & \\
\hline Aging Effect with RE0 $(\Delta \mathrm{g} / \mathrm{mi}$ per 100k mi) & 0.106 & -0.189 & 0.400 \\
\hline Aging Effect with RE15 $(\Delta \mathrm{g} / \mathrm{mi}$ per 100k mi) & $0.217^{*}$ & 0.009 & 0.425 \\
\hline Aging Effect with RE20 $(\Delta \mathrm{g} / \mathrm{mi}$ per 100k mi) & 0.204 & -0.004 & 0.413 \\
\hline
\end{tabular}

\begin{tabular}{|l|r|}
\hline \multicolumn{1}{|c|}{ Hypothesis } & p-value \\
\hline No Effect of Ethanol in the Test Fuel (Gamma = 0) & 0.56 \\
\hline No Aging Effect with RE0 (Beta0 = 0) & 0.42 \\
\hline No Effect of Ethanol in Road Fuel Aging (Beta1s=0) & 0.76 \\
\hline
\end{tabular}

* Indicates estimate is different from zero at the $95 \%$ confidence level.

Initial Odometers 4k

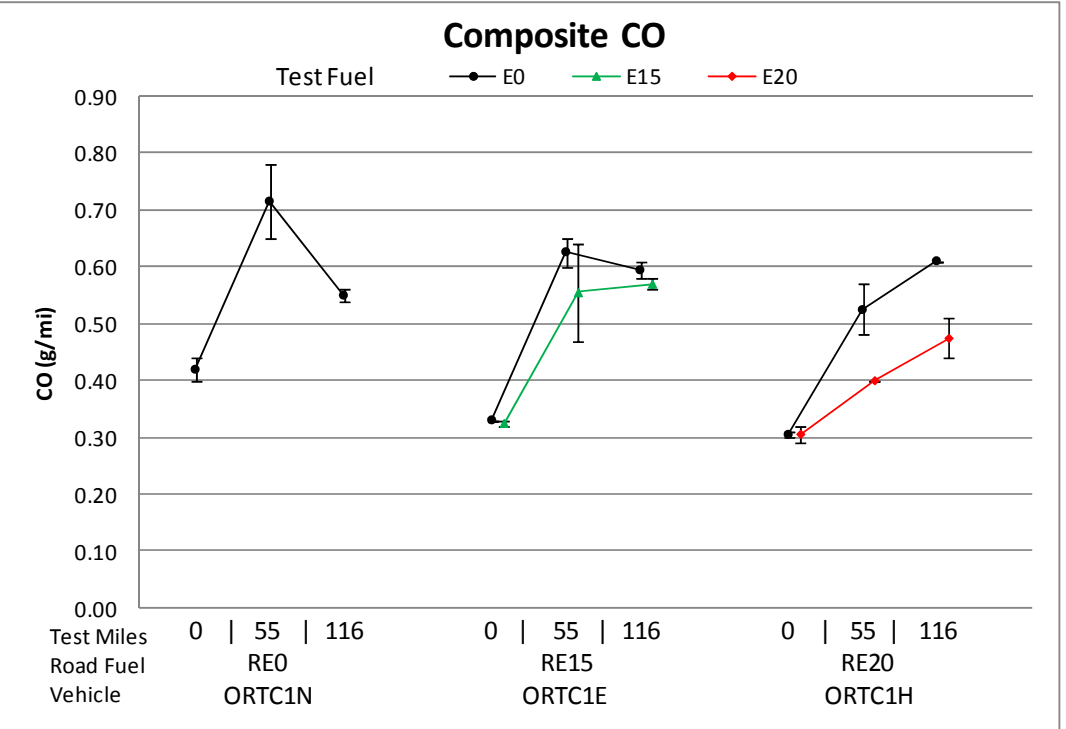

Error bars represent min and max measurements

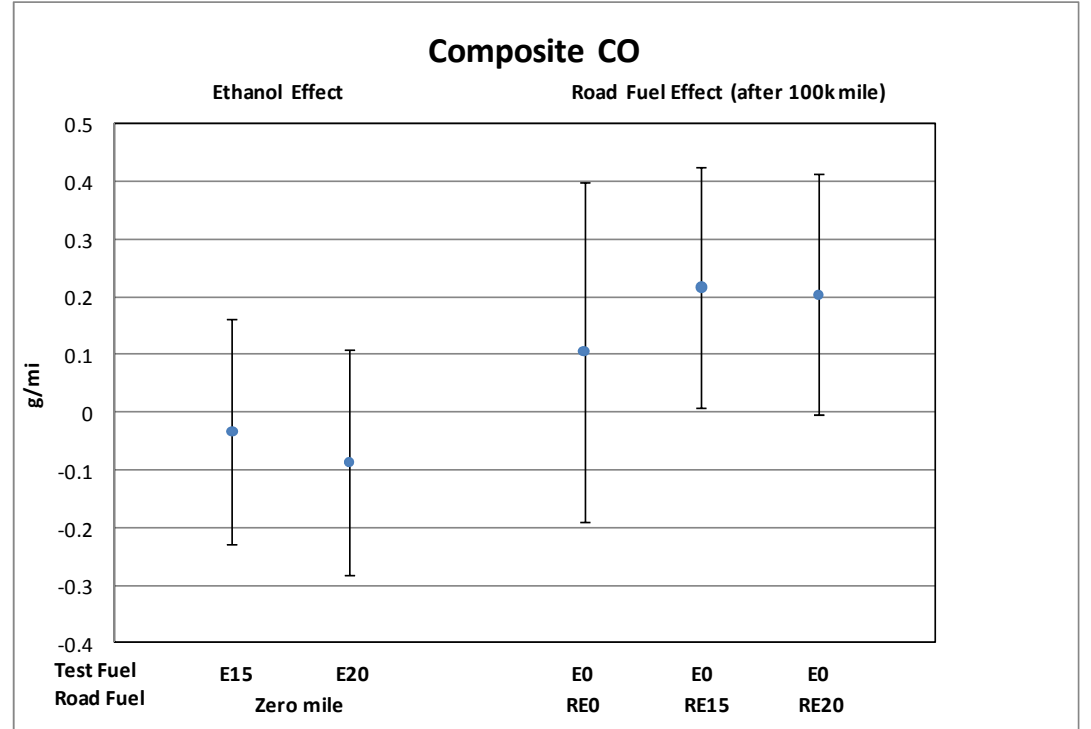

Error bars represent $95 \%$ confidence intervals on the estimated effects 
2009 Toyota Corolla (Composite NOx)

\begin{tabular}{|l|r|r|r|}
\hline \multicolumn{1}{|c|}{ Effect } & & $\begin{array}{r}95 \% \text { C.I. } \\
\text { Low }\end{array}$ & $\begin{array}{r}\text { 95 C.I. } \\
\text { Upper }\end{array}$ \\
\hline Ethanol Effect (E15 vs. E0) $(\Delta \mathrm{g} / \mathrm{mi})$ & -0.003 & -0.014 & 0.008 \\
\hline Ethanol Effect (E20 vs. E0) $(\Delta \mathrm{g} / \mathrm{mi})$ & 0.003 & -0.007 & 0.014 \\
\hline Road Fuel Aging Effect & & & \\
\hline Aging Effect with RE0 $(\Delta \mathrm{g} / \mathrm{mi}$ per 100k mi) & $0.034^{*}$ & 0.018 & 0.050 \\
\hline Aging Effect with RE15 $(\Delta \mathrm{g} / \mathrm{mi} \mathrm{per} \mathrm{100k} \mathrm{mi)}$ & $0.027^{*}$ & 0.016 & 0.038 \\
\hline Aging Effect with RE20 $(\Delta \mathrm{g} / \mathrm{mi}$ per 100k mi) & $0.018^{*}$ & 0.006 & 0.029 \\
\hline
\end{tabular}

\begin{tabular}{|l|r|}
\hline \multicolumn{1}{|c|}{ Hypothesis } & p-value \\
\hline No Effect of Ethanol in the Test Fuel (Gamma = 0) & 0.64 \\
\hline No Aging Effect with RE0 (Beta0 = 0) & $<0.01^{*}$ \\
\hline No Effect of Ethanol in Road Fuel Aging (Beta1s=0) & 0.17 \\
\hline * Indicates effect is statistically significant at the 95\% confidence level.
\end{tabular}

* Indicates estimate is different from zero at the $95 \%$ confidence level.

Initial Odometers 4k

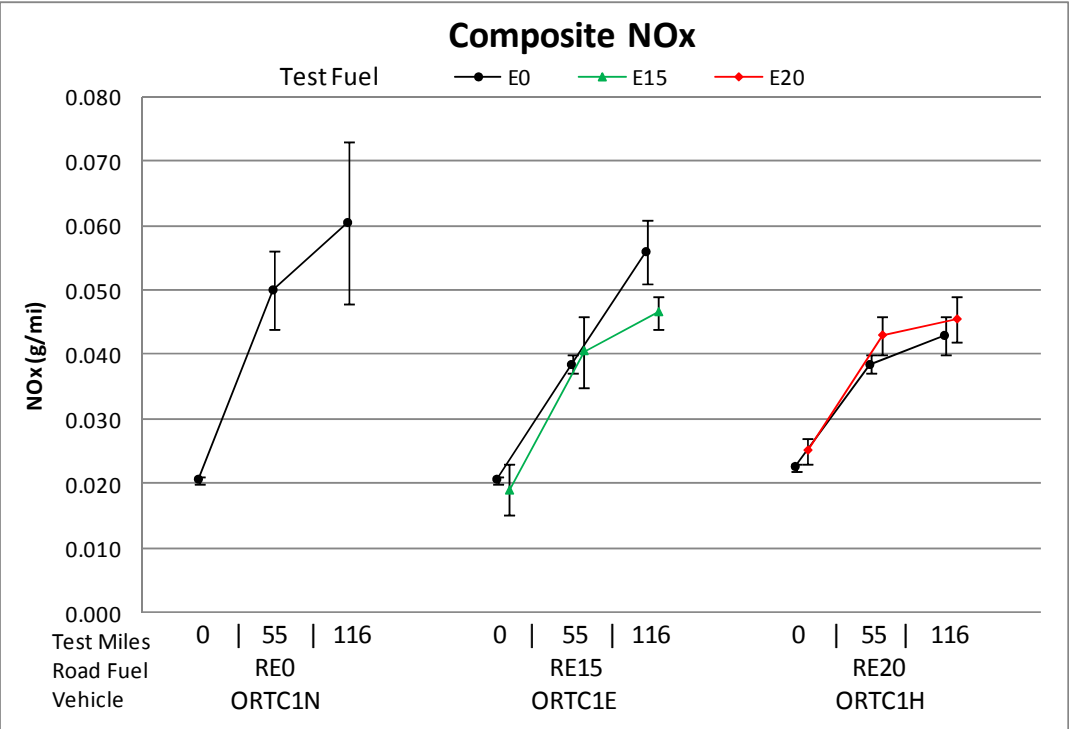

Error bars represent min and max measurements

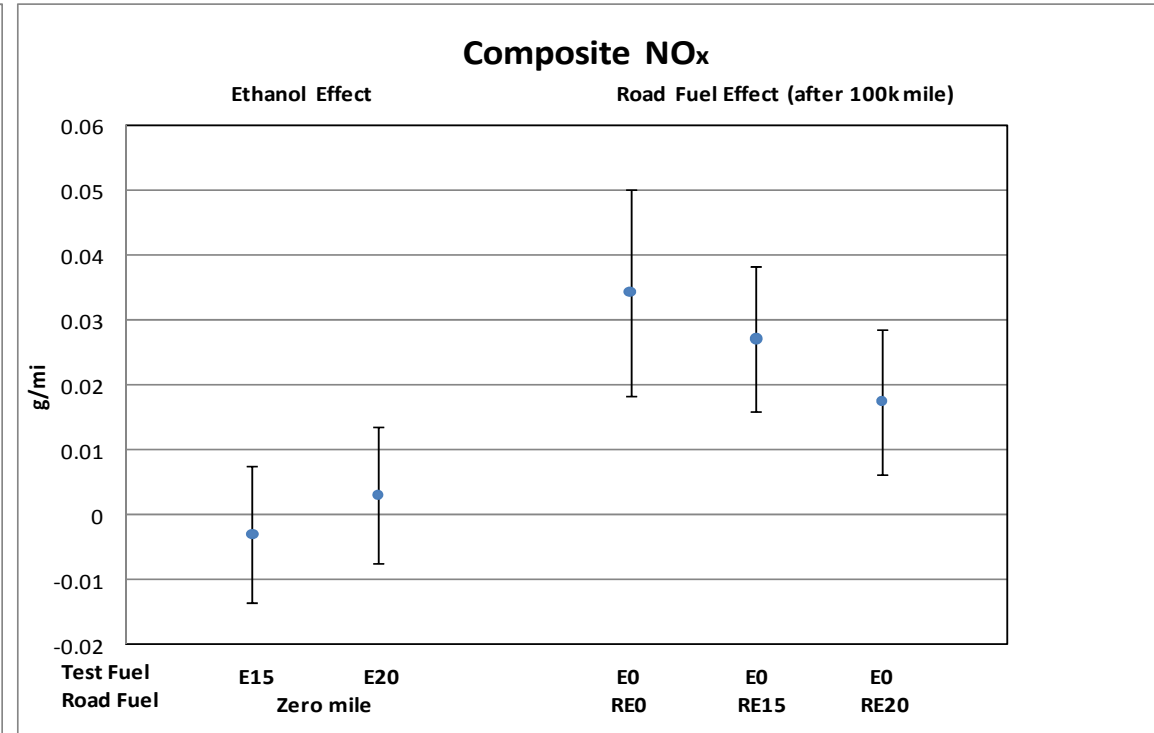

Error bars represent $95 \%$ confidence intervals on the estimated effects 
2009 Toyota Corolla (Composite Nonmethane Hydrocarbons)

\begin{tabular}{|l|r|r|r|}
\hline \multicolumn{1}{|c|}{ Effect } & & $\begin{array}{r}95 \% \text { C.I. } \\
\text { Lo5\% C.I. } \\
\text { Upper }\end{array}$ \\
\hline Ethanol Effect $(E 15 \mathrm{vs}$. E0) $(\Delta \mathrm{g} / \mathrm{mi})$ & -0.0018 & -0.0150 & 0.0114 \\
\hline Ethanol Effect $($ E20 vs. E0) $(\Delta \mathrm{g} / \mathrm{mi})$ & -0.0057 & -0.0188 & 0.0075 \\
\hline Road Fuel Aging Effect & & & \\
\hline Aging Effect with RE0 $(\Delta \mathrm{g} / \mathrm{mi}$ per 100k mi) & 0.0115 & -0.0082 & 0.0312 \\
\hline Aging Effect with RE15 $(\Delta \mathrm{g} / \mathrm{mi}$ per 100k mi) & $0.0153^{*}$ & 0.0014 & 0.0293 \\
\hline Aging Effect with RE20 $(\Delta \mathrm{g} / \mathrm{mi}$ per 100k mi) & 0.0137 & -0.0002 & 0.0277 \\
\hline
\end{tabular}

\begin{tabular}{|l|r|}
\hline \multicolumn{1}{|c|}{ Hypothesis } & -value \\
\hline No Effect of Ethanol in the Test Fuel (Gamma = 0) & 0.59 \\
\hline No Aging Effect with RE0 (Beta0 = 0) & 0.21 \\
\hline No Effect of Ethanol in Road Fuel Aging (Beta1s=0) & 0.93 \\
\hline
\end{tabular}

${ }^{*}$ Indicates estimate is different from zero at the $95 \%$ confidence level.

Initial Odometers 4k

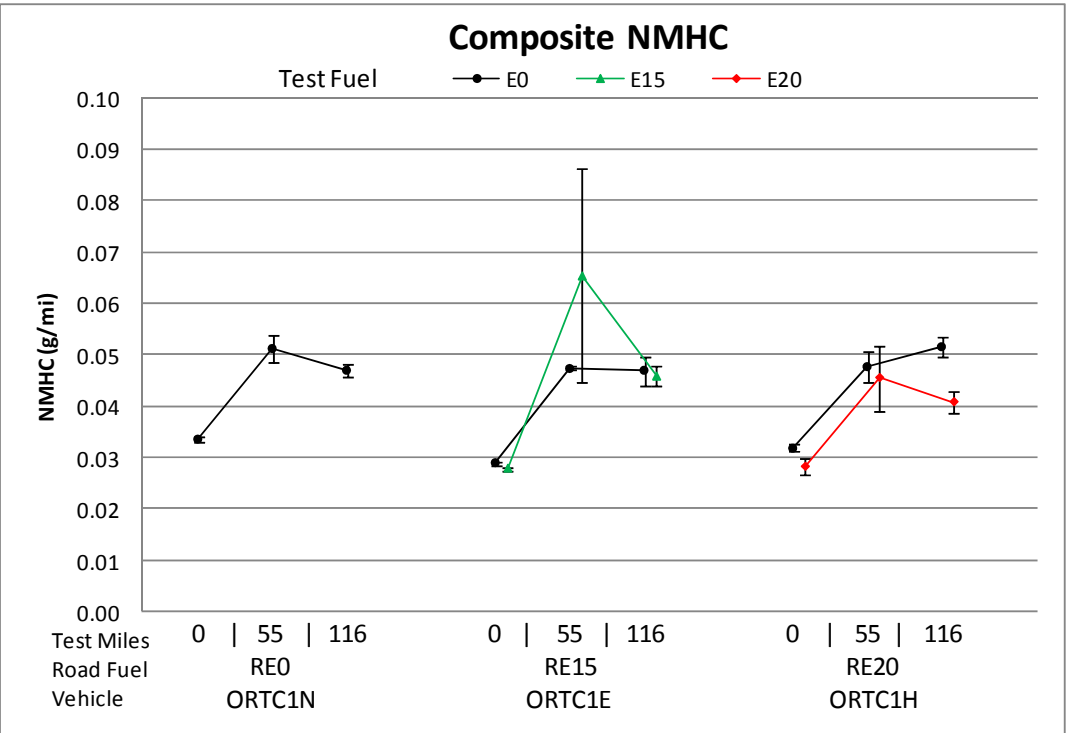

Error bars represent min and max measurements

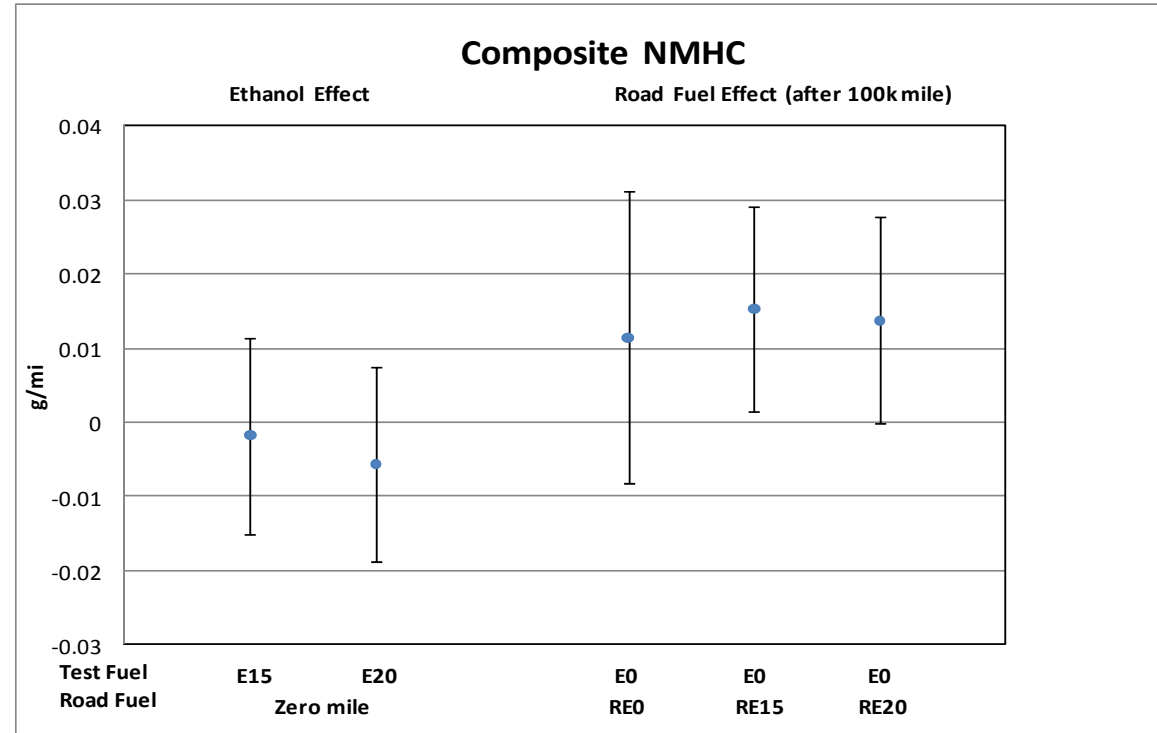

Error bars represent $95 \%$ confidence intervals on the estimated effects 
2009 Toyota Corolla (Composite Nonmethane Organic Gases)

\begin{tabular}{|l|r|r|r|}
\hline \multicolumn{1}{|c|}{ Effect } & & $\begin{array}{r}\text { 95\% C.I. } \\
\text { Low\% C.I. }\end{array}$ & $\begin{array}{r}\text { 95 } \\
\text { Upper }\end{array}$ \\
\hline Ethanol Effect $(E 15 \mathrm{vs}$. E0) $(\Delta \mathrm{g} / \mathrm{mi})$ & 0.003 & -0.012 & 0.017 \\
\hline Ethanol Effect $($ E20 vs. E0) $(\Delta \mathrm{g} / \mathrm{mi})$ & 0.000 & -0.014 & 0.014 \\
\hline Road Fuel Aging Effect & & & \\
\hline Aging Effect with RE0 $(\Delta \mathrm{g} / \mathrm{mi}$ per 100k mi) & 0.012 & -0.010 & 0.033 \\
\hline Aging Effect with RE15 $(\Delta \mathrm{g} / \mathrm{mi}$ per 100k mi) & $0.017^{*}$ & 0.002 & 0.032 \\
\hline Aging Effect with RE20 $(\Delta \mathrm{g} / \mathrm{mi}$ per 100k mi) & $0.015^{*}$ & 0.000 & 0.031 \\
\hline
\end{tabular}

\begin{tabular}{lr} 
Aging Effect with RE20 $(\Delta \mathrm{g} / \mathrm{mi}$ per $100 \mathrm{k} \mathrm{mi})$ & 0.015 \\
\hline$*$ Indicates estimate is different from zero at the $95 \%$ confidence level.
\end{tabular}

\begin{tabular}{|l|r|}
\hline \multicolumn{1}{|c|}{ Hypothesis } & p-value \\
\hline No Effect of Ethanol in the Test Fuel (Gamma = 0) & 0.90 \\
\hline No Aging Effect with RE0 (Beta0 = 0) & 0.24 \\
\hline No Effect of Ethanol in Road Fuel Aging (Beta1s=0) & 0.90 \\
\hline
\end{tabular}

Initial Odometers 4k
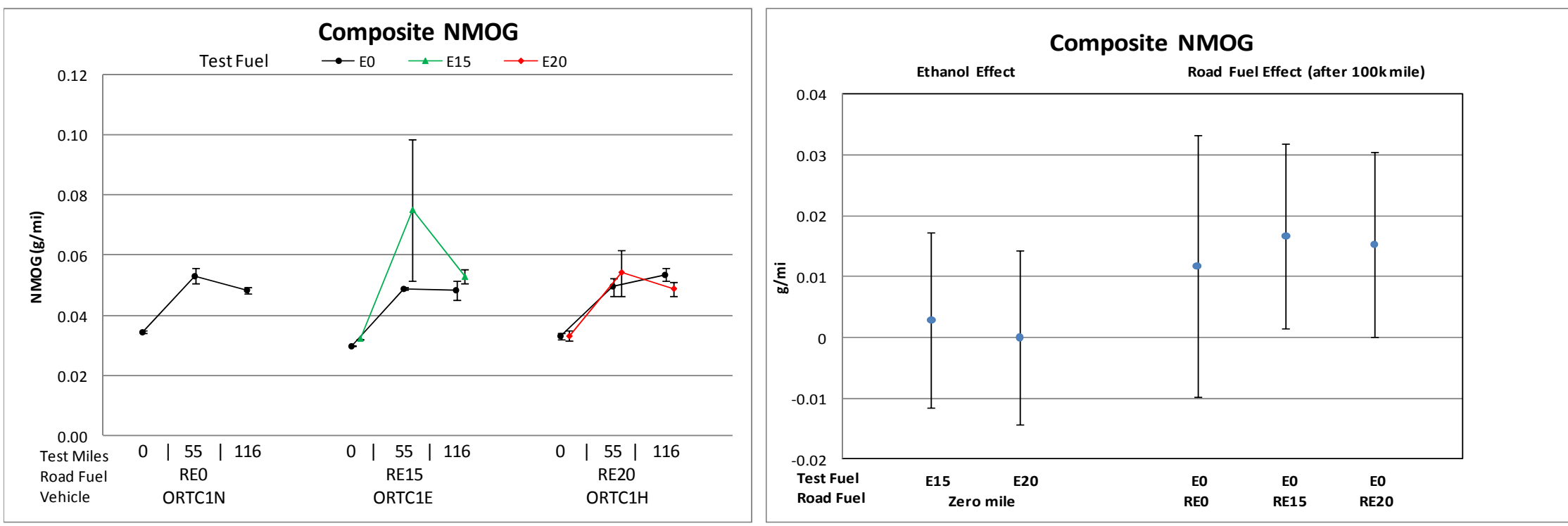

Error bars represent min and max measurements

Error bars represent $95 \%$ confidence intervals on the estimated effects 
2009 Toyota Corolla (Composite Fuel Economy)

\begin{tabular}{|l|r|r|r|}
\hline \multicolumn{1}{|c|}{ Effect } & Estimate & $\begin{array}{c}\text { 95\% C.I. } \\
\text { Lower }\end{array}$ & $\begin{array}{r}\text { 95\% C.I. } \\
\text { Upper }\end{array}$ \\
\hline Ethanol Effect (E15 vs. E0) $(\Delta \mathrm{mi} / \mathrm{gal})$ & $-1.533^{*}$ & -2.351 & -0.716 \\
\hline Ethanol Effect (E20 vs. E0) $(\Delta \mathrm{mi} / \mathrm{gal})$ & $-2.333^{*}$ & -3.150 & -1.515 \\
\hline Road Fuel Aging Effect & & & \\
\hline Aging Effect with RE0 $(\Delta \mathrm{mi} /$ gal per 100k mi) & 0.957 & -0.270 & 2.184 \\
\hline Aging Effect with RE15 $(\Delta \mathrm{mi} / \mathrm{gal}$ per 100k mi) & $0.948^{*}$ & 0.081 & 1.816 \\
\hline Aging Effect with RE20 $(\Delta \mathrm{mi} /$ gal per 100k mi) & $1.224^{*}$ & 0.357 & 2.090 \\
\hline
\end{tabular}

\begin{tabular}{|l|r|}
\hline \multicolumn{1}{|c|}{ Hypothesis } & -value \\
\hline No Effect of Ethanol in the Test Fuel (Gamma = 0) & $<0.01^{*}$ \\
\hline No Aging Effect with RE0 (Beta0 $=0$ ) & 0.11 \\
\hline No Effect of Ethanol in Road Fuel Aging (Beta1s $=0$ ) & 0.85 \\
\hline * Indicates effect is statistically significant at the 95\% confidence level.
\end{tabular}

${ }^{*}$ Indicates estimate is different from zero at the $95 \%$ confidence level.

Initial Odometers 4k

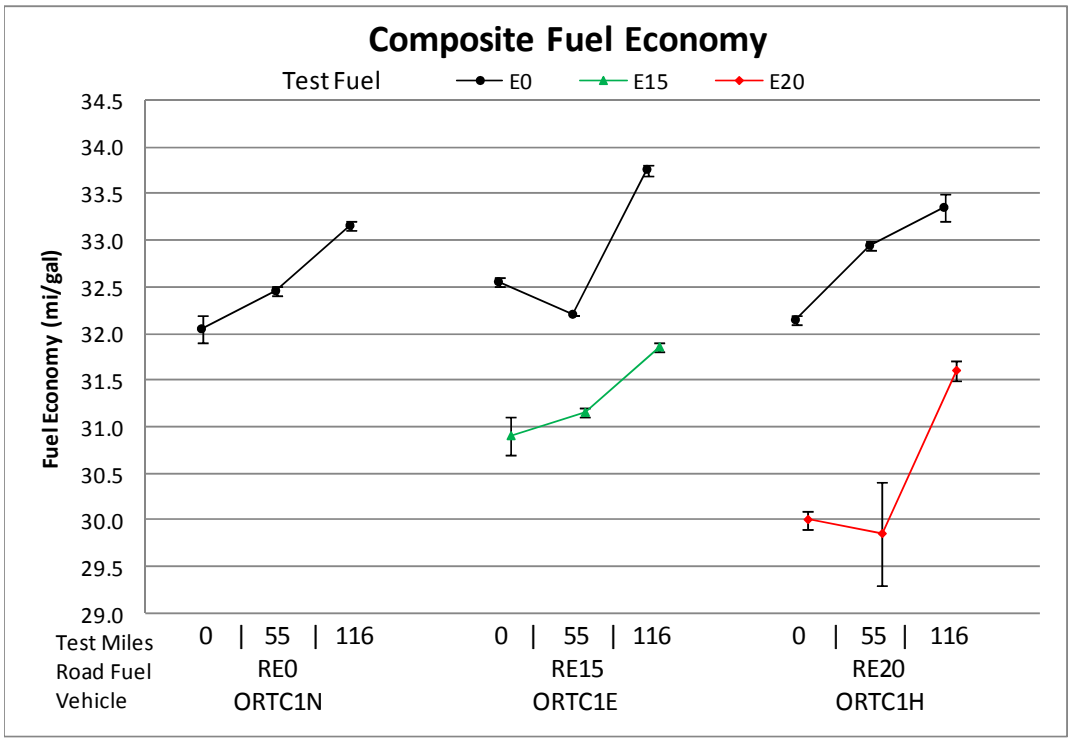

Error bars represent min and max measurements

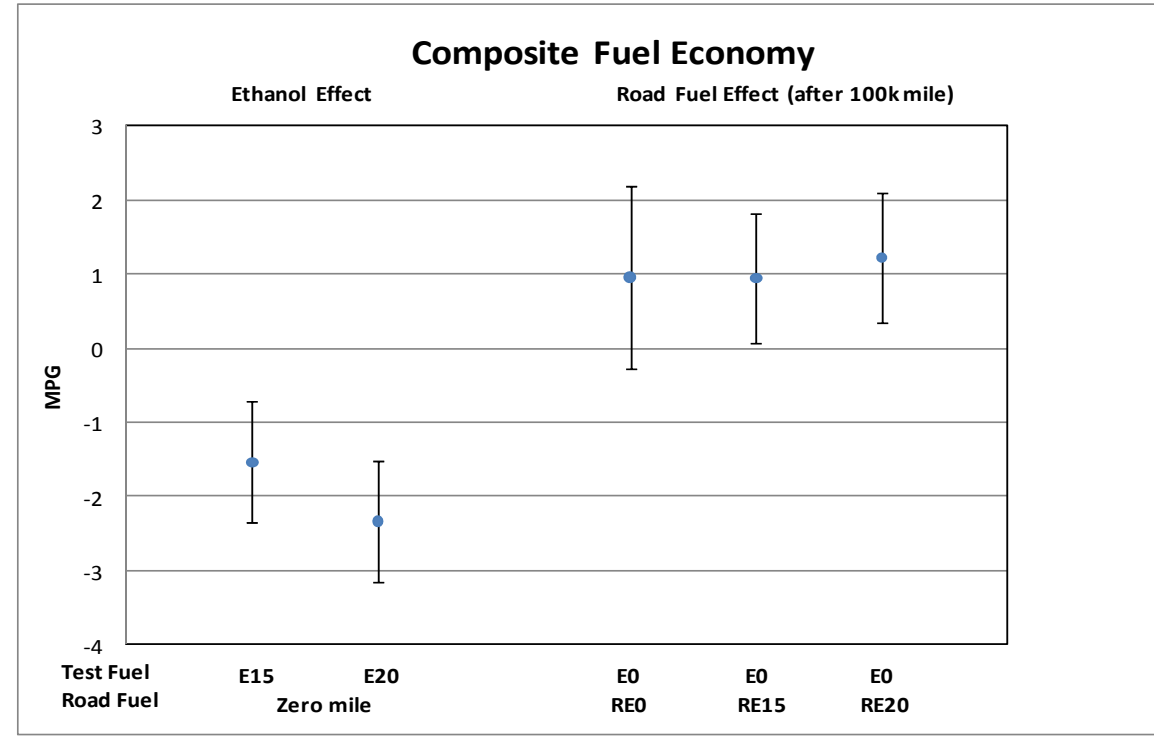

Error bars represent $95 \%$ confidence intervals on the estimated effects 
2009 Toyota Corolla (Composite Acetaldehyde)

\begin{tabular}{|l|r|r|r|}
\hline \multicolumn{1}{|c|}{ Effect } & Estimate & $\begin{array}{r}\text { 95\% C.I. } \\
\text { Lower }\end{array}$ & $\begin{array}{r}\text { 95\% C.I. } \\
\text { Upper }\end{array}$ \\
\hline Ethanol Effect (E15 vs. E0) $(\Delta \mathrm{mg} / \mathrm{mi})$ & $0.511^{*}$ & 0.167 & 0.854 \\
\hline Ethanol Effect $($ E20 vs. E0) $(\Delta \mathrm{mg} / \mathrm{mi})$ & $0.556^{*}$ & 0.167 & 0.945 \\
\hline Road Fuel Aging Effect & & & \\
\hline Aging Effect with RE0 $(\Delta \mathrm{mg} / \mathrm{mi}$ per 100k mi) & 0.073 & -0.091 & 0.237 \\
\hline Aging Effect with RE15 $(\Delta \mathrm{mg} / \mathrm{mi}$ per 100k mi) & 0.060 & -0.074 & 0.195 \\
\hline Aging Effect with RE20 $(\Delta \mathrm{mg} / \mathrm{mi}$ per 100k mi) & 0.062 & -0.100 & 0.224 \\
\hline
\end{tabular}

\begin{tabular}{|l|r|}
\hline \multicolumn{1}{|c|}{ Hypothesis } & p-value \\
\hline No Effect of Ethanol in the Test Fuel (Gamma = 0) & $<0.01^{*}$ \\
\hline No Aging Effect with RE0 (Beta0 = 0) & 0.34 \\
\hline No Effect of Ethanol in Road Fuel Aging (Beta1s=0) & 0.97 \\
\hline
\end{tabular}

* Indicates estimate is different from zero at the $95 \%$ confidence level.

Initial Odometers 4k

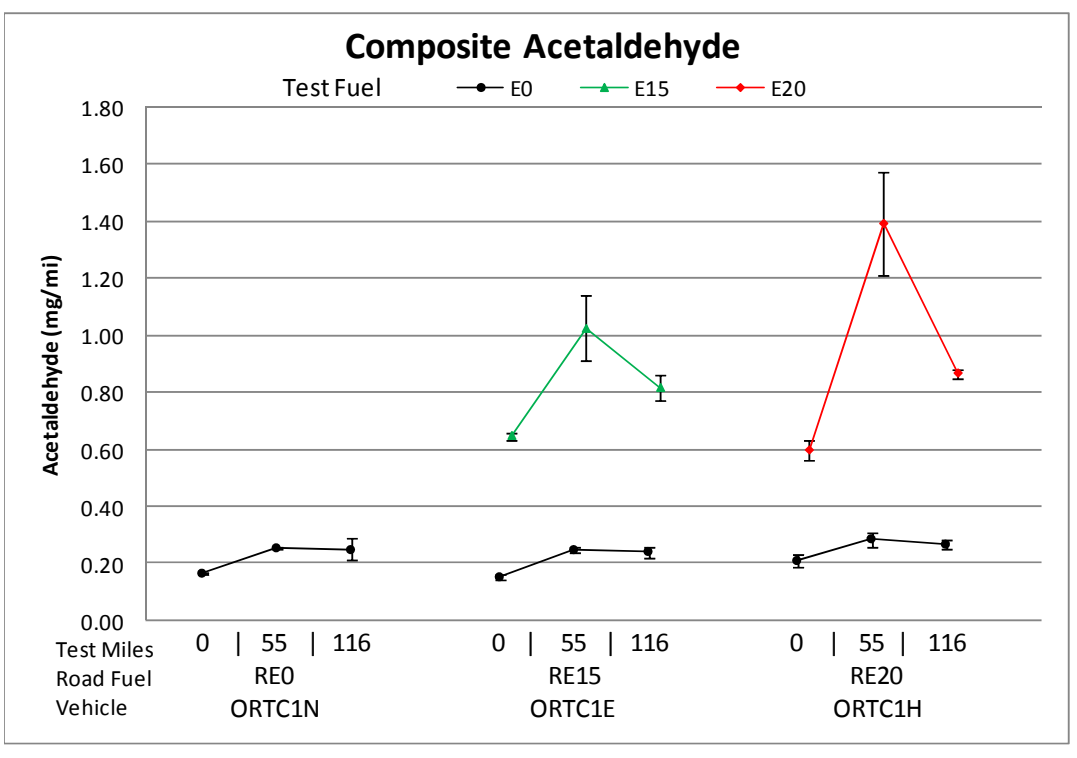

Error bars represent min and max measurements

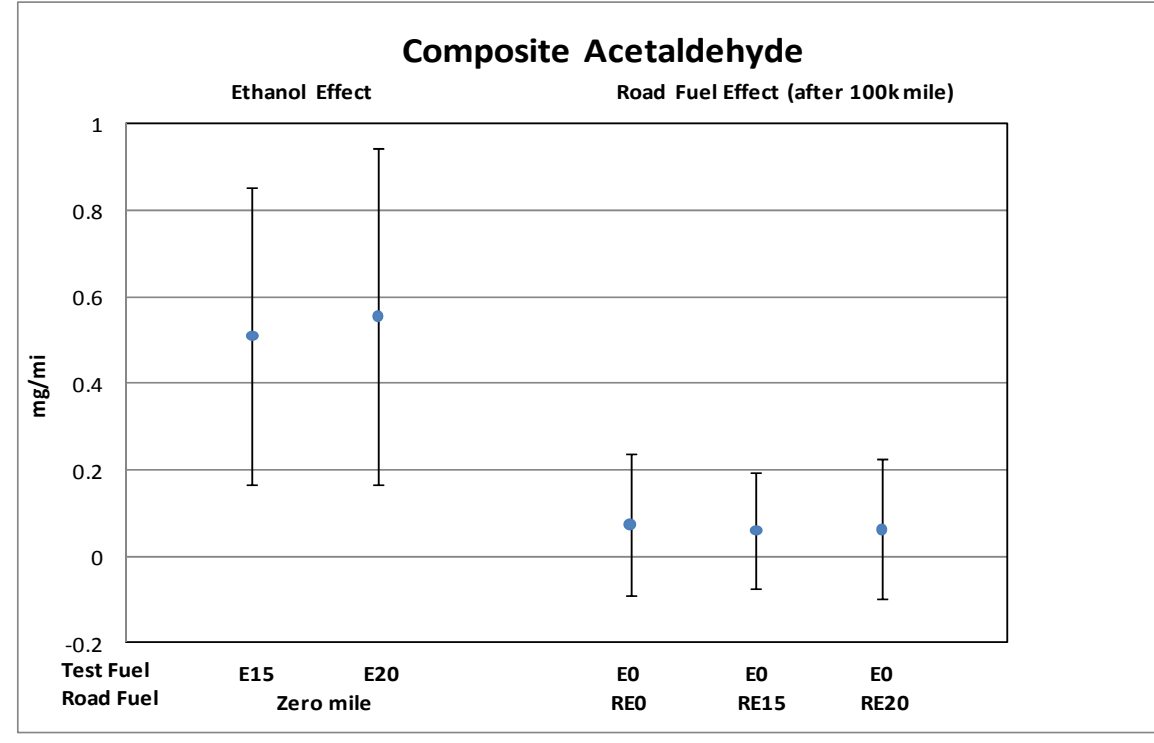

Error bars represent $95 \%$ confidence intervals on the estimated effects 
2009 Toyota Corolla (Composite Formaldehyde)

\begin{tabular}{|l|r|r|r|}
\hline \multicolumn{1}{|c|}{ Effect } & & $\begin{array}{r}\text { 95\% C.I. } \\
\text { Low\% C.I. }\end{array}$ & $\begin{array}{r}\text { 95. } \\
\text { Upper }\end{array}$ \\
\hline Ethanol Effect (E15 vs. E0) $(\Delta \mathrm{mg} / \mathrm{mi})$ & 0.101 & -0.403 & 0.605 \\
\hline Ethanol Effect (E20 vs. E0) $(\Delta \mathrm{mg} / \mathrm{mi})$ & 0.094 & -0.518 & 0.705 \\
\hline Road Fuel Aging Effect & & & \\
\hline Aging Effect with RE0 $(\Delta \mathrm{mg} / \mathrm{mi}$ per 100k mi) & 0.181 & -0.511 & 0.872 \\
\hline Aging Effect with RE15 $(\Delta \mathrm{mg} / \mathrm{mi}$ per 100k mi) & 0.086 & -0.376 & 0.547 \\
\hline Aging Effect with RE20 $(\Delta \mathrm{mg} / \mathrm{mi}$ per 100k mi) & 0.050 & -0.495 & 0.594 \\
\hline
\end{tabular}

\begin{tabular}{|l|r|}
\hline \multicolumn{1}{|c|}{ Hypothesis } & p-value \\
\hline No Effect of Ethanol in the Test Fuel (Gamma = 0) & 0.74 \\
\hline No Aging Effect with RE0 (Beta0 = 0) & 0.56 \\
\hline No Effect of Ethanol in Road Fuel Aging (Beta1s=0) & 0.94 \\
\hline
\end{tabular}

* Indicates estimate is different from zero at the $95 \%$ confidence level.

Initial Odometers 4k
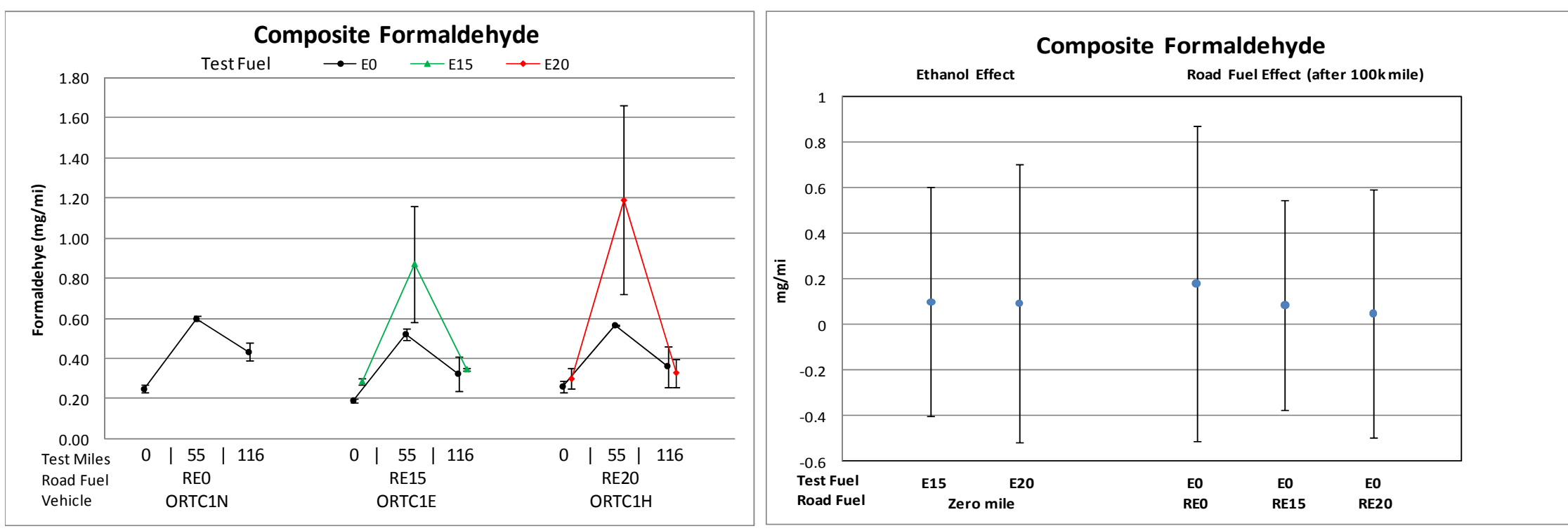

Error bars represent min and max measurements

Error bars represent $95 \%$ confidence intervals on the estimated effects 
2009 Toyota Corolla (Composite $\mathrm{CH} 4$ )

\begin{tabular}{|l|r|r|r|}
\hline \multicolumn{1}{|c|}{ Effect } & & $\begin{array}{c}95 \% \text { C.I. } \\
\text { Lower }\end{array}$ & $\begin{array}{r}\text { 95\% C.I. } \\
\text { Upper }\end{array}$ \\
\hline Ethanol Effect (E15 vs. E0) $(\Delta \mathrm{g} / \mathrm{mi})$ & 0.0008 & -0.0012 & 0.0028 \\
\hline Ethanol Effect (E20 vs. E0) $(\Delta \mathrm{g} / \mathrm{mi})$ & 0.0010 & -0.0010 & 0.0030 \\
\hline Road Fuel Aging Effect & & & \\
\hline Aging Effect with RE0 $(\Delta \mathrm{g} / \mathrm{mi}$ per 100k mi) & $0.0047^{*}$ & 0.0017 & 0.0077 \\
\hline Aging Effect with RE15 $(\Delta \mathrm{g} / \mathrm{mi} \mathrm{per} \mathrm{100k} \mathrm{mi)}$ & $0.0058^{*}$ & 0.0037 & 0.0079 \\
\hline Aging Effect with RE20 $(\Delta \mathrm{g} / \mathrm{mi}$ per 100k mi) & $0.0074^{*}$ & 0.0052 & 0.0095 \\
\hline
\end{tabular}

\begin{tabular}{|l|r|}
\hline \multicolumn{1}{|c|}{ Hypothesis } & $p$-value \\
\hline No Effect of Ethanol in the Test Fuel (Gamma $=0)$ & 0.34 \\
\hline No Aging Effect with RE0 (Beta0 = 0) & $<0.01^{*}$ \\
\hline No Effect of Ethanol in Road Fuel Aging (Beta1s=0) & 0.25 \\
\hline${ }^{*}$ Indicates effect is statistically significant at the 95\% confidence level.
\end{tabular}

* Indicates estimate is different from zero at the $95 \%$ confidence level.

Initial Odometers 4k
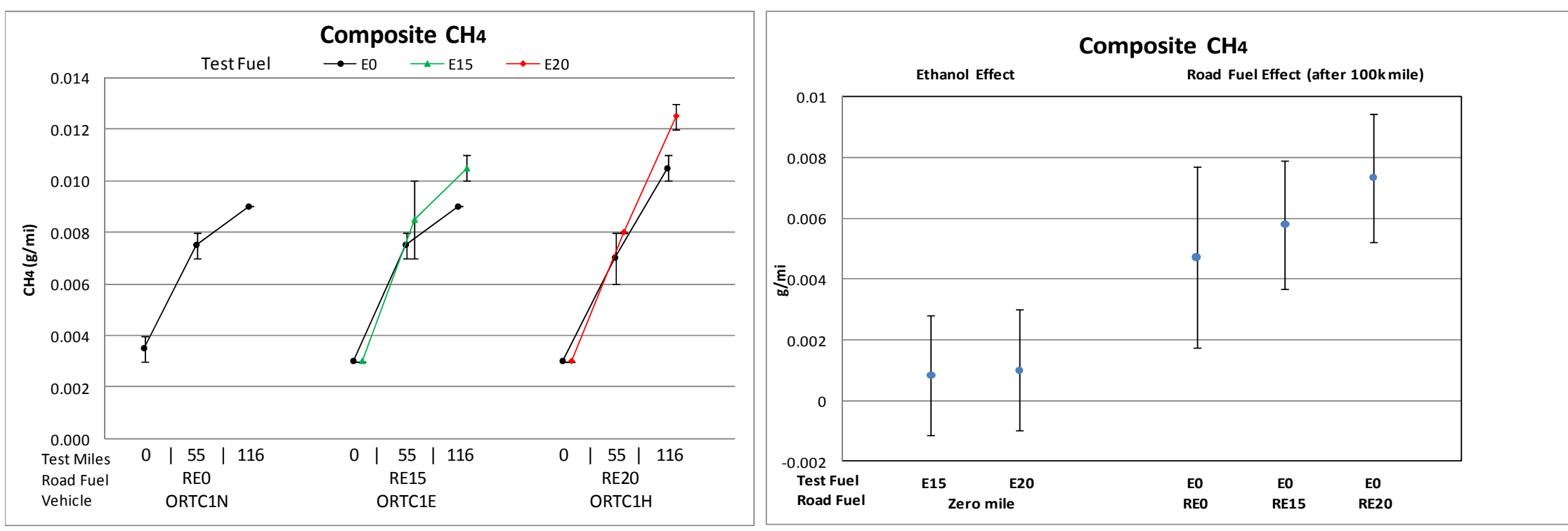

Error bars represent min and max measurements

Error bars represent $95 \%$ confidence intervals on the estimated effects 


\section{Toyota Tundra - Composite Emissions Summary}

\begin{tabular}{|c|c|c|c|c|c|c|c|c|c|c|c|c|c|c|}
\hline \multirow{2}{*}{$\begin{array}{c}\text { Emisssion Parameter } \\
\text { (units) }\end{array}$} & \multicolumn{4}{|c|}{ Ethanol Effect } & \multicolumn{2}{|c|}{ Aging Effect with REO } & \multicolumn{4}{|c|}{ RExx Aging Effect on EO Emissions } & \multirow{2}{*}{\multicolumn{3}{|c|}{\begin{tabular}{|c|} 
RExx Aging Effect on Exx Emissions \\
$\Delta$ units per $100 \mathrm{~K} \mathrm{mi}$ \\
\end{tabular}}} & \multirow{3}{*}{\begin{tabular}{|c}
$\begin{array}{c}\text { Road and Test } \\
\text { Fuel Effects } \\
\text { are Additive }\end{array}$ \\
$\begin{array}{c}\text { Overall p- } \\
\text { value }\end{array}$
\end{tabular}} \\
\hline & \multicolumn{3}{|c|}{$\Delta$ units vs. EO } & \multirow{2}{*}{$\begin{array}{l}\text { Overall } \\
p \text {-value }\end{array}$} & \multirow{2}{*}{$\begin{array}{c}\Delta \text { units per } 100 \mathrm{~K} \mathrm{mi} \\
\text { REO/EO }\end{array}$} & \multirow{2}{*}{$\begin{array}{l}\text { Overall } \\
p \text {-value }\end{array}$} & \multicolumn{3}{|c|}{$\Delta$ units per $100 \mathrm{~K} \mathrm{mi}$} & \multirow{2}{*}{$\begin{array}{l}\text { Overall } \\
p \text {-value }\end{array}$} & & & & \\
\hline Fuels & E10 & E15 & E20 & & & & RE10/E0 & RE15/E0 & RE20/E0 & & RE10/E10 & RE15/E15 & RE20/E20 & \\
\hline $\mathrm{CO}(\mathrm{g} / \mathrm{mi})$ & $\mathrm{NA}$ & -0.078 & -0.092 & 0.23 & 0.167 & 0.32 & $\mathrm{NA}$ & $0.293 *$ & $0.465^{*}$ & 0.34 & $\mathrm{NA}$ & $\mathrm{NA}$ & $\mathrm{NA}$ & 0.07 \\
\hline NOx $(\mathrm{g} / \mathrm{mi})$ & NA & 0.000 & 0.002 & 0.65 & $0.037^{*}$ & $<0.01 *$ & NA & $0.014 *$ & $0.019 *$ & $0.04 *$ & NA & NA & $\mathrm{NA}$ & 0.82 \\
\hline $\mathrm{NMHC}(\mathrm{g} / \mathrm{mi})$ & NA & -0.007 & -0.009 & 0.21 & 0.005 & 0.72 & NA & -0.015 & 0 & 0.07 & $\mathrm{NA}$ & NA & $\mathrm{NA}$ & 0.23 \\
\hline $\operatorname{NMOG}(\mathrm{g} / \mathrm{mi})$ & $\mathrm{NA}$ & -0.001 & -0.002 & 0.96 & 0.005 & 0.73 & NA & -0.018 & 0.024 & 0.06 & $\mathrm{NA}$ & $\mathrm{NA}$ & $\mathrm{NA}$ & 0.21 \\
\hline Fuel Econ (mi/gal) & NA & $-1.077^{*}$ & $-1.281^{*}$ & $<0.01^{*}$ & -0.077 & 0.89 & NA & -0.275 & -0.477 & 0.83 & NA & $\mathrm{NA}$ & $\mathrm{NA}$ & 0.84 \\
\hline Acetaldehyde $(\mathrm{mg} / \mathrm{mi})^{\#}$ & $\mathrm{NA}$ & $0.748^{*}$ & $0.984 *$ & $<0.01 *$ & -0.053 & 0.40 & NA & $-0.105 *$ & -0.044 & 0.54 & $\mathrm{NA}$ & $\mathrm{NA}$ & $\mathrm{NA}$ & 0.96 \\
\hline Formaldehyde $(\mathrm{mg} / \mathrm{mi})^{\# \#}$ & NA & $0.133^{*}$ & $0.144 *$ & $<0.01 *$ & $0.170^{*}$ & $0.05 *$ & NA & -0.119 & 0.093 & $0.01 *$ & $\mathrm{NA}$ & NA & $\mathrm{NA}$ & NA \\
\hline $\mathrm{CH}_{4}(\mathrm{~g} / \mathrm{mi})$ & $\mathrm{NA}$ & 0.0001 & 0.0017 & 0.42 & $0.0102 *$ & $0.02 *$ & NA & $0.0069 *$ & $0.0072 *$ & 0.69 & $\mathrm{NA}$ & $\mathrm{NA}$ & $\mathrm{NA}$ & 0.96 \\
\hline
\end{tabular}

\# Log-normal model was used. Results are presented as changes in emissions at 0k mile.

\#\# Data did not support the assumption of linear effects with mileage.

*Indicates estimate is different from zero at the $95 \%$ confidence level. 
2005 Toyota Tundra (Composite CO)

\begin{tabular}{|l|r|r|r|}
\hline \multicolumn{1}{|c|}{ Effect } & & $\begin{array}{r}95 \% \text { C.I. } \\
\text { Low\% C.I. } \\
\text { Upper }\end{array}$ \\
\hline Ethanol Effect $(E 15 \mathrm{vs}$. E0) $(\Delta \mathrm{g} / \mathrm{mi})$ & -0.078 & -0.227 & 0.072 \\
\hline Ethanol Effect $($ E20 vs. E0) $(\Delta \mathrm{g} / \mathrm{mi})$ & -0.092 & -0.241 & 0.058 \\
\hline Road Fuel Aging Effect & & & \\
\hline Aging Effect with RE0 $(\Delta \mathrm{g} / \mathrm{mi}$ per 100k mi) & 0.167 & -0.231 & 0.564 \\
\hline Aging Effect with RE15 $(\Delta \mathrm{g} / \mathrm{mi}$ per 100k mi) & $0.293^{*}$ & 0.014 & 0.572 \\
\hline Aging Effect with RE20 $(\Delta \mathrm{g} / \mathrm{mi}$ per 100k mi) & $0.465^{*}$ & 0.185 & 0.745 \\
\hline
\end{tabular}

\begin{tabular}{|l|r|}
\hline \multicolumn{1}{|c|}{ Hypothesis } & p-value \\
\hline No Effect of Ethanol in the Test Fuel (Gamma = 0) & 0.23 \\
\hline No Aging Effect with RE0 (Beta0 = 0) & 0.32 \\
\hline No Effect of Ethanol in Road Fuel Aging (Beta1s=0) & 0.34 \\
\hline
\end{tabular}

* Indicates estimate is different from zero at the $95 \%$ confidence level.

Initial odometers $43 k-55 k$

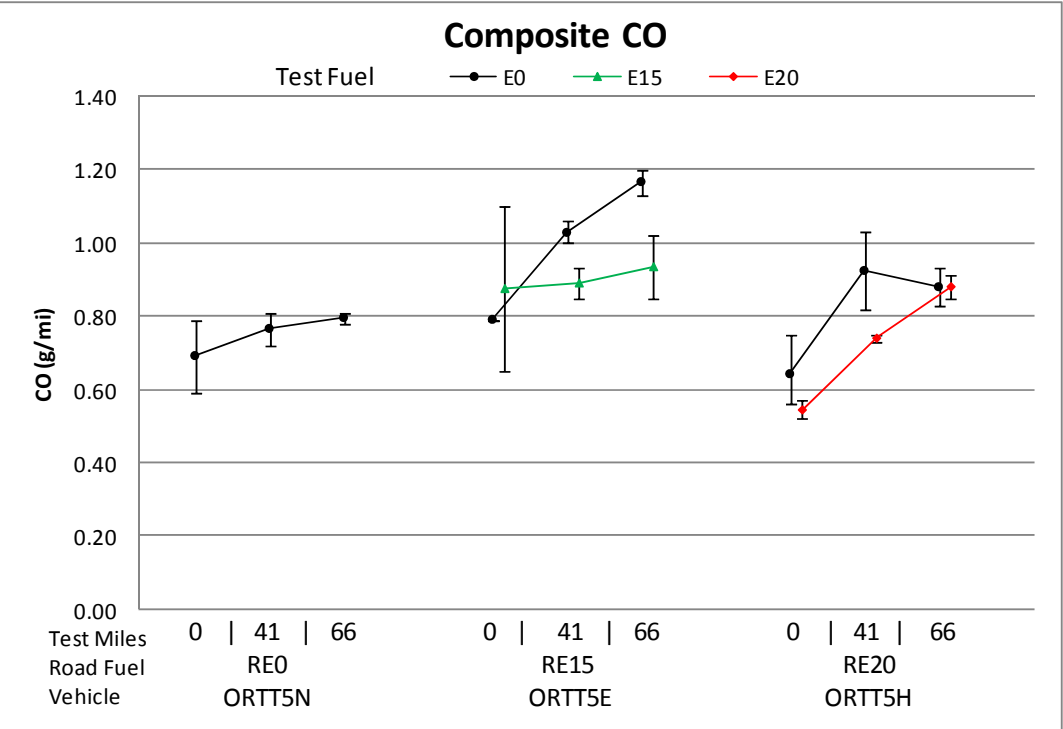

Error bars represent min and max measurements

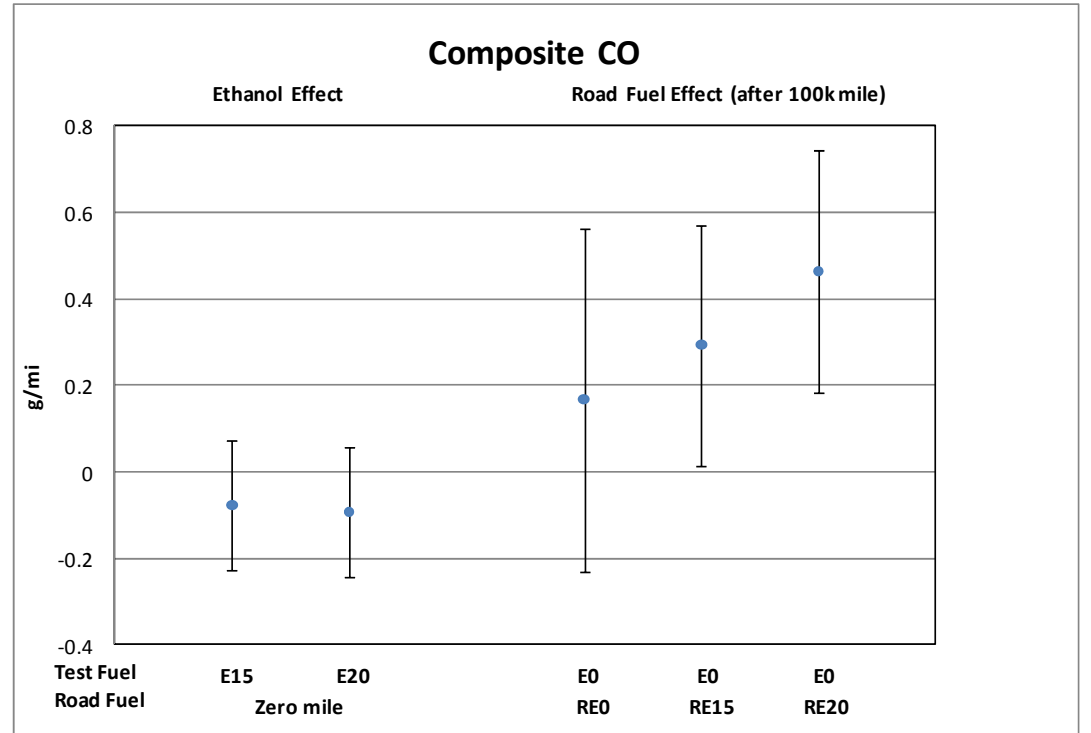

Error bars represent $95 \%$ confidence intervals on the estimated effects 
2005 Toyota Tundra (Composite NOx)

\begin{tabular}{|l|r|r|r|}
\hline \multicolumn{1}{|c|}{ Effect } & & $\begin{array}{r}95 \% \text { C.I. } \\
\text { Low\% C.I. }\end{array}$ & $\begin{array}{r}\text { 95 } \\
\text { Upper }\end{array}$ \\
\hline Ethanol Effect $(E 15 \mathrm{vs}$. E0) $(\Delta \mathrm{g} / \mathrm{mi})$ & 0.000 & -0.005 & 0.005 \\
\hline Ethanol Effect $($ E20 vs. E0) $(\Delta \mathrm{g} / \mathrm{mi})$ & 0.002 & -0.003 & 0.007 \\
\hline Road Fuel Aging Effect & & & \\
\hline Aging Effect with RE0 $(\Delta \mathrm{g} / \mathrm{mi}$ per 100k mi) & $0.037^{*}$ & 0.023 & 0.051 \\
\hline Aging Effect with RE15 $(\Delta \mathrm{g} / \mathrm{mi}$ per 100k mi) & $0.014^{*}$ & 0.004 & 0.023 \\
\hline Aging Effect with RE20 $(\Delta \mathrm{g} / \mathrm{mi}$ per 100k mi) & $0.019^{*}$ & 0.010 & 0.029 \\
\hline
\end{tabular}

\begin{tabular}{|l|r|}
\hline \multicolumn{1}{|c|}{ Hypothesis } & $p$-value \\
\hline No Effect of Ethanol in the Test Fuel (Gamma = 0) & 0.65 \\
\hline No Aging Effect with RE0 (Beta0 = 0) & $<0.01^{*}$ \\
\hline No Effect of Ethanol in Road Fuel Aging (Beta1s=0) & $0.04^{*}$ \\
\hline${ }^{*}$ Indicates effect is statistically significant at the 95\% confidence level.
\end{tabular}

${ }^{*}$ Indicates estimate is different from zero at the $95 \%$ confidence level.

Initial odometers $43 \mathrm{k}-55 \mathrm{k}$
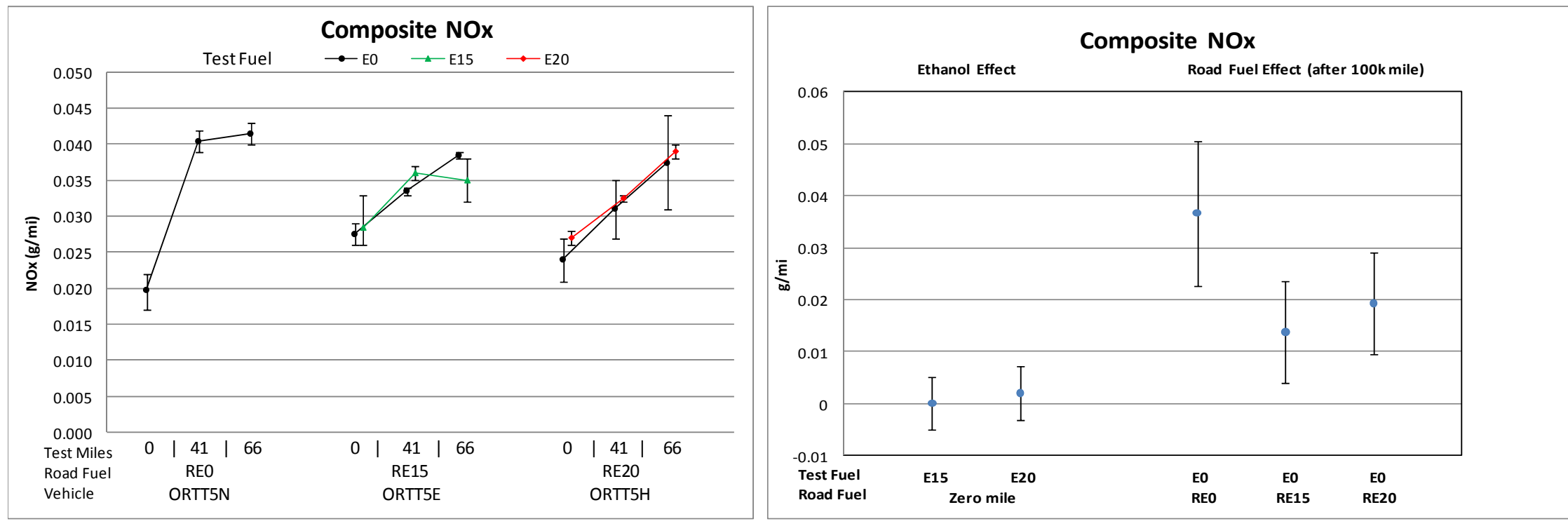

Error bars represent min and max measurements

Error bars represent $95 \%$ confidence intervals on the estimated effects 
2005 Toyota Tundra (Composite Nonmethane Hydrocarbons)

\begin{tabular}{|l|r|r|r|}
\hline \multicolumn{1}{|c|}{ Effect } & & $\begin{array}{r}\text { 95\% C.I. } \\
\text { Low\% C.I. }\end{array}$ & $\begin{array}{r}\text { 95 } \\
\text { Upper }\end{array}$ \\
\hline Ethanol Effect $(E 15 \mathrm{vs}$. E0) $(\Delta \mathrm{g} / \mathrm{mi})$ & -0.007 & -0.019 & 0.006 \\
\hline Ethanol Effect $($ E20 vs. E0) $(\Delta \mathrm{g} / \mathrm{mi})$ & -0.009 & -0.021 & 0.004 \\
\hline Road Fuel Aging Effect & & & \\
\hline Aging Effect with RE0 $(\Delta \mathrm{g} / \mathrm{mi}$ per 100k mi) & 0.005 & -0.023 & 0.034 \\
\hline Aging Effect with RE15 $(\Delta \mathrm{g} / \mathrm{mi}$ per 100k mi) & -0.015 & -0.037 & 0.006 \\
\hline Aging Effect with RE20 $(\Delta \mathrm{g} / \mathrm{mi}$ per 100k mi) & 0.021 & 0.000 & 0.043 \\
\hline
\end{tabular}

\begin{tabular}{|l|r|}
\hline \multicolumn{1}{|c|}{ Hypothesis } & -value \\
\hline No Effect of Ethanol in the Test Fuel (Gamma = 0) & 0.21 \\
\hline No Aging Effect with RE0 (Beta0 = 0) & 0.72 \\
\hline No Effect of Ethanol in Road Fuel Aging (Beta1s=0) & 0.07 \\
\hline
\end{tabular}

* Indicates estimate is different from zero at the $95 \%$ confidence level.

Initial odometers $43 \mathrm{k}-55 \mathrm{k}$

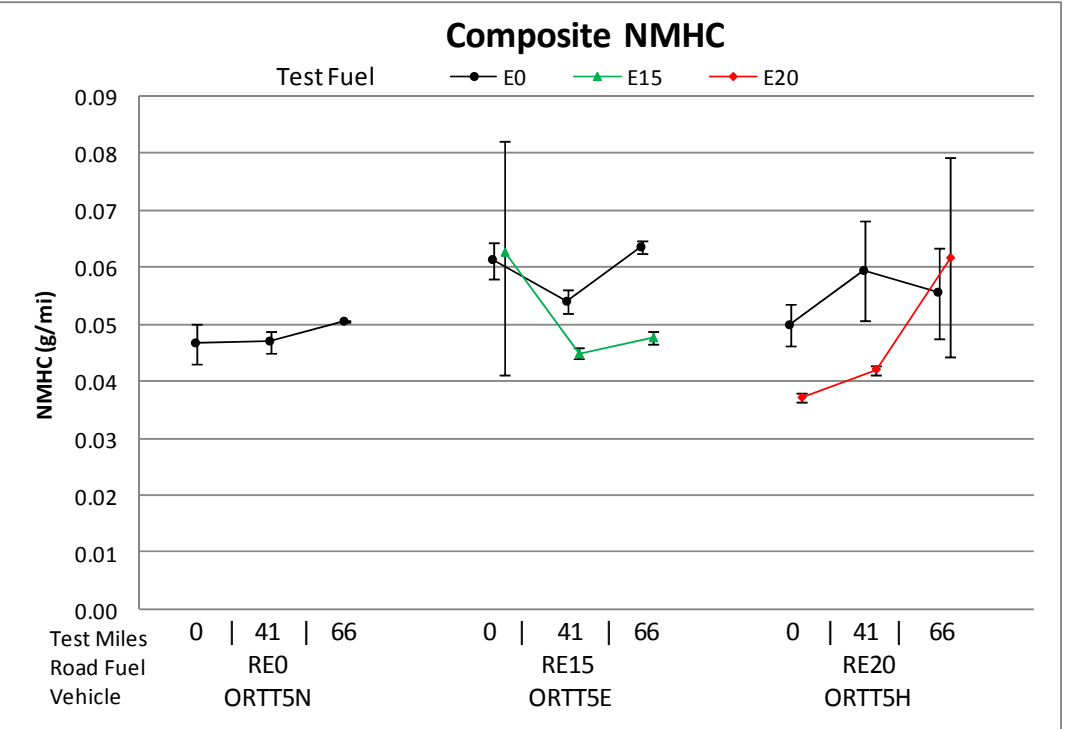

Error bars represent min and max measurements

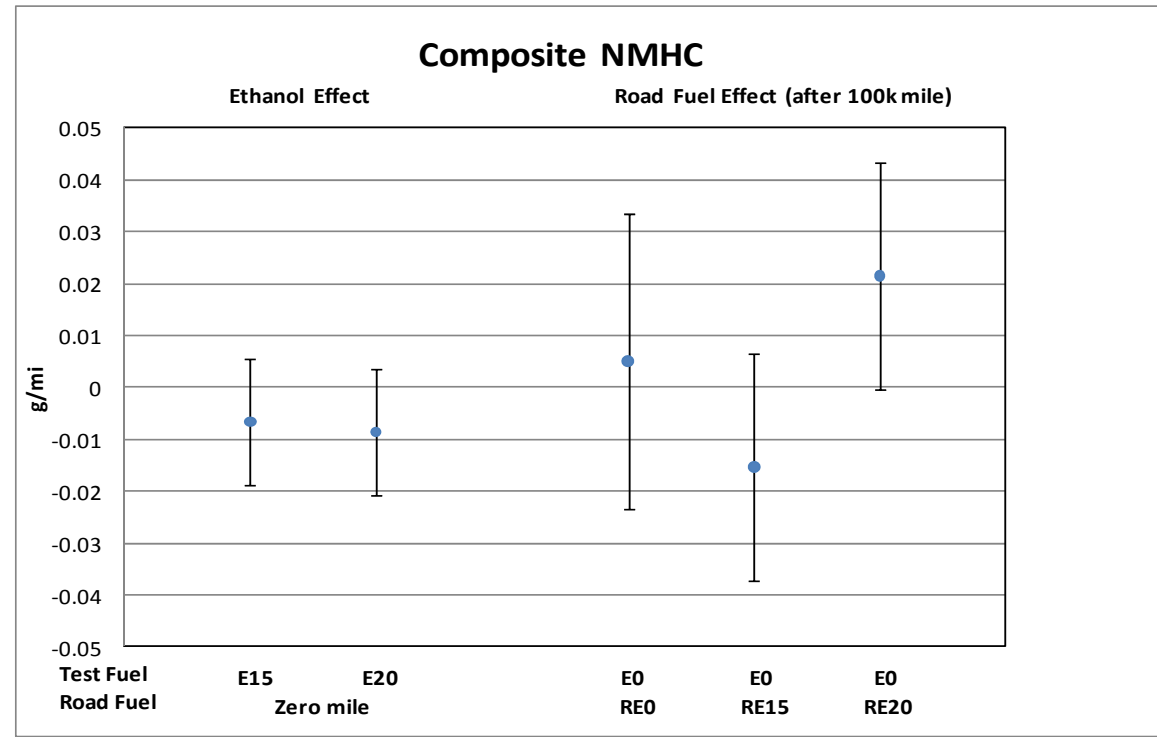

Error bars represent $95 \%$ confidence intervals on the estimated effects 
2005 Toyota Tundra (Composite Nonmethane Organic Gases)

\begin{tabular}{|l|r|r|r|}
\hline \multicolumn{1}{|c|}{ Effect } & & $\begin{array}{c}\text { 95\% C.I. } \\
\text { Lo5\% C.I. } \\
\text { Upper }\end{array}$ \\
\hline Ethanol Effect $(E 15 \mathrm{vs}$. E0) $(\Delta \mathrm{g} / \mathrm{mi})$ & -0.001 & -0.0144 & 0.0133 \\
\hline Ethanol Effect $($ E20 vs. E0) $(\Delta \mathrm{g} / \mathrm{mi})$ & -0.002 & -0.0155 & 0.0121 \\
\hline Road Fuel Aging Effect & & & \\
\hline Aging Effect with RE0 $(\Delta \mathrm{g} / \mathrm{mi}$ per 100k mi) & 0.005 & -0.0270 & 0.0378 \\
\hline Aging Effect with RE15 $(\Delta \mathrm{g} / \mathrm{mi}$ per 100k mi) & -0.018 & -0.0427 & 0.0070 \\
\hline Aging Effect with RE20 $(\Delta \mathrm{g} / \mathrm{mi}$ per 100k mi) & 0.024 & -0.0005 & 0.0493 \\
\hline
\end{tabular}

\begin{tabular}{|l|r|}
\hline \multicolumn{1}{|c|}{ Hypothesis } & p-value \\
\hline No Effect of Ethanol in the Test Fuel (Gamma = 0) & 0.96 \\
\hline No Aging Effect with RE0 (Beta0 $=0)$ & 0.73 \\
\hline No Effect of Ethanol in Road Fuel Aging (Beta1s=0) & 0.06 \\
\hline${ }^{*}$ Indicates effect is statistically significant at the 95\% confidence level.
\end{tabular}

* Indicates estimate is different from zero at the $95 \%$ confidence level.

Initial odometers $43 \mathrm{k}-55 \mathrm{k}$

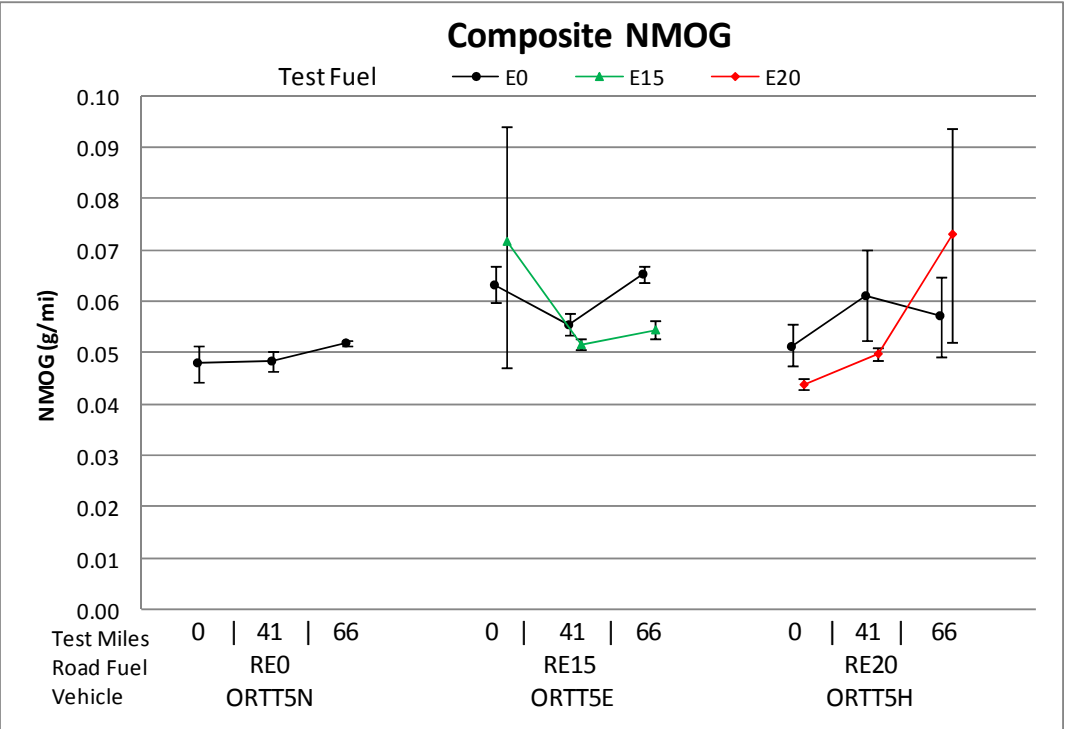

Error bars represent min and max measurements

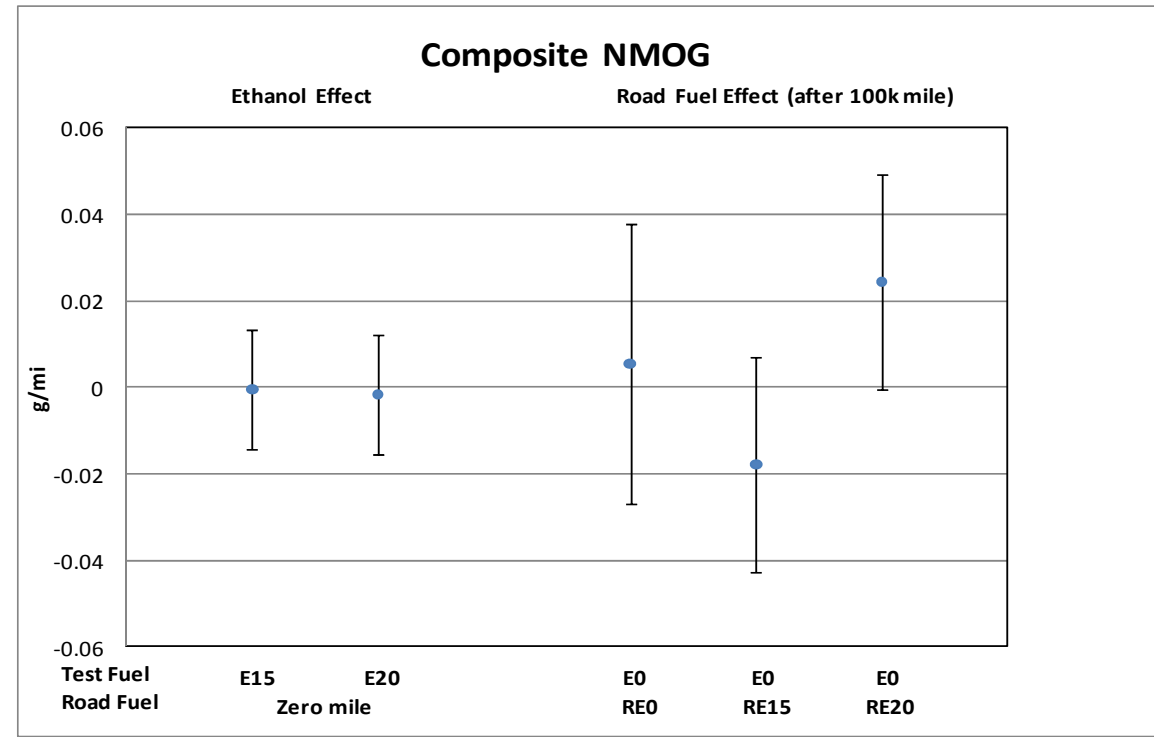

Error bars represent $95 \%$ confidence intervals on the estimated effects 
2005 Toyota Tundra (Composite Fuel Economy)

\begin{tabular}{|l|r|r|r|}
\hline \multicolumn{1}{|c|}{ Effect } & Estimate & $\begin{array}{c}\text { 95\% C.I. } \\
\text { Lower }\end{array}$ & $\begin{array}{r}\text { 95\% C.I. } \\
\text { Upper }\end{array}$ \\
\hline Ethanol Effect (E15 vs. E0) $(\Delta \mathrm{mi} / \mathrm{gal})$ & $-1.077^{*}$ & -1.597 & -0.556 \\
\hline Ethanol Effect (E20 vs. E0) $(\Delta \mathrm{mi} / \mathrm{gal})$ & $-1.281^{*}$ & -1.801 & -0.761 \\
\hline Road Fuel Aging Effect & & & \\
\hline Aging Effect with RE0 $(\Delta \mathrm{mi} /$ gal per 100k mi) & -0.077 & -1.468 & 1.314 \\
\hline Aging Effect with RE15 $(\Delta \mathrm{mi} / \mathrm{gal}$ per 100k mi) & -0.275 & -1.256 & 0.706 \\
\hline Aging Effect with RE20 $(\Delta \mathrm{mi} /$ gal per 100k mi) & -0.477 & -1.459 & 0.505 \\
\hline
\end{tabular}

\begin{tabular}{|l|r|}
\hline \multicolumn{1}{|c|}{ Hypothesis } & -value \\
\hline No Effect of Ethanol in the Test Fuel (Gamma = 0) & $<0.01^{*}$ \\
\hline No Aging Effect with RE0 (Beta0 $=0$ ) & 0.89 \\
\hline No Effect of Ethanol in Road Fuel Aging (Beta1s $=0$ ) & 0.83 \\
\hline * Indicates effect is statistically significant at the 95\% confidence level.
\end{tabular}

* Indicates estimate is different from zero at the $95 \%$ confidence level.

Initial odometers $43 \mathrm{k}-55 \mathrm{k}$

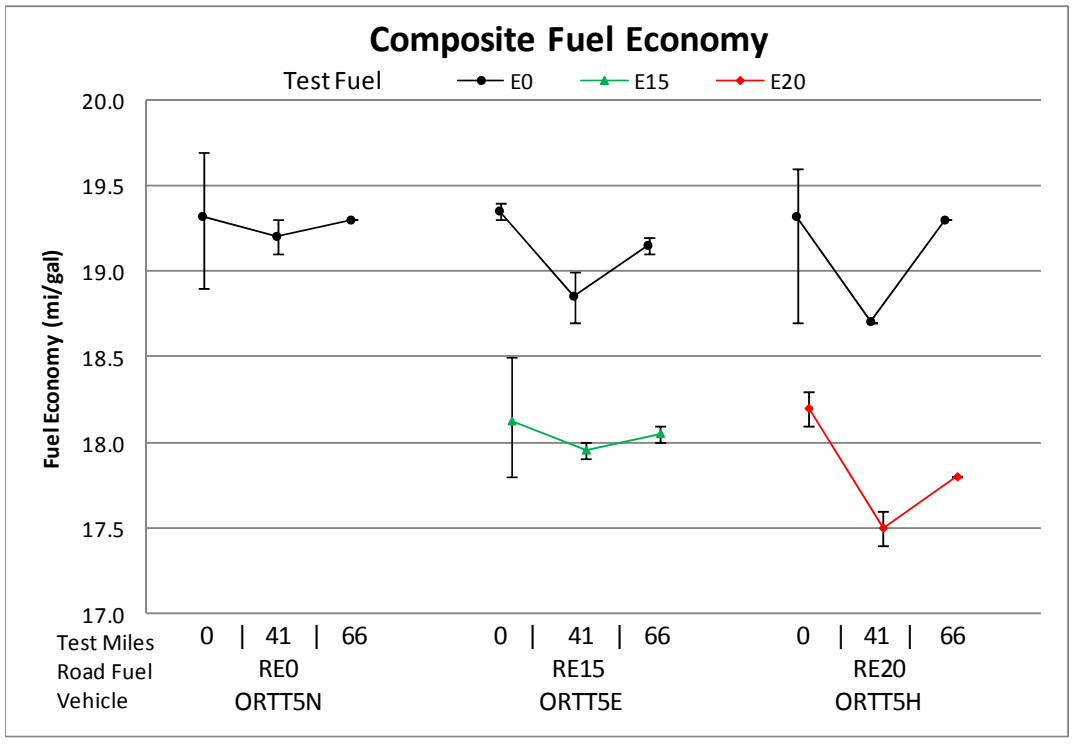

Error bars represent min and max measurements

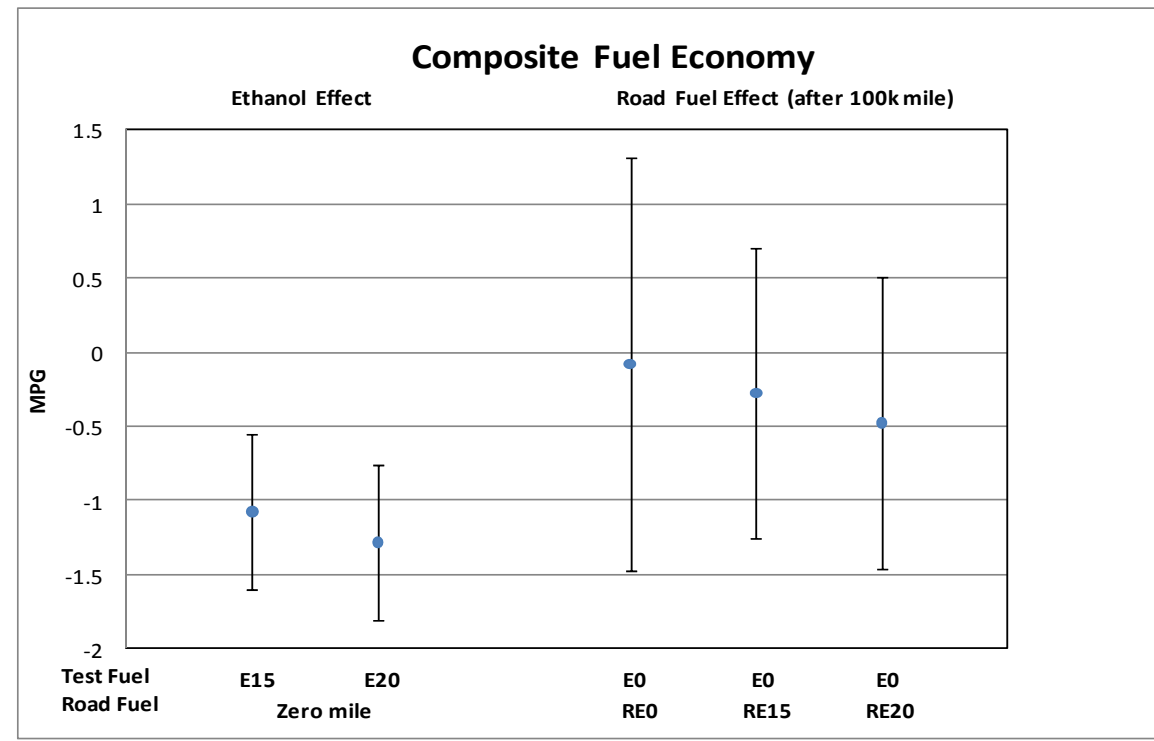

Error bars represent $95 \%$ confidence intervals on the estimated effects 
2005 Toyota Tundra (Composite Acetaldehyde)

\begin{tabular}{|l|r|r|r|}
\hline \multicolumn{1}{|c|}{ Effect } & Estimate & $\begin{array}{r}\text { 95\% C.I. } \\
\text { Lower }\end{array}$ & $\begin{array}{r}\text { 95\% C.I. } \\
\text { Upper }\end{array}$ \\
\hline Ethanol Effect (E15 vs. E0) $(\Delta \mathrm{mg} / \mathrm{mi})$ & $0.748^{*}$ & 0.438 & 1.057 \\
\hline Ethanol Effect (E20 vs. E0) $(\Delta \mathrm{mg} / \mathrm{mi})$ & $0.984^{*}$ & 0.553 & 1.416 \\
\hline Road Fuel Aging Effect & & & \\
\hline Aging Effect with RE0 $(\Delta \mathrm{mg} / \mathrm{mi}$ per 100k mi) & -0.053 & -0.221 & 0.115 \\
\hline Aging Effect with RE15 $(\Delta \mathrm{mg} / \mathrm{mi}$ per 100k mi) & $-0.105^{*}$ & -0.194 & -0.016 \\
\hline Aging Effect with RE20 $(\Delta \mathrm{mg} / \mathrm{mi}$ per 100k mi) & -0.044 & -0.168 & 0.081 \\
\hline
\end{tabular}

\begin{tabular}{|l|r|}
\hline \multicolumn{1}{|c|}{ Hypothesis } & -value \\
\hline No Effect of Ethanol in the Test Fuel (Gamma = 0) & $<0.01^{*}$ \\
\hline No Aging Effect with RE0 (Beta0 $=0$ ) & 0.40 \\
\hline No Effect of Ethanol in Road Fuel Aging (Beta1s $=0$ ) & 0.54 \\
\hline * Indicates effect is statistically significant at the 95\% confidence level.
\end{tabular}

* Indicates estimate is different from zero at the $95 \%$ confidence level.

Initial odometers $43 k-55 k$

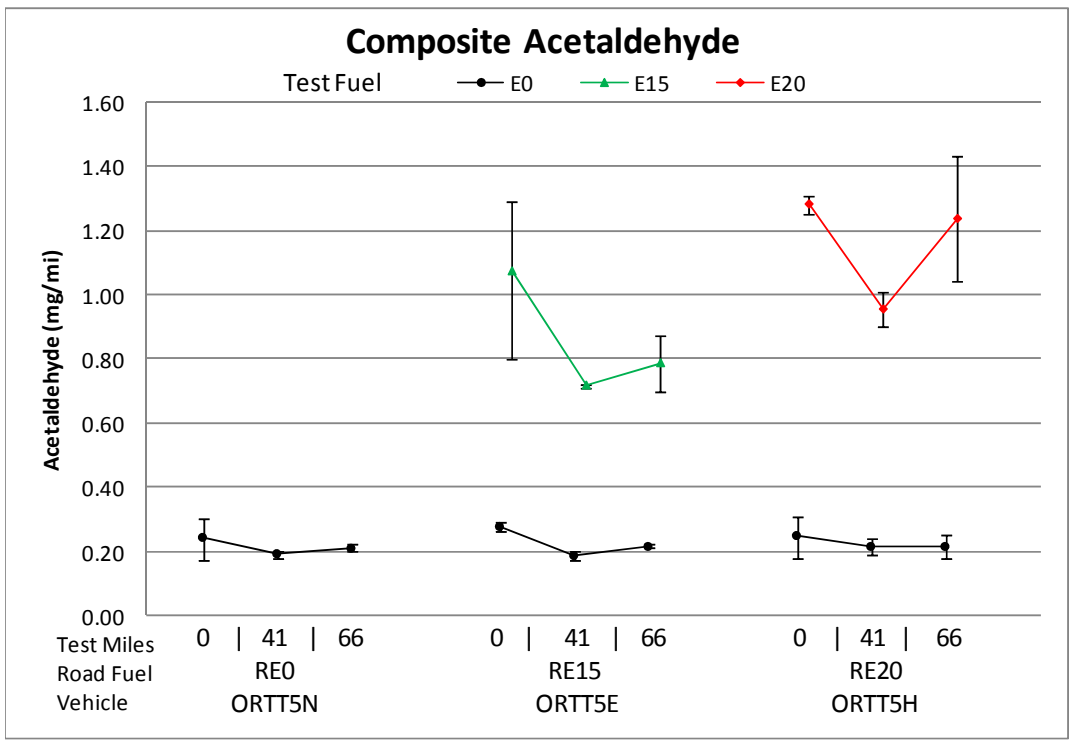

Error bars represent min and max measurements

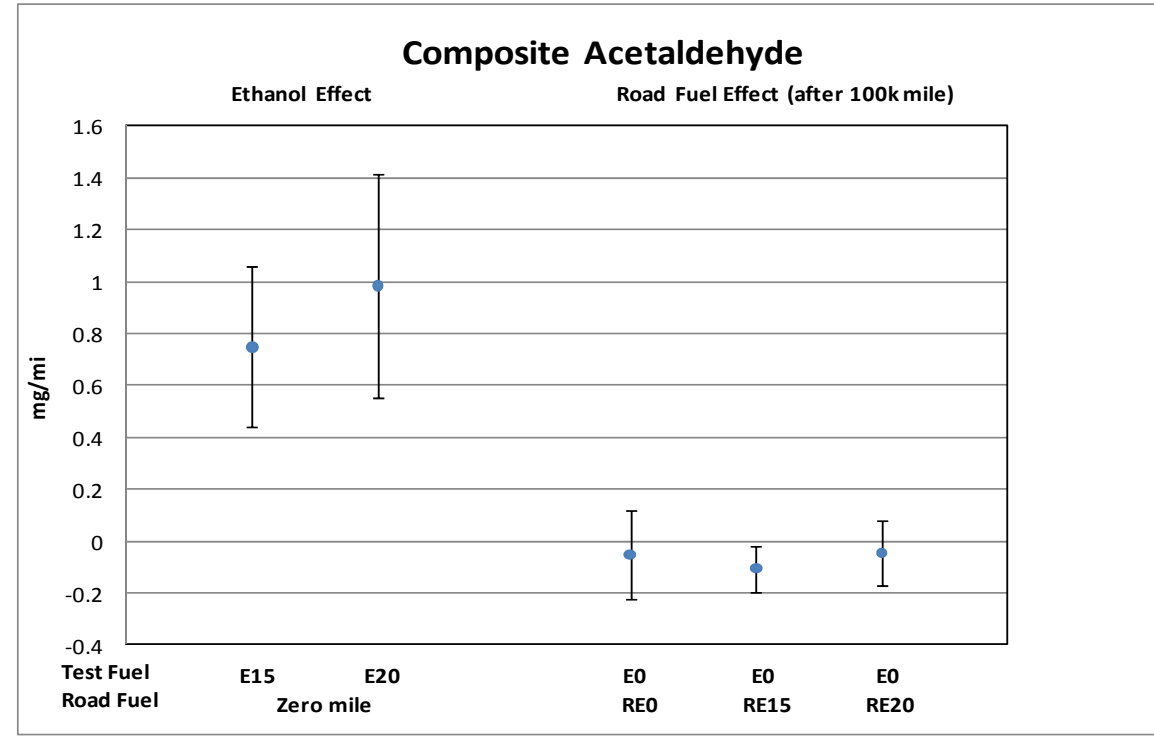

Error bars represent $95 \%$ confidence intervals on the estimated effects 
2005 Toyota Tundra (Composite Formaldehyde)

\begin{tabular}{|l|r|r|r|}
\hline \multicolumn{1}{|c|}{ Effect } & & $\begin{array}{r}\text { 95\% C.I. } \\
\text { Estimate }\end{array}$ & $\begin{array}{r}\text { 95\% C.I. } \\
\text { Upwer }\end{array}$ \\
\hline Ethanol Effect (E15 vs. E0) $(\Delta \mathrm{mg} / \mathrm{mi})$ & $0.133^{*}$ & 0.065 & 0.201 \\
\hline Ethanol Effect (E20 vs. E0) $(\Delta \mathrm{mg} / \mathrm{mi})$ & $0.144^{*}$ & 0.075 & 0.212 \\
\hline Road Fuel Aging Effect & & & \\
\hline Aging Effect with RE0 $(\Delta \mathrm{mg} / \mathrm{mi}$ per 100k mi) & $0.170^{*}$ & 0.003 & 0.337 \\
\hline Aging Effect with RE15 $(\Delta \mathrm{mg} / \mathrm{mi}$ per 100k mi) & -0.119 & -0.245 & 0.007 \\
\hline Aging Effect with RE20 $(\Delta \mathrm{mg} / \mathrm{mi}$ per 100k mi) & 0.093 & -0.033 & 0.219 \\
\hline
\end{tabular}

\begin{tabular}{|l|r|}
\hline \multicolumn{1}{|c|}{ Hypothesis } & -value \\
\hline No Effect of Ethanol in the Test Fuel (Gamma $=0)$ & $<0.01^{*}$ \\
\hline No Aging Effect with RE0 (Beta0 $=0$ ) & $0.05^{*}$ \\
\hline No Effect of Ethanol in Road Fuel Aging (Beta1s $=0$ ) & $0.01^{*}$ \\
\hline * Indicates effect is statistically significant at the 95\% confidence level.
\end{tabular}

* Indicates estimate is different from zero at the $95 \%$ confidence level.

Initial odometers $43 \mathrm{k}-55 \mathrm{k}$

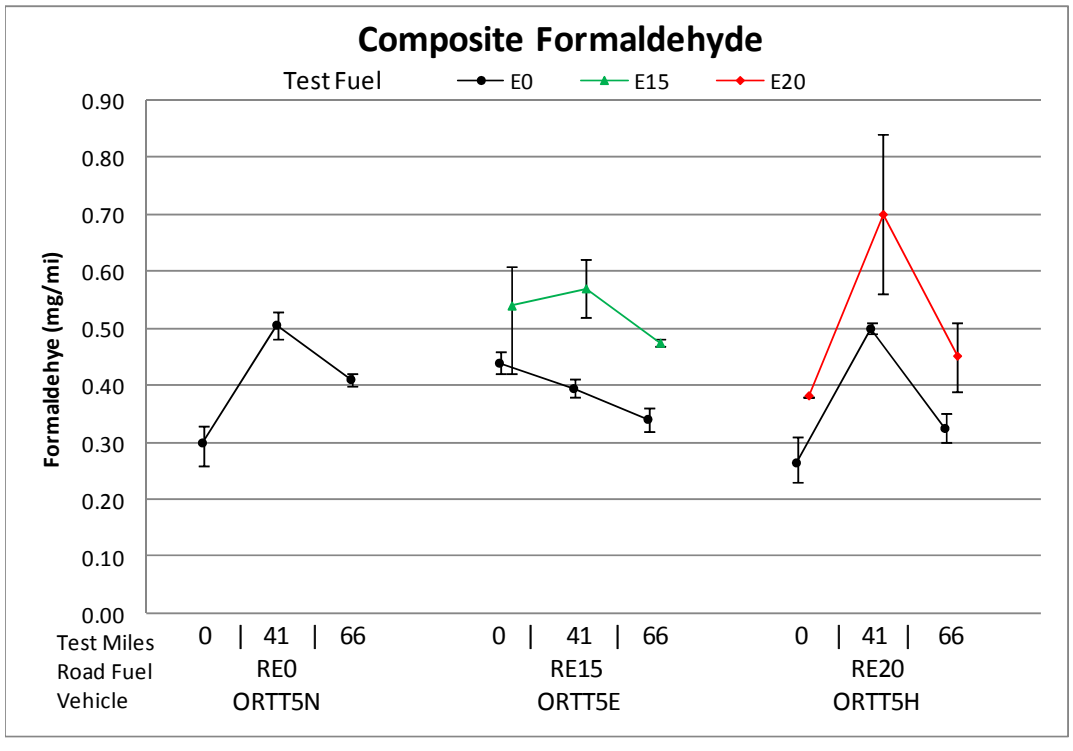

Error bars represent min and max measurements

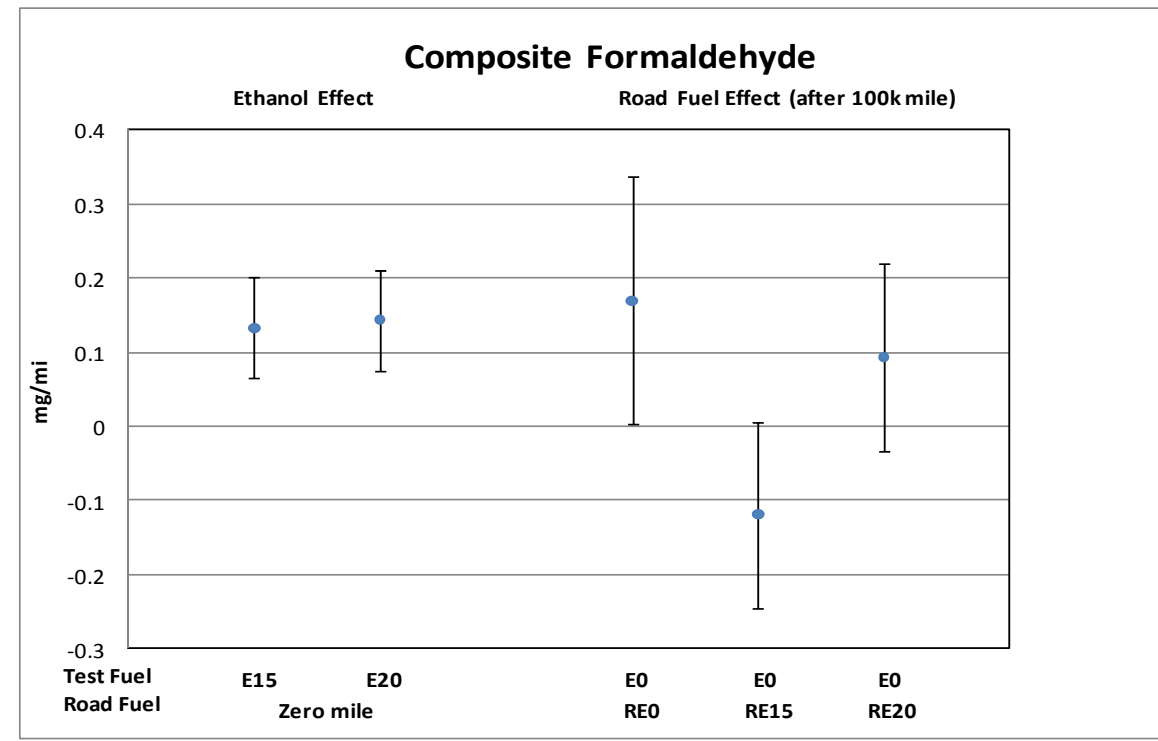

Error bars represent $95 \%$ confidence intervals on the estimated effects 
2005 Toyota Tundra (Composite $\mathrm{CH} 4$ )

\begin{tabular}{|l|r|r|r|}
\hline \multicolumn{1}{|c|}{ Effect } & & $\begin{array}{c}95 \% \text { C.I. } \\
\text { Low }\end{array}$ & $\begin{array}{r}\text { 95 C.I. } \\
\text { Upper }\end{array}$ \\
\hline Ethanol Effect (E15 vs. E0) $(\Delta \mathrm{g} / \mathrm{mi})$ & 0.0001 & -0.0028 & 0.0030 \\
\hline Ethanol Effect (E20 vs. E0) $(\Delta \mathrm{g} / \mathrm{mi})$ & 0.0017 & -0.0012 & 0.0047 \\
\hline Road Fuel Aging Effect & & & \\
\hline Aging Effect with RE0 $(\Delta \mathrm{g} / \mathrm{mi}$ per 100k mi) & $0.0102^{*}$ & 0.0024 & 0.0180 \\
\hline Aging Effect with RE15 $(\Delta \mathrm{g} / \mathrm{mi} \mathrm{per} \mathrm{100k} \mathrm{mi)}$ & $0.0069^{*}$ & 0.0014 & 0.0124 \\
\hline Aging Effect with RE20 $(\Delta \mathrm{g} / \mathrm{mi}$ per 100k mi) & $0.0072^{*}$ & 0.0016 & 0.0127 \\
\hline
\end{tabular}

\begin{tabular}{|l|r|}
\hline \multicolumn{1}{|c|}{ Hypothesis } & $p$-value \\
\hline No Effect of Ethanol in the Test Fuel (Gamma = 0) & 0.42 \\
\hline No Aging Effect with RE0 (Beta0 = 0) & $0.02^{*}$ \\
\hline No Effect of Ethanol in Road Fuel Aging (Beta1s=0) & 0.69 \\
\hline${ }^{*}$ Indicates effect is statistically significant at the 95\% confidence level.
\end{tabular}

* Indicates estimate is different from zero at the $95 \%$ confidence level.

Initial odometers $43 \mathrm{k}-55 \mathrm{k}$

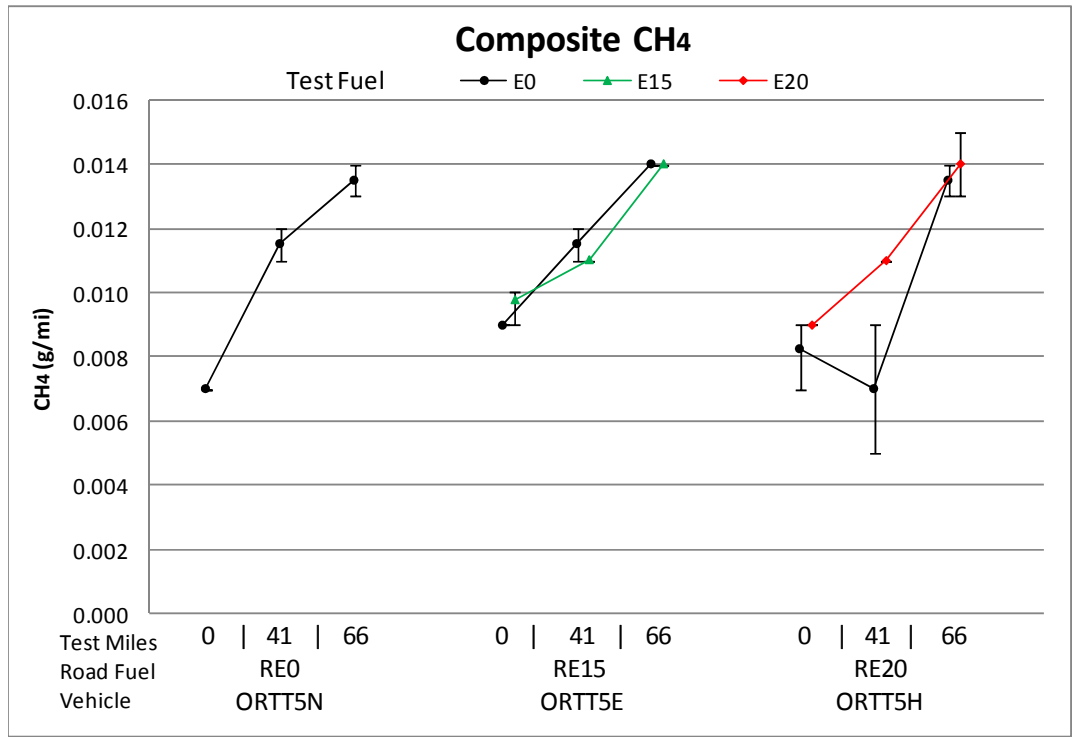

Error bars represent min and max measurements

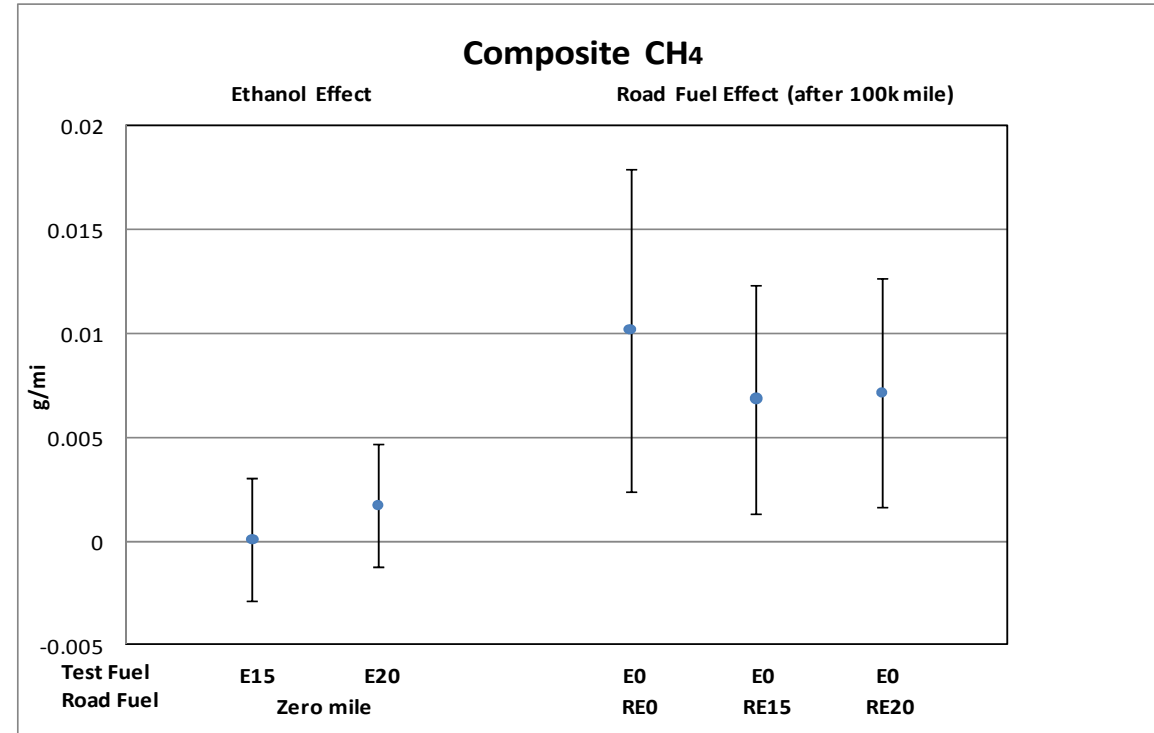

Error bars represent $95 \%$ confidence intervals on the estimated effects 


\section{Chevrolet Impala - Composite Emissions Summary}

\begin{tabular}{|c|c|c|c|c|c|c|c|c|c|c|c|c|c|c|}
\hline \multirow{2}{*}{$\begin{array}{c}\text { Emisssion Parameter } \\
\text { (units) }\end{array}$} & \multicolumn{4}{|c|}{ Ethanol Effect } & \multicolumn{2}{|c|}{ Aging Effect with REO } & \multicolumn{4}{|c|}{ RExx Aging Effect on E0 Emissions } & \multirow{2}{*}{\multicolumn{3}{|c|}{$\begin{array}{c}\text { RExx Aging Effect on Exx Emissions } \\
\Delta \text { units per } 100 \mathrm{~K} \mathrm{mi}\end{array}$}} & \multirow{3}{*}{\begin{tabular}{|c|}
$\begin{array}{l}\text { Road and Test } \\
\text { Fuel Effects } \\
\text { are Additive }\end{array}$ \\
$\begin{array}{c}\text { Overall p- } \\
\text { value }\end{array}$
\end{tabular}} \\
\hline & \multicolumn{3}{|c|}{$\Delta$ units vs. EO } & \multirow{2}{*}{$\begin{array}{l}\text { Overall } \\
p \text {-value }\end{array}$} & \multirow{2}{*}{$\frac{\Delta \text { units per } 100 \mathrm{~K} \mathrm{mi}}{\text { REO/E0 }}$} & \multirow{2}{*}{$\begin{array}{l}\text { Overall } \\
p \text {-value }\end{array}$} & \multicolumn{3}{|c|}{$\Delta$ units per $100 \mathrm{~K} \mathrm{mi}$} & \multirow{2}{*}{$\begin{array}{l}\text { Overall } \\
p \text {-value }\end{array}$} & & & & \\
\hline Fuels & E10 & E15 & E20 & & & & RE10/E0 & RE15/E0 & RE20/E0 & & RE10/E10 & RE15/E15 & RE20/E20 & \\
\hline $\mathrm{CO}(\mathrm{g} / \mathrm{mi})$ & NA & -0.117 & -0.093 & 0.41 & 0.097 & 0.67 & NA & $0.579 *$ & 0.342 & 0.25 & NA & NA & NA & 0.52 \\
\hline $\mathrm{NOx}(\mathrm{g} / \mathrm{mi})$ & $\mathrm{NA}$ & 0.002 & $0.046^{*}$ & $0.01 *$ & 0.005 & 0.67 & $\mathrm{NA}$ & 0.022 & 0.018 & 0.61 & $\mathrm{NA}$ & 0.020 & $-0.063^{*}$ & $0.01 *$ \\
\hline $\mathrm{NMHC}(\mathrm{g} / \mathrm{mi})$ & NA & -0.003 & -0.004 & 0.10 & -0.005 & 0.35 & NA & $0.010^{*}$ & 0.002 & 0.05 & $\mathrm{NA}$ & NA & NA & 0.16 \\
\hline NMOG $(\mathrm{g} / \mathrm{mi})$ & NA & 0.001 & 0.003 & 0.53 & -0.005 & 0.41 & NA & $0.010^{*}$ & 0.002 & 0.08 & $\mathrm{NA}$ & NA & NA & 0.18 \\
\hline Fuel Econ (mi/gal) & NA & $-1.267^{*}$ & $-1.486^{*}$ & $<0.01 *$ & 0.109 & 0.84 & NA & 0.439 & -0.108 & 0.60 & $\mathrm{NA}$ & NA & NA & 0.39 \\
\hline Acetaldehyde $(\mathrm{mg} / \mathrm{mi})^{\#}$ & NA & $0.453^{*}$ & $0.928^{*}$ & $<0.01 *$ & -0.040 & 0.60 & NA & -0.089 & -0.079 & 0.87 & $\mathrm{NA}$ & NA & NA & 0.10 \\
\hline Formaldehyde $(\mathrm{mg} / \mathrm{mi})^{\#}$ & NA & -0.163 & 0.201 & 0.40 & -0.165 & 0.55 & NA & -0.316 & -0.219 & 0.95 & $\mathrm{NA}$ & NA & NA & 0.97 \\
\hline $\mathrm{CH}_{4}(\mathrm{~g} / \mathrm{mi})$ & NA & 0.0010 & $0.0033^{*}$ & $<0.01^{*}$ & $0.0139 *$ & $<0.01^{*}$ & NA & $0.0197 *$ & $0.0124 *$ & $<0.01 *$ & $N A$ & NA & NA & 0.47 \\
\hline
\end{tabular}

\# Log-normal model was used. Results are presented as changes in emissions at $0 \mathrm{k}$ mile.

\#\# Data did not support the assumption of linear effects with mileage.

* Indicates estimate is different from zero at the $95 \%$ confidenceleve. 
2006 Chevrolet Impala (Composite CO)

\begin{tabular}{|l|r|r|r|}
\hline \multicolumn{1}{|c|}{ Effect } & & $\begin{array}{r}\text { 95\% C.I. } \\
\text { Low\% C.I. } \\
\text { Upper }\end{array}$ \\
\hline Ethanol Effect $(E 15 \mathrm{vs}$. E0) $(\Delta \mathrm{g} / \mathrm{mi})$ & -0.117 & -0.363 & 0.130 \\
\hline Ethanol Effect $($ E20 vs. E0) $(\Delta \mathrm{g} / \mathrm{mi})$ & -0.093 & -0.340 & 0.153 \\
\hline Road Fuel Aging Effect & & & \\
\hline Aging Effect with RE0 $(\Delta \mathrm{g} / \mathrm{mi}$ per 100k mi) & 0.097 & -0.417 & 0.611 \\
\hline Aging Effect with RE15 $(\Delta \mathrm{g} / \mathrm{mi}$ per 100k mi) & $0.579 *$ & 0.215 & 0.943 \\
\hline Aging Effect with RE20 $(\Delta \mathrm{g} / \mathrm{mi}$ per 100k mi) & 0.342 & -0.020 & 0.705 \\
\hline
\end{tabular}

\begin{tabular}{|l|r|}
\hline \multicolumn{1}{|c|}{ Hypothesis } & p-value \\
\hline No Effect of Ethanol in the Test Fuel (Gamma = 0) & 0.41 \\
\hline No Aging Effect with RE0 (Beta0 = 0) & 0.67 \\
\hline No Effect of Ethanol in Road Fuel Aging (Beta1s=0) & 0.25 \\
\hline
\end{tabular}

* Indicates estimate is different from zero at the $95 \%$ confidence level.

Initial odometers $31 \mathrm{k}-38 \mathrm{k}$

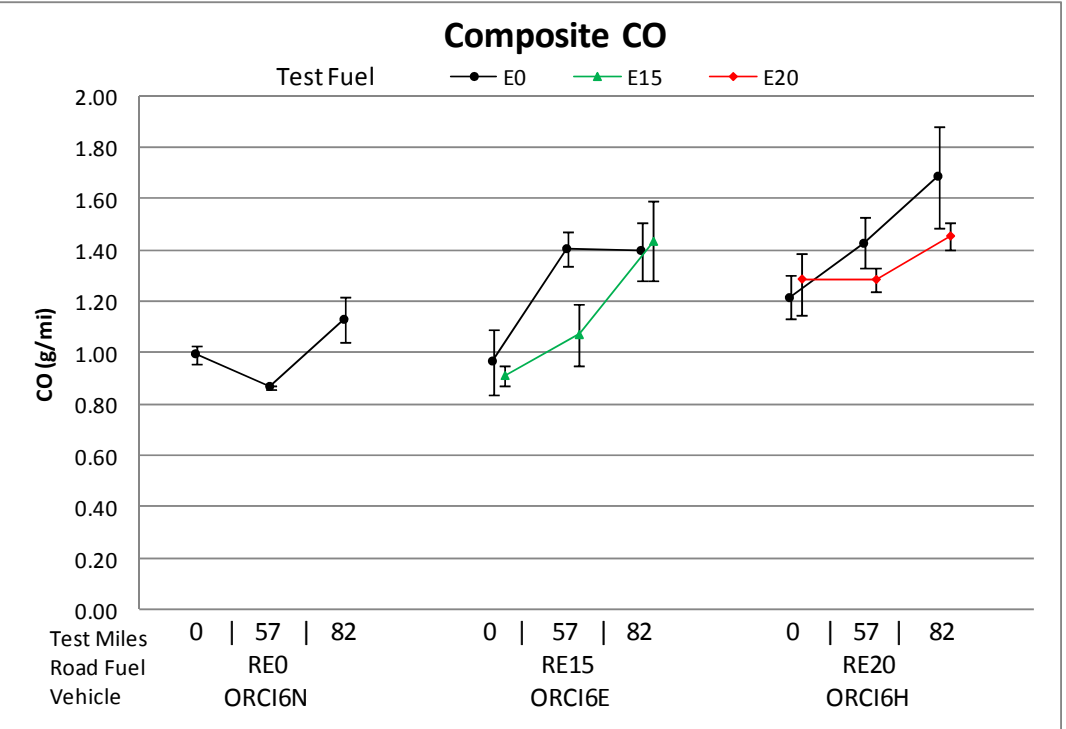

Error bars represent min and max measurements

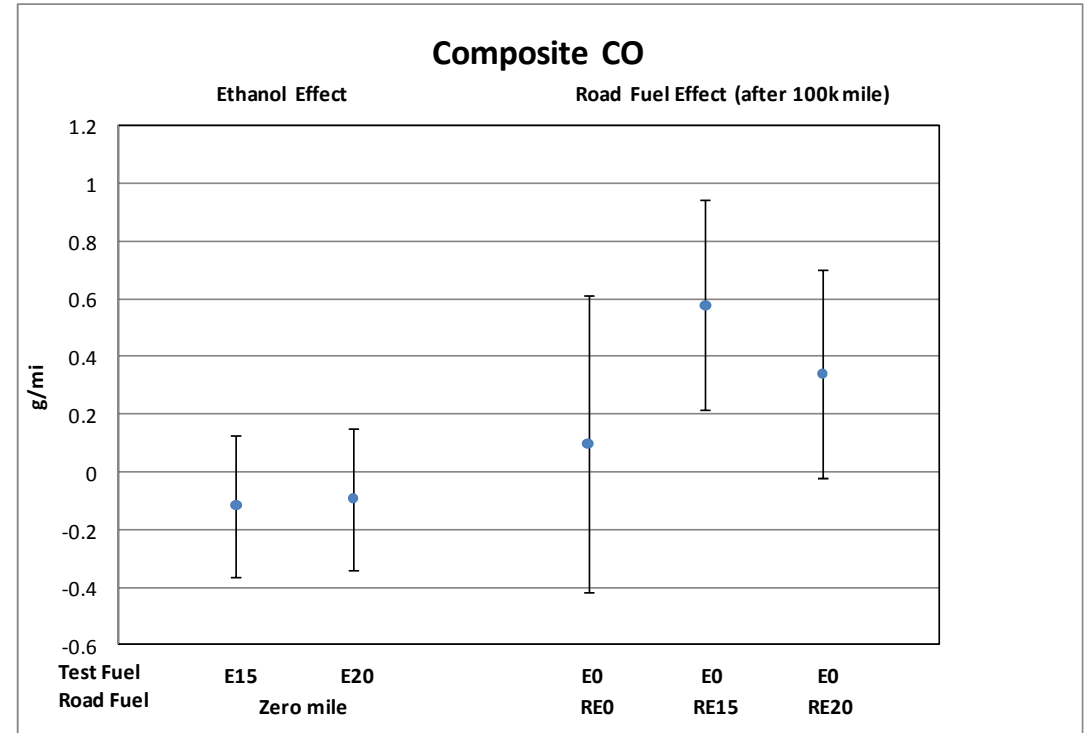

Error bars represent $95 \%$ confidence intervals on the estimated effects 
2006 Chevrolet Impala (Composite NOx)

\begin{tabular}{|c|c|c|c|}
\hline Effect & Estimate & $\begin{array}{c}\text { 95\% C.I. } \\
\text { Lower }\end{array}$ & $\begin{array}{c}\text { 95\% C.I. } \\
\text { Upper }\end{array}$ \\
\hline Ethanol Effect (E15 vs. E0) $(\Delta \mathrm{g} / \mathrm{mi})$ & 0.002 & -0.018 & 0.023 \\
\hline Ethanol Effect (E20 vs. E0) $(\Delta \mathrm{g} / \mathrm{mi})$ & $0.046^{*}$ & 0.027 & 0.064 \\
\hline \multicolumn{4}{|l|}{ Road Fuel Aging Effect } \\
\hline Aging Effect with RE0 ( $\Delta \mathrm{g} / \mathrm{mi}$ per $100 \mathrm{k} \mathrm{mi})$ & 0.005 & -0.020 & 0.031 \\
\hline Aging Effect with RE15 $(\Delta \mathrm{g} / \mathrm{mi}$ per $100 \mathrm{k} \mathrm{mi})$ & 0.022 & -0.003 & 0.047 \\
\hline Aging Effect with RE15 ( $\Delta \mathrm{g} / \mathrm{mi}$ per $100 \mathrm{k} \mathrm{mi})$ & 0.018 & -0.008 & 0.043 \\
\hline
\end{tabular}

* Indicates estimate is different from zero at the $95 \%$ confidence level.

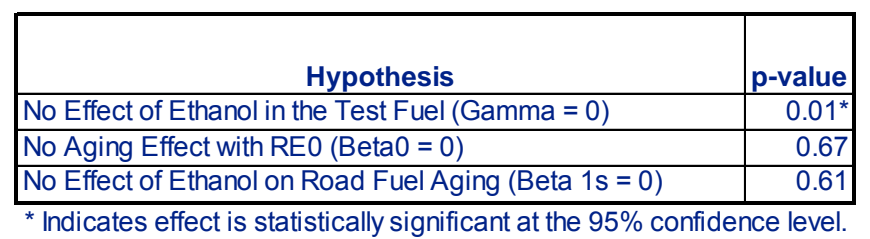

Initial odometers $31 \mathrm{k}-38 \mathrm{k}$

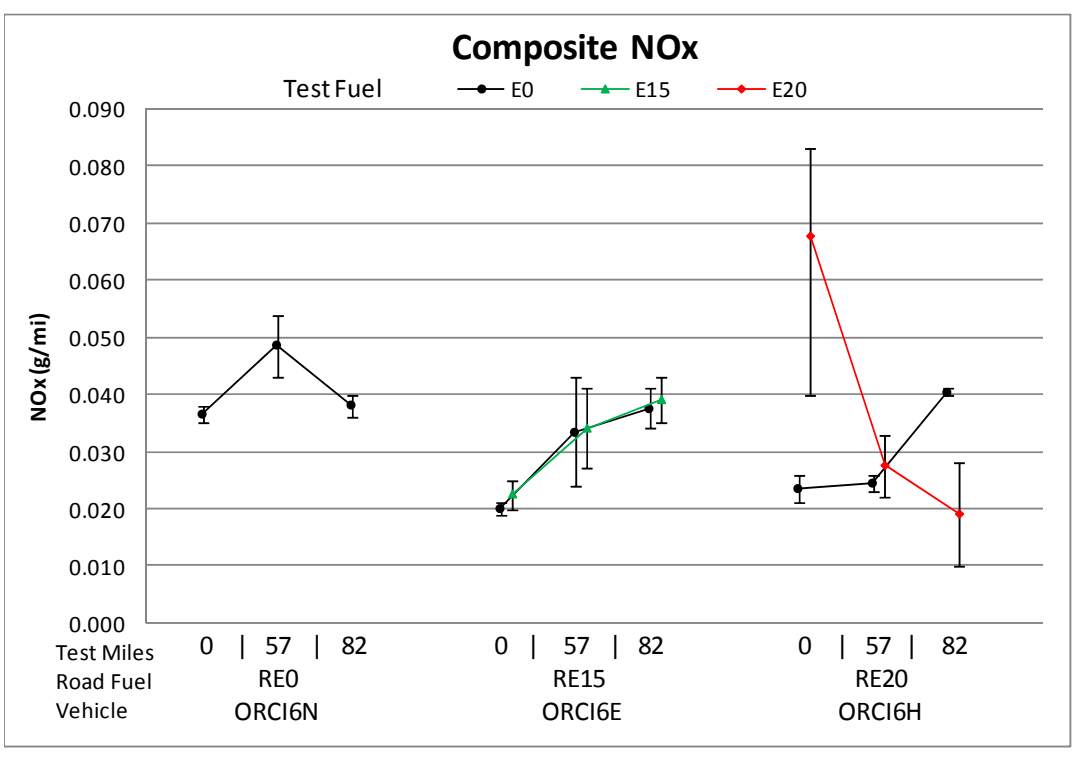

Error bars represent min and max measurements

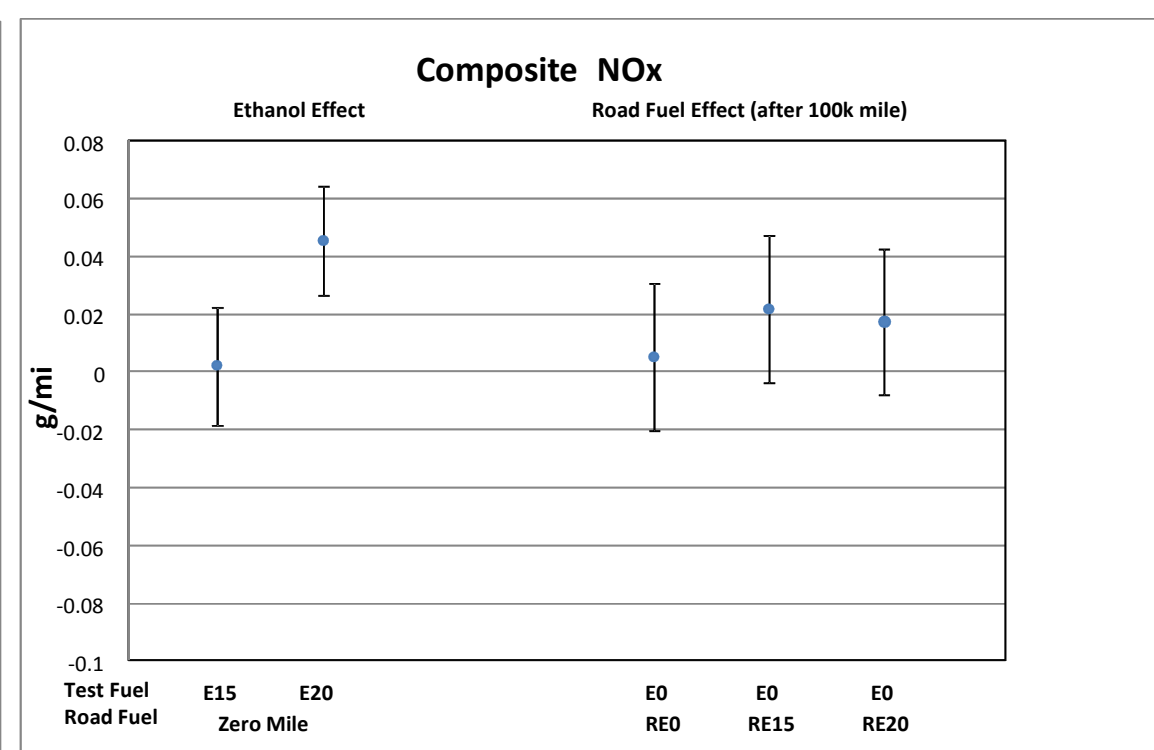

Error bars represent $95 \%$ confidence intervals on the estimated effects 
2006 Chevrolet Impala (Composite Nonmethane Hydrocarbons)

\begin{tabular}{|l|r|r|r|}
\hline \multicolumn{1}{|c|}{ Effect } & & $\begin{array}{r}95 \% \text { C.I. } \\
\text { Low\% C.I. }\end{array}$ & $\begin{array}{r}\text { 95 } \\
\text { Upper }\end{array}$ \\
\hline Ethanol Effect $(E 15 \mathrm{vs}$. E0) $(\Delta \mathrm{g} / \mathrm{mi})$ & -0.003 & -0.008 & 0.002 \\
\hline Ethanol Effect $($ E20 vs. E0) $(\Delta \mathrm{g} / \mathrm{mi})$ & -0.004 & -0.009 & 0.001 \\
\hline Road Fuel Aging Effect & & & \\
\hline Aging Effect with RE0 $(\Delta \mathrm{g} / \mathrm{mi}$ per 100k mi) & -0.005 & -0.015 & 0.005 \\
\hline Aging Effect with RE15 $(\Delta \mathrm{g} / \mathrm{mi}$ per 100k mi) & $0.010^{*}$ & 0.003 & 0.017 \\
\hline Aging Effect with RE20 $(\Delta \mathrm{g} / \mathrm{mi}$ per 100k mi) & 0.002 & -0.005 & 0.009 \\
\hline
\end{tabular}

\begin{tabular}{|l|r|}
\hline \multicolumn{1}{|c|}{ Hypothesis } & -value \\
\hline No Effect of Ethanol in the Test Fuel (Gamma = 0) & 0.10 \\
\hline No Aging Effect with RE0 (Beta0 = 0) & 0.35 \\
\hline No Effect of Ethanol in Road Fuel Aging (Beta1s=0) & 0.05 \\
\hline * Indicates effect is statistically significant at the 95\% confidence level.
\end{tabular}

* Indicates estimate is different from zero at the $95 \%$ confidence level.

Initial odometers $31 \mathrm{k}-38 \mathrm{k}$

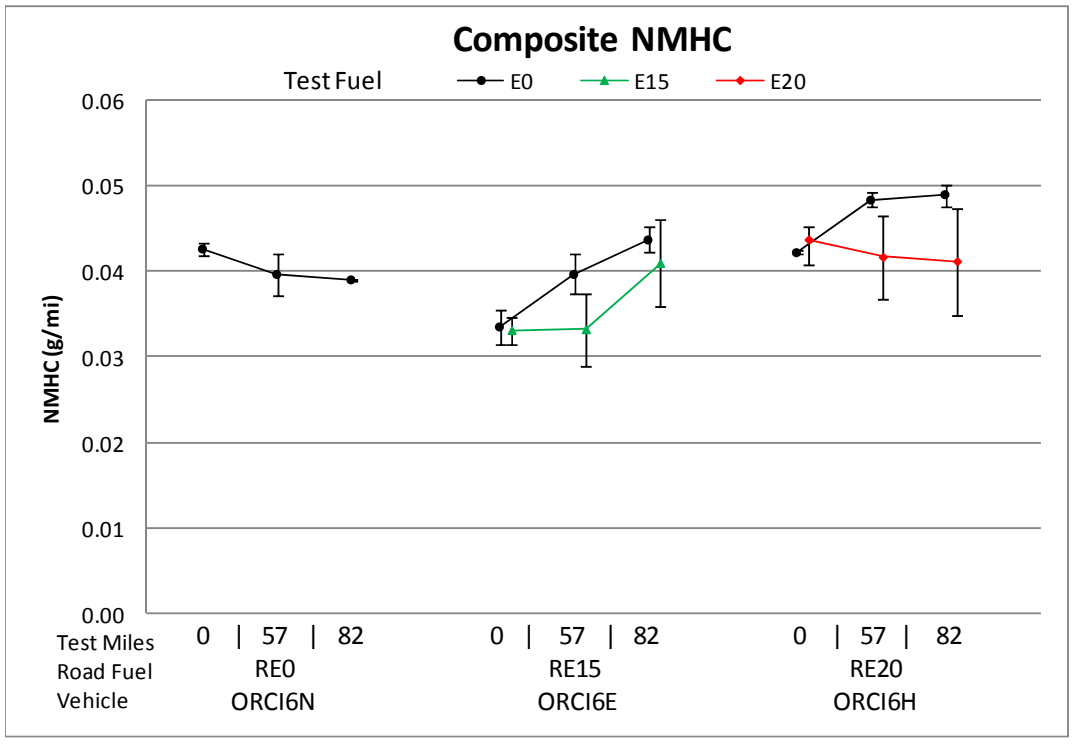

Error bars represent min and max measurements

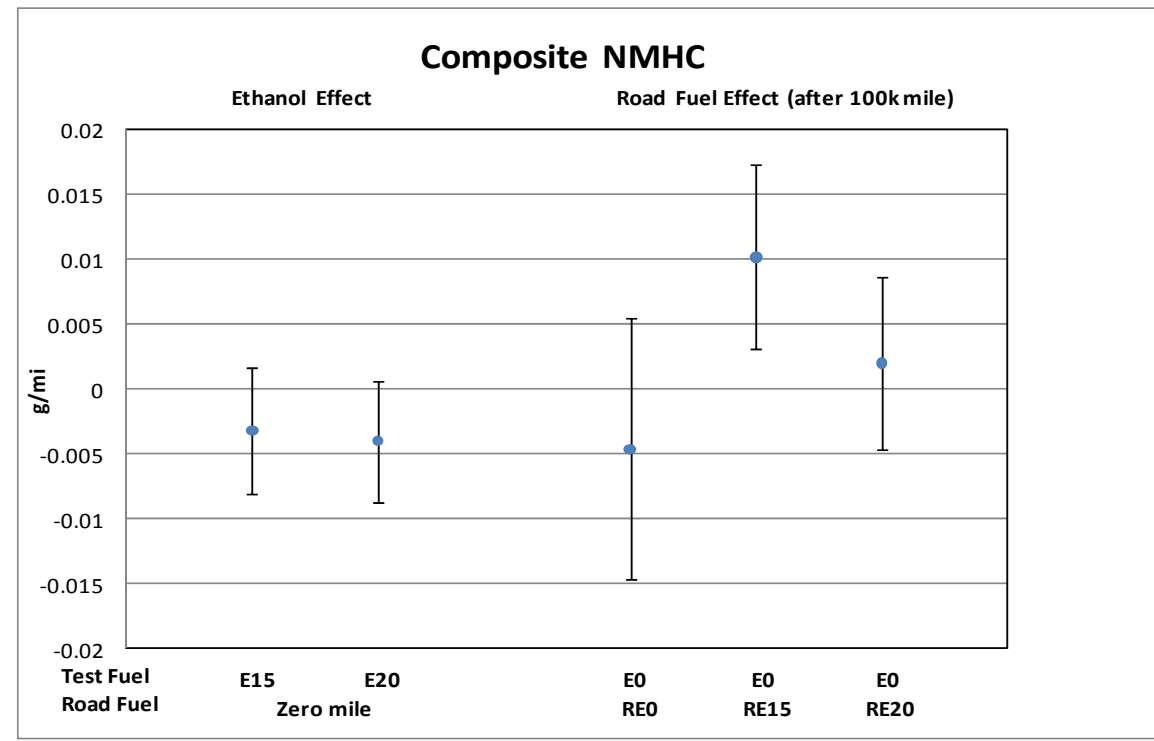

Error bars represent $95 \%$ confidence intervals on the estimated effects 
2006 Chevrolet Impala (Composite Nonmethane Organic Gases)

\begin{tabular}{|l|r|r|r|}
\hline \multicolumn{1}{|c|}{ Effect } & Estimate & $\begin{array}{c}\text { 95\% C.I. } \\
\text { Lower }\end{array}$ & $\begin{array}{r}\text { 95\% C.I. } \\
\text { Upper }\end{array}$ \\
\hline Ethanol Effect (E15 vs. E0) $(\Delta \mathrm{g} / \mathrm{mi})$ & 0.001 & -0.004 & 0.007 \\
\hline Ethanol Effect (E20 vs. E0) $(\Delta \mathrm{g} / \mathrm{mi})$ & 0.003 & -0.003 & 0.008 \\
\hline Road Fuel Aging Effect & & & \\
\hline Aging Effect with RE0 $(\Delta \mathrm{g} / \mathrm{mi}$ per 100k mi) & -0.005 & -0.016 & 0.007 \\
\hline Aging Effect with RE15 $(\Delta \mathrm{g} / \mathrm{mi}$ per 100k mi) & $0.010^{*}$ & 0.003 & 0.018 \\
\hline Aging Effect with RE20 $(\Delta \mathrm{g} / \mathrm{mi}$ per 100k mi) & 0.002 & -0.005 & 0.010 \\
\hline
\end{tabular}

\begin{tabular}{|l|r|}
\hline \multicolumn{1}{|c|}{ Hypothesis } & -value \\
\hline No Effect of Ethanol in the Test Fuel (Gamma = 0) & 0.53 \\
\hline No Aging Effect with RE0 (Beta0 = 0) & 0.41 \\
\hline No Effect of Ethanol in Road Fuel Aging (Beta1s=0) & 0.08 \\
\hline * Indicates effect is statistically significant at the 95\% confidence level.
\end{tabular}

${ }^{*}$ Indicates estimate is different from zero at the $95 \%$ confidence level.

Initial odometers $31 \mathrm{k}-38 \mathrm{k}$

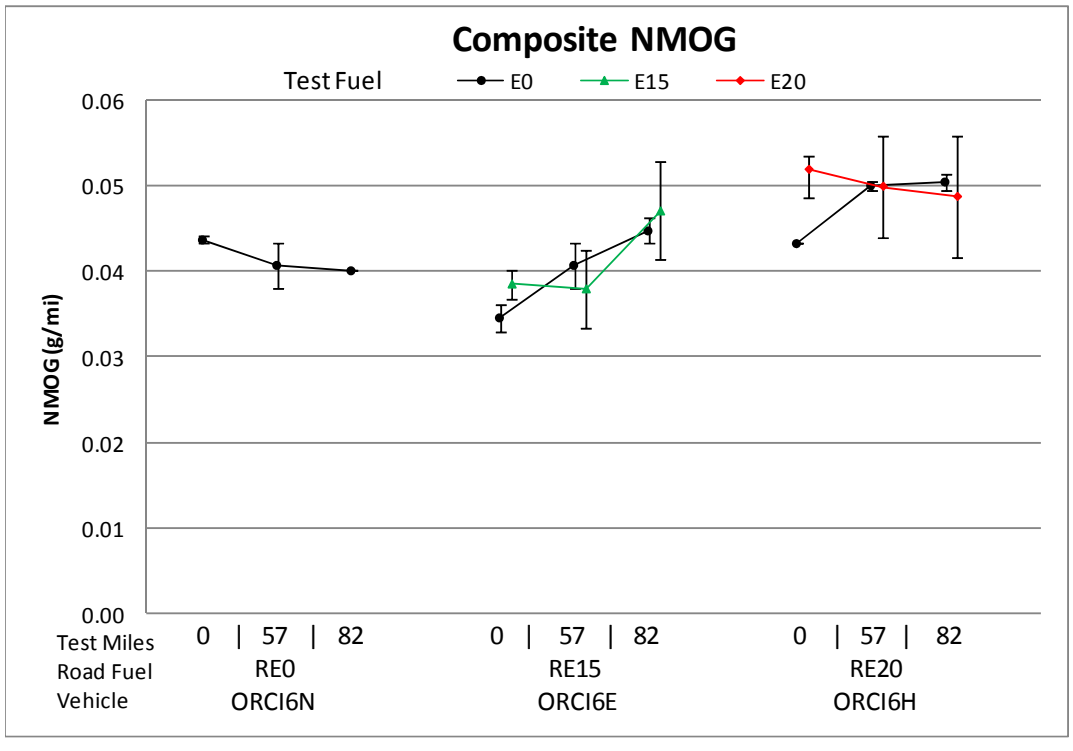

Error bars represent min and max measurements

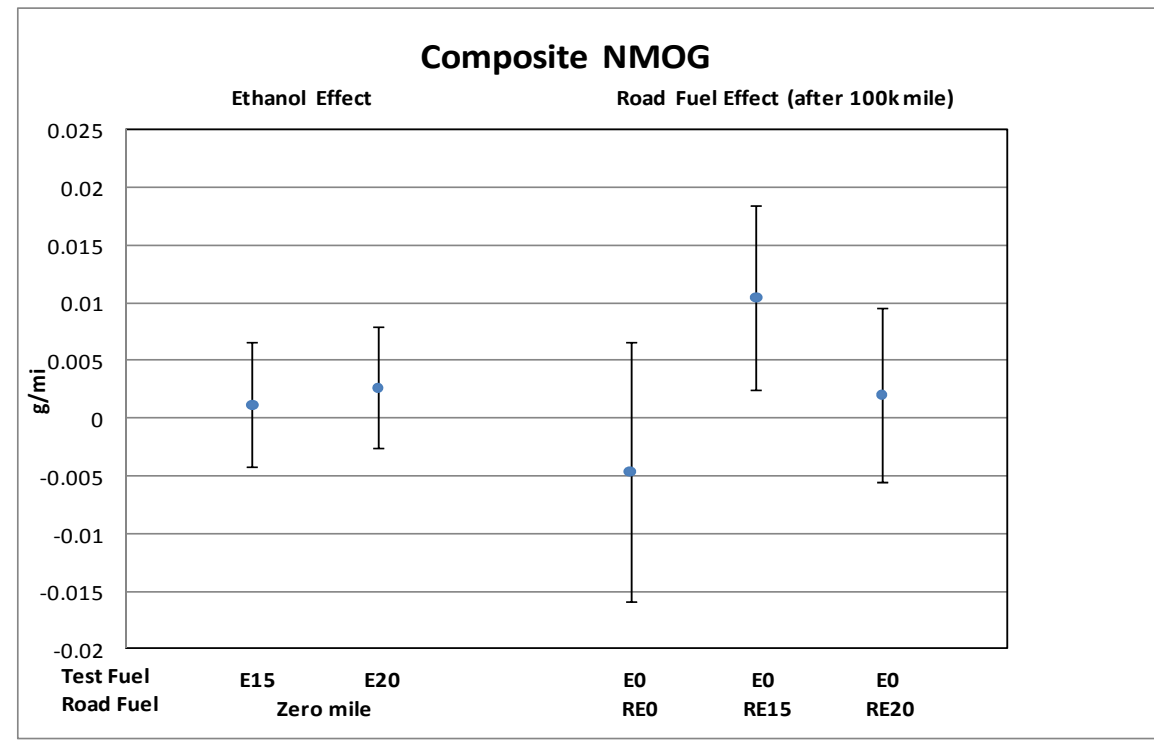

Error bars represent $95 \%$ confidence intervals on the estimated effects 
2006 Chevrolet Impala (Composite Fuel Economy)

\begin{tabular}{|l|r|r|r|}
\hline \multicolumn{1}{|c|}{ Effect } & Estimate & $\begin{array}{c}\text { 95\% C.I. } \\
\text { Lower }\end{array}$ & $\begin{array}{c}\text { 95\% C.I. } \\
\text { Upper }\end{array}$ \\
\hline Ethanol Effect (E15 vs. E0) $(\Delta \mathrm{mi} / \mathrm{gal})$ & $-1.267^{*}$ & -1.863 & -0.671 \\
\hline Ethanol Effect $($ E20 vs. E0) $(\Delta \mathrm{mi} / \mathrm{gal})$ & $-1.486^{*}$ & -2.081 & -0.890 \\
\hline Road Fuel Aging Effect & & & \\
\hline Aging Effect with RE0 $(\Delta \mathrm{mi} / \mathrm{gal}$ per 100k mi) & 0.109 & -1.133 & 1.350 \\
\hline Aging Effect with RE15 $(\Delta \mathrm{mi} / \mathrm{gal}$ per 100k mi) & 0.439 & -0.439 & 1.318 \\
\hline Aging Effect with RE20 $(\Delta \mathrm{mi} / \mathrm{gal}$ per 100k mi) & -0.108 & -0.984 & 0.769 \\
\hline
\end{tabular}

\begin{tabular}{|l|r|}
\hline \multicolumn{1}{|c|}{ Hypothesis } & -value \\
\hline No Effect of Ethanol in the Test Fuel (Gamma = 0) & $<0.01^{*}$ \\
\hline No Aging Effect with RE0 (Beta0 $=0$ ) & 0.84 \\
\hline No Effect of Ethanol in Road Fuel Aging (Beta1s $=0$ ) & 0.60 \\
\hline * Indicates effect is statistically significant at the 95\% confidence level.
\end{tabular}

* Indicates estimate is different from zero at the $95 \%$ confidence level.

Initial odometers $31 \mathrm{k}-38 \mathrm{k}$

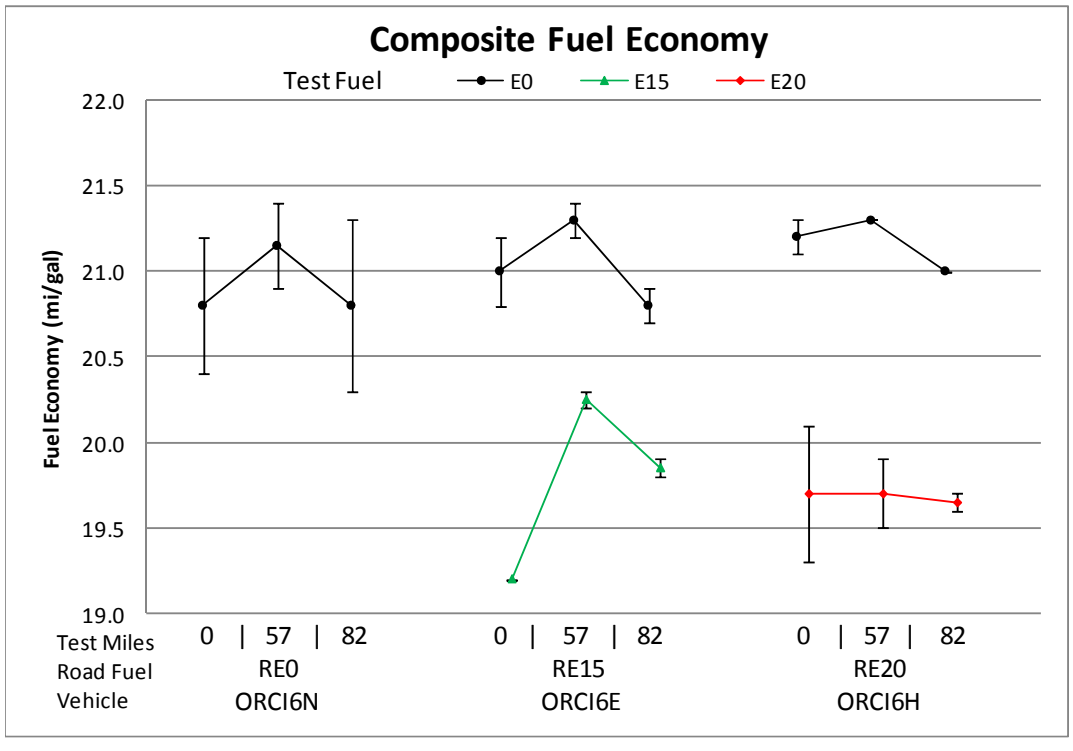

Error bars represent min and max measurements

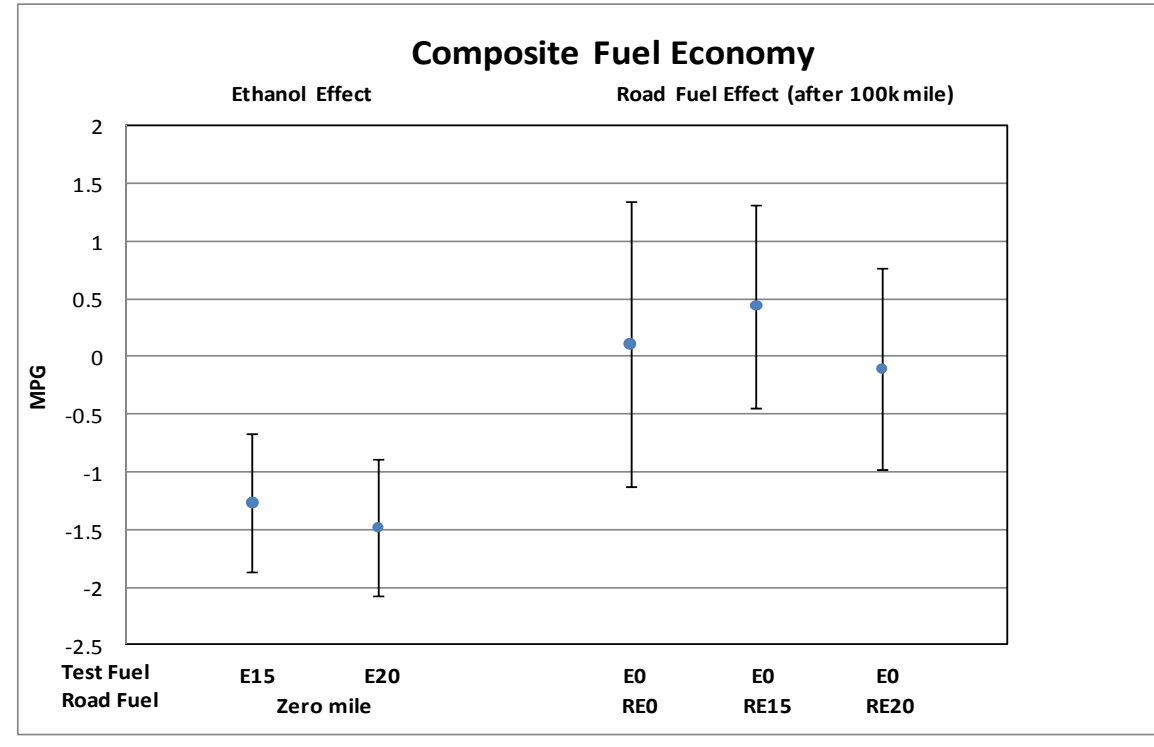

Error bars represent $95 \%$ confidence intervals on the estimated effects 
2006 Chevrolet Impala (Composite Acetaldehyde)

\begin{tabular}{|l|r|r|r|}
\hline \multicolumn{1}{|c|}{ Effect } & Estimate & $\begin{array}{r}\text { 95\% C.I. } \\
\text { Lower }\end{array}$ & $\begin{array}{r}\text { 95\% C.I. } \\
\text { Upper }\end{array}$ \\
\hline Ethanol Effect (E15 vs. E0) $(\Delta \mathrm{mg} / \mathrm{mi})$ & $0.453^{*}$ & 0.171 & 0.735 \\
\hline Ethanol Effect (E20 vs. E0) $(\Delta \mathrm{mg} / \mathrm{mi})$ & $0.928^{*}$ & 0.508 & 1.349 \\
\hline Road Fuel Aging Effect & & & \\
\hline Aging Effect with RE0 $(\Delta \mathrm{mg} / \mathrm{mi}$ per 100k mi) & -0.040 & -0.186 & 0.106 \\
\hline Aging Effect with RE15 $(\Delta \mathrm{mg} / \mathrm{mi}$ per 100k mi) & -0.089 & -0.221 & 0.043 \\
\hline Aging Effect with RE20 $(\Delta \mathrm{mg} / \mathrm{mi}$ per 100k mi) & -0.079 & -0.191 & 0.032 \\
\hline
\end{tabular}

\begin{tabular}{|l|r|}
\hline \multicolumn{1}{|c|}{ Hypothesis } & -value \\
\hline No Effect of Ethanol in the Test Fuel (Gamma = 0) & $<0.01^{*}$ \\
\hline No Aging Effect with RE0 (Beta0 $=0$ ) & 0.60 \\
\hline No Effect of Ethanol in Road Fuel Aging (Beta1s $=0$ ) & 0.87 \\
\hline * Indicates effect is statistically significant at the 95\% confidence level.
\end{tabular}

${ }^{*}$ Indicates estimate is different from zero at the $95 \%$ confidence level.

Initial odometers $31 \mathrm{k}-38 \mathrm{k}$

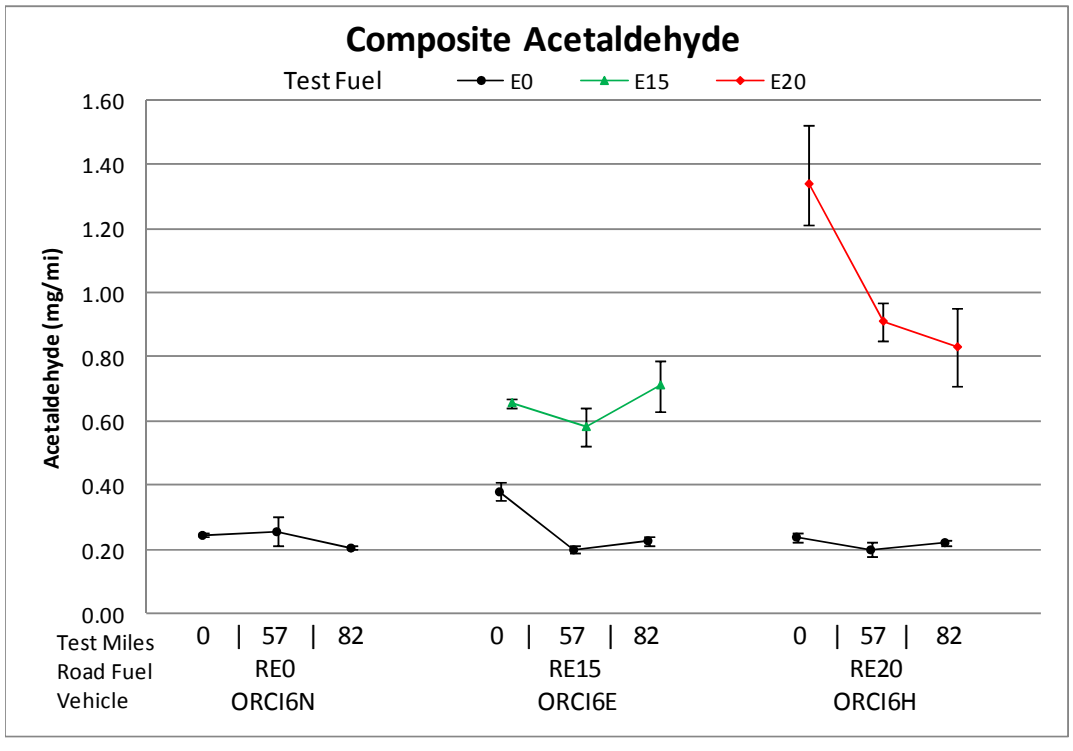

Error bars represent min and max measurements

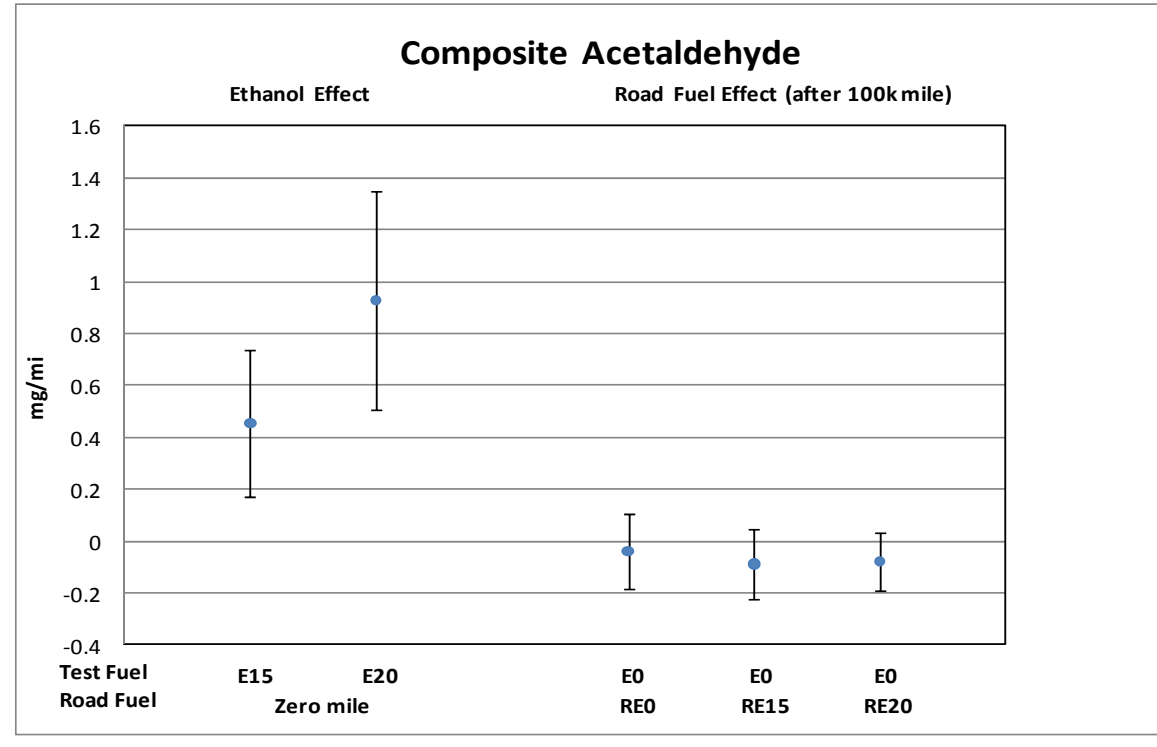

Error bars represent $95 \%$ confidence intervals on the estimated effects 
2006 Chevrolet Impala (Composite Formaldehyde)

\begin{tabular}{|l|r|r|r|}
\hline \multicolumn{1}{|c|}{ Effect } & & $\begin{array}{r}95 \% \text { C.I. } \\
\text { Low\% C.I. }\end{array}$ & $\begin{array}{r}\text { S5 } \\
\text { Upper }\end{array}$ \\
\hline Ethanol Effect (E15 vs. E0) $(\Delta \mathrm{mg} / \mathrm{mi})$ & -0.163 & -0.745 & 0.419 \\
\hline Ethanol Effect (E20 vs. E0) $(\Delta \mathrm{mg} / \mathrm{mi})$ & 0.201 & -0.430 & 0.832 \\
\hline Road Fuel Aging Effect & & & \\
\hline Aging Effect with RE0 $(\Delta \mathrm{mg} / \mathrm{mi}$ per 100k mi) & -0.165 & -0.705 & 0.375 \\
\hline Aging Effect with RE15 $(\Delta \mathrm{mg} / \mathrm{mi}$ per 100k mi) & -0.316 & -0.862 & 0.229 \\
\hline Aging Effect with RE20 $(\Delta \mathrm{mg} / \mathrm{mi}$ per 100k mi) & -0.219 & -0.697 & 0.259 \\
\hline
\end{tabular}

\begin{tabular}{|l|r|}
\hline \multicolumn{1}{|c|}{ Hypothesis } & p-value \\
\hline No Effect of Ethanol in the Test Fuel (Gamma = 0) & 0.40 \\
\hline No Aging Effect with RE0 (Beta0 $=0)$ & 0.55 \\
\hline No Effect of Ethanol in Road Fuel Aging (Beta1s=0) & 0.95 \\
\hline${ }^{*}$ Indicates effect is statistically significant at the 95\% confidence level.
\end{tabular}

${ }^{*}$ Indicates estimate is different from zero at the $95 \%$ confidence level.

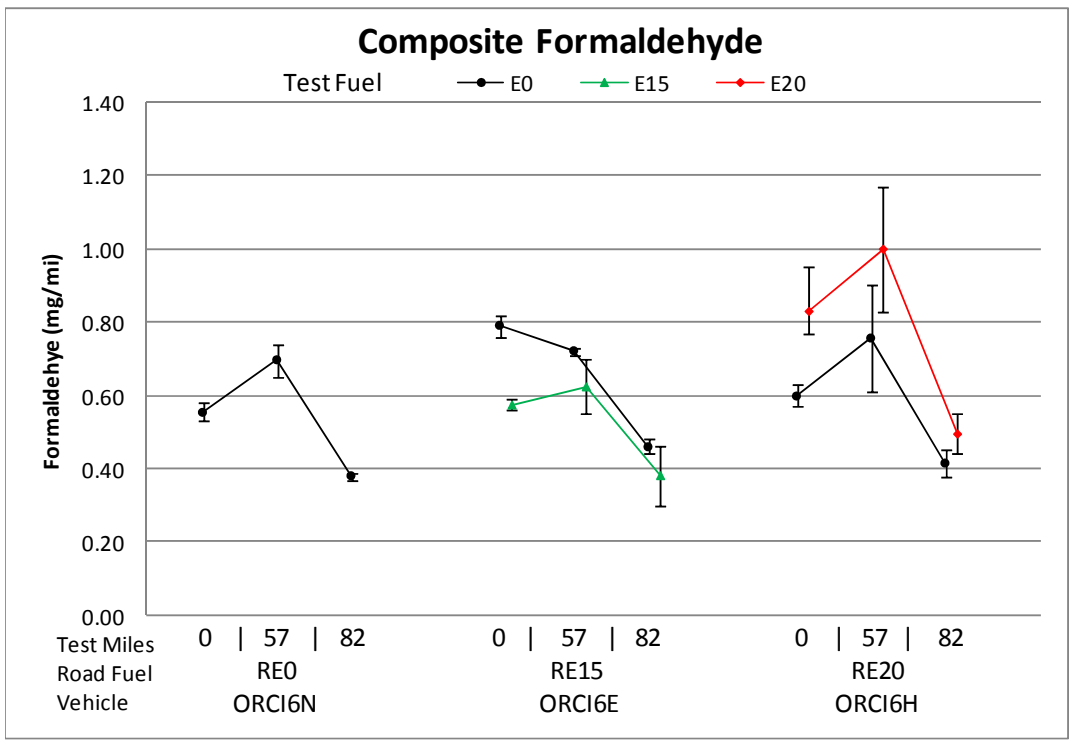

Error bars represent min and max measurements

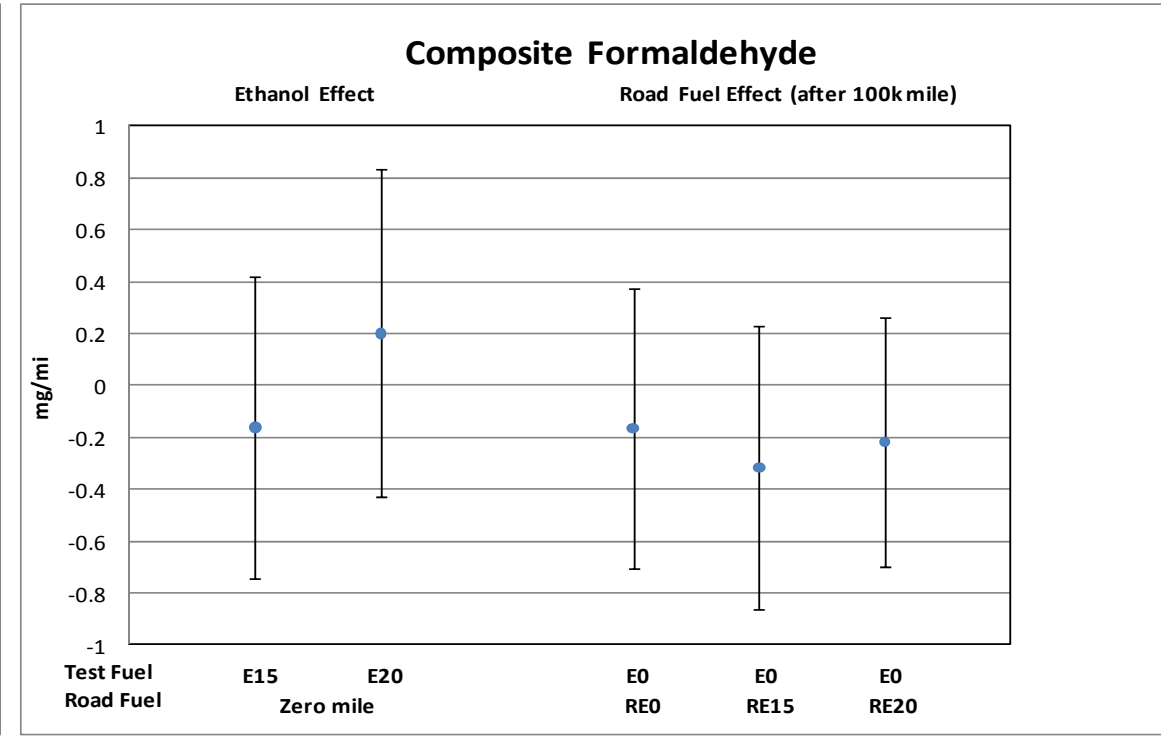

Error bars represent $95 \%$ confidence intervals on the estimated effects 
2006 Chevrolet Impala (Composite $\mathrm{CH}_{4}$ )

\begin{tabular}{|l|r|r|r|}
\hline \multicolumn{1}{|c|}{ Effect } & Estimate & $\begin{array}{c}95 \% \text { C.I. } \\
\text { Lower }\end{array}$ & $\begin{array}{c}\text { 95\% C.I. } \\
\text { Upper }\end{array}$ \\
\hline Ethanol Effect (E15 vs. E0) $(\Delta \mathrm{g} / \mathrm{mi})$ & 0.0010 & -0.0009 & 0.0029 \\
\hline Ethanol Effect $($ E20 vs. E0) $(\Delta \mathrm{g} / \mathrm{mi})$ & $0.0033^{*}$ & 0.0015 & 0.0052 \\
\hline Road Fuel Aging Effect & & & \\
\hline Aging Effect with RE0 $(\Delta \mathrm{g} / \mathrm{mi}$ per 100k mi) & $0.0139^{*}$ & 0.0099 & 0.0178 \\
\hline Aging Effect with RE15 $(\Delta \mathrm{g} / \mathrm{mi}$ per 100k mi) & $0.0197^{*}$ & 0.0169 & 0.0225 \\
\hline Aging Effect with RE20 $(\Delta \mathrm{g} / \mathrm{mi}$ per 100k mi) & $0.0124^{*}$ & 0.0098 & 0.0150 \\
\hline
\end{tabular}

\begin{tabular}{|l|c|}
\hline \multicolumn{1}{|c|}{ Hypothesis } & -value \\
\hline No Effect of Ethanol in the Test Fuel (Gamma = 0) & $<0.01^{*}$ \\
\hline No Aging Effect with RE0 (Beta0 $=0$ ) & $<0.01^{*}$ \\
\hline No Effect of Ethanol in Road Fuel Aging (Beta1s=0) & $<0.01^{*}$ \\
\hline
\end{tabular}

${ }^{*}$ Indicates estimate is different from zero at the $95 \%$ confidence level.

Initial odometers $31 \mathrm{k}-38 \mathrm{k}$

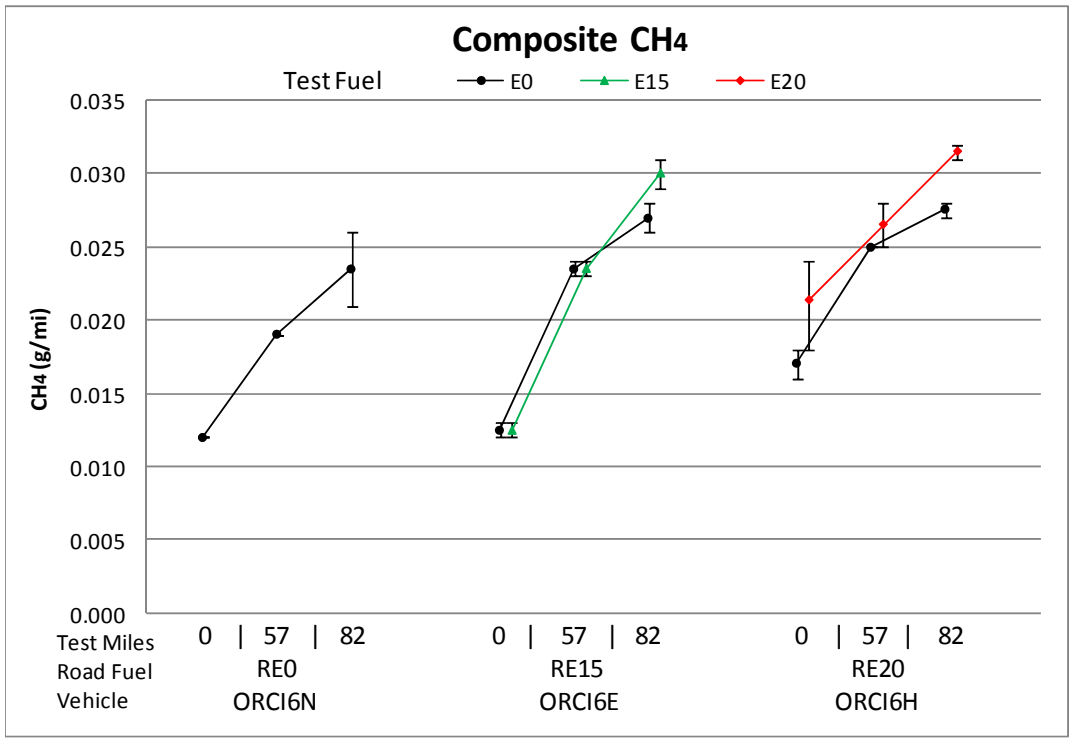

Error bars represent min and max measurements

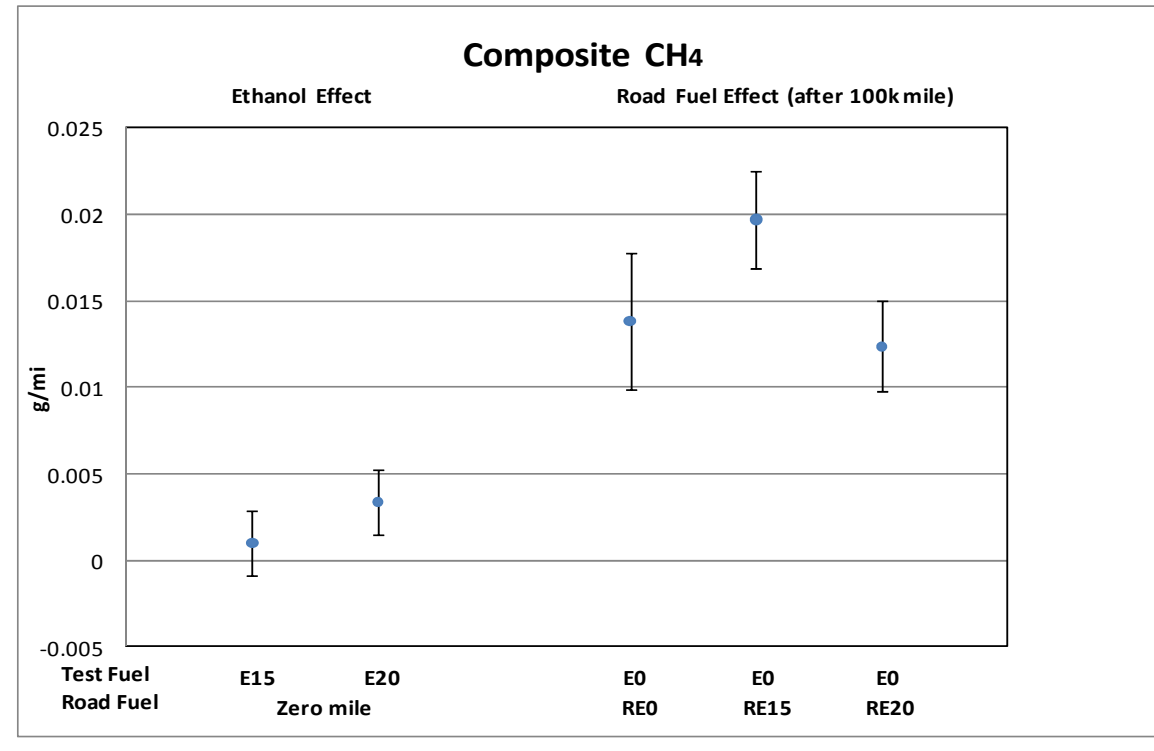

Error bars represent $95 \%$ confidence intervals on the estimated effects 
2005 Ford F150 - Composite Emissions Summary

\begin{tabular}{|c|c|c|c|c|c|c|c|c|c|c|c|c|c|c|}
\hline \multirow{3}{*}{$\begin{array}{l}\begin{array}{c}\text { Emisssion Parameter } \\
\text { (units) }\end{array} \\
\text { Fuels } \\
\end{array}$} & \multicolumn{4}{|c|}{ Ethanol Effect } & \multicolumn{2}{|c|}{ Aging Effect with REO } & \multicolumn{4}{|c|}{ RExx Aging Effect on E0 Emissions } & \multirow{2}{*}{\multicolumn{3}{|c|}{$\begin{array}{c}\text { RExx Aging Effect on Exx Emissions } \\
\Delta \text { units per } 100 \mathrm{~K} \mathrm{mi} \\
\end{array}$}} & \multirow{3}{*}{\begin{tabular}{|c|}
$\begin{array}{c}\text { Road and Test } \\
\text { Fuel Effects } \\
\text { are Additive }\end{array}$ \\
$\begin{array}{c}\text { Overall p- } \\
\text { value }\end{array}$ \\
\end{tabular}} \\
\hline & \multicolumn{3}{|c|}{$\Delta$ units vs. EO } & \multirow{2}{*}{$\mid \begin{array}{c}\text { Overall } \\
p \text {-value }\end{array}$} & \multirow{2}{*}{$\frac{\Delta \text { units per } 100 \mathrm{~K} \mathrm{mi}}{\mathrm{REO} / \mathrm{EO}}$} & \multirow{2}{*}{$\begin{array}{l}\text { Overall } \\
p \text {-value }\end{array}$} & \multicolumn{3}{|c|}{$\Delta$ units per $100 \mathrm{~K} \mathrm{mi}$} & \multirow{2}{*}{$\begin{array}{l}\text { Overall } \\
p \text {-value }\end{array}$} & & & & \\
\hline & E10 & E15 & E20 & & & & RE10/E0 & RE15/E0 & RE20/E0 & & RE10/E10 & RE15/E15 & RE20/E20 & \\
\hline $\mathrm{CO}(\mathrm{g} / \mathrm{mi})$ & NA & -0.062 & -0.389 & 0.17 & $2.840 *$ & $<0.01^{*}$ & NA & $1.404 *$ & $1.257 *$ & $0.05 *$ & $\mathrm{NA}$ & NA & $\mathrm{NA}$ & 0.80 \\
\hline $\mathrm{NOx}(\mathrm{g} / \mathrm{mi})$ & $\mathrm{NA}$ & -0.012 & -0.007 & 0.34 & $0.054^{*}$ & $0.05^{*}$ & NA & $0.062 *$ & $0.051^{*}$ & 0.88 & $\mathrm{NA}$ & NA & $\mathrm{NA}$ & 0.51 \\
\hline $\mathrm{NMHC}(\mathrm{g} / \mathrm{mi})$ & NA & $-0.015 *$ & $-0.014 *$ & $<0.01 *$ & $0.047^{*}$ & $<0.01^{*}$ & NA & $0.040 *$ & $0.020 *$ & 0.12 & $\mathrm{NA}$ & NA & $\mathrm{NA}$ & 0.52 \\
\hline NMOG (g/mi) & NA & -0.007 & -0.008 & 0.09 & $0.048 *$ & $<0.01 *$ & NA & $0.043 *$ & $0.022^{*}$ & 0.13 & $\mathrm{NA}$ & NA & $\mathrm{NA}$ & 0.61 \\
\hline \begin{tabular}{|l|} 
Fuel Econ (mi/gal) \\
\end{tabular} & NA & $-0.816 *$ & $-0.983 *$ & $<0.01 *$ & $0.565^{*}$ & $0.02 *$ & NA & 1.009* & $0.438 *$ & $0.04 *$ & $\mathrm{NA}$ & $\mathrm{NA}$ & $\mathrm{NA}$ & 0.93 \\
\hline Acetaldehyde $(\mathrm{mg} / \mathrm{mi})^{\#}$ & $N A$ & $0.655^{*}$ & $0.603 *$ & $<0.01 *$ & -0.016 & 0.73 & NA & 0.037 & -0.042 & 0.30 & $\mathrm{NA}$ & $\mathrm{NA}$ & $\mathrm{NA}$ & 0.25 \\
\hline Formaldehyde $(\mathrm{mg} / \mathrm{mi})^{\#}$ & NA & -0.127 & 0.015 & 0.65 & -0.187 & 0.39 & NA & -0.154 & $-0.348 *$ & 0.46 & $\mathrm{NA}$ & NA & $\mathrm{NA}$ & 0.86 \\
\hline $\mathrm{CH}_{4}(\mathrm{~g} / \mathrm{mi})$ & $\mathrm{NA}$ & 0.0030 & 0.0007 & 0.68 & $0.0448 *$ & $<0.01 *$ & $\mathrm{NA}$ & $0.0319 *$ & $0.0277 *$ & 0.33 & $\mathrm{NA}$ & $\mathrm{NA}$ & $\mathrm{NA}$ & 0.99 \\
\hline
\end{tabular}

\# Log-normal model was used. Results are presented as changes in emissions at 0k mile.

\#\# Data did not support the assumption of linear effects with mileage.

*Indicates estimate is different from zero at the $95 \%$ confidence level. 
2005 Ford F150 (Composite CO)

\begin{tabular}{|l|r|r|r|}
\hline \multicolumn{1}{|c|}{ Effect } & Estimate & $\begin{array}{c}\text { 95\% C.I. } \\
\text { Lower }\end{array}$ & $\begin{array}{r}\text { 95\% C.I. } \\
\text { Upper }\end{array}$ \\
\hline Ethanol Effect (E15 vs. E0) $(\Delta \mathrm{g} / \mathrm{mi})$ & -0.062 & -0.480 & 0.355 \\
\hline Ethanol Effect $($ E20 vs. E0) $(\Delta \mathrm{g} / \mathrm{mi})$ & -0.389 & -0.806 & 0.028 \\
\hline Road Fuel Aging Effect & & & \\
\hline Aging Effect with RE0 $(\Delta \mathrm{g} / \mathrm{mi}$ per 100k mi) & $2.840^{*}$ & 1.780 & 3.900 \\
\hline Aging Effect with RE15 $(\Delta \mathrm{g} / \mathrm{mi}$ per 100k mi) & $1.404^{*}$ & 0.658 & 2.149 \\
\hline Aging Effect with RE20 $(\Delta \mathrm{g} / \mathrm{mi}$ per 100k mi) & $1.257^{*}$ & 0.512 & 2.003 \\
\hline
\end{tabular}

\begin{tabular}{|l|r|}
\hline \multicolumn{1}{|c|}{ Hypothesis } & -value \\
\hline No Effect of Ethanol in the Test Fuel (Gamma = 0) & 0.17 \\
\hline No Aging Effect with RE0 (Beta0 = 0) & $<0.01^{*}$ \\
\hline No Effect of Ethanol in Road Fuel Aging (Beta1s=0) & $0.05^{*}$ \\
\hline * Indicates effect is statistically significant at the 95\% confidence level.
\end{tabular}

${ }^{*}$ Indicates estimate is different from zero at the $95 \%$ confidence level.

Initial odometers $31 \mathrm{k}-38 \mathrm{k}$

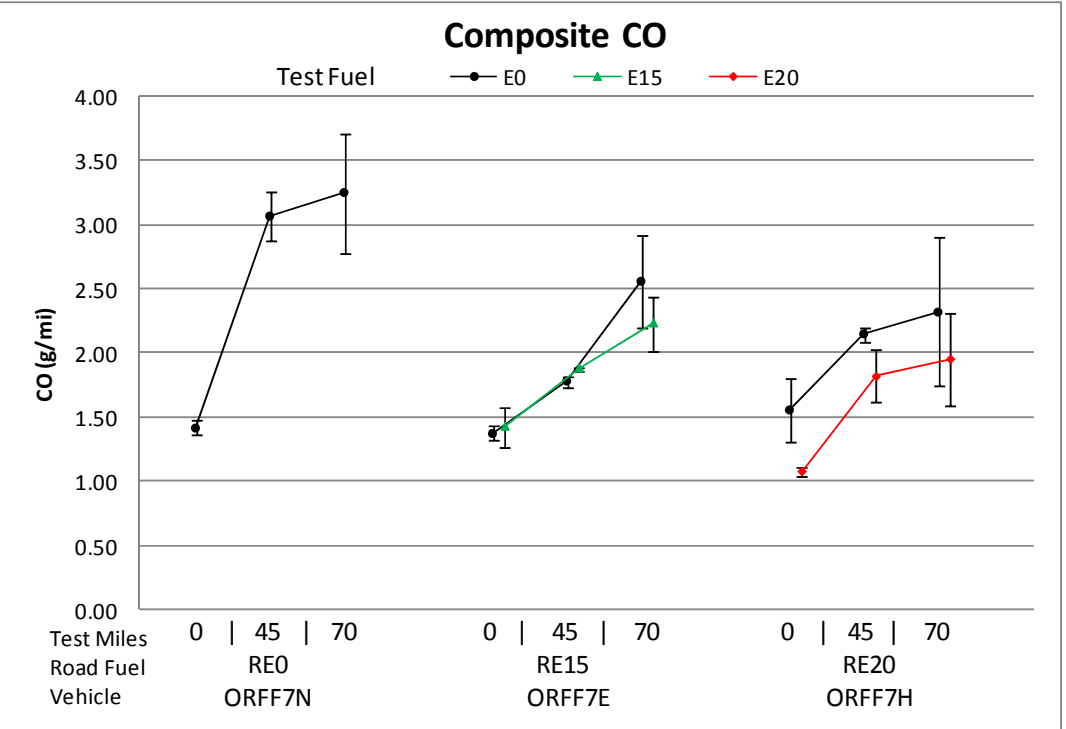

Error bars represent min and max measurements

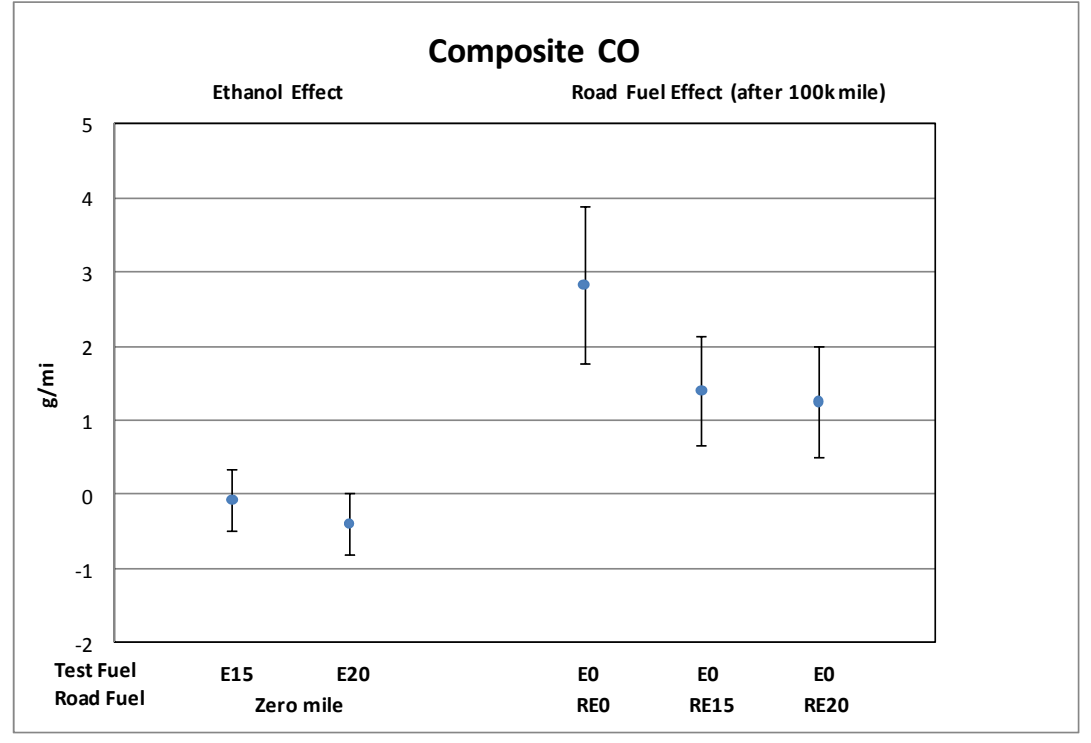

Error bars represent $95 \%$ confidence intervals on the estimated effects 
2005 Ford F150 (Composite NOx)

\begin{tabular}{|l|r|r|r|}
\hline \multicolumn{1}{|c|}{ Effect } & Estimate & $\begin{array}{c}\text { 95\% C.I. } \\
\text { Lower }\end{array}$ & $\begin{array}{r}\text { 95\% C.I. } \\
\text { Upper }\end{array}$ \\
\hline Ethanol Effect (E15 vs. E0) $(\Delta \mathrm{g} / \mathrm{mi})$ & -0.012 & -0.033 & 0.009 \\
\hline Ethanol Effect (E20 vs. E0) $(\Delta \mathrm{g} / \mathrm{mi})$ & -0.007 & -0.028 & 0.013 \\
\hline Road Fuel Aging Effect & & & \\
\hline Aging Effect with RE0 $(\Delta \mathrm{g} / \mathrm{mi}$ per 100k mi) & $0.054^{*}$ & 0.001 & 0.107 \\
\hline Aging Effect with RE15 $(\Delta \mathrm{g} / \mathrm{mi} \mathrm{per} \mathrm{100k} \mathrm{mi)}$ & $0.062^{*}$ & 0.025 & 0.099 \\
\hline Aging Effect with RE20 $(\Delta \mathrm{g} / \mathrm{mi}$ per 100k mi) & $0.051^{*}$ & 0.014 & 0.088 \\
\hline
\end{tabular}

\begin{tabular}{|l|r|}
\hline \multicolumn{1}{|c|}{ Hypothesis } & p-value \\
\hline No Effect of Ethanol in the Test Fuel (Gamma = 0) & 0.34 \\
\hline No Aging Effect with RE0 (Beta0 = 0) & $0.05^{*}$ \\
\hline No Effect of Ethanol in Road Fuel Aging (Beta1s $=0)$ & 0.88 \\
\hline * Indicates effect is statistically significant at the 95\% confidence level.
\end{tabular}

* Indicates estimate is different from zero at the $95 \%$ confidence level.

Initial odometers 31k-38k

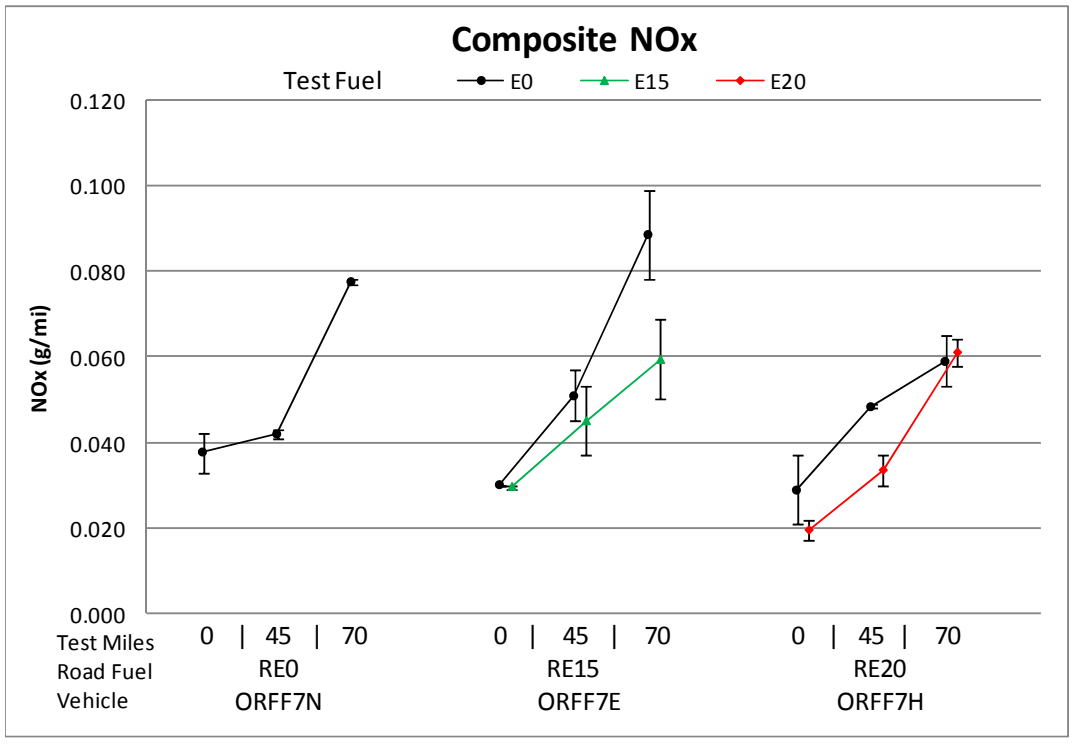

Error bars represent min and max measurements

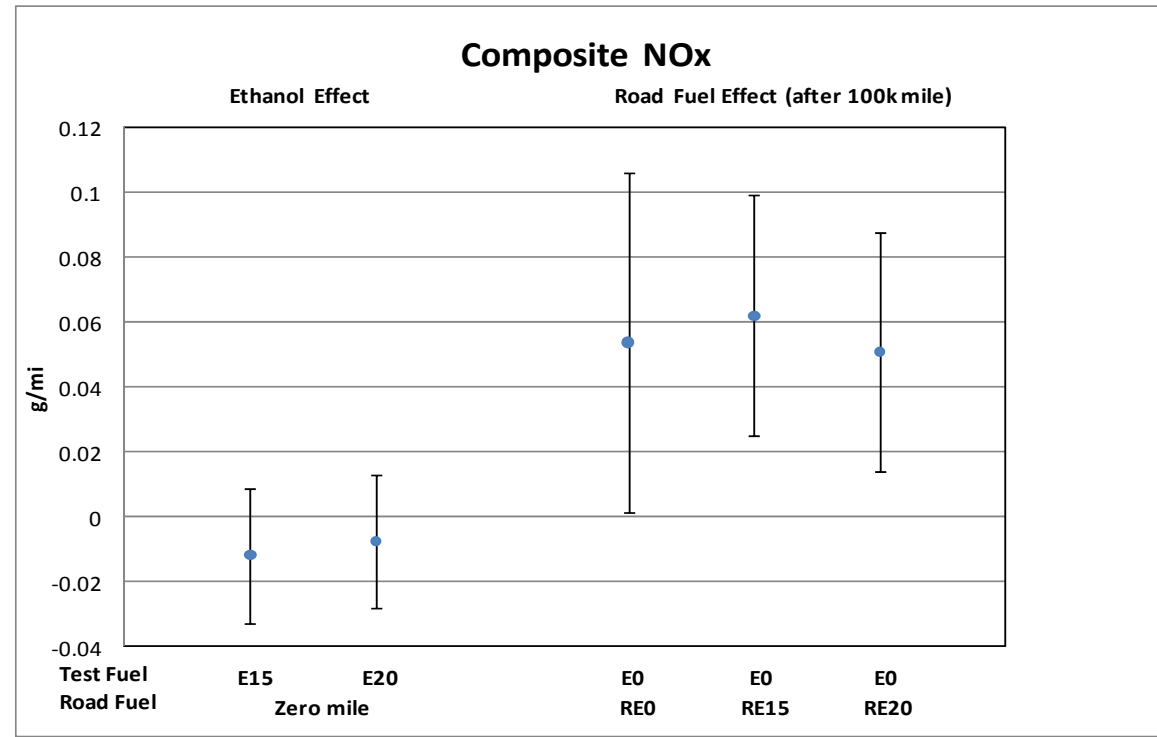

Error bars represent $95 \%$ confidence intervals on the estimated effects 
2005 Ford F150 (Composite Nonmethane Hydrocarbons)

\begin{tabular}{|l|r|r|r|}
\hline \multicolumn{1}{|c|}{ Effect } & & $\begin{array}{r}95 \% \text { C.I. } \\
\text { Estimate }\end{array}$ & $\begin{array}{r}\text { 95\% C.I. } \\
\text { Upper }\end{array}$ \\
\hline Ethanol Effect $(E 15 \mathrm{vs}$. E0) $(\Delta \mathrm{g} / \mathrm{mi})$ & $-0.015^{*}$ & -0.025 & -0.006 \\
\hline Ethanol Effect $($ E20 vs. E0) $(\Delta \mathrm{g} / \mathrm{mi})$ & $-0.014^{*}$ & -0.023 & -0.005 \\
\hline Road Fuel Aging Effect & & & \\
\hline Aging Effect with RE0 $(\Delta \mathrm{g} / \mathrm{mi}$ per 100k mi) & $0.047^{*}$ & 0.023 & 0.070 \\
\hline Aging Effect with RE15 $(\Delta \mathrm{g} / \mathrm{mi} \mathrm{per} \mathrm{100k} \mathrm{mi)}$ & $0.040^{*}$ & 0.023 & 0.056 \\
\hline Aging Effect with RE20 $(\Delta \mathrm{g} / \mathrm{mi}$ per 100k mi) & $0.020^{*}$ & 0.003 & 0.037 \\
\hline
\end{tabular}

\begin{tabular}{|l|r|}
\hline \multicolumn{1}{|c|}{ Hypothesis } & p-value \\
\hline No Effect of Ethanol in the Test Fuel (Gamma $=0)$ & $<0.01^{*}$ \\
\hline No Aging Effect with RE0 (Beta0 $=0)$ & $<0.01^{*}$ \\
\hline No Effect of Ethanol in Road Fuel Aging (Beta1s=0) & 0.12 \\
\hline${ }^{*}$ Indicates effect is statistically significant at the 95\% confidence level.
\end{tabular}

${ }^{*}$ Indicates estimate is different from zero at the $95 \%$ confidence level.

Initial odometers 31k-38k

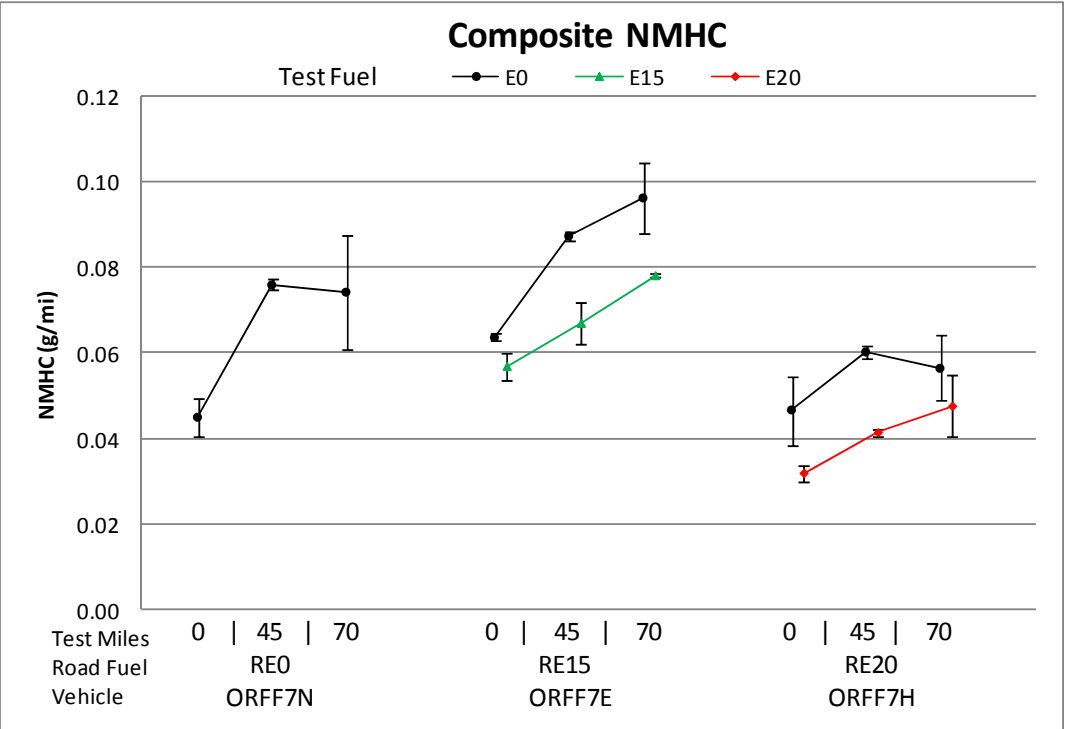

Error bars represent min and max measurements

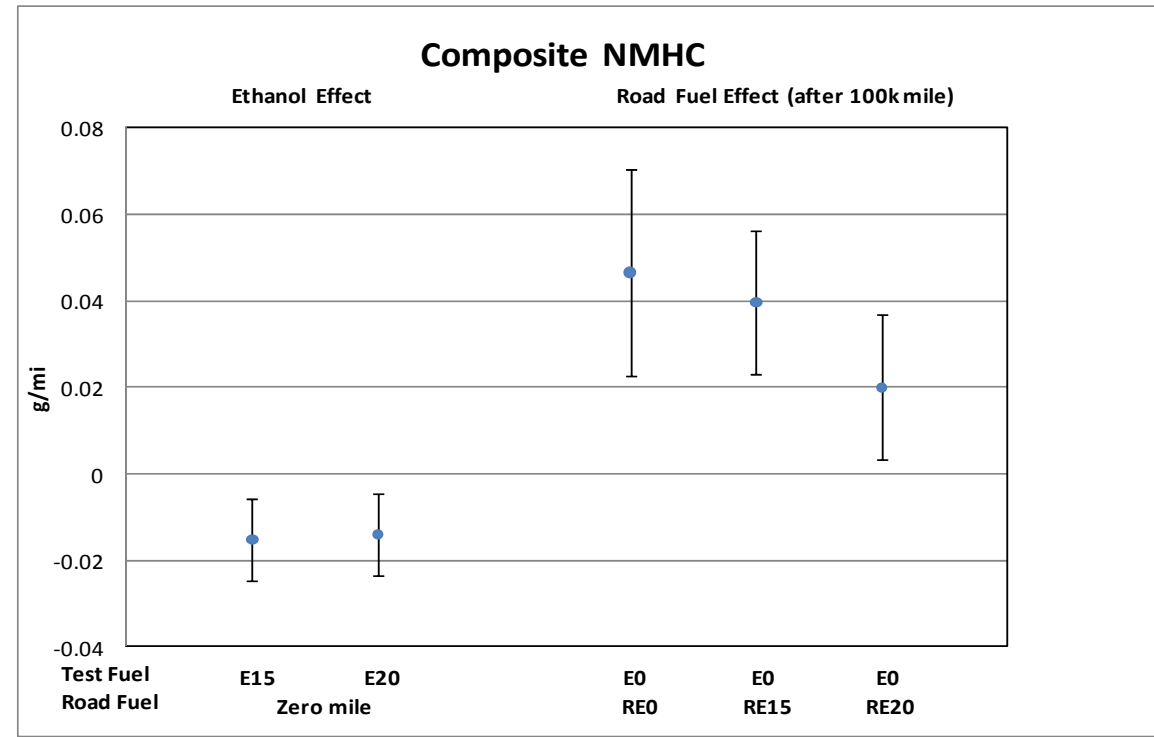

Error bars represent $95 \%$ confidence intervals on the estimated effects 
2005 Ford F150 (Composite Nonmethane Organic Gases)

\begin{tabular}{|l|r|r|r|}
\hline \multicolumn{1}{|c|}{ Effect } & & $\begin{array}{r}95 \% \text { C.I. } \\
\text { Lo5\% C.I. } \\
\text { Estimate }\end{array}$ & $\begin{array}{r}\text { Lower } \\
\text { Upper }\end{array}$ \\
\hline Ethanol Effect $(E 15 \mathrm{vs}$. E0) $(\Delta \mathrm{g} / \mathrm{mi})$ & -0.007 & -0.017 & 0.003 \\
\hline Ethanol Effect $($ E20 vs. E0) $(\Delta \mathrm{g} / \mathrm{mi})$ & -0.008 & -0.018 & 0.002 \\
\hline Road Fuel Aging Effect & & & \\
\hline Aging Effect with RE0 $(\Delta \mathrm{g} / \mathrm{mi}$ per 100k mi) & $0.048^{*}$ & 0.023 & 0.073 \\
\hline Aging Effect with RE15 $(\Delta \mathrm{g} / \mathrm{mi} \mathrm{per} \mathrm{100k} \mathrm{mi)}$ & $0.043^{*}$ & 0.026 & 0.061 \\
\hline Aging Effect with RE20 $(\Delta \mathrm{g} / \mathrm{mi}$ per 100k mi) & $0.022^{*}$ & 0.004 & 0.040 \\
\hline
\end{tabular}

\begin{tabular}{|l|r|}
\hline \multicolumn{1}{|c|}{ Hypothesis } & -value \\
\hline No Effect of Ethanol in the Test Fuel (Gamma = 0) & 0.09 \\
\hline No Aging Effect with RE0 (Beta0 = 0) & $<0.01^{*}$ \\
\hline No Effect of Ethanol in Road Fuel Aging (Beta1s $=0)$ & 0.13 \\
\hline * Indicates effect is statistically significant at the 95\% confidence level.
\end{tabular}

* Indicates estimate is different from zero at the $95 \%$ confidence level.

Initial odometers $31 \mathrm{k}-38 \mathrm{k}$

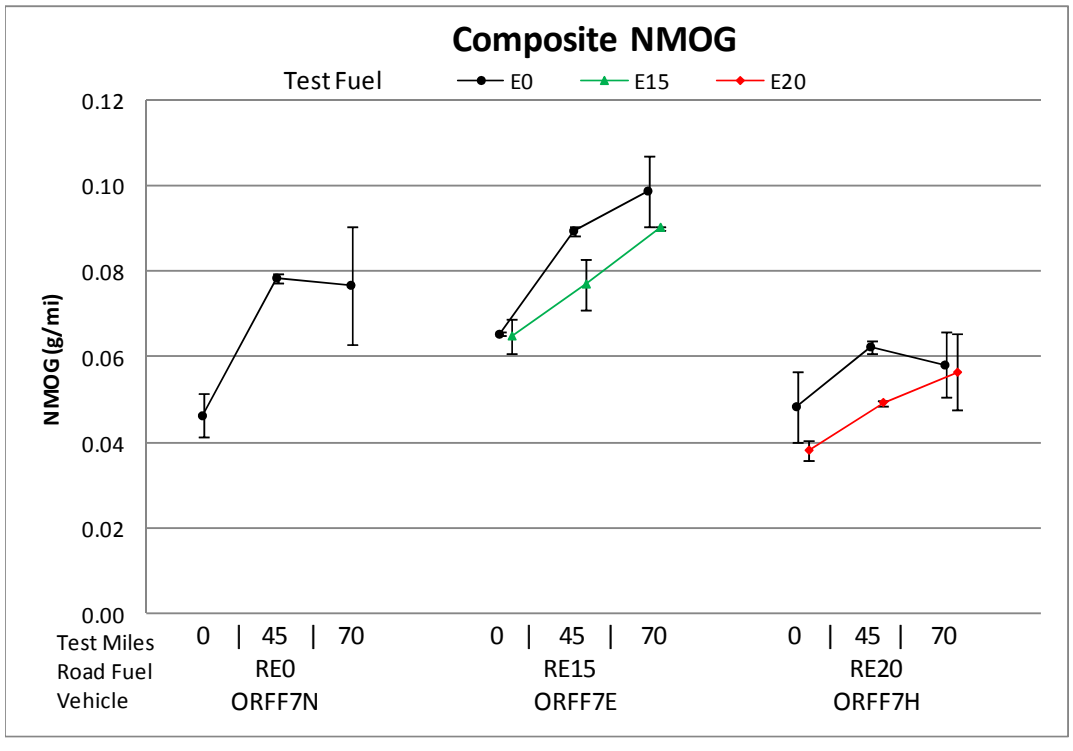

Error bars represent min and max measurements

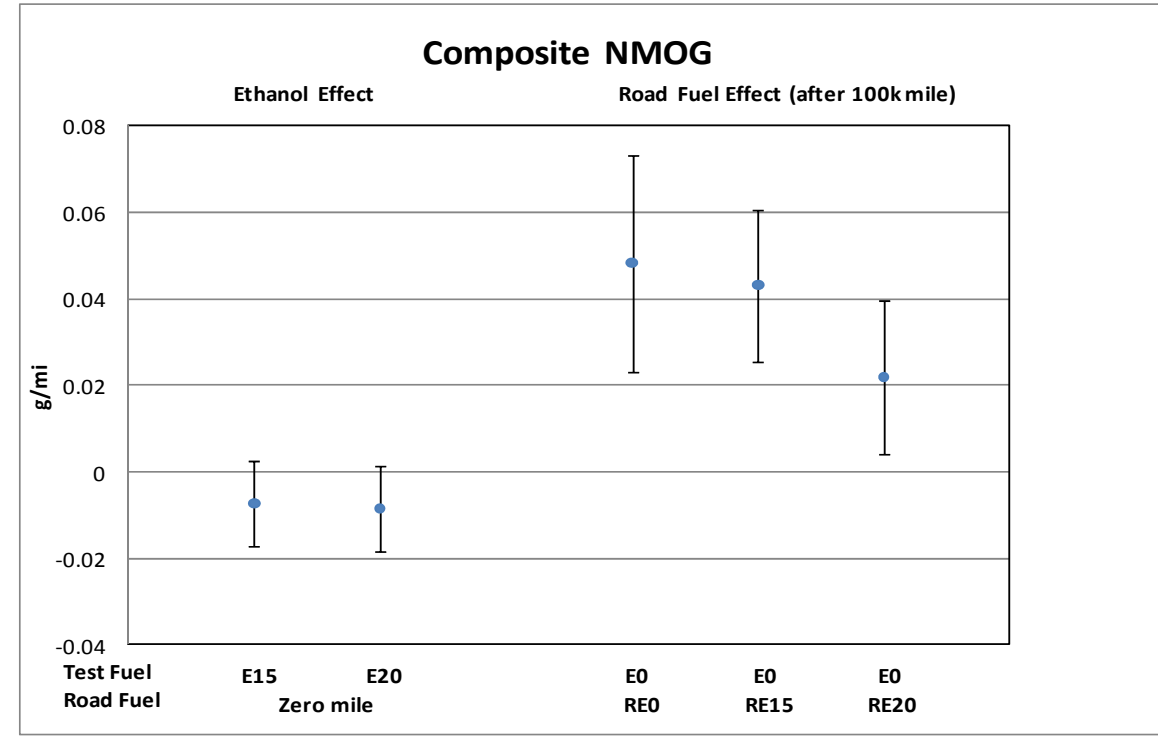

Error bars represent $95 \%$ confidence intervals on the estimated effects 
2005 Ford F150 (Composite Fuel Economy)

\begin{tabular}{|c|c|c|c|}
\hline Effect & Estimate & $\begin{array}{c}\text { 95\% C.I. } \\
\text { Lower }\end{array}$ & $\begin{array}{c}95 \% \text { C.I. } \\
\text { Upper }\end{array}$ \\
\hline Ethanol Effect (E15 vs. E0) ( $\Delta \mathrm{mi} / \mathrm{qal})$ & $-0.816^{*}$ & -0.987 & -0.645 \\
\hline Ethanol Effect (E20 vs. E0) ( $\Delta \mathrm{mi} / \mathrm{gal})$ & $-0.983^{*}$ & -1.154 & -0.812 \\
\hline \multicolumn{4}{|l|}{ Road Fuel Aging Effect } \\
\hline Aging Effect with RE0 ( $\Delta \mathrm{mi} / \mathrm{gal}$ per $100 \mathrm{k} \mathrm{mi})$ & $0.565^{\star}$ & 0.132 & 0.999 \\
\hline Aging Effect with RE15 ( $\Delta \mathrm{mi} / \mathrm{gal}$ per 100k mi) & $1.009^{*}$ & 0.704 & 1.314 \\
\hline Aging Effect with RE20 ( $\Delta \mathrm{mi} / \mathrm{gal}$ per $100 \mathrm{k} \mathrm{mi})$ & $0.438^{*}$ & 0.133 & 0.743 \\
\hline
\end{tabular}

\begin{tabular}{|l|r|}
\hline \multicolumn{1}{|c|}{ Hypothesis } & -value \\
\hline No Effect of Ethanol in the Test Fuel (Gamma $=0)$ & $<0.01^{*}$ \\
\hline No Aging Effect with RE0 (Beta0 $=0$ ) & $0.02^{*}$ \\
\hline No Effect of Ethanol in Road Fuel Aging (Beta1s=0) & $0.04^{*}$ \\
\hline * Indicates effect is statistically significant at the $95 \%$ confidence level.
\end{tabular}

${ }^{*}$ Indicates estimate is different from zero at the $95 \%$ confidence level.

Initial odometers $31 \mathrm{k}-38 \mathrm{k}$

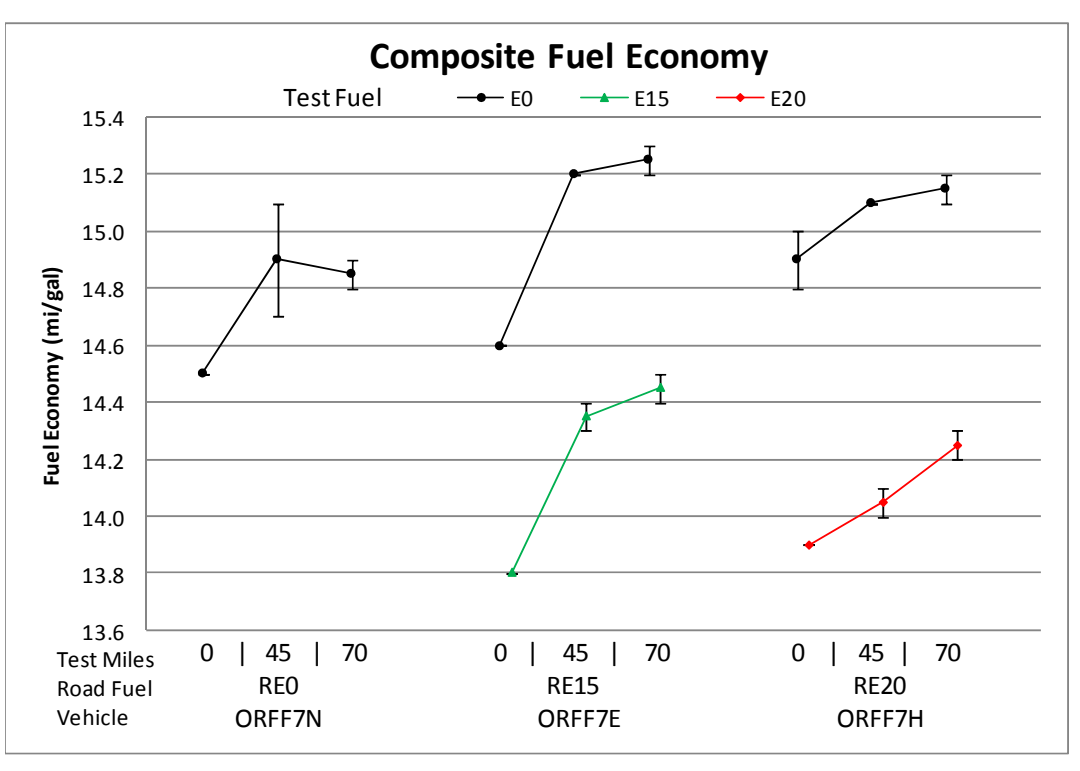

Error bars represent min and max measurements

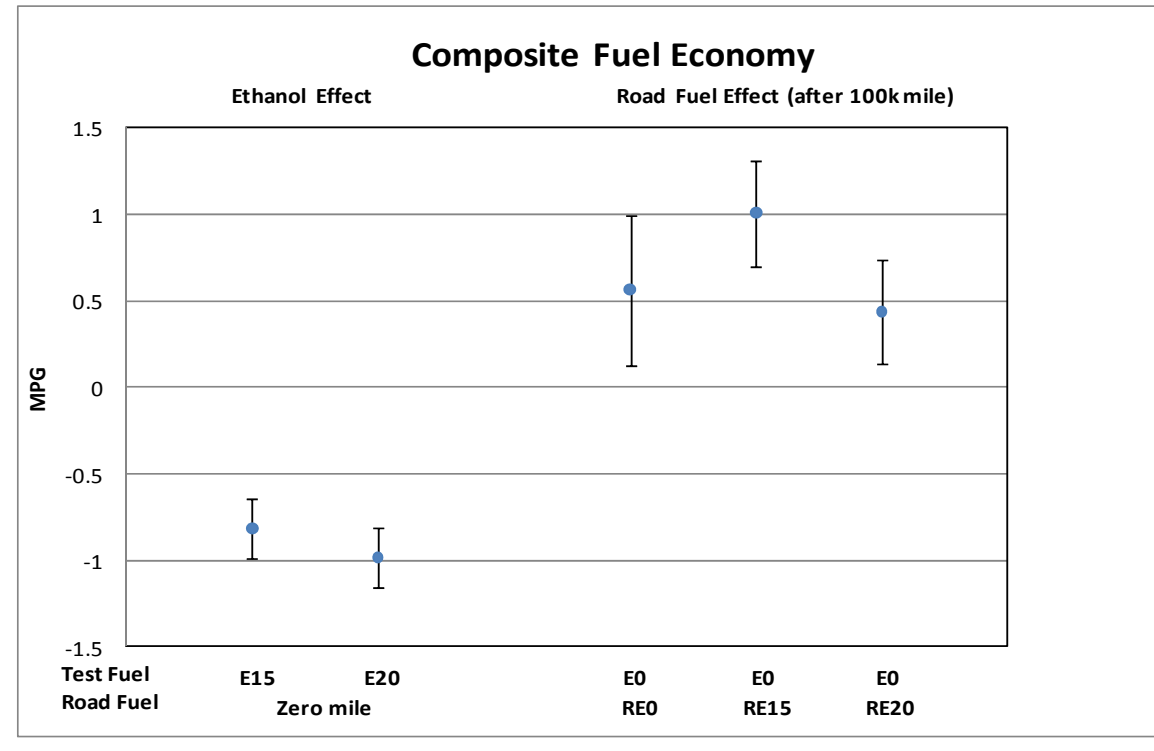

Error bars represent $95 \%$ confidence intervals on the estimated effects 
2005 Ford F150 (Composite Acetaldehyde)

\begin{tabular}{|l|r|r|r|}
\hline \multicolumn{1}{|c|}{ Effect } & & $\begin{array}{r}95 \% \text { C.I. } \\
\text { Lower }\end{array}$ & $\begin{array}{r}\text { 95\% C.I. } \\
\text { Upper }\end{array}$ \\
\hline Ethanol Effect $($ E15 vs. E0) $(\Delta \mathrm{mg} / \mathrm{mi})$ & $0.655^{*}$ & 0.465 & 0.846 \\
\hline Ethanol Effect $($ E20 vs. E0) $(\Delta \mathrm{mg} / \mathrm{mi})$ & $0.603^{*}$ & 0.431 & 0.774 \\
\hline Road Fuel Aging Effect & & & \\
\hline Aging Effect with RE0 $(\Delta \mathrm{mg} / \mathrm{mi} \mathrm{per} \mathrm{100k} \mathrm{mi)}$ & -0.016 & -0.101 & 0.069 \\
\hline Aging Effect with RE15 $(\Delta \mathrm{mg} / \mathrm{mi}$ per 100k mi) & 0.037 & -0.052 & 0.126 \\
\hline Aging Effect with RE20 $(\Delta \mathrm{mg} / \mathrm{mi}$ per 100k mi) & -0.042 & -0.103 & 0.018 \\
\hline
\end{tabular}

* Indicates estimate is different from zero at the $95 \%$ confidence level.

\begin{tabular}{|l|r|}
\hline \multicolumn{1}{|c|}{ Hypothesis } & p-value \\
\hline No Effect of Ethanol in the Test Fuel (Gamma = 0) & $<0.01^{*}$ \\
\hline No Aging Effect with RE0 (Beta0 = 0) & 0.73 \\
\hline No Effect of Ethanol in Road Fuel Aging (Beta1s=0) & 0.30 \\
\hline
\end{tabular}

Initial odometers $31 \mathrm{k}-38 \mathrm{k}$

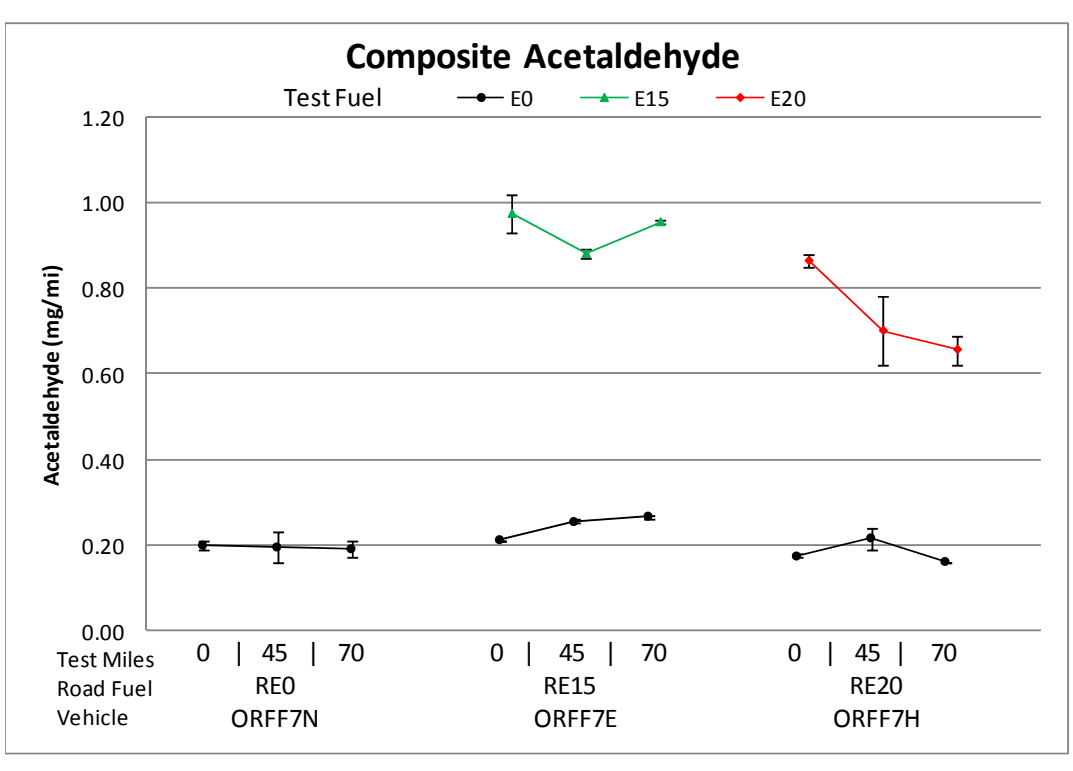

Error bars represent min and max measurements

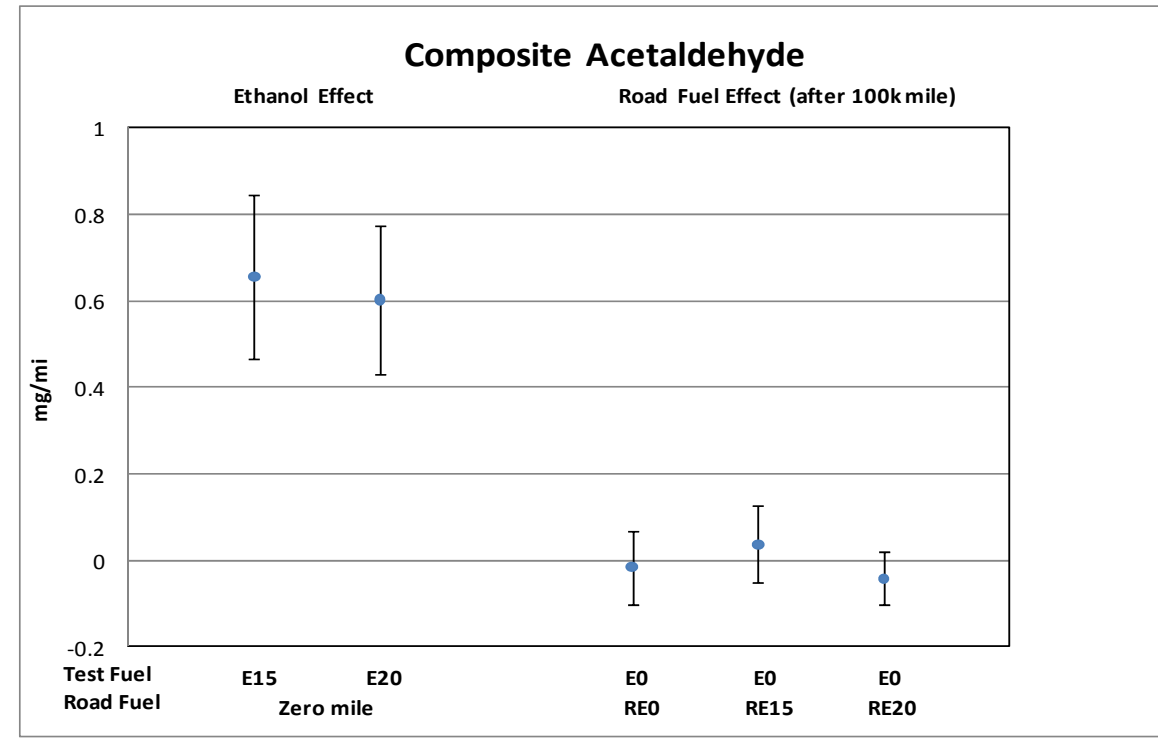

Error bars represent $95 \%$ confidence intervals on the estimated effects 
2005 Ford F150 (Composite Formaldehyde)

\begin{tabular}{|l|r|r|r|}
\hline \multicolumn{1}{|c|}{ Effect } & & $\begin{array}{c}95 \% \text { C.I. } \\
\text { Lower }\end{array}$ & $\begin{array}{r}\text { 95\% C.I. } \\
\text { Upper }\end{array}$ \\
\hline Ethanol Effect $($ E15 vs. E0) $(\Delta \mathrm{mg} / \mathrm{mi})$ & -0.127 & -0.564 & 0.310 \\
\hline Ethanol Effect $($ E20 vs. E0) $(\Delta \mathrm{mg} / \mathrm{mi})$ & 0.015 & -0.362 & 0.391 \\
\hline Road Fuel Aging Effect & & & \\
\hline Aging Effect with RE0 $(\Delta \mathrm{mg} / \mathrm{mi} \mathrm{per} \mathrm{100k} \mathrm{mi)}$ & -0.187 & -0.566 & 0.192 \\
\hline Aging Effect with RE15 $(\Delta \mathrm{mg} / \mathrm{mi}$ per 100k mi) & -0.154 & -0.650 & 0.342 \\
\hline Aging Effect with RE20 $(\Delta \mathrm{mg} / \mathrm{mi}$ per 100k mi) & $-0.348^{*}$ & -0.654 & -0.043 \\
\hline
\end{tabular}

\begin{tabular}{|l|r|}
\hline \multicolumn{1}{|c|}{ Hypothesis } & p-value \\
\hline No Effect of Ethanol in the Test Fuel (Gamma = 0) & 0.65 \\
\hline No Aging Effect with RE0 (Beta0 = 0) & 0.39 \\
\hline No Effect of Ethanol in Road Fuel Aging (Beta1s=0) & 0.46 \\
\hline * Indicates effect is statistically significant at the 95\% confidence level.
\end{tabular}

${ }^{*}$ Indicates estimate is different from zero at the $95 \%$ confidence level.

Initial odometers $31 \mathrm{k}-38 \mathrm{k}$

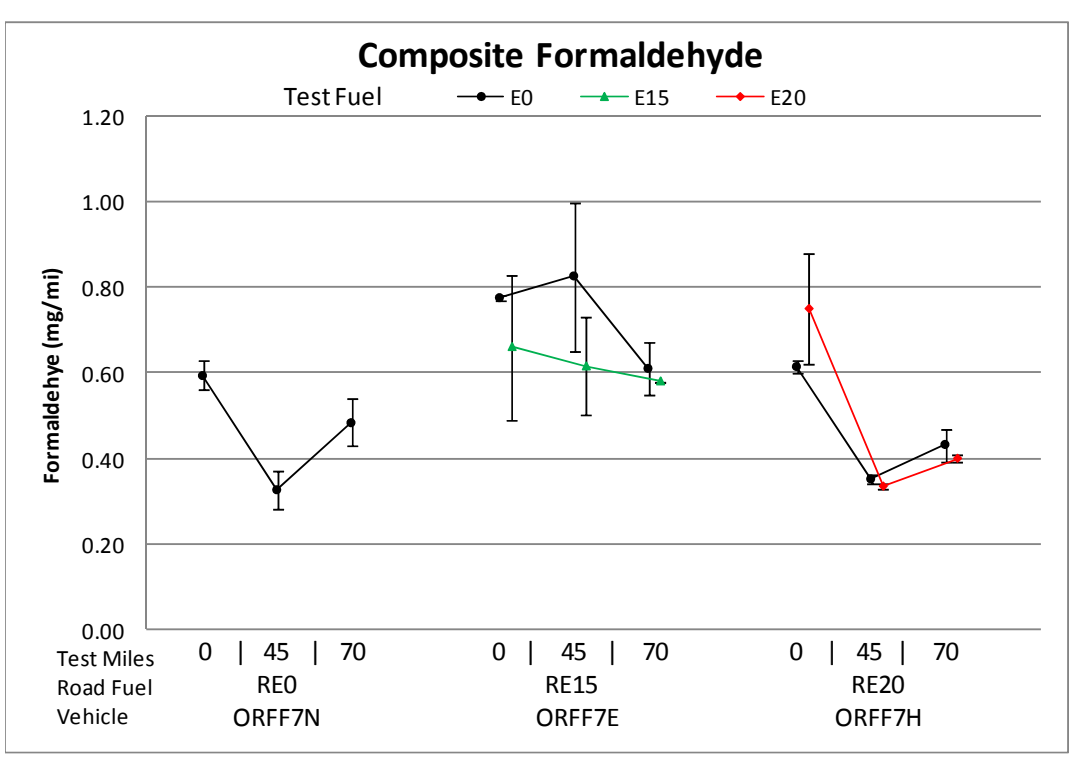

Error bars represent min and max measurements

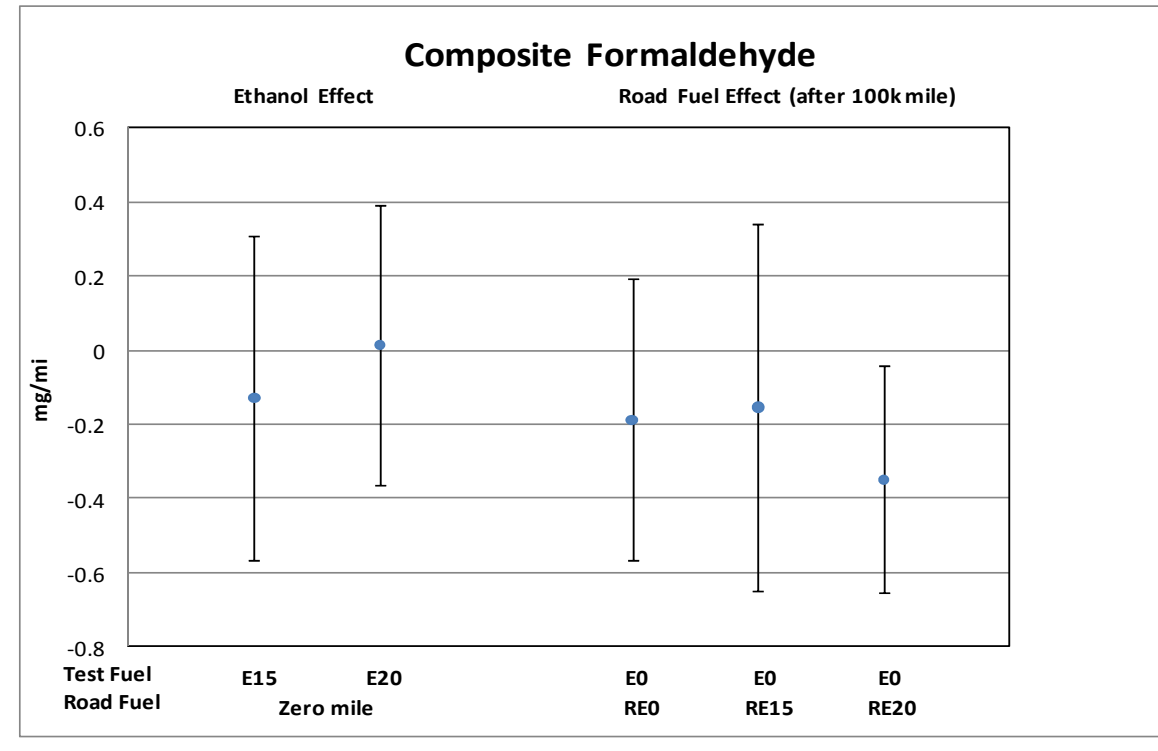

Error bars represent $95 \%$ confidence intervals on the estimated effects 
2005 Ford F150 (Composite $\mathrm{CH} 4$ )

\begin{tabular}{|l|r|r|r|}
\hline \multicolumn{1}{|c|}{ Effect } & Estimate & $\begin{array}{c}\text { 95\% C.I. } \\
\text { Lower }\end{array}$ & $\begin{array}{c}\mathbf{9 5 \%} \text { C.I. } \\
\text { Upper }\end{array}$ \\
\hline Ethanol Effect $($ E15 vs. E0) $(\Delta \mathrm{g} / \mathrm{mi})$ & 0.0030 & -0.0051 & 0.0112 \\
\hline Ethanol Effect (E20 vs. E0) $(\Delta \mathrm{g} / \mathrm{mi})$ & 0.0007 & -0.0075 & 0.0089 \\
\hline Road Fuel Aging Effect & & & \\
\hline Aging Effect with RE0 $(\Delta \mathrm{g} / \mathrm{mi}$ per 100k mi) & $0.0448^{*}$ & 0.0241 & 0.0656 \\
\hline Aging Effect with RE15 $(\Delta \mathrm{g} / \mathrm{mi} \mathrm{per} \mathrm{100k} \mathrm{mi)}$ & $0.0319^{*}$ & 0.0173 & 0.0465 \\
\hline Aging Effect with RE20 $(\Delta \mathrm{g} / \mathrm{mi} \mathrm{per} \mathrm{100k} \mathrm{mi)}$ & $0.0277^{*}$ & 0.0131 & 0.0423 \\
\hline
\end{tabular}

\begin{tabular}{|l|r|}
\hline \multicolumn{1}{|c|}{ Hypothesis } & -value \\
\hline No Effect of Ethanol in the Test Fuel (Gamma = 0) & 0.68 \\
\hline No Aging Effect with RE0 (Beta0 = 0) & $<0.01^{*}$ \\
\hline No Effect of Ethanol in Road Fuel Aging (Beta1s=0) & 0.33 \\
\hline
\end{tabular}

* Indicates estimate is different from zero at the $95 \%$ confidence level.

Initial odometers $31 \mathrm{k}-38 \mathrm{k}$
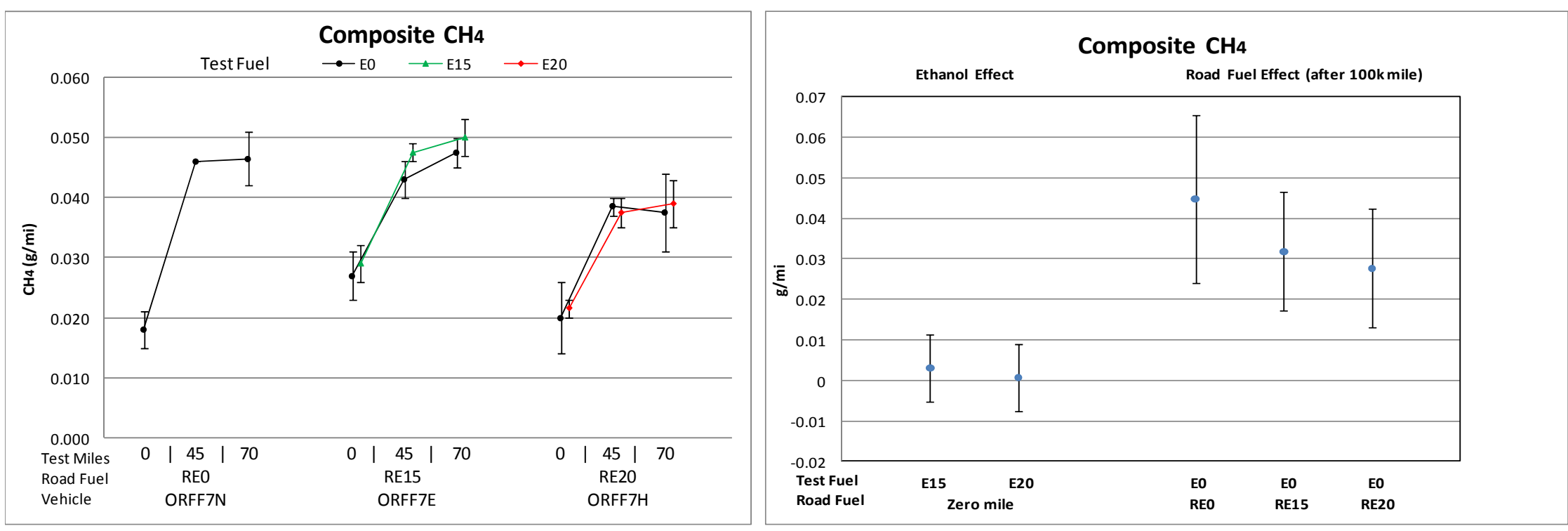

Error bars represent min and max measurements

Error bars represent $95 \%$ confidence intervals on the estimated effects 


\section{Saturn Outlook - Composite Emissions Summary}

\begin{tabular}{|c|c|c|c|c|c|c|c|c|c|c|c|c|c|c|}
\hline \multirow{2}{*}{$\begin{array}{c}\text { Emisssion Parameter } \\
\text { (units) }\end{array}$} & \multicolumn{4}{|c|}{ Ethanol Effect } & \multicolumn{2}{|c|}{ Aging Effect with REO } & \multicolumn{4}{|c|}{ RExx Aging Effect on EO Emissions } & \multirow{2}{*}{\multicolumn{3}{|c|}{\begin{tabular}{|c|} 
RExx Aging Effect on Exx Emissions \\
$\Delta$ units per $100 \mathrm{~K} \mathrm{mi}$ \\
\end{tabular}}} & \multirow{3}{*}{\begin{tabular}{|c}
$\begin{array}{c}\text { Road and Test } \\
\text { Fuel Effects } \\
\text { are Additive }\end{array}$ \\
$\begin{array}{c}\text { Overall p- } \\
\text { value }\end{array}$
\end{tabular}} \\
\hline & \multicolumn{3}{|c|}{$\Delta$ units vs. EO } & \multirow{2}{*}{$\begin{array}{c}\text { Overall } \\
p \text {-value }\end{array}$} & \multirow{2}{*}{$\begin{array}{c}\Delta \text { units per } 100 \mathrm{~K} \mathrm{mi} \\
\text { REO/EO }\end{array}$} & \multirow{2}{*}{$\begin{array}{l}\text { Overall } \\
\text { p-value }\end{array}$} & \multicolumn{3}{|c|}{$\Delta$ units per $100 \mathrm{~K} \mathrm{mi}$} & \multirow{2}{*}{$\begin{array}{l}\text { Overall } \\
p \text {-value }\end{array}$} & & & & \\
\hline Fuels & E10 & E15 & E20 & & & & RE10/E0 & RE15/E0 & RE20/E0 & & RE10/E10 & RE15/E15 & RE20/E20 & \\
\hline $\mathrm{CO}(\mathrm{g} / \mathrm{mi})$ & NA & -0.104 & $\mathrm{NA}$ & 0.05 & 0.936* & $<0.01^{*}$ & NA & $0.246 *$ & NA & $<0.01^{*}$ & $\mathrm{NA}$ & $\mathrm{NA}$ & NA & 0.10 \\
\hline $\mathrm{NOx}(\mathrm{g} / \mathrm{mi})$ & NA & -0.003 & $\mathrm{NA}$ & 0.41 & $0.032 *$ & $<0.01 *$ & $\mathrm{NA}$ & $0.007 *$ & NA & $<0.01 *$ & $\mathrm{NA}$ & $\mathrm{NA}$ & NA & 0.77 \\
\hline $\mathrm{NMHC}(\mathrm{g} / \mathrm{mi})$ & NA & 0.000 & $\mathrm{NA}$ & 0.95 & 0.018* & $<0.01^{*}$ & NA & 0.004 & NA & $0.04 *$ & NA & $\mathrm{NA}$ & NA & 0.85 \\
\hline NMOG (g/mi) & NA & 0.004 & $\mathrm{NA}$ & 0.23 & $0.019^{*}$ & $<0.01^{*}$ & NA & 0.004 & NA & $0.04 *$ & $\mathrm{NA}$ & $\mathrm{NA}$ & NA & 0.92 \\
\hline Fuel Econ (mi/gal) & $\mathrm{NA}$ & $-0.916 *$ & $\mathrm{NA}$ & $<0.01^{*}$ & 0.279 & 0.14 & NA & $0.628^{*}$ & NA & 0.13 & NA & $\mathrm{NA}$ & NA & 0.97 \\
\hline $\mathrm{CH}_{4}(\mathrm{~g} / \mathrm{mi})$ & NA & 0.0003 & $\mathrm{NA}$ & 0.73 & $0.0100^{*}$ & $<0.01^{*}$ & NA & $0.0057^{*}$ & NA & $0.04 *$ & NA & $\mathrm{NA}$ & NA & 0.84 \\
\hline
\end{tabular}

\# Log-normal model was used. Results are presented as changes in emissions at $0 \mathrm{k}$ mile.

\#\# Data did not support the assumption of linear effects with mileage.

*Indicates estimate is different from zero at the $95 \%$ confidence level. 
2009 Saturn Outlook (Composite CO)

\begin{tabular}{|l|r|r|r|}
\hline \multicolumn{1}{|c|}{ Effect } & Estimate & $\begin{array}{c}\text { 95\% C.I. } \\
\text { Lower }\end{array}$ & $\begin{array}{c}\text { 95\% C.I. } \\
\text { Upper }\end{array}$ \\
\hline Ethanol Effect (E15 vs. E0) $(\Delta \mathrm{g} / \mathrm{mi})$ & -0.104 & -0.208 & 0.001 \\
\hline Road Fuel Aging Effect & & & \\
\hline Aging Effect with RE0 $(\Delta \mathrm{g} / \mathrm{mi}$ per 100k mi) & $0.936^{*}$ & 0.764 & 1.109 \\
\hline Aging Effect with RE15 $(\Delta \mathrm{g} / \mathrm{mi}$ per 100k mi) & $0.246^{*}$ & 0.124 & 0.369 \\
\hline
\end{tabular}

\begin{tabular}{|l|r|}
\hline \multicolumn{1}{|c|}{ Hypothesis } & p-value \\
\hline No Effect of Ethanol in the Test Fuel (Gamma = 0) & 0.05 \\
\hline No Aging Effect with RE0 (Beta0 = 0) & $<0.01^{*}$ \\
\hline No Effect of Ethanol in Road Fuel Aging (Beta1s $=0$ ) & $<0.01^{*}$ \\
\hline
\end{tabular}

${ }^{*}$ Indicates estimate is different from zero at the $95 \%$ confidence level.

Initial odometers $4 \mathrm{k}$

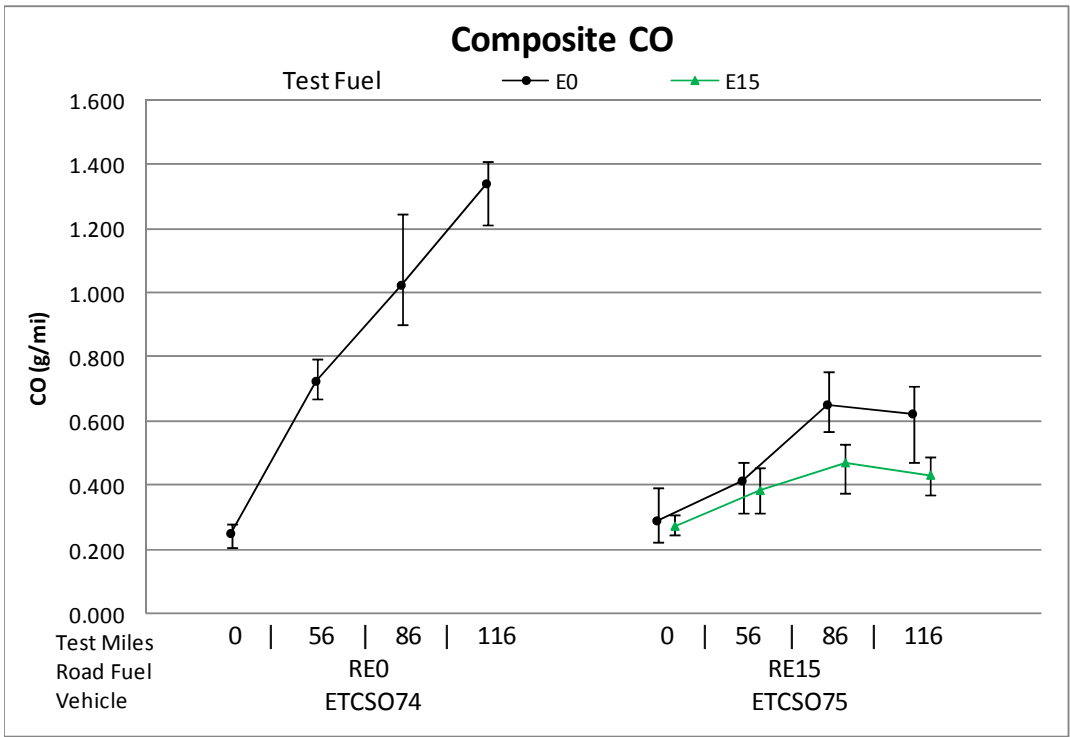

Error bars represent min and max measurements

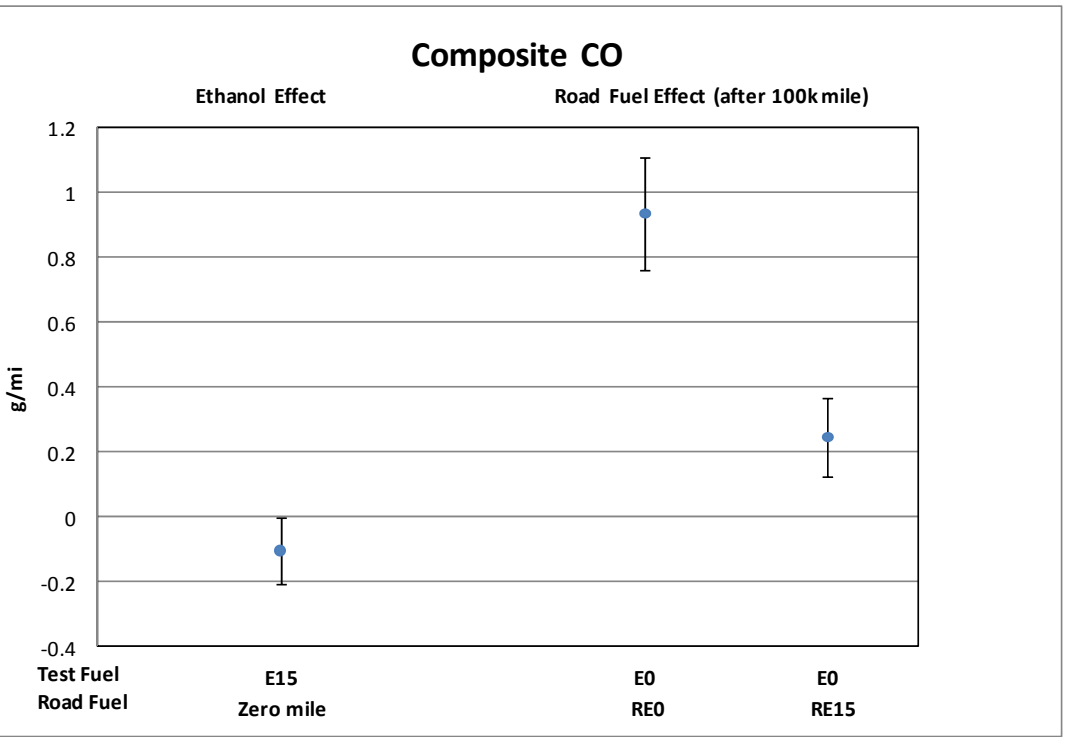

Error bars represent $95 \%$ confidence intervals on the estimated effects 
2009 Saturn Outlook (Composite NOx)

\begin{tabular}{|l|r|r|r|}
\hline \multicolumn{1}{|c|}{ Effect } & & $\begin{array}{c}95 \% \text { C.I. } \\
\text { 95\% C.I. }\end{array}$ & $\begin{array}{c}\text { E5 } \\
\text { Upper }\end{array}$ \\
\hline Ethanol Effect (E15 vs. E0) $(\Delta \mathrm{g} / \mathrm{mi})$ & -0.003 & -0.0086 & 0.0036 \\
\hline Road Fuel Aging Effect & & & \\
\hline Aging Effect with RE0 $(\Delta \mathrm{g} / \mathrm{mi}$ per 100k mi) & $0.032^{*}$ & 0.0231 & 0.0413 \\
\hline Aging Effect with RE15 $(\Delta \mathrm{g} / \mathrm{mi} \mathrm{per} \mathrm{100k} \mathrm{mi)}$ & $0.007^{*}$ & 0.0002 & 0.0144 \\
\hline
\end{tabular}

\begin{tabular}{|l|r|}
\hline \multicolumn{1}{|c|}{ Hypothesis } & -value \\
\hline No Effect of Ethanol in the Test Fuel (Gamma $=0)$ & 0.41 \\
\hline No Aging Effect with RE0 (Beta0 $=0$ ) & $<0.01^{*}$ \\
\hline No Effect of Ethanol in Road Fuel Aging (Beta1s $=0$ ) & $<0.01^{*}$ \\
\hline * Indicates effect is statistically significant at the $95 \%$ confidence level.
\end{tabular}

${ }^{*}$ Indicates estimate is different from zero at the $95 \%$ confidence level.

Initial odometers $4 \mathrm{k}$
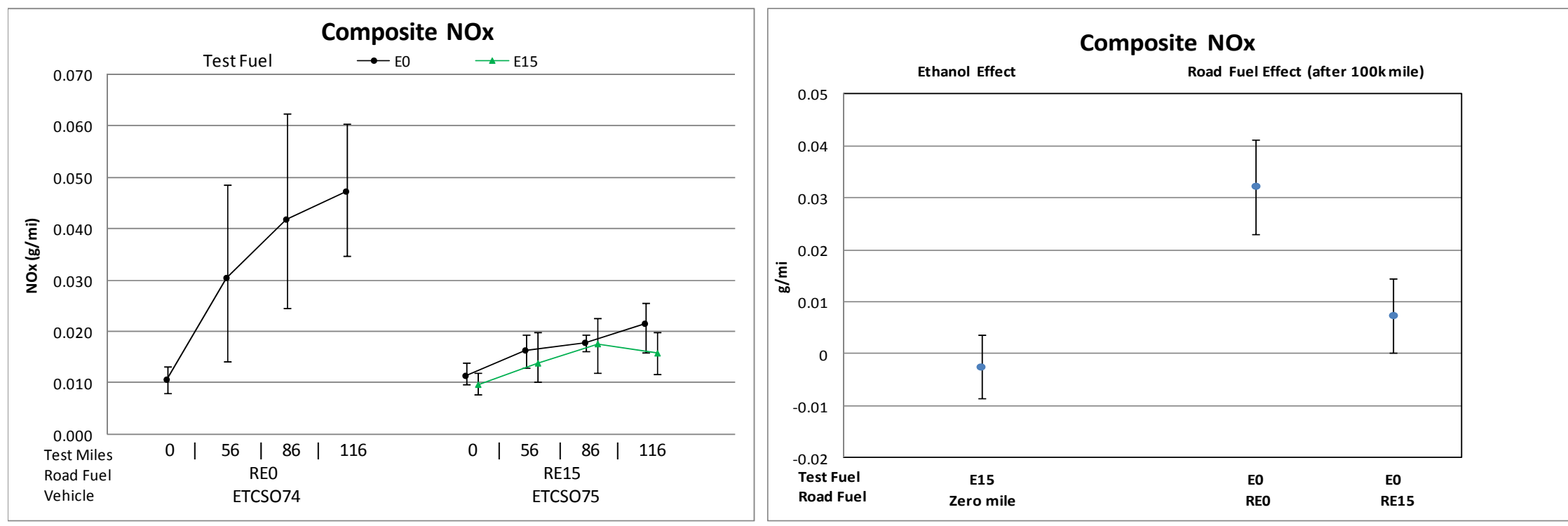

Error bars represent min and max measurements

Error bars represent $95 \%$ confidence intervals on the estimated effects 
2009 Saturn Outlook (Composite Nonmethane Hydrocarbons)

\begin{tabular}{|l|r|r|r|}
\hline \multicolumn{1}{|c|}{ Effect } & Estimate & $\begin{array}{c}\text { 95\% C.I. } \\
\text { Lower }\end{array}$ & $\begin{array}{c}\text { 95\% C.I. } \\
\text { Upper }\end{array}$ \\
\hline Ethanol Effect (E15 vs. E0) $(\Delta \mathrm{g} / \mathrm{mi})$ & 0.000 & -0.006 & 0.006 \\
\hline Road Fuel Aging Effect & & & \\
\hline Aging Effect with RE0 $(\Delta \mathrm{g} / \mathrm{mi}$ per 100k mi) & $0.018^{*}$ & 0.008 & 0.028 \\
\hline Aging Effect with RE15 $(\Delta \mathrm{g} / \mathrm{mi}$ per 100k mi) & 0.004 & -0.003 & 0.011 \\
\hline
\end{tabular}

\begin{tabular}{|l|r|}
\hline \multicolumn{1}{|c|}{ Hypothesis } & p-value \\
\hline No Effect of Ethanol in the Test Fuel (Gamma = 0) & 0.95 \\
\hline No Aging Effect with RE0 (Beta0 = 0) & $<0.01^{*}$ \\
\hline No Effect of Ethanol in Road Fuel Aging (Beta1s $=0$ ) & $0.04^{*}$ \\
\hline * Indicates effect is statistically significant at the 95\% confidence level.
\end{tabular}

* Indicates estimate is different from zero at the $95 \%$ confidence level.

Initial odometers $4 \mathrm{k}$
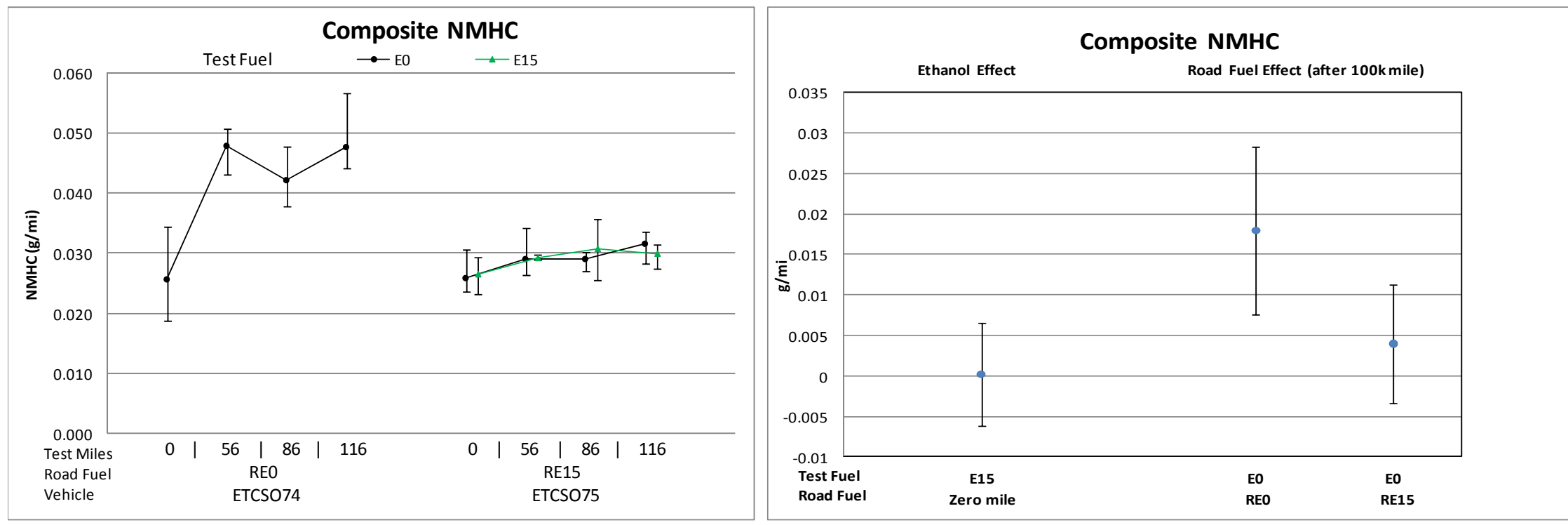

Error bars represent min and max measurements

Error bars represent $95 \%$ confidence intervals on the estimated effects 
2009 Saturn Outlook (Composite Nonmethane Organic Gases)

\begin{tabular}{|l|r|r|r|}
\hline \multicolumn{1}{|c|}{ Effect } & Estimate & $\begin{array}{c}\text { 95\% C.I. } \\
\text { Lower }\end{array}$ & $\begin{array}{c}\text { 95\% C.I. } \\
\text { Upper }\end{array}$ \\
\hline Ethanol Effect (E15 vs. E0) $(\Delta \mathrm{g} / \mathrm{mi})$ & 0.004 & -0.003 & 0.010 \\
\hline Road Fuel Aging Effect & & & \\
\hline Aging Effect with RE0 $(\Delta \mathrm{g} / \mathrm{mi}$ per 100k mi) & $0.019^{*}$ & 0.008 & 0.029 \\
\hline Aging Effect with RE15 $(\Delta \mathrm{g} / \mathrm{mi}$ per 100k mi) & 0.004 & -0.003 & 0.012 \\
\hline
\end{tabular}

\begin{tabular}{|l|r|}
\hline \multicolumn{1}{|c|}{ Hypothesis } & p-value \\
\hline No Effect of Ethanol in the Test Fuel (Gamma $=0)$ & 0.23 \\
\hline No Aging Effect with RE0 (Beta0 = 0) & $<0.01^{*}$ \\
\hline No Effect of Ethanol in Road Fuel Aging (Beta1s $=0$ ) & $0.04^{*}$ \\
\hline * Indicates effect is statistically significant at the 95\% confidence level.
\end{tabular}

* Indicates estimate is different from zero at the $95 \%$ confidence level.

Initial odometers $4 \mathrm{k}$
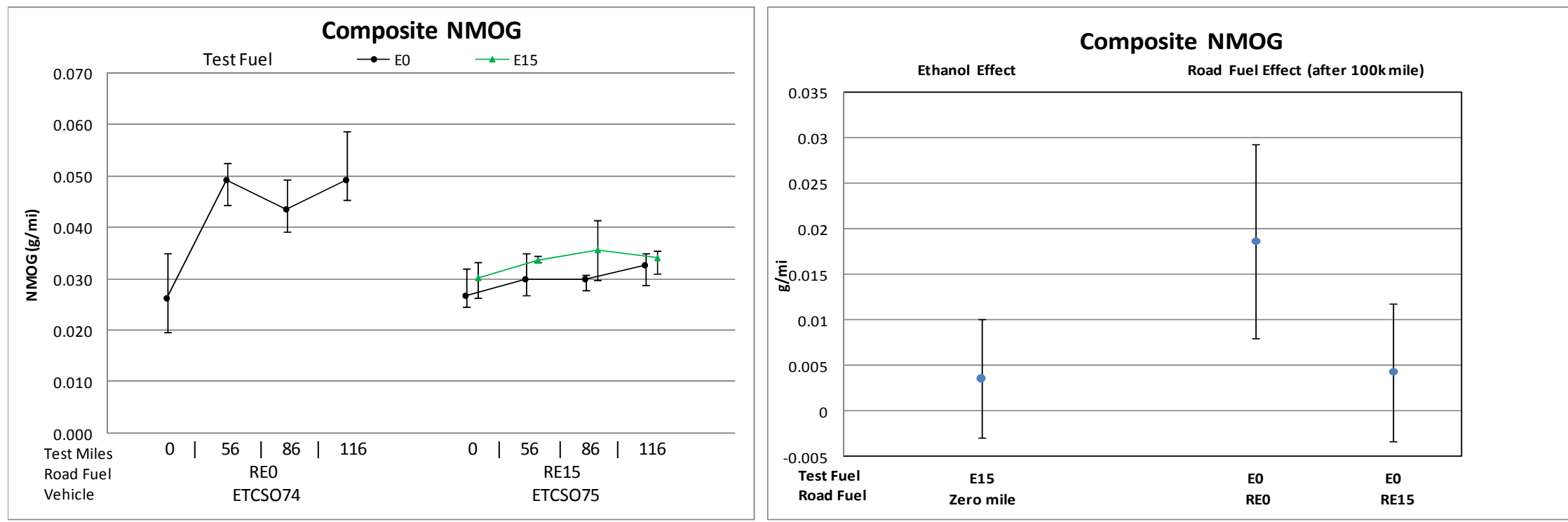

Error bars represent min and max measurements

Error bars represent $95 \%$ confidence intervals on the estimated effects 
2009 Saturn Outlook (Composite Fuel Economy)

\begin{tabular}{|l|r|r|r|}
\hline \multicolumn{1}{|c|}{ Effect } & Estimate & $\begin{array}{c}\text { 95\% C.I. } \\
\text { Lower }\end{array}$ & $\begin{array}{c}\text { 95\% C.I. } \\
\text { Upper }\end{array}$ \\
\hline Ethanol Effect (E15 vs. E0) $(\Delta \mathrm{mi} / \mathrm{gal})$ & $-0.916^{*}$ & -1.163 & -0.669 \\
\hline Road Fuel Aging Effect & & & \\
\hline Aging Effect with RE0 $(\Delta \mathrm{mi} / \mathrm{gal}$ per 100k mi) & 0.279 & -0.126 & 0.684 \\
\hline Aging Effect with RE15 $(\Delta \mathrm{mi} / \mathrm{gal}$ per 100k mi) & $0.628^{*}$ & 0.339 & 0.917 \\
\hline
\end{tabular}

\begin{tabular}{|l|r|}
\hline \multicolumn{1}{|c|}{ Hypothesis } & -value \\
\hline No Effect of Ethanol in the Test Fuel (Gamma $=0)$ & $<0.01^{*}$ \\
\hline No Aging Effect with RE0 (Beta0 = 0) & 0.14 \\
\hline No Effect of Ethanol in Road Fuel Aging (Beta1s=0) & 0.13 \\
\hline${ }^{*}$ Indicates effect is statistically significant at the $95 \%$ confidence level.
\end{tabular}

${ }^{*}$ Indicates estimate is different from zero at the $95 \%$ confidence level.

Initial odometers $4 \mathrm{k}$

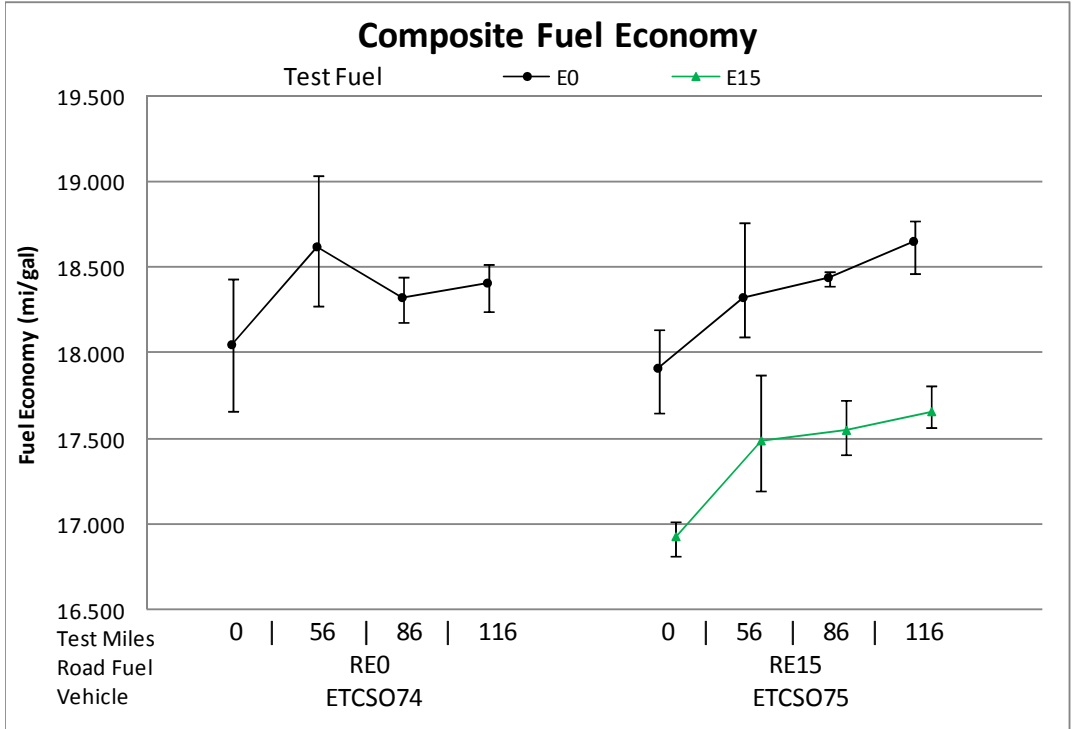

Error bars represent min and max measurements

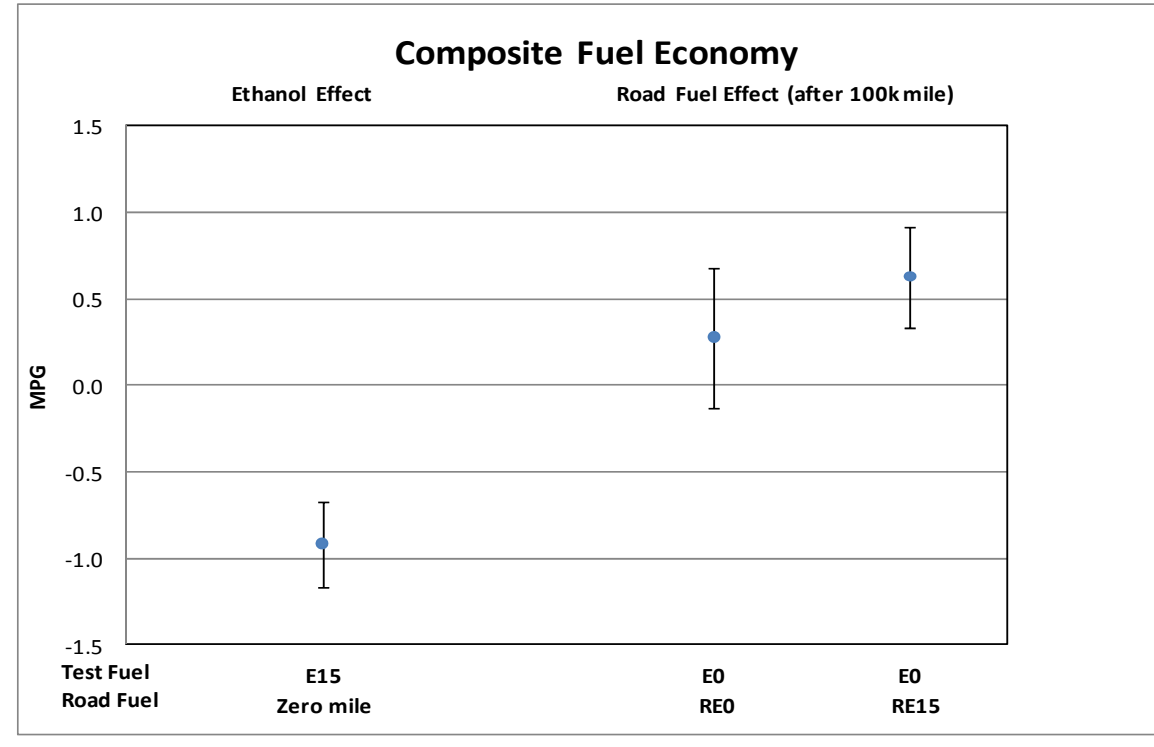

Error bars represent $95 \%$ confidence intervals on the estimated effects 
2009 Saturn Outlook (Composite $\mathrm{CH} 4$ )

\begin{tabular}{|l|r|r|r|}
\hline \multicolumn{1}{|c|}{ Effect } & Estimate & $\begin{array}{c}95 \% \text { C.I. } \\
\text { Lower }\end{array}$ & $\begin{array}{r}95 \% \text { C.I. } \\
\text { Upper }\end{array}$ \\
\hline Ethanol Effect $(E 15 \mathrm{vs}$. E0) $(\Delta \mathrm{g} / \mathrm{mi})$ & 0.0003 & -0.0017 & 0.0023 \\
\hline Road Fuel Aging Effect & & & \\
\hline Aging Effect with RE0 $(\Delta \mathrm{g} / \mathrm{mi}$ per 100k mi) & $0.0100^{*}$ & 0.0068 & 0.0132 \\
\hline Aging Effect with RE15 $(\Delta \mathrm{g} / \mathrm{mi}$ per 100k mi) & $0.0057^{*}$ & 0.0034 & 0.0080 \\
\hline
\end{tabular}

\begin{tabular}{|l|r|}
\hline \multicolumn{1}{|c|}{ Hypothesis } & p-value \\
\hline No Effect of Ethanol in the Test Fuel (Gamma = 0) & 0.73 \\
\hline No Aging Effect with RE0 (Beta0 = 0) & $<0.01^{*}$ \\
\hline No Effect of Ethanol in Road Fuel Aging (Beta1s $=0$ ) & $0.04^{*}$ \\
\hline
\end{tabular}

Initial odometers 4k

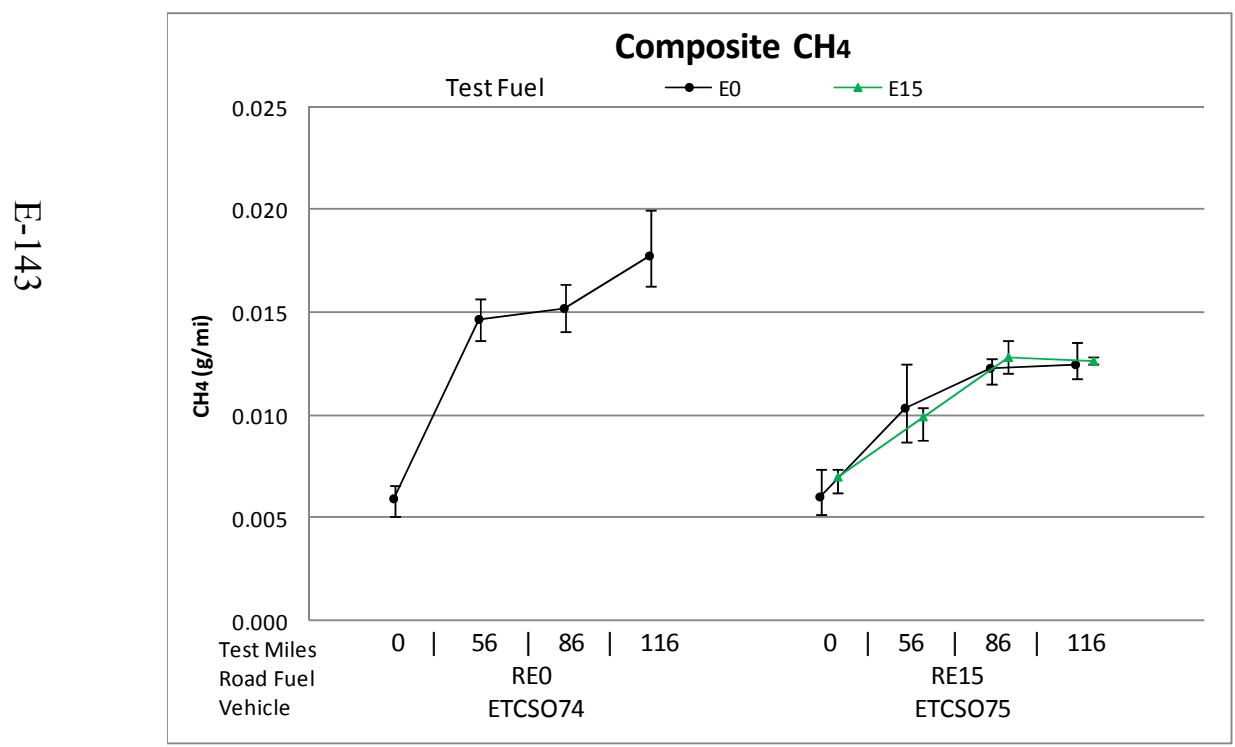

Error bars represent min and max measurements

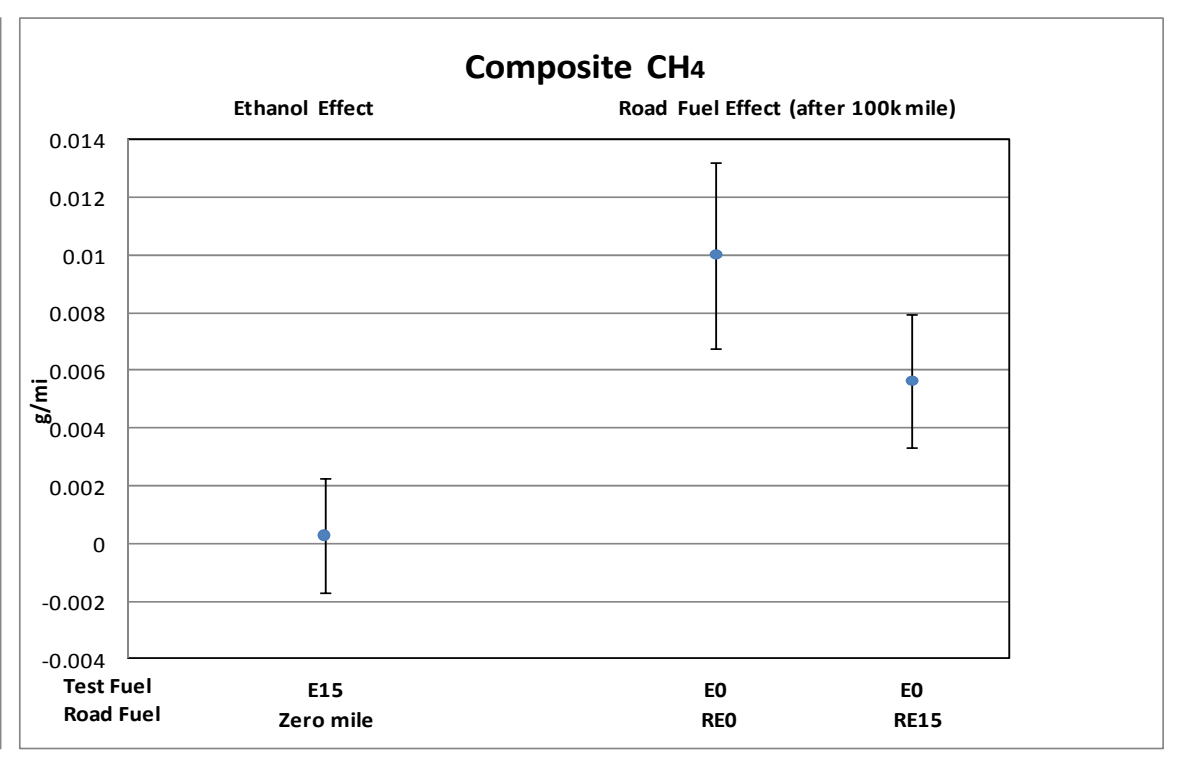

Error bars represent 95\% confidence intervals on the estimated effects 


\section{Toyota Camry - Composite Emissions Summary}

\begin{tabular}{|c|c|c|c|c|c|c|c|c|c|c|c|c|c|c|}
\hline \multirow{2}{*}{$\begin{array}{c}\text { Emisssion Parameter } \\
\text { (units) }\end{array}$} & \multicolumn{4}{|c|}{ Ethanol Effect } & \multicolumn{2}{|c|}{ Aging Effect with REO } & \multicolumn{4}{|c|}{ RExx Aging Effect on EO Emissions } & \multirow{2}{*}{\multicolumn{3}{|c|}{\begin{tabular}{|c|} 
RExx Aging Effect on Exx Emissions \\
$\Delta$ units per $100 \mathrm{~K}$ mi \\
\end{tabular}}} & \multirow{3}{*}{\begin{tabular}{|c}
$\begin{array}{l}\text { Road and Test } \\
\text { Fuel Effects } \\
\text { are Additive }\end{array}$ \\
$\begin{array}{c}\text { Overall p- } \\
\text { value }\end{array}$ \\
\end{tabular}} \\
\hline & \multicolumn{3}{|c|}{$\Delta$ units vs. EO } & \multirow{2}{*}{$\begin{array}{c}\text { Overall } \\
p \text {-value }\end{array}$} & \multirow{2}{*}{$\begin{array}{c}\Delta \text { units per } 100 \mathrm{~K} \mathrm{mi} \\
\text { REO/EO }\end{array}$} & \multirow{2}{*}{$\begin{array}{l}\text { Overall } \\
p \text {-value }\end{array}$} & \multicolumn{3}{|c|}{$\Delta$ units per $100 \mathrm{~K} \mathrm{mi}$} & \multirow{2}{*}{$\begin{array}{l}\text { Overall } \\
p \text {-value }\end{array}$} & & & & \\
\hline Fuels & E10 & E15 & E20 & & & & RE10/E0 & RE15/E0 & RE20/E0 & & RE10/E10 & RE15/E15 & RE20/E20 & \\
\hline $\mathrm{CO}(\mathrm{g} / \mathrm{mi})$ & NA & 0.006 & $\mathrm{NA}$ & 0.75 & $0.120 *$ & $<0.01^{*}$ & NA & 0.051 & NA & 0.12 & $\mathrm{NA}$ & $\mathrm{NA}$ & NA & 0.62 \\
\hline $\mathrm{NOx}(\mathrm{g} / \mathrm{mi})$ & NA & 0.006 & $\mathrm{NA}$ & 0.12 & $0.031^{*}$ & $<0.01 *$ & $\mathrm{NA}$ & $0.016 *$ & NA & 0.07 & $\mathrm{NA}$ & $\mathrm{NA}$ & NA & 0.19 \\
\hline $\mathrm{NMHC}(\mathrm{g} / \mathrm{mi})$ & NA & 0.0003 & $\mathrm{NA}$ & 0.89 & $0.0122^{*}$ & $0.01 *$ & NA & 0.0045 & NA & 0.13 & NA & $\mathrm{NA}$ & NA & 0.13 \\
\hline NMOG (g/mi) & NA & 0.0037 & $\mathrm{NA}$ & 0.16 & $0.0123 *$ & $0.01 *$ & $\mathrm{NA}$ & 0.0047 & NA & 0.15 & NA & $\mathrm{NA}$ & NA & 0.18 \\
\hline Fuel Econ (mi/gal) & NA & $-1.497^{*}$ & NA & $<0.01^{*}$ & 0.113 & 0.80 & NA & -0.020 & NA & 0.81 & NA & $\mathrm{NA}$ & NA & 0.85 \\
\hline $\mathrm{CH}_{4}(\mathrm{~g} / \mathrm{mi})$ & $\mathrm{NA}$ & 0.0001 & $N A$ & 0.92 & $0.0078^{*}$ & $<0.01^{*}$ & $\mathrm{NA}$ & $0.0055^{*}$ & NA & 0.17 & $\mathrm{NA}$ & $\mathrm{NA}$ & NA & 0.50 \\
\hline
\end{tabular}

\# Log-normal model was used. Results are presented as changes in emissions at $0 \mathrm{k}$ mile.

\#\# Data did not support the assumption of linear effects with mileage.

* Indicates estimate is different from zero at the $95 \%$ confidence level.

a test "115937" is identified as an outlier and excluded from the analysis 
2009 Toyota Camry (Composite CO)

\begin{tabular}{|l|r|r|r|}
\hline \multicolumn{1}{|c|}{ Effect } & Estimate & $\begin{array}{c}\text { 95\% C.I. } \\
\text { Lower }\end{array}$ & $\begin{array}{c}\text { 95\% C.I. } \\
\text { Upper }\end{array}$ \\
\hline Ethanol Effect (E15 vs. E0) $(\Delta \mathrm{g} / \mathrm{mi})$ & 0.006 & -0.039 & 0.052 \\
\hline Road Fuel Aging Effect & & & \\
\hline Aging Effect with RE0 $(\Delta \mathrm{g} / \mathrm{mi}$ per 100k mi) & $0.120^{*}$ & 0.046 & 0.194 \\
\hline Aging Effect with RE15 $(\Delta \mathrm{g} / \mathrm{mi}$ per 100k mi) & 0.051 & -0.003 & 0.104 \\
\hline
\end{tabular}

\begin{tabular}{|l|r|}
\hline \multicolumn{1}{|c|}{ Hypothesis } & p-value \\
\hline No Effect of Ethanol in the Test Fuel (Gamma = 0) & 0.75 \\
\hline No Aging Effect with RE0 (Beta0 = 0) & $<0.01^{*}$ \\
\hline No Effect of Ethanol in Road Fuel Aging (Beta1s=0) & 0.12 \\
\hline
\end{tabular}

${ }^{*}$ Indicates estimate is different from zero at the $95 \%$ confidence level.

Initial odometers $4 \mathrm{k}$

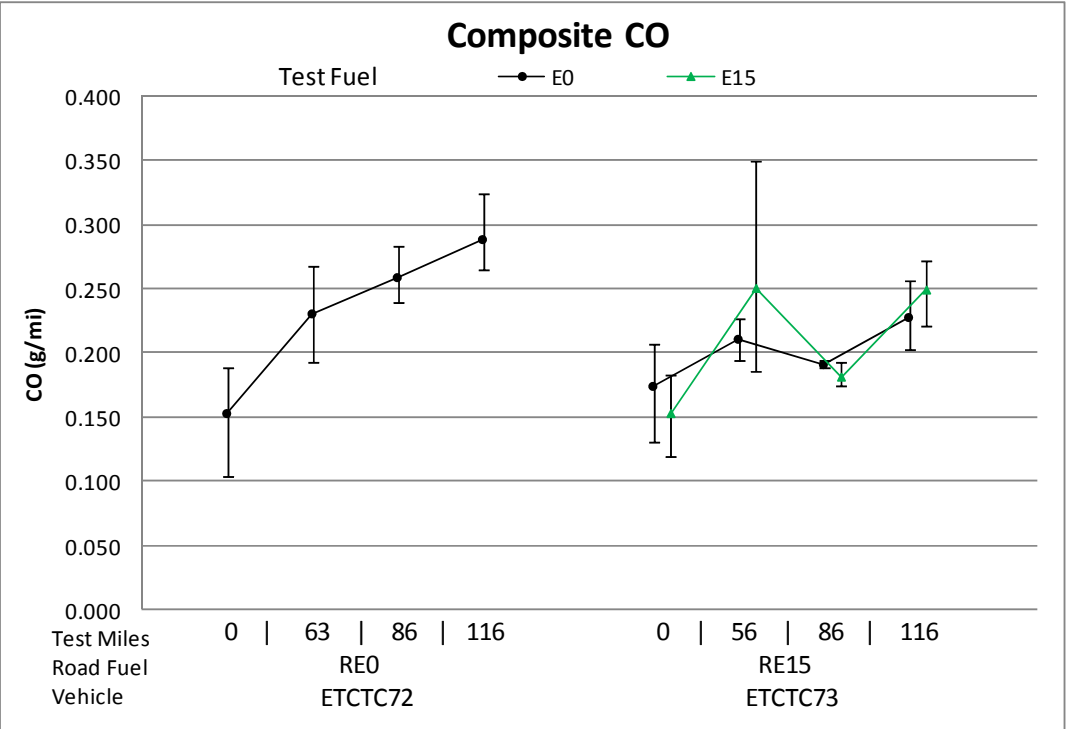

Error bars represent min and max measurements

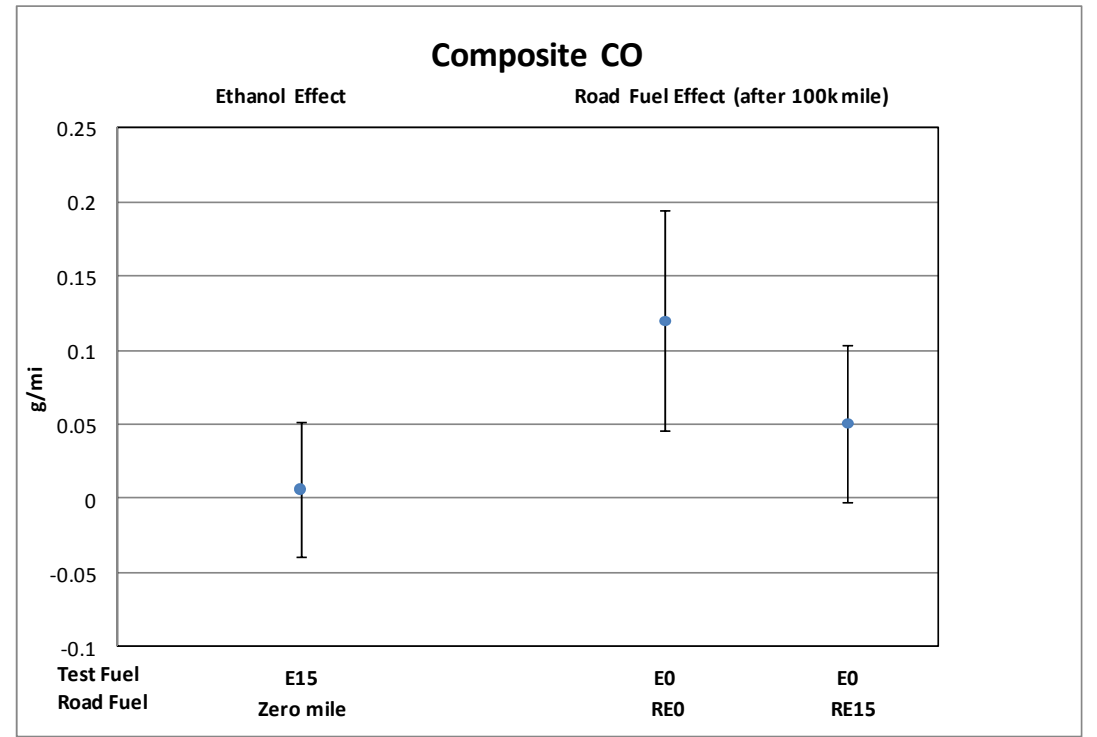

Error bars represent $95 \%$ confidence intervals on the estimated effects 
2009 Toyota Camry (Composite NOx)

\begin{tabular}{|l|r|r|r|}
\hline \multicolumn{1}{|c|}{ Effect } & Estimate & $\begin{array}{c}95 \% \text { C.I. } \\
\text { Lower }\end{array}$ & $\begin{array}{c}\text { 95\% C.I. } \\
\text { Upper }\end{array}$ \\
\hline Ethanol Effect (E15 vs. E0) $(\Delta \mathrm{g} / \mathrm{mi})$ & 0.006 & -0.002 & 0.015 \\
\hline Road Fuel Aging Effect & & & \\
\hline Aging Effect with RE0 $(\Delta \mathrm{g} / \mathrm{mi}$ per 100k mi) & $0.031^{*}$ & 0.018 & 0.045 \\
\hline Aging Effect with RE15 $(\Delta \mathrm{g} / \mathrm{mi}$ per 100k mi) & $0.016^{*}$ & 0.006 & 0.026 \\
\hline
\end{tabular}

\begin{tabular}{|l|r|}
\hline \multicolumn{1}{|c|}{ Hypothesis } & p-value \\
\hline No Effect of Ethanol in the Test Fuel (Gamma = 0) & 0.12 \\
\hline No Aging Effect with RE0 (Beta0 = 0) & $<0.01^{*}$ \\
\hline No Effect of Ethanol in Road Fuel Aging (Beta1s=0) & 0.07 \\
\hline
\end{tabular}

* Indicates estimate is different from zero at the $95 \%$ confidence level.

Initial odometers $4 \mathrm{k}$

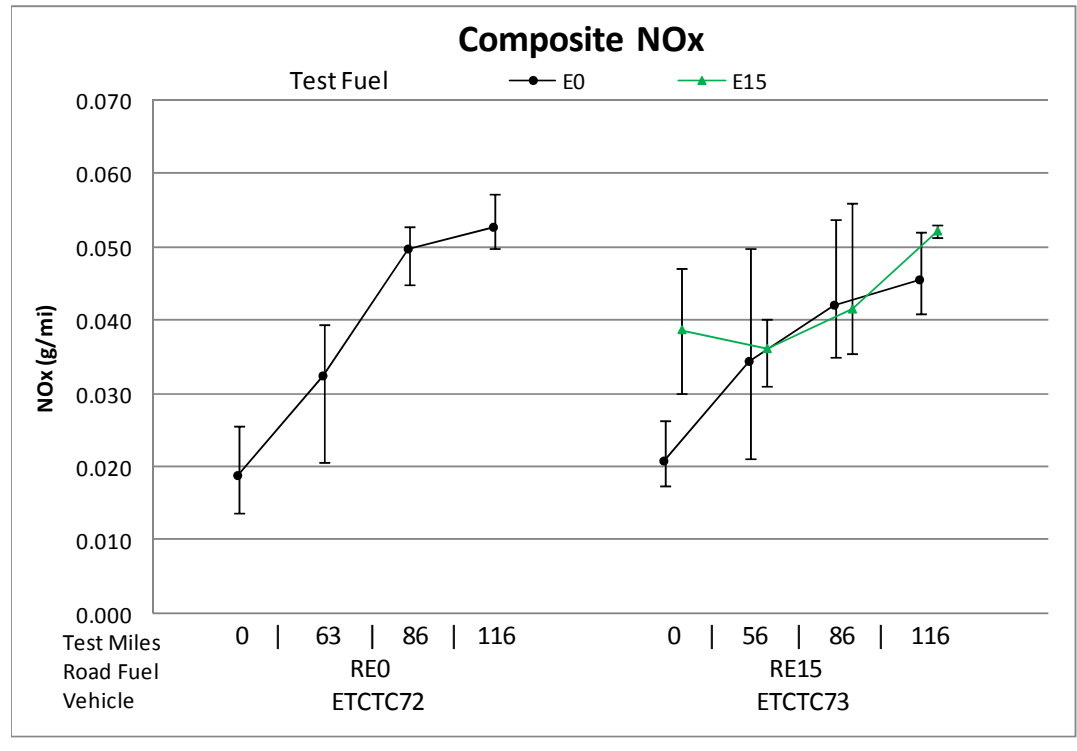

Error bars represent min and max measurements

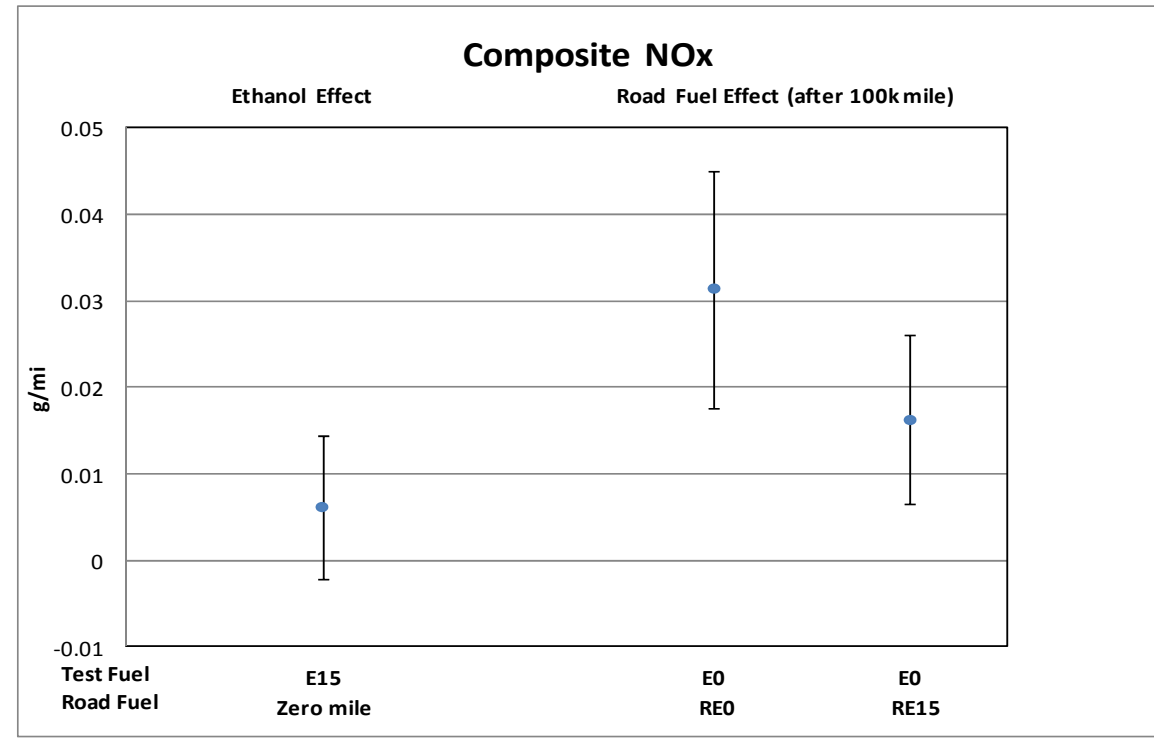

Error bars represent $95 \%$ confidence intervals on the estimated effects 
2009 Toyota Camry (Composite Nonmethane Hydrocarbons)

\begin{tabular}{|l|r|r|r|}
\hline \multicolumn{1}{|c|}{ Effect } & Estimate & $\begin{array}{c}\text { 95\% C.I. } \\
\text { Lower }\end{array}$ & $\begin{array}{c}\text { 95\% C.I. } \\
\text { Upper }\end{array}$ \\
\hline Ethanol Effect (E15 vs. E0) $(\Delta \mathrm{g} / \mathrm{mi})$ & 0.0003 & -0.0049 & 0.0056 \\
\hline Road Fuel Aging Effect & & & \\
\hline Aging Effect with RE0 $(\Delta \mathrm{g} / \mathrm{mi}$ per 100k mi) & $0.0122^{*}$ & 0.0035 & 0.0208 \\
\hline Aging Effect with RE15 $(\Delta \mathrm{g} / \mathrm{mi}$ per 100k mi) & 0.0045 & -0.0017 & 0.0107 \\
\hline
\end{tabular}

\begin{tabular}{|l|r|}
\hline \multicolumn{1}{|c|}{ Hypothesis } & p-value \\
\hline No Effect of Ethanol in the Test Fuel (Gamma = 0) & 0.89 \\
\hline No Aging Effect with RE0 (Beta0 = 0) & $0.01^{*}$ \\
\hline No Effect of Ethanol in Road Fuel Aging (Beta1s $=0)$ & 0.13 \\
\hline * Indicates effect is statistically significant at the 95\% confidence level.
\end{tabular}

* Indicates estimate is different from zero at the $95 \%$ confidence level.

\section{Initial odometers $4 \mathrm{k}$}

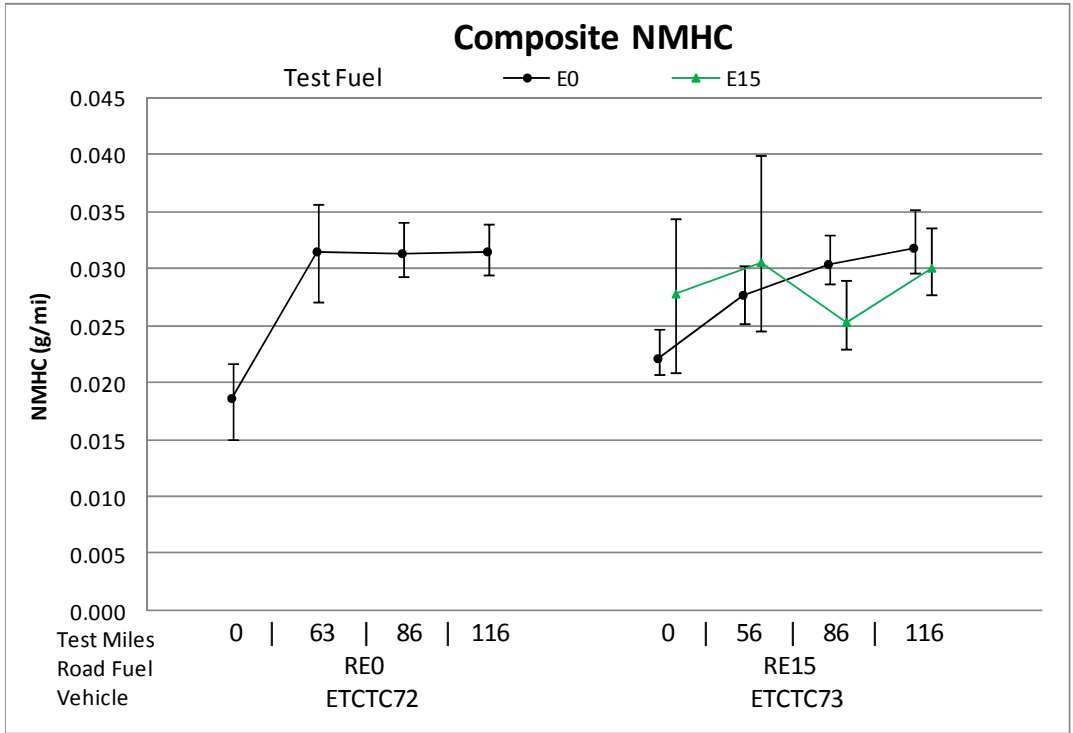

Error bars represent min and max measurements

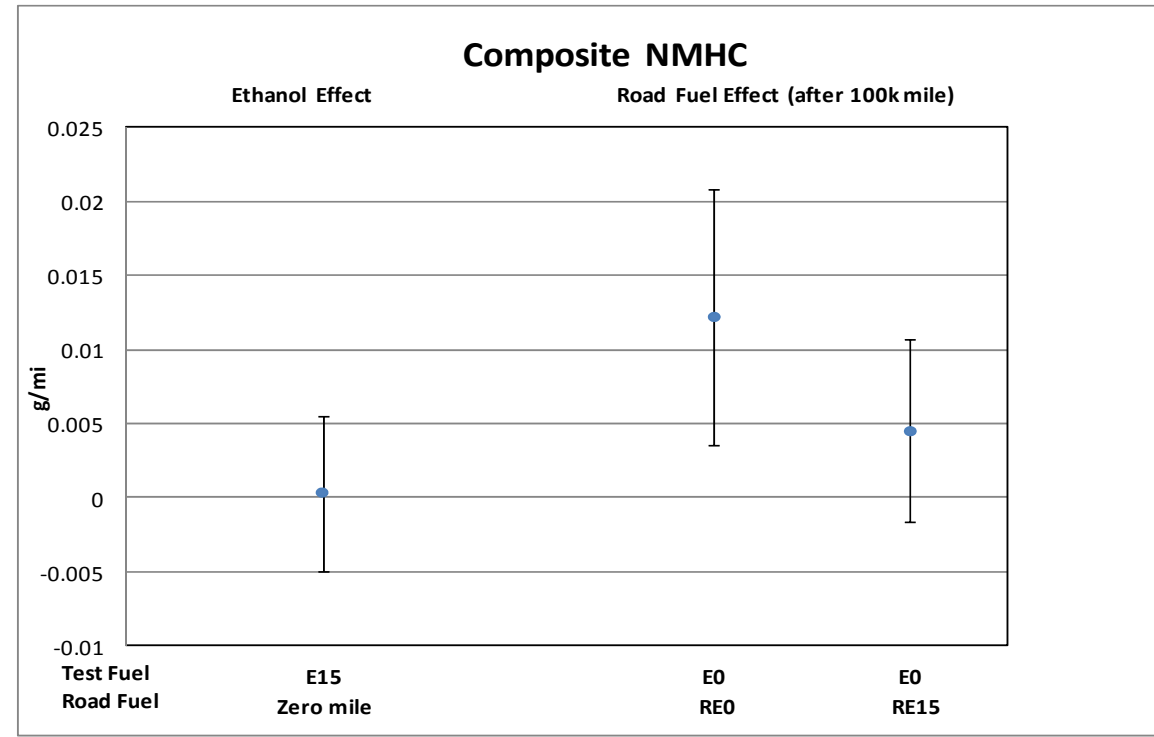

Error bars represent $95 \%$ confidence intervals on the estimated effects 
2009 Toyota Camry (Composite Nonmethane Organic Gases)

\begin{tabular}{|l|r|r|r|}
\hline \multicolumn{1}{|c|}{ Effect } & Estimate & $\begin{array}{c}\text { 95\% C.I. } \\
\text { Lower }\end{array}$ & $\begin{array}{c}\text { 95\% C.I. } \\
\text { Upper }\end{array}$ \\
\hline Ethanol Effect $($ E15 vs. E0) $(\Delta \mathrm{g} / \mathrm{mi})$ & 0.0037 & -0.0018 & 0.0092 \\
\hline Road Fuel Aging Effect & & & \\
\hline Aging Effect with RE0 $(\Delta \mathrm{g} / \mathrm{mi}$ per 100k mi) & $0.0123^{*}$ & 0.0033 & 0.0214 \\
\hline Aging Effect with RE15 $(\Delta \mathrm{g} / \mathrm{mi}$ per 100k mi) & 0.0047 & -0.0018 & 0.0112 \\
\hline
\end{tabular}

\begin{tabular}{|l|r|}
\hline \multicolumn{1}{|c|}{ Hypothesis } & p-value \\
\hline No Effect of Ethanol in the Test Fuel (Gamma $=0)$ & 0.16 \\
\hline No Aging Effect with RE0 (Beta0 = 0) & $0.01^{*}$ \\
\hline No Effect of Ethanol in Road Fuel Aging (Beta1s=0) & 0.15 \\
\hline${ }^{*}$ Indicates effect is statistically significant at the 95\% confidence level.
\end{tabular}

${ }^{*}$ Indicates estimate is different from zero at the $95 \%$ confidence level.

Initial odometers $4 \mathrm{k}$
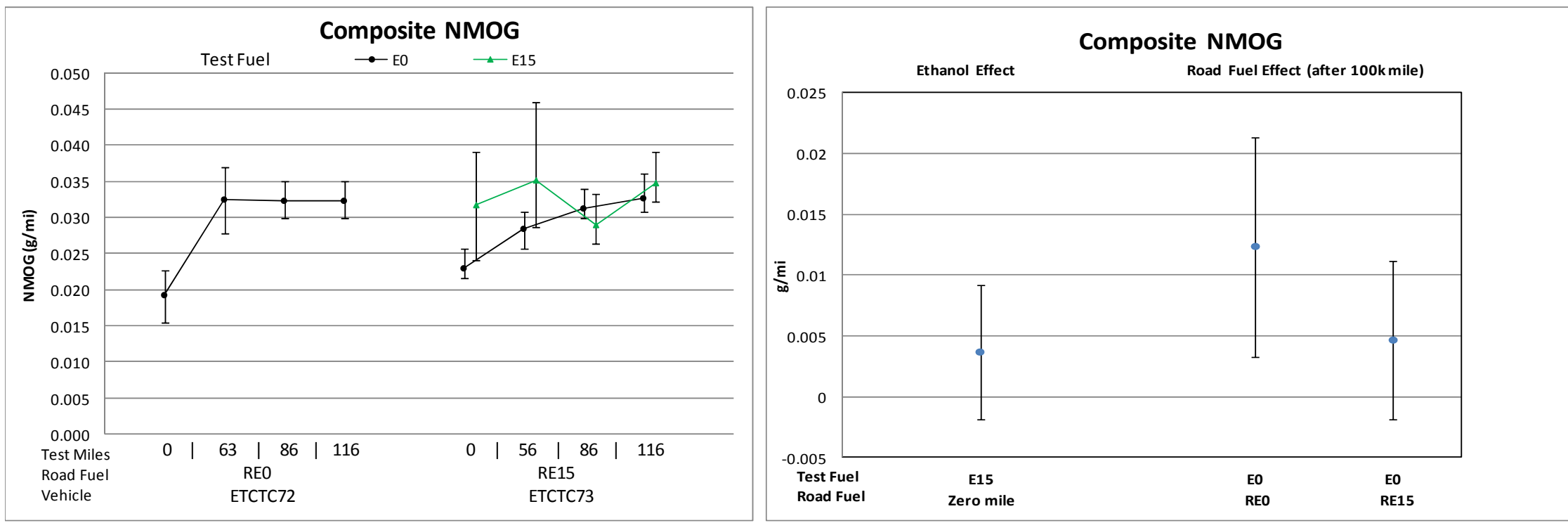

Error bars represent min and max measurements

Error bars represent $95 \%$ confidence intervals on the estimated effects 
2009 Toyota Camry (Composite Fuel Economy)

\begin{tabular}{|l|r|r|r|}
\hline \multicolumn{1}{|c|}{ Effect } & Estimate & $\begin{array}{c}95 \% \text { C.I. } \\
\text { Lower }\end{array}$ & $\begin{array}{c}\text { 95\% C.I. } \\
\text { Upper }\end{array}$ \\
\hline Ethanol Effect (E15 vs. E0) $(\Delta \mathrm{mi} / \mathrm{gal})$ & $-1.497^{*}$ & -2.127 & -0.867 \\
\hline Road Fuel Aging Effect & & & \\
\hline Aging Effect with RE0 $(\Delta \mathrm{mi} / \mathrm{gal}$ per 100k mi) & 0.113 & -0.919 & 1.145 \\
\hline Aging Effect with RE15 $(\Delta \mathrm{mi} / \mathrm{gal}$ per 100k mi) & -0.020 & -0.759 & 0.719 \\
\hline
\end{tabular}

\begin{tabular}{|l|r|}
\hline \multicolumn{1}{|c|}{ Hypothesis } & p-value \\
\hline No Effect of Ethanol in the Test Fuel (Gamma $=0)$ & $<0.01^{*}$ \\
\hline No Aging Effect with RE0 (Beta0 $=0$ ) & 0.80 \\
\hline No Effect of Ethanol in Road Fuel Aging (Beta1s $=0$ ) & 0.81 \\
\hline * Indicates effect is statistically significant at the $95 \%$ confidence level.
\end{tabular}

* Indicates estimate is different from zero at the $95 \%$ confidence level.

Initial odometers $4 \mathrm{k}$

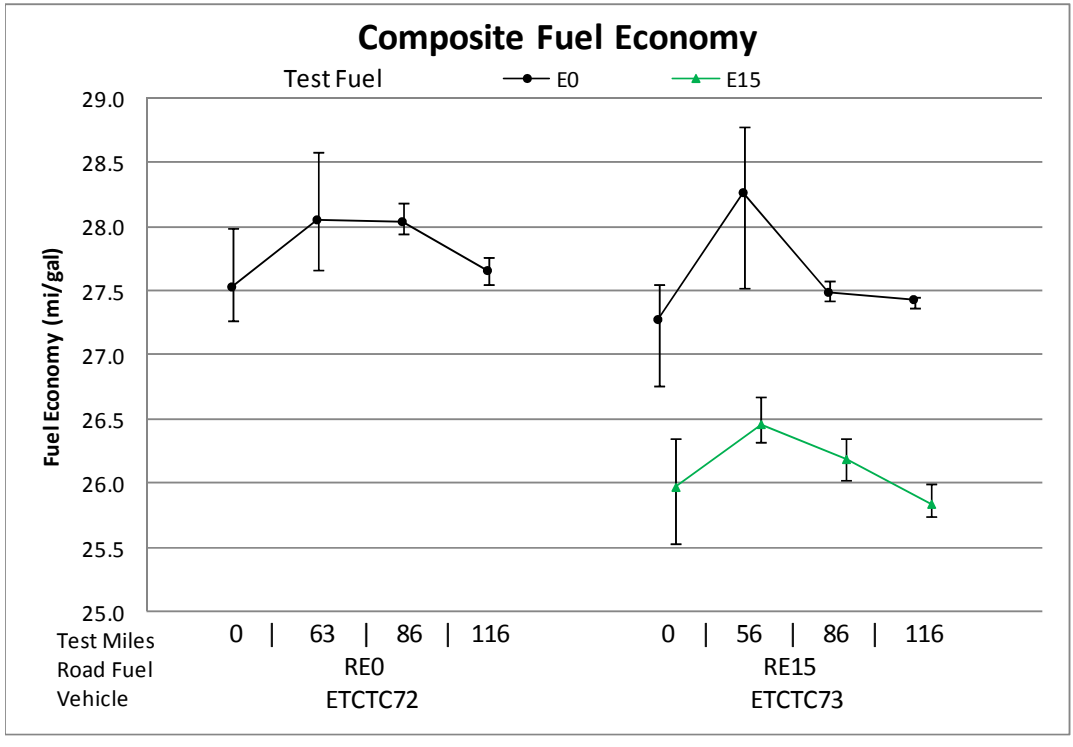

Error bars represent min and max measurements

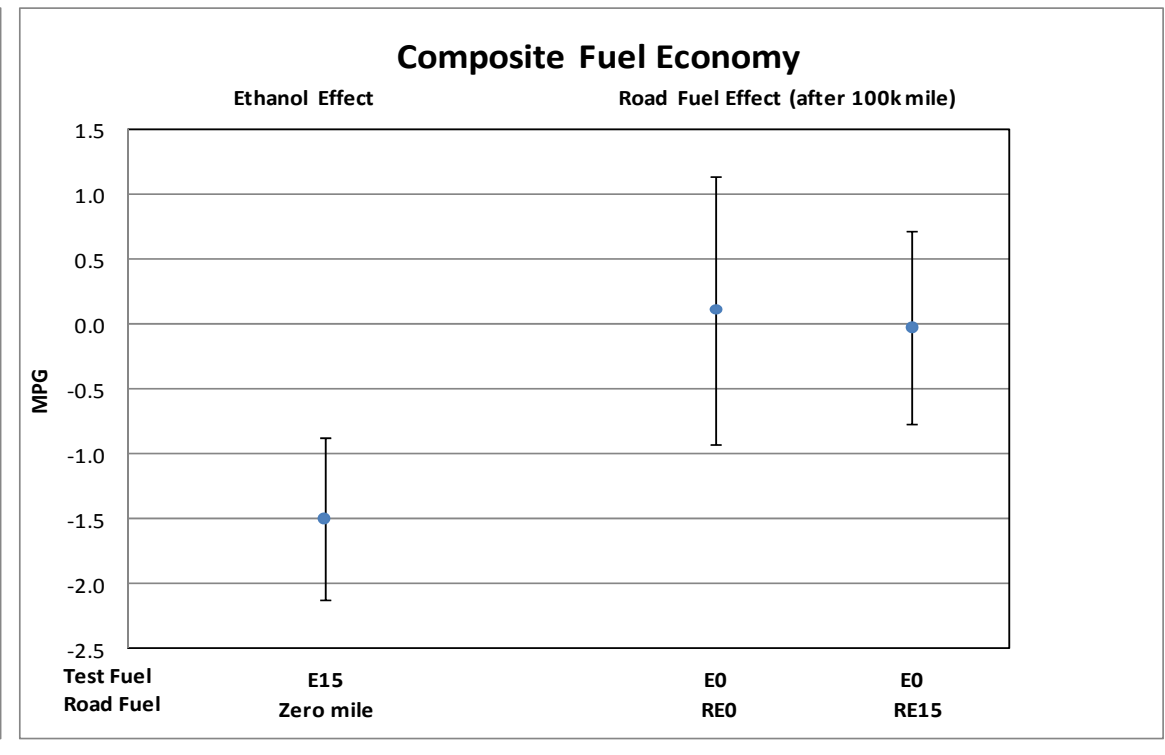

Error bars represent $95 \%$ confidence intervals on the estimated effects 


\section{Toyota Camry (Composite $\mathrm{CH} 4$ )}

\begin{tabular}{|l|r|r|r|}
\hline \multicolumn{1}{|c|}{ Effect } & & $\begin{array}{c}95 \% \text { C.I. } \\
\text { Lo5\% C.I. }\end{array}$ & $\begin{array}{c}\text { U5 } \\
\text { Upper }\end{array}$ \\
\hline Ethanol Effect (E15 vs. E0) $(\Delta \mathrm{g} / \mathrm{mi})$ & 0.0001 & -0.0017 & 0.0018 \\
\hline Road Fuel Aging Effect & & & \\
\hline Aging Effect with RE0 $(\Delta \mathrm{g} / \mathrm{mi}$ per 100k mi) & $0.0078^{*}$ & 0.0049 & 0.0106 \\
\hline Aging Effect with RE15 $(\Delta \mathrm{g} / \mathrm{mi}$ per 100k mi) & $0.0055^{*}$ & 0.0034 & 0.0075 \\
\hline
\end{tabular}

\begin{tabular}{|l|r|}
\hline \multicolumn{1}{|c|}{ Hypothesis } & p-value \\
\hline No Effect of Ethanol in the Test Fuel (Gamma = 0) & 0.92 \\
\hline No Aging Effect with RE0 (Beta0 = 0) & $<0.01^{*}$ \\
\hline No Effect of Ethanol in Road Fuel Aging (Beta1s=0) & 0.17 \\
\hline * Indicates effect is statistically significant at the 95\% confidence level.
\end{tabular}

* Indicates estimate is different from zero at the $95 \%$ confidence leve.

Initial odometers $4 \mathrm{k}$
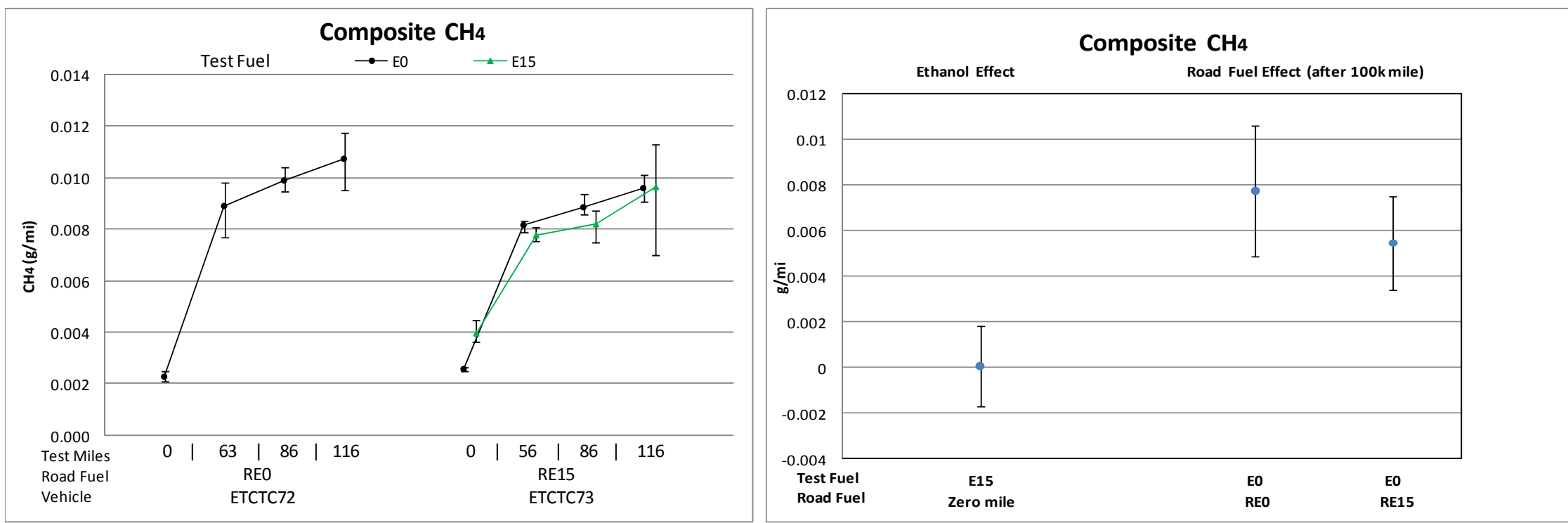

Error bars represent min and max measurements

Error bars represent $95 \%$ confidence intervals on the estimated effects 


\section{Ford Focus - Composite Emissions Summary}

\begin{tabular}{|c|c|c|c|c|c|c|c|c|c|c|c|c|c|c|}
\hline \multirow{3}{*}{$\begin{array}{c}\text { Emisssion Parameter } \\
\text { (units) }\end{array}$} & \multicolumn{4}{|c|}{ Ethanol Effect } & \multicolumn{2}{|c|}{ Aging Effect with RE0 } & \multicolumn{4}{|c|}{ RExx Aging Effect on EO Emissions } & \multirow{2}{*}{\multicolumn{3}{|c|}{\begin{tabular}{|c|} 
RExx Aging Effect on Exx Emissions \\
$\Delta$ units per $100 \mathrm{~K} \mathrm{mi}$ \\
\end{tabular}}} & \multirow{3}{*}{\begin{tabular}{|c|}
$\begin{array}{l}\text { Road and Test } \\
\text { Fuel Effects } \\
\text { are Additive }\end{array}$ \\
$\begin{array}{c}\text { Overall p- } \\
\text { value }\end{array}$ \\
\end{tabular}} \\
\hline & \multicolumn{3}{|c|}{$\Delta$ units vs. EO } & \multirow{2}{*}{$\begin{array}{l}\text { Overall } \\
p \text {-value }\end{array}$} & \multirow{2}{*}{$\begin{array}{c}\Delta \text { units per } 100 \mathrm{~K} \mathrm{mi} \\
\text { REO/EO }\end{array}$} & \multirow{2}{*}{$\begin{array}{l}\text { Overall } \\
p \text {-value }\end{array}$} & \multicolumn{3}{|c|}{$\Delta$ units per $100 \mathrm{~K} \mathrm{mi}$} & \multirow{2}{*}{$\begin{array}{l}\text { Overall } \\
p \text {-value }\end{array}$} & & & & \\
\hline & E10 & E15 & E20 & & & & RE10/E0 & RE15/E0 & RE20/E0 & & RE10/E10 & RE15/E15 & RE20/E20 & \\
\hline $\mathrm{CO}(\mathrm{g} / \mathrm{mi})$ & $\mathrm{NA}$ & -0.039 & $\mathrm{NA}$ & 0.70 & 0.366 & 0.05 & NA & 0.224 & $\mathrm{NA}$ & 0.49 & NA & $\mathrm{NA}$ & $\mathrm{NA}$ & 0.93 \\
\hline $\mathrm{NOx}(\mathrm{g} / \mathrm{mi})$ & $\mathrm{NA}$ & 0.005 & $\mathrm{NA}$ & 0.65 & $0.084 *$ & $<0.01 *$ & $\mathrm{NA}$ & $0.042^{*}$ & $\mathrm{NA}$ & 0.08 & NA & $\mathrm{NA}$ & $\mathrm{NA}$ & 0.33 \\
\hline $\mathrm{NMHC}(\mathrm{g} / \mathrm{mi})$ & $\mathrm{NA}$ & -0.009 & $\mathrm{NA}$ & 0.07 & -0.012 & 0.13 & NA & -0.001 & $\mathrm{NA}$ & 0.23 & $\mathrm{NA}$ & NA & $\mathrm{NA}$ & 0.68 \\
\hline $\operatorname{NMOG}(\mathrm{g} / \mathrm{mi})$ & $\mathrm{NA}$ & -0.006 & $\mathrm{NA}$ & 0.21 & -0.012 & 0.13 & NA & -0.001 & $\mathrm{NA}$ & 0.23 & NA & $\mathrm{NA}$ & $\mathrm{NA}$ & 0.67 \\
\hline Fuel Econ (mi/gal) & $\mathrm{NA}$ & $-1.350 *$ & $\mathrm{NA}$ & $<0.01 *$ & 1.127 & 0.10 & NA & 0.263 & $\mathrm{NA}$ & 0.27 & $\mathrm{NA}$ & NA & $\mathrm{NA}$ & 0.60 \\
\hline $\mathrm{CH} 4(\mathrm{~g} / \mathrm{mi})$ & $\mathrm{NA}$ & -0.0006 & $\mathrm{NA}$ & 0.48 & 0.0022 & 0.13 & NA & $0.0041^{*}$ & $\mathrm{NA}$ & 0.25 & NA & $\mathrm{NA}$ & $\mathrm{NA}$ & 0.46 \\
\hline
\end{tabular}

\# Log-normal model was used. Results are presented as changes in emissions at 0k mile.

\#\# Data did not support the assumption of linear effects with mileage.

*Indicates estimate is different from zero at the $95 \%$ confidence level. 
2009 Ford Focus (Composite CO)

\begin{tabular}{|l|r|r|r|}
\hline \multicolumn{1}{|c|}{ Effect } & Estimate & $\begin{array}{c}95 \% \text { C.I. } \\
\text { Lower }\end{array}$ & $\begin{array}{c}\text { 95\% C.I. } \\
\text { Upper }\end{array}$ \\
\hline Ethanol Effect (E15 vs. E0) $(\Delta \mathrm{g} / \mathrm{mi})$ & -0.039 & -0.267 & 0.189 \\
\hline Road Fuel Aging Effect & & & \\
\hline Aging Effect with RE0 $(\Delta \mathrm{g} / \mathrm{mi}$ per 100k mi) & 0.366 & -0.010 & 0.742 \\
\hline Aging Effect with RE15 $(\Delta \mathrm{g} / \mathrm{mi}$ per 100k mi) & 0.224 & -0.043 & 0.491 \\
\hline
\end{tabular}

\begin{tabular}{|l|r|}
\hline \multicolumn{1}{|c|}{ Hypothesis } & p-value \\
& \\
\hline No Effect of Ethanol in the Test Fuel (Gamma $=0)$ & 0.70 \\
\hline No Aging Effect with RE0 (Beta0 $=0$ ) & 0.05 \\
\hline No Effect of Ethanol in Road Fuel Aging (Beta1s=0) & 0.49 \\
\hline
\end{tabular}

${ }^{*}$ Indicates estimate is different from zero at the $95 \%$ confidence level.

Initial odometers $4 \mathrm{k}$

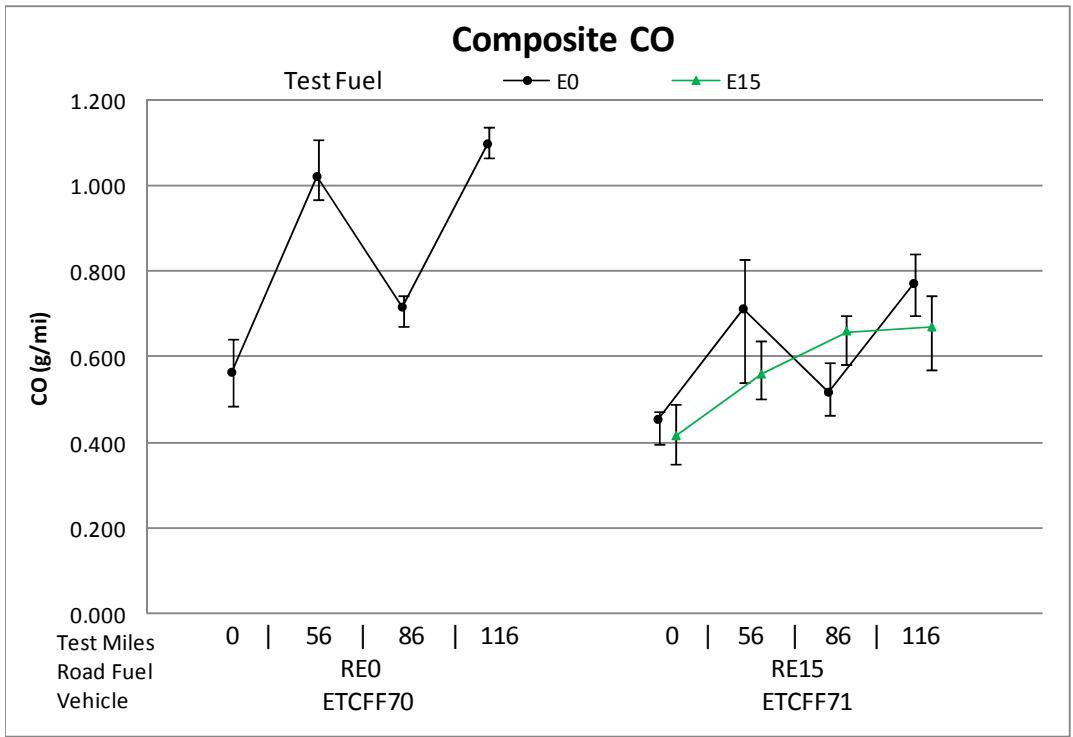

Error bars represent min and max measurements

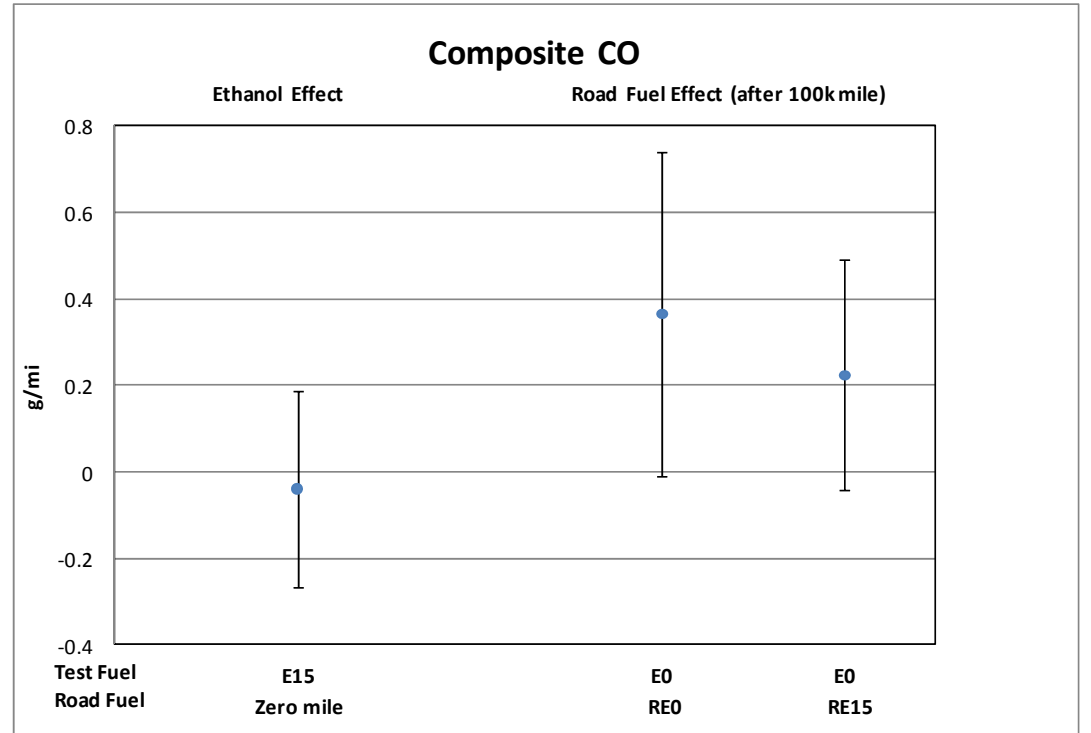

Error bars represent $95 \%$ confidence intervals on the estimated effects 
2009 Ford Focus (Composite NOx)

\begin{tabular}{|l|r|r|r|}
\hline \multicolumn{1}{|c|}{ Effect } & Estimate & $\begin{array}{c}\text { 95\% C.I. } \\
\text { Lower }\end{array}$ & $\begin{array}{c}\text { 95\% C.I. } \\
\text { Upper }\end{array}$ \\
\hline Ethanol Effect (E15 vs. E0) $(\Delta \mathrm{g} / \mathrm{mi})$ & 0.005 & -0.019 & 0.029 \\
\hline Road Fuel Aging Effect & & & \\
\hline Aging Effect with RE0 $(\Delta \mathrm{g} / \mathrm{mi}$ per 100k mi) & $0.084^{*}$ & 0.044 & 0.124 \\
\hline Aging Effect with RE15 $(\Delta \mathrm{g} / \mathrm{mi}$ per 100k mi) & $0.042^{*}$ & 0.014 & 0.070 \\
\hline
\end{tabular}

\begin{tabular}{|l|r|}
\hline \multicolumn{1}{|c|}{ Hypothesis } & p-value \\
\hline No Effect of Ethanol in the Test Fuel (Gamma = 0) & 0.65 \\
\hline No Aging Effect with RE0 (Beta0 = 0) & $<0.01^{*}$ \\
\hline No Effect of Ethanol in Road Fuel Aging (Beta1s=0) & 0.08 \\
\hline * Indicates effect is statistically significant at the 95\% confidence level.
\end{tabular}

* Indicates estimate is different from zero at the $95 \%$ confidence level.

Initial odometers $4 \mathrm{k}$

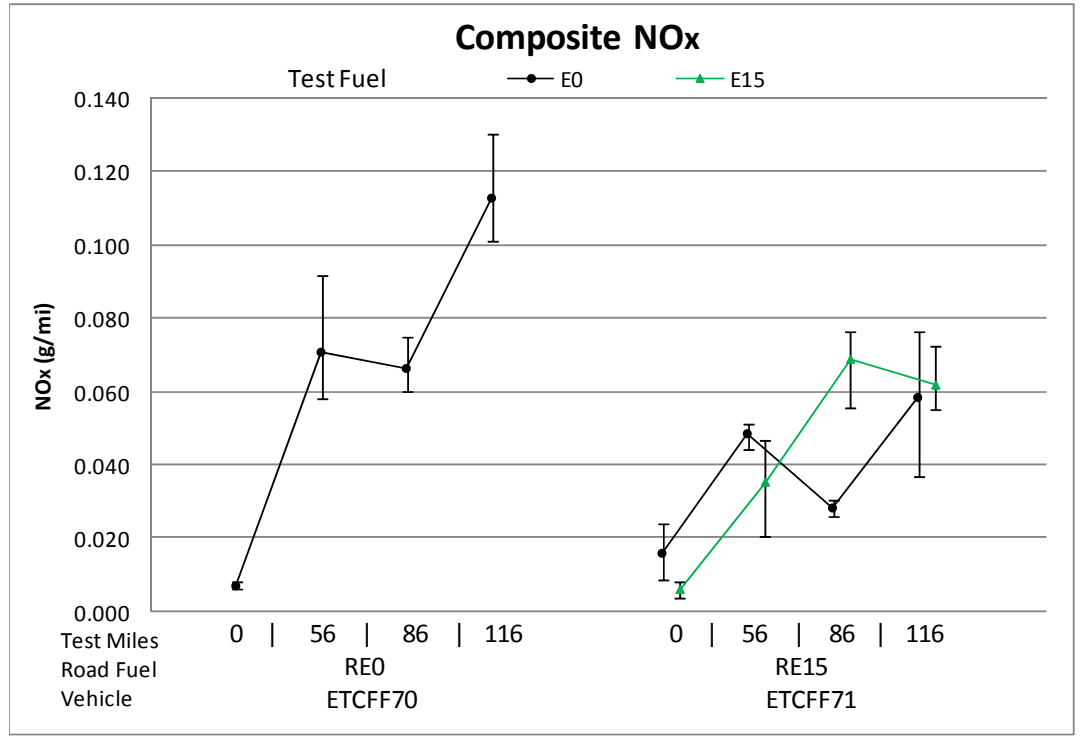

Error bars represent min and max measurements

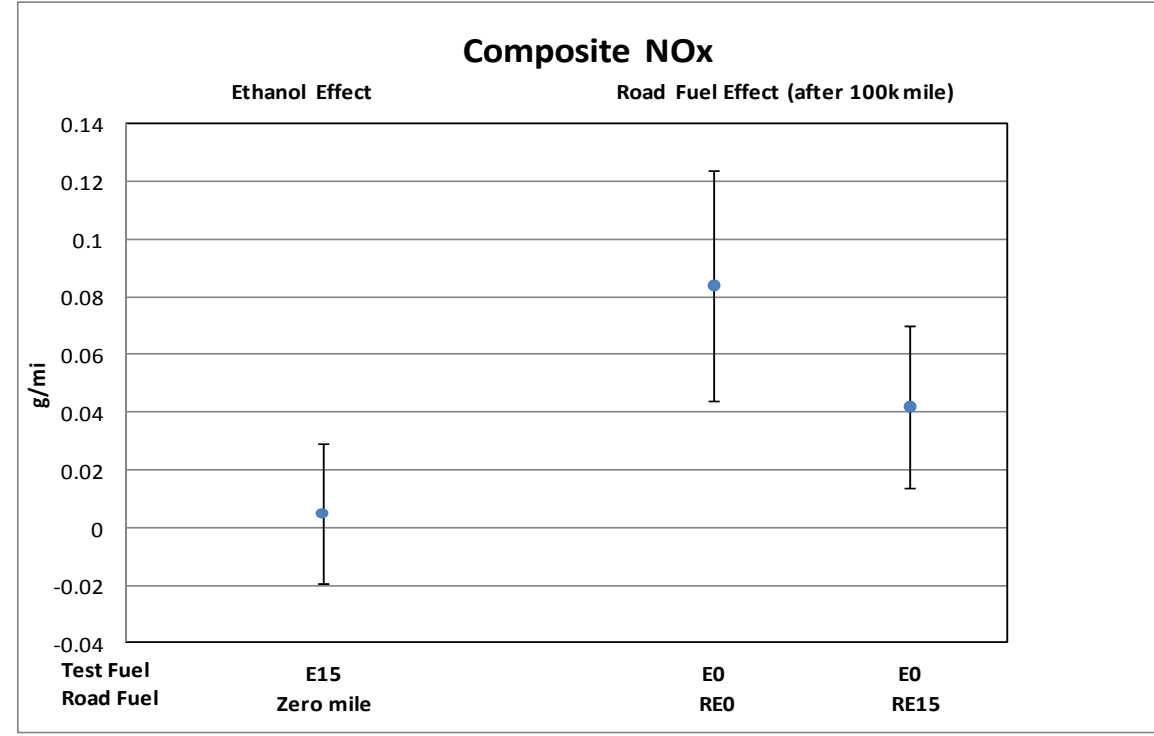

Error bars represent $95 \%$ confidence intervals on the estimated effects 
2009 Ford Focus (Composite Nonmethane Hydrocarbons)

\begin{tabular}{|l|r|r|r|}
\hline \multicolumn{1}{|c|}{ Effect } & Estimate & $\begin{array}{c}95 \% \text { C.I. } \\
\text { Lower }\end{array}$ & $\begin{array}{c}\text { 95\% C.I. } \\
\text { Upper }\end{array}$ \\
\hline Ethanol Effect (E15 vs. E0) $(\Delta \mathrm{g} / \mathrm{mi})$ & -0.009 & -0.018 & 0.001 \\
\hline Road Fuel Aging Effect & & & \\
\hline Aging Effect with RE0 $(\Delta \mathrm{g} / \mathrm{mi}$ per 100k mi) & -0.012 & -0.027 & 0.004 \\
\hline Aging Effect with RE15 $(\Delta \mathrm{g} / \mathrm{mi}$ per 100k mi) & -0.001 & -0.012 & 0.010 \\
\hline
\end{tabular}

\begin{tabular}{|l|r|}
\hline \multicolumn{1}{|c|}{ Hypothesis } & p-value \\
\hline No Effect of Ethanol in the Test Fuel (Gamma = 0) & 0.07 \\
\hline No Aging Effect with RE0 (Beta0 = 0) & 0.13 \\
\hline No Effect of Ethanol in Road Fuel Aging (Beta1s=0) & 0.23 \\
\hline * Indicates effect is statistically significant at the 95\% confidence level.
\end{tabular}

* Indicates estimate is different from zero at the $95 \%$ confidence level.

Initial odometers $4 \mathrm{k}$

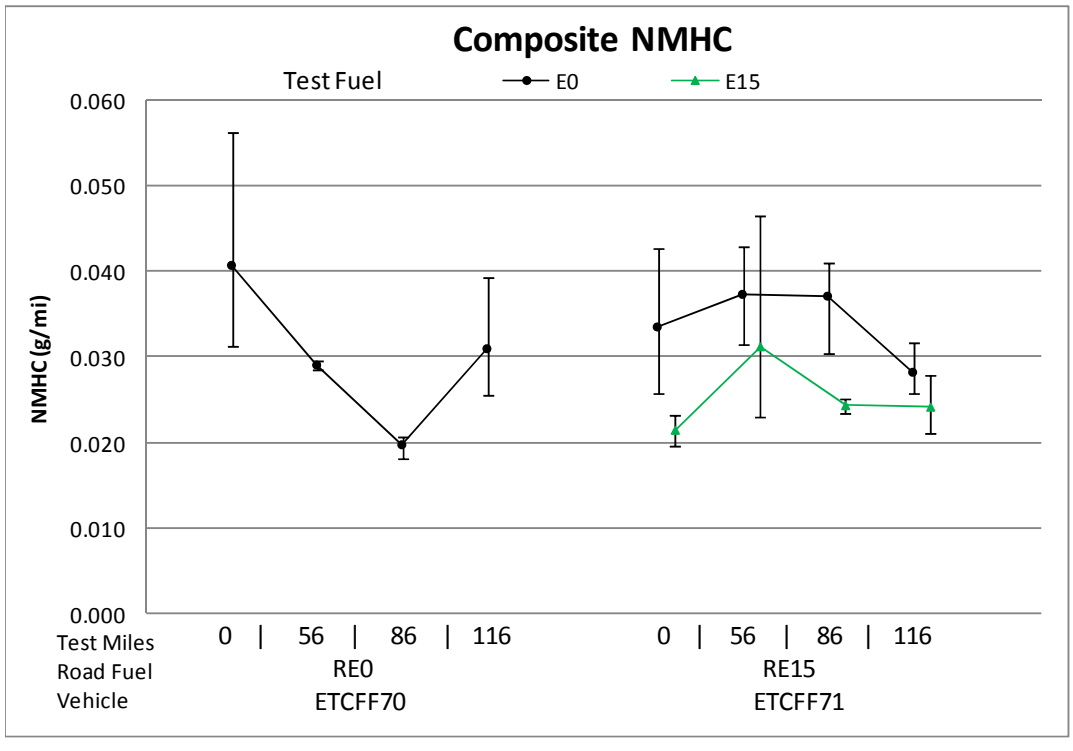

Error bars represent min and max measurements

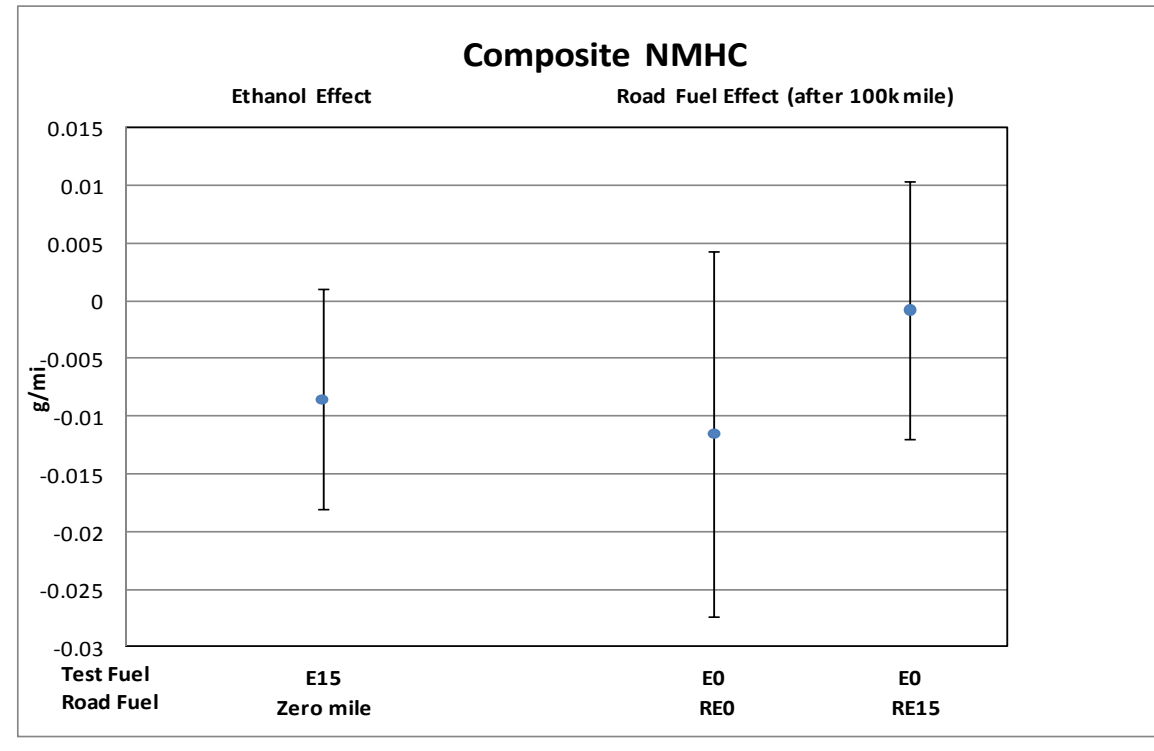

Error bars represent $95 \%$ confidence intervals on the estimated effects 
2009 Ford Focus (Composite Nonmethane Organic Gases)

\begin{tabular}{|l|r|r|r|}
\hline \multicolumn{1}{|c|}{ Effect } & & $\begin{array}{c}95 \% \text { C.I. } \\
\text { Es\% C.I. }\end{array}$ & $\begin{array}{c}\text { 95\% } \\
\text { Upper }\end{array}$ \\
\hline Ethanol Effect (E15 vs. E0) $(\Delta \mathrm{g} / \mathrm{mi})$ & -0.006 & -0.016 & 0.004 \\
\hline Road Fuel Aging Effect & & & \\
\hline Aging Effect with RE0 $(\Delta \mathrm{g} / \mathrm{mi}$ per 100k mi) & -0.012 & -0.029 & 0.004 \\
\hline Aging Effect with RE15 $(\Delta \mathrm{g} / \mathrm{mi}$ per 100k mi) & -0.001 & -0.013 & 0.011 \\
\hline
\end{tabular}

\begin{tabular}{|l|r|}
\hline \multicolumn{1}{|c|}{ Hypothesis } & p-value \\
\hline No Effect of Ethanol in the Test Fuel (Gamma = 0) & 0.21 \\
\hline No Aging Effect with RE0 (Beta0 = 0) & 0.13 \\
\hline No Effect of Ethanol in Road Fuel Aging (Beta1s=0) & 0.23 \\
\hline * Indicates effect is statistically significant at the 95\% confidence level.
\end{tabular}

* Indicates estimate is different from zero at the $95 \%$ confidence level.

Initial odometers 4k

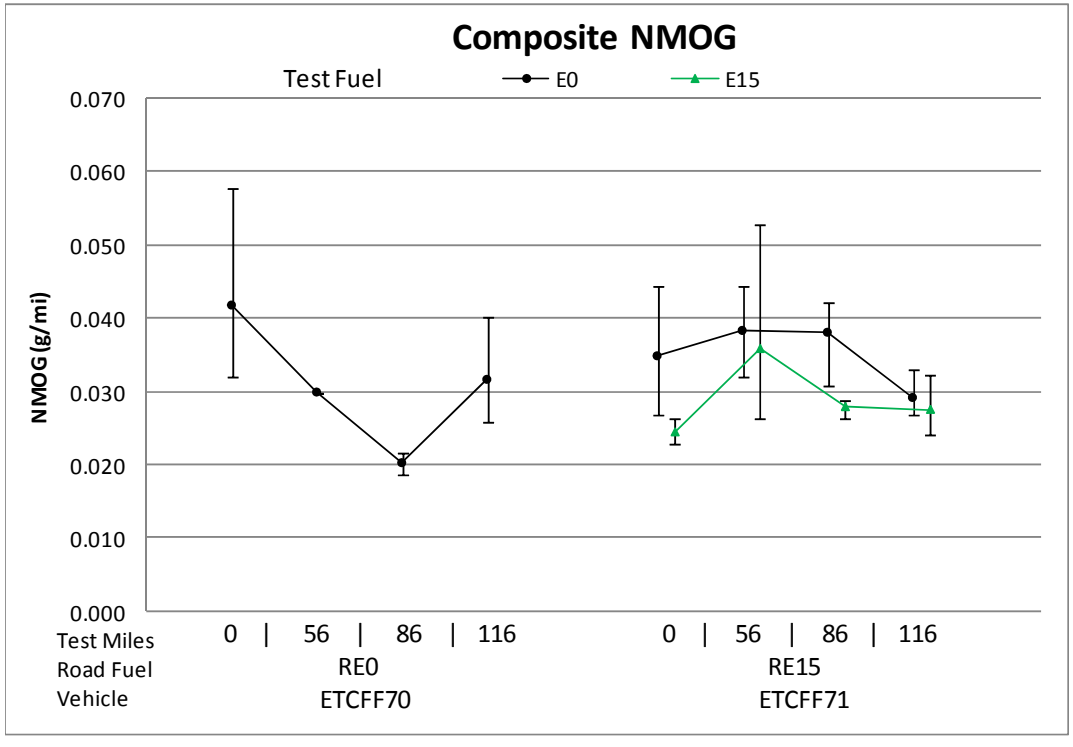

Error bars represent min and max measurements

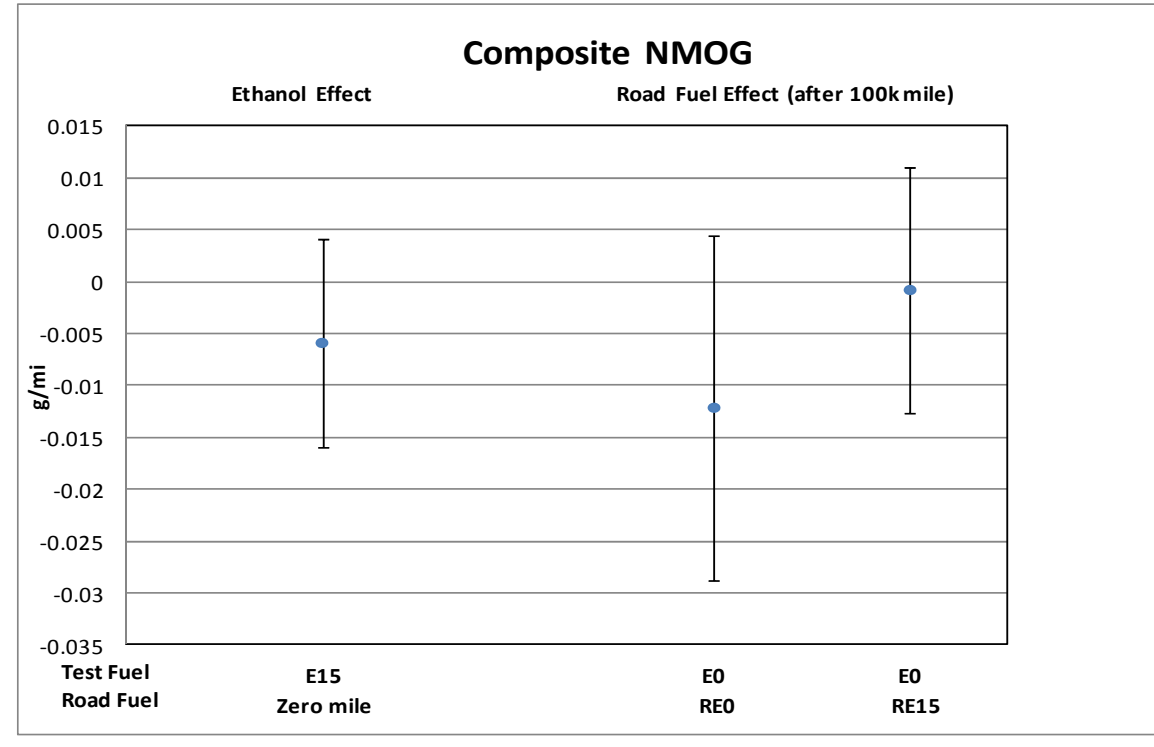

Error bars represent $95 \%$ confidence intervals on the estimated effects 
2009 Ford Focus (Composite Fuel Economy)

\begin{tabular}{|l|r|r|r|}
\hline \multicolumn{1}{|c|}{ Effect } & Estimate & $\begin{array}{c}95 \% \text { C.I. } \\
\text { Lower }\end{array}$ & $\begin{array}{c}\text { 95\% C.I. } \\
\text { Upper }\end{array}$ \\
\hline Ethanol Effect (E15 vs. E0) $(\Delta \mathrm{mi} /$ gal) & $-1.350^{*}$ & -2.188 & -0.513 \\
\hline Road Fuel Aging Effect & & & \\
\hline Aging Effect with RE0 $(\Delta \mathrm{mi} / \mathrm{gal}$ per 100k mi) & 1.127 & -0.255 & 2.508 \\
\hline Aging Effect with RE15 $(\Delta \mathrm{mi} / \mathrm{gal}$ per 100k mi) & 0.263 & -0.718 & 1.245 \\
\hline
\end{tabular}

\begin{tabular}{|l|r|}
\hline \multicolumn{1}{|c|}{ Hypothesis } & p-value \\
\hline No Effect of Ethanol in the Test Fuel (Gamma = 0) & $<0.01^{*}$ \\
\hline No Aging Effect with RE0 (Beta0 = 0) & 0.10 \\
\hline No Effect of Ethanol in Road Fuel Aging (Beta1s=0) & 0.27 \\
\hline
\end{tabular}

* Indicates estimate is different from zero at the $95 \%$ confidence level.

Initial odometers $4 \mathrm{k}$

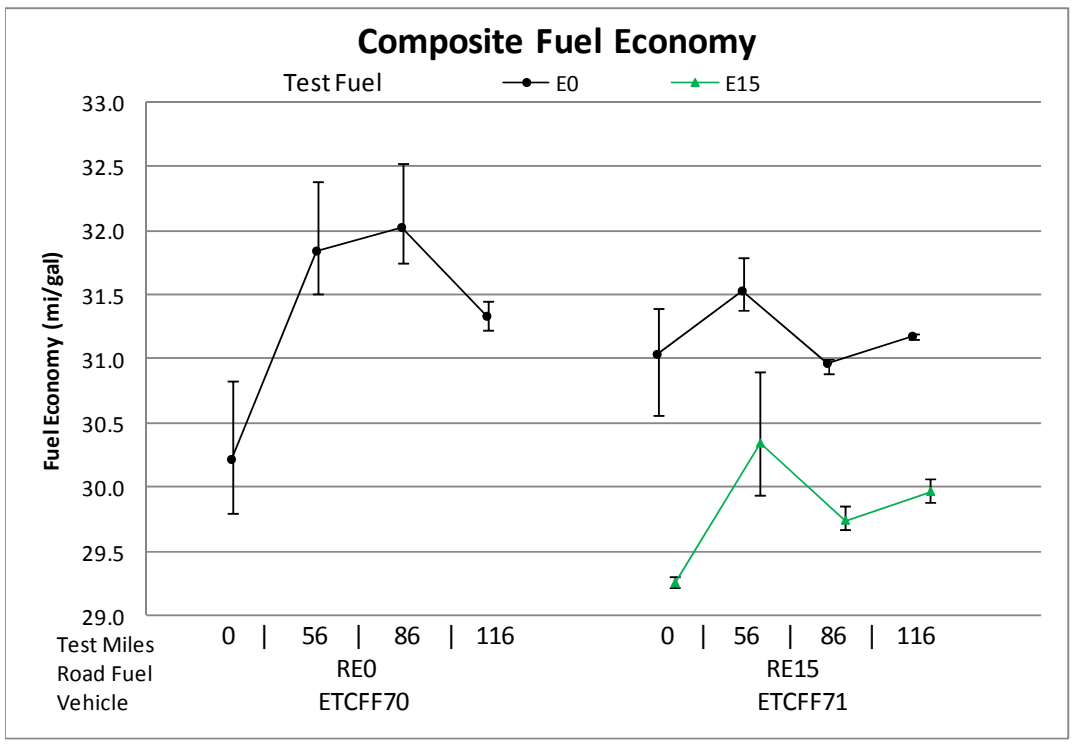

Error bars represent min and max measurements

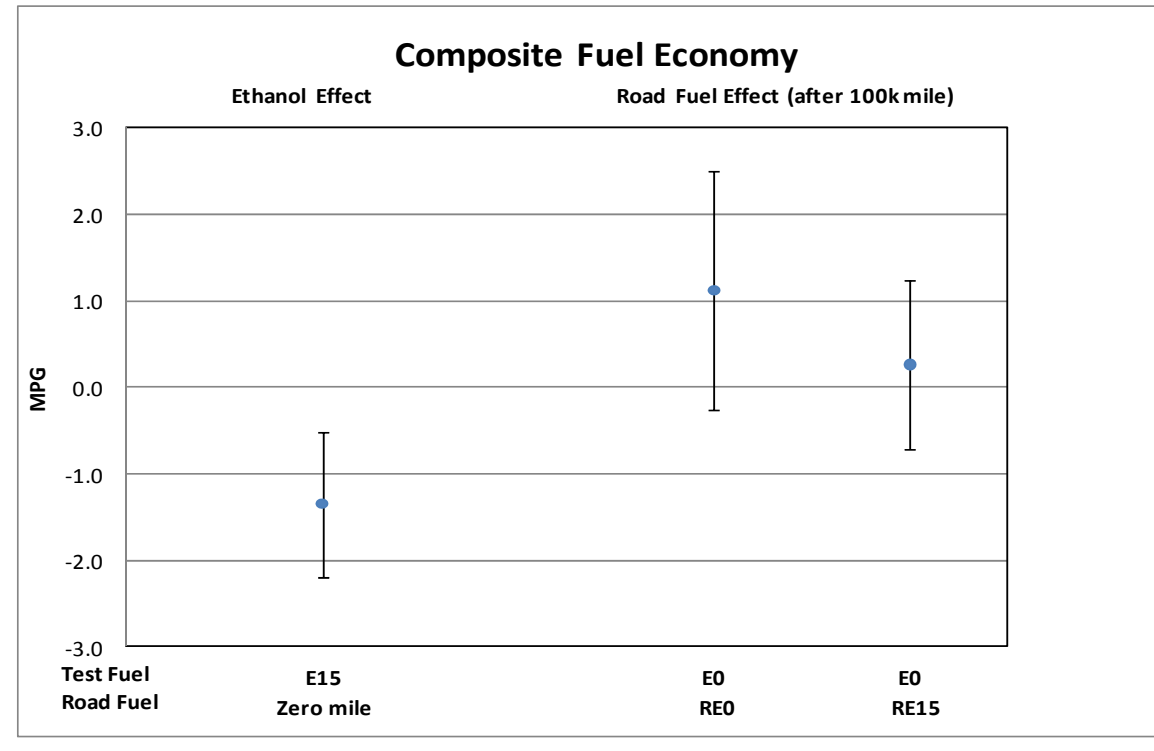

Error bars represent $95 \%$ confidence intervals on the estimated effects 
2009 Ford Focus (Composite $\mathrm{CH} 4$ )

\begin{tabular}{|l|r|r|r|}
\hline \multicolumn{1}{|c|}{ Effect } & Estimate & $\begin{array}{c}95 \% \text { C.I. } \\
\text { Lower }\end{array}$ & $\begin{array}{c}\text { 95\% C.I. } \\
\text { Upper }\end{array}$ \\
\hline Ethanol Effect $($ E15 vs. E0) $(\Delta \mathrm{g} / \mathrm{mi})$ & -0.0006 & -0.0024 & 0.0013 \\
\hline Road Fuel Aging Effect & & & \\
\hline Aging Effect with RE0 $(\Delta \mathrm{g} / \mathrm{mi}$ per 100k mi) & 0.0022 & -0.0009 & 0.0052 \\
\hline Aging Effect with RE15 $(\Delta \mathrm{g} / \mathrm{mi}$ per 100k mi) & $0.0041^{*}$ & 0.0020 & 0.0063 \\
\hline
\end{tabular}

\begin{tabular}{|l|r|}
\hline \multicolumn{1}{|c|}{ Hypothesis } & p-value \\
\hline No Effect of Ethanol in the Test Fuel (Gamma = 0) & 0.48 \\
\hline No Aging Effect with RE0 (Beta0 = 0) & 0.13 \\
\hline No Effect of Ethanol in Road Fuel Aging (Beta1s=0) & 0.25 \\
\hline
\end{tabular}

Initial odometers $4 \mathrm{k}$

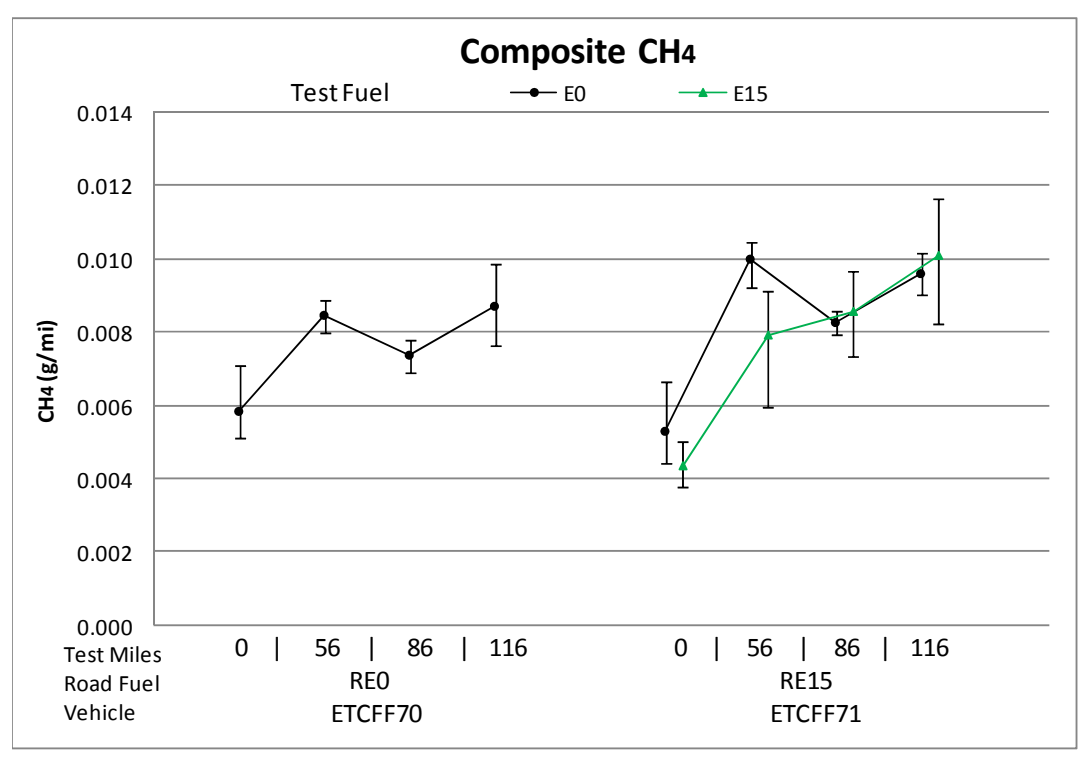

Error bars represent min and max measurements

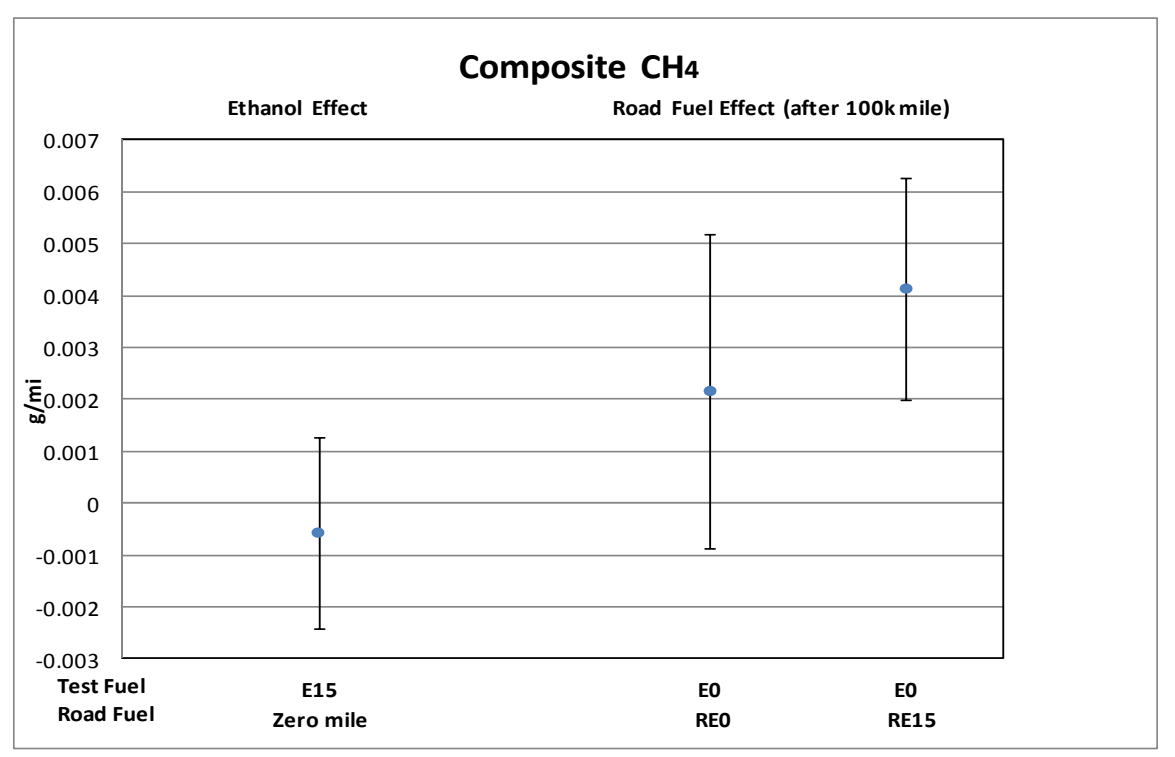

Error bars represent $95 \%$ confidence intervals on the estimated effects 


\section{Honda Odyssey - Composite Emissions Summary}

\begin{tabular}{|c|c|c|c|c|c|c|c|c|c|c|c|c|c|c|}
\hline \multirow{3}{*}{$\begin{array}{c}\text { Emisssion Parameter } \\
\text { (units) }\end{array}$} & \multicolumn{4}{|c|}{ Ethanol Effect } & \multicolumn{2}{|c|}{ Aging Effect with REO } & \multicolumn{4}{|c|}{ RExx Aging Effect on EO Emissions } & \multirow{2}{*}{\multicolumn{3}{|c|}{$\begin{array}{c}\text { RExx Aging Effect on Exx Emissions } \\
\Delta \text { units per } 100 \mathrm{~K} \mathrm{mi} \\
\end{array}$}} & \multirow{3}{*}{\begin{tabular}{|c|}
$\begin{array}{l}\text { Road and Test } \\
\text { Fuel Effects } \\
\text { are Additive }\end{array}$ \\
$\begin{array}{c}\text { Overall p- } \\
\text { value }\end{array}$ \\
\end{tabular}} \\
\hline & \multicolumn{3}{|c|}{$\Delta$ units vs. EO } & \multirow{2}{*}{$\begin{array}{l}\text { Overall } \\
p \text {-value }\end{array}$} & \multirow{2}{*}{$\begin{array}{c}\Delta \text { units per } 100 \mathrm{~K} \mathrm{mi} \\
\text { REO/EO }\end{array}$} & \multirow{2}{*}{$\begin{array}{l}\text { Overall } \\
\text { p-value }\end{array}$} & \multicolumn{3}{|c|}{$\Delta$ units per $100 \mathrm{~K} \mathrm{mi}$} & \multirow{2}{*}{$\begin{array}{l}\text { Overall } \\
p \text {-value }\end{array}$} & & & & \\
\hline & E10 & E15 & E20 & & & & RE10/E0 & RE15/E0 & RE20/E0 & & RE10/E10 & RE15/E15 & RE20/E20 & \\
\hline $\mathrm{CO}(\mathrm{g} / \mathrm{mi})$ & NA & -0.010 & $\mathrm{NA}$ & 0.76 & $0.354 *$ & $<0.01 *$ & NA & -0.001 & $\mathrm{NA}$ & $0.01 *$ & $\mathrm{NA}$ & NA & $\mathrm{NA}$ & 0.85 \\
\hline NOx (g/mi) & $\mathrm{NA}$ & 0.001 & $N A$ & 0.76 & $0.058 *$ & $<0.01 *$ & $\mathrm{NA}$ & $0.029 *$ & $N A$ & $0.01 *$ & $\mathrm{NA}$ & $\mathrm{NA}$ & $\mathrm{NA}$ & 0.82 \\
\hline NMHC (g/mi) & $\mathrm{NA}$ & -0.000 & $\mathrm{NA}$ & 0.97 & $0.023 *$ & $<0.01 *$ & $\mathrm{NA}$ & 0.001 & $N A$ & $<0.01 *$ & $\mathrm{NA}$ & NA & $\mathrm{NA}$ & 0.91 \\
\hline NMOG (g/mi) & NA & 0.003 & NA & 0.17 & $0.024 *$ & $<0.01 *$ & NA & 0.002 & NA & $<0.01 *$ & $\mathrm{NA}$ & NA & $\mathrm{NA}$ & 0.91 \\
\hline Fuel Econ (mi/gal) & NA & $-0.839 *$ & $\mathrm{NA}$ & $0.03 *$ & 0.518 & 0.33 & $\mathrm{NA}$ & 0.617 & $N A$ & 0.88 & $\mathrm{NA}$ & NA & $\mathrm{NA}$ & 0.97 \\
\hline $\mathrm{CH} 4(\mathrm{~g} / \mathrm{mi})$ & NA & 0.0007 & $\mathrm{NA}$ & 0.41 & $0.0085^{*}$ & $<0.01^{*}$ & $\mathrm{NA}$ & $0.0025^{*}$ & $N A$ & $<0.01^{*}$ & $\mathrm{NA}$ & NA & $\mathrm{NA}$ & 0.83 \\
\hline
\end{tabular}

\# Log-normal model was used. Results are presented as changes in emissions at $0 \mathrm{k}$ mile.

\#\# Data did not support the assumption of linear effects with mileage.

* Indicates estimate is different from zero at the $95 \%$ confidence level. 
2009 Honda Odyssey (Composite CO)

\begin{tabular}{|l|r|r|r|}
\hline \multicolumn{1}{|c|}{ Effect } & Estimate & $\begin{array}{c}\text { 95\% C.I. } \\
\text { Lower }\end{array}$ & $\begin{array}{c}\text { 95\% C.I. } \\
\text { Upper }\end{array}$ \\
\hline Ethanol Effect (E15 vs. E0) $(\Delta \mathrm{g} / \mathrm{mi})$ & -0.010 & -0.088 & 0.067 \\
\hline Road Fuel Aging Effect & & & \\
\hline Aging Effect with RE0 $(\Delta \mathrm{g} / \mathrm{mi}$ per 100k mi) & $0.354^{*}$ & 0.225 & 0.482 \\
\hline Aging Effect with RE15 $(\Delta \mathrm{g} / \mathrm{mi}$ per 100k mi) & -0.001 & -0.092 & 0.090 \\
\hline
\end{tabular}

\begin{tabular}{|l|r|}
\hline \multicolumn{1}{|c|}{ Hypothesis } & p-value \\
\hline No Effect of Ethanol in the Test Fuel (Gamma = 0) & 0.76 \\
\hline No Aging Effect with RE0 (Beta0 = 0) & $<0.01^{*}$ \\
\hline No Effect of Ethanol in Road Fuel Aging (Beta1s $=0$ ) & $0.01^{*}$ \\
\hline
\end{tabular}

* Indicates estimate is different from zero at the $95 \%$ confidence level.

Initial odometers $4 \mathrm{k}$

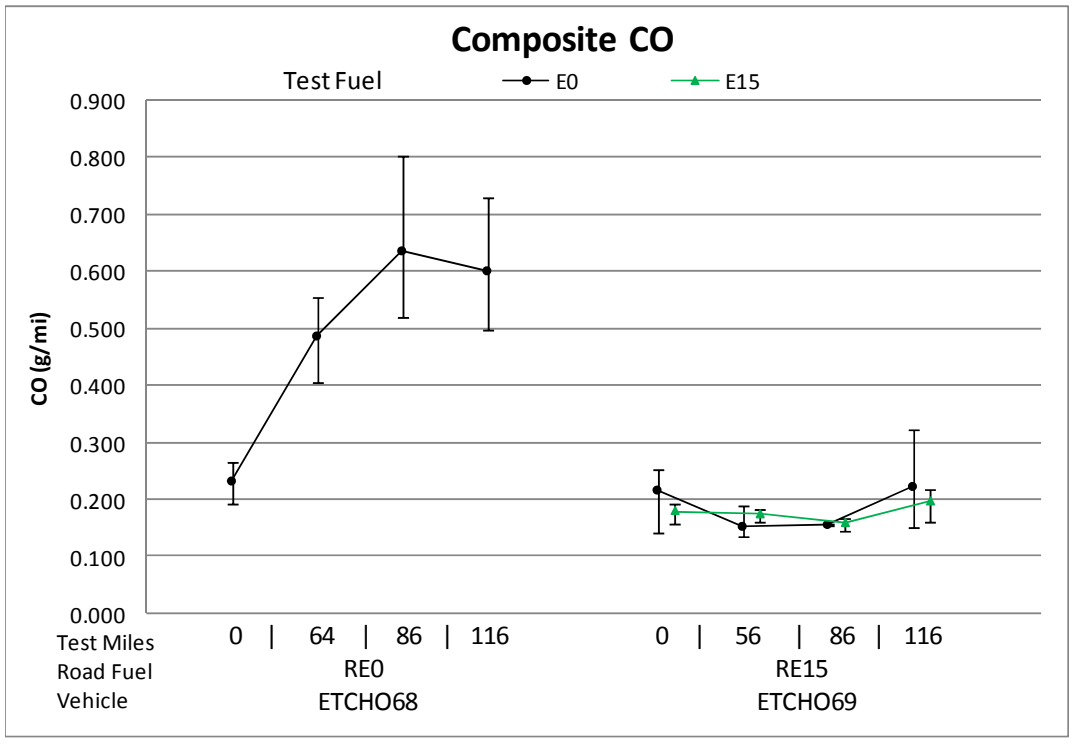

Error bars represent min and max measurements

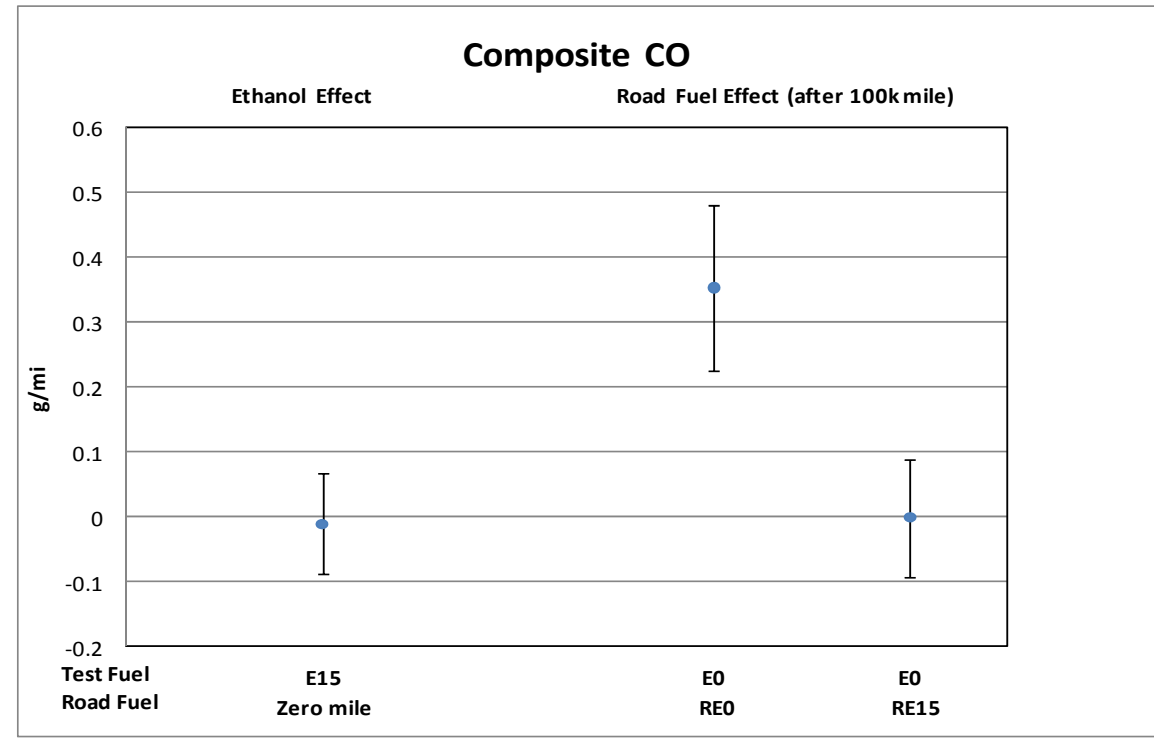

Error bars represent $95 \%$ confidence intervals on the estimated effects 


\section{Honda Odyssey (Composite NOx)}

\begin{tabular}{|l|r|r|r|}
\hline \multicolumn{1}{|c|}{ Effect } & Estimate & $\begin{array}{c}\text { 95\% C.I. } \\
\text { Lower }\end{array}$ & $\begin{array}{c}\text { 95\% C.I. } \\
\text { Upper }\end{array}$ \\
\hline Ethanol Effect (E15 vs. E0) $(\Delta \mathrm{g} / \mathrm{mi})$ & 0.001 & -0.009 & 0.011 \\
\hline Road Fuel Aging Effect & & & \\
\hline Aging Effect with RE0 $(\Delta \mathrm{g} / \mathrm{mi}$ per 100k mi) & $0.058^{*}$ & 0.041 & 0.075 \\
\hline Aging Effect with RE15 $(\Delta \mathrm{g} / \mathrm{mi}$ per 100k mi) & $0.029^{*}$ & 0.017 & 0.041 \\
\hline
\end{tabular}

\begin{tabular}{|l|r|}
\hline \multicolumn{1}{|c|}{ Hypothesis } & p-value \\
\hline No Effect of Ethanol in the Test Fuel (Gamma = 0) & 0.76 \\
\hline No Aging Effect with RE0 (Beta0 $=0$ ) & $<0.01^{*}$ \\
\hline No Effect of Ethanol in Road Fuel Aging (Beta1s $=0$ ) & $0.01^{*}$ \\
\hline
\end{tabular}

* Indicates estimate is different from zero at the $95 \%$ confidence level.

Initial odometers $4 \mathrm{k}$

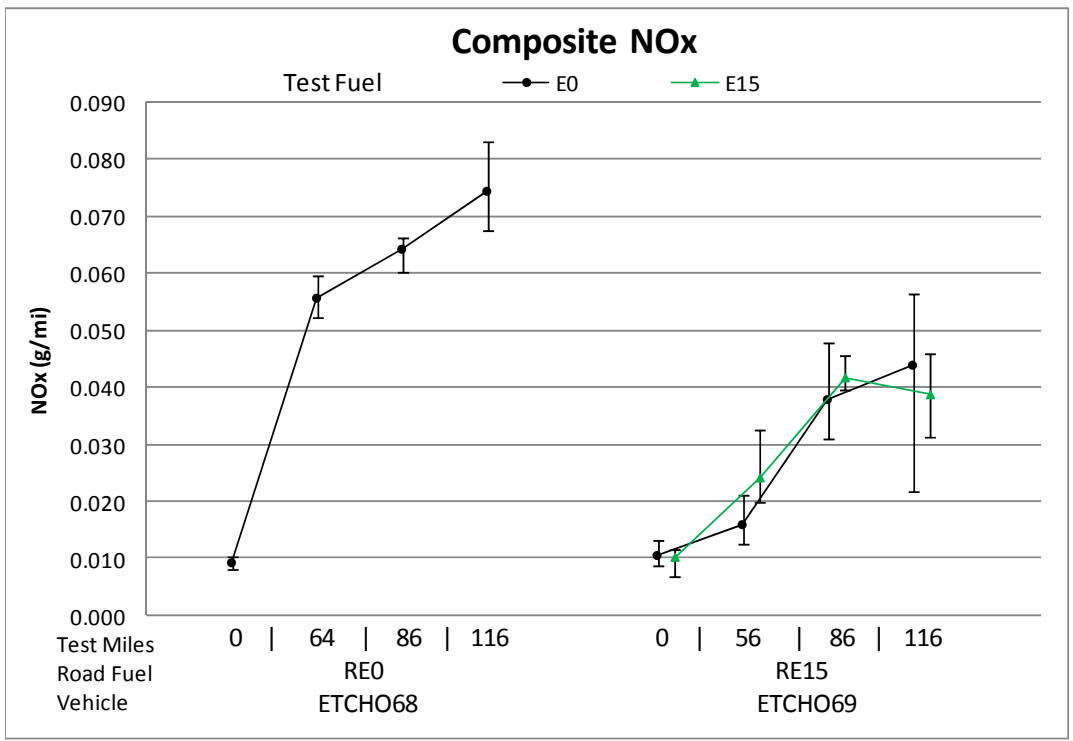

Error bars represent min and max measurements

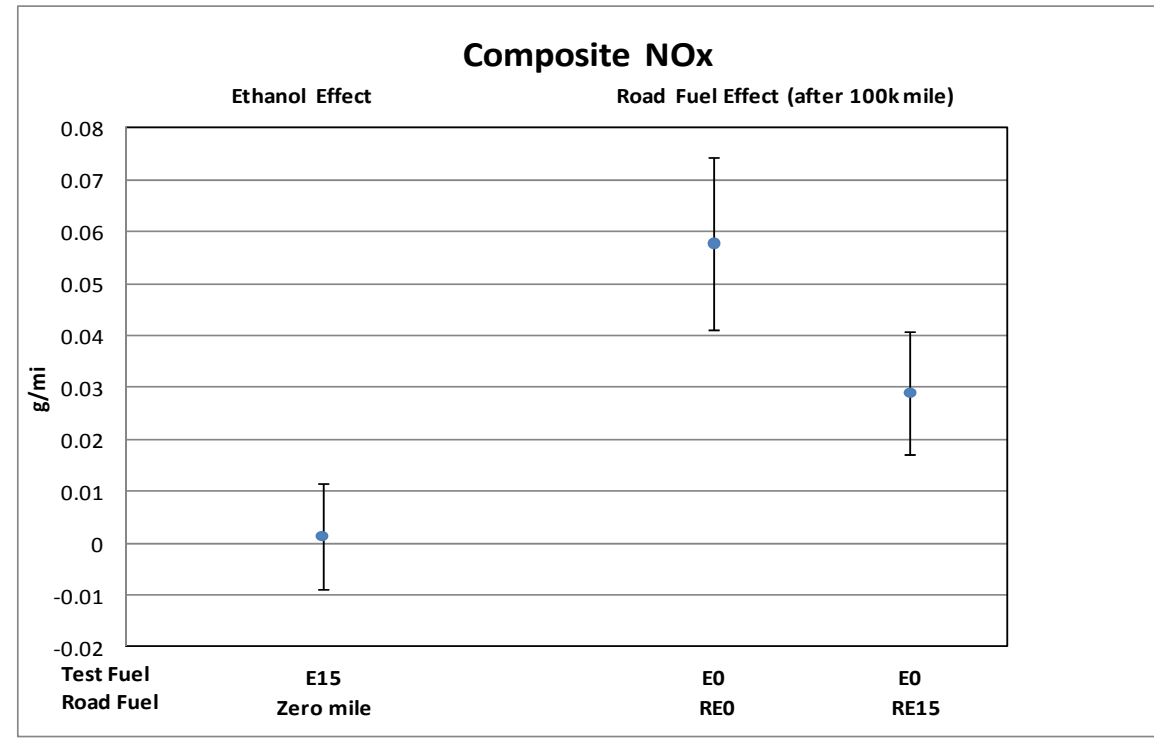

Error bars represent $95 \%$ confidence intervals on the estimated effects 
2009 Honda Odyssey (Composite Nonmethane Hydrocarbons)

\begin{tabular}{|l|r|r|r|}
\hline \multicolumn{1}{|c|}{ Effect } & Estimate & $\begin{array}{c}\text { 95\% C.I. } \\
\text { Lower }\end{array}$ & $\begin{array}{c}\text { 95\% C.I. } \\
\text { Upper }\end{array}$ \\
\hline Ethanol Effect (E15 vs. E0) $(\Delta \mathrm{g} / \mathrm{mi})$ & -0.000 & -0.004 & 0.004 \\
\hline Road Fuel Aging Effect & & & \\
\hline Aging Effect with RE0 $(\Delta \mathrm{g} / \mathrm{mi}$ per 100k mi) & $0.023^{*}$ & 0.017 & 0.030 \\
\hline Aging Effect with RE15 $(\Delta \mathrm{g} / \mathrm{mi}$ per 100k mi) & 0.001 & -0.003 & 0.006 \\
\hline
\end{tabular}

\begin{tabular}{|l|r|}
\hline \multicolumn{1}{|c|}{ Hypothesis } & p-value \\
\hline No Effect of Ethanol in the Test Fuel (Gamma = 0) & 0.97 \\
\hline No Aging Effect with RE0 (Beta0 = 0) & $<0.01^{*}$ \\
\hline No Effect of Ethanol in Road Fuel Aging (Beta1s=0) & $<0.01^{*}$ \\
\hline * Indicates effect is statistically significant at the 95\% confidence level.
\end{tabular}

* Indicates estimate is different from zero at the $95 \%$ confidence level.

Initial odometers $4 \mathrm{k}$

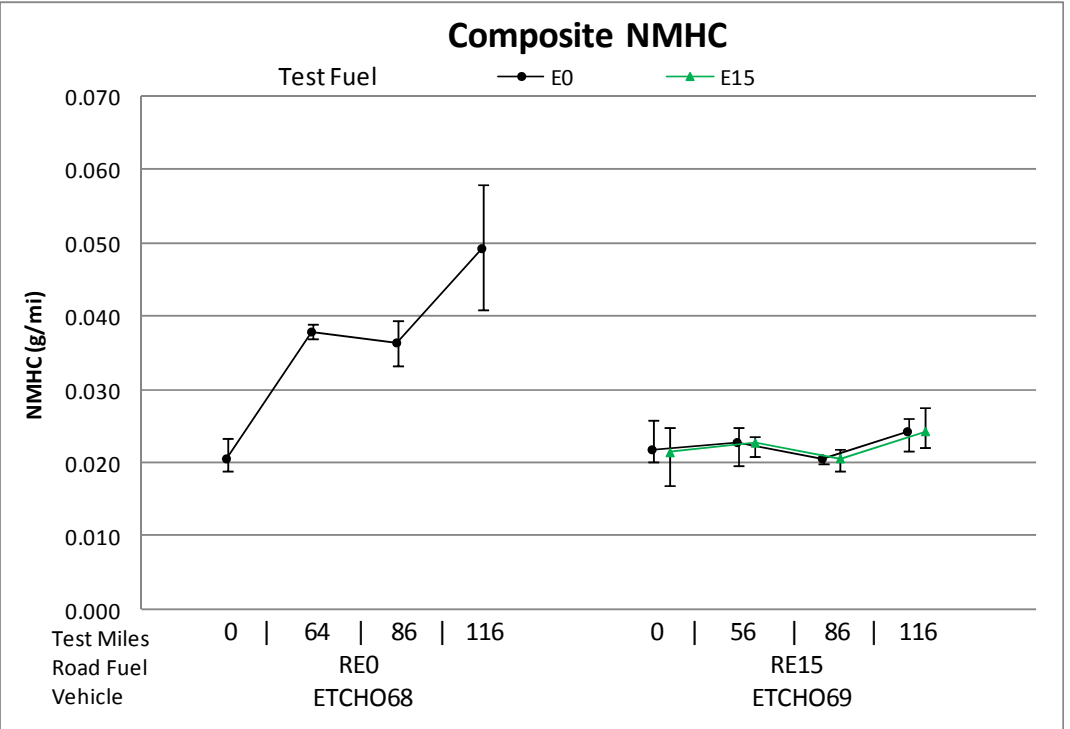

Error bars represent min and max measurements

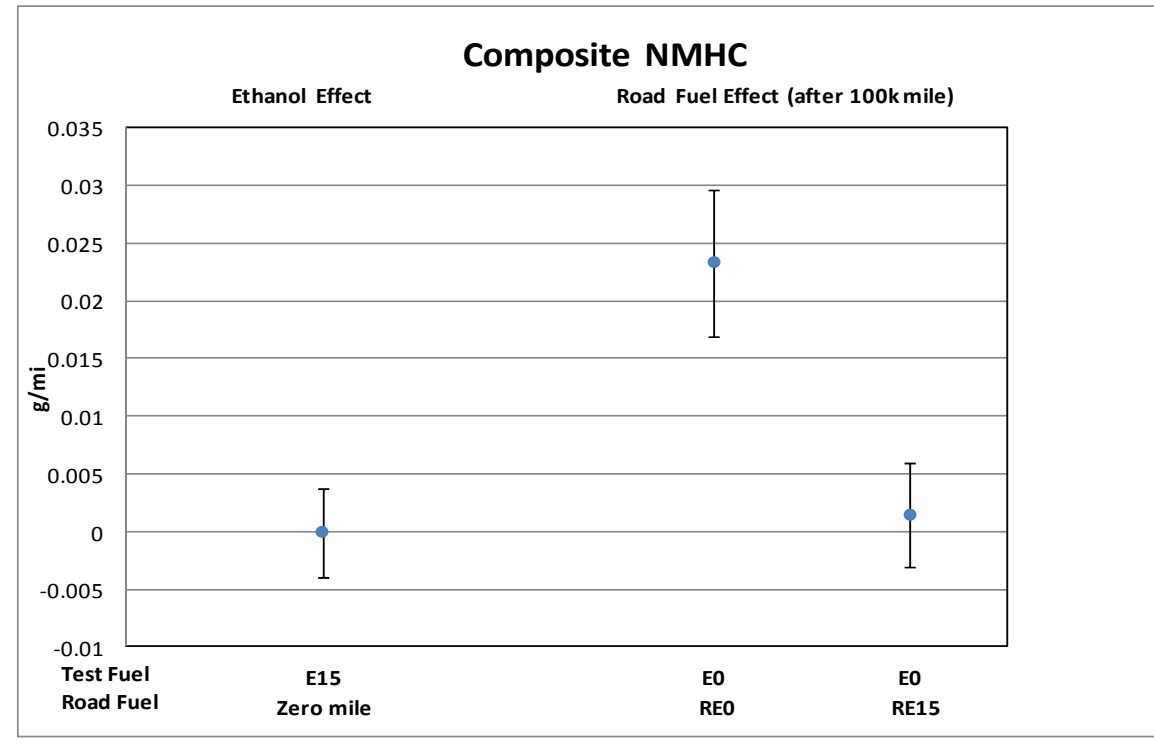

Error bars represent $95 \%$ confidence intervals on the estimated effects 
2009 Honda Odyssey (Composite Nonmethane Organic Gases)

\begin{tabular}{|l|r|r|r|}
\hline \multicolumn{1}{|c|}{ Effect } & Estimate & $\begin{array}{c}95 \% \text { C.I. } \\
\text { Lower }\end{array}$ & $\begin{array}{c}\text { 95\% C.I. } \\
\text { Upper }\end{array}$ \\
\hline Ethanol Effect $($ E15 vs. E0) $(\Delta \mathrm{g} / \mathrm{mi})$ & 0.003 & -0.001 & 0.007 \\
\hline Road Fuel Aging Effect & & & \\
\hline Aging Effect with RE0 $(\Delta \mathrm{g} / \mathrm{mi}$ per 100k mi) & $0.024^{*}$ & 0.018 & 0.031 \\
\hline Aging Effect with RE15 $(\Delta \mathrm{g} / \mathrm{mi}$ per 100k mi) & 0.002 & -0.003 & 0.006 \\
\hline
\end{tabular}

\begin{tabular}{|l|r|}
\hline \multicolumn{1}{|c|}{ Hypothesis } & p-value \\
\hline No Effect of Ethanol in the Test Fuel (Gamma = 0) & 0.17 \\
\hline No Aging Effect with RE0 (Beta0 = 0) & $<0.01^{*}$ \\
\hline No Effect of Ethanol in Road Fuel Aging (Beta1s $=0$ ) & $<0.01^{*}$ \\
\hline
\end{tabular}

${ }^{*}$ Indicates estimate is different from zero at the $95 \%$ confidence level.

Initial odometers $4 \mathrm{k}$

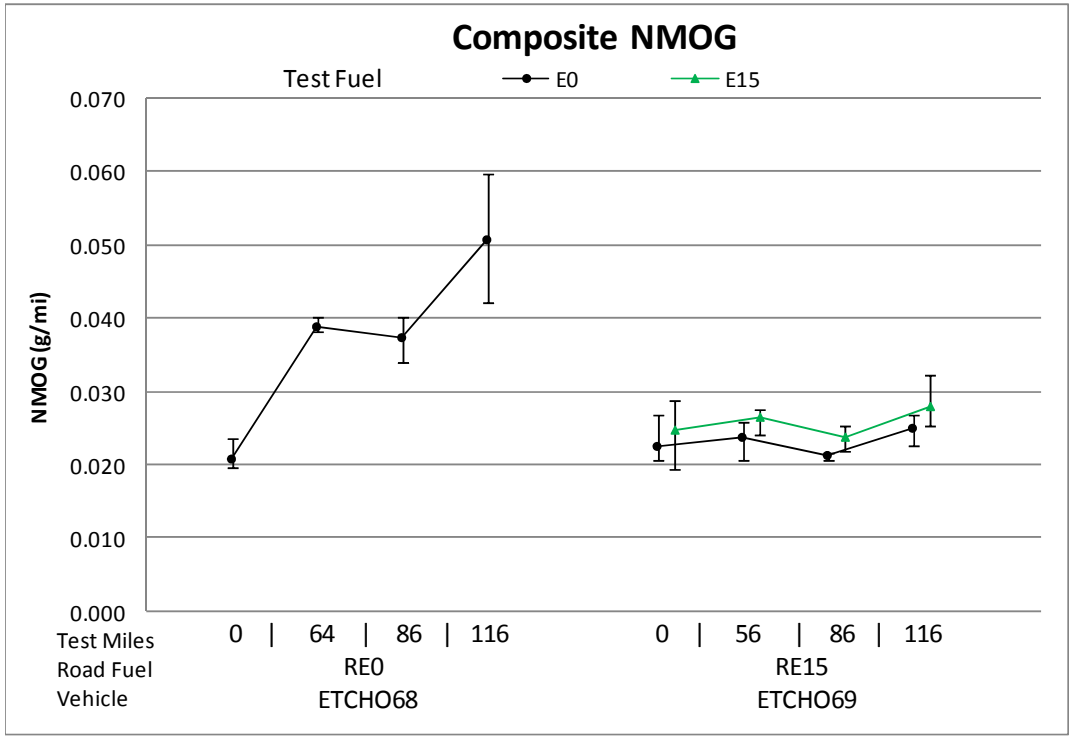

Error bars represent min and max measurements

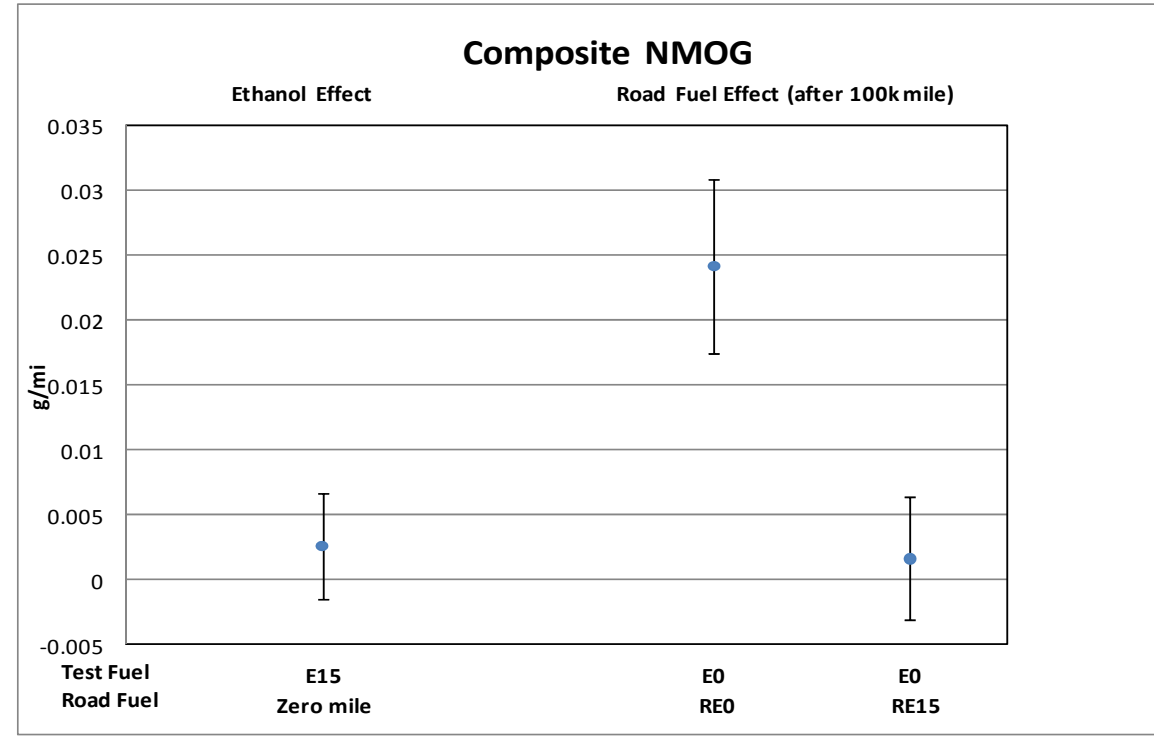

Error bars represent $95 \%$ confidence intervals on the estimated effects 
2009 Honda Odyssey (Composite Fuel Economy)

\begin{tabular}{|l|r|r|r|}
\hline \multicolumn{1}{|c|}{ Effect } & Estimate & $\begin{array}{c}\text { 95\% C.I. } \\
\text { Lower }\end{array}$ & $\begin{array}{c}\text { 95\% C.I. } \\
\text { Upper }\end{array}$ \\
\hline Ethanol Effect (E15 vs. E0) $(\Delta \mathrm{mi} / \mathrm{gal})$ & $-0.839^{*}$ & -1.552 & -0.125 \\
\hline Road Fuel Aging Effect & & & \\
\hline Aging Effect with RE0 $(\Delta \mathrm{mi} / \mathrm{gal}$ per 100k mi) & 0.518 & -0.665 & 1.701 \\
\hline Aging Effect with RE15 $(\Delta \mathrm{mi} / \mathrm{gal}$ per 100k mi) & 0.617 & -0.219 & 1.453 \\
\hline
\end{tabular}

\begin{tabular}{|l|r|}
\hline \multicolumn{1}{|c|}{ Hypothesis } & p-value \\
\hline No Effect of Ethanol in the Test Fuel (Gamma = 0) & $0.03^{*}$ \\
\hline No Aging Effect with RE0 (Beta0 = $)$ & 0.33 \\
\hline No Effect of Ethanol in Road Fuel Aging (Beta1s=0) & 0.88 \\
\hline${ }^{*}$ Indicates effect is statistically significant at the 95\% confidence level.
\end{tabular}

${ }^{*}$ Indicates estimate is different from zero at the $95 \%$ confidence level.

Initial odometers $4 \mathrm{k}$

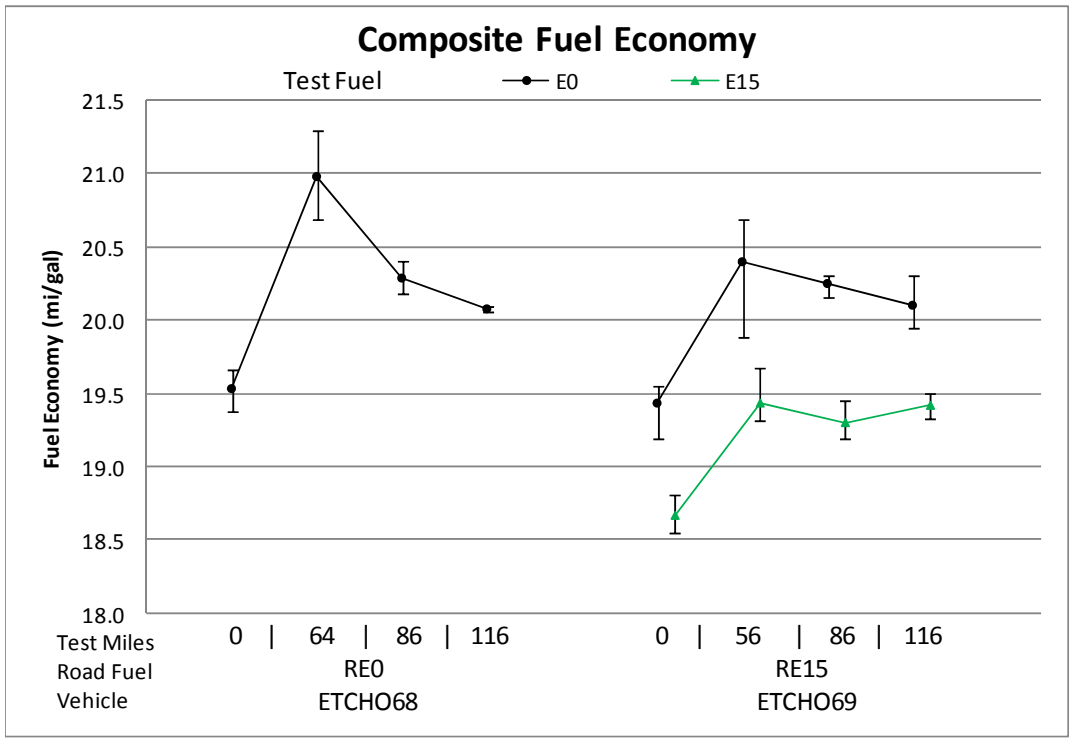

Error bars represent min and max measurements

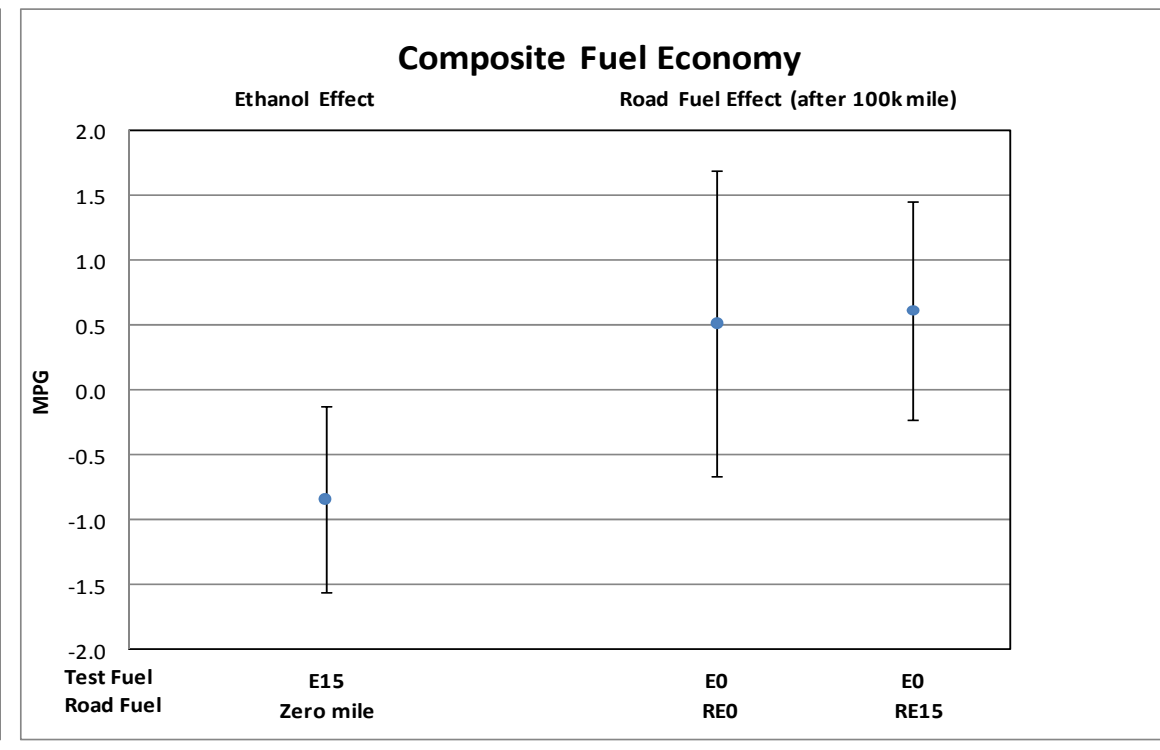

Error bars represent $95 \%$ confidence intervals on the estimated effects 


\section{Honda Odyssey (Composite $\mathrm{CH} 4$ )}

\begin{tabular}{|l|r|r|r|}
\hline \multicolumn{1}{|c|}{ Effect } & Estimate & $\begin{array}{c}95 \% \text { C.I. } \\
\text { Lower }\end{array}$ & $\begin{array}{c}95 \% \text { C.I. } \\
\text { Upper }\end{array}$ \\
\hline Ethanol Effect (E15 vs. E0) $(\Delta \mathrm{g} / \mathrm{mi})$ & 0.0007 & -0.0011 & 0.0025 \\
\hline Road Fuel Aging Effect & & & \\
\hline Aging Effect with RE0 $(\Delta \mathrm{g} / \mathrm{mi}$ per 100k mi) & $0.0085^{*}$ & 0.0055 & 0.0115 \\
\hline Aging Effect with RE15 $(\Delta \mathrm{g} / \mathrm{mi}$ per 100k mi) & $0.0025^{*}$ & 0.0004 & 0.0046 \\
\hline
\end{tabular}

\begin{tabular}{|l|r|}
\hline \multicolumn{1}{|c|}{ Hypothesis } & p-value \\
\hline No Effect of Ethanol in the Test Fuel (Gamma = 0) & 0.41 \\
\hline No Aging Effect with RE0 (Beta0 = 0) & $<0.01^{*}$ \\
\hline No Effect of Ethanol in Road Fuel Aging (Beta1s=0) & $<0.01^{*}$ \\
\hline
\end{tabular}

${ }^{*}$ Indicates estimate is different from zero at the $95 \%$ confidence leve

Initial odometers $4 \mathrm{k}$

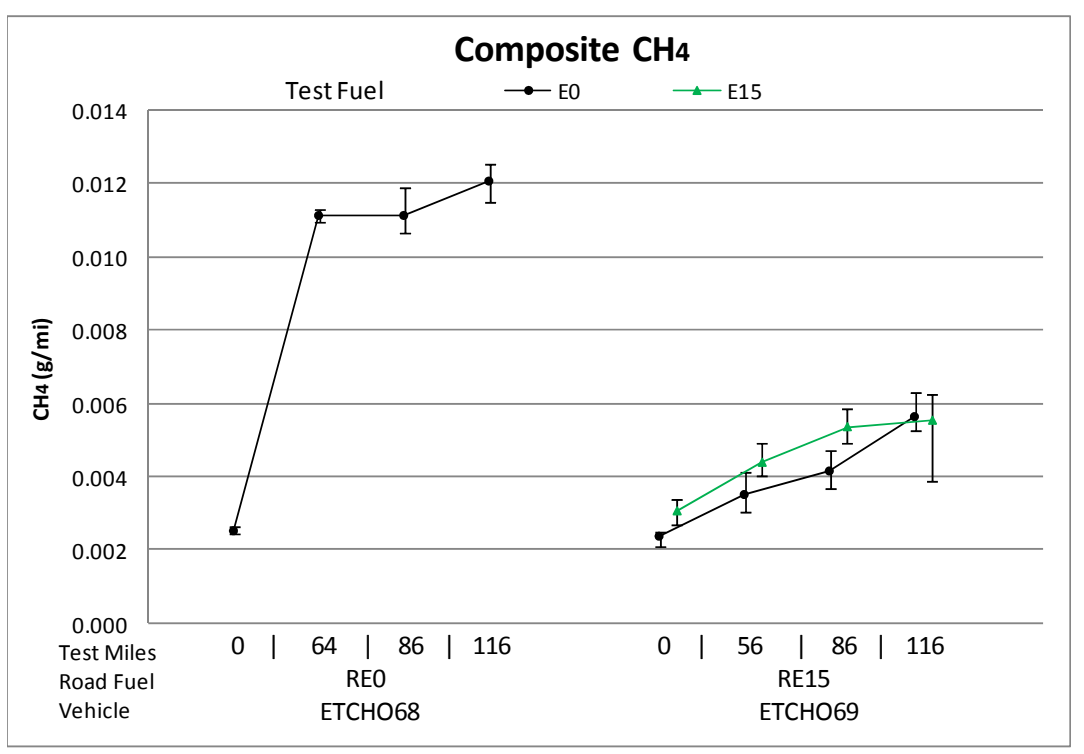

Error bars represent min and max measurements

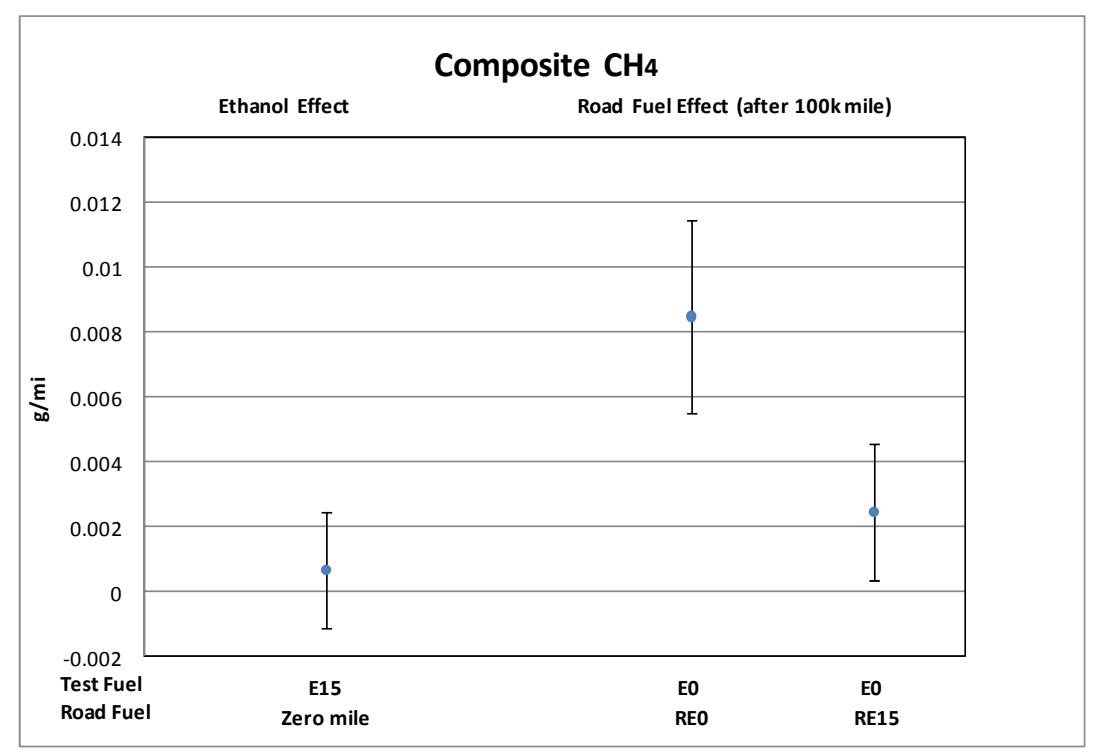

Error bars represent $95 \%$ confidence intervals on the estimated effects 


\section{Chevrolet Silverado - Composite Emissions Summary}

\begin{tabular}{|c|c|c|c|c|c|c|c|c|c|c|c|c|c|c|}
\hline \multirow{2}{*}{$\begin{array}{c}\text { Emisssion Parameter } \\
\text { (units) }\end{array}$} & \multicolumn{4}{|c|}{ Ethanol Effect } & \multicolumn{2}{|c|}{ Aging Effect with REO } & \multicolumn{4}{|c|}{ RExx Aging Effect on E0 Emissions } & \multirow{2}{*}{\multicolumn{3}{|c|}{$\begin{array}{c}\text { RExx Aging Effect on Exx Emissions } \\
\Delta \text { units per } 100 \mathrm{~K} \mathrm{mi}\end{array}$}} & \multirow{3}{*}{\begin{tabular}{|c|}
$\begin{array}{l}\text { Road and Test } \\
\text { Fuel Effects } \\
\text { are Additive }\end{array}$ \\
$\begin{array}{c}\text { Overall p- } \\
\text { value }\end{array}$
\end{tabular}} \\
\hline & \multicolumn{3}{|c|}{$\Delta$ units vs. EO } & \multirow{2}{*}{$\begin{array}{l}\text { Overall } \\
p \text {-value }\end{array}$} & \multirow{2}{*}{$\begin{array}{c}\Delta \text { units per } 100 \mathrm{~K} \mathrm{mi} \\
\mathrm{REO} / \mathrm{EO}\end{array}$} & \multirow{2}{*}{$\begin{array}{l}\text { Overall } \\
p \text {-value }\end{array}$} & \multicolumn{3}{|c|}{$\Delta$ units per $100 \mathrm{~K} \mathrm{mi}$} & \multirow{2}{*}{$\begin{array}{l}\text { Overall } \\
p \text {-value }\end{array}$} & & & & \\
\hline Fuels & E10 & E15 & E20 & & & & RE10/E0 & RE15/E0 & RE20/E0 & & RE10/E10 & RE15/E15 & RE20/E20 & \\
\hline $\mathrm{CO}(\mathrm{g} / \mathrm{mi})$ & $\mathrm{NA}$ & $-0.457 *$ & -0.230 & $0.03 *$ & 0.703 & 0.21 & NA & -0.089 & 0.789 & 0.23 & NA & $\mathrm{NA}$ & $\mathrm{NA}$ & 0.74 \\
\hline NOx $(\mathrm{g} / \mathrm{mi})$ & $\mathrm{NA}$ & -0.002 & 0.025 & 0.76 & $0.479 *$ & $<0.01 *$ & $\mathrm{NA}$ & $0.204 *$ & $0.345^{*}$ & 0.21 & $\mathrm{NA}$ & $\mathrm{NA}$ & $\mathrm{NA}$ & 0.90 \\
\hline NMHC (g/mi) & $\mathrm{NA}$ & -0.026 & -0.022 & 0.12 & 0.069 & 0.21 & NA & -0.049 & 0.037 & 0.15 & NA & $\mathrm{NA}$ & $\mathrm{NA}$ & 0.82 \\
\hline NMOG (g/mi) & $\mathrm{NA}$ & -0.0085 & -0.0000 & 0.84 & 0.0715 & 0.21 & $\mathrm{NA}$ & -0.0518 & 0.0426 & 0.14 & $\mathrm{NA}$ & $\mathrm{NA}$ & $\mathrm{NA}$ & 0.81 \\
\hline Fuel Econ (mi/gal) & $\mathrm{NA}$ & $-0.727 *$ & $-0.829 *$ & $<0.01 *$ & 0.594 & 0.35 & NA & $1.201 *$ & 0.230 & 0.29 & NA & $\mathrm{NA}$ & $\mathrm{NA}$ & 0.74 \\
\hline Ethanol $(\mathrm{mg} / \mathrm{mi})^{\# \#}$ & $\mathrm{NA}$ & $10.453 *$ & $14.629 *$ & $<0.01 *$ & -0.000 & 1.00 & $\mathrm{NA}$ & 2.003 & 4.930 & 0.76 & NA & $\mathrm{NA}$ & $\mathrm{NA}$ & $\mathrm{NA}$ \\
\hline Acetaldehyde $(\mathrm{mg} / \mathrm{mi})^{\#}$ & $\mathrm{NA}$ & $2.967^{*}$ & $3.356 *$ & $<0.01^{*}$ & 1.489 & 0.27 & NA & -0.013 & -0.058 & 0.55 & NA & $\mathrm{NA}$ & $\mathrm{NA}$ & 0.97 \\
\hline Formaldehyde $(\mathrm{mg} / \mathrm{mi})^{\text {\#\# }}$ & $\mathrm{NA}$ & 0.324 & 0.566 & 0.18 & $4.363 *$ & $<0.01^{*}$ & NA & 0.414 & -0.391 & $0.02 *$ & NA & $\mathrm{NA}$ & $\mathrm{NA}$ & $\mathrm{NA}$ \\
\hline $\mathrm{CH}_{4}(\mathrm{~g} / \mathrm{mi})$ & $\mathrm{NA}$ & 0.0016 & $0.0044 *$ & $<0.01 *$ & $0.0130 *$ & $<0.01 *$ & NA & 0.0049 & 0.0119* & 0.15 & NA & $\mathrm{NA}$ & $\mathrm{NA}$ & 0.78 \\
\hline
\end{tabular}

\# Log-normal model was used. Results are presented as changes in emissions at 0k mile.

\#\# Data did not support the assumption of linear effects with mileage.

*Indicates estimate is different from zero at the $95 \%$ confidence level. 


\section{Chevrolet Silverado (Composite CO)}

\begin{tabular}{|l|r|r|r|}
\hline \multicolumn{1}{|c|}{ Effect } & Estimate & $\begin{array}{c}\text { 95\% C.I. } \\
\text { Lower }\end{array}$ & $\begin{array}{r}\text { 95\% C.I. } \\
\text { Upper }\end{array}$ \\
\hline Ethanol Effect (E15 vs. E0) $(\Delta \mathrm{g} / \mathrm{mi})$ & $-0.457^{*}$ & -0.798 & -0.115 \\
\hline Ethanol Effect $($ E20 vs. E0) $(\Delta \mathrm{g} / \mathrm{mi})$ & -0.230 & -0.570 & 0.111 \\
\hline Road Fuel Aging Effect & & & \\
\hline Aging Effect with RE0 $(\Delta \mathrm{g} / \mathrm{mi}$ per 100k mi) & 0.703 & -0.489 & 1.895 \\
\hline Aging Effect with RE15 $(\Delta \mathrm{g} / \mathrm{mi}$ per 100k mi) & -0.089 & -0.917 & 0.739 \\
\hline Aging Effect with RE20 $(\Delta \mathrm{g} / \mathrm{mi}$ per 100k mi) & 0.789 & -0.046 & 1.624 \\
\hline
\end{tabular}

\begin{tabular}{|l|r|}
\hline \multicolumn{1}{|c|}{ Hypothesis } & p-value \\
\hline No Effect of Ethanol in the Test Fuel (Gamma $=0)$ & $0.03^{*}$ \\
\hline No Aging Effect with RE0 (Beta0 = 0) & 0.21 \\
\hline No Effect of Ethanol in Road Fuel Aging (Beta1s=0) & 0.23 \\
\hline * Indicates effect is statistically significant at the 95\% confidence level.
\end{tabular}

* Indicates estimate is different from zero at the $95 \%$ confidence level.

Initial odometers $111 \mathrm{k}-115 \mathrm{k}$

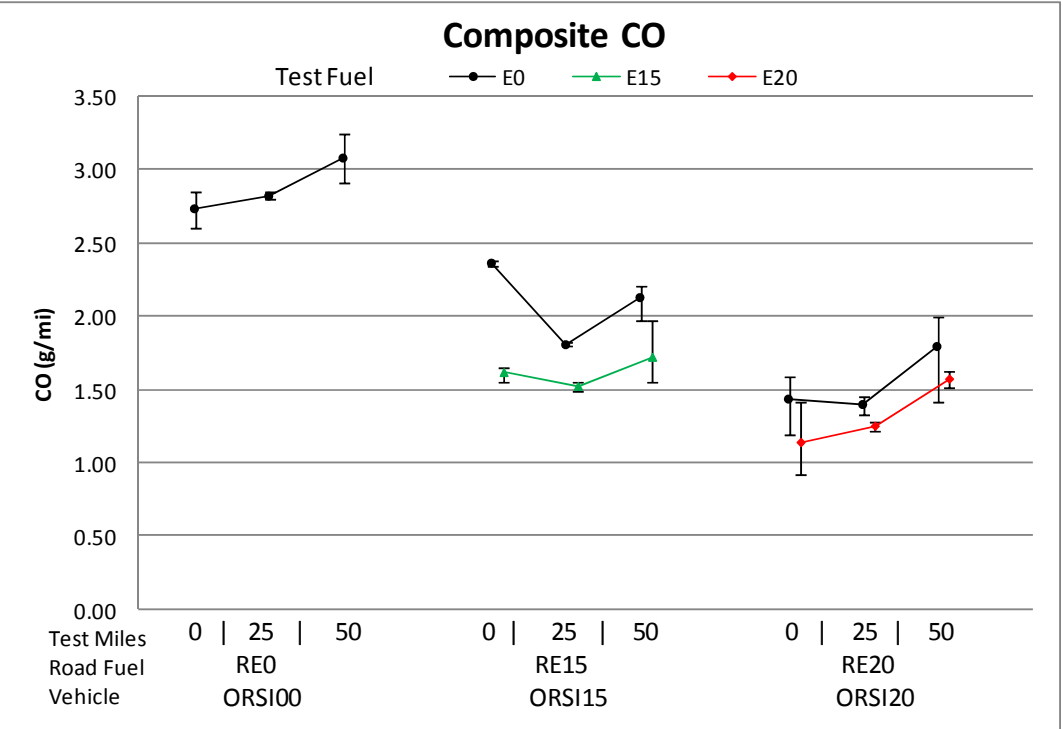

Error bars represent min and max measurements

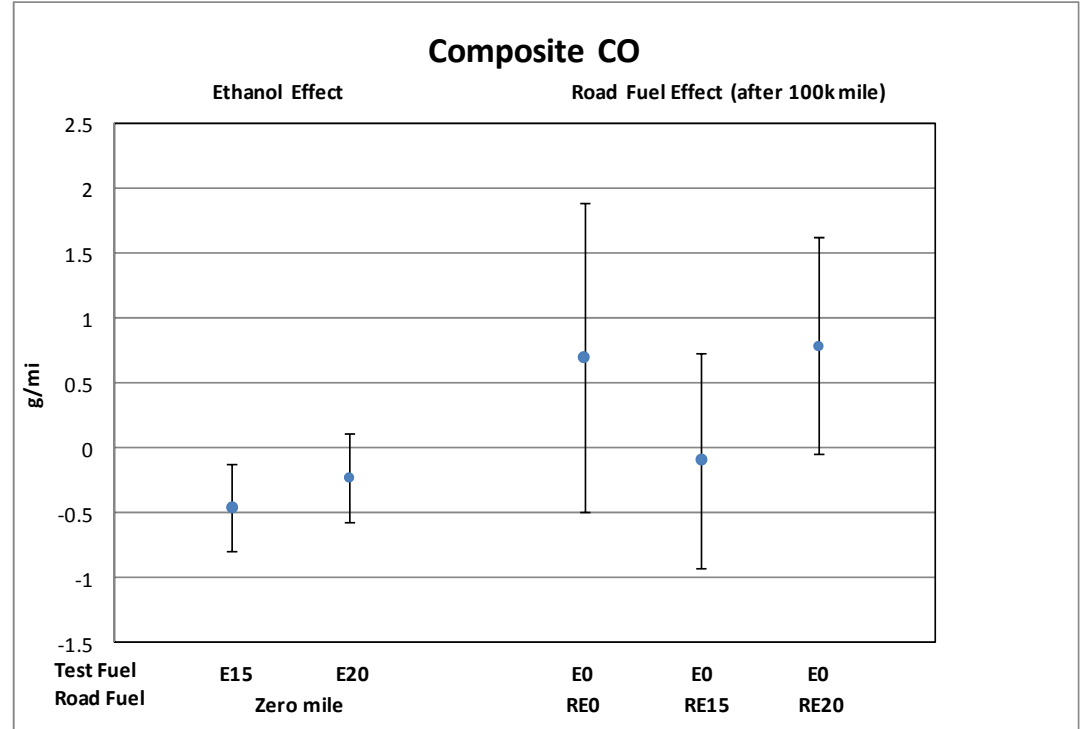

Error bars represent $95 \%$ confidence intervals on the estimated effects 


\section{Chevrolet Silverado (Composite NOx)}

\begin{tabular}{|l|r|r|r|}
\hline \multicolumn{1}{|c|}{ Effect } & Estimate & $\begin{array}{r}\text { 95\% C.I. } \\
\text { Lower }\end{array}$ & $\begin{array}{r}\text { 95\% C.I. } \\
\text { Upper }\end{array}$ \\
\hline Ethanol Effect (E15 vs. E0) $(\Delta \mathrm{g} / \mathrm{mi})$ & -0.002 & -0.082 & 0.078 \\
\hline Ethanol Effect (E20 vs. E0) $(\Delta \mathrm{g} / \mathrm{mi})$ & 0.025 & -0.055 & 0.105 \\
\hline Road Fuel Aging Effect & & & \\
\hline Aging Effect with RE0 $(\Delta \mathrm{g} / \mathrm{mi}$ per 100k mi) & $0.479^{*}$ & 0.199 & 0.758 \\
\hline Aging Effect with RE15 $(\Delta \mathrm{g} / \mathrm{mi} \mathrm{per} \mathrm{100k} \mathrm{mi)}$ & $0.204^{*}$ & 0.008 & 0.399 \\
\hline Aging Effect with RE20 $(\Delta \mathrm{g} / \mathrm{mi}$ per 100k mi) & $0.345^{*}$ & 0.148 & 0.542 \\
\hline
\end{tabular}

\begin{tabular}{|l|r|}
\hline \multicolumn{1}{|c|}{ Hypothesis } & -value \\
\hline No Effect of Ethanol in the Test Fuel (Gamma = 0) & 0.76 \\
\hline No Aging Effect with RE0 (Beta0 = 0) & $<0.01^{*}$ \\
\hline No Effect of Ethanol in Road Fuel Aging (Beta1s $=0$ ) & 0.21 \\
\hline * Indicates effect is statistically significant at the 95\% confidence level.
\end{tabular}

Initial odometers $111 \mathrm{k}-115 \mathrm{k}$

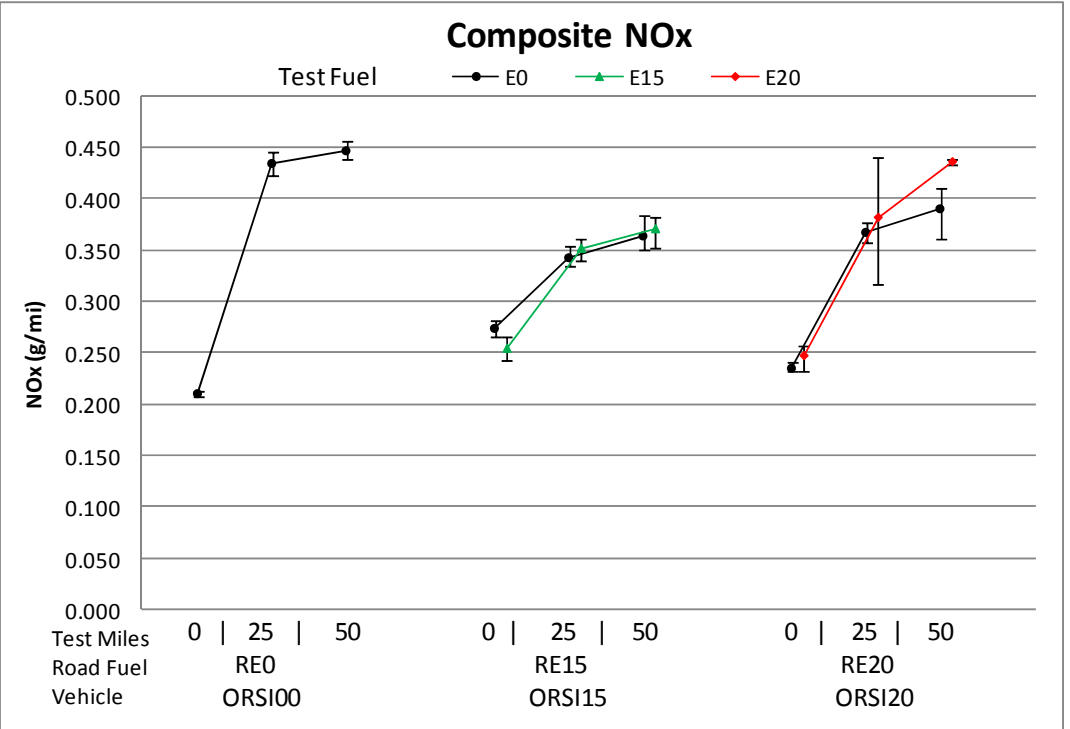

Error bars represent min and max measurements

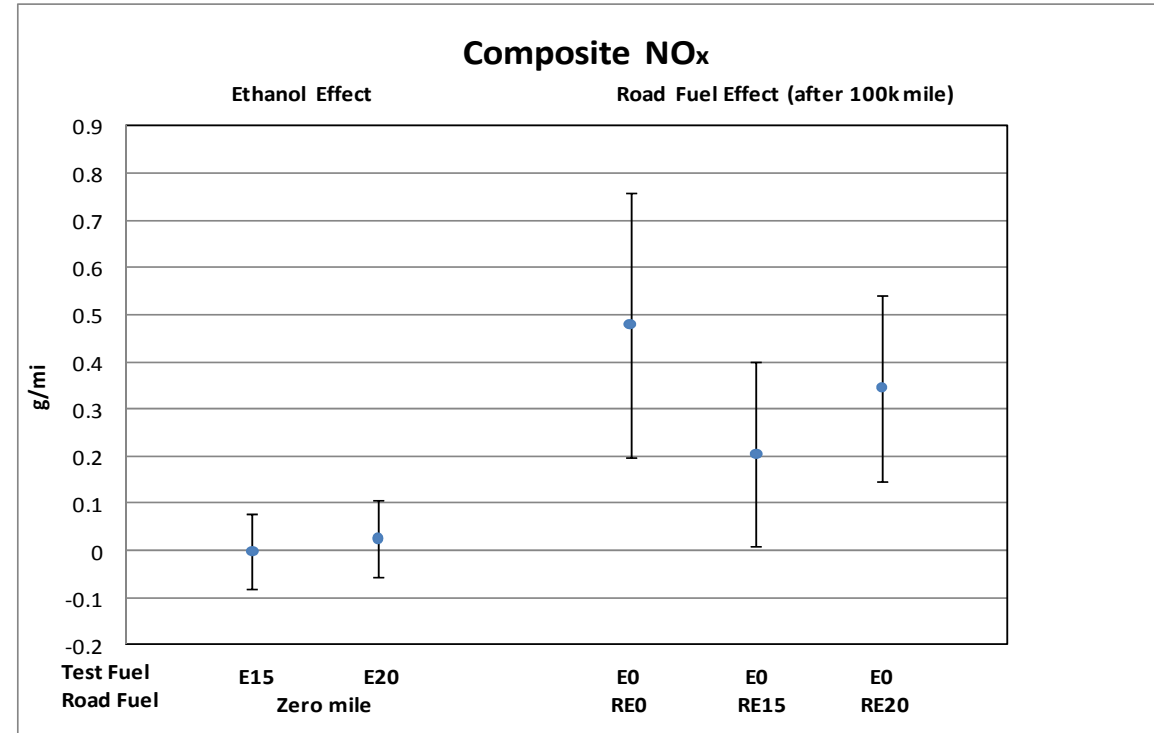

Error bars represent $95 \%$ confidence intervals on the estimated effects 
2000 Chevrolet Silverado (Composite Nonmethane Hydrocarbons)

\begin{tabular}{|l|r|r|r|}
\hline \multicolumn{1}{|c|}{ Effect } & & $\begin{array}{r}95 \% \text { C.I. } \\
\text { Low\% C.I. }\end{array}$ & $\begin{array}{r}\text { 95 } \\
\text { Upper }\end{array}$ \\
\hline Ethanol Effect $(E 15 \mathrm{vs}$. E0) $(\Delta \mathrm{g} / \mathrm{mi})$ & -0.026 & -0.060 & 0.007 \\
\hline Ethanol Effect $($ E20 vs. E0) $(\Delta \mathrm{g} / \mathrm{mi})$ & -0.022 & -0.056 & 0.011 \\
\hline Road Fuel Aging Effect & & & \\
\hline Aging Effect with RE0 $(\Delta \mathrm{g} / \mathrm{mi}$ per 100k mi) & 0.069 & -0.048 & 0.186 \\
\hline Aging Effect with RE15 $(\Delta \mathrm{g} / \mathrm{mi}$ per 100k mi) & -0.049 & -0.131 & 0.032 \\
\hline Aging Effect with RE20 $(\Delta \mathrm{g} / \mathrm{mi}$ per 100k mi) & 0.037 & -0.045 & 0.119 \\
\hline
\end{tabular}

\begin{tabular}{|l|r|}
\hline \multicolumn{1}{|c|}{ Hypothesis } & -value \\
\hline No Effect of Ethanol in the Test Fuel (Gamma = 0) & 0.12 \\
\hline No Aging Effect with RE0 (Beta0 = 0) & 0.21 \\
\hline No Effect of Ethanol in Road Fuel Aging (Beta1s=0) & 0.15 \\
\hline * Indicates effect is statistically significant at the 95\% confidence level.
\end{tabular}

* Indicates estimate is different from zero at the $95 \%$ confidence level.

Initial odometers $111 \mathrm{k}-115 \mathrm{k}$

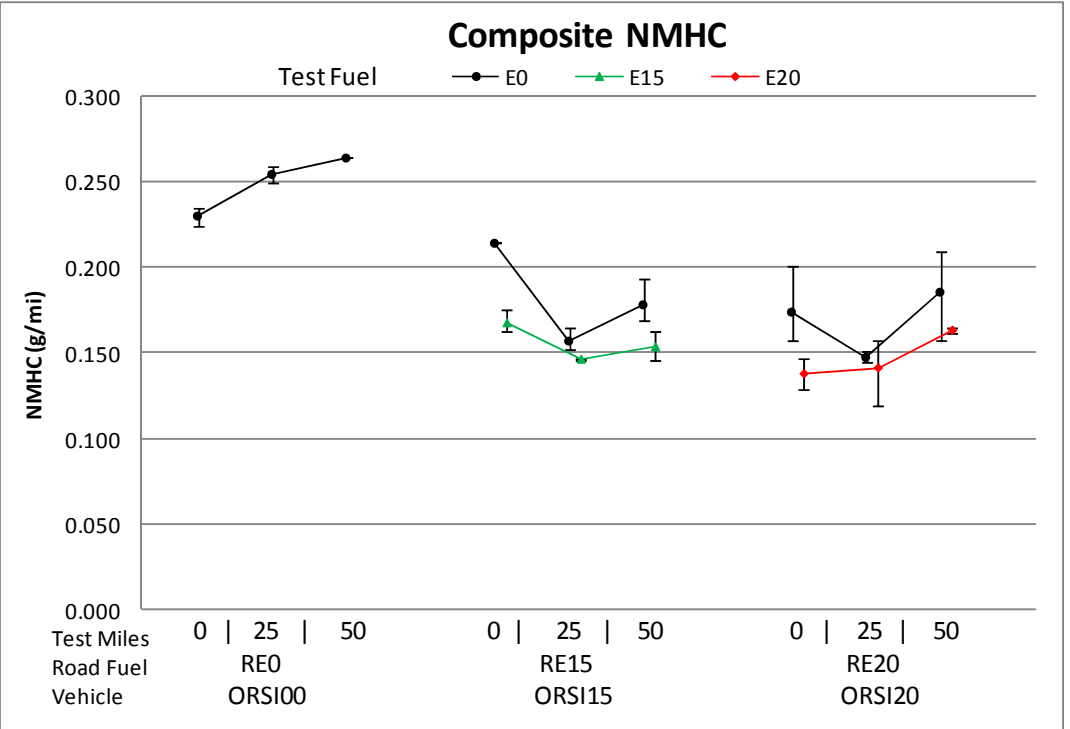

Error bars represent min and max measurements

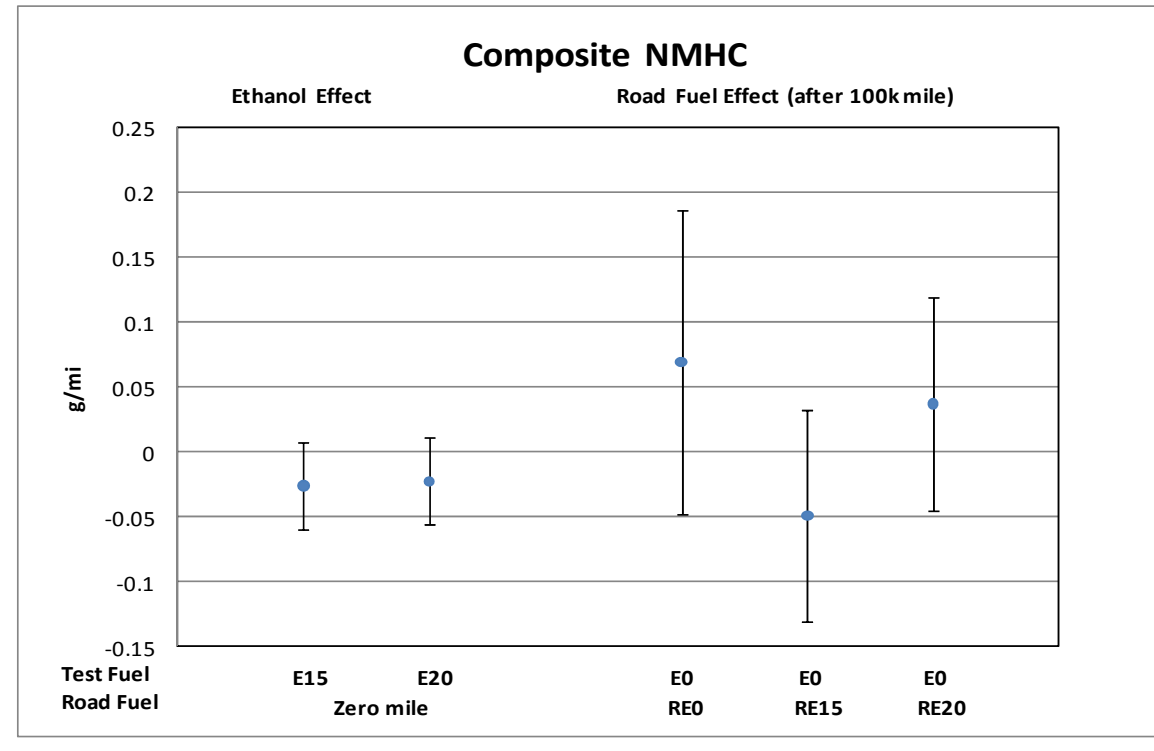

Error bars represent $95 \%$ confidence intervals on the estimated effects 
2000 Chevrolet Silverado (Composite Nonmethane Organic Gases)

\begin{tabular}{|l|r|r|r|}
\hline \multicolumn{1}{|c|}{ Effect } & Estimate & $\begin{array}{c}\text { 95\% C.I. } \\
\text { Lower }\end{array}$ & $\begin{array}{c}\text { 95\% C.I. } \\
\text { Upper }\end{array}$ \\
\hline Ethanol Effect (E15 vs. E0) $(\Delta \mathrm{g} / \mathrm{mi})$ & -0.0085 & -0.0434 & 0.0263 \\
\hline Ethanol Effect $($ E20 vs. E0) $(\Delta \mathrm{g} / \mathrm{mi})$ & -0.0000 & -0.0348 & 0.0348 \\
\hline Road Fuel Aging Effect & & & \\
\hline Aging Effect with RE0 $(\Delta \mathrm{g} / \mathrm{mi}$ per 100k mi) & 0.0715 & -0.0506 & 0.1935 \\
\hline Aging Effect with RE15 $(\Delta \mathrm{g} / \mathrm{mi}$ per 100k mi) & -0.0518 & -0.1366 & 0.0331 \\
\hline Aging Effect with RE20 $(\Delta \mathrm{g} / \mathrm{mi}$ per 100k mi) & 0.0426 & -0.0431 & 0.1282 \\
\hline
\end{tabular}

\begin{tabular}{|l|r|}
\hline \multicolumn{1}{|c|}{ Hypothesis } & -value \\
\hline No Effect of Ethanol in the Test Fuel (Gamma = 0) & 0.84 \\
\hline No Aging Effect with RE0 (Beta0 = 0) & 0.21 \\
\hline No Effect of Ethanol in Road Fuel Aging (Beta1s=0) & 0.14 \\
\hline * Indicates effect is statistically significant at the 95\% confidence level.
\end{tabular}

* Indicates estimate is different from zero at the $95 \%$ confidence level.

Initial odometers $111 \mathrm{k}-115 \mathrm{k}$

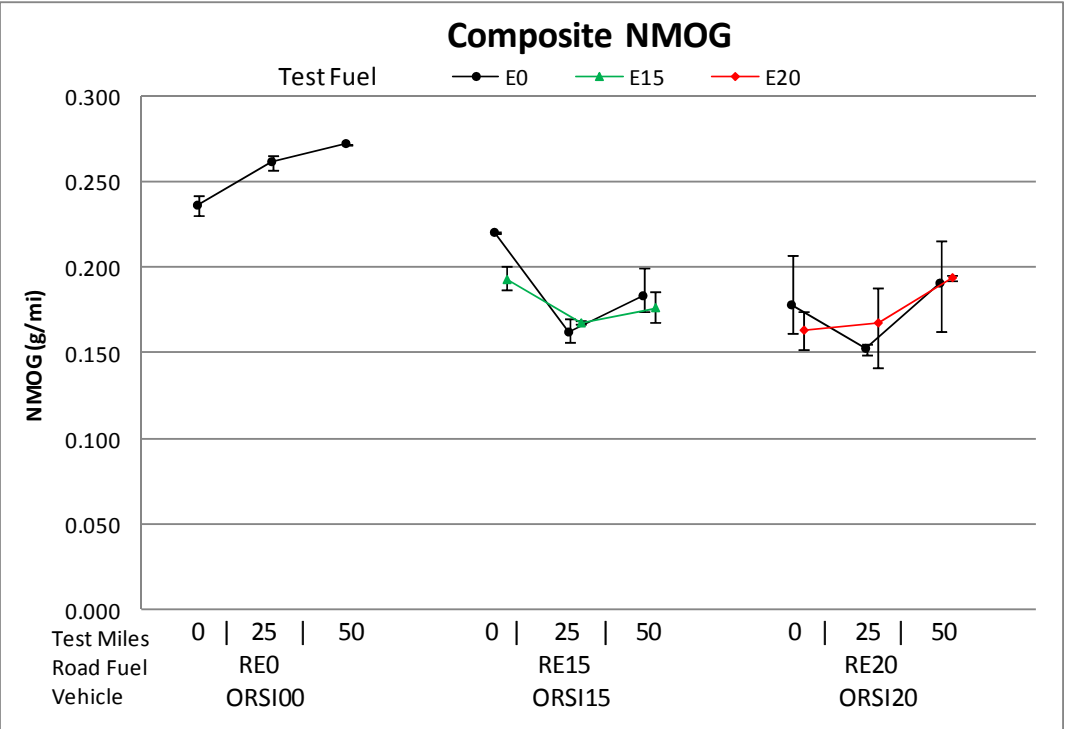

Error bars represent min and max measurements

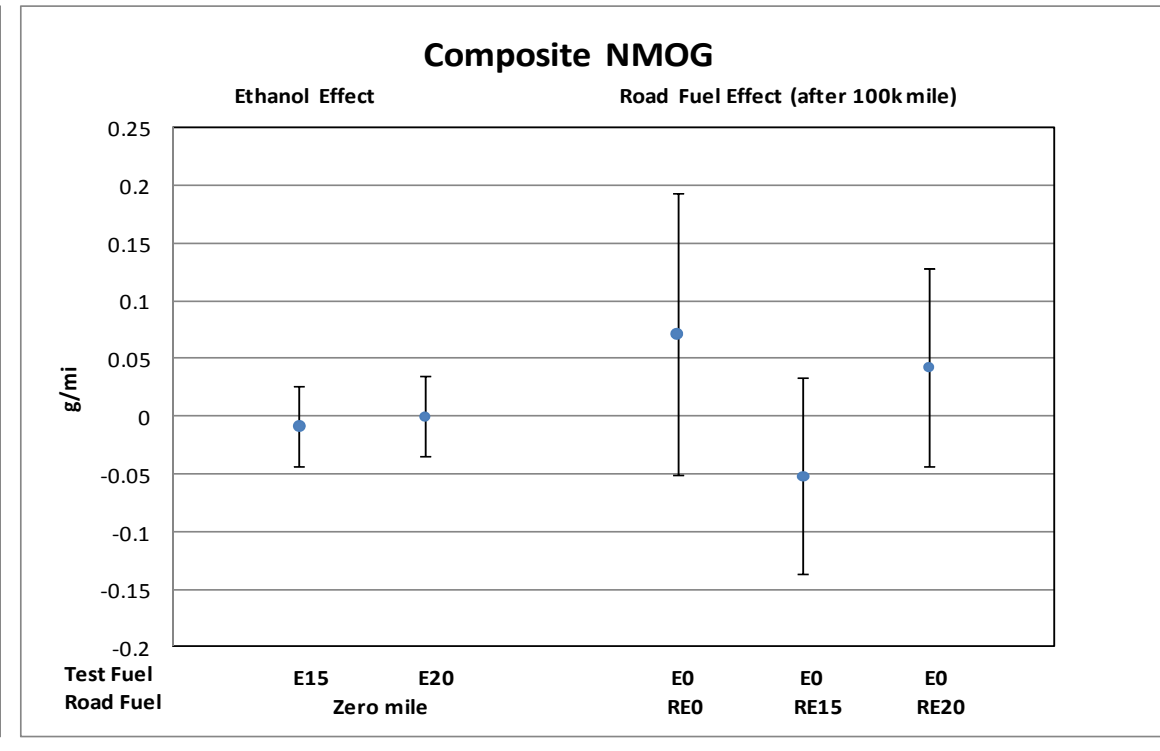

Error bars represent $95 \%$ confidence intervals on the estimated effects 
2000 Chevrolet Silverado (Composite Fuel Economy)

\begin{tabular}{|l|r|r|r|}
\hline \multicolumn{1}{|c|}{ Effect } & Estimate & $\begin{array}{r}\text { 95\% C.I. } \\
\text { Lower }\end{array}$ & $\begin{array}{r}\text { 95\% C.I. } \\
\text { Upper }\end{array}$ \\
\hline Ethanol Effect (E15 vs. E0) $(\Delta \mathrm{mi} / \mathrm{gal})$ & $-0.727^{*}$ & -1.122 & -0.332 \\
\hline Ethanol Effect (E20 vs. E0) $(\Delta \mathrm{mi} / \mathrm{gal})$ & $-0.829^{*}$ & -1.224 & -0.434 \\
\hline Road Fuel Aging Effect & & & \\
\hline Aging Effect with RE0 $(\Delta \mathrm{mi} /$ gal per 100k mi) & 0.594 & -0.788 & 1.977 \\
\hline Aging Effect with RE15 $(\Delta \mathrm{mi} / \mathrm{gal}$ per 100k mi) & $1.201^{*}$ & 0.239 & 2.163 \\
\hline Aging Effect with RE20 $(\Delta \mathrm{mi} /$ gal per 100k mi) & 0.230 & -0.742 & 1.201 \\
\hline
\end{tabular}

\begin{tabular}{|l|r|}
\hline \multicolumn{1}{|c|}{ Hypothesis } & p-value \\
\hline No Effect of Ethanol in the Test Fuel (Gamma $=0)$ & $<0.01^{*}$ \\
\hline No Aging Effect with RE0 (Beta0 $=0$ ) & 0.35 \\
\hline No Effect of Ethanol in Road Fuel Aging (Beta1s=0) & 0.29 \\
\hline${ }^{*}$ Indicates effect is statistically significant at the 95\% confidence level.
\end{tabular}

* Indicates estimate is different from zero at the $95 \%$ confidence level.

Initial odometers $111 \mathrm{k}-115 \mathrm{k}$

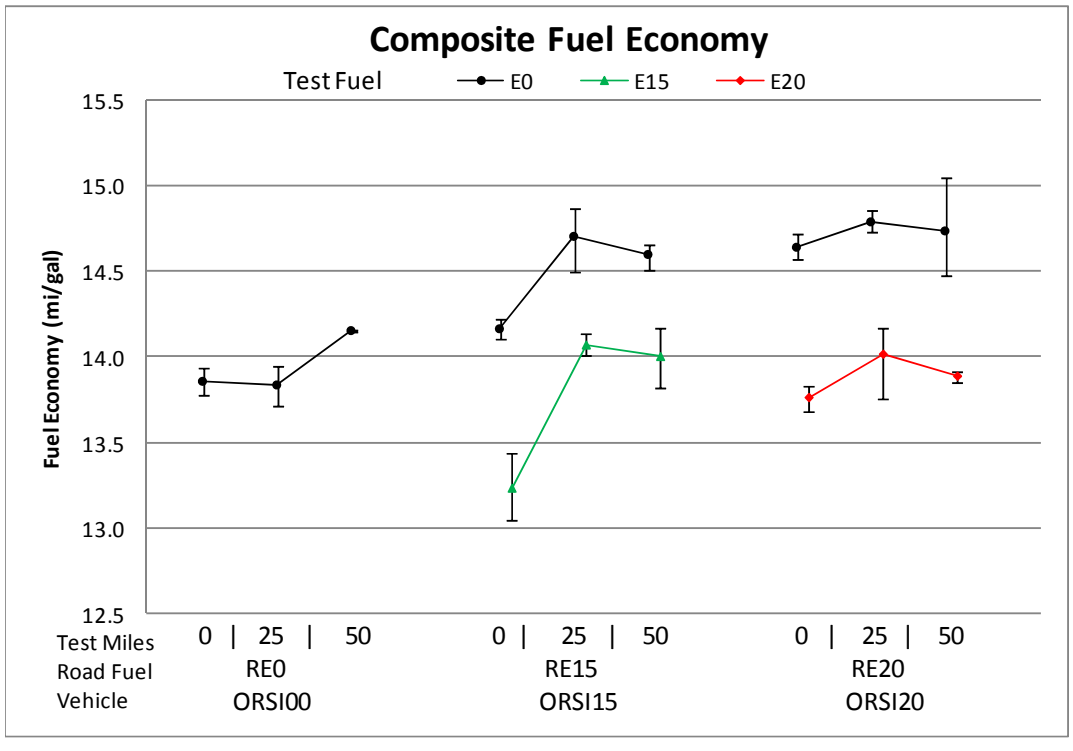

Error bars represent min and max measurements

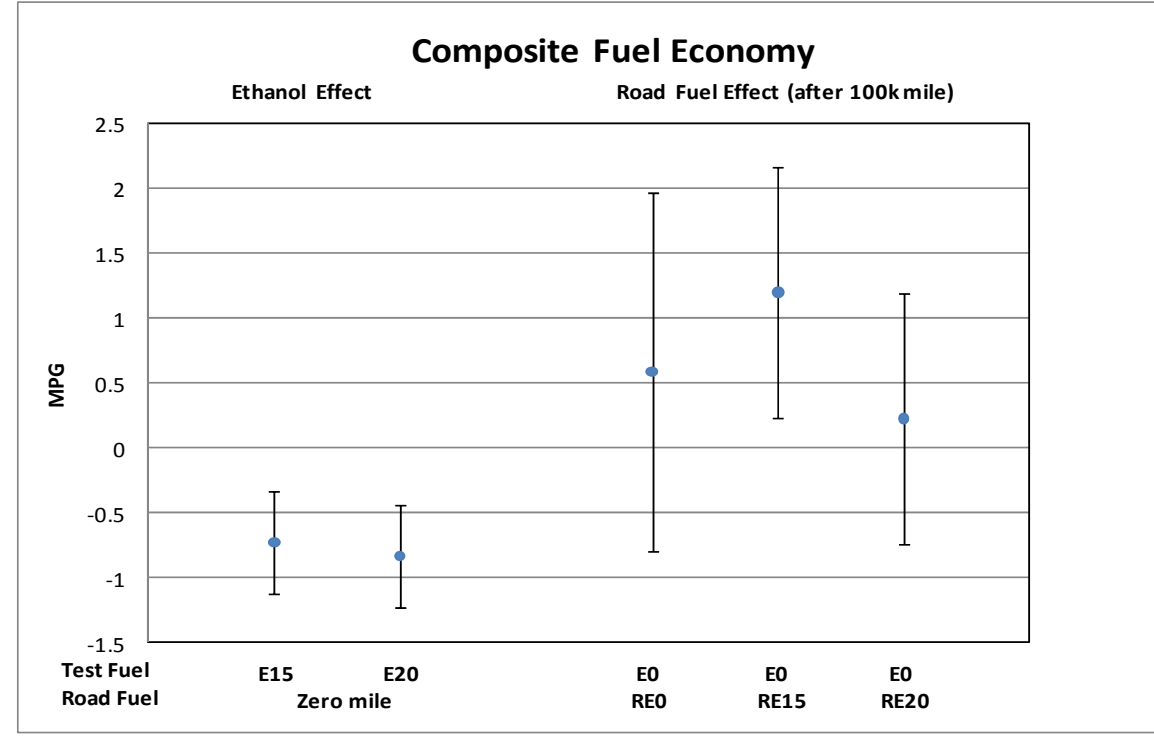

Error bars represent $95 \%$ confidence intervals on the estimated effects 
2000 Chevrolet Silverado (Composite Ethanol)

\begin{tabular}{|l|r|r|r|}
\hline \multicolumn{1}{|c|}{ Effect } & Estimate & $\begin{array}{r}\text { 95\% C.I. } \\
\text { Lower }\end{array}$ & $\begin{array}{r}\text { 95\% C.I. } \\
\text { Upper }\end{array}$ \\
\hline Ethanol Effect $(E 15 \mathrm{vs}$. E0) $(\Delta \mathrm{mg} / \mathrm{mi})$ & $10.453^{*}$ & 5.867 & 15.039 \\
\hline Ethanol Effect $($ E20 vs. E0) $(\Delta \mathrm{mg} / \mathrm{mi})$ & $14.629^{*}$ & 10.326 & 18.933 \\
\hline Road Fuel Aging Effect & & & \\
\hline Aging Effect with RE0 $(\Delta \mathrm{mg} / \mathrm{mi}$ per 100k mi) & -0.000 & -14.672 & 14.672 \\
\hline Aging Effect with RE15 $(\Delta \mathrm{mg} / \mathrm{mi}$ per 100k mi) & 2.003 & -9.262 & 13.267 \\
\hline Aging Effect with RE20 $(\Delta \mathrm{mg} / \mathrm{mi}$ per 100k mi) & 4.930 & -5.935 & 15.795 \\
\hline * Indicates estimate is different from zero at the 95\% confiden
\end{tabular}

\begin{tabular}{|l|r|}
\hline \multicolumn{1}{|c|}{ Hypothesis } & p-value \\
\hline No Effect of Ethanol in the Test Fuel (Gamma = 0) & $<0.01^{*}$ \\
\hline No Aging Effect with RE0 (Beta0 = 0) & 1.00 \\
\hline No Effect of Ethanol in Road Fuel Aging (Beta1s=0) & 0.76 \\
\hline
\end{tabular}

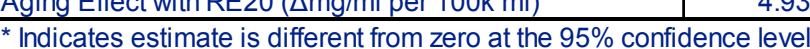

Initial odometers $111 \mathrm{k}-115 \mathrm{k}$

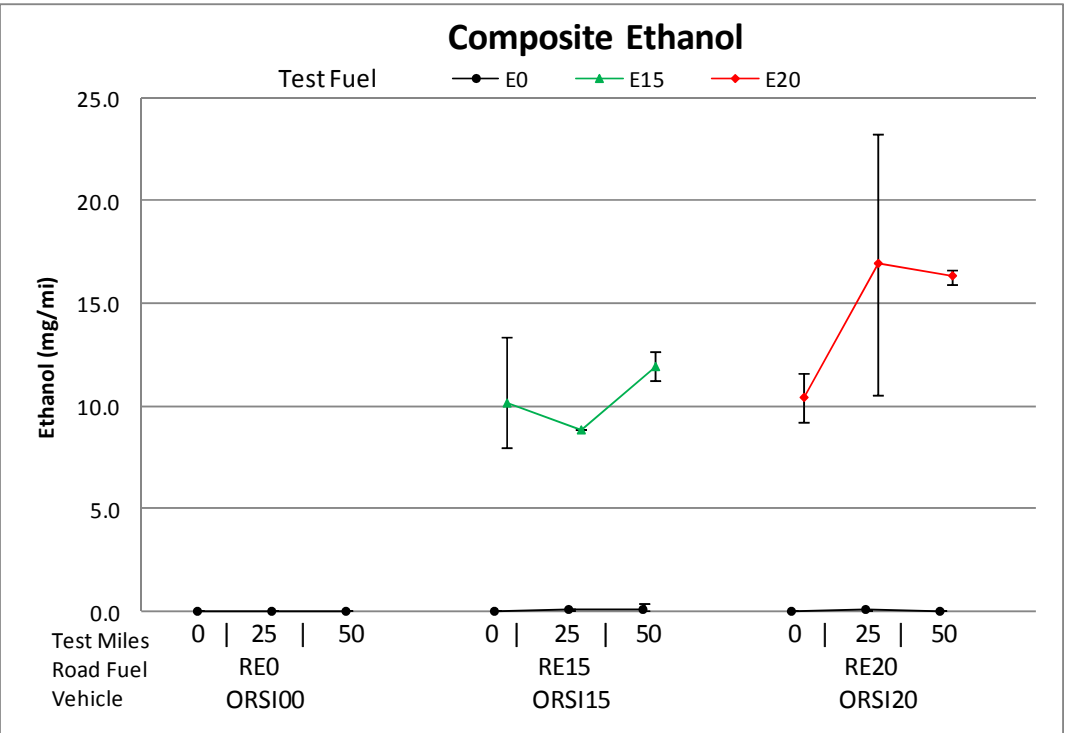

Error bars represent min and max measurements

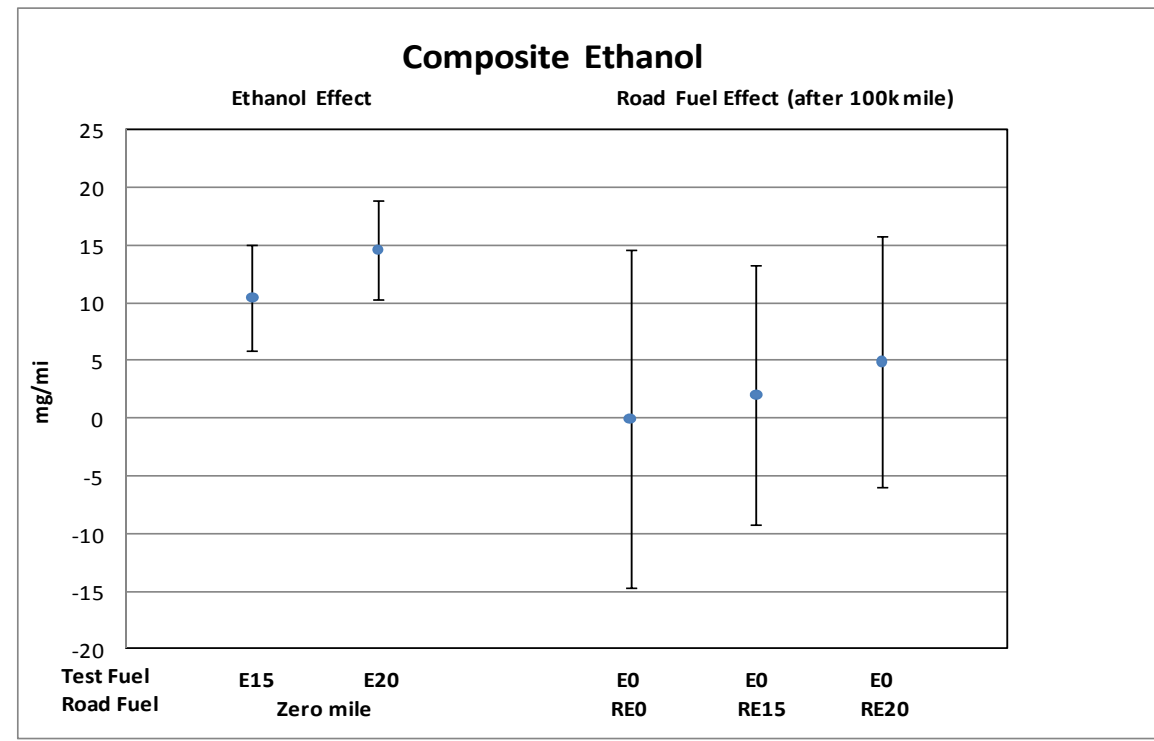

Error bars represent $95 \%$ confidence intervals on the estimated effects 
2000 Chevrolet Silverado (Composite Acetaldehyde)

\begin{tabular}{|l|r|r|r|}
\hline \multicolumn{1}{|c|}{ Effect } & Estimate & $\begin{array}{r}\text { 95\% C.I. } \\
\text { Lower }\end{array}$ & $\begin{array}{r}\text { 95\% C.I. } \\
\text { Upper }\end{array}$ \\
\hline Ethanol Effect (E15 vs. E0) $(\Delta \mathrm{mg} / \mathrm{mi})$ & $2.967^{*}$ & 1.258 & 4.676 \\
\hline Ethanol Effect (E20 vs. E0) $(\Delta \mathrm{mg} / \mathrm{mi})$ & $3.356^{*}$ & 1.655 & 5.057 \\
\hline Road Fuel Aging Effect & & & \\
\hline Aging Effect with RE0 $(\Delta \mathrm{mg} / \mathrm{mi}$ per 100k mi) & 1.489 & -1.800 & 4.778 \\
\hline Aging Effect with RE15 $(\Delta \mathrm{mg} / \mathrm{mi}$ per 100k mi) & -0.013 & -1.086 & 1.060 \\
\hline Aging Effect with RE20 $(\Delta \mathrm{mg} / \mathrm{mi}$ per 100k mi) & -0.058 & -0.692 & 0.576 \\
\hline
\end{tabular}

\begin{tabular}{|l|r|}
\hline \multicolumn{1}{|c|}{ Hypothesis } & p-value \\
\hline No Effect of Ethanol in the Test Fuel (Gamma $=0)$ & $<0.01^{*}$ \\
\hline No Aging Effect with RE0 (Beta0 $=0)$ & 0.27 \\
\hline No Effect of Ethanol in Road Fuel Aging (Beta1s=0) & 0.55 \\
\hline${ }^{*}$ Indicates effect is statistically significant at the 95\% confidence level.
\end{tabular}

Initial odometers $111 \mathrm{k}-115 \mathrm{k}$

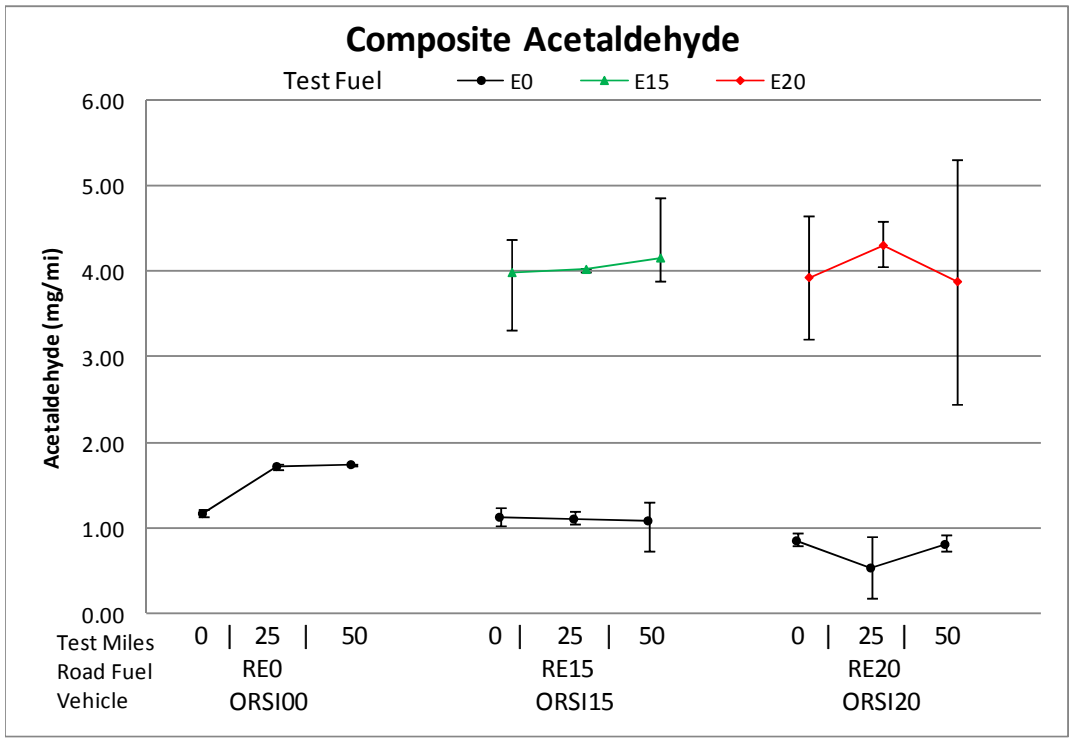

Error bars represent min and max measurements

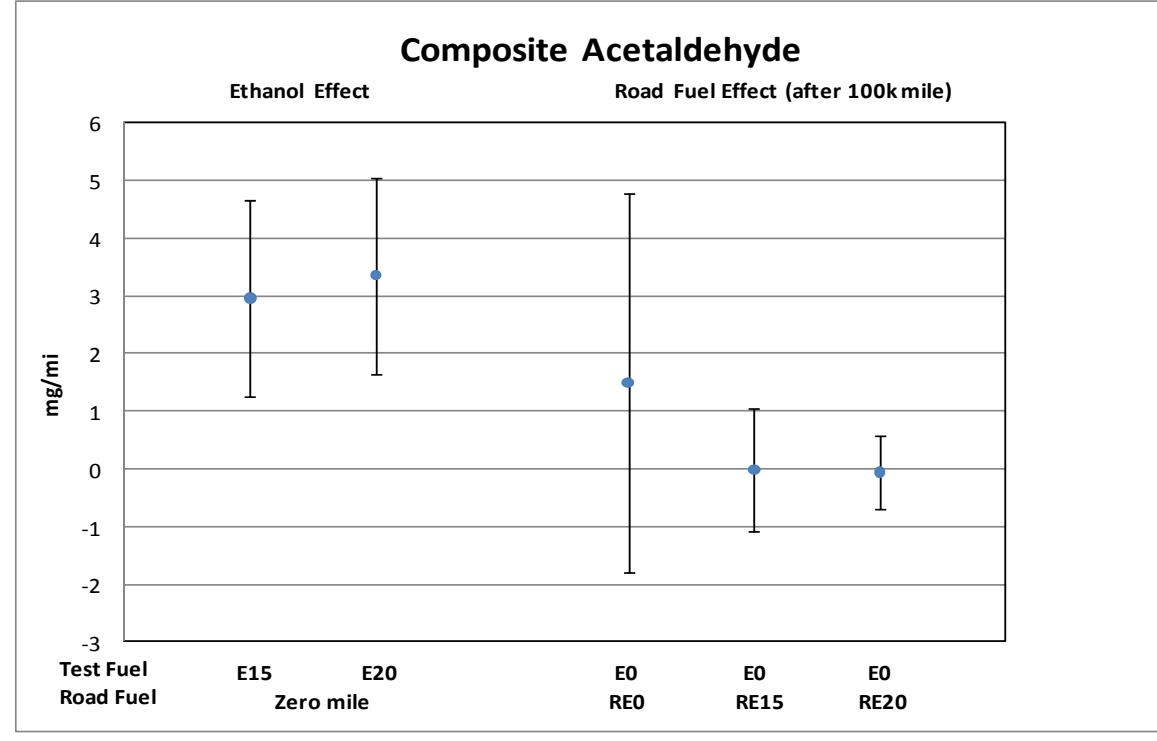

Error bars represent $95 \%$ confidence intervals on the estimated effects 
2000 Chevrolet Silverado(Composite Formaldehyde)

\begin{tabular}{|l|r|r|r|}
\hline \multicolumn{1}{|c|}{ Effect } & Estimate & $\begin{array}{r}\text { 95\% C.I. } \\
\text { Lower }\end{array}$ & $\begin{array}{r}\text { 95\% C.I. } \\
\text { Upper }\end{array}$ \\
\hline Ethanol Effect (E15 vs. E0) $(\Delta \mathrm{mg} / \mathrm{mi})$ & 0.324 & -0.332 & 0.981 \\
\hline Ethanol Effect $($ E20 vs. E0) $(\Delta \mathrm{mg} / \mathrm{mi})$ & 0.566 & -0.152 & 1.284 \\
\hline Road Fuel Aging Effect & & & \\
\hline Aging Effect with RE0 $(\Delta \mathrm{mg} / \mathrm{mi}$ per 100k mi) & $4.363^{*}$ & 1.525 & 7.202 \\
\hline Aging Effect with RE15 $(\Delta \mathrm{mg} / \mathrm{mi}$ per 100k mi) & 0.414 & -1.156 & 1.985 \\
\hline Aging Effect with RE20 $(\Delta \mathrm{mg} / \mathrm{mi}$ per 100k mi) & -0.391 & -2.110 & 1.328 \\
\hline
\end{tabular}

\begin{tabular}{|l|r|}
\hline \multicolumn{1}{|c|}{ Hypothesis } & -value \\
\hline No Effect of Ethanol in the Test Fuel (Gamma = 0) & 0.18 \\
\hline No Aging Effect with RE0 (Beta0 $=0$ ) & $<0.01^{*}$ \\
\hline No Effect of Ethanol in Road Fuel Aging (Beta1s $=0$ ) & $0.02^{*}$ \\
\hline * Indicates effect is statistically significant at the 95\% confidence level.
\end{tabular}

${ }^{*}$ Indicates estimate is different from zero at the $95 \%$ confidence level.

Initial odometers $111 \mathrm{k}-115 \mathrm{k}$

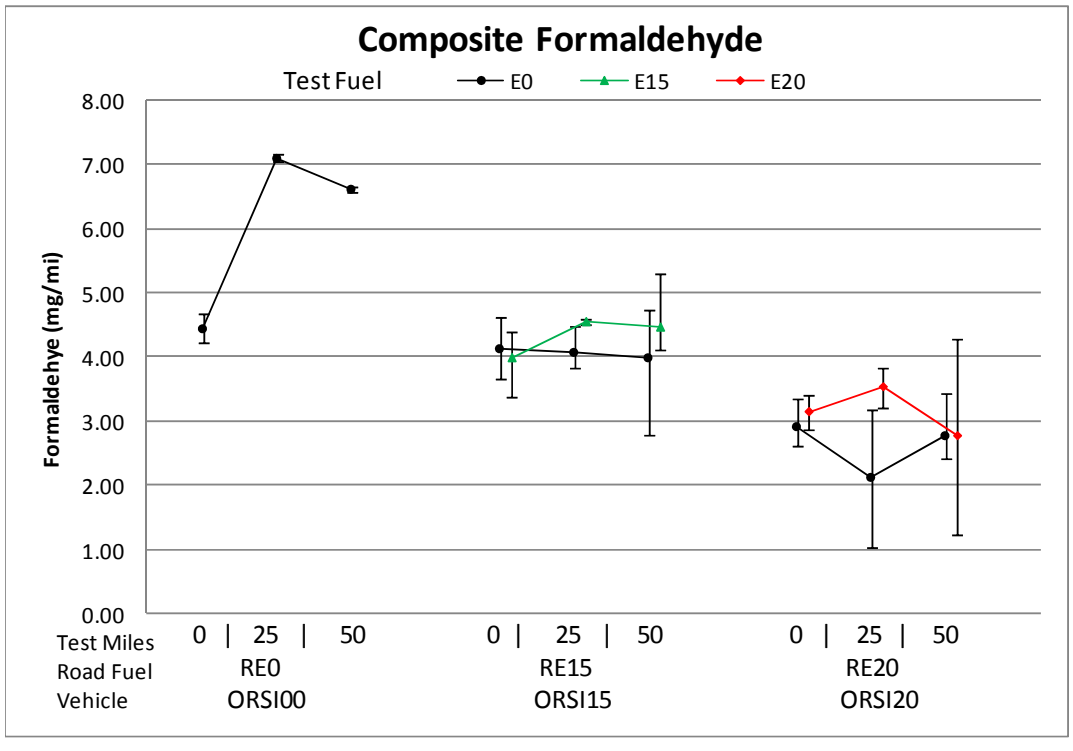

Error bars represent min and max measurements

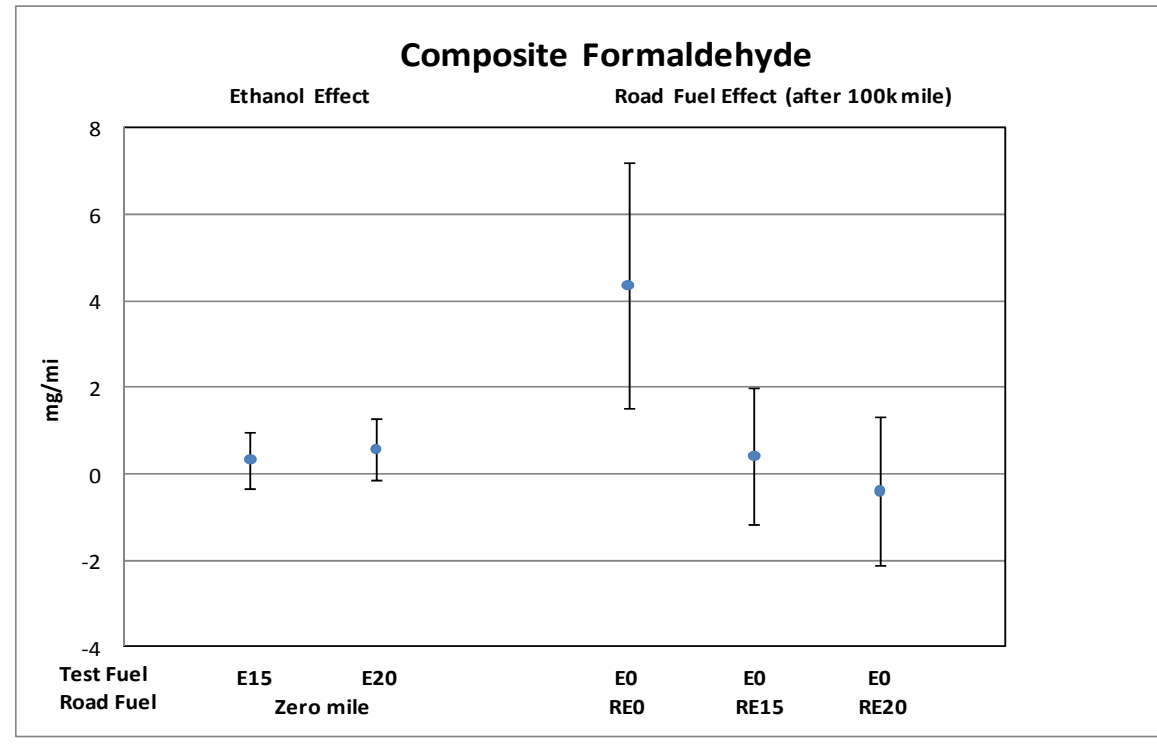

Error bars represent $95 \%$ confidence intervals on the estimated effects 
2000 Chevrolet Silverado (Composite $\mathrm{CH}_{4}$ )

\begin{tabular}{|l|r|r|r|}
\hline \multicolumn{1}{|c|}{ Effect } & Estimate & $\begin{array}{c}\text { 95\% C.I. } \\
\text { Lower }\end{array}$ & $\begin{array}{c}\text { 95\% C.I. } \\
\text { Upper }\end{array}$ \\
\hline Ethanol Effect (E15 vs. E0) $(\Delta \mathrm{g} / \mathrm{mi})$ & 0.0016 & -0.0009 & 0.0041 \\
\hline Ethanol Effect $($ E20 vs. E0) $(\Delta \mathrm{g} / \mathrm{mi})$ & $0.0044^{*}$ & 0.0019 & 0.0069 \\
\hline Road Fuel Aging Effect & & & \\
\hline Aging Effect with RE0 $(\Delta \mathrm{g} / \mathrm{mi}$ per 100k mi) & $0.0130^{*}$ & 0.0043 & 0.0217 \\
\hline Aging Effect with RE15 $(\Delta \mathrm{g} / \mathrm{mi} \mathrm{per} \mathrm{100k} \mathrm{mi)}$ & 0.0049 & -0.0011 & 0.0110 \\
\hline Aging Effect with RE20 $(\Delta \mathrm{g} / \mathrm{mi}$ per 100k mi) & $0.0119^{*}$ & 0.0058 & 0.0180 \\
\hline
\end{tabular}

\begin{tabular}{|l|r|}
\hline \multicolumn{1}{|c|}{ Hypothesis } & p-value \\
\hline No Effect of Ethanol in the Test Fuel (Gamma = 0) & $<0.01^{*}$ \\
\hline No Aging Effect with RE0 (Beta0 = 0) & $<0.01^{*}$ \\
\hline No Effect of Ethanol in Road Fuel Aging (Beta1s=0) & 0.15 \\
\hline
\end{tabular}

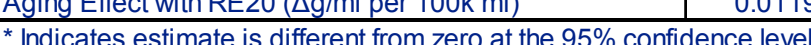

Initial odometers $111 \mathrm{k}-115 \mathrm{k}$

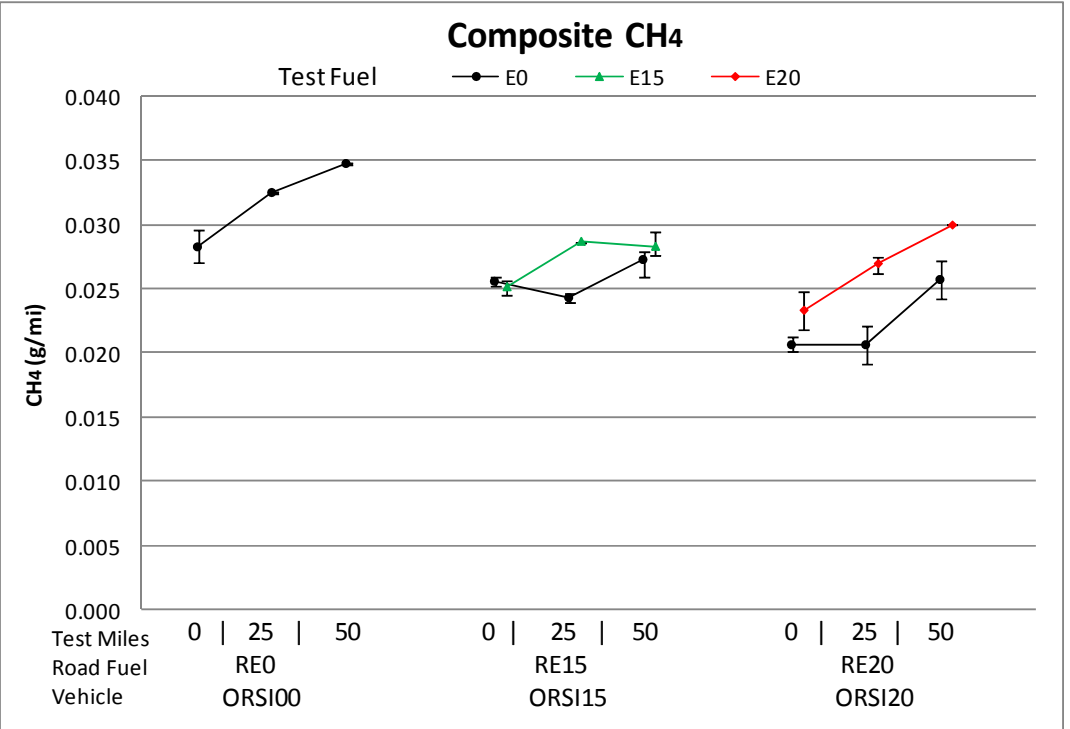

Error bars represent min and max measurements

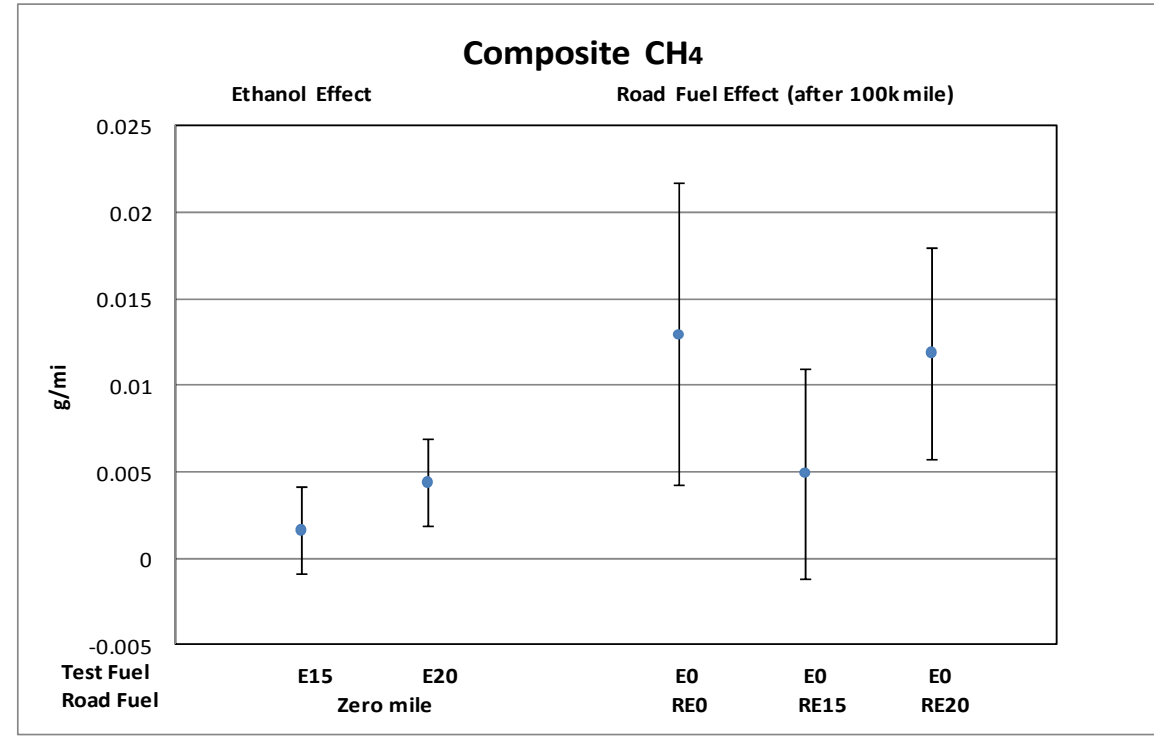

Error bars represent $95 \%$ confidence intervals on the estimated effects 
2002 Nissan Frontier - Composite Emissions Summary

\begin{tabular}{|c|c|c|c|c|c|c|c|c|c|c|c|c|c|c|}
\hline \multirow{2}{*}{$\begin{array}{c}\text { Emisssion Parameter } \\
\text { (units) }\end{array}$} & \multicolumn{4}{|c|}{ Ethanol Effect } & \multicolumn{2}{|c|}{ Aging Effect with REO } & \multicolumn{4}{|c|}{ RExx Aging Effect on E0 Emissions } & \multirow{2}{*}{\multicolumn{3}{|c|}{$\begin{array}{c}\text { RExx Aging Effect on Exx Emissions } \\
\Delta \text { units per } 100 \mathrm{~K} \mathrm{mi}\end{array}$}} & \multirow{3}{*}{\begin{tabular}{|c|}
$\begin{array}{l}\text { Road and Test } \\
\text { Fuel Effects } \\
\text { are Additive }\end{array}$ \\
$\begin{array}{c}\text { Overall p- } \\
\text { value }\end{array}$
\end{tabular}} \\
\hline & \multicolumn{3}{|c|}{$\Delta$ units vs. EO } & \multirow{2}{*}{$\mid \begin{array}{c}\text { Overall } \\
p \text {-value }\end{array}$} & \multirow{2}{*}{$\begin{array}{c}\Delta \text { units per } 100 \mathrm{~K} \mathrm{mi} \\
\text { REO/E0 }\end{array}$} & \multirow{2}{*}{$\begin{array}{l}\text { Overall } \\
p \text {-value }\end{array}$} & \multicolumn{3}{|c|}{$\Delta$ units per $100 \mathrm{~K} \mathrm{mi}$} & \multirow{2}{*}{$\begin{array}{l}\text { Overall } \\
p \text {-value }\end{array}$} & & & & \\
\hline Fuels & E10 & E15 & $\mathrm{E} 20$ & & & & RE10/E0 & RE15/E0 & RE20/E0 & & RE10/E10 & RE15/E15 & RE20/E20 & \\
\hline $\mathrm{CO}(\mathrm{g} / \mathrm{mi})$ & $\mathrm{NA}$ & 0.131 & 0.168 & 0.90 & $4.491 *$ & 0.01* & NA & $4.958 *$ & $5.305^{*}$ & 0.93 & NA & $\mathrm{NA}$ & NA & 0.87 \\
\hline $\mathrm{NOx}(\mathrm{g} / \mathrm{mi})$ & $\mathrm{NA}$ & -0.061 & 0.005 & 0.15 & 0.119 & 0.33 & NA & $0.210^{*}$ & 0.055 & 0.38 & $\mathrm{NA}$ & $\mathrm{NA}$ & $\mathrm{NA}$ & 0.23 \\
\hline $\mathrm{NMHC}(\mathrm{g} / \mathrm{mi})$ & $\mathrm{NA}$ & $-0.019 *$ & $-0.027 *$ & $<0.01 *$ & -0.022 & 0.15 & NA & $0.042 *$ & 0.005 & $<0.01 *$ & NA & $0.049 *$ & $0.059 *$ & $0.05^{*}$ \\
\hline NMOG $(\mathrm{g} / \mathrm{mi})$ & $\mathrm{NA}$ & -0.013 & $-0.018^{*}$ & $0.03 *$ & -0.023 & 0.17 & NA & $0.043 *$ & 0.004 & $<0.01 *$ & $N A$ & $0.056 *$ & $0.071 *$ & $0.02 *$ \\
\hline Fuel Econ (mi/gal) & $\mathrm{NA}$ & $-0.074 *$ & $-1.569 *$ & $<0.01 *$ & $0.953^{*}$ & $0.02 *$ & NA & -0.119 & $0.990 *$ & $0.01 *$ & $\mathrm{NA}$ & $\mathrm{NA}$ & $\mathrm{NA}$ & 0.57 \\
\hline Ethanol $(\mathrm{mg} / \mathrm{mi})^{\# \#}$ & $\mathrm{NA}$ & $5.237 *$ & $6.422 *$ & $<0.01 *$ & -0.220 & 0.89 & NA & 0.528 & 0.155 & 0.92 & $\mathrm{NA}$ & $\mathrm{NA}$ & NA & NA \\
\hline Acetaldehyde $(\mathrm{mg} / \mathrm{mi})^{\#}$ & $\mathrm{NA}$ & $0.638 *$ & $1.108 *$ & $<0.01 *$ & 0.000 & 1.00 & NA & 0.152 & 0.156 & 0.70 & NA & $\mathrm{NA}$ & NA & 0.87 \\
\hline Formaldehyde $(\mathrm{mg} / \mathrm{mi})^{\#}$ & $\mathrm{NA}$ & 0.035 & 0.166 & 0.43 & 0.236 & 0.51 & NA & 0.455 & 0.361 & 0.96 & $\mathrm{NA}$ & $\mathrm{NA}$ & NA & 0.92 \\
\hline $\mathrm{CH}_{4}(\mathrm{~g} / \mathrm{mi})$ & $\mathrm{NA}$ & 0.0026 & 0.0040 & 0.09 & $0.0479 *$ & $<0.01^{*}$ & NA & $0.0256 *$ & $0.0280 *$ & 0.05 & NA & $\mathrm{NA}$ & NA & 0.27 \\
\hline
\end{tabular}

\# Log-normal model was used. Results are presented as changes in emissions at $0 \mathrm{k}$ mile.

\#\# Data did not support the assumption of linear effects with mileage.

*Indicates estimate is different from zero at the $95 \%$ confidence level. 
2002 Nissan Frontier (Composite CO)

\begin{tabular}{|l|r|r|r|}
\hline \multicolumn{1}{|c|}{ Effect } & Estimate & $\begin{array}{r}\text { 95\% C.I. } \\
\text { Lower }\end{array}$ & $\begin{array}{r}\text { 95\% C.I. } \\
\text { Upper }\end{array}$ \\
\hline Ethanol Effect (E15 vs. E0) $(\Delta \mathrm{g} / \mathrm{mi})$ & 0.131 & -0.755 & 1.016 \\
\hline Ethanol Effect $($ E20 vs. E0) $(\Delta \mathrm{g} / \mathrm{mi})$ & 0.168 & -0.850 & 1.186 \\
\hline Road Fuel Aging Effect & & & \\
\hline Aging Effect with RE0 $(\Delta \mathrm{g} / \mathrm{mi}$ per 100k mi) & $4.491^{*}$ & 1.013 & 7.970 \\
\hline Aging Effect with RE15 $(\Delta \mathrm{g} / \mathrm{mi}$ per 100k mi) & $4.958^{*}$ & 2.888 & 7.028 \\
\hline Aging Effect with RE20 $(\Delta \mathrm{g} / \mathrm{mi}$ per 100k mi) & $5.305^{*}$ & 2.848 & 7.761 \\
\hline
\end{tabular}

\begin{tabular}{|l|r|}
\hline \multicolumn{1}{|c|}{ Hypothesis } & p-value \\
\hline No Effect of Ethanol in the Test Fuel (Gamma = 0) & 0.90 \\
\hline No Aging Effect with RE0 (Beta0 = 0) & $0.01^{*}$ \\
\hline No Effect of Ethanol in Road Fuel Aging (Beta1s=0) & 0.93 \\
\hline * Indicates effect is statistically significant at the 95\% confidence level.
\end{tabular}

${ }^{*}$ Indicates estimate is different from zero at the $95 \%$ confidence level.

Initial odometers $91 \mathrm{k}-96 \mathrm{k}$

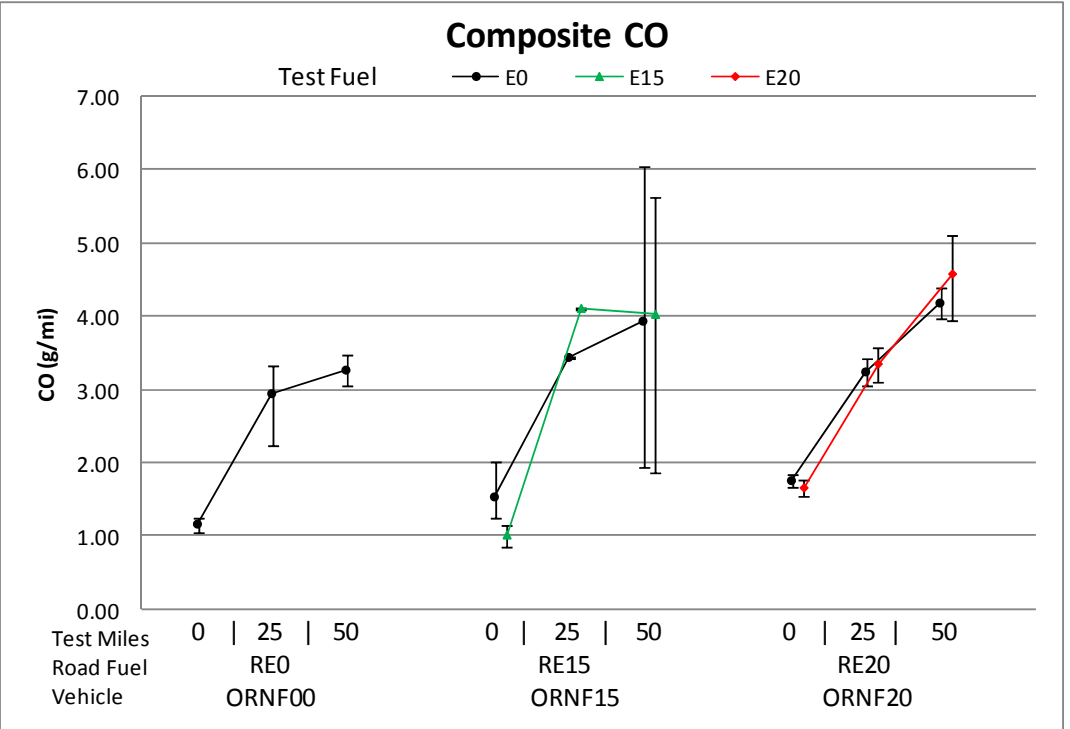

Error bars represent min and max measurements

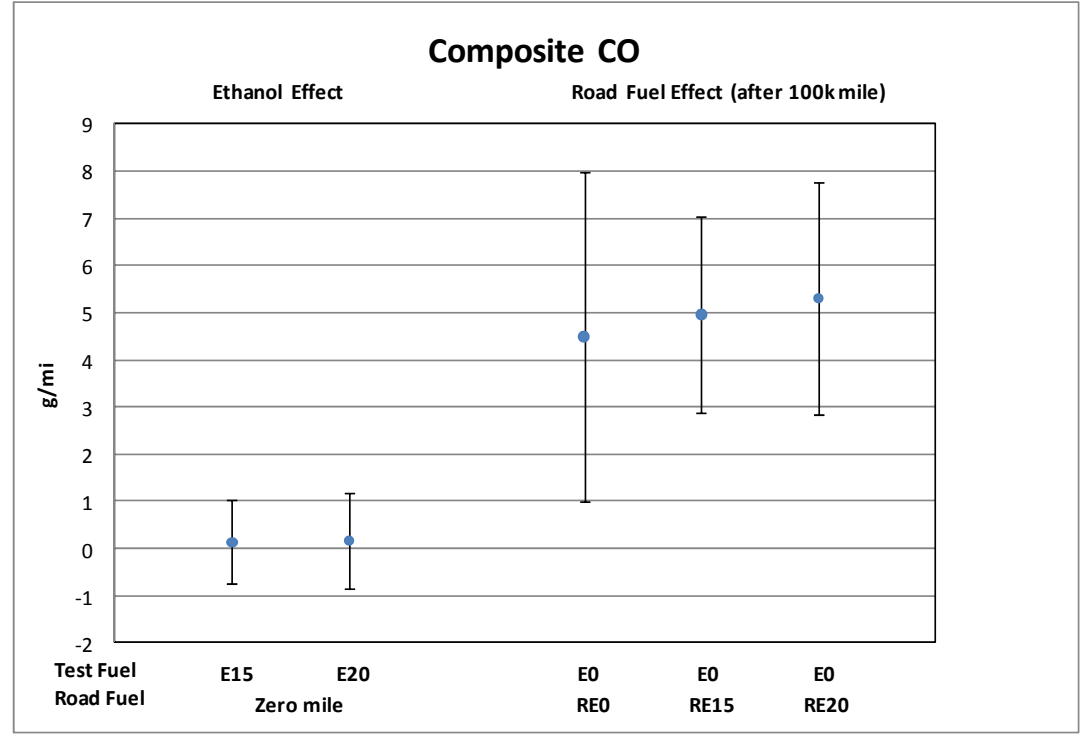

Error bars represent $95 \%$ confidence intervals on the estimated effects 
2002 Nissan Frontier (Composite NOx)

\begin{tabular}{|l|r|r|r|}
\hline \multicolumn{1}{|c|}{ Effect } & Estimate & $\begin{array}{c}\text { 95\% C.I. } \\
\text { Lower }\end{array}$ & $\begin{array}{r}\text { 95\% C.I. } \\
\text { Upper }\end{array}$ \\
\hline Ethanol Effect (E15 vs. E0) $(\Delta \mathrm{g} / \mathrm{mi})$ & -0.061 & -0.123 & 0.001 \\
\hline Ethanol Effect $($ E20 vs. E0) $(\Delta \mathrm{g} / \mathrm{mi})$ & 0.005 & -0.066 & 0.076 \\
\hline Road Fuel Aging Effect & & & \\
\hline Aging Effect with RE0 $(\Delta \mathrm{g} / \mathrm{mi}$ per 100k mi) & 0.119 & -0.125 & 0.363 \\
\hline Aging Effect with RE15 $(\Delta \mathrm{g} / \mathrm{mi}$ per 100k mi) & $0.210^{*}$ & 0.065 & 0.356 \\
\hline Aging Effect with RE20 $(\Delta \mathrm{g} / \mathrm{mi}$ per 100k mi) & 0.055 & -0.118 & 0.227 \\
\hline
\end{tabular}

\begin{tabular}{|l|r|}
\hline \multicolumn{1}{|c|}{ Hypothesis } & p-value \\
\hline No Effect of Ethanol in the Test Fuel (Gamma = 0) & 0.15 \\
\hline No Aging Effect with RE0 (Beta0 = 0) & 0.33 \\
\hline No Effect of Ethanol in Road Fuel Aging (Beta1s=0) & 0.38 \\
\hline${ }^{*}$ Indicates effect is statistically significant at the 95\% confidence level.
\end{tabular}

* Indicates estimate is different from zero at the $95 \%$ confidence level.

Initial odometers 91k-96k

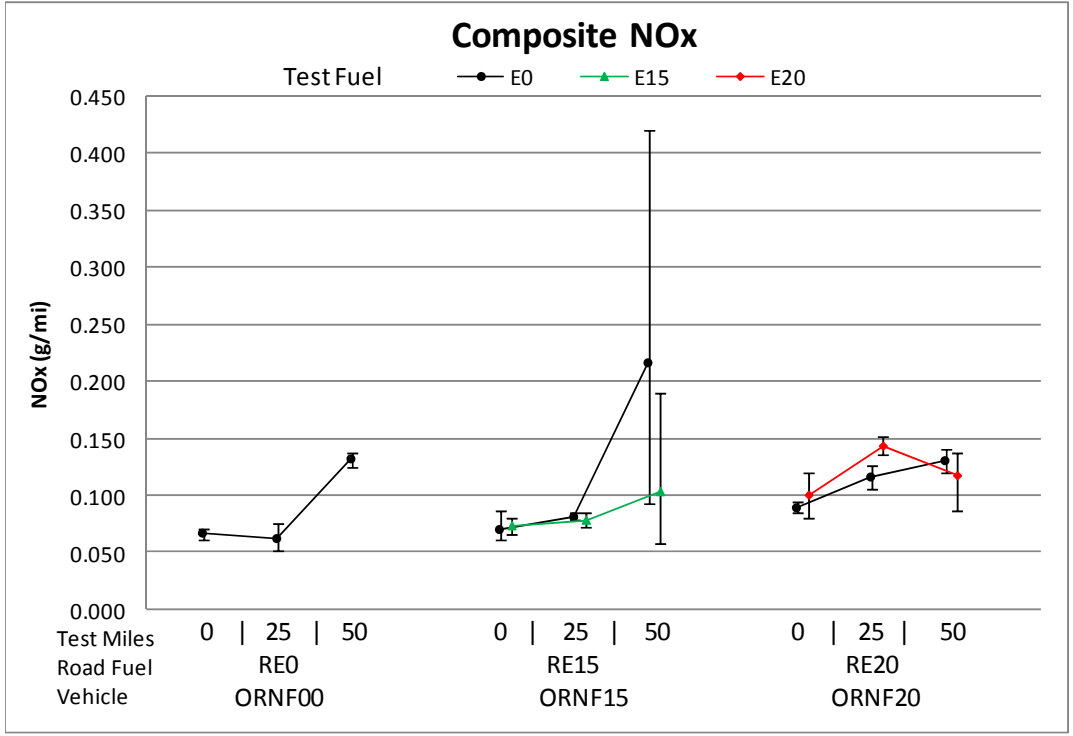

Error bars represent min and max measurements

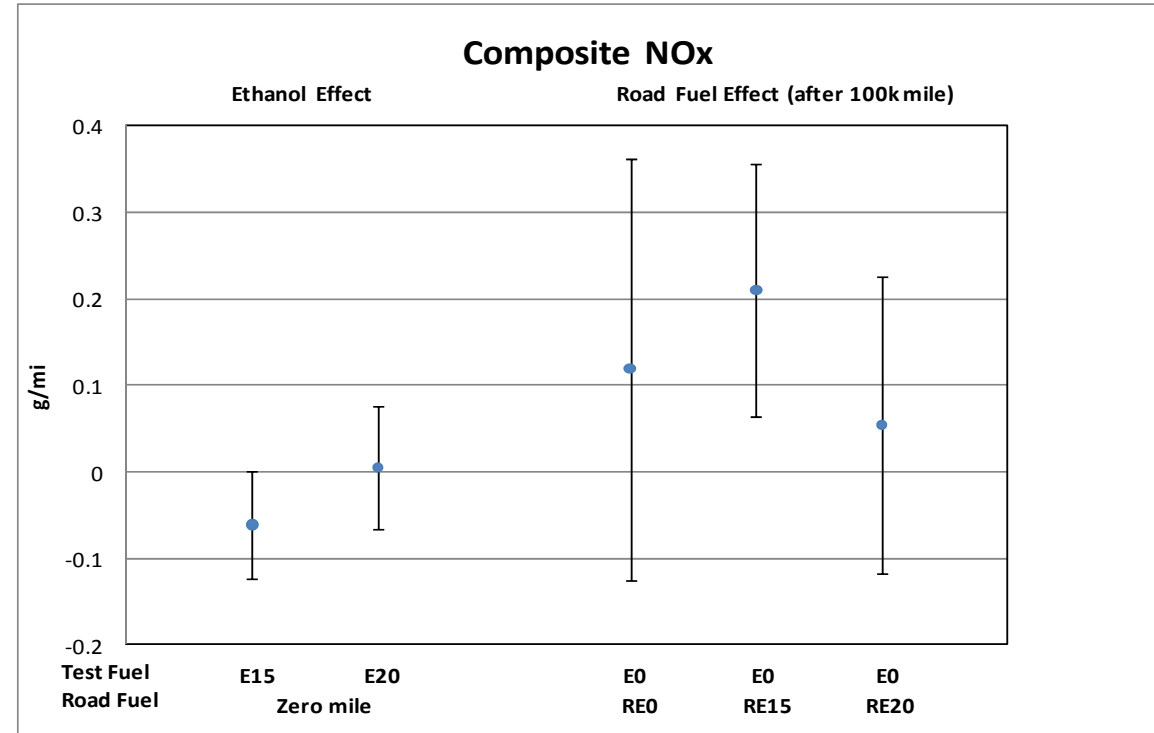

Error bars represent $95 \%$ confidence intervals on the estimated effects 
2002 Nissan Frontier (Composite Nonmethane Hydrocarbons)

\begin{tabular}{|l|r|r|r|}
\hline \multicolumn{1}{|c|}{ Effect } & & $\begin{array}{r}95 \% \text { C.I. } \\
\text { Estimate }\end{array}$ & $\begin{array}{r}\text { L5\% C.I. } \\
\text { Upper }\end{array}$ \\
\hline Ethanol Effect $(E 15$ vs. E0) $(\Delta \mathrm{g} / \mathrm{mi})$ & $-0.019^{*}$ & -0.033 & -0.005 \\
\hline Ethanol Effect $(E 20$ vs. E0) $(\Delta \mathrm{g} / \mathrm{mi})$ & $-0.027^{*}$ & -0.043 & -0.012 \\
\hline Road Fuel Aging Effect & & & \\
\hline Aging Effect with RE0 $(\Delta \mathrm{g} / \mathrm{mi} \mathrm{per} \mathrm{100k} \mathrm{mi)}$ & -0.022 & -0.052 & 0.009 \\
\hline Aging Effect with RE15 $(\Delta \mathrm{g} / \mathrm{mi}$ per 100k mi) & $0.042^{*}$ & 0.018 & 0.065 \\
\hline Aging Effect with RE20 $(\Delta \mathrm{g} / \mathrm{mi} \mathrm{per} \mathrm{100k} \mathrm{mi)}$ & 0.005 & -0.025 & 0.035 \\
\hline
\end{tabular}

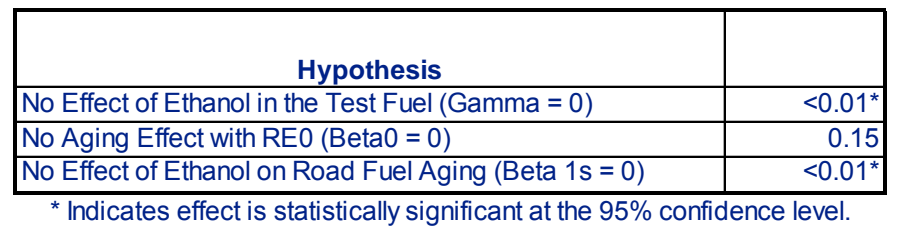

* Indicates estimate is different from zero at the $95 \%$ confidence

Initial odometers $91 \mathrm{k}-96 \mathrm{k}$

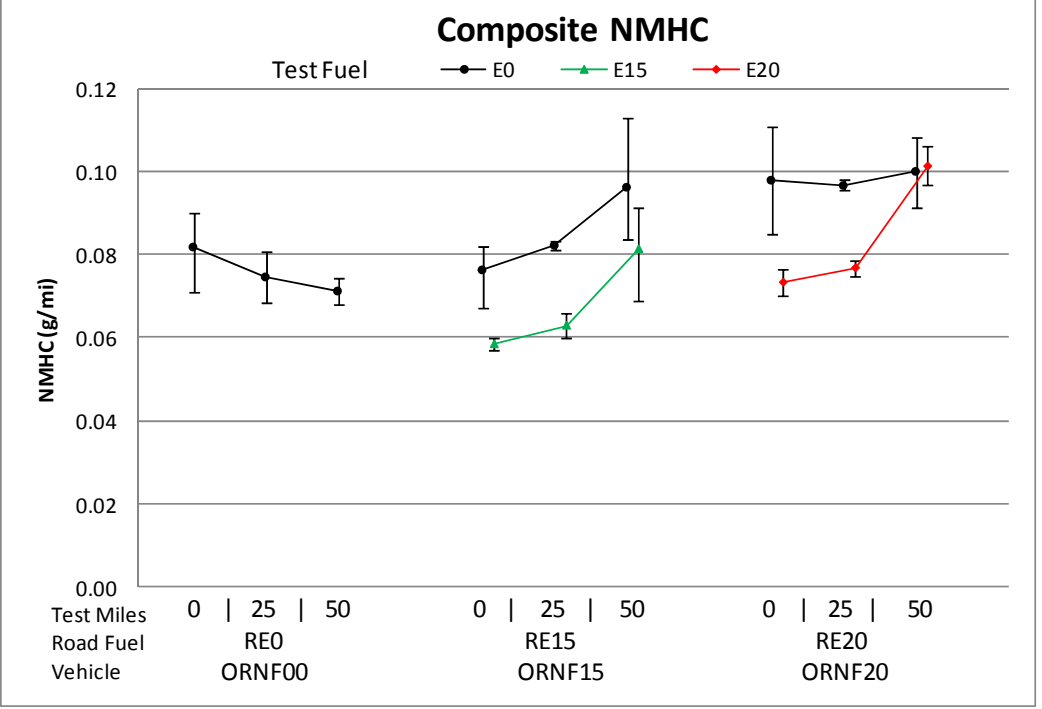

Error bars represent min and max measurements

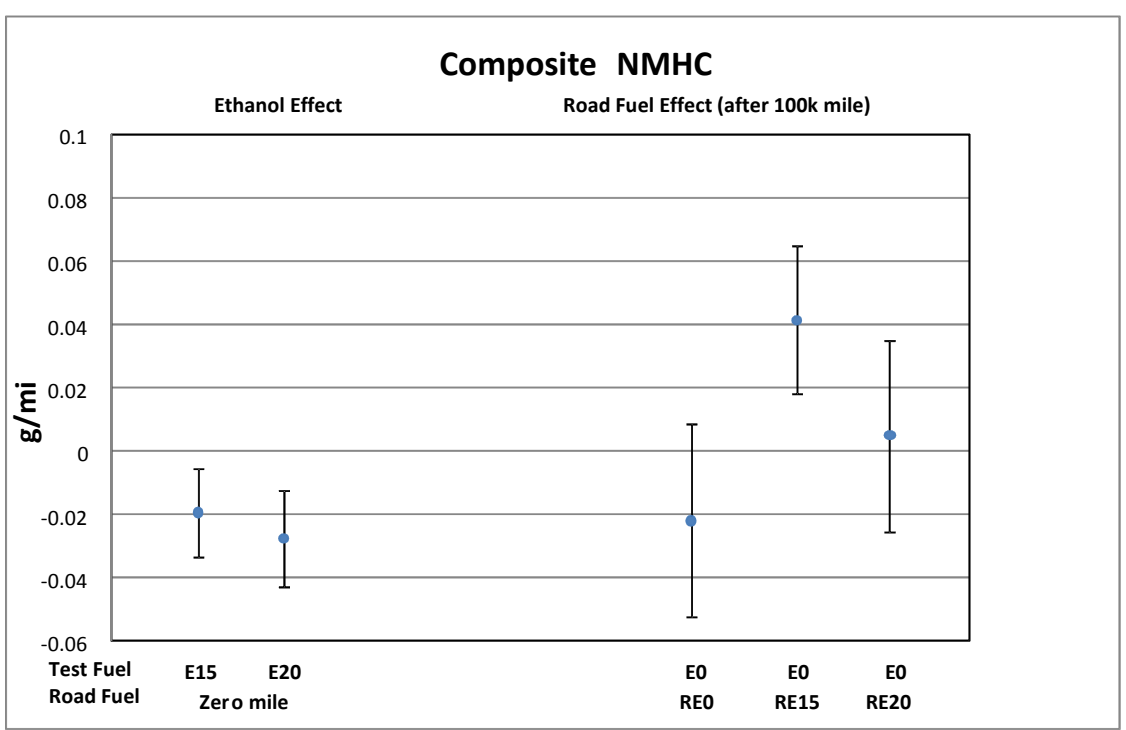

Error bars represent $95 \%$ confidence intervals on the estimated effects 
2002 Nissan Frontier (Composite Nonmethane Organic Gases)

\begin{tabular}{|c|c|c|c|}
\hline Effect & Estimate & \begin{tabular}{|c}
$\begin{array}{c}95 \% \text { C.I. } \\
\text { Lower }\end{array}$ \\
\end{tabular} & $\begin{array}{r}95 \% \text { C.I. } \\
\text { Upper } \\
\end{array}$ \\
\hline Ethanol Effect (E15 vs. E0) $(\Delta \mathrm{g} / \mathrm{mi})$ & -0.013 & -0.028 & 0.002 \\
\hline Ethanol Effect (E20 vs. E0) $(\Delta \mathrm{g} / \mathrm{mi})$ & $-0.018^{*}$ & -0.034 & -0.001 \\
\hline \multicolumn{4}{|l|}{ Road Fuel Aging Effect } \\
\hline Aging Effect with RE0 $(\Delta \mathrm{g} / \mathrm{mi}$ per $100 \mathrm{k} \mathrm{mi})$ & -0.023 & -0.055 & 0.010 \\
\hline Aging Effect with RE15 ( $\Delta \mathrm{g} / \mathrm{mi}$ per $100 \mathrm{k} \mathrm{mi})$ & $0.043^{*}$ & 0.018 & 0.068 \\
\hline Aging Effect with RE20 ( $\Delta \mathrm{g} / \mathrm{mi}$ per $100 \mathrm{k}$ mi) & 0.004 & -0.029 & 0.037 \\
\hline
\end{tabular}

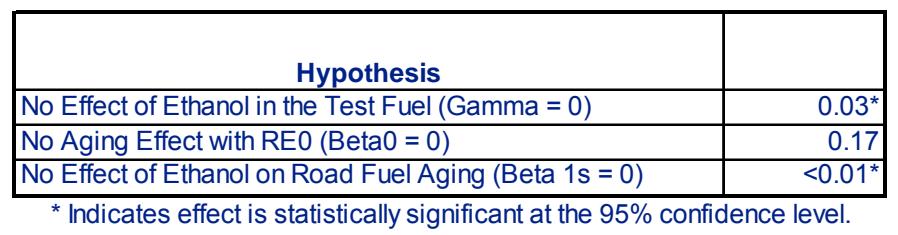

${ }^{*}$ Indicates estimate is different from zero at the $95 \%$ confidence level.

Initial odometers $91 \mathrm{k}-96 \mathrm{k}$
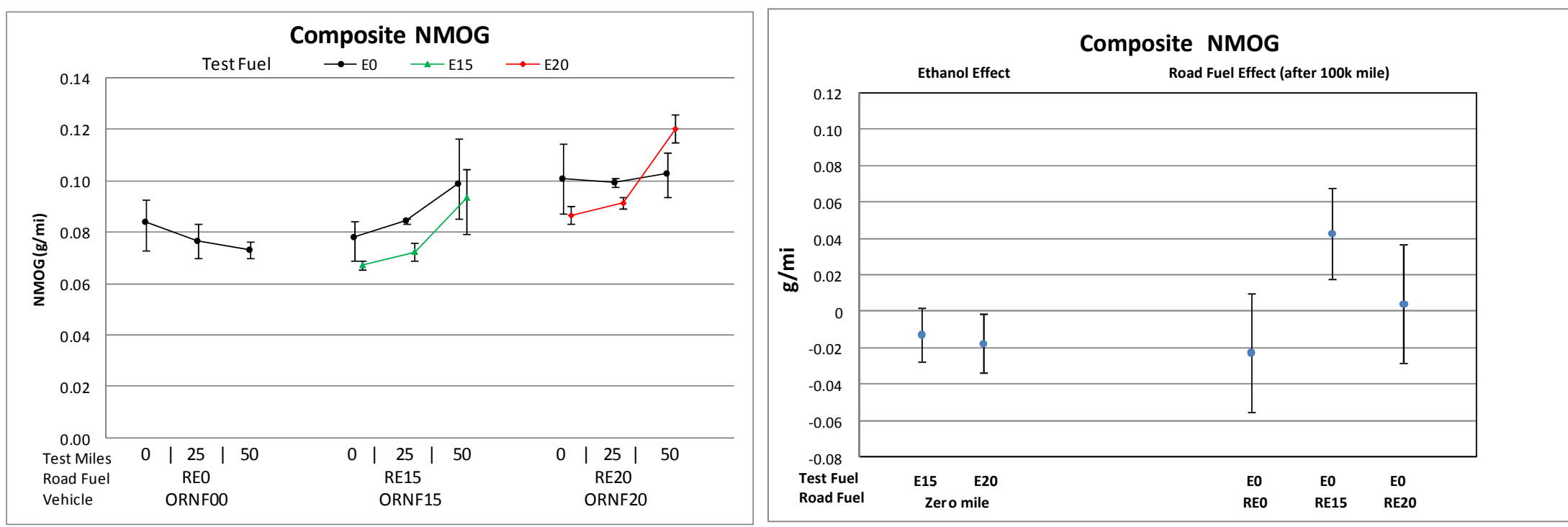

Error bars represent min and max measurements

Error bars represent 95\% confidence intervals on the estimated effects 
2002 Nissan Frontier (Composite Fuel Economy)

\begin{tabular}{|l|r|r|r|}
\hline \multicolumn{1}{|c|}{ Effect } & & $\begin{array}{r}95 \% \text { C.I. } \\
\text { Estimate }\end{array}$ & $\begin{array}{r}\text { 95\% C.I. } \\
\text { Upper }\end{array}$ \\
\hline Ethanol Effect (E15 vs. E0) $(\Delta \mathrm{mi} / \mathrm{gal})$ & $-0.074^{*}$ & -1.183 & -0.765 \\
\hline Ethanol Effect (E20 vs. E0) $(\Delta \mathrm{mi} / \mathrm{gal})$ & $-1.569^{*}$ & -1.773 & -1.365 \\
\hline Road Fuel Aging Effect & & & \\
\hline Aging Effect with RE0 $(\Delta \mathrm{mi} / \mathrm{gal}$ per 100k mi) & $0.953^{*}$ & 0.247 & 1.659 \\
\hline Aging Effect with RE15 $(\Delta \mathrm{mi} /$ gal per 100k mi) & -0.119 & -0.627 & 0.388 \\
\hline Aging Effect with RE20 $(\Delta \mathrm{mi} /$ gal per 100k mi) & $0.990^{*}$ & 0.493 & 1.487 \\
\hline
\end{tabular}

\begin{tabular}{|l|r|}
\hline \multicolumn{1}{|c|}{ Hypothesis } & -value \\
\hline No Effect of Ethanol in the Test Fuel (Gamma $=0)$ & $<0.01^{*}$ \\
\hline No Aging Effect with RE0 (Beta0 $=0$ ) & $0.02^{*}$ \\
\hline No Effect of Ethanol in Road Fuel Aging (Beta1s $=0$ ) & $0.01^{*}$ \\
\hline * Indicates effect is statistically significant at the $95 \%$ confidence level.
\end{tabular}

${ }^{*}$ Indicates estimate is different from zero at the $95 \%$ confidence level.

Initial odometers $91 \mathrm{k}-96 \mathrm{k}$

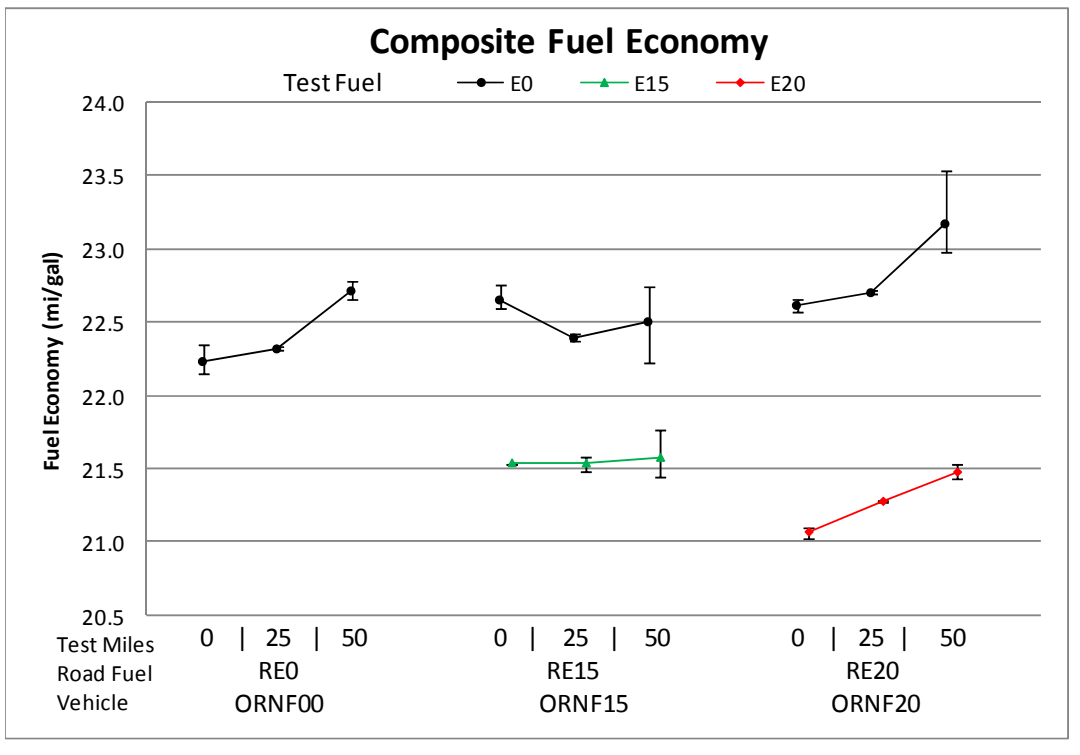

Error bars represent min and max measurements

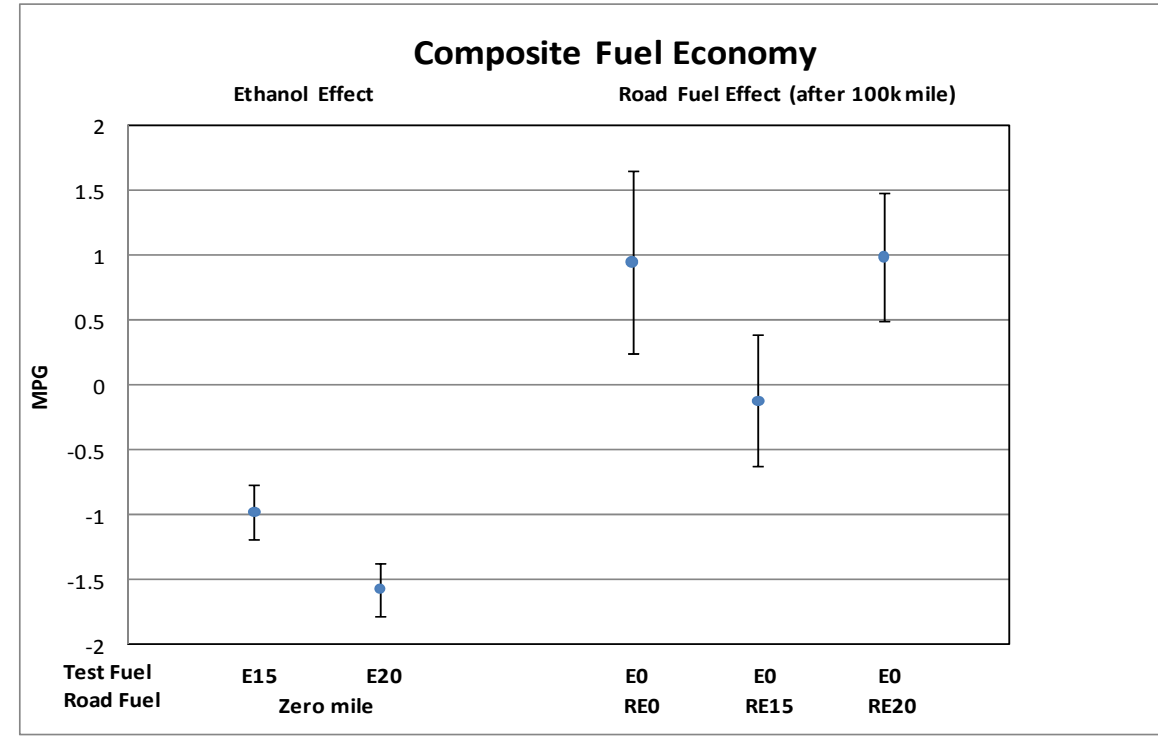

Error bars represent $95 \%$ confidence intervals on the estimated effects 
2002 Nissan Frontier (Composite Ethanol)

\begin{tabular}{|l|r|r|r|}
\hline \multicolumn{1}{|c|}{ Effect } & Estimate & $\begin{array}{r}\text { 95\% C.I. } \\
\text { Lower }\end{array}$ & $\begin{array}{r}\text { 95\% C.I. } \\
\text { Upper }\end{array}$ \\
\hline Ethanol Effect (E15 vs. E0) $(\Delta \mathrm{mg} / \mathrm{mi})$ & $5.237^{*}$ & 3.339 & 7.135 \\
\hline Ethanol Effect (E20 vs. E0) $(\Delta \mathrm{mg} / \mathrm{mi})$ & $6.422^{*}$ & 5.025 & 7.820 \\
\hline Road Fuel Aging Effect & & & \\
\hline Aging Effect with RE0 $(\Delta \mathrm{mg} / \mathrm{mi}$ per 100k mi) & -0.220 & -5.084 & 4.645 \\
\hline Aging Effect with RE15 $(\Delta \mathrm{mg} / \mathrm{mi}$ per 100k mi) & 0.528 & -3.172 & 4.228 \\
\hline Aging Effect with RE20 $(\Delta \mathrm{mg} / \mathrm{mi}$ per 100k mi) & 0.155 & -3.272 & 3.581 \\
\hline
\end{tabular}

\begin{tabular}{|l|r|}
\hline \multicolumn{1}{|c|}{ Hypothesis } & -value \\
\hline No Effect of Ethanol in the Test Fuel (Gamma = 0) & $<0.01^{*}$ \\
\hline No Aging Effect with RE0 (Beta0 $=0$ ) & 0.89 \\
\hline No Effect of Ethanol in Road Fuel Aging (Beta1s $=0$ ) & 0.92 \\
\hline * Indicates effect is statistically significant at the 95\% confidence level.
\end{tabular}

(1) 0.155

Initial odometers 91k-96k

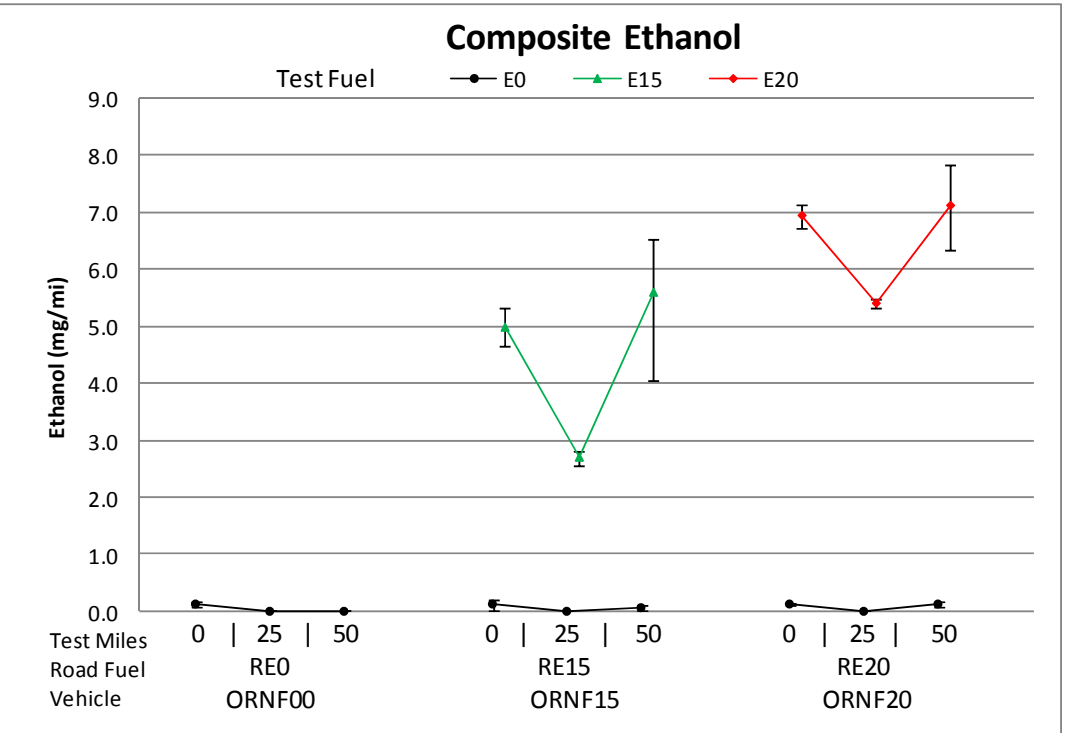

Error bars represent min and max measurements

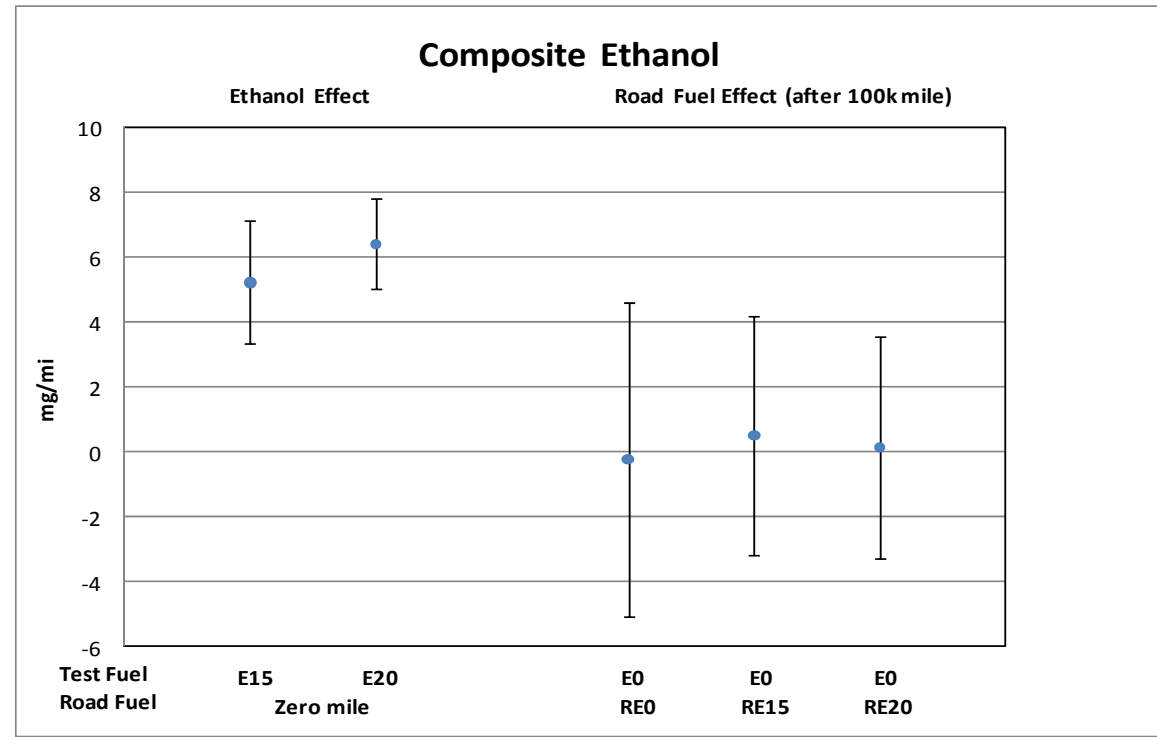

Error bars represent $95 \%$ confidence intervals on the estimated effects 
2002 Nissan Frontier (Composite Acetaldehyde)

\begin{tabular}{|l|r|r|r|}
\hline \multicolumn{1}{|c|}{ Effect } & & $\begin{array}{r}95 \% \text { C.I. } \\
\text { Estimate }\end{array}$ & $\begin{array}{r}\text { 95\% C.I. } \\
\text { Upper }\end{array}$ \\
\hline Ethanol Effect (E15 vs. E0) $(\Delta \mathrm{mg} / \mathrm{mi})$ & $0.638^{*}$ & 0.281 & 0.996 \\
\hline Ethanol Effect (E20 vs. E0) $(\Delta \mathrm{mg} / \mathrm{mi})$ & $1.108^{*}$ & 0.626 & 1.591 \\
\hline Road Fuel Aging Effect & & & \\
\hline Aging Effect with RE0 $(\Delta \mathrm{mg} / \mathrm{mi}$ per 100k mi) & 0.000 & -0.193 & 0.194 \\
\hline Aging Effect with RE15 $(\Delta \mathrm{mg} / \mathrm{mi}$ per 100k mi) & 0.152 & -0.197 & 0.501 \\
\hline Aging Effect with RE20 $(\Delta \mathrm{mg} / \mathrm{mi}$ per 100k mi) & 0.156 & -0.119 & 0.430 \\
\hline
\end{tabular}

\begin{tabular}{|l|r|}
\hline \multicolumn{1}{|c|}{ Hypothesis } & -value \\
\hline No Effect of Ethanol in the Test Fuel (Gamma $=0)$ & $<0.01^{*}$ \\
\hline No Aging Effect with RE0 (Beta0 $=0$ ) & 1.00 \\
\hline No Effect of Ethanol in Road Fuel Aging (Beta1s $=0$ ) & 0.70 \\
\hline * Indicates effect is statistically significant at the 95\% confidence level.
\end{tabular}

* Indicates estimate is different from zero at the $95 \%$ confidence level.

Initial odometers $91 \mathrm{k}-96 \mathrm{k}$
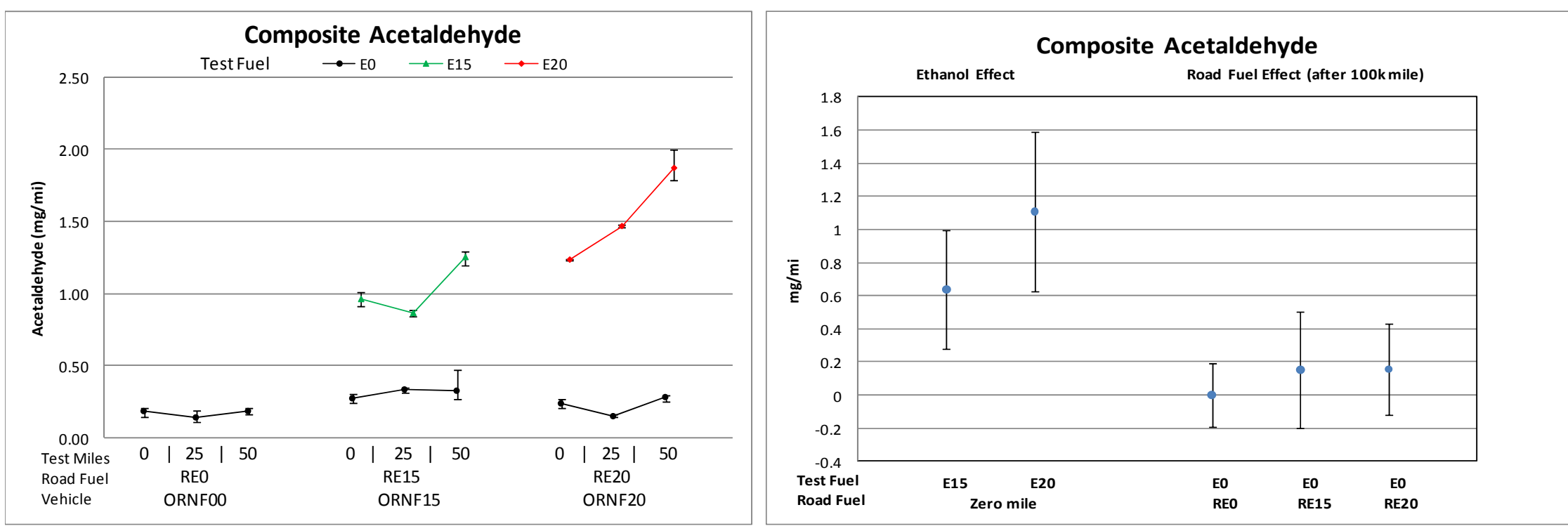

Error bars represent min and max measurements

Error bars represent $95 \%$ confidence intervals on the estimated effects 
2002 Nissan Frontier (Composite Formaldehyde)

\begin{tabular}{|l|r|r|r|}
\hline \multicolumn{1}{|c|}{ Effect } & Estimate & $\begin{array}{c}\text { 95\% C.I. } \\
\text { Lower }\end{array}$ & $\begin{array}{r}\text { 95\% C.I. } \\
\text { Upper }\end{array}$ \\
\hline Ethanol Effect (E15 vs. E0) $(\Delta \mathrm{mg} / \mathrm{mi})$ & 0.035 & -0.289 & 0.360 \\
\hline Ethanol Effect $($ E20 vs. E0) $(\Delta \mathrm{mg} / \mathrm{mi})$ & 0.166 & -0.226 & 0.559 \\
\hline Road Fuel Aging Effect & & & \\
\hline Aging Effect with RE0 $(\Delta \mathrm{mg} / \mathrm{mi}$ per 100k mi) & 0.236 & -0.573 & 1.044 \\
\hline Aging Effect with RE15 $(\Delta \mathrm{mg} / \mathrm{mi}$ per 100k mi) & 0.455 & -0.397 & 1.307 \\
\hline Aging Effect with RE20 $(\Delta \mathrm{mg} / \mathrm{mi}$ per 100k mi) & 0.361 & -0.473 & 1.196 \\
\hline
\end{tabular}

\begin{tabular}{|l|r|}
\hline \multicolumn{1}{|c|}{ Hypothesis } & -value \\
\hline No Effect of Ethanol in the Test Fuel (Gamma = 0) & 0.43 \\
\hline No Aging Effect with RE0 (Beta0 = 0) & 0.51 \\
\hline No Effect of Ethanol in Road Fuel Aging (Beta1s=0) & 0.96 \\
\hline * Indicates effect is statistically significant at the 95\% confidence level.
\end{tabular}

* Indicates estimate is different from zero at the $95 \%$ confidence level.

Initial odometers $91 \mathrm{k}-96 \mathrm{k}$

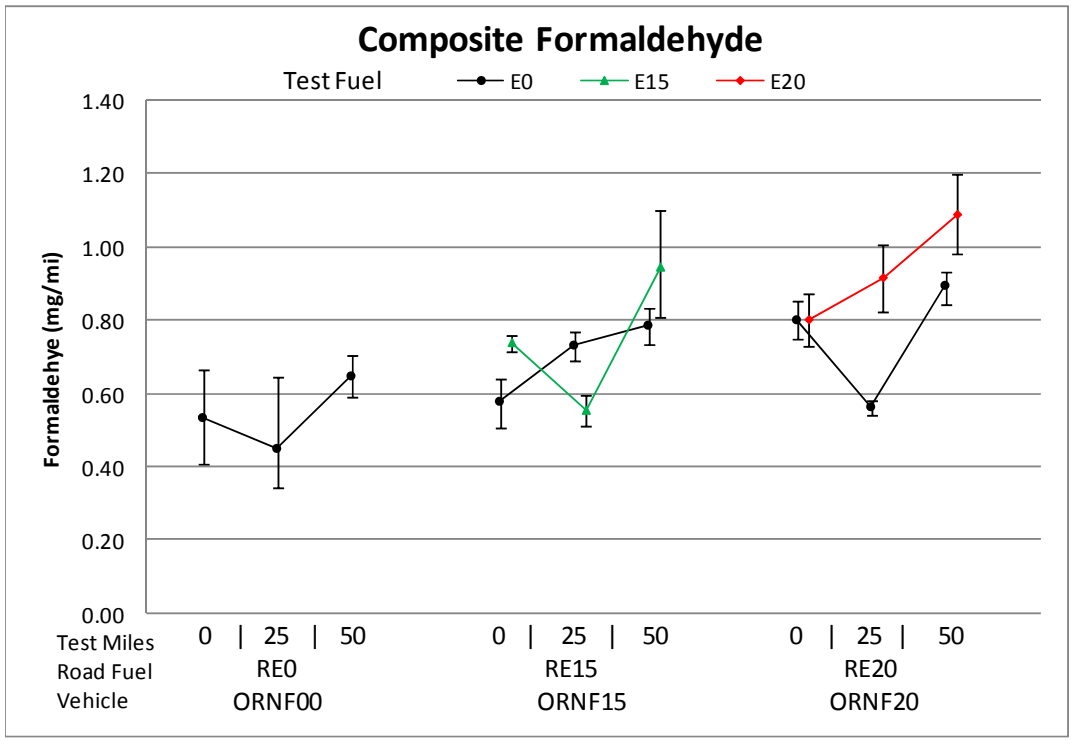

Error bars represent min and max measurements

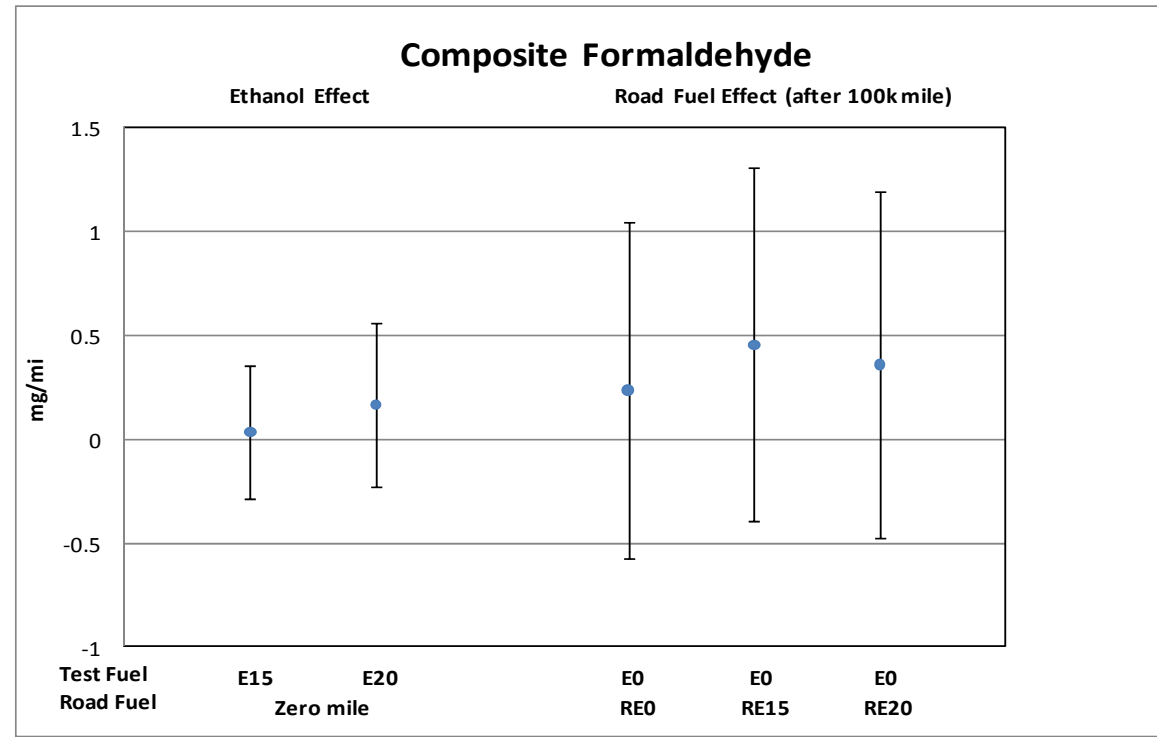

Error bars represent $95 \%$ confidence intervals on the estimated effects 
2002 Nissan Frontier (Composite $\mathrm{CH} 4$ )

\begin{tabular}{|l|r|r|r|}
\hline \multicolumn{1}{|c|}{ Effect } & Estimate & $\begin{array}{c}95 \% \text { C.I. } \\
\text { Lower }\end{array}$ & $\begin{array}{c}\text { 95\% C.I. } \\
\text { Upper }\end{array}$ \\
\hline Ethanol Effect (E15 vs. E0) $(\Delta \mathrm{g} / \mathrm{mi})$ & 0.0026 & -0.0016 & 0.0068 \\
\hline Ethanol Effect $($ E20 vs. E0) $(\Delta \mathrm{g} / \mathrm{mi})$ & 0.0040 & -0.0003 & 0.0082 \\
\hline Road Fuel Aging Effect & & & \\
\hline Aging Effect with RE0 $(\Delta \mathrm{g} / \mathrm{mi}$ per 100k mi) & $0.0479^{*}$ & 0.0332 & 0.0625 \\
\hline Aging Effect with RE15 $(\Delta \mathrm{g} / \mathrm{mi} \mathrm{per} \mathrm{100k} \mathrm{mi)}$ & $0.0256^{*}$ & 0.0154 & 0.0359 \\
\hline Aging Effect with RE20 $(\Delta \mathrm{g} / \mathrm{mi}$ per 100k mi) & $0.0280^{*}$ & 0.0177 & 0.0384 \\
\hline
\end{tabular}

\begin{tabular}{|l|r|}
\hline \multicolumn{1}{|c|}{ Hypothesis } & p-value \\
\hline No Effect of Ethanol in the Test Fuel (Gamma = 0) & 0.09 \\
\hline No Aging Effect with RE0 (Beta0 = 0) & $<0.01^{*}$ \\
\hline No Effect of Ethanol in Road Fuel Aging (Beta1s=0) & 0.05 \\
\hline * Indicates effect is statistically significant at the 95\% confidence level.
\end{tabular}

* Indicates estimate is different from zero at the $95 \%$ confidence level.

Initial odometers 91k-96k

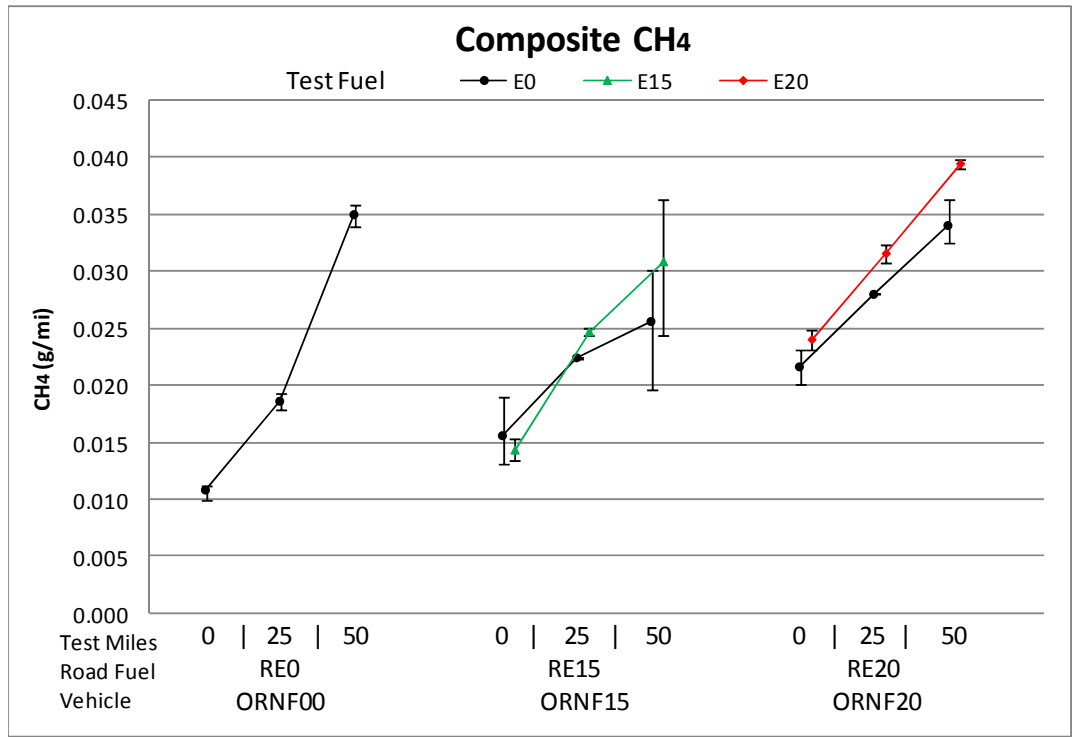

Error bars represent min and max measurements

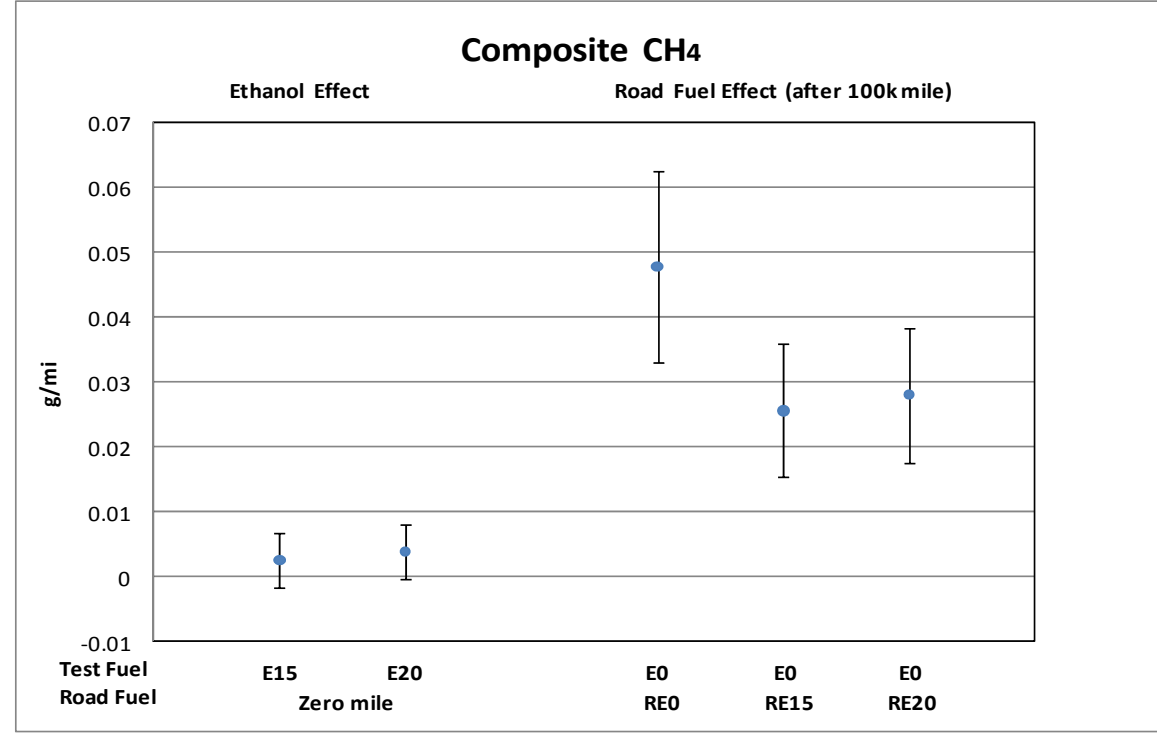

Error bars represent $95 \%$ confidence intervals on the estimated effects 


\section{Dodge Durango - Composite Emissions Summary}

\begin{tabular}{|c|c|c|c|c|c|c|c|c|c|c|c|c|c|c|}
\hline \multirow{2}{*}{$\begin{array}{l}\text { Emisssion Parameter } \\
\text { (units) }\end{array}$} & \multicolumn{4}{|c|}{ Ethanol Effect } & \multicolumn{2}{|c|}{ Aging Effect with RE0 } & \multicolumn{4}{|c|}{ RExx Aging Effect on EO Emissions } & \multirow{2}{*}{\multicolumn{3}{|c|}{\begin{tabular}{|c|} 
RExx Aging Effect on Exx Emissions \\
$\Delta$ units per $100 \mathrm{~K} \mathrm{mi}$ \\
\end{tabular}}} & \multirow{3}{*}{\begin{tabular}{|c}
$\begin{array}{l}\text { Road and Test } \\
\text { Fuel Effects } \\
\text { are Additive }\end{array}$ \\
$\begin{array}{c}\text { Overall p- } \\
\text { value }\end{array}$ \\
\end{tabular}} \\
\hline & \multicolumn{3}{|c|}{$\Delta$ units vs. EO } & \multirow{2}{*}{$\begin{array}{l}\text { Overall } \\
p \text {-value }\end{array}$} & \multirow{2}{*}{$\begin{array}{c}\Delta \text { units per } 100 \mathrm{~K} \mathrm{mi} \\
\mathrm{REO} / \mathrm{EO}\end{array}$} & \multirow{2}{*}{$\begin{array}{l}\text { Overall } \\
p \text {-value }\end{array}$} & \multicolumn{3}{|c|}{$\Delta$ units per $100 \mathrm{~K} \mathrm{mi}$} & \multirow{2}{*}{$\begin{array}{l}\text { Overall } \\
p \text {-value }\end{array}$} & & & & \\
\hline Fuels & E10 & E15 & E20 & & & & RE10/E0 & RE15/E0 & RE20/E0 & & RE10/E10 & RE15/E15 & RE20/E20 & \\
\hline $\mathrm{CO}(\mathrm{g} / \mathrm{mi})^{\mathrm{a}}$ & NA & 0.425 & 0.356 & 0.07 & -0.345 & 0.49 & NA & 0.935 & 0.537 & 0.20 & NA & -0.455 & -1.018 & $0.02 *$ \\
\hline $\mathrm{NOx}(\mathrm{g} / \mathrm{mi})$ & NA & 0.053 & 0.070 & 0.41 & 0.153 & 0.49 & $\mathrm{NA}$ & 0.308 & $0.482^{*}$ & 0.46 & NA & $\mathrm{NA}$ & NA & 0.96 \\
\hline NMHC $(\mathrm{g} / \mathrm{mi})^{\mathrm{a}}$ & NA & -0.011 & -0.012 & 0.13 & $-0.068 *$ & $0.02 *$ & NA & 0.011 & -0.020 & 0.07 & NA & $\mathrm{NA}$ & $\mathrm{NA}$ & 0.10 \\
\hline NMOG $(\mathrm{g} / \mathrm{mi})^{\mathrm{a}}$ & $\mathrm{NA}$ & 0.0047 & 0.0092 & 0.46 & $-0.0693^{*}$ & $0.02 *$ & $\mathrm{NA}$ & 0.0115 & -0.0243 & 0.08 & NA & $\mathrm{NA}$ & $\mathrm{NA}$ & 0.07 \\
\hline Fuel Econ (mi/gal) & NA & $-0.809 *$ & $-0.872 *$ & $<0.01^{*}$ & 0.673 & 0.06 & NA & 0.485 & $0.739 *$ & 0.71 & NA & $\mathrm{NA}$ & NA & 0.30 \\
\hline Ethanol $(\mathrm{mg} / \mathrm{mi})^{\text {\#\# }}$ & $\mathrm{NA}$ & 9.733* & $11.046 *$ & $<0.01 *$ & -0.299 & 0.88 & $\mathrm{NA}$ & 1.100 & 0.142 & 0.77 & NA & $\mathrm{NA}$ & $\mathrm{NA}$ & $\mathrm{NA}$ \\
\hline Acetaldehyde $(\mathrm{mg} / \mathrm{mi})^{\#}$ & NA & $1.895^{*}$ & $2.334 *$ & $<0.01^{*}$ & -0.096 & 0.32 & NA & $0.200 *$ & $0.198 *$ & 0.11 & NA & $\mathrm{NA}$ & NA & 0.85 \\
\hline Formaldehyde $(\mathrm{mg} / \mathrm{mi})^{\#}$ & NA & 0.071 & 0.322 & $0.03 *$ & $0.961 *$ & $<0.01 *$ & NA & $1.811^{*}$ & $1.641 *$ & 0.45 & NA & $\mathrm{NA}$ & NA & 0.83 \\
\hline $\mathrm{CH}_{4}(\mathrm{~g} / \mathrm{mi})^{\mathrm{b}}$ & NA & $0.0033^{*}$ & $0.0062 *$ & $<0.01 *$ & 0.0068 & 0.09 & NA & $0.0078 *$ & $0.0176 *$ & $0.05 *$ & NA & $\mathrm{NA}$ & $\mathrm{NA}$ & 0.85 \\
\hline
\end{tabular}

\# Log-normal model was used. Results are presented as changes in emissions at 0k mile.

\#\# Data did not support the assumption of linear effects with mileage.

* Indicates estimate is different from zero at the $95 \%$ confidence level.

a test "SW025516" is identified as an outlier and excluded from the analysis

b test "SW024800" is identified as an outlier and excluded from the analysis 
2002 Dodge Durango (Composite CO)

\begin{tabular}{|l|r|r|r|}
\hline \multicolumn{1}{|c|}{ Effect } & & $95 \%$ C.I. & $\begin{array}{c}95 \% \text { C.I. } \\
\text { Upper }\end{array}$ \\
\hline Ethanol Effect $(E 15$ vs. E0) $(\Delta \mathrm{g} / \mathrm{mi})$ & 0.425 & -0.042 & 0.891 \\
\hline Ethanol Effect $($ E20 vs. E0) $(\Delta \mathrm{g} / \mathrm{mi})$ & 0.356 & -0.112 & 0.825 \\
\hline Road Fuel Aging Effect & & & \\
\hline Aging Effect with RE0 $(\Delta \mathrm{g} / \mathrm{mi}$ per 100k mi) & -0.345 & -1.375 & 0.685 \\
\hline Aging Effect with RE15 $(\Delta \mathrm{g} / \mathrm{mi}$ per 100k mi) & 0.935 & -0.100 & 1.970 \\
\hline Aging Effect with RE20 $(\Delta \mathrm{g} / \mathrm{mi} \mathrm{per} \mathrm{100k} \mathrm{mi)}$ & 0.537 & -0.492 & 1.566 \\
\hline
\end{tabular}

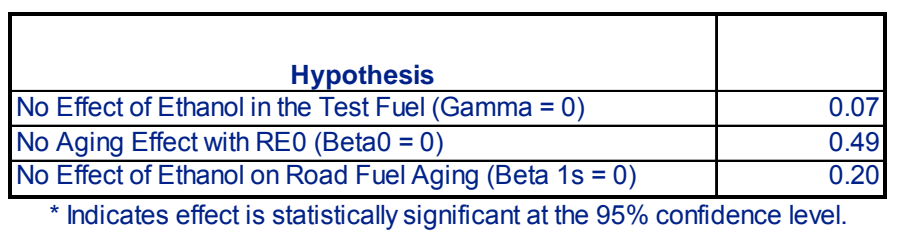

* Indicates estimate is different from zero at the $95 \%$ confidence level.

Initial odometers $60 \mathrm{k}-71 \mathrm{k}$

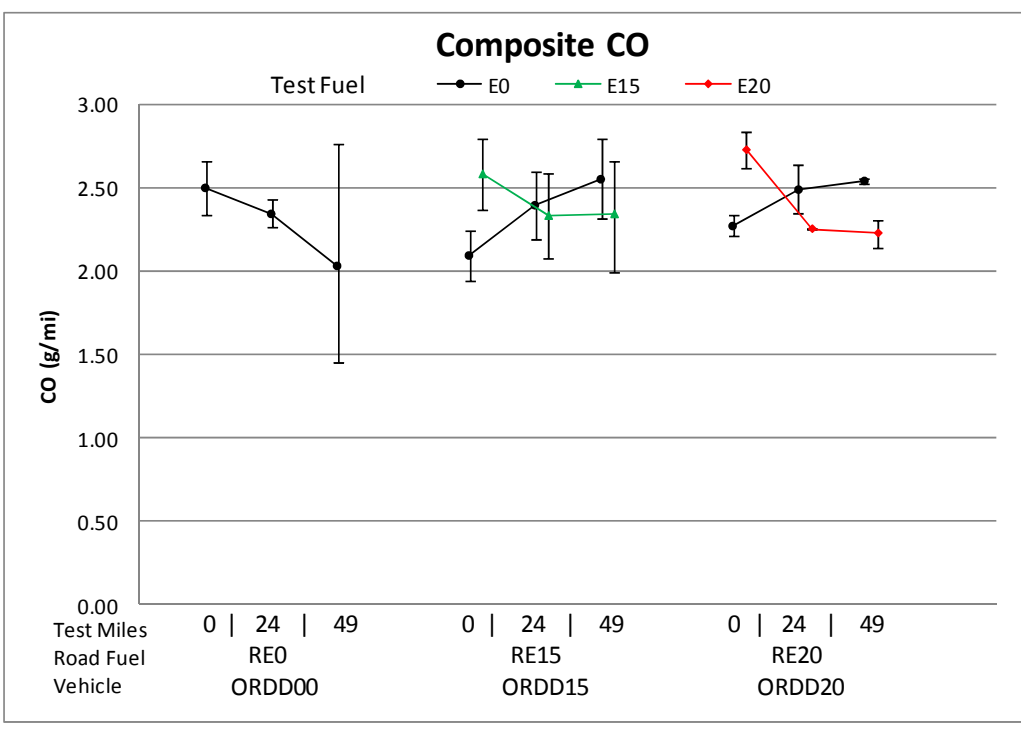

Error bars represent min and max measurements

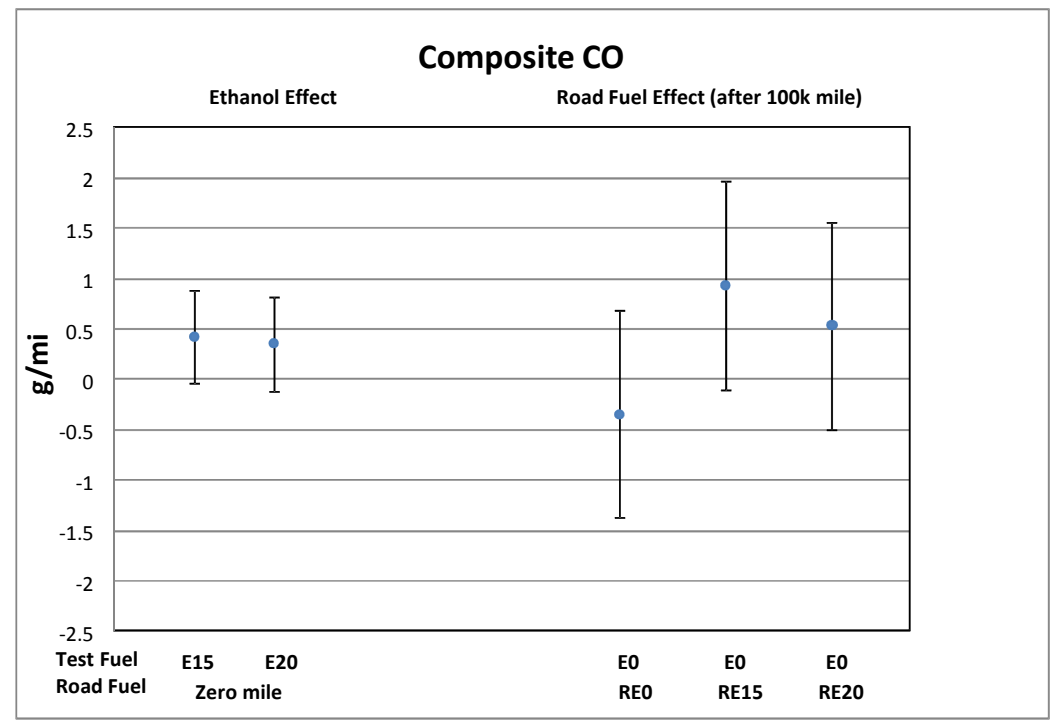

Error bars represent $95 \%$ confidence intervals on the estimated effects 
2002 Dodge Durango (Composite NOx)

\begin{tabular}{|l|r|r|r|}
\hline \multicolumn{1}{|c|}{ Effect } & Estimate & $\begin{array}{c}\text { 95\% C.I. } \\
\text { Lower }\end{array}$ & $\begin{array}{r}\text { 95\% C.I. } \\
\text { Upper }\end{array}$ \\
\hline Ethanol Effect (E15 vs. E0) $(\Delta \mathrm{g} / \mathrm{mi})$ & 0.053 & -0.091 & 0.197 \\
\hline Ethanol Effect $(E 20 \mathrm{vs.} \mathrm{E0)}(\Delta \mathrm{g} / \mathrm{mi})$ & 0.070 & -0.074 & 0.214 \\
\hline Road Fuel Aging Effect & & & \\
\hline Aging Effect with RE0 $(\Delta \mathrm{g} / \mathrm{mi}$ per 100k mi) & 0.153 & -0.348 & 0.653 \\
\hline Aging Effect with RE15 $(\Delta \mathrm{g} / \mathrm{mi}$ per 100k mi) & 0.308 & -0.048 & 0.664 \\
\hline Aging Effect with RE20 $(\Delta \mathrm{g} / \mathrm{mi}$ per 100k mi) & $0.482^{*}$ & 0.127 & 0.837 \\
\hline
\end{tabular}

\begin{tabular}{|l|r|}
\hline \multicolumn{1}{|c|}{ Hypothesis } & p-value \\
\hline No Effect of Ethanol in the Test Fuel (Gamma = 0) & 0.41 \\
\hline No Aging Effect with RE0 (Beta0 = 0) & 0.49 \\
\hline No Effect of Ethanol in Road Fuel Aging (Beta1s=0) & 0.46 \\
\hline * Indicates effect is statistically significant at the 95\% confidence level.
\end{tabular}

Initial odometers $60 \mathrm{k}-71 \mathrm{k}$

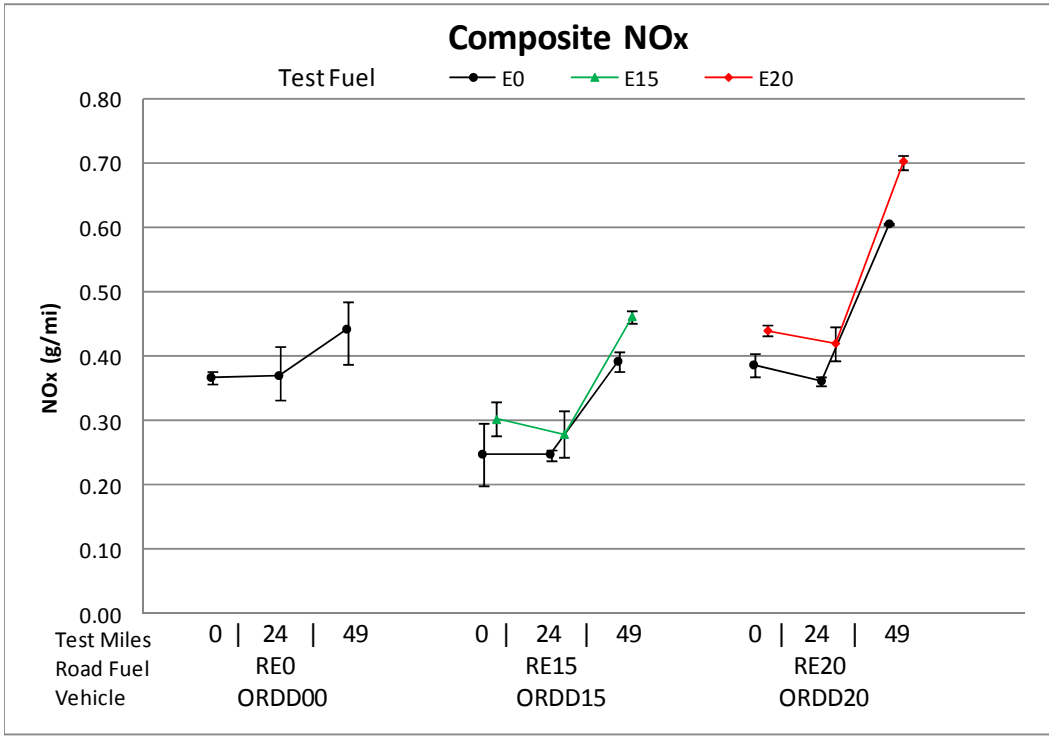

Error bars represent min and max measurements

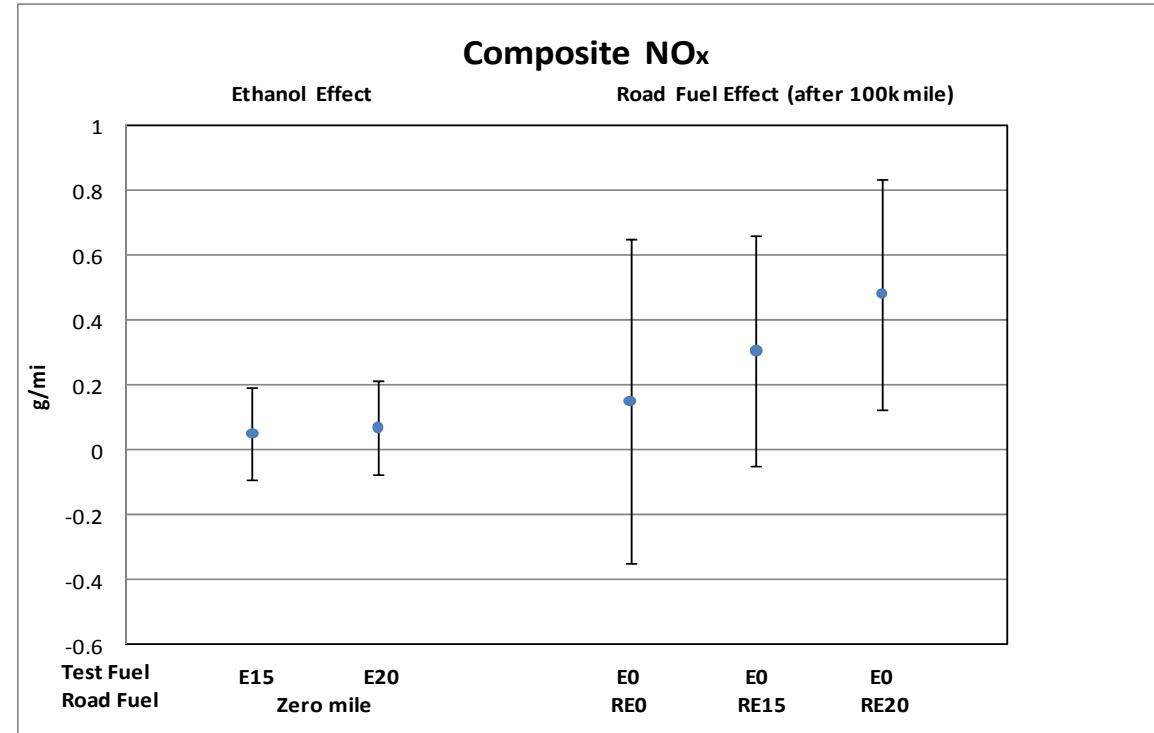

Error bars represent $95 \%$ confidence intervals on the estimated effects 
2002 Dodge Durango (Composite Nonmethane Hydrocarbons)

\begin{tabular}{|l|r|r|r|}
\hline \multicolumn{1}{|c|}{ Effect } & Estimate & $\begin{array}{c}\text { 95\% C.I. } \\
\text { Lower }\end{array}$ & $\begin{array}{r}\text { 95\% C.I. } \\
\text { Upper }\end{array}$ \\
\hline Ethanol Effect (E15 vs. E0) $(\Delta \mathrm{g} / \mathrm{mi})$ & -0.011 & -0.026 & 0.005 \\
\hline Ethanol Effect $($ E20 vs. E0) $(\Delta \mathrm{g} / \mathrm{mi})$ & -0.012 & -0.028 & 0.004 \\
\hline Road Fuel Aging Effect & & & \\
\hline Aging Effect with RE0 $(\Delta \mathrm{g} / \mathrm{mi}$ per 100k mi) & $-0.068^{*}$ & -0.124 & -0.012 \\
\hline Aging Effect with RE15 $(\Delta \mathrm{g} / \mathrm{mi}$ per 100k mi) & 0.011 & -0.027 & 0.049 \\
\hline Aging Effect with RE20 $(\Delta \mathrm{g} / \mathrm{mi}$ per 100k mi) & -0.020 & -0.060 & 0.019 \\
\hline
\end{tabular}

\begin{tabular}{|l|r|}
\hline \multicolumn{1}{|c|}{ Hypothesis } & p-value \\
\hline No Effect of Ethanol in the Test Fuel (Gamma $=0)$ & 0.13 \\
\hline No Aging Effect with RE0 (Beta0 $=0)$ & $0.02^{*}$ \\
\hline No Effect of Ethanol in Road Fuel Aging (Beta1s=0) & 0.07 \\
\hline${ }^{*}$ Indicates effect is statistically significant at the 95\% confidence level.
\end{tabular}

*

Initial odometers $60 \mathrm{k}-71 \mathrm{k}$

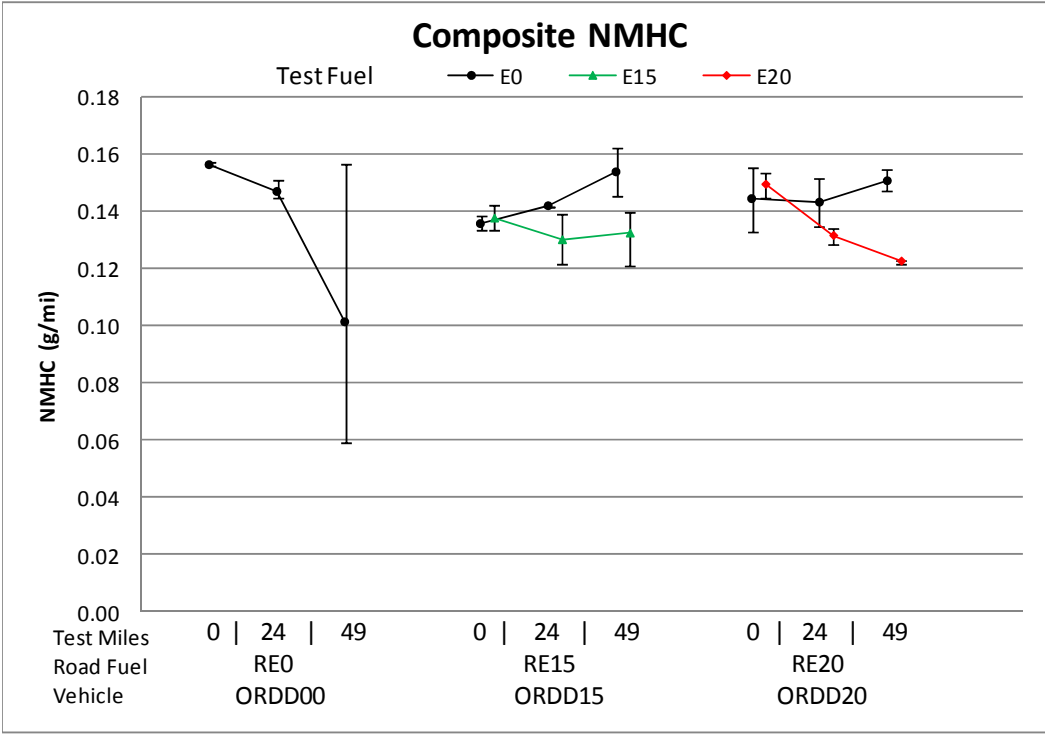

Error bars represent min and max measurements

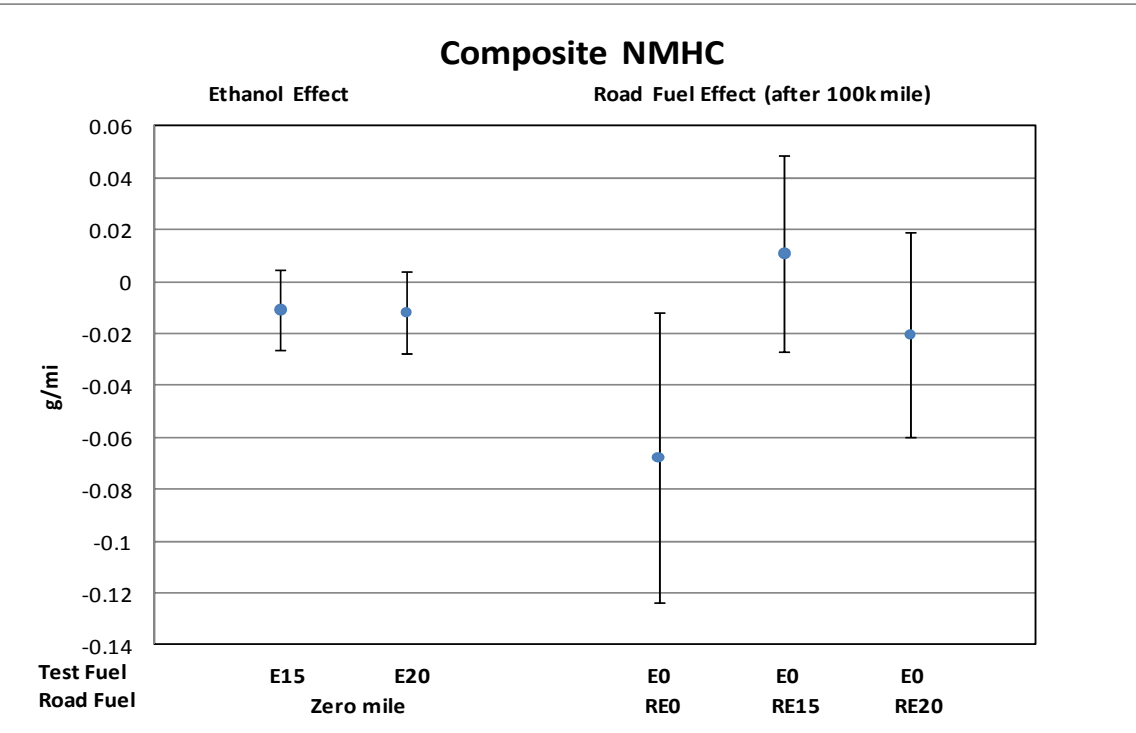

Error bars represent $95 \%$ confidence intervals on the estimated effects 
2002 Dodge Durango (Composite Nonmethane Organic Gases)

\begin{tabular}{|l|r|r|r|}
\hline \multicolumn{1}{|c|}{ Effect } & Estimate & $\begin{array}{c}\text { 95\% C.I. } \\
\text { Lower }\end{array}$ & $\begin{array}{c}\text { 95\% C.I. } \\
\text { Upper }\end{array}$ \\
\hline Ethanol Effect $(E 15 \mathrm{vs}$. E0) $(\Delta \mathrm{g} / \mathrm{mi})$ & 0.0047 & -0.0117 & 0.02109 \\
\hline Ethanol Effect $($ E20 vs. E0) $(\Delta \mathrm{g} / \mathrm{mi})$ & 0.0092 & -0.0077 & 0.02615 \\
\hline Road Fuel Aging Effect & & & \\
\hline Aging Effect with RE0 $(\Delta \mathrm{g} / \mathrm{mi}$ per 100k mi) & $-0.0693^{*}$ & -0.1283 & -0.0103 \\
\hline Aging Effect with RE15 $(\Delta \mathrm{g} / \mathrm{mi}$ per 100k mi) & 0.0115 & -0.0283 & 0.05135 \\
\hline Aging Effect with RE20 $(\Delta \mathrm{g} / \mathrm{mi}$ per 100k mi) & -0.0243 & -0.0661 & 0.01741 \\
\hline
\end{tabular}

\begin{tabular}{|l|r|}
\hline \multicolumn{1}{|c|}{ Hypothesis } & -value \\
\hline No Effect of Ethanol in the Test Fuel (Gamma = 0) & 0.46 \\
\hline No Aging Effect with RE0 (Beta0 = 0) & $0.02^{*}$ \\
\hline No Effect of Ethanol in Road Fuel Aging (Beta1s $=0$ ) & 0.08 \\
\hline * Indicates effect is statistically significant at the 95\% confidence level.
\end{tabular}

* Indicates estimate is different from zero at the $95 \%$ confidence level.

Initial odometers $60 \mathrm{k}-71 \mathrm{k}$

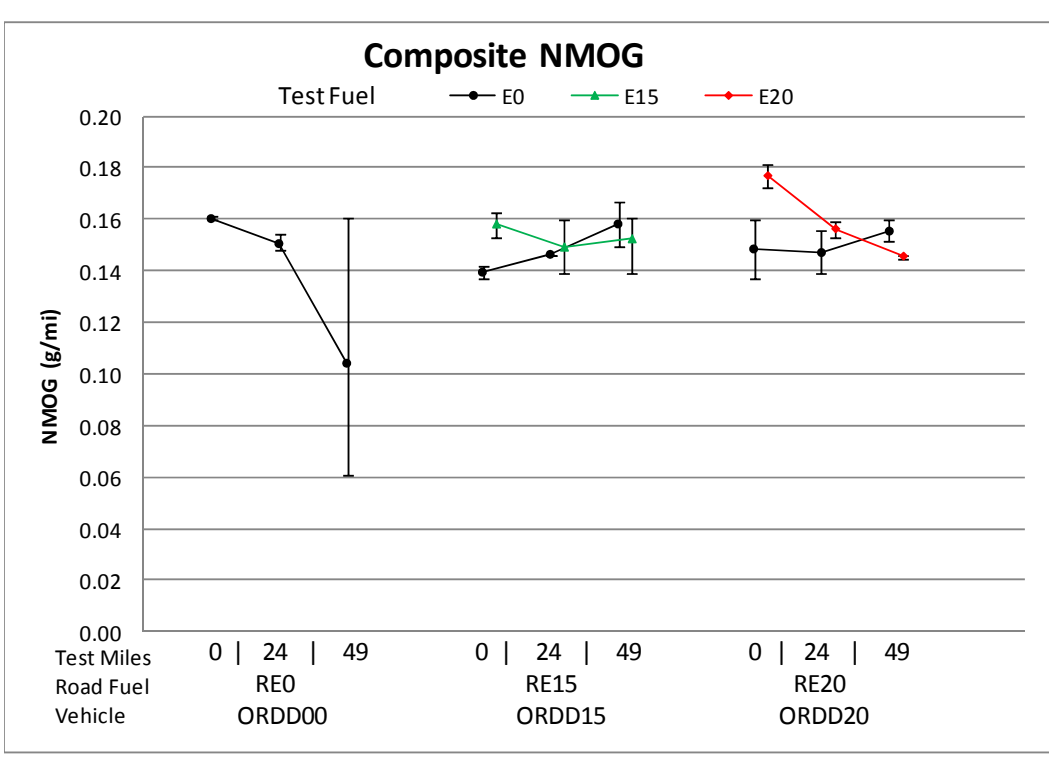

Error bars represent min and max measurements

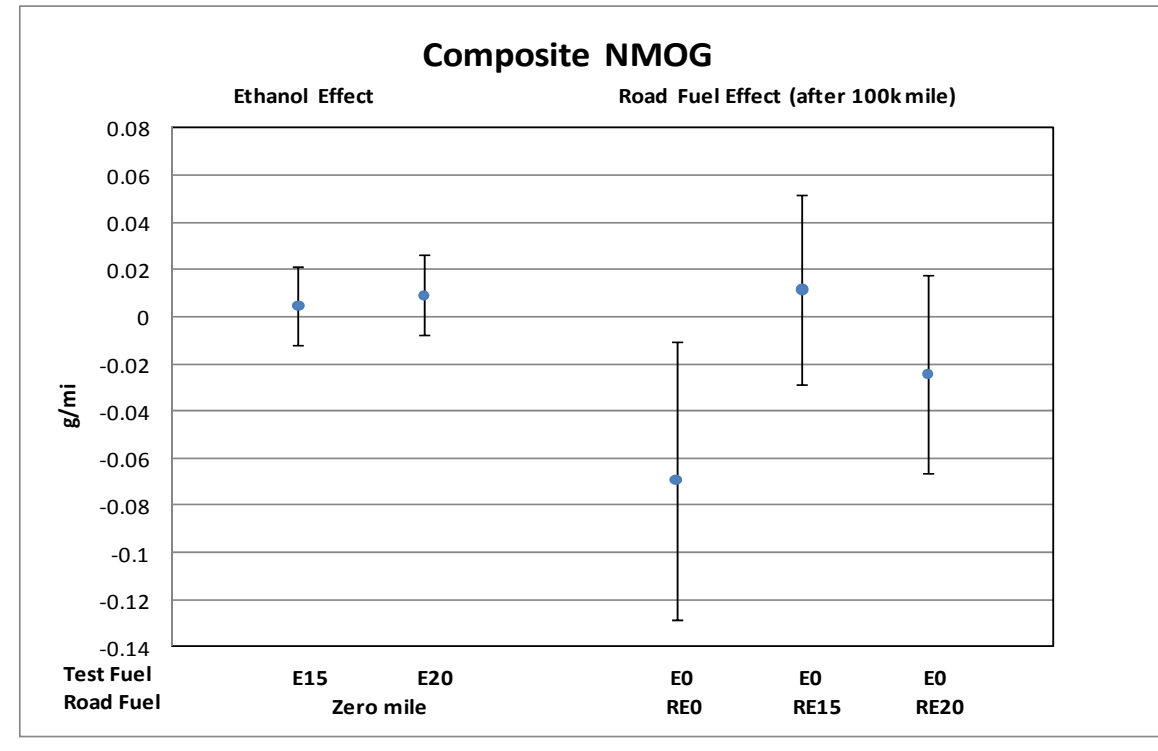

Error bars represent $95 \%$ confidence intervals on the estimated effects 
2002 Dodge Durango (Composite Fuel Economy)

\begin{tabular}{|l|r|r|r|}
\hline \multicolumn{1}{|c|}{ Effect } & Estimate & $\begin{array}{c}\text { 95\% C.I. } \\
\text { Lower }\end{array}$ & $\begin{array}{r}\text { 95\% C.I. } \\
\text { Upper }\end{array}$ \\
\hline Ethanol Effect (E15 vs. E0) $(\Delta \mathrm{mi} / \mathrm{gal})$ & $-0.809^{*}$ & -1.017 & -0.600 \\
\hline Ethanol Effect (E20 vs. E0) $(\Delta \mathrm{mi} / \mathrm{gal})$ & $-0.872^{*}$ & -1.081 & -0.664 \\
\hline Road Fuel Aging Effect & & & \\
\hline Aging Effect with RE0 $(\Delta \mathrm{mi} /$ gal per 100k mi) & 0.673 & -0.051 & 1.397 \\
\hline Aging Effect with RE15 $(\Delta \mathrm{mi} / \mathrm{gal}$ per 100k mi) & 0.485 & -0.031 & 1.000 \\
\hline Aging Effect with RE20 $(\Delta \mathrm{mi} /$ gal per 100k mi) & $0.739^{*}$ & 0.225 & 1.252 \\
\hline
\end{tabular}

\begin{tabular}{|l|r|}
\hline \multicolumn{1}{|c|}{ Hypothesis } & p-value \\
\hline No Effect of Ethanol in the Test Fuel (Gamma = 0) & $<0.01^{*}$ \\
\hline No Aging Effect with RE0 (Beta0 $=0)$ & 0.06 \\
\hline No Effect of Ethanol in Road Fuel Aging (Beta1s=0) & 0.71 \\
\hline * Indicates effect is statistically significant at the 95\% confidence level.
\end{tabular}

* Indicates estimate is different from zero at the $95 \%$ confidence level.

Initial odometers $60 \mathrm{k}-71 \mathrm{k}$

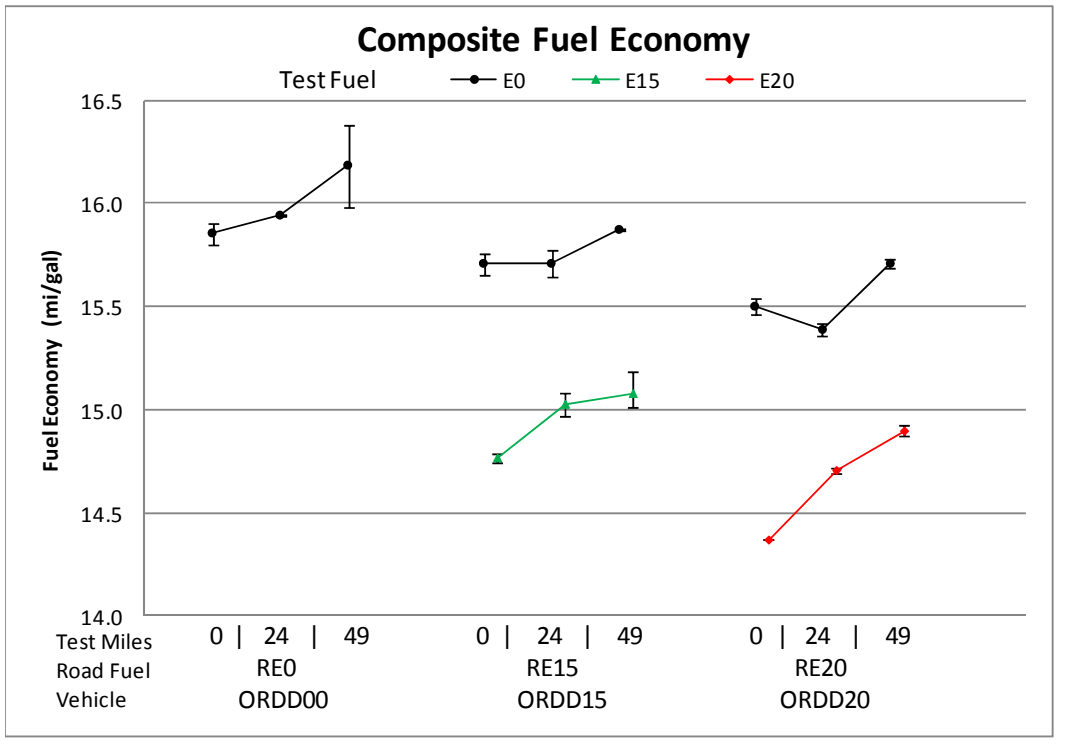

Error bars represent min and max measurements

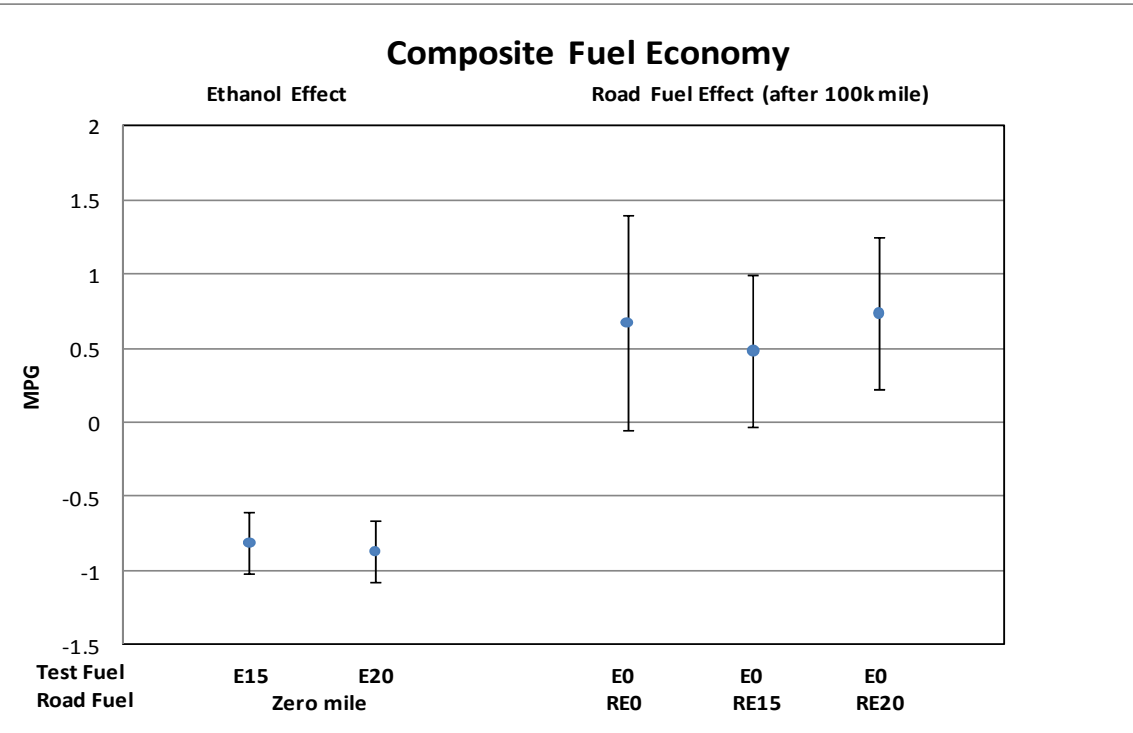

Error bars represent $95 \%$ confidence intervals on the estimated effects 
2002 Dodge Durango (Composite Ethanol)

\begin{tabular}{|c|c|c|c|}
\hline Effect & Estimate & $\begin{array}{l}95 \% \text { C.I. } \\
\text { Lower }\end{array}$ & $\begin{array}{c}95 \% \text { C.I. } \\
\text { Upper } \\
\end{array}$ \\
\hline Ethanol Effect (E15 vs. E0) $(\Delta \mathrm{mg} / \mathrm{mi})$ & $9.733^{*}$ & 8.196 & 11.271 \\
\hline Ethanol Effect (E20 vs. E0) $(\Delta \mathrm{mg} / \mathrm{mi})$ & $11.046^{*}$ & 9.518 & 12.575 \\
\hline \multicolumn{4}{|l|}{ Road Fuel Aging Effect } \\
\hline Aging Effect with RE0 $(\Delta \mathrm{mg} / \mathrm{mi}$ per $100 \mathrm{k} \mathrm{mi})$ & -0.299 & -5.690 & 5.093 \\
\hline Aging Effect with RE15 ( $\Delta \mathrm{mg} / \mathrm{mi}$ per $100 \mathrm{k} \mathrm{mi})$ & 1.100 & -2.710 & 4.911 \\
\hline Aging Effect with RE20 ( $\Delta \mathrm{mg} / \mathrm{mi}$ per $100 \mathrm{k} \mathrm{mi})$ & 0.142 & -3.905 & 3.622 \\
\hline
\end{tabular}

\begin{tabular}{|l|r|}
\hline \multicolumn{1}{|c|}{ Hypothesis } & p-value \\
\hline No Effect of Ethanol in the Test Fuel (Gamma = 0) & $<0.01^{*}$ \\
\hline No Aging Effect with RE0 (Beta0 = 0) & 0.88 \\
\hline No Effect of Ethanol in Road Fuel Aging (Beta1s=0) & 0.77 \\
\hline
\end{tabular}

\begin{tabular}{l|l}
$*$ & \\
$*$
\end{tabular}

Initial odometers $60 \mathrm{k}-71 \mathrm{k}$

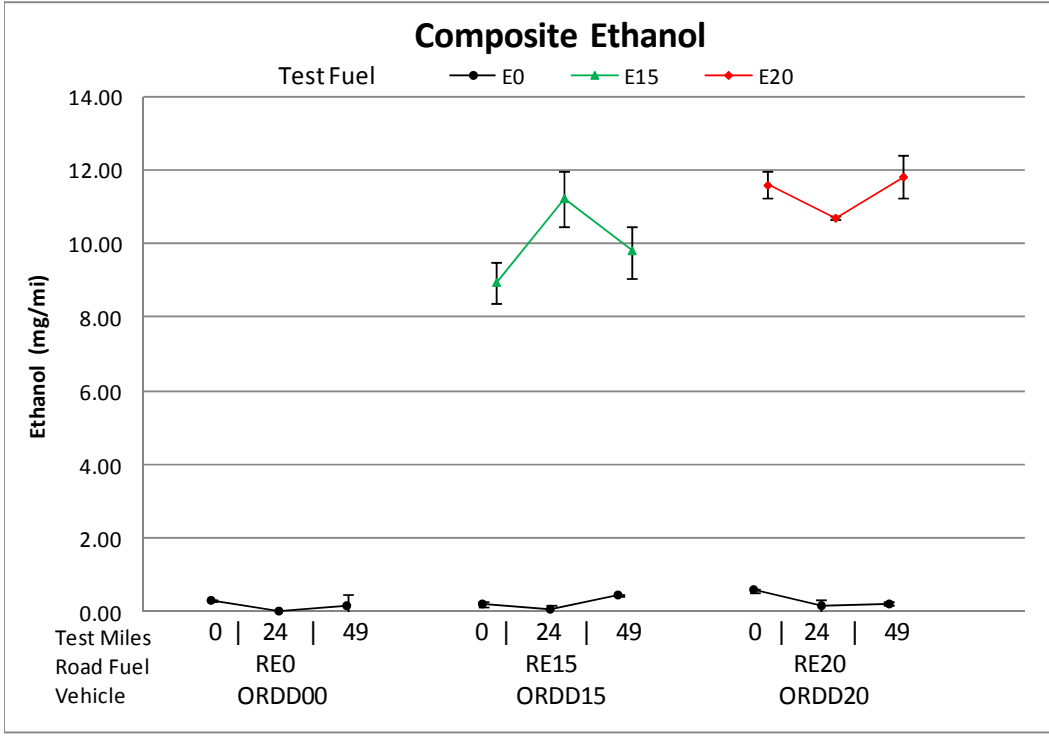

Error bars represent min and max measurements

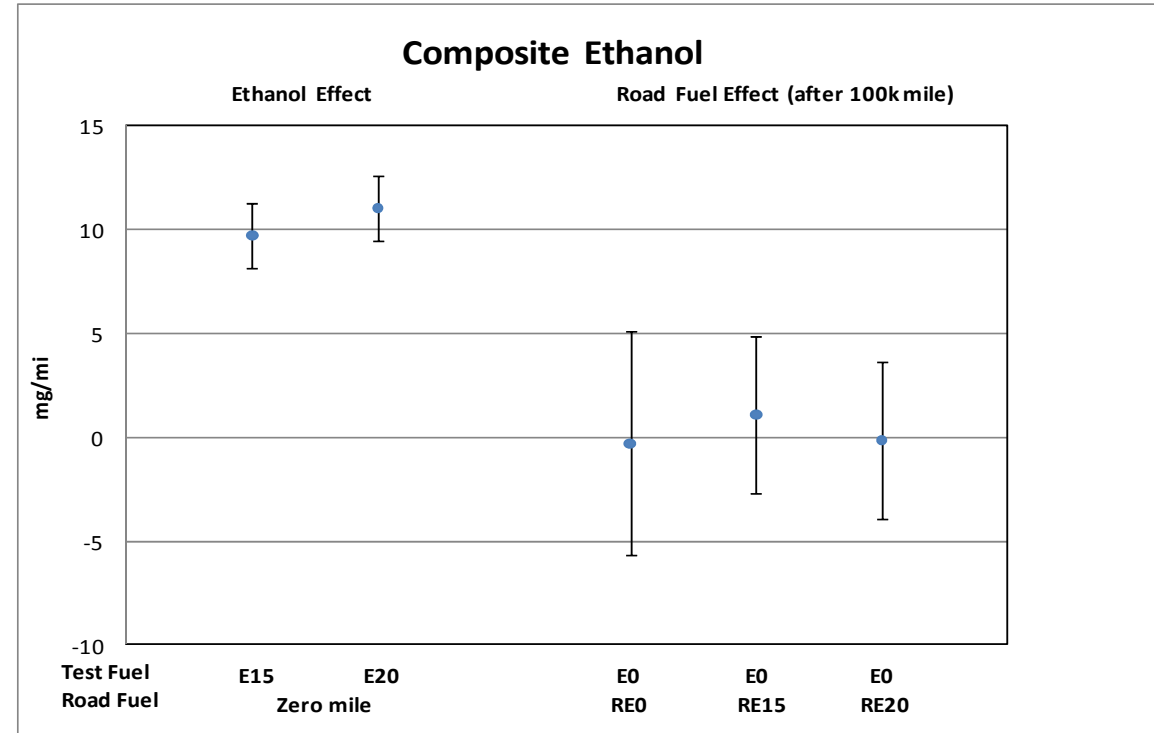

Error bars represent $95 \%$ confidence intervals on the estimated effects 
2002 Dodge Durango (Composite Acetaldehyde)

\begin{tabular}{|l|r|r|r|}
\hline \multicolumn{1}{|c|}{ Effect } & Estimate & $\begin{array}{r}\text { 95\% C.I. } \\
\text { Lower }\end{array}$ & $\begin{array}{r}\text { 95\% C.I. } \\
\text { Upper }\end{array}$ \\
\hline Ethanol Effect (E15 vs. E0) $(\Delta \mathrm{mg} / \mathrm{mi})$ & $1.895^{*}$ & 1.637 & 2.152 \\
\hline Ethanol Effect $($ E20 vs. E0) $(\Delta \mathrm{mg} / \mathrm{mi})$ & $2.334^{*}$ & 2.000 & 2.668 \\
\hline Road Fuel Aging Effect & & & \\
\hline Aging Effect with RE0 $(\Delta \mathrm{mg} / \mathrm{mi}$ per 100k mi) & -0.096 & -0.248 & 0.055 \\
\hline Aging Effect with RE15 $(\Delta \mathrm{mg} / \mathrm{mi}$ per 100k mi) & $0.200^{*}$ & 0.015 & 0.386 \\
\hline Aging Effect with RE20 $(\Delta \mathrm{mg} / \mathrm{mi}$ per 100k mi) & $0.198^{*}$ & -0.060 & 0.455 \\
\hline
\end{tabular}

\begin{tabular}{|l|r|}
\hline \multicolumn{1}{|c|}{ Hypothesis } & p-value \\
\hline No Effect of Ethanol in the Test Fuel (Gamma $=0)$ & $<0.01^{*}$ \\
\hline No Aging Effect with RE0 (Beta0 $=0)$ & 0.32 \\
\hline No Effect of Ethanol in Road Fuel Aging (Beta1s=0) & 0.11 \\
\hline${ }^{*}$ Indicates effect is statistically significant at the 95\% confidence level.
\end{tabular}

${ }^{*}$ Indicates estimate is different from zero at the $95 \%$ confidence level.

Initial odometers $60 \mathrm{k}-71 \mathrm{k}$

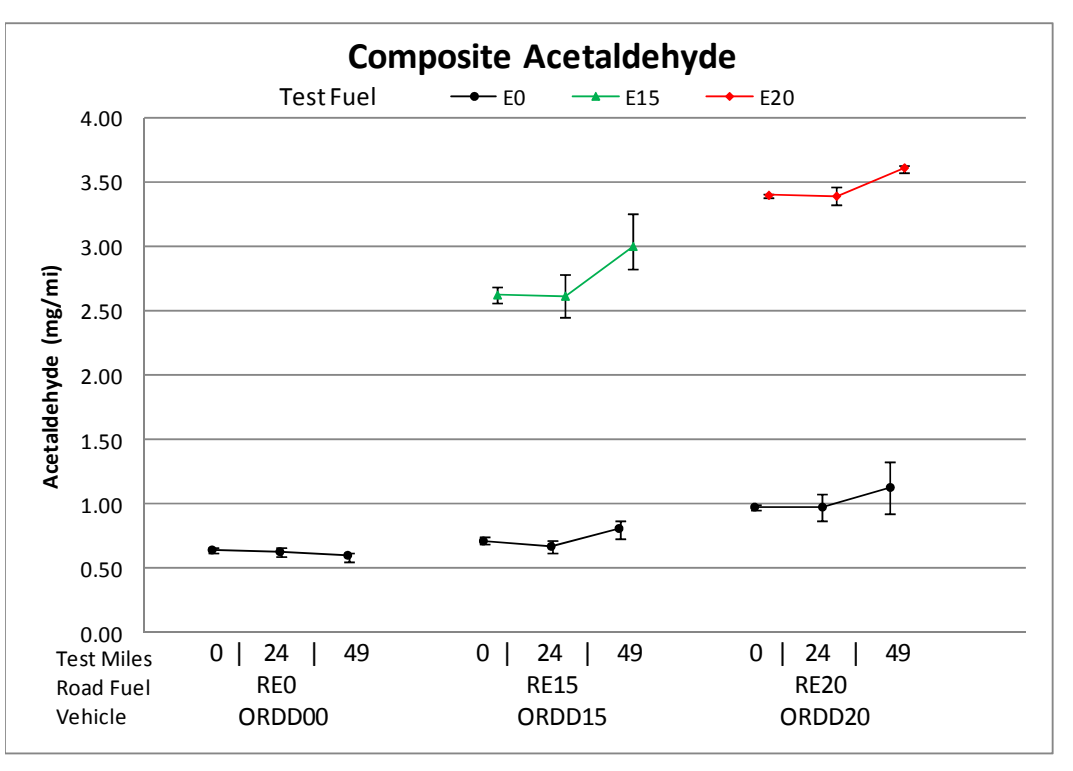

Error bars represent min and max measurements

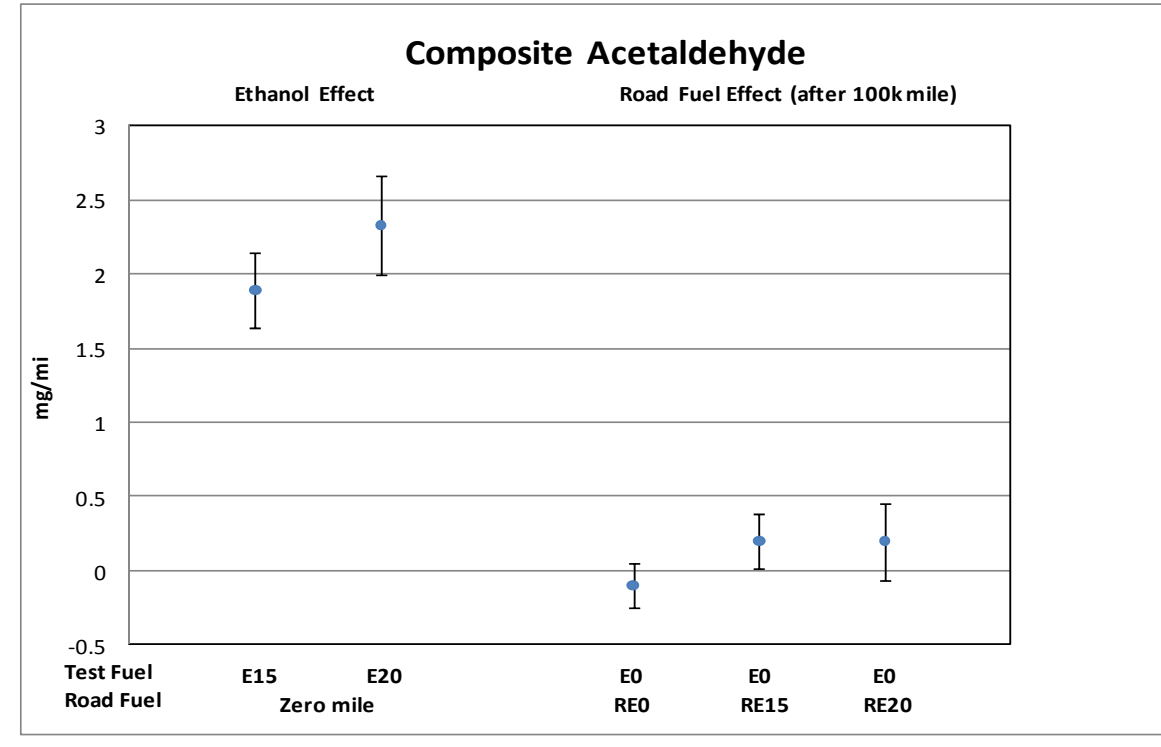

Error bars represent $95 \%$ confidence intervals on the estimated effects 
2002 Dodge Durango (Composite Formaldehyde)

\begin{tabular}{|l|r|r|r|}
\hline \multicolumn{1}{|c|}{ Effect } & & $\begin{array}{r}\text { 95\% C.I. } \\
\text { E5\% C.I. }\end{array}$ & $\begin{array}{r}\text { S5\% } \\
\text { Upper }\end{array}$ \\
\hline Ethanol Effect (E15 vs. E0) $(\Delta \mathrm{mg} / \mathrm{mi})$ & 0.071 & -0.184 & 0.326 \\
\hline Ethanol Effect (E20 vs. E0) $(\Delta \mathrm{mg} / \mathrm{mi})$ & 0.322 & -0.001 & 0.645 \\
\hline Road Fuel Aging Effect & & & \\
\hline Aging Effect with RE0 $(\Delta \mathrm{mg} / \mathrm{mi}$ per 100k mi) & $0.961^{*}$ & 0.313 & 1.608 \\
\hline Aging Effect with RE15 $(\Delta \mathrm{mg} / \mathrm{mi} \mathrm{per} \mathrm{100k} \mathrm{mi)}$ & $1.811^{*}$ & 1.111 & 2.511 \\
\hline Aging Effect with RE20 $(\Delta \mathrm{mg} / \mathrm{mi}$ per 100k mi) & $1.641^{*}$ & 0.862 & 2.419 \\
\hline
\end{tabular}

\begin{tabular}{|l|r|}
\hline \multicolumn{1}{|c|}{ Hypothesis } & p-value \\
\hline No Effect of Ethanol in the Test Fuel (Gamma $=0)$ & $0.03^{*}$ \\
\hline No Aging Effect with RE0 (Beta0 $=0)$ & $<0.01^{*}$ \\
\hline No Effect of Ethanol in Road Fuel Aging (Beta1s=0) & 0.45 \\
\hline${ }^{*}$ Indicates effect is statistically significant at the 95\% confidence level.
\end{tabular}

Initial odometers $60 \mathrm{k}-71 \mathrm{k}$

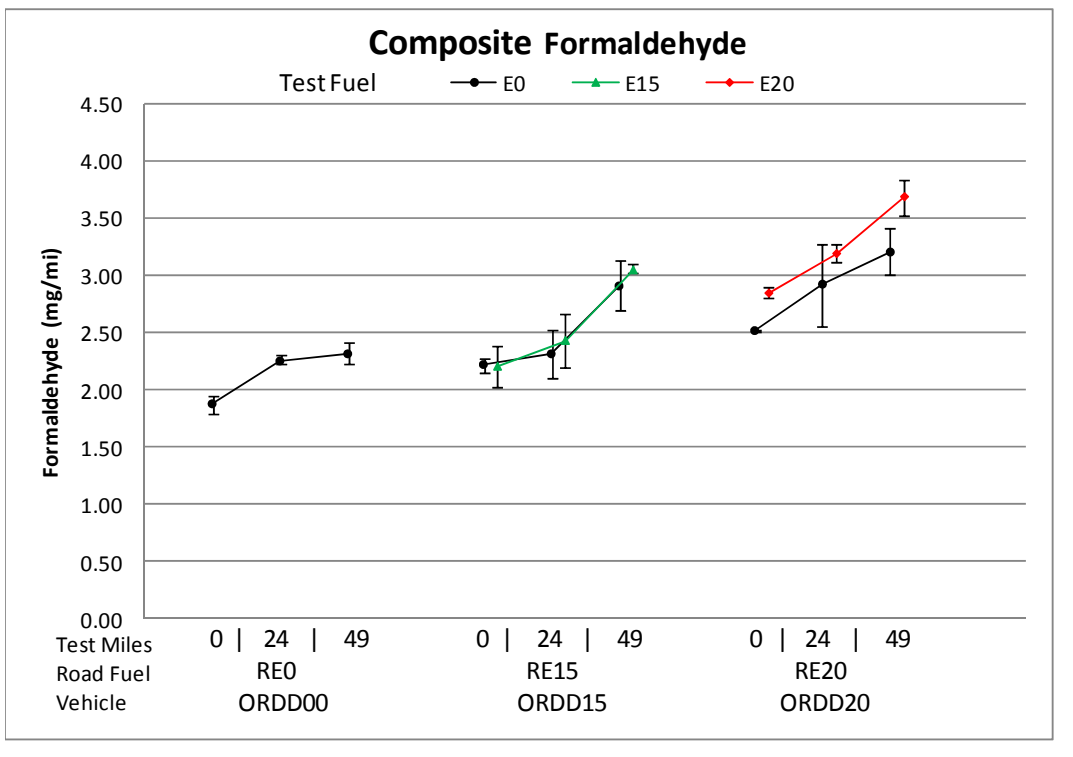

Error bars represent min and max measurements

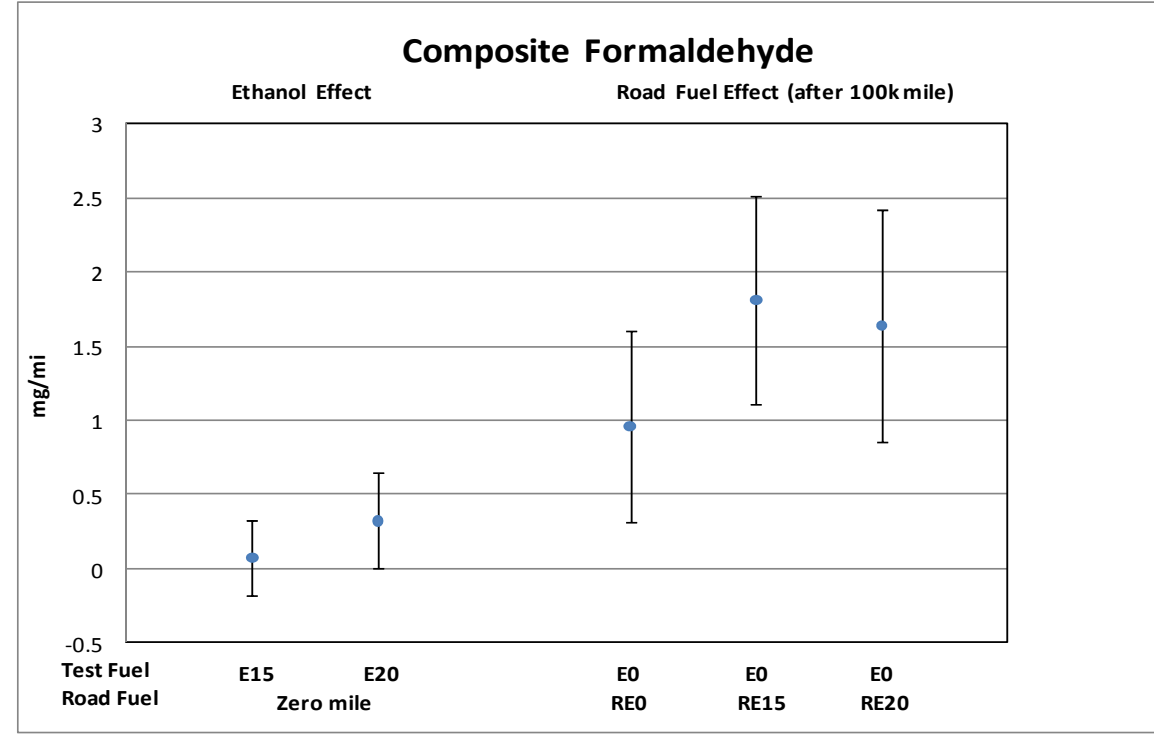

Error bars represent $95 \%$ confidence intervals on the estimated effects 


\section{Dodge Durango (Composite $\mathrm{CH} 4$ )}

\begin{tabular}{|c|c|c|c|}
\hline Effect & Estimate & $\begin{array}{c}\text { 95\% C.I. } \\
\text { Lower }\end{array}$ & $\begin{array}{c}95 \% \text { C.I. } \\
\text { Upper }\end{array}$ \\
\hline Ethanol Effect (E15 vs. E0) $(\Delta \mathrm{g} / \mathrm{mi})$ & $0.0033^{*}$ & 0.0007 & 0.0058 \\
\hline Ethanol Effect (E20 vs. E0) $(\Delta \mathrm{g} / \mathrm{mi})$ & $0.0062^{*}$ & 0.0037 & 0.0087 \\
\hline \multicolumn{4}{|l|}{ Road Fuel Aging Effect } \\
\hline Aging Effect with RE0 ( $\Delta \mathrm{g} / \mathrm{mi}$ per $100 \mathrm{k} \mathrm{mi})$ & 0.0068 & -0.0011 & 0.0148 \\
\hline Aging Effect with RE15 ( $\Delta \mathrm{g} / \mathrm{mi}$ per $100 \mathrm{k} \mathrm{mi})$ & $0.0078^{*}$ & 0.0014 & 0.0142 \\
\hline Aging Effect with RE20 ( $\Delta \mathrm{g} / \mathrm{mi}$ per $100 \mathrm{k} \mathrm{mi})$ & $0.0176^{*}$ & 0.0113 & 0.0238 \\
\hline
\end{tabular}

\begin{tabular}{|l|r|}
\hline \multicolumn{1}{|c|}{ Hypothesis } & p-value \\
\hline No Effect of Ethanol in the Test Fuel (Gamma = 0) & $<0.01^{*}$ \\
\hline No Aging Effect with RE0 (Beta0 = 0) & 0.09 \\
\hline No Effect of Ethanol in Road Fuel Aging (Beta1s=0) & $0.05^{*}$ \\
\hline${ }^{*}$ Indicates effect is statistically significant at the 95\% confidence level.
\end{tabular}

Aging Effect with RE20 $(\Delta \mathrm{g} / \mathrm{mi}$ per $100 \mathrm{k} \mathrm{mi})$ 0.0176

Initial odometers $60 \mathrm{k}-71 \mathrm{k}$

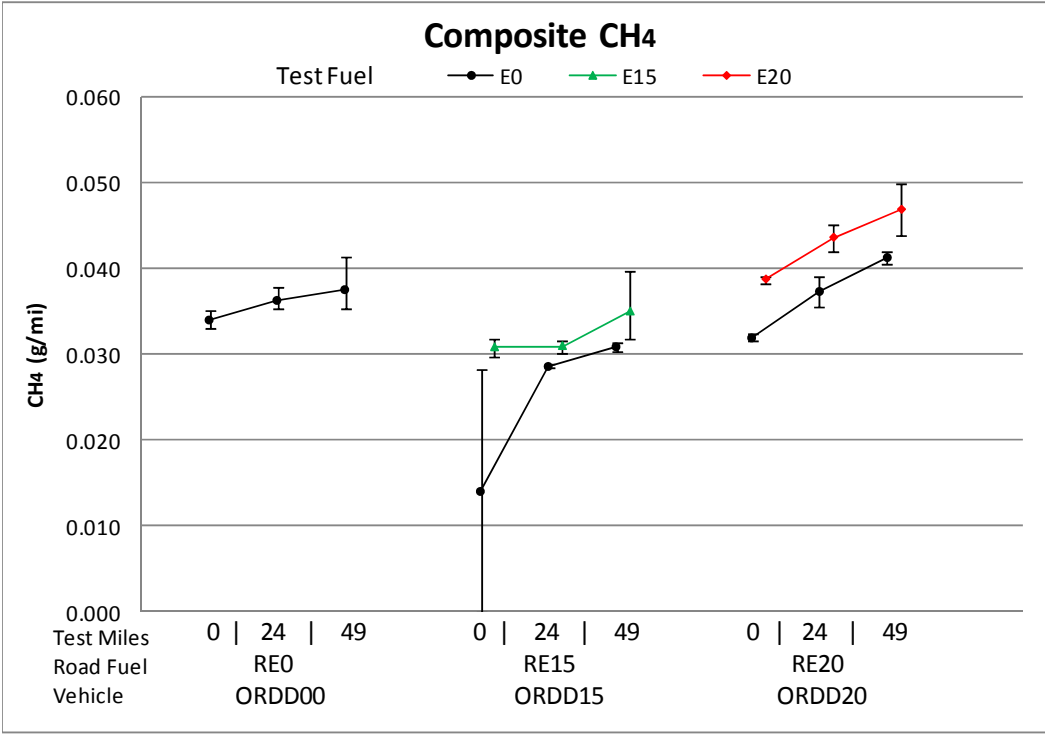

Error bars represent min and max measurements

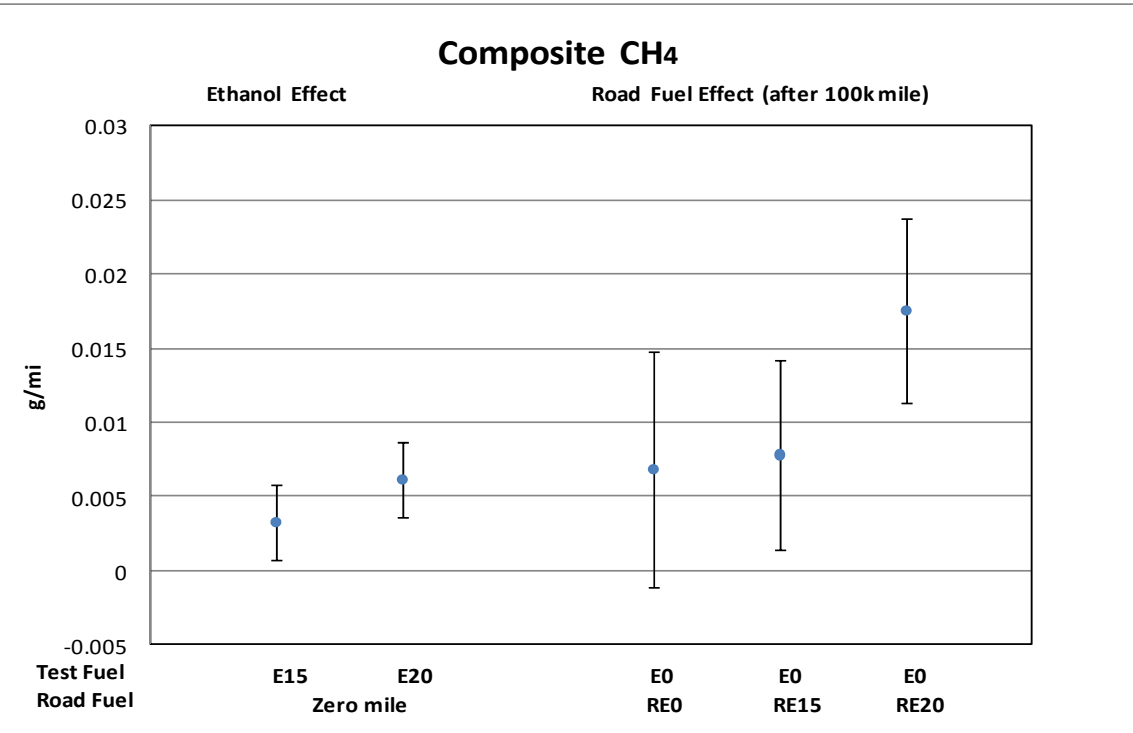

Error bars represent $95 \%$ confidence intervals on the estimated effects 


\section{Toyota Camry - Composite Emissions Summary}

\begin{tabular}{|c|c|c|c|c|c|c|c|c|c|c|c|c|c|c|}
\hline \multirow{2}{*}{$\begin{array}{c}\text { Emisssion Parameter } \\
\text { (units) }\end{array}$} & \multicolumn{4}{|c|}{ Ethanol Effect } & \multicolumn{2}{|c|}{ Aging Effect with REO } & \multicolumn{4}{|c|}{ RExx Aging Effect on EO Emissions } & \multirow{2}{*}{\multicolumn{3}{|c|}{$\begin{array}{c}\text { RExx Aging Effect on Exx Emissions } \\
\Delta \text { units per } 100 \mathrm{~K} \mathrm{mi} \\
\end{array}$}} & \multirow{3}{*}{\begin{tabular}{|c|}
$\begin{array}{l}\text { Road and Test } \\
\text { Fuel Effects } \\
\text { are Additive }\end{array}$ \\
$\begin{array}{c}\text { Overall p- } \\
\text { value }\end{array}$ \\
\end{tabular}} \\
\hline & \multicolumn{3}{|c|}{$\Delta$ units vs. EO } & \multirow{2}{*}{$\mid \begin{array}{c}\text { Overall } \\
p \text {-value }\end{array}$} & \multirow{2}{*}{$\begin{array}{c}\Delta \text { units per } 100 \mathrm{~K} \mathrm{mi} \\
\mathrm{REO} / \mathrm{EO}\end{array}$} & \multirow{2}{*}{$\begin{array}{l}\text { Overall } \\
p \text {-value }\end{array}$} & \multicolumn{3}{|c|}{$\Delta$ units per $100 \mathrm{~K} \mathrm{mi}$} & \multirow{2}{*}{$\begin{array}{c}\text { Overall } \\
p \text {-value }\end{array}$} & & & & \\
\hline Fuels & E10 & E15 & E20 & & & & RE10/E0 & RE15/E0 & RE20/E0 & & RE10/E10 & RE15/E15 & RE20/E20 & \\
\hline $\mathrm{CO}(\mathrm{g} / \mathrm{mi})^{\mathrm{a}}$ & NA & 0.007 & -0.045 & 0.95 & 0.450 & 0.29 & NA & 0.466 & 0.096 & 0.82 & NA & NA & $\mathrm{NA}$ & 0.85 \\
\hline $\mathrm{NOx}(\mathrm{g} / \mathrm{mi})^{\mathrm{a}}$ & $\mathrm{NA}$ & -0.000 & 0.019 & 0.80 & 0.083 & 0.34 & NA & 0.074 & 0.155 & 0.81 & $\mathrm{NA}$ & NA & $\mathrm{NA}$ & 0.53 \\
\hline $\mathrm{NMHC}(\mathrm{g} / \mathrm{mi})^{\mathrm{a}}$ & NA & -0.001 & -0.003 & 0.84 & 0.030 & 0.11 & NA & 0.012 & -0.018 & 0.28 & NA & NA & $\mathrm{NA}$ & 0.81 \\
\hline NMOG $(\mathrm{g} / \mathrm{mi})^{\mathrm{a}}$ & NA & 0.003 & 0.003 & 0.77 & 0.031 & 0.13 & NA & 0.014 & -0.020 & 0.30 & NA & NA & $\mathrm{NA}$ & 0.79 \\
\hline Fuel Econ (mi/gal) $^{a}$ & NA & $-1.350 *$ & $-1.650 *$ & $<0.01^{*}$ & 0.699 & 0.55 & NA & 1.376 & 4.029* & 0.27 & NA & NA & $\mathrm{NA}$ & 0.87 \\
\hline Acetaldehyde $(\mathrm{mg} / \mathrm{mi})^{\# \mathrm{a}}$ & $\mathrm{NA}$ & $0.428 *$ & $0.096 *$ & $<0.01 *$ & -0.054 & 0.73 & $\mathrm{NA}$ & -0.001 & -0.237 & 0.56 & $\mathrm{NA}$ & $\mathrm{NA}$ & $\mathrm{NA}$ & 0.72 \\
\hline Formaldehyde $(\mathrm{mg} / \mathrm{mi})^{\# \mathrm{a}}$ & $\mathrm{NA}$ & 0.125 & 0.193 & 0.56 & -0.305 & 0.54 & $N A$ & -0.105 & $-0.815^{*}$ & 0.33 & NA & $\mathrm{NA}$ & $\mathrm{NA}$ & 0.83 \\
\hline $\mathrm{CH}_{4}(\mathrm{~g} / \mathrm{mi})^{\mathrm{a}}$ & $\mathrm{NA}$ & 0.0003 & -0.0003 & 0.93 & $0.0126 *$ & $0.01 *$ & $\mathrm{NA}$ & $0.0073 *$ & 0.0029 & 0.30 & $\mathrm{NA}$ & $\mathrm{NA}$ & $\mathrm{NA}$ & 0.97 \\
\hline
\end{tabular}

\# Log-normal model was used. Results are presented as changes in emissions at 0k mile.

\#\# Data did not support the assumption of linear effects with mileage.

*Indicates estimate is different from zero at the $95 \%$ confidence level.

a RE20 vehicle had a P0420 catalyst failure MIL during mileage accumulation and TRC was instructed to complete the test program with the known problem. All emissions results at the $50 \mathrm{k}$ data point for this vehicle are excluded from the analysis. 
2003 Toyota Camry (Composite CO)

\begin{tabular}{|l|r|r|r|}
\hline \multicolumn{1}{|c|}{ Effect } & Estimate & $\begin{array}{c}\text { 95\% C.I. } \\
\text { Lower }\end{array}$ & $\begin{array}{r}\text { 95\% C.I. } \\
\text { Upper }\end{array}$ \\
\hline Ethanol Effect (E15 vs. E0) $(\Delta \mathrm{g} / \mathrm{mi})$ & 0.007 & -0.282 & 0.295 \\
\hline Ethanol Effect $($ E20 vs. E0) $(\Delta \mathrm{g} / \mathrm{mi})$ & -0.045 & -0.398 & 0.308 \\
\hline Road Fuel Aging Effect & & & \\
\hline Aging Effect with RE0 $(\Delta \mathrm{g} / \mathrm{mi}$ per 100k mi) & 0.450 & -0.526 & 1.427 \\
\hline Aging Effect with RE15 $(\Delta \mathrm{g} / \mathrm{mi}$ per 100k mi) & 0.466 & -0.223 & 1.155 \\
\hline Aging Effect with RE20 $(\Delta \mathrm{g} / \mathrm{mi}$ per 100k mi) & 0.096 & -1.260 & 1.453 \\
\hline
\end{tabular}

\begin{tabular}{|l|r|}
\hline \multicolumn{1}{|c|}{ Hypothesis } & -value \\
\hline No Effect of Ethanol in the Test Fuel (Gamma = 0) & 0.95 \\
\hline No Aging Effect with RE0 (Beta0 = 0) & 0.29 \\
\hline No Effect of Ethanol in Road Fuel Aging (Beta1s=0) & 0.82 \\
\hline * Indicates effect is statistically significant at the 95\% confidence level.
\end{tabular}

* Indicates estimate is different from zero at the $95 \%$ confidence level.

Initial Odometers 77k-81k

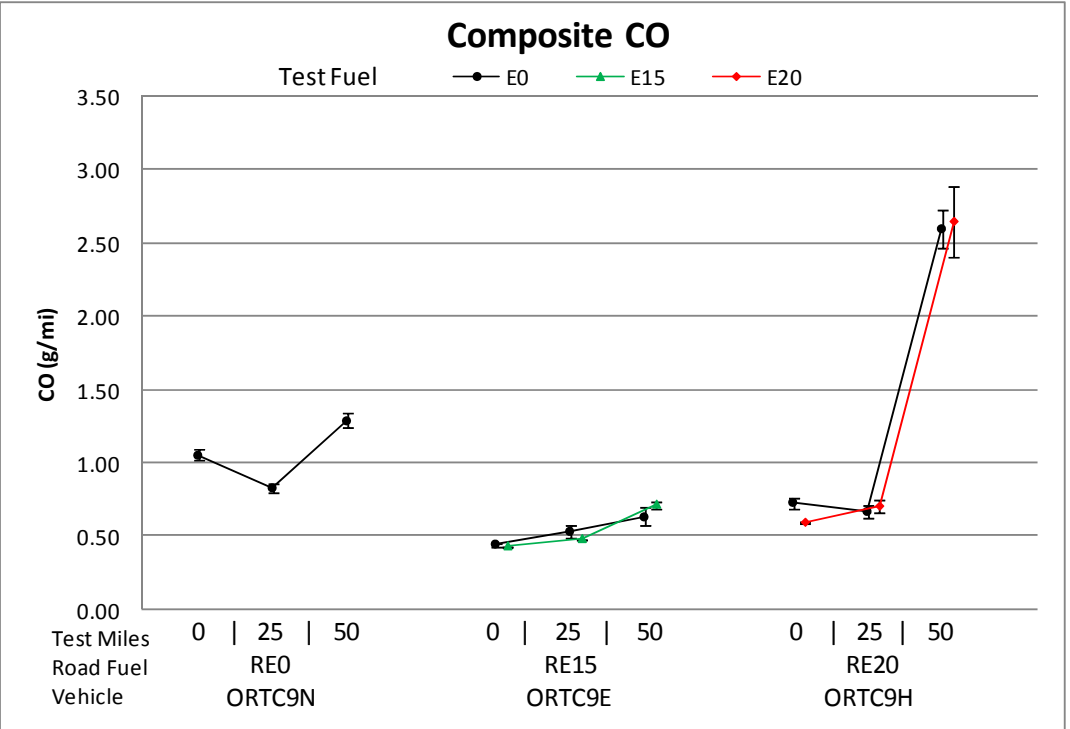

Error bars represent min and max measurements

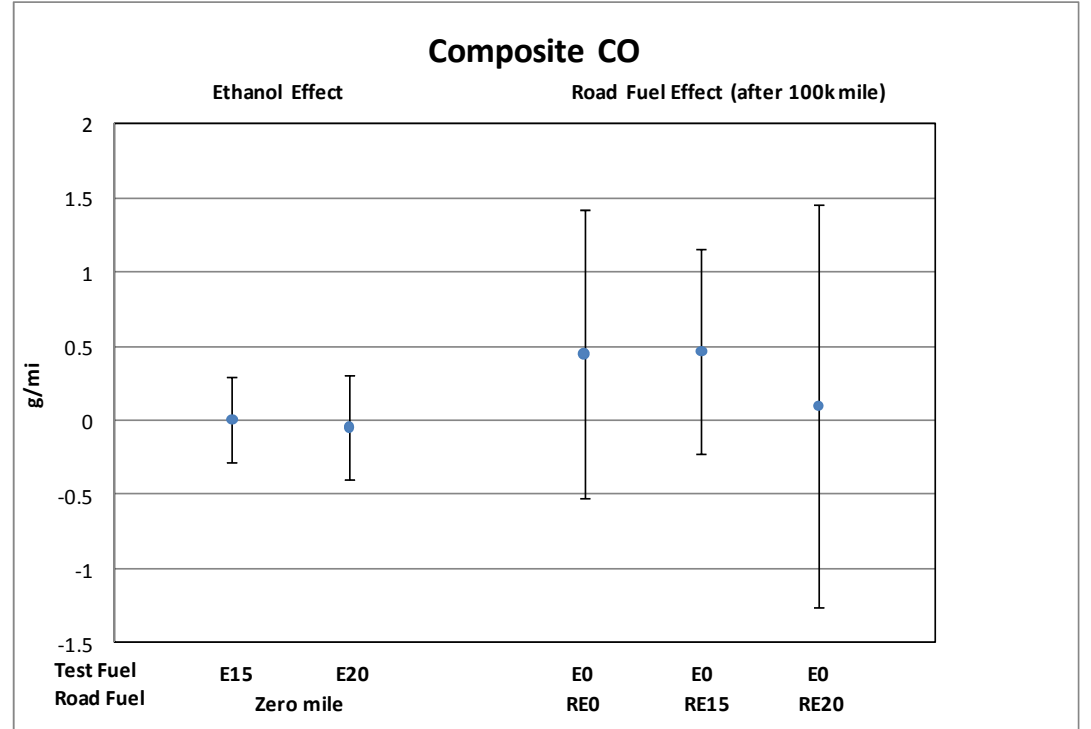

Error bars represent $95 \%$ confidence intervals on the estimated effects 
2003 Toyota Camry (Composite NOx)

\begin{tabular}{|l|r|r|r|}
\hline \multicolumn{1}{|c|}{ Effect } & & $\begin{array}{r}95 \% \text { C.I. } \\
\text { Low\% C.I. }\end{array}$ & $\begin{array}{r}\text { 95 } \\
\text { Upper }\end{array}$ \\
\hline Ethanol Effect $(E 15 \mathrm{vs}$. E0) $(\Delta \mathrm{g} / \mathrm{mi})$ & -0.000 & -0.060 & 0.059 \\
\hline Ethanol Effect $($ E20 vs. E0) $(\Delta \mathrm{g} / \mathrm{mi})$ & 0.019 & -0.054 & 0.092 \\
\hline Road Fuel Aging Effect & & & \\
\hline Aging Effect with RE0 $(\Delta \mathrm{g} / \mathrm{mi}$ per 100k mi) & 0.083 & -0.119 & 0.284 \\
\hline Aging Effect with RE15 $(\Delta \mathrm{g} / \mathrm{mi}$ per 100k mi) & 0.074 & -0.068 & 0.217 \\
\hline Aging Effect with RE20 $(\Delta \mathrm{g} / \mathrm{mi}$ per 100k mi) & 0.155 & -0.125 & 0.436 \\
\hline
\end{tabular}

\begin{tabular}{|l|r|}
\hline \multicolumn{1}{|c|}{ Hypothesis } & p-value \\
\hline No Effect of Ethanol in the Test Fuel (Gamma = 0) & 0.80 \\
\hline No Aging Effect with RE0 (Beta0 = 0) & 0.34 \\
\hline No Effect of Ethanol in Road Fuel Aging (Beta1s=0) & 0.81 \\
\hline * Indicates effect is statistically significant at the 95\% confidence level.
\end{tabular}

* Indicates estimate is different from zero at the $95 \%$ confidence level.

Initial Odometers $77 \mathrm{k}-81 \mathrm{k}$

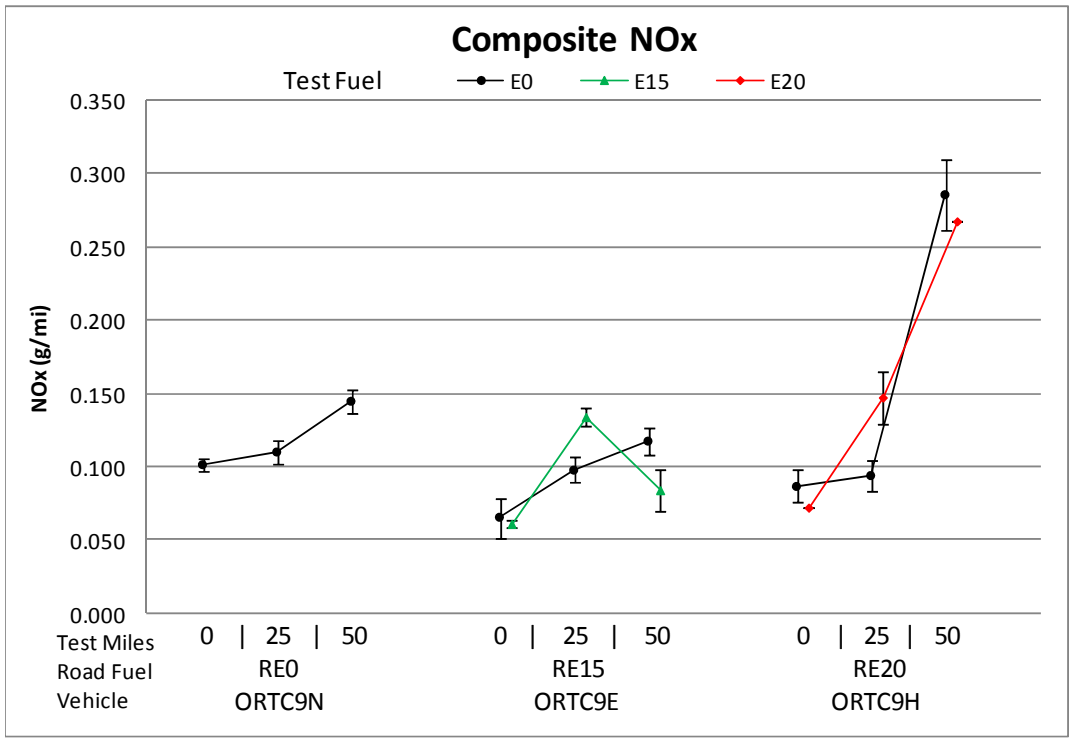

Error bars represent min and max measurements

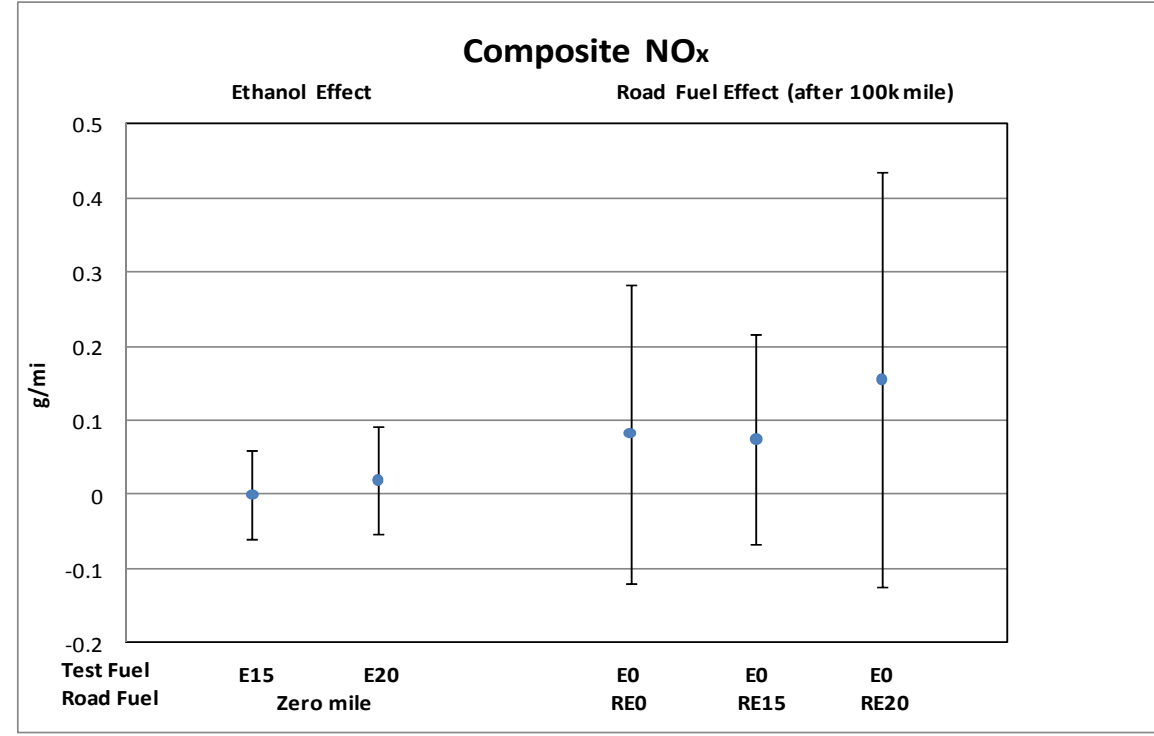

Error bars represent $95 \%$ confidence intervals on the estimated effects 
2003 Toyota Camry (Composite Nonmethane Hydrocarbons)

\begin{tabular}{|l|r|r|r|}
\hline \multicolumn{1}{|c|}{ Effect } & & $\begin{array}{r}95 \% \text { C.I. } \\
\text { Lo5\% C.I. } \\
\text { Upper }\end{array}$ \\
\hline Ethanol Effect (E15 vs. E0) $(\Delta \mathrm{g} / \mathrm{mi})$ & -0.001 & -0.013 & 0.011 \\
\hline Ethanol Effect $($ E20 vs. E0) $(\Delta \mathrm{g} / \mathrm{mi})$ & -0.003 & -0.018 & 0.011 \\
\hline Road Fuel Aging Effect & & & \\
\hline Aging Effect with RE0 $(\Delta \mathrm{g} / \mathrm{mi}$ per 100k mi) & 0.030 & -0.010 & 0.071 \\
\hline Aging Effect with RE15 $(\Delta \mathrm{g} / \mathrm{mi}$ per 100k mi) & 0.012 & -0.016 & 0.041 \\
\hline Aging Effect with RE20 $(\Delta \mathrm{g} / \mathrm{mi}$ per 100k mi) & -0.018 & -0.074 & 0.037 \\
\hline
\end{tabular}

\begin{tabular}{|l|r|}
\hline \multicolumn{1}{|c|}{ Hypothesis } & -value \\
\hline No Effect of Ethanol in the Test Fuel (Gamma = 0) & 0.84 \\
\hline No Aging Effect with RE0 (Beta0 = 0) & 0.11 \\
\hline No Effect of Ethanol in Road Fuel Aging (Beta1s=0) & 0.28 \\
\hline * Indicates effect is statistically significant at the 95\% confidence level.
\end{tabular}

* Indicates estimate is different from zero at the $95 \%$ confidence level.

\section{Initial Odometers $77 \mathrm{k}-81 \mathrm{k}$}

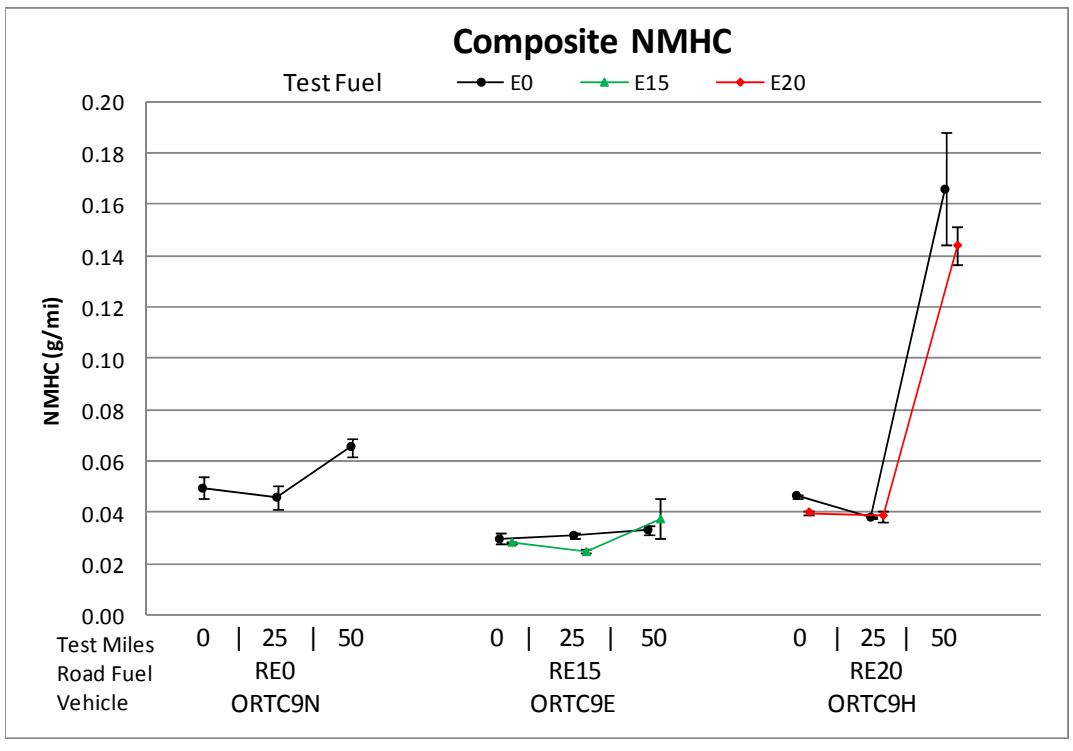

Error bars represent min and max measurements

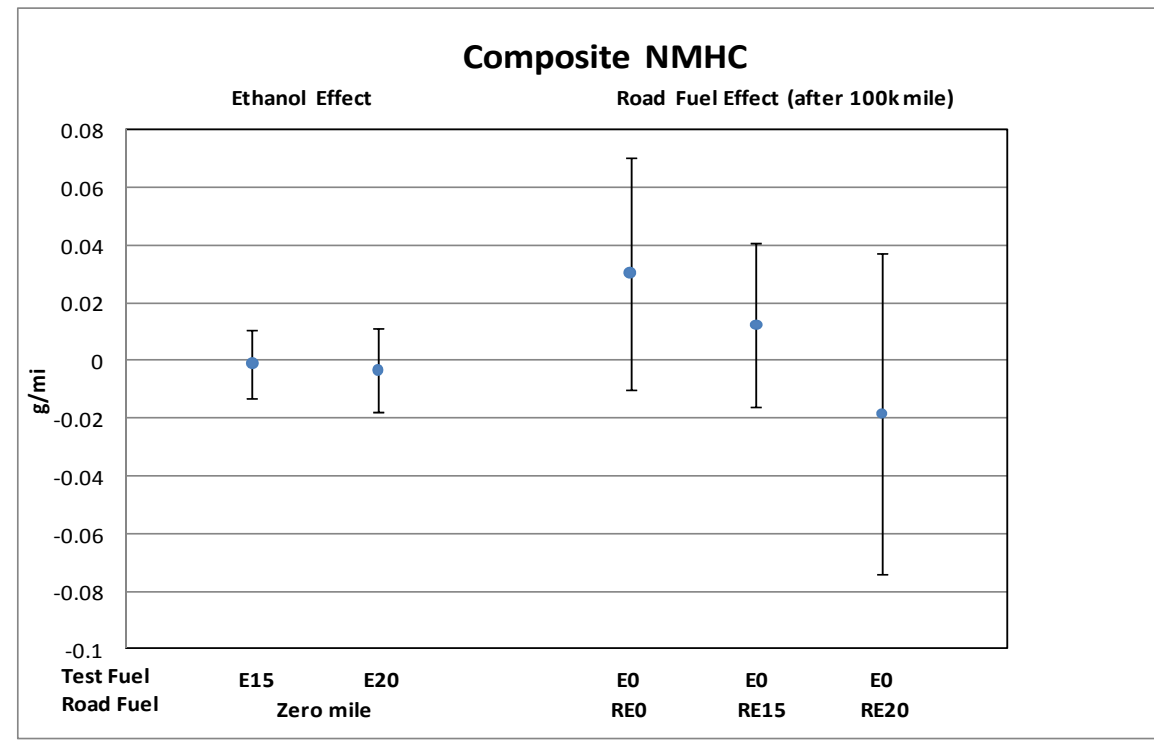

Error bars represent $95 \%$ confidence intervals on the estimated effects 
2003 Toyota Camry (Composite Nonmethane Organic Gases)

\begin{tabular}{|l|r|r|r|}
\hline \multicolumn{1}{|c|}{ Effect } & & $\begin{array}{r}95 \% \text { C.I. } \\
\text { Low\% C.I. }\end{array}$ & $\begin{array}{r}\text { 95 } \\
\text { Upper }\end{array}$ \\
\hline Ethanol Effect $(E 15 \mathrm{vs}$. E0) $(\Delta \mathrm{g} / \mathrm{mi})$ & 0.003 & -0.010 & 0.016 \\
\hline Ethanol Effect $($ E20 vs. E0) $(\Delta \mathrm{g} / \mathrm{mi})$ & 0.003 & -0.013 & 0.019 \\
\hline Road Fuel Aging Effect & & & \\
\hline Aging Effect with RE0 $(\Delta \mathrm{g} / \mathrm{mi}$ per 100k mi) & 0.031 & -0.013 & 0.074 \\
\hline Aging Effect with RE15 $(\Delta \mathrm{g} / \mathrm{mi}$ per 100k mi) & 0.014 & -0.017 & 0.044 \\
\hline Aging Effect with RE20 $(\Delta \mathrm{g} / \mathrm{mi}$ per 100k mi) & -0.020 & -0.081 & 0.040 \\
\hline
\end{tabular}

\begin{tabular}{|l|r|}
\hline \multicolumn{1}{|c|}{ Hypothesis } & -value \\
\hline No Effect of Ethanol in the Test Fuel (Gamma = 0) & 0.77 \\
\hline No Aging Effect with RE0 (Beta0 = 0) & 0.13 \\
\hline No Effect of Ethanol in Road Fuel Aging (Beta1s=0) & 0.30 \\
\hline
\end{tabular}

* Indicates estimate is different from zero at the $95 \%$ confidence level.

Initial Odometers $77 \mathrm{k}-81 \mathrm{k}$

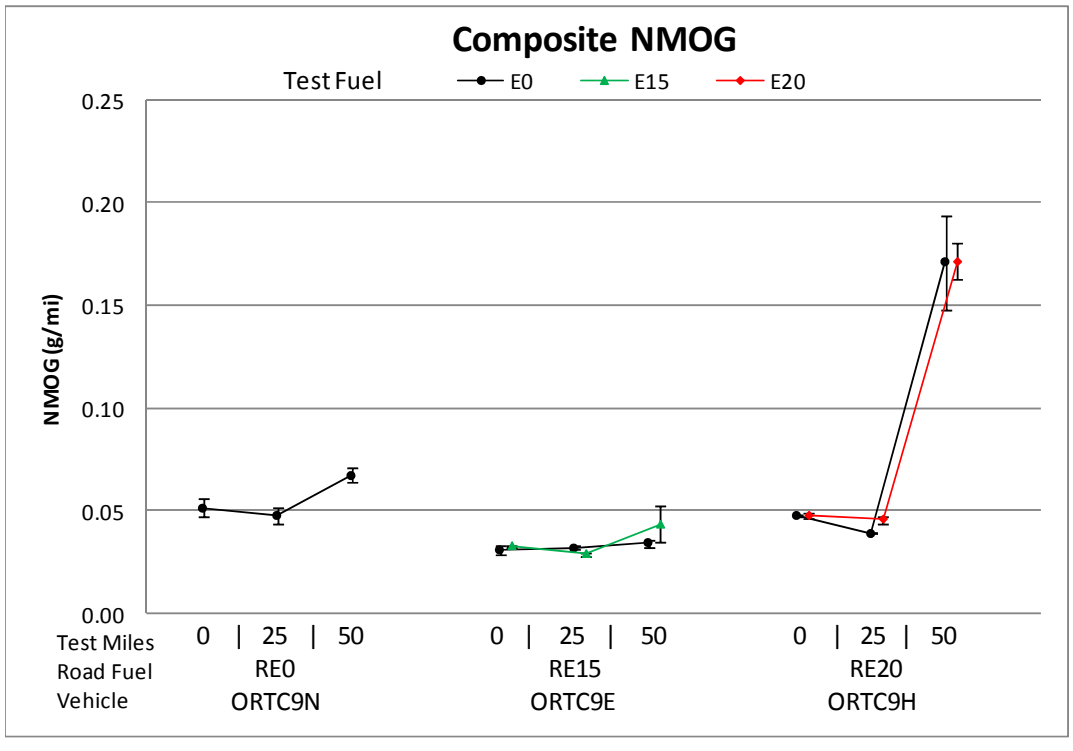

Error bars represent min and max measurements

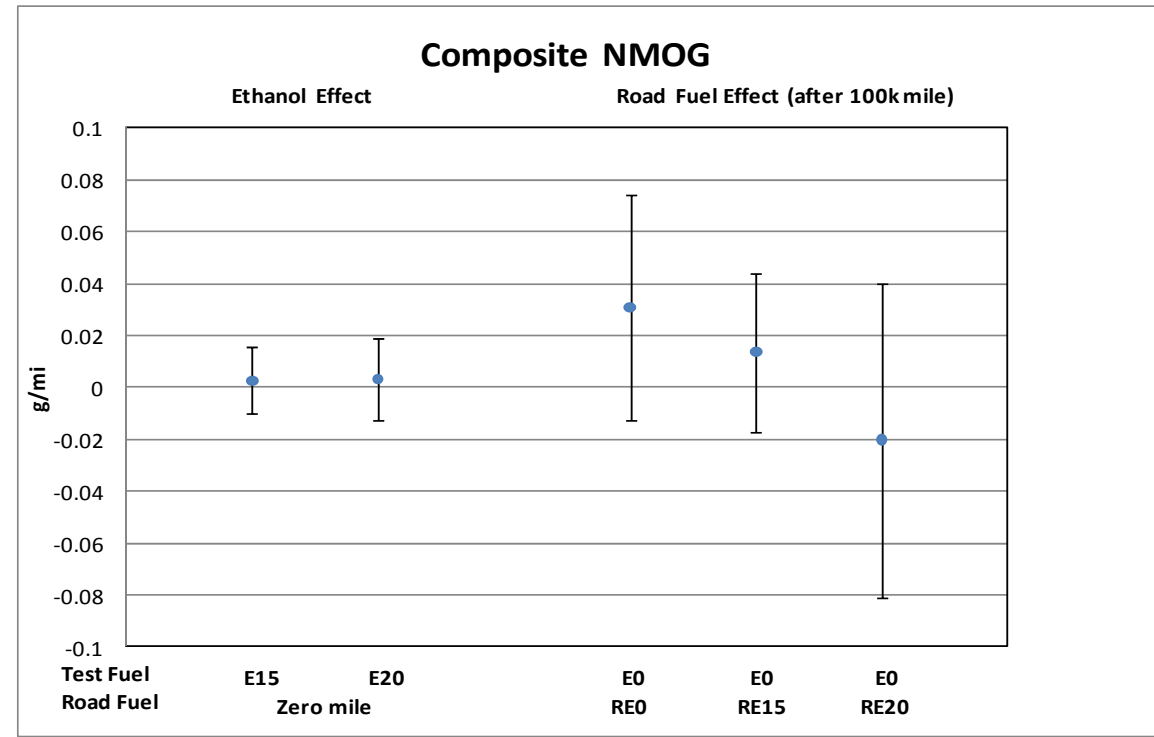

Error bars represent $95 \%$ confidence intervals on the estimated effects 
2003 Toyota Camry (Composite Fuel Economy)

\begin{tabular}{|l|r|r|r|}
\hline \multicolumn{1}{|c|}{ Effect } & & $\begin{array}{r}95 \% \text { C.I. } \\
\text { Estimate }\end{array}$ & $\begin{array}{r}\text { 95\% C.I. } \\
\text { Upper }\end{array}$ \\
\hline Ethanol Effect (E15 vs. E0) $(\Delta \mathrm{mi} / \mathrm{gal})$ & $-1.350^{*}$ & -2.169 & -0.530 \\
\hline Ethanol Effect (E20 vs. E0) $(\Delta \mathrm{mi} / \mathrm{gal})$ & $-1.650^{*}$ & -2.653 & -0.647 \\
\hline Road Fuel Aging Effect & & & \\
\hline Aging Effect with RE0 $(\Delta \mathrm{mi} / \mathrm{gal}$ per 100k mi) & 0.699 & -2.075 & 3.472 \\
\hline Aging Effect with RE15 $(\Delta \mathrm{mi} /$ gal per 100k mi) & 1.376 & -0.580 & 3.333 \\
\hline Aging Effect with RE20 $(\Delta \mathrm{mi} /$ gal per 100k mi) & $4.029^{*}$ & 0.179 & 7.880 \\
\hline
\end{tabular}

\begin{tabular}{|l|r|}
\hline \multicolumn{1}{|c|}{ Hypothesis } & p-value \\
\hline No Effect of Ethanol in the Test Fuel (Gamma = 0) & $<0.01^{*}$ \\
\hline No Aging Effect with RE0 (Beta0 = 0) & 0.55 \\
\hline No Effect of Ethanol in Road Fuel Aging (Beta1s=0) & 0.27 \\
\hline
\end{tabular}

${ }^{*}$ Indicates estimate is different from zero at the $95 \%$ confidence level.

\section{Initial Odometers 77k-81k}
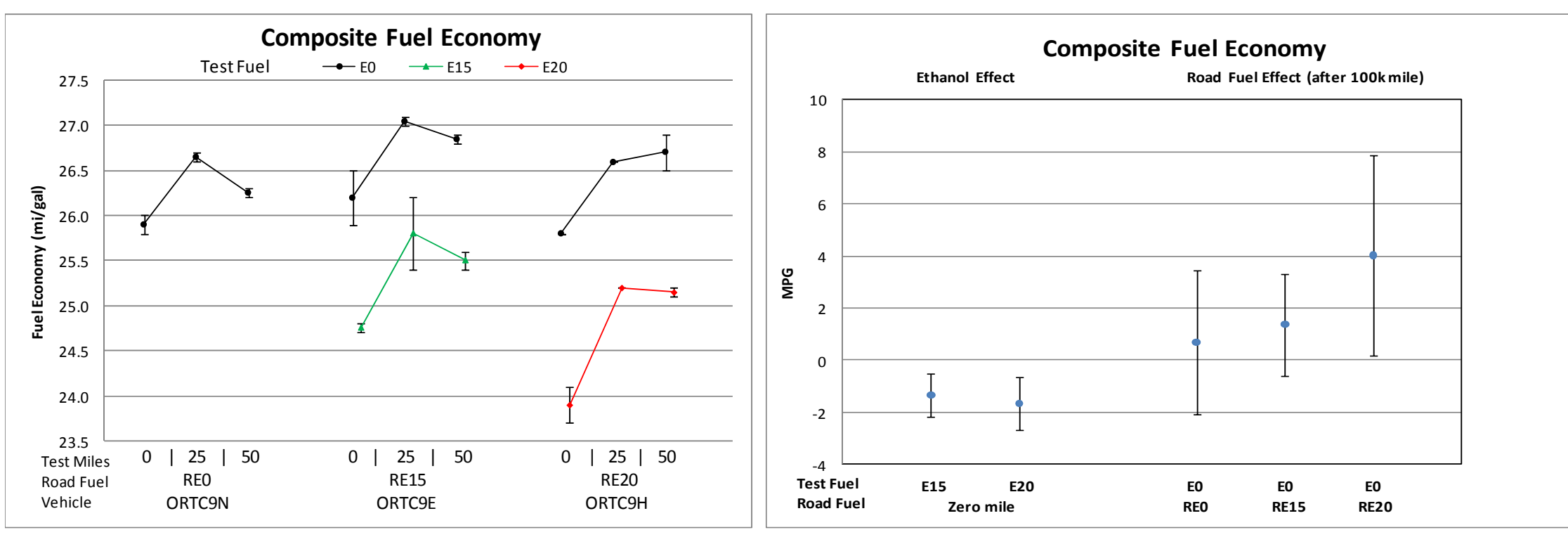

Error bars represent min and max measurements

Error bars represent $95 \%$ confidence intervals on the estimated effects 
2003 Toyota Camry (Composite Acetaldehyde)

\begin{tabular}{|l|r|r|r|}
\hline \multicolumn{1}{|c|}{ Effect } & Estimate & $\begin{array}{r}\text { 95\% C.I. } \\
\text { Lower }\end{array}$ & $\begin{array}{r}\text { 95\% C.I. } \\
\text { Upper }\end{array}$ \\
\hline Ethanol Effect (E15 vs. E0) $(\Delta \mathrm{mg} / \mathrm{mi})$ & $0.428^{*}$ & 0.131 & 0.725 \\
\hline Ethanol Effect (E20 vs. E0) $(\Delta \mathrm{mg} / \mathrm{mi})$ & $0.096^{*}$ & 0.189 & 1.623 \\
\hline Road Fuel Aging Effect & & & \\
\hline Aging Effect with RE0 $(\Delta \mathrm{mg} / \mathrm{mi}$ per 100k mi) & -0.054 & -0.348 & 0.241 \\
\hline Aging Effect with RE15 $(\Delta \mathrm{mg} / \mathrm{mi}$ per 100k mi) & -0.001 & -0.171 & 0.169 \\
\hline Aging Effect with RE20 $(\Delta \mathrm{mg} / \mathrm{mi}$ per 100k mi) & -0.237 & -0.520 & 0.046 \\
\hline
\end{tabular}

\begin{tabular}{|l|r|}
\hline \multicolumn{1}{|c|}{ Hypothesis } & -value \\
\hline No Effect of Ethanol in the Test Fuel (Gamma $=0)$ & $<0.01^{*}$ \\
\hline No Aging Effect with RE0 (Beta0 $=0)$ & 0.73 \\
\hline No Effect of Ethanol in Road Fuel Aging (Beta1s $=0$ ) & 0.56 \\
\hline * Indicates effect is statistically significant at the 95\% confidence level.
\end{tabular}

${ }^{*}$ Indicates estimate is different from zero at the $95 \%$ confidence level.

Initial Odometers 77k-81k

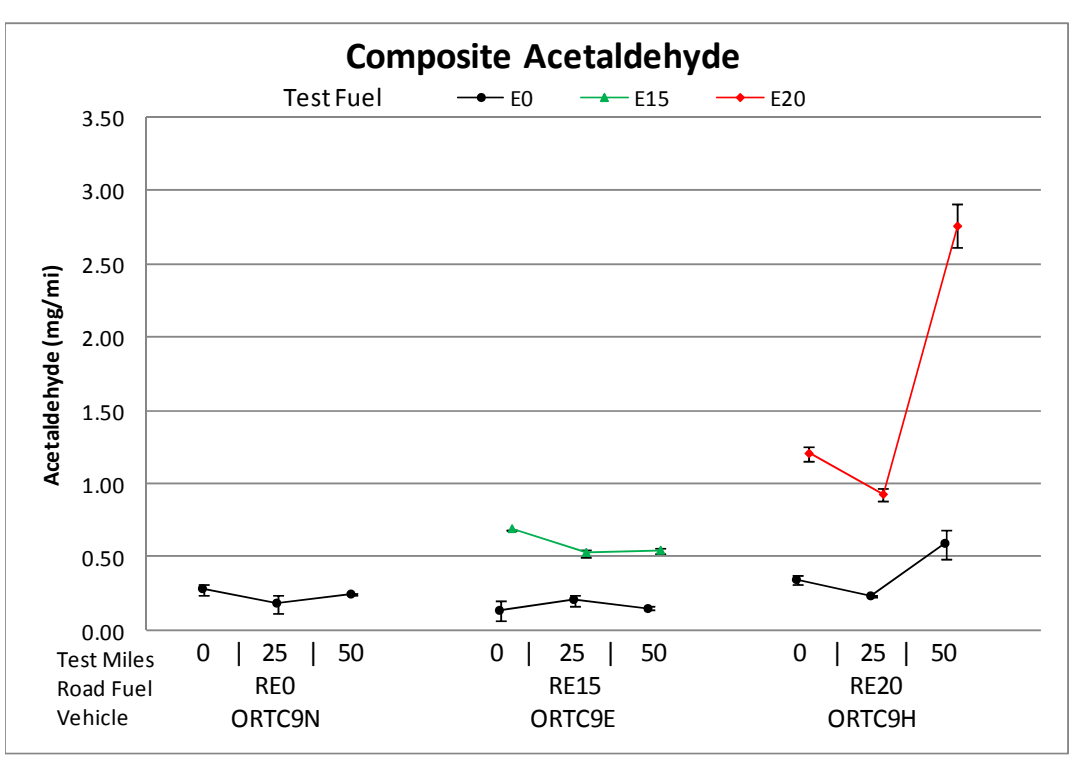

Error bars represent min and max measurements

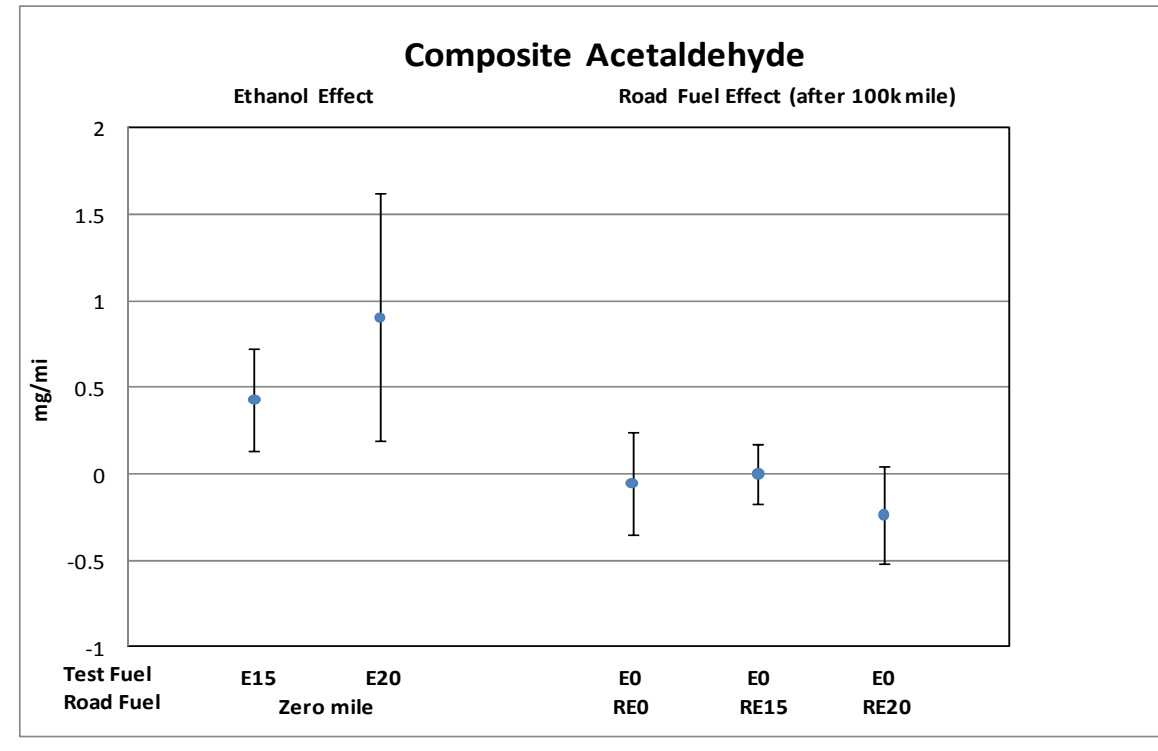

Error bars represent $95 \%$ confidence intervals on the estimated effects 
2003 Toyota Camry (Composite Formaldehyde)

\begin{tabular}{|l|r|r|r|}
\hline \multicolumn{1}{|c|}{ Effect } & Estimate & $\begin{array}{r}\text { 95\% C.I. } \\
\text { Lower }\end{array}$ & $\begin{array}{r}\text { 95\% C.I. } \\
\text { Upper }\end{array}$ \\
\hline Ethanol Effect (E15 vs. E0) $(\Delta \mathrm{mg} / \mathrm{mi})$ & 0.125 & -0.298 & 0.548 \\
\hline Ethanol Effect $($ E20 vs. E0) $(\Delta \mathrm{mg} / \mathrm{mi})$ & 0.193 & -1.057 & 1.443 \\
\hline Road Fuel Aging Effect & & & \\
\hline Aging Effect with RE0 $(\Delta \mathrm{mg} / \mathrm{mi}$ per 100k mi) & -0.305 & -1.138 & 0.528 \\
\hline Aging Effect with RE15 $(\Delta \mathrm{mg} / \mathrm{mi}$ per 100k mi) & -0.105 & -0.504 & 0.294 \\
\hline Aging Effect with RE20 $(\Delta \mathrm{mg} / \mathrm{mi}$ per 100k mi) & $-0.815^{*}$ & -1.611 & -0.019 \\
\hline
\end{tabular}

\begin{tabular}{|l|r|}
\hline \multicolumn{1}{|c|}{ Hypothesis } & p-value \\
\hline No Effect of Ethanol in the Test Fuel (Gamma = 0) & 0.56 \\
\hline No Aging Effect with RE0 (Beta0 = 0) & 0.54 \\
\hline No Effect of Ethanol in Road Fuel Aging (Beta1s=0) & 0.33 \\
\hline
\end{tabular}

* Indicates estimate is different from zero at the $95 \%$ confidence level.

Initial Odometers $77 \mathrm{k}-81 \mathrm{k}$

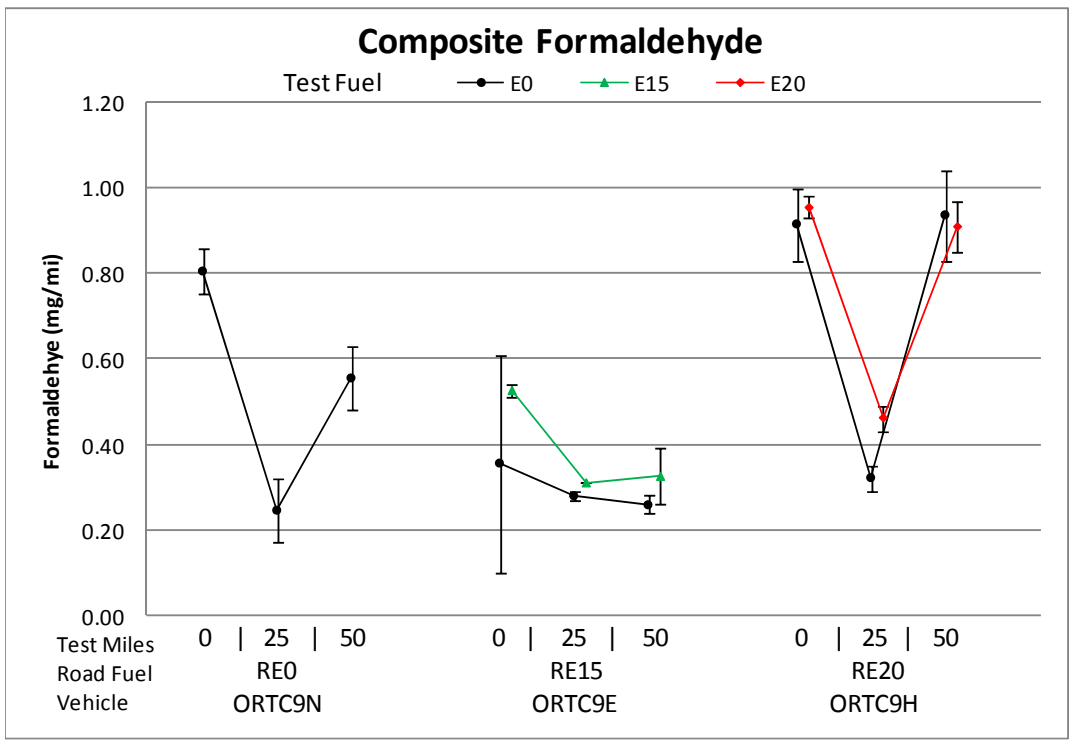

Error bars represent min and max measurements

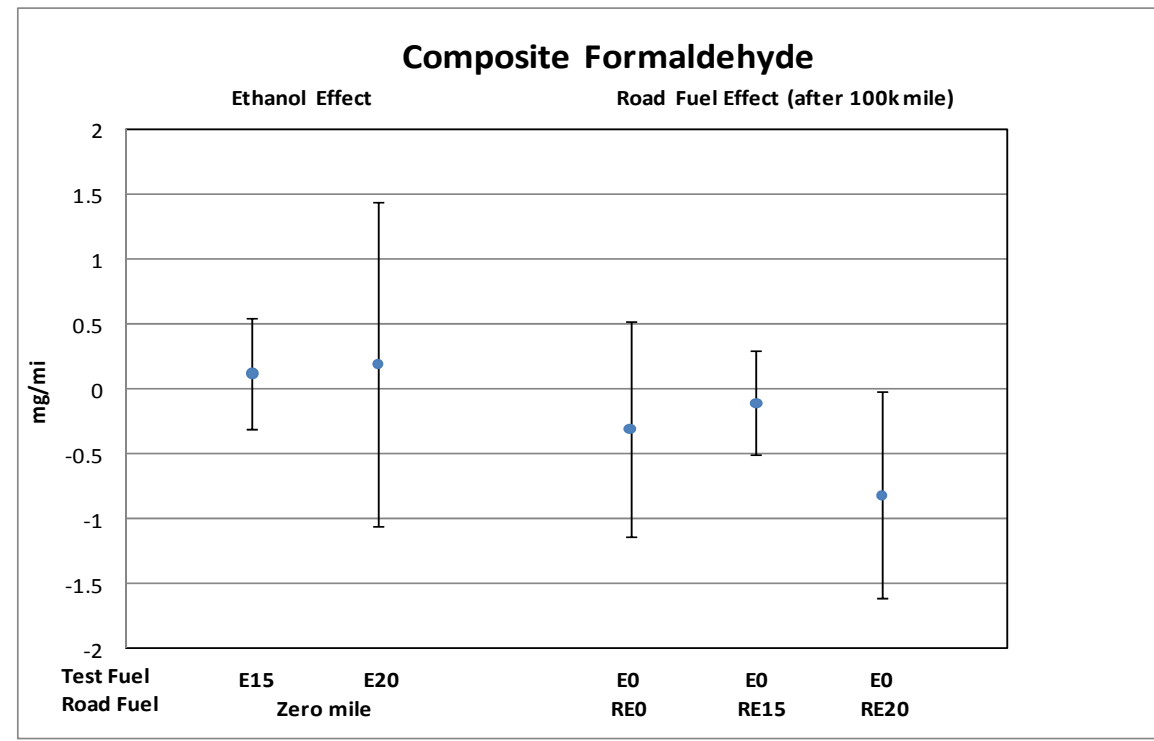

Error bars represent $95 \%$ confidence intervals on the estimated effects 
2003 Toyota Camry (Composite $\mathrm{CH} 4$ )

\begin{tabular}{|l|r|r|r|}
\hline \multicolumn{1}{|c|}{ Effect } & & $\begin{array}{c}95 \% \text { C.I. } \\
\text { Low\% C.I. } \\
\text { Upper }\end{array}$ \\
\hline Ethanol Effect $(E 15 \mathrm{vs}$. E0) $(\Delta \mathrm{g} / \mathrm{mi})$ & 0.0003 & -0.0023 & 0.0029 \\
\hline Ethanol Effect $($ E20 vs. E0) $(\Delta \mathrm{g} / \mathrm{mi})$ & -0.0003 & -0.0034 & 0.0029 \\
\hline Road Fuel Aging Effect & & & \\
\hline Aging Effect with RE0 $(\Delta \mathrm{g} / \mathrm{mi}$ per 100k mi) & $0.0126^{*}$ & 0.0039 & 0.0214 \\
\hline Aging Effect with RE15 $(\Delta \mathrm{g} / \mathrm{mi}$ per 100k mi) & $0.0073^{*}$ & 0.0011 & 0.0135 \\
\hline Aging Effect with RE20 $(\Delta \mathrm{g} / \mathrm{mi}$ per 100k mi) & 0.0029 & -0.0093 & 0.0150 \\
\hline
\end{tabular}

\begin{tabular}{|l|r|}
\hline \multicolumn{1}{|c|}{ Hypothesis } & p-value \\
\hline No Effect of Ethanol in the Test Fuel (Gamma = 0) & 0.93 \\
\hline No Aging Effect with RE0 (Beta0 = 0) & $0.01^{*}$ \\
\hline No Effect of Ethanol in Road Fuel Aging (Beta1s=0) & 0.30 \\
\hline * Indicates effect is statistically significant at the 95\% confidence level.
\end{tabular}

* Indicates estimate is different from zero at the $95 \%$ confidence level.

\section{Initial Odometers $77 \mathrm{k}-81 \mathrm{k}$}

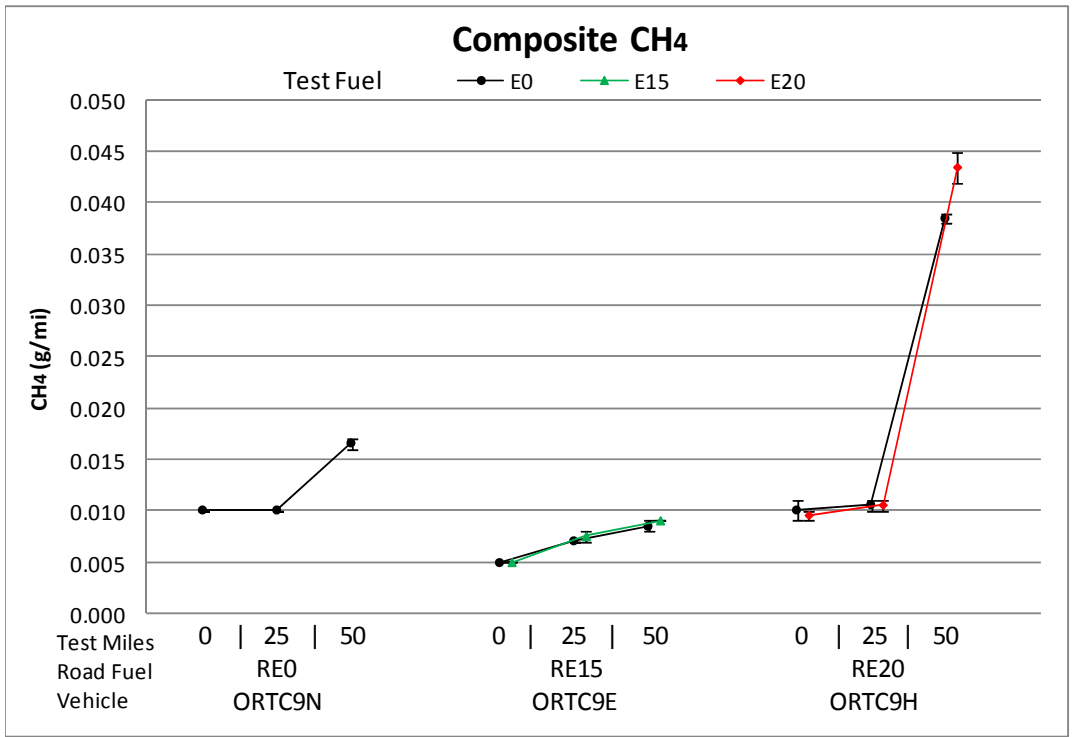

Error bars represent min and max measurements

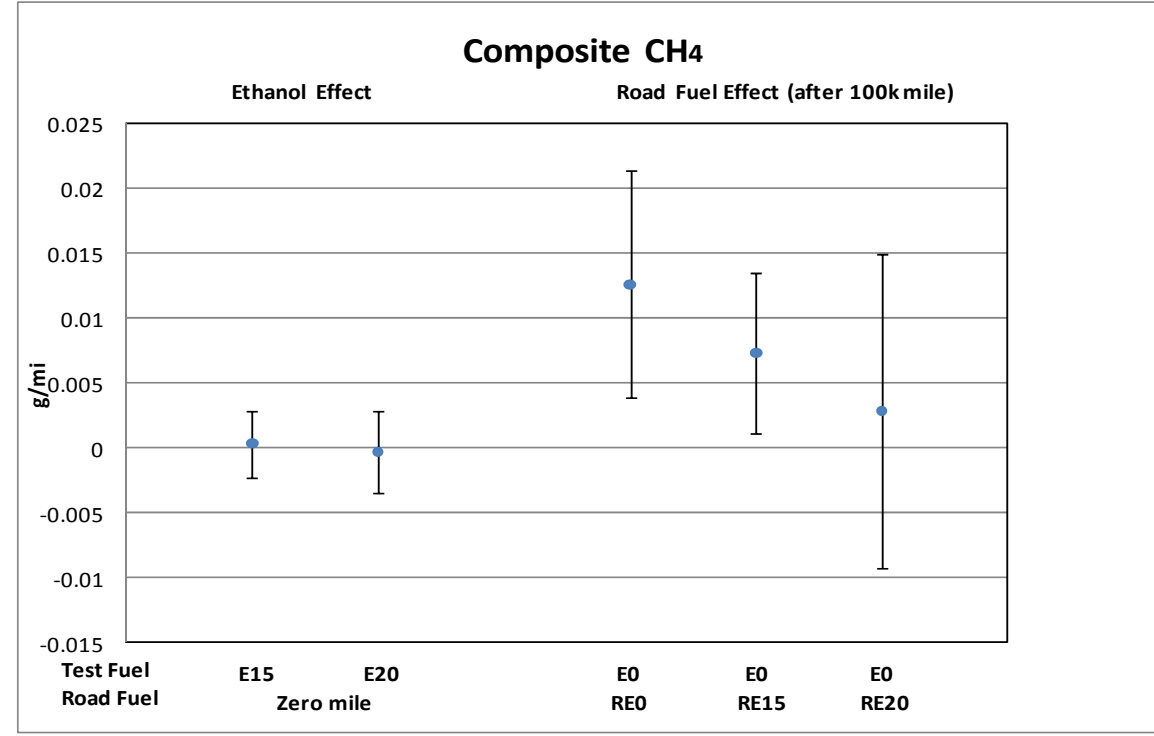

Error bars represent $95 \%$ confidence intervals on the estimated effects 
2003 Ford Taurus - Composite Emissions Summary

\begin{tabular}{|c|c|c|c|c|c|c|c|c|c|c|c|c|c|c|}
\hline \multirow{2}{*}{$\begin{array}{c}\text { Emisssion Parameter } \\
\text { (units) }\end{array}$} & \multicolumn{4}{|c|}{ Ethanol Effect } & \multicolumn{2}{|c|}{ Aging Effect with REO } & \multicolumn{4}{|c|}{ RExx Aging Effect on EO Emissions } & \multicolumn{3}{|c|}{ Exx Aging Effect on Exx Emissior } & $\begin{array}{l}\text { Road and Test } \\
\text { Fuel Effects } \\
\text { are Additive }\end{array}$ \\
\hline & \multicolumn{3}{|c|}{$\Delta$ units vs. EO } & \multirow{2}{*}{$\begin{array}{l}\text { Overall } \\
p \text {-value }\end{array}$} & \multirow{2}{*}{$\begin{array}{c}\Delta \text { units per } 100 \mathrm{~K} \mathrm{mi} \\
\text { REO/E0 }\end{array}$} & \multirow{2}{*}{$\begin{array}{l}\text { Overall } \\
p \text {-value }\end{array}$} & \multicolumn{3}{|c|}{$\Delta$ units per $100 \mathrm{~K} \mathrm{mi}$} & \multirow{2}{*}{$\begin{array}{l}\text { Overall } \\
p \text {-value }\end{array}$} & \multicolumn{3}{|c|}{$\Delta$ units per $100 \mathrm{~K} \mathrm{mi}$} & \multirow{2}{*}{$\begin{array}{l}\text { Overall p- } \\
\text { value }\end{array}$} \\
\hline Fuels & E10 & E15 & E20 & & & & RE10/E0 & RE15/E0 & RE20/E0 & & RE10/E10 & RE15/E15 & RE20/E20 & \\
\hline $\mathrm{CO}(\mathrm{g} / \mathrm{mi})$ & $\mathrm{NA}$ & $-0.197^{*}$ & $-0.337 *$ & $<0.01 *$ & -0.258 & 0.12 & $\mathrm{NA}$ & 0.055 & -0.139 & 0.25 & NA & $\mathrm{NA}$ & $\mathrm{NA}$ & 0.54 \\
\hline NOx $(\mathrm{g} / \mathrm{mi})$ & $\mathrm{NA}$ & 0.010 & $0.054^{*}$ & $<0.01 *$ & 0.014 & 0.73 & $\mathrm{NA}$ & $0.176 *$ & 0.022 & $<0.01 *$ & NA & $\mathrm{NA}$ & $\mathrm{NA}$ & 0.98 \\
\hline NMHC (g/mi) & $\mathrm{NA}$ & -0.016 & -0.024 & 0.12 & -0.028 & 0.50 & $\mathrm{NA}$ & -0.020 & -0.030 & 0.97 & NA & $\mathrm{NA}$ & $\mathrm{NA}$ & 0.95 \\
\hline NMOG (g/mi) & $\mathrm{NA}$ & -0.009 & -0.017 & 0.35 & -0.030 & 0.50 & $\mathrm{NA}$ & -0.022 & -0.034 & 0.96 & NA & $\mathrm{NA}$ & $\mathrm{NA}$ & 0.92 \\
\hline Fuel Econ (mi/gal) & $\mathrm{NA}$ & $-1.116^{*}$ & $-1.349 *$ & $<0.01 *$ & $1.385^{*}$ & $<0.01^{*}$ & $\mathrm{NA}$ & $0.646 *$ & $1.491 *$ & 0.06 & NA & $\mathrm{NA}$ & $\mathrm{NA}$ & 0.91 \\
\hline Acetaldehyde $(\mathrm{mg} / \mathrm{mi})^{\#}$ & $\mathrm{NA}$ & $0.680 *$ & $1.114^{*}$ & $<0.01 *$ & 0.051 & 0.63 & NA & 0.041 & $-0.104 *$ & 0.20 & NA & $\mathrm{NA}$ & $\mathrm{NA}$ & 0.19 \\
\hline Formaldehyde $(\mathrm{mg} / \mathrm{mi})^{\#}$ & $\mathrm{NA}$ & 0.236 & 0.166 & 0.15 & -0.252 & 0.51 & $\mathrm{NA}$ & -0.299 & $-0.498 *$ & 0.61 & NA & $\mathrm{NA}$ & $\mathrm{NA}$ & 0.88 \\
\hline $\mathrm{CH}_{4}(\mathrm{~g} / \mathrm{mi})$ & $\mathrm{NA}$ & -0.0003 & $-0.0008 *$ & 0.07 & 0.0020 & 0.12 & $\mathrm{NA}$ & $0.0030 *$ & $0.0040 *$ & 0.41 & NA & $\mathrm{NA}$ & $\mathrm{NA}$ & $\mathrm{NA}^{1}$ \\
\hline
\end{tabular}

\# Log-normal model was used. Results are presented as changes in emissions at 0k mile.

\#\# Data did not support the assumption of linear effects with mileage.

"Indicates estimate is different from zero at the $95 \%$ confidence level. 
2003 Ford Taurus (Composite CO)

\begin{tabular}{|l|r|r|r|}
\hline \multicolumn{1}{|c|}{ Effect } & Estimate & $\begin{array}{c}\text { 95\% C.I. } \\
\text { Lower }\end{array}$ & $\begin{array}{c}\text { 95\% C.I. } \\
\text { Upper }\end{array}$ \\
\hline Ethanol Effect (E15 vs. E0) $(\Delta \mathrm{g} / \mathrm{mi})$ & $-0.197^{*}$ & -0.299 & -0.095 \\
\hline Ethanol Effect $($ E20 vs. E0) $(\Delta \mathrm{g} / \mathrm{mi})$ & $-0.337^{*}$ & -0.439 & -0.235 \\
\hline Road Fuel Aging Effect & & & \\
\hline Aging Effect with RE0 $(\Delta \mathrm{g} / \mathrm{mi}$ per 100k mi) & -0.258 & -0.607 & 0.091 \\
\hline Aging Effect with RE15 $(\Delta \mathrm{g} / \mathrm{mi}$ per 100k mi) & 0.055 & -0.193 & 0.303 \\
\hline Aging Effect with RE20 $(\Delta \mathrm{g} / \mathrm{mi}$ per 100k mi) & -0.139 & -0.387 & 0.109 \\
\hline
\end{tabular}

\begin{tabular}{|l|r|}
\hline \multicolumn{1}{|c|}{ Hypothesis } & p-value \\
\hline No Effect of Ethanol in the Test Fuel (Gamma = 0) & $<0.01^{*}$ \\
\hline No Aging Effect with RE0 (Beta0 = 0) & 0.12 \\
\hline No Effect of Ethanol in Road Fuel Aging (Beta1s=0) & 0.25 \\
\hline
\end{tabular}

* Indicates estimate is different from zero at the $95 \%$ confidence level.

\section{Initial Odometers 84k-93k}
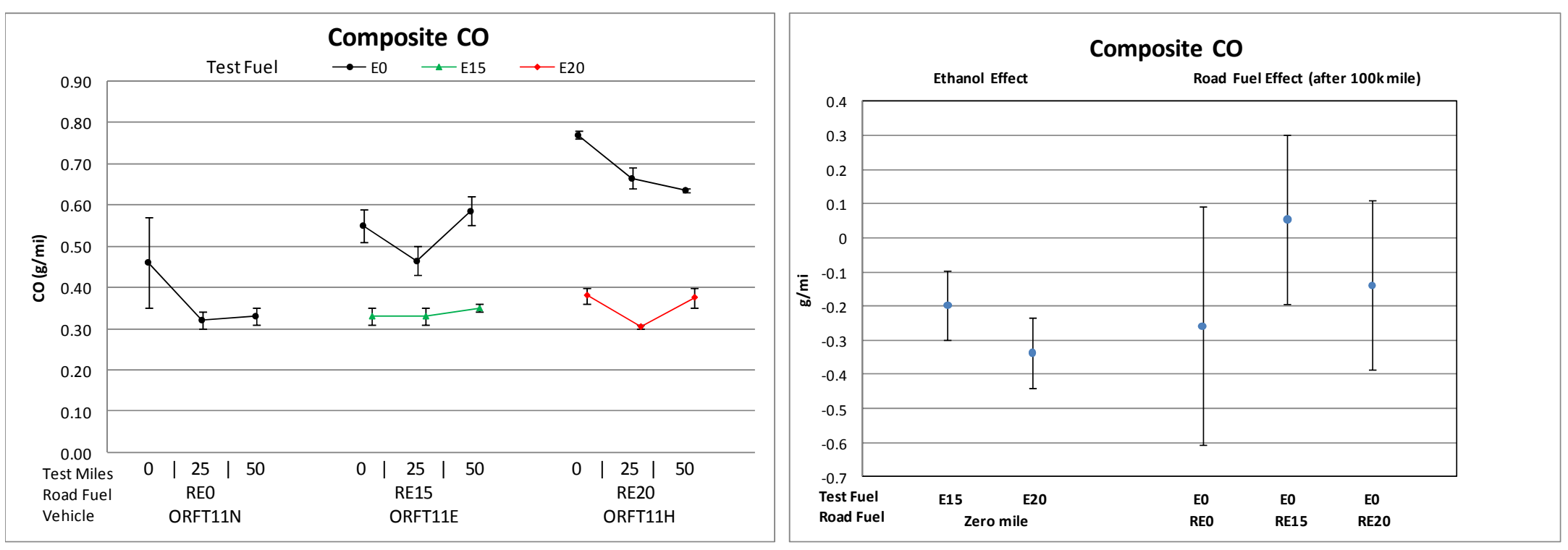

Error bars represent min and max measurements

Error bars represent $95 \%$ confidence intervals on the estimated effects 
2003 Ford Taurus (Composite NOx)

\begin{tabular}{|l|r|r|r|}
\hline \multicolumn{1}{|c|}{ Effect } & Estimate & $\begin{array}{r}\text { 95\% C.I. } \\
\text { Lower }\end{array}$ & $\begin{array}{r}\text { 95\% C.I. } \\
\text { Upper }\end{array}$ \\
\hline Ethanol Effect (E15 vs. E0) $(\Delta \mathrm{g} / \mathrm{mi})$ & 0.010 & -0.016 & 0.037 \\
\hline Ethanol Effect (E20 vs. E0) $(\Delta \mathrm{g} / \mathrm{mi})$ & $0.054^{*}$ & 0.027 & 0.080 \\
\hline Road Fuel Aging Effect & & & \\
\hline Aging Effect with RE0 $(\Delta \mathrm{g} / \mathrm{mi}$ per 100k mi) & 0.014 & -0.077 & 0.105 \\
\hline Aging Effect with RE15 $(\Delta \mathrm{g} / \mathrm{mi} \mathrm{per} \mathrm{100k} \mathrm{mi)}$ & $0.176^{*}$ & 0.111 & 0.241 \\
\hline Aging Effect with RE20 $(\Delta \mathrm{g} / \mathrm{mi}$ per 100k mi) & 0.022 & -0.042 & 0.087 \\
\hline
\end{tabular}

\begin{tabular}{|l|r|}
\hline \multicolumn{1}{|c|}{ Hypothesis } & p-value \\
\hline No Effect of Ethanol in the Test Fuel (Gamma = 0) & $<0.01^{*}$ \\
\hline No Aging Effect with RE0 (Beta0 = 0) & 0.73 \\
\hline No Effect of Ethanol in Road Fuel Aging (Beta1s=0) & $<0.01^{*}$ \\
\hline${ }^{*}$ Indicates effect is statistically significant at the 95\% confidence level.
\end{tabular}

* Indicates estimate is different from zero at the $95 \%$ confidence level.

\section{Initial Odometers 84k-93k}

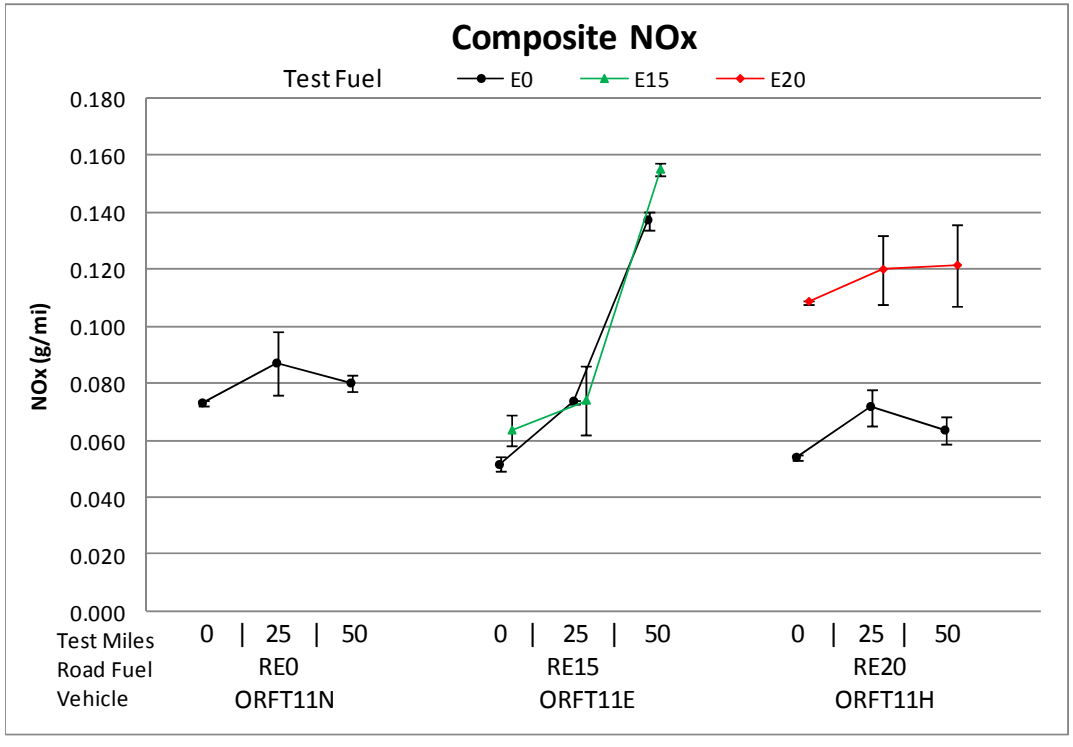

Error bars represent min and max measurements

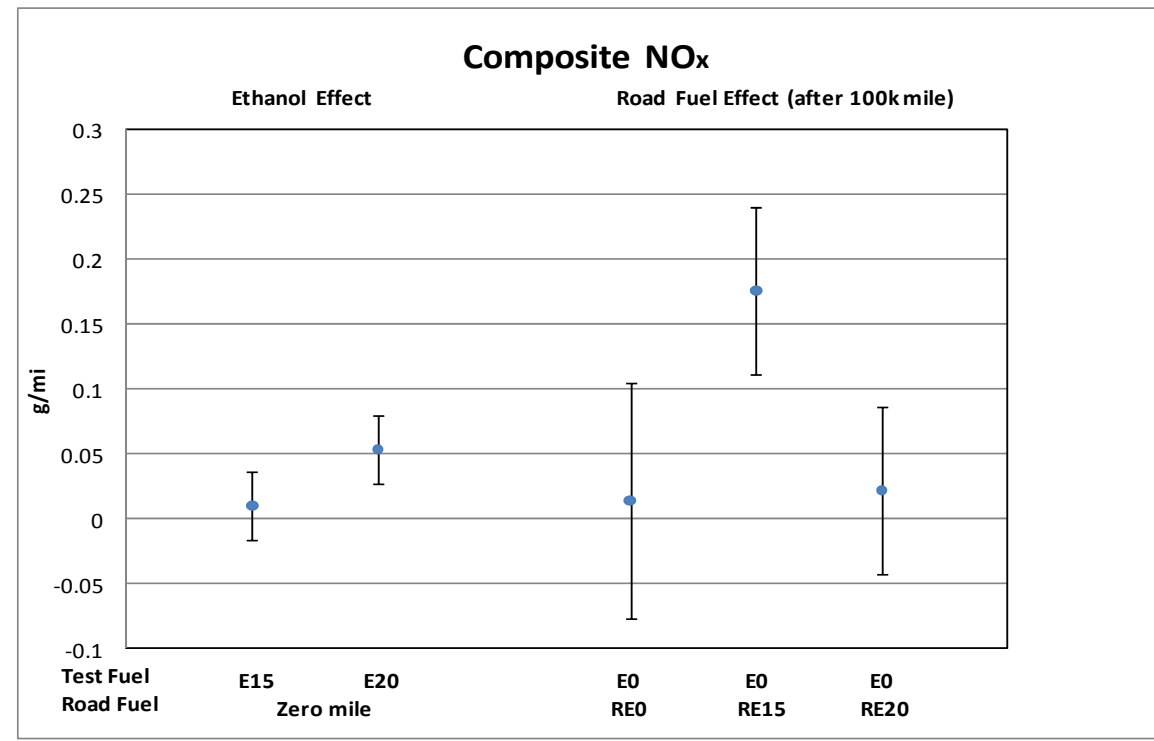

Error bars represent $95 \%$ confidence intervals on the estimated effects 
2003 Ford Taurus (Composite Nonmethane Hydrocarbons)

\begin{tabular}{|l|r|r|r|}
\hline \multicolumn{1}{|c|}{ Effect } & & $95 \%$ C.I. & 95\% C.I. \\
& Estimate & Lower & Upper \\
\hline Ethanol Effect (E15 vs. E0) $(\Delta \mathrm{g} / \mathrm{mi})$ & -0.016 & -0.043 & 0.012 \\
\hline Ethanol Effect (E20 vs. E0) $(\Delta \mathrm{g} / \mathrm{mi})$ & -0.024 & -0.051 & 0.004 \\
\hline Road Fuel Aging Effect & & & \\
\hline Aging Effect with RE0 $(\Delta \mathrm{g} / \mathrm{mi}$ per 100k mi) & -0.028 & -0.122 & 0.065 \\
\hline Aging Effect with RE15 $(\Delta \mathrm{g} / \mathrm{mi}$ per 100k mi) & -0.020 & -0.087 & 0.046 \\
\hline Aging Effect with RE20 $(\Delta \mathrm{g} / \mathrm{mi} \mathrm{per} \mathrm{100k} \mathrm{mi)}$ & -0.030 & -0.097 & 0.037 \\
\hline
\end{tabular}

\begin{tabular}{|l|r|}
\hline \multicolumn{1}{|c|}{ Hypothesis } & -value \\
\hline No Effect of Ethanol in the Test Fuel (Gamma = 0) & 0.12 \\
\hline No Aging Effect with RE0 (Beta0 = 0) & 0.50 \\
\hline No Effect of Ethanol in Road Fuel Aging (Beta1s=0) & 0.97 \\
\hline * Indicates effect is statistically significant at the 95\% confidence level.
\end{tabular}

* Indicates estimate is different from zero at the $95 \%$ confidence level.

Initial Odometers 84k-93k

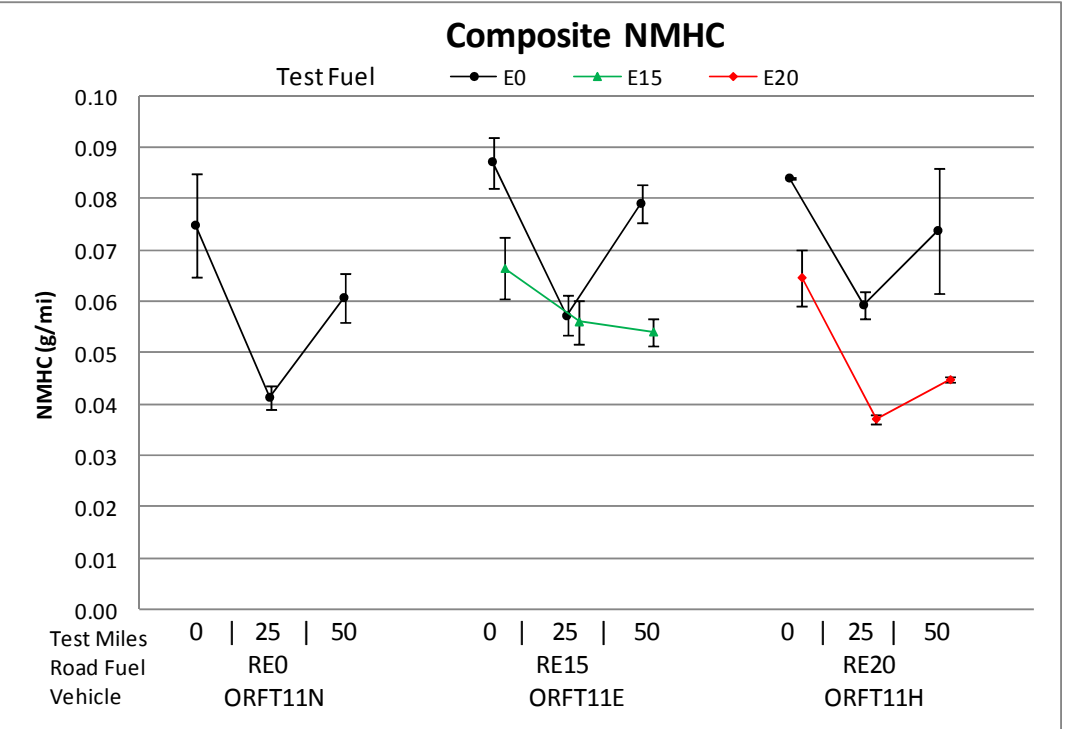

Error bars represent min and max measurements

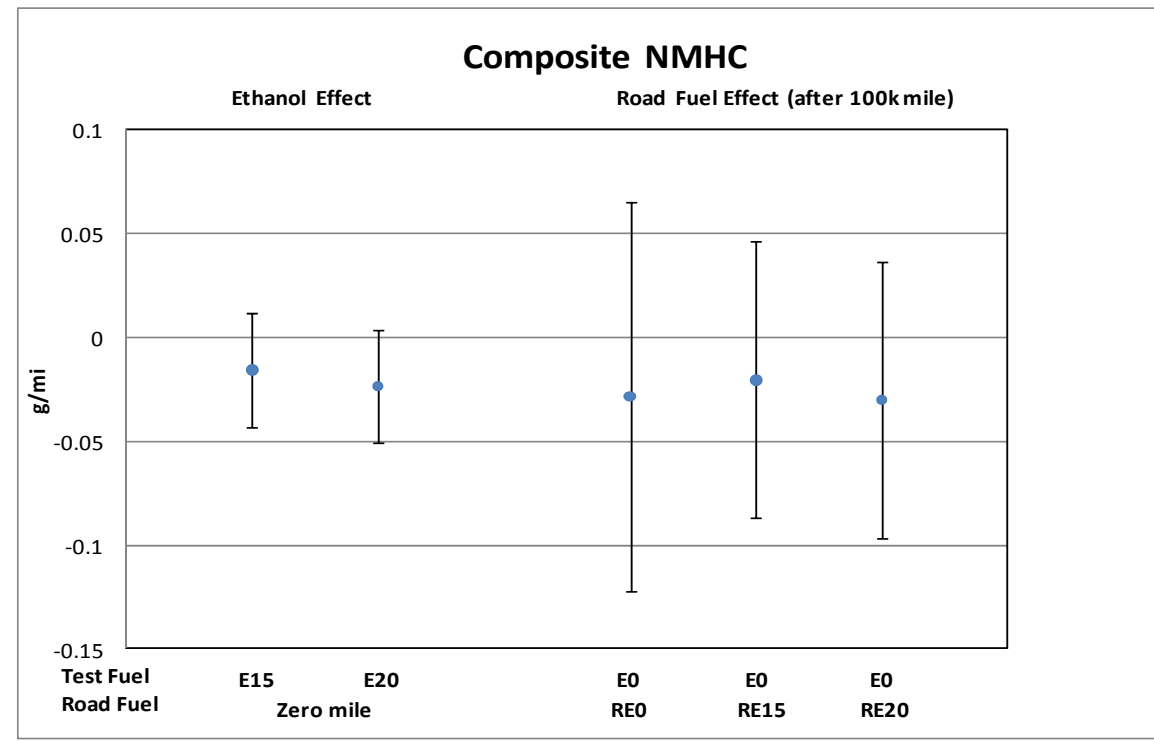

Error bars represent $95 \%$ confidence intervals on the estimated effects 
2003 Ford Taurus (Composite Nonmethane Organic Gases)

\begin{tabular}{|l|r|r|r|}
\hline \multicolumn{1}{|c|}{ Effect } & & $\begin{array}{r}\text { 95\% C.I. } \\
\text { Low }\end{array}$ & $\begin{array}{r}\text { 95\% C.I. } \\
\text { Upper }\end{array}$ \\
\hline Ethanol Effect $(E 15$ vs. E0) $(\Delta \mathrm{g} / \mathrm{mi})$ & -0.009 & -0.038 & 0.020 \\
\hline Ethanol Effect (E20 vs. E0) $(\Delta \mathrm{g} / \mathrm{mi})$ & -0.017 & -0.046 & 0.012 \\
\hline Road Fuel Aging Effect & & & \\
\hline Aging Effect with RE0 $(\Delta \mathrm{g} / \mathrm{mi}$ per 100k mi) & -0.030 & -0.129 & 0.070 \\
\hline Aging Effect with RE15 $(\Delta \mathrm{g} / \mathrm{mi}$ per 100k mi) & -0.022 & -0.093 & 0.048 \\
\hline Aging Effect with RE20 $(\Delta \mathrm{g} / \mathrm{mi}$ per 100k mi) & -0.034 & -0.105 & 0.037 \\
\hline
\end{tabular}

\begin{tabular}{|l|r|}
\hline \multicolumn{1}{|c|}{ Hypothesis } & p-value \\
\hline No Effect of Ethanol in the Test Fuel (Gamma = 0) & 0.35 \\
\hline No Aging Effect with RE0 (Beta0 $=0)$ & 0.50 \\
\hline No Effect of Ethanol in Road Fuel Aging (Beta1s=0) & 0.96 \\
\hline${ }^{*}$ Indicates effect is statistically significant at the 95\% confidence level.
\end{tabular}

* Indicates estimate is different from zero at the $95 \%$ confidence level.

Initial Odometers 84k-93k

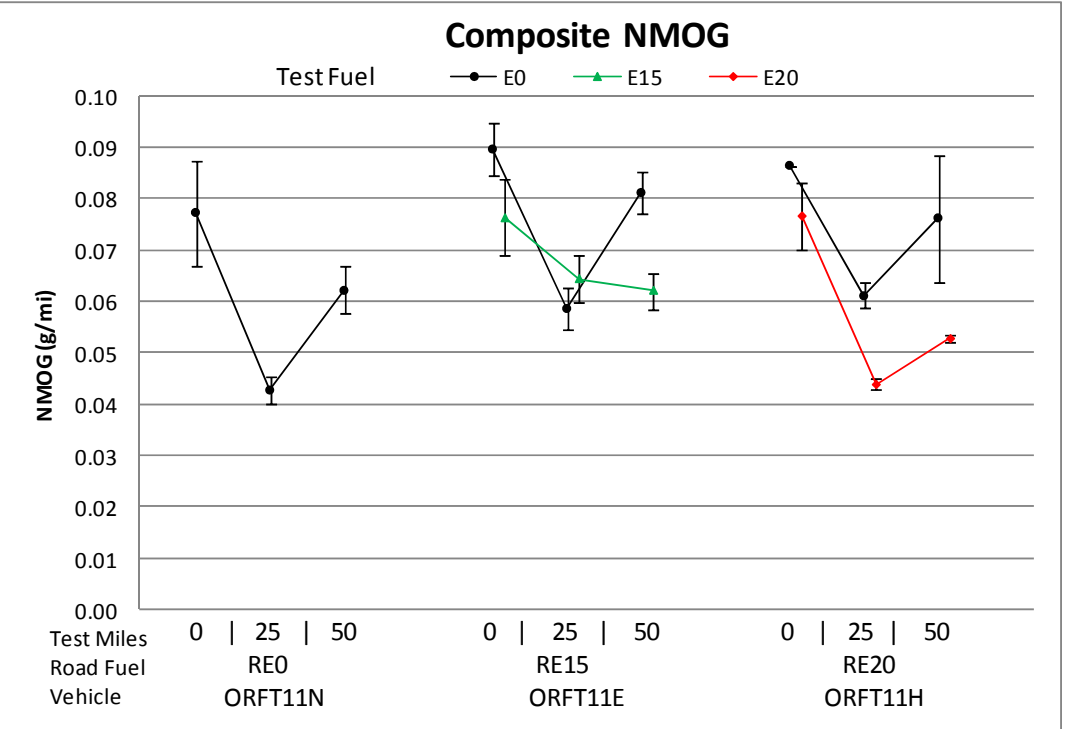

Error bars represent min and max measurements

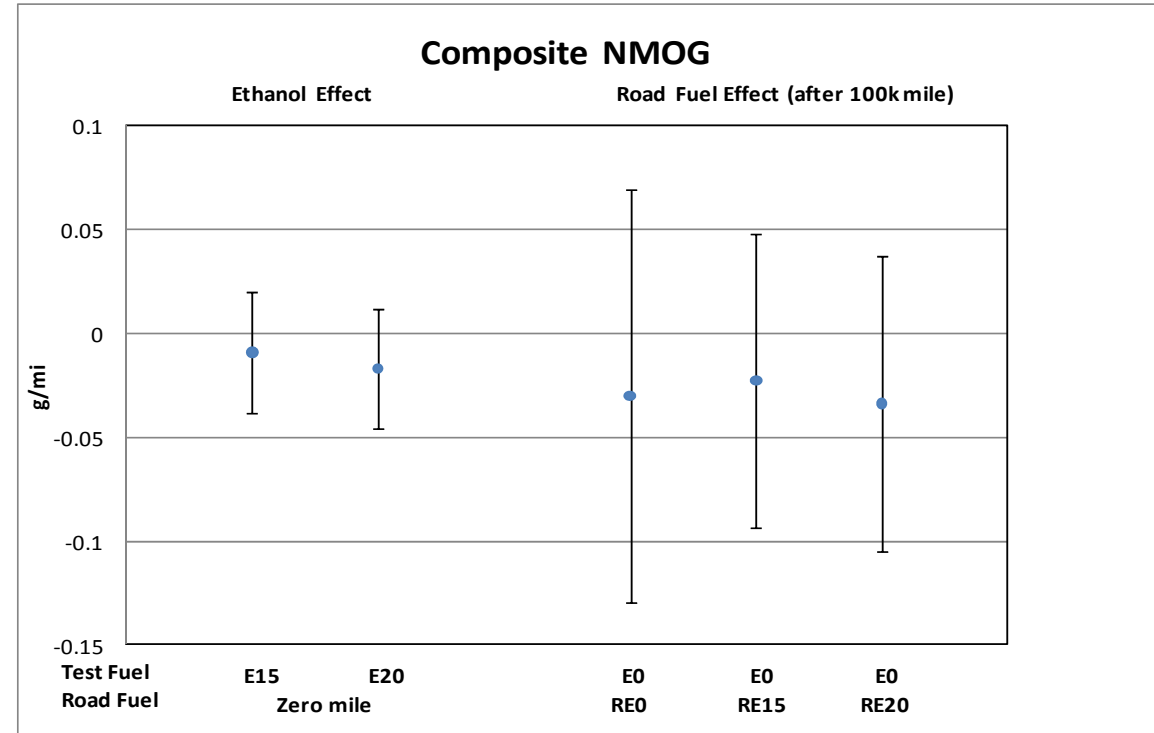

Error bars represent $95 \%$ confidence intervals on the estimated effects 
2003 Ford Taurus (Composite Fuel Economy)

\begin{tabular}{|l|r|r|r|}
\hline \multicolumn{1}{|c|}{ Effect } & Estimate & $\begin{array}{r}\text { 95\% C.I. } \\
\text { Lower }\end{array}$ & $\begin{array}{r}\text { 95\% C.I. } \\
\text { Upper }\end{array}$ \\
\hline Ethanol Effect (E15 vs. E0) $(\Delta \mathrm{mi} / \mathrm{gal})$ & $-1.116^{*}$ & -1.324 & -0.908 \\
\hline Ethanol Effect (E20 vs. E0) $(\Delta \mathrm{mi} / \mathrm{gal})$ & $-1.349^{*}$ & -1.557 & -1.141 \\
\hline Road Fuel Aging Effect & & & \\
\hline Aging Effect with RE0 $(\Delta \mathrm{mi} / \mathrm{gal}$ per 100k mi) & $1.385^{*}$ & 0.673 & 2.097 \\
\hline Aging Effect with RE15 $(\Delta \mathrm{mi} / \mathrm{gal}$ per 100k mi) & $0.646^{*}$ & 0.139 & 1.152 \\
\hline Aging Effect with RE20 $(\Delta \mathrm{mi} / \mathrm{gal}$ per 100k mi) & $1.491^{*}$ & 0.984 & 1.998 \\
\hline
\end{tabular}

* Indicates estimate is different from zero at the $95 \%$ confidence level.

\begin{tabular}{|l|r|}
\hline \multicolumn{1}{|c|}{ Hypothesis } & p-value \\
\hline No Effect of Ethanol in the Test Fuel (Gamma $=0)$ & $<0.01^{*}$ \\
\hline No Aging Effect with RE0 (Beta0 $=0$ ) & $<0.01^{*}$ \\
\hline No Effect of Ethanol in Road Fuel Aging (Beta1s=0) & 0.06 \\
\hline
\end{tabular}

Initial Odometers 84k-93k
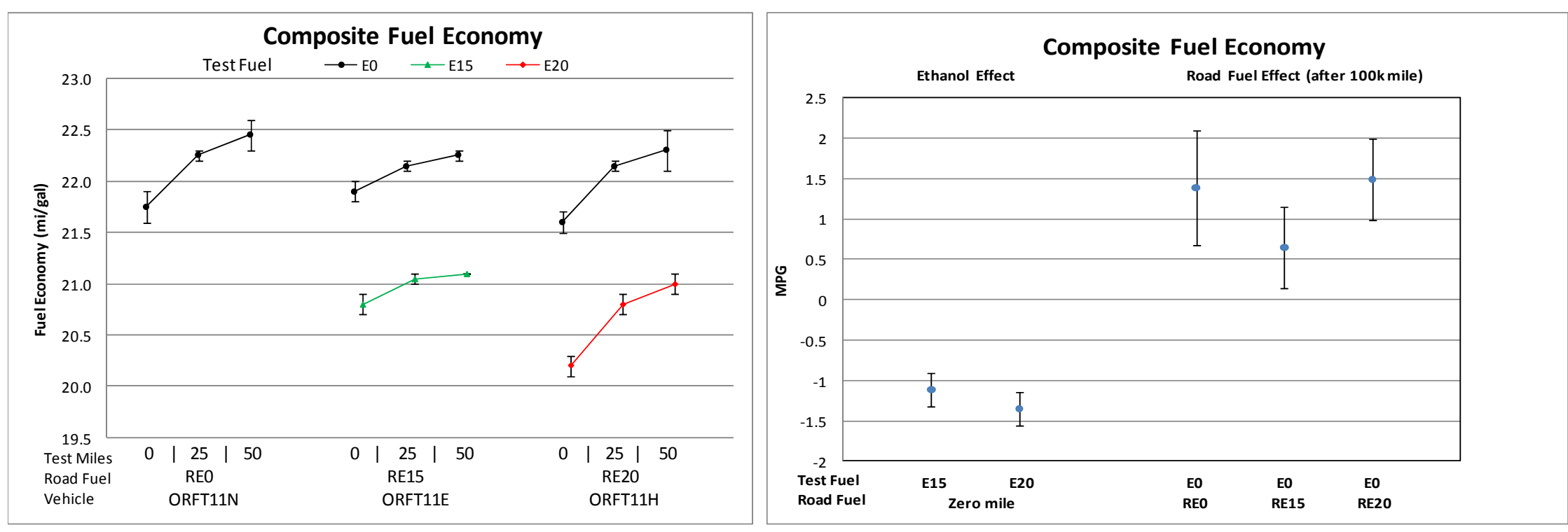

Error bars represent min and max measurements

Error bars represent $95 \%$ confidence intervals on the estimated effects 
2003 Ford Taurus (Composite Acetaldehyde)

\begin{tabular}{|l|r|r|r|}
\hline \multicolumn{1}{|c|}{ Effect } & Estimate & $\begin{array}{r}\text { 95\% C.I. } \\
\text { Lower }\end{array}$ & $\begin{array}{r}\text { 95\% C.I. } \\
\text { Upper }\end{array}$ \\
\hline Ethanol Effect (E15 vs. E0) $(\Delta \mathrm{mg} / \mathrm{mi})$ & $0.680^{*}$ & 0.481 & 0.879 \\
\hline Ethanol Effect $($ E20 vs. E0) $(\Delta \mathrm{mg} / \mathrm{mi})$ & $1.114^{*}$ & 0.822 & 1.406 \\
\hline Road Fuel Aging Effect & & & \\
\hline Aging Effect with RE0 $(\Delta \mathrm{mg} / \mathrm{mi}$ per 100k mi) & 0.051 & -0.163 & 0.266 \\
\hline Aging Effect with RE15 $(\Delta \mathrm{mg} / \mathrm{mi}$ per 100k mi) & 0.041 & -0.099 & 0.181 \\
\hline Aging Effect with RE20 $(\Delta \mathrm{mg} / \mathrm{mi}$ per 100k mi) & $-0.104^{*}$ & -0.205 & -0.004 \\
\hline
\end{tabular}

\begin{tabular}{|l|r|}
\hline \multicolumn{1}{|c|}{ Hypothesis } & -value \\
\hline No Effect of Ethanol in the Test Fuel (Gamma = 0) & $<0.01^{*}$ \\
\hline No Aging Effect with RE0 (Beta0 $=0$ ) & 0.63 \\
\hline No Effect of Ethanol in Road Fuel Aging (Beta1s $=0$ ) & 0.20 \\
\hline * Indicates effect is statistically significant at the 95\% confidence level.
\end{tabular}

* Indicates estimate is different from zero at the $95 \%$ confidence level.

Initial Odometers 84k-93k

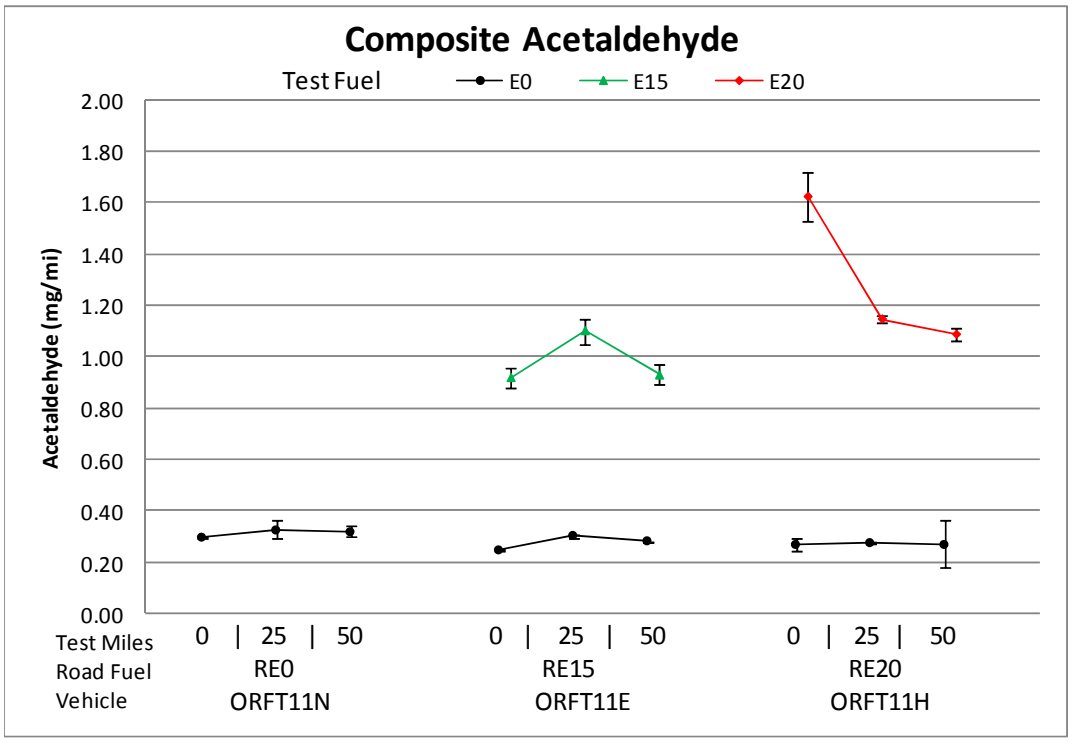

Error bars represent min and max measurements

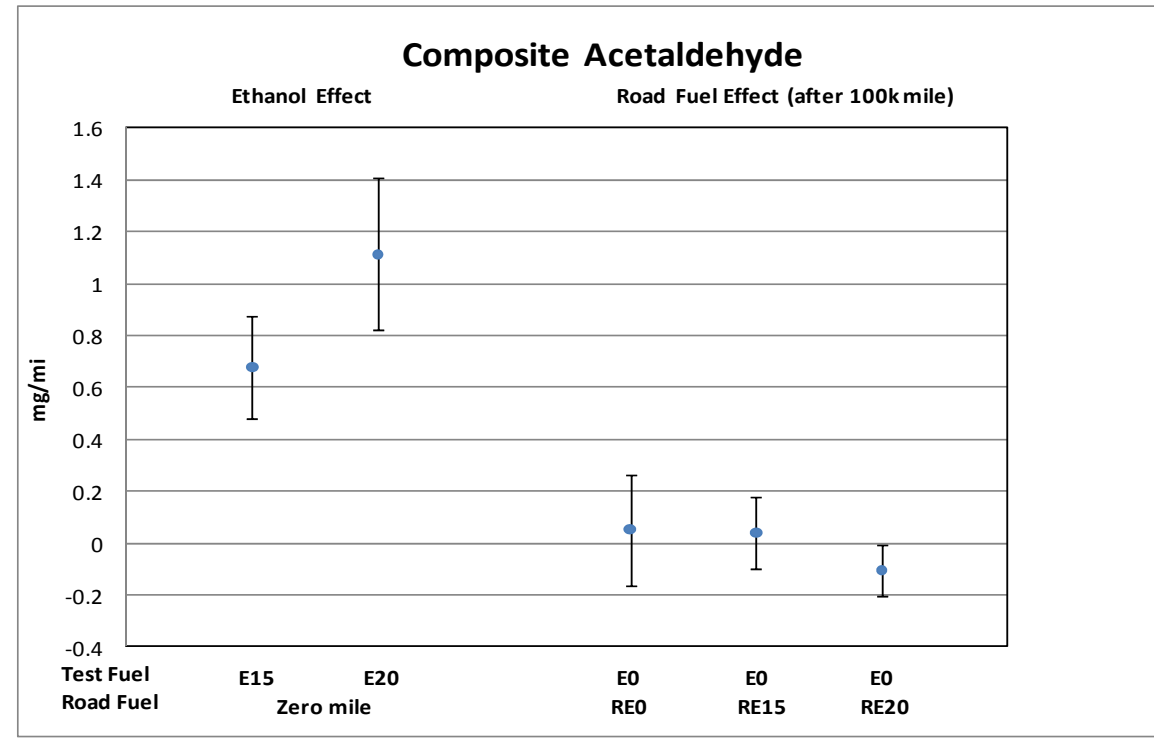

Error bars represent $95 \%$ confidence intervals on the estimated effects 
2003 Ford Taurus (Composite Formaldehyde)

\begin{tabular}{|c|c|c|c|}
\hline Effect & Estimate & $\begin{array}{c}95 \% \text { C.I. } \\
\text { Lower }\end{array}$ & $\begin{array}{c}95 \% \text { C.I. } \\
\text { Upper }\end{array}$ \\
\hline Ethanol Effect (E15 vs. E0) $(\Delta \mathrm{mg} / \mathrm{mi})$ & 0.236 & -0.166 & 0.639 \\
\hline Ethanol Effect (E20 vs. E0) $(\Delta \mathrm{mg} / \mathrm{mi})$ & 0.166 & -0.262 & 0.594 \\
\hline \multicolumn{4}{|l|}{ Road Fuel Aging Effect } \\
\hline Aging Effect with RE0 ( $\Delta \mathrm{mg} / \mathrm{mi}$ per $100 \mathrm{k} \mathrm{mi})$ & -0.252 & -0.905 & 0.401 \\
\hline Aging Effect with RE15 ( $\Delta \mathrm{mg} / \mathrm{mi}$ per $100 \mathrm{k} \mathrm{mi})$ & -0.299 & -0.680 & 0.081 \\
\hline Aging Effect with RE20 ( $\Delta \mathrm{mg} / \mathrm{mi}$ per $100 \mathrm{k} \mathrm{mi})$ & $-0.498^{*}$ & -0.848 & -0.147 \\
\hline
\end{tabular}

\begin{tabular}{|l|r|}
\hline \multicolumn{1}{|c|}{ Hypothesis } & -value \\
\hline No Effect of Ethanol in the Test Fuel (Gamma = 0) & 0.15 \\
\hline No Aging Effect with RE0 (Beta0 = 0) & 0.51 \\
\hline No Effect of Ethanol in Road Fuel Aging (Beta1s=0) & 0.61 \\
\hline * Indicates effect is statistically significant at the 95\% confidence level.
\end{tabular}

${ }^{*}$ Indicates estimate is different from zero at the $95 \%$ confidence level.

Initial Odometers 84k-93k

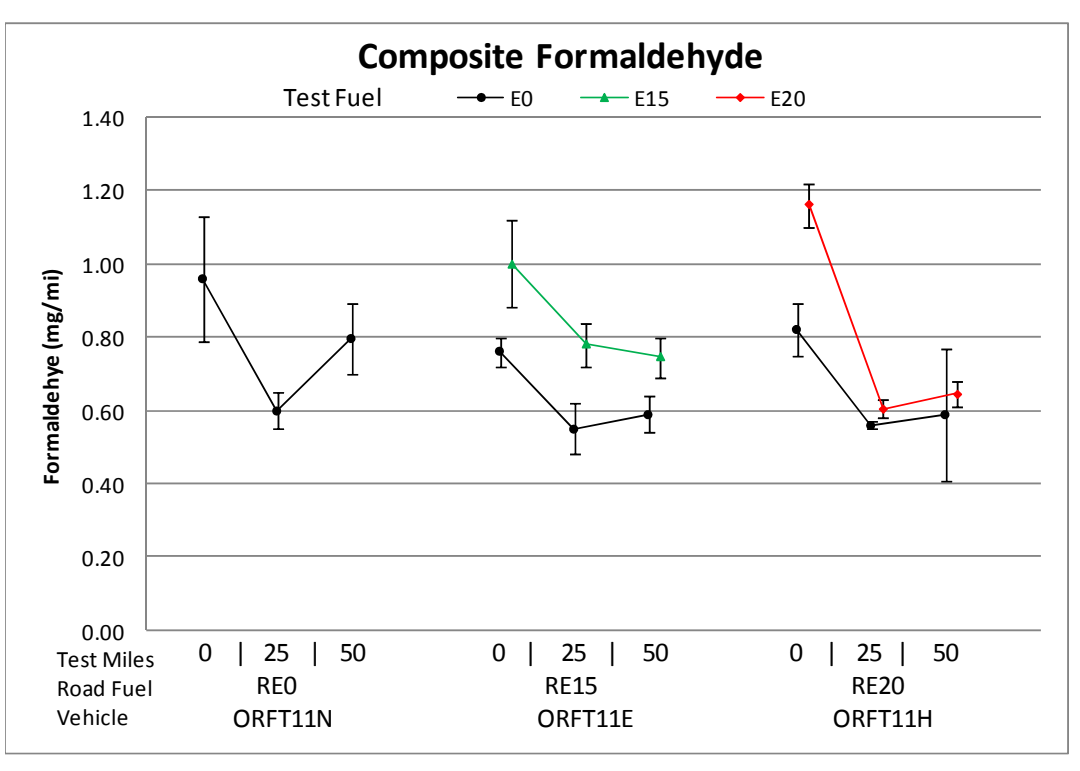

Error bars represent min and max measurements

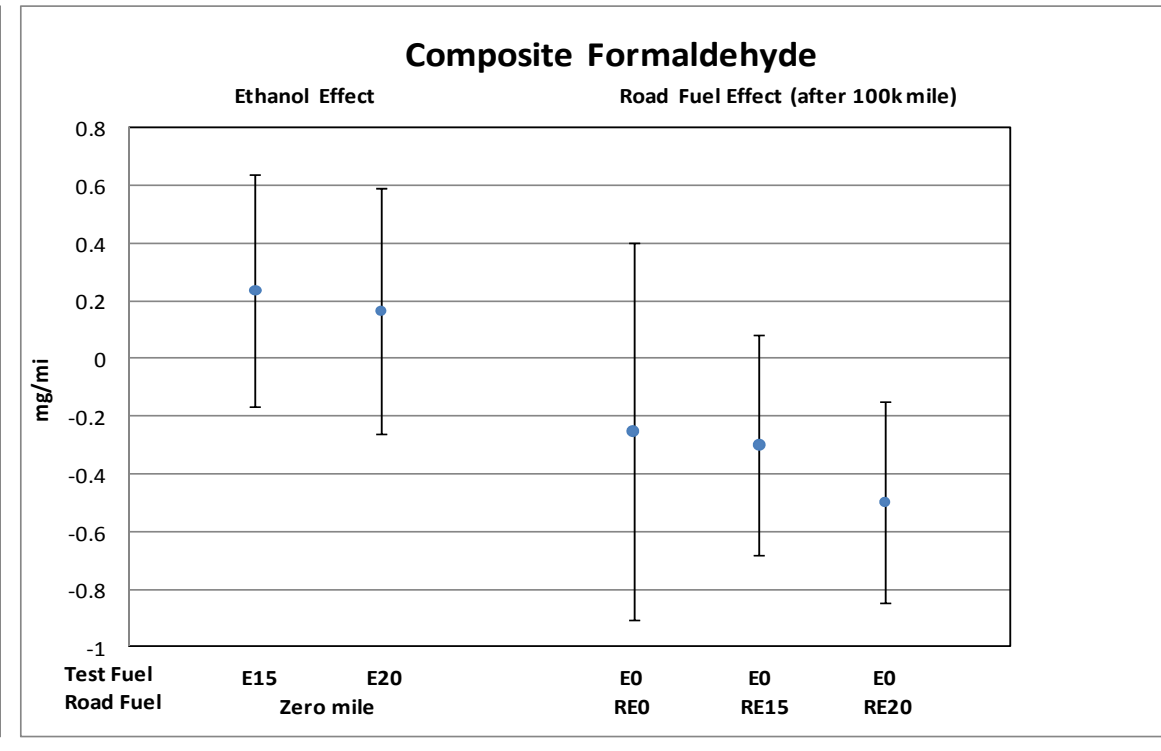

Error bars represent $95 \%$ confidence intervals on the estimated effects 
2003 Ford Taurus (Composite $\mathrm{CH} 4$ )

\begin{tabular}{|l|r|r|r|}
\hline \multicolumn{1}{|c|}{ Effect } & Estimate & $\begin{array}{c}\text { 95\% C.I. } \\
\text { Lower }\end{array}$ & $\begin{array}{c}\text { 95\% C.I. } \\
\text { Upper }\end{array}$ \\
\hline Ethanol Effect (E15 vs. E0) $(\Delta \mathrm{g} / \mathrm{mi})$ & -0.0003 & -0.0011 & 0.0004 \\
\hline Ethanol Effect (E20 vs. E0) $(\Delta \mathrm{g} / \mathrm{mi})$ & $-0.0008^{*}$ & -0.0016 & -0.0001 \\
\hline Road Fuel Aging Effect & & & \\
\hline Aging Effect with RE0 $(\Delta \mathrm{g} / \mathrm{mi}$ per 100k mi) & 0.0020 & -0.0006 & 0.0045 \\
\hline Aging Effect with RE15 $(\Delta \mathrm{g} / \mathrm{mi} \mathrm{per} \mathrm{100k} \mathrm{mi)}$ & $0.0030^{*}$ & 0.0012 & 0.0048 \\
\hline Aging Effect with RE20 $(\Delta \mathrm{g} / \mathrm{mi} \mathrm{per} \mathrm{100k} \mathrm{mi)}$ & $0.0040^{*}$ & 0.0022 & 0.0058 \\
\hline
\end{tabular}

\begin{tabular}{|l|r|}
\hline \multicolumn{1}{|c|}{ Hypothesis } & p-value \\
\hline No Effect of Ethanol in the Test Fuel (Gamma = 0) & 0.07 \\
\hline No Aging Effect with RE0 (Beta0 = 0) & 0.12 \\
\hline No Effect of Ethanol in Road Fuel Aging (Beta1s=0) & 0.41 \\
\hline${ }^{*}$ Indicates effect is statistically significant at the 95\% confidence level.
\end{tabular}

* Indicates estimate is different from zero at the $95 \%$ confidence level.

Initial Odometers 84k-93k

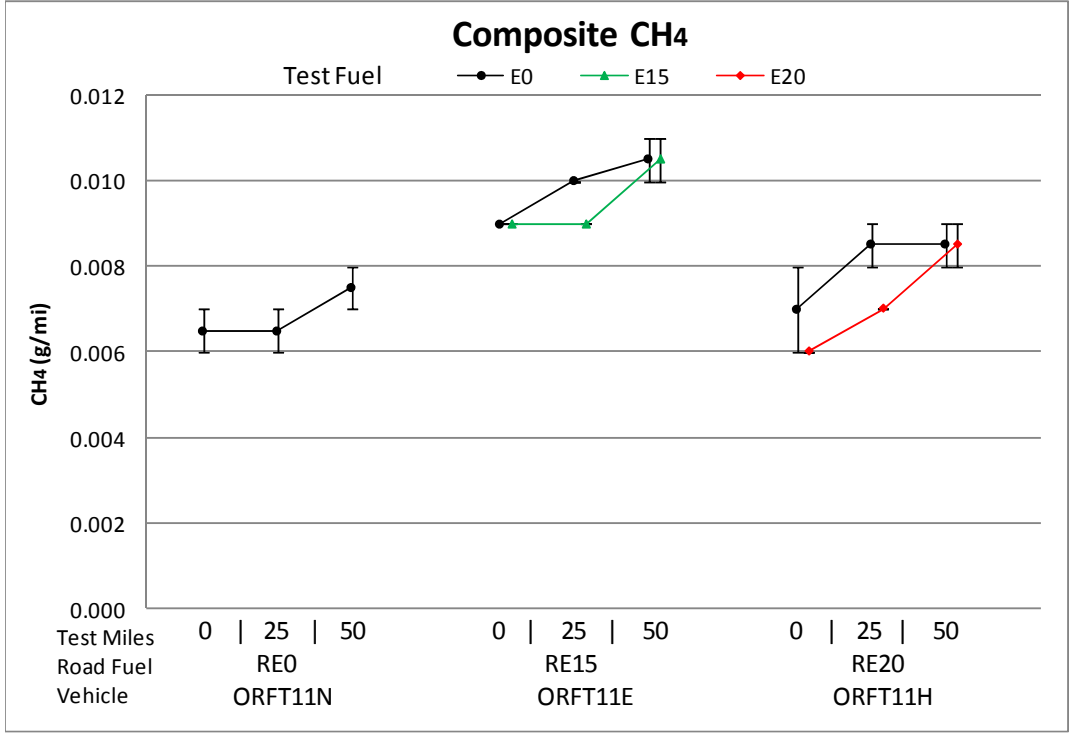

Error bars represent min and max measurements

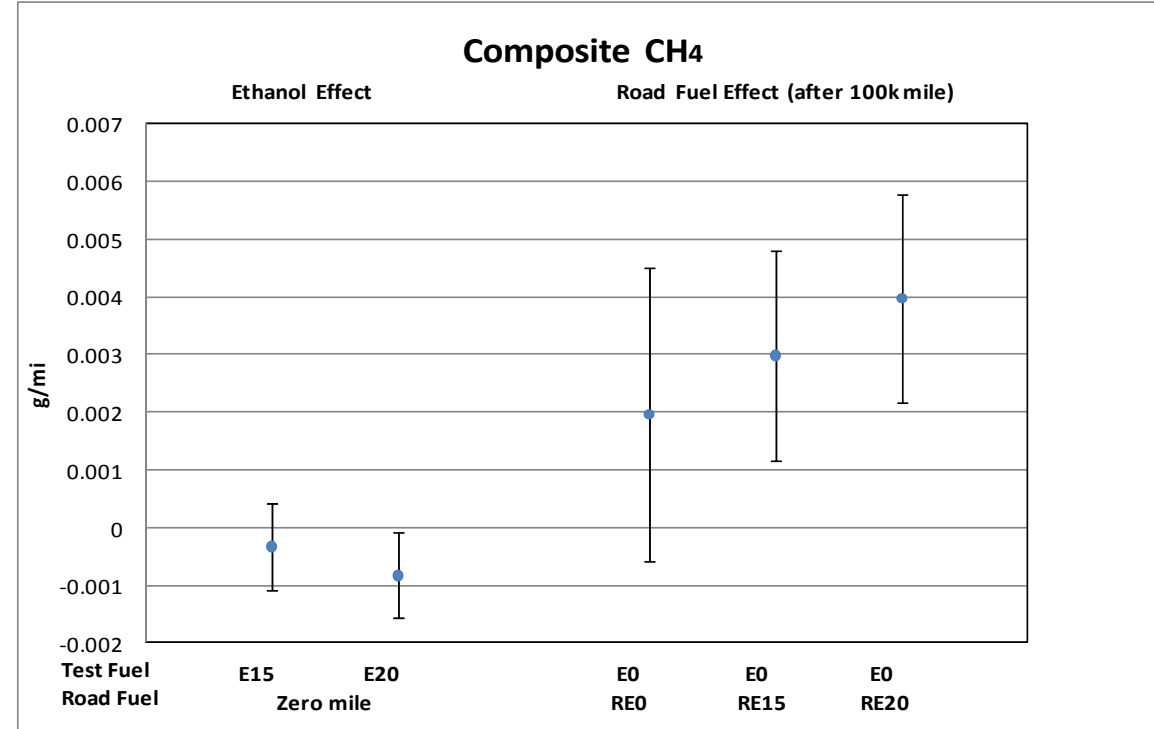

Error bars represent $95 \%$ confidence intervals on the estimated effects 


\section{Chevrolet Cavalier - Composite Emissions Summary}

\begin{tabular}{|c|c|c|c|c|c|c|c|c|c|c|c|c|c|c|}
\hline \multirow{2}{*}{$\begin{array}{c}\text { Emisssion Parameter } \\
\text { (units) }\end{array}$} & \multicolumn{4}{|c|}{ Ethanol Effect } & \multicolumn{2}{|c|}{ Aging Effect with REO } & \multicolumn{4}{|c|}{ RExx Aging Effect on E0 Emissions } & \multirow{2}{*}{\multicolumn{3}{|c|}{\begin{tabular}{|c|} 
RExx Aging Effect on Exx Emissions \\
$\Delta$ units per $100 \mathrm{~K} \mathrm{mi}$ \\
\end{tabular}}} & \multirow{3}{*}{\begin{tabular}{|c|}
$\begin{array}{c}\text { Road and Test } \\
\text { Fuel Effects } \\
\text { are Additive }\end{array}$ \\
$\begin{array}{c}\text { Overall p- } \\
\text { value }\end{array}$ \\
\end{tabular}} \\
\hline & \multicolumn{3}{|c|}{$\Delta$ units vs. EO } & \multirow{2}{*}{$-\begin{array}{c}\text { Overall } \\
p \text {-value }\end{array}$} & \multirow{2}{*}{$\begin{array}{c}\Delta \text { units per } 100 \mathrm{~K} \mathrm{mi} \\
\mathrm{REO} / \mathrm{EO}\end{array}$} & \multirow{2}{*}{ Overall } & \multicolumn{3}{|c|}{$\Delta$ units per $100 \mathrm{~K} \mathrm{mi}$} & \multirow{2}{*}{$\begin{array}{l}\text { Overall } \\
p \text {-value }\end{array}$} & & & & \\
\hline Fuels & E10 & E15 & E20 & & & & RE10/E0 & RE15/E0 & RE20/E0 & & RE10/E10 & RE15/E15 & RE20/E20 & \\
\hline $\mathrm{CO}(\mathrm{g} / \mathrm{mi})$ & NA & -0.130 & $-0.415 *$ & $<0.01 *$ & $1.611 *$ & $<0.01 *$ & $\mathrm{NA}$ & 0.120 & 0.358 & $<0.01^{*}$ & $\mathrm{NA}$ & $N A$ & $\mathrm{NA}$ & 0.87 \\
\hline $\mathrm{NOx}(\mathrm{g} / \mathrm{mi})$ & NA & -0.005 & 0.018 & 0.80 & $0.408 *$ & $<0.01 *$ & NA & $-0.185^{*}$ & -0.098 & $<0.01^{*}$ & $N A$ & NA & $\mathrm{NA}$ & 0.50 \\
\hline NMHC (g/mi) & NA & -0.0058 & 0.0000 & 0.67 & $0.0854 *$ & $<0.01 *$ & $\mathrm{NA}$ & 0.0012 & 0.0491* & $0.04 *$ & $\mathrm{NA}$ & $N A$ & $\mathrm{NA}$ & 0.98 \\
\hline NMOG $(\mathrm{g} / \mathrm{mi})$ & NA & -0.0001 & 0.0128 & 0.28 & $0.0872 *$ & $0.01 *$ & NA & 0.0018 & $0.0540^{*}$ & 0.06 & $\mathrm{NA}$ & NA & $\mathrm{NA}$ & 0.95 \\
\hline Fuel Econ (mi/gal) & NA & $-1.476^{*}$ & $-1.466 *$ & $<0.01 *$ & $-2.320^{*}$ & $<0.01 *$ & NA & 1.613* & 0.694 & $<0.01^{*}$ & $\mathrm{NA}$ & NA & $\mathrm{NA}$ & 0.28 \\
\hline Acetaldehyde $(\mathrm{mg} / \mathrm{mi})^{\#}$ & $\mathrm{NA}$ & $0.414^{*}$ & $0.592^{*}$ & $<0.01 *$ & 0.257 & 0.15 & $\mathrm{NA}$ & -0.066 & $0.376 *$ & $0.04^{*}$ & $\mathrm{NA}$ & NA & $\mathrm{NA}$ & 0.26 \\
\hline Formaldehyde $(\mathrm{mg} / \mathrm{mi})^{\#}$ & NA & 0.034 & 0.191 & 0.15 & 0.619 & 0.26 & NA & $-0.546^{*}$ & 0.161 & $0.04 *$ & $\mathrm{NA}$ & NA & $\mathrm{NA}$ & 0.64 \\
\hline $\mathrm{CH}_{4}(\mathrm{~g} / \mathrm{mi})$ & NA & -0.0008 & -0.0013 & 0.56 & $0.0271 *$ & $<0.01 *$ & NA & 0.0028 & 0.0055 & $0.01 *$ & $N A$ & $N A$ & $\mathrm{NA}$ & 0.99 \\
\hline
\end{tabular}

\# Log-normal model was used. Results are presented as changes in emissions at 0k mile.

\#\# Data did not support the assumption of linear effects with mileage.

*Indicates estimate is different from zero at the $95 \%$ confidence level. 
2003 Chevrolet Cavalier (Composite CO)

\begin{tabular}{|l|r|r|r|}
\hline \multicolumn{1}{|c|}{ Effect } & & $\begin{array}{r}95 \% \text { C.I. } \\
\text { Lo5\% C.I. } \\
\text { Upper }\end{array}$ \\
\hline Ethanol Effect $(E 15 \mathrm{vs}$. E0) $(\Delta \mathrm{g} / \mathrm{mi})$ & -0.130 & -0.279 & 0.018 \\
\hline Ethanol Effect $($ E20 vs. E0) $(\Delta \mathrm{g} / \mathrm{mi})$ & $-0.415^{*}$ & -0.563 & -0.266 \\
\hline Road Fuel Aging Effect & & & \\
\hline Aging Effect with RE0 $(\Delta \mathrm{g} / \mathrm{mi}$ per 100k mi) & $1.611^{*}$ & 1.092 & 2.130 \\
\hline Aging Effect with RE15 $(\Delta \mathrm{g} / \mathrm{mi}$ per 100k mi) & 0.120 & -0.241 & 0.481 \\
\hline Aging Effect with RE20 $(\Delta \mathrm{g} / \mathrm{mi}$ per 100k mi) & 0.358 & -0.004 & 0.719 \\
\hline
\end{tabular}

\begin{tabular}{|l|c|}
\hline \multicolumn{1}{|c|}{ Hypothesis } & -value \\
\hline No Effect of Ethanol in the Test Fuel (Gamma $=0)$ & $<0.01^{*}$ \\
\hline No Aging Effect with RE0 (Beta0 $=0$ ) & $<0.01^{*}$ \\
\hline No Effect of Ethanol in Road Fuel Aging (Beta1s $=0$ ) & $<0.01^{*}$ \\
\hline * Indicates effect is statistically significant at the $95 \%$ confidence level.
\end{tabular}

* Indicates estimate is different from zero at the $95 \%$ confidence level.

\section{Initial Odometers 81k-89k}
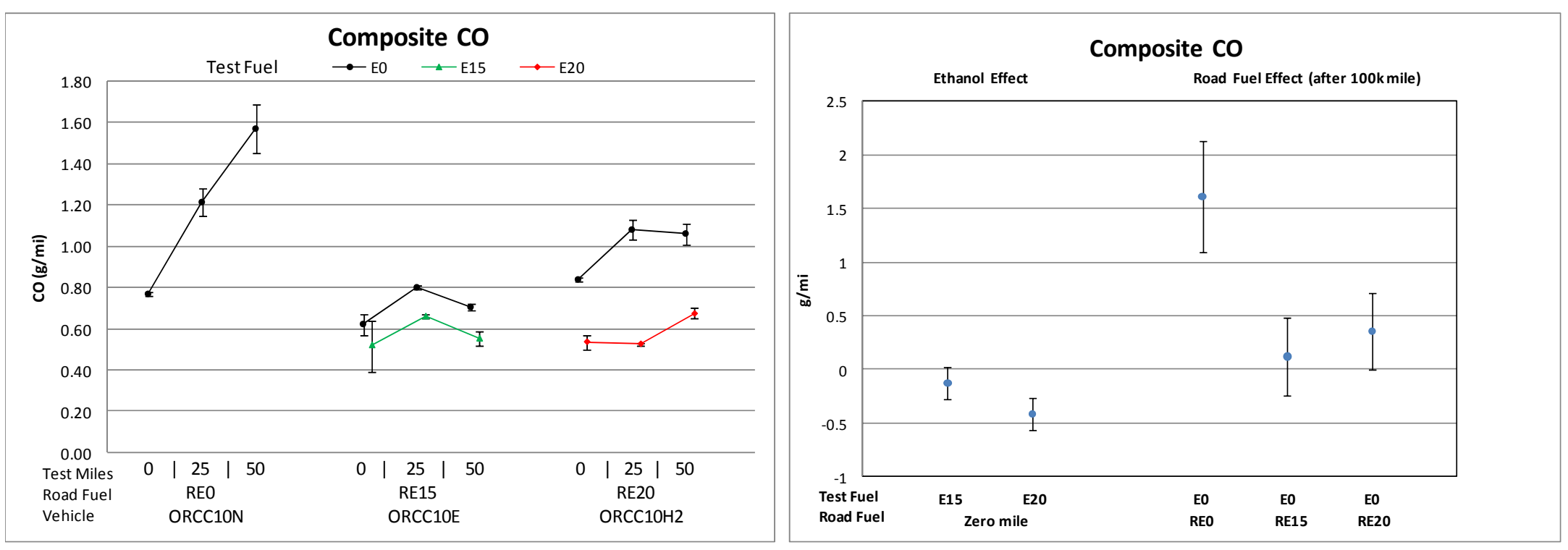

Error bars represent min and max measurements

Error bars represent $95 \%$ confidence intervals on the estimated effects 
2003 Chevrolet Cavalier (Composite NOx)

\begin{tabular}{|l|r|r|r|}
\hline \multicolumn{1}{|c|}{ Effect } & & $\begin{array}{r}95 \% \text { C.I. } \\
\text { Low\% C.I. } \\
\text { Upper }\end{array}$ \\
\hline Ethanol Effect $(E 15 \mathrm{vs}$. E0) $(\Delta \mathrm{g} / \mathrm{mi})$ & -0.005 & -0.071 & 0.061 \\
\hline Ethanol Effect $($ E20 vs. E0) $(\Delta \mathrm{g} / \mathrm{mi})$ & 0.018 & -0.048 & 0.084 \\
\hline Road Fuel Aging Effect & & & \\
\hline Aging Effect with RE0 $(\Delta \mathrm{g} / \mathrm{mi}$ per 100k mi) & $0.408^{*}$ & 0.177 & 0.639 \\
\hline Aging Effect with RE15 $(\Delta \mathrm{g} / \mathrm{mi}$ per 100k mi) & $-0.185^{*}$ & -0.345 & -0.025 \\
\hline Aging Effect with RE20 $(\Delta \mathrm{g} / \mathrm{mi}$ per 100k mi) & -0.098 & -0.259 & 0.063 \\
\hline
\end{tabular}

\begin{tabular}{|l|r|}
\hline \multicolumn{1}{|c|}{ Hypothesis } & -value \\
\hline No Effect of Ethanol in the Test Fuel (Gamma = 0) & 0.80 \\
\hline No Aging Effect with RE0 (Beta0 = 0) & $<0.01^{*}$ \\
\hline No Effect of Ethanol in Road Fuel Aging (Beta1s $=0$ ) & $<0.01^{*}$ \\
\hline * Indicates effect is statistically significant at the 95\% confidence level.
\end{tabular}

* Indicates estimate is different from zero at the $95 \%$ confidence level.

Initial Odometers 81k-89k
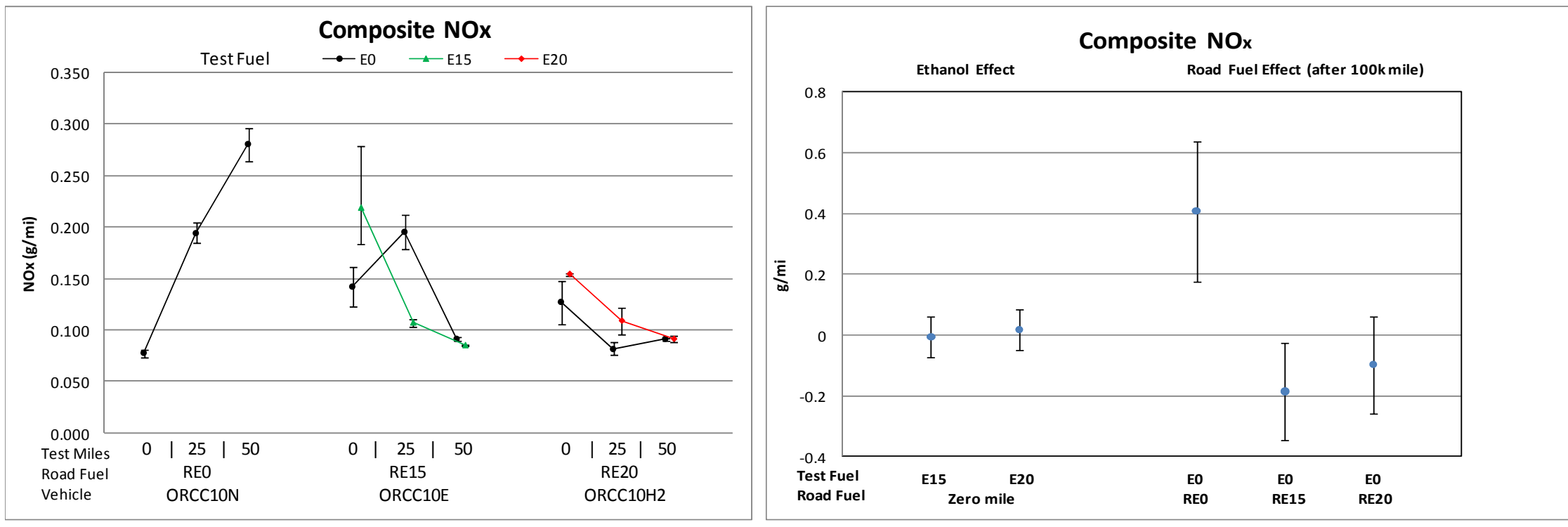

Error bars represent min and max measurements

Error bars represent $95 \%$ confidence intervals on the estimated effects 
2003 Chevrolet Cavalier (Composite Nonmethane Hydrocarbons)

\begin{tabular}{|l|r|r|r|}
\hline \multicolumn{1}{|c|}{ Effect } & & $\begin{array}{r}95 \% \text { C.I. } \\
\text { Low\% C.I. } \\
\text { Upper }\end{array}$ \\
\hline Ethanol Effect $(E 15 \mathrm{vs}$. E0) $(\Delta \mathrm{g} / \mathrm{mi})$ & -0.0058 & -0.0208 & 0.0092 \\
\hline Ethanol Effect $($ E20 vs. E0) $(\Delta \mathrm{g} / \mathrm{mi})$ & 0.0000 & -0.0150 & 0.0151 \\
\hline Road Fuel Aging Effect & & & \\
\hline Aging Effect with RE0 $(\Delta \mathrm{g} / \mathrm{mi}$ per 100k mi) & $0.0854^{*}$ & 0.0329 & 0.1379 \\
\hline Aging Effect with RE15 $(\Delta \mathrm{g} / \mathrm{mi}$ per 100k mi) & 0.0012 & -0.0354 & 0.0377 \\
\hline Aging Effect with RE20 $(\Delta \mathrm{g} / \mathrm{mi}$ per 100k mi) & $0.0491^{*}$ & 0.0125 & 0.0857 \\
\hline
\end{tabular}

\begin{tabular}{|l|r|}
\hline \multicolumn{1}{|c|}{ Hypothesis } & -value \\
\hline No Effect of Ethanol in the Test Fuel (Gamma = 0) & 0.67 \\
\hline No Aging Effect with RE0 (Beta0 = 0) & $<0.01^{*}$ \\
\hline No Effect of Ethanol in Road Fuel Aging (Beta1s $=0$ ) & $0.04^{*}$ \\
\hline * Indicates effect is statistically significant at the 95\% confidence level.
\end{tabular}

* Indicates estimate is different from zero at the $95 \%$ confidence level.

Initial Odometers $81 \mathrm{k}-89 \mathrm{k}$

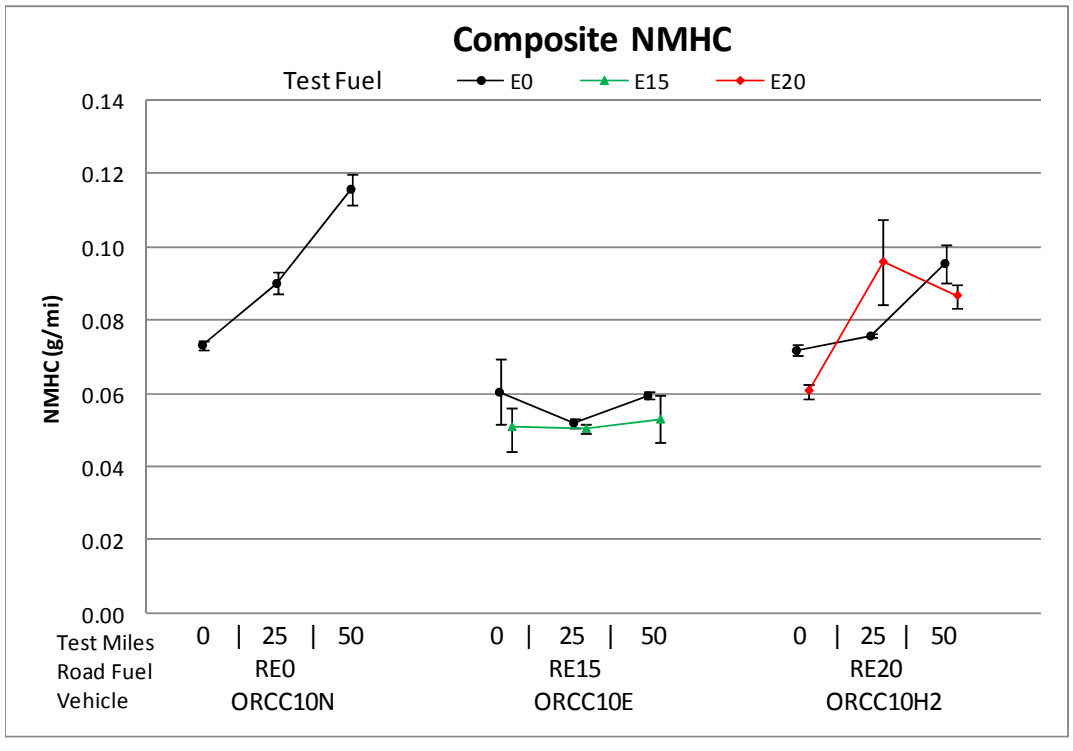

Error bars represent min and max measurements

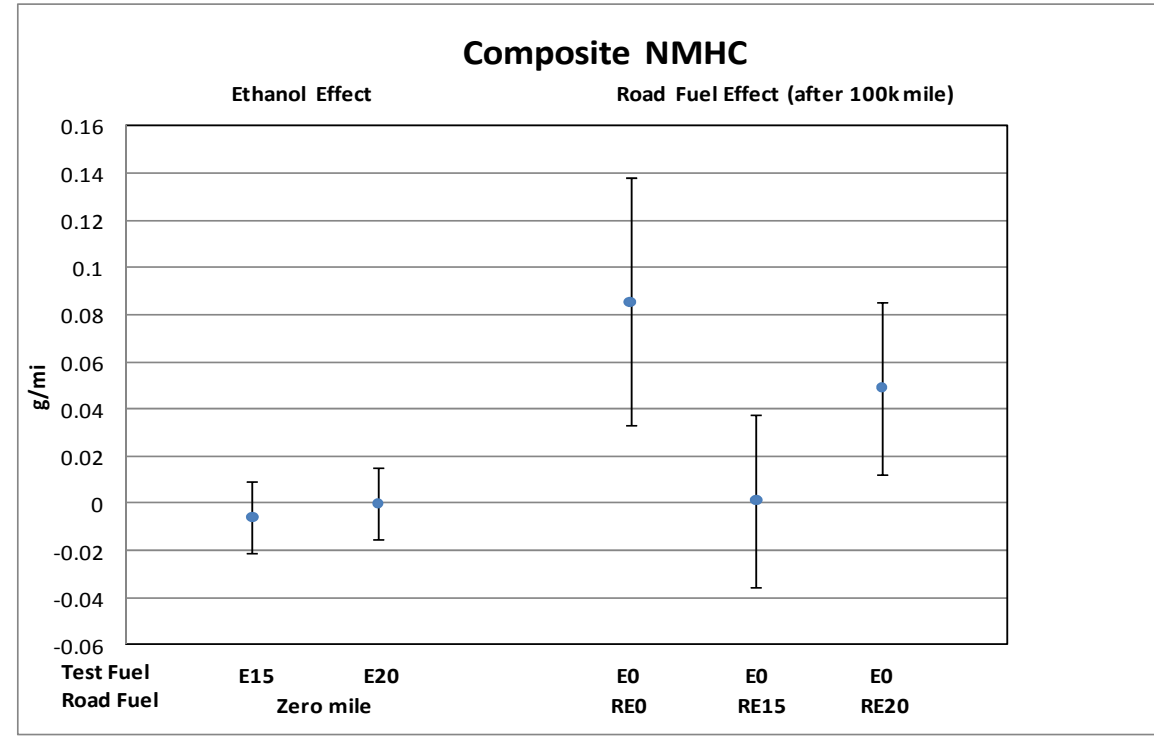

Error bars represent $95 \%$ confidence intervals on the estimated effects 
2003 Chevrolet Cavalier (Composite Nonmethane Organic Gases)

\begin{tabular}{|c|c|c|c|}
\hline Effect & Estimate & $\begin{array}{l}95 \% \text { C.I. } \\
\text { Lower }\end{array}$ & $\begin{array}{c}95 \% \text { C.I. } \\
\text { Upper }\end{array}$ \\
\hline Ethanol Effect (E15 vs. E0) $(\Delta \mathrm{g} / \mathrm{mi})$ & -0.0001 & -0.0174 & 0.0172 \\
\hline Ethanol Effect (E20 vs. E0) $(\Delta \mathrm{g} / \mathrm{mi})$ & 0.0128 & -0.0045 & 0.0302 \\
\hline \multicolumn{4}{|l|}{ Road Fuel Aging Effect } \\
\hline Aging Effect with RE0 ( $\Delta \mathrm{g} / \mathrm{mi}$ per $100 \mathrm{k} \mathrm{mi})$ & $0.0872^{*}$ & 0.0267 & 0.1476 \\
\hline Aging Effect with RE15 $(\Delta \mathrm{g} / \mathrm{mi}$ per $100 \mathrm{k} \mathrm{mi})$ & 0.0018 & -0.0403 & 0.0439 \\
\hline Aging Effect with RE20 ( $\Delta \mathrm{g} / \mathrm{mi}$ per $100 \mathrm{k} \mathrm{mi})$ & $0.0540^{*}$ & 0.0119 & 0.0962 \\
\hline
\end{tabular}

\begin{tabular}{|l|r|}
\hline \multicolumn{1}{|c|}{ Hypothesis } & p-value \\
\hline No Effect of Ethanol in the Test Fuel (Gamma = 0) & 0.28 \\
\hline No Aging Effect with RE0 (Beta0 = 0) & $0.01^{*}$ \\
\hline No Effect of Ethanol in Road Fuel Aging (Beta1s $=0)$ & 0.06 \\
\hline * Indicates effect is statistically significant at the 95\% confidence level.
\end{tabular}

${ }^{*}$ Indicates estimate is different from zero at the $95 \%$ confidence level.

Initial Odometers 81k-89k

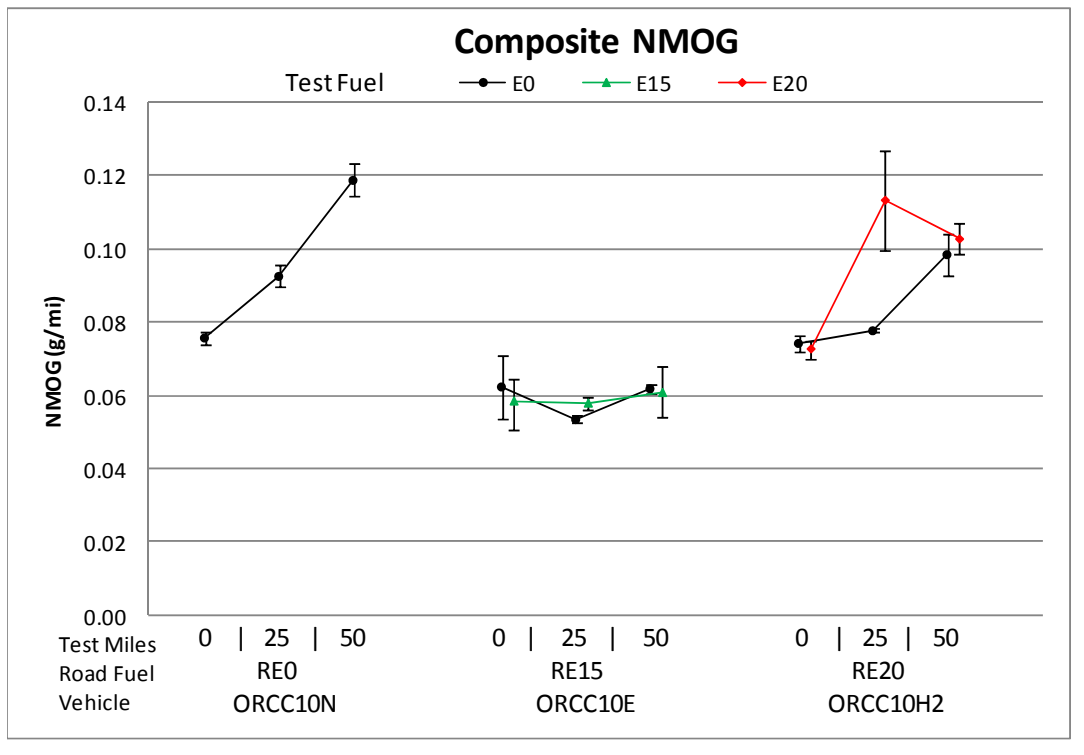

Error bars represent min and max measurements

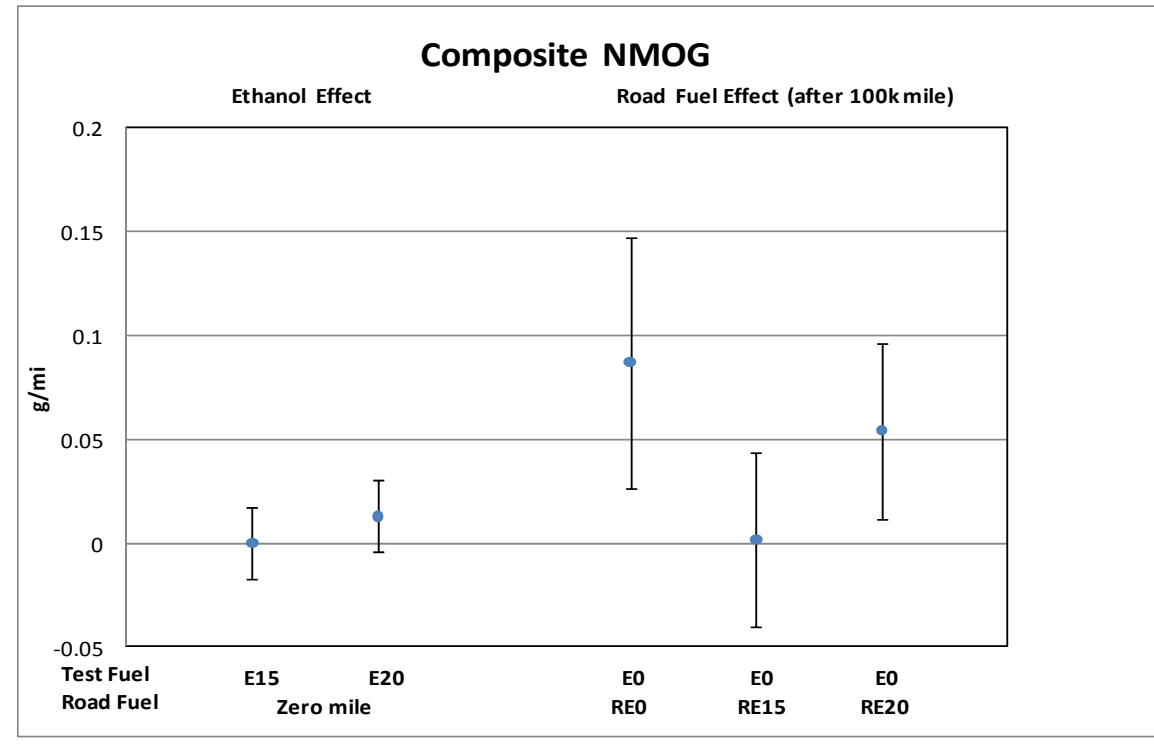

Error bars represent $95 \%$ confidence intervals on the estimated effects 
2003 Chevrolet Cavalier (Composite Fuel Economy)

\begin{tabular}{|l|r|r|r|}
\hline \multicolumn{1}{|c|}{ Effect } & & $\begin{array}{r}\text { 95\% C.I. } \\
\text { Estimate }\end{array}$ & $\begin{array}{r}\text { 95\% C.I. } \\
\text { Upwer }\end{array}$ \\
\hline Ethanol Effect (E15 vs. E0) $(\Delta \mathrm{mi} / \mathrm{gal})$ & $-1.476^{*}$ & -1.851 & -1.101 \\
\hline Ethanol Effect (E20 vs. E0) $(\Delta \mathrm{mi} / \mathrm{gal})$ & $-1.466^{*}$ & -1.842 & -1.090 \\
\hline Road Fuel Aging Effect & & & \\
\hline Aging Effect with RE0 $(\Delta \mathrm{mi} / \mathrm{gal}$ per 100k mi) & $-2.320^{*}$ & -3.633 & -1.007 \\
\hline Aging Effect with RE15 $(\Delta \mathrm{mi} /$ gal per 100k mi) & $1.613^{*}$ & 0.703 & 2.523 \\
\hline Aging Effect with RE20 $(\Delta \mathrm{mi} /$ gal per 100k mi) & 0.694 & -0.220 & 1.609 \\
\hline
\end{tabular}

\begin{tabular}{|l|c|}
\hline \multicolumn{1}{|c|}{ Hypothesis } & -value \\
\hline No Effect of Ethanol in the Test Fuel (Gamma $=0)$ & $<0.01^{*}$ \\
\hline No Aging Effect with RE0 (Beta0 $=0$ ) & $<0.01^{*}$ \\
\hline No Effect of Ethanol in Road Fuel Aging (Beta1s $=0$ ) & $<0.01^{*}$ \\
\hline * Indicates effect is statistically significant at the $95 \%$ confidence level.
\end{tabular}

* Indicates estimate is different from zero at the $95 \%$ confidence level.

Initial Odometers 81k-89k
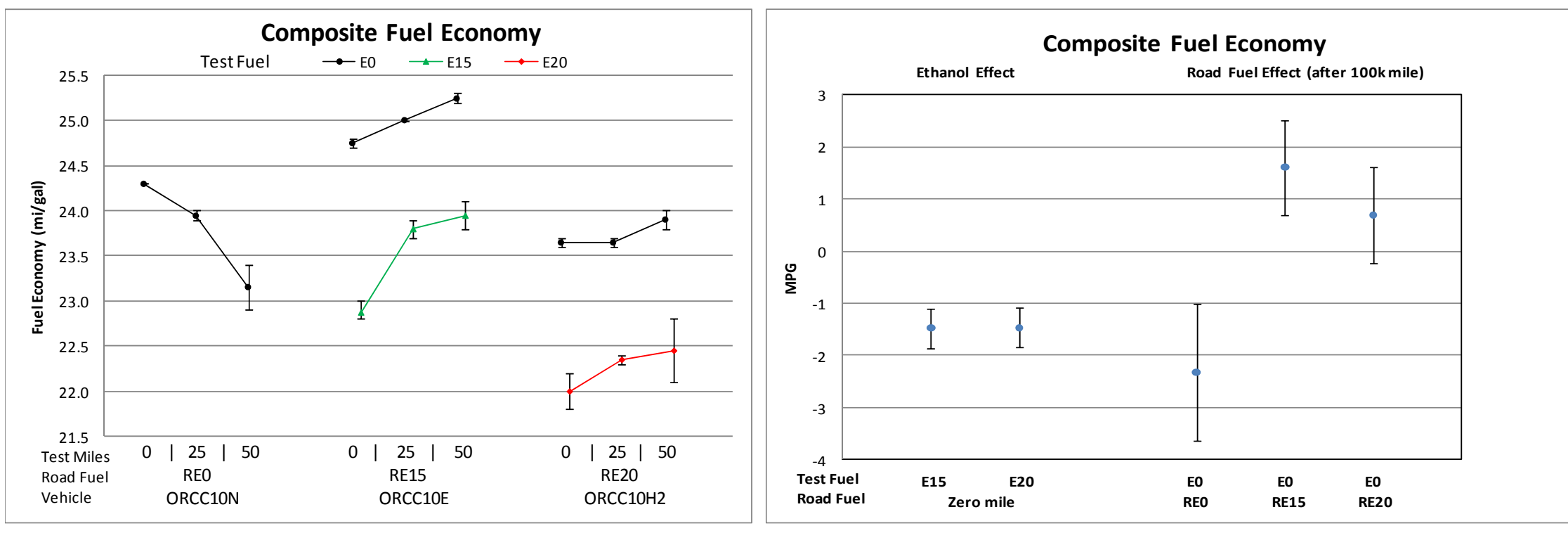

Error bars represent min and max measurements

Error bars represent $95 \%$ confidence intervals on the estimated effects 
2003 Chevrolet Cavalier (Composite Acetaldehyde)

\begin{tabular}{|l|r|r|r|}
\hline \multicolumn{1}{|c|}{ Effect } & Estimate & $\begin{array}{r}\text { 95\% C.I. } \\
\text { Lower }\end{array}$ & $\begin{array}{r}\text { 95\% C.I. } \\
\text { Upper }\end{array}$ \\
\hline Ethanol Effect (E15 vs. E0) $(\Delta \mathrm{mg} / \mathrm{mi})$ & $0.414^{*}$ & 0.223 & 0.604 \\
\hline Ethanol Effect (E20 vs. E0) $(\Delta \mathrm{mg} / \mathrm{mi})$ & $0.592^{*}$ & 0.373 & 0.810 \\
\hline Road Fuel Aging Effect & & & \\
\hline Aging Effect with RE0 $(\Delta \mathrm{mg} / \mathrm{mi}$ per 100k mi) & 0.257 & -0.157 & 0.672 \\
\hline Aging Effect with RE15 $(\Delta \mathrm{mg} / \mathrm{mi} \mathrm{per} \mathrm{100k} \mathrm{mi)}$ & -0.066 & -0.196 & 0.064 \\
\hline Aging Effect with RE20 $(\Delta \mathrm{mg} / \mathrm{mi}$ per 100k mi) & $0.376^{*}$ & 0.047 & 0.706 \\
\hline
\end{tabular}

\begin{tabular}{|l|r|}
\hline \multicolumn{1}{|c|}{ Hypothesis } & p-value \\
\hline No Effect of Ethanol in the Test Fuel (Gamma = 0) & $<0.01^{*}$ \\
\hline No Aging Effect with RE0 (Beta0 = 0) & 0.15 \\
\hline No Effect of Ethanol in Road Fuel Aging (Beta1s=0) & $0.04^{*}$ \\
\hline * Indicates effect is statistically significant at the 95\% confidence level.
\end{tabular}

* Indicates estimate is different from zero at the $95 \%$ confidence level.

Initial Odometers 81k-89k

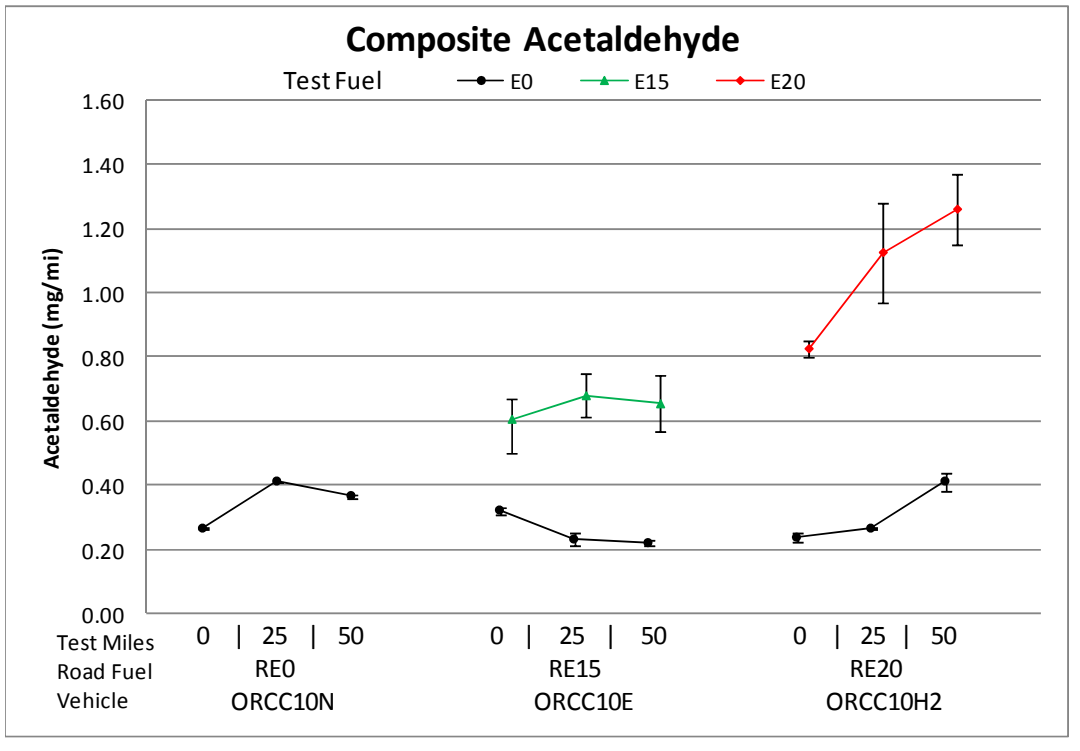

Error bars represent min and max measurements

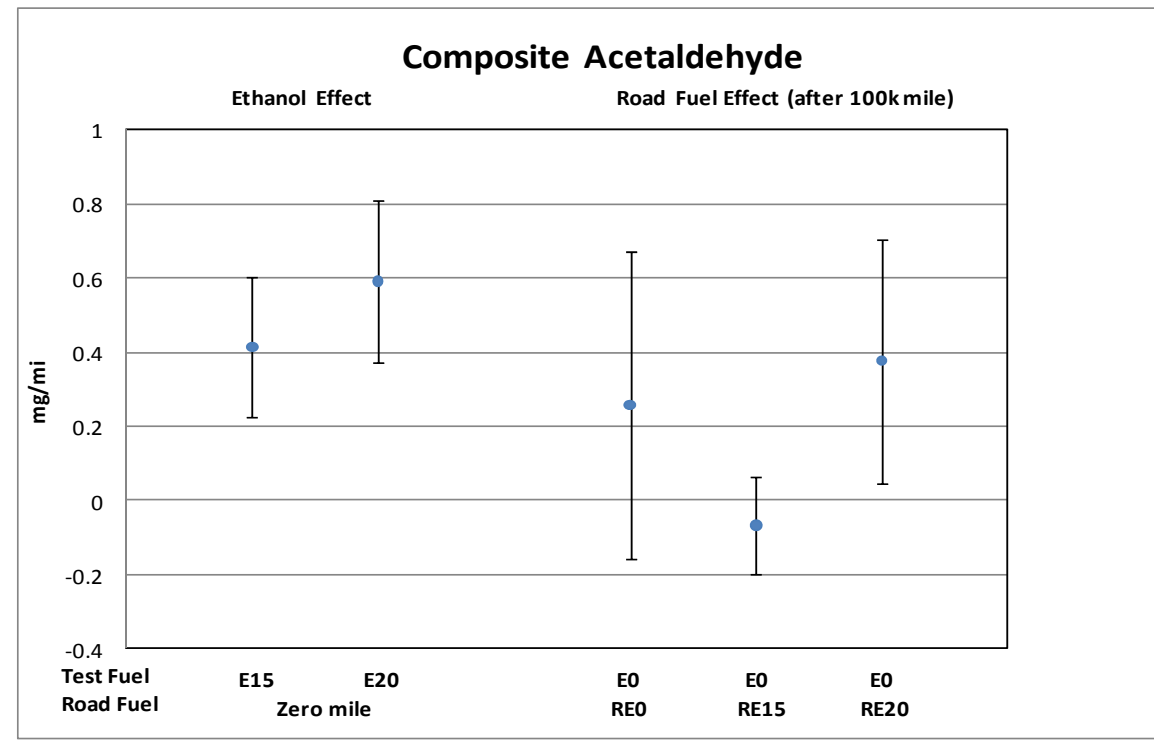

Error bars represent $95 \%$ confidence intervals on the estimated effects 
2003 Chevrolet Cavalier (Composite Formaldehyde)

\begin{tabular}{|l|r|r|r|}
\hline \multicolumn{1}{|c|}{ Effect } & Estimate & $\begin{array}{c}\text { 95\% C.I. } \\
\text { Lower }\end{array}$ & $\begin{array}{r}\text { 95\% C.I. } \\
\text { Upper }\end{array}$ \\
\hline Ethanol Effect (E15 vs. E0) $(\Delta \mathrm{mg} / \mathrm{mi})$ & 0.034 & -0.351 & 0.419 \\
\hline Ethanol Effect (E20 vs. E0) $(\Delta \mathrm{mg} / \mathrm{mi})$ & 0.191 & -0.081 & 0.463 \\
\hline Road Fuel Aging Effect & & & \\
\hline Aging Effect with RE0 $(\Delta \mathrm{mg} / \mathrm{mi}$ per 100k mi) & 0.619 & -0.680 & 1.919 \\
\hline Aging Effect with RE15 $(\Delta \mathrm{mg} / \mathrm{mi}$ per 100k mi) & $-0.546^{*}$ & -0.864 & -0.228 \\
\hline Aging Effect with RE20 $(\Delta \mathrm{mg} / \mathrm{mi}$ per 100k mi) & 0.161 & -0.307 & 0.630 \\
\hline
\end{tabular}

\begin{tabular}{|l|r|}
\hline \multicolumn{1}{|c|}{ Hypothesis } & -value \\
\hline No Effect of Ethanol in the Test Fuel (Gamma = 0) & 0.15 \\
\hline No Aging Effect with RE0 (Beta0 = 0) & 0.26 \\
\hline No Effect of Ethanol in Road Fuel Aging (Beta1s $=0$ ) & $0.04^{*}$ \\
\hline * Indicates effect is statistically significant at the 95\% confidence level.
\end{tabular}

* Indicates estimate is different from zero at the $95 \%$ confidence level.

Initial Odometers $81 \mathrm{k}-89 \mathrm{k}$

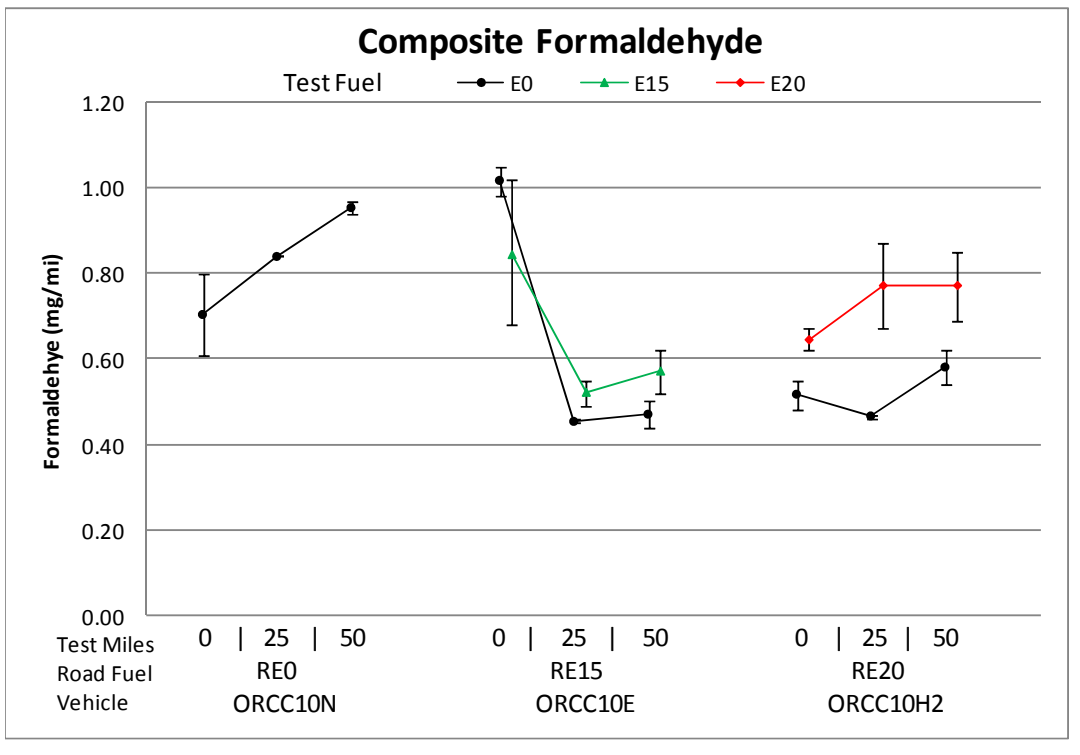

Error bars represent min and max measurements

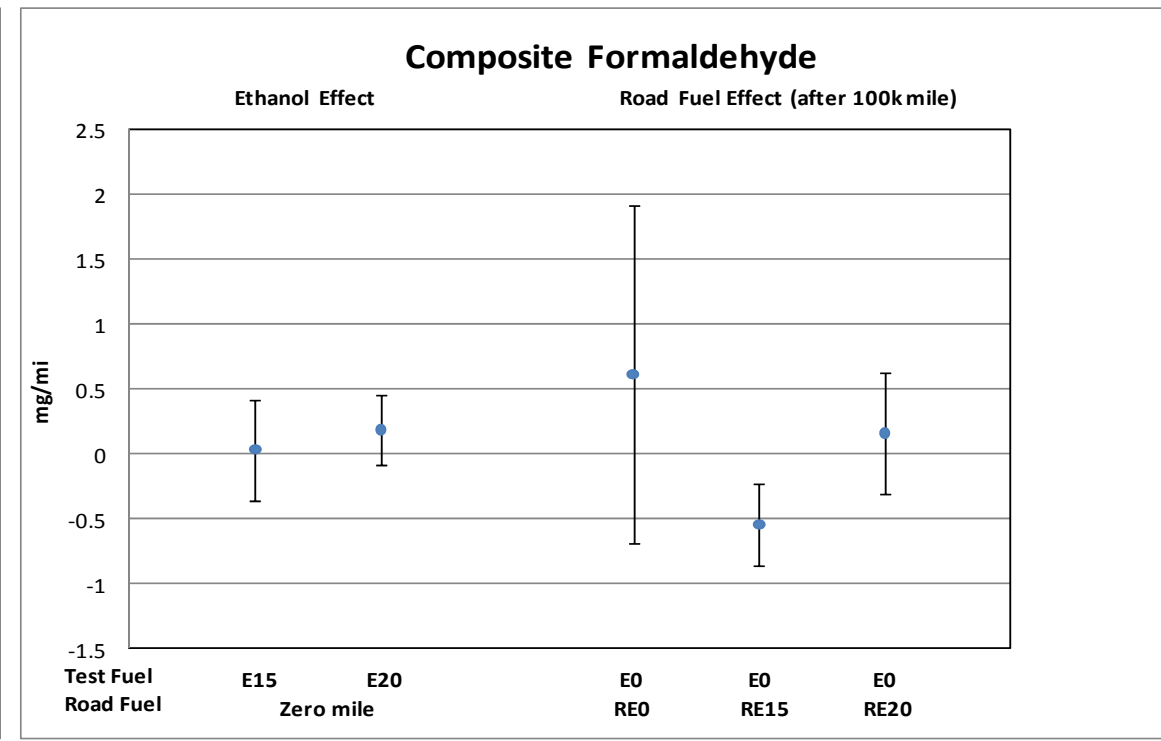

Error bars represent $95 \%$ confidence intervals on the estimated effects 
2003 Chevrolet Cavalier (Composite $\mathrm{CH} 4$ )

\begin{tabular}{|l|r|r|r|}
\hline \multicolumn{1}{|c|}{ Effect } & & $\begin{array}{r}95 \% \text { C.I. } \\
\text { Lo5\% C.I. } \\
\text { Upper }\end{array}$ \\
\hline Ethanol Effect $(E 15 \mathrm{vs}$. E0) $(\Delta \mathrm{g} / \mathrm{mi})$ & -0.0008 & -0.0040 & 0.0025 \\
\hline Ethanol Effect $($ E20 vs. E0) $(\Delta \mathrm{g} / \mathrm{mi})$ & -0.0013 & -0.0046 & 0.0019 \\
\hline Road Fuel Aging Effect & & & \\
\hline Aging Effect with RE0 $(\Delta \mathrm{g} / \mathrm{mi}$ per 100k mi) & $0.0271^{*}$ & 0.0158 & 0.0384 \\
\hline Aging Effect with RE15 $(\Delta \mathrm{g} / \mathrm{mi}$ per 100k mi) & 0.0028 & -0.0051 & 0.0107 \\
\hline Aging Effect with RE20 $(\Delta \mathrm{g} / \mathrm{mi}$ per 100k mi) & 0.0055 & -0.0024 & 0.0133 \\
\hline
\end{tabular}

\begin{tabular}{|l|r|}
\hline \multicolumn{1}{|c|}{ Hypothesis } & -value \\
\hline No Effect of Ethanol in the Test Fuel (Gamma = 0) & 0.56 \\
\hline No Aging Effect with RE0 (Beta0 $=0$ ) & $<0.01^{*}$ \\
\hline No Effect of Ethanol in Road Fuel Aging (Beta1s $=0$ ) & $0.01^{*}$ \\
\hline * Indicates effect is statistically significant at the 95\% confidence level.
\end{tabular}

* Indicates estimate is different from zero at the $95 \%$ confidence level.

\section{Initial Odometers $81 \mathrm{k}-89 \mathrm{k}$}
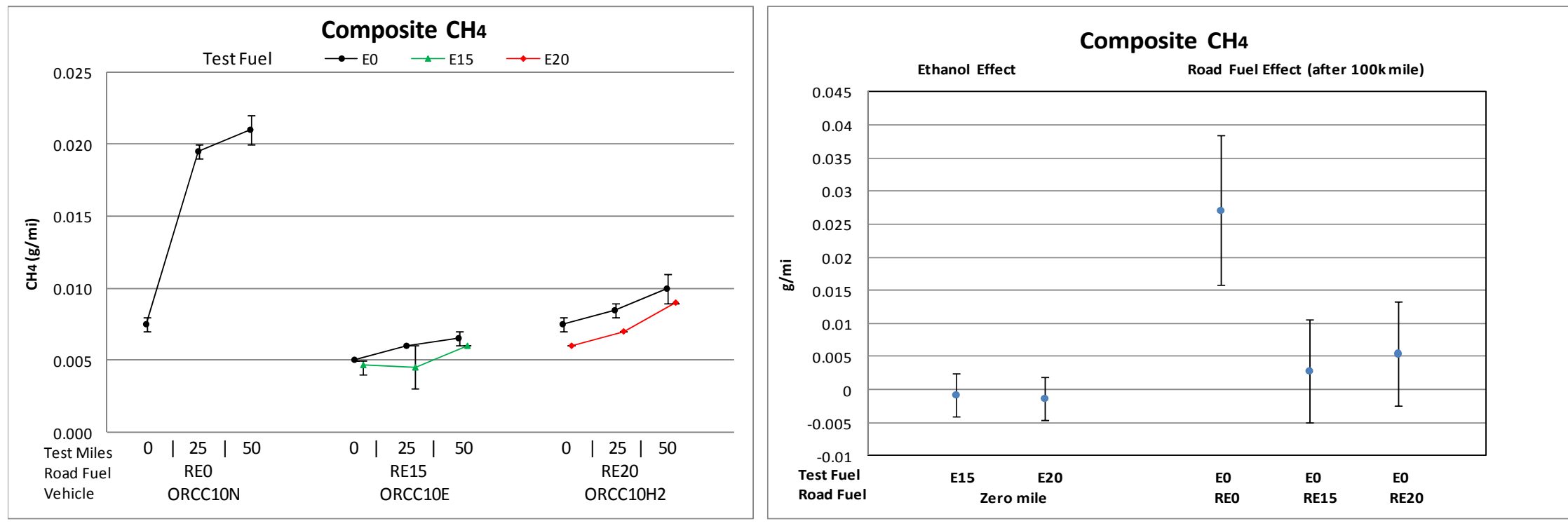

Error bars represent min and max measurements

Error bars represent $95 \%$ confidence intervals on the estimated effects 


\section{Honda Accord - Composite Emissions Summary}

\begin{tabular}{|c|c|c|c|c|c|c|c|c|c|c|c|c|c|c|}
\hline \multirow{2}{*}{$\begin{array}{c}\text { Emisssion Parameter } \\
\text { (units) }\end{array}$} & \multicolumn{4}{|c|}{ Ethanol Effect } & \multicolumn{2}{|c|}{ Aging Effect with REO } & \multicolumn{4}{|c|}{ RExx Aging Effect on EO Emissions } & \multirow{2}{*}{\multicolumn{3}{|c|}{\begin{tabular}{|c|} 
RExx Aging Effect on Exx Emissions \\
$\Delta$ units per $100 \mathrm{~K} \mathrm{mi}$ \\
\end{tabular}}} & \multirow{3}{*}{\begin{tabular}{|c}
$\begin{array}{c}\text { Road and Test } \\
\text { Fuel Effects } \\
\text { are Additive }\end{array}$ \\
$\begin{array}{c}\text { Overall p- } \\
\text { value }\end{array}$
\end{tabular}} \\
\hline & \multicolumn{3}{|c|}{$\Delta$ units vs. EO } & \multirow{2}{*}{$\begin{array}{l}\text { Overall } \\
p \text {-value }\end{array}$} & \multirow{2}{*}{$\begin{array}{c}\Delta \text { units per } 100 \mathrm{~K} \mathrm{mi} \\
\text { REO/EO }\end{array}$} & \multirow{2}{*}{$\begin{array}{l}\text { Overall } \\
p \text {-value }\end{array}$} & \multicolumn{3}{|c|}{$\Delta$ units per $100 \mathrm{~K} \mathrm{mi}$} & \multirow{2}{*}{$\begin{array}{l}\text { Overall } \\
\text { p-value }\end{array}$} & & & & \\
\hline Fuels & E10 & E15 & E20 & & & & RE10/E0 & RE15/E0 & RE20/E0 & & RE10/E10 & RE15/E15 & RE20/E20 & \\
\hline $\mathrm{CO}(\mathrm{g} / \mathrm{mi})$ & $\mathrm{NA}$ & -1.251 & -0.124 & 0.24 & 7.933* & $0.01 *$ & NA & 2.760 & 0.482 & 0.09 & $\mathrm{NA}$ & NA & $\mathrm{NA}$ & 0.99 \\
\hline $\mathrm{NOx}(\mathrm{g} / \mathrm{mi})$ & $\mathrm{NA}$ & -0.004 & 0.015 & 0.71 & 0.104 & 0.14 & $\mathrm{NA}$ & $0.175 *$ & 0.036 & 0.15 & $\mathrm{NA}$ & NA & $\mathrm{NA}$ & 0.69 \\
\hline $\mathrm{NMHC}(\mathrm{g} / \mathrm{mi})$ & $\mathrm{NA}$ & -0.011 & -0.001 & 0.80 & $0.159 *$ & $0.03 *$ & $\mathrm{NA}$ & 0.073 & 0.036 & 0.28 & $\mathrm{NA}$ & NA & $\mathrm{NA}$ & 0.95 \\
\hline $\operatorname{NMOG}(\mathrm{g} / \mathrm{mi})$ & $\mathrm{NA}$ & -0.003 & 0.007 & 0.91 & $0.165^{*}$ & $0.03^{*}$ & $\mathrm{NA}$ & 0.080 & 0.040 & 0.30 & $\mathrm{NA}$ & $\mathrm{NA}$ & $\mathrm{NA}$ & 0.92 \\
\hline Fuel Econ (mi/gal) & NA & $-1.201^{*}$ & $-1.740 *$ & $<0.01^{*}$ & 0.043 & 0.96 & $\mathrm{NA}$ & -0.208 & 0.105 & 0.91 & $\mathrm{NA}$ & $\mathrm{NA}$ & $\mathrm{NA}$ & 0.64 \\
\hline $\mathrm{CH}_{4}(\mathrm{~g} / \mathrm{mi})$ & $\mathrm{NA}$ & -0.0040 & -0.0000 & 0.60 & $0.0500 *$ & $<0.01 *$ & $\mathrm{NA}$ & $0.0372 *$ & 0.0051 & $0.05 *$ & $\mathrm{NA}$ & NA & $\mathrm{NA}$ & 0.93 \\
\hline
\end{tabular}

\# Log-normal model was used. Results are presented as changes in emissions at 0k mile.

\#\# Data did not support the assumption of linear effects with mileage.

* Indicates estimate is different from zero at the $95 \%$ confidence level. 
2000 Honda Accord (Composite CO)

\begin{tabular}{|l|r|r|r|}
\hline \multicolumn{1}{|c|}{ Effect } & Estimate & $\begin{array}{c}\text { 95\% C.I. } \\
\text { Lower }\end{array}$ & $\begin{array}{r}\text { 95\% C.I. } \\
\text { Upper }\end{array}$ \\
\hline Ethanol Effect (E15 vs. E0) $(\Delta \mathrm{g} / \mathrm{mi})$ & -1.251 & -2.834 & 0.331 \\
\hline Ethanol Effect $($ E20 vs. E0) $(\Delta \mathrm{g} / \mathrm{mi})$ & -0.124 & -1.707 & 1.459 \\
\hline Road Fuel Aging Effect & & & \\
\hline Aging Effect with RE0 $(\Delta \mathrm{g} / \mathrm{mi}$ per 100k mi) & $7.933^{*}$ & 2.457 & 13.410 \\
\hline Aging Effect with RE15 $(\Delta \mathrm{g} / \mathrm{mi}$ per 100k mi) & 2.760 & -1.077 & 6.597 \\
\hline Aging Effect with RE20 $(\Delta \mathrm{g} / \mathrm{mi}$ per 100k mi) & 0.482 & -3.379 & 4.344 \\
\hline
\end{tabular}

\begin{tabular}{|l|r|}
\hline \multicolumn{1}{|c|}{ Hypothesis } & p-value \\
\hline No Effect of Ethanol in the Test Fuel (Gamma = 0) & 0.24 \\
\hline No Aging Effect with RE0 (Beta0 = 0) & $0.01^{*}$ \\
\hline No Effect of Ethanol in Road Fuel Aging (Beta1s=0) & 0.09 \\
\hline
\end{tabular}

* Indicates estimate is different from zero at the $95 \%$ confidence level.

Initial Odometers 89k-106k

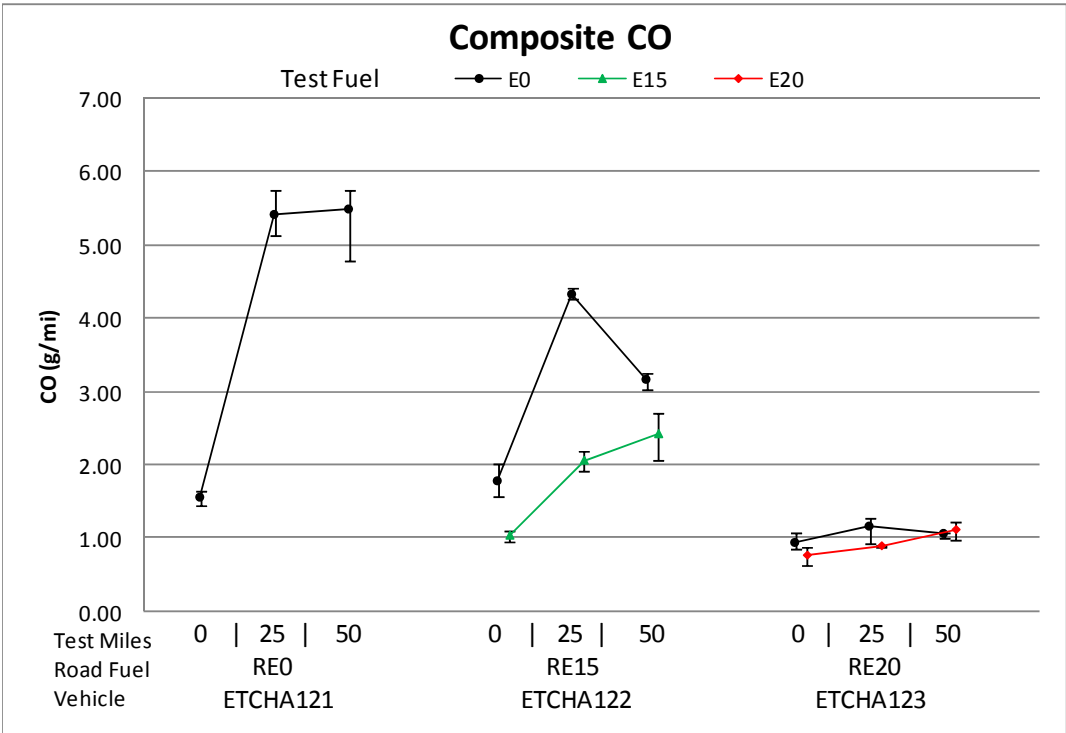

Error bars represent min and max measurements

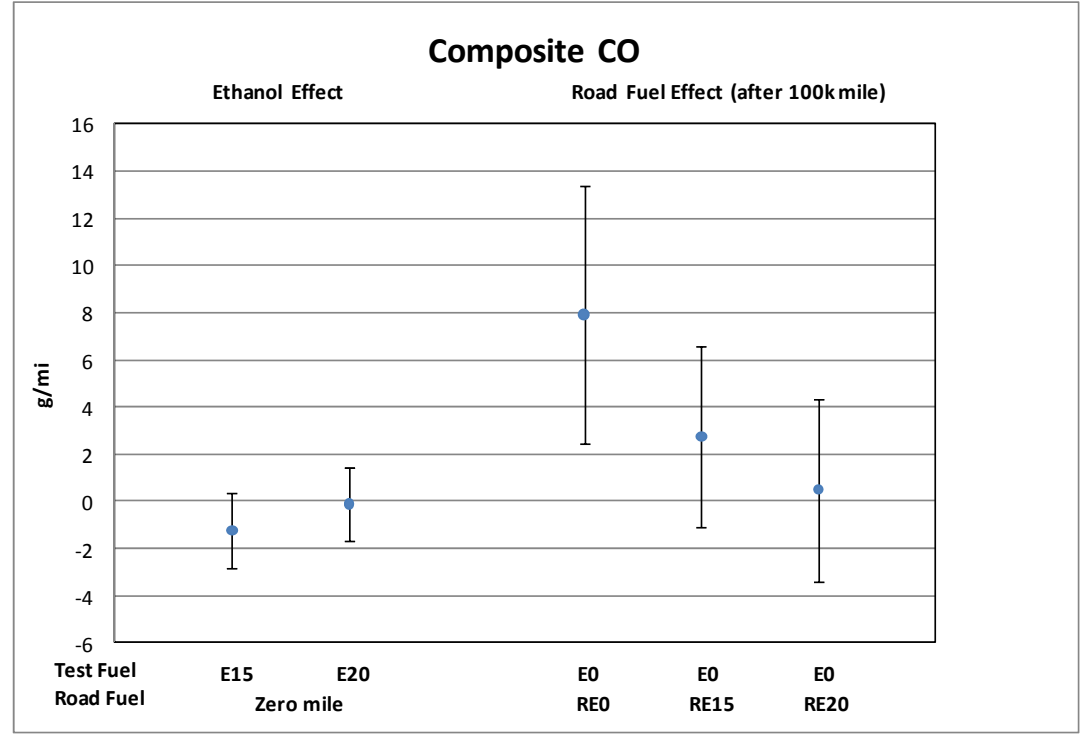

Error bars represent $95 \%$ confidence intervals on the estimated effects 
2000 Honda Accord (Composite NOx)

\begin{tabular}{|l|r|r|r|}
\hline \multicolumn{1}{|c|}{ Effect } & Estimate & $\begin{array}{c}\text { 95\% C.I. } \\
\text { Lower }\end{array}$ & $\begin{array}{r}\text { 95\% C.I. } \\
\text { Upper }\end{array}$ \\
\hline Ethanol Effect (E15 vs. E0) $(\Delta \mathrm{g} / \mathrm{mi})$ & -0.004 & -0.047 & 0.038 \\
\hline Ethanol Effect (E20 vs. E0) $(\Delta \mathrm{g} / \mathrm{mi})$ & 0.015 & -0.028 & 0.057 \\
\hline Road Fuel Aging Effect & & & \\
\hline Aging Effect with RE0 $(\Delta \mathrm{g} / \mathrm{mi}$ per 100k mi) & 0.104 & -0.043 & 0.252 \\
\hline Aging Effect with RE15 $(\Delta \mathrm{g} / \mathrm{mi}$ per 100k mi) & $0.175^{\star}$ & 0.072 & 0.279 \\
\hline Aging Effect with RE20 $(\Delta \mathrm{g} / \mathrm{mi}$ per 100k mi) & 0.036 & -0.068 & 0.140 \\
\hline
\end{tabular}

\begin{tabular}{|l|r|}
\hline \multicolumn{1}{|c|}{ Hypothesis } & p-value \\
\hline No Effect of Ethanol in the Test Fuel (Gamma = 0) & 0.71 \\
\hline No Aging Effect with RE0 (Beta0 = 0) & 0.14 \\
\hline No Effect of Ethanol in Road Fuel Aging (Beta1s=0) & 0.15 \\
\hline${ }^{*}$ Indicates effect is statistically significant at the 95\% confidence level.
\end{tabular}

Initial Odometers 89k-106k
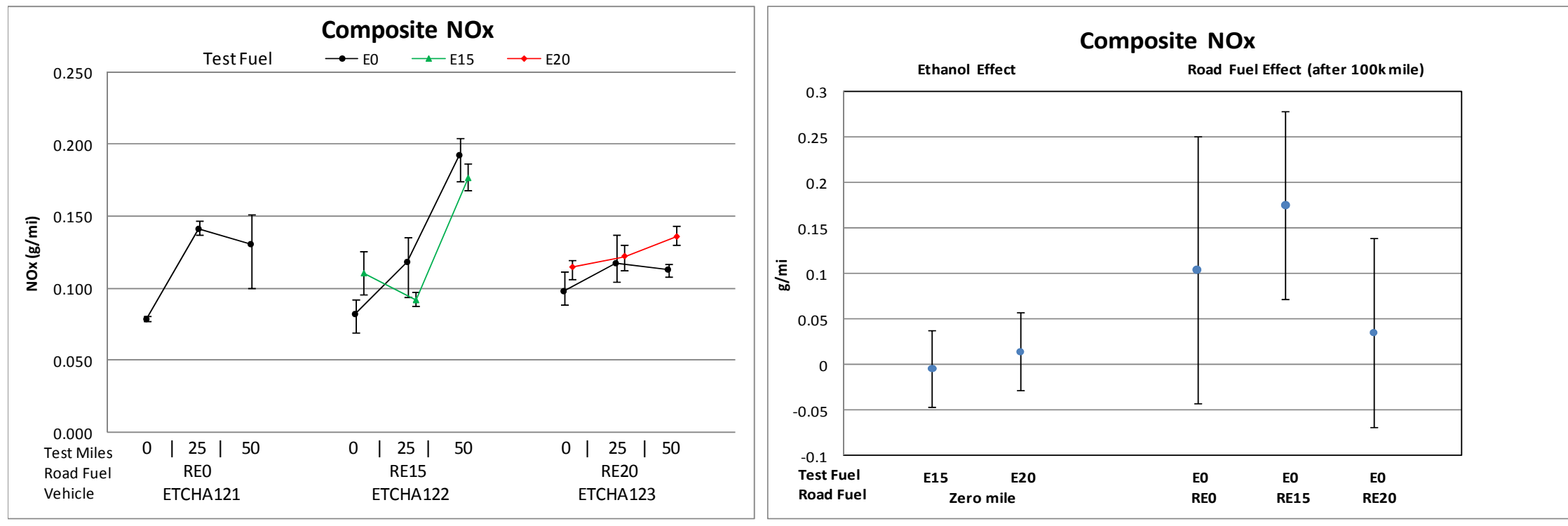

Error bars represent min and max measurements

Error bars represent $95 \%$ confidence intervals on the estimated effects 
2000 Honda Accord (Composite Nonmethane Hydrocarbons)

\begin{tabular}{|l|r|r|r|}
\hline \multicolumn{1}{|c|}{ Effect } & & $\begin{array}{r}95 \% \text { C.I. } \\
\text { Lo5\% C.I. } \\
\text { Upper }\end{array}$ \\
\hline Ethanol Effect $(E 15 \mathrm{vs}$. E0) $(\Delta \mathrm{g} / \mathrm{mi})$ & -0.011 & -0.051 & 0.028 \\
\hline Ethanol Effect $($ E20 vs. E0) $(\Delta \mathrm{g} / \mathrm{mi})$ & -0.001 & -0.040 & 0.039 \\
\hline Road Fuel Aging Effect & & & \\
\hline Aging Effect with RE0 $(\Delta \mathrm{g} / \mathrm{mi}$ per 100k mi) & $0.159^{*}$ & 0.022 & 0.297 \\
\hline Aging Effect with RE15 $(\Delta \mathrm{g} / \mathrm{mi}$ per 100k mi) & 0.073 & -0.023 & 0.169 \\
\hline Aging Effect with RE20 $(\Delta \mathrm{g} / \mathrm{mi}$ per 100k mi) & 0.036 & -0.061 & 0.133 \\
\hline
\end{tabular}

\begin{tabular}{|l|r|}
\hline \multicolumn{1}{|c|}{ Hypothesis } & p-value \\
\hline No Effect of Ethanol in the Test Fuel (Gamma $=0)$ & 0.80 \\
\hline No Aging Effect with RE0 (Beta0 $=0)$ & $0.03^{*}$ \\
\hline No Effect of Ethanol in Road Fuel Aging (Beta1s $=0)$ & 0.28 \\
\hline * Indicates effect is statistically significant at the 95\% confidence level.
\end{tabular}

* Indicates estimate is different from zero at the $95 \%$ confidence level.

Initial Odometers 89k-106k
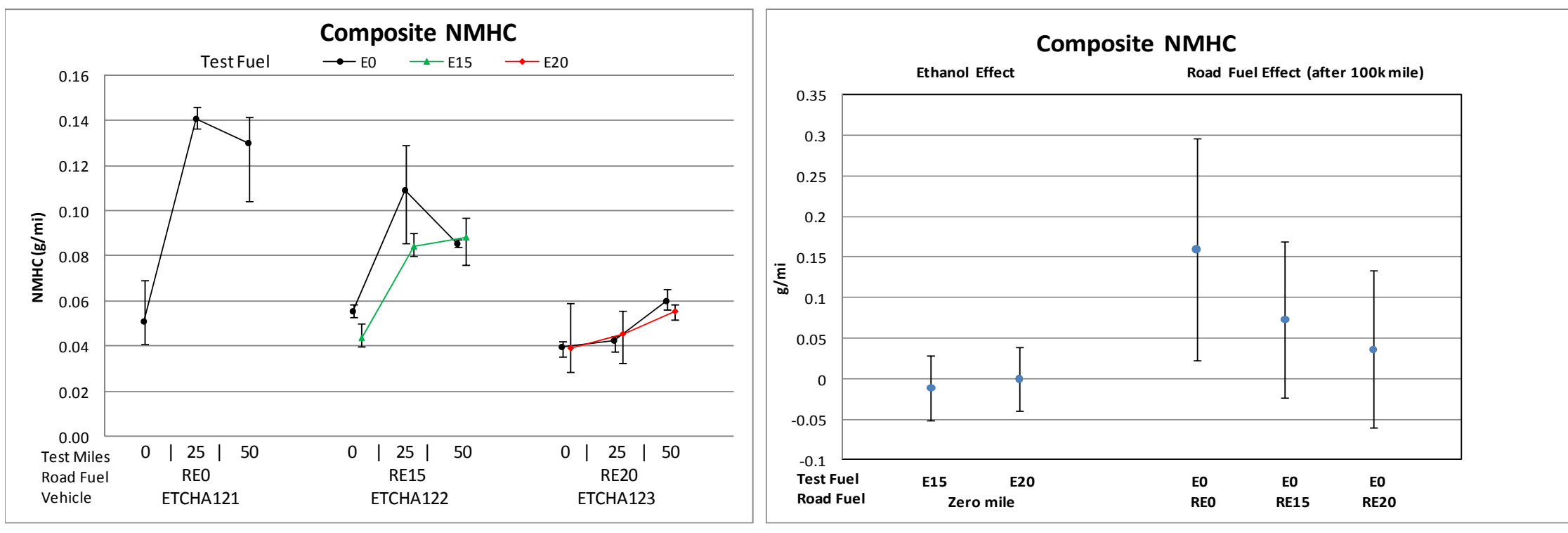

Error bars represent min and max measurements

Error bars represent $95 \%$ confidence intervals on the estimated effects 
2000 Honda Accord (Composite Nonmethane Organic Gases)

\begin{tabular}{|l|r|r|r|}
\hline \multicolumn{1}{|c|}{ Effect } & Estimate & $\begin{array}{c}\text { 95\% C.I. } \\
\text { Lower }\end{array}$ & $\begin{array}{r}\text { 95\% C.I. } \\
\text { Upper }\end{array}$ \\
\hline Ethanol Effect (E15 vs. E0) $(\Delta \mathrm{g} / \mathrm{mi})$ & -0.003 & -0.045 & 0.038 \\
\hline Ethanol Effect (E20 vs. E0) $(\Delta \mathrm{g} / \mathrm{mi})$ & 0.007 & -0.034 & 0.049 \\
\hline Road Fuel Aging Effect & & & \\
\hline Aging Effect with RE0 $(\Delta \mathrm{g} / \mathrm{mi}$ per 100k mi) & $0.165^{*}$ & 0.021 & 0.308 \\
\hline Aging Effect with RE15 $(\Delta \mathrm{g} / \mathrm{mi} \mathrm{per} \mathrm{100k} \mathrm{mi)}$ & 0.080 & -0.021 & 0.180 \\
\hline Aging Effect with RE20 $(\Delta \mathrm{g} / \mathrm{mi}$ per 100k mi) & 0.040 & -0.061 & 0.141 \\
\hline
\end{tabular}

\begin{tabular}{|l|r|}
\hline \multicolumn{1}{|c|}{ Hypothesis } & p-value \\
\hline No Effect of Ethanol in the Test Fuel (Gamma $=0)$ & 0.91 \\
\hline No Aging Effect with RE0 (Beta0 $=0)$ & $0.03^{*}$ \\
\hline No Effect of Ethanol in Road Fuel Aging (Beta1s=0) & 0.30 \\
\hline${ }^{*}$ Indicates effect is statistically significant at the 95\% confidence level.
\end{tabular}

* Indicates estimate is different from zero at the $95 \%$ confidence level.

Initial Odometers 89k-106k
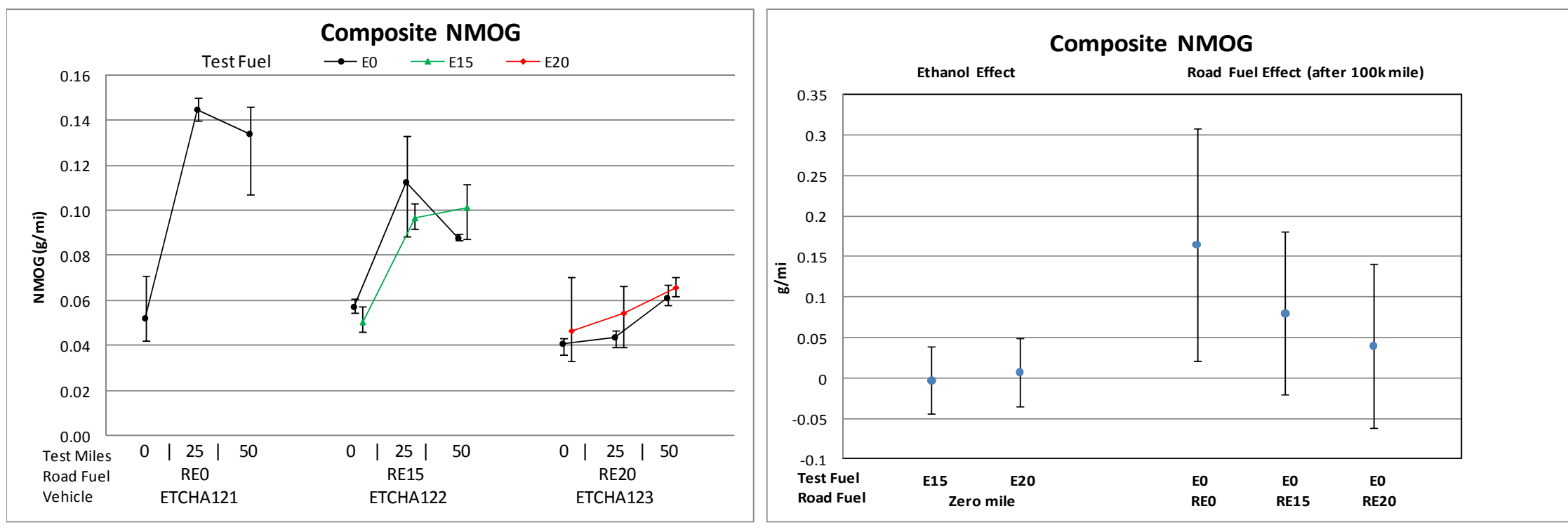

Error bars represent min and max measurements

Error bars represent $95 \%$ confidence intervals on the estimated effects 
2000 Honda Accord (Composite Fuel Economy)

\begin{tabular}{|l|r|r|r|}
\hline \multicolumn{1}{|c|}{ Effect } & Estimate & $\begin{array}{r}\text { 95\% C.I. } \\
\text { Lower }\end{array}$ & $\begin{array}{r}\text { 95\% C.I. } \\
\text { Upper }\end{array}$ \\
\hline Ethanol Effect (E15 vs. E0) $(\Delta \mathrm{mi} / \mathrm{gal})$ & $-1.201^{*}$ & -1.715 & -0.686 \\
\hline Ethanol Effect $($ E20 vs. E0) $(\Delta \mathrm{mi} / \mathrm{gal})$ & $-1.740^{*}$ & -2.255 & -1.226 \\
\hline Road Fuel Aging Effect & & & \\
\hline Aging Effect with RE0 $(\Delta \mathrm{mi} / \mathrm{gal}$ per 100k mi) & 0.043 & -1.732 & 1.818 \\
\hline Aging Effect with RE15 $(\Delta \mathrm{mi} / \mathrm{gal}$ per 100k mi) & -0.208 & -1.455 & 1.039 \\
\hline Aging Effect with RE20 $(\Delta \mathrm{mi} / \mathrm{gal}$ per 100k mi) & 0.105 & -1.150 & 1.360 \\
\hline
\end{tabular}

\begin{tabular}{|l|r|}
\hline \multicolumn{1}{|c|}{ Hypothesis } & p-value \\
\hline No Effect of Ethanol in the Test Fuel (Gamma $=0)$ & $<0.01^{*}$ \\
\hline No Aging Effect with RE0 (Beta0 $=0$ ) & 0.96 \\
\hline No Effect of Ethanol in Road Fuel Aging (Beta1s $=0$ ) & 0.91 \\
\hline * Indicates effect is statistically significant at the 95\% confidence level.
\end{tabular}

* Indicates estimate is different from zero at the $95 \%$ confidence level.

Initial Odometers 89k-106k
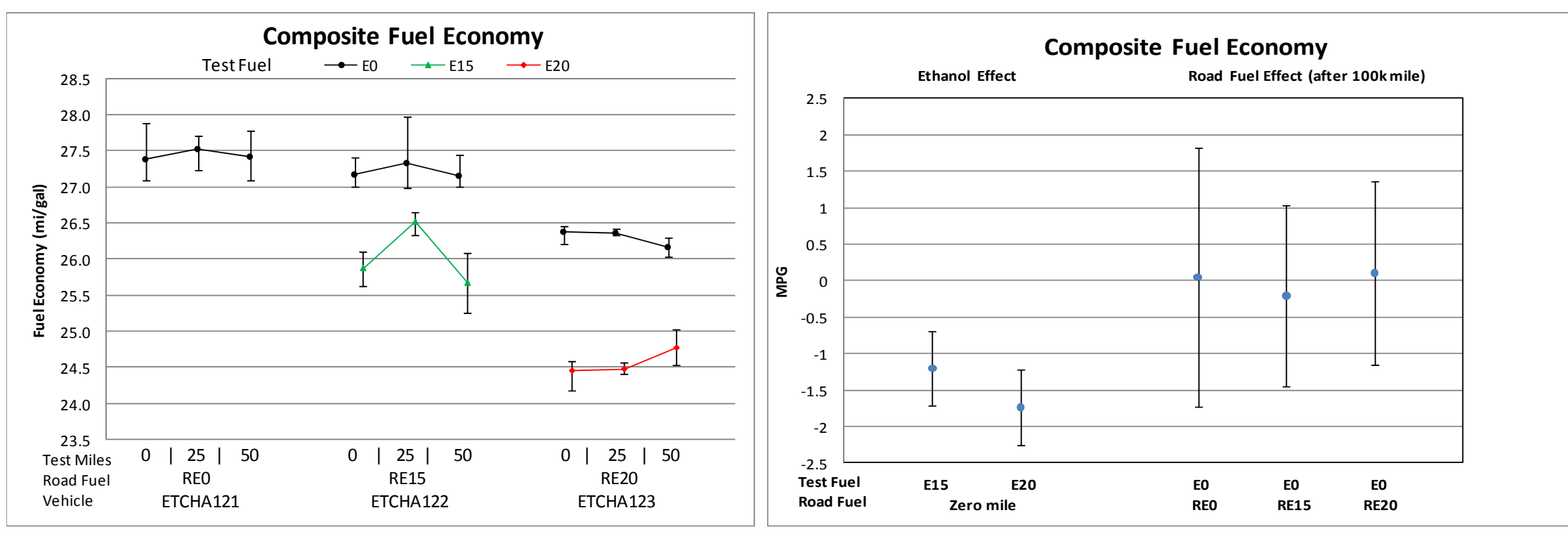

Error bars represent min and max measurements

Error bars represent $95 \%$ confidence intervals on the estimated effects 
2000 Honda Accord (Composite $\mathrm{CH}_{4}$ )

\begin{tabular}{|l|r|r|r|}
\hline \multicolumn{1}{|c|}{ Effect } & & $\begin{array}{c}95 \% \text { C.I. } \\
\text { Lo5\% C.I. }\end{array}$ & $\begin{array}{c}\text { L5 } \\
\text { Upper }\end{array}$ \\
\hline Ethanol Effect (E15 vs. E0) $(\Delta \mathrm{g} / \mathrm{mi})$ & -0.0040 & -0.0131 & 0.0050 \\
\hline Ethanol Effect (E20 vs. E0) $(\Delta \mathrm{g} / \mathrm{mi})$ & -0.0000 & -0.0091 & 0.0090 \\
\hline Road Fuel Aging Effect & & & \\
\hline Aging Effect with RE0 $(\Delta \mathrm{g} / \mathrm{mi} \mathrm{per} \mathrm{100k} \mathrm{mi)}$ & $0.0500^{*}$ & 0.0185 & 0.0813 \\
\hline Aging Effect with RE15 $(\Delta \mathrm{g} / \mathrm{mi}$ per 100k mi) & $0.0372^{*}$ & 0.0152 & 0.0592 \\
\hline Aging Effect with RE20 $(\Delta \mathrm{g} / \mathrm{mi} \mathrm{per} \mathrm{100k} \mathrm{mi)}$ & 0.0051 & -0.0170 & 0.0272 \\
\hline
\end{tabular}

\begin{tabular}{|l|r|}
\hline \multicolumn{1}{|c|}{ Hypothesis } & $p$-value \\
\hline No Effect of Ethanol in the Test Fuel (Gamma = 0) & 0.60 \\
\hline No Aging Effect with RE0 (Beta0 = 0) & $<0.01^{*}$ \\
\hline No Effect of Ethanol in Road Fuel Aging (Beta1s $=0)$ & $0.05^{*}$ \\
\hline${ }^{*}$ Indicates effect is statistically significant at the 95\% confidence level.
\end{tabular}

${ }^{*}$ Indicates estimate is different from zero at the $95 \%$ confidence leve

Initial Odometers 89k-106k
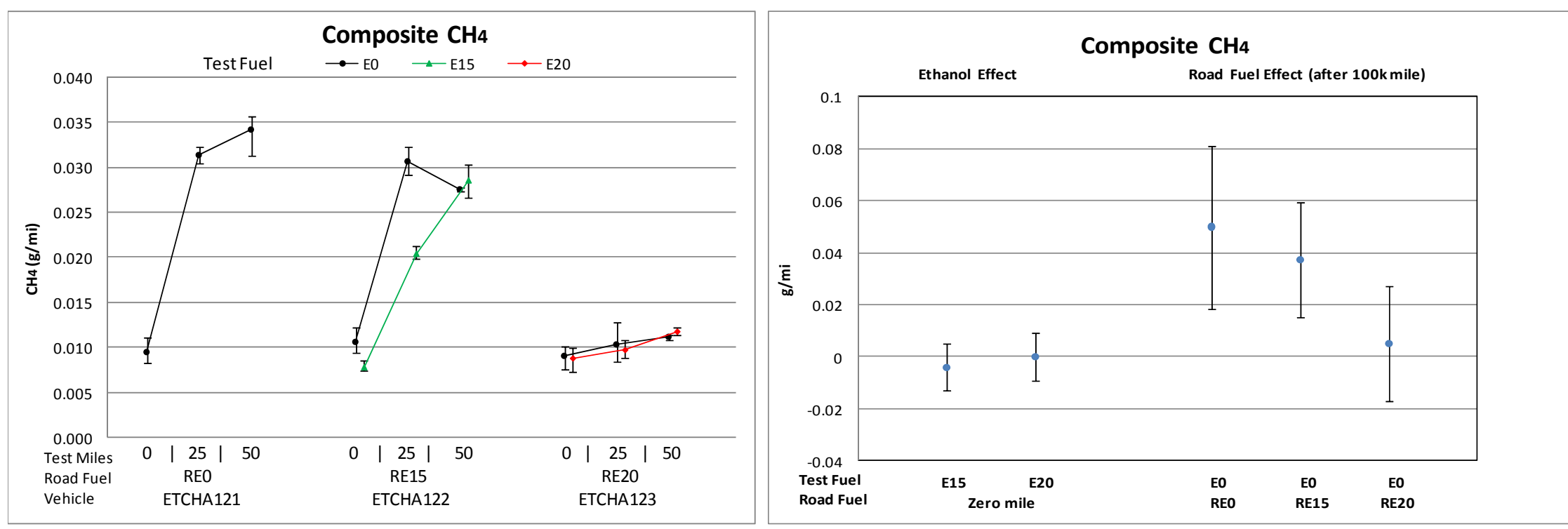

Error bars represent min and max measurements

Error bars represent $95 \%$ confidence intervals on the estimated effects 


\section{Ford Focus- Composite Emissions Summary}

\begin{tabular}{|c|c|c|c|c|c|c|c|c|c|c|c|c|c|c|}
\hline \multirow{3}{*}{$\begin{array}{l}\begin{array}{c}\text { Emisssion Parameter } \\
\text { (units) }\end{array} \\
\text { Fuels }\end{array}$} & \multicolumn{4}{|c|}{ Ethanol Effect } & \multicolumn{2}{|c|}{ Aging Effect with REO } & \multicolumn{4}{|c|}{ RExx Aging Effect on EO Emissions } & \multirow{2}{*}{\multicolumn{3}{|c|}{$\begin{array}{c}\text { RExx Aging Effect on Exx Emissions } \\
\Delta \text { units per } 100 \mathrm{~K} \mathrm{mi}\end{array}$}} & \multirow{3}{*}{\begin{tabular}{|c|}
$\begin{array}{c}\text { Road and Test } \\
\text { Fuel Effects } \\
\text { are Additive }\end{array}$ \\
$\begin{array}{c}\text { Overall p- } \\
\text { value }\end{array}$ \\
\end{tabular}} \\
\hline & \multicolumn{3}{|c|}{$\Delta$ units vs. EO } & \multirow{2}{*}{$\begin{array}{l}\text { Overall } \\
p \text {-value }\end{array}$} & \multirow{2}{*}{$\frac{\Delta \text { units per } 100 \mathrm{~K} \mathrm{mi}}{\text { REO/EO }}$} & \multirow{2}{*}{$\begin{array}{l}\text { Overall } \\
\text { p-value }\end{array}$} & \multicolumn{3}{|c|}{$\Delta$ units per $100 \mathrm{~K} \mathrm{mi}$} & \multirow{2}{*}{$\begin{array}{l}\text { Overall } \\
p \text {-value }\end{array}$} & & & & \\
\hline & E10 & E15 & E20 & & & & RE10/E0 & RE15/E0 & RE20/E0 & & RE10/E10 & RE15/E15 & RE20/E20 & \\
\hline $\mathrm{CO}(\mathrm{g} / \mathrm{mi})^{\mathrm{a}}$ & NA & -0.135 & -0.372 & 0.12 & $1.389 *$ & $0.04 *$ & $\mathrm{NA}$ & 0.028 & $1.672 *$ & 0.06 & $\mathrm{NA}$ & $N A$ & $\mathrm{NA}$ & 0.35 \\
\hline $\mathrm{NOx}(\mathrm{g} / \mathrm{mi})$ & NA & 0.030 & 0.013 & 0.51 & 0.028 & 0.77 & NA & 0.061 & $0.194 *$ & 0.29 & $\mathrm{NA}$ & $\mathrm{NA}$ & $N A$ & 0.26 \\
\hline NMHC (g/mi) & NA & -0.013 & -0.002 & 0.68 & 0.015 & 0.78 & NA & -0.040 & 0.048 & 0.28 & $\mathrm{NA}$ & $\mathrm{NA}$ & $N A$ & 0.79 \\
\hline NMOG (g/mi) & NA & -0.010 & 0.006 & 0.77 & 0.015 & 0.78 & NA & -0.041 & 0.052 & 0.27 & $\mathrm{NA}$ & $\mathrm{NA}$ & $N A$ & 0.83 \\
\hline Fuel Econ (mi/gal) & $\mathrm{NA}$ & $-0.752 *$ & $-1.753^{*}$ & $<0.01^{*}$ & $-1.494 *$ & $0.05 *$ & $N A$ & -0.992 & 0.198 & 0.11 & $\mathrm{NA}$ & $\mathrm{NA}$ & $\mathrm{NA}$ & 0.30 \\
\hline $\mathrm{CH}_{4}(\mathrm{~g} / \mathrm{mi})$ & $\mathrm{NA}$ & 0.0005 & -0.0003 & 0.87 & 0.0055 & 0.20 & $N A$ & 0.0047 & $0.0133 *$ & 0.13 & $\mathrm{NA}$ & $\mathrm{NA}$ & $\mathrm{NA}$ & 0.79 \\
\hline
\end{tabular}

\# Log-normal model was used. Results are presented as changes in emissions at 0k mile.

\#\# Data did not support the assumption of linear effects with mileage.

* Indicates estimate is different from zero at the $95 \%$ confidence level.

a test "116866" and test "116873" are identified outliers and excluded from the analysis 
2000 Ford Focus (Composite CO)

\begin{tabular}{|l|r|r|r|}
\hline \multicolumn{1}{|c|}{ Effect } & & $\begin{array}{r}95 \% \text { C.I. } \\
\text { Lo5\% C.I. } \\
\text { Upper }\end{array}$ \\
\hline Ethanol Effect $(E 15 \mathrm{vs}$. E0) $(\Delta \mathrm{g} / \mathrm{mi})$ & -0.135 & -0.521 & 0.252 \\
\hline Ethanol Effect $($ E20 vs. E0) $(\Delta \mathrm{g} / \mathrm{mi})$ & -0.372 & -0.761 & 0.017 \\
\hline Road Fuel Aging Effect & & & \\
\hline Aging Effect with RE0 $(\Delta \mathrm{g} / \mathrm{mi}$ per 100k mi) & $1.389^{*}$ & 0.050 & 2.727 \\
\hline Aging Effect with RE15 $(\Delta \mathrm{g} / \mathrm{mi}$ per 100k mi) & 0.028 & -0.920 & 0.975 \\
\hline Aging Effect with RE20 $(\Delta \mathrm{g} / \mathrm{mi}$ per 100k mi) & $1.672^{*}$ & 0.718 & 2.626 \\
\hline
\end{tabular}

\begin{tabular}{|l|r|}
\hline \multicolumn{1}{|c|}{ Hypothesis } & p-value \\
\hline No Effect of Ethanol in the Test Fuel (Gamma = 0) & 0.12 \\
\hline No Aging Effect with RE0 (Beta0 = 0) & $0.04^{*}$ \\
\hline No Effect of Ethanol in Road Fuel Aging (Beta1s=0) & 0.06 \\
\hline
\end{tabular}

* Indicates estimate is different from zero at the $95 \%$ confidence level.

Initial Odometers $85 \mathrm{k}-103 \mathrm{k}$

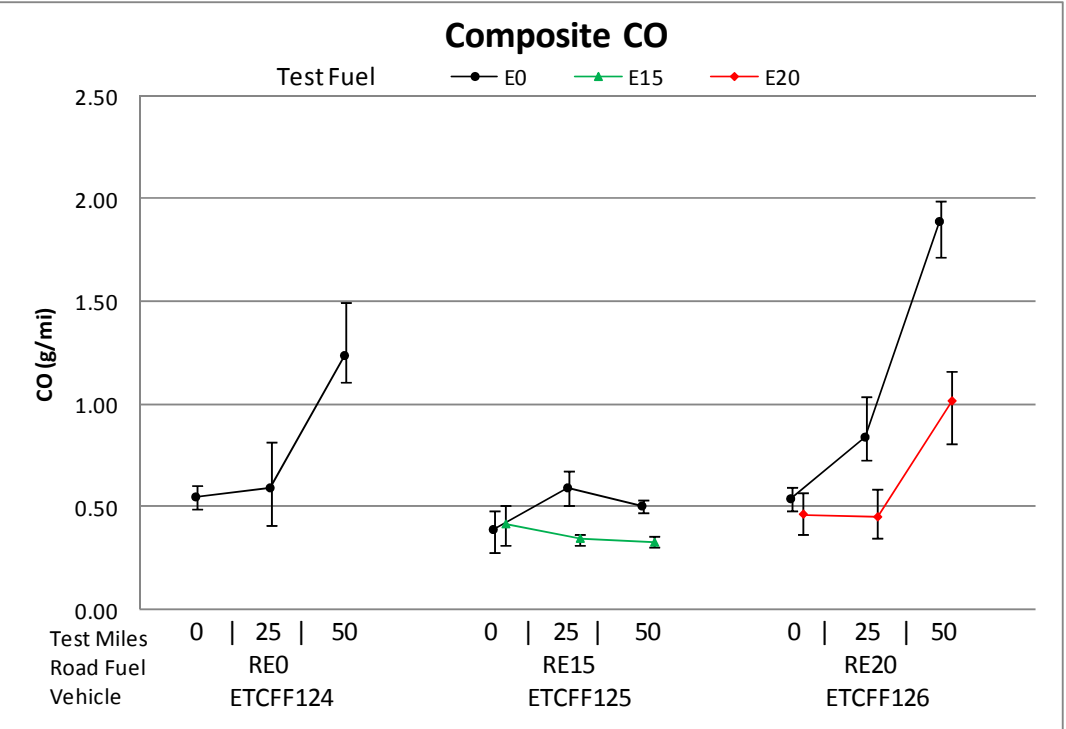

Error bars represent min and max measurements

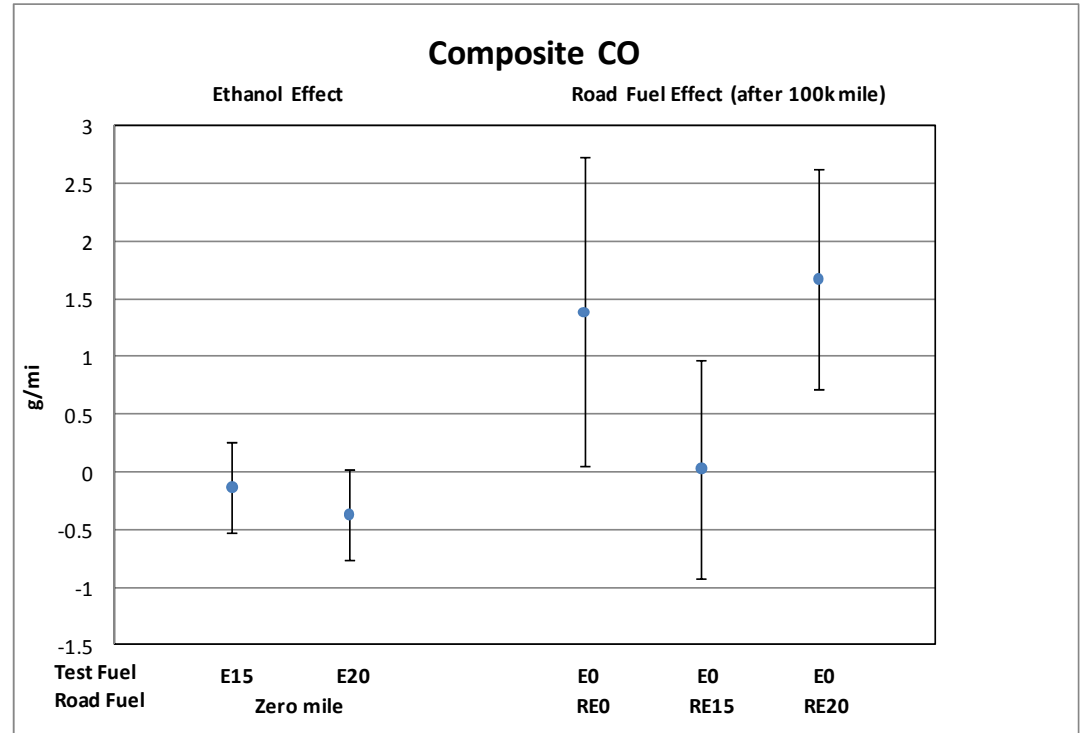

Error bars represent $95 \%$ confidence intervals on the estimated effects 
2000 Ford Focus (Composite NOx)

\begin{tabular}{|l|r|r|r|}
\hline \multicolumn{1}{|c|}{ Effect } & & $\begin{array}{r}95 \% \text { C.I. } \\
\text { Lower }\end{array}$ & $\begin{array}{r}\text { 95\% C.I. } \\
\text { Upper }\end{array}$ \\
\hline Ethanol Effect (E15 vs. E0) $(\Delta \mathrm{g} / \mathrm{mi})$ & 0.030 & -0.034 & 0.094 \\
\hline Ethanol Effect (E20 vs. E0) $(\Delta \mathrm{g} / \mathrm{mi})$ & 0.013 & -0.051 & 0.077 \\
\hline Road Fuel Aging Effect & & & \\
\hline Aging Effect with RE0 $(\Delta \mathrm{g} / \mathrm{mi}$ per 100k mi) & 0.028 & -0.193 & 0.249 \\
\hline Aging Effect with RE15 $(\Delta \mathrm{g} / \mathrm{mi} \mathrm{per} \mathrm{100k} \mathrm{mi)}$ & 0.061 & -0.096 & 0.218 \\
\hline Aging Effect with RE20 $(\Delta \mathrm{g} / \mathrm{mi}$ per 100k mi) & $0.194^{*}$ & 0.038 & 0.350 \\
\hline
\end{tabular}

\begin{tabular}{|l|r|}
\hline \multicolumn{1}{|c|}{ Hypothesis } & p-value \\
\hline No Effect of Ethanol in the Test Fuel (Gamma = 0) & 0.51 \\
\hline No Aging Effect with RE0 (Beta0 = 0) & 0.77 \\
\hline No Effect of Ethanol in Road Fuel Aging (Beta1s=0) & 0.29 \\
\hline * Indicates effect is statistically significant at the 95\% confidence level.
\end{tabular}

* Indicates estimate is different from zero at the $95 \%$ confidence level.

Initial Odometers $85 \mathrm{k}-103 \mathrm{k}$
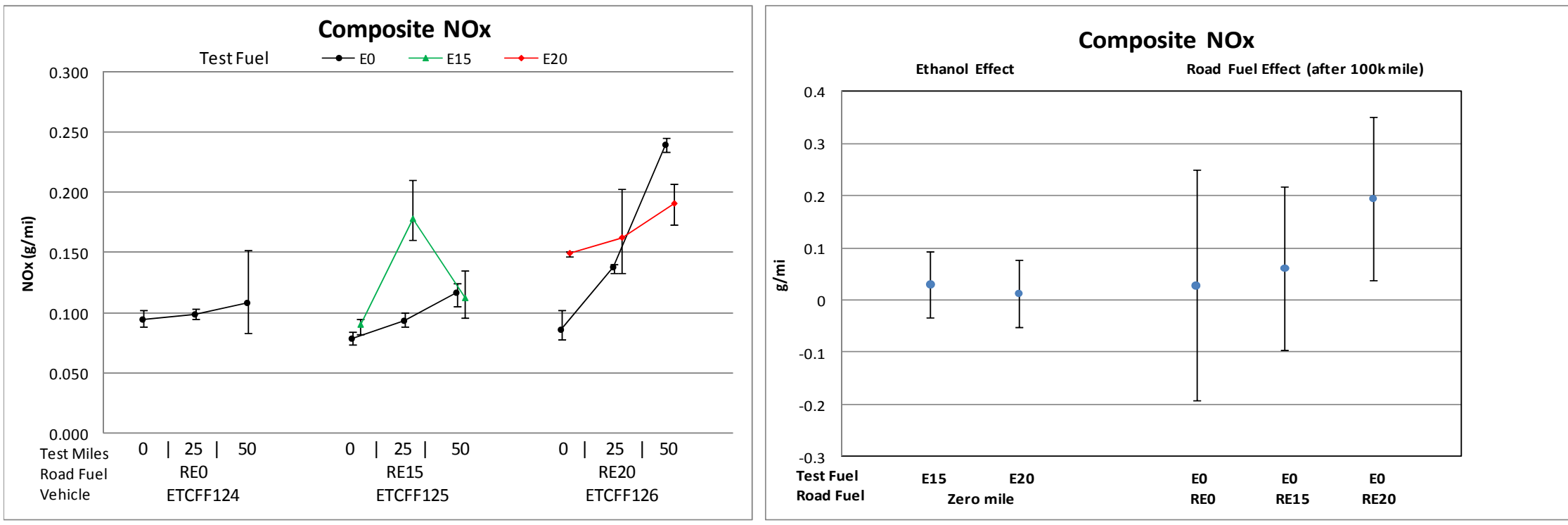

Error bars represent min and max measurements

Error bars represent $95 \%$ confidence intervals on the estimated effects 
2000 Ford Focus (Composite Nonmethane Hydrocarbons)

\begin{tabular}{|l|r|r|r|}
\hline \multicolumn{1}{|c|}{ Effect } & & $\begin{array}{r}95 \% \text { C.I. } \\
\text { Lower }\end{array}$ & $\begin{array}{r}\text { 95\% C.I. } \\
\text { Upper }\end{array}$ \\
\hline Ethanol Effect (E15 vs. E0) $(\Delta \mathrm{g} / \mathrm{mi})$ & -0.013 & -0.048 & 0.022 \\
\hline Ethanol Effect (E20 vs. E0) $(\Delta \mathrm{g} / \mathrm{mi})$ & -0.002 & -0.037 & 0.033 \\
\hline Road Fuel Aging Effect & & & \\
\hline Aging Effect with RE0 $(\Delta \mathrm{g} / \mathrm{mi}$ per 100k mi) & 0.015 & -0.106 & 0.135 \\
\hline Aging Effect with RE15 $(\Delta \mathrm{g} / \mathrm{mi} \mathrm{per} \mathrm{100k} \mathrm{mi)}$ & -0.040 & -0.126 & 0.045 \\
\hline Aging Effect with RE20 $(\Delta \mathrm{g} / \mathrm{mi}$ per 100k mi) & 0.048 & -0.037 & 0.132 \\
\hline
\end{tabular}

\begin{tabular}{|l|r|}
\hline \multicolumn{1}{|c|}{ Hypothesis } & p-value \\
\hline No Effect of Ethanol in the Test Fuel (Gamma $=0)$ & 0.68 \\
\hline No Aging Effect with RE0 (Beta0 $=0)$ & 0.78 \\
\hline No Effect of Ethanol in Road Fuel Aging (Beta1s=0) & 0.28 \\
\hline${ }^{*}$ Indicates effect is statistically significant at the 95\% confidence level.
\end{tabular}

* Indicates estimate is different from zero at the $95 \%$ confidence level.

Initial Odometers $85 \mathrm{k}-103 \mathrm{k}$

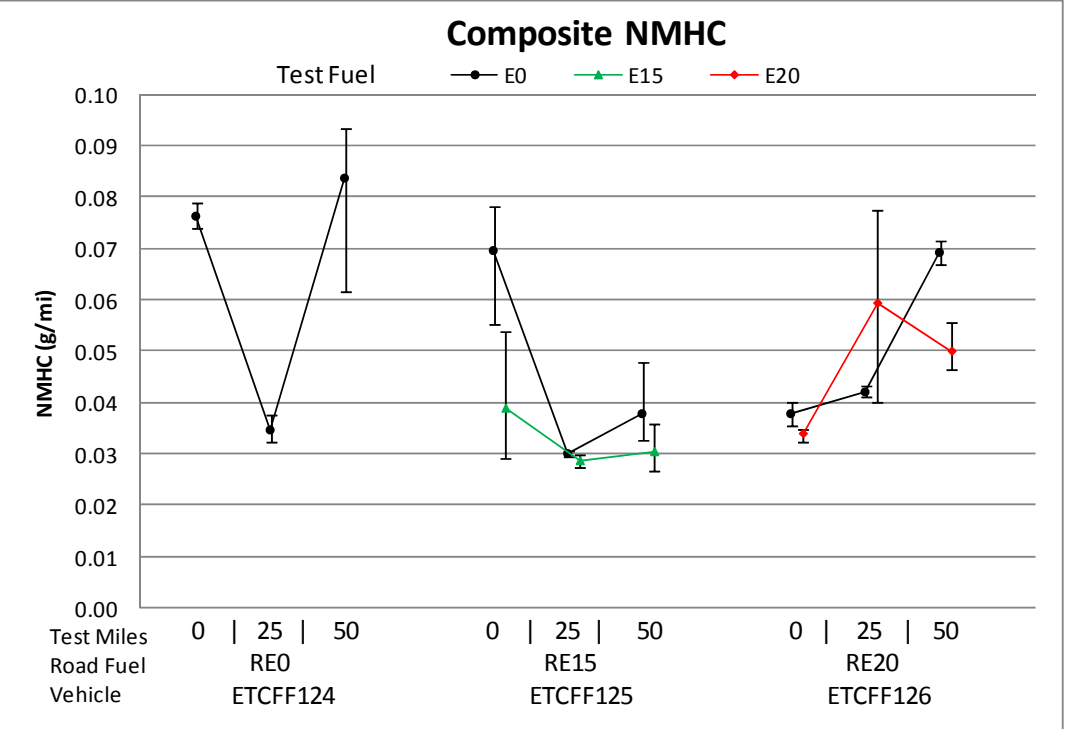

Error bars represent min and max measurements

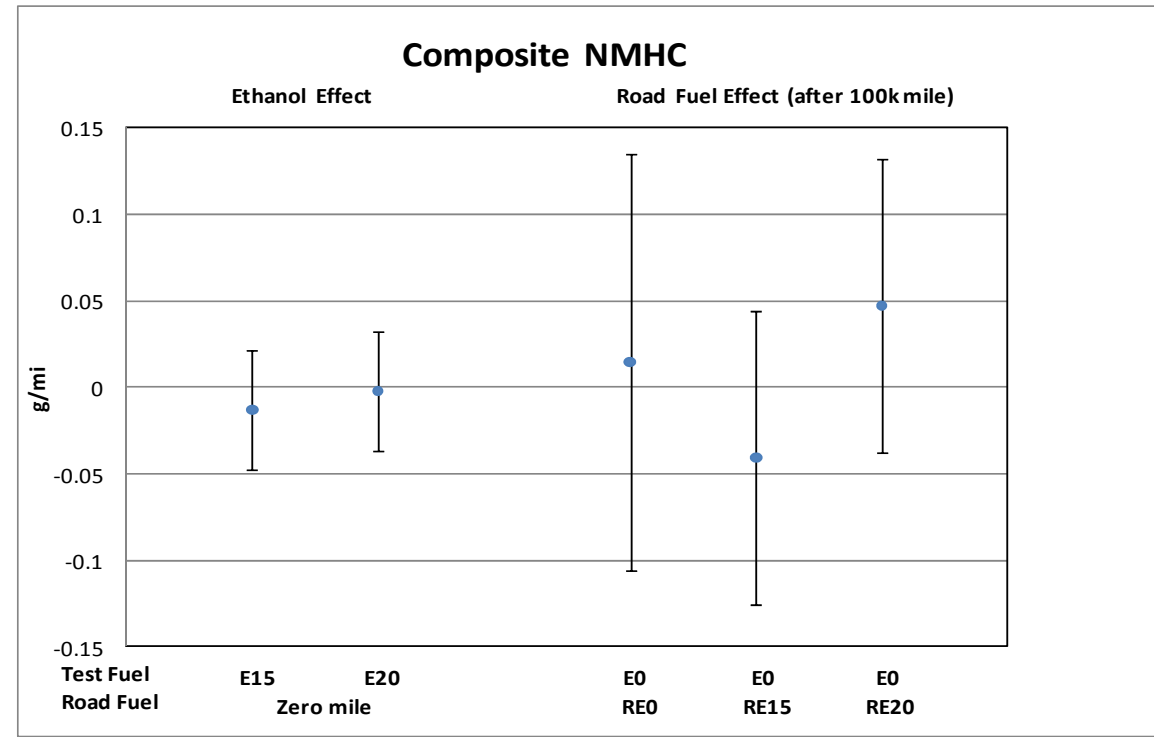

Error bars represent $95 \%$ confidence intervals on the estimated effects 
2000 Ford Focus (Composite Nonmethane Organic Gases)

\begin{tabular}{|l|r|r|r|}
\hline \multicolumn{1}{|c|}{ Effect } & & $\begin{array}{r}95 \% \text { C.I. } \\
\text { Low }\end{array}$ & $\begin{array}{r}\text { 95 C.I. } \\
\text { Upper }\end{array}$ \\
\hline Ethanol Effect $(E 15 \mathrm{vs}$. E0) $(\Delta \mathrm{g} / \mathrm{mi})$ & -0.010 & -0.046 & 0.026 \\
\hline Ethanol Effect $($ E20 vs. E0) $(\Delta \mathrm{g} / \mathrm{mi})$ & 0.006 & -0.030 & 0.042 \\
\hline Road Fuel Aging Effect & & & \\
\hline Aging Effect with RE0 $(\Delta \mathrm{g} / \mathrm{mi}$ per 100k mi) & 0.015 & -0.109 & 0.140 \\
\hline Aging Effect with RE15 $(\Delta \mathrm{g} / \mathrm{mi}$ per 100k mi) & -0.041 & -0.129 & 0.047 \\
\hline Aging Effect with RE20 $(\Delta \mathrm{g} / \mathrm{mi}$ per 100k mi) & 0.052 & -0.036 & 0.140 \\
\hline
\end{tabular}

\begin{tabular}{|l|r|}
\hline \multicolumn{1}{|c|}{ Hypothesis } & p-value \\
\hline No Effect of Ethanol in the Test Fuel (Gamma = 0) & 0.77 \\
\hline No Aging Effect with RE0 (Beta0 $=0)$ & 0.78 \\
\hline No Effect of Ethanol in Road Fuel Aging (Beta1s=0) & 0.27 \\
\hline${ }^{*}$ Indicates effect is statistically significant at the 95\% confidence level.
\end{tabular}

* Indicates estimate is different from zero at the $95 \%$ confidence level.

Initial Odometers 85k-103k
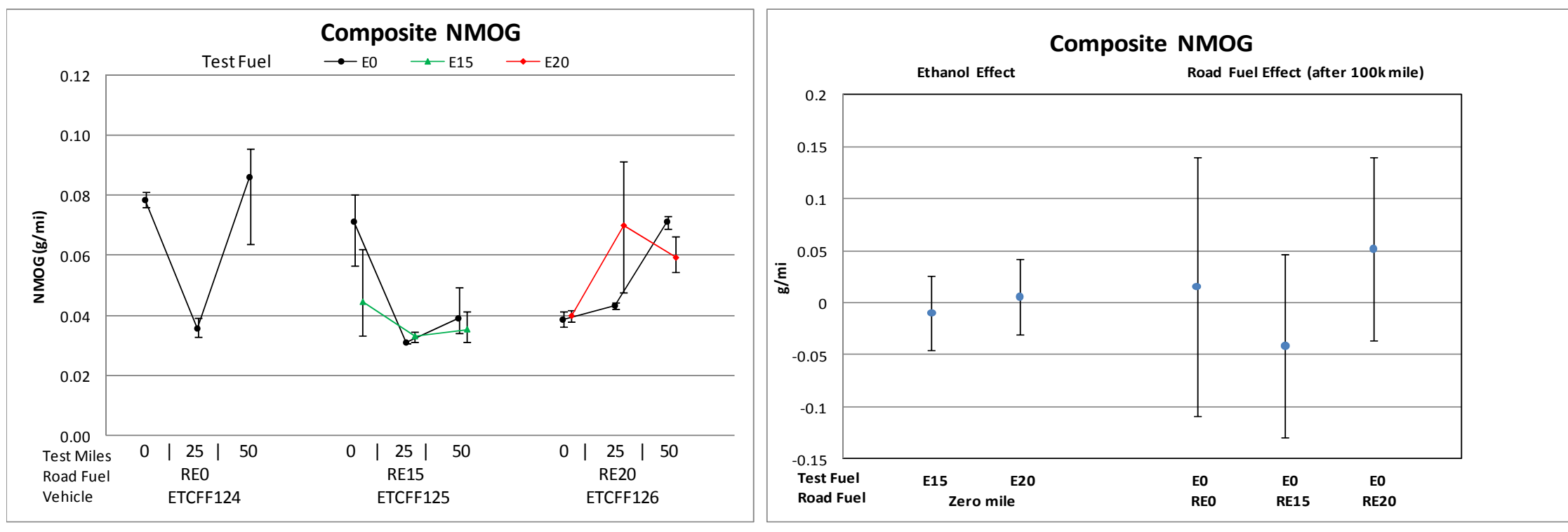

Error bars represent min and max measurements

Error bars represent $95 \%$ confidence intervals on the estimated effects 
2000 Ford Focus (Composite Fuel Economy)

\begin{tabular}{|l|r|r|r|}
\hline \multicolumn{1}{|c|}{ Effect } & Estimate & $\begin{array}{c}\text { 95\% C.I. } \\
\text { Lower }\end{array}$ & $\begin{array}{c}\text { 95\% C.I. } \\
\text { Upper }\end{array}$ \\
\hline Ethanol Effect (E15 vs. E0) $(\Delta \mathrm{mi} / \mathrm{gal})$ & $-0.752^{*}$ & -1.173 & -0.332 \\
\hline Ethanol Effect $($ E20 vs. E0) $(\Delta \mathrm{mi} / \mathrm{gal})$ & $-1.753^{*}$ & -2.174 & -1.333 \\
\hline Road Fuel Aging Effect & & & \\
\hline Aging Effect with RE0 $(\Delta \mathrm{mi} / \mathrm{gal}$ per 100k mi) & $-1.494^{*}$ & -2.946 & -0.042 \\
\hline Aging Effect with RE15 $(\Delta \mathrm{mi} / \mathrm{gal}$ per 100k mi) & -0.992 & -2.022 & 0.037 \\
\hline Aging Effect with RE20 $(\Delta \mathrm{mi} /$ gal per 100k mi) & 0.198 & -0.829 & 1.225 \\
\hline
\end{tabular}

\begin{tabular}{|l|r|}
\hline \multicolumn{1}{|c|}{ Hypothesis } & p-value \\
\hline No Effect of Ethanol in the Test Fuel (Gamma $=0)$ & $<0.01^{*}$ \\
\hline No Aging Effect with RE0 (Beta0 $=0$ ) & $0.05^{*}$ \\
\hline No Effect of Ethanol in Road Fuel Aging (Beta1s $=0$ ) & 0.11 \\
\hline * Indicates effect is statistically significant at the 95\% confidence level.
\end{tabular}

* Indicates estimate is different from zero at the $95 \%$ confidence level.

Initial Odometers 85k-103k
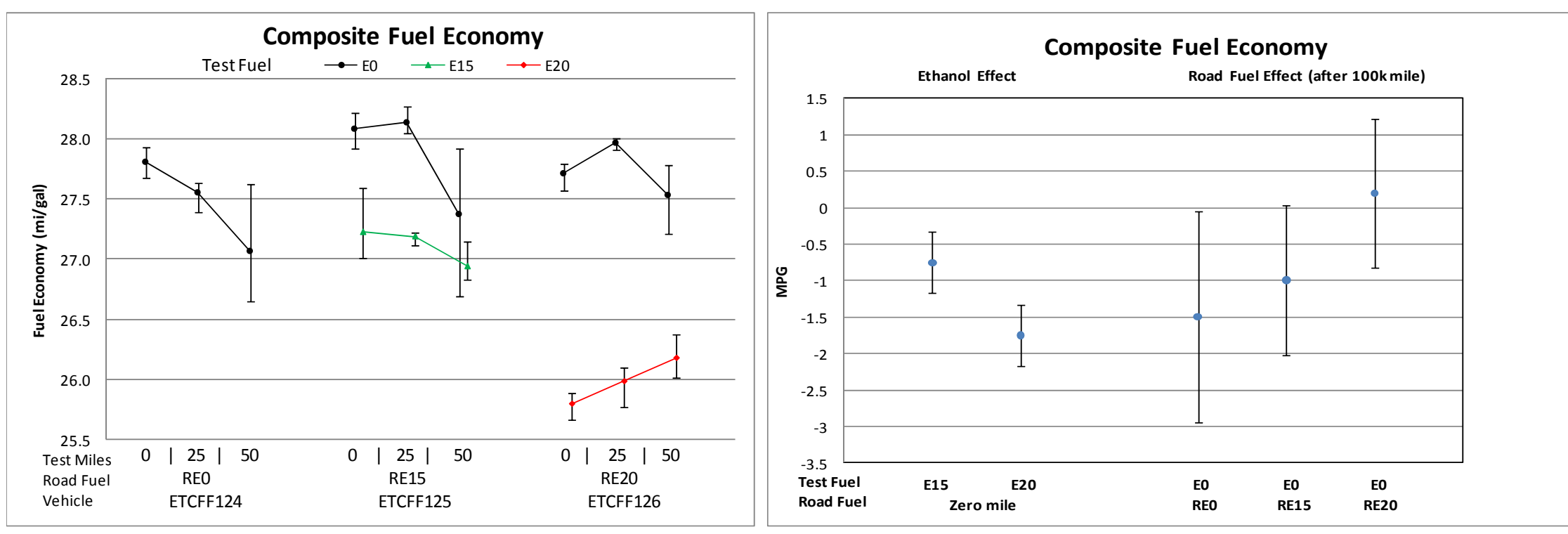

Error bars represent min and max measurements

Error bars represent $95 \%$ confidence intervals on the estimated effects 
2000 Ford Focus (Composite $\mathrm{CH} 4$ )

\begin{tabular}{|l|r|r|r|}
\hline \multicolumn{1}{|c|}{ Effect } & & $\begin{array}{c}95 \% \text { C.I. } \\
\text { Lo5\% C.I. }\end{array}$ & $\begin{array}{c}\text { L5 } \\
\text { Upper }\end{array}$ \\
\hline Ethanol Effect (E15 vs. E0) $(\Delta \mathrm{g} / \mathrm{mi})$ & 0.0005 & -0.0021 & 0.0032 \\
\hline Ethanol Effect (E20 vs. E0) $(\Delta \mathrm{g} / \mathrm{mi})$ & -0.0003 & -0.0030 & 0.0024 \\
\hline Road Fuel Aging Effect & & & \\
\hline Aging Effect with RE0 $(\Delta \mathrm{g} / \mathrm{mi} \mathrm{per} \mathrm{100k} \mathrm{mi)}$ & 0.0055 & -0.0037 & 0.0147 \\
\hline Aging Effect with RE15 $(\Delta \mathrm{g} / \mathrm{mi}$ per 100k mi) & 0.0047 & -0.0019 & 0.0112 \\
\hline Aging Effect with RE20 $(\Delta \mathrm{g} / \mathrm{mi} \mathrm{per} \mathrm{100k} \mathrm{mi)}$ & $0.0133^{*}$ & 0.0068 & 0.0199 \\
\hline
\end{tabular}

\begin{tabular}{|l|r|}
\hline \multicolumn{1}{|c|}{ Hypothesis } & -value \\
\hline No Effect of Ethanol in the Test Fuel (Gamma = 0) & 0.87 \\
\hline No Aging Effect with RE0 (Beta0 = 0) & 0.20 \\
\hline No Effect of Ethanol in Road Fuel Aging (Beta1s=0) & 0.13 \\
\hline * Indicates effect is statistically significant at the 95\% confidence level.
\end{tabular}

${ }^{*}$ Indicates estimate is different from zero at the $95 \%$ confidence level.

Initial Odometers 85k-103k
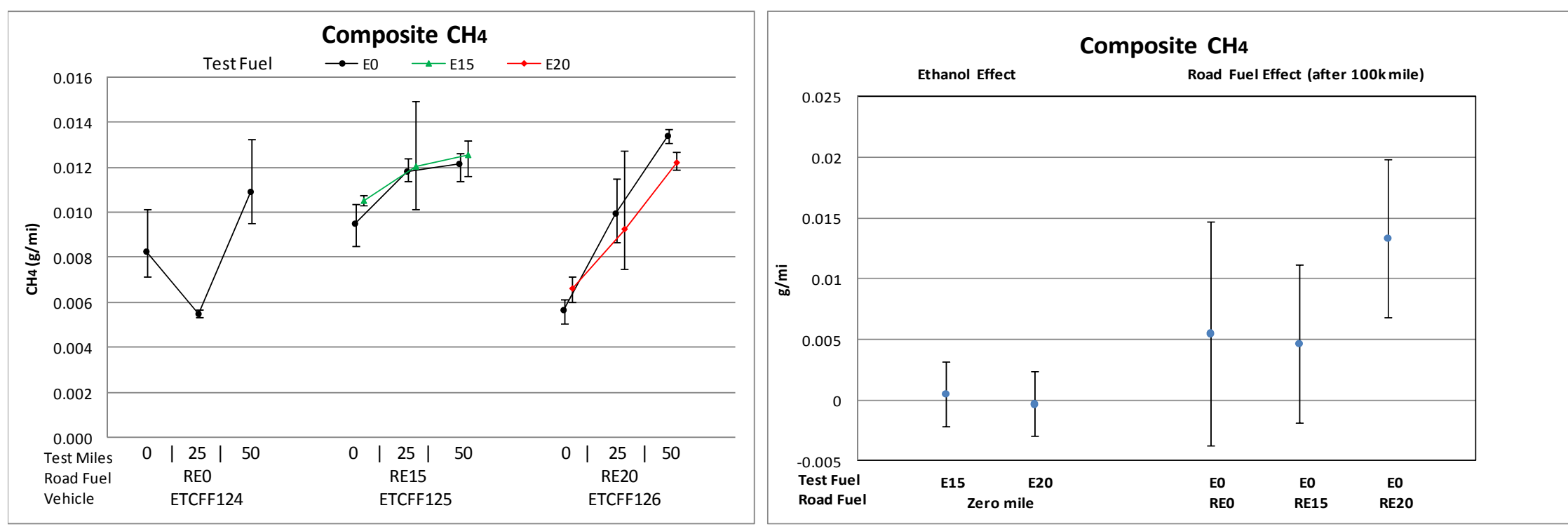

Error bars represent min and max measurements

Error bars represent $95 \%$ confidence intervals on the estimated effects 
